
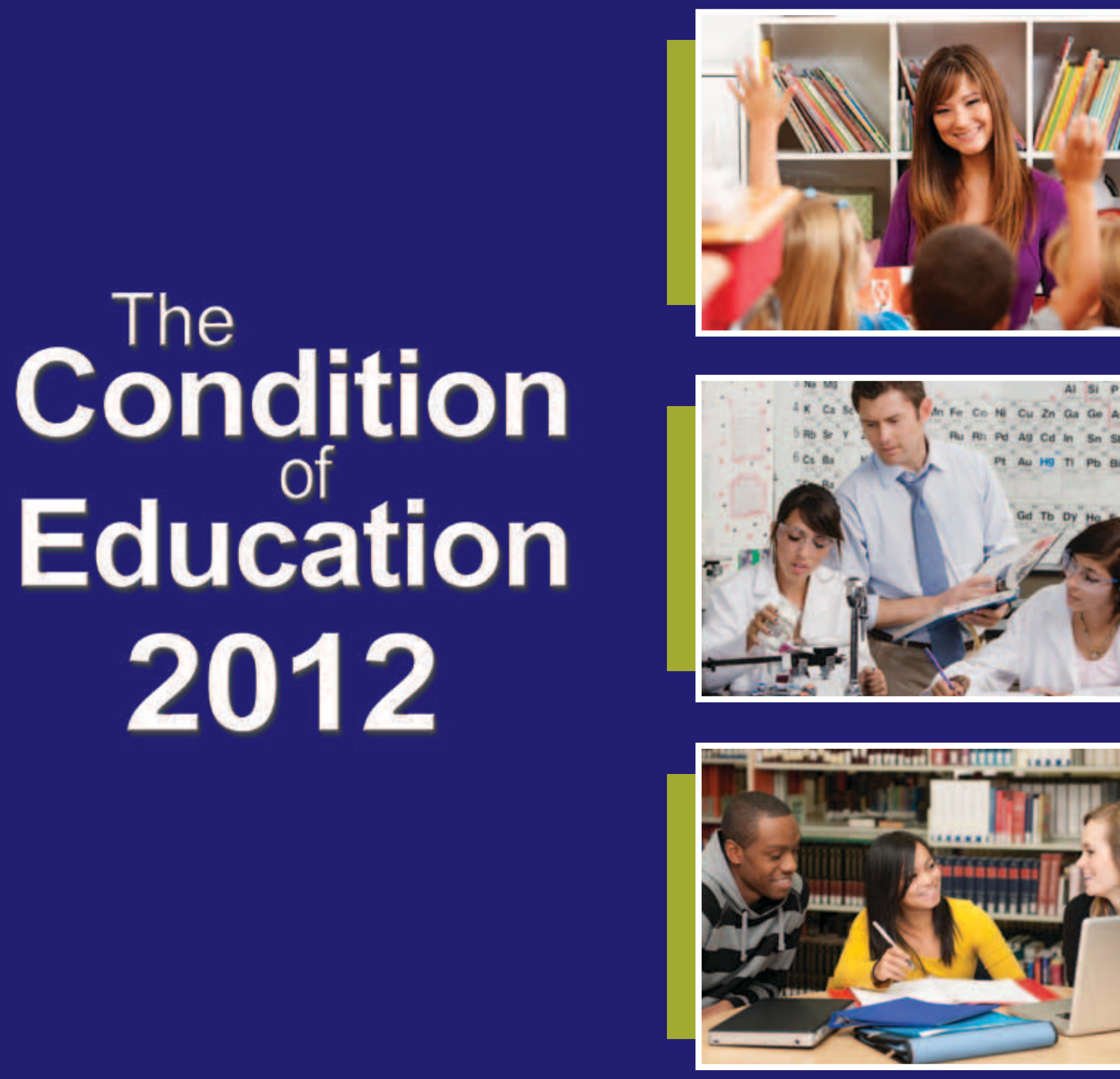



\section{The Condition of Education 2012}

\section{MAY 2012}

Susan Aud

William Hussar

Frank Johnson

Grace Kena

Erin Roth

National Center for Education Statistics

Eileen Manning

Xiaolei Wang

Jijun Zhang

American Institutes for Research

Liz Notter

Production Manager

Synergy Enterprises, Inc.

Thomas Nachazel

Senior Editor

Carolyn Yohn

Editor

American Institutes for Research 


\section{U.S. Department of Education}

Arne Duncan

Secretary

\section{Institute of Education Sciences}

John Q. Easton

Director

\section{National Center for Education Statistics}

Jack Buckley

Commissioner

The National Center for Education Statistics (NCES) is the primary federal entity for collecting, analyzing, and reporting data related to education in the United States and other nations. It fulfills a congressional mandate to collect, collate, analyze, and report full and complete statistics on the condition of education in the United States; conduct and publish reports and specialized analyses of the meaning and significance of such statistics; assist state and local education agencies in improving their statistical systems; and review and report on education activities in foreign countries.

NCES activities are designed to address high-priority education data needs; provide consistent, reliable, complete, and accurate indicators of education status and trends; and report timely, useful, and high-quality data to the U.S. Department of Education, the Congress, the states, other education policymakers, practitioners, data users, and the general public. Unless specifically noted all information contained herein is in the public domain.

We strive to make our products available in a variety of formats and in language that is appropriate to a variety of audiences. You, as our customer, are the best judge of our success in communicating information effectively. If you have any comments or suggestions about this or any other NCES product or report, we would like to hear from you. Please direct your comments to

NCES, IES, U.S. Department of Education

1990 K Street NW

Washington, DC 20006-5651

\section{May 2012}

The NCES Home Page address is http://nces.ed.gov.

The NCES Publications and Products address is http://nces.ed.gov/pubsearch.

This publication is only available online. To download, view, and print the report as a PDF file, go to the NCES Publications and Products address shown above.

This report was prepared for the National Center for Education Statistics under Contract No. ED-IES-12-000176 with American Institutes for Research. Mention of trade names, commercial products, or organizations does not imply endorsement by the U.S. Government.

\section{Suggested Citation}

Aud, S., Hussar, W., Johnson, F., Kena, G., Roth, E., Manning, E., Wang, X., and Zhang, J. (2012). The Condition of Education 2012 (NCES 2012-045). U.S. Department of Education, National Center for Education Statistics.

Washington, DC. Retrieved [date] from http://nces.ed.gov/pubsearch.

\section{Content Contact}

Susan Aud

(202) 219-7013

susan.aud@ed.gov 


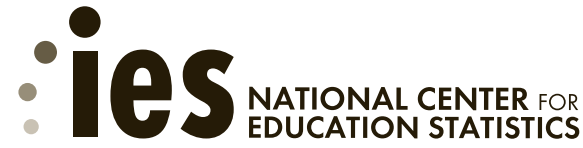 \\ Institute of Education Sciences}

\section{Letter from the Commissioner of the National Center for Education Statistics}

May 2012

To help policymakers and the public monitor the progress of education in the United States, Congress has mandated that the National Center for Education Statistics (NCES) produce an annual report, The Condition of Education. This year's report presents 49 indicators of important developments and trends in U.S. education. These indicators focus on participation in education, elementary and secondary education and outcomes, and postsecondary education and outcomes. The report also uses a group of the indicators to take a closer look at high school in the United States over the last twenty years. Since 1990, there have been many demographic and policy changes that have affected our high schools. We explore what these changes look like and what they have meant, in terms of achievement and other outcomes.

Enrollment in U.S. schools is expected to grow in the coming years. From 2011 through 2021, public elementary and secondary enrollment is projected to increase to 53.1 million students. Undergraduate enrollment is expected to increase from 18.1 million students in 2010 to 20.6 million in 2021. Enrollment in postbaccalaureate programs is projected to increase through 2021 to 3.5 million students. These increases in enrollment have been accompanied by an increase in diversity of the student population.

Overall, progress on national assessments in reading and mathematics has been made among 4th- and 8th-graders since the early 1990's. On both mathematics and reading assessments, significant gaps among racial/ethnic groups remain, though the mathematics and reading gaps between White and Black 4th-graders have narrowed since the assessments were first given. The averaged freshman graduation rate (AFGR) in 2009 was 75.5 percent, a measure that has increased since 2001, when it was 71.7 percent. Other measures of improvement are the status dropout rate, which has declined among all racial/ethnic groups, and rates of postsecondary degree attainment, which have increased for Black, Hispanic, Asian/Pacific Islander, and American Indian/Alaska Native students.

NCES produces an array of reports each year that present findings about the U.S. education system. The Condition of Education 2012 is the culmination of a year-long project. It includes data that were available by March 2012. In the coming months, other reports and surveys informing the nation about education will be released. Along with the indicators in this volume, NCES intends these surveys and reports to help inform policymakers and the American public about trends and conditions in U.S. education.

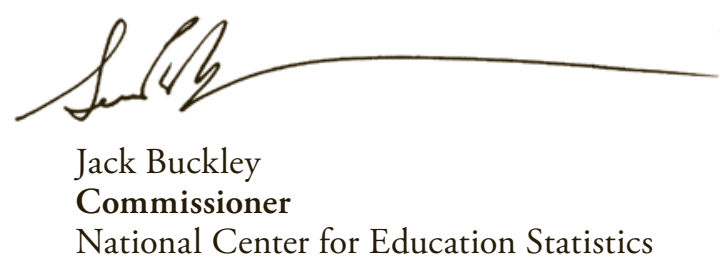


This page intentionally left blank.

iv The Condition of Education 2012 


\section{Reader's Guide}

The Condition of Education is available in three forms: this print volume for 2012 and on the National Center for Education Statistics (NCES) website (http://nces.ed.gov/ programs/coe), an electronic version, and a downloadable e-book. The Condition of Education website includes the entire content of the 2012 print volume, plus special analyses from the 2000 through 2011 editions, as well as selected indicators from earlier editions of The Condition of Education. (See pages 1 through 6 for a list of all the indicators that appear on The Condition of Education website.)

The print volume of The Condition of Education 2012 is divided into three sections of indicators. Each indicator consists of one page of key findings and technical notes, two figures on the adjacent page, and one or more tables, found in Appendix A. The tables feature the estimates used in the indicator discussion as well as additional estimates related to the indicator. Where applicable, tables of standard errors for estimate tables are available on the NCES website (http://nces.ed.gov/programs/coe). Additional information on data sources can be found in Appendix B. Information on analyses conducted, definitions of variables, and measures can be found in the notes in Appendix C. Finally, a glossary of key terms, a bibliography, and an index are featured in Appendixes $D$ through $F$.

(i) This icon on the main indicator page lists references for related indicators, tables, glossary terms, and other sources that provide more information related to the indicator. Indicators use the most recent national and international data available during production from either NCES or other sources relevant to the indicator. When the source is an NCES publication, such as the Digest of Education Statistics, the publication can be viewed on the NCES website (http://nces.ed.gov/pubsearch).

\section{Data Sources and Estimates}

The data in this report were obtained from many different sources-including students and teachers, state education agencies, local elementary and secondary schools, and colleges and universities - using surveys and compilations of administrative records. Users of The Condition of Education should be cautious when comparing data from different sources. Differences in aspects such as procedures, timing, question phrasing, and interviewer training can affect the comparability of results across data sources.

Most indicators in The Condition of Education summarize data from surveys conducted by NCES or by the Census Bureau with support from NCES. Brief explanations of the major NCES surveys used in this edition of The Condition of Education can be found in Appendix B - Guide to Sources of this volume. More detailed explanations can be obtained on the NCES website (http://nces.ed.gov) under "Surveys and Programs."
Appendix $B$ also includes information on non-NCES sources used to compile indicators, such as the American Community Survey (ACS) and the Current Population Survey (CPS). These are Census Bureau surveys used extensively in The Condition of Education. For further details on the ACS, see http://www.census.gov/acs/www/. For further details on the CPS, see http://www.census. gov/cps/.

Data for indicators reported in this volume are obtained primarily from two types of surveys: universe surveys and sample surveys. In universe surveys, information is collected from every member of the population. For example, in a survey regarding certain expenditures of public elementary and secondary schools, data would be obtained from each school district in the United States. When data from an entire population are available, estimates of the total population or a subpopulation are made by simply summing the units in the population or subpopulation.

Since a universe survey is often expensive and time consuming, many surveys collect data from a sample of the population of interest (sample survey). For example, the National Assessment of Educational Progress (NAEP) assesses a representative sample of students rather than the entire population of students. When a sample survey is used, statistical uncertainty is introduced, because the data come from only a portion of the entire population. This statistical uncertainty must be considered when reporting estimates and making comparisons.

Various types of statistics derived from universe and sample surveys are reported in The Condition of Education. Many indicators report the size of a population or a subpopulation, and often the size of a subpopulation is expressed as a percentage of the total population. In addition, the average (or mean) value of some characteristic of the population or subpopulation may be reported. The average is obtained by summing the values for all members of the population and dividing the sum by the size of the population. An example is the annual average salaries of full-time instructional faculty at degree-granting postsecondary institutions. Another measure that is sometimes used is the median. The median is the midpoint value of a characteristic at or above which 50 percent of the population is estimated to fall, and at or below which 50 percent of the population is estimated to fall. An example is the median annual earnings of young adults who are full-time, full-year wage and salary workers.

\section{Standard Errors}

Using estimates calculated from data based on a sample of the population requires consideration of several factors before the estimates become meaningful. When using data from a sample, some margin of error will always be present in estimations of characteristics of the total 
population or subpopulation because the data are available from only a portion of the total population. Consequently, data from samples can provide only an approximation of the true or actual value. The margin of error of an estimate, or the range of potential true or actual values, depends on several factors such as the amount of variation in the responses, the size and representativeness of the sample, and the size of the subgroup for which the estimate is computed. The magnitude of this margin of error is measured by what statisticians call the "standard error" of an estimate.

When data from sample surveys are reported, the standard error is calculated for each estimate. The standard errors for all estimated totals, means, medians, or percentages reported in the tables of The Condition of Education can be viewed on the NCES website (http:// nces.ed.gov/programs/coe).

In order to caution the reader when interpreting findings in The Condition of Education, estimates from sample surveys are flagged with a "!" when the standard error is 30 percent of the estimate or greater, and suppressed with a “ $\ddagger$ " when the standard error is 50 percent of the estimate or greater.

\section{Data Analysis and Interpretation}

When estimates are from a sample, caution is warranted when drawing conclusions about one estimate in comparison to another, or about whether a time series of estimates is increasing, decreasing, or staying the same. Although one estimate may appear to be larger than another, a statistical test may find that the apparent difference between them is not reliably measurable due to the uncertainty around the estimates. In this case, the estimates will be described as having no measurable difference, meaning that the difference between them is not statistically significant.

Whether differences in means or percentages are statistically significant can be determined using the standard errors of the estimates. In this publication and others produced by NCES, when differences are statistically significant, the probability that the difference occurred by chance is less than 5 percent, according to NCES standards.

Data presented in The Condition of Education do not investigate more complex hypotheses, account for interrelationships among variables, or support causal inferences. We encourage readers who are interested in more complex questions and in-depth analysis to explore other NCES resources, including publications, online data tools, and public- and restricted-use datasets at http:// nces.ed.gov.

For all indicators in The Condition of Education that report estimates based on samples, differences between estimates (including increases and decreases) are stated only when they are statistically significant. To determine whether differences reported are statistically significant, two-tailed $t$ tests at the .05 level are typically used. The $t$ test formula for determining statistical significance is adjusted when the samples being compared are dependent. The $t$ test formula is not adjusted for multiple comparisons. When the difference between estimates is not statistically significant, tests of equivalence can be used. An equivalence test determines the probability (generally at the .15 level) that the estimates are statistically equivalent, that is, within the margin of error that the two estimates are not substantively different. When the difference is found to be equivalent, language such as " $x$ " and " $y$ " "were similar" or "about the same" has been used. When the variables to be tested are postulated to form a trend, the relationship may be tested using linear regression, logistic regression, or ANOVA trend analysis instead of a series of $t$ tests. These alternate methods of analysis test for specific relationships (e.g., linear, quadratic, or cubic) among variables. For more information on data analysis, please see the NCES Statistical Standards, Standard 5-1, available at http://nces.ed.gov/statprog/2002/std5 1.asp.

A number of considerations influence the ultimate selection of the data years to feature in The Condition of Education. To make analyses as timely as possible, the latest year of available data is shown. The choice of comparison years is often also based on the need to show the earliest available survey year, as in the case of the NAEP and the international assessment surveys. In the case of surveys with long time frames, such as surveys measuring enrollment, the decade's beginning year (e.g., 1980 or 1990) often starts the trend line. In the figures and tables of the indicators, intervening years are selected in increments in order to show the general trend. The narrative for the indicators typically compares the most current year's data with those from the initial year and then with those from a more recent period. Where applicable, the narrative may also note years in which the data begin to diverge from previous trends.

\section{Rounding and Other Considerations}

All calculations within The Condition of Education are based on unrounded estimates. Therefore, the reader may find that a calculation, such as a difference or a percentage change, cited in the text or figure may not be identical to the calculation obtained by using the rounded values shown in the accompanying tables. Although values reported in the supplemental tables are generally rounded to one decimal place (e.g., 76.5 percent), values reported in each indicator are generally rounded to whole numbers (with any value of 0.50 or above rounded to the next highest whole number). Due to rounding, cumulative percentages may sometimes equal 99 or 101 percent rather than 100 percent.

Indicators in this volume that use the Consumer Price Index (CPI) use a base academic year of 2010-11 and a base calendar year of 2011 for constant dollar calculations. For more information on the CPI, see Appendix C - Finances. 


\section{Race and ethnicity}

The categories denoting race and ethnicity in The Condition of Education are in accordance with the 1997 Office of Management and Budget (OMB) standard classification scheme. These classifications are based primarily on the respondent's self-identification, as is the case with data collected by the U.S. Census Bureau, or, in rare instances, on observer identification. Under the $\mathrm{OMB}$ standards, race and ethnicity are considered separate concepts. "Hispanic or Latino" is an ethnicity category, not a race category. Race categories presented in The Condition of Education 2012 exclude persons of Hispanic ethnicity; thus, the race/ethnicity categories are mutually exclusive.

Ethnicity is categorized as follows:

- Hispanic or Latino: A person of Cuban, Mexican, Puerto Rican, South or Central American, or other Spanish culture or origin, regardless of race.

Racial groupings are as follows:

- American Indian or Alaska Native: A person having origins in any of the original peoples of North and South America (including Central America) who maintains tribal affiliation or community attachment.

- Asian: A person having origins in any of the original peoples of the Far East, Southeast Asia, and the Indian subcontinent; for example, Cambodia, China, India, Japan, Korea, Malaysia, Pakistan, the Philippines, Thailand, and Vietnam.

- Black: A person having origins in any of the Black racial groups of Africa.

- Native Hawaiian or Other Pacific Islander: A person having origins in any of the original peoples of Hawaii, Guam, Samoa, or other Pacific Islands.

- White: A person having origins in any of the original peoples of Europe, North Africa, or the Middle East.

- Two or more races: A person who selected two or more of the following racial categories when offered the option of selecting one or more racial designations: White, Black, Asian, Native Hawaiian or Other Pacific Islander, or American Indian or Alaska Native.

In The Condition of Education, the following terms are typically used to represent the above categories: White, Black, Hispanic, Pacific Islander, American Indian/Alaska Native, and Two or more races. Not all categories are shown in all indicators. For more information on race/ ethnicity, see Appendix C - Commonly Used Measures.

\section{Symbols}

In accordance with the NCES Statistical Standards, many tables in this volume use a series of symbols to alert the reader to special statistical notes. These symbols, and their meanings, are as follows:

— Not available.

$\dagger$ Not applicable.

\# Rounds to zero.

! Interpret data with caution. The coefficient of variation (CV) for this estimate is 30 percent or greater.

$\ddagger$ Reporting standards not met. Either there are too few cases or the coefficient of variation (CV) for this estimate is 50 percent or greater.

${ }^{*} p<.05$ Significance level. 
This page intentionally left blank.

viii The Condition of Education 2012 


\section{Contents}

Letter from the Commissioner of the National Center for Education Statistics

Reader's Guide

List of Tables xii

List of Figures .xvii

Introduction. 1

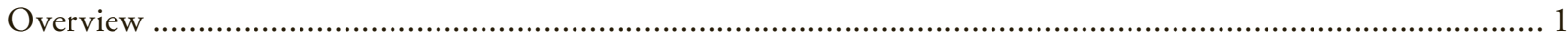

A Closer Look at High School Students in the United States Over the Last 20 Years ..................................... 6

Section 1-Participation in Education ........................................................................... 15

See page 14 for a brief introduction to this section.

\section{All Ages}

1 Enrollment Trends by Age.

\section{Preprimary Education}

2 Early Education and Child Care Arrangements of Young Children 18

\section{Elementary/Secondary Education}

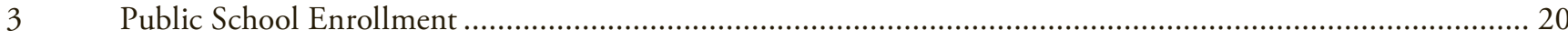

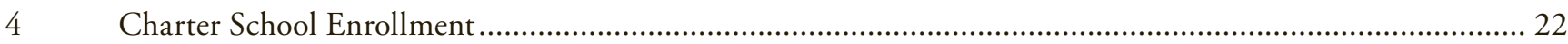

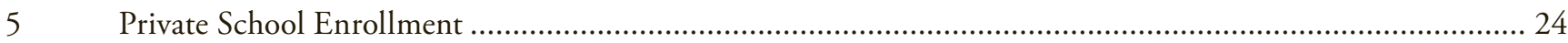

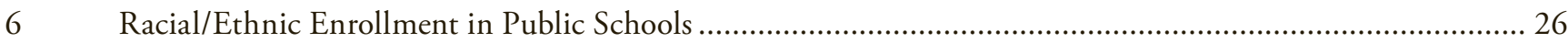

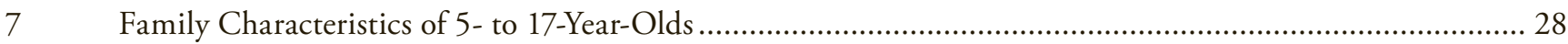

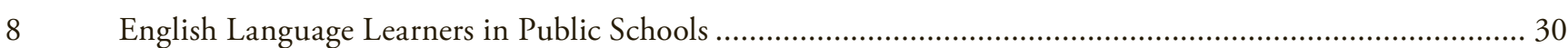

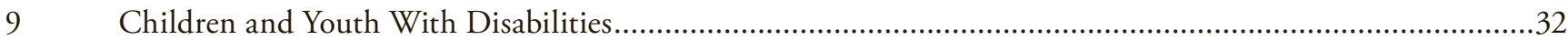

\section{Postsecondary Enrollment}

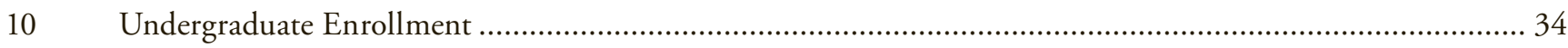

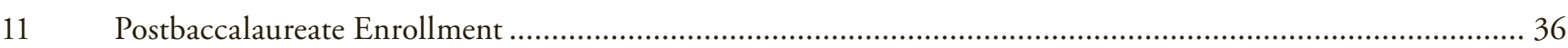

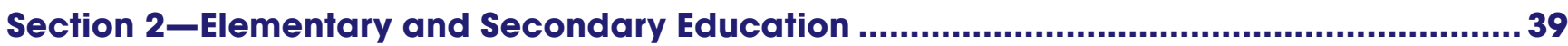

See page 38 for a brief introduction to this section.

\section{School Characteristics and Climate}

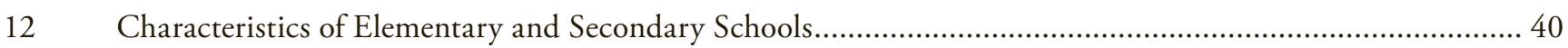

13 Concentration of Public School Students Eligible for Free or Reduced-Price Lunch..................................... 42

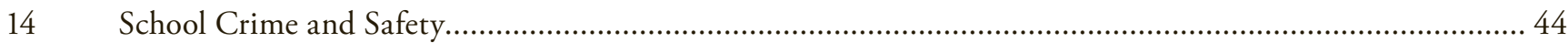

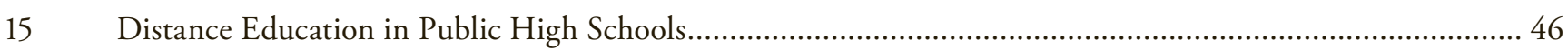

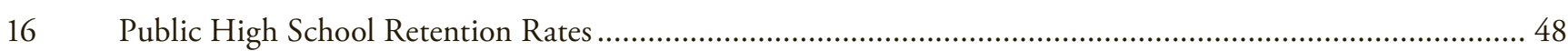

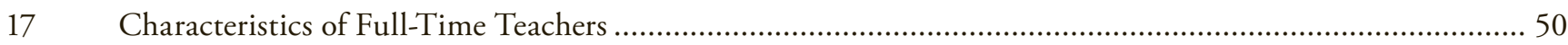

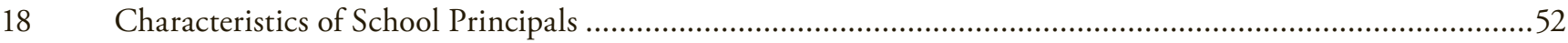




\section{Finance}

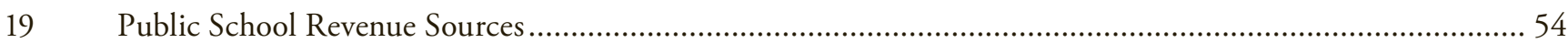

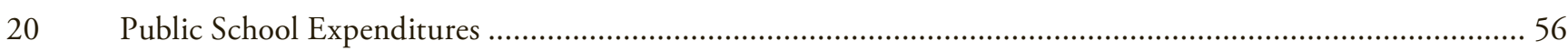

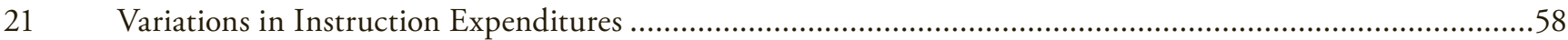

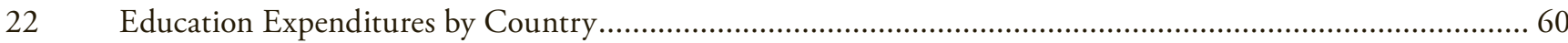

\section{Assessments}

23 Reading Performance.

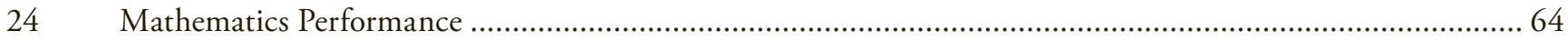

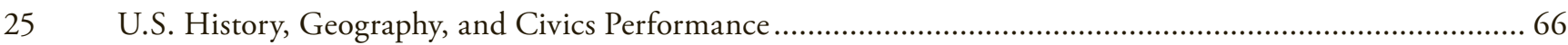

26 International Reading, Mathematics, and Science Proficiency .............................................................. 68

\section{Student Effort, Persistence, and Progress}

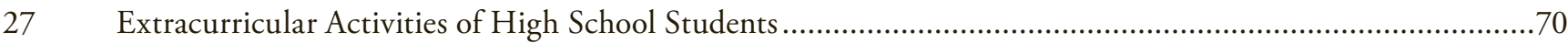

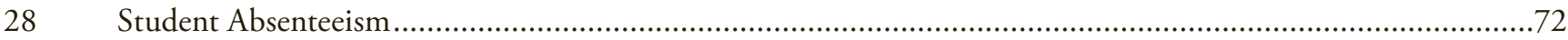

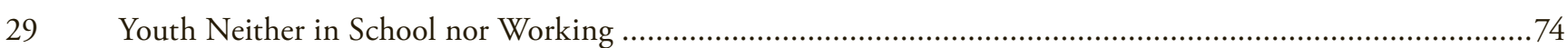

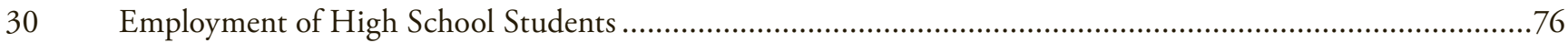

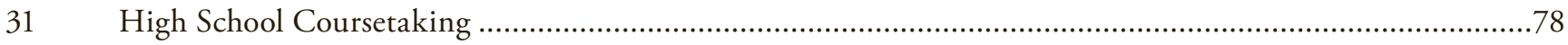

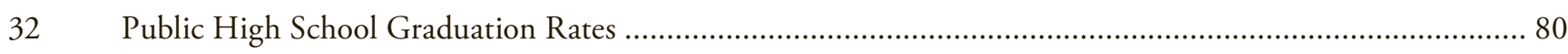

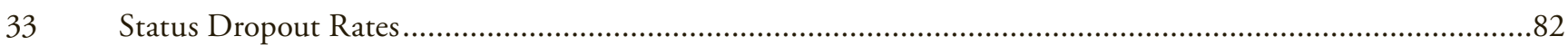

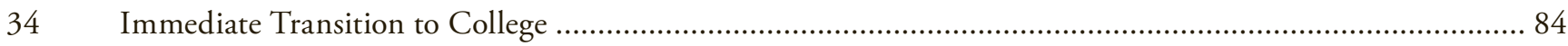

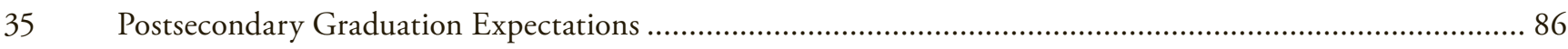

Section 3-Postsecondary Education ...........................................................................89

See page 88 for a brief introduction to this section.

\section{Characteristics of Postsecondary Students}

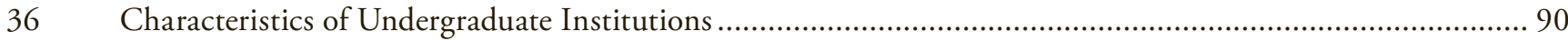

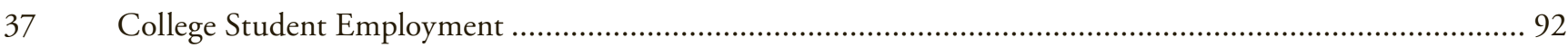

\section{Programs and Courses}

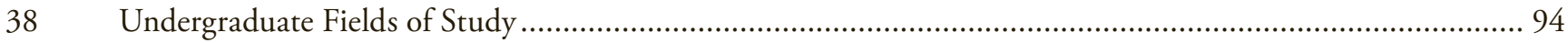

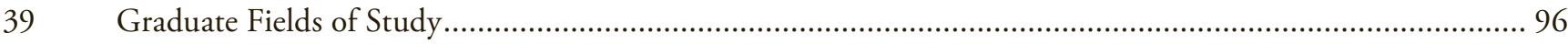

\section{Finance and Resources}

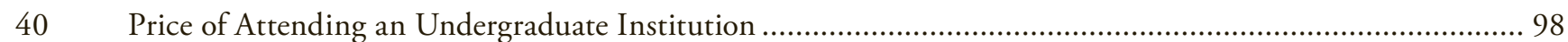

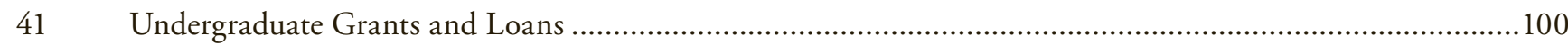

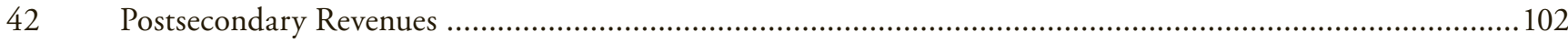

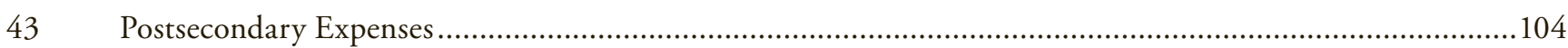

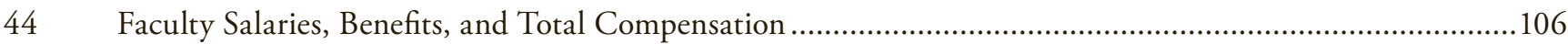

\section{Completions}

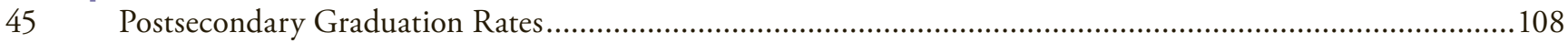

46 Degrees Conferred by Public and Private Institutions ......................................................................... 110

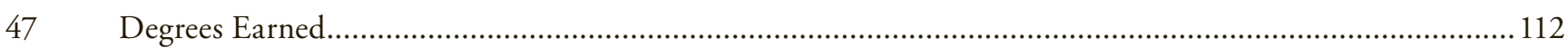

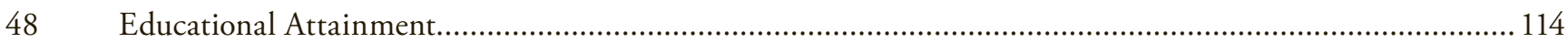




\section{Economic Outcomes}

49 Annual Earnings of Young Adults....

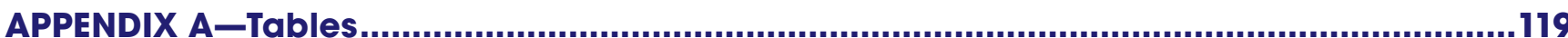

The supplemental tables are listed in the List of Tables on the following pages.

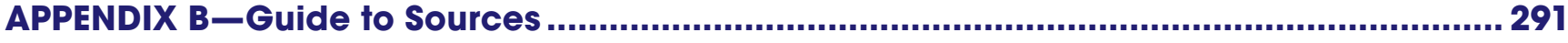

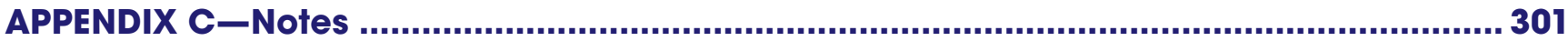

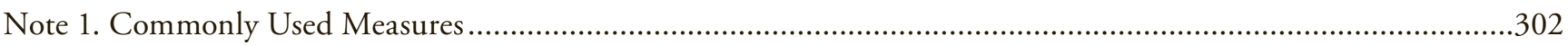

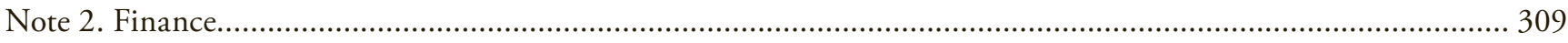

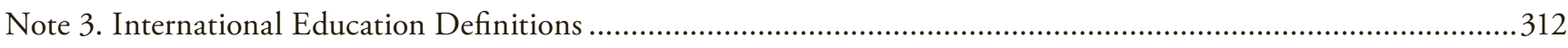

APPENDIX D-Glossary................................................................................................ 315

APPENDIX E-Bibliography.......................................................................................... 325

APPENDIX F-IndeX.......................................................................................................... 329 


\section{List of Tables}

Table

\section{Section 3-Postsecondary Education}

46-1. Number of degrees conferred by postsecondary degree-granting institutions and percent change,

by control of institution and level of degree: Academic years 1999-2000 and 2009-10

\section{Appendix A-Tables}

A-1-1. Percentage of the population ages 3-34 enrolled in school, by age group: October 1970-2010

A-1-2. Age range for compulsory school attendance, policies on kindergarten education, and percentage of the population ages 3-34 enrolled in school, by age group and state or jurisdiction: 2010

A-2-1. Enrollment of 3-, 4-, and 5-year-old children in preprimary programs, by level of program, control of program, and attendance status: Selected years, 1980 through 2010

A-2-2. Percentage of 3-, 4-, and 5-year-old children enrolled in preprimary programs, by attendance status, level of program, and selected child and family characteristics: October 2010.

A-3-1. Actual and projected public school enrollment in grades prekindergarten (preK) through 12, by grade level and region: Selected school years, 1970-71 through 2021-22.

A-3-2. Number and percent change in public school enrollment in grades prekindergarten (preK) through 12, by grade level, region, and state or jurisdiction: School years 1989-90 and 2010-11

A-3-3. Actual and projected number and projected percent change in public school enrollment in grades prekindergarten (preK) through 12, by grade level, region, and state or jurisdiction: School years 2010-11 and 2021-22.

A-4-1. Number and percentage distribution of public charter schools and students, by selected student and school characteristics: Selected school years, 1999-2000 through 2009-10.

A-4-2. Number, percentage, and percentage distribution of public charter schools and students, by region and state or jurisdiction: School years 1999-2000 and 2009-10

A-5-1. Total enrollment and percentage distribution of students enrolled in private elementary and secondary schools, by school type and grade level: Various school years, 1995-96 through 2009-10

A-5-2. Private elementary and secondary school enrollment and private enrollment as a percentage of total enrollment in public and private schools, by region and grade level: Various school years, 1995-96 through 2009-10.

A-5-3. Percentage distribution of students enrolled in private elementary and secondary schools, by school type and selected characteristics: $2009-10$

A-6-1. Number and percentage distribution of public school students enrolled in prekindergarten through 12th grade by race/ethnicity: October 1990-October 2010 .

A-6-2. Number of public school students enrolled in prekindergarten through 12th grade, by race/ethnicity and region: Selected years, October 1990-October 2010

A-6-3. Percentage distribution of public school students enrolled in prekindergarten through 12th grade, by race/ethnicity and region: Selected years, October 1990-October 2010

A-6-4. Percentage distribution of public school students enrolled in prekindergarten through 12th grade, by race/ethnicity and state or jurisdiction: 2010

A-7-1. Percentage distribution of 5- to 17-year-olds, by race/ethnicity and selected family characteristics: Selected years, 1990-2011

A-8-1. Number of public school students and number and percentage of public school students who were English language learners (ELLs), by state: Selected school years, 2000-01 through 2009-10.

A-8-2. Number of public school students and number and percentage of public school students who were English language learners (ELLs), by locale: School year 2009-10..... 
A-9-1. Number and percentage distribution of children and youth ages 3-21 served under the Individuals with Disabilities Education Act (IDEA), Part B, and number served as a percentage of total public school enrollment, by disability type: Selected school years, 1980-81 through 2009-10

A-9-2. Percentage distribution of students ages 6-21 served under the Individuals with Disabilities Education Act (IDEA), Part B, by educational environment and disability type: Selected school years, 1990-91 through 2009-10

A-10-1. Number and percentage of actual and projected undergraduate enrollment in degree-granting postsecondary institutions, by sex, attendance status, and control of institution: Selected years, fall 1970-2021

A-10-2. Actual and projected undergraduate enrollment in degree-granting 4- and 2-year postsecondary institutions, by sex, attendance status, and control of institution: Selected years, fall 1970-2021

A-10-3. Undergraduate enrollment of U.S. residents and percentage distribution of students in degreegranting postsecondary institutions, by race/ethnicity and sex: Selected years, fall 1976-2010

A-11-1. Number and percentage distribution of actual and projected postbaccalaureate enrollment in degree-granting postsecondary institutions, by sex, attendance status, and control of institution: Fall 1976-2021

A-11-2. Postbaccalaureate enrollment of U.S. residents and percentage distribution of students in degree-granting postsecondary institutions, by race/ethnicity and sex: Selected years, fall 1976-fall 2010

A-12-1. Number and percentage distribution of schools, by control and selected school characteristics: School years 1999-2000 and 2009-10

A-13-1. Number of public school students and percentage distribution of students, by school concentration of students eligible for free or reduced-price lunch, race/ethnicity, and school level:

School year 2009-10

A-13-2. Number of public school students and percentage distribution of students, by school concentration of students eligible for free or reduced-price lunch, school locale, and race/ethnicity:

School year 2009-10

A-14-1. Percentage of public schools recording and reporting to the police at least one incident of crime that occurred at school, by type of incident: Selected school years, 1999-2000 through 2009-10

A-14-2. Percentage of public schools recording incidents of crime that occurred at school, by type of incident, number of incidents, and selected school characteristics: School year 2009-10.

A-15-1. Percentage of public school districts with any high school students enrolled in distance education courses and number of student enrollments in distance education, by selected district characteristics: School years 2002-03, 2004-05, and 2009-10

A-15-2. Percentage of public school districts that offered distance education, by locale and selected characteristics: School years 2004-05 and 2009-10

A-16-1. Number and percentage distribution of public high schools and 12th-grade students, by student retention rate: Academic years 1990-91 through 2009-10

A-16-2. Number and percentage distribution of public high schools, by student retention rate and selected school characteristics: Academic year 2009-10

A-17-1. Number and percentage distribution of full-time teachers, by school level, school type, and selected teacher characteristics: School years 2003-04 and 2007-08.

A-17-2. Number and percentage distribution of full-time teachers, by school level, school type, and selected teaching characteristics: School years 2003-04 and 2007-08.

A-18-1. Number and percentage distribution of school principals, by school level, school type, and selected principal characteristics: School years 1999-2000 and 2007-08.....

A-19-1. Total revenues, gross domestic product, and percentage distribution for public elementary and secondary schools, by revenue source: School years 1988-89 through 2008-09 
A-19-2. Total revenues and percentage distribution for public elementary and secondary schools, by revenue source and state: School year 2008-09.

A-20-1. Total expenditures per student in fall enrollment in public elementary and secondary schools, percentage distribution of current expenditures, and percent change of total expenditures by type and object: School years 1988-89, 1998-99, and 2008-09

A-20-2. Current expenditures per student in fall enrollment in public elementary and secondary schools, percentage distribution of current expenditures, and percent change of current expenditures, by function and object: School years 1988-89, 1998-99, and 2008-09......

A-21-1. Variation and percentage distribution of variation in instruction expenditures per student in unified public elementary and secondary school districts, by source of variation: School years 1989-90 through 2008-09

A-22-1. Annual educational expenditures on public and private institutions per student and as a percentage of gross domestic product (GDP), and GDP per capita, by country and level of education: 2008

A-23-1. Average reading scale scores, selected percentile scores, and percentage of students at each achievement level, by grade: Selected years, 1992-2011.....

A-23-2. Average reading scale scores, by grade and selected student and school characteristics: Selected years, 1992-2011.....

A-23-3. Average reading scale scores and achievement-level results for public school students, by grade and state or jurisdiction: 2009 and 2011 .....

A-24-1. Average mathematics scale scores, selected percentile scores, and percentage of students at each achievement level, by grade: Selected years, 1990-2011....

A-24-2. Average mathematics scale scores, by grade and selected student and school characteristics: Selected years, 1990-2011

A-24-3. Average mathematics scale scores and percentage of students at selected achievement levels for public school students, by grade and state or jurisdiction: 2009 and 2011

A-25-1. Average U.S. history scale scores, by grade and selected characteristics: Selected years, 1994-2010......

A-25-2. Average geography scale scores, by grade and selected characteristics: Selected years, 1994-2010

A-25-3. Average civics scale scores, by grade and selected characteristics: Selected years, 1998-2010

A-25-4. Average scale scores and achievement-level results for 12th-grade students, by subject and selected characteristics: 1994,1998 , and 2010.

A-26-1. Percentage of 15-year-old students scoring at selected Program for International Student Assessment proficiency levels on the combined reading literacy scale, by country: 2000 and 2009.

A-26-2. Percentage of 15-year-old students scoring at selected Program for International Student Assessment proficiency levels on the mathematics literacy scale, by country: 2003 and 2009

A-26-3. Percentage of 15-year-old students scoring at selected Program for International Student Assessment proficiency levels on the science literacy scale, by country: 2006 and 2009 .......

A-27-1. Percentage of high school students who participated in various extracurricular activities, by type of activity, grade level, and sex: Selected years, 1990 through 2010

A-27-2. Percentage of high school seniors who participated in various extracurricular activities, by type of activity, sex, college plans, and region: 2010 .

A-28-1. Percentage distribution and average National Assessment of Educational Progress reading scale scores of 4th-, 8th-, and 12th-grade students, by the number of days of school they reported missing in the previous month: Various years, 1992-2011

A-28-2. Percentage of 8th- and 12th-grade students performing at or above Basic proficiency on National Assessment of Educational Progress reading assessments, by number of days of school missed in the previous month and selected characteristics: 2009 and 2011 
A-29-1. Percentage of youth ages 16-24 who were neither enrolled in school nor working, by selected characteristics: Selected years, 1990-2011

A-29-2. Number and percentage distribution of youth ages 16-24 who were neither enrolled in school nor working, by selected characteristics: 2011

A-30-1. Percentage of high school students ages 16 years and older who were employed, by hours worked per week and sex: Selected years, 1980 to 2010

A-30-2. Percentage distribution of high school students ages 16 years and older who were employed, by hours worked per week and selected student characteristics: 2010 .....

A-31-1. Percentage of high school graduates who completed selected mathematics and science courses in high school, by year and selected student and school characteristics: Selected years, 1990-2009

A-31-2. Average National Assessment of Educational Progress (NAEP) 12th-grade mathematics scale scores of high school graduates, by highest mathematics course taken and selected student and school characteristics: 2009 .....

A-32-1. Averaged freshman graduation rate for public high school students and number of graduates, by state or jurisdiction: Selected school years, 1990-91 through 2008-09.....

A-33-1. Status dropout rates of 16- through 24-year-olds in the civilian, noninstitutionalized population, by race/ethnicity: October Current Population Survey (CPS) 1990-2010.

A-33-2. Number of status dropouts and status dropout rates of 16-through 24-year-olds in the noninstitutionalized group quarters and household population, by nativity and selected characteristics: American Community Survey (ACS) 2010

A-33-3. Number of status dropouts and status dropout rates of 16-through 24-year-olds in the institutionalized group quarters and noninstitutionalized group quarters and household population, by selected characteristics: American Community Survey (ACS) 2010.

A-34-1. Percentage of high school completers who were enrolled in 2- or 4-year colleges the October immediately following high school completion, by family income: 1975-2010

A-34-2. Percentage of high school completers who were enrolled in 2- or 4-year colleges the October immediately following high school completion, by race/ethnicity: 1975-2010

A-34-3. Percentage of high school completers who were enrolled in 2- or 4-year colleges the October immediately following high school completion, by sex and level of institution: 1975-2010.

A-35-1. Percentage of 12th-grade students with definite plans to engage in various postsecondary activities, by sex, race/ethnicity, and parents' highest level of education: 1990, 2000, and 2010

A-36-1. Number and percentage distribution of fall undergraduate enrollment in degree-granting institutions, by control and level of institution and selected student characteristics: Fall 2010

A-36-2. Number and percentage distribution of degree-granting institutions, retention rates, and overall graduation rates, by student attendance status, acceptance rate, and level and control of institution: 2010

A-37-1. Percentage of 16- to 24-year-old college students who were employed, by attendance status, hours worked per week, and level and control of institution: Selected years, October 1970 through October 2010

A-37-2. Percentage of 16- to 24-year-old college students who were employed, by attendance status, hours worked per week, and selected characteristics: October 2010.

A-38-1. Number of associate's and bachelor's degrees awarded by degree-granting institutions, percentage of total, number and percentage awarded to females, and percent change, by selected fields of study: Academic years 1999-2000 and 2009-10.

A-39-1. Number of master's and doctor's degrees awarded by degree-granting institutions, percentage of total, number and percentage awarded to females, and percent change, by selected fields of study: Academic years 1999-2000 and 2009-10. 
A-40-1. Average total costs of attending an undergraduate institution for first-time, full-time students, by control and level of institution, living arrangement, and component of student costs: Academic years 2009-10 and 2010-11 ....

A-40-2. Average amount of grant and scholarship aid and average net price for first-time, full-time students receiving aid and percentage distribution of students, by institution control and level and income level: Academic year 2009-10.....

A-41-1. Participation of full-time, first-time, degree-seeking undergraduate students in financial aid programs, by institution control, level, and type of aid: Academic year 2009-10.

A-41-2. Participation of full-time, first-time, degree-seeking undergraduate students in financial aid programs, by institution control, level, and type of aid: Academic years 2006-07 through 2009-10 .

A-42-1. Total and per full-time-equivalent (FTE) student revenue of postsecondary degree-granting institutions, by control of institution and source of funds: Academic years 2004-05 and 2009-10...

A-42-2. Total and per full-time-equivalent (FTE) student revenue of postsecondary degree-granting institutions, by institution level, institution control, and source of funds: Academic years 2004-05 and $2009-10$

A-43-1. Total and per full-time-equivalent (FTE) student expenses, by control of institution and purpose for degree-granting postsecondary institutions: Academic years 2004-05 and 2009-10.

A-43-2. Total and per full-time-equivalent (FTE) student expenses, by level and control of institution and purpose for degree-granting postsecondary institutions: Academic years 2004-05 and 2009-10.

A-44-1. Percentage distribution of full-time faculty and average total compensation, salary, and fringe benefits in current-year dollars for faculty on 9- and 10-month contracts at degree-granting institutions, by academic rank and control and level of institution: Academic years 1989-90, 1999-2000, and 2010-11 .....276

A-44-2. Inflation-adjusted average total compensation, salary, and fringe benefits for full-time faculty on 9and 10 -month contracts at degree-granting institutions, with percentage change, by academic rank and control and level of institutions: Academic years 1989-90, 1999-2000, and 2010-11

A-45-1. Percentage of students seeking a bachelor's degree at 4-year institutions who completed a bachelor's degree, by control of institution, sex, and time to degree attainment: Starting cohort years 1996 and 2004 ......

A-45-2. Percentage of students seeking a bachelor's degree at 4-year institutions who completed a bachelor's degree within 6 years, by selected characteristics: Starting cohort years 1996 and 2004

A-45-3. Percentage of students seeking a certificate or associate's degree at 2-year institutions who completed a certificate or associate's degree within 150 percent of the normal time required to do so, by race/ethnicity, control of institution, and sex: Starting cohort years 2000 and 2007.

A-46-1. Number and percentage distribution of degrees conferred by postsecondary degree-granting institutions, by control of institution and level of degree: Academic years 1999-2000 through 2009-10

A-47-1. Number of degrees conferred by degree-granting institutions and percentage of degrees conferred to females, by level of degree: Academic years 1999-2000 through 2009-10.....

A-47-2. Number and percentage change in degrees conferred to U.S. residents by degree-granting institutions, percentage distribution of degrees conferred, and percentage of degrees conferred to females, by level of degree and race/ethnicity: Academic years 1999-2000, 2004-05, and 2009-10 .

A-48-1. Percentage of 25- to 29-year-olds who attained selected levels of education, by race/ethnicity and sex: Selected years, 1980-2011

A-49-1. Median annual earnings and percentage of full-time, full-year wage and salary workers ages 25-34, by educational attainment, sex, and race/ethnicity: Selected years, 1995-2010 ...... 


\section{List of Figures}

Figure

\section{Introduction}

\section{Overview}

$1 \quad$ Percentage of the population ages 3-34 enrolled in school, by age group: October 1970-2010 ...................... 1

2 Averaged freshman graduation rate for public high school students, by state or jurisdiction: School year 2008-09.

3 Percentage of degrees conferred to U.S.-resident females by degree-granting institutions, by level of degree and race/ethnicity: Academic year 2009-10

\section{Closer Look}

CL-1. Actual and projected public school enrollment in grades 9 through 12: School years 1990-91 through 2021-22

CL-2. Percentage of high school graduates who completed selected mathematics and science courses in high school: 1990 and 2009

CL-3. Percentage of high school students ages 16 years and older who were employed, by sex: Selected years, 1990 to 2010

CL-4. Average scale scores of 12th-grade students, by subject: Selected years, 1994-2010

CL-5. Status dropout rates of 16- through 24-year-olds in the civilian, noninstitutionalized population, by race/ethnicity: October Current Population Survey (CPS) 1990-2010.

CL-6. Percentage of 12th-grade students with definite plans to graduate from a 4-year college, by parents' highest level of education: 1990, 2000, and 2010

\section{Section 1-Participation in Education}

1-1. Percentage of the population ages 3-34 enrolled in school, by age group: October 1970-2010 _.....................17

1-2. Percentage of the population ages 3-34 enrolled in school, by age group: October 2010 ..............................17

2-1. Percentage of 3-, 4-, and 5-year-old children enrolled in full-day preprimary programs:

Selected years, 1980 through 2010

2-2. Percentage of 3-, 4-, and 5-year old children enrolled in preprimary programs, by race/ethnicity and attendance status: October 2010

3-1. Actual and projected public school enrollment in grades prekindergarten (preK) through 12, by grade level: School years 1970-71 through 2021-22

3-2. Projected percent change in public school enrollment in grades prekindergarten (preK) through 12, by state or jurisdiction: Between school years 2010-11 and 2021-22.

4-1. Number of students enrolled in public charter schools: Selected school years, 1999-2000 through 2009-10

4-2. Percentage of all public students who are in charter schools, by state: School year 2009-10

5-1. Number of private school students in prekindergarten through grade 12, by school type: Various school years, 1995-96 through 2009-10

5-2. Percentage distribution of private school enrollment, by school type and level: 2009-10

6-1. Percentage distribution of public school students enrolled in prekindergarten through 12th grade, by race/ethnicity: Selected years, October 1990-October 2010 .

6-2. Number of public school students enrolled in prekindergarten through 12th grade, by region and race/ethnicity: October 1990-October 2010......

7-1. Percentage of 5- to 17-year-olds living in two-parent households, by race/ethnicity: 1990, 2000, and 2011 
7-2. Percentage of 5- to 17-year-olds who were living in poor households, by race/ethnicity: 2006 and 2011 ........29

8-1. Percentage of public school students who are English language learners (ELLs), by state: School year 2009-10

8-2. Percentage of public school students who are English language learners (ELLs), by locale: School year 2009-10

9-1. Percentage distribution of children and youth ages 3-21 served under the Individuals with Disabilities Education Act (IDEA), by disability type: School year 2009-10.

9-2. Percentage of students ages 6-21 served under the Individuals with Disabilities Education Act (IDEA), Part B, placed in a regular school environment, by amount of time spent in general classes:

Selected school years, 1990-91 through 2009-10.

10-1. Actual and projected undergraduate enrollment in degree-granting postsecondary institutions, by sex and attendance status: Fall 1970-2021 .....

10-2. Percentage distribution for undergraduate enrollment of U.S. residents in degree-granting postsecondary institutions, by race/ethnicity: Fall 1980, 1990, 2000, and 2010...

11-1. Actual and projected postbaccalaureate enrollment in degree-granting postsecondary institutions, by sex: Fall 1976-2021 .

11-2. Percentage distribution for postbaccalaureate enrollment of U.S. residents in degree-granting postsecondary institutions, by race/ethnicity: Selected years, fall 1980-2010...

\section{Section 2-Elementary and Secondary Education}

12-1. Percentage distribution of schools, by control and racial/ethnic concentration of schools: School years 1999-2000 and 2009-10

12-2. Percentage distribution of schools, by locale and control: School year 2009-10

13-1. Percentage distribution of public school students, by school locale and poverty level: School year 2009-10

13-2. Percentage of public school students in high-poverty schools and low-poverty schools, by race/ethnicity and school level: School year 2009-10 .....

14-1. Percentage of public schools recording and reporting to the police at least one incident or one serious violent incident of crime that occurred at school: Selected school years, 1999-2000 through 2009-10.....

14-2. Percentage of public schools recording violent incidents of crime that occurred at school, by number of incidents and school locale: School year 2009-10

15-1. Number of public high school student enrollments in distance education courses: School years 2002-03, 2004-05, and 2009-10.

15-2. Percentage of public school districts that offered distance education, by locale and selected primary modes of instructional delivery: School years 2004-05 and 2009-10

16-1. Percentage distribution of public high schools, by student retention rate: Selected academic years, 1990-91 through 2009-10

16-2. Percentage distribution of public high schools, by student retention rate and percentage of students eligible for free or reduced-price lunch: Academic year 2009-10

17-1. Percentage distribution of full-time school teachers, by school level and highest degree earned:

School years 2003-04 and 2007-08.

17-2. Percentage distribution of full-time secondary level teachers, by school type and years of experience: School years 2003-04 and 2007-08...

18-1. Percentage of male principals, by school type and level: School years 1999-2000 and 2007-08 ........

18-2. Percentage distribution of public school principals, by school level and years of experience as a principal: School years 1999-2000 and 2007-08 
19-1. Revenues for public elementary and secondary schools, by revenue source: School years 1989-90 through 2008-09.

19-2. Local revenues for public elementary and secondary schools as a percentage of total school revenues, by state: School year 2008-09.....

20-1. Percentage change in total expenditures per student in fall enrollment in public elementary and secondary schools, by expenditure type and objects of current expenditures, in constant 2010-11 dollars: School years 1988-89 to 2008-09

20-2. Current expenditures per student in fall enrollment in public elementary and secondary schools in constant 2010-11 dollars, by expenditure object: School years 1988-89, 1998-99, and 2008-09

21-1. Variation in instruction expenditures per student in unified public elementary and secondary school districts, by source of variation: School years 1989-90 through 2008-09.

21-2. Percentage distribution of source of variation in instruction expenditures per student in unified public elementary and secondary school districts: Selected school years, 1989-90 through 2008-09

22-1. Annual expenditures per student for elementary and secondary education in selected Organization for Economic Cooperation and Development (OECD) countries, by gross domestic product (GDP) per capita: 2008

22-2. Annual expenditures per student for postsecondary education in selected Organization for Economic Cooperation and Development (OECD) countries, by gross domestic product (GDP) per capita: 2008.

23-1. Average reading scale scores of 4th-, 8th-, and 12th-grade students: Selected years, 1992-2011

23-2. Percentage distribution of 4th- and 8th-grade students across National Assessment of Educational Progress (NAEP) reading achievement levels: Selected years, 1992-2011

24-1. Average mathematics scale scores of 4th- and 8th-grade students: Selected years, 1990-2011

24-2. Percentage distribution of 4th- and 8th-grade students across National Assessment of Educational Progress (NAEP) mathematics achievement levels: Selected years, 1990-2011.....

25-1. Average scale scores of 4th-, 8th-, and 12th-grade students, by subject: Selected years, 1994-2010

25-2. Percentage of 12th-grade students at selected National Assessment of Educational Progress (NAEP) achievement levels, by subject: 1994, 1998, and 2010 .....

26-1. Percentage of 15-year-old students on the combined reading literacy scale in the United States and Organization for Economic Co-operation and Development (OECD) countries, by selected Program for International Student Assessment (PISA) proficiency levels: 2000 and 2009.

26-2. Percentage of 15-year-old students on the mathematics and science literacy scales in the United States and Organization for Economic Co-operation and Development (OECD) countries, by selected Program for International Student Assessment (PISA) proficiency levels: 2003, 2006, and 2009.

27-1. Percentage of high school seniors who participated in various extracurricular activities, by type of activity: Selected years, 1990 through 2010

27-2. Percentage of high school seniors who participated in various extracurricular activities, by college plans: 2010

28-1. Average National Assessment of Educational Progress reading scale scores of 12th-grade students, by the number of days of school they reported missing in the previous month: Various years, 1992-2009 .....73

28-2. Percentage of 8th- and 12th-grade students, by number of days of school missed in the previous month and race/ethnicity: 2009 and 2011

29-1. Percentage of youth ages 16-24 who were neither enrolled in school nor working, by sex:

Selected years, 1990-2011

29-2. Percentage of youth ages 16-24 who were neither enrolled in school nor working, by household type and citizenship: 2011

30-1. Percentage of high school students ages 16 years and older who were employed, by sex: Selected years, 1980 to 2010 ........ 
30-2. Percentage of employed high school students ages 16 years and older who worked more than 15 hours per week, by selected student characteristics: 2010

31-1. Percentage of high school graduates who completed selected mathematics and science courses in high school: 1990 and 2009 .

31-2. Average National Assessment of Educational Progress (NAEP) 12th-grade mathematics scale scores of high school graduates, by highest mathematics course taken and race/ethnicity: 2009 .....

32-1. Averaged freshman graduation rate for public high school students, by state or jurisdiction: School year 2008-09.

32-2. Averaged freshman graduation rate for public high school students: Selected school years 1990-91 through 2008-09

33-1. Status dropout rates of 16- through 24-year-olds in the civilian, noninstitutionalized population, by race/ethnicity: October Current Population Survey (CPS) 1995-2010

33-2. Status dropout rates of 16- through 24-year-olds in the noninstitutionalized group quarters and household population, by nativity and race/ethnicity: American Community Survey (ACS) 2010

34-1. Percentage of high school completers who were enrolled in 2- or 4-year colleges the October immediately following high school completion, by family income: $1975-2010$.....

34-2. Percentage of high school completers who were enrolled in 2- or 4-year colleges the October immediately following high school completion, by race/ethnicity: 1975-2010

35-1. Percentage of 12th-grade students with definite plans to graduate from a 4-year college, by sex and race/ethnicity: 1990, 2000, and 2010 .

35-2. Percentage of 12th-grade students with definite plans to graduate from a 4-year college,

by parents' highest level of education: 1990, 2000, and 2010 .

\section{Section 3-Postsecondary Education}

36-1. Percentage distribution of fall undergraduate enrollment in degree-granting institutions, by student attendance status and control and level of institution: Fall 2010.

36-2. Annual retention rates and graduation rates within 150 percent of normal time at all 4-year degree-granting institutions, by student attendance status and acceptance rate: Fall 2010.

37-1. Percentage of 16- to 24-year-old college students who were employed, by attendance status and hours worked per week: October 1970 through October 2010

37-2. Percentage of 16- to 24-year-old college students who were employed, by attendance status, hours worked per week, and sex: October 2010 .....

38-1. Number of bachelor's degrees awarded by degree-granting institutions in selected fields of study:

Academic years 1999-2000 and 2009-10.

38-2. Percentage of bachelor's degrees awarded to females by degree-granting institutions in selected fields of study: Academic year 2009-10

39-1. Number of master's degrees awarded by degree-granting institutions in selected fields of study: Academic years 1999-2000 and 2009-10..

39-2. Percentage of master's degrees awarded to females by degree-granting institutions in selected fields of study: Academic year 2009-10

40-1. Total cost of attending an undergraduate institution for first-time, full-time students receiving aid, by level and control of institution and living arrangement: Academic year 2010-11

40-2. Average total price, grants and scholarship aid, and net price for first-time, full-time students receiving aid at 4-year institutions, by income level: Academic year 2009-10 .

41-1. Percentage of first-time, full-time undergraduate students receiving any financial aid at 4-year institutions, by institution control: Academic years 2006-07 through 2009-10 . 
41-2. Average amount of aid received by full-time, first-time, degree-seeking undergraduate students in financial aid programs, by institution level, control, and type of aid: Academic year 2009-10......

42-1. Revenue per full-time-equivalent (FTE) student from tuition and fees for postsecondary degree-granting institutions, by institution control and level: Academic year 2009-10

42-2. Percentage distribution of total revenues at postsecondary degree-granting institutions, by institution level, institution control, and source of funds: Academic year 2009-10

43-1. Expenses per full-time-equivalent (FTE) student at degree-granting postsecondary institutions, by control of institution and purpose: Academic year 2009-10.

43-2. Total expenses per full-time-equivalent (FTE) student at 2-year and 4-year degree-granting postsecondary institutions, by control of institution: Academic years 2004-05 and 2009-10

44-1. Average salary for full-time instructional faculty on 9- and 10-month contracts at degree-granting postsecondary institutions, by control and level of institution: Academic year 2010-11

44-2. Inflation-adjusted average total compensation, salary, and fringe benefits for full-time faculty on 9and 10-month contracts at degree-granting institutions, with percentage change, by academic rank and control and level of institutions: Academic years 1989-90, 1999-2000, and 2010-11

45-1. Percentage of students seeking a bachelor's degree at 4-year institutions who completed a bachelor's degree within 6 years, by control of institution and cohort year: Starting cohort years 1996 and 2004 .

45-2. Percentage of students seeking a bachelor's degree at 4-year institutions who completed a

bachelor's degree within 6 years, by control of institution and race/ethnicity:

Starting cohort year 2004 .

46-1. Number of degrees conferred by postsecondary degree-granting institutions, by level of degree: Academic years 1999-2000 through 2009-10.

47-1. Number of degrees conferred by degree-granting institutions, by level of degree: Academic years 1999-2000, 2004-05, and 2009-10

47-2. Percentage of degrees conferred to U.S.-resident females by degree-granting institutions, by level of degree and race/ethnicity: Academic year 2009-10

48-1. Percentage of 25- to 29-year-olds who completed at least a high school diploma or equivalency, by race/ethnicity: 1980-2011.

48-2. Percentage of 25- to 29-year-olds with a bachelor's degree or higher, by race/ethnicity: 1980-2011

49-1. Median annual earnings of full-time, full-year wage and salary workers ages 25-34, by educational attainment: $1995-2010$

49-2. Median annual earnings of full-time, full-year wage and salary workers ages 25-34, by educational attainment and sex: 2010 . 
This page intentionally left blank.

xxii The Condition of Education 2012 


\section{Introduction}

To ensure reliable, accurate, and timely data, which are necessary to monitor the progress of education in the United States, Congress has mandated that the National Center for Education Statistics (NCES) produce an annual report, The Condition of Education. This year's report presents 49 indicators of important developments and trends in U.S. education. These indicators focus on participation in education, elementary and secondary education and outcomes, and postsecondary education and outcomes.

This introduction features an Overview and a Closer Look. The Overview summarizes each section of the volume by highlighting each indicator, which is referenced by its number (e.g., indicator 19). Each figure in the Overview can also be found in an indicator in the volume. For indicators with figures highlighted in the Overview, the Overview figure number will be followed by the indicator figure number in its reference (i.e., figure 3 is figure 47-2). The Closer Look examines a subset of indicators on high school education over the last twenty years using data from the full indicators. The relevant figures are included and referenced tables can be found in Appendix A.

\section{Overview}

\section{Section 1 - Participation in Education in the United States}

- Between 2000 and 2010, enrollment rates increased for young adults ages 18-19 and adults ages 20-24, 25-29, and 30-34; students in these age groups are typically enrolled in college or graduate school (indicator 1).

- The percentage of 3-to 5-year-olds enrolled in full-day preprimary programs increased from 32 percent in 1980 to 58 percent in 2010 (indicator 2).

- From school years 2010-11 through 2021-22, public elementary and secondary school enrollment is projected to increase by 7 percent from 49.5 to 53.1 million students, but with changes across states ranging from an increase of 22 percent to a decrease of 15 percent (indicator 3 ).

From 1999-2000 to 2009-10, the number of students enrolled in public charter schools more than quadrupled from 0.3 million to 1.6 million students. In 2009-10, some 5 percent of all public schools were charter schools (indicator 4 ).

- Private school enrollment in prekindergarten through grade 12 increased from 5.9 million in $1995-96$ to 6.3 million in 2001-02 then decreased to 5.5 million

Figure 1. (Figure 1-1) Percentage of the population ages 3-34 enrolled in school, by age group: October 1970-2010

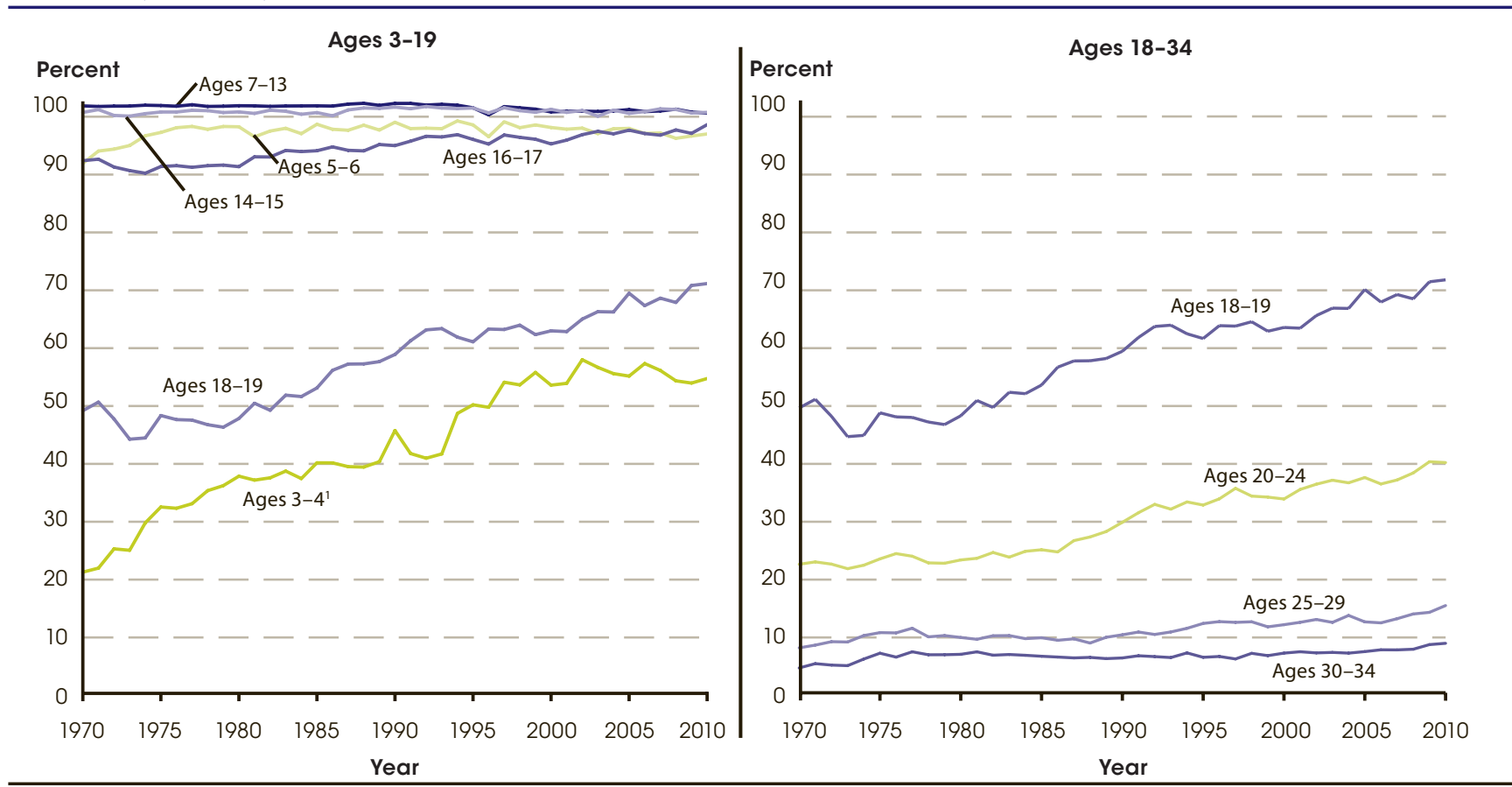

Beginning in 1994, new procedures were used to collect enrollment data on children ages 3-4. As a result, pre-1994 data may not be comparable to data from 1994 or later.

NOTE: Includes enrollment in any type of graded public or parochial or other private schools and includes nursery schools or preschools, kindergartens, elementary schools, secondary schools, colleges, universities, and professional schools. Excludes enrollments in schools that do not advance students toward a regular school degree (e.g., trade schools, business colleges, and correspondence courses). The enrollment rate for ages 18-19 includes enrollment at both the secondary level and the college level. For more information on the Current Population Survey (CPS), see Appendix B - Guide to Sources.

SOURCE: U.S. Department of Commerce, Census Bureau, Current Population Survey (CPS), October Supplement, 1970-2010. 
in 2009-10. Some 10 percent of all elementary and secondary school students were in private schools in 2009-10 (indicator 5).

- Between 1990 and 2010, the percentage of public school students who were White decreased from 67 to 54 percent, and the percentage of those who were Hispanic increased from 12 percent (5.1 million students) to 23 percent (12.1 million students) (indicator 6).

- In 2011, higher percentages of Black (37 percent), Hispanic (34 percent), American Indian/Alaska Native (33 percent), Native Hawaiian/Pacific Islander (32 percent) children, and children of two or more races (20 percent) were living in families below the poverty threshold than were White (12 percent) and Asian (14 percent) children (indicator 7).

- The percentage of public school students in the United States who were English language learners (ELLs) was higher in 2009-10 at 10 percent (or an estimated 4.7 million students) than in 2000-01 at 8 percent (or an estimated 3.7 million students) (indicator 8).

- The number of children and youth ages 3-21 receiving special education services was 6.5 million in 2009-10, or about 13 percent of all public school students. Some 38 percent of the students receiving special education services had specific learning disabilities (indicator 9).

- Between 2000 and 2010, undergraduate enrollment in degree-granting postsecondary institutions increased by 37 percent, from 13.2 to 18.1 million students. Projections indicate that undergraduate enrollment will continue to increase, reaching 20.6 million students in 2021 (indicator 10).

- Postbaccalaureate enrollment has increased every year since 1983, reaching 2.9 million students in 2010. In each year since 1988, women have comprised more than half of postbaccalaureate enrollment. In 2010, postbaccalaureate enrollment was 59 percent female (indicator 11).

\section{Section 2 - Elementary and Secondary Education and Outcomes}

- In 2009-10, some 5 percent of traditional public schools were combined schools (schools with both elementary and secondary grades), whereas 19 percent of charter schools and 28 percent of private schools were combined schools (indicator 12).

- Among public school students in 2009-10, higher percentages of Hispanic (37 percent), Black (37 percent), and American Indian/Alaska Native students (29 percent) attended high-poverty schools than did Asian/Pacific Islander (12 percent) and White students (6 percent) (indicator 13$)$.
- Sixteen percent of public schools recorded at least one incident of serious violent crime in 2009-10; this was lower than the 20 percent of schools recording at least one incident in 1999-2000 (indicator 14).

- In 2009-10, some 53 percent of public school districts had high school students enrolled in distance education courses. In these districts, there were over 1.3 million high school student enrollments in distance education in 2009-10, compared to 0.3 million 5 years earlier (indicator 15).

- Of approximately 15,500 regular high schools with at least 10 seniors in 2009-10, there were 890 schools (6 percent) in which the number of seniors divided by the number of freshmen 4 years earlier was between 10 and 50 percent (indicator 16).

A larger percentage of full-time teachers held a postbaccalaureate degree in 2007-08 than in 200304 . Forty-nine percent of elementary school teachers and 54 percent of secondary school teachers held a postbaccalaureate degree in 2007-08, compared with 45 and 50 percent, respectively, in 2003-04 (indicator 17).

- From 1999-2000 to 2007-08, the percentage of principals who were female increased from 52 to 59 percent at public elementary schools and from 22 to 29 percent at public secondary schools (indicator 18).

- From school year 1988-89 through 2008-09, total elementary and secondary public school revenues increased from $\$ 350$ billion to $\$ 611$ billion, a 74 percent increase after adjusting for inflation (indicator 19).

- Total expenditures per student in public elementary and secondary schools rose 46 percent in constant dollars from 1988-89 through 2008-09, with interest on school debt increasing faster than current expenditures or capital outlay (indicator 20).

- After increasing every year from 1997-98 to 2007-08, total variation in instruction expenditures per student was lower among public school districts in 2008-09 than in 2007-08 (indicator 21).

- In 2008, the United States spent $\$ 10,995$ per student on elementary and secondary education, which was 35 percent higher than the Organization for Economic Co-operation and Development (OECD) average of $\$ 8,169$. At the postsecondary level, U.S. expenditures per student were $\$ 29,910$, more than twice as high as the OECD average of $\$ 13,461$ (indicator 22).

- The average grade 4 reading score in 2011 was not measurably different from that in 2009. The average grade 8 score, however, was 1 point higher in 2011 than in 2009 (indicator 23).

- At grades 4 and 8 , the average mathematics scores in 2011 were higher than the average scores for those grades in all previous assessment years (indicator 24). 
- At grade 12, the National Assessment of Educational Progress (NAEP) U.S. history score was 2 points higher in 2010 than in 1994, while the geography score was 2 points lower. There was no measurable difference in the civics score from 1998 to 2010 (indicator 25).

- In 2009, the percentage of high-performing 15-yearolds in the United States was higher in reading literacy, lower in mathematics literacy, and not measurably different in science literacy than the respective percentages in the OECD countries on average (indicator 26).

- In 2010, some 40 percent of high school seniors participated in athletics, including 44 percent of males and 36 percent of females (indicator 27).

- In 2009, the average NAEP reading score of 12th-grade students with perfect attendance (292) was not measurably different from the score of those who reported missing 1-2 days in the previous month (290), but was higher than the scores of those who reported missing 3-4 days (284) and missing 5 or more days (273) (indicator 28).

- In 2011, about 14 percent of youth ages 16-24 were neither enrolled in school nor working (indicator 29).
Between 1980 and 2010, the percentage of high school students age 16 years or above who were employed decreased from 36 percent to 16 percent. For male high school students, the decrease was from 37 percent in 1980 to 14 percent in 2010 (indicator $30)$.

- The percentages of high school graduates who took mathematics courses in geometry, algebra II/trigonometry, analysis/precalculus, statistics/ probability, and calculus while in high school were higher in 2009 than in 1990 (indicator 31).

- In school year 2008-09, more than three-quarters of public high school students graduated on time with a regular diploma (indicator 32).

- Between 1990 and 2010, status dropout rates declined for Whites, Blacks, and Hispanics. Over this period, the status dropout rate was generally lowest for Asians/Pacific Islanders, followed by Whites, Blacks, and Hispanics (indicator 33).

- Over the 35-year period between 1975 and 2010, the rate of immediate college enrollment after high school ranged from a low of 49 percent in 1979 and 1980, to a high of 70 percent in 2009. This rate increased most recently from 2001 to 2009 . (indicator 34).

Figure 2. (Figure 32-1) Averaged freshman graduation rate for public high school students, by state or jurisdiction: School year 2008-09

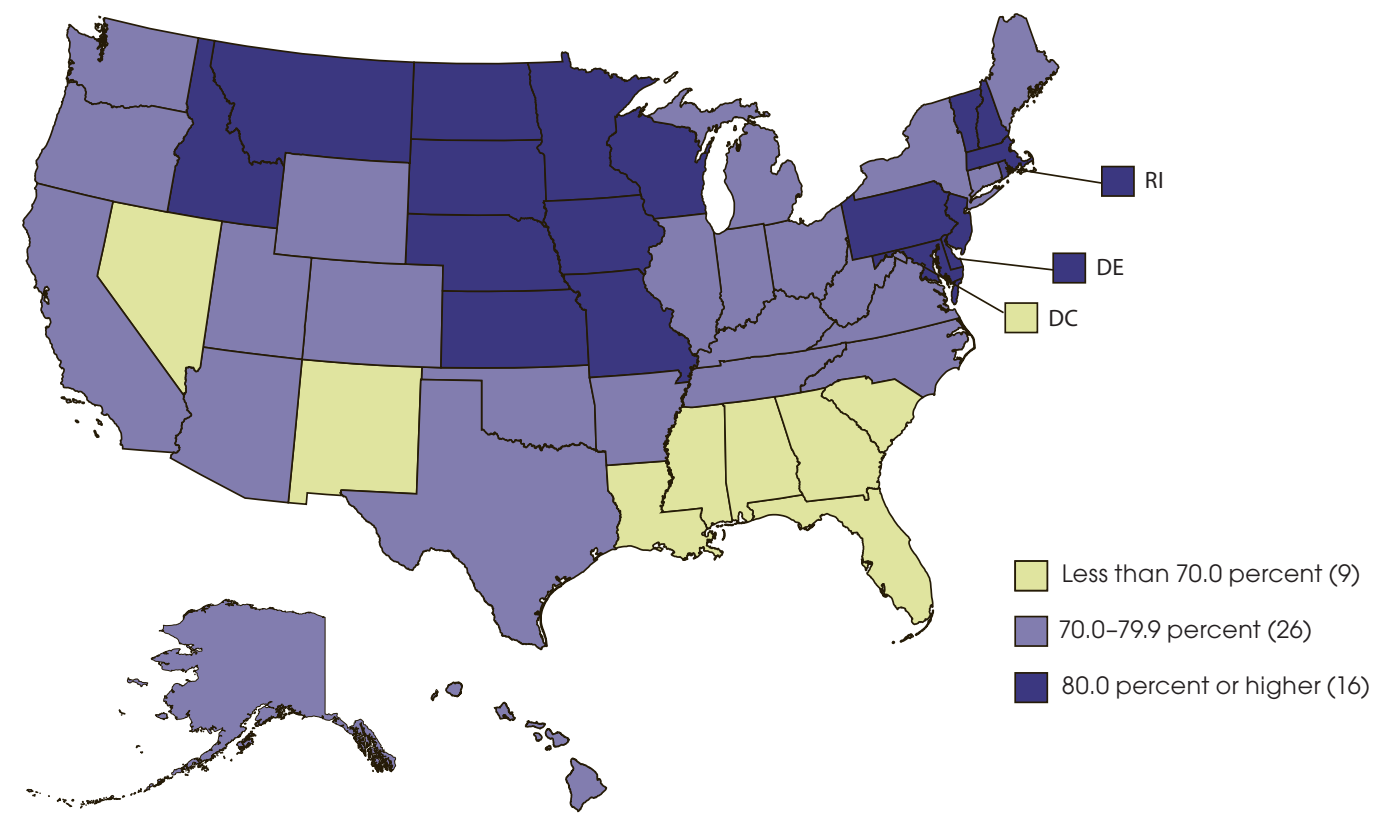

NOTE: The averaged freshman graduation rate is the number of graduates divided by the estimated freshman enrollment count 4 years earlier. This count is the sum of the number of 8th-graders 5 years earlier, the number of 9th-graders 4 years earlier, and the number of 10 th-graders 3 years earlier, divided by 3. Ungraded students were allocated to individual grades proportional to each state's enrollment in those grades. Graduates include only those who earned regular diplomas or diplomas for advanced academic achievement (e.g., honors diploma) as defined by the state or jurisdiction. Data for California and Nevada were imputed. For more information on measures of student progress and persistence, see Appendix C - Commonly Used Measures. For more information on the Common Core of Data (CCD), see Appendix B - Guide to Sources.

SOURCE: U.S. Department of Education, National Center for Education Statistics, Common Core of Data (CCD), "NCES Common Core of Data State Dropout and Completion Data File," school year 2008-09, version 1 a. 
- In 1990, 2000, and 2010, higher percentages of female than male 12th-grade students had definite plans to graduate from a 4-year college. This gap in expectations by sex was larger in 2010 than in 1990 (13 vs. 5 percentage points) (indicator 35).

\section{Section 3 - Postsecondary Education and Outcomes}

- Of the 18 million undergraduate students at degreegranting institutions in the United States in fall 2010, some 76 percent attended public institutions, 15 percent attended private nonprofit institutions, and 10 percent attended private for-profit institutions (indicator 36).

- In 2010, about 40 percent of full-time and 73 percent of part-time college students ages 16 to 24 were employed (indicator 37).

- In 2009-10, more than half of the 1.7 million bachelor's degrees awarded were in five fields: business, management, marketing, and personal and culinary services (22 percent); social sciences and history (10 percent); health professions and related programs (8 percent); education (6 percent); and psychology (6 percent) (indicator 38 ).

- Overall, 693,000 master's degrees and 159,000 doctor's degrees were awarded in 2009-10; these numbers represent increases of 50 and 34 percent, respectively, over the numbers awarded in 1999-2000. In 2009-10, females earned 60 percent of master's degrees and 52 percent of doctor's degrees awarded (indicator 39).

- The average total cost of attendance in 2010-11 for first-time, full-time students living on campus and paying in-state tuition was $\$ 20,100$ at public 4-year institutions and $\$ 39,800$ at private nonprofit 4-year institutions (indicator 40).

- From 2006-07 to 2009-10, the percentage of first-time, full-time undergraduates receiving any financial aid increased from 75 to 85 percent at 4-year institutions (indicator 41).

- In academic year 2009-10, total revenues per fulltime-equivalent (FTE) student were 1 percent less than in 2004-05 in public postsecondary degreegranting institutions (in constant 2010-11 dollars). Total revenues per student went from $\$ 28,966$ in $2004-05$ to $\$ 28,781$ in $2009-10$ (indicator 42 ).

- In academic year 2009-10, instruction was the largest per-FTE-student expense at public $(\$ 7,239)$ and private nonprofit institutions $(\$ 15,321)$. At private for-profit institutions, instruction was the second largest expense category, at $\$ 3,017$ per student (indicator 43).

Figure 3. (Figure 47-2) Percentage of degrees conferred to U.S.-resident females by degree-granting institutions, by level of degree and race/ethnicity: Academic year 2009-10

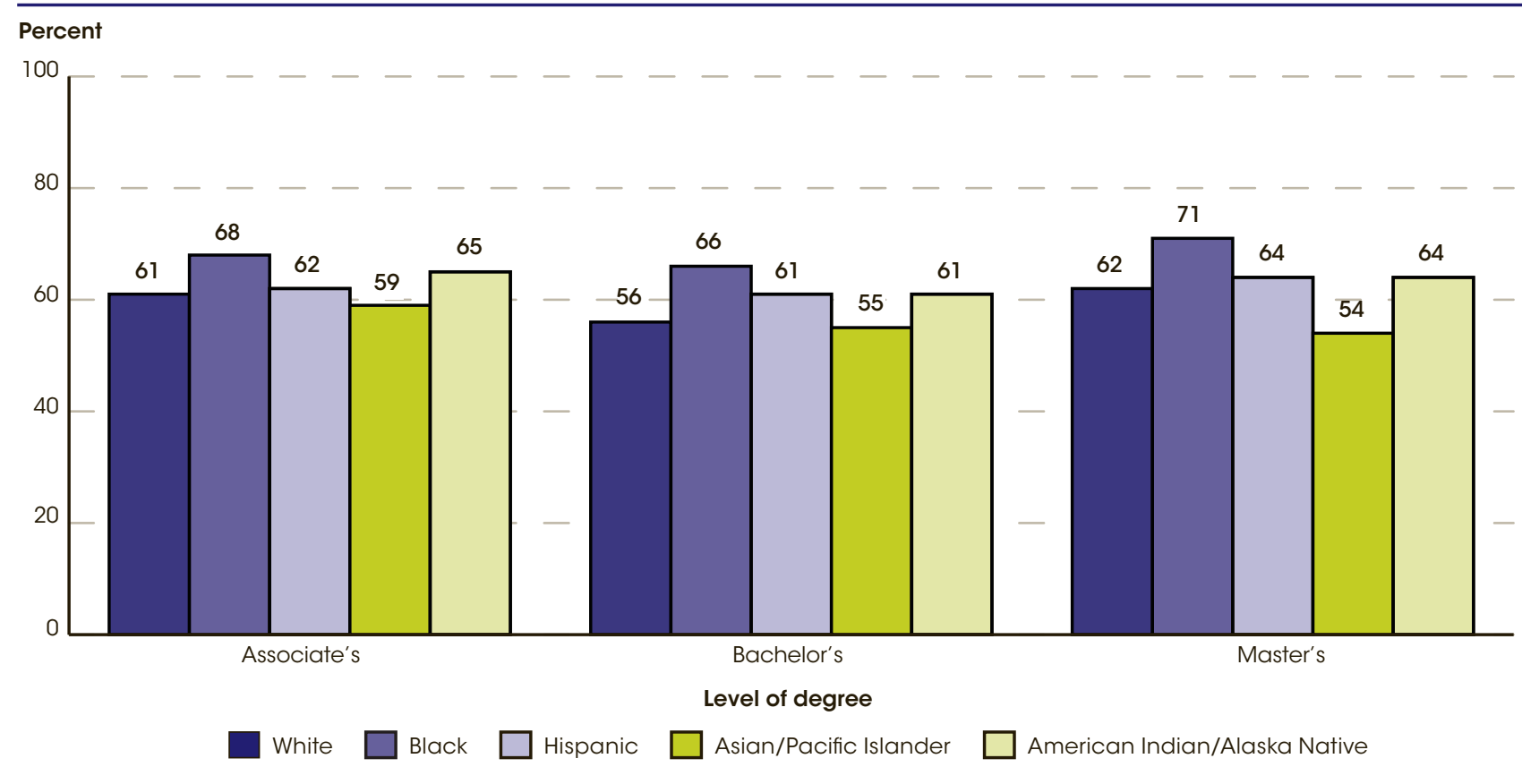

NOTE: Degree-granting institutions grant associate's or higher degrees and participate in Title IV federal financial aid programs. Reported racial/ethnic distributions of students by type of degree, field of degree, and sex were used to estimate race/ethnicity for students whose race/ethnicity was not reported. Race categories exclude persons of Hispanic ethnicity. Nonresident aliens are excluded because information about their race/ethnicity is not available. For more information on race/ethnicity and the Integrated Postsecondary Education Data System (IPEDS) classification of degree levels, see Appendix C - Commonly Used Measures. For more information on IPEDS, see Appendix B - Guide to Sources.

SOURCE: U.S. Department of Education, National Center for Education Statistics, Integrated Postsecondary Education Data System (IPEDS), Fall 2010, Completions component. 
- Combining salary with benefits, faculty received an average total compensation package in academic year 2010-11 that was about 8 percent higher than the package they received in 1999-2000, after adjusting for inflation. In 2010-11, the average total compensation package for faculty was about $\$ 97,200$, including $\$ 75,500$ in salaries and $\$ 21,700$ in benefits (indicator 44).

- Approximately 56 percent of male and 61 percent of female first-time, full-time students who sought a bachelor's degree at a 4-year institution in fall 2004 completed their degree at that institution within 6 years (indicator 45).

- From academic years 1999-2000 to 2009-10, the number of postsecondary degrees conferred by private for-profit institutions increased by a larger percentage than the number conferred by public institutions and private nonprofit institutions; this was true for all levels of degrees (indicator 46 ).
- Between academic years 1999-2000 and 2009-10, the number of degrees earned increased by 50 percent each for associate's and master's degrees, 33 percent for bachelor's degrees, and 34 percent for doctor's degrees. For all levels of degrees in 2009-10, females earned the majority of degrees awarded (indicator 47).

In 2011, some 32 percent of 25- to 29-year-olds had completed a bachelor's degree or higher. From 1980 to 2011, the gap in the attainment of a bachelor's degree or higher between Whites and Hispanics widened from 17 to 26 percentage points, and the gap between Whites and Blacks widened from 13 to 19 percentage points (indicator 48).

- In 2010, young adults ages 25-34 with a bachelor's degree earned 114 percent more than young adults without a high school diploma or its equivalent, 50 percent more than young adult high school completers, and 22 percent more than young adults with an associate's degree (indicator 49). 


\section{A Closer Look at High School Students in the United States Over the Last 20 Years}

In the United States, the compulsory age for school attendance is determined by each state and the maximum age ranges between 16 and 18 years old (see indicator 1). Enrollment rates for 16- and 17-year-olds have exceeded 90 percent for the past twenty years. Over this same time period the percentage of 25- to 29-year-olds with at least a high school diploma or similar credential has exceeded 85 percent (see indicator 48).

In the last two decades certain aspects of the high school experience, and of the students themselves, have changed. Several indicators in this volume describe high school students in terms of enrollment, coursetaking, afterschool activities (including work), achievement and other outcomes, and their expectations for the future. In this section, we take a closer look at high school in the United States by examining how these indicators have changed, or not, over the last 20 years. Note: For those indicators where 20 years of data are not available, the earliest data are used as the starting point.

\section{High Schools and High School Enrollment}

In 2010-11, there were approximately 14.9 million public school students in grades 9-12 (see indicator 3). Public school enrollment in grades 9-12 increased from 11.3 million in 1990-91 to just over 15 million through 2007-08, but declined through 2010-11. Public school enrollment in grades $9-12$ is projected to continue declining through 2012-13. From 2013-14 through 2021-22, enrollment in grades $9-12$ is projected to increase from 14.8 million to 15.5 million.
There has been variation in the increase in public high school enrollment by region. Between 1989-90 and 2010-11, the number of public school students in grades 9-12 increased by 14 percent in the Midwest, from 2.9 million to 3.3 million, by 19 percent in the Northeast, from 2.1 million students to 2.5 million, by 35 percent in the South, from 4.0 million to 5.4 million, and by 52 percent in the West, from 2.4 million to 3.7 million.

Of the 12.5 million public high school students in 1995-96, some 67 percent were White, 16 percent were Black, 12 percent were Hispanic, 4 percent were Asian, and 1 percent were American Indian/Alaska Native (see Projections of Education Statistics to 2020, NCES 2011$026,5)$. In 2010-11, public school enrollment in grades 9-12 was 56 percent White, 17 percent Black, 20 percent Hispanic, 5 percent Asian, and 1 percent American Indian/Alaska Native. By 2019-20, it is projected that public high school enrollment will be 53 percent White, 16 percent Black, 23 percent Hispanic, 7 percent Asian, and 1 percent American Indian/Alaska Native.

There were 1.3 million private school students in grades 9-12 in the United States in 2009-10 (see indicator 5).

These students accounted for 8 percent of total high school enrollment in that year. Of these students, 618,000 attended Catholic schools, 411,000 attended other religious schools, and 280,000 attended nonsectarian schools. In 1995-96, there were also 618,000 high school students attending Catholic schools. However, Catholic high school enrollment increased over the next six years to 641,000 in $2001-02$, before declining back to the 1995-96 level. In the Northeast in 2009-10, some 13 percent of students in grades 9-12 attended private schools, compared to 8 percent of students in the Midwest, 7 percent of students in the South, and 6 percent of students in the West.

\section{Figure CL-1. Actual and projected public school enrollment in grades 9 through 12: School years 1990-91 through}

2021-22

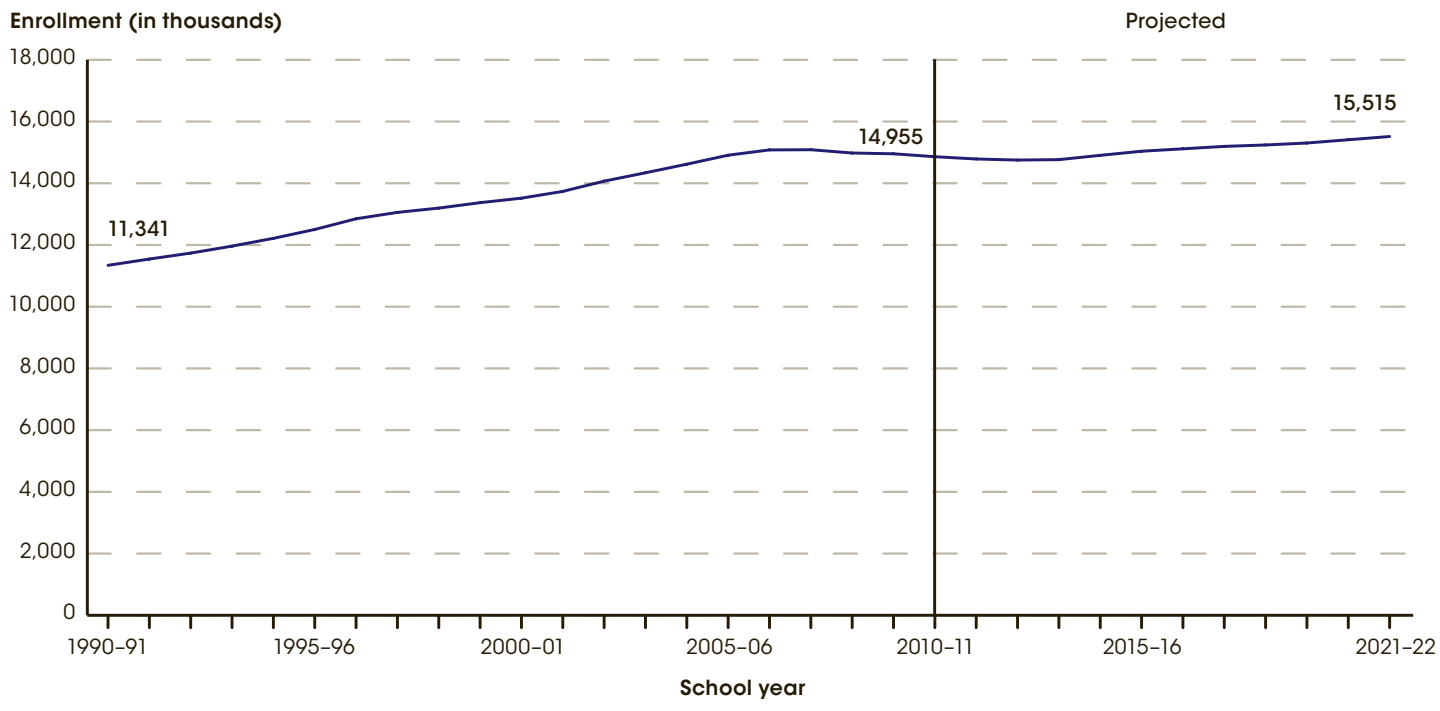

NOTE: The most recent year of actual data is 2010-11, and 2021-22 is the last year for which projected data are available. For more information on projections, see NCES 2012-044. Detail may not sum to totals because of rounding. Some data have been revised from previously published figures. SOURCE: U.S. Department of Education, National Center for Education Statistics, Common Core of Data (CCD), "State Nonfiscal Survey of Public Elementary/ Secondary Education," 1990-91 through 2010-11, and National Elementary and Secondary Enrollment Model, 1990-2010. 
In 2009-10, there were 27,500 secondary schools (schools that enrolled students in at least one of the grades between 9 and 12) in the United States (see indicator 12). Of these schools, some 23,300 were traditional public schools, some 1,300 were public charter schools, and 2,800 were private schools. High school students can also attend combined schools, with both elementary and secondary grade spans. In 2009-10, some 25 percent of public schools were secondary schools and 6 percent of public schools were combined schools. In that same year, some 8 percent of private schools were secondary schools and 28 percent were combined schools. In 2009-10, some 75 percent of private secondary schools were Catholic schools (see indicator 5).

\section{Activities Inside School}

In this section, we look at how activities inside high schools have changed in the last twenty years, including coursetaking, distance education, absenteeism, and school crime and safety.

In 1983, the National Commission on Excellence in Education, appointed by the U.S. Department of Education, released a report titled $A$ Nation at Risk: The Imperative for Educational Reform. The report contained five recommendations to improve our education system, and the first recommendation was that "state and local high school graduation requirements be strengthened and that, at a minimum, all students seeking a diploma be required to lay the foundations in the Five New Basics by taking the following curriculum during their 4 years of high school: (a) 4 years of English; (b) 3 years of mathematics; (c) 3 years of science; (d) 3 years of social studies; and (e) one-half year of computer science."
More recently, concerns have been raised that our postsecondary system is not producing enough graduates in fields focused on science, technology, engineering, and mathematics (STEM). For that to happen, high school students must take related course work to prepare them for rigorous college programs in STEM fields.

The percentage of high school graduates who took mathematics and science courses (or combinations of these courses) while in high school-namely, algebra I, geometry, algebra II/trigonometry, analysis/precalculus, statistics/probability, calculus, biology, chemistry, physics, both biology and chemistry, and all three science courses (biology, chemistry, and physics)_increased from 1990 to 2009 in all subjects except algebra I, for which the percentage decreased (see indicator 31). The decrease in the percentage of students taking Algebra I in high school is likely due to an increase in the percentage taking it prior to high school. For example, 7 percent of 1990 graduates had taken calculus in high school, compared with 16 percent of 2009 graduates, and 1 percent of 1990 graduates had taken statistics/probability, compared with 11 percent of graduates in 2009 . In science, 49 percent of 1990 graduates had taken chemistry and 21 percent had taken physics. These percentages were 70 percent for chemistry and 36 percent for physics for 2009 graduates. Similarly, 19 percent of 1990 graduates had taken biology, chemistry, and physics in high school, compared with 30 percent of 2009 graduates.

A more recent change in coursetaking has been an increase in enrollments in distance education courses. Distance education courses are defined as courses that are credit-granting, technology-delivered, have either the instructor in a different location than the students and/

\section{Figure CL-2. Percentage of high school graduates who completed selected mathematics and science courses in high}

school: 1990 and 2009

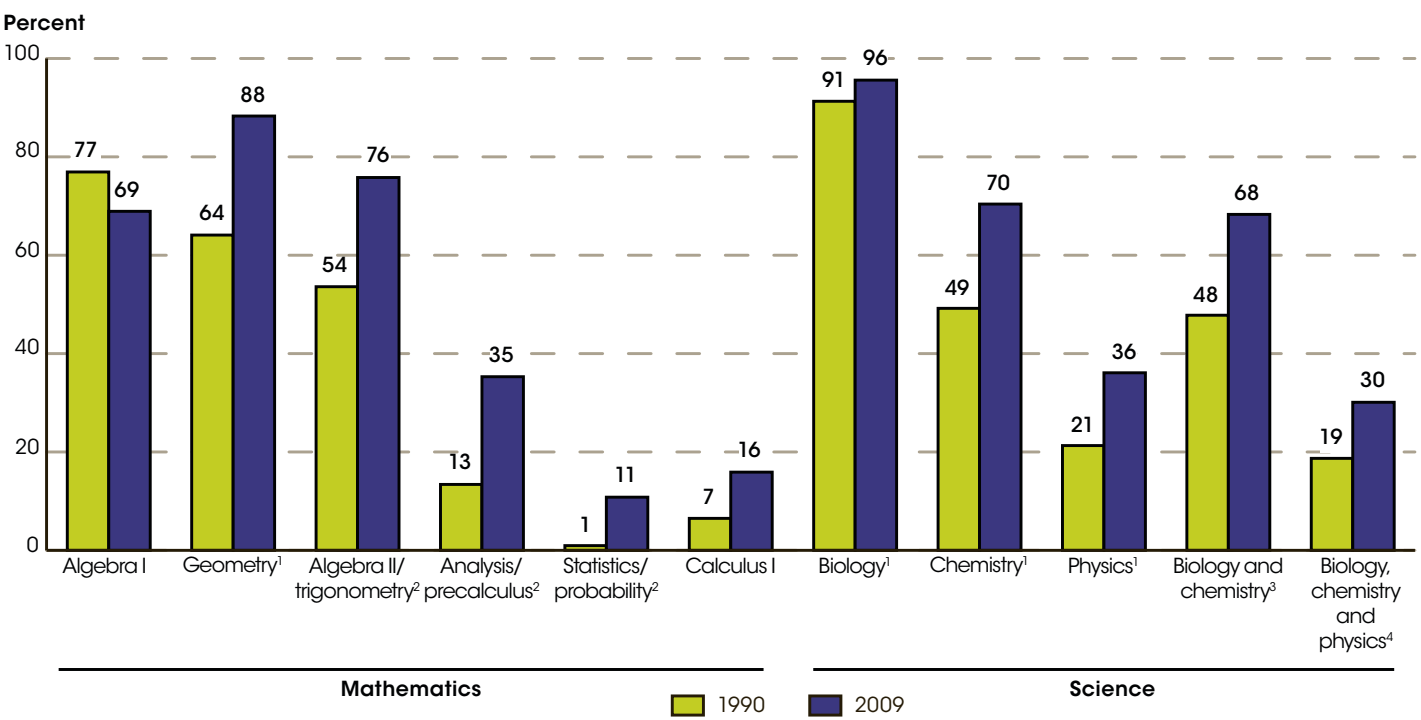

Percentages are for students who earned at least one Carnegie credit.

2 Percentages are for students who earned at least one-half of a Carnegie credit.

${ }^{3}$ Percentages are for students who earned at least one Carnegie credit each in biology and chemistry.

${ }^{4}$ Percentages are for students who earned at least one Carnegie credit each in biology, chemistry, and physics.

NOTE: For a transcript to be included in the analyses, it had to meet three requirements: (1) the graduate received either a standard or honors diploma,

(2) the graduate's transcript contained 16 or more Carnegie credits, and (3) the graduate's transcript contained more than 0 Carnegie credits in English

courses. For more information on race/ethnicity, free or reduced-price lunch, or locale, see Appendix C - Commonly Used Measures. For more information on

the National Assessment of Educational Progress (NAEP) or the High School Transcript Study (HSTS), see Appendix B - Guide to Sources.

SOURCE: U.S. Department of Education, National Center for Education Statistics, High School Transcript Study (HSTS), 1990 and 2009. 
or have the course content developed in, or delivered from, a different location than that of the students. There were over 1.3 million high school student enrollments in distance education courses in 2009-10, an increase of over 1 million enrollments from 2002-03, when there were 222,000 enrollments (see indicator 15).

In 2009-10, some 53 percent of school districts in the United States had high school students enrolled in distance education courses. Twenty-two percent of districts that offered distance education courses in 2009-10 reported that students enrolled in regular high school programs could take a full course load in an academic term using only distance education courses, while 12 percent reported that students could fulfill all high school graduation requirements using only distance education. In 2009-10, the most widely used technology for the instructional delivery of distance education courses was via the internet using asynchronous (not simultaneous) instruction, with 63 percent of districts that offered distance education courses reporting this as the prime delivery mode.

In 2009, when asked about their school attendance in the previous month, 38 percent of 12 th-grade students reported perfect attendance, 39 percent reported missing 1-2 days, 15 percent reported missing 3-4 days, and 8 percent reported missing 5 or more days (see indicator 28). A higher percentage reported perfect attendance in 2009 than in 1992 (38 vs. 35 percent, respectively), and there were lower percentages in 2009 than in 1992 that reported missing 3-4 days (15 vs. 17 percent) and missing 5 or more days (8 vs. 9 percent).

In general, lower student performance is associated with higher student absenteeism. For 12th-grade students, there was no measureable difference in reading scores on the National Assessment of Educational Progress (NAEP) in either 1992 or 2009 between students who had perfect attendance (296 and 292, respectively) and those who reported missing 1-2 days in the previous month (295 and 290). However, in both years, these scores were higher than for those who reported missing 3-4 days (287 and 284 , respectively) and 5 or more days (279 and 273).

Another factor in the school environment is safety, including the rate of nonfatal incidents of crime against students ages $12-18$ at school. Nonfatal crime includes theft and all violent crime; violent crime includes serious violent crime (rape, sexual assault, robbery, and aggravated assault) and simple assault. The rate of nonfatal crime against students ages 12-18 declined between 1992 and 2010 (see Indicators of School Crime and Safety 2011, NCES 2012-002, 2.1). This pattern held for the following three subcategories: theft, violent crime, and serious violent crime. Specifically, from 1992 to 2010, the rate of nonfatal crime against students at school declined from 154 to 32 crimes per 1,000 students; the theft victimization rate, from 101 to 18 thefts per 1,000 students; the violent crime rate, from 53 to 14 crimes per
1,000 students; and the serious violent crime rate, from 8 to 4 crimes per 1,000 students.

\section{Activities Outside School}

In this section we look at two activities that high school students may or may not have participated in outside of school-extracurricular activities and work.

In 2010, some 40 percent of high school seniors participated on athletic teams as an extracurricular activity, which was higher than the percentage who participated in other school clubs/activities (32 percent), music/performing arts (23 percent), academic clubs (14 percent), newspaper/yearbook (10 percent), and student council/government (9 percent) (see indicator 27). Since 1990, there has been little change in the participation of high school seniors in extracurricular activities, other than an increase in the percentage that participate in athletics (from 36 to 40 percent).

In 2010, a higher percentage of female than male high school seniors participated on a newspaper/yearbook (13 vs. 6 percent), in music/performing arts ( 28 vs. 18 percent), in academic clubs (18 vs. 11 percent), in student council/government (12 vs. 6 percent), and in other school clubs/activities (41 vs. 24 percent), while a higher percentage of male than female high school seniors participated on athletic teams (44 vs. 36 percent). For each of these activities, other than athletics and student council/government, the participation rates for males and females were not measurably different in each group from 1990 to 2010. For the activity of athletics, the percentage of female high school seniors that participated was higher in 2010 (36 percent) than in 1990 (28 percent). For student council/government, the percentage of male high school seniors that participated was lower in 2010 (6 percent) than in 1990 (9 percent).

Between 1990 and 2010, the percentage of high school students ages 16 or older who were employed decreased from 32 percent to 16 percent (see indicator 30). For male high school students, the decrease was from 33 percent in 1990 to 14 percent in 2010. For females, the decrease was from 31 percent to 18 percent. In 1990, some 12 percent of high school students were employed less than 15 hours per week, and 20 percent were employed for 15 or more hours per week; these percentages declined to 7 percent and 8 percent, respectively, by 2010. The percentage of males who were employed for less than 15 hours per week declined from 11 percent in 1990 to 6 percent in 2010 . For females, the percentages who were employed less than 15 hours per week declined from 12 percent to 8 percent over the same time period. For male students employed 15 or more hours per week, the decline was from 21 percent in 1990 to 7 percent in 2010; for females, some 18 percent were employed 15 or more hours per week in 1990 and 9 percent were in 2010. 


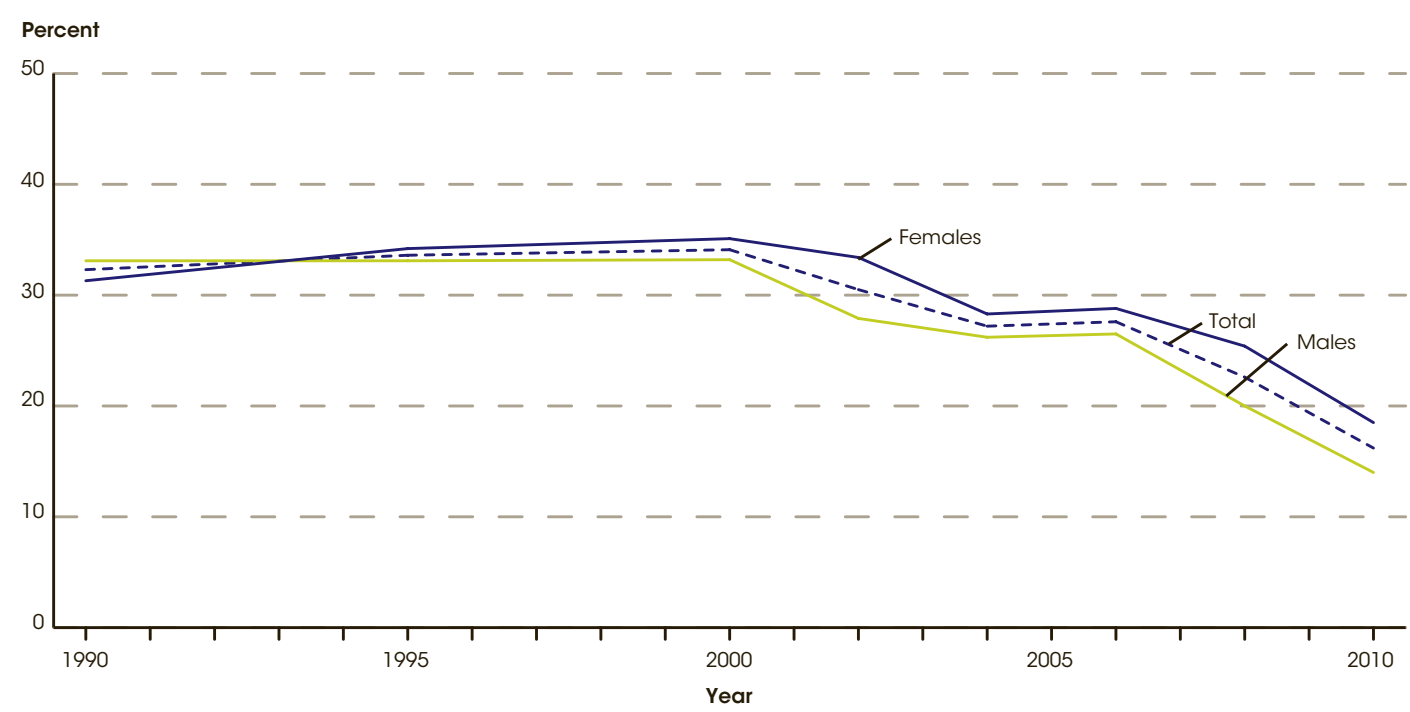

NOTE: "Percent employed" includes those who were employed but not at work during the survey week. For more information on the Current Population Survey (CPS), see Appendix B - Guide to Sources.

SOURCE: U.S. Department of Commerce, Census Bureau, Current Population Survey (CPS), October Supplement, Selected years, October $1990-2010$.

\section{Achievement}

In this section, we examine how the achievement of high school students has changed over the last two decades. We look at the long-term trend NAEP to see trends in reading and mathematics for 17-year-olds since 1973, the main NAEP to see how scores have changed for 12th-graders in history, geography and civics since the mid-1990s, and the Program for International Student Assessment (PISA) to see how the performance of U.S. 15-year-olds has changed relative to the rest of the world in reading since 2000 and in mathematics since 2003.

The long-term trend NAEP provides information on the reading and mathematics achievement of 9-, 13-, and 17-year-olds in the United States. Data have been collected every 2 to 5 years since 1971 for reading and since 1973 for mathematics. Since 1990, reading and mathematics assessments have been administered in the same years. All scores are on a scale of 0 to 500 (see The Condition of Education 2010, indicator 13).

The performance of 17-year-olds on the 2008 reading and mathematics assessments was not measurably different from their performance in the early 1970 s. The average reading score for 17-year-olds was lower in 2008 (286) than in 1990 (290), but was not significantly different from the score in 1971 (285). In mathematics, the average score for 17-year-olds in 2008 (306) was not significantly different from the scores in either 1990 (305) or 1973 (304).

Main NAEP tests measure student performance in mathematics and reading every two years. Other subjects, such as science and writing, are also assessed. Although long-term trend and main NAEP both assess mathematics and reading, there are several differences, in particular in the content assessed, how often the assessment is administered, and how the results are reported. Students are selected by grade $(4,8$, and 12$)$ for the main NAEP, rather than by age. Students represent the nation and, in some assessments, their states or selected large urban districts. To provide state- and district-level results, far more students must participate than for national results only; these larger sample sizes permit even more detailed results.

In 2010, the main NAEP assessed students' knowledge of U.S. history, geography, and civics in grades 4, 8, and 12 (see indicator 25). For U.S. history, the average score for 12th-grade students was higher in 2010 (288) than in 1994 (286). At grade 12, the U.S. history scores were higher in 2010 than in 1994 for White (296 vs. 292 points), Hispanic (275 vs. 267 points), and Asian/Pacific Islander students (293 vs. 283 points). Male 12th-graders scored 4 points higher than female 12th-graders $(290$ vs. 286 points) in the 2010 U.S. history assessment. The grade 12 U.S. history score for male students was 2 points higher in 2010 (290) than in 1994 (288), while the score for female students was not measurably different.

For geography, the score for 12th-grade students was lower in 2010 (282) than in 1994 (285). At grade 12, none of the racial/ethnic groups had geography scores that were measurably different between 1994 and 2010 . Male 12th-graders scored 5 points higher than female 12 th-graders ( 285 vs. 280 points) in the 2010 geography assessment. The geography score for male 12 th-graders was lower in 2010 (285) than in 1994 (288), while the score for female 12th-graders was not measurably different. 

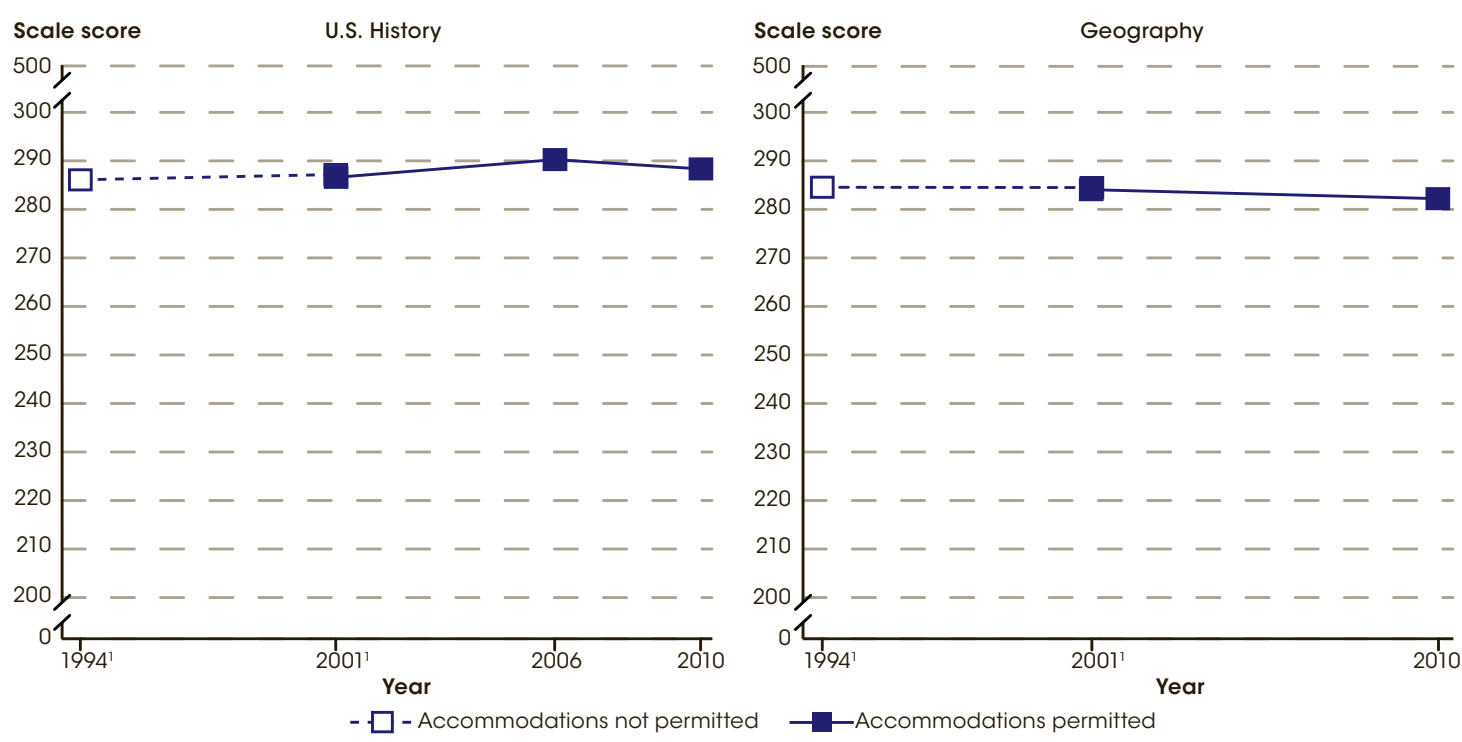

1 Testing accommodations (e.g., extended time, small group testing) for children with disabilities and English language learners were not permitted in 1994. Students were tested with and without accommodations in 2001.

NOTE: NAEP U.S. history and geography scores range from 0 to 500. For more information on the National Assessment of Educational Progress (NAEP), see Appendix B - Guide to Sources.

SOURCE: U.S. Department of Education, National Center for Education Statistics, National Assessment of Educational Progress (NAEP), selected years, 1994-2010 U.S. History Assessments, and selected years, 1994-2010 Geography Assessments, NAEP Data Explorer.

For civics, the average score for 12 th-grade students was not measurably different in 2010 (148) than in 1998 (150). At grade 12, the average civics score for Hispanic students was higher in 2010 (137) than in 1998 (132), but the scores for other racial/ethnic groups were not measurably different. The average civics score for female 12th-grade students was lower in 2010 (148) than in 1998 (152), while the score for male 12th-grade students was not measurably different between the 2 years.

The 2009 Program for International Student Assessment (PISA) reports the performance of 15-year-old students in reading and mathematics literacy in 65 countries and other education systems, including the 34 Organization for Economic Co-operation and Development (OECD) countries, 26 non-OECD countries, and 5 other education systems. The OECD countries are a group of the world's most advanced economies. Other education systems refer to non-national entities such as ShanghaiChina. PISA scores are reported on a scale from 0 to 1,000 .

The U.S. students' average score on the PISA combined reading literacy scale $(500)$ was not measurably different from the average score of OECD countries (493) (see The Condition of Education 2011, indicator 15). Compared with the other 64 countries and other education systems, the U.S. average was lower than the average in 9 countries and other education systems (6 OECD countries, 1 non-OECD country, and 2 education systems) and higher than the average in 39 countries and other education systems (13 OECD countries, 24 non-OECD countries, and 2 other education systems).
The U.S. average in reading literacy in 2000 (504), the earliest PISA cycle in which reading literacy was assessed in depth, was not measurably different from the average in 2009 (500). There were no measurable differences between the U.S. average and the OECD average in 2000 (504 and 496, respectively) or in 2009 (500 and 495, respectively).

The average U.S. mathematics literacy score (487) in 2009 was lower than the average score of the 34 OECD countries (496) (see The Condition of Education 2011, indicator 16). In comparison with students in all 64 other countries and education systems, students in the United States on average scored lower than students in 23 countries and other education systems (17 OECD countries, 2 non-OECD countries, and 4 other education systems) and higher than students in 29 countries and other education systems (5 OECD countries, 23 non-OECD countries, and 1 other education system). No measurable difference was found between the average U.S. mathematics literacy scores in 2009 (487) and 2003 (483), the earliest time point to which PISA 2009 mathematics literacy scores can be compared. In both years, the U.S. average score was lower than the OECD average score.

\section{High School Completion}

There are several ways to determine if high schools are successful at having students complete their high school education. In this section we look at retention rates for high schools, meaning the enrollment of 12th-grade students as a percentage of the 9th-grade class four years earlier. We also look at status dropout rates and the 
averaged freshman graduation rate (AFGR), and how both of these have changed over time.

Public high schools with senior classes that are substantially smaller than the entering class 4 years earlier are referred to as low-retention high schools. Low-retention high schools are defined here as those with a senior class size that is 70 percent or less of the size of the freshman class that had entered 4 years earlier (see indicator 16). To be included, a high school must have had at least 10 seniors in the given year and at least 10 freshman 4 years earlier. In 2009-10, there were approximately 15,500 regular public high schools in the United States with at least 10 seniors that had at least 10 freshmen 4 years earlier.

In 1990-91, some 24 percent of regular public high schools (or 3,100 schools) were low-retention schools (5 percent retained between 10 and 50 percent of their students and 19 percent retained between 51 and 70 percent). The percentage of low-retention high schools declined to 22 percent in 1992-93 (2,800 high schools), then increased to 32 percent $(4,600$ high schools) in 2000-01 before declining to approximately 26 percent in 2005-06. The percentage then remained relatively sat
26 percent through 2009-10, when 4,100 high schools met the definition. Approximately 518,000 high school seniors attended low-retention high schools in 1990-91, compared to 845,000 in $2000-01$ and 755,000 in 2009-10.

The status dropout rate represents the percentage of 16- through 24-year-olds who are not enrolled in school and have not earned a high school credential (either a diploma or an equivalency credential such as a General Educational Development [GED] certificate). Based on the Current Population Survey (CPS), the status dropout rate declined from 12 percent in 1990 to 7 percent in 2010 (see indicator 33). Between 1990 and 2010, status dropout rates also declined for Whites (from 9 percent to 5 percent), Blacks (from 13 percent to 8 percent), and Hispanics (from 32 percent to 15 percent). Over this period, the status dropout rate was generally lowest for Asians/Pacific Islanders, followed by Whites, Blacks, and Hispanics. The gap between Whites and Hispanics narrowed from 23 percentage points in 1990 to 10 percentage points in 2010; the gaps between Whites and Blacks in these two years were not measurably different (4 vs. 3 percentage points).

Figure CL-5. Status dropout rates of 16- through 24-year-olds in the civilian, noninstitutionalized population, by race/ ethnicity: October Current Population Survey (CPS) 1990-2010

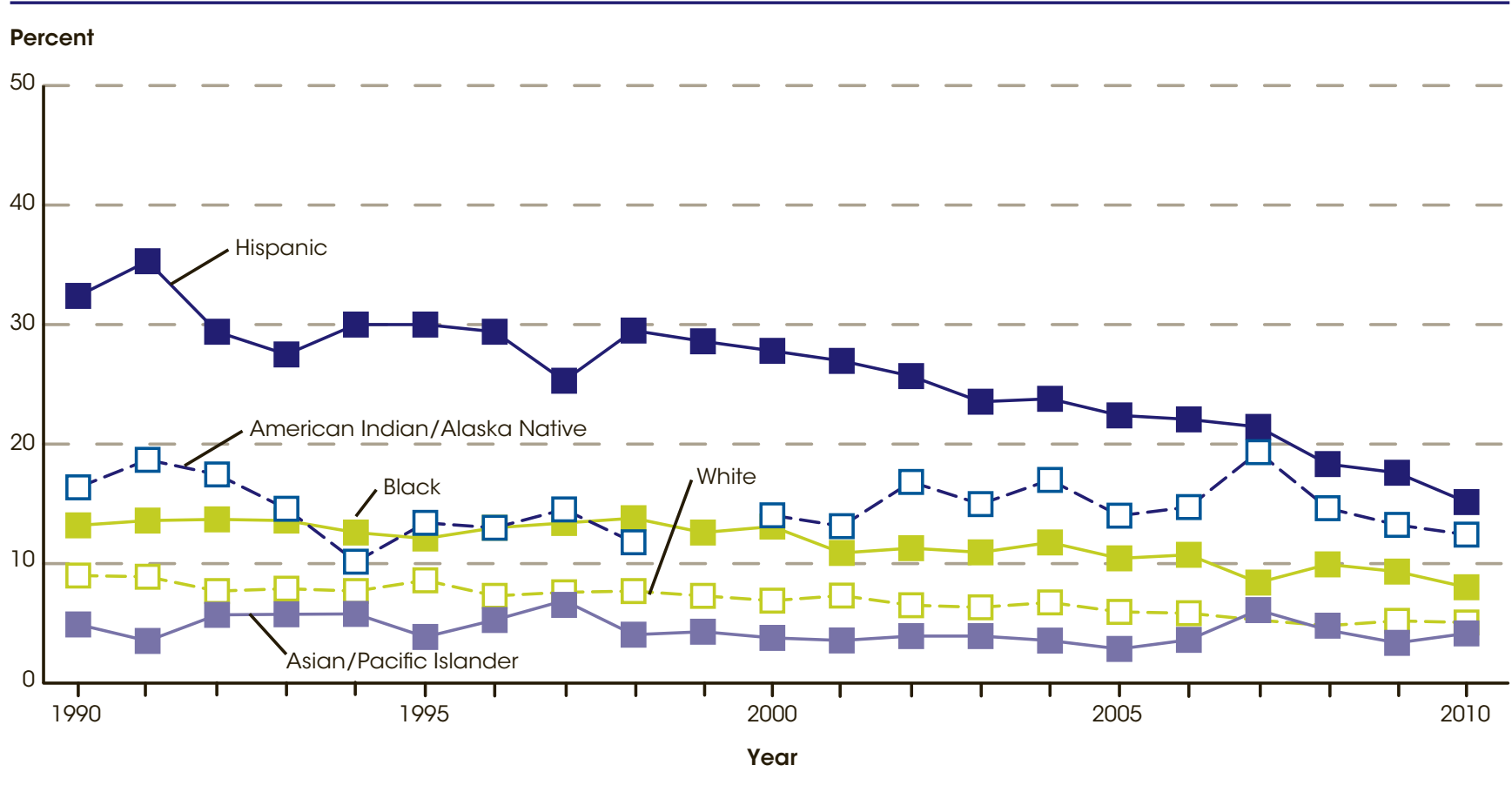

NOTE: Data for American Indians/Alaska Natives in 1999 have been suppressed due to unsestimates. Race categories exclude persons of Hispanic ethnicity. For more information on race/ethnicity and the status dropout rate, see Appendix C - Commonly Used Measures. For more information on the Current Population Survey (CPS), see Appendix B - Guide to Sources.

SOURCE: U.S. Department of Commerce, Census Bureau, Current Population Survey (CPS), October Supplement, 1990-2010. 
The averaged freshman graduation rate measures the percentage of public high school students who graduate on time with a regular diploma (see indicator 32). To do so, it uses an estimate of the number of regular diplomas issued in a given year divided by an estimate of the averaged enrollment base for the freshman class 4 years earlier. For each year, the averaged freshman enrollment base is the sum of the number of 8 th-graders 5 years earlier, the number of 9th-graders 4 years earlier (when current-year seniors were freshmen), and the number of 10th-graders 3 years earlier, divided by 3 . The intent of this averaging is to account for the high rate of grade retention in the freshman year, which adds 9th-grade repeaters from the previous year to the number of students in the incoming freshman class each year.

The overall averaged freshman graduation rate was higher for the graduating class of 2008-09 (75.5 percent) than it was for the graduating class of 1990-91 (73.7 percent). However, from school year 1990-91 to 1995-96, the overall averaged freshman graduation rate decreased from 73.7 percent to 71.0 percent. In terms of changes by state, there was an increase in the graduation rate in 30 states and the District of Columbia from school year 1990-91 to 2008-09. In 1 state (Vermont), the rate increased by more than 10 percentage points; in 6 others (Louisiana, Missouri, New Hampshire, New York, Tennessee, and Wisconsin) and the District of Columbia, rates increased by more than 5 percentage points. The graduation rate decreased from 1990-91 to 2008-09 in 20 states (Alaska, Arizona, Arkansas, Connecticut, Georgia, Hawaii, Indiana, Kansas, Maine, Minnesota, Mississippi, Montana, Nebraska, Nevada, New Mexico, North Dakota, South Carolina, South Dakota, Washington, and Wyoming), with decreases of greater than 5 percentage points occurring in New Mexico (5.3 percent), Wyoming (6.0 percent), and Nevada (20.7 percent).

\section{Postsecondary Plans}

Finally, we look at the postsecondary plans for high school students, including the rate at which high school graduates enroll in a 2-year or 4-year college within a year of completing high school, as well as the changing expectations for the attainment of a college degree.

The immediate college enrollment rate is defined as the percentage of high school completers of a given year who enroll in 2- or 4-year colleges in the fall immediately after completing high school. Between 1990 and 2010, the immediate college enrollment rate ranged from 60 to 70 percent (see indicator 34). This rate increased from 1990 to 1997 (60 to 67 percent), declined from 1997 to 2001 (to 62 percent), then increased from 2001 to 2009 (to 70 percent). The rate remained steady from 2009 to 2010.

In each year between 1990 and 2010, the immediate college enrollment rates of high school completers from low- and middle-income families were lower than those of high school completers from high-income families. Most recently, in 2010, the immediate college enrollment rate of high school completers from low-income families was 52 percent, 30 percentage points lower than the rate of high school completers from high-income families (82 percent). The immediate college enrollment rate of high school completers from middle-income families (67 percent) also trailed the rate of their peers from high-income families by 15 percentage points. In 1990, these gaps were 32 percentage points between high school completers from high-income and those from low-income families, and 22 percentage points between high school completers from high-income and those from middle-income families.

Between 1990 and 2010, immediate college enrollment rates increased for both males and females: the rate for males increased from 58 to 63 percent and that for females, from 62 to 74 percent. Overall, there was no measurable difference in the immediate college enrollment rates between males and females in 1990. By 2010, the immediate college enrollment rate was higher for females than for males. Thus, the enrollment pattern has shifted over time to higher enrollment rates for females than males.

The percentage of 12 th-grade students who had definite plans to graduate from a 4-year college was higher in 2010 (60 percent) than in 1990 (48 percent) (see indicator 35). In 2010, the percentage of 12 th-grade males with plans to graduate from a 4 -year college was higher than the percentage in 1990 (53 vs. 46 percent); for female 12th-graders, the percentage with plans to graduate from college was also higher in 2010 than in 1990 (66 vs. 51 percent). In both years, higher percentages of female than male 12th-graders planned to graduate from college. This gap in expectations regarding college completion by sex was larger in 2010 than in 1990 (13 vs. 5 percentage points).

The percentages of 12 th-grade students who planned to graduate from a 4-year college were higher in 2010 than in 1990 at each level of parents' educational attainment (46 vs. 32 percent for those whose parents attained high school completion or less, 57 vs. 47 percent for those whose parents attained some college, 66 vs. 58 percent for those whose parents attained a bachelor's degree, and 78 vs. 72 percent for those whose parents attained a graduate or professional degree). In each year shown, higher percentages of 12th-graders whose parents had more education planned to graduate from college when compared with their peers whose parents had less education. For example, in 2010, some 78 percent of 12th-graders whose parents had a graduate or professional degree planned to graduate from college, compared with 46 percent of 12th-graders whose parents had completed a high school education or less. Also in that year, a higher percentage of 12th-graders whose parents had a bachelor's degree (66 percent) planned to graduate from college than their peers whose parents had completed high school 
Figure CL-6. Percentage of 12th-grade students with definite plans to graduate from a 4-year college, by parents' highest level of education: 1990, 2000, and 2010

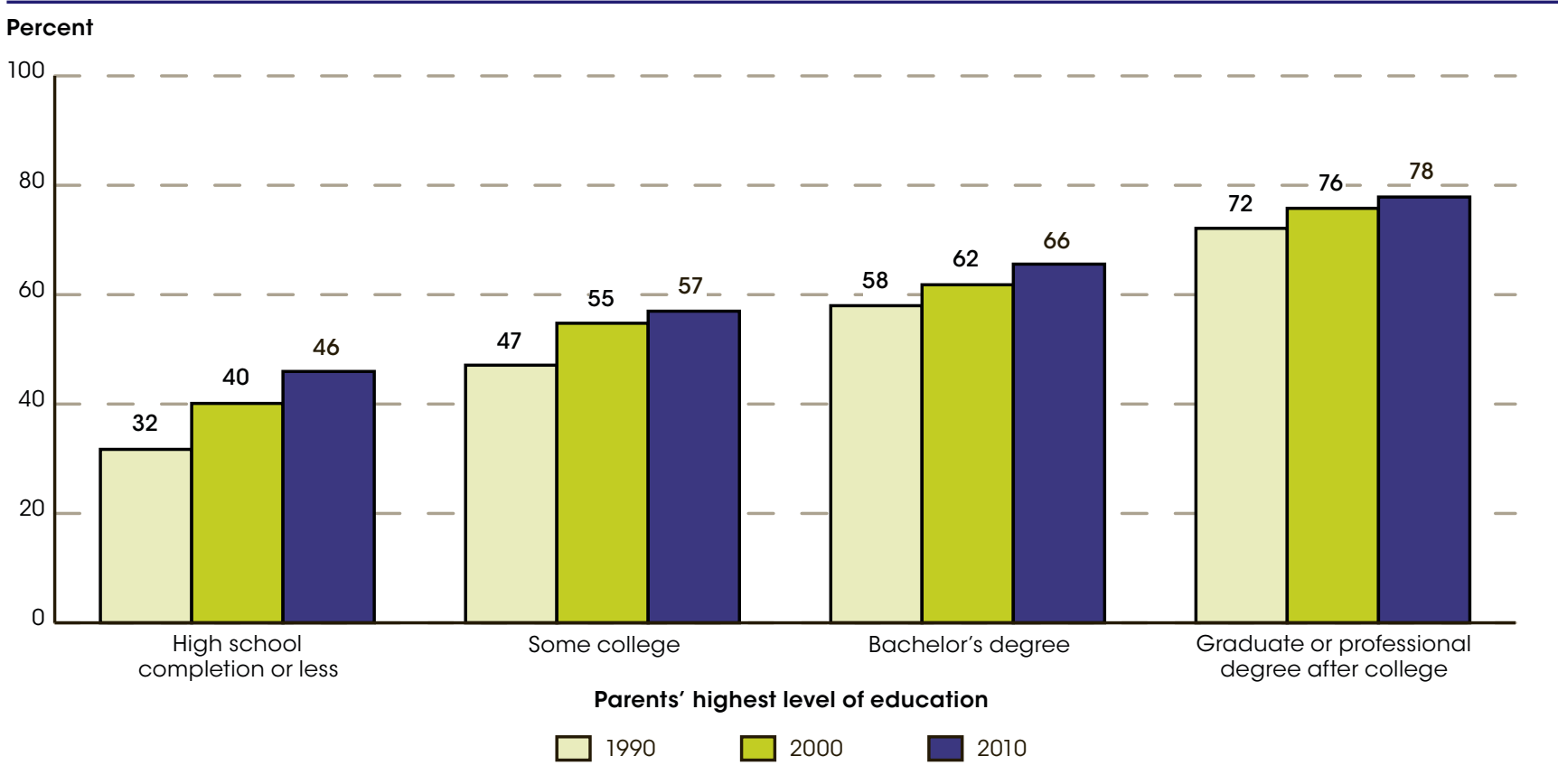

NOTE: Percentages reflect students who indicated that they "definitely will" graduate from a 4-year college. Parents' highest level of education reflects a combination of responses for father's and mother's level of education. For more information on parents' education, please see Appendix C - Commonly Used Measures. For more information on the Monitoring the Future study, please see Appendix B - Guide to Sources.

SOURCE: University of Michigan, Institute for Social Research, Monitoring the Future, 1990, 2000, and 2010, http://www.monitoringthefuture.org/.

or less. However, the gaps in expectations regarding college completion among these groups of 12 th-graders were smaller in 2010 than in 1990. In 2010, there was a 32 percentage point difference between those whose parents had completed high school or less versus those whose parents had a graduate or professional degree. In
1990, this difference was 40 percentage points. Similarly, in 1990 there was a 26 percentage point difference in expectations regarding college degree completion between those 12th-graders whose parents had a bachelor's degree and those whose parents had completed high school or less. 
The indicators in this section of The Condition of Education report trends in enrollments across all levels of education. Enrollment is a key indicator of the scope of and access to educational opportunities and functions as a basic descriptor of American education. Changes in enrollment have implications for the demand for educational resources such as qualified teachers, physical facilities, and funding levels, all of which are required to provide high-quality education for our nation's students.

The indicators in this section include information on enrollment rates reported by age group, as well as enrollment by level of the education system. These levels are preprimary education, elementary and secondary education, undergraduate education, graduate and professional education, and adult education. Some of the indicators in this section provide information about the characteristics of the students who are enrolled in formal education and, in some cases, how enrollment rates of different types of students vary across schools.

Indicators on participation in education from previous editions of The Condition of Education not included in this volume are available at http://nces.ed.gov/programs/coe. 


\section{SECTION 1}

Participation in Education

\section{All Ages}

Indicator 1. Enrollment Trends by Age

\section{Preprimary Education}

Indicator 2. Early Education and Child Care Arrangements of Young Children

\section{Elementary/Secondary Enrollment}

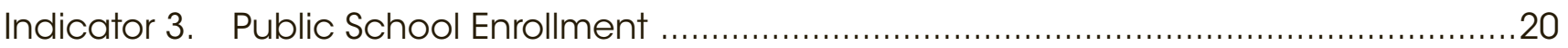

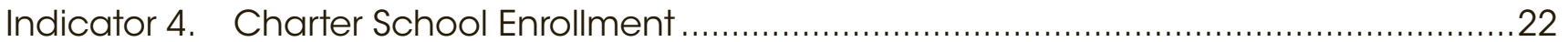

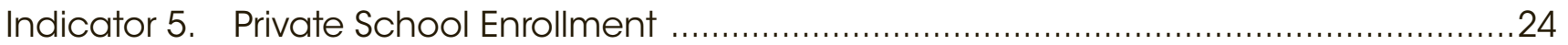

Indicator 6. Racial/Ethnic Enrollment in Public Schools ..................................................26

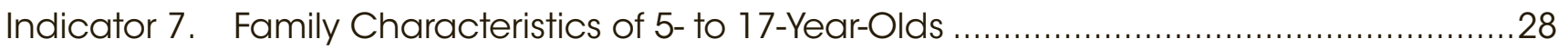

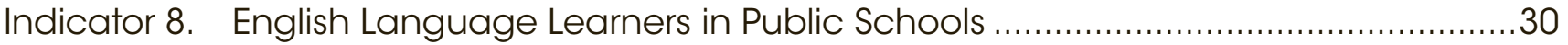

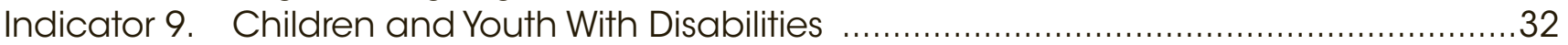

\section{Postsecondary Enrollment}

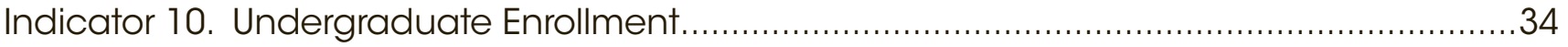

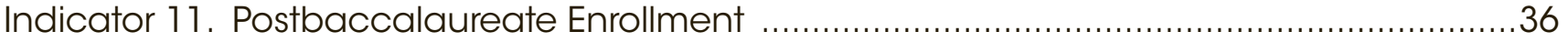




\section{Indicator 1 \\ Enrollment Trends by Age}

\section{Between 2000 and 2010, enrollment rates increased for young adults ages 18-19 and adults ages 20-24, 25-29, and 30-34; students in these age groups are typically enrolled in college or graduate school.}

School enrollment rates for most age groups from 3 to 34 were higher in 2010 than in the 1970s; however, the enrollment rate for 7- to 13-year-olds was lower in 2010 (98 percent) than in 1970 (99 percent). The rates of youth ages 14-15 fluctuated between 97 and 99 percent throughout this period (see table A-1-1). Enrollment patterns may reflect changes in attendance requirements or prevalence of home schooling, the perceived value or cost of education, and the time taken to complete degrees.

Between 1970 and 2010, the enrollment rate for children ages 3-4 (the ages at which children are typically enrolled in nursery or preschool) increased from 20 to 53 percent. The enrollment rate for children ages 5-6, who are typically enrolled in kindergarten or first grade, rose from 90 percent in 1970 to 97 percent in 1994 , then decreased to 94 percent in 2010 .

The enrollment rates for 7- to 13-year-olds and 14- to 15 -year-olds were generally higher than the rate for 16 - to 17-year-olds, but the rate for 16- to 17-year-olds did increase from 90 percent in 1970 to 96 percent in 2010 (see table A-1-1). As of August 2011, the maximum compulsory age of attendance was 18 years in 20 states and the District of Columbia (D.C.), 17 years in 11 states, and 16 years in 19 states (see table A-1-2).

Young adults ages $18-19$ are typically transitioning into college education or the workforce. Between 1970 and 2010, the overall enrollment rate (including enrollment at both the secondary level and the college level) for young adults ages 18-19 increased from 48 to 69 percent (see table A-1-1). During this period, the enrollment rate for
18- and 19-year-olds at the secondary level increased from 10 to 18 percent, while the rate at the college level rose from 37 to 51 percent. Between 2000 and 2010, the college enrollment rate increased from 45 to 51 percent.

Adults ages 20-34 who are in school are usually enrolled in college or graduate school. Between 1970 and 2010, the enrollment rate for adults ages 20-24 increased from 22 to 39 percent, and the rate for adults ages 25-29 increased from 8 to 15 percent. The enrollment rate for adults ages 30-34 increased from 4 percent in 1970 to 8 percent in 2010. Between 2000 and 2010, the enrollment rate for adults ages 20-24 increased from 32 to 39 percent; for adults ages 25-29, it increased from 11 to 15 percent; and for adults ages $30-34$, it increased from 7 to 8 percent.

Enrollment rates for all age groups varied by state in 2010 (see table A-1-2). Rates for ages 3-4 ranged from 31 percent in North Dakota to 73 percent in D.C. For ages 5-17, rates ranged from 93 percent (North Dakota) to 98 percent (California, Connecticut, Nebraska, and D.C.). Among 18- and 19-year-olds, total rates ranged from 59 percent in Nevada to 86 percent in Rhode Island. Secondary enrollment rates of 18- and 19-year-olds ranged from 12 percent in D.C. to 39 percent in Alaska, and college enrollment rates ranged from 29 percent in Alaska to 72 percent in Rhode Island. Rates for 20- to 24-yearolds ranged from 30 percent (Nevada) to 51 percent (Massachusetts), and rates for 25- to 34-year-olds ranged from 10 percent (Maine) to 19 percent (D.C.).

Tables A-1-1 and A-1-2

Glossary: College, Secondary school

\section{Technical Notes}

Current Population Survey (CPS) estimates include enrollment in any type of graded public or parochial or other private schools and include nursery schools or preschools, kindergartens, elementary schools, secondary schools, colleges, universities, and professional schools. The American Community Survey (ACS) has a similar coverage, except that it includes homeschooling as private school enrollment. Both the ACS and the CPS exclude enrollments in schools that do not advance students toward a regular school degree, such as trade schools, business colleges, and correspondence courses. Due to the methodological differences between the CPS and ACS, enrollment estimates from the two surveys are not directly comparable. Beginning in 1994, new procedures were used in the CPS to collect enrollment data on children ages 3-4. As a result, pre-1994 data on children ages 3-4 may not be comparable to data from 1994 or later. For more information on the CPS and the ACS, see Appendix B - Guide to Sources. 


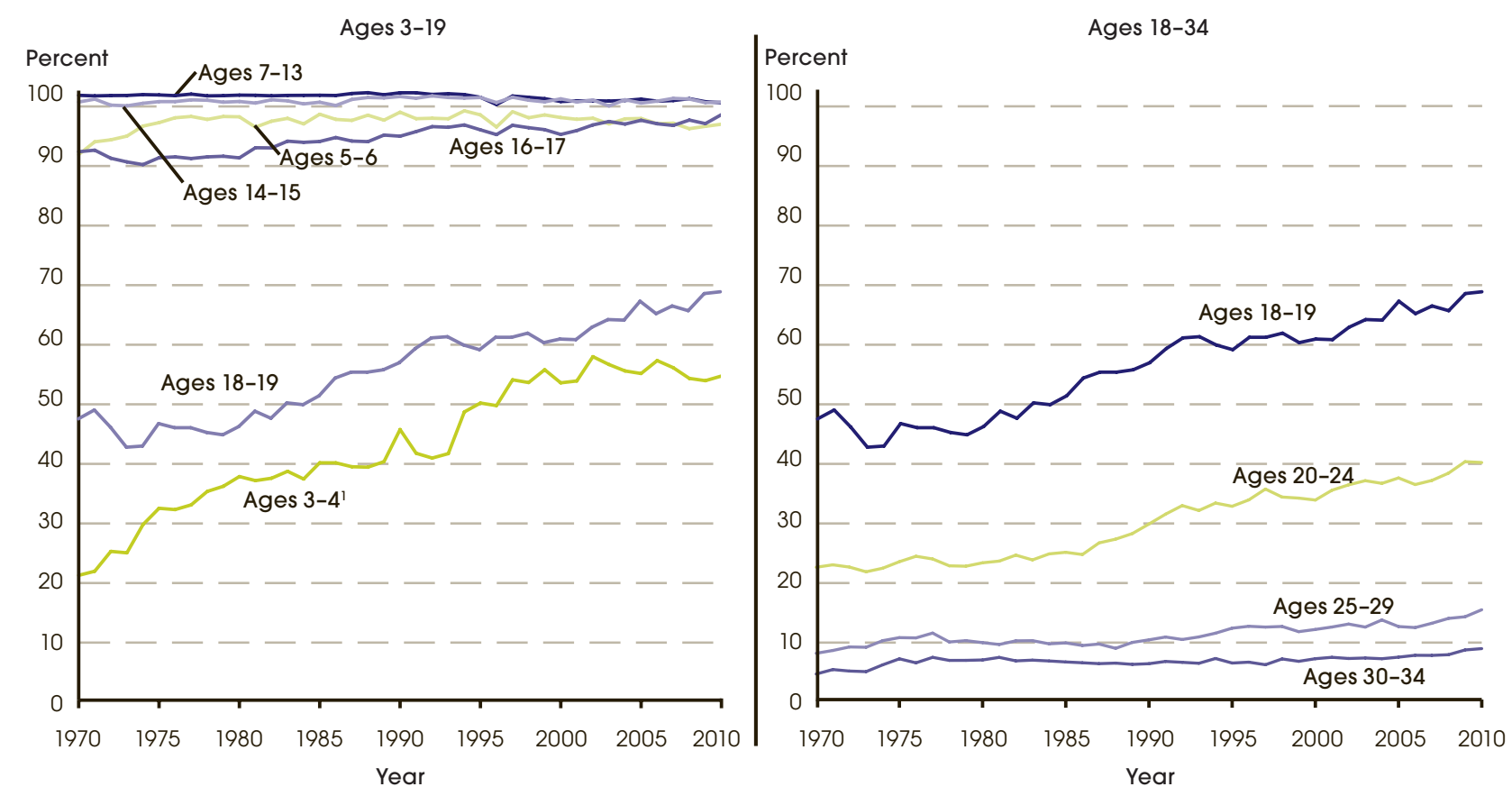

Beginning in 1994, new procedures were used to collect enrollment data on children ages 3-4. As a result, pre-1994 data may not be comparable to data from 1994 or later.

NOTE: Includes enrollment in any type of graded public or parochial or other private schools and include nursery schools or preschools, kindergartens, elementary schools, secondary schools, colleges, universities, and professional schools. Excludes enrollments in schools that do not advance students toward a regular school degree (e.g., trade schools, business colleges, and correspondence courses). The enrollment rate for ages 18-19 includes enrollment at both the secondary level and the college level. For more information on the Current Population Survey (CPS), see Appendix B - Guide to Sources.

SOURCE: U.S. Department of Commerce, Census Bureau, Current Population Survey (CPS), October Supplement, $1970-2010$.

Figure 1-2. Percentage of the population ages 3-34 enrolled in school, by age group: October 2010

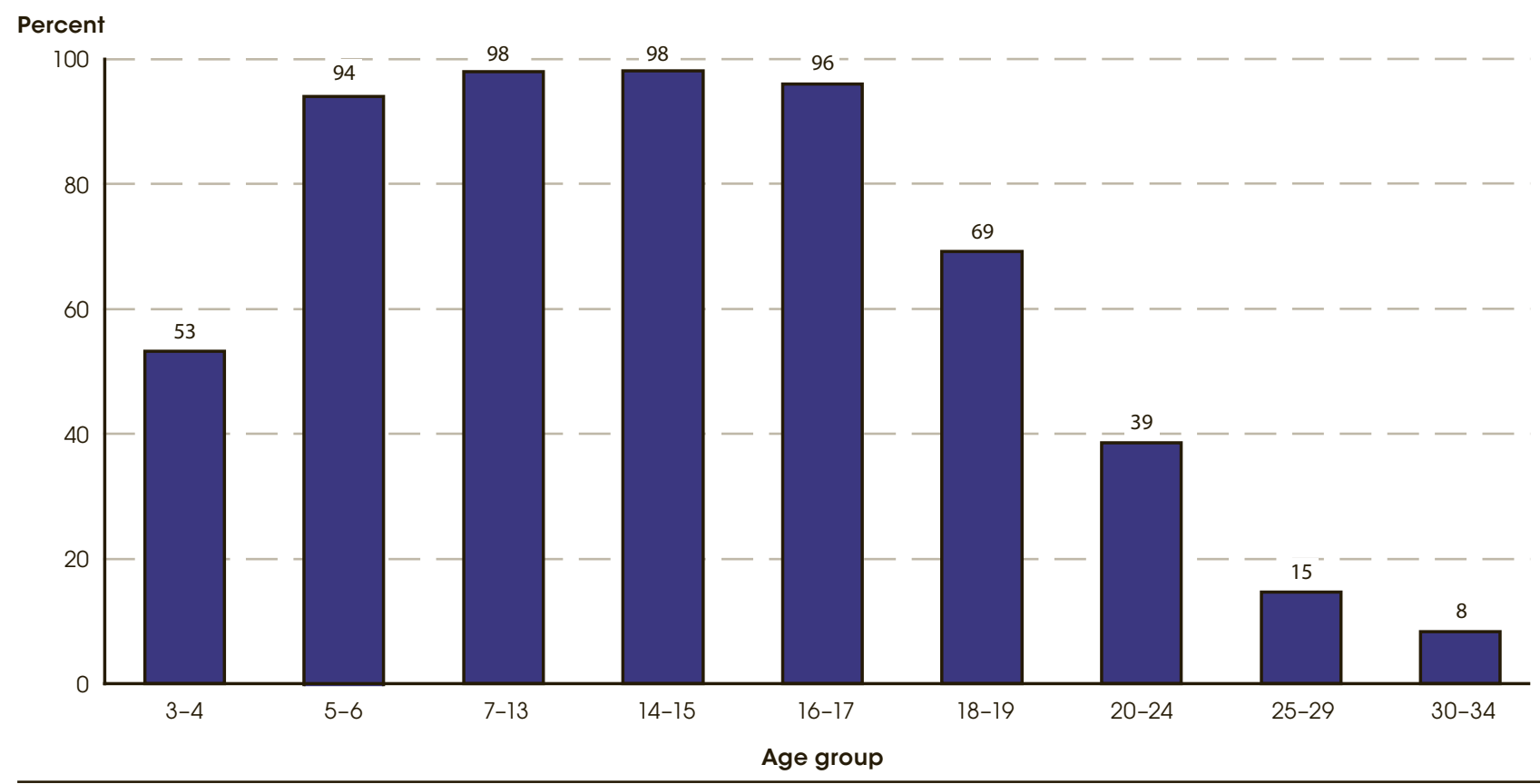

NOTE: Include enrollment in any type of graded public or parochial or other private schools and include nursery schools or preschools, kindergartens, elementary schools, secondary schools, colleges, universities, and professional schools. Excludes enrollments in schools that do not advance students toward a regular school degree (e.g., trade schools, business colleges, and correspondence courses). The enrollment rate for ages 18-19 includes enrollment at both the secondary level and the college level. For more information on the Current Population Survey (CPS), see Appendix B - Guide to Sources.

SOURCE: U.S. Department of Commerce, Census Bureau, Current Population Survey (CPS), October Supplement, 2010. 


\section{The percentage of 3- to 5-year-olds enrolled in full-day preprimary programs increased from 32 percent in 1980 to 58 percent in 2010.}

The percentage of 3- to 5-year-olds enrolled in full-day preprimary programs increased from 32 percent in 1980 to 58 percent in 2010 (see table A-2-1). Preprimary programs are groups or classes that are organized to provide educational experiences for children and include kindergarten, preschool, and nursery school programs. In addition to the overall increase, the full-day attendance percentage increased for each age group. More specifically, from 1980 to 2010, the percentage of 3-yearolds enrolled in full-day preprimary programs increased from 37 to 50 percent, the percentage of 4 -year-olds from 33 to 47 percent, and the percentage of 5-year-olds from 29 to 72 percent.

The total numbers of 3- to 5-year-olds enrolled in either public or private nursery schools or kindergartens all increased over time except for enrollment in private kindergarten. More specifically, from 1980 to 2010, the total number of 3 - to 5 -year-olds enrolled in public nursery schools increased from 0.6 to 2.7 million. The total number of 3 - to 5 -year-olds enrolled in private nursery schools was also higher in 2010 than in 1980 (2.0 vs. 1.4 million). The total number of 3 - to 5 -year-olds enrolled in public kindergarten was greater in 2010 than in 1980 (3.1 vs. 2.4 million). However, the total number of 3 - to 5-year-olds enrolled in private kindergarten was lower in 2010 than in 1980 (0.4 vs. 0.5 million).

Looking more closely at 2010, the percentage of Asian children enrolled in preprimary programs was 71 percent, and was higher than the percentage of Hispanic children enrolled in preprimary programs (56 percent), though not measurably different from the percentages enrolled among other racial/ethnic groups (see table A-2-2). The percentages of children enrolled in full-day and part-day programs in 2010 also differed by race/ethnicity. Black children had the highest percentage of enrollment in full-day preprimary programs (52 percent) and one of the lowest percentages of children enrolled in part-day preprimary programs (13 percent). Higher percentages of Asian (34 percent) and White (31 percent) children were enrolled in part-day preprimary programs than Hispanic children (24 percent).

Enrollment patterns also varied by parents' highest level of education, defined as the highest level of achievement attained by the most educated parent. Higher percentages of 3- to 5-year-olds whose parents have either a graduate or professional degree (78 percent) or a bachelor's degree (72 percent) were enrolled in preprimary programs than children of parents with any other level of educational attainment, which ranged from 48 to 62 percent. Children whose parents have less than a high school credential had the lowest percentage of enrollment in preprimary programs. Enrollment in full-day and part-day preprimary programs also differed by the highest educational attainment of parents or guardians. Fortythree percent of 3- to 5-year-olds whose parents have a graduate or professional degree were enrolled in full-day preprimary programs, a higher percentage than those of children whose parents or guardians have any other level of educational attainment (30 to 38 percent). Children whose parents have a graduate or professional degree and children whose parents have a bachelor's degree also were enrolled in part-day preprimary programs in the highest percentages ( 35 and 34 percent, respectively). For instance, 18 percent of 3 - to 5-year-olds whose parents have less than a high school credential were enrolled in part-day preprimary programs.

Tables A-2-1 and A-2-2

Glossary: Private institution, Public institution, Nursery school

\section{Technical Notes}

Current Population Survey (CPS) data from 1994 to 2010 were collected using new procedures and may not be comparable with data prior to 1994. Enrollment data for 5-year-olds include only those students in preprimary programs and do not include those enrolled in primary programs. Data are based on sample surveys of the civilian noninstitutional population. Race categories exclude persons of Hispanic ethnicity. For more information on race/ethnicity, see Appendix C - Commonly Used Measures. For more information on the CPS, see Appendix B - Guide to Sources. 
Figure 2-1. Percentage of 3-, 4-, and 5-year-old children enrolled in full-day preprimary programs: Selected years, 1980 through 2010

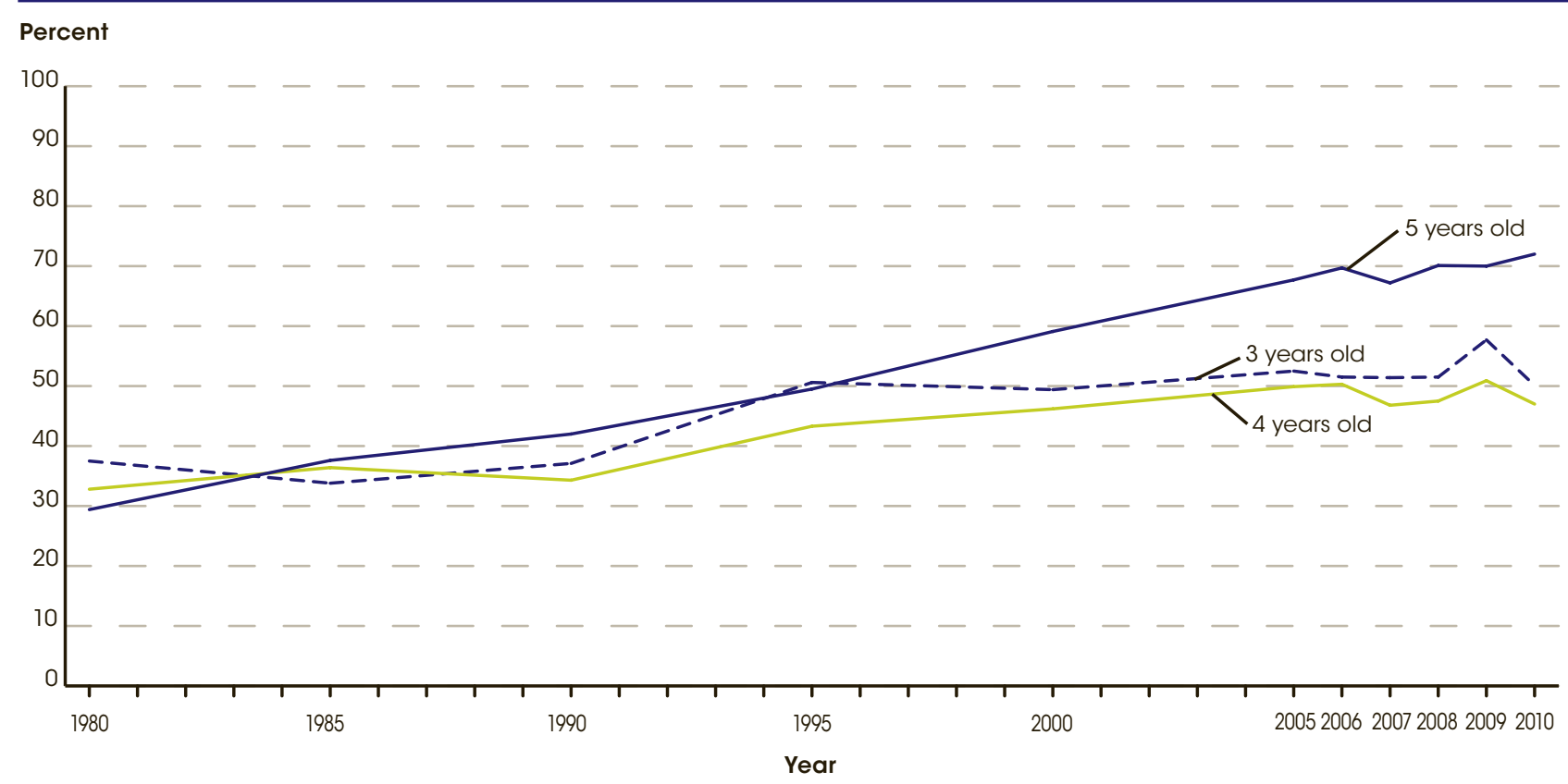

NOTE: Data from 1995 to 2010 were collected using new procedures and may not be comparable with data prior to 1995. Preprimary programs are groups or classes that are organized to provide educational experiences for children and include kindergarten, preschool, and nursery school programs Enrollment data for 5-year-olds include only those students in preprimary programs and do not include those enrolled in primary programs. Data are based on sample surveys of the civilian noninstitutional population. For more information on the Current Population Survey (CPS), see Appendix B Guide to Sources.

SOURCE: U.S. Department of Commerce, Census Bureau, Current Population Survey (CPS), October 1980 through 2010

Figure 2-2. Percentage of 3-, 4-, and 5-year old children enrolled in preprimary programs, by race/ethnicity and attendance status: October 2010

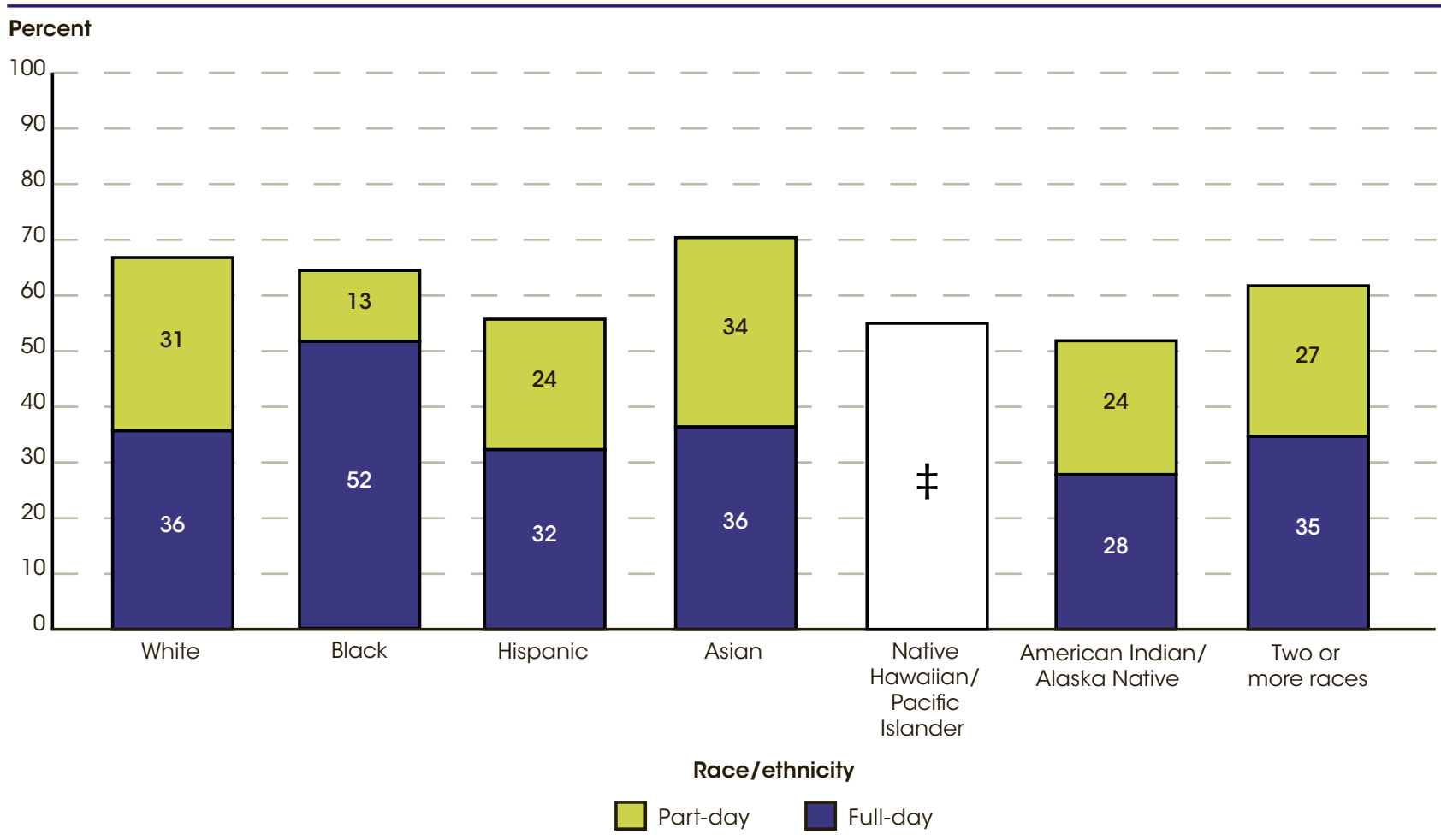

¥ Reporting standards not met (too few cases).

NOTE: Preprimary programs are groups or classes that are organized to provide educational experiences for children and include kindergarten, preschool, and nursery school programs. Enrollment data for 5-year-olds include only those students in preprimary programs and do not include those enrolled in primary programs. Race categories exclude persons of Hispanic ethnicity. Data are based on sample surveys of the civilian noninstitutional population. For more information on race/ethnicity, see Appendix C - Commonly Used Measures. For more information on the Current Population Survey (CPS), see Appendix B - Guide to Sources

SOURCE: U.S. Department of Commerce, Census Bureau, Current Population Survey (CPS), October 2010. 


\section{Indicator 3}

\section{Public School Enrollment}

\section{From school years 2010-11 through 2021-22, public elementary and secondary school enrollment is projected to increase by 7 percent from 49.5 to 53.1 million students, but with changes across states ranging from an increase of 22 percent to a decrease of 15 percent.}

In school year 2010-11, some 49.5 million students were enrolled in public elementary and secondary schools. Of these students, 34.6 million were enrolled in prekindergarten (preK) through grade 8, and 14.9 million were enrolled in grades 9 through 12 (see table A-3-1).

Public school enrollment declined during the 1970 s and early 1980s and rose in the latter part of the 1980s. Enrollment continued to increase throughout the 1990 s and early 2000s (see table A-3-1). By school year 1997-98, public school enrollment had reached 46.1 million students and had surpassed its early 1970 s peak. Between 2000-01 and 2006-07, public school enrollment increased by 2.1 million students, reaching 49.3 million students in school year 2006-07, where it remained until 2008-09. Total public school enrollment reached 49.5 million in 2010-11. From 2010-11 to 2021-22, total public school enrollment is projected to increase by 7 percent to 53.1 million (2021-22 is the last year for which projected data are available).

Enrollment trends in grades preK-8 and 9-12 have differed over time as successive cohorts of students moved through the public school system. For example, enrollment in grades preK-8 decreased throughout the 1970s and early 1980s, while enrollment in grades 9-12 generally decreased in the late 1970s and throughout the 1980s (see table A-3-1). Enrollment in grades preK-8 increased from 1985-86 through 2003-04 and fluctuated between 34.2 million and 34.6 million between 2003-04 and 2010-11. Public school enrollment in grades preK-8 is projected to increase from 34.6 million in 2010-11 to an estimated 37.6 million in 2021-22, an increase of 9 percent. Public school enrollment in grades 9-12 increased from 1991-92 through 2007-08, but declined through 2010-11 and is projected to continue declining through 2012-13. From 2013-14 through 2021-22, enrollment in grades 9-12 is projected to increase and to surpass its 2007-08 level by 2021-22. Overall, public school enrollment in grades $9-12$ is projected to increase 4 percent between 2010-11 and 2021-22.
Total public enrollment increased in each region between school years 1989-90 and 2010-11, with enrollment increasing more rapidly in the West and South (35 and 29 percent, respectively) and less rapidly in the Northeast and Midwest (12 and 8 percent, respectively) (see table A-3-2). Total public enrollment is projected to increase from 2010-11 to 2021-22 most rapidly in the West and South (13 and 9 percent, respectively) (see table A-3-3). Total public enrollment is projected to increase 2 percent in both the Midwest and Northeast.

Public school enrollment in grades preK-12 increased in 41 states from 1989-90 to 2010-11, with the greatest increases occurring in Nevada and Arizona (134 and 76 percent, respectively) (see table A-3-2). During that period, total enrollment declined in 9 states and the District of Columbia. From 2010-11 to 2021-22, Alaska, Nevada, and Arizona are projected to see the greatest percentage increases in total enrollment (22, 21, and 20, respectively) (see table A-3-3). The District of Columbia is projected to see the largest percentage decrease in total enrollment over the same time period (15 percent).

From 2010-11 to 2021-22, the changes in public elementary and secondary enrollments are projected to differ among the states. Reflecting the larger national enrollment increase expected at the pre $\mathrm{K}-8$ than at the grade 9-12 level, 43 states are expected to have enrollment increase at the preK-8 level between 2009-10 to 2021-22, while 36 states are expected to have increases at the grade 9-12 level during that period. In grades preK-8, enrollment is projected to increase more than 20 percent in Alaska, Nevada, Arizona, and Washington but decrease 13 and 11 percent, respectively, in the District of Columbia and West Virginia. Enrollment in grades 9-12 in Texas is expected to increase more than 20 percent, while enrollment in these grades in the District of Columbia is projected to decrease 20 percent or more.

Tables A-3-1, A-3-2, and A-3-3

Glossary: Elementary/secondary school, Prekindergarten, Public school

\section{Technical Notes}

The most recent year of actual data is 2010-11, and 2021-22 is the last year for which projected data are available. For more information on projections, see NCES 2012-044. Some data have been revised from previously published figures. Detail may not sum to totals due to rounding. For a list of the states in each region, see Appendix C - Commonly Used Measures. 
Figure 3-1. Actual and projected public school enrollment in grades prekindergarten (preK) through 12, by grade level: School years 1970-71 through 2021-22

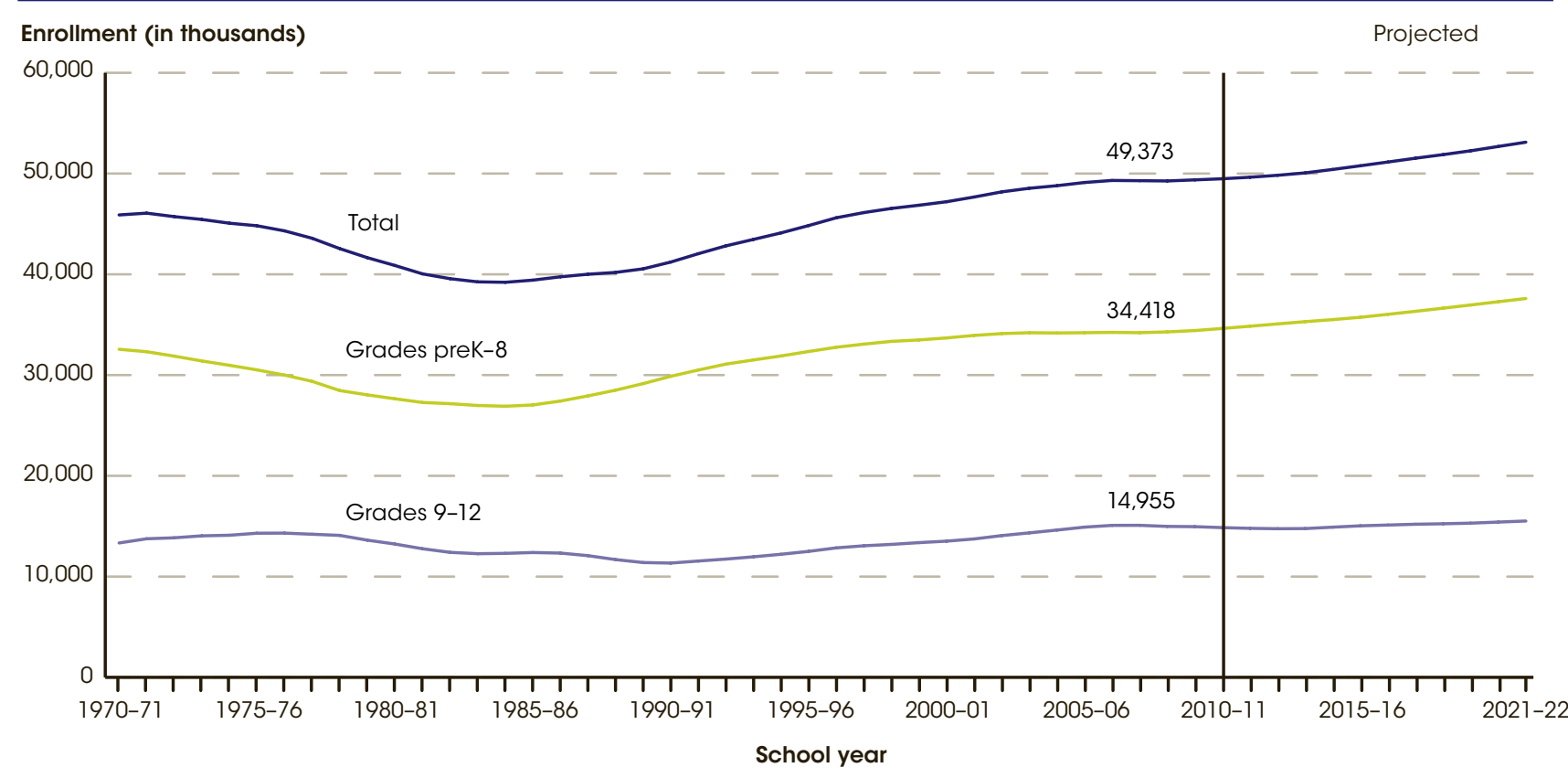

NOTE: The most recent year of actual data is 2010-11, and 2021-22 is the last year for which projected data are available. For more information on projections, see NCES 2012-044. Detail may not sum to totals because of rounding. Some data have been revised from previously published figures. SOURCE: U.S. Department of Education, National Center for Education Statistics, Statistics of Public Elementary and Secondary Day Schools, $1970-71$ through 1984-85; Common Core of Data (CCD), "State Nonfiscal Survey of Public Elementary/Secondary Education," 1985-86 through 2010-11, and National Elementary and Secondary Enrollment Model, 1972-2010.

Figure 3-2. Projected percent change in public school enrollment in grades prekindergarten (preK) through 12, by state or jurisdiction: Between school years 2010-11 and 2021-22

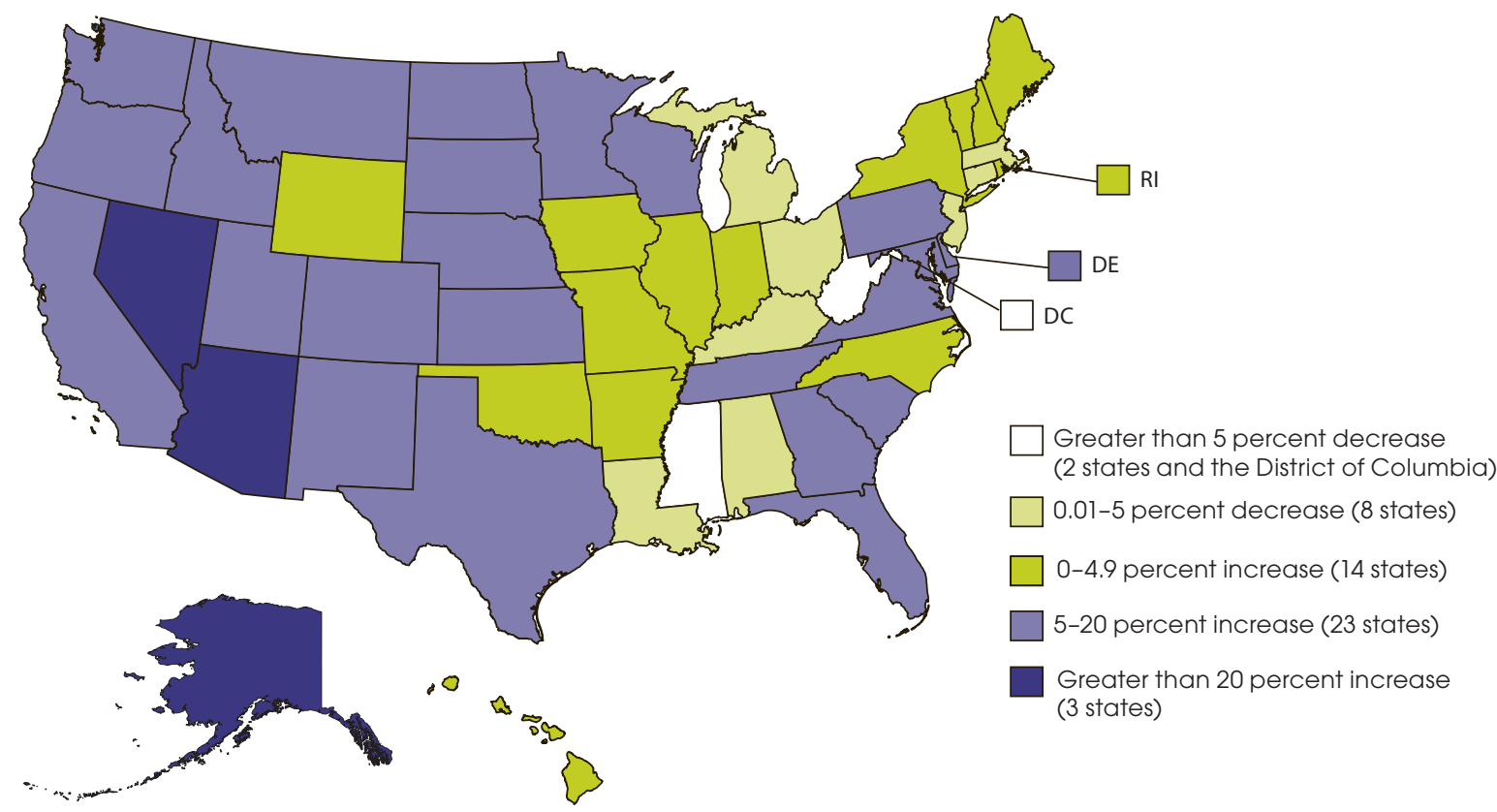

NOTE: The most recent year of actual data is 2010-11, and 2021-22 is the last year for which projected data are available. For more information on projections, see NCES 2012-044

SOURCE: U.S. Department of Education, National Center for Education Statistics, Common Core of Data (CCD), "State Nonfiscal Survey of Public Elementary/Secondary Education," 2010-11; and Public State Elementary and Secondary Enrollment Model, 1980-2010. 


\section{Indicator 4}

\section{Charter School Enrollment}

\section{From 1999-2000 to 2009-10, the number of students enrolled in public charter schools more than quadrupled from 0.3 million to 1.6 million students. In 2009-10, some 5 percent of all public schools were charter schools.}

A public charter school is a publicly funded school that is typically governed by a group or organization under a legislative contract or charter with the state or jurisdiction. The charter exempts the school from selected state or local rules and regulations. In return for funding and autonomy, the charter school must meet the accountability standards articulated in its charter. A school's charter is reviewed periodically (typically every 3 to 5 years) and can be revoked if guidelines on curriculum and management are not followed or if the standards are not met (U.S. Department of Education 2000). In 2009-10, charter schools operated in 40 states and the District of Columbia. In the following states, a charter school law has not been passed: Alabama, Kentucky, Maine, Montana, Nebraska, North Dakota, South Dakota, Vermont, Washington, and West Virginia.

From 1999-2000 to 2009-10, the number of students enrolled in public charter schools more than quadrupled from 0.3 million to 1.6 million students (see table A-4-1). During this period, the percentage of all public schools that were public charter schools increased from 2 to 5 percent, comprising 5,000 schools in 2009-10 (see table A-4-2). In addition to the increase in the number of charter schools, the enrollment size of charter schools has grown over time. The percentage of charter schools with enrollments under 300 students decreased from 77 percent in 1999-2000 to 61 percent in 2009-10 (see table A-4-1). The percentage of charter schools with enrollments of 300-499 students increased from 12 to 21 percent during this period; the percentage with 500-999 students, from 9 to 14 percent; and the percentage with 1,000 students or more, from 2 to 4 percent.

The percentages of students in public charter schools who were White, Black, and American Indian/Alaska Native decreased between 1999-2000 and 2009-10 (42 vs. 37,34 vs. 30 , and 2 vs. 1 percent respectively). The percentages who were Hispanic and Asian/Pacific Islander increased between 1999-2000 and 2009-10 (20 vs. 26, and 3 vs. 4 percent respectively). The percentage of charter schools that were high-poverty schools - where more than 75 percent of students were eligible for free or reducedprice lunch (FRPL) — was 33 percent in 2009-10 and the percentage of charter schools that were low-poverty schools-where 25 percent or fewer of students were eligible for FRPL-was 19 percent.

In 2009-10, over half (54 percent) of charter schools were elementary schools. Secondary and combined schools accounted for 27 and 19 percent of charter schools, respectively. In that year, about 55 percent of charter schools were located in cities, 21 percent were in suburban areas, 8 percent were in towns, and 16 percent were in rural areas.

The proportion of public school students enrolled in charter schools varied by region and state or jurisdiction. In 2009-10, in the District of Columbia and Arizona more than 10 percent of public school students were enrolled in charter schools (see table A-4-2). In 13 additional states, between 4 and 8 percent of public school students were enrolled in charter schools. Six of the states with 4 percent or more public school students enrolled in charter schools were in the West; three, plus the District of Columbia, were in the South; four were in the Midwest; and one was in the Northeast. California enrolled the most students in charter schools $(317,000)$ and the District of Columbia enrolled the highest percentage of public school students in charter schools - 37 percent, representing some 26,000 students.

Tables A-4-1 and A-4-2

Glossary: Combined school, Elementary school, Free or reduced-price lunch, National School Lunch Program, Public charter school, Secondary school, Student membership, Traditional public school

\section{Technical Notes}

Data are based on schools reporting student membership. For more information on the CCD, see Appendix B - Guide to Sources. For more information on poverty status, locale, and geographic region, see Appendix C Commonly Used Measures. 


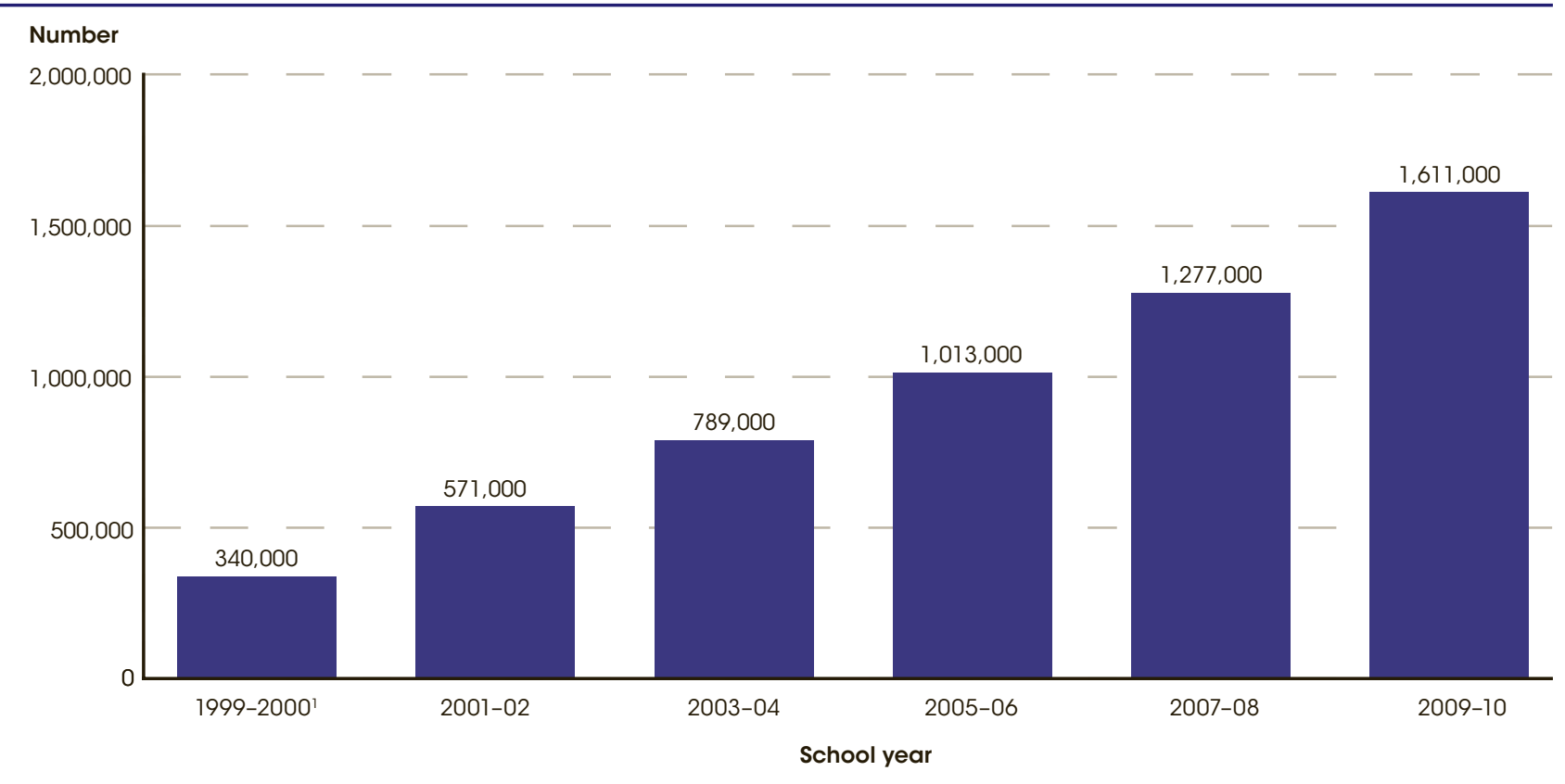

Data for New Jersey were not available and therefore not included in the estimates.

NOTE: Data are for schools reporting student membership. The Common Core of Data (CCD) allows students to be reported for only a single school, even if they attend a "shared time" school, such as a vocational school. For more information on the CCD, see Appendix B - Guide to Sources.

SOURCE: U.S. Department of Education, National Center for Education Statistics, Common Core of Data (CCD), "Public Elementary/Secondary School

Universe Survey," 1999-2000 (version 1b), 2001-02 (version 1a), 2003-04 (version 1a), 2005-06 (version 1a), $2007-08$ (version 1b), and 2009-10 (version 1a),

\section{Figure 4-2. Percentage of all public students who are in charter schools, by state: School year 2009-10}

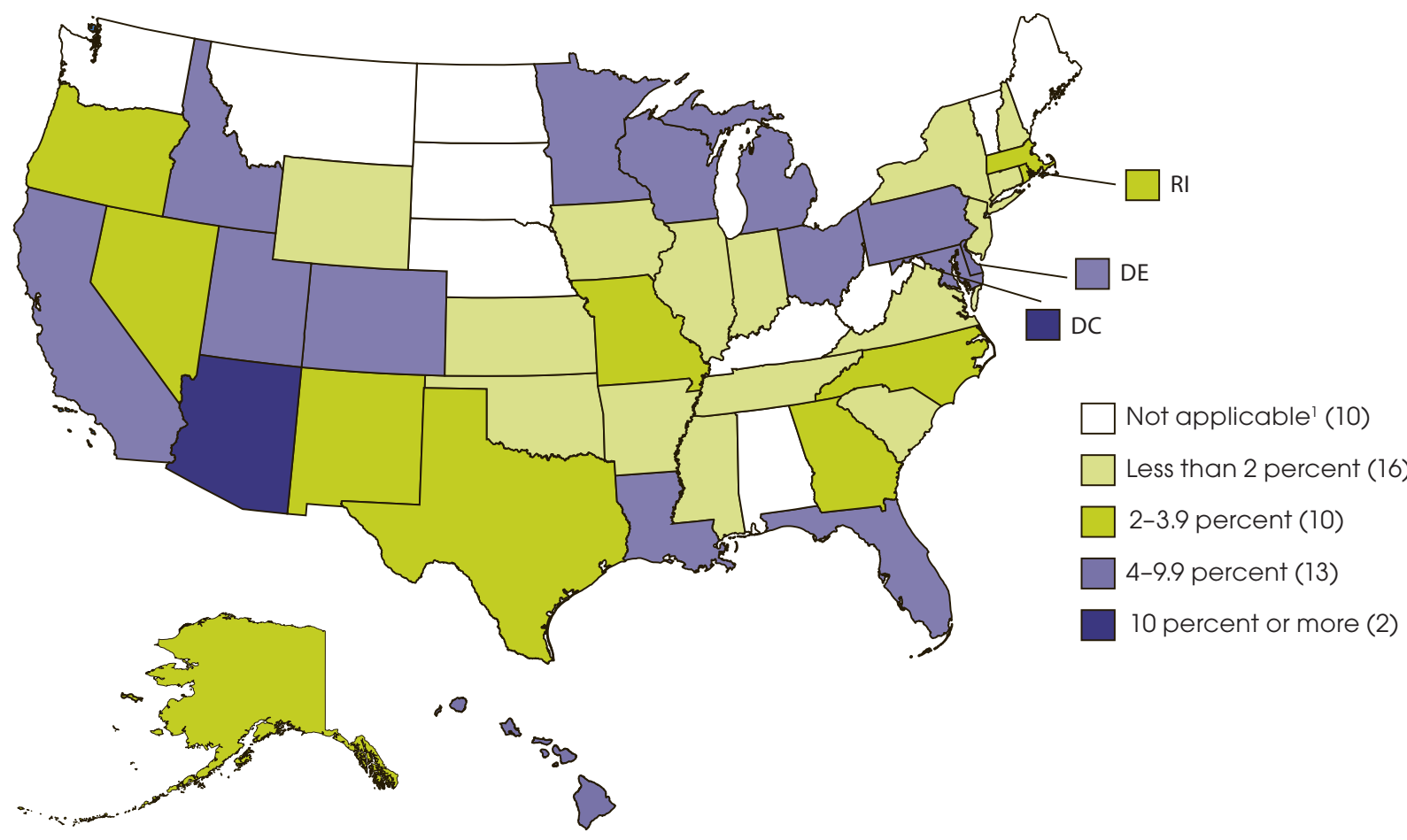

Not applicable. State has not passed a charter school law.

NOTE: Data are for schools reporting student membership. The Common Core of Data (CCD) allows students to be reported for only a single school, even if they attend a "shared time" school, such as a vocational school. For more information on geographic region, see Appendix C - Commonly Used Measures. For more information on the CCD, see Appendix B - Guide to Sources.

SOURCE: U.S. Department of Education, National Center for Education Statistics, Common Core of Data (CCD), "Public Elementary/Secondary School Universe Survey," 2009-10 (version 1a). 


\section{Indicator 5}

\section{Private School Enrollment}

\section{Private school enrollment in prekindergarten through grade 12 increased from 5.9 million in 1995-96 to 6.3 million in 2001-02 then decreased to 5.5 million in 2009-10. Some 10 percent of all elementary and secondary school students were in private schools in 2009-10.}

Private school enrollment in prekindergarten through grade 12 increased from 5.9 million in 1995-96 to 6.3 million in 2001-02 then decreased to 5.5 million in 2009-10. Some 10 percent of all elementary and secondary school students were in private schools in 2009-10, which was lower than the percentage in 1995-96 (12 percent) (see tables A-5-1 and A-5-2).

Between 1995-96 and 2005-06, Catholic schools maintained the largest share of total private school enrollment. However, the percentage of all private school students enrolled in Catholic schools decreased from 45 percent in 1995-96 to 39 percent in 2009-10 (see table A-5-1). The number of students enrolled in Catholic schools in 2009-10 was higher than the number of students enrolled in other religious schools. The decrease in Catholic school enrollment stemmed from the decline of students enrolled in parochial schools (those run by a parish, not by a diocese or independently). The numbers of students enrolled in Conservative Christian and Affiliated schools also were lower in 2009 than in 1995. In contrast, the number of students enrolled in Unaffiliated schools increased 35 percent from 1995-96 to 2009-10.

In 2009-10, most private secondary school students were enrolled in Catholic schools (75 percent; see table A-5-3). In that same year, 2 percent of private secondary school students were enrolled in Conservative Christian schools, 6 percent each were enrolled in Affiliated and Unaffiliated religious schools, and 12 percent were enrolled in

Nonsectarian schools. Similarly, more private elementary school students were enrolled in Catholic schools than in any other school type (50 percent; see table A-5-3). In contrast to the large percentage of private school students enrolled in Catholic secondary and elementary schools, Catholic students made up the minority of private school students enrolled in combined schools, at only 7 percent.

In 2009-10, the percentage of all students who were enrolled in private schools was higher in the Northeast (14 percent) than in the Midwest (11 percent), the South (9 percent), and the West (8 percent) (see table A-5-2). The percentage of students enrolled in private schools was lower in 2009-10 than in 1995-96 in all four regions. More than half of private school students in the Midwest attended Catholic schools (56 percent), as compared to the Northeast (46 percent), the West (33 percent), and the South (27 percent).

There were differences in attendance by school type within racial/ethnic groups. Hispanic, Asian, and American Indian/Alaska Native students and students of two or more races all had higher percentages of students attending Catholic schools than other religious or Nonsectarian schools (see table A-5-3). In contrast, there was a higher percentage of Black students attending other religious schools than attending Catholic schools. White, Black, and Pacific Islander students had higher percentages of students attending Catholic schools than nonsectarian schools. However, the percentages of White and Pacific Islander students attending Catholic schools were not measurably different than the percentages attending other religious schools.

Tables A-5-1, A-5-2, and A-5-3

Glossary: Prekindergarten, Private schools

\section{Technical Notes}

Excludes prekindergarten students not enrolled in schools that offered kindergarten or higher grades. Other religious schools are those with a religious orientation or purpose but are not Catholic. Conservative Christian schools are those with membership in at least 1 of 4 associations, and Affiliated schools are those with membership in 1 of 11 associations. Unaffiliated schools are those that have a more general religious orientation or purpose but are not classified as Conservative Christian or affiliated with a specific religion. Nonsectarian schools do not have a religious orientation or purpose. For more information on private schools and the Private School Universe Survey (PSS), see Appendix B - Guide to Sources. Race categories exclude persons of Hispanic ethnicity. For more information on geographic region and race/ethnicity, see Appendix C - Commonly Used Measures. 
Figure 5-1. Number of private school students in prekindergarten through grade 12, by school type: Various school years, 1995-96 through 2009-10

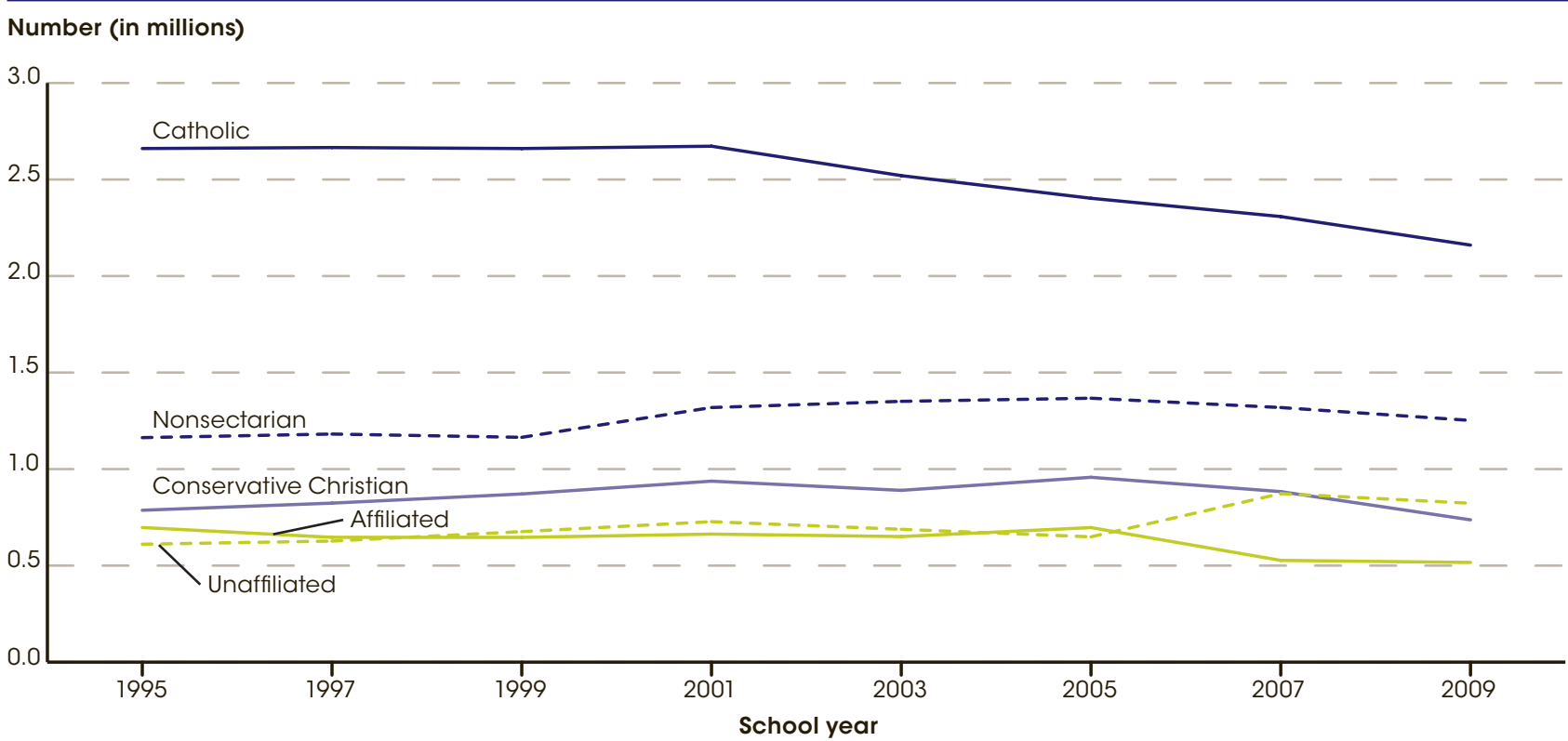

NOTE: Excludes prekindergarten students not enrolled in schools that offered kindergarten or higher grades. Catholic schools include parochial, diocesan, and private Catholic schools. Affiliated religious schools have a specific religious orientation or purpose but are not Catholic. Unaffiliated schools have a more general religious orientation or purpose but are not classified as Conservative Christian or affiliated with a specific religion. Nonsectarian schools do not have a religious orientation or purpose. For more information on the Private School Universe Survey (PSS), see Appendix B - Guide to Sources. SOURCE: U.S. Department of Education, National Center for Education Statistics, Private School Universe Survey (PSS), various years, $1995-96$ through 2009-10.

Figure 5-2. Percentage distribution of private school enrollment, by school type and level: 2009-10

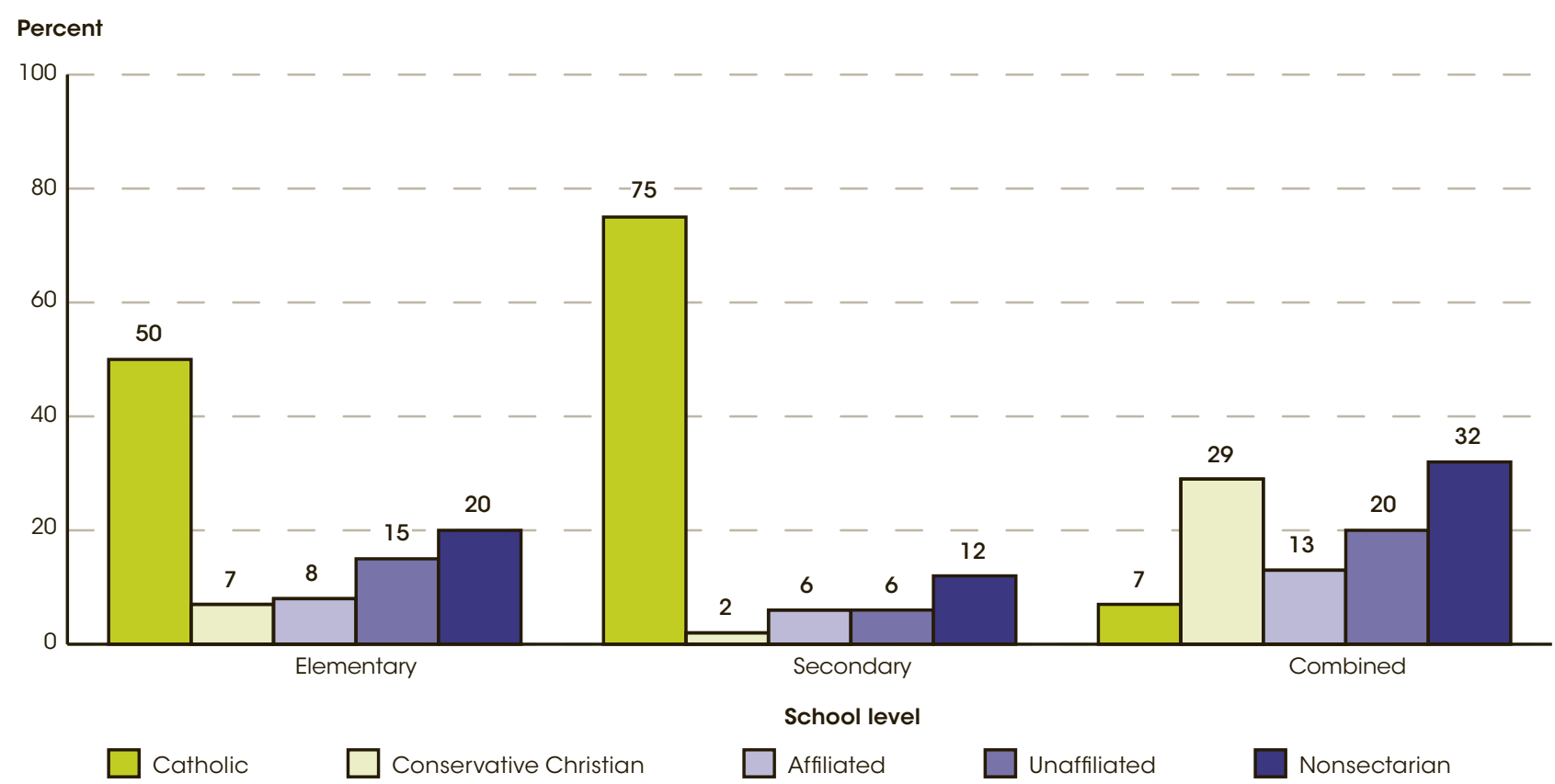

NOTE: Excludes prekindergarten students not enrolled in schools that offered kindergarten or higher grades. Catholic schools include parochial, diocesan, and private Catholic schools. Affiliated religious schools have a specific religious orientation or purpose but are not Catholic. Unaffiliated schools have a more general religious orientation or purpose but are not classified as Conservative Christian or affiliated with a specific religion. Nonsectarian schools do not have a religious orientation or purpose. Ungraded students are prorated into preK-8 and 9-12 enrollment totals. Detail may not sum to totals because of rounding. For more information on the Private School Universe Survey (PSS), see Appendix B - Guide to Sources. SOURCE: U.S. Department of Education, National Center for Education Statistics, Private School Universe Survey (PSS), $2009-10$. 


\section{Indicator 6}

\section{Racial/Ethnic Enrollment in Public Schools}

\section{Between 1990 and 2010, the percentage of public school students who were White decreased from 67 to 54 percent, and the percentage of those who were Hispanic increased from 12 percent (5.1 million students) to 23 percent (12.1 million students).}

From 1990 through 2010, the number of White students in U.S. public schools decreased from 29.0 million to 27.7 million, and their share of enrollment decreased from 67 to 54 percent (see table A-6-1). In contrast, Hispanic enrollment during this period increased from 5.1 to 12.1 million students, and the percentage of public school students who were Hispanic increased from 12 to 23 percent. While the total number of Black students fluctuated, their share of enrollment decreased from 17 to 15 percent during this time. In 2002, the percentage of public school students who were Hispanic surpassed the percentage who were Black and has remained higher than the Black share of enrollment in each year through 2010.

Between 1990 and 2010, overall enrollment fluctuated in the Northeast and Midwest (see table A-6-2). Enrollment increased from 15.1 to 19.6 million in the South and from 9.4 to 12.8 million in the West.

The change in racial/ethnic distribution of public school enrollment differed by region from 1990 to 2010 (see table A-6-3). The number and percentage enrollment of White students decreased in all regions, with the exception of the South, where enrollment of Whites fluctuated and percentage enrollment decreased during this period. The number of Black students fluctuated in all four regions and the percentage of Black students fluctuated in the Northeast and Midwest, while decreasing in the West and South. The number of Hispanic students increased in all four regions as did their share of enrollment. The number and percentage enrollment of Asian students increased in all regions in which data were reported except in the West, where enrollment, in terms of number and percentage, fluctuated during this time period. Native Hawaiian/Pacific Islander and American Indian/Alaska Native students each represented 1 percent or less of student enrollment in all regions of the United States in 2010. Students of two or more races made up 4 percent of enrollment in the West, 3 percent in the Midwest, and 2 percent each in the Northeast and South.

In 2010, White students made up 50 percent or less of school enrollment in 12 states and the District of Columbia (see table A-6-4). Black students had the largest share of public school enrollment in Mississippi and the District of Columbia. Hispanic students had the largest share of public school enrollment in Arizona, California, New Mexico, and Texas. Of all the jurisdictions, the District of Columbia enrolled the highest percentage of Black students (77 percent), New Mexico enrolled the highest percentage of Hispanic students (59 percent), and Hawaii enrolled the highest percentages of Asian students (26 percent) and students of two or more races (30 percent).

Tables A-6-1, A-6-2, A-6-3, and A-6-4

Glossary: Public school

Population Survey (CPS) and ACS, enrollment estimates from the two surveys are not directly comparable. For more information on the ACS and the CPS, see Appendix B - Guide to Sources. For more information on racel ethnicity, see Appendix C - Commonly Used Measures. 
Figure 6-1. Percentage distribution of public school students enrolled in prekindergarten through 12th grade, by race/ethnicity: Selected years, October 1990-October 2010

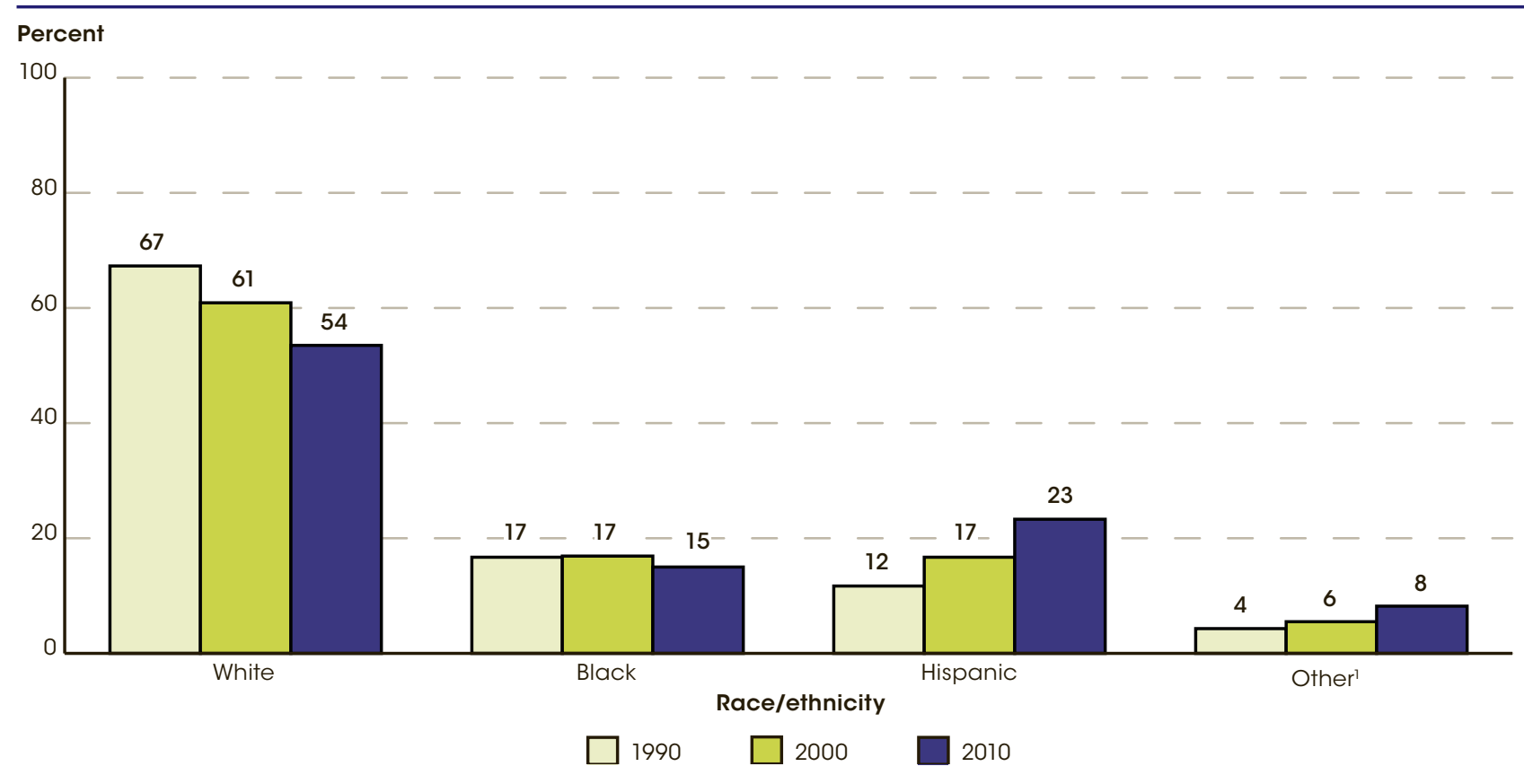

1 Other includes all students who identified themselves as being Asian, Native Hawaiian, Alaska Native, Pacific Islander, American Indian, or two or more races.

NOTE: Over time, the Current Population Survey (CPS) has had different response options for race/ethnicity. For more information on the Current Population Survey (CPS), see Appendix B - Guide to Sources. Race categories exclude persons of Hispanic ethnicity. Totals include other race/ethnicity categories not shown separately. Detail may not sum to totals because of rounding. For more information on race/ethnicity, see Appendix $\mathrm{C}$ - Commonly Used Measures.

SOURCE: U.S. Department of Commerce, Census Bureau, Current Population Survey (CPS), October Supplement, 1990, 2000, and 2010.

Figure 6-2. Number of public school students enrolled in prekindergarten through 12th grade, by region and race/ ethnicity: October 1990-October 2010

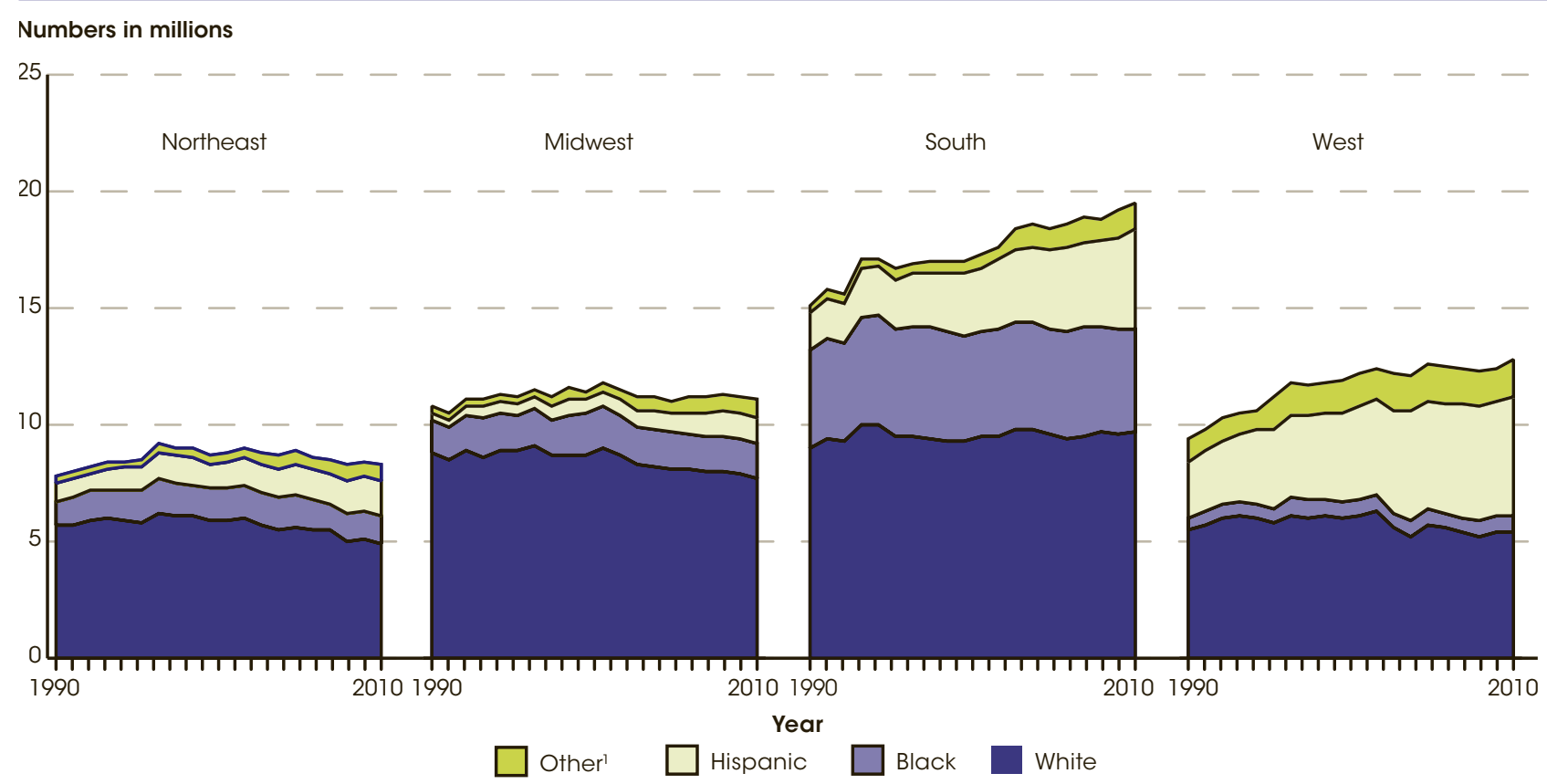

Other includes all students who identified themselves as being Asian, Native Hawaiian, Alaska Native, Pacific Islander, American Indian, or two or more races.

NOTE: Over time, the Current Population Survey (CPS) has had different response options for race/ethnicity. For more information on the Current Population Survey (CPS), see Appendix B - Guide to Sources. Race categories exclude persons of Hispanic ethnicity. For more information on race/ ethnicity and region, see Appendix C - Commonly Used Measures.

SOURCE: U.S. Department of Commerce, Census Bureau, Current Population Survey (CPS), October Supplement, $1990-2010$. 


\section{Indicator 7}

\section{Family Characteristics of 5- to 17-Year-Olds}

\section{In 2011 , higher percentages of Black (37 percent), Hispanic (34 percent), American Indian/Alaska Native (33 percent), Native Hawaiian/Pacific Islander (32 percent) children, and children of two or more races (20 percent) were living in families below the poverty threshold than were White (12 percent) and Asian (14 percent) children.}

\begin{abstract}
The percentage of school-age children (ages 5-17) whose parents' highest educational attainment was a bachelor's degree or higher increased from 26 percent in 1990 to 37 percent in 2011 (see table A-7-1); this same measure increased for White children (from 31 to 48 percent), Black children (from 11 to 22 percent), and Hispanic children (from 8 to 16 percent). In 2011, higher percentages of Asian and White children (60 and 48 percent, respectively) had parents who had completed at least a bachelor's degree, compared with children of two or more races (33 percent), Native Hawaiian/Pacific Islander (27 percent), Black (22 percent), American Indian/Alaska Native (19 percent), and Hispanic (16 percent) children.
\end{abstract}

The percentage of school-age children living in two-parent households decreased from 72 percent in 1990 to 67 percent in 2011. Some 24 percent of children lived only with their mother and 4 percent only with their father in 2011. Approximately one-third of Black children (35 percent) lived in two-parent households, compared with 85 percent of Asian children, 75 percent of White children, 74 percent of Native Hawaiian/Pacific Islander children, 65 percent of Hispanic children, 59 percent of children of two or more races, and 52 percent of American Indian/Alaska Native children. Some 52 percent of Black children lived in mother-only households; this percentage was higher than the percentages for children from any other racial/ethnic group (ranging from 10 percent of
Asian children to 31 percent of children of two or more races).

The percentage of school-age children living in poor households - that is, with families living below the poverty threshold - varied in the years between 1990 and 2011; but between 2007 and 2011, this percentage increased from 17 percent to 21 percent. This general pattern was also observed for White, Black, and Hispanic children. For example, the percentage of Black children living in poor households varied from 41 percent in 1990, to 32 percent in 2000 and 34 percent in 2006. Since 2007 , this percentage has steadily increased from 31 percent to 37 percent in 2011. Higher percentages of Black (37 percent), Hispanic (34 percent), American Indian/Alaska Native (33 percent), Native Hawaiian/ Pacific Islander (32 percent) children, and children of two or more races (20 percent) were living in families below the poverty threshold in 2011 than were White (12 percent) and Asian (14 percent) children.

In 2011, some 95 percent of all school-age children were born in the United States, not measurably different from the percentage in 2000 (the first year for which nativity data are shown in this indicator). A higher percentage of Hispanics were born in the United States in 2011 (90 percent) than in 2000 (83 percent).

Tables A-7-1

Glossary: Bachelor's degree

\section{Technical Notes}

Estimates are for all 5- to 17-year-olds regardless of their school enrollment status. Prior to 1992, high school completers referred to those who completed 12 years of schooling, and some college meant completing 1 or more years of college. Beginning in 1992, high school completers referred to those who received a high school diploma or equivalency certificate, and some college meant completing any college at all. In 1990 and 2000, included in the U.S. population totals but not shown separately are estimates for children from other racial/ ethnic categories. Poor is defined to include families below the poverty threshold. For more information on educational attainment, poverty, and race/ethnicity, see Appendix C - Commonly Used Measures. Some estimates have been revised from previous published figures. For more information on the Current Population Survey (CPS), see Appendix B - Guide to Sources. 
Figure 7-1. Percentage of 5- to 17-year-olds living in two-parent households, by race/ethnicity: 1990, 2000, and 2011

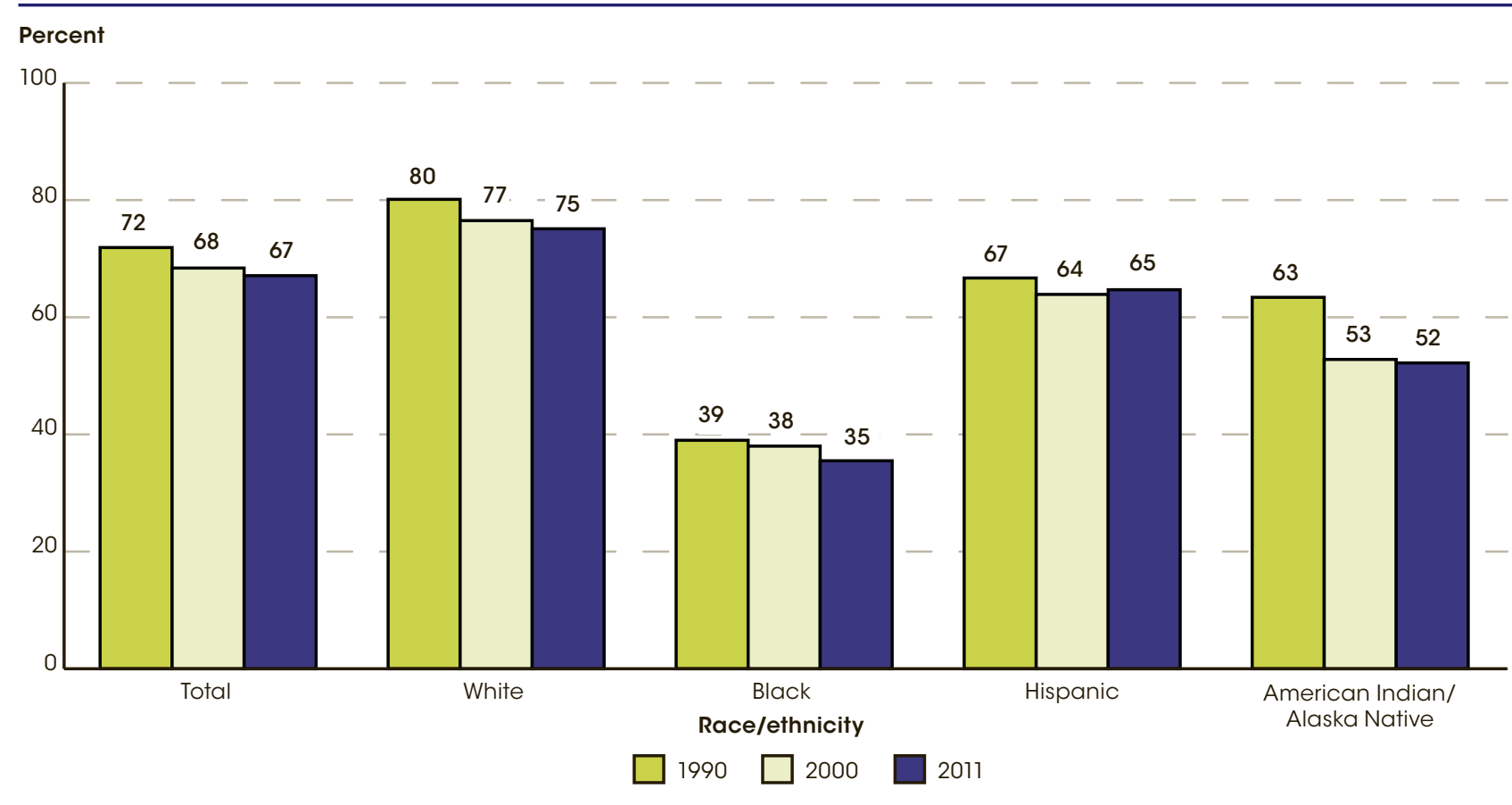

NOTE: Estimates are for all 5- to 17-year-olds regardless of their school enrollment status. Totals for 1990 and 2000 include other racial/ethnic groups not shown separately in the table. Data for Asian children, Pacific Islander children, and children of two or more races in 1990 and 2000 were not available; therefore, data for these groups are not shown in the figure. Race categories exclude persons of Hispanic ethnicity. For more information on race/ethnicity, see Appendix C - Commonly Used Measures. For more information on the Current Population Survey (CPS), see Appendix B - Guide to Sources.

SOURCE: U.S. Department of Commerce, Census Bureau, Current Population Survey (CPS), March Supplement, 1990, 2000, and 201 1.

\section{Figure 7-2. Percentage of 5- to 17-year-olds who were living in poor households, by race/ethnicity: 2006 and 2011}

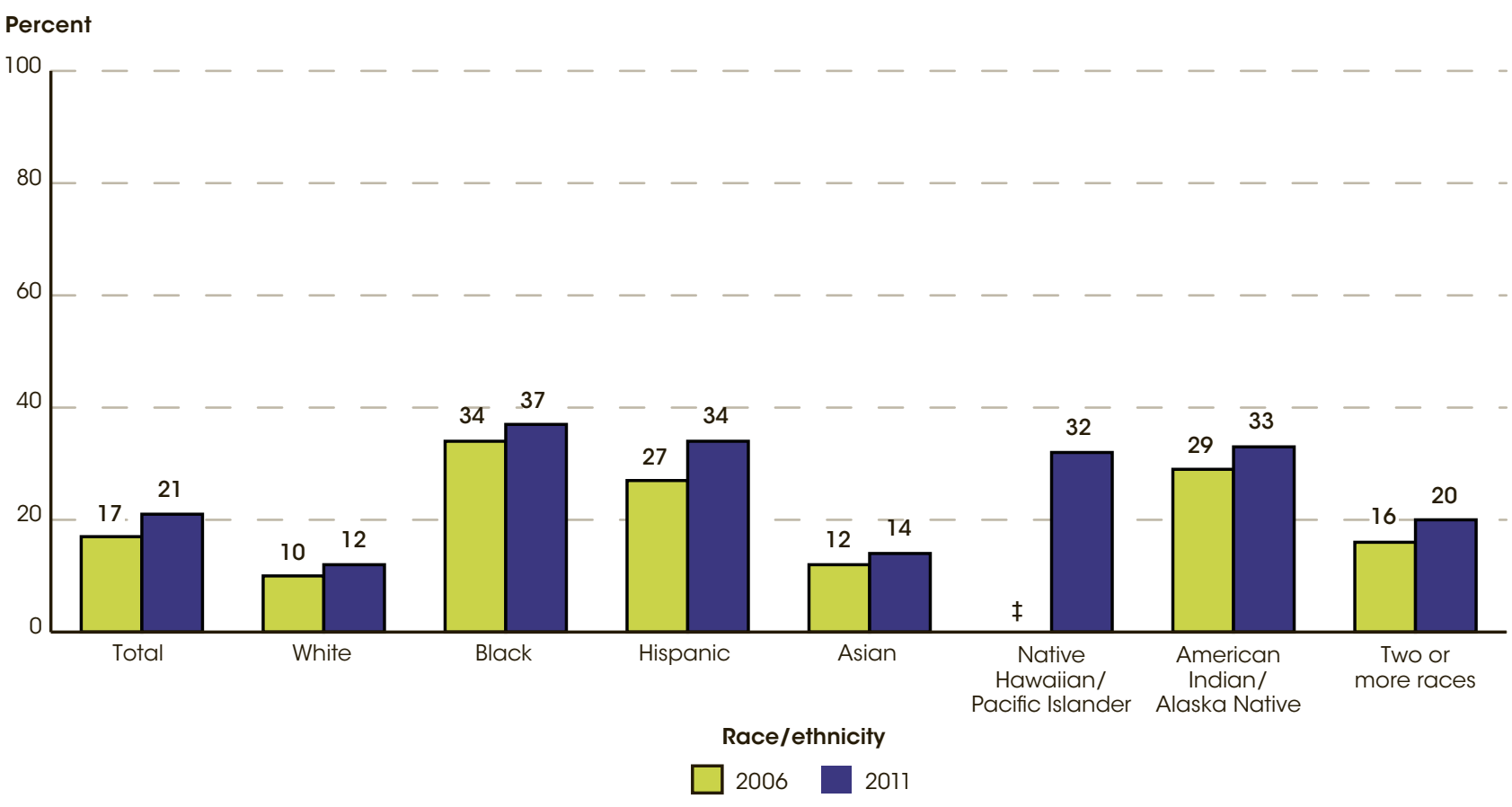

‡ Reporting standards not met (†oo few cases)

NOTE: Estimates are for all 5- to 17-year-olds regardless of their school enrollment status. Race categories exclude persons of Hispanic ethnicity. Poor is defined to include families below the poverty threshold. For more information on race/ethnicity and poverty, see Appendix $\mathrm{C}$ - Commonly Used Measures. For more information on the Current Population Survey (CPS), see Appendix B - Guide to Sources.

SOURCE: U.S. Department of Commerce, Census Bureau, Current Population Survey (CPS), March Supplement, 2006 and 2011. 


\section{English Language Learners in Public Schools}

\section{The percentage of public school students in the United States who were English language learners (ELLS) was higher in 2009-10 at 10 percent (or an estimated 4.7 million students) than in 2000-01 at 8 percent (or an estimated 3.7 million students.)}

The percentage of public school students in the United States who were English language learners (ELLs) was higher in 2009-10 (10 percent, or an estimated 4.7 million students) than in 2000-01 (8 percent, or an estimated 3.7 million students). The total number of public school students in the United States was 46.6 million in 2000-01 and 48.0 million students in 2009-10 (see table A-8-1).

In 2009-10, the percentage of ELL students in public schools was less than 4 percent in 15 states; this percentage was between 4 and 7 percent in 18 states. Twelve states and the District of Columbia had percentages of ELL public school enrollment between 7 and 14 percent. In addition to the District of Columbia, these states were Virginia, North Carolina, New York, Kansas, Arizona, Utah, Illinois, Florida, Hawaii, Oregon, Alaska, and Colorado. In four states, 14 percent or more of the public school students were English language learners-Texas, New Mexico, Nevada, and Californiawith ELL students constituting 29 percent of public school enrollment in California.

The percentage of ELL students in public schools was higher in 2009-10 than in 2000-01 in all but 13 states, with the largest positive percentage-point changes occurring in Nevada ( 9 percentage points), Delaware, and Kansas (5 percentage points each). The percentage of ELL students in public schools was higher in 2009-10 than in 2008-09 in just over half of the states (28 states), with the largest positive change in percentage points occurring in California ( 5 percentage points).

In cities in 2009-10, ELL students made up an average of 14 percent of total public school enrollment, ranging from 11 percent in small cities to 18 percent in large cities (see table A-8-2). In suburban areas, ELL students constituted an average of 8 percent of public student enrollment, ranging from 7 percent in midsize suburban areas to 10 percent in large suburban areas. In towns, ELL students made up an average of 7 percent of public student enrollment, ranging from 6 percent in both distant and remote areas to 9 percent in fringe areas. Towns and rural areas are subdivided into fringe, distant, and remote according to their proximity to urban centers, with fringe being the closest to an urban center and remote being the farthest from one. In rural areas, ELL students made up an average of 4 percent of public student enrollment, ranging from 2 percent in distant areas to 4 percent each in fringe and remote areas.

Tables A-8-1 and A-8-2

Glossary: English language learner

(or estimations) for states that did not report ELL data; 6.6 percent of the ELL enrollment data were imputed in this year. For more information on locale, see Appendix $\mathrm{C}-$ Commonly Used Measures. For more information on the Common Core of Data, see Appendix B - Guide to Sources. 

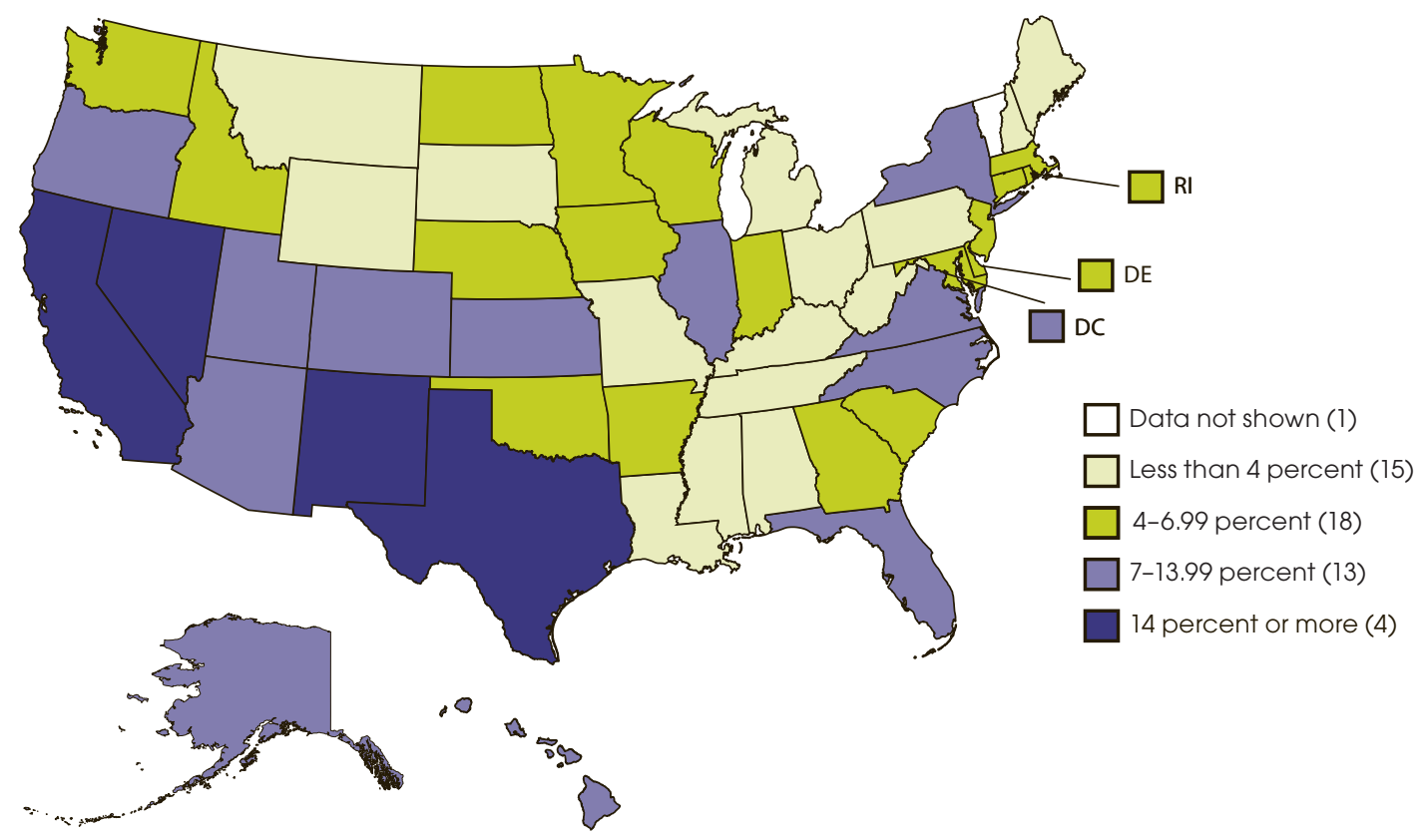

NOTE: For more information on the Common Core of Data, please see Appendix B - Guide to Sources.

SOURCE: U.S. Department of Education, National Center for Education Statistics, Common Core of Data (CCD), "Public Elementary/Secondary School

Universe Survey," 2000-01 (version 1a), 2005-06 (version 1a), 2008-09 (version 1a), and 2009-10 (version 1a).

Figure 8-2. Percentage of public school students who are English language learners (ELLs), by locale: School year 2009-10

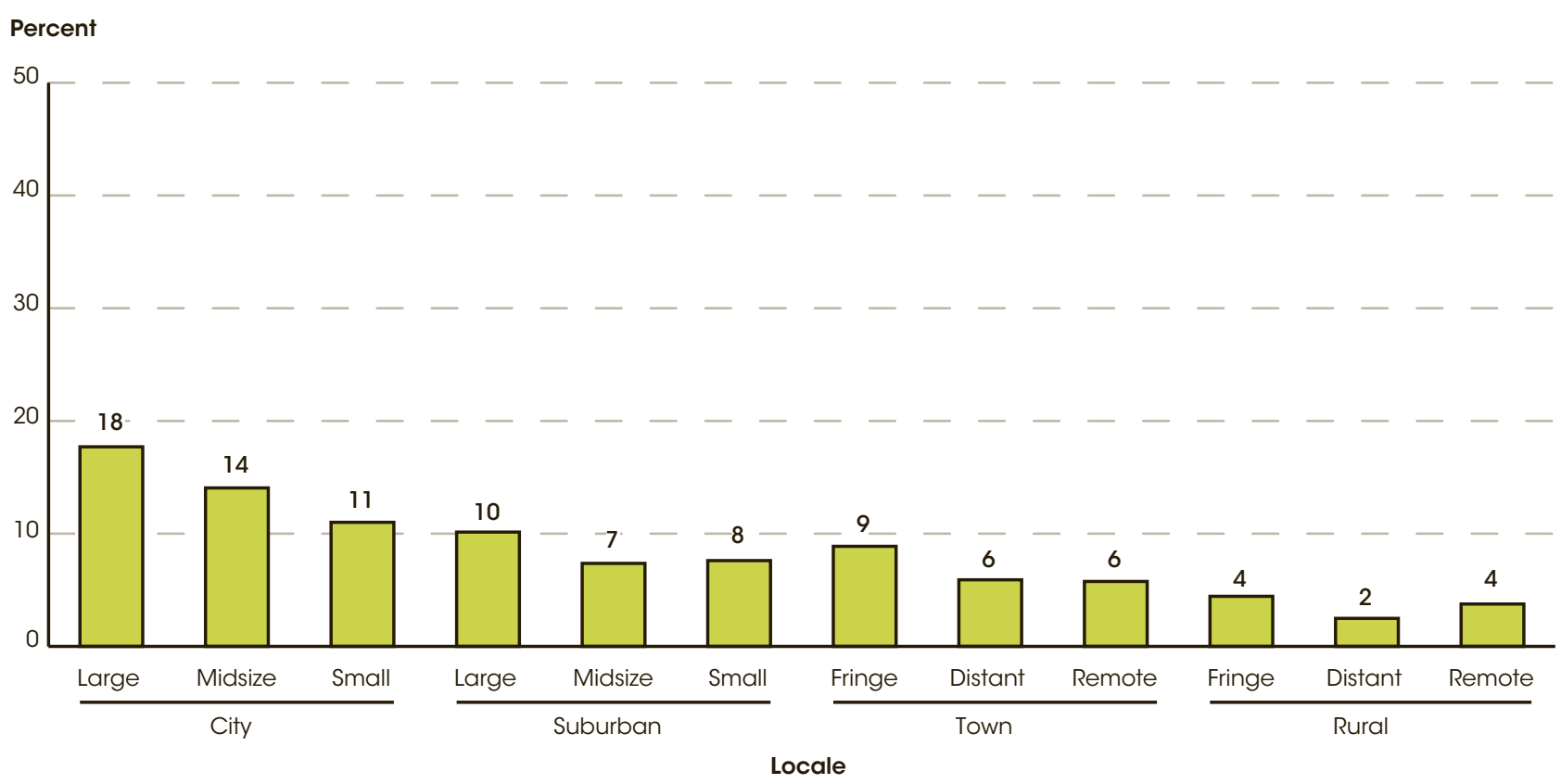

NOTE: For more information on locale, see Appendix C - Commonly Used Measures. For more information on the Common Core of Data, see Appendix B - Guide to Sources.

SOURCE: U.S. Department of Education, National Center for Education Statistics, Common Core of Data (CCD), "Public Elementary/Secondary School Universe Survey," 2009-10 (version 1a). 


\section{Indicator 9}

\section{Children and Youth With Disabilities}

\section{The number of children and youth ages 3-21 receiving special education services was 6.5 million in 2009-10, or about 13 percent of all public school students. Some 38 percent of the students receiving special education services had specific learning disabilities.}

Enacted in 1975, the Individuals with Disabilities Education Act (IDEA), formerly known as The Education for All Handicapped Children Act (EAHCA), mandates the provision of a free and appropriate public school education for children and youth ages 3-21 who have disabilities. Data collection activities to monitor compliance with IDEA began in 1976. From school years 1980-81 through 2004-05, the number of children and youth ages 3-21 who received special education services increased, as did their percentage of total public school students (see table A-9-1). The number and percentage of children and youth served under IDEA have declined each year from 2005-06 through 2009-10. In 1980-81, some 4.1 million children and youth ages 3-21 received special education services. The number of children and youth served under IDEA increased to 6.7 million in 2004-05, or about 14 percent of total public school enrollment. By 2009-10, the number of children and youth receiving services declined to 6.5 million, corresponding to about 13 percent of total public school enrollment.

Generally, a greater percentage of children and youth ages 3-21 received special education services under IDEA for specific learning disabilities than for any other type of disability in school years between 1980-81 and 2009-10 (some data not shown). A specific learning disability is a disorder in one or more of the basic psychological processes involved in understanding or in using language, spoken or written, that may manifest itself in an imperfect ability to listen, think, speak, read, write, spell, or do mathematical calculations. In 2009-10, some 38 percent of all children and youth receiving special education services had specific learning disabilities, 22 percent had speech or language impairments, and 11 percent had other health impairments. Students with disabilities such as intellectual disabilities, emotional disturbances, developmental delay, and autism each accounted for between 6 and 7 percent of children and youth served under IDEA. Children and youth with multiple disabilities; hearing impairments, orthopedic impairments, and visual impairments; traumatic brain injury; and deaf-blindness each accounted for 2 percent or less of children served under IDEA.

About 95 percent of school-age children and youth ages 6-21 who were served under IDEA in school year 2009-10 were enrolled in regular schools (see table A-9-2). Some 3 percent of children and youth ages 6-21 who were served under IDEA were enrolled in separate schools (public or private) for students with disabilities; 1 percent were placed by their parents in regular private schools; and less than 1 percent each were in separate residential facilities (public and private), homebound or in hospitals, or in correctional facilities. Among all children and youth ages 6-21 who were enrolled in regular schools, the percentage of children and youth who spent most of their school day (more than 80 percent) in general classes was highest in 2009-10 (among school years since 1990-91, when the data were first compiled). For example, in 2009-10, some 59 percent of children and youth spent most of their school day in general class, compared to 33 percent in 1990-91 and 47 percent in 2000-01. In 2009-10, the percentage of students who spent most of their school day in general classes was highest for students with speech or language impairments (86 percent). Sixty-three percent each of students with specific learning disabilities and of students with visual impairments spent most of their school day in general classes. In contrast, 17 percent of students with intellectual disabilities and 13 percent of students with multiple disabilities spent most of their school day in general classes.

Tables A-9-1 and A-9-2

Glossary: Disabilities, Individuals with Disabilities Education Act (IDEA)

\section{Technical Notes}

Special education services through the Individuals with Disabilities Education Act (IDEA) are available only for eligible children and youth. Eligible children and youth are those identified by a team of professionals as having a disability that adversely affects academic performance and as being in need of special education and related services. Intellectual disability includes the condition formerly known as mental retardation. Data include children and youth in the 50 states, the District of Columbia, and the Bureau of Indian Education schools. For more information on the student disabilities presented, see Appendix C - Commonly Used Measures. For more information on the Common Core of Data (CCD), see Appendix B - Guide to Sources. 
Figure 9-1. Percentage distribution of children and youth ages 3-21 served under the Individuals with Disabilities Education Act (IDEA), by disability type: School year 2009-10

Disability type

Specific learning disabilities

Speech or language impairments

Other health impairments

Intellectual disability

Emotional disturbance

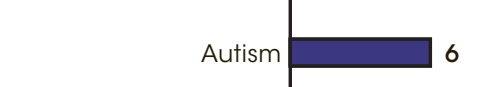

Developmental delay 6

Multiple disabilities

Hearing impairments

Orthopedic impairments

2
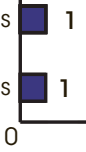

1

0

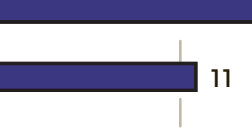

11

NOTE: Deaf-blindness, traumatic brain injury, and visual impairments are not shown because they each account for less than 1 percent of children served under IDEA. Due to categories not shown, detail does not sum to total. Includes children and youth in the 50 states, the District of Columbia, and the Bureau of Indian Education schools. For more information on student disabilities, see Appendix C - Commonly Used Measures.

SOURCE: U.S. Department of Education, Office of Special Education Programs, Individuals with Disabilities Education Act (IDEA) database, retrieved

September 15, 2011, from https://www.ideadata.org/DACAnalyticTool/Intro 2.asp.

Figure 9-2. Percentage of students ages 6-21 served under the Individuals with Disabilities Education Act (IDEA), Part B, placed in a regular school environment, by amount of time spent in general classes: Selected school years, 1990-91 through 2009-10

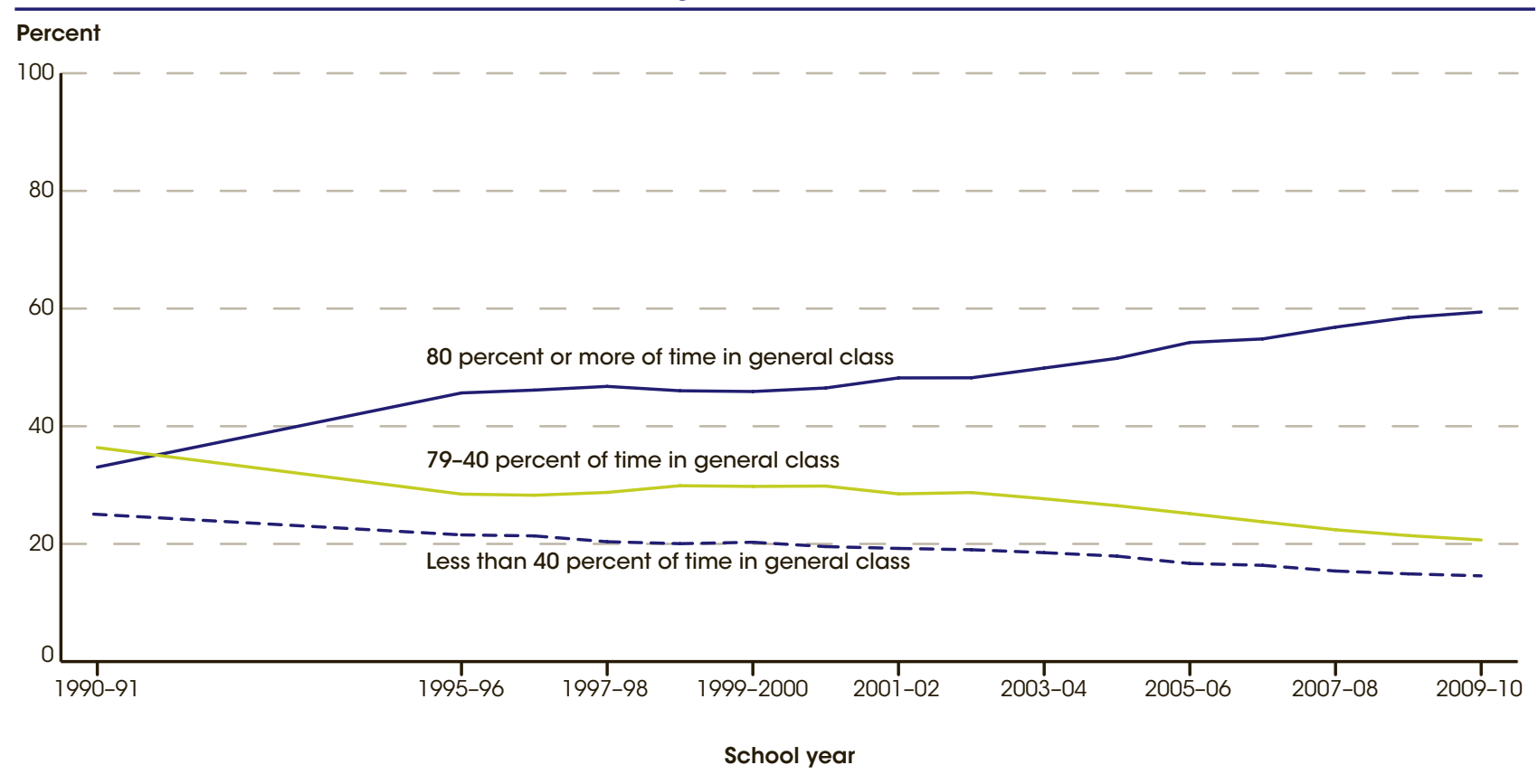

NOTE: Includes children and youth in the 50 states, the District of Columbia, and the Bureau of Indian Education schools. Data for $2007-08$ and 2008-09 do not include Vermont. Detail may not sum to totals because of rounding. For more information on student disabilities, see Appendix $\mathrm{C}$ - Commonly Used Measures.

SOURCE: U.S. Department of Education, Office of Special Education Programs, Annual Report to Congress on the Implementation of the Individuals with Disabilities Education Act, selected years, 1990 through 2009; and Individuals with Disabilities Education Act (IDEA) database, retrieved September 14, 2011, from http://www.ideadata.org/PartBdata.asp. 


\section{Between 2000 and 2010, undergraduate enrollment in degree-granting postsecondary institutions increased by 37 percent, from 13.2 to 18.1 million students. Projections indicate that undergraduate enrollment will continue to increase, reaching 20.6 million students in 2021.}

Total undergraduate enrollment in degree-granting postsecondary institutions increased from 7.4 million students in fall 1970 to 13.2 million in fall 2000 and 18.1 million in fall 2010 (see table A-10-1). According to projections, undergraduate enrollment is expected to reach 20.6 million in fall 2021 (the last year for which projected data are available).

Undergraduate enrollment grew at a faster rate during the 1970s (42 percent) than it did in more recent decades; it continued to increase throughout the 1980s and 1990s, but at slower rates (14 and 10 percent, respectively). From 2000 to 2010, undergraduate enrollment rose by 37 percent. During this period, male enrollment grew 36 percent, from 5.8 million to 7.8 million students, while female enrollment grew 39 percent, from 7.4 to 10.2 million students. In 2010, females accounted for 57 percent of undergraduate enrollment and males, 43 percent. Enrollments for both males and females are expected to increase through 2021, reaching 8.6 and 12.0 million students, respectively.

Undergraduate enrollment in public institutions increased from 10.5 million students in 2000 to 13.7 million in 2010, a 30 percent increase. Private institutions experienced a higher rate of growth over this period, increasing 67 percent, from 2.6 to 4.4 million students. Most of the growth in private institution enrollment between 2000 and 2010 occurred among for-profit institutions-their enrollment increased more than 300 percent, from 0.4 to 1.7 million students. Enrollment at private nonprofit institutions increased by 20 percent, from 2.2 to 2.7 million students.

Between 2000 and 2010, undergraduate enrollment at 4-year institutions increased from 7.2 to 10.4 million students and is expected to reach 11.8 million in 2021 (see table A-10-2). Enrollment increased 34 percent (from 4.8 to 6.5 million) at public 4 -year institutions,
22 percent at private nonprofit 4-year institutions (from 2.2 to 2.6 million), and 513 percent at private for-profit 4 -year institutions (from 0.2 to 1.3 million). During the same period, enrollment at 2-year institutions increased from 5.9 to 7.7 million students and is expected to reach 8.8 million students by 2021 . Between 2000 and 2010, enrollment decreased 44 percent at private nonprofit 2-year institutions (from 59,000 to 33,000) and increased 124 percent at private for-profit 2-year institutions (from $192,000$ to 430,000$)$ and 26 percent at public 2-year institutions (from 5.7 to 7.2 million).

Undergraduate enrollment of U.S. residents generally increased between 1980 and 2010 for each racial/ethnic group (see table A-10-3). In 1980, some 8.5 million (83 percent) of the undergraduate enrollment of U.S. residents were White, compared with 9.0 million (70 percent) in 2000. By 2010, the number of White students had grown to 10.9 million, but the percentage had decreased to 62 percent. The number of Black undergraduate students who were U.S. residents increased 163 percent between 1980 and 2010, from 1.0 million (10 percent) to 2.7 million students (15 percent). Hispanic and Asian/Pacific Islander enrollments increased 487 and 337 percent, respectively, from 1980 to 2010. In 1980, Hispanics and Asians/Pacific Islanders represented 4 and 2 percent of enrollment, respectively, compared to 14 and 6 percent in 2010. American Indian/Alaska Native enrollment increased from 78,000 to 179,000 students from 1980 to 2010 ( 1 percent of total enrollment in each year). There were about 294,000 undergraduate students who were of two or more races in 2010. In previous years, these students were included in the other racial/ethnic groups.

Tables A-10-1, A-10-2, and A-10-3

Glossary: Four-year postsecondary institution, Full-time enrollment, Nonresident alien, Part-time enrollment, Private institution, Public institution, Two-year postsecondary institution, Undergraduate student

\section{Technical Notes}

Projections are based on data through 2010. The most recent year of actual data is 2010, and 2021 is the last year for which projected data are available. For more information on projections, see NCES 2012-044. Data through 1995 are for institutions of higher education, while later data are for degree-granting institutions. Because of underreporting and nonreporting of racial/ ethnic data and nonresident aliens, some estimates on table A-10-3 are slightly lower than corresponding data in other published tables. Race categories exclude persons of Hispanic ethnicity. For more information on racel ethnicity and the classification of postsecondary education institutions, see Appendix C - Commonly Used Measures. For more information on the Integrated Postsecondary Education Data System (IPEDS), see Appendix B - Guide to Sources. All actual data presented in this indicator are IPEDS fall enrollment data and thus reflect the enrollment in the fall of the academic year. 
Figure 10-1. Actual and projected undergraduate enrollment in degree-granting postsecondary institutions, by sex and attendance status: Fall 1970-2021

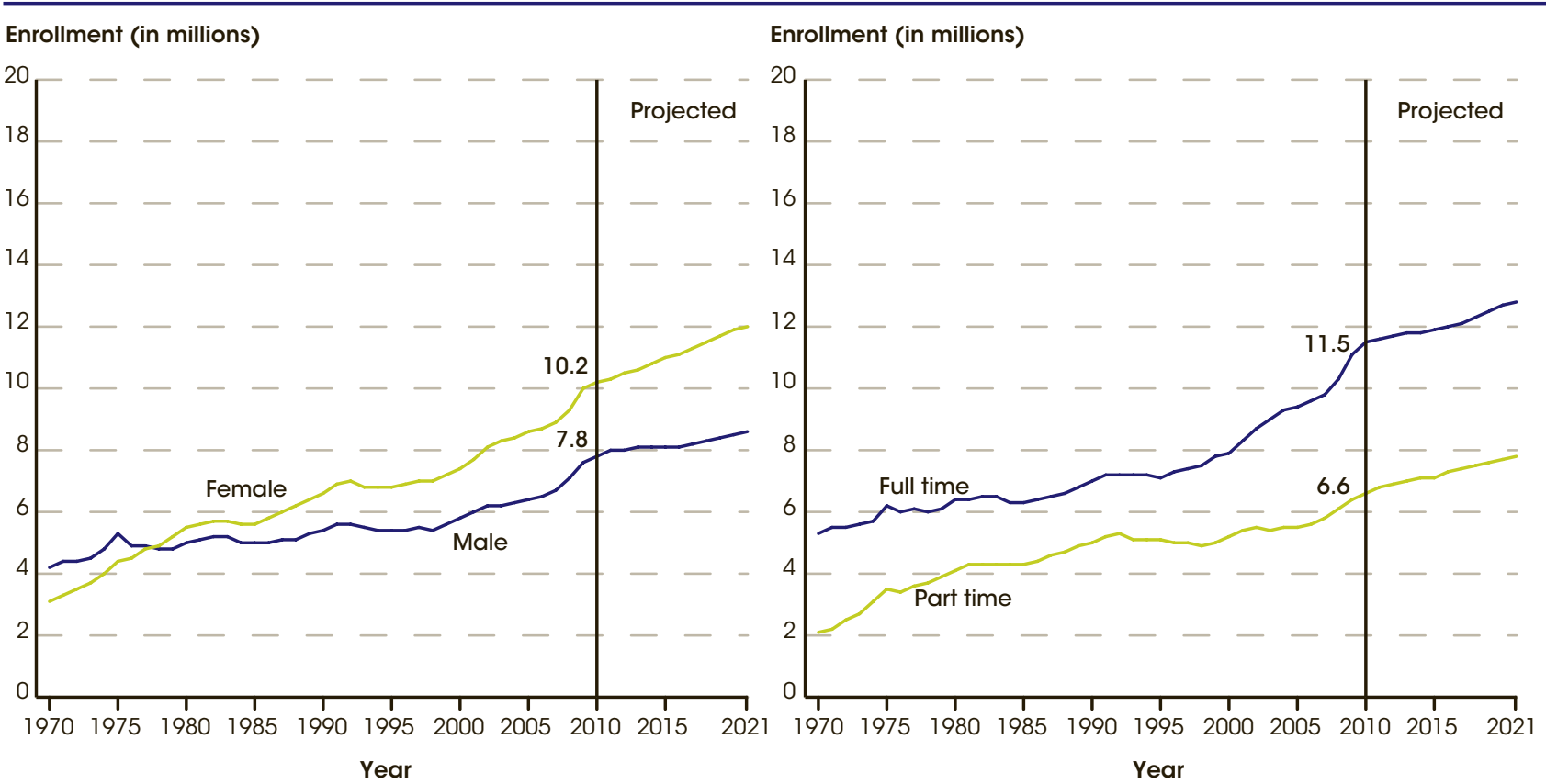

NOTE: Projections are based on data through 2010. For more information on projections, see NCES 2012-044. Data through 1995 are for institutions of higher education, while later data are for degree-granting institutions. Some data have been revised from previously published figures. For more information on the Integrated Postsecondary Education Data System (IPEDS), see Appendix B - Guide to Sources. For more information on the classification of postsecondary education institutions, see Appendix C - Commonly Used Measures. See Appendix D - Glossary for definitions of full-time and part-time enrollment.

SOURCE: U.S. Department of Education, National Center for Education Statistics, Higher Education General Information Survey (HEGIS), "Fall Enrollment in Colleges and Universities" surveys, 1970 through 1985; Integrated Postsecondary Education Data System (IPEDS), "Fall Enrollment Survey" (IPEDS-EF:90-99), and Spring 2001 through Spring 201 1, Enrollment component; and Enrollment in Degree-Granting Institutions Model, 1980-2010.

Figure 10-2. Percentage distribution for undergraduate enrollment of U.S. residents in degree-granting postsecondary institutions, by race/ethnicity: Fall 1980, 1990, 2000, and 2010

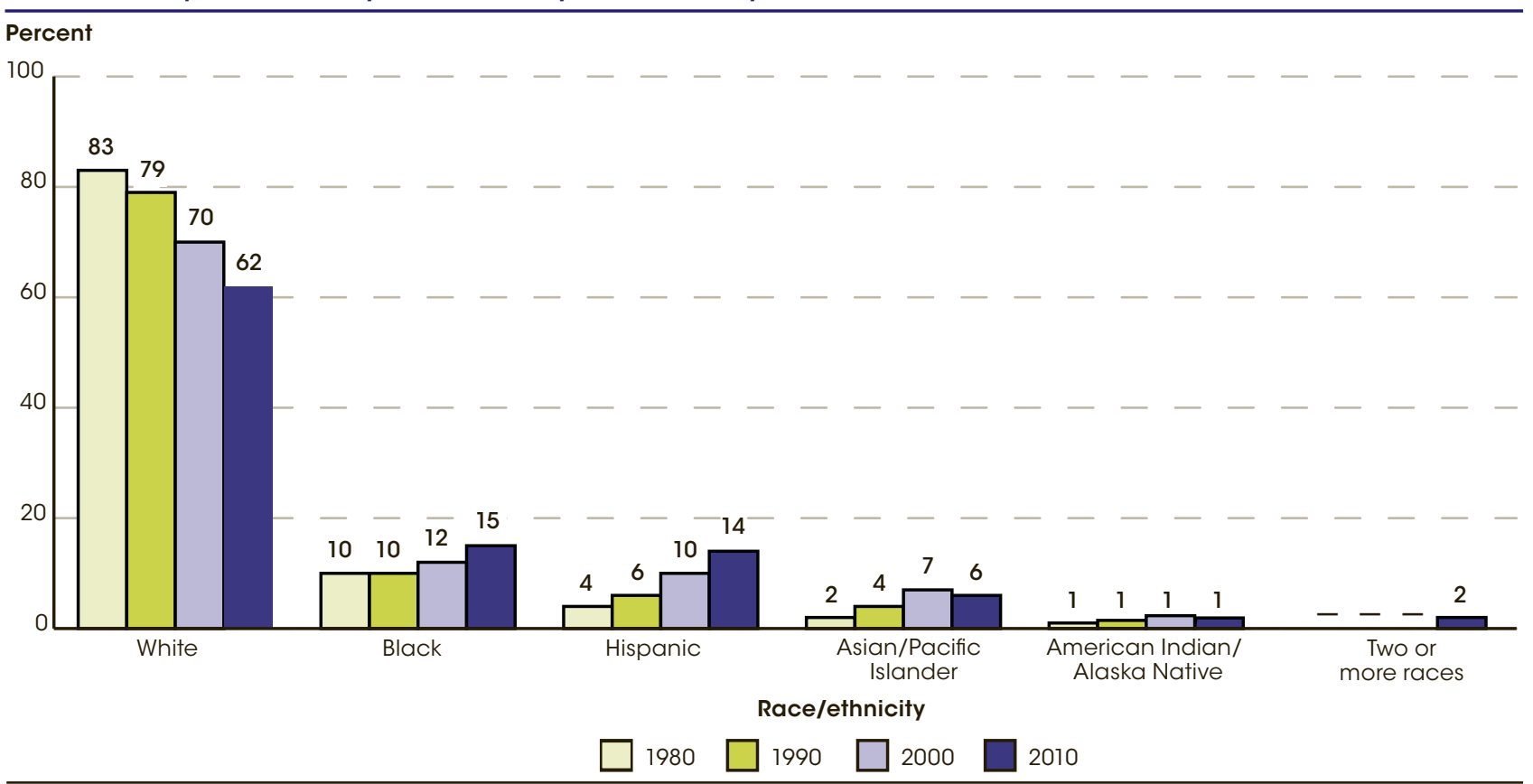

- Not available

NOTE: Data for 1980 and 1990 are for institutions of higher education, and data for 2000 and 2010 are for degree-granting institutions. Detail may not sum to totals because of rounding. Race categories exclude persons of Hispanic ethnicity. Because of underreporting and nonreporting of racial/ethnic data and nonresident aliens, some estimates are slightly lower than corresponding data in other published tables. For more information on race/ethnicity or the classification of postsecondary education institutions, see Appendix C - Commonly Used Measures. For more information on the Integrated Postsecondary Education Data System (IPEDS), see Appendix B - Guide to Sources.

SOURCE: U.S. Department of Education, National Center for Education Statistics, Higher Education General Information Survey (HEGIS), "Fall Enrollment in Colleges and Universities" surveys, 1980; and Integrated Postsecondary Education Data System (IPEDS), "Fall Enrollment Survey" (IPEDS-EF:90), and Spring 2001 and Spring 2011, Enrollment component. 


\section{Postbaccalaureate enrollment has increased every year since 1983, reaching 2.9 million students in 2010. In each year since 1988, women have comprised more than half of postbaccalaureate enrollment. In 2010, postbaccalaureate enrollment was 59 percent female.}

In fall 1976, some 1.6 million students were enrolled in postbaccalaureate programs, which include master's and doctoral programs, as well as programs formerly classified as first-professional such as law, medicine, and dentistry (see table A-11-1). Postbaccalaureate enrollment fluctuated during the period from the mid-1970s to the early 1980s, but between 1983 and 2010 it increased from 1.6 to 2.9 million students. Fall enrollment in postbaccalaureate programs is projected to increase through 2021 to 3.5 million students.

More females than males have been enrolled in postbaccalaureate programs every year since 1988 . In 1976, some 673,000 females were enrolled in a postbaccalaureate program, compared with 905,000 males. In 1988, female enrollment exceeded male enrollment, and by 2010 postbaccalaureate enrollment consisted of 1.7 million females (59 percent) and 1.2 million males ( 41 percent). Projections indicate that females will continue to enroll in postbaccalaureate programs at a higher rate than males, and in 2021 postbaccalaureate enrollment is expected to consist of 2.1 million females (61 percent) and 1.4 million males (39 percent).

As postbaccalaureate enrollment has grown, the distribution of students by attendance status and control of institutions has changed. In 1976, more students attended part time than full time, but in each year since 2000 full-time enrollment has been higher than part-time enrollment. Additionally, the percentage of postbaccalaureate students who attended private institutions increased between 1976 and 2010. In 1976, about 35 percent of postbaccalaureate students were enrolled in private institutions, compared with 51 percent in 2010. The growth in total private enrollment is attributable to the growth in enrollment at both private for-profit and private nonprofit institutions. The number of students attending private for-profit institutions increased from 3,000 students in 1976 (less than 1 percent of total enrollment) to 297,000 students in 2010 (10 percent), while the number of students attending private nonprofit institutions increased from 541,000 students in 1976 (34 percent) to 1.2 million students in 2010 (41 percent).

Postbaccalaureate enrollment of U.S. residents was higher in 2010 than in 1980 for each racial/ethnic group (see table A-11-2). While White postbaccalaureate enrollment was higher in 2010 that in 1980 (1.8 million vs. 1.4 million), it accounted for a smaller percentage of the postbaccalaureate enrollment of U.S. residents in 2010 than in 1980 (69 vs. 89 percent). Black postbaccalaureate enrollment was 311 percent higher in 2010 than in 1980 $(362,000$ vs. 88,000$)$. It accounted for a higher percentage of enrollment in 2010 than in 1980 (14 vs. 6 percent). Both Hispanic and Asian/Pacific Islander enrollments were over 400 percent higher in 2010 than in 1980 (408 and 411 percent, respectively). Each accounted for a higher percentage of enrollment in 2010 than in 1980 (8 vs. 3 percent for Hispanics and 7 vs. 2 percent for Asians/Pacific Islanders, respectively). While American Indian/Alaska Native enrollment was higher in 2010 than in 1980 (17,000 vs. 6,000), it accounted for less than 1 percent of enrollment in 2010 . There were about 32,000 students who were of two or more races in 2010. In previous years, they were included in the other racial/ ethnic groups.

In 1980, for Whites, Hispanics, and Asians/ Pacific Islanders, males outnumbered females in postbaccalaureate programs; however, in 2010, females outnumbered males in all racial/ethnic groups. The largest relative gap between female and male postbaccalaureate enrollment within a single racial/ethnic group in 2010 occurred among Blacks. In fall 2010, some 71 percent of Black students were female.

Tables A-11-1 and A-11-2

Glossary: Nonresident alien, Postbaccalaureate enrollment, Private institution, Public institution

\section{Technical Notes}

The most recent year of actual data is 2010, and 2021 is the last year for which projected data are available. For more information on projections, see NCES 2012-044. Because of underreporting and nonreporting of racial/ ethnic data and nonresident aliens, some estimates are slightly lower than corresponding data in other published tables. Race categories exclude persons of Hispanic ethnicity. For more information on race/ethnicity and the classification of postsecondary education institutions, see Appendix C - Commonly Used Measures. For information on the Integrated Postsecondary Education Data System (IPEDS), see Appendix B - Guide to Sources. All actual data presented in this indicator are IPEDS fall enrollment data and thus measure the enrollment in the fall of the academic year. Enrollment data by race/ethnicity for 1976 are available on table A-11-2. 
Figure 11-1. Actual and projected postbaccalaureate enrollment in degree-granting postsecondary institutions, by sex: Fall 1976-2021

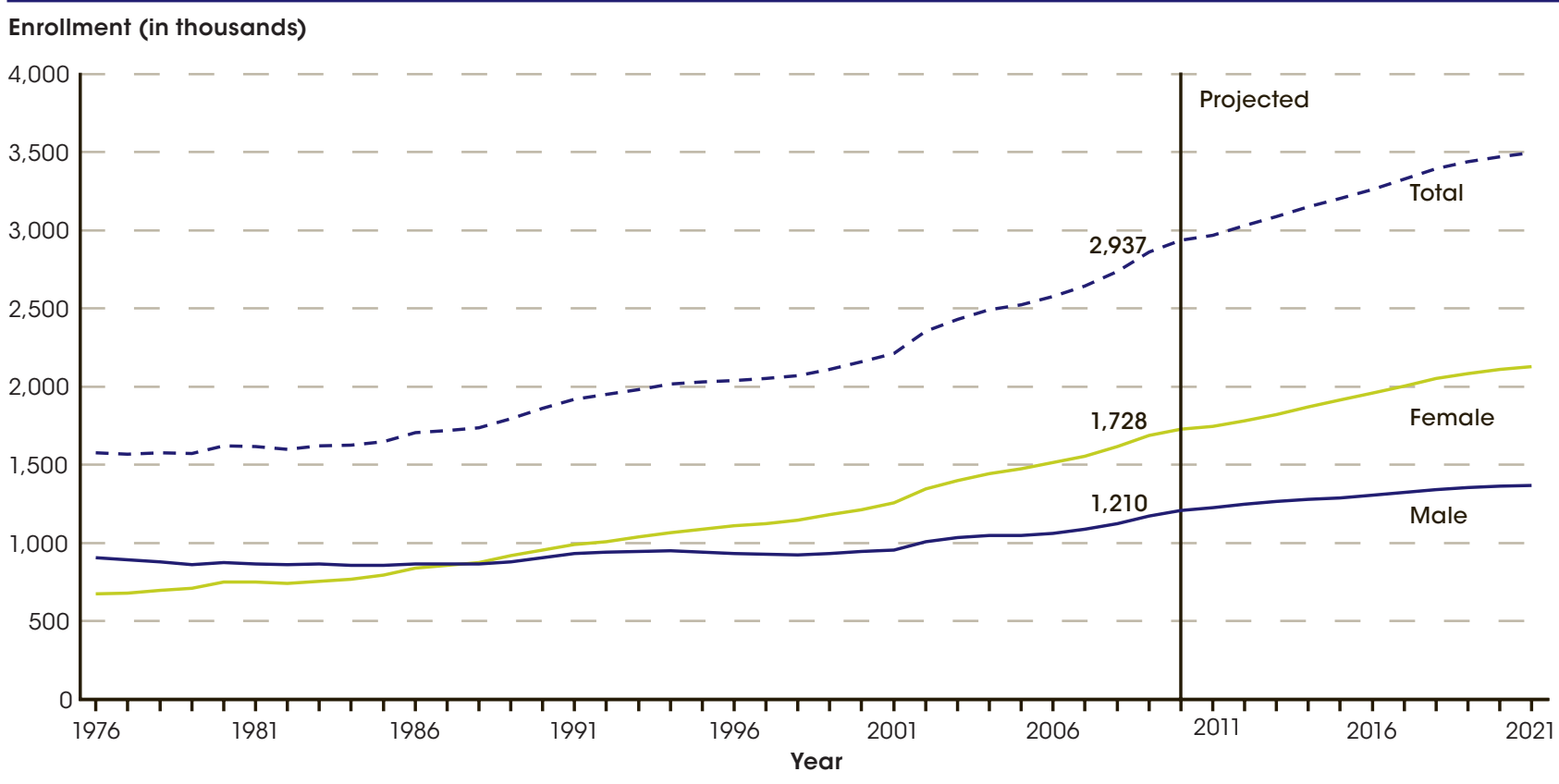

NOTE: Postbaccalaureate enrollment is the number of students with a bachelor's degree who are enrolled in master's or doctoral programs, including those formerly classified as first-professional programs. Projections are based on reported data through 2010. The most recent year of actual data is 2010 , and 2021 is the last year for which projected data are available. For more information on projections, see NCES 2012-044. For more information on the Integrated Postsecondary Education Data System (IPEDS), see Appendix B - Guide to Sources.

SOURCE: U.S. Department of Education, National Center for Education Statistics, Higher Education General Information Survey (HEGIS), "Fall Enrollment in Colleges and Universities" surveys, 1970 through 1985; Integrated Postsecondary Education Data System (IPEDS), "Fall Enrollment Survey" (IPEDS-EF:90-99); IPEDS Spring 2001 through Spring 2011, Enrollment component; and Enrollment in Degree-Granting Institutions Model, 1980-2010.

Figure 11-2. Percentage distribution for postbaccalaureate enrollment of U.S. residents in degree-granting postsecondary institutions, by race/ethnicity: Selected years, fall 1980-2010

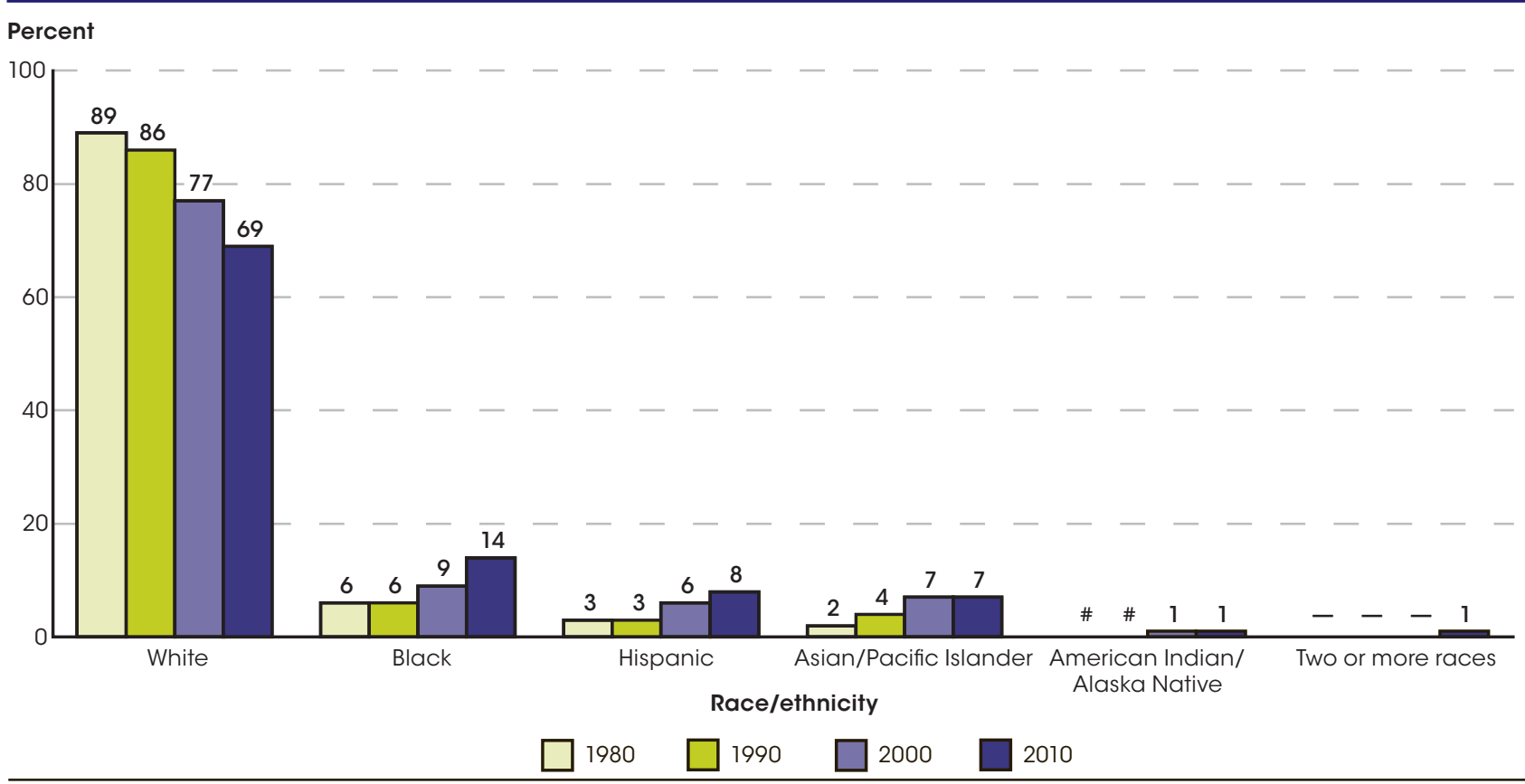

\section{\# Rounds to zero.}

- Not available.

NOTE: Postbaccalaureate enrollment is the number of students with a bachelor's degree who are enrolled in master's or doctoral programs, including those formerly classified as first-professional programs. Detail may not sum to totals because of rounding. Race categories exclude persons of Hispanic ethnicity. For more information on race/ethnicity, see Appendix C - Commonly Used Measures. For more information on the Integrated Postsecondary Education Data System (IPEDS), see Appendix B - Guide to Sources. Enrollment data by race/ethnicity for 1976 is available on table A-GRE-2.

SOURCE: U.S. Department of Education, National Center for Education Statistics, Higher Education General Information Survey (HEGIS), "Fall Enrollment in Colleges and Universities" surveys, 1980; Integrated Postsecondary Education Data System (IPEDS), "Fall Enrollment Survey" (IPEDS-EF:90); and IPEDS Spring 2001 and Spring 2011, Enrollment component. 
The indicators in this section of The Condition of Education measure aspects of elementary and secondary education in the United States. The indicators examine school characteristics and climate; principals, teachers and staff; elementary and secondary financial resources; student assessments; and other measures of the progress students make as they move through the education system, such as graduation rates.

In this section, particular attention is given to how various subgroups in the population proceed through school and attain different levels of education, as well as the factors that are associated with their progress along the way. The indicators on student achievement illustrate how students are performing on assessments in reading, mathematics, science, and other academic subject areas. Others examine aspects of the context of learning in elementary and secondary schools.

Indicators on elementary and secondary education and outcomes from previous editions of The Condition of Education not included in this volume are available at http://nces.ed.gov/programs/coe. 


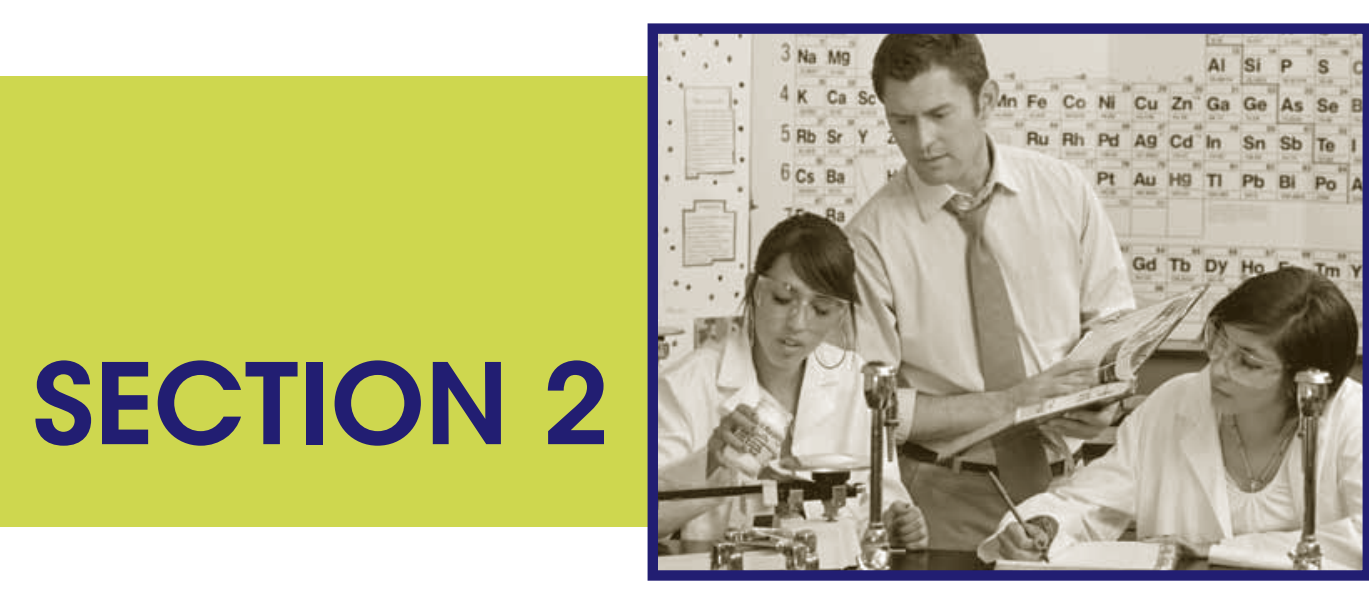

\section{Elementary and Secondary Education}

\section{School Characteristics and Climate}

Indicator 12. Characteristics of Elementary and Secondary Schools.

Indicator 13. Concentration of Public School Students Eligible for Free or Reduced-Price Lunch

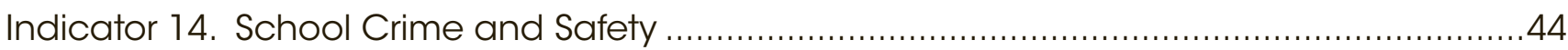

Indicator 15. Distance Education in Public High Schools ..................................................46

Indicator 16. Public High School Retention Rates...........................................................48

Indicator 17. Characteristics of Full-Time Teachers............................................................5

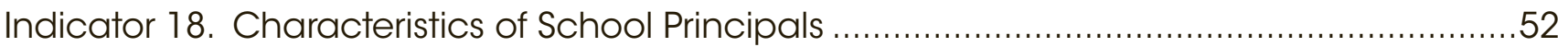

\section{Finance}

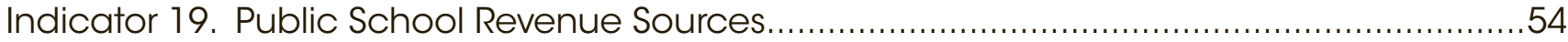

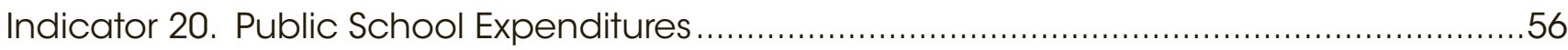

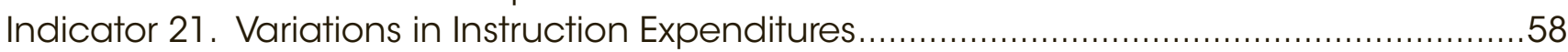

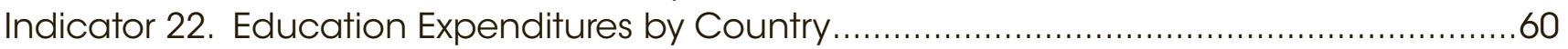

\section{Assessments}

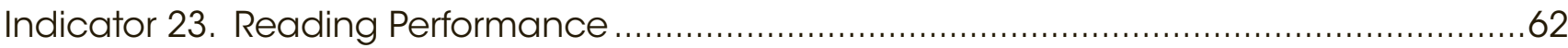

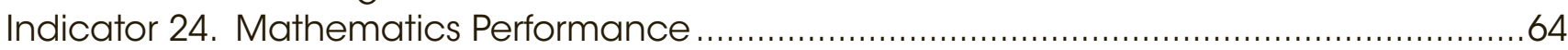

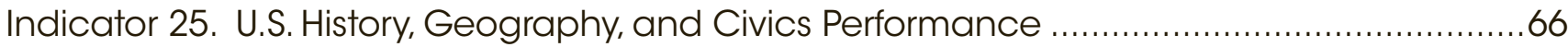

Indicator 26. International Reading, Mathematics, and Science Proficiency .......................68

\section{Student Effort, Persistence, and Progress}

Indicator 27. Extracurricular Activities of High School Students..........................................70

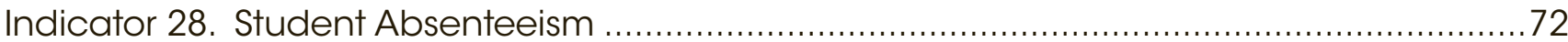

Indicator 29. Youth Neither in School Nor Working ........................................................

Indicator 30. Employment of High School Students ........................................................

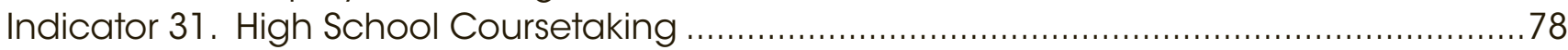

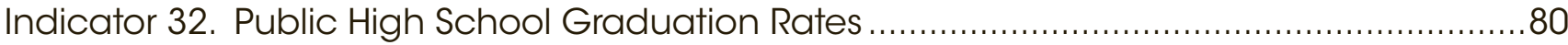

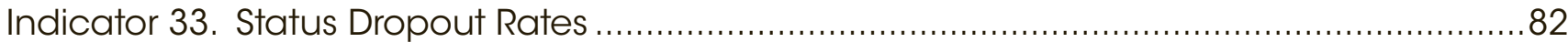

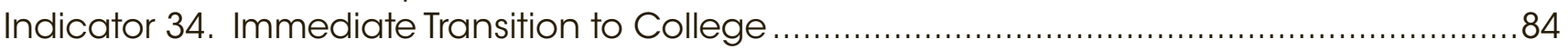

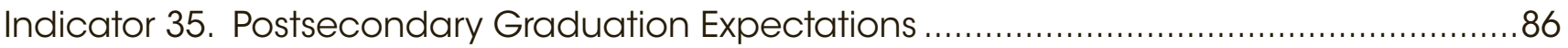




\section{Characteristics of Elementary and Secondary Schools}

\section{In 2009-10, some 5 percent of traditional public schools were combined schools (schools with both elementary and secondary grades), whereas 19 percent of charter schools and 28 percent of private schools were combined schools.}

In 2009-10, there were 132,200 schools in the United States, including 93,900 traditional public schools, some 5,000 charter schools, and 33,400 private schools (see table A-12-1). Of the total schools in the United States in that year, approximately two-thirds (67 percent) were elementary schools, 21 percent were secondary schools, 11 percent were combined schools (namely, schools with both elementary and secondary grades) and 1 percent were ungraded. However, there was variation in the distribution of schools at each level by school control, that is, whether they were traditional public, charter or private. For example, 25 percent of traditional public schools and 27 percent of charter schools were secondary schools, compared to 8 percent of private schools. In addition, 5 percent of traditional public schools were combined schools, compared to 19 percent of charter schools and 28 percent of private schools.

The distribution of schools by school size differed by school control in 2009-10. Some 30 percent of traditional public schools were small (enrollment of fewer than 300 students), as compared to 61 percent of charter schools and 85 percent of private schools. In that same year, 9 percent of traditional public schools were large $(1,000$ or more students), as compared to 4 percent of charter schools and 1 percent of private schools.

The percentage of schools where White students accounted for more than 50 percent of enrollment was lower in 2009-10 than in 1999-2000 (66 vs. 73 percent). In contrast, the percentage of schools where Hispanic students accounted for more than 50 percent of enrollment was higher in 2009-10 than in 1999-2000 (12 vs. 7 percent). In both years, the percentage of schools where Black students accounted for more than 50 percent of enrollment was approximately the same (10 percent). In 2009-10, White students accounted for more than 50 percent of enrollment in 75 percent of private schools, compared to 63 percent of traditional public schools and

\section{Technical Notes}

The percentage distributions for school size and race/ ethnicity exclude schools that did not report enrollment. For more information on locale, poverty, and race/ ethnicity, see Appendix C - Commonly Used Measures.
41 percent of charter schools. In contrast, Black students accounted for more than 50 percent of enrollment at 26 percent of charter schools, compared to 11 percent of traditional public schools and 8 percent of private schools. Hispanic students accounted for more than 50 percent of enrollment at 20 percent of charter schools in 2009-10, compared to 14 percent of traditional public schools and 5 percent of private schools.

The percentage of public schools (data for private schools are not available) that were high-poverty schools (i.e., schools where more than 75 percent of the students were eligible for the free or reduced-price lunch program) was higher in 2009-10 (20 percent) than in 1999-2000 (12 percent). Conversely, the percentage of public schools that were low-poverty schools (i.e., schools where 25 percent or less of the students were eligible for the free or reducedprice lunch program) was lower in 2009-10 (20 percent) than in 1999-2000 (31 percent). The distributions of public schools by poverty level differed by whether public schools were traditional or charter. In 2009-10, about 33 percent of charter schools were high-poverty schools, compared to 19 percent of traditional public schools.

In 2009-10, the largest percentage of traditional public schools were in rural areas (33 percent), followed by schools in suburban areas (28 percent), cities (25 percent), and towns (14 percent). In contrast, the largest percentage of charter schools was in cities (55 percent); suburban areas had 21 percent of charter schools, rural areas had 16 percent and towns had 8 percent. The largest percentages of private schools were in suburban areas (35 percent) and cities (32 percent), followed by rural areas ( 23 percent), and towns (10 percent).

Table A-12-1

Glossary: Charter school, Combined school, Elementary school, Private school, Secondary school, Traditional public school

For more information on the Common Core of Data (CCD) or the Private School Survey (PSS), see Appendix B - Guide to Sources. 
Figure 12-1. Percentage distribution of schools, by control and racial/ethnic concentration of schools: School years 1999-2000 and 2009-10

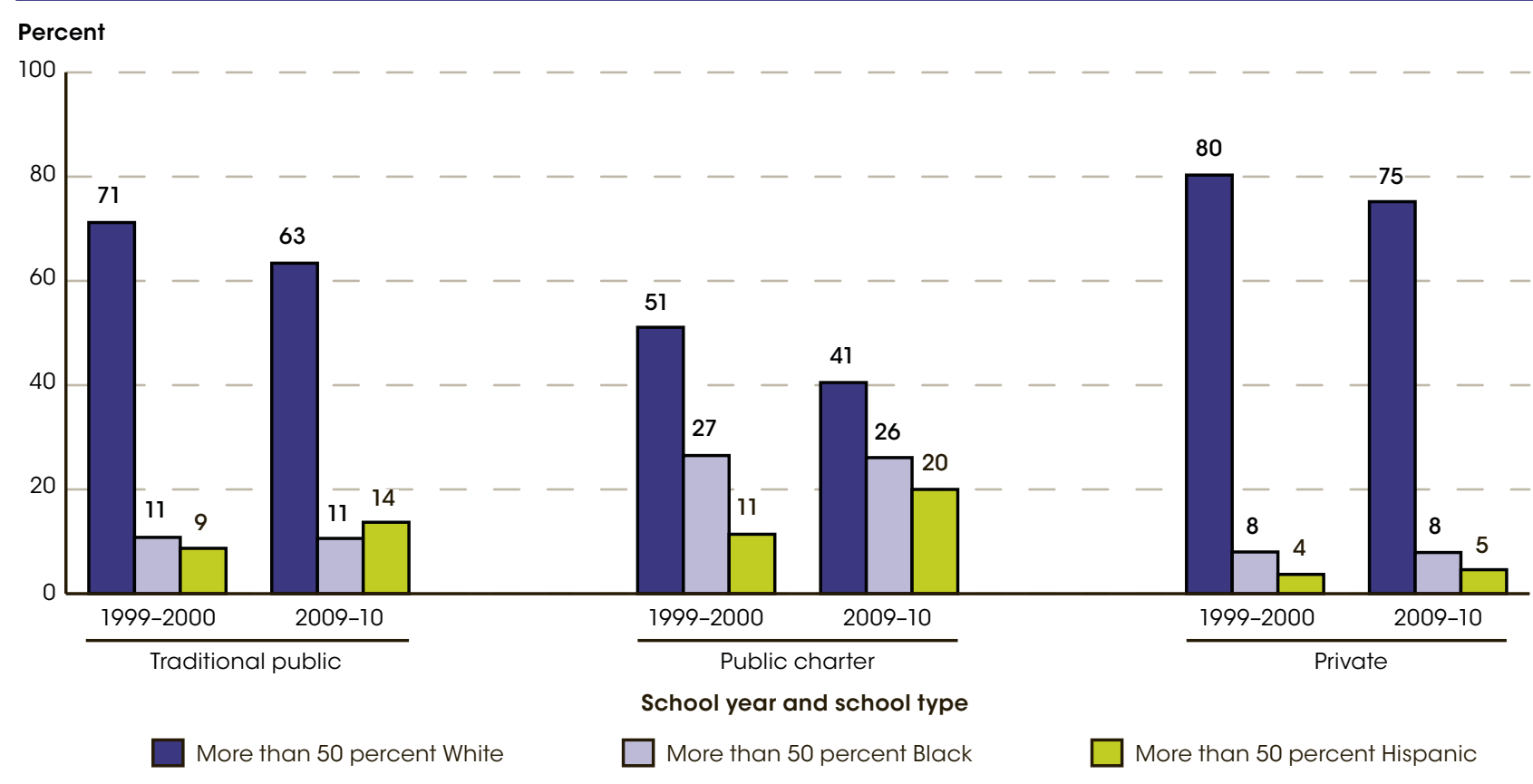

NOTE: Race categories exclude persons of Hispanic ethnicity. For more information on race/ethnicity, see Appendix C - Commonly Used Measures. For more information on the Common Core of Data (CCD) or the Private School Survey (PSS), see Appendix B - Guide to Sources.

SOURCE: U.S. Department of Education, National Center for Education Statistics, Common Core of Data (CCD), "Public Elementary/Secondary School

Universe Survey," 1999-2000 (version 1b); and 2009-10 (version 1b), and Private School Survey (PSS), 1999-2000 and 2009-10.

Figure 12-2. Percentage distribution of schools, by locale and control: School year 2009-10

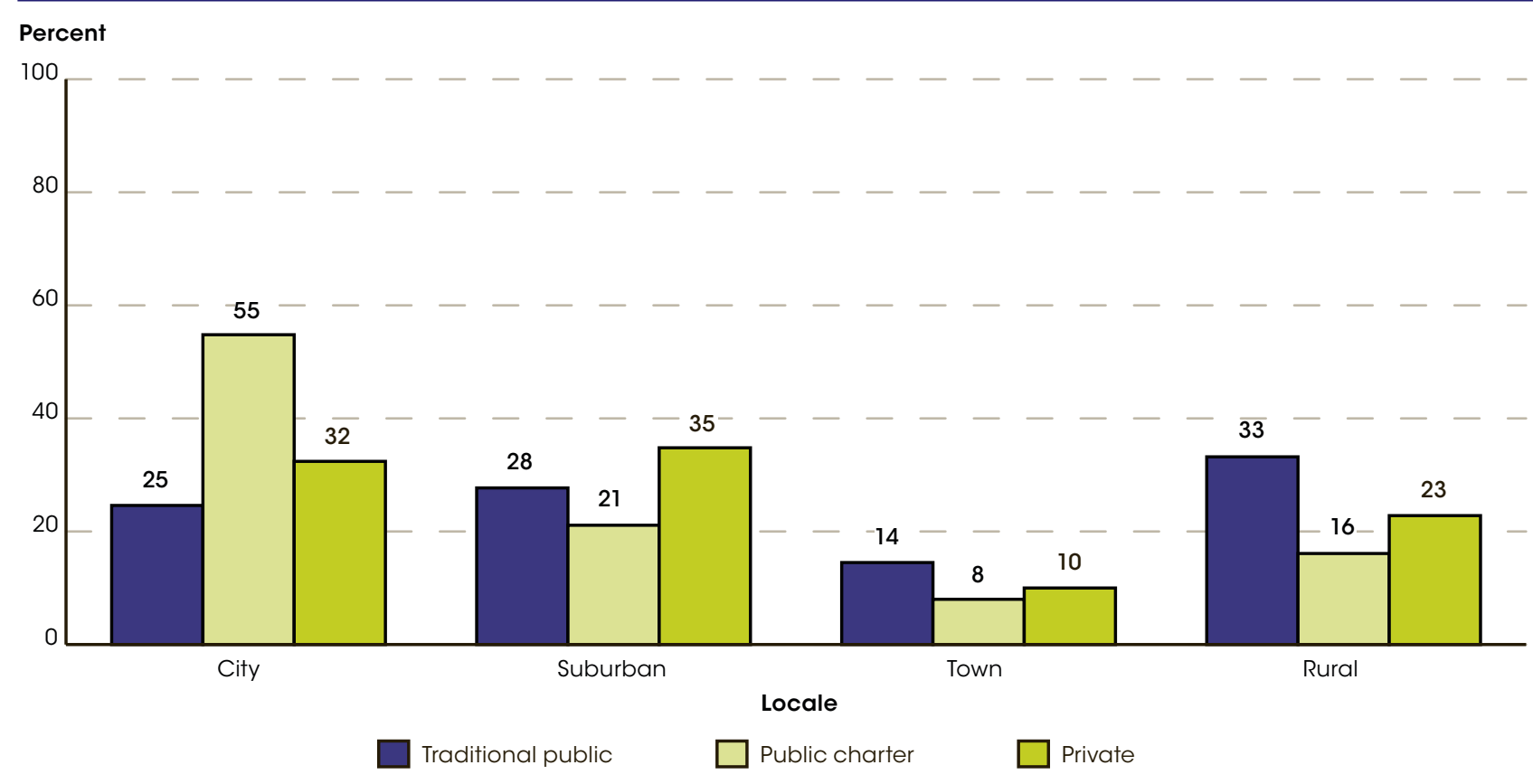

NOTE: For more information on locale, see Appendix C - Commonly Used Measures. For more information on the Common Core of Data (CCD) or the Private School Survey (PSS), see Appendix B - Guide to Sources.

SOURCE: U.S. Department of Education, National Center for Education Statistics, Common Core of Data (CCD), "Public Elementary/Secondary School Universe Survey," 2009-10 (version 1b); and Private School Survey (PSS), 2009-10. 


\section{Concentration of Public School Students Eligible for Free or Reduced-Price Lunch}

\section{Among public school students in 2009-10, higher percentages of Hispanic (37 percent), Black (37 percent), and American Indian/Alaska Native students (29 percent) attended high-poverty schools than did Asian/Pacific Islander (12 percent) and White students (6 percent).}

The percentage of students eligible for the free or reduced-price lunch (FRPL) program provides a proxy measure for the concentration of low-income students within a school. In this indicator, public schools are divided into categories by FRPL eligibility: low-poverty schools are defined as public schools where 25 percent or fewer students are eligible, and high-poverty schools are defined as public schools where 76 percent or more students are eligible. In 2009-10, approximately 25 percent of students attended low-poverty public schools, and 19 percent attended high-poverty public schools (table A-13-1).

In 2009-10, both the percentage of students attending high-poverty schools and the percentage attending low-poverty schools varied by school level and school locale (tables A-13-1 and A-13-2). A higher percentage of elementary-school students than secondary-school students attended high-poverty schools (23 vs. 9 percent), while a lower percentage of elementary-school students than secondary-school students attended low-poverty schools (22 vs. 30 percent) (table A-13-1). Some 33 percent of students in city schools were enrolled in high-poverty schools, compared with 9 percent in rural schools, 14 percent in suburban schools, and 15 percent attending schools in towns (table A-13-2). On the other hand, the percentage of students in suburban schools (38 percent) who attended low-poverty schools was more than twice as large as the percentages of students in city schools and in town schools that were low-poverty schools (14 and 12 percent, respectively). The percentage of students in suburban schools who attended low-poverty schools was also higher than the corresponding percentage of students in rural schools (25 percent).
In terms of the 2009-10 racial/ethnic distribution of students across schools of different poverty levels, higher percentages of Hispanic (37 percent), Black (37 percent), and American Indian/Alaska Native students (29 percent) attended high-poverty public schools than did Asian/ Pacific Islander (12 percent) and White students (6 percent) (table A-13-1). In contrast, higher percentages of Asian/Pacific Islander (37 percent) and White students (34 percent) attended low-poverty schools than did American Indian/Alaska Native (12 percent), Hispanic (12 percent), and Black students (8 percent).

The overall national pattern of higher percentages of Black, Hispanic, and American Indian/Alaska Native students attending high-poverty schools was also found by school level (elementary and secondary) and by school locale (city, suburban, town, and rural). For example, at the elementary school level in 2009-10, some 46 percent of Black, 45 percent of Hispanic, and 35 percent of American Indian/Alaska Native students attended high-poverty schools, compared with 14 percent of Asian/Pacific Islander and 7 percent of White students (table A-13-1). At the secondary school level, higher percentages of Hispanic (21 percent), Black (21 percent), and American Indian/Alaska Native students (17 percent) attended high-poverty public schools than did Asian/ Pacific Islander ( 7 percent) and White students (2 percent). Among students attending city schools, higher percentages of Black (48 percent), Hispanic (46 percent), and American Indian/Alaska Native students (30 percent) were in high-poverty schools than were Asian/Pacific Islander (18 percent) and White (12 percent) students (table A-13-2).

Tables A-13-1 and A-13-2

Glossary: National School Lunch Program, Public school

\section{Technical Notes}

Race categories exclude persons of Hispanic ethnicity. For more information on race/ethnicity, locale, and poverty, see Appendix C - Commonly Used Measures. For more information on the Common Core of Data (CCD), see Appendix B - Guide to Sources. Percent detail may not sum to percent totals because of rounding. 
Figure 13-1. Percentage distribution of public school students, by school locale and poverty level: School year 2009-10

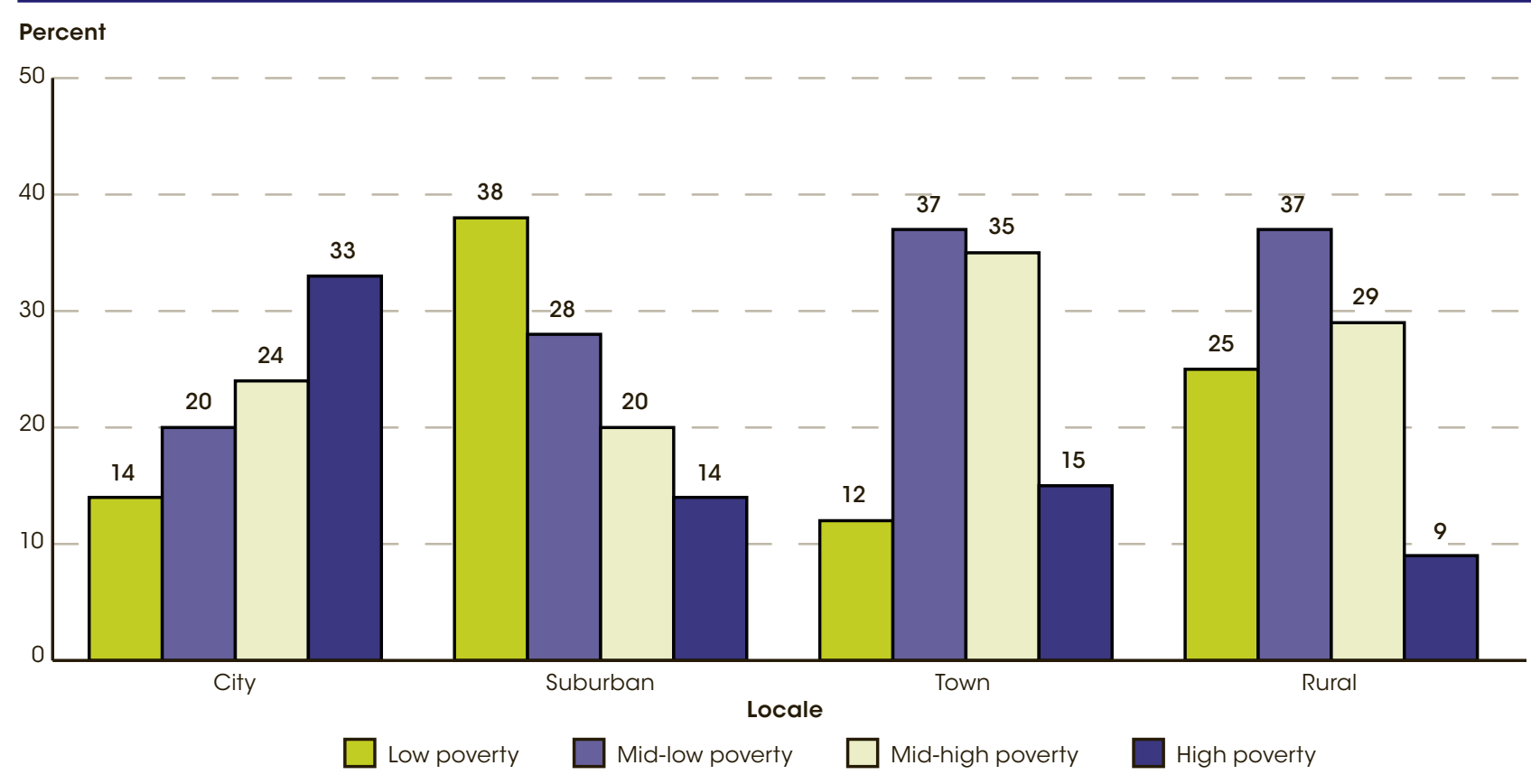

NOTE: Low-poverty schools are defined as public schools where 25 percent or fewer students are eligible for the free or reduced-price lunch (FRPL) program, and mid-low poverty schools are those schools where 26 percent to 50 percent of students are eligible for FRPL. Mid-high poverty schools are defined as public schools where 51 percent to 75 percent of students are eligible, and high-poverty schools are those schools where 76 percent or more students are eligible for FRPL. Schools that are missing information on FRPL or did not participate in FRPL are not shown in this figure. For more information on locale and poverty, see Appendix C - Commonly Used Measures. For more information on the Common Core of Data (CCD), see Appendix B - Guide to Sources. Detail may not sum to totals because of rounding.

SOURCE: U.S. Department of Education, National Center for Education Statistics, Common Core of Data (CCD), "Public Elementary/Secondary School Universe Survey," 2009-10.

Figure 13-2. Percentage of public school students in high-poverty schools and low-poverty schools, by race/ ethnicity and school level: School year 2009-10

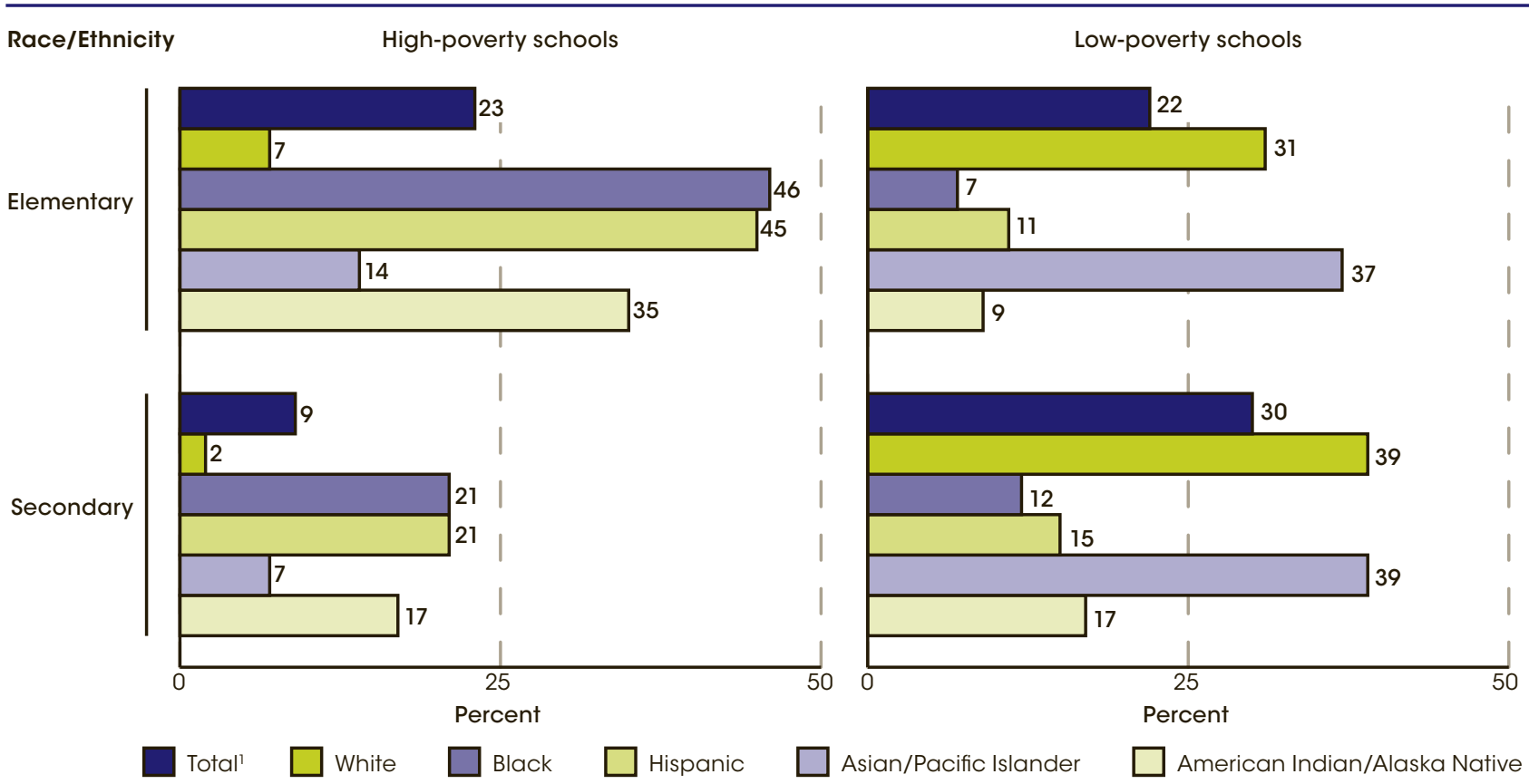

1 Includes students whose racial/ethnic group was not reported

NOTE: High-poverty schools are defined as public schools where 76 percent or more students are eligible for the free or reduced-price lunch (FRPL) program; and low-poverty schools are those schools where 25 percent or fewer students are eligible for FRPL. Race categories exclude persons of Hispanic ethnicity. Persons of unknown race/ethnicity are not shown. For more information on race/ethnicity and poverty, see Appendix C - Commonly Used Measures. For more information on the Common Core of Data (CCD), see Appendix B - Guide to Sources.

SOURCE: U.S. Department of Education, National Center for Education Statistics, Common Core of Data (CCD), "Public Elementary/Secondary School Universe Survey," 2009-10. 


\section{Sixteen percent of public schools recorded at least one incident of serious violent crime in 2009-10; this was lower than the 20 percent of schools recording at least one incident in 1999-2000.}

In the School Survey on Crime and Safety (SSOCS), public school principals were asked to provide the number of incidents of specific crimes that were recorded as occurring at their schools, as well as the number of these incidents that were reported to the police. Incidents of crime were then categorized as serious violent incidents, violent incidents (which include serious violent incidents), theft/larceny, and "other" incidents. Violent incidents include physical attacks or fights without a weapon, or threats of physical attacks without a weapon, plus serious violent incidents. Serious violent incidents include rape or attempted rape, sexual battery other than rape, physical attacks or fights with a weapon or threats of physical attacks with a weapon, and robbery with or without a weapon. During the 2009-10 school year, 85 percent of public schools indicated that one or more of these crime incidents had taken place, a percentage not measurably different from that in either 1999-2000 (86 percent) or 2007-08 (85 percent) (see table A-14-1). About 60 percent of public schools reported at least one incident of crime to the police in 2009-10, a percentage not measurably different from that in 1999-2000 or 2007-08 (62 percent each).

There was no consistent pattern of change between 1999-2000 and 2009-10 in the percentage of schools recording at least one violent incident or the percentage reporting at least one violent incident to the police; nor were measurable differences detected in the percentages between 2007-08 and 2009-10. However, the percentage of schools recording one or more serious violent incidents declined between 1999-2000 and 2009-10 from 20 to 16 percent. The percentage of schools that reported at least one serious violent incident to the police declined between 1999-2000 and 2009-10 from 15 to 10 percent; the percentage also declined between school years 2007-08 (13 percent) and 2009-10.

Although 26 percent of schools recorded no violent incidents in 2009-10, many schools recorded multiple incidents. Some 8 percent of schools recorded 1 or 2 incidents, 29 percent recorded 3-9 incidents, 18 percent recorded $10-19$ incidents, and 19 percent recorded 20 or more such incidents. Although most schools (84 percent) recorded no serious violent incidents, some schools recorded one or more such incidents. Eleven percent of schools recorded 1 or 2 violent incidents, 4 percent recorded 3-9 violent incidents, and 2 percent recorded 10 or more such incidents.

The percentage of public schools that recorded incidents of violent crime or incidents of serious violent crime in 2009-10 varied by school characteristics. For example, a lower percentage of rural schools (14 percent) than suburban (19 percent), town (21 percent), and city schools (25 percent) recorded 20 or more violent incidents (see table A-14-2). The percentage of low-poverty schools recording at least one serious violent incident (10 percent) was lower than the percentages of mid-low-poverty schools (16 percent), mid-high-poverty schools (16 percent), and high-poverty schools (23 percent) doing so. Low-poverty schools are those where 25 percent or less of the students were eligible for free or reduced-price lunch (FRPL). Mid-low-poverty, mid-high-poverty, and high-poverty schools are those where 26 to 50 percent, 51 to 75 percent, and 76 percent or more of the students, respectively, were eligible for FRPL.

Tables A-14-1 and A-14-2

Glossary: Free or reduced-price lunch, High school, Middle school, Primary school

\section{Technical Notes}

Theft/larceny (taking things worth over $\$ 10$ without personal confrontation) includes pocket picking, stealing a purse or backpack (if left unattended or no force was used to take it from owner), theft from a building, theft from a motor vehicle or of motor vehicle parts or accessories, theft of bicycles, theft from vending machines, and all other types of thefts. Other incidents include possession of a firearm or explosive device; possession of a knife or sharp object; inappropriate distribution, possession, or use of prescription drugs; distribution, possession, or use of illegal drugs or alcohol; vandalism; and student sexual harassment of other students. "At school" was defined to include activities that happen in school buildings, on school grounds, on school buses, and at places that hold school-sponsored events or activities. Respondents were instructed to include incidents that occurred before, during, or after normal school hours or when school activities or events were in session. For more information on the School Survey on Crime and Safety (SSOCS), see Appendix B - Guide to Sources. Race categories exclude persons of Hispanic ethnicity. For more information on race/ethnicity, locale, and poverty, see Appendix C Commonly Used Measures. 
Figure 14-1. Percentage of public schools recording and reporting to the police at least one incident or one serious violent incident of crime that occurred at school: Selected school years, 1999-2000 through 2009-10

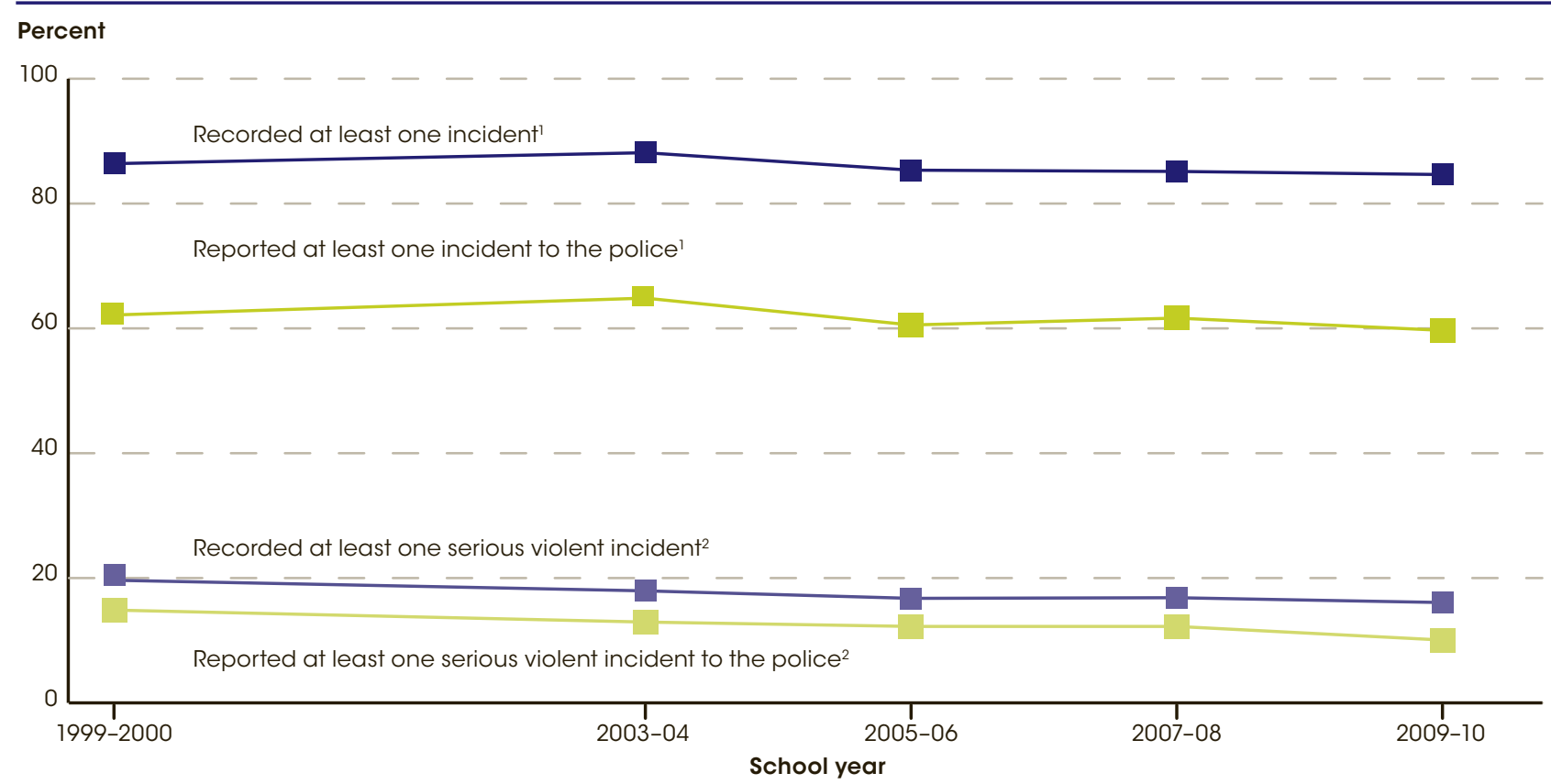

1 Incidents of crime include serious violent incidents, violent incidents (which include serious violent incidents), theft/larceny, and "other" incidents. ${ }^{2}$ Serious violent incidents include rape or attempted rape, sexual battery other than rape, physical attack or fight with a weapon, threat of physical attack with a weapon, and robbery with or without a weapon.

NOTE: "At school" was defined to include activities that happen in school buildings, on school grounds, on school buses, and at places that hold schoolsponsored events or activities. Respondents were instructed to include incidents that occurred before, during, or after normal school hours or when school activities or events were in session. For more information on the School Survey on Crime and Safety (SSOCS), see Appendix B - Guide to Sources. SOURCE: U.S. Department of Education, National Center for Education Statistics, 1999-2000, 2003-04, 2005-06, 2007-08, and 2009-10 School Survey on

Crime and Safety (SSOCS), 2000, 2004, 2006, 2008, and 2010

Figure 14-2. Percentage of public schools recording violent incidents of crime that occurred at school, by number of incidents and school locale: School year 2009-10

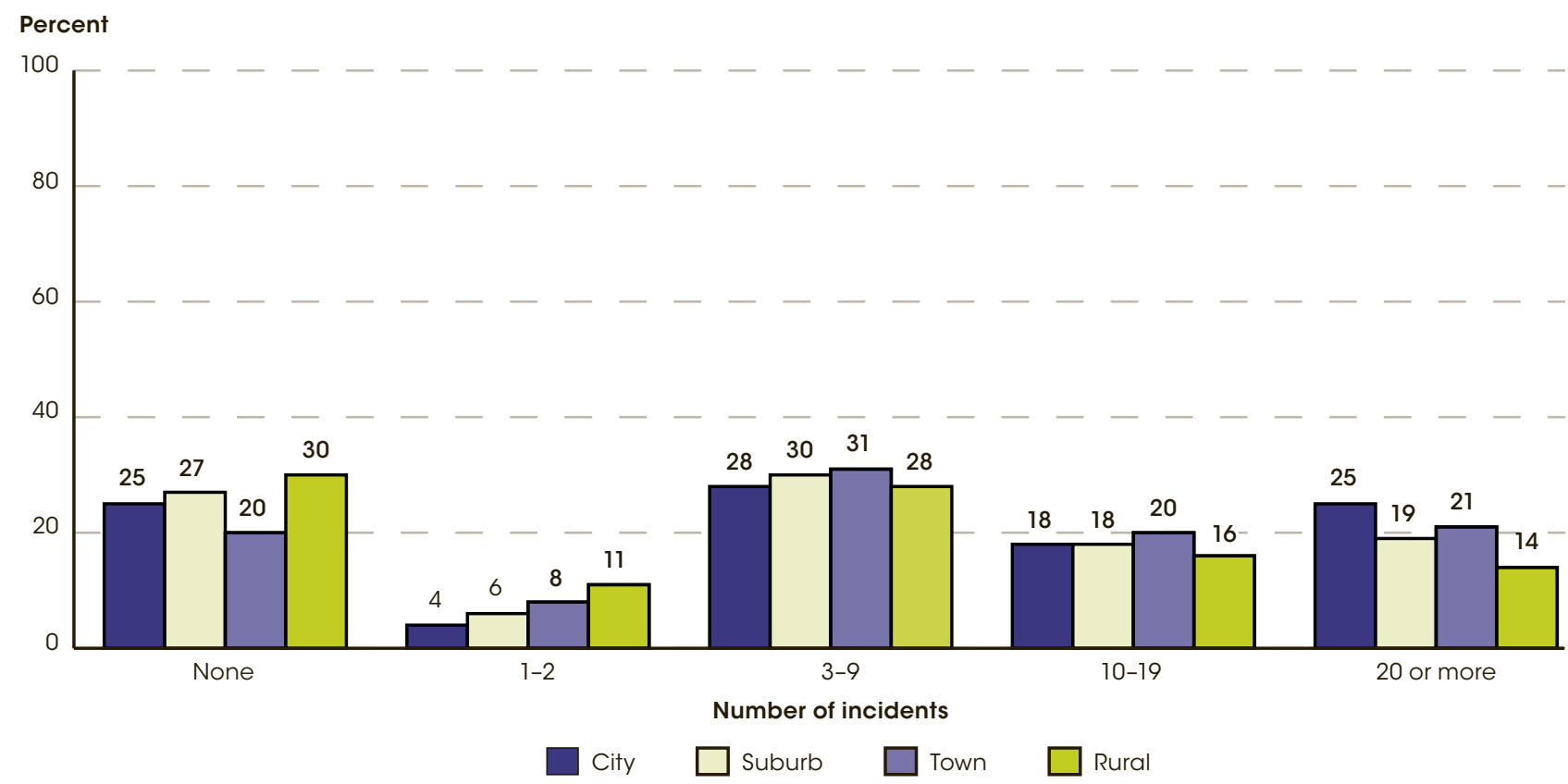

NOTE: Violent incidents include serious violent incidents (rape or attempted rape, sexual battery other than rape, physical attack or fight with a weapon, threat of physical attack with a weapon, and robbery with or without a weapon), physical attack or fight without a weapon, and threat of physical attack without a weapon. "At school" was defined to include activities that happen in school buildings, on school grounds, on school buses, and at places that hold school-sponsored events or activities. Respondents were instructed to include incidents that occurred before, during, or after normal school hours or when school activities or events were in session. Detail may not sum to totals because of rounding. For more information on locale, see Appendix C Commonly Used Measures. For more information on the School Survey on Crime and Safety (SSOCS), see Appendix B - Guide to Sources. SOURCE: U.S. Department of Education, National Center for Education Statistics, 2009-10 School Survey on Crime and Safety (SSOCS), 2010. 


\section{Distance Education in Public High Schools}

\section{In 2009-10, some 53 percent of public school districts had high school students enrolled in distance education courses. In these districts, there were over 1.3 million high school student enrollments in distance education in 2009-10, compared with 0.3 million five years earlier.}

In 2009-10, some 53 percent of public school districts had high school students enrolled in distance education courses (see table A-15-1). Distance education courses are defined as courses that are credit-granting, technologydelivered, have either the instructor in a different location than the students and/or have the course content developed in, or delivered from, a different location than that of the students. By comparison, in 2002-03, approximately 30 percent of public school districts had high school students enrolled in distance education courses. In 2009-10, there was some variation by locale in the percentage of public school districts with students enrolled in distance education courses. Sixty-six percent of public school districts in towns had high school students in distance education courses, which was higher than the percentage for rural (56 percent), suburban (45 percent), or city districts (37 percent).

There were over 1.3 million high school student enrollments in distance education courses in 2009-10, an increase of over 1 million enrollments from 2004-05, when there were just over 300,000 enrollments. By comparison, between 2002-03 and 2004-05, there was an increase of less than 100,000 in the number of high school student enrollments in distance education courses (from 222,000 to 310,000).

Fifty percent of districts that offered distance education courses in 2009-10 reported that a postsecondary institution in the United States delivered the courses in which students were enrolled (see table A-15-2). Other frequently reported entities delivering distance education were independent vendors ( 47 percent) and a state virtual school in the student's state (33 percent). While half of all public school districts that offered distance education courses in 2009-10 reported that postsecondary institutions delivered the courses, 61 percent of rural school districts did, compared with 44 percent of town, 37 percent of suburban, and 30 percent of city school districts.

In 2004-05, internet courses using asynchronous (not simultaneous) instruction and two-way interactive video were the most widely used technologies for delivering distance education courses, with 40 and 41 percent, respectively, of districts that offered distance education reporting these as the primary delivery mode. In 2009-10, however, 63 percent of districts that offered distance education reported that internet courses using asynchronous instruction were the primary delivery mode, and 17 percent of districts reported that two-way interactive video was the primary delivery mode.

Twenty-two percent of districts that offered distance education courses in 2009-10 reported that students enrolled in regular high school programs could take a full course load in an academic term using only distance education courses, and 12 percent reported that students could fulfill all high school graduation requirements using only distance education. Eight percent of rural school districts offering distance education courses reported that students could fulfill all high school graduation requirements using only distance education, compared to 15 percent of suburban, 18 percent of town, and 20 percent of city school districts.

Tables A-15-1 and A-15-2

Glossary: High school, Public school

\section{Technical Notes}

Distance education courses are defined as courses that are credit-granting, technology-delivered, have either the instructor in a different location than the students and/ or have the course content developed in, or delivered from, a different location than that of the students. For delivery entities, response options in the questionnaire were "yes," "no," and "don't know." Percentages are based on districts with students enrolled in distance education courses. For instructional delivery, "synchronous" refers to simultaneous, or "real time," instruction. Poverty estimates for school districts were based on Title I data provided to the U.S. Department of Education by the U.S. Census Bureau. For more information on locale and poverty, see Appendix C - Commonly Used Measures. For more information on the Fast Response Survey System (FRSS), see Appendix B - Guide to Sources. 
Figure 15-1. Number of public high school student enrollments in distance education courses: School years 2002-03, 2004-05, and 2009-10

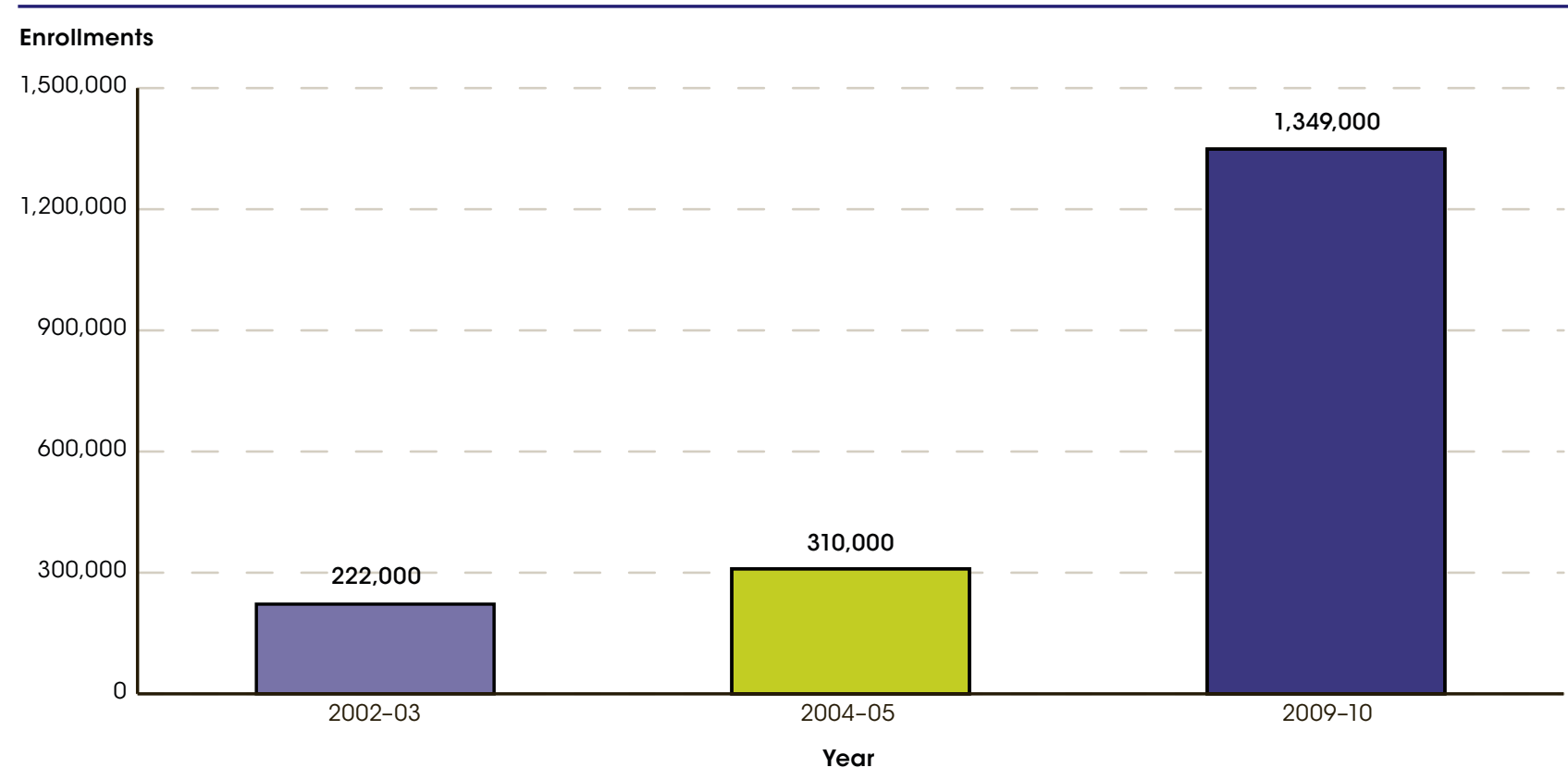

NOTE: Distance education courses are defined as courses that are credit-granting, technology-delivered, have either the instructor in a different location than the students and/or have the course content developed in, or delivered from, a different location than that of the students. For more information on the Fast Response Survey System (FRSS), see Appendix B - Guide to Sources.

SOURCE: U.S. Department of Education, National Center for Education Statistics (NCES), Fast Response Survey System (FRSS), "Distance Education Courses for Public School Elementary and Secondary Students: 2002-03," FRSS 84, 2003; "Distance Education Courses for Public Elementary and Secondary School Students: 2004-05," FRSS 89, 2005; and "Distance Education Courses for Public Elementary and Secondary School Students: $2009-10, "$ FRSS $98,2010$.

Figure 15-2. Percentage of public school districts that offered distance education, by locale and selected primary modes of instructional delivery: School years 2004-05 and 2009-10

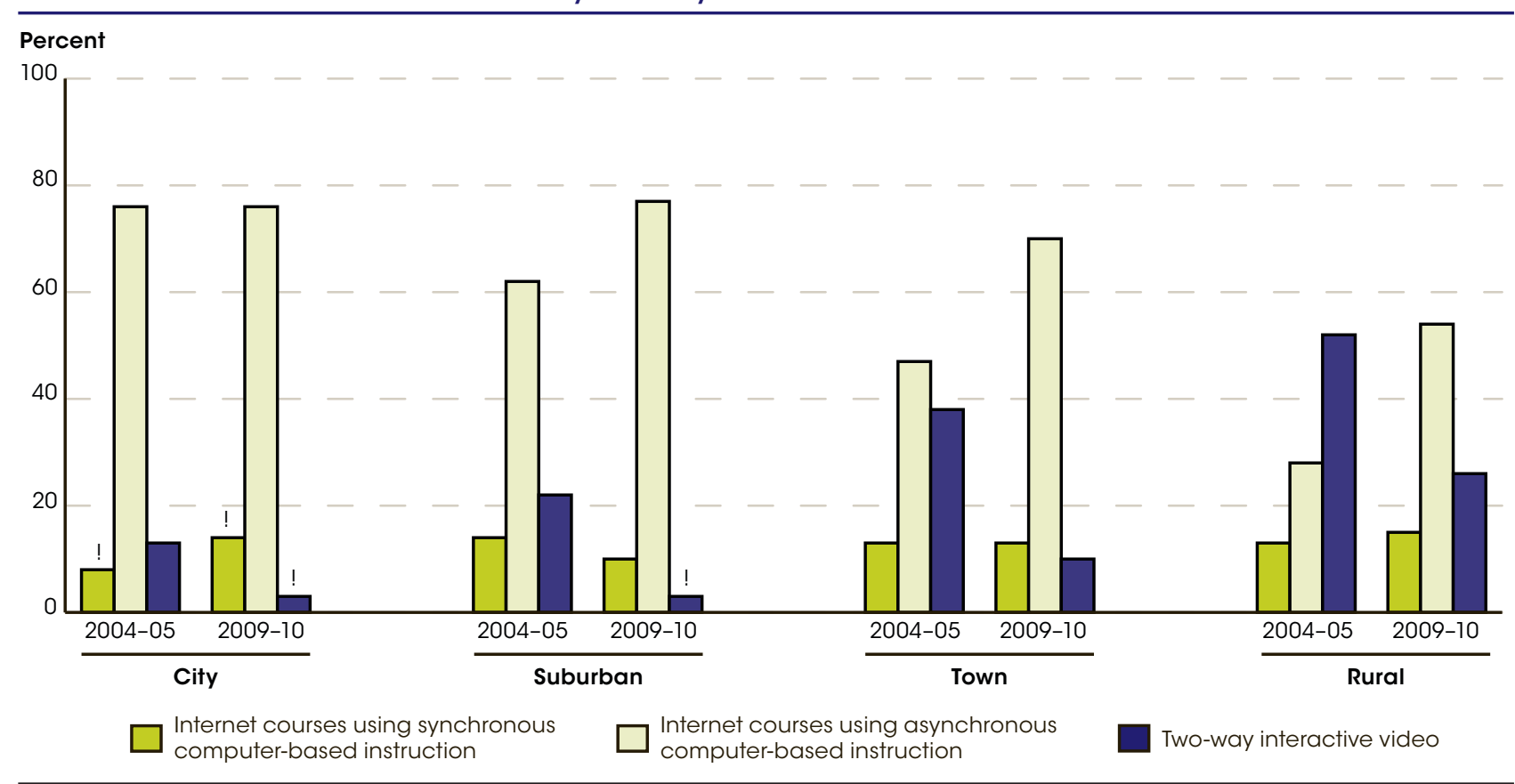

! Interpret with caution. The coefficient of variation (CV) for this estimate is 30 percent or greater

NOTE: Distance education courses are defined as courses that are credit-granting, technology-delivered, have either the instructor in a different location than the students and/or have the course content developed in, or delivered from, a different location than that of the students. Percentages are based on districts with students enrolled in distance education courses. For instructional delivery, synchronous refers to simultaneous, or "real time," instruction. For more information on the Fast Response Survey System (FRSS), see Appendix B - Guide to Sources.

SOURCE: U.S. Department of Education, National Center for Education Statistics (NCES), Fast Response Survey System (FRSS), "Distance Education Courses for Public School Elementary and Secondary Students: 2004-05," FRSS 89, 2005; and "Distance Education Courses for Public Elementary and Secondary School Students: 2009-10," FRSS 98, 2010. 


\section{Of approximately 15,500 regular high schools with at least 10 seniors in 2009-10, there were 890 schools (6 percent) in which the number of seniors divided by the number of freshmen 4 years earlier was between 10 and 50 percent.}

In academic year 2009-10, there were approximately 15,500 regular high schools in the United States with at least 10 seniors that had at least 10 freshmen 4 years earlier, representing over 97 percent of regular schools with seniors in that year (see table A-16-1). In over 4,800 of these schools (or 31 percent of the total) the number of seniors in 2009-10 was between 91 and 150 percent of the number of freshmen 4 years earlier. By contrast, in 890 schools (or 6 percent of the total) the number of seniors in 2009-10 was between 10 and 50 percent of the number of freshmen 4 years earlier. This ratio of the number of seniors in a given year to the number of freshmen 4 years earlier is the retention rate. High schools with senior classes that are substantially smaller than the entering class 4 years earlier are considered to be "low-retention schools." For this indicator, low-retention high schools are defined as those with a senior class size that is between 10 and 70 percent of the size of the freshman class that had entered 4 years earlier.

In academic year 1990-91, some 24 percent of regular high schools were low-retention schools 5 percent retained between 10 and 50 percent of their students and 19 percent retained between 51 and 70 percent). The percentage of low-retention high schools declined to 22 percent in 1992-93, then increased to 32 percent (4,581 high schools) in 2000-01 before declining to approximately 26 percent in $2005-06$, and then remained relatively stable at 26 percent through 2009-10. Approximately 518,000 high school seniors attended low-retention high schools in 1990-91, compared to 845,000 in 2000-01 and 755,000 in 2009-10.
In academic year 2009-10, some 6 percent of low-poverty high schools, meaning those in which 25 percent or less of the students qualified for free or reduced-price lunch, were low retention, compared to 60 percent of high-poverty schools, meaning those in which 76 percent or more of the students qualified for free or reduced-price lunch (see table A-16-2). In contrast, 57 percent of low-poverty schools had retention rates of 91 to 150 percent, compared to 13 percent of high-poverty schools.

Fifty percent of regular high schools in cities were low-retention schools in academic year 2009-10, including 18 percent that retained 10 to 50 percent of their freshman class from 4 years earlier. In that same year, 19 percent of rural high schools, 22 percent of suburban high schools, and 24 percent of town high schools met the definition of low retention.

For regular high schools with more than 50 percent White enrollment, some 16 percent were low-retention schools, compared to 48 percent of regular high schools with more than 50 percent Hispanic enrollment and 67 percent of high schools with more than 50 percent Black enrollment. In contrast, some 39 percent of regular high schools with more than 50 percent White enrollment retained 91 to 150 percent of their students from 2006-07 to 2009-10, which was higher than high schools with more than 50 percent Hispanic enrollment (13 percent) and high schools with more than 50 percent Black enrollment (8 percent).

\section{Tables A-16-1 and A-16-2}

Glossary: Free or reduced-price lunch, High school, Public school, Regular school

\section{Technical Notes}

Retention rate is defined as the number of 12 th-grade students in a given academic year divided by the number of 9th-grade students 4 years prior (the base year). This indicator includes only regular public schools (not alternative, special education or vocational schools) that had 10 or more 9th-grade students in the base year and 10 or more 12th-grade students in the academic year 4 years later. Less than 3 percent of regular schools had less than ten 12th-graders in 2009-10 and less than ten 9th-graders four years earlier. Race categories exclude persons of Hispanic ethnicity. For more information on free or reduced-price lunch, race/ethnicity, or locale, see Appendix C - Commonly Used Measures. For more information on the Common Core of Data (CCD), see Appendix B - Guide to Sources. 
Figure 16-1. Percentage distribution of public high schools, by student retention rate: Selected academic years, 1990-91 through 2009-10

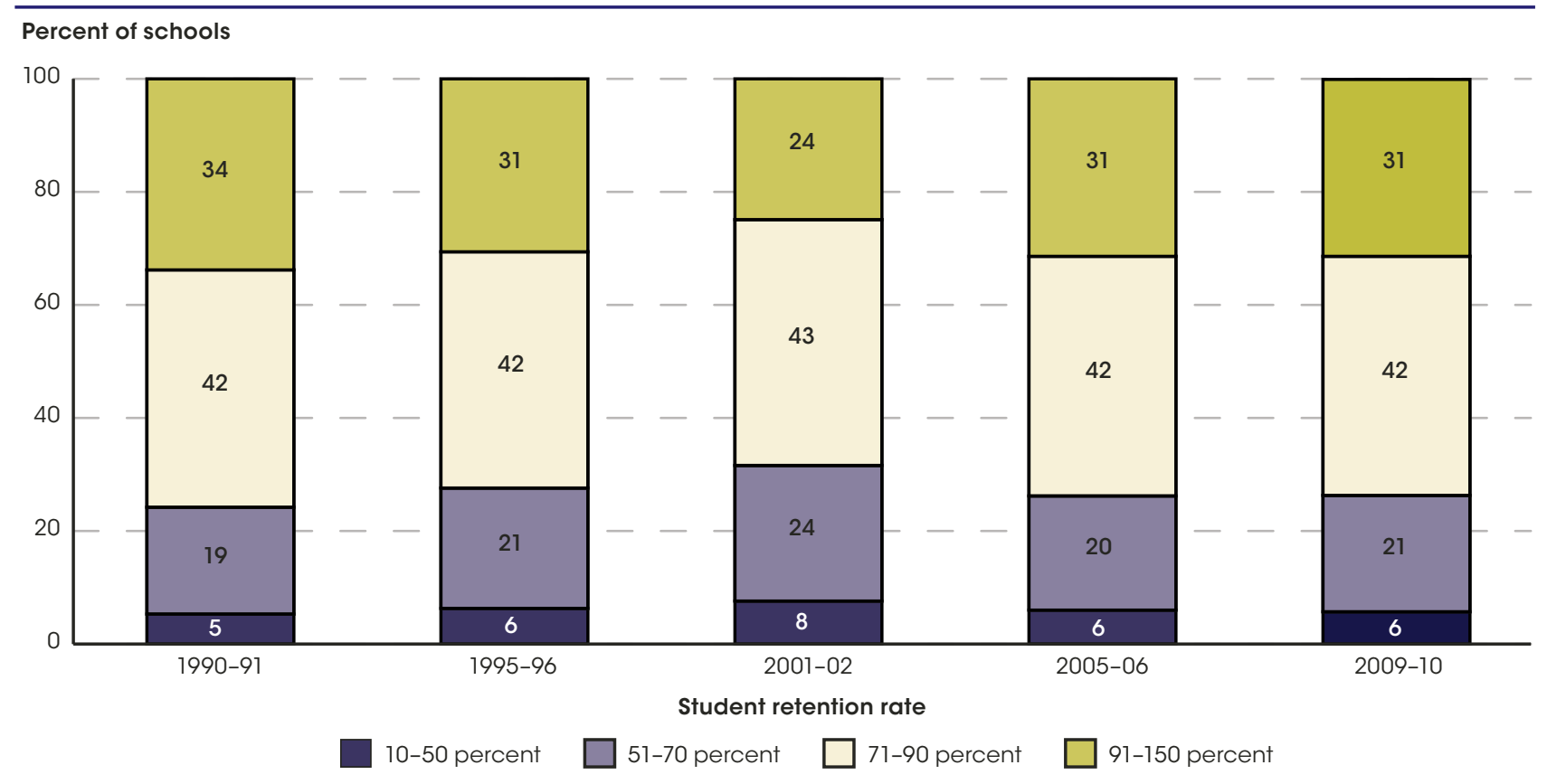

NOTE: Retention rate is defined as the number of 12th-grade students in a given academic year divided by the number of 9th-grade students 4 years prior (the base year). Includes only regular public schools that had 10 or more 9th-grade students in the base year and 10 or more 12 th-grade students in the academic year shown. Retention rates were limited to between 10 and 150 percent to eliminate outliers. For more information on the Common Core of Data (CCD), see Appendix B - Guide to Sources.

SOURCE: U.S. Department of Education, National Center for Education Statistics, Common Core of Data (CCD), "Public Elementary/Secondary School Universe Survey," 1990-91 through 2009-10.

Figure 16-2. Percentage distribution of public high schools, by student retention rate and percentage of students eligible for free or reduced-price lunch: Academic year 2009-10

\section{Percent}

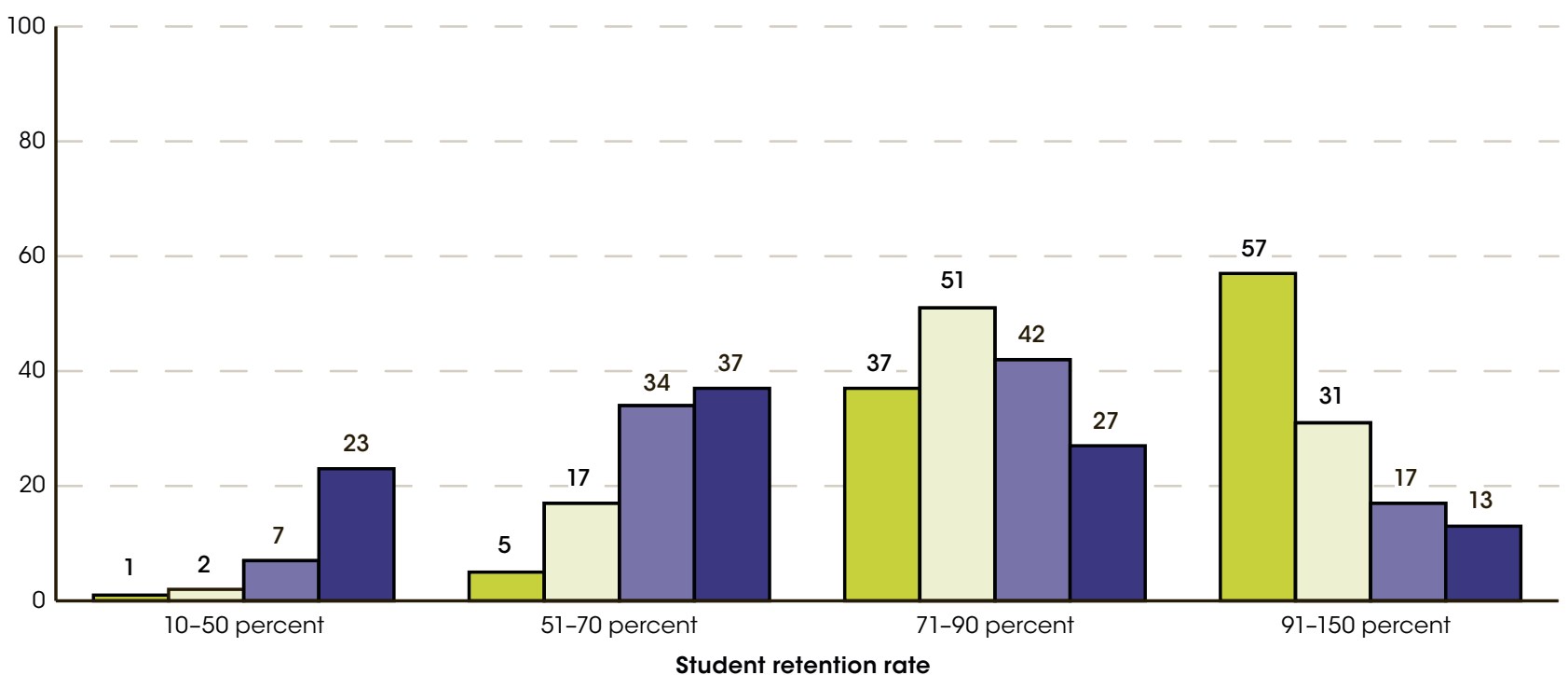

Percent of students eligible for free or reduced-price lunch

0-25 percent $\square$ 26-50 percent $\square$ 51-75 percent

76-100 percent

NOTE: Retention rate is defined as the number of 12th-grade students in a given academic year divided by the number of 9th-grade students 4 years prior. Includes only regular public schools that had 10 or more 9th-grade students in 2006-07 and 10 or more 12 th-grade students in $2009-10$. Retention rates were limited to between 10 and 150 percent to eliminate outliers. For more information on the Common Core of Data (CCD), see Appendix B - Guide to Sources. For more information on free or reduced-price lunch, see Appendix C - Commonly Used Measures. Detail may not sum to totals because of rounding.

SOURCE: U.S. Department of Education, National Center for Education Statistics, Common Core of Data (CCD), "Public Elementary/Secondary School Universe Survey," 2009-10. 


\section{A larger percentage of full-time teachers held a postbaccalaureate degree in 2007-08 than in 2003-04. Forty-nine percent of elementary school teachers and 54 percent of secondary school teachers held a postbaccalaureate degree in 2007- 08, compared with 45 and 50 percent, respectively, in 2003-04.}

In the 2007-08 school year, there were 3.5 million full-time teachers, up from 3.3 million in 2003-04. From 2003-04 to 2007-08, there were no measurable changes in the number of full-time elementary school teachers; however, the number of secondary school teachers grew from 1.0 million in 2003-04 to 1.1 million in 2007-08 (see table A-17-1). The number of public secondary school teachers increased from 0.9 million in 2003-04 to 1.0 million in 2007-08. The number of private school teachers was not measurably different between 2003-04 and 2007-08 at either level.

Approximately 75 percent of full-time teachers were women in 2007-08. At the elementary level, 84 percent of public school and 87 percent of private school teachers were female. At the secondary level, 59 percent of public school teachers were female, up from 57 percent in 2003-04. Females represented 53 percent of private secondary school teachers in 2007-08. Eighty-three percent of full-time teachers were White, 7 percent were Black, 7 percent were Hispanic, and 1 percent were Asian in 2007-08. The racial/ethnic distribution of full-time teachers was similar at both the elementary and secondary level.

A larger percentage of full-time teachers held a postbaccalaureate degree (master's degree, education specialist or professional diploma, first-professional degree, or doctoral degree) in 2007-08 than in 2003-04. Forty-nine percent of elementary school teachers and 54 percent of secondary school teachers held a postbaccalaureate degree in 2007-08, compared with 45 and 50 percent, respectively, in 2003-04. In 2007-08, a higher percentage of public elementary school teachers held such degrees than did private elementary school teachers (50 vs. 30 percent). No measurable difference was found between public and private school teachers at the secondary level.
In 2007-08 teachers averaged 14 years of experience, about the same as in 2003-04 (see table A-17-2). Nationally, about 17 percent of teachers had 3 or fewer years of experience, 28 percent had 4-9 years of experience, 27 percent had 10-19 years of experience, and 27 percent had 20 or more years of experience. For the most part, this distribution did not change between 2003-04 and 2007-08; however, the percentage of teachers with 20 or more years of experience was lower in 2007-08 than it was in 2003-04 (30 percent). In public schools, the percentage of teachers with 20 or more years of experience was also lower in 2007-08 than in 2003-04 at both the elementary ( 27 vs. 30 percent) and secondary ( 28 vs. 32 percent) levels. This change was not observed for private schools. Examined by school type, a lower percentage of public school teachers had 3 or fewer years of experience, compared to their private school counterparts, in $2007-08$ (17 vs. 20 percent). This difference between public and private school teachers was echoed at the elementary level in 2007-08 (17 vs. 20 percent), but was not observed at the secondary level.

In 2007-08, some 28 percent of full-time teachers taught in city schools, 35 percent taught in suburban schools, 13 percent taught in town schools, and 24 percent taught in rural schools (see table A-17-1). The distribution of elementary and secondary school teachers by locale varied between public and private school teachers. For example, 27 percent of public elementary school teachers taught in city schools, compared with 42 percent of private elementary school teachers, and 26 percent of public secondary school teachers taught in city schools, compared with 49 percent of private secondary school teachers.

Tables A-17-1 and A-17-2

Glossary: Doctor's degree, Education specialist/ professional diploma, Elementary school, Firstprofessional degree, Master's degree, Private school, Public school, Secondary school

\section{Technical Notes}

Race categories exclude persons of Hispanic ethnicity. For more information on race/ethnicity see Appendix $\mathrm{C}$ - Commonly Used Measures. Regular certification includes regular or standard state certificates and advanced professional certificates for both public and private school teachers. Full certificates granted by an accrediting or certifying body other than the state are not included. Probationary certificates are for those who have satisfied all requirements except the completion of a probationary period. For more information on the Schools and Staffing Survey (SASS), see Appendix B - Guide to Sources. 
Figure 17-1. Percentage distribution of full-time school teachers, by school level and highest degree earned: School years 2003-04 and 2007-08

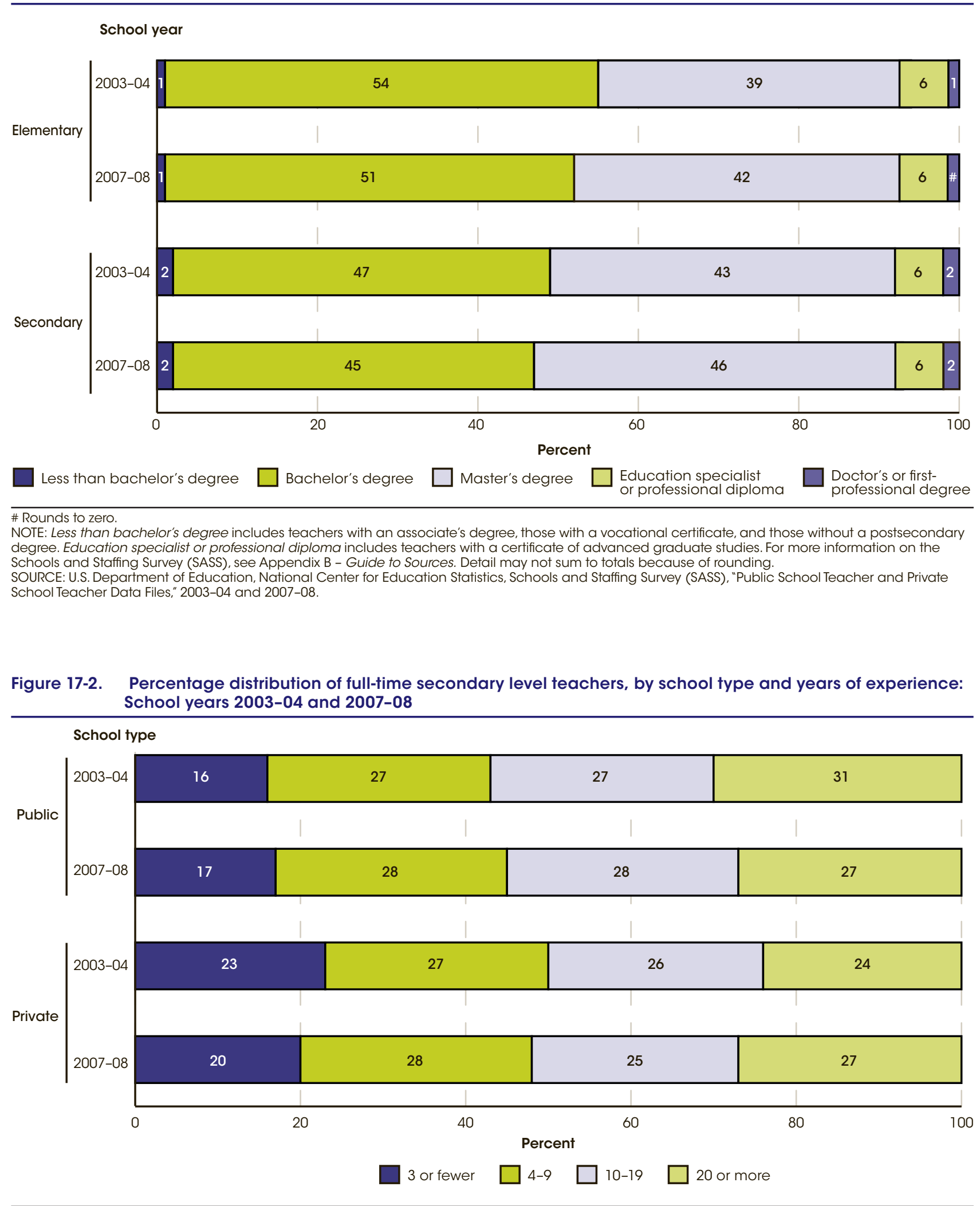

NOTE: For more information on the Schools and Staffing Survey (SASS), see Appendix B - Guide to Sources. Detail may not sum to totals because of rounding.

SOURCE: U.S. Department of Education, National Center for Education Statistics, Schools and Staffing Survey (SASS), "Public School Teacher and Private School Teacher Data Files," 2003-04 and 2007-08. 


\section{From 1999-2000 to 2007-08, the percentage of principals who were female increased from 52 to 59 percent at public elementary schools and from 22 to 29 percent at public secondary schools.}

Schools employed 118,400 principals in the 2007-08 school year, up from 110,000 principals in 1999-2000 (see table A-18-1). In 2007-08 there were 78,500 elementary school principals, with 79 percent at public and 21 percent at private schools. At the secondary level there were 24,500 principals, with 88 percent at public and 12 percent at private schools.

The percentage of public school principals who were female increased at both the elementary and secondary levels from 1999-2000 to 2007-08, although the gender distribution varied. The percentage of female principals increased from 52 to 59 percent at public elementary schools and from 22 to 29 percent at public secondary schools. There was no measurable change in this percentage at either private school level.

At public elementary and secondary schools, the percentage of principals under age 40 increased from 1999-2000 to 2007-08, as did the percentage of principals age 55 and over. The percentages of principals ages 45 to 49 and 50 to 54 decreased. For example, 10 percent of public elementary school principals were under age 40 in 1999-2000, compared with 19 percent in 2007-08. The percentage of public elementary school principals who were age 55 and over increased from 22 to 33 percent during this time. From 1999-2000 to 200708 , the percentage of private school principals ages 55 and over also increased at the elementary and secondary levels, while the percentage of principals ages 45 to 49 and 50 to 54 decreased at both levels. However, unlike their public school peers, the percentages of elementary and secondary principals at private schools who were under age 40 in 1999-2000 were not measurably different from the percentages in 2007-08.

The percentage of public secondary school principals with 20 or more years of experience as a principal decreased from 10 to 5 percent from 1999-2000 to 2007-08. About 36 percent of public secondary school principals had 3 or fewer years' experience as a principal in 2007-08, compared with 30 percent in 1999-2000. A similar pattern occurred at the public elementary school level. Higher percentages of private school principals had 20 or more years of experience as principals in 2007-08 than did public school principals. For example, 19 percent of private elementary school principals had 20 or more years of experience as a principal, compared with 8 percent of their public school peers. However, in 2007-08, a greater percentage of elementary private school principals had 3 or fewer years of teaching experience (26 percent) than did public school principals (3 percent).

Educational attainment differed between public and private school principals. In 2007-08, about 32 percent of private elementary school principals and 18 percent of private secondary school principals had a bachelor's degree or less, while 1 percent each of public elementary and public secondary school teachers had a bachelor's degree or less. A higher percentage of public elementary school principals held a doctor's or first-professional degree $(8$ percent) than did private elementary school principals (5 percent); there was no measurable difference between the percentages of public versus private secondary school principals who held a doctor's or first-professional degree.

Principals' median annual salary, calculated in constant 2010-11 dollars, was generally higher in 2007-08 than in 1999-2000. The median salary of public secondary school principals increased from $\$ 88,600$ to $\$ 91,900$ during this time. Secondary school principals received higher salaries than elementary school principals, and public school principals received higher salaries than private school principals. For example, principals at public elementary schools had a median salary of $\$ 87,700$ in $2007-08$, compared with $\$ 91,900$ for principals at public secondary schools. Private elementary school principals earned a median $\$ 52,200$ salary, compared to $\$ 68,900$ in private secondary schools.

\section{Table A-18-1}

Glossary: Elementary school, Private school, Public school, Secondary school

\section{Technical Notes}

Median annual salary estimates were adjusted using the Consumer Price Index (CPI). For more information on the CPI, see Appendix C - Finance. For more information on the Schools and Staffing Survey (SASS), see Appendix B - Guide to Sources. 


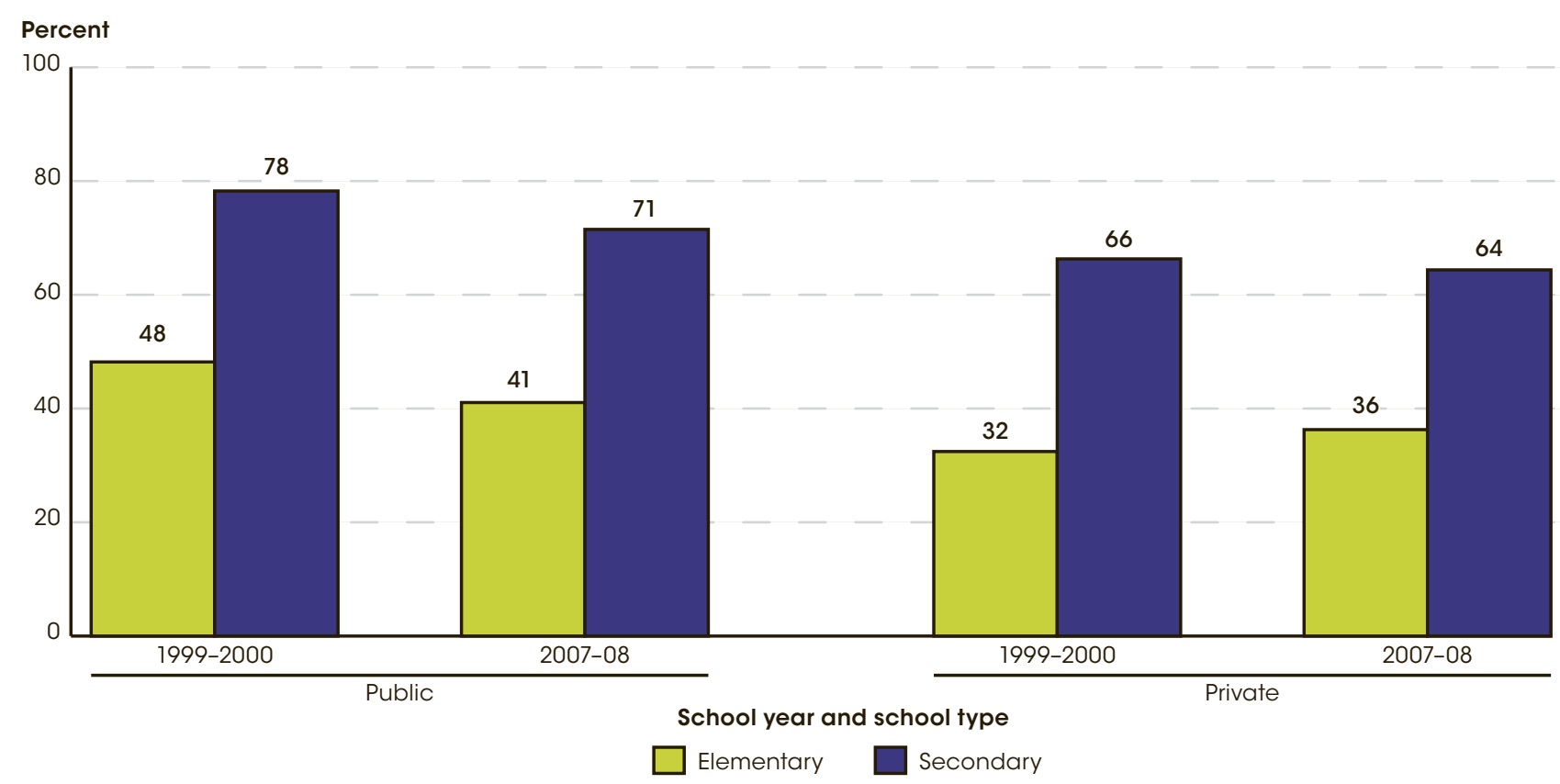

NOTE: Detail may not sum to totals because of rounding. For more information on the Schools and Staffing Survey (SASS), see Appendix B - Guide to Sources.

SOURCE: U.S. Department of Education, National Center for Education Statistics, Schools and Staffing Survey (SASS), "Public School Principal and Private School Principal Data Files," 1999-2000 and 2007-08, and "Charter School Principal Data File," 1999-2000.

Figure 18-2. Percentage distribution of public school principals, by school level and years of experience as a principal: School years 1999-2000 and 2007-08

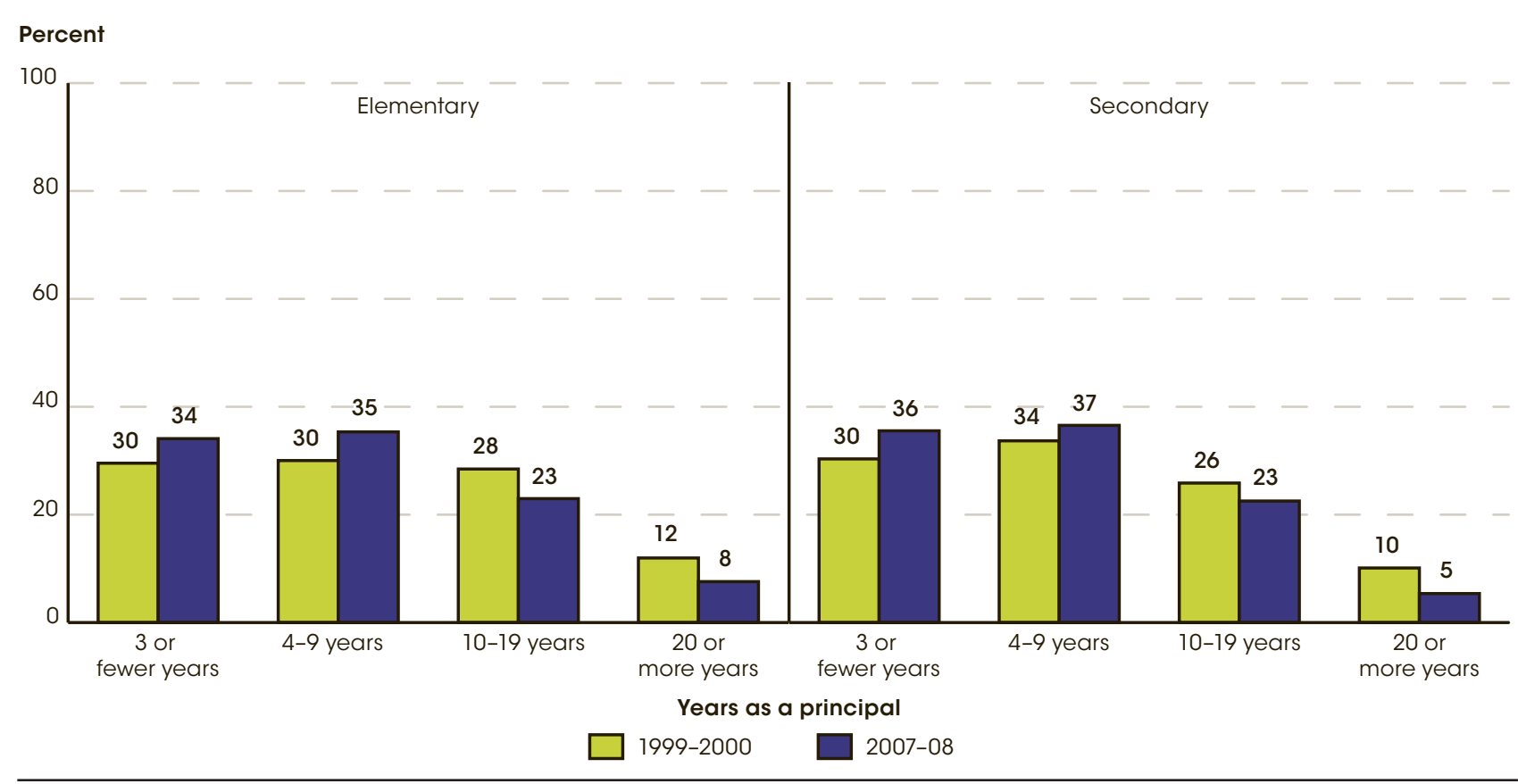

NOTE: Detail may not sum to totals because of rounding. For more information on the Schools and Staffing Survey (SASS), see Appendix B - Guide to Sources.

SOURCE: U.S. Department of Education, National Center for Education Statistics, Schools and Staffing Survey (SASS), "Public School Principal and Private School Principal Data Files," 1999-2000 and 2007-08, and "Charter School Principal Data File," $1999-2000$. 


\section{Indicator 19}

\section{Public School Revenue Sources}

\section{From school years 1988-89 through 2008-09, total elementary and secondary public school revenues increased from $\$ 350$ billion to $\$ 611$ billion, a 74 percent increase after adjusting for inflation.}

From school years 1988-89 through 2008-09, total elementary and secondary public school revenues increased from $\$ 350$ billion to $\$ 611$ billion (in constant 2010-11 dollars), a 74 percent increase (see table A-19-1). During this period, the total amounts from each revenue source (federal, state, and local) increased, but the percentage of increase differed by revenue source. Federal revenues, the smallest of the three revenue sources, increased by 169 percent, compared with increases of 70 percent for state revenues and 66 percent for local revenues.

The percentage of total revenues for public elementary and secondary education that came from local sources declined from 46 percent in school year 1988-89 to 44 percent in 2008-09. While the percentage coming from state sources was nearly the same in school years 1988-89 and 2008-09 (48 and 47 percent, respectively), the percentage fluctuated between these two years from a low of 45 percent in 1993-94 to a high of 50 percent in 2000-01. The percentage of total revenues from federal sources increased from 6 percent in school year 1989-90 to 10 percent in school year 2008-09.

Looking at revenues from school years 2007-08 to 2008-09, state revenues declined by $\$ 9.7$ billion. This decline, which occurred in 25 states (data not shown), is the largest decline in state revenues from the previous year since World War II. Local revenue from sources other than property taxes also declined. Total revenues for public education increased slightly, however, due to an

\section{Technical Notes}

Revenues have been adjusted for the effects of inflation using the Consumer Price Index (CPI) and are in constant 2010-11 dollars. For more information about the CPI, see Appendix C - Finance. Both the District of Columbia and Hawaii have only one school district each; therefore, neither is comparable to the other states. Other local government revenue includes revenues from
$\$ 8.6$ billion increase in federal revenues and a $\$ 6.8$ billion increase in local property taxes.

In school year 2008-09, there were significant variations across the states in the percentages of public school revenues coming from each revenue source. In 21 states, more than half of education revenues came from state governments, while in 14 states and the District of Columbia more than half came from local revenues. In the remaining 15 states, no single revenue source made up more than half of education revenues (see table A-19-2).

In school year 2008-09, the percentages of revenues coming from state sources were highest in Vermont and Hawaii (86 and 82 percent, respectively). The percentages of revenues coming from state sources were lowest in Nevada and Illinois (31 and 28 percent, respectively). The District of Columbia does not receive any state revenue. The percentages of revenues coming from federal sources were highest in South Dakota and Louisiana (16 percent each) and lowest in New Jersey and Connecticut (4 percent each). Among the states, the percentages of revenues coming from local sources were highest in Illinois (61 percent) and lowest in Hawaii ( 3 percent) and Vermont ( 8 percent). The percentages of revenues from property taxes also differed by state, ranging from a high of 55 percent in Connecticut and New Hampshire to lows of zero or nearly zero percent in Hawaii and Vermont.

Tables A-19-1 and A-19-2

Glossary: Consumer Price Index (CPI), Elementary school, Property tax, Public school, Revenues, Secondary school

sources such as local nonproperty taxes and investments, as well as revenues from student activities, textbook fees, transportation and tuition fees, and food services. For more information about revenues for public elementary and secondary schools, see Appendix C - Finance. For more information about the Common Core of Data, see Appendix B - Guide to Sources. 
Figure 19-1. Revenues for public elementary and secondary schools, by revenue source: School years 1989-90 through 2008-09

Revenue (in billions)

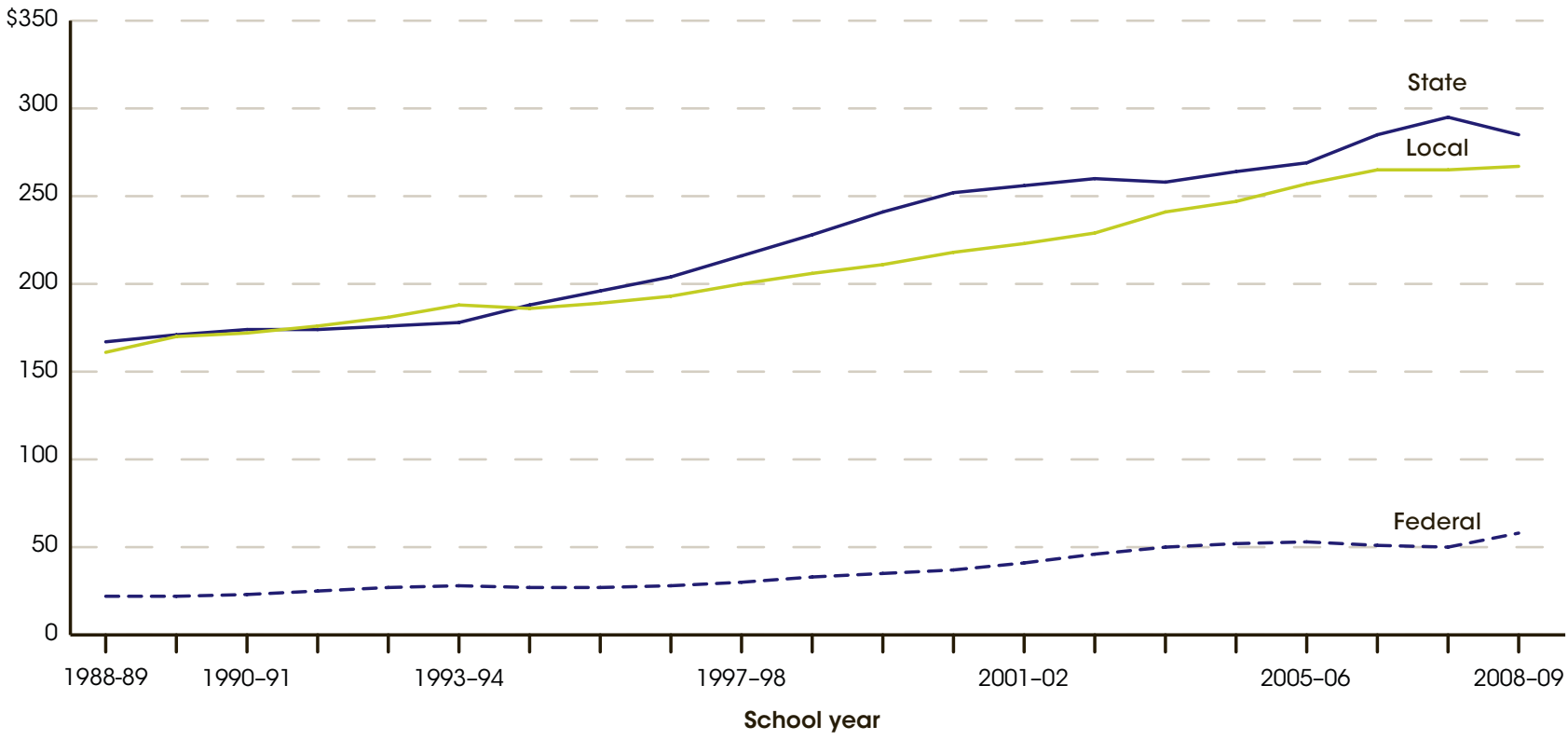

NOTE: Revenues are in constant 2010-11 dollars, adjusted using the Consumer Price Index (CPI). For more information about the CPI and revenues for public elementary and secondary schools, see Appendix C - Finance. For more information about the Common Core of Data, see Appendix B - Guide to Sources.

SOURCE: U.S. Department of Education, National Center for Education Statistics, Common Core of Data (CCD), "National Public Education Financial Survey," 1990-91 through 2008-09.

Figure 19-2. Local revenues for public elementary and secondary schools as a percentage of total school revenues, by state: School year 2008-09

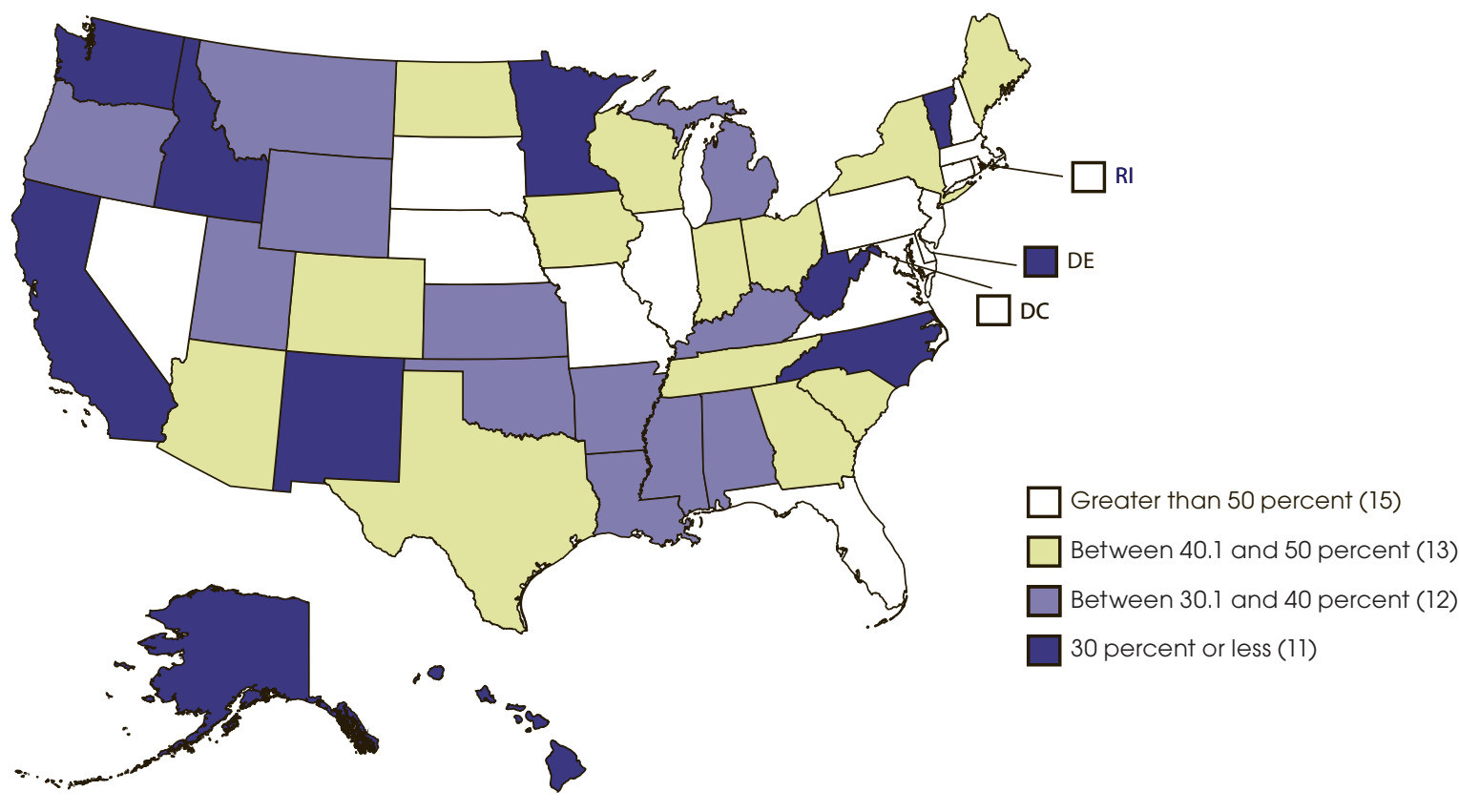

NOTE: Both the District of Columbia and Hawaii have only one school district each; therefore, neither is comparable to the other states. For more information about revenues for public elementary and secondary schools, see Appendix C - Finance. For more information about the Common Core of Data, see Appendix B - Guide to Sources.

SOURCE: U.S. Department of Education, National Center for Education Statistics, Common Core of Data (CCD), "National Public Education Financial Survey," 2008-09. 


\section{Total expenditures per student in public elementary and secondary schools rose 46 percent in constant dollars from 1988-89 through 2008-09, with interest on school debt increasing faster than current expenditures or capital outlay.}

Total expenditures per student in fall enrollment in public elementary and secondary schools rose from $\$ 8,634$ in $1988-89$ to $\$ 12,643$ in $2008-09$, a 46 percent increase as measured in constant 2010-11 dollars (see table A-20-1). Most of this increase occurred after 1998-99. The various components of total expenditures experienced different percent increases during this time period. Spending on interest on school debt per student had the highest percent increase (149 percent, from $\$ 141$ to $\$ 351$ ), followed by capital outlay, e.g., buildings, at 117 percent (from $\$ 637$ to $\$ 1,383$ ) and employee benefits at 75 percent (from $\$ 1,267$ to $\$ 2,222)$.

In 2008-09, salary and employee benefits for school staff amounted to $\$ 8,797$ per student, or about 81 percent of current expenditures. From 1988-89 through 2008-09, combined salary and employee benefit expenditures per student increased by 38 percent, with the salary component increasing by 29 percent and the employee benefits component increasing by 75 percent. During this period, the amount of current expenditures spent on purchased services, e.g., contractor services, increased 62 percent. As a result of these different percent increases, salaries as a share of current expenditures decreased from 65 to 60 percent between 1988-89 and 2008-09, while the percentage of current expenditures spent on employee benefits rose from 16 to 20 percent, and the percentage spent on purchased services increased from 8 to 10 percent. The percentage spent on tuition and other items remained around 2 percent throughout the period. Whereas expenditures per student for salaries have increased by 29 percent between 1988-89 and 2008-09, salaries for teachers and other staff have remained nearly flat. The increase in salary expenditures results from increases in staff greater than the increase in students.

Among the major functions of current expenditures, spending on student and staff support had the highest percent increase (74 percent) between 1988-89 and 2008-09, followed by instruction (39 percent) and transportation (37 percent) (see table A-20-2). Spending increased by a smaller percentage on three other major functions of current expenditures: administration (34 percent), food services (25 percent), and operation and maintenance (23 percent). Expenditures for enterprise operations increased 38 percent, but only made up 0.2 percent of current expenditures. None of the seven major functions of current expenditures declined over this period.

In the 2008-09 school year, 61 percent of the $\$ 10,909$ spent on current expenditures in public elementary and secondary schools went toward instruction expenditures such as salaries and benefits of teachers (see table A-20-2). About 11 percent went towards administration, 10 percent toward student and staff support; 10 percent for operation and maintenance; 4 percent each for transportation and food services; and less than 1 percent for enterprise operations.

Tables A-20-1 and A-20-2

Glossary: Consumer Price Index (CPI), Expenditures, Public School, Salary

\section{Technical Notes}

Expenditures have been adjusted for the effects of inflation using the Consumer Price Index (CPI) and are in constant 2010-11 dollars. Current expenditures, which is one component of total expenditures, can be broken down by both the service or commodity bought (object) as well as the activity that is supported by the service or commodity bought (function). Total expenditures exclude "Other current expenditures" such as community services, private school programs, adult education, and other programs not allocable to expenditures per student at public schools. Enterprise operations include expenditures for operations funded by sales of products or services, along with amounts for direct program support made available by state education agencies for local school districts. For more information about the CPI and classifications of expenditures, see Appendix C - Finance. For more information about the Common Core of Data, see Appendix B - Guide to Sources. 
Figure 20-1. Percentage change in total expenditures per student in fall enrollment in public elementary and secondary schools, by expenditure type and objects of current expenditures, in constant 2010-11 dollars: School years 1988-89 to 2008-09

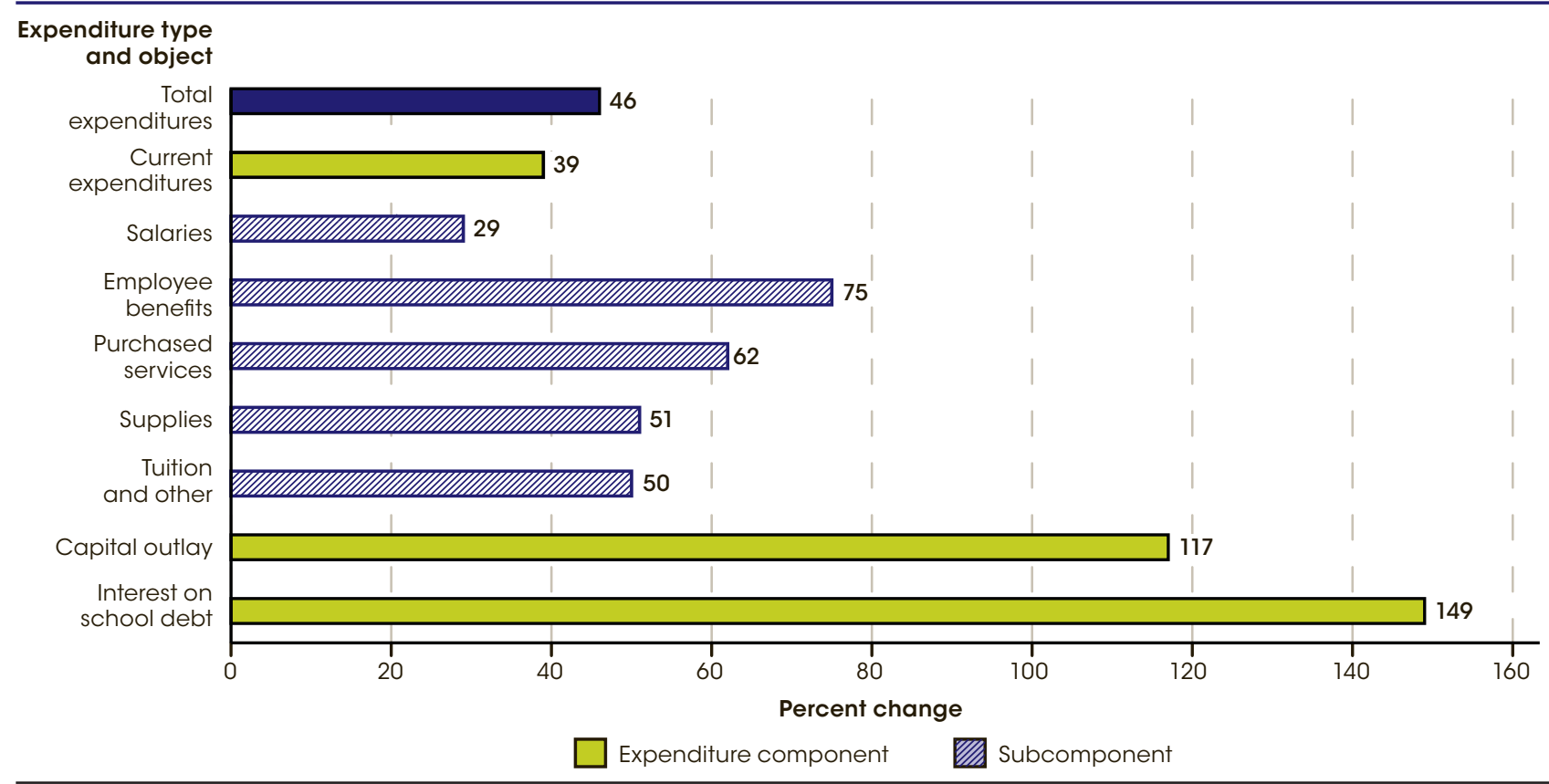

NOTE: "Current expenditures," "Capital outlay," and "Interest on school debt" are subcategories of "Total expenditures"; "Salaries," "Employee benefits," "Purchased services," "Supplies," and "Tuition and other" are subcategories of "Current expenditures." Expenditures have been adjusted for the effects of inflation using the Consumer Price Index (CPI) and are in 2010-11 constant dollars. For more information about the CPI and classifications of expenditures, see Appendix C - Finance. For more information about the Common Core of Data (CCD), see Appendix B - Guide to Sources. SOURCE: U.S. Department of Education, National Center for Education Statistics, Common Core of Data (CCD), "National Public Education Financial Survey," 1988-89 and 2008-09.

Figure 20-2. Current expenditures per student in fall enrollment in public elementary and secondary schools in constant 2010-11 dollars, by expenditure object: School years 1988-89, 1998-99, and 2008-09

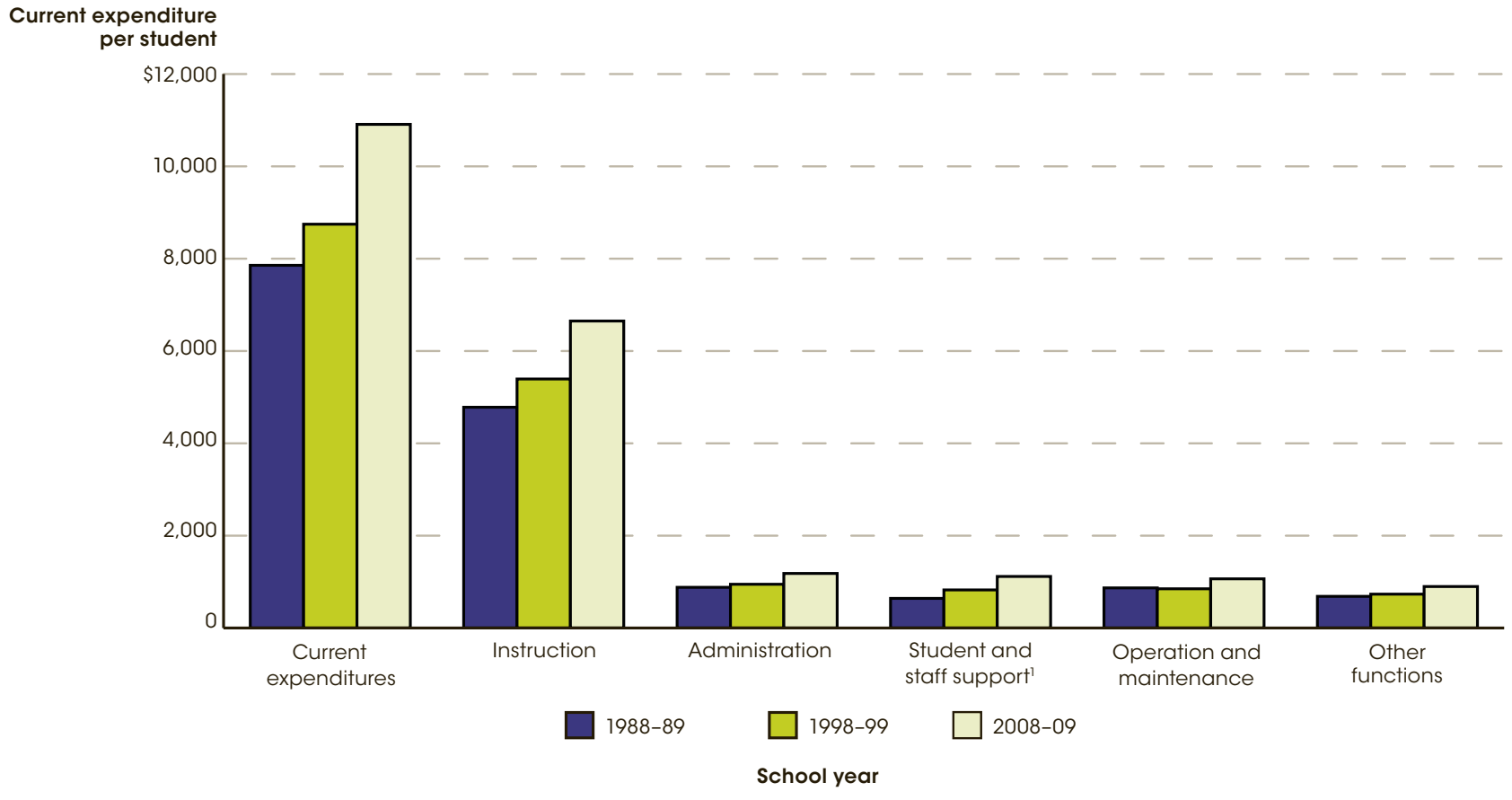

Includes expenditures for student support services and instructional support services.

NOTE: Expenditures are in constant 2010-11 dollars, adjusted using the Consumer Price Index (CPI). Current expenditures consist of all of the categories shown. Other functions include student transportation, food services, and enterprise operations. For more information about the CPI and classifications of expenditures, see Appendix C - Finance. For more information about the Common Core of Data (CCD), see Appendix B - Guide to Sources.

SOURCE: U.S. Department of Education, National Center for Education Statistics, Common Core of Data (CCD), "National Public Education Financial

Survey," 1988-89, 1998-99, and 2008-09. 


\section{After increasing every year from 1997-98 to 2007-08, total variation in instruction expenditures per student was lower among public school districts in 2008-09 than in 2007-08.}

A number of methods can be used to measure the variation between districts and states in the amount that school districts spend per student on instruction. The variation in instruction expenditures per student over time may reflect differences across school districts in the amount of services or goods purchased, such as the number of classroom teachers hired. These changes may, in part, reflect various state finance litigation, school finance reform efforts, and changes in the composition of student enrollment. Further, some of the variation in expenditures per pupil may be due to cost differences across states and districts within states. Changes in cost differences across and within states may also affect the changes in the variation over time.

This indicator uses the Theil coefficient to measure the variation in the instruction expenditures per student in unified public school districts for prekindergarten through grade 12 . The Theil coefficient provides a national measure of differences in instruction expenditures per student that can be decomposed into separate components to measure school district-level variations both between and within states. The between-state and within-state components indicate whether the national variation in instruction expenditures per student is primarily due to differences in expenditures between states or within states. Similarly, the trends in the two components indicate whether the change over time in the national variation of instruction expenditures per student is primarily due to changes between states or changes within states. The Theil coefficient can range from zero, indicating no variation, to a maximum possible value of 1.0. The value of the Theil coefficient remains unchanged if expenditures in all districts are increased by the same percentage; it would therefore not be necessary to adjust instruction expenditures for inflation at the national level.

Across U.S. districts, the total variation in instruction expenditures per student decreased between school years 1989-90 and 1997-98, then increased between 1997-98 and 2007-08 (see table A-21-1). The total variation in instruction expenditures per student was greater in 2007-08 than it was in the early 1990s. Total variation was lower in 2008-09 than in 2007-08, but was still higher than in any year from 1989-90 through 2005-06. Both the between-state and within-state variations in instruction expenditures per student decreased between 1989-90 and 1997-98, and increased between 1997-98 and 2007-08. Like the total variation, both between-state and within-state variations were lower in 2008-09 than in 2007-08.

Between 1989-90 and 2008-09, differences between states accounted for a greater proportion of the variation in instruction expenditures per student among public school districts than did differences within states. The percentage of the total variation due to between-state differences increased from 72 percent in 1989-90 to 79 percent in 2008-09, while the percentage of the total variation due to within-state differences decreased from 28 to 21 percent.

Table A-21-1

Glossary: Expenditures, Public school

\section{Technical Notes}

For more information on the variation in expenditures per student, the Theil coefficient, and the classifications of expenditures for elementary and secondary education, see Appendix C - Finance. This indicator only includes unified public elementary and secondary districts. Unified districts serve both elementary and secondary grades. The Theil coefficient was calculated for unified districts only in order to limit any variations in expenditures per pupil due to the grade levels of the school districts or due to districts serving only students in special programs. In 2008-09, approximately 92 percent of all public elementary and secondary school students were enrolled in unified school districts. For more information on the Common Core of Data, see Appendix B - Guide to Sources. 
Figure 21-1. Variation in instruction expenditures per student in unified public elementary and secondary school districts, by source of variation: School years 1989-90 through 2008-09

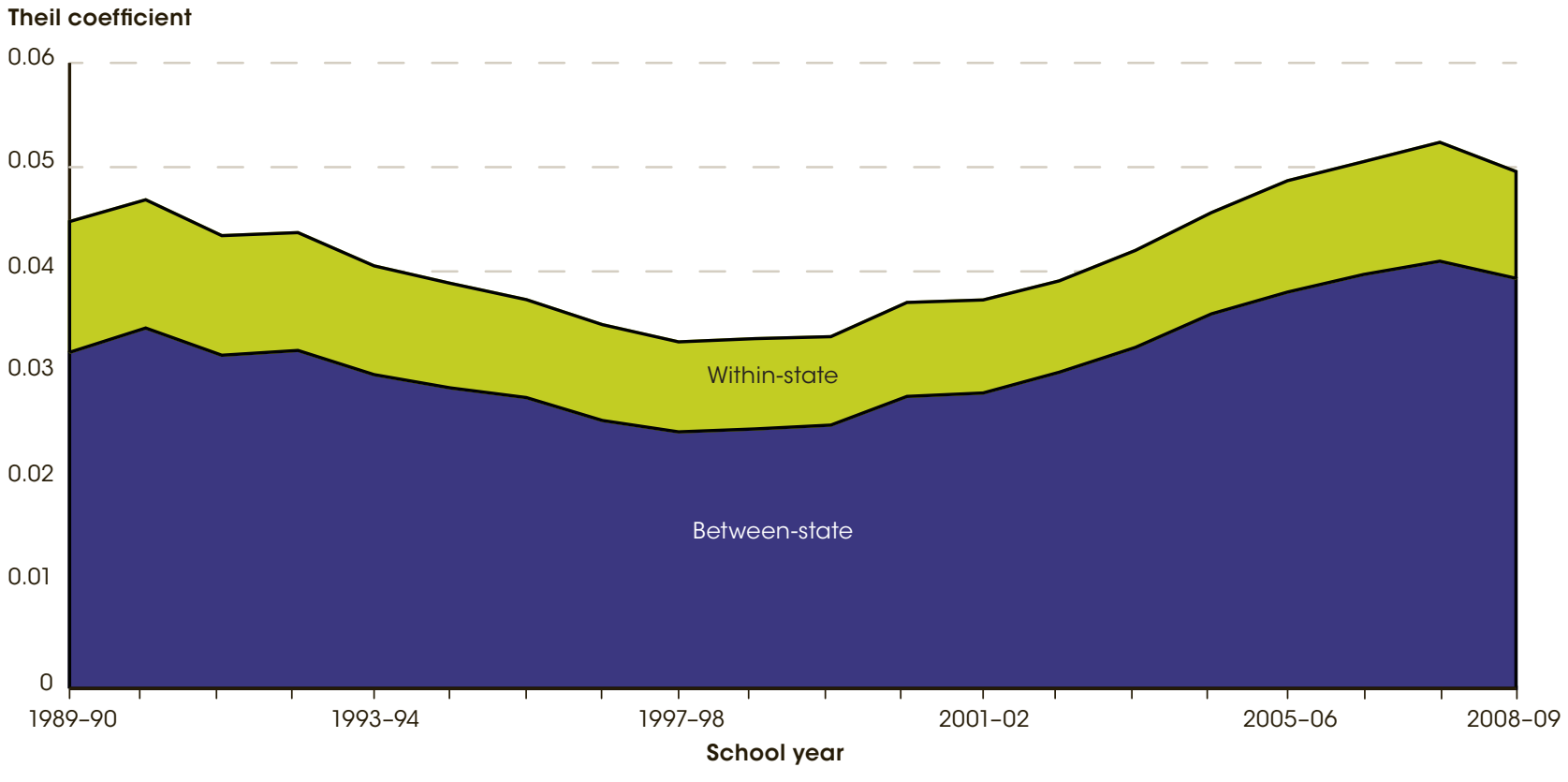

NOTE: The Theil coefficient measures variation for groups within a set (i.e., states within the country) and indicates relative variation and any differences that may exist among them. It can be decomposed into components measuring between-state and within-state variation in expenditures per student. It has a minimum value of zero, and increasing values indicate increases in the variation, with a maximum possible value of 1.0 . For more information on the variation in expenditures per student and the Theil coefficient, see Appendix C - Finance. For more information on the Common Core of Data (CCD), see Appendix B - Guide to Sources.

SOURCE: U.S. Department of Education, National Center for Education Statistics (NCES), Common Core of Data (CCD), "NCES Longitudinal School District Fiscal-Nonfiscal (FNF) File, Fiscal Years 1990 through 2002" and "School District Finance Survey (Form F-33)," 2002-03 through 2008-09.

Figure 21-2. Percentage distribution of source of variation in instruction expenditures per student in unified public elementary and secondary school districts: Selected school years, 1989-90 through 2008-09

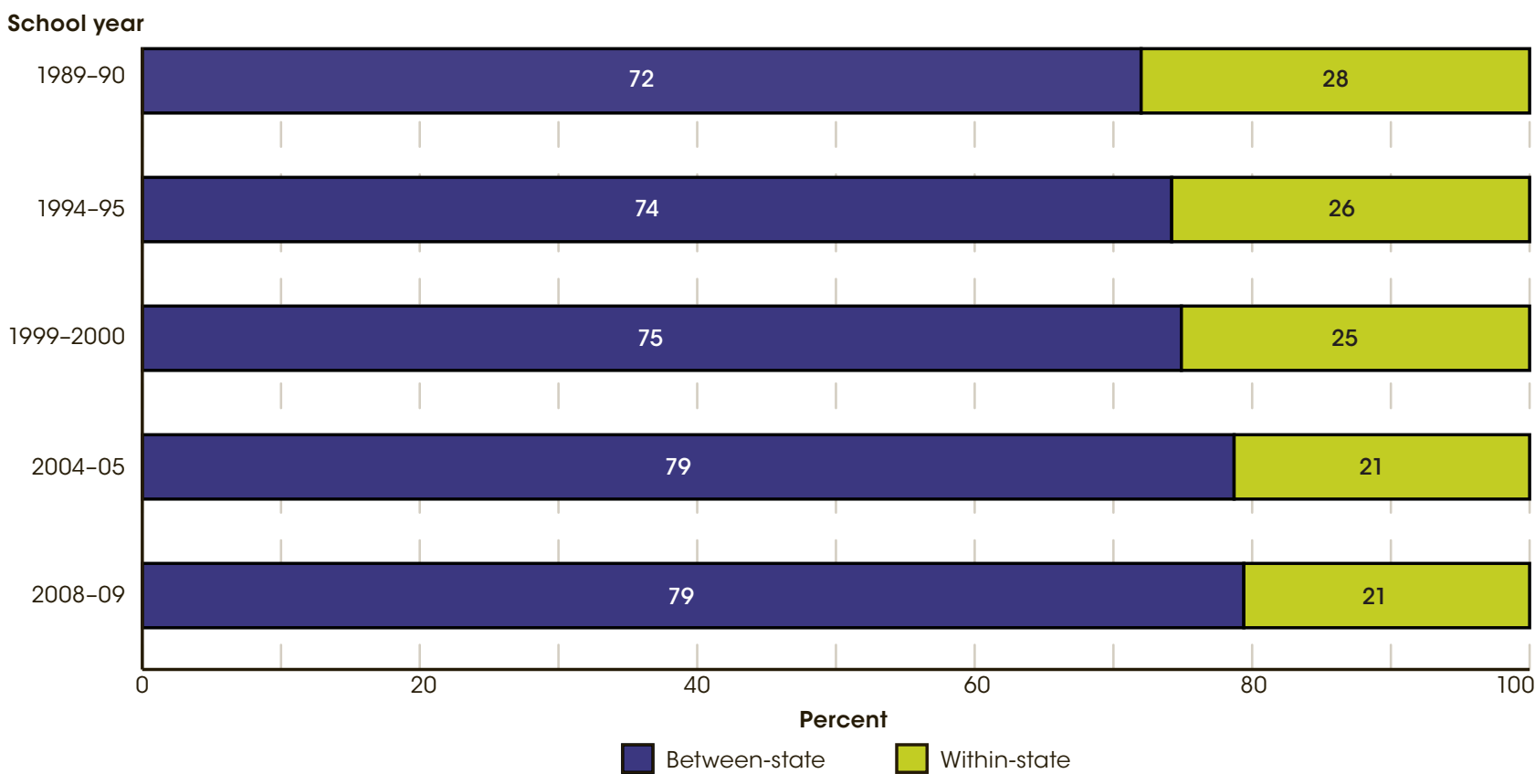

NOTE: The Theil coefficient measures variation for groups within a set (i.e., states within the country) and indicates relative variation and any differences that may exist among them. It can be decomposed into components measuring between-state and within-state variation in expenditures per student. It has a minimum value of zero, and increasing values indicate increases in the variation, with a maximum possible value of 1.0 . For more information on the variation in expenditures per student and the Theil coefficient, see Appendix C - Finance. For more information on the Common Core of Data (CCD), see Appendix B - Guide to Sources.

SOURCE: U.S. Department of Education, National Center for Education Statistics (NCES), Common Core of Data (CCD), "NCES Longitudinal School District Fiscal-Nonfiscal (FNF) File, Fiscal Years 1990 through 2000" and "School District Finance Survey (Form F-33)," 2004-05 and 2008-09. 


\section{In 2008, the United States spent \$10,995 per student on elementary and secondary education, which was 35 percent higher than the OECD average of $\$ 8,169$. At the postsecondary level, U.S. expenditures per student were $\$ 29,910$, more than twice as high as the OECD average of $\$ 13,461$.}

This indicator uses material from the Organization for Economic Co-operation and Development (OECD) report Education at a Glance to compare countries' expenditures on education using expenditures per student from both public and private sources and total education expenditures as a percentage of gross domestic product (GDP). The latter measure allows a comparison of countries' expenditures relative to their ability to finance education. Private sources of expenditures include payments from households for school-based expenses such as tuition, transportation fees, book rentals, or food services, as well as private funds raised by institutions.

In 2008, expenditures per student for the United States were $\$ 10,995$ at the combined elementary and secondary level, which was 35 percent higher than the average of $\$ 8,169$ for the OECD member countries reporting data (see table A-22-1). The expenditure per student measure is based on full-time-equivalent (FTE) student enrollment rather than headcounts. At the postsecondary level, U.S. expenditures per student were $\$ 29,910$, which was more than twice as high as the OECD average of $\$ 13,461$. Expenditures per student varied widely across the OECD countries: at the combined elementary and secondary level, expenditures ranged from \$2,284 in Mexico and $\$ 2,635$ in Chile to $\$ 16,909$ in Luxembourg; at the postsecondary level, they ranged from $\$ 5,780$ in Estonia to $\$ 20,903$ in Canada, $\$ 21,648$ in Switzerland, and $\$ 29,910$ in the United States.

Among the OECD countries reporting data in 2008, the top five countries spending the highest percentage of their GDP on total education expenditures were Iceland (7.9 percent), Korea (7.6 percent), Israel (7.3 percent), Norway (7.3 percent), and the United States ( 7.2 percent) (see table A-22-1). Looking at education expenditures by level, the percentage of its GDP (4.1 percent) that the United States spent on elementary and secondary education was higher than the average of GDP spent by other reporting OECD countries (3.8 percent). Compared with the percentage of its GDP that the United States spent on elementary and secondary education, 10 countries spent a higher percentage, 20 countries spent a lower percentage, and 1 country spent the same percentage. Among OECD countries, Iceland spent the highest percentage (5.1 percent) of its GDP on elementary and secondary education. At the postsecondary level, the United States spent 2.7 percent of its GDP on education, which was higher than the average percentage spent by OECD countries (1.5 percent) and higher than the percentage spent by any other OECD country reporting data.

A country's wealth (defined as GDP per capita) is positively associated with expenditures per student on education at the combined elementary/secondary level and at the postsecondary level. For example, the education expenditures per student (both elementary/secondary and postsecondary) for each of the 7 OECD countries with the highest GDP per capita in 2008 were higher than the OECD average expenditures per student. The expenditures per student for the 10 OECD countries with the lowest GDP per capita were below the OECD average at both the elementary/secondary level and at the postsecondary level.

\section{Table A-22-1}

Glossary: Elementary/secondary school, Expenditures per student, Full-time-equivalent (FTE) enrollment, Gross Domestic Product (GDP), Postsecondary education, Purchasing Power Parity (PPP) indexes

\section{Technical Notes}

Education expenditures are from public revenue sources (governments) and private revenue sources. Private sources include payments from households for school-based expenses such as tuition, transportation fees, book rentals, or food services, as well as funds raised by institutions through endowments or returns on investments. Data for private school expenditures at the elementary and secondary levels are estimated for some countries, including the United States. Per-student expenditures are based on public and private full-time-equivalent (FTE) enrollment figures and on current expenditures and capital outlays from both public and private sources, where data are available. Purchasing power parity (PPP) indexes are used to convert other currencies to U.S. dollars (i.e., absolute terms). Within-country consumer price indexes are used to adjust the PPP indexes to account for inflation because the fiscal year has a different starting date in different countries. Luxembourg data are excluded from the graphs because of anomalies with respect to their GDP per capita data (large revenues from international finance institutions distort the wealth of the population). For more information on classification of expenditures for international comparisons, see Appendix C - Finance. For more information on the Organization for Economic Co-operation and Development (OECD), see Appendix C - International Education Definitions. 
Figure 22-1. Annual expenditures per student for elementary and secondary education in selected Organization for Economic Co-operation and Development (OECD) countries, by gross domestic product (GDP) per capita: 2008

\section{Expenditures per student}

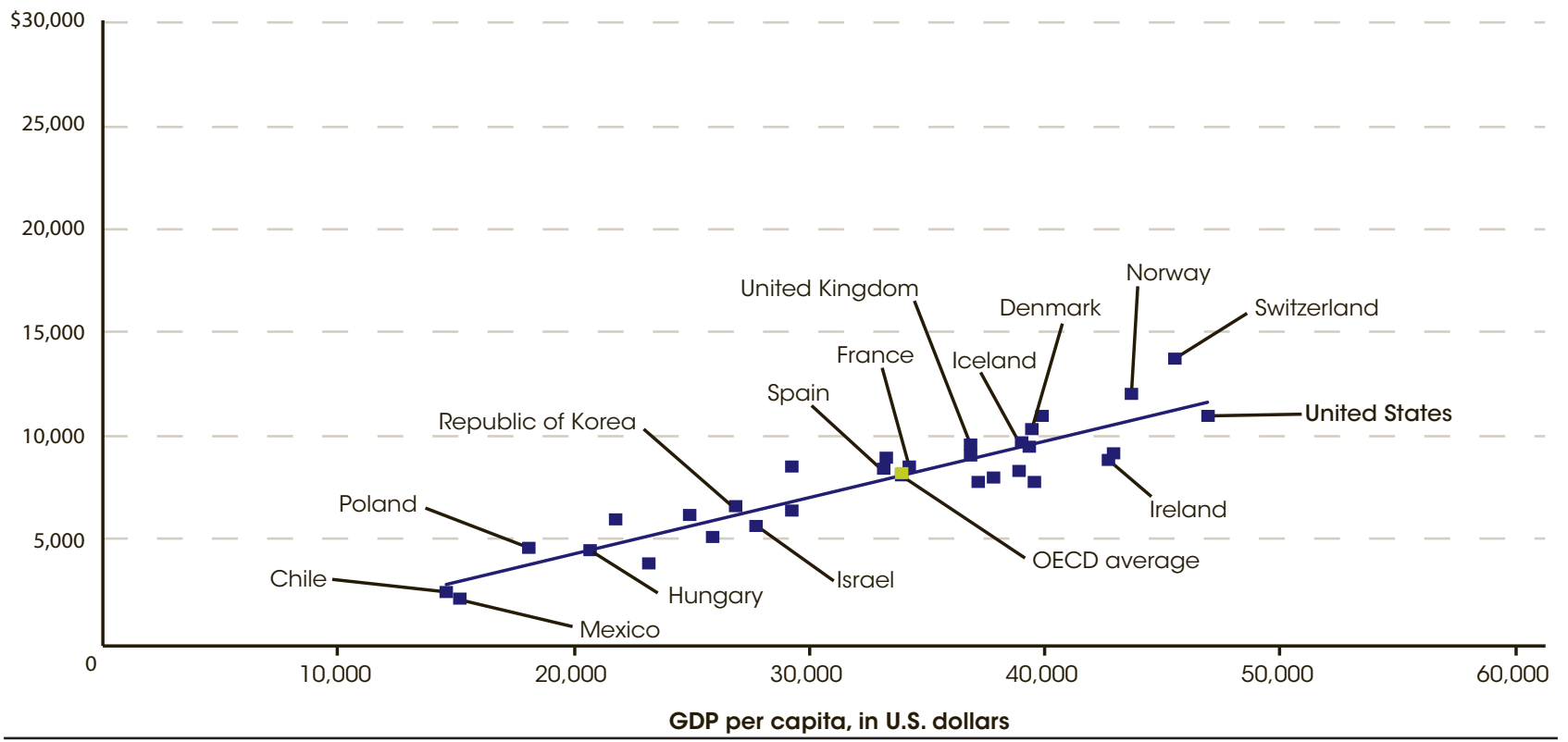

- Linear relationship between spending and country wealth for 31 OECD countries reporting data (elementary/secondary): $\mathrm{r}^{2}=.84 ;$ slope $=.27$; intercept $=-992$

NOTE: Luxembourg data are excluded because of anomalies with respect to their Gross Domestic Product (GDP) per capita data. (Large revenues from international finance institutions distort the wealth of the population.) For more information on classification of expenditures for international comparisons, see Appendix C - Finance. For more information on the International Standard Classification of Education (ISCED), see Appendix C International Education Definitions.

SOURCE: Organization for Economic Co-operation and Development (OECD), Center for Educational Research and Innovation. (201 1 ). Education at a Glance, 2017: OECD Indicators, tables B1.2 and X2.1

Figure 22-2. Annual expenditures per student for postsecondary education in selected Organization for Economic Co-operation and Development (OECD) countries, by gross domestic product (GDP) per capita: 2008

Expenditures per student

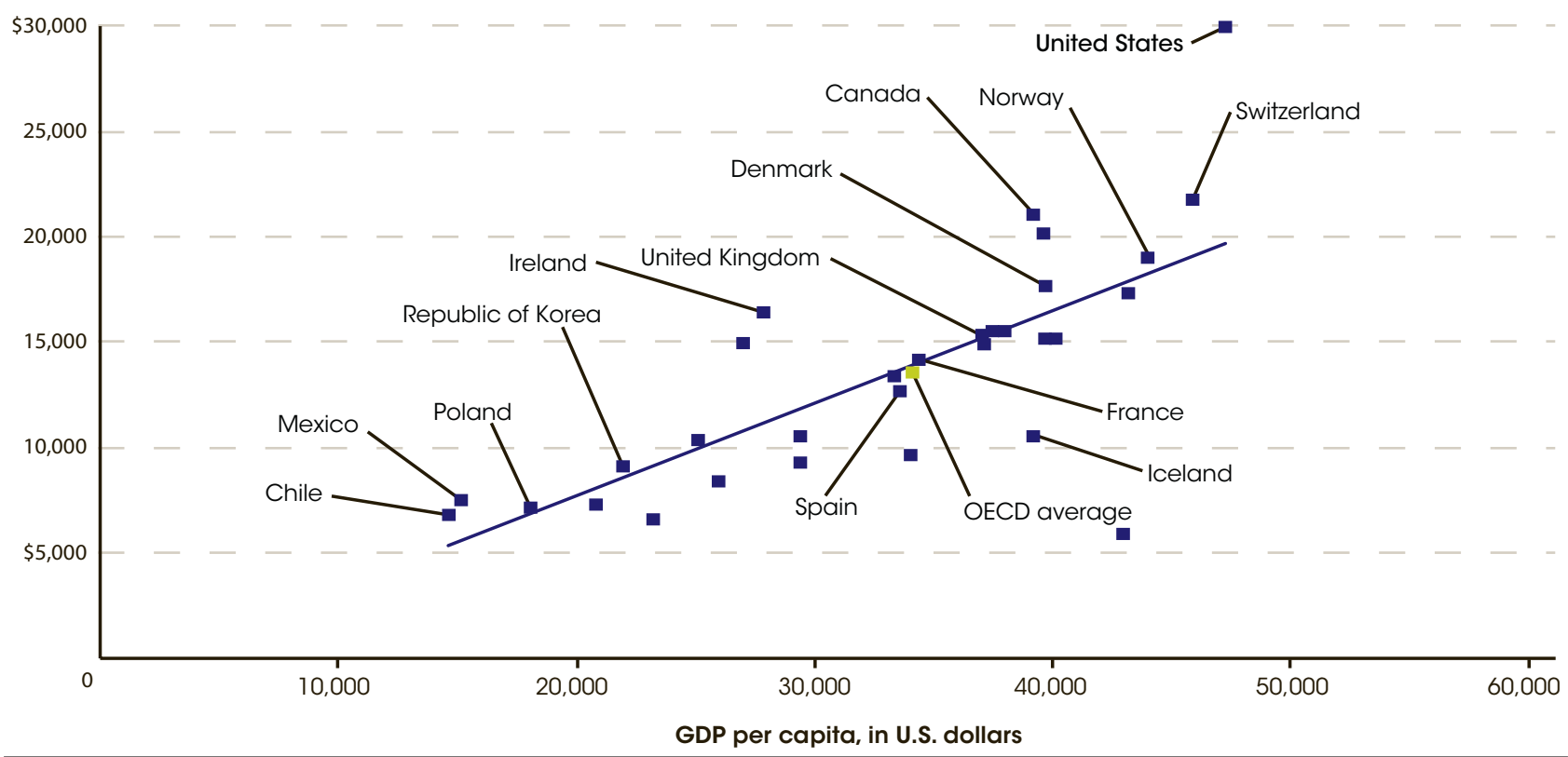

- Linear relationship between spending and country wealth for 31 OECD countries reporting data $\left(\right.$ postsecondary): $r^{2}=.53 ;$ slope $=.44$; intercept $=$ $-1,082$.

NOTE: Luxembourg data are excluded because they do not report data for postsecondary institutions. For more information on classification of expenditures for international comparisons, see Appendix C - Finance. For more information on the International Standard Classification of Education (ISCED), see Appendix C - International Education Definitions.

SOURCE: Organization for Economic Co-operation and Development (OECD), Center for Educational Research and Innovation. (201 1 ). Education at a Glance, 2017: OECD Indicators, tables B1.2 and X2.1. 


\section{The average grade 4 reading score in 2011 was not measurably different from that in 2009. The average grade 8 score, however, was 1 point higher in 2011 than in 2009.}

The National Assessment of Educational Progress (NAEP) most recently assessed 4th- and 8th-grade students' reading skills in 2011, and 12th-grade students were most recently assessed in 2009. In 2011, the average reading score for 4th-grade students (221) was not measurably different from the 2009 score (221), but it was higher than the scores on assessments between 1992 (217) and 2005 (219) (see table A-23-1). For 8th-grade students, the average reading score in 2011 (265) was 1 point higher than in 2009 (264) and 5 points higher than in 1992 (260), but was not always measurably different from scores on assessments given in other years. In 2009, the average reading score for 12th-grade students (288) was 2 points higher than in 2005 (286) but 4 points lower than in 1992 (292).

In 2011, the percentages of 4th-grade students performing at or above the Basic (67 percent), at or above the Proficient (34 percent), and at the Advanced (8 percent) achievement levels in reading showed no measurable change from 2009, but were higher than in 1992. Among 8th-grade students, the percentage performing at or above Basic in 2011 (76 percent) was not measurably different from that in 2009 ( 75 percent) but was higher than the percentage in 1992 (69 percent). A higher percentage of 8th-grade students performed at or above Proficient in 2011 (34 percent) than in 2009 (32 percent) and 1992 (29 percent). The percentage at the Advanced level in 2011 (3.4 percent) was half a percentage point higher than the percentage performing at Advanced in 2009 (2.8 percent) but was not measurably different from the percentage in 1992 (2.9 percent). Among 12th-grade students, the percentage performing at or above Basic (74 percent) in 2009 was not significantly different from the percentage in 2005 (73 percent), but was lower than the percentage in 1992 (80 percent). The percentage at or above Proficient was higher in 2009 (38 percent) than in 2005 (35 percent) but not significantly different from the percentage in 1992 (40 percent). There was no measurable change in the percentage of 12th-graders performing at Advanced from 2005 to 2009 (5 percent each), although the 2009 percentage was 1 percentage point higher than that in 1992.

At grade 4, the average reading scores in 2011 for White, Black, Hispanic, Asian/Pacific Islander, and American Indian/Alaska Native students were not measurably different from their scores in 2009 (see table A-23-2). The 2011 grade 4 reading scores for White, Black, Hispanic, and Asian/Pacific Islander students were, however, higher than their scores in 1992. At grade 8, average reading scores for White, Black, and Hispanic students were higher in 2011 than their scores in any of the previous assessment years. At grade 12, average scores showed no measurable differences from 1992 to 2009 for White, Black, Hispanic, Asian/Pacific Islander, and American Indian/Alaska Native students.

NAEP results also permit state-level comparisons of the reading abilities of 4th- and 8th-grade students in public schools. While there was no measurable change from 2009 to 2011 in the overall average score for 4th-grade public school students in the nation, average scores were higher in 2011 than in 2009 in Alabama, Hawaii, Maryland, and Massachusetts, and scores were lower in 2011 in Missouri and South Dakota (see table A-23-3). At grade 8 , although the average score for public school students in the nation was 2 points higher in 2011 than in 2009, only ten states had higher scores in 2011 than in 2009. These states were Colorado, Connecticut, Hawaii, Idaho, Maryland, Michigan, Montana, Nevada, North Carolina, and Rhode Island. In the remaining states and the District of Columbia, scores showed no measurable change.

Tables A-23-1, A-23-2, and A-23-3

Glossary: Achievement levels

\section{Technical Notes}

National Assessment of Educational Progress (NAEP) reading scores range from 0 to 500 . The 12 th-grade NAEP reading assessment was not administered in 2003,2007 , or 2011. The achievement levels define what students should know and be able to do: Basic indicates partial mastery of fundamental skills, Proficient indicates demonstrated competency over challenging subject matter, and Advanced indicates superior performance.
Testing accommodations (e.g., extended time, small group testing) for children with disabilities and English language learners were not permitted in 1992. For more information on NAEP, see Appendix B - Guide to Sources. Race categories exclude persons of Hispanic ethnicity. For more information on race/ethnicity, see Appendix C Commonly Used Measures. 
Figure 23-1. Average reading scale scores of 4th-, 8th-, and 12th-grade students: Selected years, 1992-2011

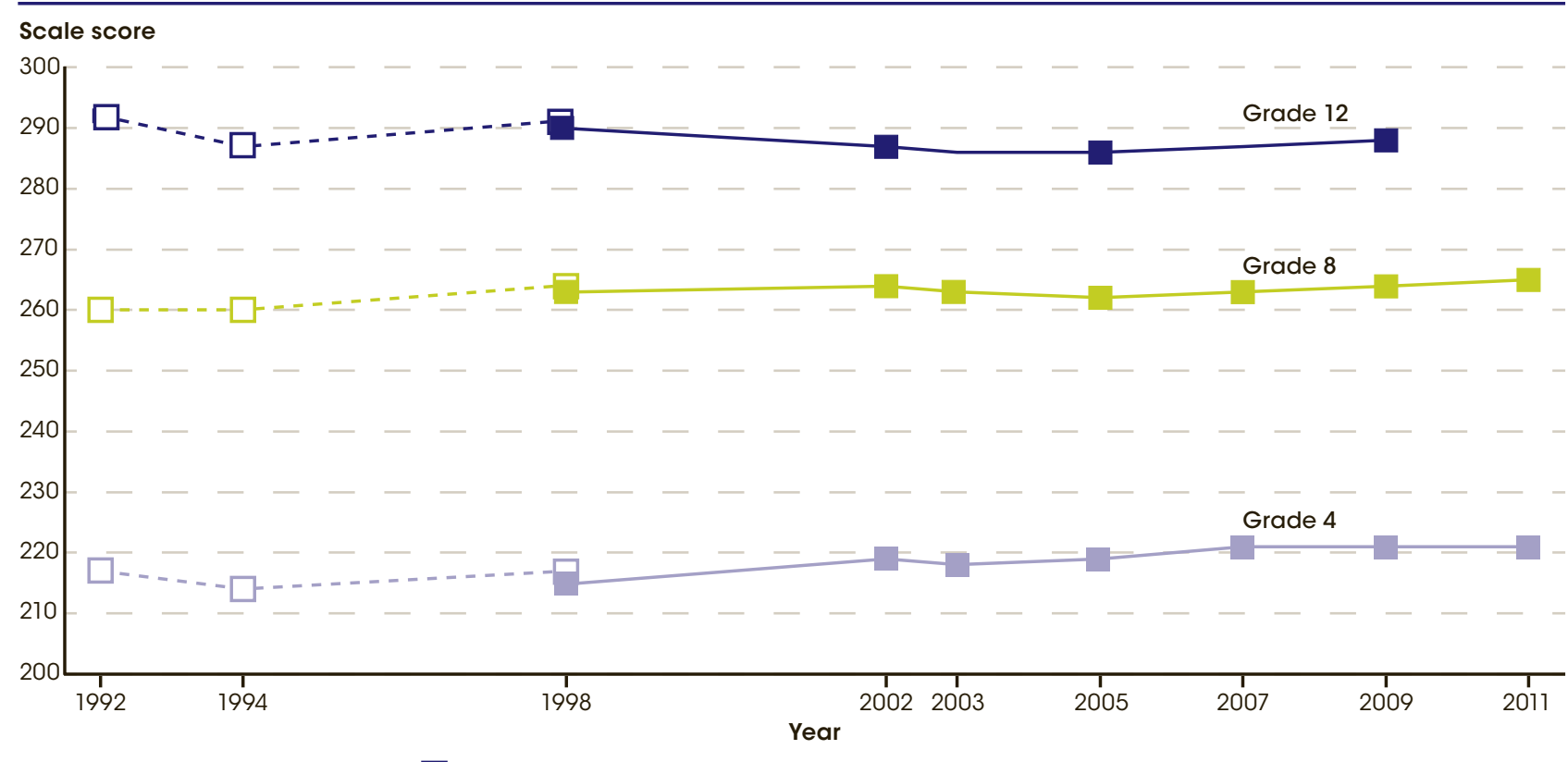

- $\square$ - Accomodations not permitted $\rightarrow$ - Accomodations permitted

NOTE: The National Assessment of Educational Progress (NAEP) reading scale ranges from 0 to 500 . Student assessments are not designed to permi comparisons across subjects or grades. Testing accommodations (e.g., extended time, small group testing) for children with disabilities and English language learners were not permitted in 1992 and 1994; students were tested with and without accommodations in 1998. The 12th-grade NAEP reading assessment was not administered in 2003, 2007, or 2011. For more information on NAEP, see Appendix B - Guide to Sources.

SOURCE: U.S. Department of Education, National Center for Education Statistics, National Assessment of Educational Progress (NAEP), selected years, 1992-2011 Reading Assessments, NAEP Data Explorer.

Figure 23-2. Percentage distribution of 4th- and 8th-grade students across National Assessment of Educational Progress reading achievement levels: Selected years, 1992-2011

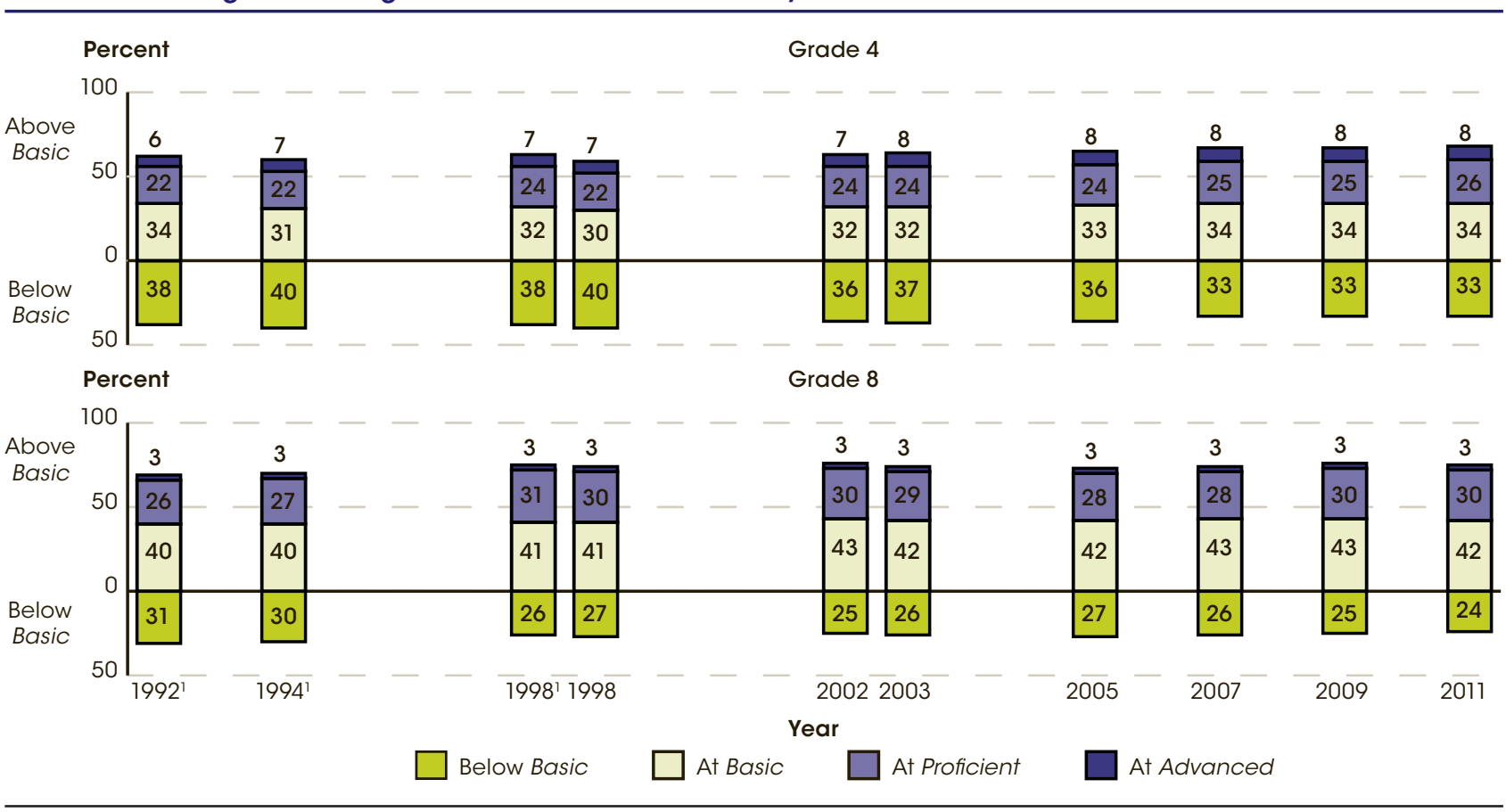

${ }^{1}$ Testing accommodations (e.g., extended time, small group testing) for children with disabilities and English language learners were not permitted during these assessments. Students were tested with and without accommodations in 1998.

NOTE: Achievement levels define what students should know and be able to do: Basic indicates partial mastery of fundamental skills, Proficient indicates demonstrated competency over challenging subject matter, and Advanced indicates superior performance. Detail may not sum to totals because of rounding. For more information on the National Assessment of Educational Progress (NAEP), see Appendix B - Guide to Sources.

SOURCE: U.S. Department of Education, National Center for Education Statistics, National Assessment of Educational Progress (NAEP), selected years,

1992-2011 Reading Assessments, NAEP Data Explorer. 


\section{At grades 4 and 8, the average mathematics scores in 2011 were higher than the average scores for those grades in all previous assessment years.}

In 2011, the average National Assessment of Educational Progress (NAEP) mathematics scores for 4th-grade and 8th-grade students were higher than their average scores in all previous assessment years (see table A-24-1). From 1990 to 2011, the average 4th-grade NAEP mathematics score increased by 28 points, from 213 to 241 . During that same time period, the average 8 th-grade score increased by 21 points, from 263 to 284 . Twelfth-graders were most recently assessed in 2009; in that year, the average 12th-grade mathematics score was 3 points higher than in 2005, the first year that the revised assessment was administered.

In 2011, some 82 percent of 4th-grade students performed at or above the Basic achievement level, 40 percent performed at or above the Proficient level, and 7 percent performed at the Advanced level. While the percentage of students at or above the Basic level in 2011 was not measurably different from that in 2009 or 2007 (both 82 percent), it was higher than the percentage in 1990 (50 percent). Higher percentages of 4 th-grade students performed at or above Proficient and at Advanced in 2011 than in all previous assessment years. In 2011, some 73 percent of 8th-grade students performed at or above Basic, 35 percent performed at or above Proficient, and 8 percent performed at Advanced. The percentage of 8 th-grade students performing at or above Proficient increased by 1 percentage point from 2009 to 2011 . The percentages at or above Basic and at Advanced in 2011 showed no measurable change from 2009, but were higher than the percentages in all assessment years prior to 2009. The percentages of 12th-grade students performing at or above Basic (64 percent) and at or above Proficient (26 percent) were each 3 percentage points higher in 2009 than in 2005. The percentages performing at the Advanced level in 2005 and 2009 were not measurably different ( 2 and 3 percent, respectively).
At grade 4, the average mathematics scores in 2011 for White (249), Black (224), and Hispanic students (229) were higher than their scores in both 2009 and 1990 (see table A-24-2). The 2011 score for Asian/Pacific Islander 4 th-graders (256) was not measurably different from the 2009 score (255), but was higher than the score in 1990. At grade 8, the average mathematics score for Hispanic students was 4 points higher in 2011 (270) than in 2009 (266), but the scores for White, Black, and Asian/Pacific Islander students did not measurably change. The 2011 scores for these four groups were, however, higher than their scores in 1990. The 2011 score for American Indian/ Alaska Native 8th-grade students was not measurably different from their score in 2009. At grade 12, average mathematics scores were higher in 2009 than in 2005 for all racial/ethnic groups. For example, the average score for Asian/Pacific Islander 12th-grade students increased by 13 points, and the average score for American Indian/Alaska Native students increased by 10 points.

NAEP results also permit state-level comparisons of the mathematics achievement of 4th- and 8th-grade students in public schools. The average mathematics scores for 4th-grade public school students increased from 2009 to 2011 in eight states (Alabama, Arizona, Georgia, Hawaii, Maryland, New Mexico, Rhode Island, and Wyoming) and the District of Columbia and decreased in New York (see table A-24-3). At grade 8, scores were higher in 2011 than in 2009 in 12 states (Arkansas, Colorado, Hawaii, Maine, Mississippi, Nevada, New Mexico, Ohio, Oklahoma, Rhode Island, Texas, and West Virginia) and the District of Columbia. The average 8th-grade score in Missouri decreased.

Tables A-24-1, A-24-2, and A-24-3

Glossary: Achievement levels

\section{Technical Notes}

NAEP mathematics scores range from 0 to 500 for grades 4 and 8 . The framework for the 12 th-grade mathematics assessment was revised in 2005; as a result, the 2005 and 2009 results cannot be compared with those from previous years. At grade 12, mathematics scores on the revised assessment range from 0 to 300 . The achievement levels define what students should know and be able to do: Basic indicates partial mastery of fundamental skills, Proficient indicates demonstrated competency over challenging subject matter, and Advanced indicates superior performance. Testing accommodations (e.g., extended time, small group testing) for children with disabilities and English language learners were not permitted in 1990 and 1992. Students in grades 4 and 8 were tested with and without accommodations in 1996. For more information on NAEP, see Appendix B - Guide to Sources. Race categories exclude persons of Hispanic ethnicity. For more information on race/ethnicity, see Appendix C - Commonly Used Measures. 


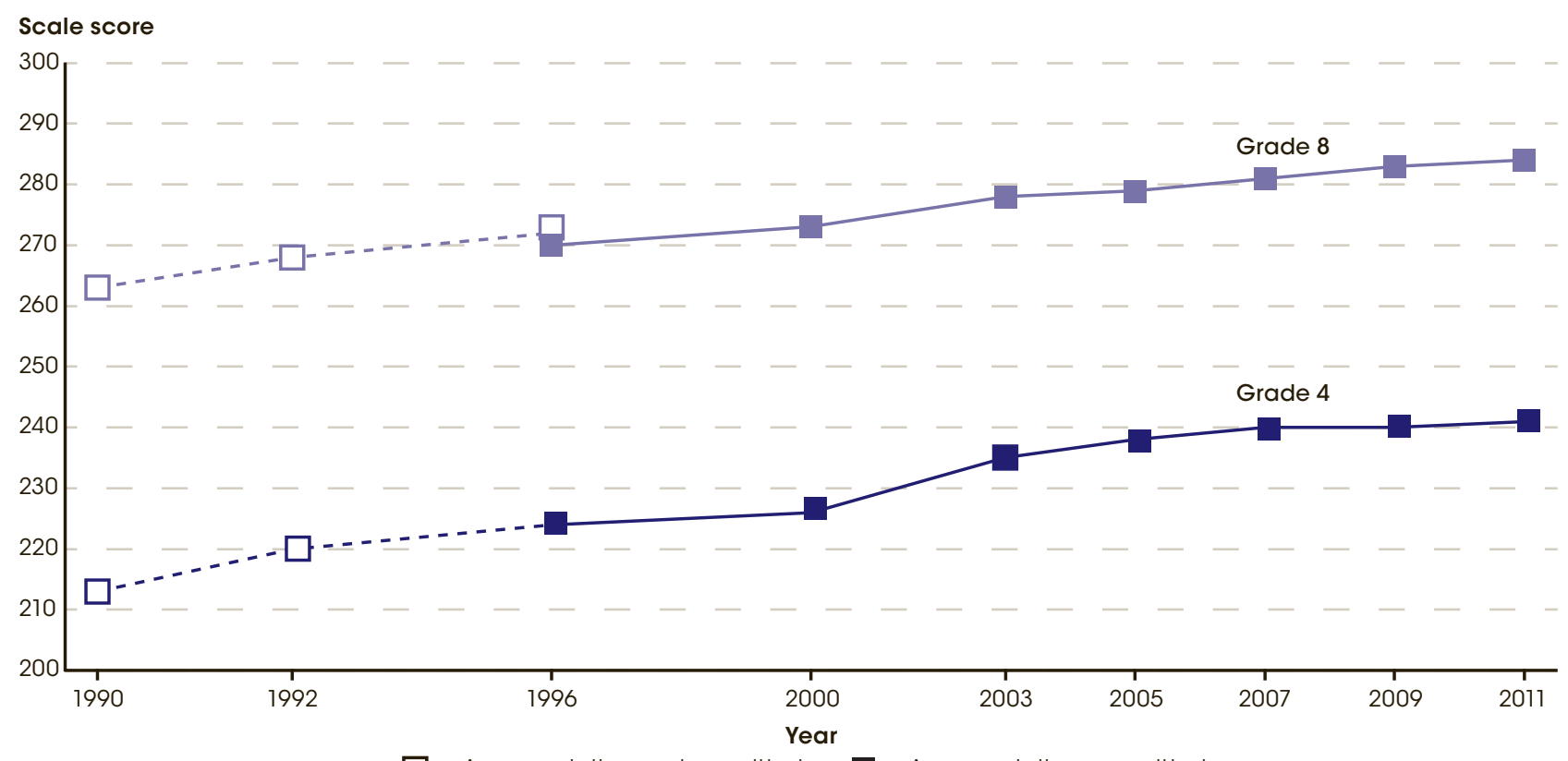

- Є- Accomodations not permitted - Accomodations permitted

NOTE: At grades 4 and 8, the National Assessment of Educational Progress (NAEP) mathematics scale ranges from 0 to 500 . Testing accommodations (e.g., extended time, small group testing) for children with disabilities and English language learners were not permitted in 1990 and $1992 ;$ students were tested with and without accommodations in 1996. For more information on NAEP, see Appendix B - Guide to Sources.

SOURCE: U.S. Department of Education, National Center for Education Statistics, National Assessment of Educational Progress (NAEP), selected years, 1990-2011 Mathematics Assessments, NAEP Data Explorer.

Figure 24-2. Percentage distribution of 4th- and 8th-grade students across National Assessment of Educational Progress mathematics achievement levels: Selected years, 1990-2011

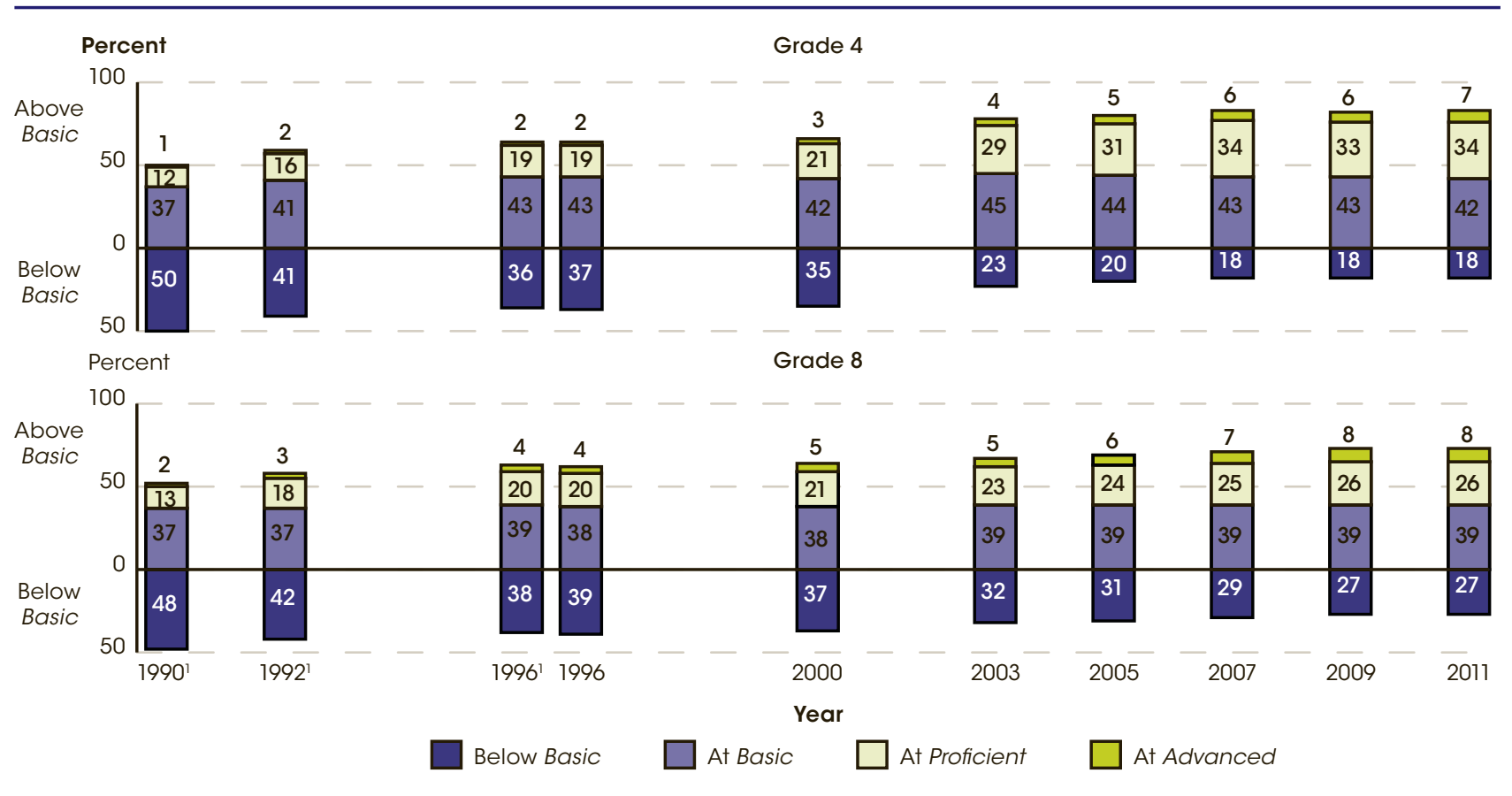

${ }^{1}$ Testing accommodations (e.g., extended time, small group testing) for children with disabilities and English language learners were not permitted during these assessments. Students were tested with and without accommodations in 1996.

NOTE: Achievement levels define what students should know and be able to do: Basic indicates partial mastery of fundamental skills; Proficient indicates demonstrated competency over challenging subject matter; and Advanced indicates superior performance. Detail may not sum to totals because of rounding. For more information on the National Assessment of Educational Progress (NAEP), see Appendix B - Guide to Sources.

SOURCE: U.S. Department of Education, National Center for Education Statistics, National Assessment of Educational Progress (NAEP), selected years, 1990-201 1 Mathematics Assessments, NAEP Data Explorer. 


\section{At grade 12, the NAEP U.S. history score was 2 points higher in 2010 than in 1994, while the geography score was 2 points lower. There was no measurable difference in the civics score from 1998 to 2010.}

In 2010, the National Assessment of Educational Progress (NAEP) assessed students' knowledge of U.S. history, geography, and civics in grades 4,8 , and 12 . For U.S. history, the average scores were higher in 2010 than in 1994 at all grades (see table A-25-1). From 1994 to 2010, the U.S. history scores increased from 205 points to 214 points for 4th-grade students, from 259 points to 266 points for 8 th-grade students, and from 286 points to 288 points for 12 th-grade students. At grade 12 , the U.S. history scores were higher in 2010 than in 1994 for White (296 vs. 292 points), Hispanic (275 vs. 267 points), and Asian/Pacific Islander students (293 vs. 283 points). In 2010, the scores for White and Asian/Pacific Islander 12th-grade students (296 and 293, respectively) were not measurably different from each other, but both were higher than the scores for Black (268), Hispanic (275), and American Indian/Alaska Native students (278). The grade 12 U.S. history score for male students was 2 points higher in 2010 (290) than in 1994 (288), while the 2010 score for female students was not measurably different from the 1994 score. Male 12th-graders scored 4 points higher than female 12th-graders on the 2010 U.S. history assessment.

For geography, the average score for 4th-grade students was higher in 2010 (213) than in 1994 (206) (see table A-25-2), while the 2010 average score for 8 th-grade students was not measurably different from the 1994 score. For 12th-grade students, the score was lower in 2010 (282) than in 1994 (285). At grade 12, none of the racial/ethnic groups had geography scores that were measurably different between 1994 and 2010. In 2010, White students had the highest average geography score (290), followed by Asian/Pacific Islander (285), American Indian/Alaska Native (277), Hispanic (270), and Black (261) students. The geography score for male 12 th-graders was lower in 2010 (285) than in 1994 (288), while the 2010 score for female 12 th-graders was not measurably different from the 1994 score. Male 12th-graders scored 5 points higher than female 12th-graders on the 2010 geography assessment.
For civics, the average score for 4 th-grade students was higher in 2010 (157) than in 1998 (150), the first year the assessment was administered (see table A-25-3), but the scores for 8 th-grade and 12th-grade students were not measurably different between 2010 and 1998. At grade 12, the average civics score for Hispanic students was higher in 2010 (137) than in 1998 (132), but the scores for the other racial/ethnic groups were not measurably different between the two years. In 2010, the average scores of White (156) and Asian/Pacific Islander 12th-graders (153) students were not measurably different from each other, and both were higher than the average scores for Black (127) and Hispanic 12th-graders (137). The average civics score for female 12th-grade students was lower in 2010 (148) than in 1998 (152), while the 2010 and 1998 civics scores for male 12 th-grade students were not measurably different.

In 2010, in each of the three subjects, less than one-quarter of 12th-grade students performed at or above the Proficient achievement level (see table A-25-4). At grade 12 , the percentages of students performing at or above Basic ( 45 percent) and at or above Proficient (12 percent) on the 2010 U.S. history assessment were not measurably different from the percentages performing at or above Basic and at or above Proficient on the 1994 assessment. On the geography assessment, the percentage of students performing at or above Basic in 2010 (70 percent) was not measurably different from the percentage performing at or above Basic in 1994. The percentage performing at or above Proficient in 2010 (20 percent) was lower than in 1994 (27 percent). On the 2010 civics assessment, the percentages of students performing at or above Basic (64 percent) and at or above Proficient (24 percent) were not measurably different from the percentages performing at or above Basic and at or above Proficient in 1998.

Tables A-25-1, A-25-2, A-25-3, and A-25-4

Glossary: Achievement levels

\section{Technical Notes}

National Assessment of Educational Progress (NAEP) U.S. history and geography scores range from 0 to 500. Civics scores range from 0 to 300 . The NAEP achievement levels define what students should know and be able to do. Basic indicates partial mastery of fundamental skills, and Proficient indicates demonstrated competency over challenging subject matter. Testing accommodations (e.g., extended time, small group testing) for children with disabilities and English language learners were not permitted in 1994. Students were tested with and without accommodations in the 2001 U.S. history and geography assessments. Race categories exclude persons of Hispanic ethnicity. For more information on race/ethnicity, see Appendix C - Commonly Used Measures. For more information on NAEP, see Appendix B - Guide to Sources. 
Figure 25-1. Average scale scores of 4th-, 8th-, and 12th-grade students, by subject: Selected years, 1994-2010

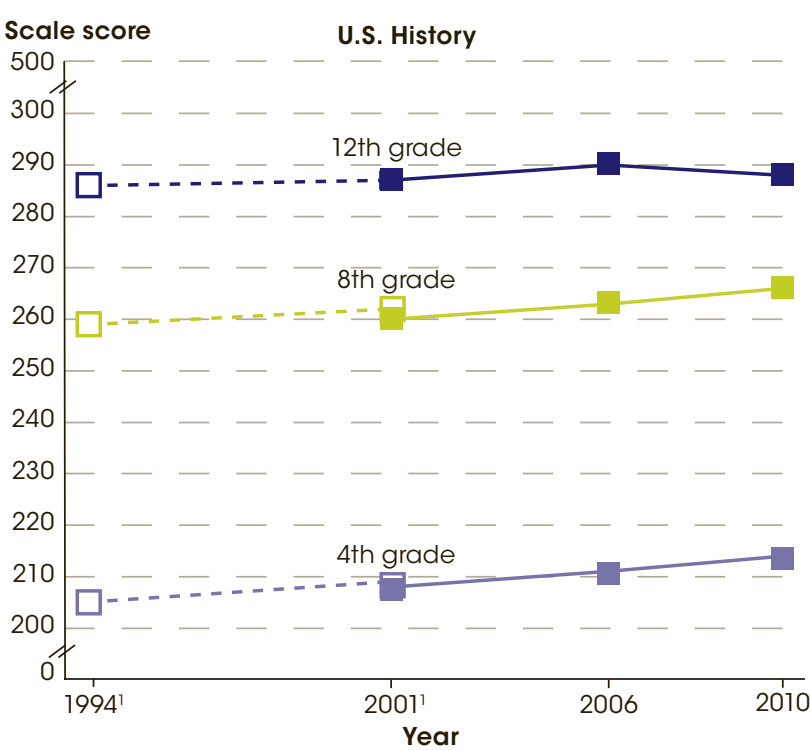

$-\square-$ Accomodations not permitted

- Accomodations permitted

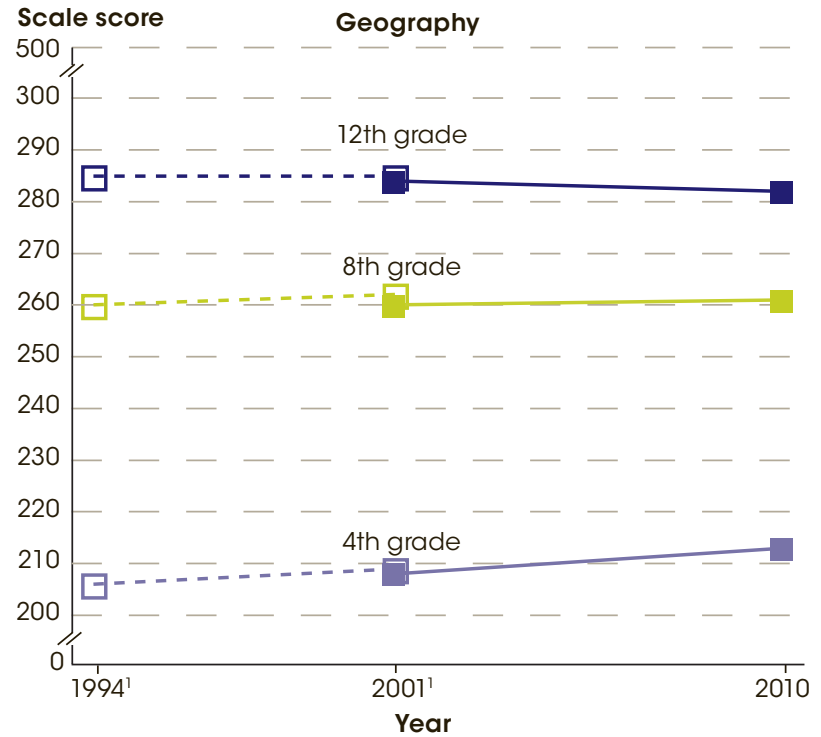

$-\square-$ Accomodations not permitted

- Accomodations permitted

Testing accommodations (e.g., extended time, small group testing) for children with disabilities and English language learners were not permitted in 1994. Students were tested with and without accommodations in 2001.

NOTE: National Assessment of Educational Progress (NAEP) U.S. history and geography scores range from 0 to 500 . For more information on the NAEP, see Appendix B - Guide to Sources.

SOURCE: U.S. Department of Education, National Center for Education Statistics, National Assessment of Educational Progress (NAEP), selected years, 1994-2010 U.S. History Assessments, and selected years, 1994-2010 Geography Assessments, NAEP Data Explorer.

Figure 25-2. Percentage of 12th-grade students at selected National Assessment of Educational Progress achievement levels, by subject: 1994, 1998, and 2010

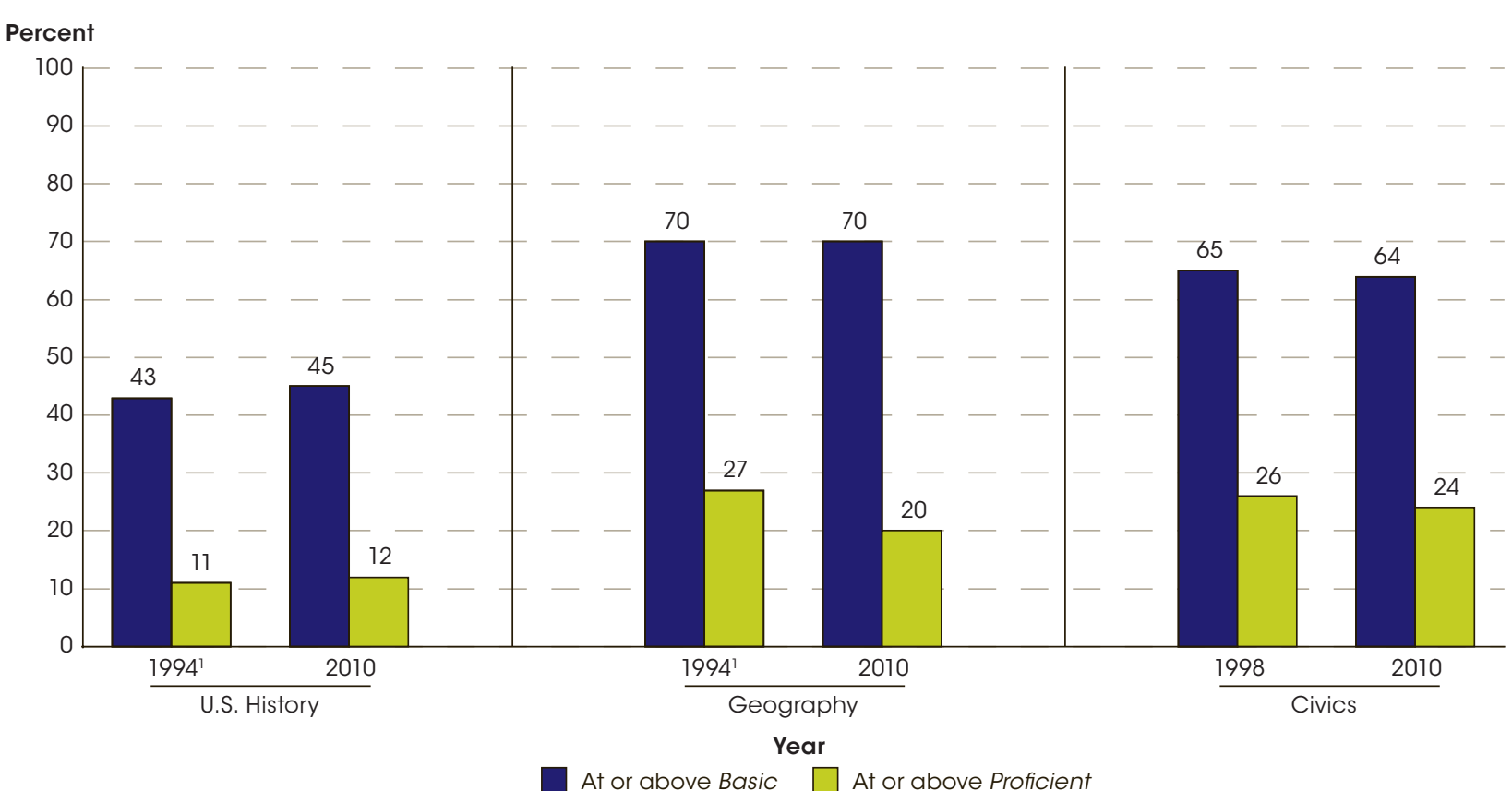

${ }^{1}$ Testing accommodations (e.g., extended time, small group testing) for children with disabilities and English language learners were not permitted in 1994.

NOTE: Achievement levels define what students should know and be able to do. Basic indicates partial mastery of fundamental skills, and Proficient indicates demonstrated competency over challenging subject matter. For more information on the National Assessment of Educational Progress (NAEP), see Appendix B - Guide to Sources.

SOURCE: U.S. Department of Education, National Center for Education Statistics, National Assessment of Educational Progress (NAEP), 1994 and 2010 U.S History Assessments, 1994 and 2010 Geography Assessments, and 1998 and 2010 Civics Assessments, NAEP Data Explorer. 


\section{International Reading, Mathematics, and Science Proficiency}

\section{In 2009, the percentage of high-performing 15-year-olds in the United States was higher in reading literacy, lower in mathematics literacy, and not measurably different in science literacy than the respective percentages in the OECD countries on average.}

The Program for International Student Assessment (PISA) is an international assessment that reports on the performance of 15 -year-olds in reading, mathematics, and science literacy using both average scale scores and the distribution of students reaching proficiency levels. Proficiency levels for each subject are associated with descriptions of tasks students are expected to complete at each level, with level 2 serving as the baseline level at which students begin to demonstrate the competencies enabling them to participate effectively in life situations, and levels 5 and above representing the high end of the skill distribution. This indicator presents PISA data on the low performers (students scoring below level 2) and on the high performers (students scoring at level 5 and above).

In 2009, the percentage of U.S. low performers on the reading literacy scale (18 percent) was not measurably different from the percentage of low performers in the Organization for Economic Co-operation and Development (OECD) countries on average (19 percent) (see table A-26-1). In 2009, a higher percentage of U.S. students (10 percent) were high performers in reading literacy than were students in the OECD countries on average (8 percent). From 2000 to 2009, there was no measurable change in the percentage of U.S. low performers in reading literacy; however, the percentage of low performers in the OECD countries on average was higher in 2000 (19 percent) than in 2009 (18 percent). While there was no measurable change in the percentage of U.S. high performers in reading literacy, the percentage of high performers in the OECD countries on average was higher in 2000 (9 percent) than in 2009 (8 percent).

In 2009, the percentage of U.S. low performers on the mathematics literacy scale (23 percent) was not measurably different from the percentage of low performers in the OECD countries on average (22 percent); however, a lower percentage of U.S. students were high performers on the mathematics literacy scale (10 percent) than were students in the OECD countries on average (13 percent) (see table A-26-2). While no measurable change was seen in the percentage of U.S. low performers from 2003 to 2009 (2003 being the first time point to which PISA 2009 mathematics literacy scores can be compared), the percentage of low performers in the OECD countries on average was lower in 2003 (21 percent) than in 2009 (22 percent). There was no measurable change in the percentage of U.S. high performers on the mathematics literacy scale from 2003 to 2009; however, the percentage of high performers in the OECD countries on average was higher in 2003 (15 percent) than in 2009 (13 percent).

In 2009, the percentages of both the U.S. low as well as high performers on the science literacy scale were not measurably different from the corresponding percentages in the OECD countries on average (18 percent for low and 9 percent for high performers, respectively) (see table A-26-3). On the science literacy scale, the percentage of low performers was higher in 2006 compared to 2009 for both the United States (24 to 18 percent) and in the OECD countries on average (20 to 18 percent) (2006 being the first time point to which PISA 2009 science literacy scores can be compared). While there was no measurable change in the percentage of U.S. high performers in science literacy between these two time points, the percentage of high performers across OECD countries on average was higher in 2006 than in 2009 when comparing unrounded data.

Tables A-26-1, A-26-2, and A-26-3

\section{Technical Notes}

Participants in PISA 2009 include 65 countries and other education systems, including 34 OECD countries, which represent many of the world's advanced and emerging economies. The OECD average used for comparisons across countries in 2009 is the average of the national averages of the $34 \mathrm{OECD}$ member countries, with each country weighted equally. The PISA 2000 and 2009 OECD averages used in the analysis of trends in reading literacy are based on the averages of 27 OECD countries reporting comparable data in both years. The PISA 2003 and 2009 OECD averages used in the analysis of trends in mathematics literacy are based on the averages of 29 OECD countries reporting comparable data in both years. The PISA 2006 and 2009 OECD averages used in the analysis of trends in science literacy are based on the averages of all 34 OECD countries. Scale scores range from 0 to 1,000 . For more information on PISA proficiency levels, see Appendix B - Guide to Sources. 
Figure 26-1. Percentage of 15-year-old students on the combined reading literacy scale in the United States and Organization for Economic Co-operation and Development countries, by selected Program for International Student Assessment proficiency levels: 2000 and 2009

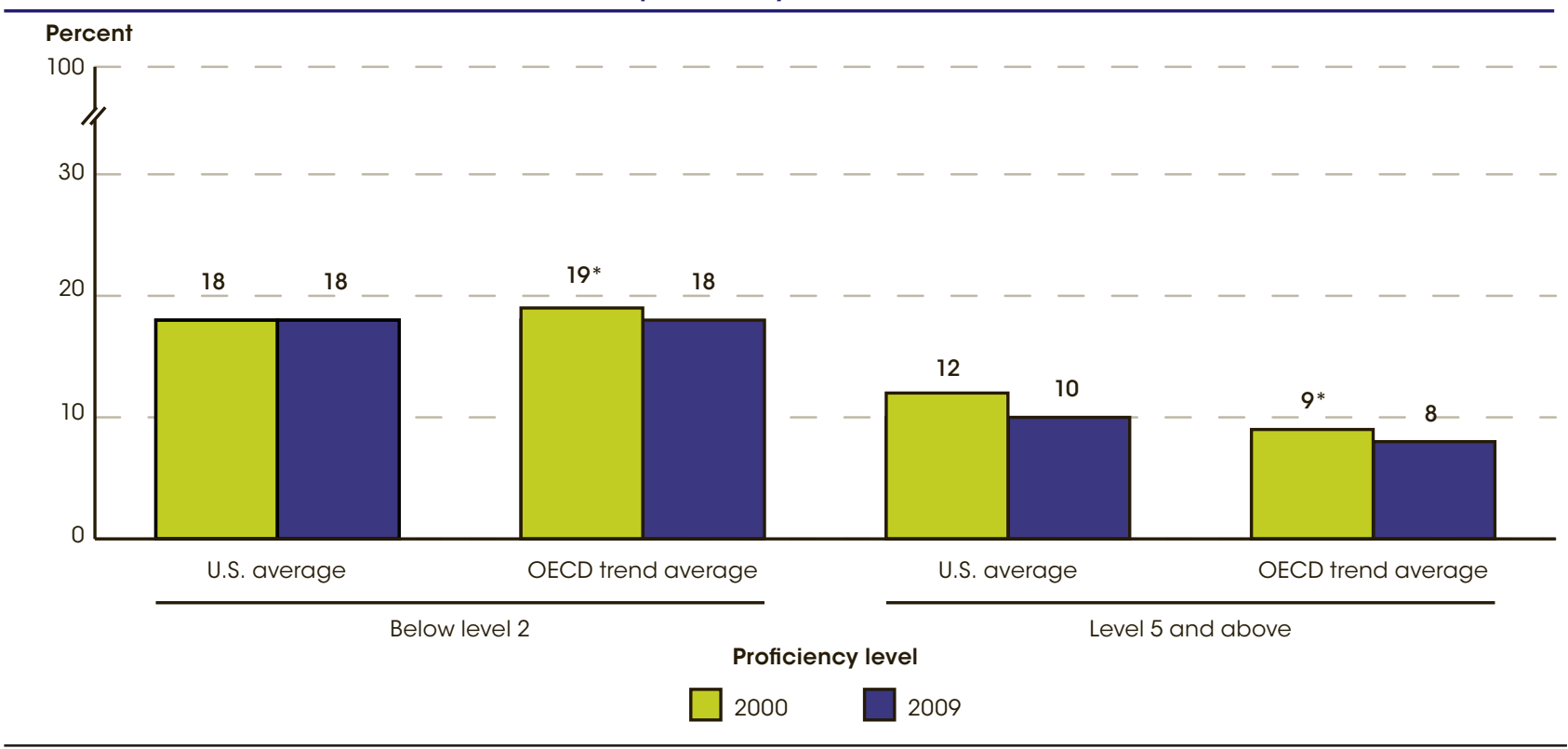

$* p<.05$. Significantly different from average in 2009 at the .05 level of statistical significance.

NOTE: The Organization for Economic Co-operation and Development (OECD) trend average used for the analysis of reading literacy trends is based on the averages of 27 OECD countries with comparable data for 2000 and 2009, with each country weighted equally. In the Program for International Student Assessment (PISA), proficiency in reading was defined in terms of levels based on student performance scores on each literacy scale. Reading literacy was assessed along a continuum, with proficiency below level 2 indicative of the low-performing students and proficiency level 5 and above indicative of the high-performing students. In reading, proficiency below level 2 is defined by scoring below 407 , and proficiency at level 5 and above is defined by scoring 626 and above. Scores are reported on a scale from 0 to 1,000. For more information on PISA, see Appendix B - Guide to Sources. SOURCE: Fleischman, H.L., Hopstock, P.J., Pelczar, M.P., and Shelley, B.E. (2010). Highlights From PISA 2009: Performance of U.S. 15-Year-Old Students in Reading, Mathematics, and Science Literacy in an International Context (NCES 2011-004), table R7A; OECD. (2010). PISA 2009 Results: Learning Trends Changes in Student Performance Since 2000 (Volume V), table V.2.2; and OECD, previously unpublished tabulations (October 2011).

Figure 26-2. Percentage of 15-year-old students on the mathematics and science literacy scales in the United States and Organization for Economic Co-operation and Development countries, by selected Program for International Student Assessment proficiency levels: 2003, 2006, and 2009

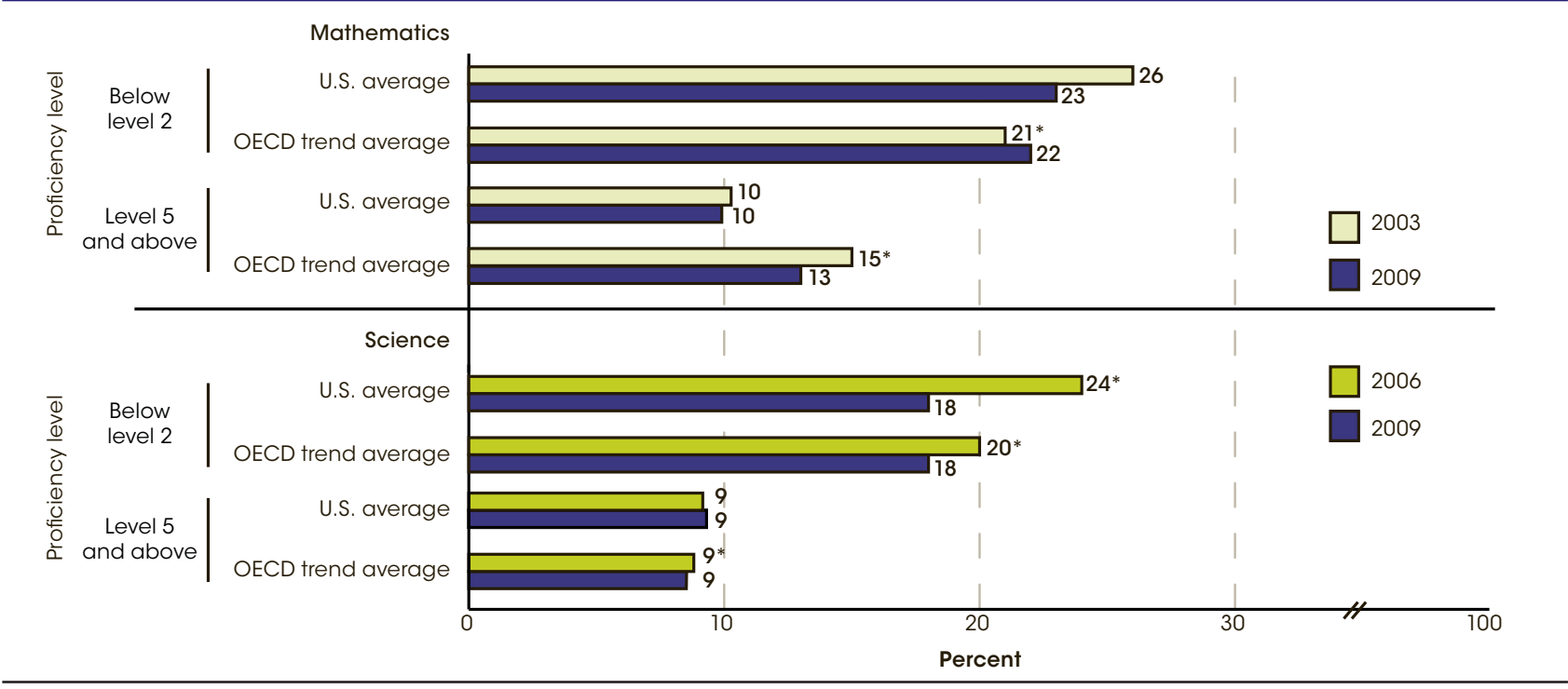

$* p<.05$. Significantly different from the average in 2009 at the .05 level of statistical significance.

NOTE: The Organization for Economic Co-operation and Development (OECD) trend average used for the analysis of mathematics literacy trends is based on the averages of the 29 OECD countries with comparable data for 2003 and 2009 , with each country weighted equally. The OECD trend average used for the analysis of science literacy trends is based on the averages of the 34 OECD countries with comparable data for 2006 and 2009 , with each country weighted equally. In the Program for International Student Assessment (PISA), proficiency in both mathematics and science was defined in terms of levels based on student performance scores. Mathematics literacy was assessed along a continuum, with proficiency below level 2 indicative of the low-performing students and proficiency level 5 and above indicative of the high-performing students. In mathematics, proficiency below level 2 is defined by scoring below 420, and proficiency level 5 and above is defined by scoring 607 and above. Science literacy was assessed along a continuum, with proficiency below level 2 indicative of the low-performing students and proficiency level 5 and above indicative of the high-performing students. In science, proficiency below level 2 is defined by scoring below 410, and proficiency level 5 and above is defined by scoring 633 and above. Scores are reported on a scale from 0 to 1,000. For more information on PISA, see Appendix B - Guide to Sources.

SOURCE: Fleischman, H.L., Hopstock, P.J., Pelczar, M.P., and Shelley, B.E. (2010). Highlights From PISA 2009: Performance of U.S. 15-Year-Old Students in Reading, Mathematics, and Science Literacy in an International Context (NCES 2011-004), tables M4A and S4A; OECD. (2010). PISA 2009 Results: Learning Trends - Changes in Student Performance Since 2000 (Volume V), tables V.3.2 and V.3.5; and OECD, previously unpublished tabulations (October 201 1). 


\section{In 2010, some 40 percent of high school seniors participated in athletics, including 44 percent of males and 36 percent of females.}

In 2010, some 40 percent of high school seniors participated in athletics as an extracurricular activity, which was higher than the percentage who participated in other school clubs/activities (32 percent), music/ performing arts (23 percent), academic clubs (14 percent), newspaper/yearbook (10 percent), and student council/ government (9 percent) (see table A-27-1). Since 1990, there has been no measurable change in the participation of high school seniors in the extracurricular activities of newspaper/yearbook, music/performing arts, academic clubs, and other school clubs/activities. However, the percentage of high school seniors who participated in athletics in 2010 (40 percent) was higher than the percentage who participated in 1990 (36 percent), and the percentage who participated in student council/ government was lower in 2010 (9 percent) than in 1990 (11 percent).

As was the case with high school seniors in 2010, a higher percentage of sophomores participated in athletics than in other extracurricular activities. Forty-three percent of high school sophomores participated in athletics in 2010, some 28 percent participated in other clubs/activities, 23 percent participated in music/performing arts, and 4 percent participated on a newspaper/yearbook.

In 2010, a higher percentage of female than male high school seniors participated on a newspaper/yearbook (13 vs. 6 percent), in music/performing arts (28 vs. 18 percent), in academic clubs (18 vs. 11 percent), in student council/government (12 vs. 6 percent), and in other school clubs/activities (41 vs. 24 percent), while a higher percentage of male than female high school seniors participated in athletics (44 vs. 36 percent). For each of these activities, other than for athletics and student council/government, the participation rates were not measurably different in 2010 than they were in 1990. For athletics, the percentage of female high school seniors who participated was higher in 2010 (36 percent) than in 1990 (28 percent). For student council/government, the percentage of male high school seniors who participated was lower in 2010 (6 percent) than in 1990 (9 percent).

High school seniors who planned on attending college had higher participation rates in various extracurricular activities in 2010 than those who did not have college plans (see table A-27-2). For example, 43 percent of those who had college plans participated in athletics, compared to 25 percent of those who did not plan to attend college. Among those with plans to attend college, 37 percent participated in other clubs/activities, 25 percent participated in music/performing arts, 17 percent participated in academic clubs, and 11 percent (each) participated in student council/government and on a newspaper/yearbook. For those who did not plan on attending college, the participation rates were 15 percent for other school clubs/activities, 14 percent for music/ performing arts, 5 percent for academic clubs, 2 percent for student council/government, and 5 percent for newspaper/yearbook.

Tables A-27-1 and A-27-2

Glossary: High school

\section{Technical Notes}

Percentages reflect the proportion of students who responded that they participated in these activities "to a considerable extent" or "to a great extent." The 10th-grade and 12th-grade data for "other school clubs/activities" are not comparable because the available response alternatives were not the same. The response rates for Monitoring the Future (MTF) do not meet National Center for Education Statistics (NCES) standards. For more information on MTF, see Appendix B - Guide to Sources. 
Figure 27-1. Percentage of high school seniors who participated in various extracurricular activities, by type of activity: Selected years, 1990 through 2010

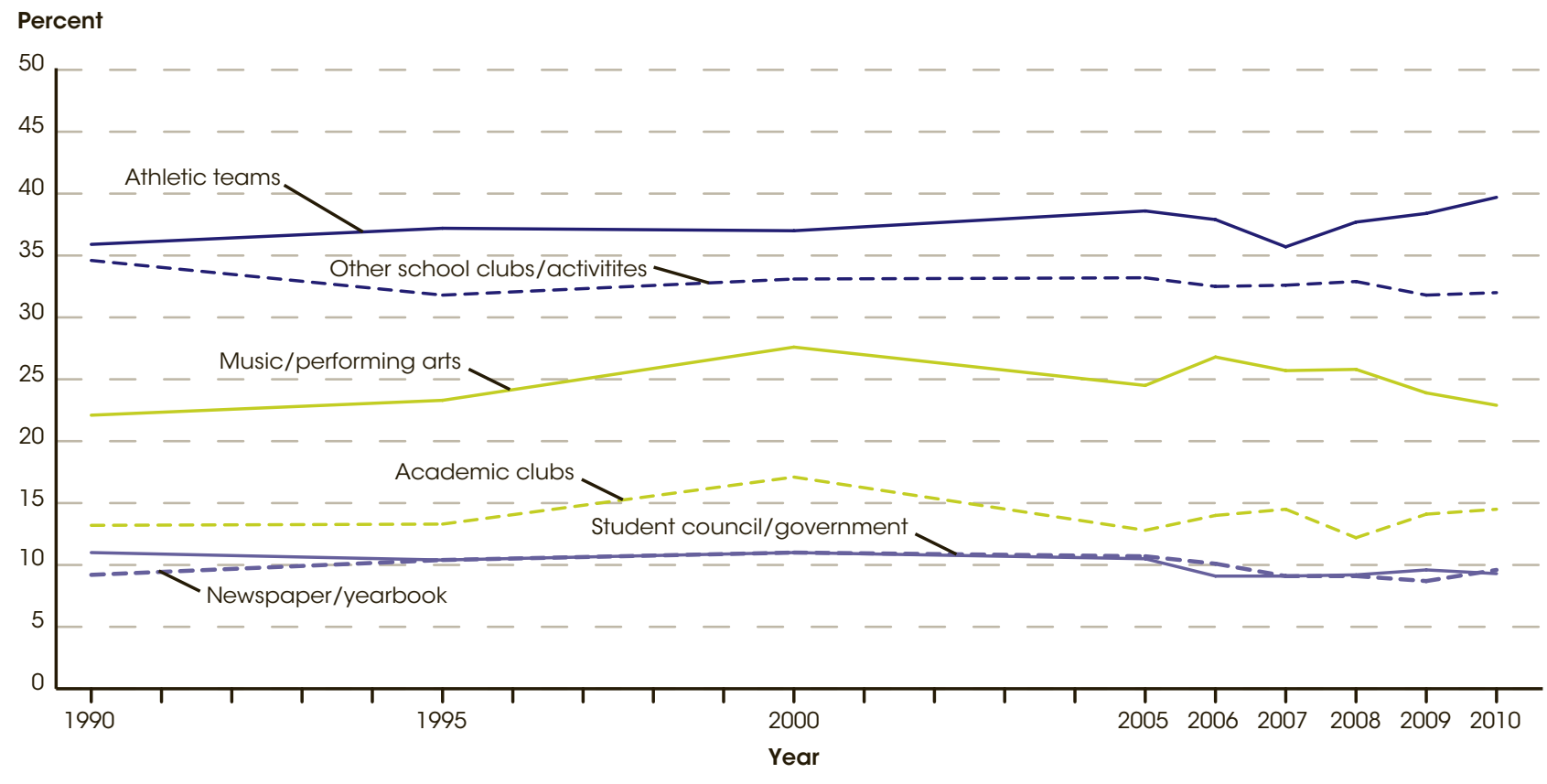

NOTE: Percentages reflect the proportion of seniors who responded that they participated in these activities "to a considerable extent" or "to a great extent." The response rates for this survey do not meet National Center for Education Statistics (NCES) standards. For more information on Monitoring the Future, see Appendix B - Guide to Sources.

SOURCE: University of Michigan, Institute for Social Research, Monitoring the Future, selected years, 1990-2010.

Figure 27-2. Percentage of high school seniors who participated in various extracurricular activities, by college plans: 2010

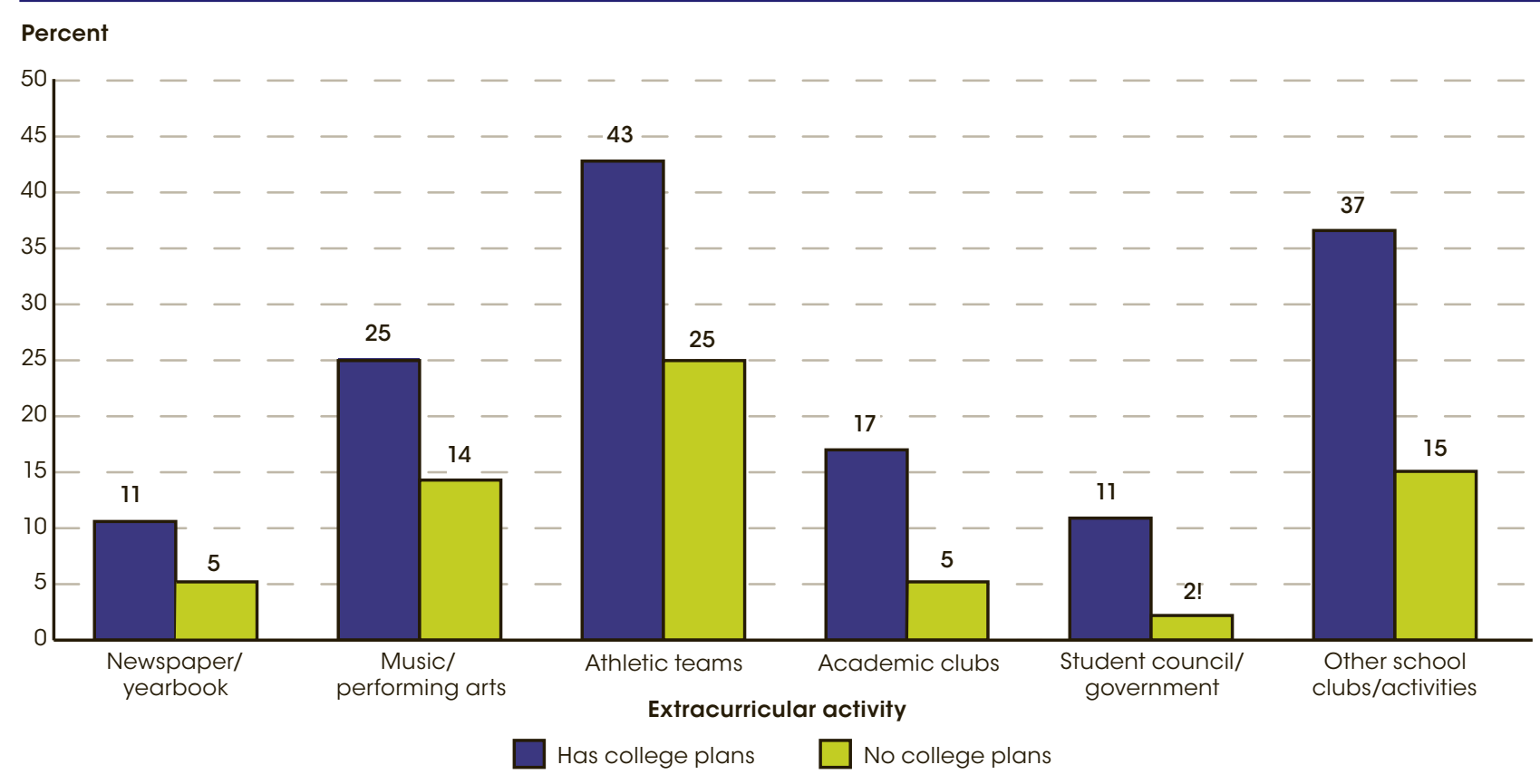

! Interpret data with caution (coefficient of variation is greater than 30 percent)

NOTE: Percentages reflect the proportion of seniors who responded that they participated in these activities "to a considerable extent" or "to a great extent." The response rates for this survey do not meet National Center for Education Statistics (NCES) standards. For more information on Monitoring the Future, see Appendix B - Guide to Sources.

SOURCE: University of Michigan, Institute for Social Research, Monitoring the Future, 2010 


\section{In 2009, the average National Assessment of Educational Progress (NAEP) reading score of 12th-grade students with perfect attendance (292) was not measurably different from the score of those who reported missing 7-2 days in the previous month (290), but was higher than those who reported missing 3-4 days (284), and missing 5 or more days (273).}

In 2011, when asked about their school attendance in the previous month, 51 percent of 4 th-grade students and 45 percent of 8 th-grade students reported having perfect attendance (i.e., no absences from school) (see table A-28-1). In that same year, 30 percent of 4 th-grade students reported missing 1-2 days, 12 percent missed 3-4 days, and 7 percent missed 5 or more days of school in the previous month. Thirty-five percent of 8 th-grade students missed 1-2 days, 13 percent missed 3-4 days, and 6 percent reported missing 5 or more days of school. In 2009 in 12th grade, the latest year for which data are available, 38 percent of students reported perfect attendance, 39 percent reported missing 1-2 days, 15 percent reported missing 3-4 days, and 8 percent reported missing 5 or more days.

Absenteeism patterns remained relatively stable for 4th-grade students between 1994 and 2011 (see table A-28-1). For 8th-grade students, there was no measurable change over this period in the percentages reporting perfect attendance in the previous month or missing 3-4 days. Higher percentages of 8 th-grade students reported missing 1-2 days in 2011 than in 1992 (35 vs. 33 percent). Lower percentages of 8 th-grade students reported missing 5 or more days (6 vs. 8 percent). For 12 th-grade students, a higher percentage reported perfect attendance in 2009 than in 1992 (38 vs. 35 percent), while lower percentages reported missing 3-4 days (15 vs. 17 percent) and missing 5 or more days (8 vs. 9 percent).

In general, students with higher absenteeism have lower scores on the National Assessment of Educational Progress (NAEP) reading assessment. There was no measurable difference in the 4 th-grade reading scores on the NAEP in 1994 between students with perfect attendance (217) and those who reported missing 1-2 days of school in the previous month (215), although both scores were higher than those for students missing 3-4 days (208) and 5 or more days (198) (see table A-28-2). In 2011, 4th-grade students with perfect attendance in the previous month had higher reading scale scores (225) than those who reported missing 1-2 days (221), those missing 3-4 days (216), and those missing 5 or more days (207). This scoring pattern was similar for 8 th-grade students. In 1992, 8th-grade students who reported missing no days or 1-2 days of school in the previous month had higher reading scale scores (263 and 264, respectively) than those who reported missing 3-4 days (256) and 5 or more days (244). The average reading score of 8 th-grade students with perfect attendance (269) was higher in 2011 than those who reported missing 1-2 days in the previous month (266), missing 3-4 days (258), and missing 5 or more days (248). For 12th-grade students, there was no measurable difference in reading scores in either 1992 or 2009 between students who had perfect attendance (296 and 292, respectively) and those who reported missing 1-2 days in the previous month (295 and 290). However, in both years, these scores were higher than for those who reported missing 3-4 days (287 and 284, respectively) and 5 or more days (279 and 273).

The percentages of students in 2011 who reported missing 3 or more days of school in the previous month varied by student and school characteristics. For example, at the 8th-grade level, 11 percent of Asian/Pacific Islander students reported missing 3 or more days of school in the previous month, compared to 18 percent of White students, 20 percent of students of two or more races, 21 percent of Hispanic students, 23 percent of Black students, and 31 percent of American Indian/Alaska Native students (see table A-28-2). For 12th-grade students, 26 percent of those who qualify for free or reduced-price lunch reported missing 3 or more days of school in the previous month, compared to 22 percent of students who did not qualify.

Tables A-28-1 and A-28-2

Glossary: Free or reduced-price lunch, National School Lunch Program

\section{Technical Notes}

From 1994 to 2000, students responded to the question, "How many days of school did you miss last month?" After 2001, students were asked "How many days were you absent from school in the last month?" Race categories exclude persons of Hispanic ethnicity. For more information on race/ethnicity, free or reduced-price lunch, or locale, see Appendix C-Commonly Used Measures. For more information on the National Assessment of Educational Progress (NAEP), see Appendix B - Guide to Sources. 
Figure 28-1. Average National Assessment of Educational Progress reading scale scores of 12th-grade students, by the number of days of school they reported missing in the previous month: Various years, 1992-2009

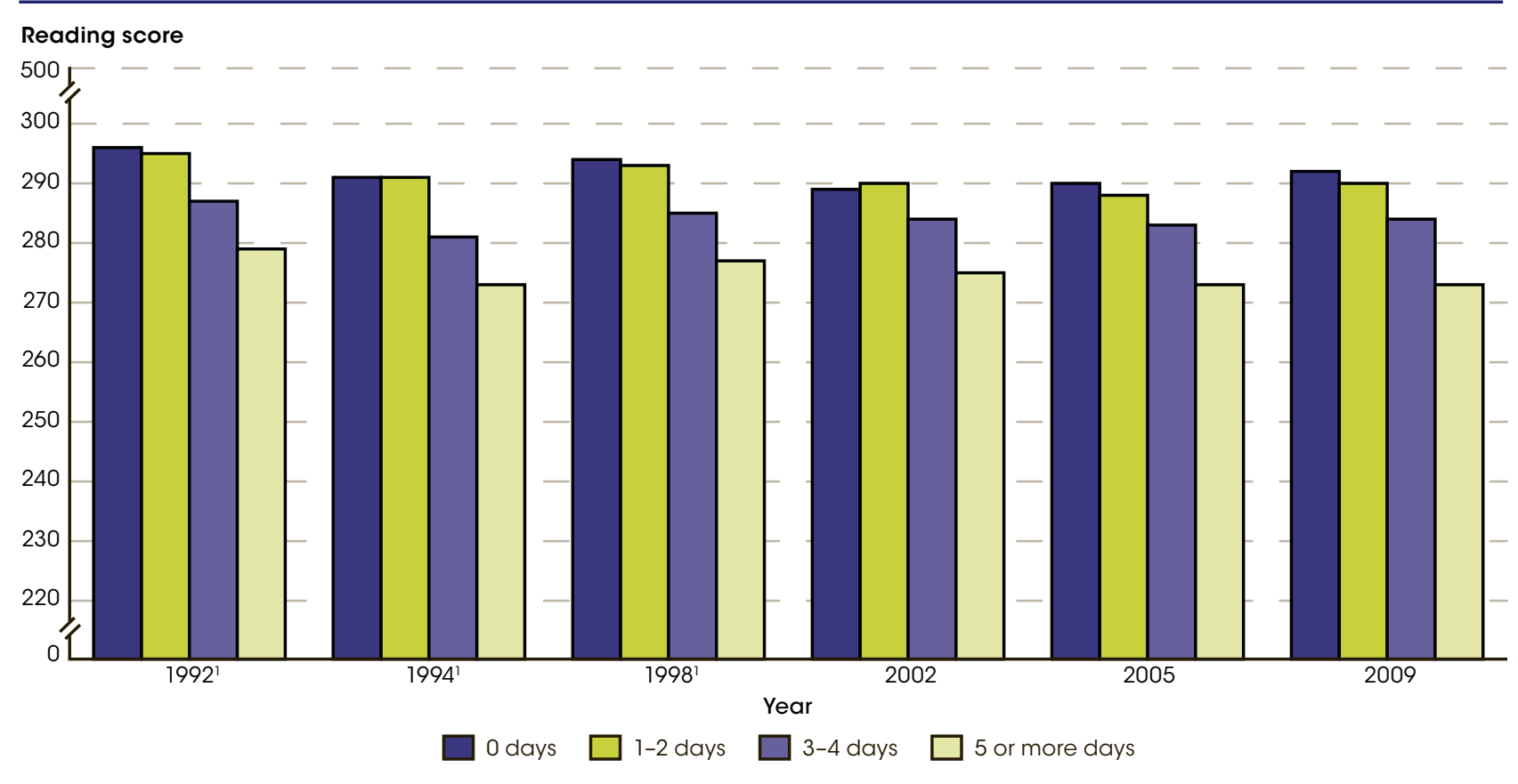

Testing accommodations (e.g., extended time, small group testing) for children with disabilities and English language learners were not permitted in 1992 and 1994; students were tested with and without accommodations in 1998, and the number shown is with accommodations.

NOTE: From 1992 to 2000, students responded to the question "How many days of school did you miss last month?" After 2001, students were asked "How many days were you absent from school in the last month?" The National Assessment of Educational Progress (NAEP) reading scale ranges from 0-500. For more information on NAEP, see Appendix B - Guide to Sources.

SOURCE: U.S. Department of Education, National Center for Education Statistics, National Assessment of Educational Progress (NAEP), various years,

1992-2009 Reading Assessments, NAEP Data Explorer.

Figure 28-2. Percentage of 8th- and 12th-grade students, by number of days of school missed in the previous month and race/ethnicity: 2009 and 2011

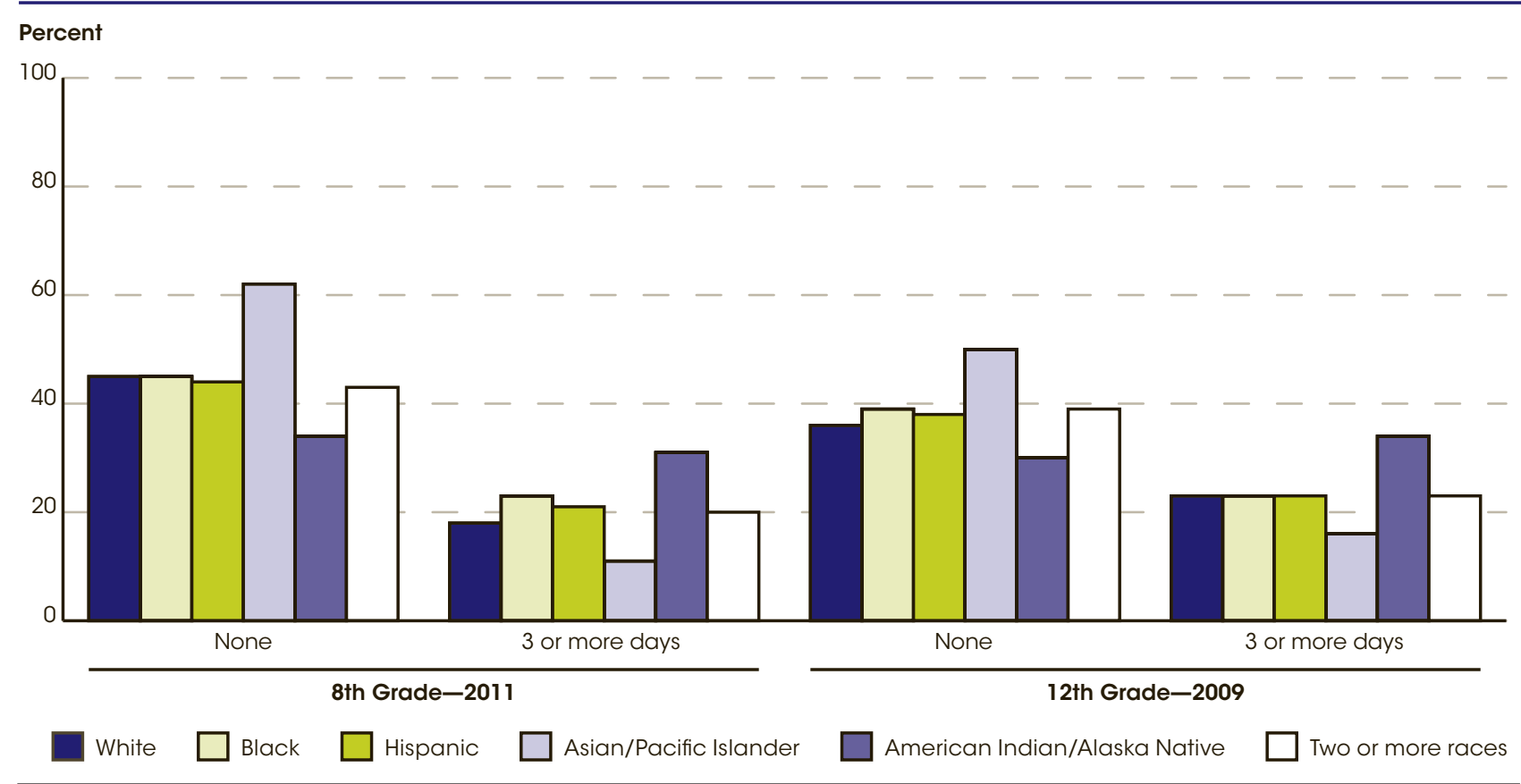

NOTE: The National Assessment of Educational Progress (NAEP) reading assessment was not administered to 12 th-graders in 2011 . For more information on NAEP, see Appendix B - Guide to Sources. Race categories exclude persons of Hispanic ethnicity. For more information on race/ethnicity, see Appendix C - Commonly Used Measures.

SOURCE: U.S. Department of Education, National Center for Education Statistics, National Assessment of Educational Progress (NAEP), 2009 and 2011 Reading Assessments, NAEP Data Explorer. 


\section{In 2011, about 14 percent of youth ages 16-24 were neither enrolled in school nor working.}

There are many reasons why youth between the ages of 16 and 24 may be neither enrolled in school nor working. For example, they may be seeking but unable to find work, or they may have left the workforce or school, either temporarily or permanently, to start a family. This indicator provides information on youth at an age when most are transitioning into postsecondary education or the workforce. This is a critical period for young people as they pursue their educational goals and career paths.

From 1990 through 2011, the percentage of youth ages 16-24 neither enrolled in school nor working remained between 11 and 16 percent annually (see table A-29-1). Within any single year, the percentage of such youth varied across certain subgroups of the population. In 2011, for example, the percentage of such youth varied by race/ethnicity, citizenship, family poverty, age,

household type, and geographic region, though it was not measurably different by sex.

Higher percentages of Black and Hispanic youth than White youth were neither enrolled in school nor working in each year observed $(1990,1995,2000,2005,2010$, and 2011). In 2011, some 19 percent of Black youth and 18 percent of Hispanic youth were neither enrolled in school nor working, compared with 12 percent of Whites and 9 percent of Asians/Pacific Islanders. Also in that year, a greater percentage of non-U.S. citizen youth (20 percent) were neither enrolled in school nor working than U.S.born youth (14 percent).

Family poverty was related to the prevalence of youth who were neither enrolled in school nor working. In each year observed, the percentage of youth neither enrolled in school nor working was higher for those from poor families than for those from nonpoor families. In 2011, the percentages for these groups were 27 percent and 11 percent, respectively.

In 2011, about 14 percent of youth ages 16-24 (approximately 5.6 million) were neither enrolled in school nor working. The percent neither enrolled in school nor working varied across age groups. For example, about 20 percent of youth ages 20-24 (approximately 4.2 million) were neither in school nor working, compared with 3 percent of youth ages 16-17 (approximately 0.3 million). This pattern of higher percentages of youth ages 20-24 than youth ages 16-17 neither enrolled in school nor working held across all years observed.

Although the percentages of Black and Hispanic youth who were neither enrolled nor working in 2011 were higher than the percentage of White youth, the majority of youth with these characteristics were White (see table A-29-2). That is, higher numbers of youth neither enrolled in school nor working were White (2.8 million) than Black (1.1 million), Hispanic (1.4 million), or Asian/ Pacific Islander (151,000). In 2011, about 0.6 million non-U.S. citizens ages 16-24 were neither enrolled in school nor working, compared to 4.9 million of their U.S.-born counterparts. Also, in the South, more youth ages 16-24 were neither enrolled in school nor working than in all other regions of the United States in 2011 (2.2 million in the South vs. 1 million in the Northeast, 1 million in the Midwest, and 1.4 million in the West).

Tables A-29-1 and A-29-2

\section{Technical Notes}

The data presented here represent the percentage of civilian, noninstitutionalized 16- to 24-year-olds who are neither enrolled in school nor working. Poor is defined to include families below the poverty threshold; nonpoor is defined to include families at or above the poverty threshold. U.S.-born includes foreign-born U.S. citizens. Naturalized U.S. citizens are those who, having been born in another country or otherwise reared as a foreigner, have been granted U.S. citizenship and the rights and privileges of that status. Race categories exclude persons of Hispanic ethnicity. For more information on the Current Population Survey (CPS), see Appendix B - Guide to Sources. For more information on poverty or race/ ethnicity, see Appendix C - Commonly Used Measures. 
Figure 29-1. Percentage of youth ages 16-24 who were neither enrolled in school nor working, by sex: Selected years, 1990-2011

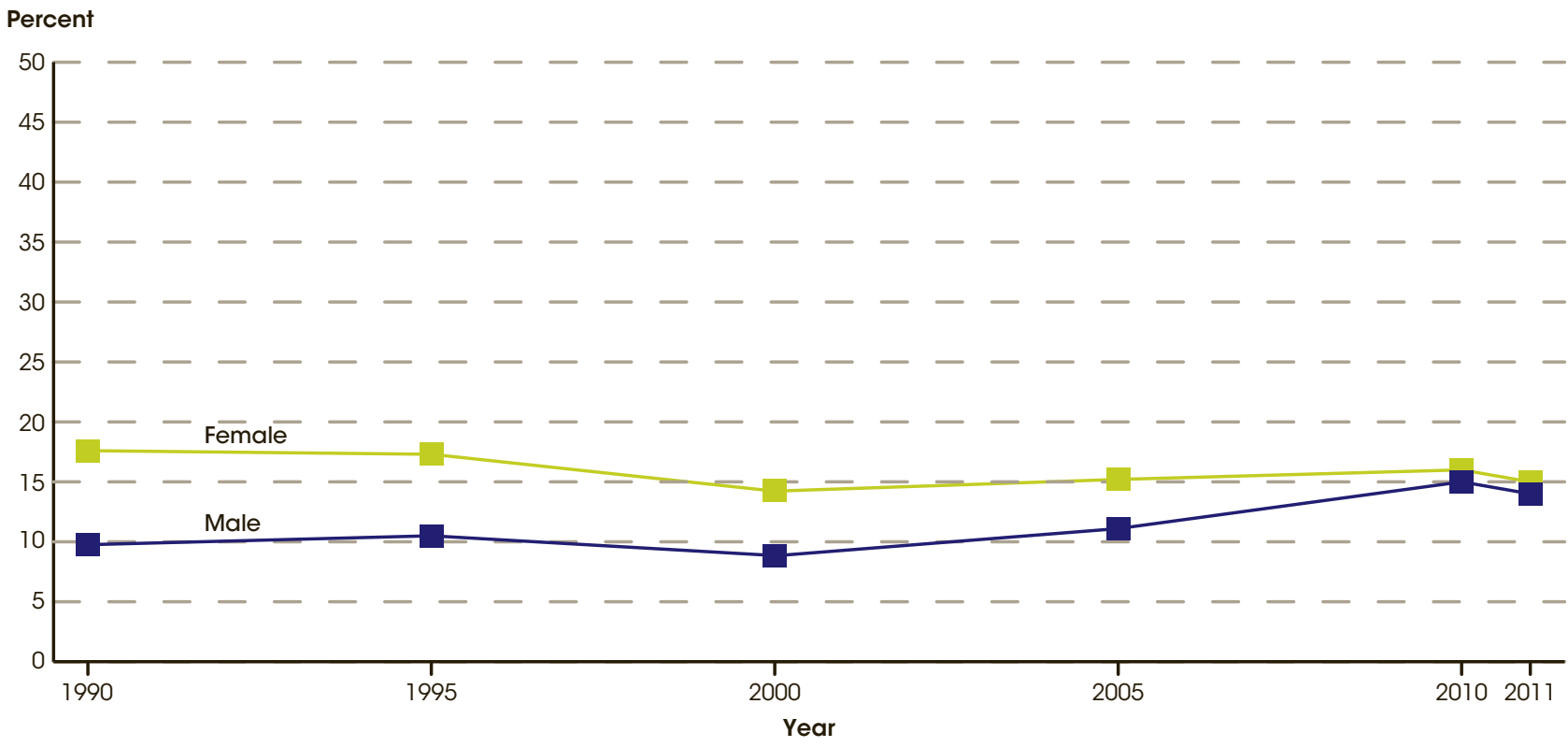

NOTE: The data presented here represent the percentage of civilian, noninstitutionalized 16- to 24 -year-olds who were neither enrolled in school nor working. For more information on the Current Population Survey (CPS), see Appendix B - Guide to Sources.

SOURCE: U.S. Department of Commerce, Census Bureau, Current Population Survey (CPS), March and Annual Social and Economic Supplement, selected years, $1990-2011$.

Figure 29-2. Percentage of youth ages 16-24 who were neither enrolled in school nor working, by household type and citizenship: 2011

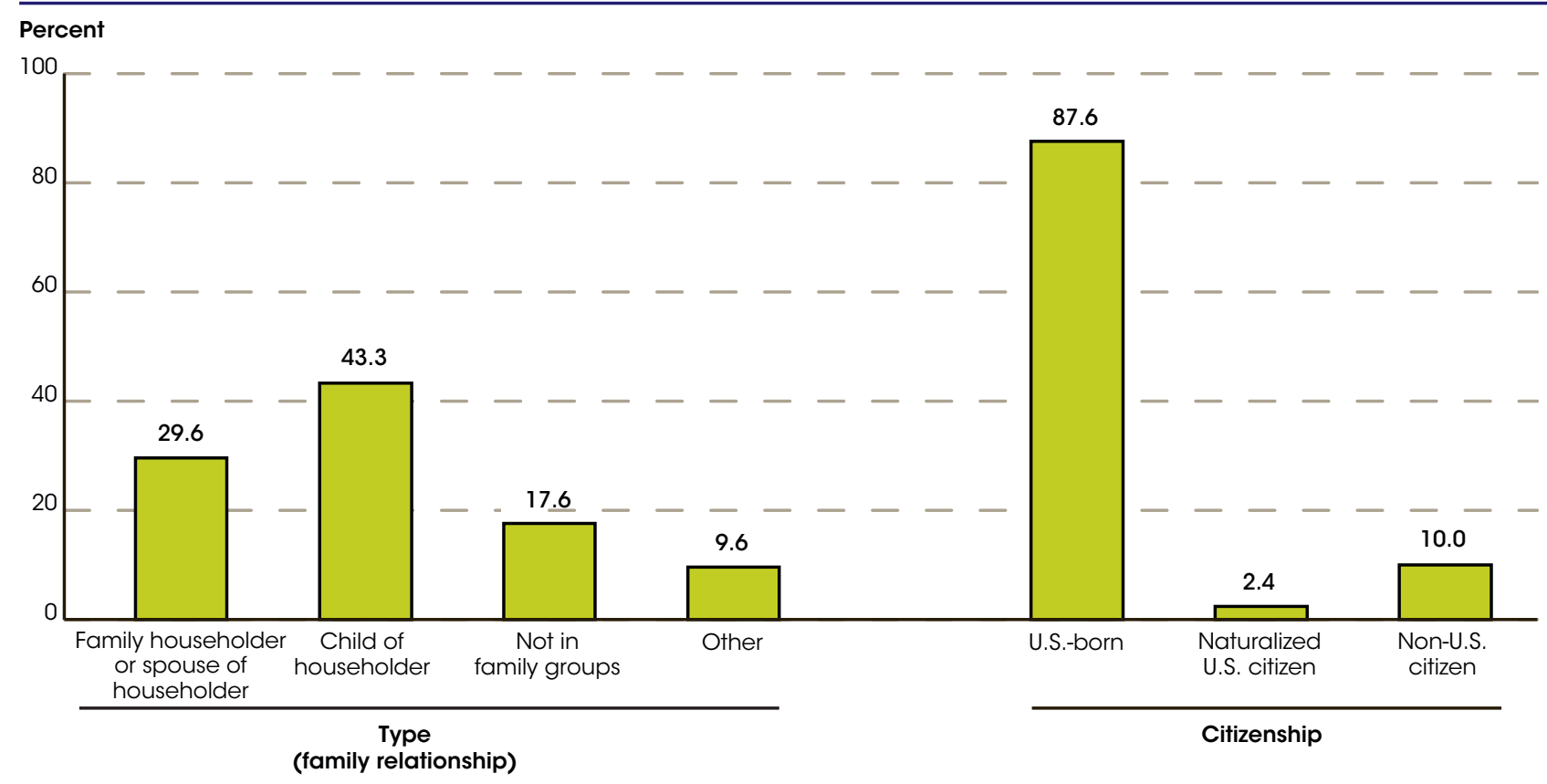

NOTE: The data presented here represent the number of civilian, noninstitutionalized 16- to 24-year-olds who were neither enrolled in school nor working. For more information on the Current Population Survey (CPS), see Appendix B - Guide to Sources.

SOURCE: U.S. Department of Commerce, Census Bureau, Current Population Survey (CPS), March and Annual Social and Economic Supplement, 2011. 


\section{Between 1980 and 2010, the percentage of high school students age 16 years and above who were employed decreased from 36 percent to 16 percent. For male high school students, the decrease was from 37 percent in 1980 to 14 percent in 2010.}

In 2010, approximately 16 percent of high school students age 16 years and above were employed; 7 percent were employed for less than 15 hours per week and 8 percent were employed for 15 or more hours per week. The percentage of female high school students age 16 years and above who were employed (18 percent) was higher than the percentage of male high school students age 16 years and above who were employed (14 percent). The same pattern held for those who worked less than 15 hours per week as well as for those who worked 15 hours per week or more (see table A-30-1).

Between 1980 and 2010, the percentage of high school students age 16 years and above who were employed decreased from 36 percent to 16 percent. For male high school students age 16 years and above, the decrease was from 37 percent in 1980 to 14 percent in 2010. In 1980, some 14 percent of high school students age 16 years and above were employed less than 15 hours per week and 21 percent were employed for 15 or more hours per week; these percentages declined to 7 percent and 8 percent, respectively, by 2010 . The percentage of males age 16 years and above who were employed for less than 15 hours per week declined from 14 percent in 1980 to 6 percent in 2010. For females, the percentages who were employed less than 15 hours per week declined from 14 percent to 8 percent over the same time period. For male students age 16 years and above employed 15 or more hours per week, the decline was from 22 percent in 1980 to 7 percent in
2010; for females, 19 percent were employed 15 or more hours per week in 1980 and 9 percent were in 2010.

In 2010, some 47 percent of high school students age 16 years and above who were employed worked less than 15 hours, and 53 percent worked 15 or more hours per week (see table A-30-2). Hours worked per week varied by student characteristic. Forty-eight percent of younger (16 to 17 years old) high school students who were employed worked 15 or more hours per week, compared to 66 percent of older (18 years old and older) high school students who were employed.

In 2010, about 44 percent of employed high school students age 16 years and above from high-income families (the top 20 percent of family incomes) worked 15 or more hours per week, compared with 56 percent of employed students from middle-income families (the middle 60 percent of family incomes), and 62 percent of employed students from low-income families (the bottom 20 percent of family incomes). For native-born employed high school students age 16 years and above (those who were born in the 50 states and the District of Columbia), 52 percent worked 15 or more hours per week, compared to 75 percent of foreign-born employed high school students.

Tables A-30-1 and A-30-2

Glossary: Family income, High school, Hours worked per week

\section{Technical Notes}

The percentage of employed high school students includes those who were employed but not at work during the survey week. Hours worked per week refers to the number of hours the respondent worked at all jobs during the survey week. Native-born refers to high school students born in the 50 states and the District of Columbia. For more information on family income, see Appendix $\mathrm{C}$ - Commonly Used Measures. For more information on the Current Population Survey (CPS), see Appendix B Guide to Sources. 
Figure 30-1. Percentage of high school students age 16 years and above who were employed, by sex: Selected years, 1980 to 2010

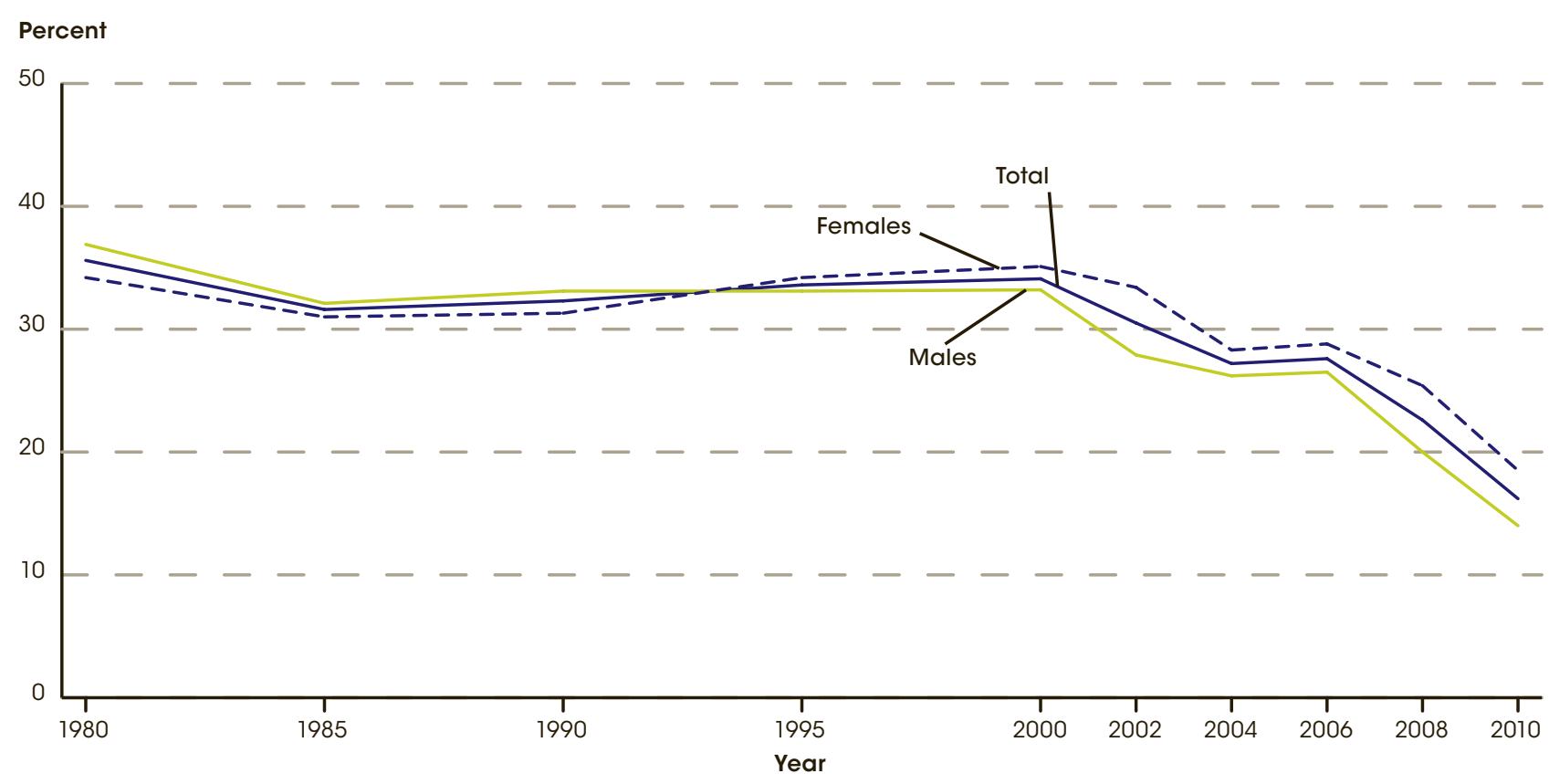

NOTE: The data presented here represent the percentage of civilian, noninstitutionalized 16- to 24-year-olds who were neither enrolled in school nor working. For more information on the Current Population Survey (CPS), see Appendix B - Guide to Sources.

SOURCE: U.S. Department of Commerce, Census Bureau, Current Population Survey (CPS), March and Annual Social and Economic Supplement, selected years, 1990-2011.

Figure 30-2. Percentage of employed high school students age 16 years and above who worked more than 15 hours per week, by selected student characteristics: 2010

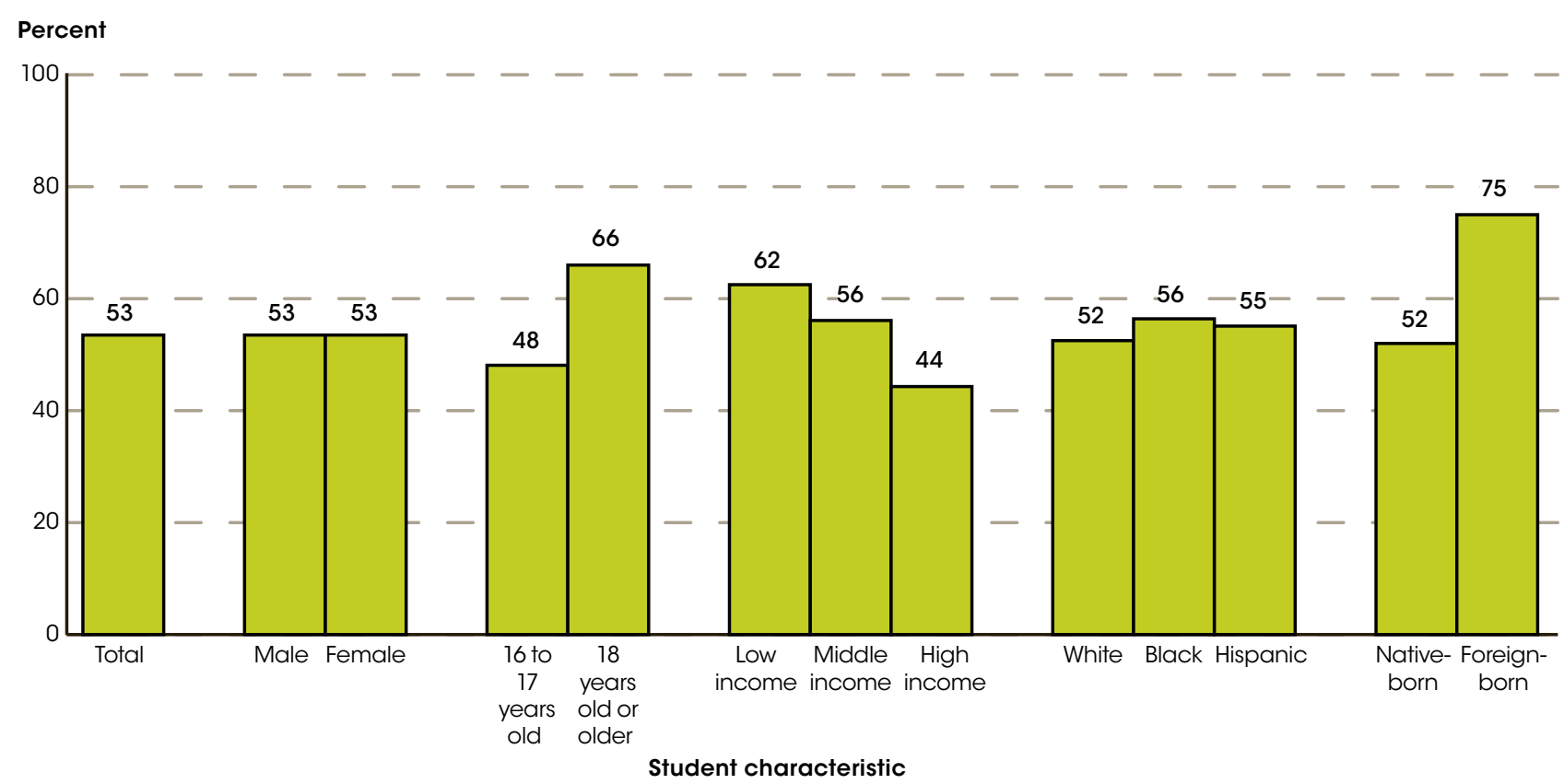

NOTE: The data presented here represent the number of civilian, noninstitutionalized 16- to 24-year-olds who were neither enrolled in school nor working. For more information on the Current Population Survey (CPS), see Appendix B - Guide to Sources.

SOURCE: U.S. Department of Commerce, Census Bureau, Current Population Survey (CPS), March and Annual Social and Economic Supplement, 2011. 


\section{Indicator 31}

\section{High School Coursetaking}

\section{The percentages of high school graduates who took mathematics courses in geometry, algebra II/trigonometry, analysis/precalculus, statistics/probability, and calculus while in high school were higher in 2009 than in 1990.}

The percentages of high school graduates who took mathematics courses in geometry, algebra II/trigonometry, analysis/precalculus, statistics/probability, and calculus while in high school were higher in 2009 than in 1990 (see table A-31-1). Similarly, the percentages of high school graduates who took science courses in biology, chemistry, physics, both biology and chemistry, or in all three of these science courses while in high school were higher in 2009 than in 1990. For example, while in high school, 16 percent of 2009 graduates versus 7 percent of 1990 graduates took calculus, and 30 percent of 2009 graduates took biology, chemistry, and physics in high school versus 19 percent of 1990 graduates. In contrast, 69 percent of 2009 graduates took algebra I in high school versus 77 percent of 1990 graduates. Looking at more recent changes, the percentages of graduates who took mathematics and science courses were higher in 2009 than in 2005 for all courses except algebra I and the combination of biology, chemistry, and physics, for which no measurable differences were found.

Across subgroups, the percentages of high school graduates who had taken calculus and biology, chemistry, and physics were generally higher in 2009 than in 1990. For example, 9 percent of Hispanic 2009 high school graduates had taken calculus versus 4 percent of 1990 graduates. Also, 28 percent of female 2009 graduates had taken biology, chemistry, and physics versus 16 percent of 1990 graduates. Comparing 2009 with 2005, the percentages of graduates who had taken these courses were higher for some subgroups. For instance, 12 percent of 2009 graduates with disabilities had taken biology, chemistry, and physics versus 7 percent of 2005 graduates.

For both calculus and biology, chemistry, and physics, higher percentages of certain 2009 graduates took these courses while in high school than their peers in other subgroups. For example, higher percentages of Asian/
Pacific Islander (42 percent) and White graduates (18 percent) had taken calculus than their Black ( 6 percent) and Hispanic peers (9 percent). Calculus coursetaking was also more prevalent for private than public school graduates and for graduates of suburban high schools than their peers from city, town, and rural schools. Among 2009 graduates who had taken biology, chemistry, and physics, a higher percentage of males than females had taken these courses (32 vs. 28 percent). Also, a higher percentage of high school graduates who attended schools with 25 percent or fewer students eligible for free or reduced-price lunch (low-poverty schools) had taken these courses than those who attended schools with more than 75 percent of students eligible for free or reduced-price lunch (high-poverty schools).

For 2009 high school graduates, higher average scale scores on the National Assessment of Educational Progress (NAEP) 12th-grade mathematics assessment were associated with higher levels of mathematics coursetaking in high school (see table A-31-2). For example, graduates who had taken only algebra I or below had an average scale score of 114 (on a scale of $0-300$ ), whereas graduates who had taken calculus had an average scale score of 193 . In addition, at each mathematics level in 2009, certain graduates had higher average scale scores than their peers in other subgroups. Looking at graduates who had taken calculus, the average scale score was higher for males than females (197 vs. 190). Average scale scores were also higher for calculus takers who were Asian/Pacific Islander (203) and White (194) than for their Hispanic (179) and Black (170) peers. Among calculus takers, the average scale score for those who had attended low-poverty schools was 199 versus a score of 163 for their peers at high-poverty schools.

Tables A-31-1 and A-31-2

Glossary: Charter school, Free or reduced-price lunch, High school, Private school, Public school

\section{Technical Notes}

Data reflect only the percentage of graduates who earned course credit while in high school (grades 9-12). For a transcript to be included in the analyses, it had to meet three requirements: (1) the graduate received either a standard or honors diploma, (2) the graduate's transcript contained 16 or more Carnegie credits, and (3) the graduate's transcript contained more than 0 Carnegie credits in English courses. Coursetaking estimates should be considered within the context of course access, which can vary across schools. Estimates for public schools exclude charter schools. Race categories exclude persons of Hispanic ethnicity. For more information on race/ethnicity, free or reduced-price lunch, or locale, see Appendix C - Commonly Used Measures. For more information on the National Assessment of Educational Progress (NAEP) or the High School Transcript Study (HSTS), see Appendix B - Guide to Sources. 
Figure 31-1. Percentage of high school graduates who completed selected mathematics and science courses in high school: 1990 and 2009

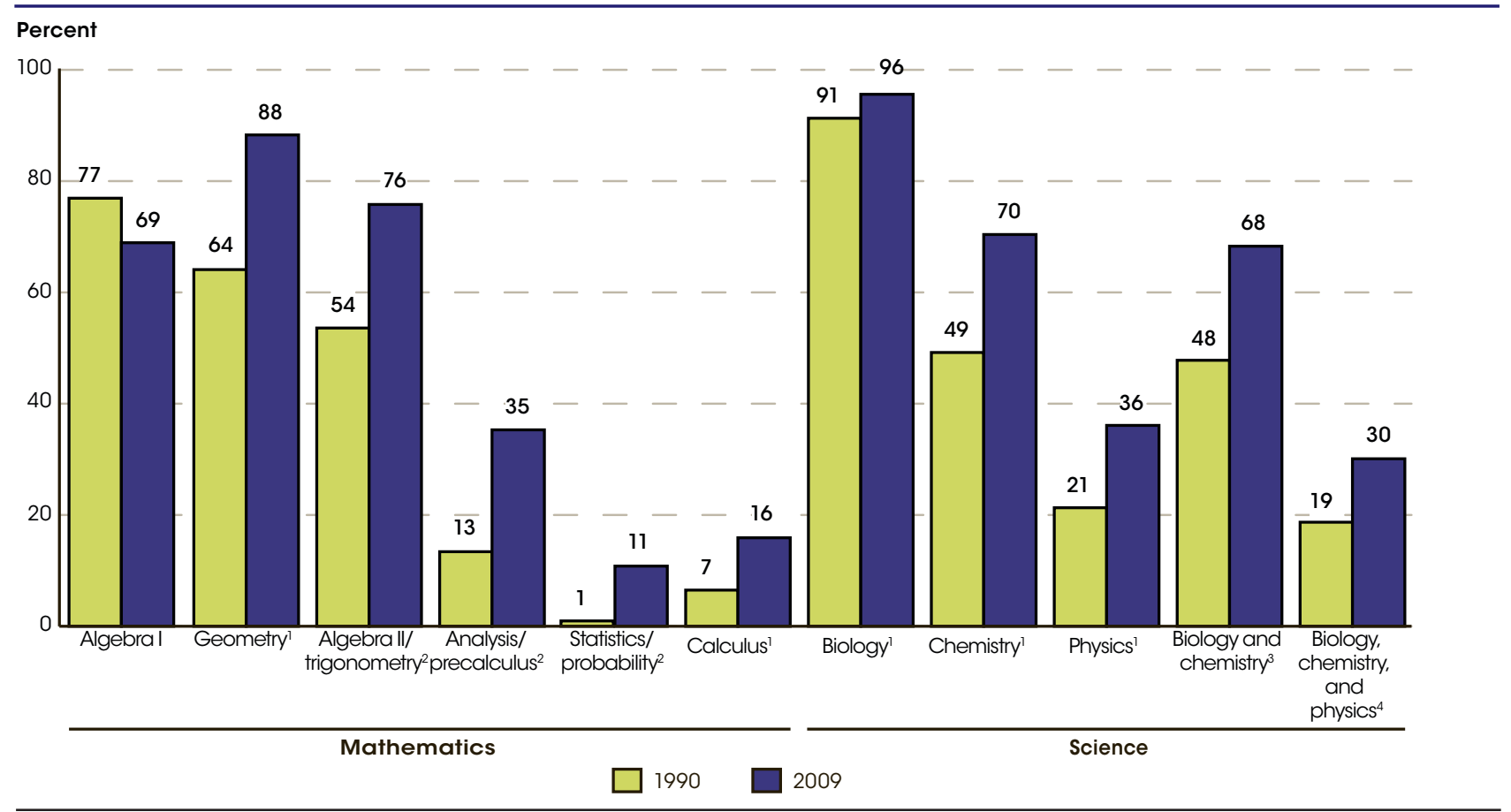

${ }^{1}$ Percentages are for students who earned at least one Carnegie credit.

2 Percentages are for students who earned at least one-half of a Carnegie credit.

${ }_{3}^{3}$ Percentages are for students who earned at least one Carnegie credit each in biology and chemistry.

${ }^{4}$ Percentages are for students who earned at least one Carnegie credit each in biology, chemistry, and physics.

NOTE: For a transcript to be included in the analyses, it had to meet three requirements: (1) the graduate received either a standard or honors diploma,

(2) the graduate's transcript contained 16 or more Carnegie credits, and (3) the graduate's transcript contained more than 0 Carnegie credits in

English courses. For more information on the National Assessment of Educational Progress (NAEP) or the High School Transcript Study (HSTS), see Appendix B - Guide to Sources.

SOURCE: U.S. Department of Education, National Center for Education Statistics, High School Transcript Study (HSTS), 1990 and 2009.

Figure 31-2. Average National Assessment of Educational Progress (NAEP) 12th-grade mathematics scale scores of high school graduates, by highest mathematics course taken and race/ethnicity: 2009

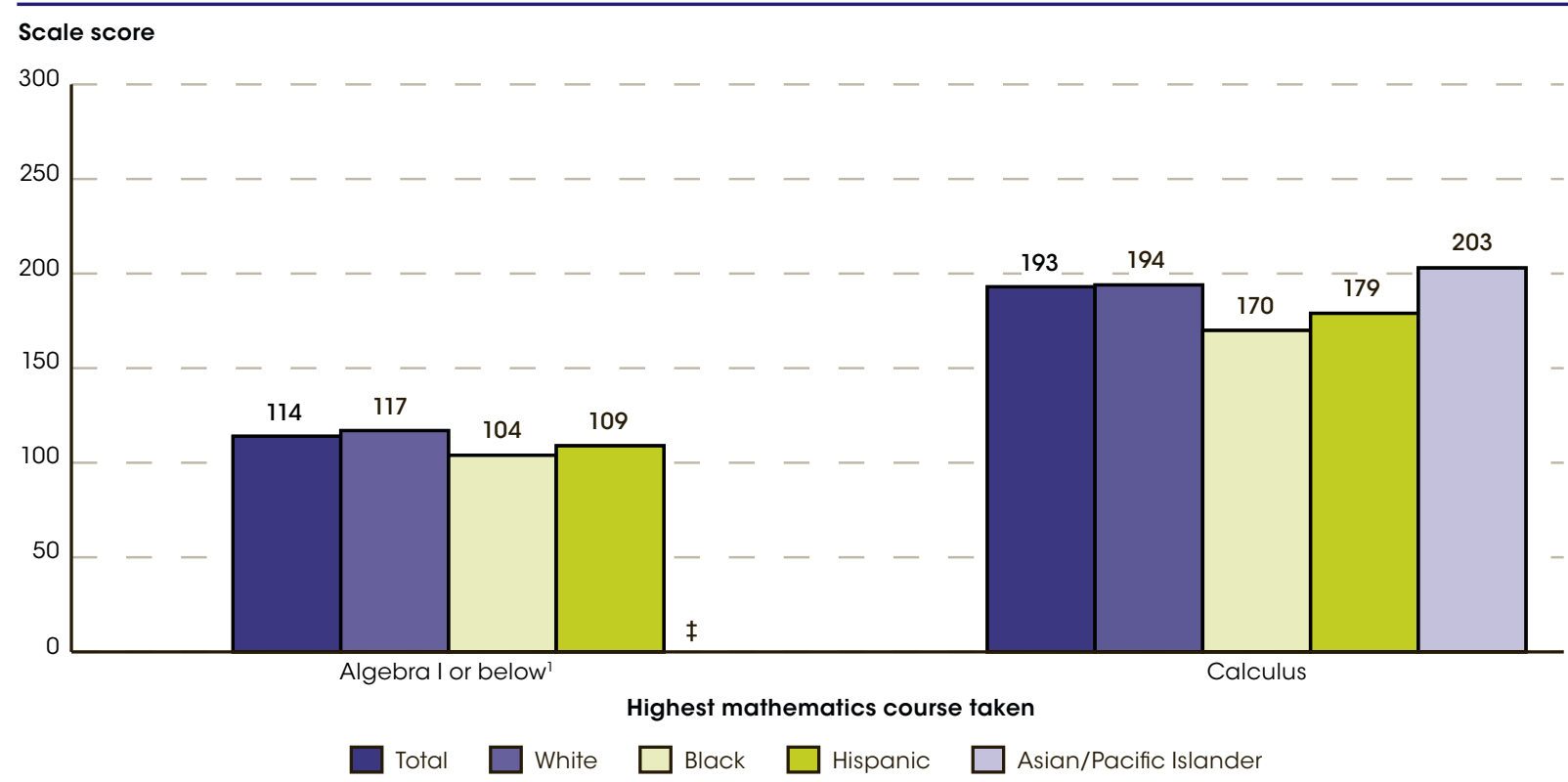

\footnotetext{
¥ Reporting standards not met (too few cases).
}

${ }^{1}$ Includes basic math, general math, applied math, pre-algebra, and algebra I.

NOTE: The scale of the National Assessment for Educational Progress (NAEP) mathematics assessment for grade 12 ranges from 0 to 300 . For a transcript to be included in the analyses, it had to meet three requirements: (1) the graduate received either a standard or honors diploma, (2) the graduate's transcript contained 16 or more Carnegie credits, and (3) the graduate's transcript contained more than 0 Carnegie credits in English courses. Race categories exclude persons of Hispanic ethnicity. Reporting standards were not met for American Indian/Alaska Native estimates, therefore, data for this racial group are not shown in the figure. For more information on race/ethnicity, see Appendix C - Commonly Used Measures. For more information on the National Assessment of Educational Progress (NAEP) or the High School Transcript Study (HSTS), see Appendix B - Guide to Sources.

SOURCE: U.S. Department of Education, National Center for Education Statistics, National Assessment of Educational Progress (NAEP), 2009 Mathematics Assessment; and High School Transcript Study (HSTS), 2009. 


\section{In school year 2008-09, more than three-quarters of public high school students graduated on time with a regular diploma.}

This indicator examines the percentage of public high school students who graduate on time with a regular diploma. To do so, it uses the averaged freshman graduation rate (AFGR) — an estimate of the number of regular diplomas issued in a given year divided by an estimate of the averaged enrollment base for the freshman class 4 years earlier. For each year, the averaged freshman enrollment base is the sum of the number of 8th-graders 5 years earlier, the number of 9 th-graders 4 years earlier (when current-year seniors were freshmen), and the number of 10th-graders 3 years earlier, divided by 3 . The intent of this averaging is to account for the high rate of grade retention in the freshman year, which adds 9th-grade repeaters from the previous year to the number of students in the incoming freshman class each year.

Among public high school students in the class of 2008-09, the averaged freshman graduation rate was 75.5 percent; that is, just over 3 million students graduated on time (see table A-32-1). Wisconsin had the highest graduation rate, at 90.7 percent. Fifteen other states had rates of 80 percent or more (ordered from high to low): Vermont, Minnesota, North Dakota, Iowa, New Jersey, New Hampshire, Massachusetts, Missouri, Nebraska, Montana, South Dakota, Idaho, Pennsylvania, Kansas, and Maryland. Nevada had the lowest rate, at 56.3 percent. Seven other states and the District of Columbia had graduation rates below 70 percent (ordered from high to low): Alabama, Florida, Georgia, Louisiana, South Carolina, New Mexico, the District of Columbia, and Mississippi.

The overall AFGR was higher for the graduating class of 2008-09 (75.5 percent) than it was for the graduating class of 1990-91 (73.7 percent). However, from school year 1990-91 to 1995-96, the overall averaged freshman graduation rate decreased from 73.7 percent to 71.0 percent. In terms of changes by state, there was an increase in the graduation rate in 30 states and the District of Columbia from school year 1990-91 to 2008-09. In 1 state (Vermont) the rate increased by more than 10 percentage points; in 6 others (Louisiana, Missouri, New Hampshire, New York, Tennessee, and Wisconsin) and the District of Columbia, rates increased by more than 5 percentage points. The graduation rate decreased from 1990-91 to 2008-09 in 20 states (Alaska, Arizona, Arkansas, Connecticut, Georgia, Hawaii, Indiana, Kansas, Maine, Minnesota, Mississippi, Montana, Nebraska, Nevada, New Mexico, North Dakota, South Carolina, South Dakota, Washington, and Wyoming), with decreases of greater than 5 percentage points occurring in New Mexico (5.3 percent), Wyoming (6.0 percent), and Nevada (20.7 percent).

Table A-32-1

Glossary: High school, High school diploma, Public school

\section{Technical Notes}

Ungraded students were allocated to individual grades proportional to each state's enrollment in those grades. Graduates include only those who earned regular diplomas or diplomas for advanced academic achievement (e.g., honors diploma) as defined by the state or jurisdiction. The 2003-04 national estimates include imputed data for New York and Wisconsin. The 2005-06 national estimates include imputed data for the District of Columbia, Pennsylvania, and South Carolina. The 2007-08 estimate for Maine includes graduates from semi-private schools. The 2008-09 national estimates include imputed data for California and Nevada. The
2008-09 imputations for individual states are constructed from the prior year's AFGR by race/ethnicity applied to the AFGR population base. By way of example, this computation results in an imputed overall AFGR for California that is minimally different from the prior year ( 0.2 percent), and the impact of the estimate on the U.S. value is also minimal. For more information on the Common Core of Data (CCD), see Appendix B - Guide to Sources. For more information on measures of student progress and persistence, see Appendix C - Commonly Used Measures. 
Figure 32-1. Averaged freshman graduation rate for public high school students, by state or jurisdiction: School year 2008-09

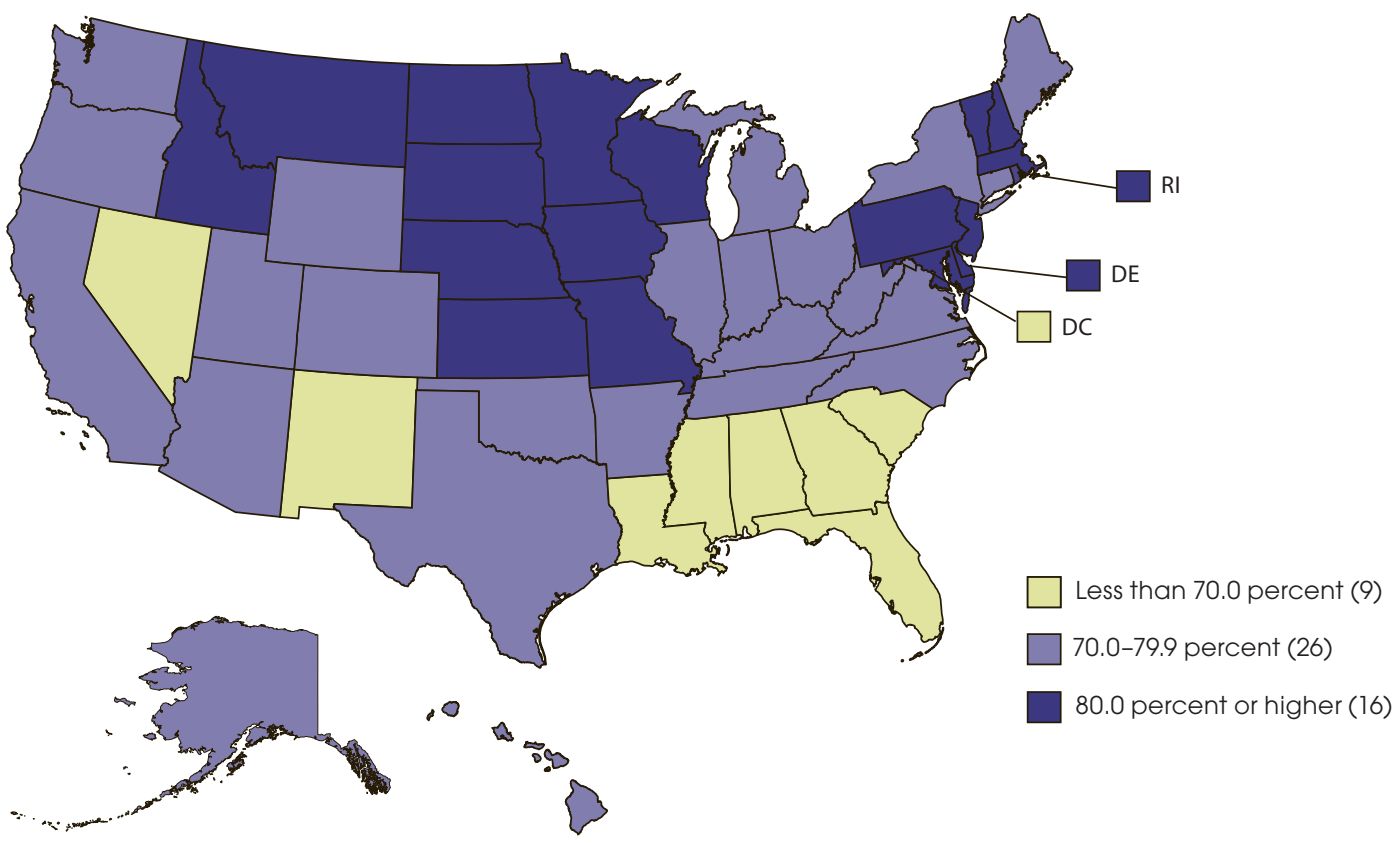

NOTE: The averaged freshman graduation rate is the number of graduates divided by the estimated freshman enrollment count 4 years earlier. This count is the sum of the number of 8th-graders 5 years earlier, the number of 9th-graders 4 years earlier, and the number of 10 th-graders 3 years earlier, divided by 3. Ungraded students were allocated to individual grades proportional to each state's enrollment in those grades. Graduates include only those who earned regular diplomas or diplomas for advanced academic achievement (e.g., honors diploma) as defined by the state or jurisdiction. Data for California and Nevada were imputed. For more information on measures of student progress and persistence, see Appendix C - Commonly Used Measures. For more information on the Common Core of Data (CCD), see Appendix B - Guide to Sources.

SOURCE: U.S. Department of Education, National Center for Education Statistics, Common Core of Data (CCD), "NCES Common Core of Data State Dropout and Completion Data File," school year 2008-09, version 1a.

Figure 32-2. Averaged freshman graduation rate for public high school students: Selected school years 1990-91 through 2008-09

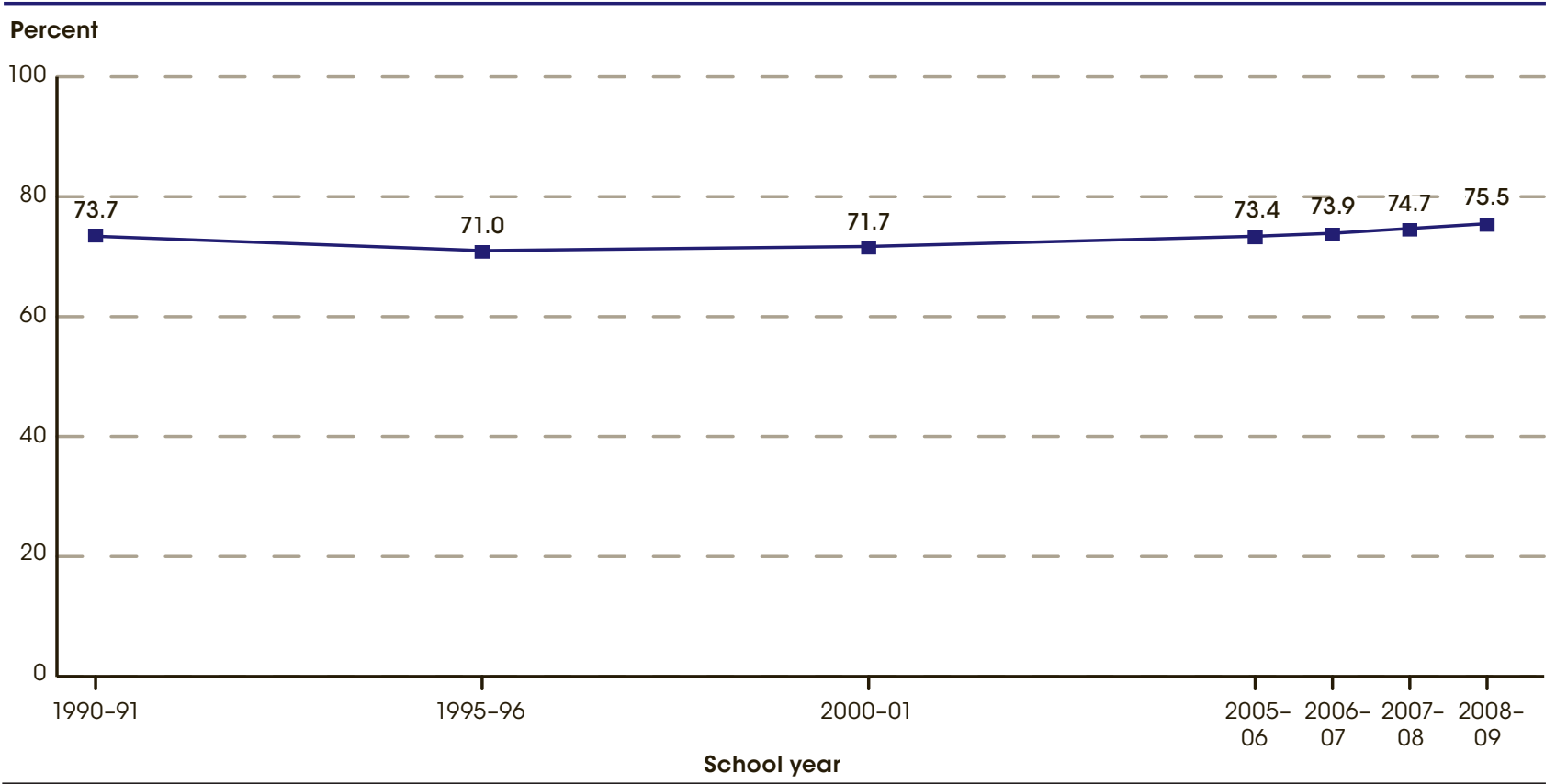

NOTE: The averaged freshman graduation rate is the number of graduates divided by the estimated freshman enrollment count 4 years earlier. This count is the sum of the number of 8th-graders 5 years earlier, the number of 9th-graders 4 years earlier, and the number of 10 th-graders 3 years earlier, divided by 3 . Ungraded students were allocated to individual grades proportional to each state's enrollment in those grades. Graduates include only those who earned regular diplomas or diplomas for advanced academic achievement (e.g., honors diploma) as defined by the state or jurisdiction. The 2005-06 national estimates include imputed data for the District of Columbia, Pennsylvania, and South Carolina. The 2007-08 estimate for Maine includes graduates from semiprivate schools. The 2008-09 national estimates include imputed data for California and Nevada. For more information on measures of student progress and persistence, see Appendix C - Commonly Used Measures. For more information on the Common Core of Data (CCD), see Appendix B - Guide to Sources.

SOURCE: U.S. Department of Education, National Center for Education Statistics, Common Core of Data (CCD), "NCES Common Core of Data State Dropout and Completion Data File," school year 2007-08; 2008-09, version 1a; and "State Nonfiscal Survey of Public Elementary/Secondary Education," 1990-91, Version 1b; 1995-96, Version 1b; 2000-01, Version 1b; 2005-06, Version 1b, and 2006-07, Version $1 \mathrm{~b}$. 


\section{Between 1990 and 2010, status dropout rates declined for Whites, Blacks, and Hispanics. Over this period, the status dropout rate was generally lowest for Asians/ Pacific Islanders, followed by Whites, Blacks, and Hispanics.}

The status dropout rate represents the percentage of 16- through 24-year-olds who are not enrolled in school and have not earned a high school credential (either a diploma or an equivalency credential such as a General Educational Development [GED] certificate). In this indicator, status dropout rates are estimated using both the Current Population Survey (CPS) and the American Community Survey (ACS). Data for the CPS have been collected annually over the last few decades, allowing for detailed consideration of long-term trends for those in the civilian, noninstitutionalized population. Nationallevel data from the ACS are available from 2000 onward, and include noninstitutionalized and institutionalized populations. The 2010 ACS has larger sample sizes than the CPS, which allows for more detailed comparisons of status dropout rates by sex, race/ethnicity, and nativity.

Based on the CPS, the status dropout rate declined from 12 percent in 1990 to 7 percent in 2010 (see table A-33-1). Between 1990 and 2010, status dropout rates also declined for Whites (from 9 percent to 5 percent), Blacks (from 13 percent to 8 percent), and Hispanics (from 32 percent to 15 percent). Over this period, the status dropout rate was generally lowest for Asians/Pacific Islanders, followed by Whites, Blacks, and Hispanics. In 2010, the status dropout rate for Asians/Pacific Islanders and Whites ( 4 percent and 5 percent, respectively) were not measurably different from each other, but both were lower than the status dropout rates for Blacks (8 percent), and Hispanics (15 percent). The gap between Whites and Hispanics narrowed from 23 percentage points in 1990 to 10 percentage points in 2010; the gaps between Whites and Blacks in these two years were not measurably different.

The ACS allows for comparisons of status dropout rates for 16-through 24-year-olds residing in households, as well as those in noninstitutionalized group quarters (such as college housing and military quarters), and institutionalized group quarters (such as adult and juvenile correctional facilities and nursing facilities). Among those living in households and noninstitutionalized group quarters, the status dropout rate was 8 percent in 2010 (see table A-33-2). A higher percentage of males than females were status dropouts (9 vs. 7 percent). This pattern was evident across all racial/ ethnic groups, except for Native Hawaiians/Pacific Islanders. In 2010, the status dropout rate among the institutionalized population was 37 percent (see table A-33-3).

The status dropout rate includes all 16-through 24-year-old dropouts, regardless of when they last attended school, as well as individuals who may never have attended school in the United States and may never have earned a high school credential. In order to highlight the experiences of young people in our education system, it is possible to isolate data for immigrants, who may have had little or no experiences with the U.S. education system, from those born in the United States, who presumably did attend U.S. schools. In 2010, the status dropout rate for Hispanics born in the United States was higher than the rates for Asians and Whites born in the United States. No measurable differences were found, however, between the rates of U.S.-born Hispanics and Blacks. Overall, the status dropout rate for U.S.-born 16- through 24-year-olds was lower than the rate for their peers born outside of the United States (7 vs. 18 percent). Hispanics and Asians born in the United States had lower status dropout rates than did their counterparts born outside of the United States, whereas U.S.-born Whites and Blacks had higher status dropout rates than did their foreign-born counterparts. A higher dropout rate among Hispanics who were foreign born (31 percent) versus those who were native born (10 percent) partially accounts for the relatively high overall Hispanic dropout rate (16 percent).

Tables A-33-1, A-33-2, and A-33-3

Glossary: Dropout, GED certificate, High school diploma, High school equivalency certificate

\section{Technical Notes}

The United States refers to the 50 states and the District of Columbia. The Current Population Survey (CPS) estimates of the status dropout rate include civilian, noninstitutionalized 16-through 24-year-olds. Young adults in the military or those who are incarcerated, for instance, are not included in the CPS measure. However, the American Community Survey (ACS) estimates of the status dropout rate include those living in noninstitutionalized and institutionalized group quarters. Due to the methodological differences between the CPS and the ACS, status dropout estimates from the two surveys are not directly comparable. Race categories exclude persons of Hispanic ethnicity. For more information on race/ethnicity and the status dropout rate, see Appendix C - Commonly Used Measures. For more information on the CPS and the ACS, see Appendix B Guide to Sources. 
Figure 33-1. Status dropout rates of 16- through 24-year-olds in the civilian, noninstitutionalized population, by race/ ethnicity: October Current Population Survey (CPS) 1995-2010

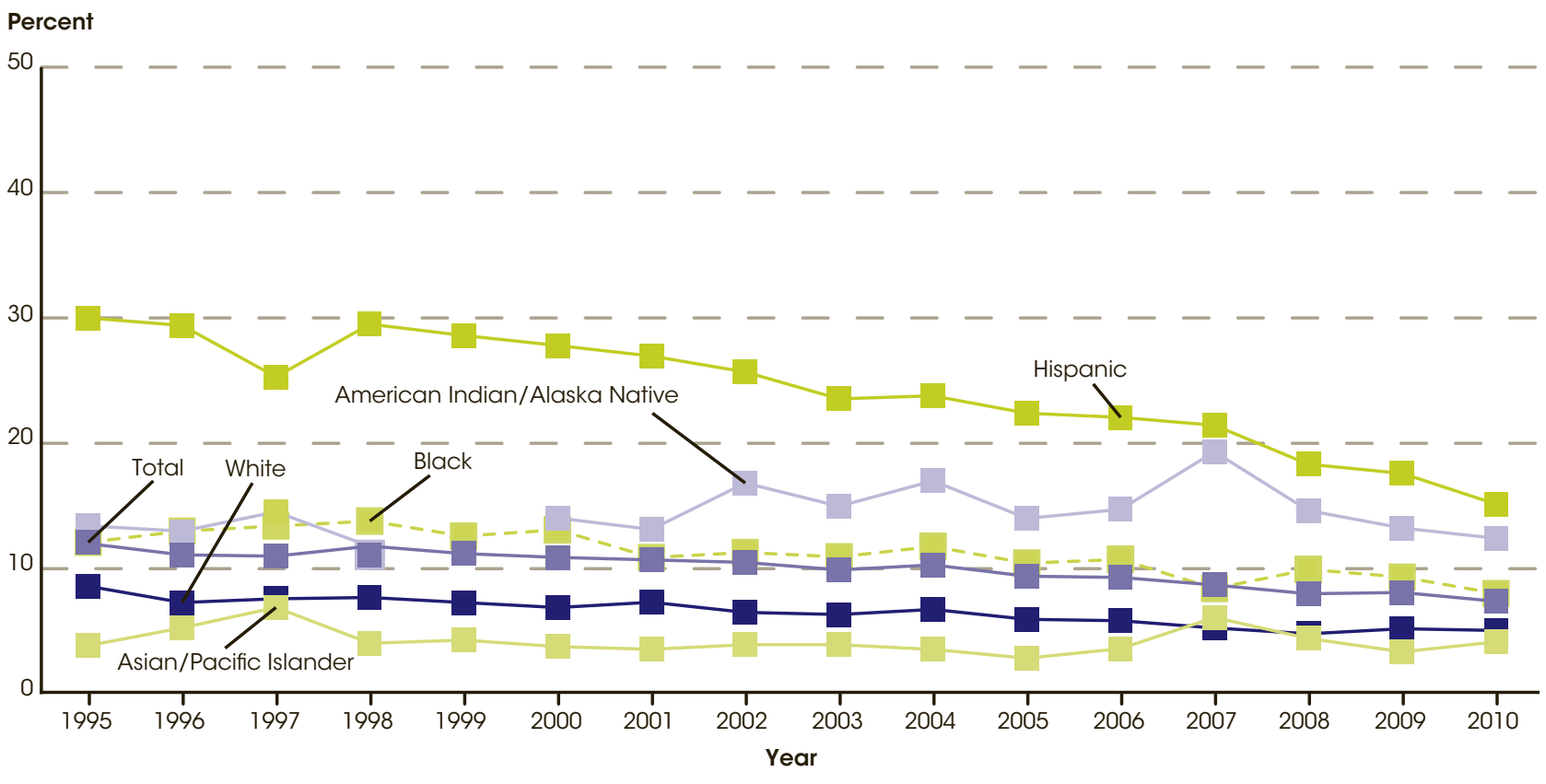

NOTE: Data for American Indians/Alaska Natives in 1999 have been suppressed due to unstable estimates. This figure uses a different data source than figure 33-2; therefore, estimates for 2010 are not directly comparable to the estimates in figure 33-2. Race categories exclude persons of Hispanic ethnicity. For more information on race/ethnicity and the status dropout rate, see Appendix C - Commonly Used Measures. For more information on the Current Population Survey (CPS), see Appendix B - Guide to Sources.

SOURCE: U.S. Department of Commerce, Census Bureau, Current Population Survey (CPS), October Supplement, 1995-2010.

Figure 33-2. Status dropout rates of 16- through 24-year-olds in the noninstitutionalized group quarters and household population, by nativity and race/ethnicity: American Community Survey (ACS) 2010

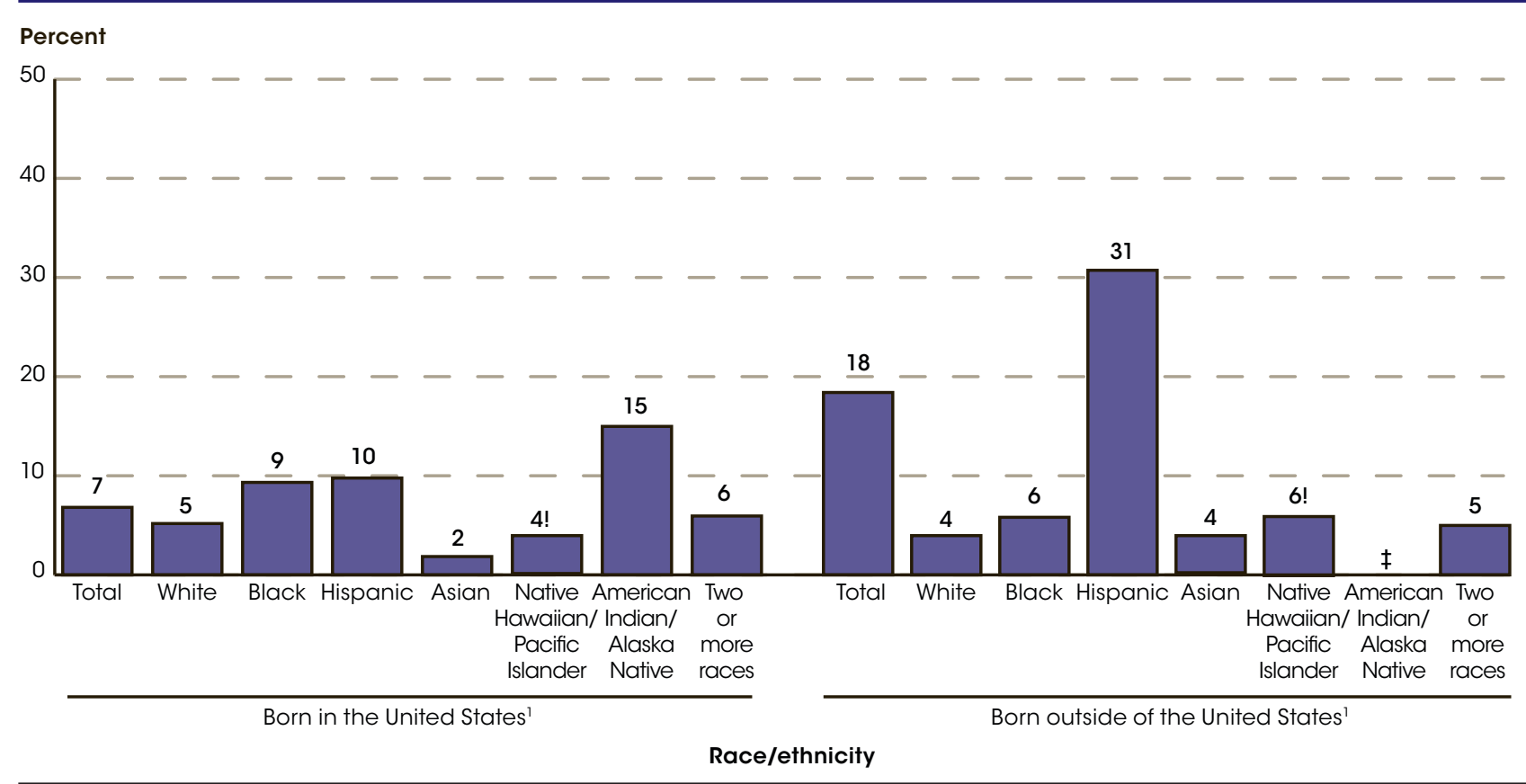

$\ddagger$ Reporting standards not met (†oo few cases).

United States refers to the 50 states and the District of Columbia.

NOTE: This figure uses a different data source than figure 33-1; therefore, estimates are not directly comparable to the 2010 estimates in figure 33-1.

Noninstitutionalized group quarters include college and university housing, military quarters, facilities for workers and religious groups, and temporary shelters for the homeless. Among those counted in noninstitutionalized group quarters in the American Community Survey (ACS), only the residents of military barracks are not included in the civilian noninstitutionalized population in the Current Population Survey. Race categories exclude persons of Hispanic ethnicity. For more information on race/ethnicity and the status dropout rate, see Appendix C - Commonly Used Measures. For more information on the ACS, see Appendix B - Guide to Sources.

SOURCE: U.S. Department of Commerce, Census Bureau, American Community Survey (ACS), 2010. 


\section{Over the 35-year period between 1975 and 2010, the rate of immediate college enrollment after high school ranged from a low of 49 percent in 1979 and 1980 , to a high of 70 percent in 2009. This rate increased most recently from 2001 to 2009.}

The immediate college enrollment rate is defined as the percentage of high school completers of a given year who enroll in 2- or 4-year colleges in the fall immediately after completing high school. During the period of 1975 through 2010, the immediate college enrollment rate ranged from a low of 49 percent to a high of 70 percent (see table A-34-1). Specifically, this rate increased from 1975 to 1997 (51 to 67 percent), declined from 1997 to 2001 (to 62 percent), then increased from 2001 to 2009 (to 70 percent). There was no measurable difference between the rate for 2009 and that for 2010 (68 percent).

In each year between 1975 and 2010, the immediate college enrollment rates of high school completers from low- and middle-income families were lower than those of high school completers from high-income families. Most recently, in 2010, the immediate college enrollment rate of high school completers from low-income families was 52 percent, 30 percentage points lower than the rate of high school completers from high-income families (82 percent). The immediate college enrollment rate of high school completers from middle-income families (67 percent) was 15 percentage points lower than the rate of their peers from high-income families.

Separate data on Asian high school completers have been collected since 2003. Between 2003 and 2010, immediate college enrollment rates increased for Asian high school completers from 80 to 88 percent (see table A-34-2). Despite some apparent increases, there were no measurable differences over this period in the rates for White, Black, or Hispanic high school completers. During the longer period of 1975 to 2010, immediate college enrollment rates increased for White (51 vs. 70 percent) and Black high school completers (43 vs. 66 percent). After accounting for possible sampling error, there was no measurable difference in Hispanic rates over this period of time (approximately 60 percent in both years). In each year between 2003 and 2010, the immediate college enrollment rate of Asian high school completers was higher than the rates of White, Black, and Hispanic high school completers. The immediate college enrollment rate of White high school completers was also higher than the rate for Hispanic students in every year during this period and for Black students in every year from 2003 to 2009. In 2010, there was no measurable difference between the rates for Whites and for Blacks.

Overall, the immediate college enrollment rates of high school completers at both 2-and 4-year colleges increased between 1975 and 2010 (see table A-34-3). In 1975, about 18 percent of high school completers enrolled at a 2 -year college immediately after high school, while 27 percent did so in 2010. Similarly, in 1975, some 33 percent of high school completers enrolled at a 4 -year college immediately after high school, compared with 41 percent in 2010. In each year during this period, immediate college enrollment rates at 2 -year colleges were lower than those at 4-year colleges.

Between 1975 and 2010, immediate college enrollment rates increased for both males and females: the rate for males increased from 53 to 63 percent and that for females, from 49 to 74 percent. Thus, the enrollment pattern has shifted over time to higher enrollment rates for females than males. The percentage of male high school completers who enrolled in a 2 -year college immediately after high school (29 percent) was not measurably different from the percentage for their female peers ( 25 percent). In contrast, the percentage of high school completers who enrolled in a 4 -year college immediately after high school was lower for males than females (34 vs. 49 percent).

Tables A-34-1, A-34-2, and A-34-3

Glossary: Family income, High school completer

\section{Technical Notes}

This indicator provides data on high school completers ages 16-24, who account for about 98 percent of all high school completers in a given year. Enrollment rates were calculated using data from the Current Population Survey (CPS). Before 1992, high school completer referred to those who had completed 12 years of schooling. As of 1992, high school completer refers to those who have received a high school diploma or equivalency certificate. Low income refers to the bottom 20 percent of all family incomes, high income refers to the top 20 percent of all family incomes, and middle income refers to the 60 percent in between. Race categories exclude persons of Hispanic ethnicity. Estimates for Black, Hispanic, Asian, and low-income categories are based on moving averages, which were calculated due to short-term data fluctuations in some years associated with small sample sizes for these groups. For more information on the CPS, see Appendix B - Guide to Sources. For more information on educational attainment, family income, and race/ ethnicity, see Appendix C-Commonly Used Measures. 
Figure 34-1. Percentage of high school completers who were enrolled in 2- or 4-year colleges the October immediately following high school completion, by family income: 1975-2010

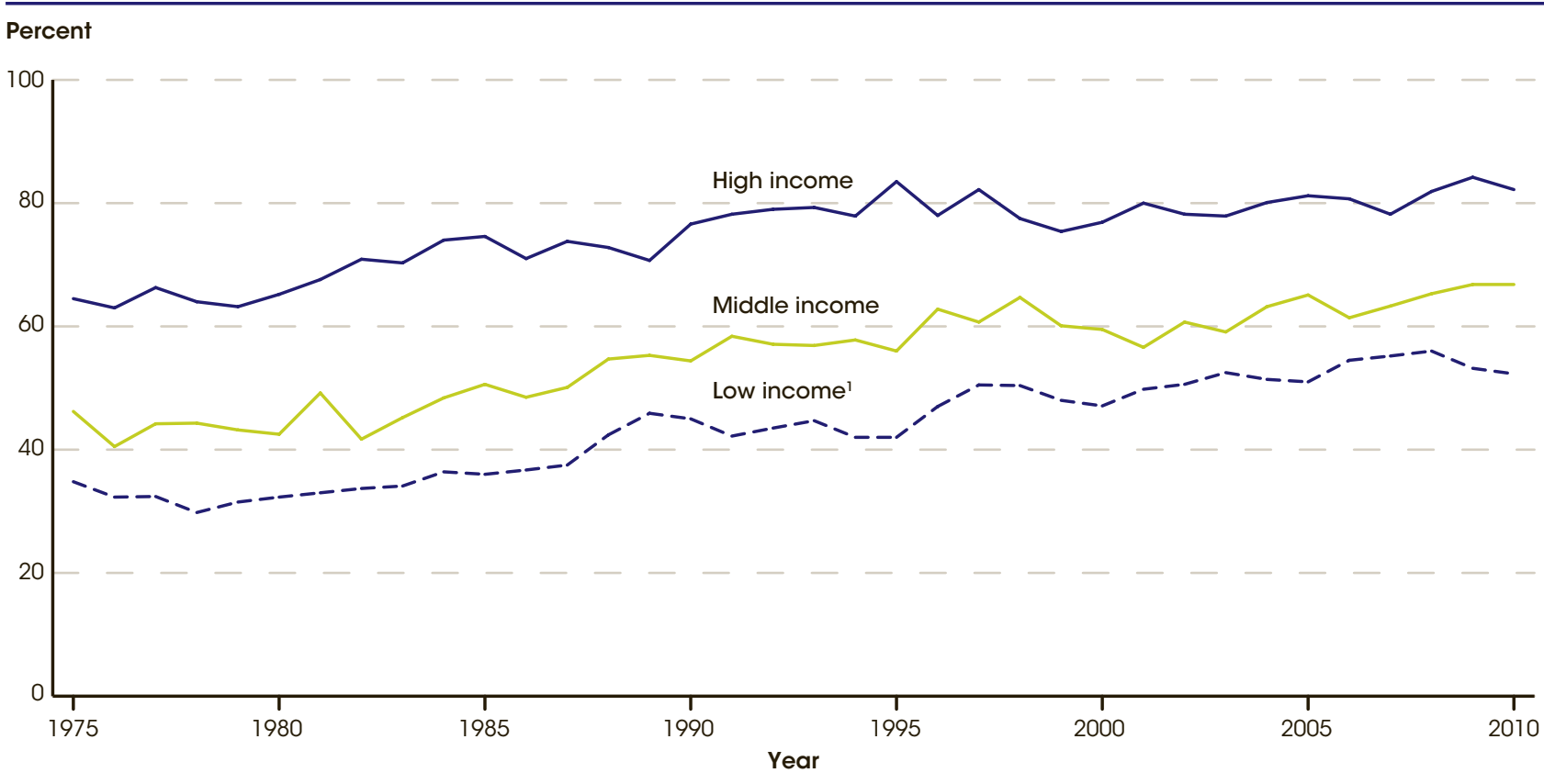

'Due to the small sample size for the low-income category, data are subject to relatively large sampling errors. Therefore, moving averages are used to produce more stable estimates. The 3-year moving average is an arithmetic average of the year indicated, the year immediately preceding, and the yea immediately following. For 1975 and 2010, a 2-year moving average is used: data for 1975 reflect an average of 1975 and 1976 , and data for 2010 reflect an average of 2009 and 2010.

NOTE: Includes high school completers ages 16-24, who account for about 98 percent of all high school completers in a given year. Low income refers to the bottom 20 percent of all family incomes, high income refers to the top 20 percent of all family incomes, and middle income refers to the 60 percent in between. For more information on the Current Population Survey (CPS), see Appendix B - Guide to Sources. For more information on educational attainment and family income, see Appendix C - Commonly Used Measures.

SOURCE: U.S. Department of Commerce, Census Bureau, Current Population Survey (CPS), October Supplement, 1975-2010.

Figure 34-2. Percentage of high school completers who were enrolled in 2- or 4-year colleges the October immediately following high school completion, by race/ethnicity: 1975-2010

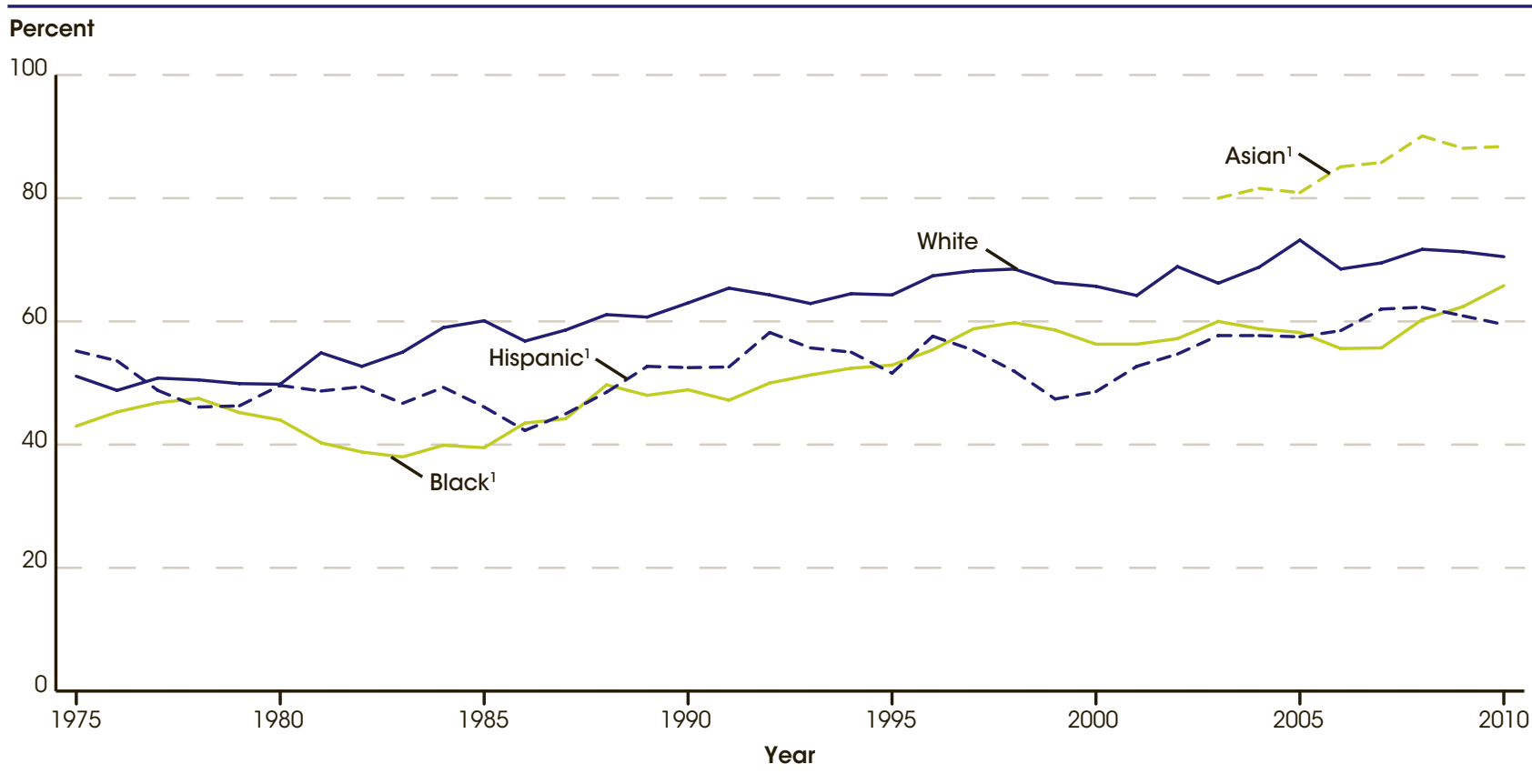

'Due to the small sample sizes for the Black, Hispanic, and Asian categories, data are subject to relatively large sampling errors. Therefore, moving averages are used to produce more stable estimates. The 3-year moving average is an arithmetic average of the year indicated, the year immediately preceding, and the year immediately following. For 1975 and 2010, a 2-year moving average is used: data for 1975 reflect an average of 1975 and 1976 , and data for 2010 reflect an average of 2009 and 2010.

NOTE: Includes high school completers ages 16-24, who account for about 98 percent of all high school completers in a given year. Race categories exclude persons of Hispanic ethnicity. From 2003 onward, data for Asians and Pacific Islanders were collected separately. Separate data for the Asian category are not available prior to 2003. For more information on the Current Population Survey (CPS), see Appendix B - Guide to Sources. For more information on educational attainment and race/ethnicity, see Appendix C - Commonly Used Measures.

SOURCE: U.S. Department of Commerce, Census Bureau, Current Population Survey (CPS), October Supplement, 1975-2010. 


\section{In 1990, 2000, and 2010, higher percentages of female than male 12th-grade students had definite plans to graduate from a 4-year college. This gap in expectations by sex was larger in 2010 than in 1990 (13 vs. 5 percentage points).}

The percentage of 12 th-grade students who had definite plans to graduate from a 4-year college was higher in both 2010 (60 percent) and 2000 (56 percent) than in 1990 (48 percent), but there was no measurable difference between the 2000 and 2010 percentages (see table A-35-1).

In 2010, the percentage of 12th-grade males with plans to graduate from a 4-year college was higher than the percentage in 1990 (53 vs. 46 percent), but was not measurably different from the percentage in 2000 (52 percent). For female 12th-graders, the percentage with plans to graduate from college was higher in 2010 than the respective percentages in both 1990 and 2000 (66 vs. 51 and 61 percent). In all three years, higher percentages of female than male 12th-graders planned to graduate from college. This gap in expectations regarding college completion by sex was larger in 2010 than in 1990 (13 vs. 5 percentage points).

The percentage of White 12th-graders who had definite plans to graduate from a 4-year college was higher in 2010 than in 1990 (61 vs. 50 percent), but not measurably different from the percentage in 2000 (57 percent). Similarly, for Black 12th-graders, the percentage who planned to graduate from college was higher in 2010 than in 1990 (59 vs. 38 percent), but not measurably different from the percentage in 2000 (57 percent). The percentage of Hispanic 12th-graders who planned to graduate from college was also higher in 2010 than in 1990 (50 vs. 38 percent), but not measurably different from the percentage in 2000 (43 percent). In 1990, a higher percentage of White than Black and Hispanic 12th-graders had definite plans to graduate from college. In both 2000 and 2010, there was no measurable difference in the percentage of White and Black 12th-graders who planned to complete college. However, the percentages of both White 12th-graders and Black 12th-graders with definite plans to graduate from college were higher in those years than the percentage of Hispanic 12th-graders with definite plans to graduate from college. Despite some apparent differences, the sizes of the gaps in expectations regarding college completion between Hispanics and Whites and between Hispanics and Blacks were not measurably different between 1990 and 2010 .

The percentages of 12th-grade students who planned to graduate from a 4-year college were higher in 2010 than in 1990 at each level of parents' educational attainment (46 vs. 32 percent for those whose parents attained high school completion or less, 57 vs. 47 percent for those whose parents attained some college, 66 vs. 58 percent for those whose parents attained a bachelor's, and 78 vs. 72 percent for those whose parents attained a graduate or professional degree). In each year shown, higher percentages of 12 th-graders whose parents had more education planned to graduate from college when compared with their peers whose parents had less education. For example, in 2010, some 78 percent of 12 th-graders whose parents had a graduate or professional degree planned to graduate from college, compared with 46 percent of 12 th-graders whose parents had completed a high school education or less. Also in this year, a higher percentage of 12th-graders whose parents had a bachelor's degree (66 percent) planned to graduate from college than their peers whose parents had completed high school or less. However, the gaps in expectations among these groups of 12th-graders were smaller in 2010 than in 1990 (32 vs. 40 percentage points and 20 vs. 26 percentage points, respectively).

\section{Table A-35-1}

\section{Technical Notes}

Percentages reflect 12 th-grade students who indicated that they "definitely will" graduate from college, which refers here to a 4-year degree program. Parents' highest level of education reflects an average of mother's education and father's education based on the respondent's answers about the highest level of education achieved by each parent using the following scale: (1) completed grade school or

less, (2) some high school, (3) completed high school, (4) some college, (5) completed college, (6) graduate or professional school after college. Race categories exclude persons of Hispanic ethnicity. For more information on race/ethnicity, please see Appendix C - Commonly Used Measures. For more information on the Monitoring the Future study, please see Appendix B - Guide to Sources. 
Figure 35-1. Percentage of 12th-grade students with definite plans to graduate from a 4-year college, by sex and race/ethnicity: 1990, 2000, and 2010

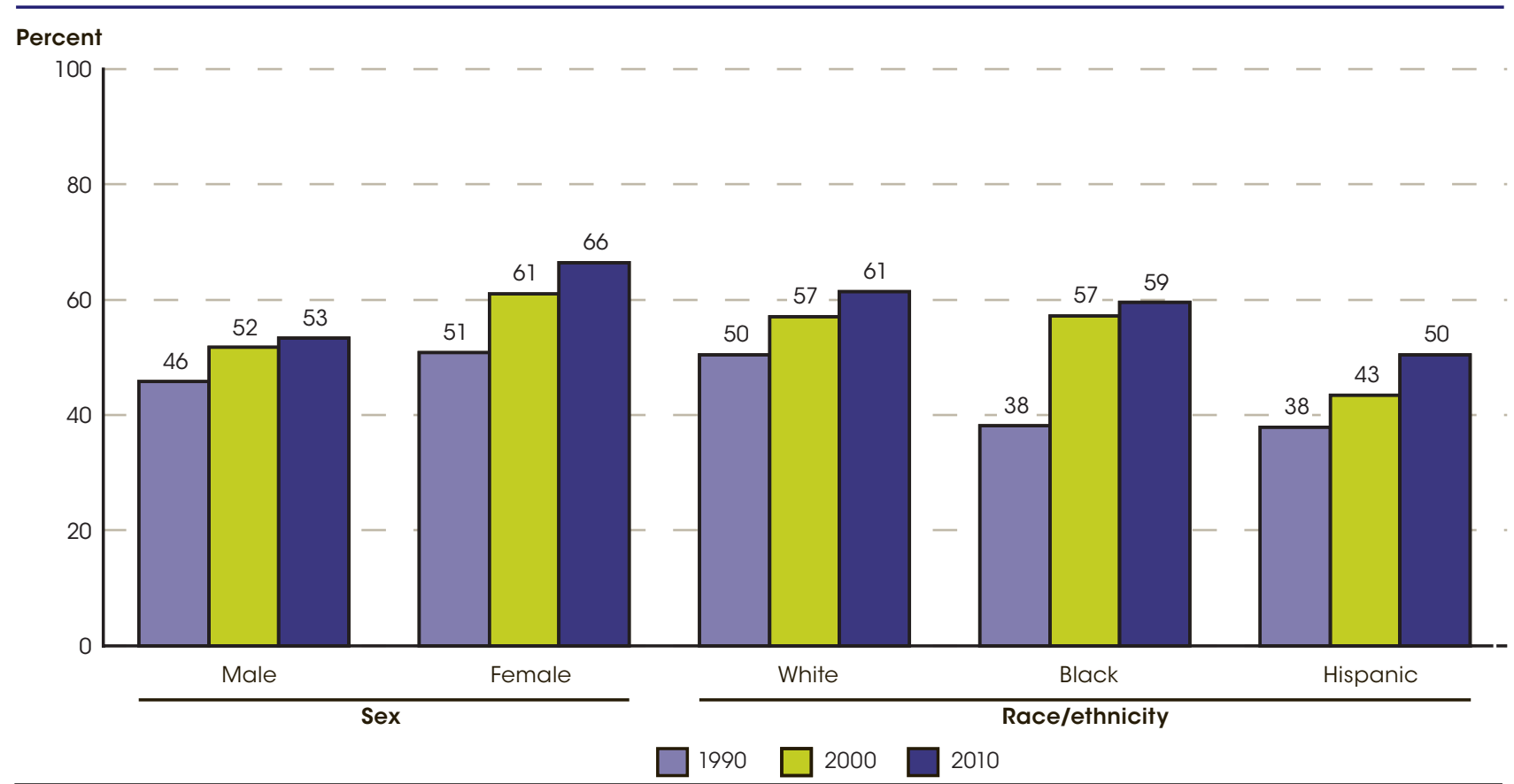

NOTE: Percentages reflect students who indicated that they "definitely will" graduate from a 4-year college. Race categories exclude persons of Hispanic ethnicity. For more information on race/ethnicity, please see Appendix C - Commonly Used Measures. For more information on the Monitoring the Future study, please see Appendix B - Guide to Sources.

SOURCE: University of Michigan, Institute for Social Research, Monitoring the Future, 1990, 2000, and 2010, http://www.monitoringthefuture.org/.

Figure 35-2. Percentage of 12th-grade students with definite plans to graduate from a 4-year college, by parents' highest level of education: 1990, 2000, and 2010

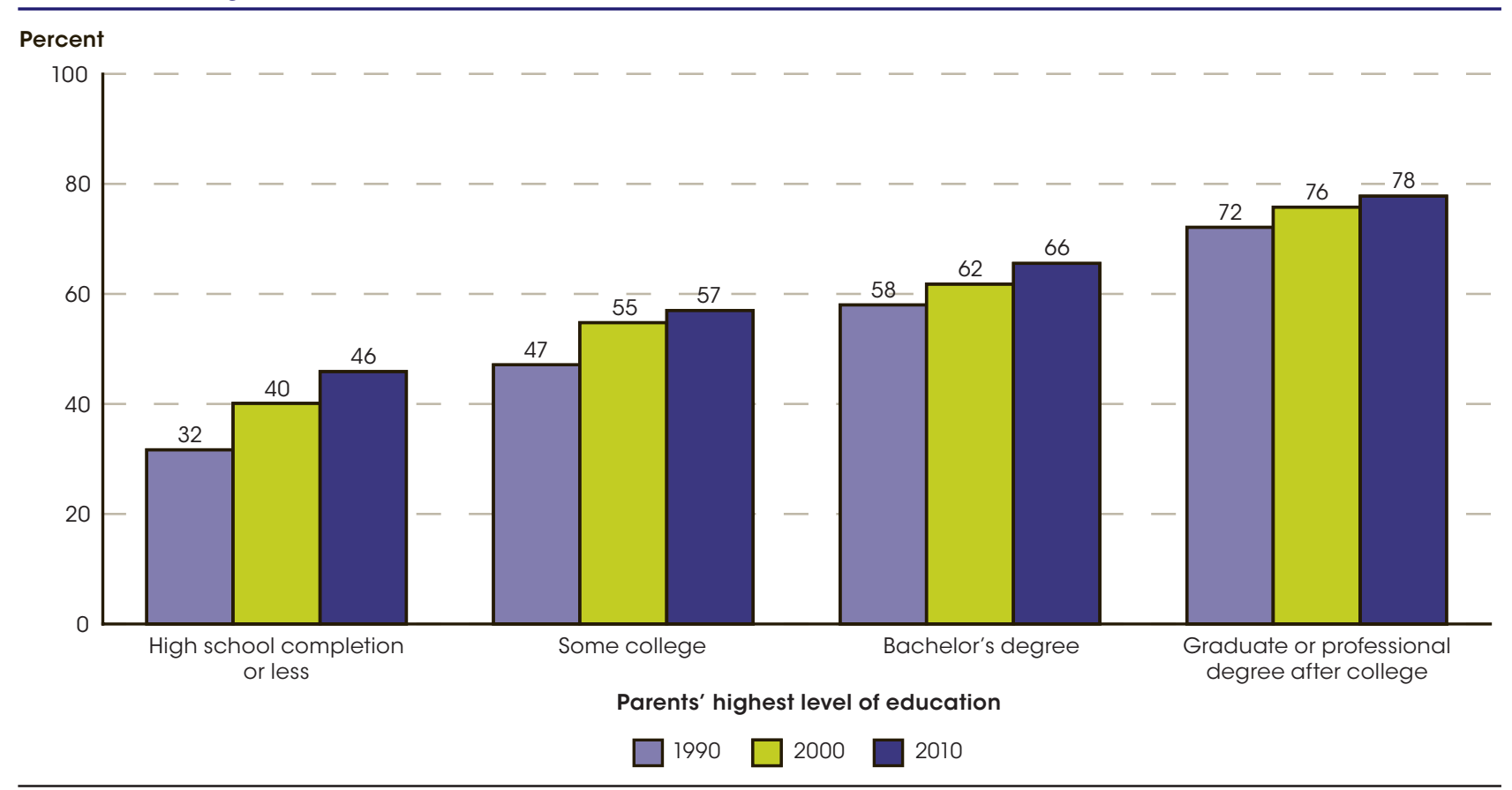

NOTE: Percentages reflect students who indicated that they "definitely will" graduate from a 4-year college. Parents' highest level of education reflects an average of mother's education and father's education based on the respondent's answers about the highest level of education achieved by each parent. For more information on parents' education, please see Appendix C - Commonly Used Measures. For more information on the Monitoring the Future study, please see Appendix B - Guide to Sources.

SOURCE: University of Michigan, Institute for Social Research, Monitoring the Future, 1990, 2000, and 2010, http://www.monitoringthefuture.org/. 
The indicators in this section of The Condition of Education examine features of postsecondary education, many of which parallel those presented in the previous section on elementary and secondary education. The indicators examine the characteristics of postsecondary students; postsecondary programs and courses of study; finance and resources; postsecondary completions; and economic outcomes, both for postsecondary graduates and the general population.

Postsecondary education is characterized by diversity both in the types of institutions and in the characteristics of students. Postsecondary institutions vary by the types of degrees awarded, control (public or private), and whether they are operated on a not-for-profit or for-profit basis. Beyond these basic differences, postsecondary institutions have distinctly different missions and provide students with a wide range of learning environments.

Indicators on postsecondary education and outcomes from previous editions of The Condition of Education not included in this volume are available at http://nces.ed.gov/programs/coe. 


\section{SECTION 3}

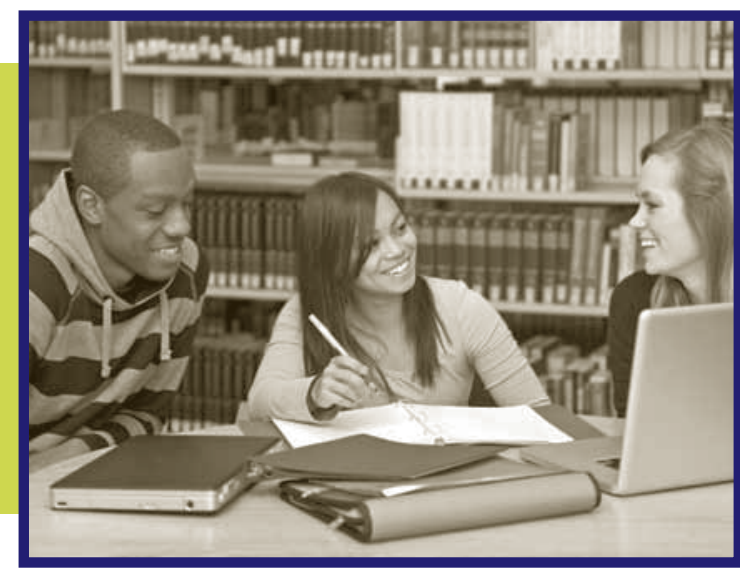

\section{Postsecondary Education}

\section{Characteristics of Postsecondary Students}

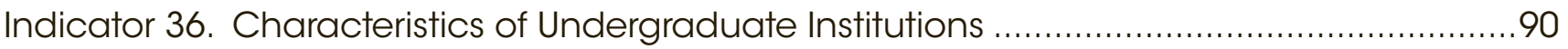

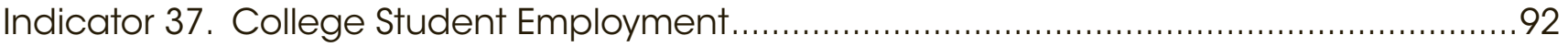

\section{Programs and Courses}

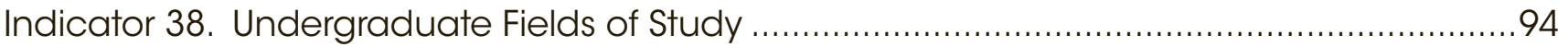

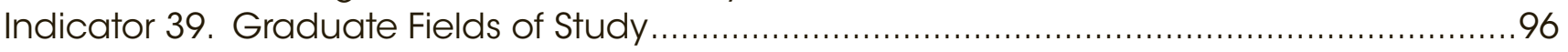

Finance and Resources

Indicator 40. Price of Attending an Undergraduate Institution ..........................................98

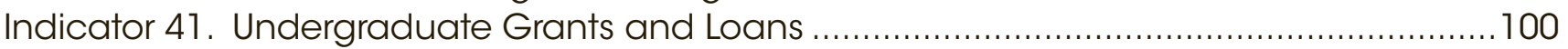

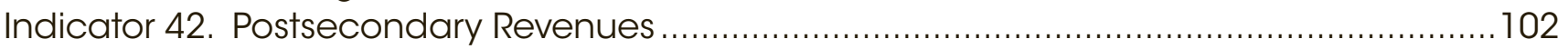

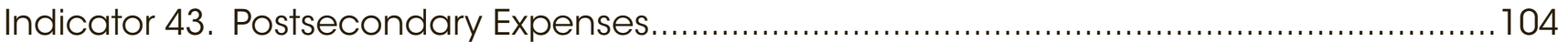

Indicator 44. Faculty Salaries, Benefits, and Total Compensation .....................................106

\section{Completions}

Indicator 45. Postsecondary Graduation Rates .......................................................... 108

Indicator 46. Degrees Conferred by Public and Private Institutions .................................. 110

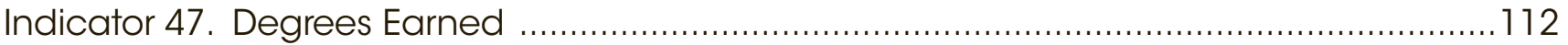

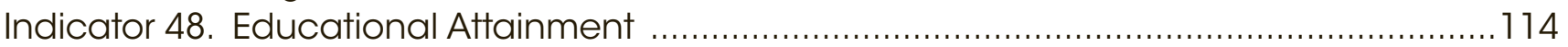

Economic Outcomes

Indicator 49. Annual Earnings of Young Adults 


\section{Of the 18 million undergraduate students at degree-granting institutions in the United States in fall 2010, some 76 percent attended public institutions, 15 percent attended private nonprofit institutions, and 10 percent attended private for-profit institutions.}

Of the 18 million undergraduate students at degreegranting institutions in the United States in fall 2010, some 76 percent attended public, 15 percent attended private nonprofit, and 10 percent attended private for-profit institutions (see table A-36-1). Enrollment patterns by institutional control varied by race/ethnicity. For example, 18 percent of Black undergraduates attended private for-profit institutions in fall 2010, compared with 5 percent of Asian students. Fifty-one percent of Hispanic and 45 percent of both American Indian/Alaska Native and Native Hawaiian/Pacific Islander undergraduates attended public 2-year institutions, compared with 38 percent of White, 40 percent of Black, and 41 percent of Asian students.

Some 11 million undergraduate students attended institutions full time in fall 2010, while 7 million attended part time. Among full-time students, the largest percentage (44 percent) attended public 4-year institutions, followed by 26 percent at public 2 -year institutions and 19 percent at private nonprofit 4-year institutions. In contrast, about two-thirds of part-time students (64 percent) attended public 2-year institutions, 22 percent attended public 4-year institutions, and 7 percent attended private nonprofit 4-year institutions.

Some 79 percent of first-time, full-time students and 45 percent of first-time, part-time students who entered 4-year institutions in 2009 returned the following year to continue their studies; this percentage is known as the retention rate (see table A-36-2). At 2-year institutions, the retention rates for those who first entered school in 2009 were 61 percent for full-time and 42 percent for part-time students. Retention rates of first-time students varied by institutional control. For example, among first-time, full-time undergraduates at 4-year institutions, retention rates were higher at private nonprofit and public institutions (80 and 79 percent, respectively) than at private for-profit institutions (52 percent). However, among first-time, full-time undergraduates at 2 -year institutions, retention rates at private for-profit institutions (67 percent) were higher than those at public and private nonprofit institutions (60 and 59 percent, respectively).

At 4-year institutions, retention rates of first-time students also varied by the percentage of applicants accepted for admission. At 4-year institutions with open admissions policies, 61 percent of first-time, full-time students and 41 percent of first-time, part-time students who enrolled in fall 2009 returned the following year. In contrast, at 4-year institutions that accepted less than a fourth of their applicants, 96 percent of first-time, full-time students and 82 percent of first-time, part-time students who enrolled in fall 2009 returned the following year.

At public 4-year institutions with open admissions policies, 29 percent of students who began as full-time, first-time undergraduates in 2004 completed a bachelor's degree within 6 years (by fall 2010). In contrast, at public 4 -year institutions that accepted less than a fourth of their applicants, 82 percent of such students completed a bachelor's degree within 6 years. At private nonprofit and private for-profit institutions with open admissions policies, the 6-year graduation rates of bachelor's degree recipients in the 2004 cohort were 36 and 23 percent, respectively.

Tables A-36-1 and A-36-2

Glossary: College, Four-year postsecondary institution, Full-time enrollment, Part-time enrollment, Private institution, Public institution, Two-year postsecondary institution

\section{Technical Notes}

Degree-granting institutions grant associate's or higher degrees and participate in Title IV federal financial aid programs. For 4-year institutions, the retention rate is the percentage of first-time, bachelor's degree-seeking students enrolled in the fall who return to the institution to continue their studies in the following fall. For 2-year institutions, the retention rate is the percentage of firsttime degree/certificate-seeking students enrolled in the fall who either return to the institution or successfully complete their program by the following fall. The overall graduation rate is the percentage of full-time, first-time students who enrolled in the fall and graduated out of the institution within 150 percent of normal program completion time. For a bachelor's degree, this represents 6 years. Students who transferred to another institution and graduated are not counted as completers at either of the institutions attended. Race categories exclude persons of Hispanic ethnicity. For more information on the Integrated Postsecondary Education Data System (IPEDS), see Appendix B - Guide to Sources. Institutions in this indicator are classified based on the highest degree offered. For more information on the classification of postsecondary institutions or race/ethnicity, see Appendix C - Commonly Used Measures. 
Figure 36-1. Percentage distribution of fall undergraduate enrollment in degree-granting institutions, by student attendance status and control and level of institution: Fall 2010

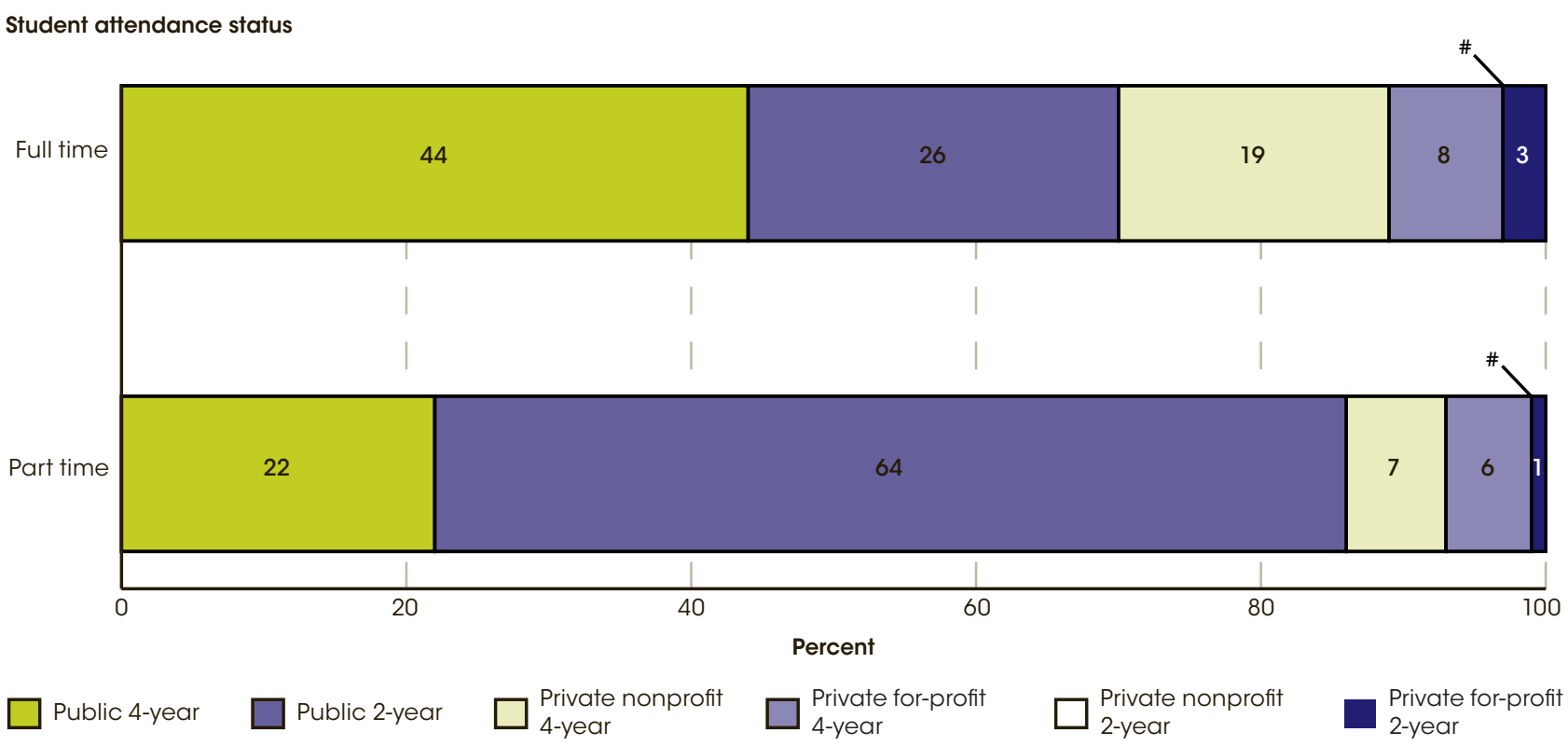

\# The percentage share for private nonprofit 2-year institutions rounds to zero.

NOTE: Degree-granting institutions grant associate's or higher degrees and participate in Title IV federal financial aid programs. Institutions in this indicator are classified based on the highest degree offered. For more information on the classification of postsecondary institutions, see Appendix $\mathrm{C}$ - Commonly Used Measures. For more information on IPEDS, see Appendix B - Guide to Sources.

SOURCE: U.S. Department of Education, National Center for Education Statistics, Integrated Postsecondary Education Data System (IPEDS), Spring 2011, Enrollment component.

Figure 36-2. Annual retention rates and graduation rates within 150 percent of normal time at all 4-year degreegranting institutions, by student attendance status and acceptance rate: Fall 2010

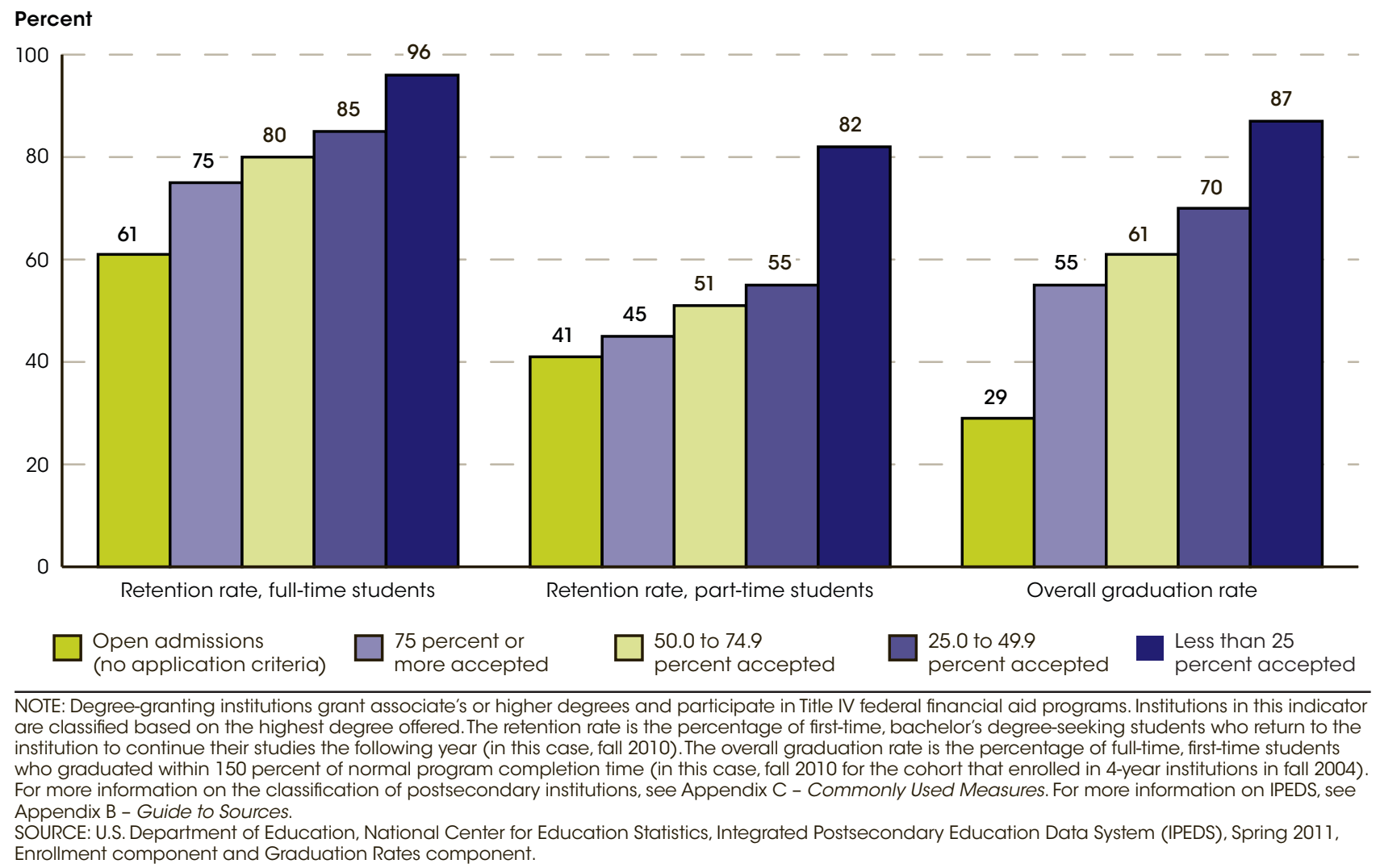




\section{In 2010, about 40 percent of full-time and 73 percent of part-time college students ages 16 to 24 were employed.}

In 2010, about 40 percent of full-time and 73 percent of part-time college students ages 16 to 24 were employed. The percentage of full-time college students ages 16 to 24 who were employed differed by sex and race/ethnicity. A higher percentage of female full-time students were employed than were male full-time students (42 vs. 37 percent) (see table A-37-2). A higher percentage of White students were employed ( 44 percent) than were Hispanic, Black, or Asian students (35 percent, 33 percent, and 30 percent, respectively).

The percentage of students who were employed in 2010 also differed by student enrollment level. The percentage of part-time graduate students who were employed was higher than the percentage of part-time undergraduate students who were employed (90 percent vs. 72 percent). At both the part-time and full-time levels, higher percentages of graduate than undergraduate students worked 35 or more hours per week.

The percentage of full-time college students ages 16 to 24 who were employed increased from 34 to 52 percent between 1970 and 2000 and then decreased to 40 percent in 2010 (see table A-37-1). Among full-time students in this age group, 10 percent worked 20-34 hours per week in 1970, 22 percent in 2000, and 17 percent in 2010. The percentage of these students who worked 35 or more hours per week increased from 4 percent in 1970 to 9 percent in 2000, then fluctuated between 9 and 6 percent between 2000 and 2010 .

Between 1970 and 2000, the percentage of part-time college students who were employed fluctuated between 81 percent and 86 percent, then dropped to 73 percent in 2010. The percentage of part-time college students working 35 or more hours per week decreased from 60 to 47 percent from 1970 to 2000 , decreasing again to 33 percent in 2010 .
At public 4-year institutions, the percentage of full-time students who were employed fluctuated between 43 percent in 1990 and 51 percent in 2000, then declined to 41 percent in 2010. At private 4 -year institutions, the percentage of full-time students who were employed increased from 38 percent in 1990 to 46 percent in 2000, then decreased to 36 percent in 2010. At public 2 -year institutions, the percentages of both full-time and parttime students who were employed did not measurably change between 1990 and 2000, but decreased between 2000 and 2010. Similarly, the percentage of part-time students in public 4-year institutions who were employed did not measurably change from 1990 to 2000, but decreased from 87 percent in 2000 to 70 percent in 2010 . The percentage of part-time students in private 4-year institutions who were employed did not show an overall trend between 1990 and 2010 .

In general, the percentage of full-time students who were employed was higher at public 2-year institutions than at public and private 4-year institutions for most years of data shown between 1990 and 2009. The percentage of full-time students who were employed was higher at public institutions than at private institutions for all years of data shown until 2010, when there were no measurable differences between full-time students at public 2-year, public 4-year, and private 4-year institutions (41 percent, 41 percent, and 36 percent, respectively). The percentage of part-time students who were employed generally did not differ by level and control of institution between 1990 and 2010. In 2010, the percentage of part-time students at private 4-year institutions who were employed was not measurably different from that at public 4-year or public 2-year institutions.

Tables A-37-1 and A-37-2

Glossary: Four-year postsecondary institution, Full-time enrollment, Part-time enrollment, Private institution, Public institution, Two-year postsecondary institution

\section{Technical Notes}

College includes both 2- and 4-year institutions. College students were classified as full-time if they were taking at least 12 hours of classes (or at least 9 hours of graduate classes) during an average school week and as part-time if they were taking fewer hours. Percent employed estimates include those who were employed but not at work during the survey week. Hours worked per week refers to the number of hours the respondent worked at all jobs during

the survey week; these estimates exclude those who were employed but not at work during the survey week. Race categories exclude persons of Hispanic ethnicity. For more information on race/ethnicity and the classification of postsecondary education institutions, see Appendix $\mathrm{C}$ - Commonly Used Measures. For more information on the Current Population Survey (CPS), see Appendix B Guide to Sources. 
Figure 37-1. Percentage of 16- to 24-year-old college students who were employed, by attendance status and hours worked per week: October 1970 through October 2010

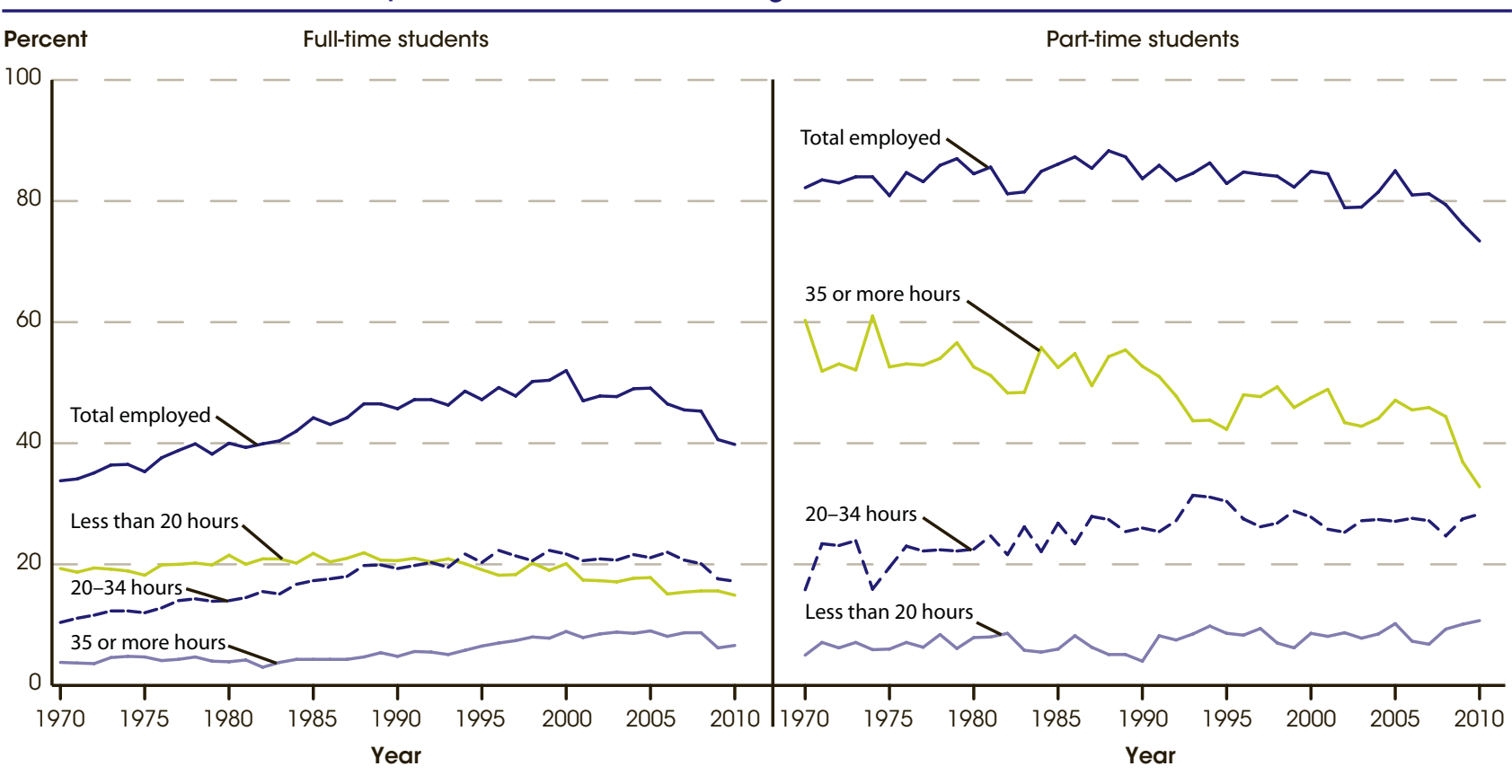

NOTE: College includes both 2- and 4-year institutions. College students were classified as full-time if they were taking at least 12 hours of classes (or at least 9 hours of graduate classes) during an average school week and as part-time if they were taking fewer hours. For more information on the classification of postsecondary education institutions, see Appendix C - Commonly Used Measures. Total employed estimates include those who were employed but not at work during the survey week. Hours worked per week refers to the number of hours the respondent worked at all jobs during the survey week. These estimates exclude those who were employed but not at work during the survey week; therefore, detail may not sum to total percentage employed. For more information on the Current Population Survey (CPS), see Appendix B - Guide to Sources.

SOURCE: U.S. Department of Commerce, Census Bureau, Current Population Survey (CPS), October Supplement, 1970-2010.

Figure 37-2. Percentage of 16- to 24-year-old college students who were employed, by attendance status, hours worked per week, and sex: October 2010

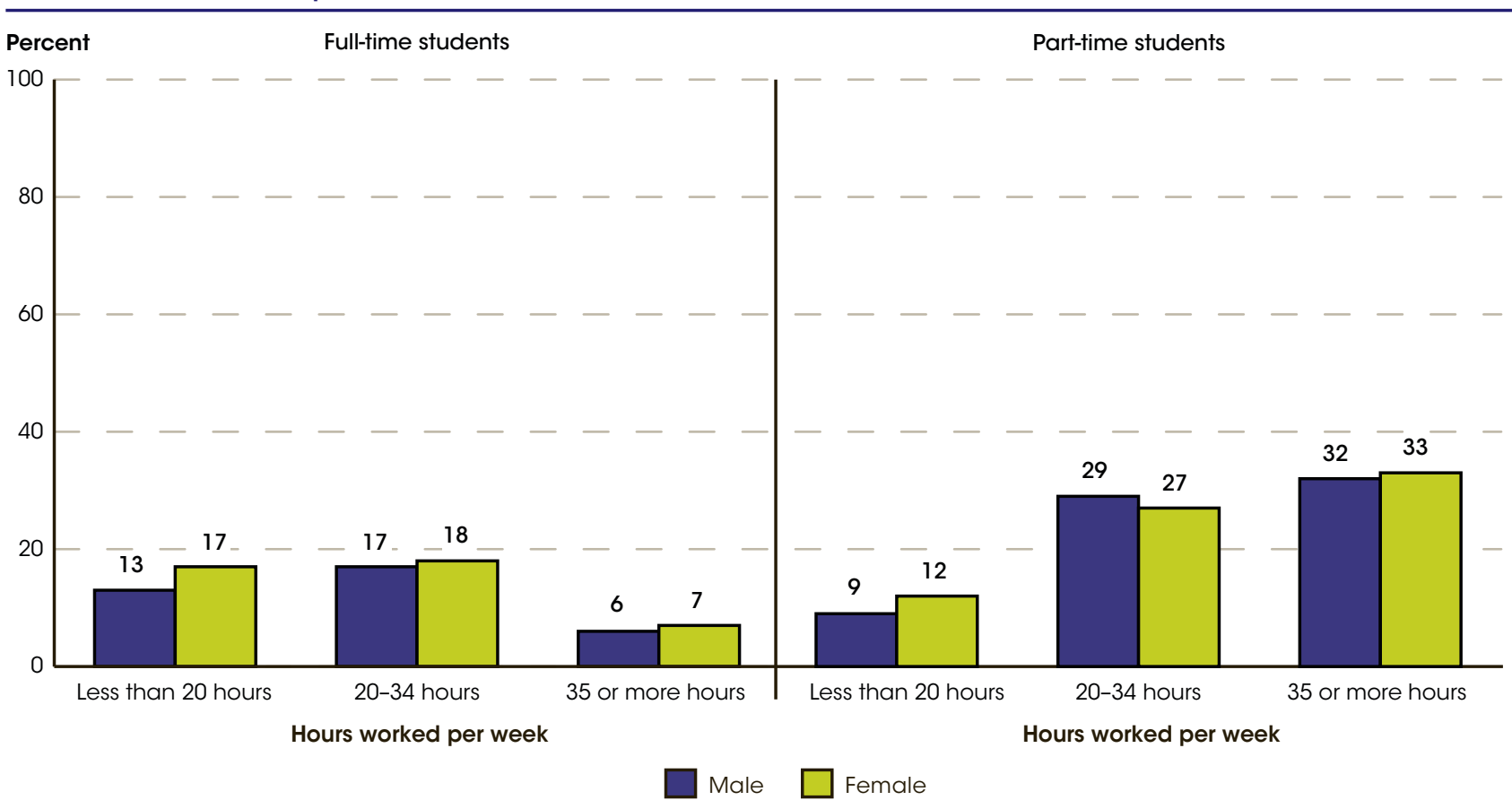

NOTE: College includes both 2- and 4-year institutions. College students were classified as full-time if they were taking at least 12 hours of classes (or at least 9 hours of graduate classes) during an average school week and as part-time if they were taking fewer hours. For more information on the classification of postsecondary education institutions, see Appendix C - Commonly Used Measures. Hours worked per week refers to the number of hours the respondent worked at all jobs during the survey week. These estimates exclude those who were employed but not at work during the survey week; therefore, detail may not sum to total percentage employed. For more information on the Current Population Survey (CPS), see Appendix B - Guide to Sources.

SOURCE: U.S. Department of Commerce, Census Bureau, Current Population Survey (CPS), October Supplement, 2010. 


\section{Indicator 38 \\ Undergraduate Fields of Study}

\section{In 2009-10, more than half of the 1.7 million bachelor's degrees awarded were in five fields: business, management, marketing, and personal and culinary services (22 percent); social sciences and history (10 percent); health professions and related programs (8 percent); education (6 percent); and psychology (6 percent).}

Of the 1.7 million bachelor's degrees awarded in 2009-10, over half were concentrated in five fields: business, management, marketing, and personal and culinary services (22 percent); social sciences and history (10 percent); health professions and related programs (8 percent); education (6 percent); and psychology (6 percent) (see table A-38-1). The fields of visual and performing arts (6 percent), engineering and engineering technologies (5 percent), biological and biomedical sciences (5 percent), and communication and communications technologies (5 percent) represented an additional 21 percent of all bachelor's degrees awarded in 2009-10.

Undergraduate enrollment increased from 12.7 million students in fall 1999 to 17.6 million in fall 2009 (see indicator 10). Overall, 33 percent more bachelor's degrees were awarded in 2009-10 than in 1999-2000 (an increase of 412,000 degrees). Bachelor's degrees awarded in the field of parks, recreation, leisure, and fitness studies exhibited the largest percent increase of all fields (from 17,600 to 33,300 degrees, a 90 percent increase). The next largest percent increase was in the field of homeland security, law enforcement, firefighting, and related protective services (from 24,900 to 43,700 degrees, a 76 percent change). Education was the only field in which fewer bachelor's degrees were awarded in 2009-10 than in 1999-2000 (from 108,000 to 101,000, a decrease of 6 percent).

Over half of all bachelor's degrees conferred in 2009-10 were awarded to females (57 percent), similar to the percentage awarded to females in 1999-2000. Females earned between 49 and 85 percent of the degrees awarded in the five most prevalent bachelor's degree fields. In 2009-10, females earned the smallest percentages of bachelor's degrees relative to males in the fields of engineering and engineering technologies (17 percent) and computer and information sciences and support services (18 percent).

From 1999-2000 to 2009-10, the percentages of bachelor's degrees conferred to females changed in several fields of study. For example, of all the bachelor's degrees conferred in the field of homeland security, law enforcement, firefighting, and related protective services, the percentage conferred to females increased from 43 percent in 1999-2000 to 49 percent in 2009-10. In contrast, of all the bachelor's degrees conferred in the field of computer and information sciences and support services, the percentage conferred to females decreased from 28 percent in 1999-2000 to 18 percent in 2009-10.

Of the 849,000 associate's degrees earned in 2009-10, about 54 percent were awarded in two broad areas of study: liberal arts and sciences, general studies, and humanities (34 percent) and health professions and related programs (21 percent). Overall, the number of associate's degrees awarded from 1999-2000 to 2009-10 increased by 50 percent, or by 285,000 degrees. The field of psychology experienced the largest percent increase in the number of associate's degrees awarded over this time period (352 percent, from 1,500 to 6,600 degrees). Of the 20 fields of study in which the most associate's degrees were awarded in 2009-10, two fields experienced a decline from the number of degrees awarded in 1999-2000: some 770 fewer associate's degrees were awarded in agriculture and natural resources (a decrease of 12 percent), and 4,200 fewer degrees were awarded in engineering and engineering technologies (a decrease of 7 percent).

In 2009-10, females earned 62 percent of all associate's degrees awarded. The fields in which females earned the highest percentage of associate's degrees included family and consumer sciences/human sciences (95 percent were awarded to females) and legal professions and studies (88 percent). Females earned fewer associate's degrees than males in fields such as precision production (6 percent) and engineering and engineering technologies (10 percent).

\section{Table A-38-1}

Glossary: Associate's degree, Bachelor's degree, Classification of Instructional Programs (CIP), STEM fields, Undergraduate student

\section{Technical Notes}

This indicator includes only institutions that participated in Title IV federal financial aid programs. The new Classification of Instructional Programs was initiated in 2009-10. Estimates for 1999-2000 have been reclassified when necessary to conform to the new taxonomy. For more information on the classification of postsecondary education institutions, see Appendix C - Commonly Used Measures. For more information on the Integrated Postsecondary Education Data System (IPEDS), see Appendix B - Guide to Sources. 
Figure 38-1. Number of bachelor's degrees awarded by degree-granting institutions in selected fields of study: Academic years 1999-2000 and 2009-10

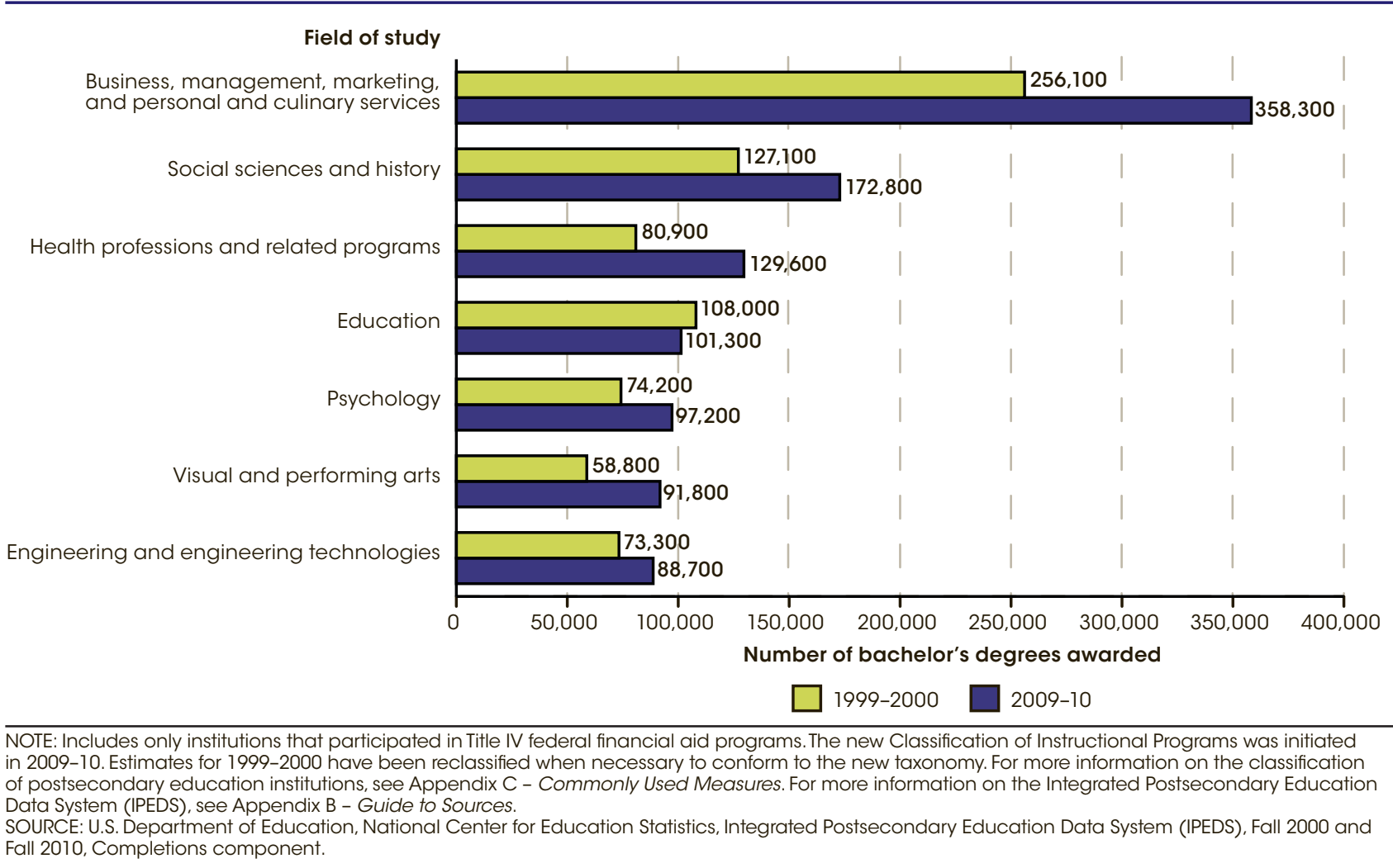

Figure 38-2. Percentage of bachelor's degrees awarded to females by degree-granting institutions in selected fields of study: Academic year 2009-10

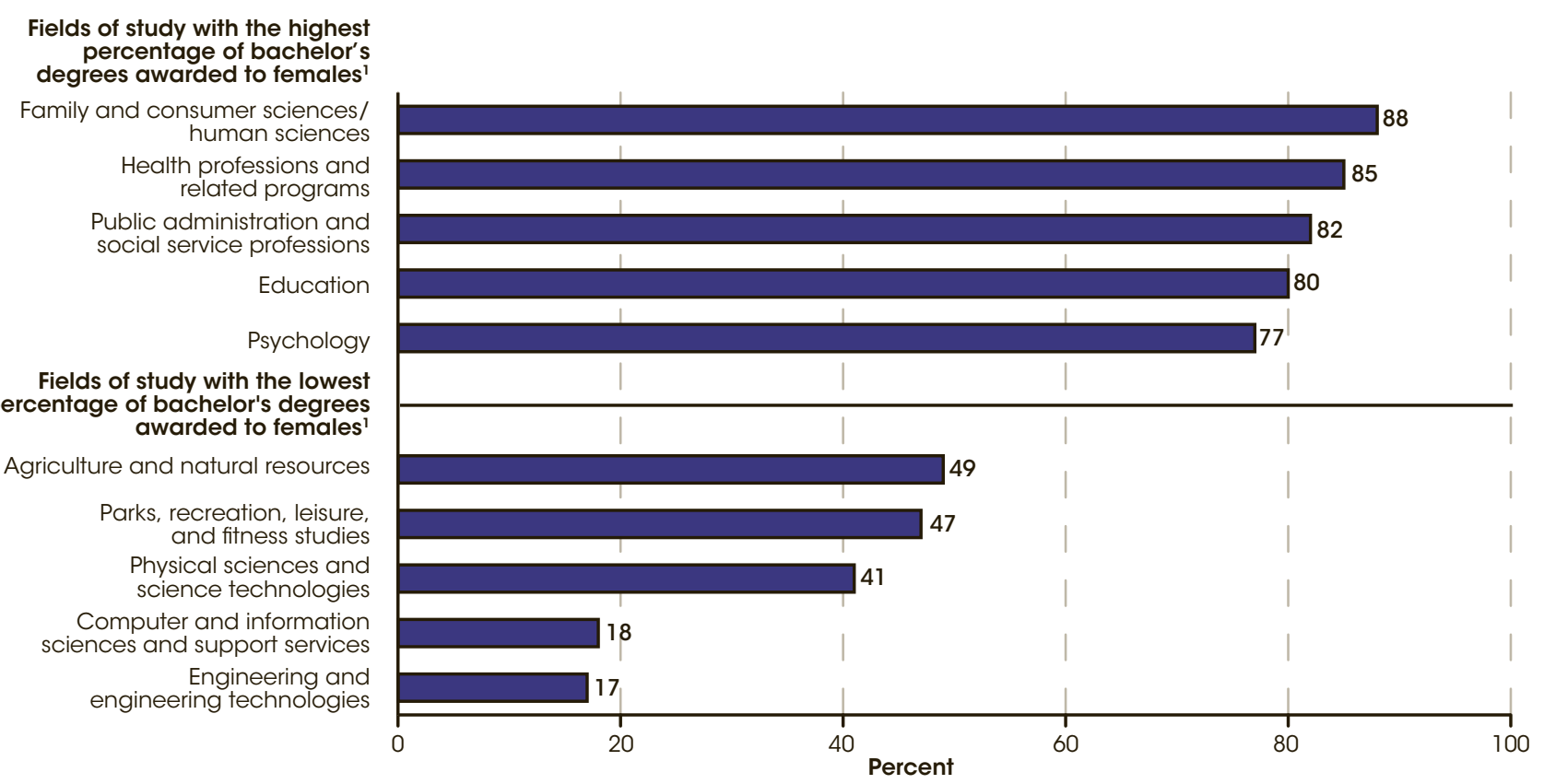

1 Of the 20 fields of study in which the most bachelor's degrees were awarded in 2009-10.

NOTE: Includes only institutions that participated in Title IV federal financial aid programs. For more information on the classification of postsecondary education institutions, see Appendix C - Commonly Used Measures. For more information on the Integrated Postsecondary Education Data System (IPEDS), see Appendix B - Guide to Sources.

SOURCE: U.S. Department of Education, National Center for Education Statistics, Integrated Postsecondary Education Data System (IPEDS), Fall 2010, Completions component. 


\section{Overall, 693,000 master's degrees and 159,000 doctor's degrees were awarded in 2009-10; these numbers represent increases of 50 and 34 percent, respectively, over the numbers awarded in 1999-2000. In 2009-10, females earned 60 percent of master's degrees and 52 percent of doctor's degrees awarded.}

Of the 693,000 master's degrees awarded in 2009-10, over 50 percent were concentrated in two fields: education and business (26 percent each) (see table A-39-1). These are the same two fields in which the majority of master's degrees were awarded in 1999-2000. In 2009-10, an additional 10 percent of all master's degrees were awarded in the field of health professions and related programs.

Overall, 50 percent more master's degrees were awarded in 2009-10 than in 1999-2000 (an increase of 230,000 degrees). During this period, the two fields awarding the most master's degrees, education and business, had increases of 48 and 59 percent, respectively, in the number of degrees awarded. In each of the 20 fields of study in which the most master's degrees were awarded in 2009-10, the number of master's degrees awarded was higher in 2009-10 than in 1999-2000. The field of homeland security, law enforcement, and firefighting had the largest percent increase (157 percent) in the number of master's degrees awarded (from 2,600 to 6,700 degrees). The field of theology and religious vocations saw the smallest percent increase (10 percent) in the number of master's degrees awarded over this period (from 11,700 to 12,800 degrees).

Females earned 60 percent of all master's degrees awarded in 2009-10. From 1999-2000 to 2009-10, there were two fields where the portion of master's degrees awarded to females increased from less than half to more than half: homeland security, law enforcement, and firefighting (from 41 percent to 53 percent) and legal professions and studies (from 42 percent to 51 percent). In the two fields awarding the most master's degrees in 2009-10, education and business, females earned 77 and 46 percent, respectively. In addition, females earned 81 percent of all master's degrees awarded in the field of health professions and related programs that year. In fields such as engineering and engineering technologies and computer and information sciences, females earned fewer master's degrees than males in 2009-10: some 22 percent of the master's degrees awarded in engineering and engineering technologies and 27 percent of the master's degrees awarded in computer and information sciences were awarded to females.

Almost two-thirds of the 159,000 doctor's degrees awarded in 2009-10 were either health professions and related programs degrees (36 percent) or legal professions and studies degrees (28 percent). Overall, there were 34 percent more doctor's degrees awarded in 2009-10 than in 1999-2000 (an increase of 39,800 degrees). In all but two of the 20 most popular fields of study (i.e., English language and literature/letters, and agriculture and natural resources), the numbers of doctor's degrees awarded were higher in 2009-10 than in 1999-2000. The field of computer and information sciences had the largest percentage increase (105 percent) in the number of doctor's degrees awarded (from 780 to 1,600 degrees). The field of English language and literature/letters had the largest percentage decrease ( 9 percent) in the number of doctor's degrees awarded (from 1,500 to 1,300 degrees).

Females earned about 82,000 doctor's degrees (or 52 percent of all doctor's degrees awarded) in 2009-10, a 52 percent increase over the number awarded to females in 1999-2000. From 1999-2000 to 2009-10, there were two fields in which the portion of doctor's degrees awarded to females increased from less than half to more than half: health professions and related programs (from 47 percent to 59 percent) and biological and biomedical sciences (from 44 percent to 53 percent). Of the 20 fields of study in which the most doctor's degrees were awarded in 2009-10, females earned the smallest percentages of doctor's degrees relative to males in the fields of computer and information sciences ( 22 percent) and engineering and engineering technologies (23 percent). In contrast, females earned the greatest percentages of doctor's degrees relative to males in psychology ( 73 percent) and education (67 percent).

Table A-39-1

Glossary: Classification of Instructional Programs (CIP), Doctor's degree, Master's degree

\section{Technical Notes}

This indicator includes only institutions that participated in Title IV federal financial aid programs. The new Classification of Instructional Programs was initiated in 2009-10. The estimates for 1999-2000 have been reclassified when necessary to make them conform to the new taxonomy. Doctor's degrees include Ph.D., Ed.D., and comparable degrees at the doctoral level, as well as most degrees formerly classified as first-professional, such as M.D., D.D.S., and law degrees. For more information on the Integrated Postsecondary Education Data System (IPEDS) classification of institutions and degree levels, see Appendix C - Commonly Used Measures. For more information on IPEDS, see Appendix B - Guide to Sources. 
Figure 39-1. Number of master's degrees awarded by degree-granting institutions in selected fields of study: Academic years $1999-2000$ and $2009-10$

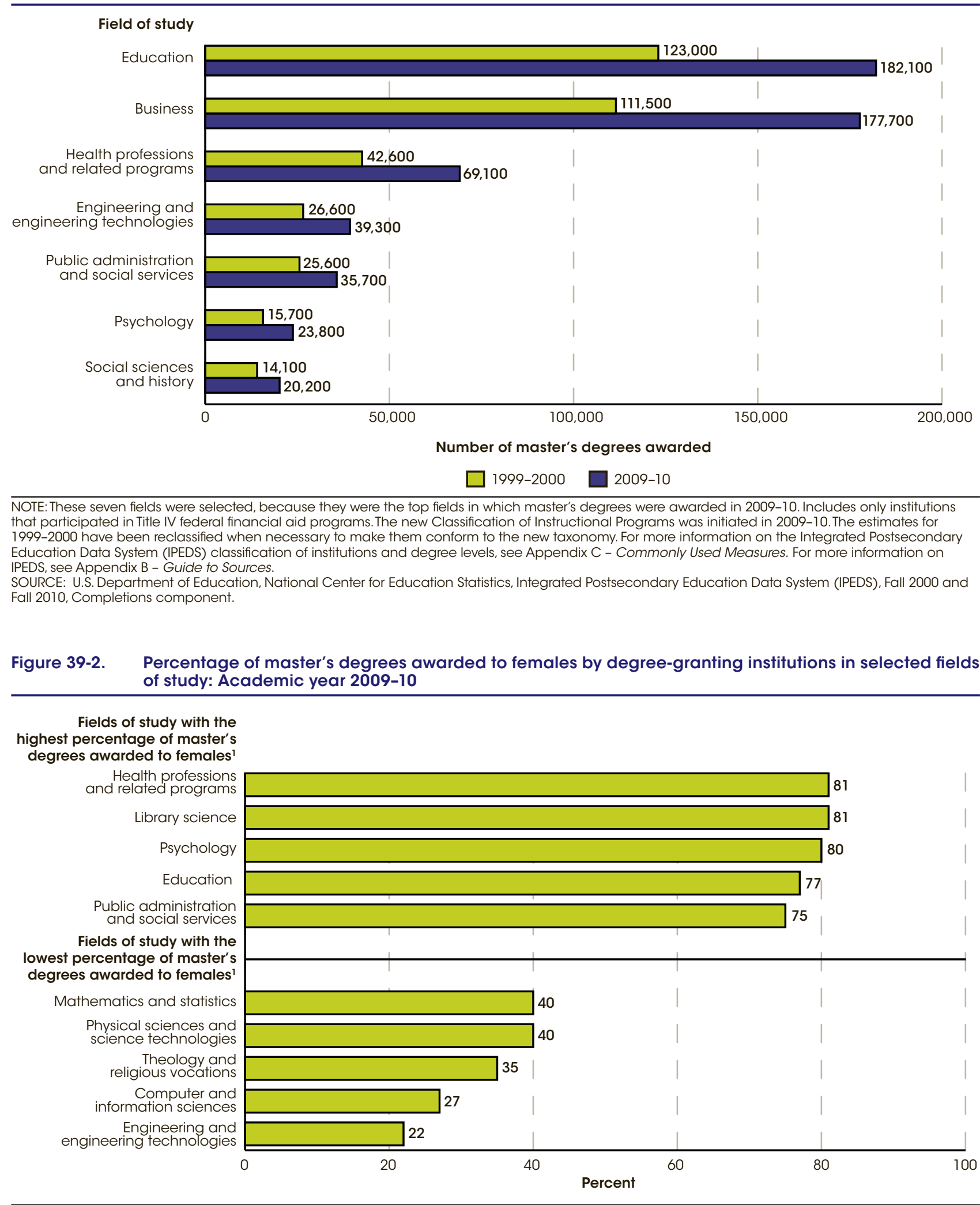

1 Of the 20 fields of study in which the most master's degrees were awarded in 2009-10.

NOTE: Includes only institutions that participated in Title IV federal financial aid programs. The new Classification of Instructional Programs was initiated in 2009-10. For more information on the Integrated Postsecondary Education Data System (IPEDS) classification of institutions and degree levels, see Appendix C - Commonly Used Measures. For more information on IPEDS, see Appendix B - Guide to Sources.

SOURCE: U.S. Department of Education, National Center for Education Statistics, Integrated Postsecondary Education Data System (IPEDS), Fall 2010, Completions component. 


\section{The average total cost of attendance in 2010-1 1 for first-time, full-time students living on campus and paying in-state tuition was $\$ 20,100$ at public 4-year institutions and $\$ 39,800$ at private nonprofit 4-year institutions.}

The total cost of attending a postsecondary institution is the sum of published tuition and required fees, books and supplies, and the average for room, board and other expenses. In 2010-11, the total cost of attendance differed by institution level and control and by student living arrangements. The average total cost of attendance for first-time, full-time students living on campus and paying in-state tuition was $\$ 20,100$ at public 4-year institutions and $\$ 39,800$ at private nonprofit 4-year institutions (see table A-40-1). The lowest total costs were for students living with family and paying in-state tuition at public 2-year institutions $(\$ 7,900)$ and at public 4-year institutions $(\$ 12,600)$.

Out of these total costs, the cost of books and supplies and of room and board differed by institution level and control and student living arrangements. The cost of books and supplies ranged from $\$ 800$ at private for-profit 4-year institutions to $\$ 1,500$ at private for-profit 2-year institutions. The cost of room and board ranged from $\$ 5,400$ for first-time, full-time students living on campus and paying in-state tuition at 2-year public institutions to $\$ 9,500$ for first-time, full-time students living on campus at private nonprofit 4-year institutions.

Many students and their families do not pay the full price of attendance because they receive financial aid to help cover their expenses. The primary types of financial aid are grants, which do not have to be repaid, and loans, which must be repaid. Grants, including scholarships, may be awarded on the basis of financial need, merit, or both, and may include tuition aid from employers. In 2009-10, first-time, full-time students who received aid received an average of $\$ 8,400$ at 4 -year institutions and $\$ 4,400$ at 2-year institutions (see table A-40-2).

The average amount of aid received differed by income level; in general, the lower the income, the greater the total amount of aid received. In 2009-10, across all 4-year institutions, for first-time, full-time students receiving aid, the average amount of aid received ranged from a low of $\$ 900$ for those with incomes above $\$ 110,000$ at private for-profit institutions to $\$ 18,400$ at private nonprofit institutions for those with incomes ranging from $\$ 30,001$ to $\$ 48,000$. The overall average amount of aid received across all 4-year institutions was \$8,400 in 2009-10.

The net price is an estimate of the cash outlay, including loans that students and their families need to pay in a given year to cover educational expenses. It is calculated here as the total cost of attendance minus grants (which decrease the price). Tax credits and deductions are excluded from the calculation of net price. In 4-year institutions, average net price in 2009-10 for first-time, full-time students receiving aid ranged from $\$ 7,900$ for those with incomes in the $\$ 0$ to $\$ 30,000$ range at public institutions to $\$ 33,200$ at private for-profit institutions for those with incomes above $\$ 110,001$. For first-time, full-time students receiving aid at 2-year institutions, the lowest average net price was $\$ 5,500$ for those with incomes in the $\$ 0$ to $\$ 30,000$ range at public institutions and the highest average net price was $\$ 32,500$ at private for-profit institutions for those with incomes of $\$ 110,001$ or more.

Tables A-40-1 and A-40-2

Glossary: Financial aid, Private institution, Public institution, Tuition

\section{Technical Notes}

Data on total cost of attendance pertain to first-time, full-time undergraduate students who paid the in-state or in-district tuition rate. These data are weighted by the number of first-time, full-time students at the institution receiving Title IV aid and living on campus, living off campus, or living with their family off campus. Title IV aid includes grant aid, work study aid, and loan aid. Grant aid refers to federal, state, and local government, as well as institutional, grants and scholarships. Year-to-year changes in cost may be affected by changes in enrollment. Data on average amount of grant aid and scholarship aid and net price are only for students receiving Title IV financial aid and include both dependent and independent students. For those Title IV recipients, net price is reported by income category and includes students who received federal aid, even if none of that aid was provided in the form of grants. While Title IV status defines the cohort of students for which the data are reported, the definition of net price remains the same-total cost of attendance minus grant aid. For more information on the Integrated Postsecondary Education Data System (IPEDS), see Appendix B - Guide to Sources. 
Figure 40-1. Total cost of attending an undergraduate institution for first-time, full-time students, by level and control of institution and living arrangement: Academic year 2010-11

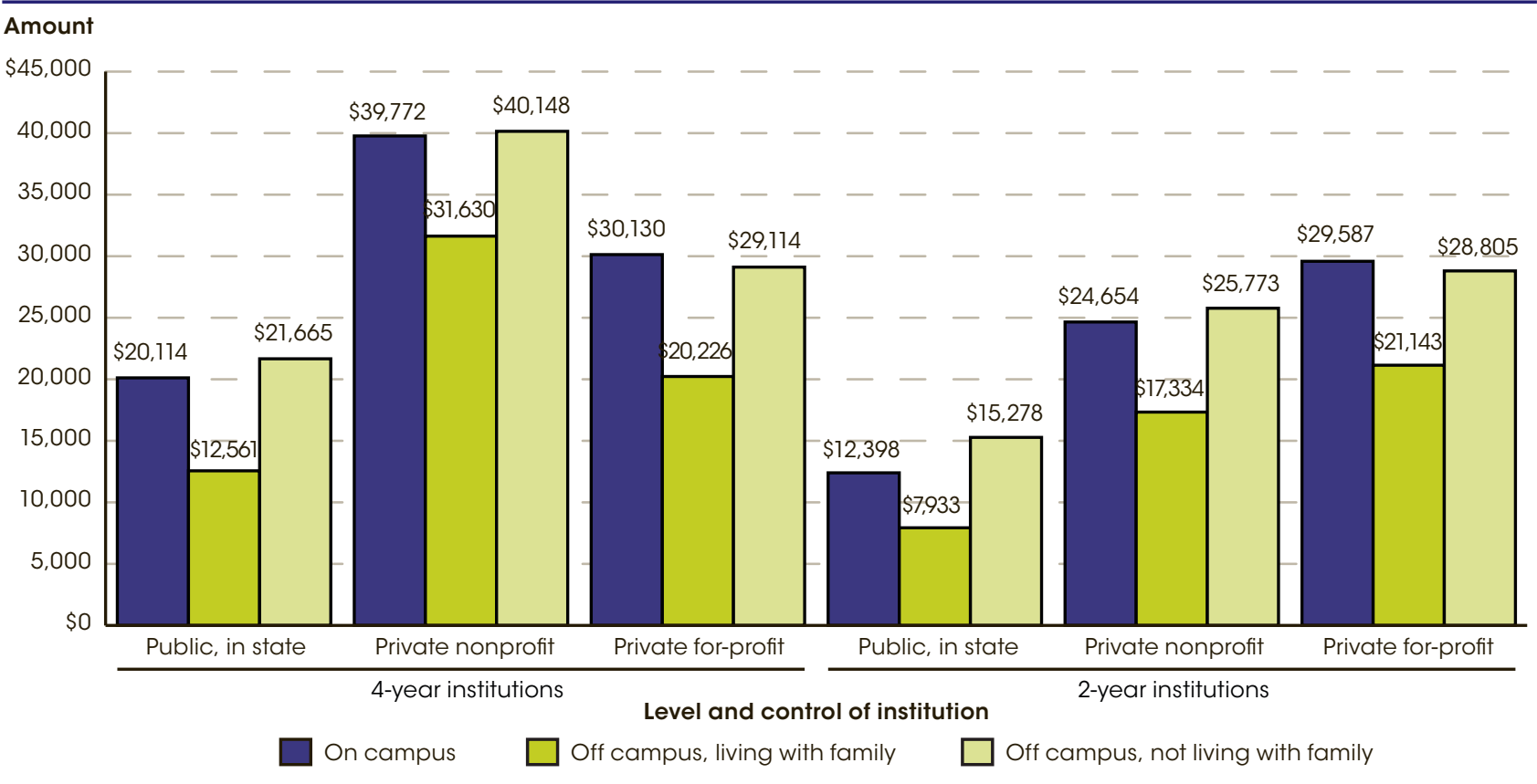

NOTE: Excludes students who have already attended another postsecondary institution. For more information on the Integrated Postsecondary Education Data System (IPEDS), see Appendix B - Guide to Sources.

SOURCE: U.S. Department of Education, National Center for Education Statistics, Integrated Postsecondary Education Data System (IPEDS), Spring 201 1 ,

Student Financial Aid component; and Fall 2010, Institutional Characteristics component.

Figure 40-2. Average total price, grants and scholarship aid, and net price for first-time, full-time students receiving aid at 4-year institutions, by income level: Academic year 2009-10

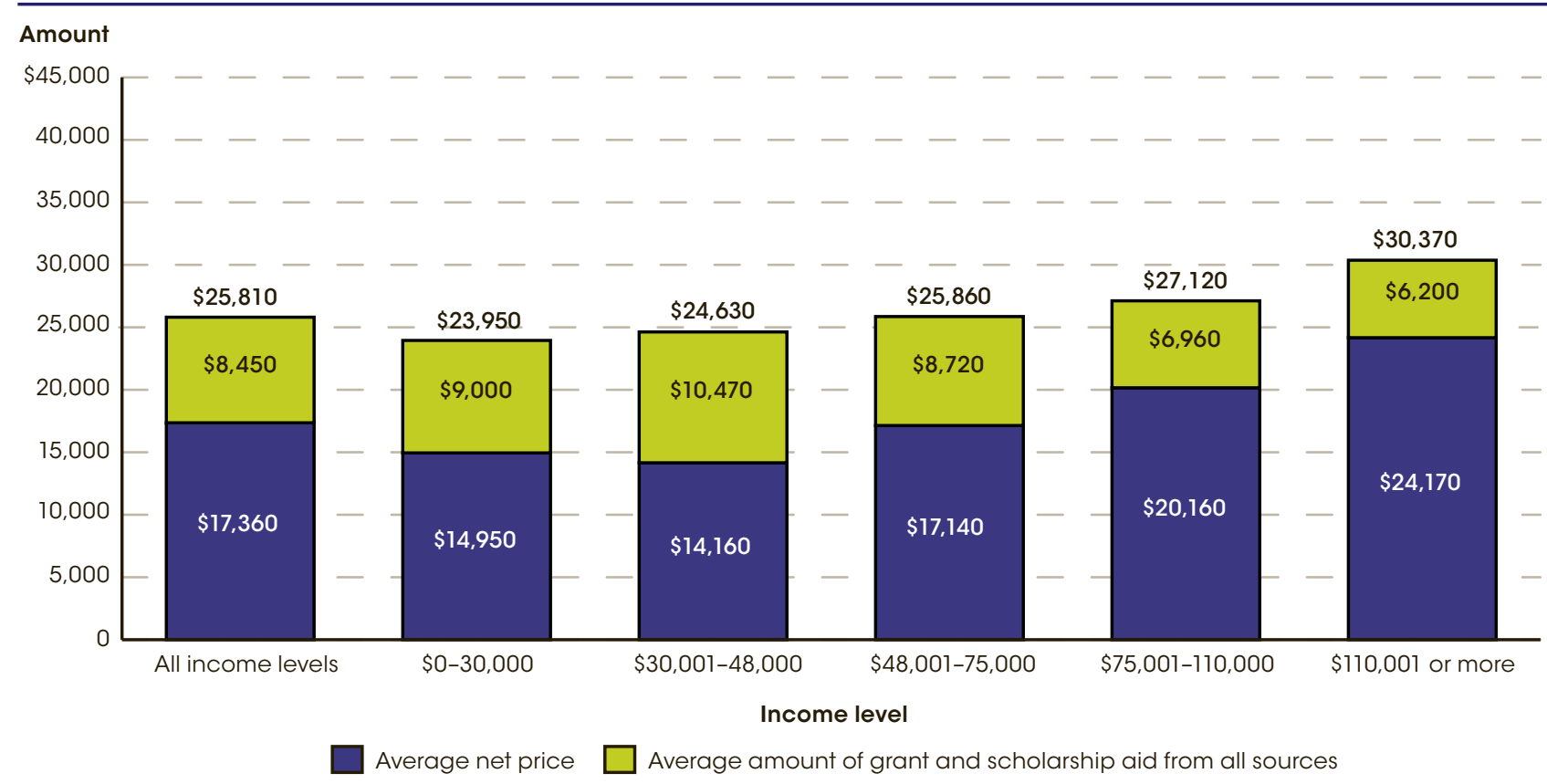

NOTE: First-time, full-time students are those who are entering postsecondary education for the first time. This data refers to first-time, full-time students who paid the in-state or in-district tuition rate and were awarded Title IV aid by income. Students not receiving aid (18.7 percent) were excluded from this analysis. Title IV aid to students includes grant aid, work study aid, and loan aid. These grants include: Federal Pell Grant, Federal Supplemental Educational Opportunity Grant (FSEOG), Academic Competitiveness Grant (ACG), National Science and Mathematics Access to Retain Talent Grant (National SMART Grant), Teacher Education Assistance for College and Higher Education (TEACH) Grant, and Federal Work-Study. For those Title IV recipients, net price is reported by income category and includes students who received federal aid even if none of that aid was provided in the form of grants. While Title IV status defines the cohort of student for which the data are reported, the definition of net price remains the same-total cost of attendance minus grant aid. Data are weighted by the number of students at the institution receiving Title IV aid. Detail may not sum to total due to rounding. For more information on the Integrated Postsecondary Education Data System (IPEDS), see Appendix B - Guide to Sources.

SOURCE: U.S. Department of Education, National Center for Education Statistics, Integrated Postsecondary Education Data System (IPEDS), Spring 201 1.

Student Financial Aid component. 


\section{Indicator 41 \\ Undergraduate Grants and Loans}

\section{From 2006-07 to 2009-10, the percentage of first-time, full-time undergraduates receiving any financial aid increased from 75 to 85 percent at 4-year institutions.}

Grants and loans are the major forms of federal financial aid for degree-seeking undergraduate students. Federal grants, which do not need to be repaid, are available to degree-seeking undergraduates who qualify by economic need, whereas loans are available to all students. In addition to federal financial aid, there are also grants from state and local governments, institutions, and private sources.

From 2006-07 to 2009-10, the percentage of first-time, full-time undergraduate students receiving any financial aid increased from 75 to 85 percent at 4-year institutions (see table A-41-2). During this time, the largest increase in first-time, full-time students receiving aid was at 4-year private for-profit institutions, from 55 to 92 percent. The percentage of first-time, full-time undergraduate students receiving aid at public 4-year institutions increased from 75 to 82 percent, while 4-year private nonprofit institutions had a smaller increase, from 85 to 89 percent. For 2-year institutions, the percentage of first-time, full-time undergraduate students receiving aid was higher in 2009-10 than in 2006-07 in all institutions except private for-profit institutions, in which the percentage receiving aid in 2009-10 (88 percent) was less than in 2006-07 (89 percent).

In 2009-10, about 67 percent of first-time, full-time undergraduate students at public 4-year institutions received grant or scholarship aid, as compared to 84 percent in private nonprofit institutions and 81 percent in private for-profit institutions (see table A-41-1). Out of all 4-year institutions, the percentage of first-time, full-time undergraduate students receiving student loan aid was

\section{Technical Notes}

Any student financial aid includes students receiving Federal Work-Study aid and aid from other sources in addition to those listed in table A-41-1. Discontinuity in the time series could be due to a change in the highest at private for-profit institutions (86 percent). In comparison, 63 percent of 4-year nonprofit students and 50 percent of 4-year public students received student loan aid.

For first-time, full-time undergraduate students at 2-year institutions in 2009-10, 67 percent received grant or scholarship aid and 39 percentage received student loan aid. As in 4-year institutions, the percent of first-time, full-time undergraduate students receiving student loan aid at 2-year institutions was highest at private for-profit institutions (78 percent). By comparison, 59 percent of students at 2-year private nonprofit institutions and 24 percent of students at 2-year public institutions received student loan aid. The percentage of first-time, full-time undergraduate students at 2-year institutions receiving grant or scholarship aid was highest at private nonprofit institutions (85 percent).

In 2009-10, in 4-year institutions, the average amount of student loan aid received was highest in private for-profit institutions (\$9,641). First-time, full-time undergraduate students at 4-year private nonprofit institutions received an average amount of $\$ 7,466$, and students at 4-year public institutions received an average amount of $\$ 6,063$ in student loan aid. Similarly, among 2-year institutions, the average amount of student loan aid received was highest in private for-profit institutions $(\$ 8,035)$.

Tables A-41-1 and A-41-2

Glossary: Four-year postsecondary institution, Private institution, Public institution, Two-year postsecondary institution

structure of the reporting forms. For more information on the Integrated Postsecondary Education Data System (IPEDS), see Appendix B - Guide to Sources. 
Figure 41-1. Percentage of first-time, full-time undergraduate students receiving any financial aid at 4-year institutions, by institution control: Academic years 2006-07 through 2009-10

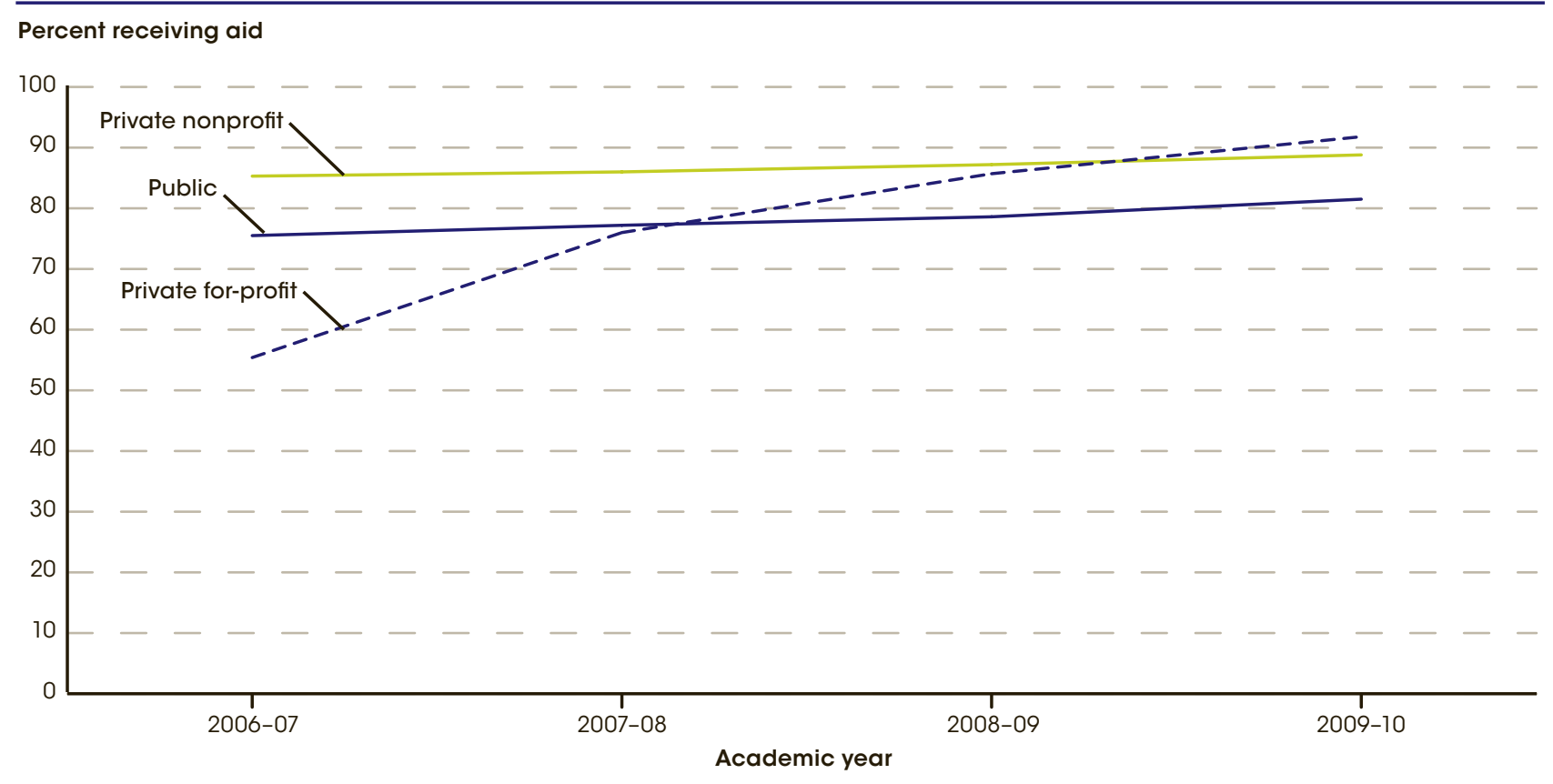

NOTE: Any student financial aid includes students who were awarded any Federal Work-Study, loans to students, or grant or scholarship aid from the federal government, state/local government, the institution, or other sources known to the institution.

SOURCE: U.S. Department of Education, National Center for Education Statistics, Integrated Postsecondary Education Data System (IPEDS), Spring 2008 through Spring 2011 , Student Financial Aid component.

Figure 41-2. Average amount of aid received by full-time, first-time, degree-seeking undergraduate students in financial aid programs, by institution level, control, and type of aid: Academic year 2009-10

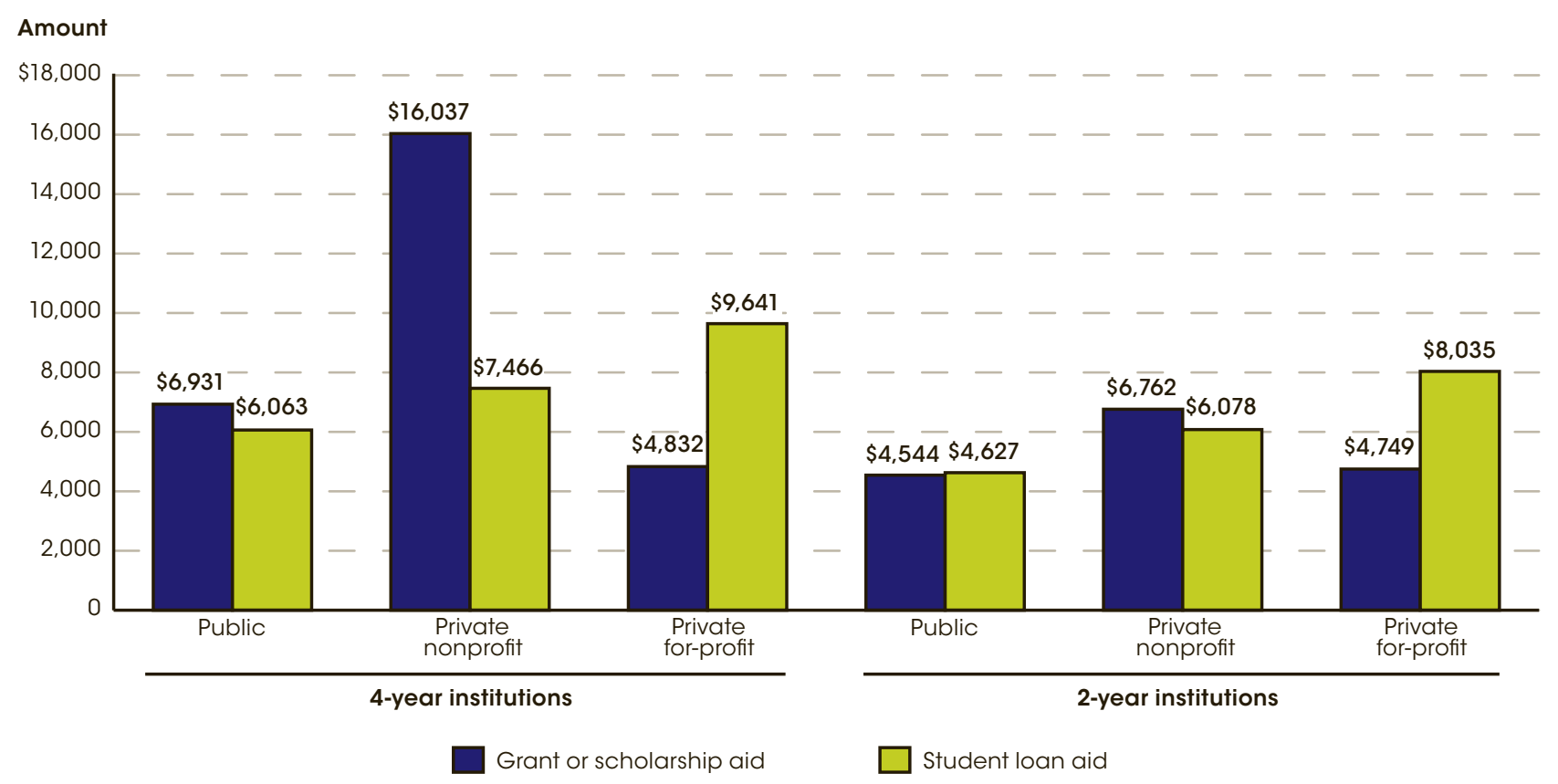

NOTE: Any student financial aid includes students who were awarded any Federal Work-Study, loans to students, or grant or scholarship aid from the federal government, state/local government, the institution, or other sources known to the institution.

SOURCE: U.S. Department of Education, National Center for Education Statistics, Integrated Postsecondary Education Data System (IPEDS), Spring 201 1,

Student Financial Aid component. 


\section{In academic year 2009-10, total revenues per full-time-equivalent (FTE) student were 1 percent less than in 2004-05 in public postsecondary degree-granting institutions (in constant 2010-11 dollars). Total revenues per student went from $\$ 28,966$ in 2004-05 to $\$ 28,781$ in 2009-10.}

In academic year 2009-10, total revenue was $\$ 309$

billion (in constant $2010-11$ dollars) at public

postsecondary degree-granting institutions, $\$ 172$ billion at private nonprofit institutions, and $\$ 25$ billion at private for-profit institutions (see table A-42-1). The category of student tuition and fees typically accounts for a large percentage of total revenue and was the largest revenue source at both private nonprofit and for-profit institutions in 2009-10 (33 and 91 percent, respectively). At public institutions, the percentage of revenue from tuition and fees (18 percent) was the second largest to that from state appropriations (21 percent). Revenue from tuition and fees made up over half of all revenue for all private for-profit institutions and 2-year nonprofit institutions (see table A-42-2).

In 2009-10, total revenues per full-time-equivalent (FTE) student in public institutions were 1 percent less than in 2004-05 in public postsecondary institutions (see table A-42-1). Total revenues per student went from $\$ 28,966$ in 2004-05 to $\$ 28,781$ in 2009-10 (see table A-42-1). Total revenues were 14 percent higher in 2004-05 than in 2009-10 for public institutions, but FTE enrollment was 15 percent higher $(9,348,081$ in 2004-05 and 10,750,132 in 2009-10). Tuition and fees per student were 12 percent higher in 2009-10 than in 2004-05, and nonoperating revenue from government grants per student were 373 percent higher in 2009-10 than in 2004-05 (See table A-42-1). These increases were not enough to offset the drop in revenue per student from most other revenue sources.

In 2-year public postsecondary institutions, total revenue per student in 2009-10 was higher in constant 2010-11 dollars than in $2004-05$ (from $\$ 12,765$ to $\$ 13,107$ ), but total revenue per student was less in 2009-10 than in 2004-05 in all other 2-year institutions and in all 4-year institutions (see table A-42-2). Revenue per student from tuition and fees was nearly 15 percent higher for 4-year public institutions in 2009-10 than in 2004-05 and 9 percent higher in 4-year private nonprofit institutions in 2009-10 than in 2004-05. Tuition and fees per student increased by a small percentage in private 2-year institutions and 4-year for-profit institutions.

In 4-year private nonprofit institutions, decreases per student in 2009-10 compared to 2004-05 in investment returns and private gifts grants and contracts were larger than other revenue sources and resulted in a net loss in total revenue per student (from \$56,746 in 2004-05 compared to $\$ 54,703$ in $2009-10$ ). In 4 -year private for-profit institutions, decreases per student in 2009-10 compared to $2004-05$ in other revenue (from $\$ 135$ to $-\$ 375$ ) and auxiliary enterprises (from $\$ 420$ to $\$ 307$ ) were the major factors leading to a drop in total revenue per student (from $\$ 16,019$ to $\$ 15,679$ ). In public 2-year institutions, declines in per-student operating revenue from government grants and contracts and nonoperating government appropriations were offset by increases in nonoperating revenue government grants.

Investment returns or investment income accounted for less than 5 percent of overall revenues for all postsecondary sectors except for nonprofit 4-year private schools. Investment returns or investment income fell for all postsecondary sectors between 2004-05 and 2009-10, except for-profit 4-year schools (where investment returns made up 0.2 percent or less of total revenues). The biggest decline in investment returns was seen for nonprofit 4 -year schools, where investment returns fell by $\$ 6$ billion between these two time points.

Tables A-42-1 and A-42-2

Glossary: Consumer Price Index (CPI), Full-timeequivalent (FTE) enrollment, Private institution, Public institution, Revenues, Tuition

\section{Technical Notes}

Auxiliary enterprises are essentially self-supporting operations, such as residence halls, that exist to provide a service to students, faculty, or staff and that charge a fee that is directly related to, although not necessarily equal to, the cost of the service. Operating revenue is revenue from providing specific goods and services. Nonoperating revenue is revenue that is not in exchange for providing specific goods and services. Government grants can be operating revenue or nonoperating revenue. Full-timeequivalent students include the count of full-time students plus the full-time equivalent of part-time students.
Public institutions use Governmental Accounting Standards Board (GASB) accounting standards, and private institutions use Financial Accounting Standards Board (FASB) accounting standards. Data are adjusted by the Consumer Price Index (CPI) to constant 2010-11 dollars. For more information on the CPI, see Appendix $\mathrm{C}$ - Finance. For more information on the Integrated Postsecondary Education Data System (IPEDS) and IPEDS classification of institutions, see Appendix B Guide to Sources. 
Figure 42-1. Revenue per full-time-equivalent (FTE) student from tuition and fees for postsecondary degree-granting institutions, by institution control and level: Academic year 2009-10

[In constant 2010-11 dollars]

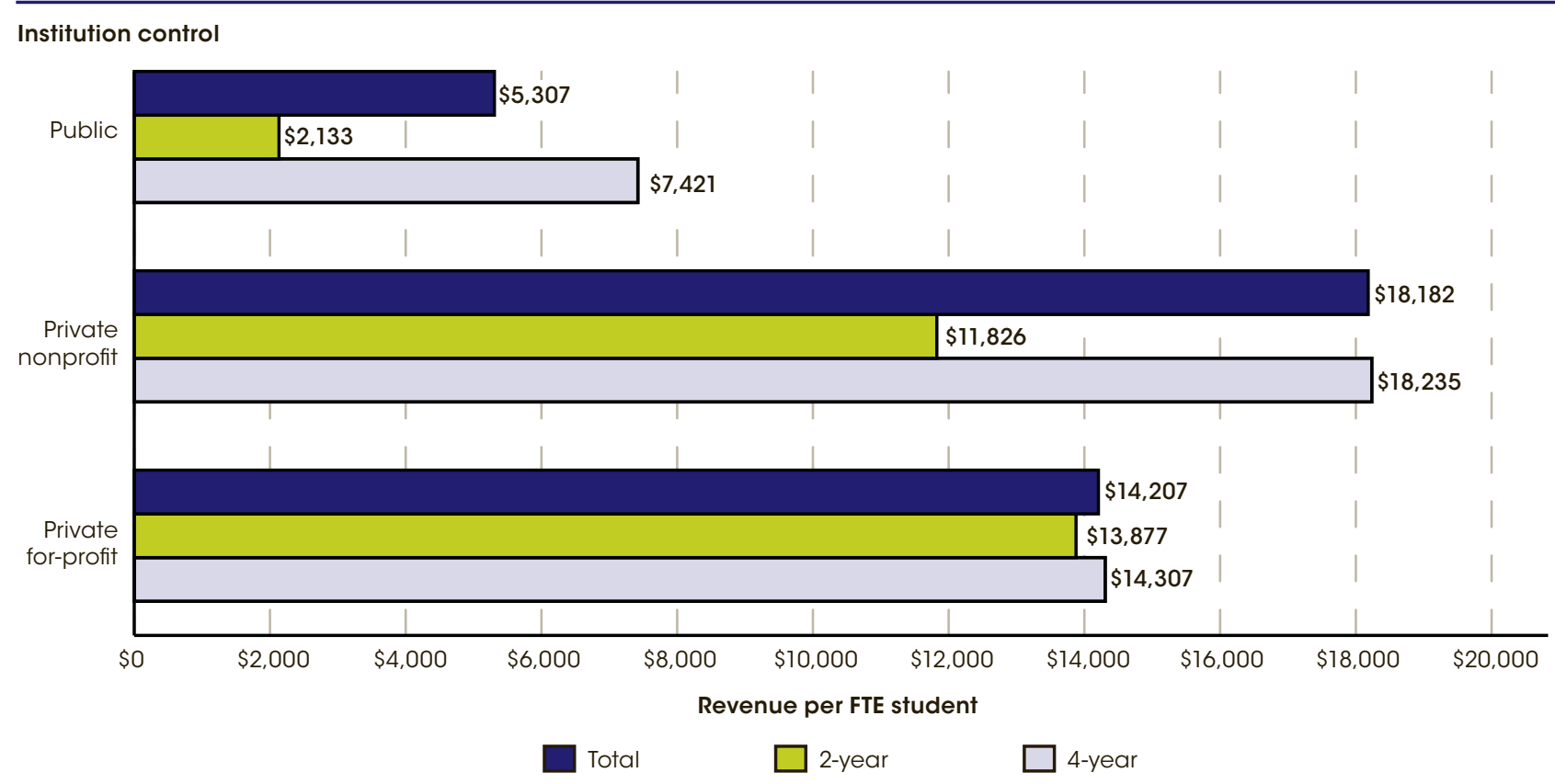

NOTE: Full-time-equivalent (FTE) enrollment includes full-time students plus the full-time equivalent of part-time students. Data are adjusted by the Consumer Price Index (CPI) to constant 2010-11 dollars. For more information on the CPI, see Appendix $C$ - Finance. For more information on the Integrated Postsecondary Education Data System (IPEDS), see Appendix B - Guide to Sources.

SOURCE: U.S. Department of Education, National Center for Education Statistics, Integrated Postsecondary Education Data System, Spring 2010, Enrollment component; and Spring 2011, Finance component.

Figure 42-2. Percentage distribution of total revenues at postsecondary degree-granting institutions, by institution level, institution control, and source of funds: Academic year 2009-10

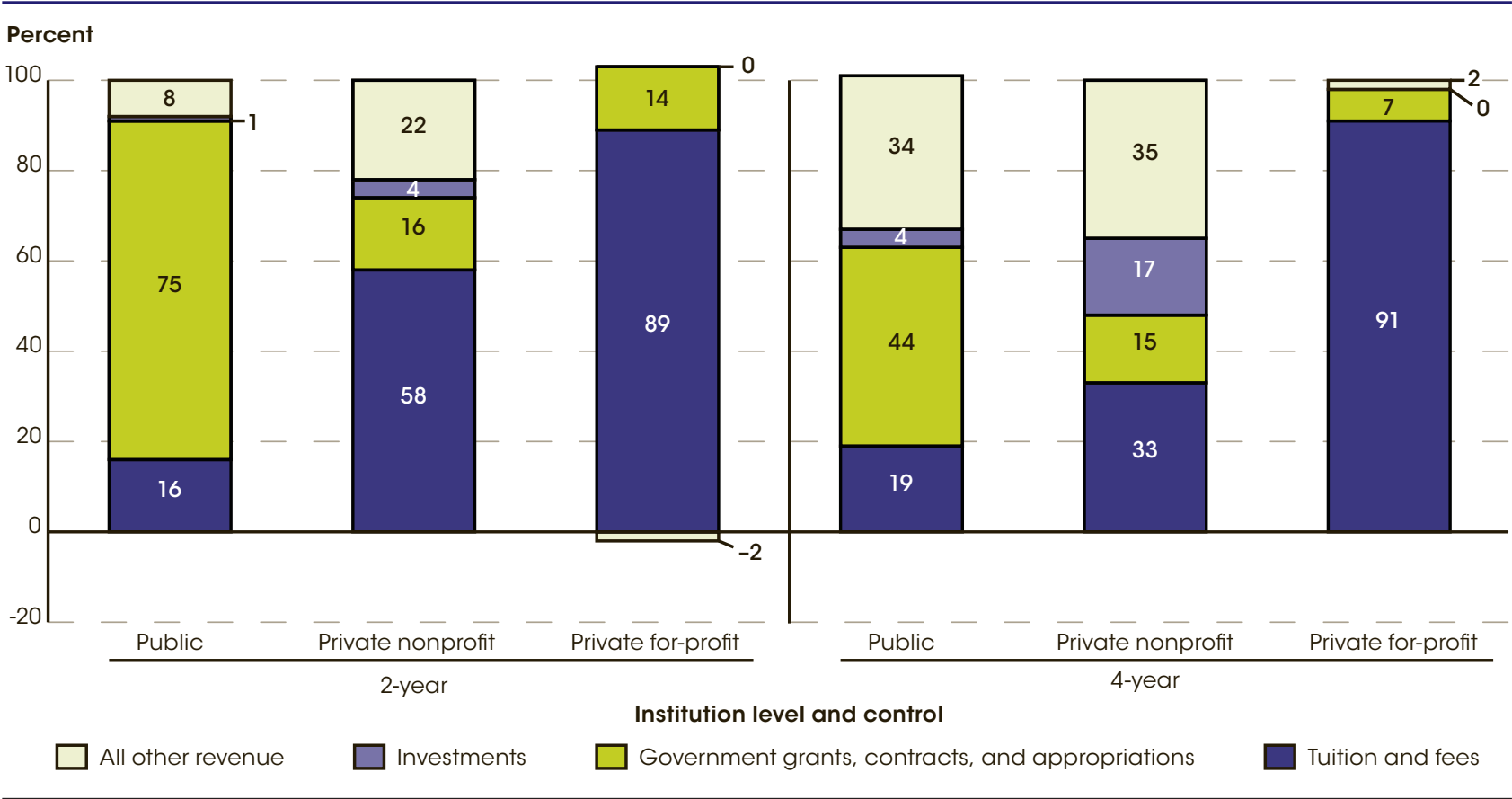

NOTE: All other revenue includes gifts, grants, contracts, auxillary enterprises, and other revenue. In public institutions, all other revenue also includes revenue from sales and service of educational activities. Government grants, contracts and appropriations includes revenue from federal, state, and local governments. Data are adjuated by the Consumer Price Index (CPI) to constant 2010-11 dollars. For more information on the CPI, see Appendix C - Finance. For more information on the Integrated Postsecondary Education Data System (IPEDS) and IPEDS classification of institutions, see Appendix B - Guide to Sources.

SOURCE: U.S. Department of Education, National Center for Education Statistics, Integrated Postsecondary Education Data System, Spring 2010, Enrollment component; and Spring 2011, Finance component. 


\section{Postsecondary Expenses}

\section{In academic year 2009-10, instruction was the largest per full-time-equivalent (FTE) student expense at public $(\$ 7,239)$ and private nonprofit institutions $(\$ 15,321)$. At private for-profit institutions, instruction was the second largest expense category, at $\$ 3,017$ per student.}

This indicator examines general patterns in expenses of postsecondary degree-granting institutions. Only some financial data may be comparable across institutions by control categories (i.e., between public, private nonprofit, and private for-profit institutions) because of differences in accounting procedures. In addition, comparisons by institutional level (i.e., between 2-year and 4-year institutions) may also be limited because of different institutional control.

In academic year 2009-10, total expenses were \$287 billion at public institutions, $\$ 148$ billion at private nonprofit institutions, and $\$ 20$ billion at private for-profit institutions (see table A-43-1). At public and private nonprofit institutions, instruction was the largest expense category (at 27 and 33 percent, respectively). At private for-profit institutions, instruction constituted 24 percent of total expenses but student services and academic and institutional support (a category which covers a wide range of costs) was the largest category at 66 percent. Other relatively large categories at public institutions (those accounting for 8-10 percent of expenses) were research, institutional support, and hospitals. At private nonprofit institutions, some of the other larger categories (those accounting for 8-14 percent of expenses) were research, academic support, student services, institutional support, auxiliary enterprises, and hospitals. Expenses for student services and academic and institutional support made up 19 percent of total expenses in public institutions and 30 percent in nonprofit institutions, less than half of the share spent by private for-profit institutions (66 percent).

Total expenses per full-time equivalent (FTE) student were much higher for private nonprofit institutions (\$46,287 in 2009-10) than for public institutions $(\$ 26,697$ in 2009-10) and private for-profit institutions
(\$12,683 in 2009-10). Private nonprofit institutions spent more than twice as much per student on instruction $(\$ 15,321)$ as public institutions $(\$ 7,239)$. A similar pattern was found for most other expense classifications such as academic support $(\$ 4,175$ for nonprofit institutions vs. $\$ 1,791$ for public institutions) and institutional support $(\$ 6,270$ for nonprofit institutions vs. $\$ 2,152$ for public institutions).Expenses per student for public service were an exception to this pattern, with public institutions spending more than nonprofit institutions (\$1,092 vs. \$674). Expenses per student for instruction were more than twice as high in public institutions as in private for-profit institutions $(\$ 7,239$ vs. $\$ 3,017)$, but expenses per student for student services, academic, and institutional support were higher in for-profit institutions $(\$ 8,310)$ than in public institutions $(\$ 5,190)$.

Differences were found between expenses at 2- and 4-year institutions in academic year 2009-10. For example, 2-year institutions (for all levels of control) spent a greater share of their budgets on instruction than did their 4-year counterparts (35 vs. 25 percent for public institutions, 34 vs. 33 percent for private nonprofit institutions, and 32 vs. 21 percent for private for-profit institutions) (see table A-43-2). Expenses per FTE student for instruction in 2009-10 were less (in constant 2010-11 dollars) at 2-year institutions than they were in 2004-05, but were slightly higher at 4-year public and 4-year nonprofit institutions (less than 1 percent higher at public institutions and nearly 5 percent higher at nonprofit institutions).

Instruction expenses per student in private for-profit 4 -year institutions were less in 2009-10 $(\$ 2,692)$ than in 2004-05 (\$2,978).

Tables A-43-1 and A-43-2

Glossary: Consumer Price Index (CPI), Full-timeequivalent (FTE) enrollment, Private institution, Public institution, Revenues, Tuition

\section{Technical Notes}

"Auxiliary" enterprises are essentially self-supporting operations, such as residence halls, that exist to provide a service to students, faculty, or staff, and that charge a fee that is directly related to, although not necessarily equal to, the cost of the service. "Academic support" includes services that directly support an institution's primary missions of instruction, research, or public service. "Institutional support" includes general administrative services, executive direction and planning, legal and fiscal operations, and community relations. "Student services" include expenses associated with admissions, registrar activities, and activities whose primary purpose is to contribute to students' emotional and physical well-being and to their intellectual, cultural, and social development outside the context of the formal instructional program. FTE students is the full-time student enrollment, plus the full-time equivalent of the part-time students. Data are adjusted by the Consumer Price Index (CPI) to constant 2010-11 dollars. For more information on the CPI, see Appendix C - Finance. For more information on the Integrated Postsecondary Education Data System (IPEDS) and IPEDS classification of institutions, see Appendix B - Guide to Sources. 
Figure 43-1. Expenses per full-time-equivalent student at degree-granting postsecondary institutions, by control of institution and purpose: Academic year 2009-10

[In constant 2010-11 dollars]

Control of institution

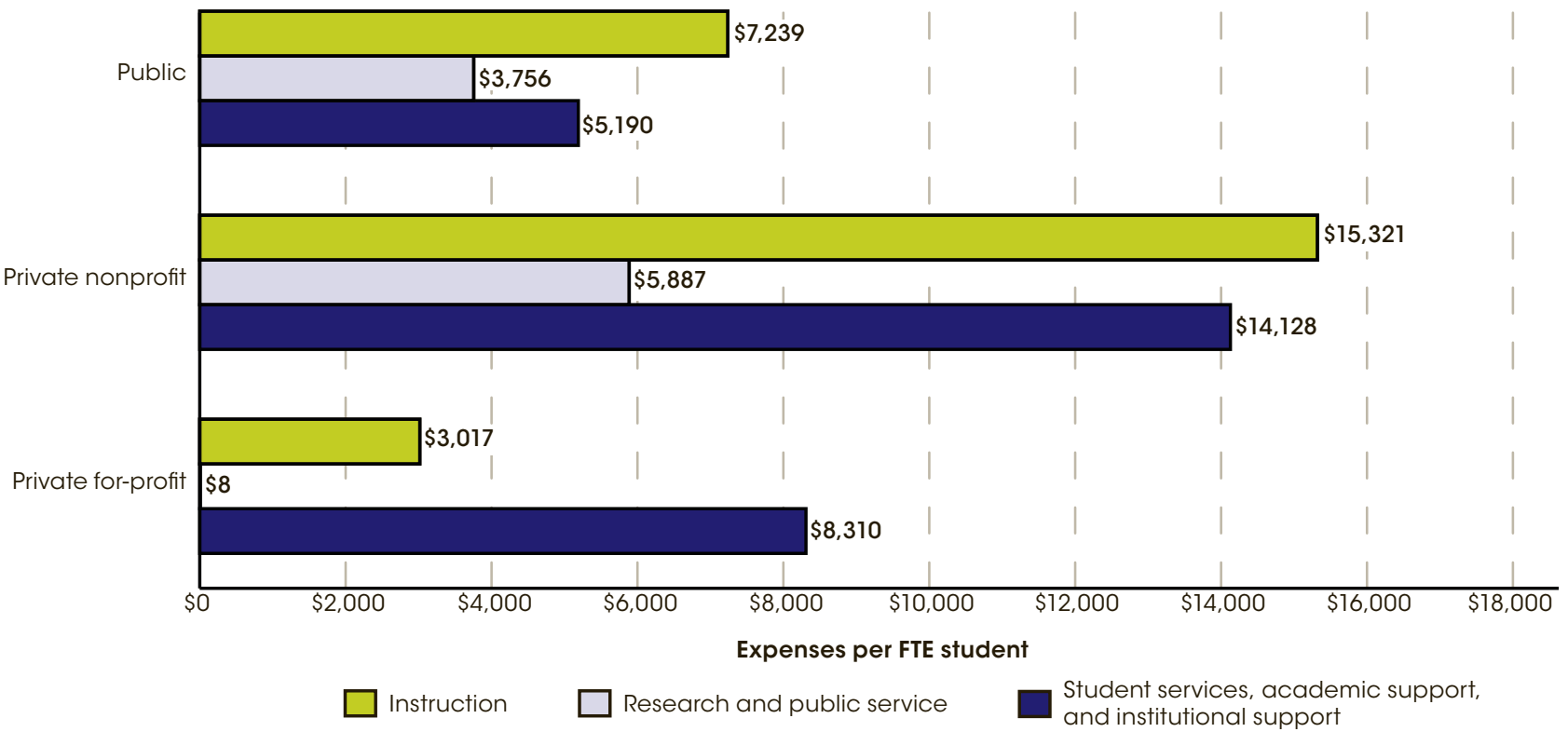

NOTE: Full-time-equivalent (FTE) student includes full-time students plus the full-time equivalent of part-time students. Data are adjusted by the Consumer Price Index (CPI) to constant 2010-11 dollars. For more information on the CPI, see Appendix C - Finance. For more information on the Integrated Postsecondary Education Data System (IPEDS), see Appendix B - Guide to Sources.

SOURCE: U.S. Department of Education, National Center for Education Statistics, Integrated Postsecondary Education Data System (IPEDS), Spring 2010,

Enrollment component; and Spring 2011, Finance component.

Figure 43-2. Total expenses per full-time-equivalent student at 2-year and 4-year degree-granting postsecondary institutions, by control of institution: Academic years 2004-05 and 2009-10

[In constant 2010-11 dollars]

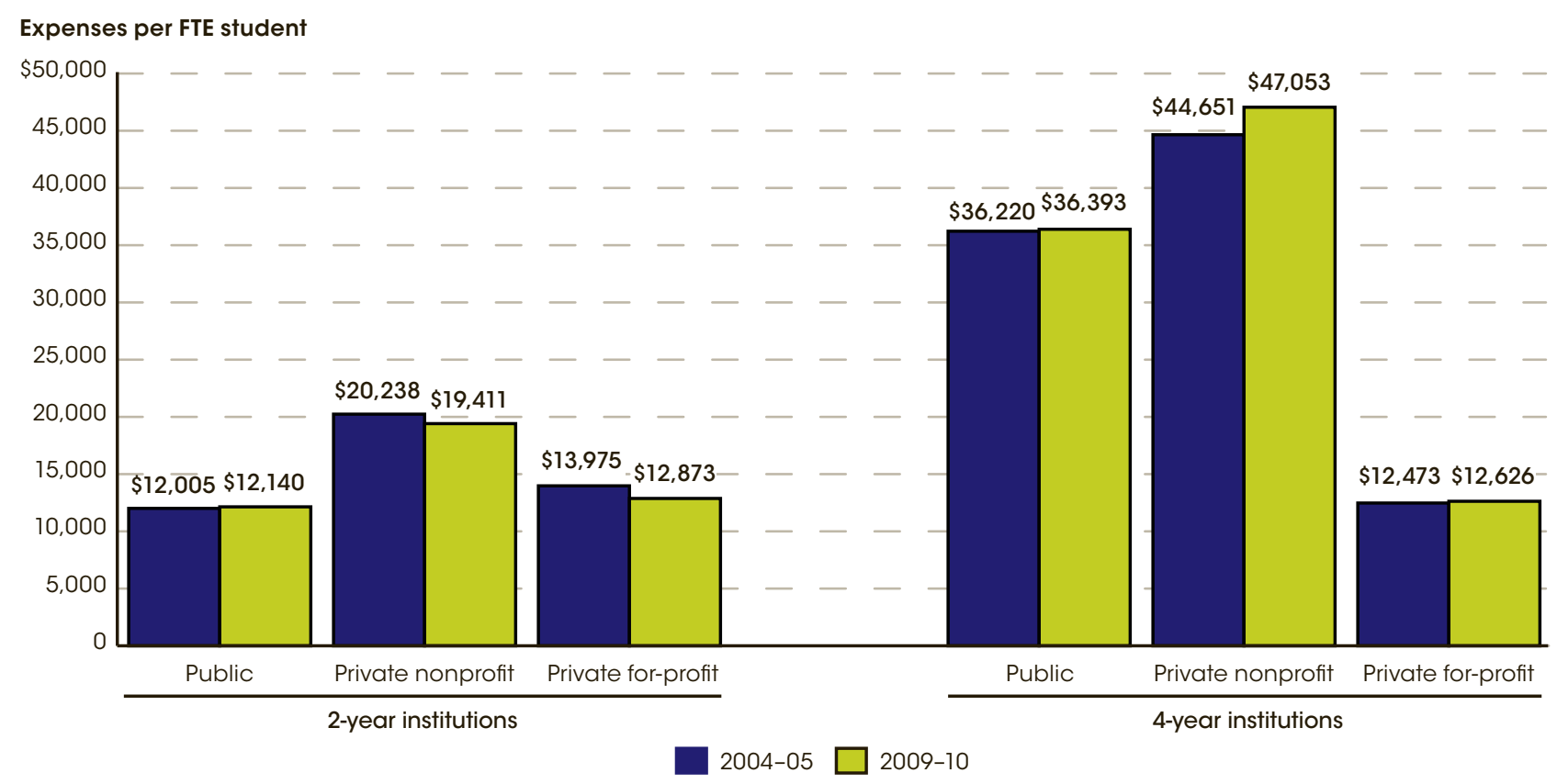

NOTE: Full-time-equivalent (FTE) students includes full-time students plus the full-time equivalent of part-time students. Data are adjusted by the Consumer Price Index (CPI) to constant 2010-11 dollars. For more information on the CPI, see Appendix C - Finance. For more information on the Integrated Postsecondary Education Data System (IPEDS), see Appendix B - Guide to Sources.

SOURCE: U.S. Department of Education, National Center for Education Statistics, Integrated Postsecondary Education Data System (IPEDS), Spring 2005 and Spring 2010, Enrollment component; and Spring 2011, Finance component, Spring 2005. 


\section{Faculty Salaries, Benefits, and Total Compensation}

\section{Combining salary with benefits, faculty received an average total compensation package in academic year 2010-11 that was about 8 percent higher than the package they received in 1999-2000, after adjusting for inflation. In 2010-11, the average total compensation package for faculty was about \$97,200, including $\$ 75,500$ in salaries and $\$ 21,700$ in benefits.}

In academic year 2010-11, the average salary for full-time instructional faculty on 9- and 10-month contracts at postsecondary degree-granting institutions was $\$ 75,500$, ranging from $\$ 56,500$ for other faculty to $\$ 105,000$ for professors (see table A-44-1). By control and level of institution, salaries ranged from $\$ 40,100$ at private for-profit 2-year colleges to $\$ 95,000$ at private nonprofit doctoral universities. Combining salary with benefits, faculty received an average total compensation package in 2010-11 that was about 8 percent higher than the package they received in 1999-2000, after adjusting for inflation. In 2010-11, the average compensation package for faculty was about $\$ 97,200$, including $\$ 75,500$ in salaries and $\$ 21,700$ in benefits.

The average salary for all full-time instructional faculty on 9- and 10-month contracts was 8 percent higher in 2010-11 than it was in 1989-90, after adjusting for inflation (see table A-44-2). By faculty type, salary increases were 14 percent higher for professors, 11 percent higher for assistant professors, 9 percent higher for associate professors, and 7 percent higher for other faculty. Average salaries were also higher in 2010-11 than they were in 1989-90 by institutional control, with two exceptions: public master's colleges/universities (3 percent lower) and public other 4-year colleges (2 percent lower). Salary increases ranged from 4 percent higher at public 2 -year colleges to 30 percent higher at private for-profit master's colleges/universities between 1989-90 and 2010-11.

Inflation-adjusted faculty salaries were 5 percent higher in 1999-2000 than in 1989-90, and faculty salaries increased by 3 percent between 1999-2000 and 2010-11. Salary increases from 1999-2000 to 2010-11 tended to occur in private institutions (with the exception of private 2-year institutions). Except for public doctoral

\section{Technical Notes}

Average total compensation is the sum of salary and fringe benefits (which may include benefits such as retirement plans, medical/dental plans, group life insurance, or other benefits). Faculty categories (professor, associate professor, assistant professor, and other faculty) are defined by the institution. Other faculty include faculty with no rank titles such as professor or instructor. Private institutions include private nonprofit and for-profit institutions.

Institutions are classified by the number of highest degrees awarded (doctor's, master's, bachelor's, or associate's). For example, institutions that award 20 or more doctoral degrees per year are classified as doctoral universities. For more information on the classification of postsecondary universities, salaries for faculty in public universities/ colleges were generally lower from 1999-2000 to 2010-11 by 1 percent to 3 percent. In private institutions, except for private 2-year colleges, salaries were generally higher by 1 percent to 8 percent. Increases in salaries at private for-profit institutions varied more between 1999-2000 and 2010-11. In private for-profit private doctoral universities, salaries were lower by 37 percent, while the faculty salaries in private for-profit other 4-year colleges were higher by 39 percent. At private 2 -year colleges, salaries were lower by 6 percent at nonprofit colleges but higher by 26 percent at for-profit colleges.

Fringe benefits (adjusted for inflation) for all faculty increased by a greater percentage, on average, than average faculty salaries (52 vs. 8 percent) between 1989-90 and 2010-11. As a result, fringe benefits accounted for a larger share of total faculty compensation for faculty in 2010-11 than they did in 1989-90. Fringe benefits also increased, on average, by a larger percentage than faculty salaries (26 vs. 3 percent) between 1999-2000 and 2010-11. These increases in fringe benefits were higher at public institutions than at private institutions. For example, average benefits at public master's colleges/universities were higher by 30 percent between 1999-2000 and 2010-11, compared with 16 percent at private master's colleges/universities. At private institutions, variations in fringe benefits differed between nonprofit versus for-profit institutions. For example, benefits were lower by 8 percent at nonprofit 2-year colleges between 1999-2000 and 2010-11, but were higher by 89 percent at private for-profit 2-year colleges over the same time period.

Tables A-44-1 and A-44-2

Glossary: Consumer Price Index (CPI), Faculty, Four-year postsecondary institution, Private institution, Public institution, Salary, Two-year postsecondary institution institutions, see Appendix C - Commonly Used Measures. Data do not include institutions at which all faculty were part time, contributed their services, were in the military, or taught preclinical or clinical medicine. Salaries reflect an average of all faculty on 9-and 10-month contracts rather than a weighted average based on contract length, as in some other National Center for Education Statistics reports. Data exclude faculty on 11- and 12-month contracts. Data are adjusted by the Consumer Price Index (CPI) to constant 2010-11 dollars. For more information on the CPI, see Appendix C - Finance. For more information on the Integrated Postsecondary Education Data System (IPEDS), see Appendix B - Guide to Sources. 
Figure 44-1. Average salary for full-time instructional faculty on 9- and 10-month contracts at degree-granting postsecondary institutions, by control and level of institution: Academic year 2010-11

Control and level of institution

Public doctoral universities

Private nonprofit doctoral universities

Private for-profit doctoral universities

Public master's colleges/universities

Private nonprofit master's colleges/universities

Private for-profit master's colleges/universities

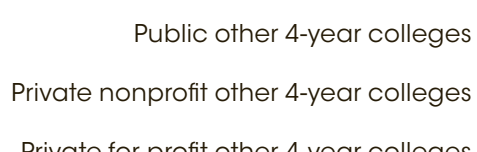

Private for-profit other 4-year colleges

Public 2-year colleges

Private nonprofit 2-year colleges

Private for-profit 2-year colleges

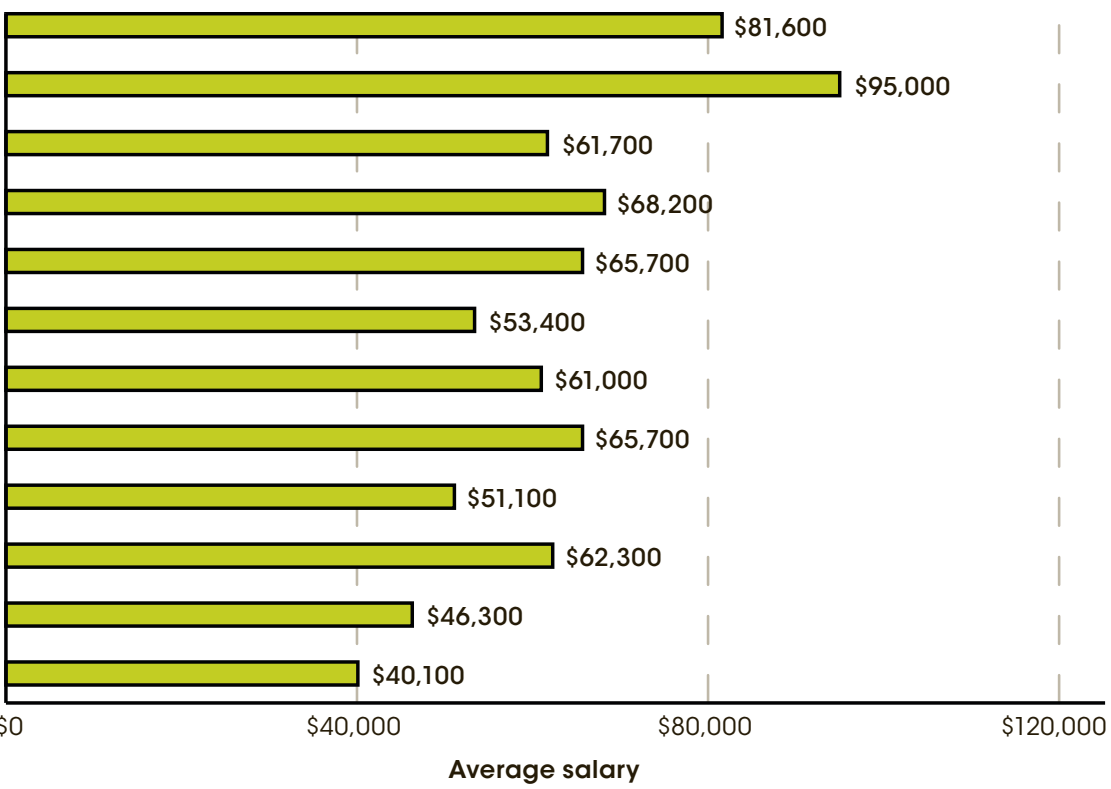

NOTE: Institutions are classified based on the number of highest degrees awarded. For more information on the classification of postsecondary institutions, see Appendix C - Commonly Used Measures. Salaries reflect an average of all faculty on 9-and 10-month contracts rather than a weighted average based on contract length that appears in some other reports of the National Center for Education Statistics. For more information on the Integrated Postsecondary Education Data System (IPEDS), see Appendix B - Guide to Sources.

SOURCE: U.S. Department of Education, National Center for Education Statistics, Integrated Postsecondary Education Data System (IPEDS), Fall 2010, Completions component and Winter 2010-11, Human Resources component, Salaries section.

Figure 44-2. Inflation-adjusted average total compensation, salary, and fringe benefits for full-time faculty on 9- and 10 -month contracts at degree-granting institutions, with percentage change, by academic rank and control and level of institutions: Academic years 1989-90, 1999-2000, and 2010-11 [In constant 2010-11 dollars]

\section{Compensation}

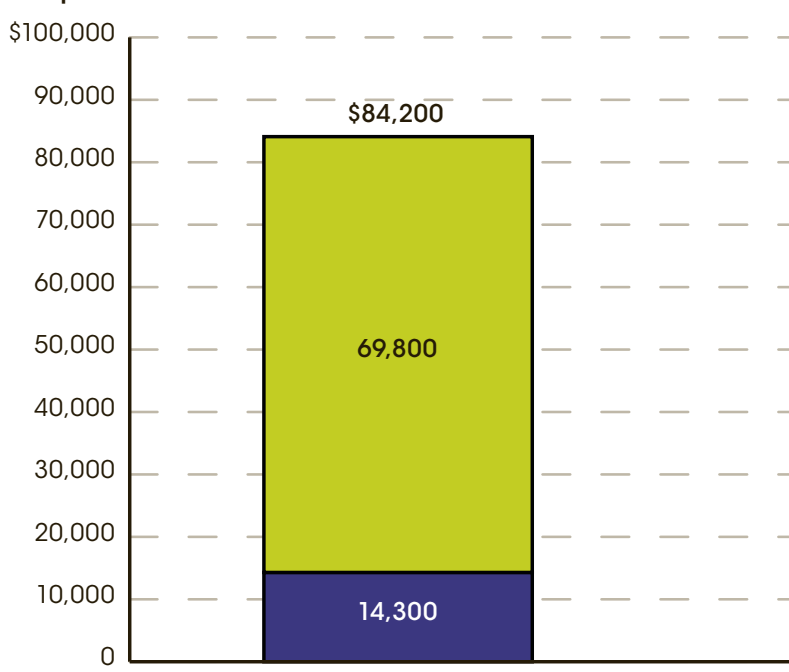

1989-90

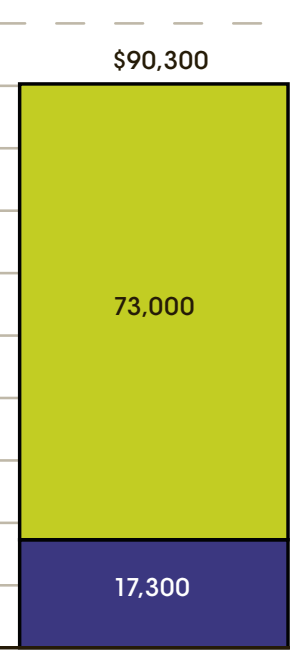

1999-2000
$\$ 97,200$

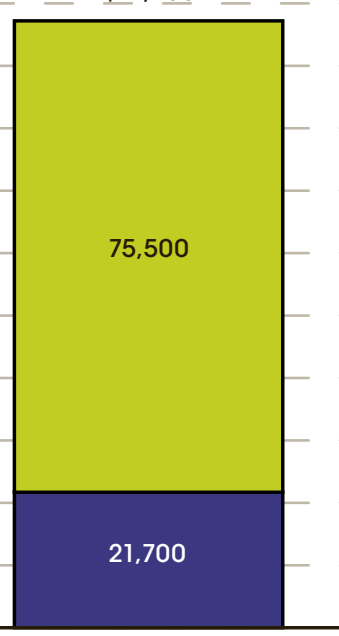

2010-11

Academic year

Salary

Benefits

NOTE: Average total compensation is the sum of salary (which excludes outside income) and fringe benefits (which may include benefits such as retirement plans, medical/dental plans, group life insurance, or other benefits). Salaries reflect an average of all faculty on 9-and 10-month contracts rather than a weighted average based on contract length that appears in some other reports of the National Center for Education Statistics. Salaries, benefits, and compensation adjusted by the Consumer Price Index (CPI) to constant 2010-11 dollars. For more information on the CPI, see Appendix C Finance. For more information on the Integrated Postsecondary Education Data System (IPEDS), see Appendix B - Guide to Sources.

SOURCE: U.S. Department of Education, National Center for Education Statistics, Integrated Postsecondary Education Data System (IPEDS), "Salaries, Tenure, and Fringe Benefits of Full-Time Instructional Faculty Survey" (IPEDS-SA:89-99); "Completions Survey" (IPEDS-C:89-99), Fall 2010, Completions component and Winter 2010-11, Human Resources component, Salaries section. 


\section{Approximately 56 percent of male and 61 percent of female first-time, full-time students who sought a bachelor's degree at a 4-year institution in fall 2004 completed their degree at that institution within 6 years.}

Approximately 58 percent of first-time, full-time students who began seeking a bachelor's degree at a 4-year institution in fall 2004 completed a bachelor's degree at that institution within 6 years or 150 percent of normal completion time to degree (see table A-45-1). In comparison, 55 percent of first-time, full-time students who began seeking a bachelor's degree in fall 1996 earned a bachelor's degree within 6 years at that institution.

Completion rates for bachelor's degree seeking students who enrolled at a 4-year institution in fall 2004 varied by institutional control. Students at private nonprofit institutions had the highest graduation rates, followed by students at public institutions and private for-profit institutions. For example, the 6-year graduation rate at private nonprofit institutions was 65 percent, compared with 56 percent at public institutions and 28 percent at private for-profit institutions.

At both public and private nonprofit 4-year institutions, the 6-year graduation rates of first-time, full-time female students who sought a bachelor's degree in fall 2004 were higher than those of males. At public institutions, about 58 percent of females seeking a bachelor's degree graduated within 6 years, compared with 53 percent of males; at private nonprofit institutions, 67 percent of females graduated within 6 years, compared with 63 percent of males. However, at private for-profit institutions, the 6-year graduation rate was higher for males (30 percent) than for females (27 percent).

Completion rates for first-time, full-time students who sought a bachelor's degree in fall 2004 also varied by race/ ethnicity. Asian/Pacific Islander students had the highest 6-year graduation rate (69 percent), followed by White students (62 percent), Hispanic students (50 percent), and Black and American Indian/Alaska Native students (39 percent each) (see table A-45-2).

At both public and private nonprofit institutions, the 6 -year graduation rates for first-time, full-time students who sought a bachelor's degree in fall 2004 varied by the acceptance rate of the institution. Graduation rates were highest at institutions with the lowest admissions acceptance rates. For example, at public 4-year institutions with open admissions policies, 29 percent of students completed a bachelor's degree within 6 years (see table A-45-2). At public 4-year institutions where the acceptance rate was less than 25 percent of applicants, the 6 -year graduation rate was 82 percent.

At 2-year institutions, approximately 30 percent of first-time, full-time students who enrolled in fall 2007 completed a certificate or associate's degree within 150 percent of the normal time required to complete such a degree (see table A-45-3). For the cohort that enrolled in fall 2000, the completion rate was about 31 percent.

The certificate or associate's degree completion rate of students who enrolled in 2-year institutions in fall 2007 varied by institutional control. For example, 60 percent of students graduated within 150 percent of the normal time at private for-profit institutions, 51 percent did so at private nonprofit institutions, and 20 percent did so at public institutions.

Tables A-45-1, A-45-2, and A-45-3

Glossary: Associate's degree, Bachelor's degree, Fouryear postsecondary institution, Private institution, Public institution, Two-year postsecondary institution

\section{Technical Notes}

The graduation rate was calculated as the total number of students who completed a degree within 150 percent of the normal time to degree attainment (for example, 6 years for bachelor's degrees) divided by the number of students in the revised cohort (i.e., the cohort minus any allowable exclusions). For this indicator, the revised cohorts use spring 2011 estimates of the number of first-time, full-time undergraduates who entered (1) a 4-year institution in fall 2004 seeking a bachelor's degree or (2) a 2-year institution in fall 2007 seeking a certificate or associate's degree, and spring 2003 estimates of the number of students who entered (3) a 4-year institution in fall 1996 seeking a bachelor's degree or (4) a 2-year institution in fall 2000 seeking a certificate or associate's degree. Students who transferred to another institution and graduated are not counted as completers at their initial institution. Included in the totals, but not shown separately, are estimates for persons with unknown race/ ethnicity and nonresident aliens. Race categories exclude persons of Hispanic ethnicity. For more information on race/ethnicity and classification of postsecondary education institutions, see Appendix C - Commonly Used Measures. For more information on the Integrated Postsecondary Education Data System (IPEDS), see Appendix B - Guide to Sources. 
Figure 45-1. Percentage of students seeking a bachelor's degree at 4-year institutions who completed a bachelor's degree within 6 years, by control of institution and cohort year: Starting cohort years 1996 and 2004

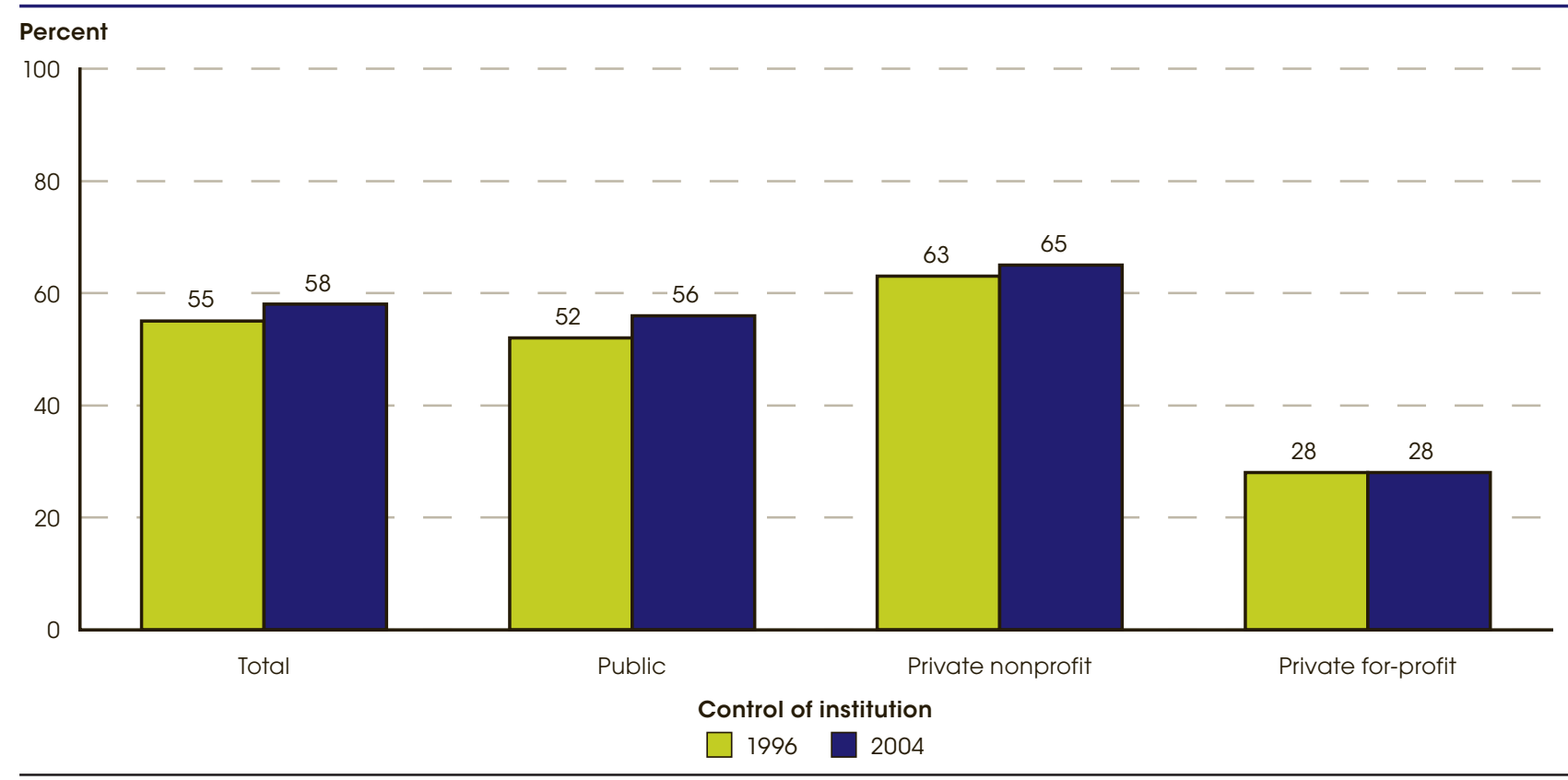

NOTE: The graduation rate was calculated as the total number of students who completed a degree within 150 percent of the normal time to degree attainment (for example, for bachelor's degrees, 6 years) divided by the number of students in the revised cohort (i.e., the cohort minus any allowable exclusions). For this indicator, the revised cohorts are the spring 2011 estimates of the number of students who entered a 4 -year institution in fall 2004 and the spring 2003 estimates of the number of students who entered a 4 -year institution in fall 1996 as first-time, full-time undergraduates seeking a bachelor's or equivalent degree. Students who transferred to another institution and graduated are not counted as completers at their initial institution. For more information on the Integrated Postsecondary Education Data System (IPEDS), see Appendix B - Guide to Sources.

SOURCE: U.S. Department of Education, National Center for Education Statistics, Integrated Postsecondary Education Data System (IPEDS), Spring 2003 and Spring 2011, Graduation Rates and Institutional Characteristics components.

Figure 45-2. Percentage of students seeking a bachelor's degree at 4-year institutions who completed a bachelor's degree within 6 years, by control of institution and race/ethnicity: Starting cohort year 2004

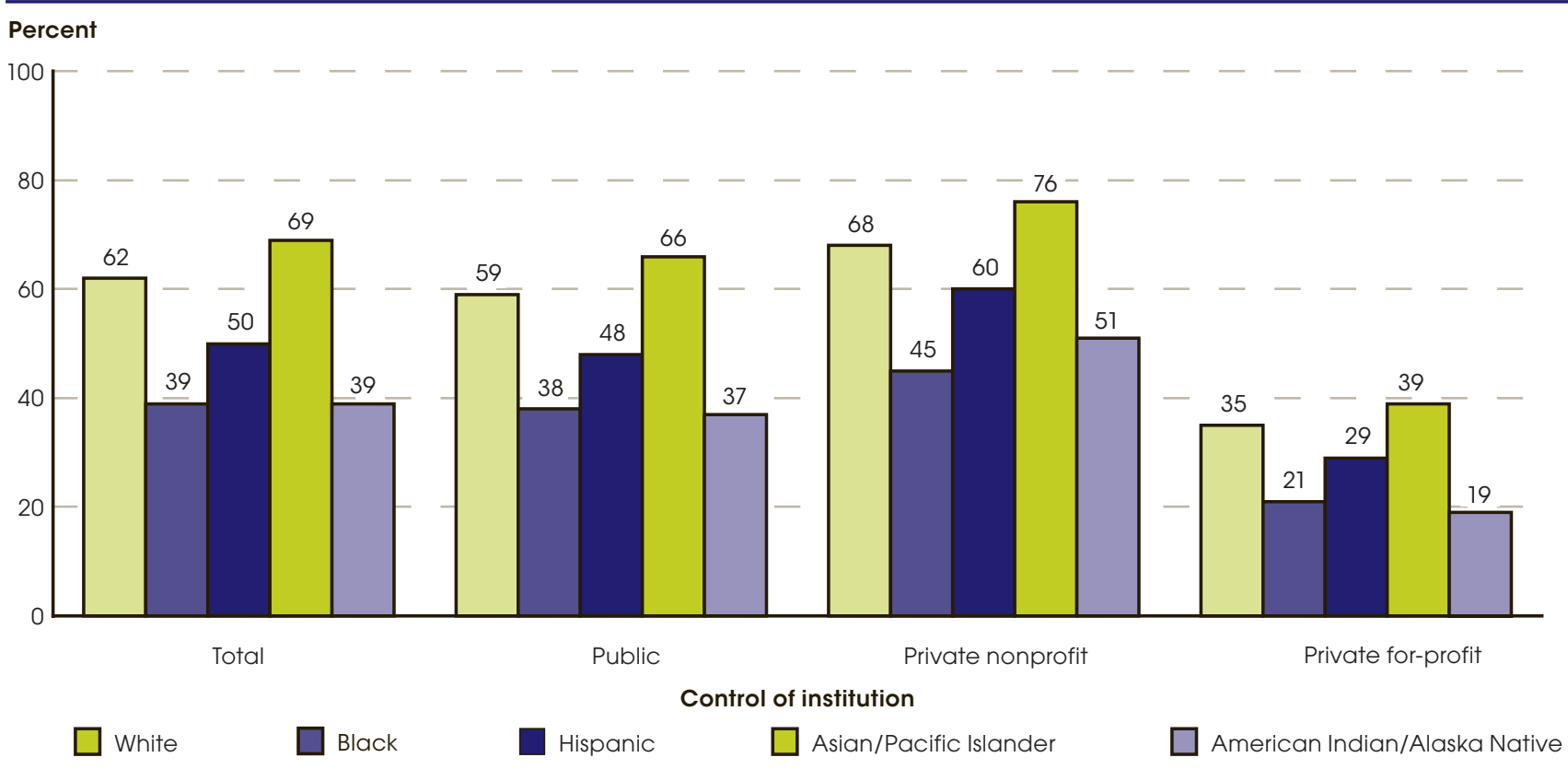

NOTE: The graduation rate was calculated as the total number of students who completed a degree within 150 percent of the normal time to degree attainment (for example, for bachelor's degrees, 6 years) divided by the number of students in the revised cohort (i.e., the cohort minus any allowable exclusions). For this indicator, the revised cohorts are the spring 2011 estimates of the number of students who entered a 4 -year institution in fall 2004 and the spring 2003 estimates of the number of students who entered a 4-year institution in fall 1996 as first-time, full-time undergraduates seeking a bachelor's or equivalent degree. Students who transferred to another institution and graduated are not counted as completers at their initial institution. Included in the totals, but not shown separately, are estimates for persons with unknown race/ethnicity and nonresident aliens. Race categories exclude persons of Hispanic ethnicity. For more information on race/ethnicity and classification of postsecondary education institutions, see Appendix C -

Commonly Used Measures. For more information on the Integrated Postsecondary Education Data System (IPEDS), see Appendix B - Guide to Sources. SOURCE: U.S. Department of Education, National Center for Education Statistics, Integrated Postsecondary Education Data System (IPEDS), Spring 2011, Graduation Rates and Institutional Characteristics components. 


\section{Indicator 46}

\section{Degrees Conferred by Public and Private Institutions}

\section{From academic years 1999-2000 to 2009-10, the number of postsecondary degrees conferred by private for-profit institutions increased by a larger percentage than the number conferred by public institutions and private nonprofit institutions; this was true for all levels of degrees.}

\begin{abstract}
Between academic years 1999-2000 and 2009-10, the number of postsecondary degrees conferred by public, private for-profit, and private nonprofit institutions increased for each level of degree. The number of associate's degrees awarded increased by 50 percent, bachelor's degrees increased by 33 percent, master's degrees increased by 50 percent, and doctor's degrees increased by 34 percent. For all postsecondary degree levels, the percentage increases from 1999-2000 to 2009-10 were smaller for public and private nonprofit institutions than for private for-profit institutions.
\end{abstract}

The number of associate's degrees awarded from academic years 1999-2000 to 2009-10 increased by 43 percent for public institutions (from 448,400 to 640,100 degrees), by 1 percent for private nonprofit institutions (from 46,300 to 46,700 degrees), and by 132 percent for private for-profit institutions (from 70,200 to 162,700 degrees). Due to these changes, the share of all associate's degrees conferred by private for-profit institutions increased from 12 percent in 1999-2000 to 19 percent in 2009-10, while the share conferred by public and private nonprofit institutions decreased during this period (from 79 to 75 percent and from 8 to 5 percent, respectively) (see table A-46-1).

From academic years 1999-2000 to 2009-10, the number of bachelor's degrees awarded by public institutions increased by 29 percent (from 810,900 to 1,049,100 degrees), the number awarded by private nonprofit institutions increased by 24 percent (from 407,000 to 503,200 degrees), and the number awarded by private for-profit institutions increased by 387 percent (from 20,100 to 97,800 degrees). Despite the gain made by private for-profit institutions, they awarded 6 percent of all bachelor's degrees conferred in 2009-10, while public institutions awarded 64 percent and private nonprofit institutions awarded 30 percent.

The number of master's degrees awarded by private nonprofit institutions increased 43 percent (from 209,700 to 299,900 degrees) from academic years 1999-2000 to 2009-10, yet the percentage of all master's degrees conferred by these institutions declined from 45 to 43 percent. The number of master's degrees conferred by public institutions increased at a lower rate (33 percent, from 243,200 to 322,200 degrees) over the same time period, resulting in a decrease in their share of all master's degrees (from 52 to 46 percent). In contrast, the number of master's degrees conferred by private for-profit institutions increased by 588 percent (from 10,300 to 70,900 degrees) from $1999-2000$ to 2009-10, resulting in an increase in their share of total master's degrees conferred. Private for-profit institutions conferred 2 percent of all master's degrees in 1999-2000 and 10 percent in 2009-10.

From academic years 1999-2000 to 2009-10, the number of doctor's degrees conferred increased by 30 percent at public institutions (from 60,700 to 78,800 degrees), by 32 percent at private nonprofit institutions (from 57,000 to 75,200 degrees), and by over 300 percent at private for-profit institutions (from 1,100 to 4,600 degrees). In 2009-10, public institutions awarded 50 percent of all doctor's degrees, private nonprofit institutions awarded 47 percent, and private for-profit institutions awarded 3 percent.

Table A-46-1

Glossary: Associate's degree, Bachelor's degree, Doctor's degree, Master's degree, Private institution, Public institution

\section{Technical Notes}

This indicator includes only postsecondary degreegranting institutions that participated in Title IV federal financial aid programs. Doctor's degrees include Ph.D., Ed.D., and comparable degrees at the doctoral level, as well as most degrees formerly classified as firstprofessional, such as M.D., D.D.S., and law degrees.
For more information on the Integrated Postsecondary Education Data System (IPEDS), see Appendix B Guide to Sources. For more information on the IPEDS classification of institutions and degree levels, see Appendix C - Commonly Used Measures. 
Table 46-1. Number of degrees conferred by postsecondary degree-granting institutions and percent change, by control of institution and level of degree: Academic years 1999-2000 and 2009-10

\begin{tabular}{|c|c|c|c|c|c|}
\hline \multirow[b]{2}{*}{ Level of degree and academic year } & \multirow[b]{2}{*}{ Total } & \multirow[b]{2}{*}{ Public } & \multicolumn{3}{|c|}{ Private } \\
\hline & & & Total & Nonprofit & For-profit \\
\hline \multicolumn{6}{|l|}{ Associate's } \\
\hline 1999-2000 & 564,933 & 448,446 & 116,487 & 46,337 & 70,150 \\
\hline $2009-10$ & 849,452 & 640,113 & 209,339 & 46,673 & 162,666 \\
\hline Percent change & 50.4 & 42.7 & 79.7 & 0.7 & 131.9 \\
\hline \multicolumn{6}{|l|}{ Bachelor's } \\
\hline 1999-2000 & $1,237,875$ & 810,855 & 427,020 & 406,958 & 20,062 \\
\hline $2009-10$ & $1,650,014$ & $1,049,057$ & 600,957 & 503,164 & 97,793 \\
\hline Percent change & 33.3 & 29.4 & 40.7 & 23.6 & 387.5 \\
\hline \multicolumn{6}{|l|}{ Master's } \\
\hline 1999-2000 & 463,185 & 243,157 & 220,028 & 209,720 & 10,308 \\
\hline 2009-10 & 693,025 & 322,243 & 370,782 & 299,911 & 70,871 \\
\hline Percent change & 49.6 & 32.5 & 68.5 & 43.0 & 587.5 \\
\hline \multicolumn{6}{|l|}{ Doctor's ${ }^{1}$} \\
\hline 1999-2000 & 118,736 & 60,655 & 58,081 & 56,972 & 1,109 \\
\hline 2009-10 & 158,558 & 78,779 & 79,779 & 75,166 & 4,613 \\
\hline Percent change & 33.5 & 29.9 & 37.4 & 31.9 & 316.0 \\
\hline
\end{tabular}

Figure 46-1. Number of degrees conferred by postsecondary degree-granting institutions, by level of degree: Academic years 1999-2000 through 2009-10

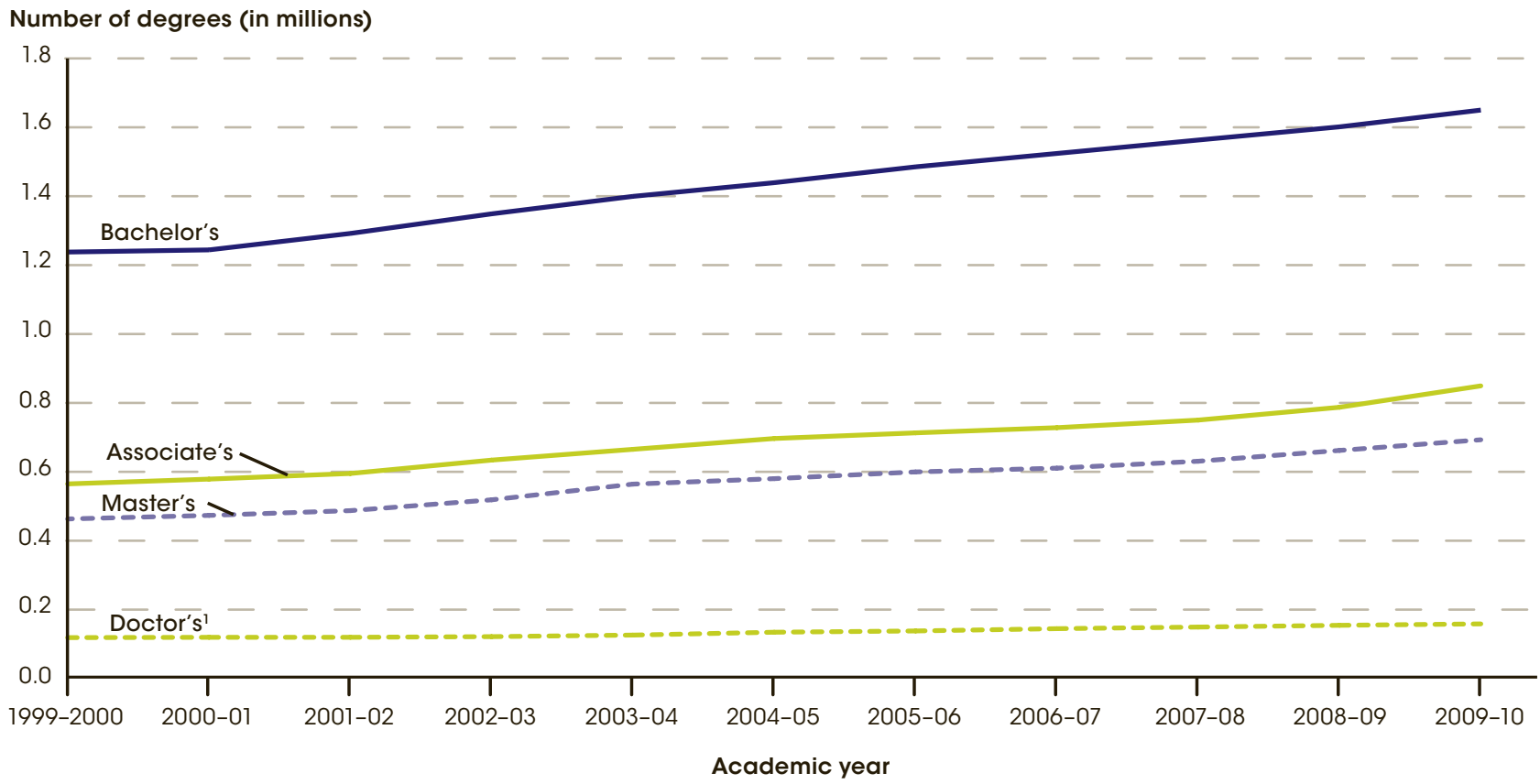

'Includes Ph.D., Ed.D., and comparable degrees at the doctoral level. Includes most degrees formerly classified as first-professional, such as M.D., D.D.S., and law degrees.

NOTE: Includes only postsecondary institutions that participated in Title IV federal financial aid programs. For more information on the Integrated Postsecondary Education Data System (IPEDS), see Appendix B - Guide to Sources. For more information on the IPEDS classification of institutions and degree levels, see Appendix C - Commonly Used Measures. See the glossary for the definition of doctor's degree.

SOURCE: U.S. Department of Education, National Center for Education Statistics, Integrated Postsecondary Education Data System (IPEDS), Fall 2000 through Fall 2010, Completions component. 


\section{Between academic years 1999-2000 and 2009-10, the number of degrees earned increased by 50 percent each for associate's and master's degrees, 33 percent for bachelor's degrees, and 34 percent for doctor's degrees. For all levels of degrees in 2009-10, females earned the majority of degrees awarded.}

Postsecondary enrollment in degree-granting institutions increased by 38 percent, from 14.8 million students in fall 1999 to 20.4 million students in fall 2009 (see indicators 10 and 11). This growth was accompanied by a 41 percent increase, from 2.4 million to 3.4 million, in the number of degrees earned in the same time period. The number of degrees earned increased by 50 percent each for associate's and master's degrees, 33 percent for bachelor's degrees, and 34 percent for doctor's degrees (see table A-47-1).

From 1999-2000 to 2009-10, the number of degrees earned among U.S. residents increased for students of all racial/ethnic groups for each level of degree, but at varying rates (see table A-47-2). For associate's, bachelor's, and master's degrees, the change in percentage distribution of degree recipients was characterized by an increase in the numbers of degrees conferred to Black and Hispanic students. For doctor's degrees, the change in percentage distribution of degree recipients was characterized by an increase in the numbers of degrees conferred to Hispanic and Asian/Pacific Islander students. (For more information on changing enrollment patterns in postsecondary education by race/ethnicity, see tables A-10-3 and A-11-2.)

Among U.S. residents, the number of associate's degrees earned by Hispanic students more than doubled from academic years 1999-2000 to 2009-10 (increasing by 118 percent), and the number earned by Black students increased by 89 percent (see table A-47-2). As a result, Blacks earned 14 percent and Hispanics earned 13 percent of all associate's degrees awarded in 2009-10, up from 11 percent and 9 percent, respectively, in 1999-2000. During the same time period, the number of bachelor's degrees awarded to Black students increased by 53 percent, and the number awarded to Hispanic students increased by 87 percent. In 2009-10, Black students earned 10 percent and Hispanics earned 9 percent of all bachelor's degrees conferred, versus the 9 and 6 percent, respectively, earned in 1999-2000. Similarly, the numbers of master's degrees earned by Black and Hispanic students more than doubled from 1999-2000 to 2009-10 (increasing by 109 percent and 125 percent, respectively). As a result, among U.S. residents in 2009-10, Black students earned 12 percent and Hispanics earned 7 percent of all master's degrees conferred, up from 9 percent and 5 percent, respectively, in 1999-2000. In addition, the number of doctor's degrees awarded increased by 60 percent for Hispanic students and by 47 percent for Black students.

From 1999-2000 to 2009-10, the percentage of degrees earned by females remained between approximately 60 and 62 percent for associate's degrees and between 57 and 58 percent for bachelor's degrees (see table A-47-1). In contrast, the percentages of both master's and doctor's degrees earned by females increased from 1999-2000 to 2009-10 (from 58 to 60 percent and from 45 to 52 percent, respectively). Within each racial/ethnic group, women earned the majority of degrees at all levels in 2009-10. For example, among U.S. residents, Black females earned 68 percent of associate's degrees, 66 percent of bachelor's degrees, 71 percent of master's degrees, and 65 percent of all doctor's degrees awarded to Black students (see table A-47-2). Hispanic females earned 62 percent of associate's degrees, 61 percent of bachelor's degrees, 64 percent of master's degrees, and 55 percent of all doctor's degrees awarded to Hispanic students.

Tables A-47-1 and A-47-2

Glossary: Associate's degree, Bachelor's degree, Doctor's degree, Master's degree, Private institution, Public institution

\section{Technical Notes}

Degree-granting institutions grant associate's or higher degrees and participate in Title IV federal financial aid programs. Reported racial/ethnic distributions of students by level of degree, field of degree, and sex were used to estimate race/ethnicity for students whose race/ ethnicity was not reported. Race categories exclude persons of Hispanic ethnicity. Doctor's degrees include Ph.D., Ed.D., and comparable degrees at the doctoral level, as well as most degrees formerly classified as firstprofessional, such as M.D., D.D.S., and law degrees.
Nonresident aliens are included in figure 47-1 and table A-47-1, but are excluded from figure 47-2 and table A-47-2 because information about their race/ethnicity is not available. For more information on race/ethnicity and the Integrated Postsecondary Education Data System (IPEDS) classification of degree levels, see Appendix $\mathrm{C}-$ Commonly Used Measures. For more information on IPEDS, see Appendix B - Guide to Sources. See the glossary for the detailed definition of doctor's degree. 
Figure 47-1. Number of degrees conferred by degree-granting institutions, by level of degree: Academic years 1999-2000, 2004-05, and 2009-10

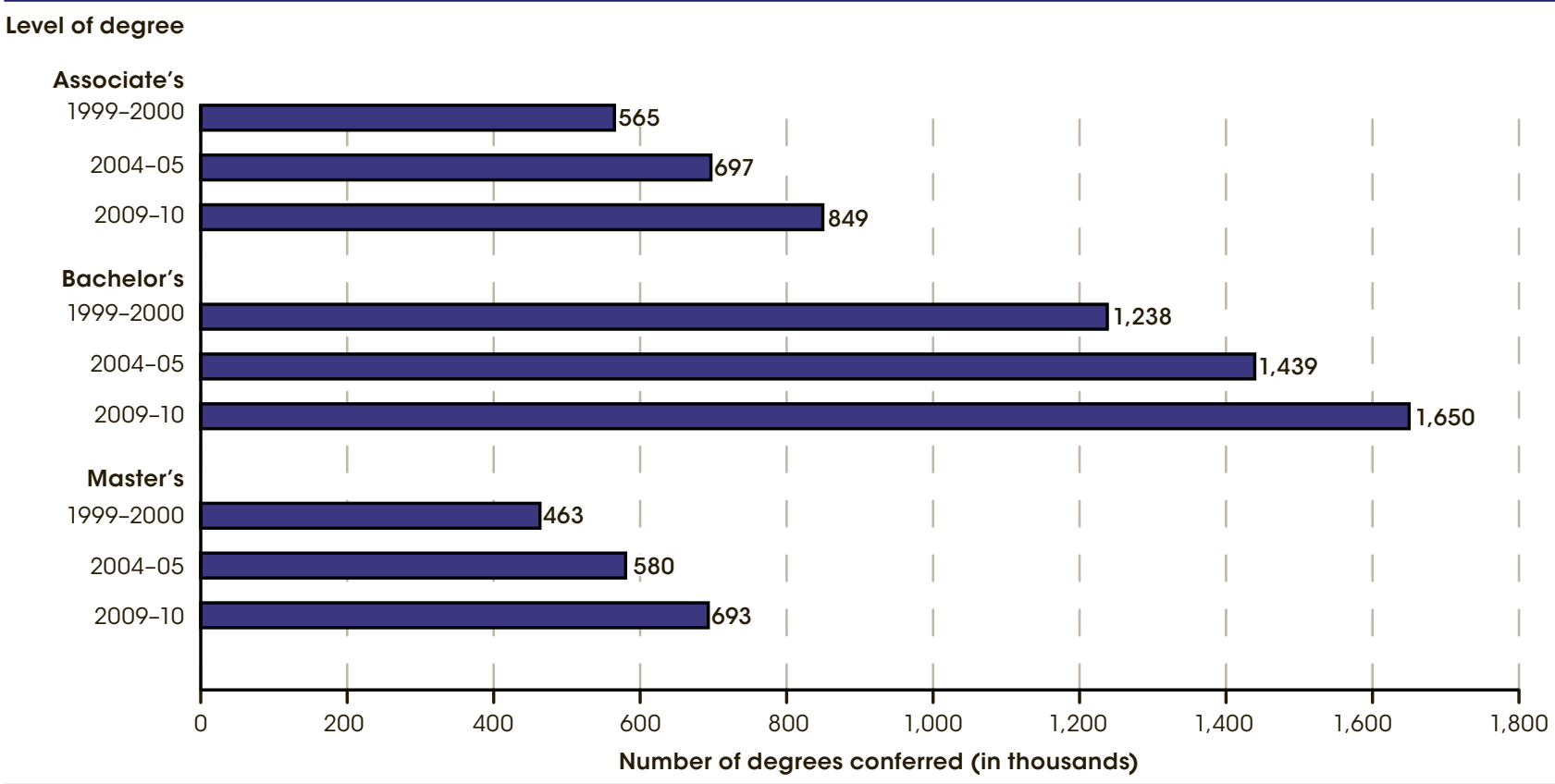

NOTE: Degree-granting institutions grant associate's or higher degrees and participate in Title IV federal financial aid programs. For more information on the Integrated Postsecondary Education Data System (IPEDS) classification of degree levels, see Appendix C - Commonly Used Measures. For more information on IPEDS, see Appendix B - Guide to Sources.

SOURCE: U.S. Department of Education, National Center for Education Statistics, Integrated Postsecondary Education Data System (IPEDS), Fall 2000, Fall 2005, and Fall 2010, Completions component

Figure 47-2. Percentage of degrees conferred to U.S.-resident females by degree-granting institutions, by level of degree and race/ethnicity: Academic year 2009-10

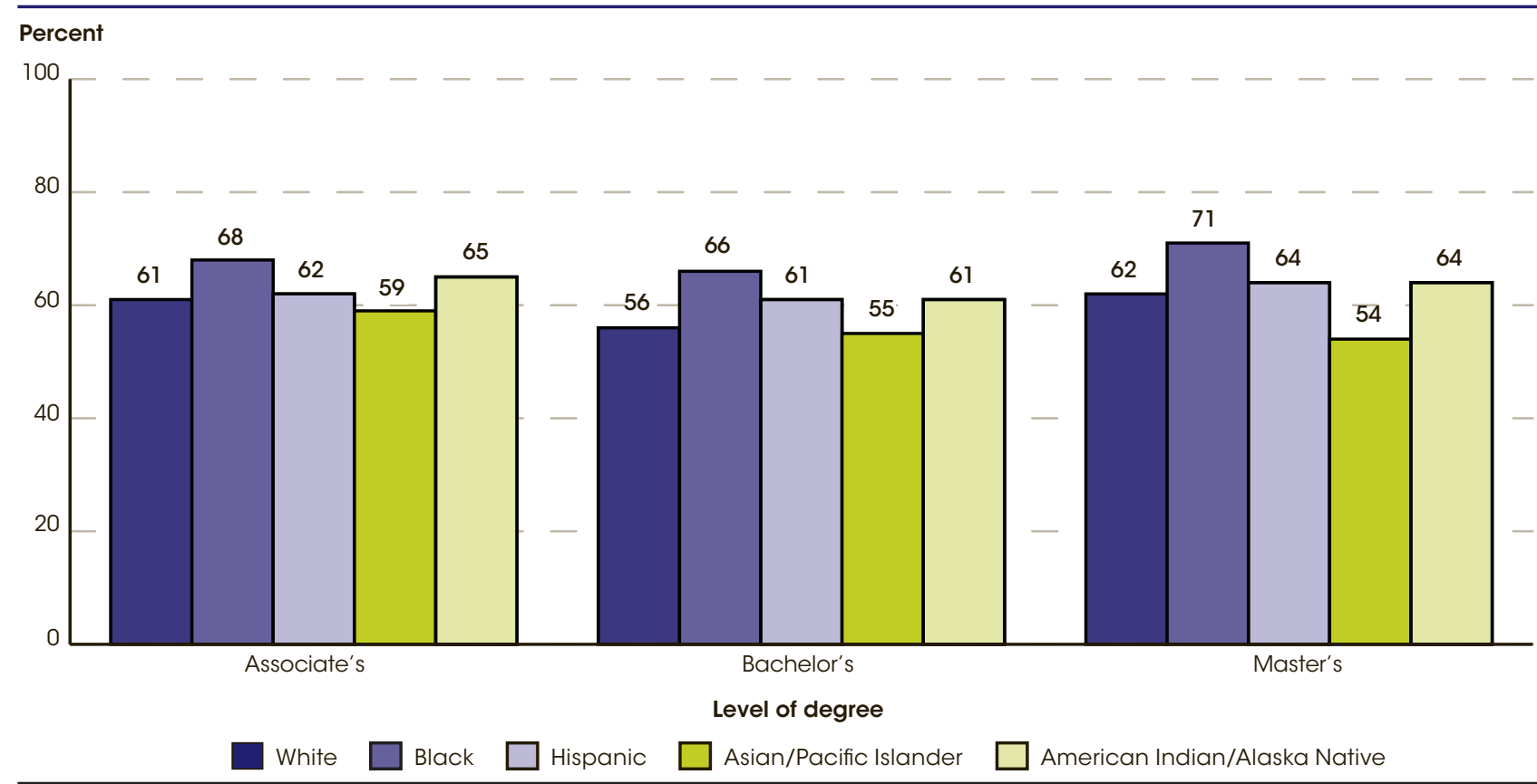

NOTE: Degree-granting institutions grant associate's or higher degrees and participate in Title IV federal financial aid programs. Reported racial/ethnic distributions of students by type of degree, field of degree, and sex were used to estimate race/ethnicity for students whose race/ethnicity was not reported. Race categories exclude persons of Hispanic ethnicity. Nonresident aliens are excluded because information about their race/ethnicity is not available. For more information on race/ethnicity and the Integrated Postsecondary Education Data System (IPEDS) classification of degree levels, see Appendix C - Commonly Used Measures. For more information on IPEDS, see Appendix B - Guide to Sources.

SOURCE: U.S. Department of Education, National Center for Education Statistics, Integrated Postsecondary Education Data System (IPEDS), Fall 2010, Completions component. 


\section{In 2011 , some 32 percent of 25- to 29-year-olds had completed a bachelor's degree or higher. From 1980 to 201 1, the gap in the attainment of a bachelor's degree or higher between Whites and Hispanics widened from 17 to 26 percentage points, and the gap between Whites and Blacks widened from 13 to 19 percentage points.}

For the purpose of this indicator, educational attainment represents the percentage of 25- to 29-year-olds who achieved at least the cited credential (i.e., a high school diploma or equivalency, some college, a bachelor's degree, or a master's degree). Between 1980 and 2011, educational attainment among 25- to 29-year-olds increased: the percentage who had received at least a high school diploma or equivalency increased from 85 to 89 percent, and the percentage who had completed a bachelor's degree or higher increased from 22 to 32 percent. In 2011, some 7 percent of 25- to 29-year-olds had completed a master's degree or higher, a 2-percentage-point increase from 1995 (see table A-48-1).

Between 1980 and 2011, the attainment rate of at least a high school diploma or equivalency increased for Whites (from 89 to 94 percent), Blacks (from 77 to 88 percent), and Hispanics (from 58 to 71 percent). Between 1990 (when educational attainment data were first available for Asians/Pacific Islanders) and 2011, the completion rate for at least high school or equivalency for Asians/Pacific Islanders increased from 90 to 95 percent. In both 1980 and 2011, the percentage of Whites who had completed at least high school or equivalency was higher than that of Blacks and Hispanics; however, the gaps between Whites and Blacks and Whites and Hispanics narrowed over the years. Between 1980 and 2011, the gap between Blacks and Whites decreased from 12 to 6 percentage points, and the gap between Hispanics and Whites decreased from 31 to 23 percentage points.

From 1980 to 2011, the percentage of 25- to 29-year-olds who had attained a bachelor's degree or higher increased from 25 to 39 percent for Whites, from 12 to 20 percent for Blacks, and from 8 to 13 percent for Hispanics. For Asians/Pacific Islanders, the attainment rate of at least a bachelor's degree in 2011 (56 percent) was higher than the rate in 1990 (42 percent). Between 1980 and
2011, the gap in the attainment of a bachelor's degree or higher between Blacks and Whites increased from 13 to 19 percentage points, and the gap between Whites and Hispanics increased from 17 to 26 percentage points.

In 2011, some 7 percent of 25- to 29-year-olds had completed at least a master's degree. From 1995 to 2011, the attainment rate of a master's degree or higher increased for Whites (from 5 to 8 percent), Blacks (from 2 to 4 percent), and Asians/Pacific Islanders (from 11 to 17 percent). In 2011, the percentage of Asians/Pacific Islanders who had attained at least a master's degree in 2011 (17 percent) was higher than that of their peers of any other race/ethnicity: 8 percent of Whites, 4 percent of Blacks, and 3 percent of Hispanics. Between 1995 and 2011, the gap in the attainment of a master's degree or higher between Blacks and Whites was not measurably different, while the gap between Whites and Hispanics increased from 4 to 5 percentage points.

Differences in educational attainment by gender have shifted over the past few decades, with female attainment now greater than male attainment at each education level. For example, in 1980, the percentages of males (85 percent) and females (86 percent) who had completed at least high school or equivalency were not measurably different, but in 2011, the percentage of females (91 percent) was higher than the percentage of males (87 percent) by 3 percentage points. The percentage of females (21 percent) who had attained at least a bachelor's degree was 3 points lower than the percentage of males (24 percent) in 1980, but in 2011 the percentage of females (36 percent) was 8 points higher than the percentage of males (28 percent).

Table A-48-1

Glossary: Educational attainment

\section{Technical Notes}

This indicator uses March Current Population Survey (CPS) data to estimate the percentage of civilian, noninstitutionalized people ages 25 through 29 who are out of high school. In 1992, the CPS question on educational attainment was revised. Prior to 1992, a high school diploma meant completing 12 years of schooling; some college meant completing 1 or more years of college ("some college" may have included students who earned an associate's degree); a bachelor's degree meant completing 4 years of college; and data on attainment of a master's degree were not available. From 1992 onward, a high school diploma means a high school diploma or equivalency certificate; some college means completing any college at all; and a bachelor's degree means earning a bachelor's degree. Included in the totals, but not shown separately, are estimates for persons from other racial/ethnic groups. Race categories exclude persons of Hispanic ethnicity. For more information on race/ethnicity and educational attainment, see Appendix C - Commonly Used Measures. For more information on the CPS, see Appendix B Guide to Sources. Some estimates are revised from previous publications. 
Figure 48-1. Percentage of 25- to 29-year-olds who completed at least a high school diploma or equivalency, by race/ethnicity: 1980-2011

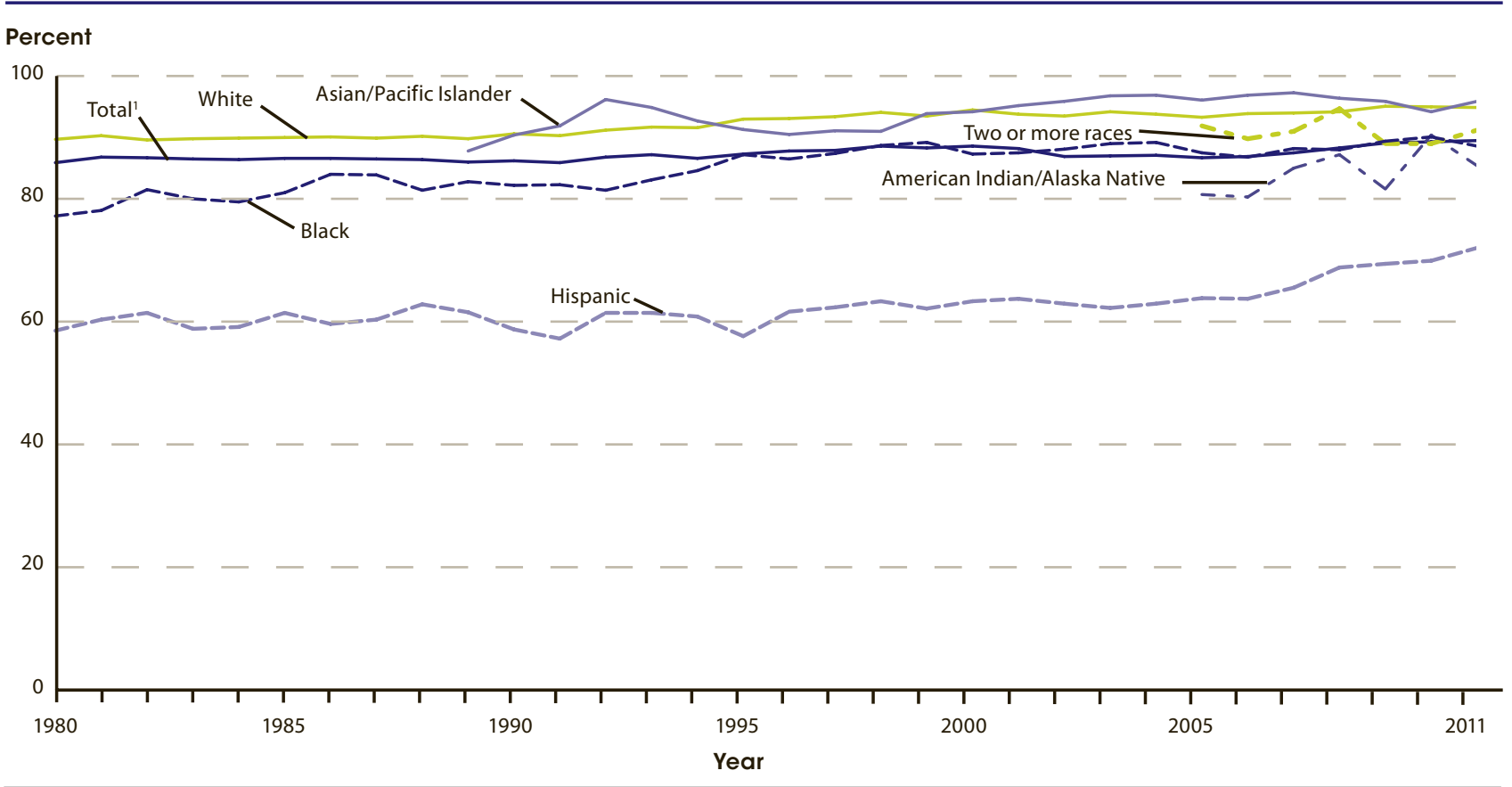

1 Included in the totals but not shown separately are estimates for persons from other racial/ethnic groups.

NOTE: In 1992, the question on educational attainment was revised. Prior to 1992, a high school diploma meant completing 12 years of schooling; from 1992 onward, a high school diploma means a high school diploma or equivalency certificate. Race categories exclude persons of Hispanic ethnicity. For more information on race/ethnicity and educational attainment, see Appendix C - Commonly Used Measures. For more information on the Current Population Survey (CPS), see Appendix B - Guide to Sources

SOURCE: U.S. Department of Commerce, Census Bureau, Current Population Survey (CPS), Annual Social and Economic Supplement, $1980-2011$.

Figure 48-2. Percentage of 25- to 29-year-olds with a bachelor's degree or higher, by race/ethnicity: 1980-2011

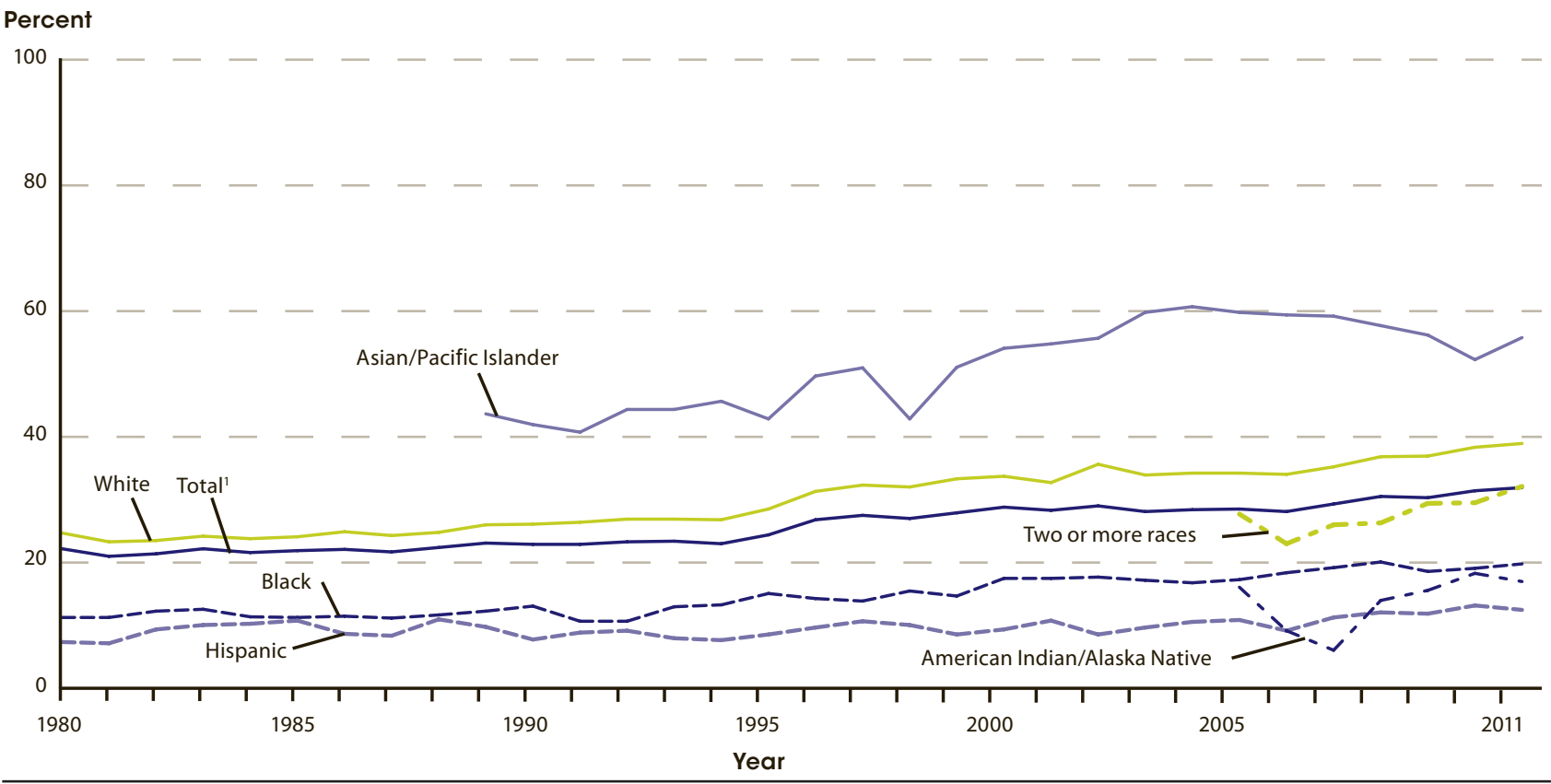

1 Included in the totals but not shown separately are estimates for persons from other racial/ethnic groups.

NOTE: In 1992, the question on educational attainment was revised. Prior to 1992, a bachelor's degree meant completing 4 years of college; from 1992 onward, a bachelor's degree means earning a bachelor's degree. Race categories exclude persons of Hispanic ethnicity. For more information on race/ ethnicity and educational attainment, see Appendix C - Commonly Used Measures. For more information on the Current Population Survey (CPS), see Appendix B - Guide to Sources.

SOURCE: U.S. Department of Commerce, Census Bureau, Current Population Survey (CPS), Annual Social and Economic Supplement, $1980-2011$ 


\section{Annual Earnings of Young Adults}

\section{In 2010, young adults ages 25-34 with a bachelor's degree earned 114 percent more than young adults without a high school diploma or its equivalent, 50 percent more than young adult high school completers, and 22 percent more than young adults with an associate's degree.}

In 2010, some 62 percent of young adults ages 25-34 who were in the labor force were employed full time throughout a full year (table A-49-1). The percentage of young adults working full time throughout a full year was generally higher for those with higher levels of educational attainment. For example, 71 percent of young adults with a bachelor's degree or higher were full-time, full-year workers in 2010, compared with 57 percent of young adults with a high school diploma or its equivalent.

For young adults ages $25-34$ who worked full time throughout a full year, higher educational attainment was associated with higher median earnings. This pattern of higher median earnings corresponding with higher levels of educational attainment was consistent for each year examined between 1995 and 2010 (see table A-491). For example, young adults with a bachelor's degree consistently had higher median earnings than those with less education. This pattern also held across sex and race/ ethnicity subgroups.

In 2010, the median of earnings for young adults with a bachelor's degree was $\$ 45,000$, while the median was $\$ 21,000$ for those without a high school diploma or its equivalent, $\$ 29,900$ for those with a high school diploma or its equivalent, and $\$ 37,000$ for those with an associate's degree. In other words, young adults with a bachelor's degree earned more than twice as much as those without a high school diploma or its equivalent in 2010 (i.e., 114 percent more), 50 percent more than young adult high school completers, and 22 percent more than young adults with an associate's degree. In 2010, the median of earnings for young adults with a master's degree or higher was $\$ 54,700$, some 21 percent more than the median for young adults with a bachelor's degree.

The difference (in constant 2010 dollars) in median earnings between those with a bachelor's degree or higher and those without a high school diploma or its equivalent increased between 1995 and 2010. For example, in 1995, the median of earnings for young adults with a bachelor's degree or higher was $\$ 24,500$ greater than the median for those without a high school diploma or its equivalent; in 2010 , this earnings differential was $\$ 27,700$. There was no measurable difference, however, between the 1995 median earnings differential and the 2010 median earnings differential of those with a bachelor's degree or higher over those with a high school diploma or its equivalent. Nor was there a measurable difference between the 1995 median earnings differential and the 2010 median earnings differential of those with a master's degree or higher over those with a bachelor's degree.

Earnings differences were also observed by sex and race/ ethnicity. In 2010, the median of earnings for young adult males was higher than the median for young adult females at every education level. For example, in 2010, young adult males with a bachelor's degree earned $\$ 49,800$, while their female counterparts earned $\$ 40,000$. In the same year, the median of earnings by education level for White young adults generally exceeded the corresponding medians for Black and Hispanic young adults. Asian young adults with a bachelor's degree or with a master's degree or higher had higher median earnings than did their White, Black, and Hispanic counterparts in 2010. For example, the median of earnings in 2010 for young adults with at least a master's degree was $\$ 68,300$ for Asians, $\$ 54,300$ for Whites, $\$ 49,100$ for Blacks, and $\$ 48,800$ for Hispanics.

Table A-49-1

Glossary: Bachelor's degree, Consumer Price Index (CPI), Constant dollars, Educational attainment, High school completer, Master's degree

\section{Technical Notes}

High school completers are those who earned a high school diploma or equivalent (e.g., a General Educational Development [GED] certificate). Median earnings are presented in 2010 constant dollars by means of the Consumer Price Index (CPI) to eliminate inflationary factors and to allow for direct comparison across years. For more information on the CPI, see Appendix $\mathrm{C}-$ Finance. Full-year workers refers to those who were employed 50 or more weeks during the previous year; full-time workers refers to those who were usually employed 35 or more hours per week. Beginning in 2005, standard errors were computed using replicate weights, which produced more precise values than the methodology used in prior years. For more information on the Current Population Survey, see Appendix B - Guide to Sources. Race categories exclude persons of Hispanic ethnicity. For more information on race/ethnicity, see Appendix $\mathrm{C}-$ Commonly Used Measures. 
Figure 49-1. Median annual earnings of full-time, full-year wage and salary workers ages 25-34, by educational attainment: 1995-2010

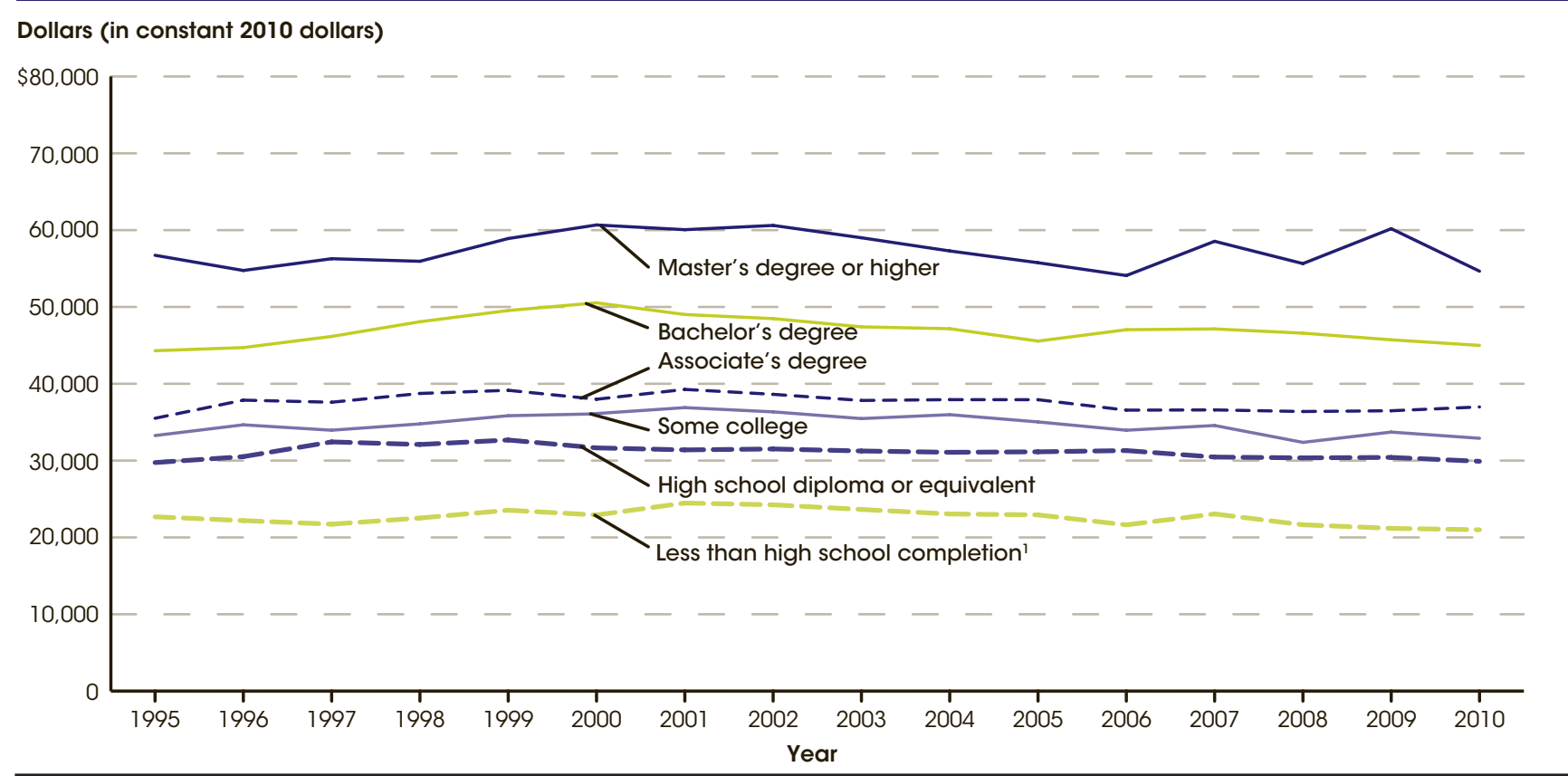

Young adults in this category did not earn a high school diploma or receive alternative credentials such as a General Educational Development (GED) certificate.

NOTE: Earnings are presented in constant dollars by means of the Consumer Price Index (CPI) to eliminate inflationary factors and to allow for direct comparison across years. For more information on the CPI, see Appendix C - Finance. Full-year workers refers to those who were employed 50 or more weeks during the previous year: full-time workers refers to those who were usually employed 35 or more hours per week. For more information on the Current Population Survey, see Appendix B - Guide to Sources. Race categories exclude persons of Hispanic ethnicity. For more information on race/ethnicity, see Appendix C - Commonly Used Measures.

SOURCE: U.S. Department of Commerce, Census Bureau, Current Population Survey (CPS), Annual Social and Economic Supplement, $1996-2011$.

Figure 49-2. Median annual earnings of full-time, full-year wage and salary workers ages 25-34, by educational attainment and sex: 2010

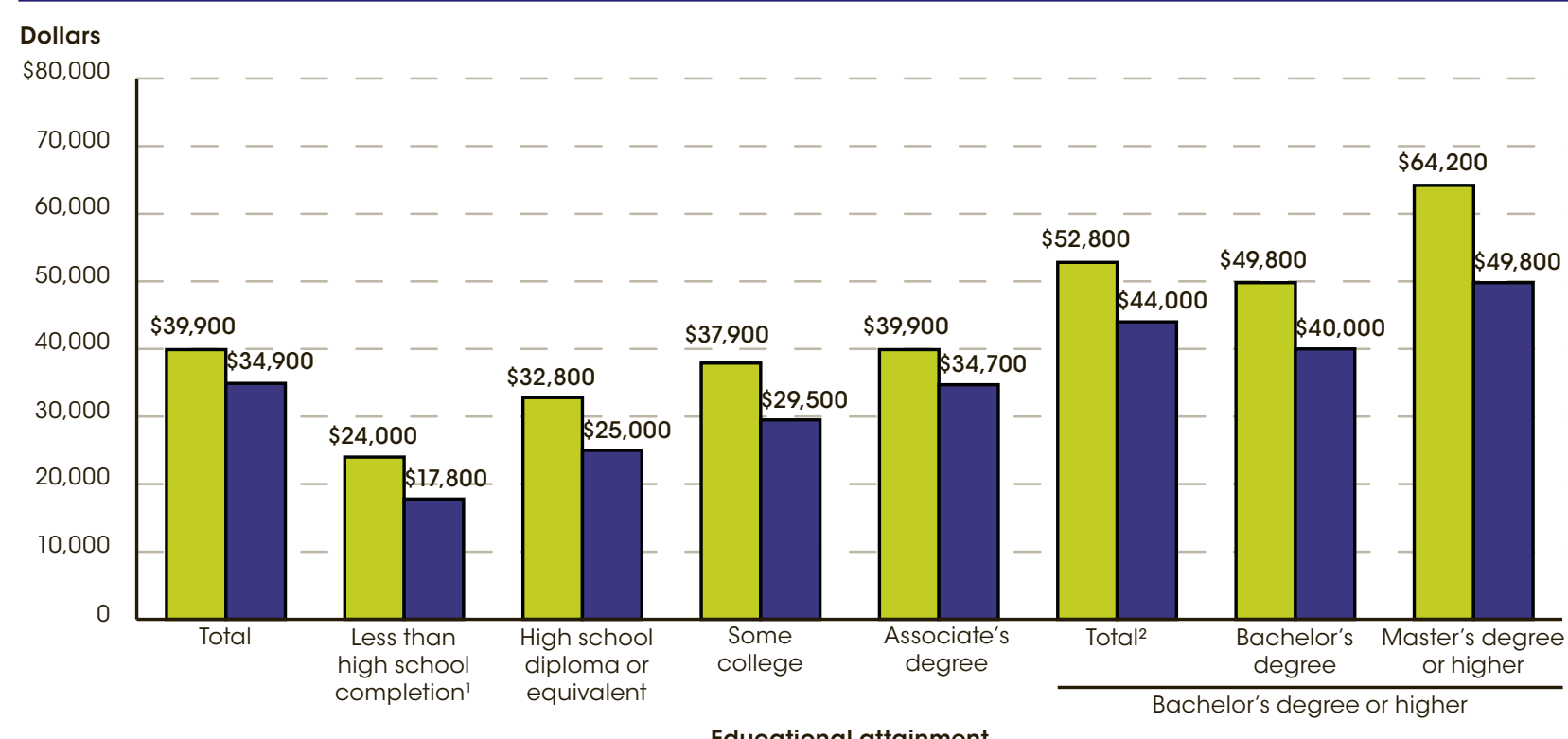

Educational attainment

Young adults in this category did not earn a high school diploma or receive alternative credentials, such as a General Educational Development (GED) certificate.

2 Total represents median annual earnings of young adults with a bachelor's degree or higher

NOTE: Full-year workers refers to those who were employed 50 or more weeks during the previous year; full-time workers refers to those who were usually

employed 35 or more hours per week. For more information on the Current Population Survey, see Appendix B - Guide to Sources.

SOURCE: U.S. Department of Commerce, Census Bureau, Current Population Survey (CPS), Annual Social and Economic Supplement, 2011. 
118 The Condition of Education 2012 


\section{APPENDIX A}

Tables 
Table A-1-1. Percentage of the population ages 3-34 enrolled in school, by age group: October 1970-2010

\begin{tabular}{|c|c|c|c|c|c|c|c|c|c|c|c|c|c|c|}
\hline \multirow[b]{2}{*}{ Year } & \multirow[b]{2}{*}{$\begin{array}{r}\text { Total, } \\
\text { ages } \\
3-34 \\
\end{array}$} & \multirow[b]{2}{*}{$\begin{array}{r}\text { Ages } \\
3-4^{1} \\
\end{array}$} & \multirow[b]{2}{*}{$\begin{array}{r}\text { Ages } \\
5-6 \\
\end{array}$} & \multirow[b]{2}{*}{$\begin{array}{r}\text { Ages } \\
7-13 \\
\end{array}$} & \multirow[b]{2}{*}{$\begin{array}{r}\text { Ages } \\
14-15 \\
\end{array}$} & \multirow[b]{2}{*}{$\begin{array}{r}\text { Ages } \\
16-17 \\
\end{array}$} & \multicolumn{3}{|c|}{ Ages 18-19 } & \multicolumn{3}{|c|}{ Ages 20-24 } & \multirow[b]{2}{*}{$\begin{array}{r}\text { Ages } \\
25-29 \\
\end{array}$} & \multirow[b]{2}{*}{$\begin{array}{r}\text { Ages } \\
30-34 \\
\end{array}$} \\
\hline & & & & & & & Total & $\begin{array}{r}\text { In } \\
\text { sec- } \\
\text { ondary } \\
\end{array}$ & $\begin{array}{r}\text { In } \\
\text { col- } \\
\text { lege } \\
\end{array}$ & Total & $\begin{array}{r}\text { Ages } \\
20-21 \\
\end{array}$ & $\begin{array}{r}\text { Ages } \\
22-24\end{array}$ & & \\
\hline 1970 & 56.4 & 20.5 & 89.5 & 99.2 & 98.1 & 90.0 & 47.7 & 10.5 & 37.3 & 21.5 & 31.9 & 14.9 & 7.5 & 4.2 \\
\hline 1971 & 56.2 & 21.2 & 91.6 & 99.1 & 98.6 & 90.2 & 49.2 & 11.5 & 37.7 & 21.9 & 32.2 & 15.4 & 8.0 & 4.9 \\
\hline 1972 & 54.9 & 24.4 & 91.9 & 99.2 & 97.6 & 88.9 & 46.3 & 10.4 & 35.9 & 21.6 & 31.4 & 14.8 & 8.6 & 4.6 \\
\hline 1973 & 53.5 & 24.2 & 92.5 & 99.2 & 97.5 & 88.3 & 42.9 & 10.0 & 32.9 & 20.8 & 30.1 & 14.5 & 8.5 & 4.5 \\
\hline 1974 & 53.6 & 28.8 & 94.2 & 99.3 & 97.9 & 87.9 & 43.1 & 9.9 & 33.2 & 21.4 & 30.2 & 15.1 & 9.6 & 5.7 \\
\hline 1975 & 53.7 & 31.5 & 94.7 & 99.3 & 98.2 & 89.0 & 46.9 & 10.2 & 36.7 & 22.4 & 31.2 & 16.2 & 10.1 & 6.6 \\
\hline 1976 & 53.1 & 31.3 & 95.5 & 99.2 & 98.2 & 89.1 & 46.2 & 10.2 & 36.0 & 23.3 & 32.0 & 17.1 & 10.0 & 6.0 \\
\hline 1977 & 52.5 & 32.0 & 95.8 & 99.4 & 98.5 & 88.9 & 46.2 & 10.4 & 35.7 & 22.9 & 31.8 & 16.5 & 10.8 & 6.9 \\
\hline 1978 & 51.2 & 34.2 & 95.3 & 99.1 & 98.4 & 89.1 & 45.4 & 9.8 & 35.6 & 21.8 & 29.5 & 16.3 & 9.4 & 6.4 \\
\hline 1979 & 50.3 & 35.1 & 95.8 & 99.2 & 98.1 & 89.2 & 45.0 & 10.3 & 34.6 & 21.7 & 30.2 & 15.8 & 9.6 & 6.4 \\
\hline 1980 & 49.7 & 36.7 & 95.7 & 99.3 & 98.2 & 89.0 & 46.4 & 10.5 & 35.9 & 22.3 & 31.0 & 16.3 & 9.3 & 6.4 \\
\hline 1981 & 48.9 & 36.0 & 94.0 & 99.2 & 98.0 & 90.6 & 49.0 & 11.5 & 37.5 & 22.5 & 31.6 & 16.5 & 9.0 & 6.9 \\
\hline 1982 & 48.6 & 36.4 & 95.0 & 99.2 & 98.5 & 90.6 & 47.8 & 11.3 & 36.5 & 23.5 & 34.0 & 16.8 & 9.6 & 6.3 \\
\hline 1983 & 48.4 & 37.5 & 95.4 & 99.2 & 98.3 & 91.7 & 50.4 & 12.8 & 37.6 & 22.7 & 32.5 & 16.6 & 9.6 & 6.4 \\
\hline 1984 & 47.9 & 36.3 & 94.5 & 99.2 & 97.8 & 91.5 & 50.1 & 11.5 & 38.6 & 23.7 & 33.9 & 17.3 & 9.1 & 6.3 \\
\hline 1985 & 48.3 & 38.9 & 96.1 & 99.2 & 98.1 & 91.7 & 51.6 & 11.2 & 40.4 & 24.0 & 35.3 & 16.9 & 9.2 & 6.1 \\
\hline 1986 & 48.2 & 38.9 & 95.3 & 99.2 & 97.6 & 92.3 & 54.6 & 13.1 & 41.5 & 23.6 & 33.0 & 17.9 & 8.8 & 6.0 \\
\hline 1987 & 48.6 & 38.3 & 95.1 & 99.5 & 98.6 & 91.7 & 55.6 & 13.1 & 42.5 & 25.5 & 38.7 & 17.5 & 9.0 & 5.8 \\
\hline 1988 & 48.7 & 38.2 & 96.0 & 99.7 & 98.9 & 91.6 & 55.6 & 13.9 & 41.8 & 26.1 & 39.1 & 18.2 & 8.3 & 5.9 \\
\hline 1989 & 49.0 & 39.1 & 95.2 & 99.3 & 98.8 & 92.7 & 56.0 & 14.4 & 41.6 & 27.0 & 38.5 & 19.9 & 9.3 & 5.7 \\
\hline 1990 & 50.2 & 44.4 & 96.5 & 99.6 & 99.0 & 92.5 & 57.2 & 14.5 & 42.7 & 28.6 & 39.7 & 21.0 & 9.7 & 5.8 \\
\hline 1991 & 50.7 & 40.5 & 95.4 & 99.6 & 98.8 & 93.3 & 59.6 & 15.6 & 44.0 & 30.2 & 42.0 & 22.2 & 10.2 & 6.2 \\
\hline 1992 & 51.4 & 39.7 & 95.5 & 99.4 & 99.1 & 94.1 & 61.4 & 17.1 & 44.3 & 31.6 & 44.0 & 23.7 & 9.8 & 6.1 \\
\hline 1993 & 51.8 & 40.4 & 95.4 & 99.5 & 98.9 & 94.0 & 61.6 & 17.2 & 44.4 & 30.8 & 42.7 & 23.6 & 10.2 & 5.9 \\
\hline 1994 & 53.3 & 47.3 & 96.7 & 99.4 & 98.8 & 94.4 & 60.2 & 16.2 & 43.9 & 32.0 & 44.9 & 24.0 & 10.8 & 6.7 \\
\hline 1995 & 53.7 & 48.7 & 96.0 & 98.9 & 98.9 & 93.6 & 59.4 & 16.3 & 43.1 & 31.5 & 44.9 & 23.2 & 11.6 & 5.9 \\
\hline 1996 & 54.1 & 48.3 & 94.0 & 97.7 & 98.0 & 92.8 & 61.5 & 16.7 & 44.9 & 32.5 & 44.4 & 24.8 & 11.9 & 6.1 \\
\hline 1997 & 55.6 & 52.6 & 96.5 & 99.1 & 98.9 & 94.3 & 61.5 & 16.7 & 44.7 & 34.3 & 45.9 & 26.4 & 11.8 & 5.7 \\
\hline 1998 & 55.8 & 52.1 & 95.6 & 98.9 & 98.4 & 93.9 & 62.2 & 15.7 & 46.4 & 33.0 & 44.8 & 24.9 & 11.9 & 6.6 \\
\hline 1999 & 56.0 & 54.2 & 96.0 & 98.7 & 98.2 & 93.6 & 60.6 & 16.5 & 44.1 & 32.8 & 45.3 & 24.5 & 11.1 & 6.2 \\
\hline 2000 & 55.9 & 52.1 & 95.6 & 98.2 & 98.7 & 92.8 & 61.2 & 16.5 & 44.7 & 32.5 & 44.1 & 24.6 & 11.4 & 6.7 \\
\hline 2001 & 56.4 & 52.4 & 95.3 & 98.3 & 98.1 & 93.4 & 61.1 & 17.1 & 44.0 & 34.1 & 46.1 & 25.5 & 11.8 & 6.9 \\
\hline 2002 & 57.1 & 56.4 & 95.5 & 98.3 & 98.5 & 94.4 & 63.2 & 17.6 & 45.7 & 35.0 & 48.5 & 26.0 & 12.3 & 6.7 \\
\hline 2003 & 56.2 & 55.1 & 94.5 & 98.3 & 97.5 & 94.9 & 64.5 & 17.9 & 46.6 & 35.6 & 48.3 & 27.8 & 11.8 & 6.8 \\
\hline 2004 & 56.2 & 54.0 & 95.4 & 98.4 & 98.5 & 94.5 & 64.4 & 16.6 & 47.8 & 35.2 & 48.9 & 26.3 & 13.0 & 6.6 \\
\hline 2005 & 56.5 & 53.6 & 95.4 & 98.6 & 98.0 & 95.1 & 67.6 & 18.3 & 49.3 & 36.1 & 48.7 & 27.3 & 11.9 & 6.9 \\
\hline 2006 & 56.0 & 55.7 & 94.6 & 98.3 & 98.3 & 94.6 & 65.5 & 19.3 & 46.2 & 35.0 & 47.5 & 26.7 & 11.7 & 7.2 \\
\hline 2007 & 56.1 & 54.5 & 94.7 & 98.4 & 98.7 & 94.3 & 66.8 & 17.9 & 48.9 & 35.7 & 48.4 & 27.3 & 12.4 & 7.2 \\
\hline 2008 & 56.2 & 52.8 & 93.8 & 98.7 & 98.6 & 95.2 & 66.0 & 17.4 & 48.6 & 36.9 & 50.1 & 28.2 & 13.2 & 7.3 \\
\hline 2009 & 56.5 & 52.4 & 94.1 & 98.2 & 98.0 & 94.6 & 68.9 & 19.1 & 49.8 & 38.7 & 51.7 & 30.4 & 13.5 & 8.1 \\
\hline$\underline{2010}$ & 56.6 & 53.2 & 94.5 & 98.0 & 98.1 & 96.1 & 69.2 & 18.1 & 51.2 & 38.6 & 52.4 & 28.9 & 14.6 & 8.3 \\
\hline
\end{tabular}

1 Beginning in 1994, new procedures were used to collect enrollment data on children ages 3-4. As a result, pre-1994 data may not be comparable to data from 1994 or later.

NOTE: Detail may not sum to totals because of rounding. Includes enrollment in any type of graded public or parochial or other private schools

and include nursery schools or preschools, kindergartens, elementary schools, secondary schools, colleges, universities, and professional schools.

Excludes enrollments in schools that do not advance students toward a regular school degree (e.g., trade schools, business colleges, and

correspondence courses). This table uses a different data source than table A-OPE-2; therefore, the enrollment estimates for 2010 are not directly

comparable to the total enrollment estimates in table A-OPE-2. For more information on the Current Population Survey (CPS), see Appendix B - Guide

to Sources.

SOURCE: U.S. Department of Commerce, Census Bureau, Current Population Survey (CPS), October Supplement, $1970-2010$. 
This indicator continues on page 122. 
Table A-1-2. Age range for compulsory school attendance, policies on kindergarten education, and percentage of the population ages 3-34 enrolled in school, by age group and state or jurisdiction: 2010

\begin{tabular}{|c|c|c|c|c|c|c|c|c|c|c|c|}
\hline \multirow[b]{3}{*}{ State or jurisdiction } & \multirow[b]{3}{*}{$\begin{array}{c}\text { Compul- } \\
\text { sory age } \\
\text { of atten- } \\
\text { dance }\end{array}$} & \multicolumn{3}{|c|}{ Kindergarten education' } & \multicolumn{7}{|c|}{ Percentage of the population ages 3-34 enrolled in school } \\
\hline & & \multirow[b]{2}{*}{$\begin{array}{r}\text { Atten- } \\
\text { dance } \\
\text { re- } \\
\text { quired }\end{array}$} & \multicolumn{2}{|c|}{$\begin{array}{l}\text { School districts } \\
\text { required to offer }\end{array}$} & \multirow[b]{2}{*}{$\begin{array}{r}\text { Ages } \\
3-4\end{array}$} & \multirow[b]{2}{*}{$\begin{array}{l}\text { Ages } \\
5-17\end{array}$} & \multicolumn{3}{|c|}{ Ages 18-19 } & \multirow[b]{2}{*}{$\begin{array}{l}\text { Ages } \\
20-24\end{array}$} & \multirow[b]{2}{*}{$\begin{array}{r}\text { Ages } \\
25-34\end{array}$} \\
\hline & & & Program & $\begin{array}{l}\text { Full-day } \\
\text { program }\end{array}$ & & & Total & $\begin{array}{l}\text { In } \\
\text { sec- } \\
\text { ond- } \\
\text { ary }\end{array}$ & $\begin{array}{l}\text { In col- } \\
\text { lege }\end{array}$ & & \\
\hline United States & $\dagger$ & $\dagger$ & $\dagger$ & $t$ & 47.7 & 96.9 & 74.1 & 26.4 & 47.6 & 42.4 & 13.9 \\
\hline Alabama & 7 to 17 & & $x$ & $x$ & 45.6 & 96.6 & 71.8 & 27.2 & 44.7 & 40.0 & 13.1 \\
\hline Alaska & 7 to 16 & & & & 40.6 & 96.0 & 68.3 & 39.5 & 28.9 & 30.9 & 13.9 \\
\hline Arizona & 6 to $16^{2}$ & & $x$ & & 34.2 & 95.6 & 67.8 & 25.7 & 42.1 & 35.8 & 14.8 \\
\hline Arkansas & 5 to $17^{2,3}$ & $x$ & $x$ & $x$ & 53.8 & 96.3 & 67.0 & 26.4 & 40.6 & 37.8 & 12.6 \\
\hline California & 6 to 18 & & $x$ & & 49.9 & 97.5 & 75.0 & 22.9 & 52.1 & 44.5 & 14.5 \\
\hline Colorado & 6 to 17 & & $x$ & & 48.9 & 96.4 & 75.7 & 27.1 & 48.7 & 42.5 & 13.3 \\
\hline Connecticut & 5 to $18^{3}$ & $x$ & $x$ & & 63.1 & 97.8 & 80.5 & 25.8 & 54.7 & 46.5 & 13.7 \\
\hline Delaware & 5 to 16 & $x$ & $x$ & $x$ & 54.2 & 96.5 & 80.3 & 26.1 & 54.2 & 44.1 & 12.4 \\
\hline District of Columbia & 5 to 18 & $x$ & $x$ & & 73.3 & 97.9 & 81.3 & 12.0 & 69.4 & 43.1 & 18.9 \\
\hline Florida & 6 to $16^{4}$ & & $x$ & & 50.8 & 96.8 & 72.4 & 29.6 & 42.8 & 43.6 & 14.6 \\
\hline Georgia & 6 to 16 & & $x$ & $x$ & 49.4 & 97.0 & 70.7 & 28.9 & 41.8 & 38.9 & 14.4 \\
\hline Hawaii & 6 to 18 & & $x$ & & 55.8 & 96.4 & 67.9 & 21.4 & 46.5 & 36.7 & 14.6 \\
\hline Idaho & 7 to 16 & & & & 43.2 & 96.1 & 65.9 & 27.2 & 38.8 & 37.2 & 14.9 \\
\hline Illinois & 7 to 17 & & $x$ & & 54.7 & 97.3 & 78.9 & 28.0 & 51.0 & 44.7 & 13.0 \\
\hline Indiana & 7 to $18^{2}$ & & $x$ & & 40.0 & 96.0 & 76.8 & 32.7 & 44.1 & 42.8 & 13.8 \\
\hline lowa & 6 to 16 & & $x$ & & 46.6 & 97.1 & 76.7 & 25.8 & 50.8 & 46.0 & 14.1 \\
\hline Kansas & 7 to $18^{2}$ & & $x$ & & 50.4 & 96.7 & 75.7 & 26.8 & 48.9 & 42.8 & 13.3 \\
\hline Kentucky & 6 to 16 & & $x$ & & 42.7 & 97.3 & 63.3 & 27.6 & 35.8 & 35.4 & 13.9 \\
\hline Louisiana & 7 to $18^{2}$ & $x$ & $x$ & $x$ & 52.0 & 96.6 & 65.3 & 27.2 & 38.2 & 36.5 & 10.7 \\
\hline Maine & 7 to $17^{2}$ & & $x$ & & 45.9 & 97.4 & 74.2 & 26.0 & 48.1 & 42.0 & 9.9 \\
\hline Maryland & 5 to $16^{3}$ & $x$ & $x$ & $x$ & 51.3 & 97.3 & 74.7 & 19.6 & 55.2 & 43.0 & 16.8 \\
\hline Massachusetts & 6 to $16^{2}$ & & $x$ & & 58.3 & 97.3 & 84.2 & 23.8 & 60.3 & 51.2 & 15.8 \\
\hline Michigan & 6 to 18 & & & & 45.8 & 96.9 & 75.8 & 26.2 & 49.5 & 47.7 & 16.9 \\
\hline Minnesota & 7 to $16^{2}$ & & $x$ & & 46.0 & 96.5 & 82.6 & 30.9 & 51.8 & 46.4 & 13.8 \\
\hline Mississippi & 6 to 17 & & $x$ & $x$ & 51.9 & 95.5 & 69.5 & 27.3 & 42.2 & 39.9 & 13.0 \\
\hline Missouri & 7 to 17 & & $x$ & & 43.3 & 96.2 & 71.8 & 29.3 & 42.5 & 41.3 & 14.4 \\
\hline Montana & 7 to $16^{2}$ & & $x$ & & 42.0 & 95.6 & 78.9 & 29.6 & 49.4 & 38.8 & 14.0 \\
\hline Nebraska & 6 to 18 & & $x$ & & 47.9 & 97.7 & 83.8 & 28.9 & 54.9 & 47.3 & 13.9 \\
\hline Nevada & 7 to $18^{2}$ & $x$ & $x$ & & 32.4 & 95.8 & 59.5 & 28.3 & 31.1 & 29.9 & 12.7 \\
\hline New Hampshire & 6 to 18 & & & & 51.1 & 97.0 & 81.4 & 24.2 & 57.3 & 43.9 & 10.6 \\
\hline
\end{tabular}

See notes at end of table. 
Table A-1-2. Age range for compulsory school attendance, policies on kindergarten education, and percentage of the population ages 3-34 enrolled in school, by age group and state or jurisdiction: 2010-Continued

\begin{tabular}{|c|c|c|c|c|c|c|c|c|c|c|c|}
\hline \multirow[b]{3}{*}{ State or jurisdiction } & \multirow[b]{3}{*}{$\begin{array}{c}\text { Compul- } \\
\text { sory age } \\
\text { of atten- } \\
\text { dance }\end{array}$} & \multicolumn{3}{|c|}{ Kindergarten education ${ }^{1}$} & \multicolumn{7}{|c|}{ Percentage of the population ages 3-34 enrolled in school } \\
\hline & & \multirow[b]{2}{*}{$\begin{array}{r}\text { Atten- } \\
\text { dance } \\
\text { re- } \\
\text { quired }\end{array}$} & \multicolumn{2}{|c|}{$\begin{array}{l}\text { School districts } \\
\text { required to offer }\end{array}$} & \multirow[b]{2}{*}{$\begin{array}{r}\text { Ages } \\
3-4 \\
\end{array}$} & \multirow[b]{2}{*}{$\begin{array}{r}\text { Ages } \\
5-17 \\
\end{array}$} & \multicolumn{3}{|c|}{ Ages 18-19 } & \multirow[b]{2}{*}{$\begin{array}{l}\text { Ages } \\
20-24\end{array}$} & \multirow[b]{2}{*}{$\begin{array}{r}\text { Ages } \\
25-34 \\
\end{array}$} \\
\hline & & & Program & $\begin{array}{l}\text { Full-day } \\
\text { program }\end{array}$ & & & Total & $\begin{array}{l}\text { In } \\
\text { sec- } \\
\text { ond- } \\
\text { ary }\end{array}$ & $\begin{array}{l}\text { In col- } \\
\text { lege }\end{array}$ & & \\
\hline United States & $\dagger$ & $\dagger$ & $\dagger$ & $\dagger$ & 47.7 & 96.9 & 74.1 & 26.4 & 47.6 & 42.4 & 13.9 \\
\hline New Jersey & 6 to 16 & & & & 62.7 & 96.9 & 78.3 & 27.9 & 50.4 & 45.7 & 12.9 \\
\hline New Mexico & 5 to $18^{2}$ & $x$ & $x$ & & 34.4 & 95.2 & 66.9 & 27.7 & 39.2 & 39.3 & 15.7 \\
\hline New York & 6 to $16^{5}$ & & & & 57.8 & 97.2 & 78.0 & 21.5 & 56.5 & 46.1 & 13.0 \\
\hline North Carolina & 7 to 16 & & $x$ & $x$ & 41.8 & 96.4 & 73.9 & 25.7 & 48.2 & 40.2 & 13.7 \\
\hline North Dakota & 7 to 16 & & & & 30.6 & 92.7 & 81.7 & 25.3 & 56.3 & 46.8 & 12.0 \\
\hline Ohio & 6 to 18 & $x$ & $x$ & $x^{6}$ & 44.3 & 96.4 & 74.4 & 29.4 & 45.0 & 44.3 & 15.4 \\
\hline Oklahoma & 5 to 18 & $x$ & $x$ & $\left({ }^{7}\right)$ & 45.8 & 97.0 & 69.9 & 30.1 & 39.8 & 37.7 & 13.4 \\
\hline Oregon & 7 to 18 & & $x$ & & 41.2 & 96.2 & 70.1 & 25.7 & 44.4 & 41.2 & 14.0 \\
\hline Pennsylvania & 8 to $17^{2}$ & & & & 48.9 & 96.7 & 79.9 & 26.9 & 53.0 & 46.4 & 13.2 \\
\hline Rhode Island & 6 to 16 & $x$ & $x$ & & 44.5 & 95.9 & 86.0 & 13.9 & 72.2 & 50.2 & 14.8 \\
\hline South Carolina & 5 to $17^{3}$ & $x$ & $x$ & $x^{8}$ & 51.8 & 97.1 & 72.9 & 30.0 & 42.9 & 39.9 & 12.1 \\
\hline South Dakota & 6 to $18^{2,9}$ & $x$ & $x$ & & 38.6 & 96.2 & 75.2 & 28.7 & 46.5 & 43.2 & 13.9 \\
\hline Tennessee & 6 to $17^{3}$ & $x$ & $x$ & & 41.1 & 96.7 & 69.2 & 26.7 & 42.5 & 37.5 & 12.6 \\
\hline Texas & 6 to 18 & & $x$ & & 42.9 & 97.2 & 69.3 & 28.7 & 40.6 & 37.6 & 12.9 \\
\hline Utah & 6 to 18 & & $x$ & & 40.9 & 96.5 & 66.2 & 21.6 & 44.6 & 44.9 & 16.4 \\
\hline Vermont & 6 to $16^{2}$ & & $x$ & & 49.4 & 97.0 & 79.2 & 20.6 & 58.5 & 48.3 & 11.3 \\
\hline Virginia & 5 to $18^{2,3}$ & $x$ & $x$ & & 48.3 & 96.7 & 73.2 & 24.1 & 49.0 & 40.6 & 14.8 \\
\hline Washington & 8 to 18 & & $x$ & & 39.1 & 96.0 & 73.3 & 30.8 & 42.6 & 37.2 & 12.2 \\
\hline West Virginia & 6 to 17 & $x$ & $x$ & $x$ & 33.4 & 97.3 & 72.4 & 26.9 & 45.6 & 41.1 & 11.8 \\
\hline Wisconsin & 6 to 18 & & $x$ & & 42.3 & 96.8 & 75.5 & 25.4 & 50.1 & 44.2 & 13.7 \\
\hline Wyoming & 7 to $16^{2}$ & & $x$ & & 33.9 & 94.9 & 74.6 & 27.0 & 47.7 & 36.7 & 10.9 \\
\hline
\end{tabular}

† Not applicable.

$X$ State has policy.

1 Requirements are for 2011. Program refers to any kindergarten program, either full-day program or part-day program.

${ }^{2}$ Child may be exempted from compulsory attendance if he/she meets state requirements for early withdrawal without meeting conditions for a diploma or equivalency.

${ }^{3}$ Parent/guardian may delay child's entry until a later age, per state law/regulation.

${ }^{4}$ Attendance is compulsory until age 18 for Manatee County students unless they earn a high school diploma prior to reaching their 18 th birthday.

${ }^{5} \mathrm{New}$ York City and Buffalo require school attendance until age 17, unless employed; Syracuse requires kindergarten attendance at age 5.

${ }^{6}$ State requires districts with full-day programs to allow half-day attendance.

${ }^{7}$ Beginning in 2011-12, it will be mandatory for all districts in Oklahoma to offer full-day kindergarten.

${ }^{8}$ Parents may request either a full-day or a half-day program. For students enrolled in half-day programs, child care must be provided for the remainder of the school day.

${ }^{9}$ Compulsory attendance beginning at age 5, effective July 1, 2010

NOTE: Include enrollment in public, private, and home schools and includes nursery schools, kindergartens, elementary and secondary schools, colleges, and graduate or professional schools. Excludes enrollments in schools that do not advance students toward a regular school degree, such as trade schools, business colleges, and correspondence courses. This table uses a different data source than table A-OPE-1; therefore, the total enrollment estimates are not directly comparable to the 2010 estimates in table A-OPE-1. For more information on the American Community Survey (ACS), see Appendix B - Guide to Sources.

SOURCE: Education Commission of the States (ECS), ECS StateNotes, State Characteristics: Kindergarten, retrieved August 24, 2011, from http://www. ecs.org/clearinghouse/90/71/9071.pdf; ECS StateNotes, District Offering of Full-Day Kindergarten, retrieved August 24, 2011, from http://ecs.force.

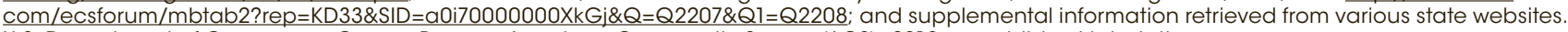
U.S. Department of Commerce, Census Bureau, American Community Survey (ACS), 2010, unpublished tabulations. 
Table A-2-1. Enrollment of 3-, 4-, and 5-year-old children in preprimary programs, by level of program, control of program, and attendance status: Selected years, 1980 through 2010

[Numbers in thousands]

\begin{tabular}{|c|c|c|c|c|c|c|c|c|c|c|}
\hline \multirow[b]{3}{*}{ Age and year } & \multirow{3}{*}{$\begin{array}{r}\text { Total } \\
\text { popula- } \\
\text { tion, } 3 \text { to } \\
5 \text { years } \\
\text { old } \\
\end{array}$} & \multicolumn{6}{|c|}{ Enrollment by level and control } & \multicolumn{3}{|c|}{ Enrollment by attendance } \\
\hline & & \multirow[b]{2}{*}{ Total } & \multirow{2}{*}{$\begin{array}{l}\text { Percent } \\
\text { enrolled }\end{array}$} & \multicolumn{2}{|c|}{ Nursery school } & \multicolumn{2}{|c|}{ Kindergarten } & \multirow[b]{2}{*}{ Full-day } & \multirow[b]{2}{*}{ Part-day } & \multirow{2}{*}{$\begin{array}{l}\text { Percent } \\
\text { full-day }\end{array}$} \\
\hline & & & & Public & Private & Public & Private & & & \\
\hline \multicolumn{11}{|c|}{ Total, 3 to 5 years old } \\
\hline 1980 & 9,284 & 4,878 & 52.5 & 628 & 1,353 & 2,438 & 459 & 1,551 & 3,327 & 31.8 \\
\hline 1985 & 10,733 & 5,865 & 54.6 & 846 & 1,631 & 2,847 & 541 & 2,144 & 3,722 & 36.6 \\
\hline 1990 & 11,207 & 6,659 & 59.4 & 1,199 & 2,180 & 2,772 & 509 & 2,577 & 4,082 & 38.7 \\
\hline 1995 & 12,518 & 7,739 & 61.8 & 1,950 & 2,381 & 2,800 & 608 & 3,689 & 4,051 & 47.7 \\
\hline 2000 & 11,858 & 7,592 & 64.0 & 2,146 & 2,180 & 2,701 & 565 & 4,008 & 3,584 & 52.8 \\
\hline 2005 & 12,134 & 7,801 & 64.3 & 2,409 & 2,120 & 2,804 & 468 & 4,548 & 3,253 & 58.3 \\
\hline 2006 & 12,186 & 8,010 & 65.7 & 2,481 & 2,156 & 2,960 & 413 & 4,723 & 3,286 & 59.0 \\
\hline 2007 & 12,326 & 8,056 & 65.4 & 2,532 & 2,037 & 3,088 & 400 & 4,578 & 3,478 & 56.8 \\
\hline 2008 & 12,583 & 7,928 & 63.0 & 2,609 & 1,961 & 2,982 & 376 & 4,615 & 3,313 & 58.2 \\
\hline 2009 & 12,718 & 8,076 & 63.5 & 2,703 & 1,945 & 3,144 & 284 & 4,916 & 3,160 & 60.9 \\
\hline 2010 & 12,949 & 8,246 & 63.7 & 2,749 & 2,048 & 3,080 & 369 & 4,813 & 3,432 & 58.4 \\
\hline \multicolumn{11}{|l|}{3 years old } \\
\hline 1980 & 3,143 & 857 & 27.3 & 221 & 604 & $16 !$ & $17 !$ & 321 & 536 & 37.5 \\
\hline 1985 & 3,594 & 1,035 & 28.8 & 278 & 679 & 52 & 26 & 350 & 685 & 33.8 \\
\hline 1990 & 3,692 & 1,205 & 32.6 & 347 & 840 & $11 !$ & $\ddagger$ & 447 & 758 & 37.1 \\
\hline 1995 & 4,148 & 1,489 & 35.9 & 511 & 947 & $15 !$ & $17 !$ & 754 & 736 & 50.6 \\
\hline 2000 & 3,929 & 1,541 & 39.2 & 644 & 854 & $27 !$ & $16 !$ & 761 & 779 & 49.4 \\
\hline 2005 & 4,151 & 1,715 & 41.3 & 777 & 869 & 54 & $15 !$ & 901 & 814 & 52.5 \\
\hline 2006 & 4,043 & 1,716 & 42.4 & 733 & 912 & 54 & $17 !$ & 884 & 833 & 51.5 \\
\hline 2007 & 4,142 & 1,717 & 41.5 & 766 & 832 & 106 & $13 !$ & 883 & 834 & 51.4 \\
\hline 2008 & 4,204 & 1,655 & 39.4 & 755 & 802 & 90 & $\ddagger$ & 852 & 803 & 51.5 \\
\hline 2009 & 4,361 & 1,776 & 40.7 & 837 & 861 & 61 & 17 & 1,024 & 752 & 57.7 \\
\hline 2010 & 4,492 & 1,718 & 38.2 & 824 & 818 & 54 & 22 & 861 & 857 & 50.1 \\
\hline \multicolumn{11}{|l|}{4 years old } \\
\hline 1980 & 3,072 & 1,423 & 46.3 & 363 & 701 & 239 & 120 & 467 & 956 & 32.8 \\
\hline 1985 & 3,598 & 1,766 & 49.1 & 496 & 859 & 276 & 135 & 643 & 1,123 & 36.4 \\
\hline 1990 & 3,723 & 2,087 & 56.1 & 695 & 1,144 & 157 & 91 & 716 & 1,371 & 34.3 \\
\hline 1995 & 4,145 & 2,553 & 61.6 & 1,054 & 1,208 & 207 & 84 & 1,104 & 1,449 & 43.3 \\
\hline 2000 & 3,940 & 2,556 & 64.9 & 1,144 & 1,121 & 227 & 65 & 1,182 & 1,374 & 46.2 \\
\hline 2005 & 4,028 & 2,668 & 66.2 & 1,295 & 1,083 & 215 & 75 & 1,332 & 1,336 & 49.9 \\
\hline 2006 & 4,095 & 2,817 & 68.8 & 1,401 & 1,067 & 306 & 43 & 1,418 & 1,399 & 50.3 \\
\hline 2007 & 4,092 & 2,774 & 67.8 & 1,417 & 993 & 295 & 69 & 1,297 & 1,476 & 46.8 \\
\hline 2008 & 4,241 & 2,804 & 66.1 & 1,525 & 995 & 234 & 49 & 1,332 & 1,472 & 47.5 \\
\hline 2009 & 4,176 & 2,698 & 64.6 & 1,512 & 905 & 256 & $25 !$ & 1,372 & 1,326 & 50.9 \\
\hline 2010 & 4,358 & 2,988 & 68.6 & 1,587 & 1,016 & 331 & 55 & 1,405 & 1,584 & 47.0 \\
\hline \multicolumn{11}{|l|}{5 years old } \\
\hline 1980 & 3,069 & 2,598 & 84.7 & 44 & 48 & 2,183 & 322 & 763 & 1,835 & 29.4 \\
\hline 1985 & 3,542 & 3,065 & 86.5 & 73 & 94 & 2,519 & 379 & 1,151 & 1,914 & 37.6 \\
\hline 1990 & 3,792 & 3,367 & 88.8 & 157 & 196 & 2,604 & 411 & 1,414 & 1,953 & 42.0 \\
\hline 1995 & 4,224 & 3,697 & 87.5 & 385 & 226 & 2,578 & 507 & 1,830 & 1,867 & 49.5 \\
\hline 2000 & 3,989 & 3,495 & 87.6 & 359 & 206 & 2,447 & 484 & 2,065 & 1,431 & 59.1 \\
\hline 2005 & 3,955 & 3,418 & 86.4 & 337 & 168 & 2,535 & 378 & 2,316 & 1,102 & 67.7 \\
\hline 2006 & 4,049 & 3,476 & 85.9 & 346 & 178 & 2,599 & 353 & 2,422 & 1,054 & 69.7 \\
\hline 2007 & 4,091 & 3,565 & 87.1 & 349 & 212 & 2,687 & 317 & 2,397 & 1,168 & 67.2 \\
\hline 2008 & 4,137 & 3,470 & 83.9 & 329 & 163 & 2,659 & 320 & 2,432 & 1,038 & 70.1 \\
\hline 2009 & 4,180 & 3,601 & 86.1 & 354 & 179 & 2,827 & 242 & 2,519 & 1,082 & 70.0 \\
\hline 2010 & 4,099 & 3,540 & 86.3 & 338 & 214 & 2,695 & 292 & 2,548 & 992 & 72.0 \\
\hline
\end{tabular}

! Interpret data with caution. The coefficient of variation (CV) for this estimate is 30 percent or greater.

$\ddagger$ Reporting standards not met. The coefficient of variation (CV) for this estimate is 50 percent or greater.

NOTE: Data from 1995 to 2010 were collected using new procedures and may not be comparable with data prior to 1995. Preprimary programs are groups or classes that are organized to provide educational experiences for children, and include kindergarten, preschool, and nursery school

programs. Enrollment data for 5-year-olds include only those students in preprimary programs and do not include those enrolled in primary programs.

Data are based on sample surveys of the civilian noninstitutional population. Detail may not sum to totals due to rounding. For more information on the

Current Population Survey (CPS), see Appendix B - Guide to Sources.

SOURCE: U.S. Department of Commerce, Census Bureau, Current Population Survey (CPS), October 1980 through 2010. 
Table A-2-2. Percentage of 3-, 4-, and 5-year old children enrolled in preprimary programs, by attendance status, level of program, and selected child and family characteristics: October 2010

\begin{tabular}{|c|c|c|c|c|c|c|c|}
\hline \multirow[b]{2}{*}{ Selected child and family characteristics } & \multirow[b]{2}{*}{ Total } & \multicolumn{3}{|c|}{ Full-day } & \multicolumn{3}{|c|}{ Part-day } \\
\hline & & Total & $\begin{array}{r}\text { Nursery } \\
\text { school }\end{array}$ & $\begin{array}{r}\begin{array}{r}\text { Kindergar- } \\
\text { ten }\end{array} \\
\end{array}$ & Total & $\begin{array}{r}\text { Nursery } \\
\text { school }\end{array}$ & $\begin{array}{c}\text { Kindergar- } \\
\text { ten }\end{array}$ \\
\hline Total & 63.7 & 37.2 & 17.7 & 19.4 & 26.5 & 19.3 & 7.2 \\
\hline \multicolumn{8}{|l|}{ Sex } \\
\hline Male & 63.2 & 36.5 & 18.0 & 18.5 & 26.7 & 19.7 & 7.0 \\
\hline Female & 64.2 & 37.9 & 17.5 & 20.4 & 26.3 & 18.9 & 7.4 \\
\hline \multicolumn{8}{|l|}{ Age of child } \\
\hline 3 years old & 38.2 & 19.2 & 18.3 & $0.8 !$ & 19.1 & 18.2 & 0.9 \\
\hline 4 years old & 68.6 & 32.2 & 27.4 & 4.8 & 36.3 & 32.3 & 4.0 \\
\hline 5 years old & 86.3 & 62.2 & 6.8 & 55.4 & 24.2 & 6.7 & 17.5 \\
\hline \multicolumn{8}{|l|}{ Race/ethnicity of child } \\
\hline White & 67.0 & 35.8 & 17.1 & 18.7 & 31.2 & 24.0 & 7.2 \\
\hline Black & 64.5 & 51.7 & 26.1 & 25.6 & 12.8 & 8.3 & 4.5 \\
\hline Hispanic & 56.0 & 32.4 & 13.8 & 18.6 & 23.5 & 15.3 & 8.2 \\
\hline Asian & 70.6 & 36.5 & 19.0 & 17.5 & 34.1 & 22.3 & 11.8 \\
\hline Native Hawaiian/Pacific Islander & 54.6 & $\ddagger$ & $\ddagger$ & $\ddagger$ & $\ddagger$ & $\ddagger$ & $\ddagger$ \\
\hline American Indian/Alaska Native & 52.1 & $27.9 !$ & 12.6 & $15.4 !$ & $24.1 !$ & $22.5 !$ & $\ddagger$ \\
\hline Two or more races & 61.9 & 34.8 & 21.5 & 13.3 & 27.1 & 21.5 & $5.6 !$ \\
\hline \multicolumn{8}{|l|}{$\begin{array}{l}\text { Number of parents/guardians in the } \\
\text { household }\end{array}$} \\
\hline One parent or guardian & 60.0 & 40.7 & 20.2 & 20.5 & 19.4 & 13.5 & 5.8 \\
\hline Two parents or guardians & 65.1 & 35.8 & 16.8 & 19.0 & 29.4 & 21.6 & 7.7 \\
\hline \multicolumn{8}{|l|}{ Mother's current employment status } \\
\hline Employed & 68.5 & 43.0 & 22.2 & 20.9 & 25.5 & 18.7 & 6.7 \\
\hline Unemployed & 61.0 & 37.6 & 16.2 & 21.4 & 22.8 & 16.8 & 6.1 \\
\hline Not in the labor force & 57.4 & 28.3 & 11.3 & 17.0 & 29.1 & 20.9 & 8.3 \\
\hline \multicolumn{8}{|l|}{ Father's current employment status } \\
\hline Employed & 65.1 & 35.5 & 16.7 & 18.8 & 29.6 & 21.7 & 7.9 \\
\hline Unemployed & 59.3 & 36.6 & 16.7 & 20.0 & 22.7 & 15.6 & 7.1 \\
\hline Not in the labor force & 65.5 & 38.1 & 17.3 & 20.7 & 27.5 & 22.3 & 5.1 \\
\hline \multicolumn{8}{|l|}{$\begin{array}{l}\text { Highest educational attainment of } \\
\text { parents/guardians }\end{array}$} \\
\hline Less than high school & 48.5 & 30.0 & 13.4 & 16.6 & 18.5 & 12.1 & 6.4 \\
\hline High school/GED & 58.1 & 37.6 & 16.5 & 21.1 & 20.5 & 13.0 & 7.4 \\
\hline $\begin{array}{l}\text { Vocational/technical or some } \\
\text { college }\end{array}$ & 62.3 & 37.1 & 17.6 & 19.5 & 25.2 & 18.0 & 7.2 \\
\hline Associate's degree & 59.4 & 35.2 & 19.7 & 15.4 & 24.2 & 19.2 & 5.0 \\
\hline Bachelor's degree & 71.8 & 37.7 & 18.3 & 19.4 & 34.1 & 26.2 & 7.9 \\
\hline Graduate or professional degree & 77.6 & 42.6 & 21.9 & 20.7 & 35.0 & 27.7 & 7.3 \\
\hline
\end{tabular}

! Interpret data with caution. The coefficient of variation (CV) for this estimate is 30 percent or greater.

$\ddagger$ Reporting standards not met. Either there are too few cases or the coefficient of variation (CV) is 50 percent or greater.

NOTE: Preprimary programs are groups or classes that are organized to provide educational experiences for children, and include kindergarten, preschool, and nursery school programs. Enrollment data for 5-year-olds include only those students in preprimary programs and do not include those enrolled in primary programs. Race categories exclude persons of Hispanic ethnicity. Data are based on sample surveys of the civilian noninstitutional population. Detail may not sum to totals because of rounding. For more information on race/ethnicity, see Appendix C - Commonly Used Measures. For more information on the Current Population Survey (CPS), see Appendix B - Guide to Sources.

SOURCE: U.S. Department of Commerce, Census Bureau, Current Population Survey (CPS), October 2010. 
Table A-3-1. Actual and projected public school enrollment in grades prekindergarten (preK) through 12, by grade level and region: Selected school years, 1970-71 through 2021-22

[Totals in thousands]

\begin{tabular}{|c|c|c|c|c|c|c|c|c|c|c|c|}
\hline \multirow[b]{3}{*}{ School year } & \multicolumn{3}{|c|}{ Total enrollment } & \multicolumn{8}{|c|}{ Total and percent enrollment for grades preK-12, by region } \\
\hline & \multirow{2}{*}{$\begin{array}{c}\text { Grades } \\
\text { preK-12 }\end{array}$} & \multirow{2}{*}{$\begin{array}{c}\text { Grades } \\
\text { preK-8 }\end{array}$} & \multirow{2}{*}{$\begin{array}{r}\text { Grades } \\
9-12 \\
\end{array}$} & \multicolumn{2}{|c|}{ Northeast } & \multicolumn{2}{|c|}{ Midwest } & \multicolumn{2}{|c|}{ South } & \multicolumn{2}{|c|}{ West } \\
\hline & & & & Total & Percent & Total & Percent & Total & Percent & Total & Percent \\
\hline 1970-71 & 45,894 & 32,558 & 13,336 & 9,860 & 21.5 & 12,936 & 28.2 & 14,759 & 32.2 & 8,339 & 18.2 \\
\hline 1975-76 & 44,819 & 30,515 & 14,304 & 9,679 & 21.6 & 12,295 & 27.4 & 14,654 & 32.7 & 8,191 & 18.3 \\
\hline $1980-81$ & 40,877 & 27,647 & 13,231 & 8,215 & 20.1 & 10,698 & 26.2 & 14,134 & 34.6 & 7,831 & 19.2 \\
\hline 1985-86 & 39,422 & 27,034 & 12,388 & 7,318 & 18.6 & 9,862 & 25.0 & 14,117 & 35.8 & 8,124 & 20.6 \\
\hline 1990-91 & 41,217 & 29,876 & 11,341 & 7,282 & 17.7 & 9,944 & 24.1 & 14,807 & 35.9 & 9,184 & 22.3 \\
\hline 1991-92 & 42,047 & 30,503 & 11,544 & 7,407 & 17.6 & 10,080 & 24.0 & 15,081 & 35.9 & 9,479 & 22.5 \\
\hline 1992-93 & 42,823 & 31,086 & 11,737 & 7,526 & 17.6 & 10,198 & 23.8 & 15,357 & 35.9 & 9,742 & 22.7 \\
\hline 1993-94 & 43,465 & 31,502 & 11,963 & 7,654 & 17.6 & 10,289 & 23.7 & 15,591 & 35.9 & 9,931 & 22.8 \\
\hline 1994-95 & 44,111 & 31,896 & 12,215 & 7,760 & 17.6 & 10,386 & 23.5 & 15,851 & 35.9 & 10,114 & 22.9 \\
\hline 1995-96 & 44,840 & 32,338 & 12,502 & 7,894 & 17.6 & 10,512 & 23.4 & 16,118 & 35.9 & 10,316 & 23.0 \\
\hline 1996-97 & 45,611 & 32,762 & 12,849 & 8,006 & 17.6 & 10,638 & 23.3 & 16,373 & 35.9 & 10,594 & 23.2 \\
\hline 1997-98 & 46,127 & 33,071 & 13,056 & 8,085 & 17.5 & 10,704 & 23.2 & 16,563 & 35.9 & 10,775 & 23.4 \\
\hline 1998-99 & 46,539 & 33,344 & 13,195 & 8,145 & 17.5 & 10,722 & 23.0 & 16,713 & 35.9 & 10,959 & 23.5 \\
\hline 1999-2000 & 46,857 & 33,486 & 13,371 & 8,196 & 17.5 & 10,726 & 22.9 & 16,842 & 35.9 & 11,093 & 23.7 \\
\hline 2000-01 & 47,204 & 33,686 & 13,517 & 8,222 & 17.4 & 10,730 & 22.7 & 17,007 & 36.0 & 11,244 & 23.8 \\
\hline 2001-02 & 47,672 & 33,936 & 13,736 & 8,250 & 17.3 & 10,745 & 22.5 & 17,237 & 36.2 & 11,440 & 24.0 \\
\hline 2002-03 & 48,183 & 34,114 & 14,069 & 8,297 & 17.2 & 10,819 & 22.5 & 17,471 & 36.3 & 11,596 & 24.1 \\
\hline 2003-04 & 48,540 & 34,201 & 14,339 & 8,292 & 17.1 & 10,809 & 22.3 & 17,673 & 36.4 & 11,766 & 24.2 \\
\hline 2004-05 & 48,795 & 34,178 & 14,618 & 8,271 & 17.0 & 10,775 & 22.1 & 17,892 & 36.7 & 11,857 & 24.3 \\
\hline 2005-06 & 49,113 & 34,204 & 14,909 & 8,240 & 16.8 & 10,819 & 22.0 & 18,103 & 36.9 & 11,951 & 24.3 \\
\hline 2006-07 & 49,316 & 34,235 & 15,081 & 8,258 & 16.7 & 10,819 & 21.9 & 18,294 & 37.1 & 11,945 & 24.2 \\
\hline 2007-08 & 49,293 & 34,205 & 15,087 & 8,122 & 16.5 & 10,770 & 21.8 & 18,425 & 37.4 & 11,976 & 24.3 \\
\hline 2008-09 & 49,266 & 34,286 & 14,980 & 8,053 & 16.3 & 10,743 & 21.8 & 18,491 & 37.5 & 11,979 & 24.3 \\
\hline 2009-10 & 49,373 & 34,418 & 14,955 & 8,093 & 16.4 & 10,672 & 21.6 & 18,652 & 37.8 & 11,956 & 24.2 \\
\hline 2010-11 & 49,484 & 34,625 & 14,860 & 8,071 & 16.3 & 10,610 & 21.4 & 18,805 & 38.0 & 11,998 & 24.2 \\
\hline \multicolumn{12}{|l|}{ Projected } \\
\hline $2011-12$ & 49,636 & 34,849 & 14,787 & 8,110 & 16.3 & 10,581 & 21.3 & 18,896 & 38.1 & 12,049 & 24.3 \\
\hline 2012-13 & 49,828 & 35,076 & 14,752 & 8,104 & 16.3 & 10,575 & 21.2 & 19,028 & 38.2 & 12,121 & 24.3 \\
\hline 2013-14 & 50,067 & 35,301 & 14,766 & 8,106 & 16.2 & 10,580 & 21.1 & 19,165 & 38.3 & 12,216 & 24.4 \\
\hline 2014-15 & 50,407 & 35,502 & 14,905 & 8,114 & 16.1 & 10,613 & 21.1 & 19,333 & 38.4 & 12,347 & 24.5 \\
\hline 2015-16 & 50,773 & 35,735 & 15,038 & 8,127 & 16.0 & 10,652 & 21.0 & 19,505 & 38.4 & 12,489 & 24.6 \\
\hline 2016-17 & 51,146 & 36,029 & 15,116 & 8,140 & 15.9 & 10,688 & 20.9 & 19,669 & 38.5 & 12,648 & 24.7 \\
\hline 2017-18 & 51,524 & 36,329 & 15,195 & 8,158 & 15.8 & 10,728 & 20.8 & 19,828 & 38.5 & 12,809 & 24.9 \\
\hline 2018-19 & 51,880 & 36,639 & 15,241 & 8,175 & 15.8 & 10,759 & 20.7 & 19,972 & 38.5 & 12,974 & 25.0 \\
\hline 2019-20 & 52,260 & 36,956 & 15,304 & 8,197 & 15.7 & 10,789 & 20.6 & 20,124 & 38.5 & 13,150 & 25.2 \\
\hline 2020-21 & 52,688 & 37,278 & 15,410 & 8,224 & 15.6 & 10,830 & 20.6 & 20,297 & 38.5 & 13,337 & 25.3 \\
\hline 2021-22 & 53,113 & 37,598 & 15,515 & 8,248 & 15.5 & 10,868 & 20.5 & 20,481 & 38.6 & 13,516 & 25.4 \\
\hline
\end{tabular}

NOTE: The most recent year of actual data is 2010-11, and 2021-22 is the last year for which projected data are available. For more information on projections, see NCES 2012-044. Some data have been revised from previously published figures. For a list of states in each region, see Appendix $C$ Commonly Used Measures. Detail may not sum to totals because of rounding.

SOURCE: U.S. Department of Education, National Center for Education Statistics, Statistics of Public Elementary and Secondary Day Schools, $1970-71$

through 1984-85; Common Core of Data (CCD), "State Nonfiscal Survey of Public Elementary/Secondary Education," 1985-86 through 2010-11, and National Elementary and Secondary Enrollment Model, 1972-2010. 
This indicator continues on page 128. 
Public School Enrollment

Table A-3-2. Number and percent change in public school enrollment in grades prekindergarten (preK) through 12 , by grade level, region, and state or jurisdiction: School years 1989-90 and 2010-11

\begin{tabular}{|c|c|c|c|c|c|c|c|c|c|}
\hline \multirow[b]{2}{*}{$\begin{array}{l}\text { Region and state or } \\
\text { jurisdiction }\end{array}$} & \multicolumn{3}{|c|}{ Grades preK-12 } & \multicolumn{3}{|c|}{ Grades preK-8 } & \multicolumn{3}{|c|}{ Grades 9-12 } \\
\hline & 1989-90 & 2010-11 & $\begin{array}{l}\text { Percent } \\
\text { change }\end{array}$ & 1989-90 & 2010-11 & $\begin{array}{l}\text { Percent } \\
\text { change }\end{array}$ & 1989-90 & 2010-11 & $\begin{array}{l}\text { Percent } \\
\text { change }\end{array}$ \\
\hline United States & 40,543 & 49,484 & 22.1 & 29,150 & 34,625 & 18.8 & 11,393 & 14,860 & 30.4 \\
\hline Northeast & 7,200 & 8,071 & 12.1 & 5,076 & 5,540 & 9.1 & 2,124 & 2,531 & 19.2 \\
\hline Connecticut & 462 & 561 & 21.4 & 338 & 387 & 14.5 & 123 & 173 & 40.5 \\
\hline Maine & 214 & 189 & -11.6 & 152 & 129 & -15.3 & 62 & 60 & -2.2 \\
\hline Massachusetts & 826 & 956 & 15.7 & 590 & 666 & 12.9 & 235 & 289 & 22.9 \\
\hline New Hampshire & 172 & 195 & 13.4 & 124 & 132 & 5.8 & 47 & 63 & 33.5 \\
\hline New Jersey & 1,076 & 1,403 & 30.3 & 766 & 981 & 28.2 & 310 & 421 & 35.8 \\
\hline New York & 2,566 & 2,735 & 6.6 & 1,790 & 1,869 & 4.4 & 776 & 866 & 11.5 \\
\hline Pennsylvania & 1,655 & 1,793 & 8.3 & 1,148 & 1,210 & 5.4 & 507 & 584 & 15.0 \\
\hline Rhode Island & 136 & 144 & 5.9 & 98 & 98 & -0.7 & 37 & 46 & 23.4 \\
\hline Vermont & 95 & 97 & 2.2 & 69 & 68 & -1.6 & 26 & 29 & 12.4 \\
\hline Midwest & 9,849 & 10,610 & 7.7 & 6,996 & 7,349 & 5.0 & 2,852 & 3,260 & 14.3 \\
\hline Illinois & 1,797 & 2,092 & 16.4 & 1,280 & 1,455 & 13.7 & 517 & 637 & 23.1 \\
\hline Indiana & 954 & 1,047 & 9.8 & 671 & 729 & 8.7 & 283 & 318 & 12.2 \\
\hline lowa & 478 & 496 & 3.6 & 338 & 348 & 2.9 & 140 & 148 & 5.4 \\
\hline Kansas & 431 & 484 & 12.3 & 314 & 343 & 9.4 & 117 & 141 & 20.0 \\
\hline Michigan & 1,577 & 1,587 & 0.7 & 1,128 & 1,076 & -4.6 & 449 & 511 & 14.0 \\
\hline Minnesota & 740 & 838 & 13.3 & 529 & 570 & 7.8 & 211 & 268 & 27.0 \\
\hline Missouri & 808 & 919 & 13.7 & 576 & 643 & 11.6 & 232 & 276 & 19.0 \\
\hline Nebraska & 271 & 299 & 10.2 & 194 & 210 & 8.3 & 77 & 88 & 15.0 \\
\hline North Dakota & 118 & 96 & -18.2 & 85 & 66 & -22.2 & 33 & 30 & -7.9 \\
\hline Ohio & 1,764 & 1,754 & -0.6 & 1,239 & 1,223 & -1.3 & 525 & 531 & 1.1 \\
\hline South Dakota & 127 & 126 & -0.9 & 94 & 88 & -6.0 & 34 & 38 & 13.2 \\
\hline Wisconsin & 783 & 872 & 11.4 & 549 & 598 & 9.0 & 234 & 274 & 17.1 \\
\hline
\end{tabular}

See notes at end of table. 
Table A-3-2. Number and percent change in public school enrollment in grades prekindergarten (preK) through 12, by grade level, region, and state or jurisdiction: School years 1989-90 and 2010-11-Continued [Numbers in thousands]

\begin{tabular}{|c|c|c|c|c|c|c|c|c|c|}
\hline \multirow[b]{2}{*}{$\begin{array}{l}\text { Region and state or } \\
\text { jurisdiction }\end{array}$} & \multicolumn{3}{|c|}{ Grades preK-12 } & \multicolumn{3}{|c|}{ Grades preK-8 } & \multicolumn{3}{|c|}{ Grades 9-12 } \\
\hline & 1989-90 & $2010-11$ & $\begin{array}{l}\text { Percent } \\
\text { change }\end{array}$ & 1989-90 & $2010-11$ & $\begin{array}{l}\text { Percent } \\
\text { change }\end{array}$ & 1989-90 & $2010-11$ & $\begin{array}{l}\text { Percent } \\
\text { change }\end{array}$ \\
\hline United States & 40,543 & 49,484 & 22.1 & 29,150 & 34,625 & 18.8 & 11,393 & 14,860 & 30.4 \\
\hline South & 14,605 & 18,805 & 28.8 & 10,617 & 13,435 & 26.5 & 3,988 & 5,370 & 34.7 \\
\hline Alabama & 724 & 756 & 4.4 & 526 & 534 & 1.5 & 198 & 222 & 12.1 \\
\hline Arkansas & 435 & 482 & 10.8 & 311 & 346 & 11.2 & 124 & 136 & 10.0 \\
\hline Delaware & 98 & 129 & 32.3 & 71 & 90 & 27.7 & 27 & 39 & 44.3 \\
\hline District of Columbia & 81 & 71 & -12.3 & 61 & 54 & -11.7 & 21 & 18 & -14.0 \\
\hline Florida & 1,790 & 2,643 & 47.7 & 1,303 & 1,858 & 42.6 & 486 & 785 & 61.3 \\
\hline Georgia & 1,127 & 1,677 & 48.9 & 828 & 1,202 & 45.2 & 298 & 475 & 59.2 \\
\hline Kentucky & 631 & 673 & 6.7 & 452 & 480 & 6.3 & 179 & 193 & 7.8 \\
\hline Louisiana & 783 & 697 & -11.0 & 582 & 512 & -11.9 & 201 & 184 & -8.5 \\
\hline Maryland & 699 & 852 & 22.0 & 507 & 588 & 16.0 & 192 & 264 & 37.6 \\
\hline Mississippi & 502 & 491 & -2.3 & 369 & 351 & -5.0 & 133 & 140 & 5.4 \\
\hline North Carolina & 1,081 & 1,491 & 37.9 & 770 & 1,058 & 37.5 & 311 & 432 & 39.0 \\
\hline Oklahoma & 579 & 660 & 14.1 & 421 & 483 & 14.9 & 158 & 176 & 11.9 \\
\hline South Carolina & 616 & 726 & 17.8 & 444 & 516 & 16.2 & 172 & 210 & 21.9 \\
\hline Tennessee & 820 & 987 & 20.5 & 590 & 702 & 18.9 & 230 & 286 & 24.5 \\
\hline Texas & 3,329 & 4,936 & 48.3 & 2,443 & 3,587 & 46.8 & 885 & 1,349 & 52.4 \\
\hline Virginia & 985 & 1,251 & 27.0 & 712 & 871 & 22.3 & 273 & 380 & 39.2 \\
\hline West Virginia & 328 & 283 & -13.6 & 227 & 201 & -11.4 & 100 & 81 & -18.8 \\
\hline West & 8,889 & 11,998 & 35.0 & 6,460 & 8,300 & 28.5 & 2,428 & 3,698 & 52.3 \\
\hline Alaska & 109 & 132 & 20.9 & 82 & 92 & 12.6 & 28 & 40 & 45.4 \\
\hline Arizona & 608 & 1,072 & 76.4 & 451 & 752 & 66.6 & 156 & 320 & 104.6 \\
\hline California & 4,772 & 6,290 & 31.8 & 3,469 & 4,294 & 23.8 & 1,303 & 1,996 & 53.2 \\
\hline Colorado & 563 & 843 & 49.9 & 408 & 601 & 47.5 & 155 & 242 & 56.0 \\
\hline Hawaii & 169 & 180 & 6.0 & 123 & 128 & 3.3 & 46 & 52 & 13.2 \\
\hline Idaho & 215 & 276 & 28.3 & 157 & 194 & 24.0 & 58 & 82 & 40.1 \\
\hline Montana & 151 & 142 & -6.3 & 110 & 98 & -10.3 & 41 & 43 & 4.2 \\
\hline Nevada & 187 & 437 & 134.0 & 137 & 307 & 123.6 & 49 & 130 & 163.0 \\
\hline New Mexico & 296 & 338 & 14.2 & 203 & 239 & 17.8 & 93 & 99 & 6.3 \\
\hline Oregon & 472 & 571 & 20.8 & 340 & 393 & 15.4 & 132 & 178 & 34.8 \\
\hline Utah & 439 & 586 & 33.5 & 324 & 425 & 31.2 & 115 & 161 & 40.1 \\
\hline Washington & 810 & 1,044 & 28.8 & 586 & 714 & 21.9 & 224 & 330 & 46.9 \\
\hline Wyoming & 97 & 89 & -8.4 & 70 & 63 & -10.5 & 27 & 26 & -3.0 \\
\hline
\end{tabular}

NOTE: Detail may not sum to totals because of rounding.

SOURCE: U.S. Department of Education, National Center for Education Statistics, Common Core of Data (CCD), "State Nonfiscal Survey of Public Elementary/Secondary Education," 1989-90 and 2010-11. 
Table A-3-3. Actual and projected number and projected percent change in public school enrollment in grades prekindergarten (preK) through 12, by grade level, region, and state or jurisdiction: School years 2010-11 and 2021-22

[Numbers in thousands]

\begin{tabular}{|c|c|c|c|c|c|c|c|c|c|}
\hline \multirow[b]{2}{*}{$\begin{array}{l}\text { Region and state } \\
\text { or jurisdiction }\end{array}$} & \multicolumn{3}{|c|}{ Grades preK-12 } & \multicolumn{3}{|c|}{ Grades preK-8 } & \multicolumn{3}{|c|}{ Grades 9-12 } \\
\hline & $\begin{array}{r}\text { Actual } \\
\text { enrollment } \\
2010-11 \\
\end{array}$ & $\begin{array}{r}\text { Projected } \\
\text { enrollment } \\
2021-22 \\
\end{array}$ & $\begin{array}{r}\text { Projected } \\
\text { percent } \\
\text { change }\end{array}$ & $\begin{array}{r}\text { Actual } \\
\text { enrollment } \\
2010-11 \\
\end{array}$ & $\begin{array}{r}\text { Projected } \\
\text { enrollment } \\
2021-22 \\
\end{array}$ & $\begin{array}{r}\text { Projected } \\
\text { percent } \\
\text { change }\end{array}$ & $\begin{array}{r}\text { Actual } \\
\text { enrollment } \\
2010-11 \\
\end{array}$ & $\begin{array}{r}\text { Projected } \\
\text { enrollment } \\
2021-22 \\
\end{array}$ & $\begin{array}{r}\text { Projected } \\
\text { percent } \\
\text { change } \\
\end{array}$ \\
\hline United States & 49,484 & 53,113 & 7.3 & 34,625 & 37,598 & 8.6 & 14,860 & 15,515 & 4.4 \\
\hline Northeast & 8,071 & 8,248 & 2.2 & 5,540 & 5,703 & 2.9 & 2,531 & 2,545 & 0.6 \\
\hline Connecticut & 561 & 551 & -1.7 & 387 & 396 & 2.1 & 173 & 155 & -10.2 \\
\hline Maine & 189 & 190 & 0.5 & 129 & 134 & 4.3 & 60 & 56 & -7.5 \\
\hline Massachusetts & 956 & 944 & -1.2 & 666 & 666 & -0.1 & 289 & 278 & -3.8 \\
\hline New Hampshire & 195 & 199 & 2.0 & 132 & 141 & 7.5 & 63 & 57 & -9.4 \\
\hline New Jersey & 1,403 & 1,394 & -0.6 & 981 & 991 & 1.0 & 421 & 403 & -4.2 \\
\hline New York & 2,735 & 2,815 & 2.9 & 1,869 & 1,887 & 1.0 & 866 & 928 & 7.2 \\
\hline Pennsylvania & 1,793 & 1,903 & 6.1 & 1,210 & 1,306 & 7.9 & 584 & 598 & 2.4 \\
\hline Rhode Island & 144 & 151 & 4.9 & 98 & 107 & 9.4 & 46 & 44 & -4.7 \\
\hline Vermont & 97 & 101 & 4.0 & 68 & 75 & 10.6 & 29 & 25 & -11.7 \\
\hline Midwest & 10,610 & 10,868 & 2.4 & 7,349 & 7,629 & 3.8 & 3,260 & 3,240 & -0.6 \\
\hline Illinois & 2,092 & 2,109 & 0.8 & 1,455 & 1,485 & 2.1 & 637 & 624 & -2.0 \\
\hline Indiana & 1,047 & 1,077 & 2.9 & 729 & 756 & 3.6 & 318 & 322 & 1.2 \\
\hline lowa & 496 & 500 & 0.9 & 348 & 350 & 0.6 & 148 & 150 & 1.6 \\
\hline Kansas & 484 & 512 & 5.8 & 343 & 359 & 4.8 & 141 & 152 & 8.3 \\
\hline Michigan & 1,587 & 1,551 & -2.2 & 1,076 & 1,092 & 1.6 & 511 & 459 & -10.3 \\
\hline Minnesota & 838 & 965 & 15.1 & 570 & 672 & 17.9 & 268 & 293 & 9.3 \\
\hline Missouri & 919 & 946 & 3.0 & 643 & 667 & 3.8 & 276 & 279 & 1.0 \\
\hline Nebraska & 299 & 323 & 8.1 & 210 & 223 & 5.9 & 88 & 100 & 13.2 \\
\hline North Dakota & 96 & 104 & 8.4 & 66 & 71 & 6.9 & 30 & 34 & 11.9 \\
\hline Ohio & 1,754 & 1,718 & -2.1 & 1,223 & 1,210 & -1.0 & 531 & 507 & -4.5 \\
\hline South Dakota & 126 & 134 & 6.2 & 88 & 93 & 6.1 & 38 & 41 & 6.5 \\
\hline Wisconsin & 872 & 929 & 6.5 & 598 & 650 & 8.6 & 274 & 279 & 1.7 \\
\hline
\end{tabular}


Table A-3-3. Actual and projected number and projected percent change in public school enrollment in grades prekindergarten (preK) through 12, by grade level, region, and state or jurisdiction: School years 2010-11 and 2021-22-Continued

[Numbers in thousands]

\begin{tabular}{|c|c|c|c|c|c|c|c|c|c|}
\hline \multirow[b]{2}{*}{$\begin{array}{l}\text { Region and state } \\
\text { or jurisdiction }\end{array}$} & \multicolumn{3}{|c|}{ Grades preK-12 } & \multicolumn{3}{|c|}{ Grades preK-8 } & \multicolumn{3}{|c|}{ Grades 9-12 } \\
\hline & $\begin{array}{r}\text { Actual } \\
\text { enrollment } \\
2010-11 \\
\end{array}$ & $\begin{array}{r}\text { Projected } \\
\text { enrollment } \\
2021-22 \\
\end{array}$ & $\begin{array}{r}\text { Projected } \\
\text { percent } \\
\text { change }\end{array}$ & $\begin{array}{r}\text { Actual } \\
\text { enrollment } \\
2010-11 \\
\end{array}$ & $\begin{array}{r}\text { Projected } \\
\text { enrollment } \\
2021-22 \\
\end{array}$ & $\begin{array}{r}\text { Projected } \\
\text { percent } \\
\text { change }\end{array}$ & $\begin{array}{r}\text { Actual } \\
\text { enrollment } \\
2010-11 \\
\end{array}$ & $\begin{array}{r}\text { Projected } \\
\text { enrollment } \\
2021-22 \\
\end{array}$ & $\begin{array}{r}\text { Projected } \\
\text { percent } \\
\text { change }\end{array}$ \\
\hline United States & 49,484 & 53,113 & 7.3 & 34,625 & 37,598 & 8.6 & 14,860 & 15,515 & 4.4 \\
\hline South & 18,805 & 20,481 & 8.9 & 13,435 & 14,689 & 9.3 & 5,370 & 5,792 & 7.8 \\
\hline Alabama & 756 & 751 & -0.6 & 534 & 528 & -1.1 & 222 & 223 & 0.6 \\
\hline Arkansas & 482 & 494 & 2.5 & 346 & 351 & 1.5 & 136 & 143 & 5.0 \\
\hline Delaware & 129 & 143 & 10.3 & 90 & 100 & 11.1 & 39 & 42 & 8.4 \\
\hline $\begin{array}{l}\text { District of } \\
\text { Columbia }\end{array}$ & 71 & 60 & -15.2 & 54 & 46 & -13.2 & 18 & 14 & -21.2 \\
\hline Florida & 2,643 & 2,936 & 11.1 & 1,858 & 2,122 & 14.2 & 785 & 814 & 3.7 \\
\hline Georgia & 1,677 & 1,828 & 9.0 & 1,202 & 1,320 & 9.8 & 475 & 508 & 7.1 \\
\hline Kentucky & 673 & 660 & -1.9 & 480 & 469 & -2.3 & 193 & 191 & -0.8 \\
\hline Louisiana & 697 & 685 & -1.6 & 512 & 496 & -3.2 & 184 & 189 & 2.6 \\
\hline Maryland & 852 & 972 & 14.0 & 588 & 693 & 17.8 & 264 & 279 & 5.6 \\
\hline Mississippi & 491 & 465 & -5.2 & 351 & 331 & -5.8 & 140 & 134 & -3.8 \\
\hline North Carolina & 1,491 & 1,555 & 4.3 & 1,058 & 1,120 & 5.8 & 432 & 435 & 0.6 \\
\hline Oklahoma & 660 & 692 & 4.9 & 483 & 498 & 3.1 & 176 & 194 & 10.0 \\
\hline South Carolina & 726 & 768 & 5.8 & 516 & 543 & 5.2 & 210 & 225 & 7.1 \\
\hline Tennessee & 987 & 1,046 & 5.9 & 702 & 751 & 7.0 & 286 & 295 & 3.1 \\
\hline Texas & 4,936 & 5,782 & 17.2 & 3,587 & 4,162 & 16.0 & 1,349 & 1,621 & 20.1 \\
\hline Virginia & 1,251 & 1,384 & 10.6 & 871 & 980 & 12.4 & 380 & 405 & 6.5 \\
\hline West Virginia & 283 & 259 & -8.3 & 201 & 180 & -10.7 & 81 & 79 & -2.5 \\
\hline West & 11,998 & 13,516 & 12.7 & 8,300 & 9,577 & 15.4 & 3,698 & 3,939 & 6.5 \\
\hline Alaska & 132 & 161 & 21.9 & 92 & 117 & 26.8 & 40 & 44 & 10.5 \\
\hline Arizona & 1,072 & 1,288 & 20.1 & 752 & 940 & 25.0 & 320 & 348 & 8.7 \\
\hline California & 6,290 & 7,013 & 11.5 & 4,294 & 4,909 & 14.3 & 1,996 & 2,104 & 5.4 \\
\hline Colorado & 843 & 954 & 13.1 & 601 & 677 & 12.6 & 242 & 277 & 14.4 \\
\hline Hawaii & 180 & 184 & 2.6 & 128 & 132 & 3.5 & 52 & 52 & 0.4 \\
\hline Idaho & 276 & 305 & 10.4 & 194 & 217 & 11.8 & 82 & 88 & 7.1 \\
\hline Montana & 142 & 150 & 5.8 & 98 & 105 & 7.0 & 43 & 45 & 3.0 \\
\hline Nevada & 437 & 528 & 20.7 & 307 & 387 & 26.0 & 130 & 141 & 8.2 \\
\hline New Mexico & 338 & 368 & 8.9 & 239 & 258 & 8.0 & 99 & 110 & 11.2 \\
\hline Oregon & 571 & 641 & 12.4 & 393 & 456 & 16.1 & 178 & 185 & 4.1 \\
\hline Utah & 586 & 616 & 5.3 & 425 & 459 & 7.9 & 161 & 158 & -1.8 \\
\hline Washington & 1,044 & 1,215 & 16.4 & 714 & 857 & 20.0 & 330 & 358 & 8.6 \\
\hline Wyoming & 89 & 93 & 4.4 & 63 & 63 & 0.4 & 26 & 30 & 14.1 \\
\hline
\end{tabular}

NOTE: The most recent year of actual data is 2010-11, and 2021-22 is the last year for which projected data are available. Detail may not sum to totals because of rounding. For more information on projections, see NCES 2012-044.

SOURCE: U.S. Department of Education, National Center for Education Statistics, Common Core of Data (CCD), "State Nonfiscal Survey of Public

Elementary/Secondary Education," 2010-11; and Public State Elementary and Secondary Enrollment Model, $1980-2010$. 
Table A-4-1. Number and percentage distribution of public charter schools and students, by selected student and school characteristics: Selected school years, 1999-2000 through 2009-10

\begin{tabular}{|c|c|c|c|c|c|c|}
\hline Student and school characteristics & $1999-2000^{1}$ & $2001-02$ & 2003-04 & $2005-06$ & 2007-08 & $2009-10$ \\
\hline \multicolumn{7}{|l|}{ Student characteristics } \\
\hline Total, number & 339,678 & 571,029 & 789,479 & $1,012,906$ & $1,276,731$ & $1,611,332$ \\
\hline \multicolumn{7}{|l|}{ Sex } \\
\hline Male & 51.1 & 50.8 & 50.4 & 49.9 & 49.5 & 49.5 \\
\hline Female & 48.9 & 49.2 & 49.6 & 50.1 & 50.5 & 50.5 \\
\hline \multicolumn{7}{|l|}{ Race/ethnicity } \\
\hline White & 42.5 & 42.6 & 41.8 & 40.5 & 38.8 & 37.3 \\
\hline Black & 33.5 & 32.5 & 31.9 & 32.1 & 31.8 & 30.3 \\
\hline Hispanic & 19.6 & 20.1 & 21.5 & 22.4 & 24.5 & 26.1 \\
\hline Asian/Pacific Islander & 2.8 & 3.1 & 3.2 & 3.6 & 3.8 & 3.8 \\
\hline American Indian/Alaska Native & 1.5 & 1.7 & 1.5 & 1.4 & 1.2 & 1.1 \\
\hline Other $^{2}$ & $\dagger$ & $\dagger$ & $\dagger$ & $\dagger$ & $\dagger$ & 1.4 \\
\hline \multicolumn{7}{|l|}{ School characteristics } \\
\hline Total, number & 1,524 & 2,348 & 2,977 & 3,780 & 4,388 & 4,952 \\
\hline Total, number reporting membership & 1,456 & 2,261 & 2,921 & 3,690 & 4,289 & 4,891 \\
\hline \multicolumn{7}{|l|}{ School level ${ }^{3}$} \\
\hline Elementary & 55.7 & 51.7 & 52.1 & 52.9 & 54.1 & 54.3 \\
\hline Secondary & 24.9 & 24.6 & 26.4 & 28.1 & 27.5 & 26.7 \\
\hline Combined & 18.9 & 23.0 & 21.4 & 18.8 & 18.4 & 18.8 \\
\hline \multicolumn{7}{|l|}{ Enrollment size } \\
\hline Under 300 & 77.0 & 73.5 & 70.9 & 69.5 & 65.5 & 61.3 \\
\hline $300-499$ & 12.0 & 13.7 & 15.6 & 16.6 & 19.4 & 21.0 \\
\hline $500-999$ & 8.7 & 10.0 & 10.3 & 10.9 & 12.0 & 14.0 \\
\hline 1,000 or more & 2.4 & 2.8 & 3.2 & 3.0 & 3.1 & 3.7 \\
\hline \multicolumn{7}{|l|}{ Racial/ethnic concentration } \\
\hline More than 50 percent White & 50.9 & 50.7 & 48.2 & 46.0 & 42.7 & 39.8 \\
\hline More than 50 percent Black & 26.6 & 23.7 & 24.4 & 26.0 & 26.1 & 25.5 \\
\hline More than 50 percent Hispanic & 11.4 & 12.4 & 13.4 & 14.8 & 17.7 & 19.7 \\
\hline \multicolumn{7}{|l|}{$\begin{array}{l}\text { Percentage of students in school eligible } \\
\text { for free or reduced-price lunch }\end{array}$} \\
\hline 0-25 percent & 37.4 & 30.0 & 29.2 & 33.5 & 20.6 & 19.4 \\
\hline 26-50 percent & 11.6 & 12.2 & 16.3 & 15.6 & 15.9 & 17.5 \\
\hline 51-75 percent & 10.6 & 12.5 & 16.3 & 17.3 & 19.3 & 21.2 \\
\hline 76-100 percent & 13.0 & 14.1 & 20.3 & 23.2 & 22.9 & 33.3 \\
\hline Missing/school did not participate & 27.3 & 31.3 & 17.9 & 10.4 & 21.3 & 8.6 \\
\hline \multicolumn{7}{|l|}{ Locale } \\
\hline City & $\dagger$ & $\dagger$ & 52.5 & 53.4 & 54.6 & 54.8 \\
\hline Suburban & $\dagger$ & $\dagger$ & 22.2 & 21.9 & 21.8 & 21.1 \\
\hline Town & $\dagger$ & $\dagger$ & 9.6 & 8.8 & 8.5 & 8.0 \\
\hline Rural & $t$ & t & 15.8 & 15.8 & 15.2 & 16.1 \\
\hline
\end{tabular}

† Not applicable.

' Data for New Jersey were not available and therefore not included in the estimates.

2 Includes data for states reporting students of two or more races.

${ }^{3}$ The sum of the percentages does not does always sum to 100 percent because the total may include ungraded schools and schools that did not report grade spans.

NOTE: Data are for schools reporting student membership. The Common Core of Data (CCD) allows students to be reported for only a single school, even if they attend a "shared time" school, such as a vocational school. Detail may not sum to totals due to rounding. The percentage distribution for each student/school characteristic was based on the students/schools for whom that characteristic was reported, which may be less than the total number of students/schools. Race categories exclude persons of Hispanic ethnicity. For more information on race/ethnicity, percentage of students in school eligible for free or reduced-price lunch, and locale, see Appendix C - Commonly Used Measures. For more information on the CCD, see Appendix B - Guide to Sources.

SOURCE: U.S. Department of Education, National Center for Education Statistics, Common Core of Data (CCD), "Public Elementary/Secondary School Universe Survey," 1999-2000 (version 1b), 2001-02 (version 1a), 2003-04 (version 1a), 2005-06 (version 1a), $2007-08$ (version 1b), and 2009-10 (version 1a). 
This indicator continues on page 134. 
Table A-4-2. Number, percentage, and percentage distribution of public charter schools and students, by region and state or jurisdiction: School years 1999-2000 and 2009-10

\begin{tabular}{|c|c|c|c|c|c|c|c|c|c|c|}
\hline \multirow[b]{3}{*}{$\begin{array}{l}\text { Region and state or } \\
\text { jurisdiction }\end{array}$} & \multicolumn{5}{|c|}{ 1999-2000 } & \multicolumn{5}{|c|}{ 2009-10 } \\
\hline & \multicolumn{3}{|c|}{ Schools } & \multicolumn{2}{|c|}{ Students } & \multicolumn{3}{|c|}{ Schools } & \multicolumn{2}{|c|}{ Students } \\
\hline & Number & $\begin{array}{r}\text { As a per- } \\
\text { centage } \\
\text { of all } \\
\text { public } \\
\text { schools } \\
\end{array}$ & $\begin{array}{r}\text { Percent- } \\
\text { age } \\
\text { distri- } \\
\text { bution }\end{array}$ & Number & $\begin{array}{l}\text { As a per- } \\
\text { centage } \\
\text { of all } \\
\text { public } \\
\text { schools } \\
\end{array}$ & Number & $\begin{array}{r}\text { As a } \\
\text { percent- } \\
\text { age of } \\
\text { all public } \\
\text { schools } \\
\end{array}$ & $\begin{array}{r}\text { Percent- } \\
\text { age } \\
\text { distri- } \\
\text { bution }\end{array}$ & Number & $\begin{array}{r}\text { As a per- } \\
\text { centage } \\
\text { of all } \\
\text { public } \\
\text { schools } \\
\end{array}$ \\
\hline United States & 1,456 & 1.6 & 100.0 & 339,678 & 0.7 & 4,891 & 5.1 & 100.0 & $1,611,332$ & 3.3 \\
\hline Northeast & 105 & 0.7 & 7.2 & 26,525 & 0.3 & 446 & 3.0 & 9.1 & 182,768 & 2.3 \\
\hline Connecticut & 16 & 1.5 & 1.1 & 2,148 & 0.4 & 18 & 1.6 & 0.4 & 5,215 & 0.9 \\
\hline Maine & $\dagger$ & $\dagger$ & $\dagger$ & $\dagger$ & $\dagger$ & $\dagger$ & $\dagger$ & $\dagger$ & $\dagger$ & $\dagger$ \\
\hline Massachusetts & 40 & 2.1 & 2.7 & 12,518 & 1.3 & 62 & 3.4 & 1.3 & 27,393 & 2.9 \\
\hline New Hampshire & 0 & 0.0 & 0.0 & 0 & 0.0 & 14 & 2.9 & 0.3 & 816 & 0.4 \\
\hline New Jersey & $\dagger$ & $\dagger$ & $\dagger$ & $\dagger$ & $\dagger$ & 70 & 2.7 & 1.4 & 22,981 & 1.7 \\
\hline New York & 0 & 0.0 & 0.0 & 0 & 0.0 & 136 & 2.9 & 2.8 & 43,963 & 1.6 \\
\hline Pennsylvania & 47 & 1.5 & 3.2 & 11,413 & 0.6 & 134 & 4.2 & 2.7 & 79,167 & 4.5 \\
\hline Rhode Island & 2 & 0.6 & 0.1 & 446 & 0.3 & 12 & 3.9 & 0.2 & 3,233 & 2.3 \\
\hline Vermont & $\dagger$ & $\dagger$ & $\dagger$ & $\dagger$ & $\dagger$ & $\dagger$ & $\dagger$ & $\dagger$ & $\dagger$ & $\dagger$ \\
\hline Midwest & 354 & 1.4 & 24.3 & 77,697 & 0.7 & 1,169 & 4.6 & 23.9 & 351,552 & 3.3 \\
\hline Illinois & 17 & 0.4 & 1.2 & 6,152 & 0.3 & 39 & 0.9 & 0.8 & 35,836 & 1.7 \\
\hline Indiana & $\dagger$ & $\dagger$ & $\dagger$ & $\dagger$ & $\dagger$ & 53 & 2.8 & 1.1 & 18,488 & 1.8 \\
\hline lowa & $\dagger$ & $\dagger$ & $\dagger$ & $\dagger$ & $\dagger$ & 3 & 0.2 & 0.1 & 593 & 0.1 \\
\hline Kansas & 0 & 0.0 & 0.0 & 0 & 0.0 & 35 & 2.5 & 0.7 & 4,684 & 1.0 \\
\hline Michigan & 172 & 4.8 & 11.8 & 46,078 & 2.8 & 288 & 7.8 & 5.9 & 110,845 & 6.9 \\
\hline Minnesota & 57 & 2.8 & 3.9 & 7,794 & 0.9 & 179 & 8.0 & 3.7 & 35,375 & 4.2 \\
\hline Missouri & 15 & 0.7 & 1.0 & 4,303 & 0.5 & 48 & 2.1 & 1.0 & 18,415 & 2.0 \\
\hline Nebraska & $\dagger$ & $\dagger$ & $\dagger$ & $\dagger$ & $\dagger$ & $\dagger$ & $\dagger$ & $\dagger$ & $\dagger$ & $\dagger$ \\
\hline North Dakota & $\dagger$ & $\dagger$ & $\dagger$ & $\dagger$ & $\dagger$ & $\dagger$ & $\dagger$ & $\dagger$ & $\dagger$ & $\dagger$ \\
\hline Ohio & 48 & 1.3 & 3.3 & 9,809 & 0.5 & 321 & 8.6 & 6.6 & 90,989 & 5.2 \\
\hline South Dakota & $\dagger$ & $\dagger$ & $\dagger$ & $\dagger$ & $\dagger$ & $\dagger$ & $\dagger$ & $\dagger$ & $\dagger$ & $\dagger$ \\
\hline Wisconsin & 45 & 2.1 & 3.1 & 3,561 & 0.4 & 203 & 9.1 & 4.2 & 36,153 & 4.1 \\
\hline South & 431 & 1.5 & 29.6 & 76,304 & 0.5 & 1,451 & 4.5 & 29.7 & 474,154 & 2.5 \\
\hline Alabama & $\dagger$ & $\dagger$ & $\dagger$ & $\dagger$ & $\dagger$ & $\dagger$ & $\dagger$ & $\dagger$ & $\dagger$ & $\dagger$ \\
\hline Arkansas & 0 & 0.0 & 0.0 & 0 & 0.0 & 38 & 3.5 & 0.8 & 8,662 & 1.8 \\
\hline Delaware & 1 & 0.5 & 0.1 & 115 & 0.1 & 18 & 8.8 & 0.4 & 9,173 & 7.3 \\
\hline District of Columbia & 27 & 14.3 & 1.9 & 6,432 & 8.3 & 93 & 43.1 & 1.9 & 25,813 & 37.3 \\
\hline Florida & 112 & 3.6 & 7.7 & 17,251 & 0.7 & 410 & 10.8 & 8.4 & 137,887 & 5.2 \\
\hline Georgia & 18 & 1.0 & 1.2 & 11,005 & 0.8 & 62 & 2.7 & 1.3 & 37,545 & 2.3 \\
\hline Kentucky & $\dagger$ & $\dagger$ & $\dagger$ & $\dagger$ & $\dagger$ & $\dagger$ & $\dagger$ & $\dagger$ & $\dagger$ & $\dagger$ \\
\hline Louisiana & 15 & 1.0 & 1.0 & 2,449 & 0.3 & 77 & 5.3 & 1.6 & 31,467 & 4.6 \\
\hline Maryland & $\dagger$ & $\dagger$ & $\dagger$ & $\dagger$ & $\dagger$ & 42 & 3.0 & 0.9 & 11,995 & 1.4 \\
\hline Mississippi & 1 & 0.1 & 0.1 & 347 & 0.1 & 1 & 0.1 & $\#$ & 375 & 0.1 \\
\hline North Carolina & 77 & 3.6 & 5.3 & 12,691 & 1.0 & 96 & 3.8 & 2.0 & 38,973 & 2.6 \\
\hline Oklahoma & 0 & 0.0 & 0.0 & 0 & 0.0 & 18 & 1.0 & 0.4 & 6,315 & 1.0 \\
\hline South Carolina & 4 & 0.4 & 0.3 & 327 & $\#$ & 38 & 3.3 & 0.8 & 13,035 & 1.8 \\
\hline Tennessee & $\dagger$ & $\dagger$ & $\dagger$ & $\dagger$ & $\dagger$ & 19 & 1.1 & 0.4 & 4,343 & 0.4 \\
\hline Texas & 176 & 2.4 & 12.1 & 25,687 & 0.6 & 536 & 6.3 & 11.0 & 148,392 & 3.1 \\
\hline Virginia & 0 & 0.0 & 0.0 & 0 & 0.0 & 3 & 0.2 & 0.1 & 179 & \# \\
\hline West Virginia & $\dagger$ & $\dagger$ & $\dagger$ & $\dagger$ & $t$ & $\dagger$ & $\dagger$ & $\dagger$ & $t$ & $\dagger$ \\
\hline
\end{tabular}

See notes at end of table. 
Table A-4-2. Number, percentage, and percentage distribution of public charter schools and students, by region and state or jurisdiction: School years 1999-2000 and 2009-10-Continued

\begin{tabular}{|c|c|c|c|c|c|c|c|c|c|c|}
\hline \multirow[b]{3}{*}{$\begin{array}{l}\text { Region and state or } \\
\text { jurisdiction }\end{array}$} & \multicolumn{5}{|c|}{ 1999-2000 } & \multicolumn{5}{|c|}{$2009-10$} \\
\hline & \multicolumn{3}{|c|}{ Schools } & \multicolumn{2}{|c|}{ Students } & \multicolumn{3}{|c|}{ Schools } & \multicolumn{2}{|c|}{ Students } \\
\hline & Number & $\begin{array}{r}\text { As a per- } \\
\text { centage } \\
\text { of all } \\
\text { public } \\
\text { schools } \\
\end{array}$ & $\begin{array}{r}\text { Percent- } \\
\text { age } \\
\text { distri- } \\
\text { bution }\end{array}$ & Number & $\begin{array}{l}\text { As a per- } \\
\text { centage } \\
\text { of all } \\
\text { public } \\
\text { schools } \\
\end{array}$ & Number & $\begin{array}{r}\text { As a } \\
\text { percent- } \\
\text { age of } \\
\text { all public } \\
\text { schools } \\
\end{array}$ & $\begin{array}{r}\text { Percent- } \\
\text { age } \\
\text { distri- } \\
\text { bution }\end{array}$ & Number & $\begin{array}{r}\text { As a per- } \\
\text { centage } \\
\text { of all } \\
\text { public } \\
\text { schools } \\
\end{array}$ \\
\hline United States & 1,456 & 1.6 & 100.0 & 339,678 & 0.7 & 4,891 & 5.1 & 100.0 & $1,611,332$ & 3.3 \\
\hline West & 566 & 2.9 & 38.9 & 159,152 & 1.4 & 1,825 & 8.2 & 37.3 & 603,163 & 5.1 \\
\hline Alaska & 18 & 3.6 & 1.2 & 2,300 & 1.7 & 25 & 5.0 & 0.5 & 5,196 & 3.9 \\
\hline Arizona & 220 & 14.2 & 15.1 & 31,176 & 3.7 & 499 & 23.9 & 10.2 & 113,974 & 10.6 \\
\hline California & 236 & 2.8 & 16.2 & 104,730 & 1.8 & 796 & 8.1 & 16.3 & 317,363 & 5.1 \\
\hline Colorado & 69 & 4.4 & 4.7 & 17,822 & 2.5 & 158 & 8.8 & 3.2 & 66,826 & 8.0 \\
\hline Hawaii & 2 & 0.8 & 0.1 & 790 & 0.4 & 31 & 10.8 & 0.6 & 7,869 & 4.4 \\
\hline Idaho & 8 & 1.2 & 0.5 & 915 & 0.4 & 36 & 5.0 & 0.7 & 14,529 & 5.3 \\
\hline Montana & $\dagger$ & $\dagger$ & $\dagger$ & $\dagger$ & $\dagger$ & $\dagger$ & $\dagger$ & $\dagger$ & $\dagger$ & $\dagger$ \\
\hline Nevada & 5 & 1.0 & 0.3 & 898 & 0.3 & 32 & 5.1 & 0.7 & 11,614 & 2.7 \\
\hline New Mexico & 1 & 0.1 & 0.1 & 22 & $\#$ & 72 & 8.5 & 1.5 & 13,090 & 3.9 \\
\hline Oregon & 1 & 0.1 & 0.1 & 109 & $\#$ & 101 & 7.8 & 2.1 & 18,334 & 3.3 \\
\hline Utah & 6 & 0.8 & 0.4 & 390 & 0.1 & 72 & 7.3 & 1.5 & 33,968 & 5.8 \\
\hline Washington & $\dagger$ & $\dagger$ & $\dagger$ & $\dagger$ & $\dagger$ & $\dagger$ & $\dagger$ & $\dagger$ & $\dagger$ & $\dagger$ \\
\hline Wyoming & 0 & 0.0 & 0.0 & 0 & 0.0 & 3 & 0.8 & 0.1 & 269 & 0.3 \\
\hline
\end{tabular}

† Not applicable. State did not have a charter law, or, for New Jersey in 1999-2000, data were not available.

\# Rounds to zero.

NOTE: Data are for schools reporting student membership. The Common Core of Data (CCD) allows students to be reported for only a single school, even if they attend a "shared time" school, such as a vocational school. Detail may not sum to totals due to rounding. For more information on geographic region, see Appendix C - Commonly Used Measures. For more information on the CCD, see Appendix B - Guide to Sources.

SOURCE: U.S. Department of Education, National Center for Education Statistics, Common Core of Data (CCD), "Public Elementary/Secondary School Universe Survey," 1999-2000 (version 1b) and 2009-10 (version 1a). 


\section{Private School Enrollment}

Table A-5-1. Total enrollment and percentage distribution of students enrolled in private elementary and secondary schools, by school type and grade level: Various school years, 1995-96 through 2009-10

\begin{tabular}{|c|c|c|c|c|c|c|c|c|c|c|}
\hline \multirow[b]{2}{*}{$\begin{array}{l}\text { Grade level and } \\
\text { school year }\end{array}$} & \multirow[b]{2}{*}{ Total } & \multicolumn{4}{|c|}{ Catholic } & \multicolumn{4}{|c|}{ Other religious } & \multirow[b]{2}{*}{ Nonsectarian } \\
\hline & & Total & Parochial & Diocesan & $\begin{array}{r}\text { Private } \\
\text { (indepen- } \\
\text { dent) }\end{array}$ & Total & $\begin{array}{c}\text { Conser- } \\
\text { vative } \\
\text { Christian }\end{array}$ & Affiliated & $\begin{array}{r}\text { Unaffili- } \\
\text { ated }\end{array}$ & \\
\hline & \multicolumn{10}{|c|}{ Enrollment, in thousands } \\
\hline \multicolumn{11}{|l|}{ Grades preK-12 } \\
\hline 1995-96 & 5,918 & 2,660 & 1,459 & 851 & 351 & 2,095 & 787 & 697 & 611 & 1,163 \\
\hline 1997-98 & 5,944 & 2,666 & 1,439 & 874 & 353 & 2,097 & 824 & 647 & 627 & 1,182 \\
\hline 1999-2000 & 6,018 & 2,660 & 1,398 & 881 & 382 & 2,193 & 871 & 646 & 676 & 1,164 \\
\hline 2001-02 & 6,320 & 2,673 & 1,310 & 979 & 384 & 2,328 & 937 & 663 & 728 & 1,319 \\
\hline 2003-04 & 6,099 & 2,520 & 1,183 & 963 & 374 & 2,228 & 890 & 651 & 688 & 1,351 \\
\hline $2005-06$ & 6,073 & 2,403 & 1,063 & 957 & 383 & 2,303 & 957 & 697 & 649 & 1,367 \\
\hline 2007-08 & 5,910 & 2,308 & 946 & 970 & 392 & 2,283 & 883 & 527 & 873 & 1,319 \\
\hline 2009-10 & 5,488 & 2,160 & 856 & 909 & 395 & 2,076 & 737 & 516 & 823 & 1,252 \\
\hline \multicolumn{11}{|l|}{ Grades preK-8 } \\
\hline 1995-96 & 4,756 & 2,042 & 1,368 & 575 & 98 & 1,753 & 651 & 575 & 527 & 961 \\
\hline 1997-98 & 4,759 & 2,047 & 1,353 & 598 & 96 & 1,744 & 679 & 529 & 537 & 968 \\
\hline 1999-2000 & 4,789 & 2,034 & 1,317 & 608 & 109 & 1,818 & 713 & 529 & 576 & 937 \\
\hline 2001-02 & 5,023 & 2,032 & 1,227 & 688 & 118 & 1,927 & 765 & 536 & 626 & 1,064 \\
\hline 2003-04 & 4,788 & 1,887 & 1,108 & 671 & 107 & 1,836 & 722 & 519 & 594 & 1,066 \\
\hline $2005-06$ & 4,724 & 1,780 & 993 & 673 & 113 & 1,865 & 765 & 561 & 539 & 1,079 \\
\hline 2007-08 & 4,546 & 1,685 & 879 & 688 & 118 & 1,834 & 699 & 418 & 717 & 1,027 \\
\hline 2009-10 & 4,179 & 1,542 & 782 & 643 & 117 & 1,666 & 579 & 401 & 685 & 972 \\
\hline \multicolumn{11}{|l|}{ Grades 9-12 } \\
\hline $1995-96$ & 1,163 & 618 & 91 & 275 & 252 & 342 & 136 & 122 & 84 & 202 \\
\hline 1997-98 & 1,185 & 619 & 86 & 275 & 257 & 353 & 145 & 117 & 90 & 214 \\
\hline 1999-2000 & 1,229 & 627 & 80 & 273 & 273 & 375 & 158 & 117 & 100 & 228 \\
\hline 2001-02 & 1,296 & 641 & 83 & 292 & 266 & 401 & 172 & 127 & 102 & 255 \\
\hline 2003-04 & 1,311 & 634 & 75 & 292 & 266 & 392 & 167 & 131 & 94 & 285 \\
\hline $2005-06$ & 1,349 & 623 & 70 & 284 & 270 & 438 & 192 & 136 & 110 & 288 \\
\hline 2007-08 & 1,364 & 623 & 67 & 282 & 274 & 450 & 184 & 109 & 156 & 292 \\
\hline 2009-10 & 1,309 & 618 & 74 & 266 & 278 & 411 & 158 & 115 & 138 & 280 \\
\hline
\end{tabular}

See notes at end of table. 
Table A-5-1. Total enrollment and percentage distribution of students enrolled in private elementary and secondary schools, by school type and grade level: Various school years, 1995-96 through 2009-10-Continued

\begin{tabular}{|c|c|c|c|c|c|c|c|c|c|c|}
\hline \multirow[b]{2}{*}{$\begin{array}{l}\text { Grade level and } \\
\text { school year }\end{array}$} & \multirow[b]{2}{*}{ Total } & \multicolumn{4}{|c|}{ Catholic } & \multicolumn{4}{|c|}{ Other religious } & \multirow[b]{2}{*}{ Nonsectarian } \\
\hline & & Total & Parochial & Diocesan & $\begin{array}{r}\text { Private } \\
\text { (indepen- } \\
\text { dent) }\end{array}$ & Total & $\begin{array}{c}\text { Conser- } \\
\text { vative } \\
\text { Christian } \\
\end{array}$ & Affiliated & $\begin{array}{r}\text { Unaffili- } \\
\text { ated }\end{array}$ & \\
\hline & \multicolumn{10}{|c|}{ Percentage distribution } \\
\hline \multicolumn{11}{|l|}{ Grades preK-12 } \\
\hline $1995-96$ & 100.0 & 45.0 & 24.7 & 14.4 & 5.9 & 35.4 & 13.3 & 11.8 & 10.3 & 19.7 \\
\hline 1997-98 & 100.0 & 44.8 & 24.2 & 14.7 & 5.9 & 35.3 & 13.9 & 10.9 & 10.5 & 19.9 \\
\hline 1999-2000 & 100.0 & 44.2 & 23.2 & 14.6 & 6.4 & 36.4 & 14.5 & 10.7 & 11.2 & 19.3 \\
\hline $2001-02$ & 100.0 & 42.3 & 20.7 & 15.5 & 6.1 & 36.8 & 14.8 & 10.5 & 11.5 & 20.9 \\
\hline 2003-04 & 100.0 & 41.3 & 19.4 & 15.8 & 6.1 & 36.5 & 14.6 & 10.7 & 11.3 & 22.1 \\
\hline $2005-06$ & 100.0 & 39.6 & 17.5 & 15.8 & 6.3 & 37.9 & 15.8 & 11.5 & 10.7 & 22.5 \\
\hline 2007-08 & 100.0 & 39.1 & 16.0 & 16.4 & 6.6 & 38.6 & 14.9 & 8.9 & 14.8 & 22.3 \\
\hline 2009-10 & 100.0 & 39.4 & 15.6 & 16.6 & 7.2 & 37.8 & 13.4 & 9.4 & 15.0 & 22.8 \\
\hline \multicolumn{11}{|l|}{ Grades preK-8 } \\
\hline 1995-96 & 100.0 & 42.9 & 28.8 & 12.1 & 2.1 & 36.9 & 13.7 & 12.1 & 11.1 & 20.2 \\
\hline 1997-98 & 100.0 & 43.0 & 28.4 & 12.6 & 2.0 & 36.7 & 14.3 & 11.1 & 11.3 & 20.3 \\
\hline 1999-2000 & 100.0 & 42.5 & 27.5 & 12.7 & 2.3 & 38.0 & 14.9 & 11.1 & 12.0 & 19.6 \\
\hline 2001-02 & 100.0 & 40.5 & 24.4 & 13.7 & 2.3 & 38.4 & 15.2 & 10.7 & 12.5 & 21.2 \\
\hline 2003-04 & 100.0 & 39.4 & 23.1 & 14.0 & 2.2 & 38.3 & 15.1 & 10.8 & 12.4 & 22.3 \\
\hline $2005-06$ & 100.0 & 37.7 & 21.0 & 14.2 & 2.4 & 39.5 & 16.2 & 11.9 & 11.4 & 22.8 \\
\hline 2007-08 & 100.0 & 37.1 & 19.3 & 15.1 & 2.6 & 40.3 & 15.4 & 9.2 & 15.8 & 22.6 \\
\hline 2009-10 & 100.0 & 36.9 & 18.7 & 15.4 & 2.8 & 39.9 & 13.9 & 9.6 & 16.4 & 23.2 \\
\hline \multicolumn{11}{|l|}{ Grades 9-12 } \\
\hline 1995-96 & 100.0 & 53.2 & 7.8 & 23.7 & 21.7 & 29.4 & 11.7 & 10.5 & 7.2 & 17.4 \\
\hline 1997-98 & 100.0 & 52.2 & 7.3 & 23.2 & 21.7 & 29.8 & 12.2 & 9.9 & 7.6 & 18.0 \\
\hline 1999-2000 & 100.0 & 51.0 & 6.5 & 22.2 & 22.2 & 30.5 & 12.9 & 9.5 & 8.1 & 18.5 \\
\hline 2001-02 & 100.0 & 49.4 & 6.4 & 22.5 & 20.5 & 31.0 & 13.3 & 9.8 & 7.8 & 19.6 \\
\hline 2003-04 & 100.0 & 48.3 & 5.7 & 22.3 & 20.3 & 29.9 & 12.8 & 10.0 & 7.2 & 21.8 \\
\hline $2005-06$ & 100.0 & 46.2 & 5.2 & 21.0 & 20.0 & 32.5 & 14.3 & 10.1 & 8.1 & 21.4 \\
\hline 2007-08 & 100.0 & 45.7 & 4.9 & 20.6 & 20.1 & 33.0 & 13.5 & 8.0 & 11.4 & 21.4 \\
\hline 2009-10 & 100.0 & 47.2 & 5.7 & 20.3 & 21.2 & 31.4 & 12.1 & 8.8 & 10.5 & 21.4 \\
\hline
\end{tabular}

NOTE: Prekindergarten students who are enrolled in private schools that do not offer kindergarten or higher grades are not included in this analysis.

Catholic schools include parochial, diocesan, and private Catholic schools. Affiliated religious schools have a specific religious orientation or purpose but are not Catholic. Unaffiliated schools have a more general religious orientation or purpose but are not classified as Conservative Christian or affiliated with a specific religion. Nonsectarian schools do not have a religious orientation or purpose. Ungraded students are prorated into preK-8 and 9-12 enrollment totals. Detail may not sum to totals because of rounding. For more information on the Private School Universe Survey (PSS), see Appendix B - Guide to Sources.

SOURCE: U.S. Department of Education, National Center for Education Statistics, Private School Universe Survey (PSS), various years, 1995-96 through 2009-10. 
Private School Enrollment

Table A-5-2. Private elementary and secondary school enrollment and private enrollment as a percentage of total enrollment in public and private schools, by region and grade level: Various school years, 1995-96 through 2009-10

[Numbers in thousands]

\begin{tabular}{|c|c|c|c|c|c|c|c|c|c|c|}
\hline \multirow[b]{2}{*}{$\begin{array}{l}\text { Grade level and } \\
\text { school year }\end{array}$} & \multicolumn{2}{|c|}{ Total enrollment } & \multicolumn{2}{|c|}{ Northeast } & \multicolumn{2}{|c|}{ Midwest } & \multicolumn{2}{|c|}{ South } & \multicolumn{2}{|c|}{ West } \\
\hline & Total & $\begin{array}{r}\text { Percent } \\
\text { of total } \\
\text { enroll- } \\
\text { ment }\end{array}$ & Total & $\begin{array}{r}\text { Percent } \\
\text { of total } \\
\text { Northeast } \\
\text { enroll- } \\
\text { ment }\end{array}$ & Total & $\begin{array}{r}\text { Percent } \\
\text { of total } \\
\text { Midwest } \\
\text { enroll- } \\
\text { ment } \\
\end{array}$ & Total & $\begin{array}{r}\text { Percent } \\
\text { of total } \\
\text { South } \\
\text { enroll- } \\
\text { ment } \\
\end{array}$ & Total & $\begin{array}{r}\text { Percent } \\
\text { of total } \\
\text { West } \\
\text { enroll- } \\
\text { ment } \\
\end{array}$ \\
\hline \multicolumn{11}{|l|}{ Grades preK-12 } \\
\hline $1995-96$ & 5,918 & 11.7 & 1,509 & 16.0 & 1,525 & 12.7 & 1,744 & 9.8 & 1,141 & 10.0 \\
\hline 1997-98 & 5,944 & 11.4 & 1,496 & 15.6 & 1,528 & 12.5 & 1,804 & 9.8 & 1,116 & 9.4 \\
\hline 1999-2000 & 6,018 & 11.4 & 1,507 & 15.5 & 1,520 & 12.4 & 1,863 & 10.0 & 1,127 & 9.2 \\
\hline $2001-02$ & 6,320 & 11.7 & 1,581 & 16.1 & 1,556 & 12.6 & 1,975 & 10.3 & 1,208 & 9.6 \\
\hline 2003-04 & 6,099 & 11.2 & 1,513 & 15.4 & 1,460 & 11.9 & 1,944 & 9.9 & 1,182 & 9.1 \\
\hline $2005-06$ & 6,073 & 11.0 & 1,430 & 14.8 & 1,434 & 11.7 & 1,976 & 9.8 & 1,234 & 9.4 \\
\hline $2007-08$ & 5,910 & 10.7 & 1,426 & 14.9 & 1,352 & 11.2 & 1,965 & 9.6 & 1,167 & 8.9 \\
\hline 2009-10 & 5,488 & 10.0 & 1,310 & 14.0 & 1,296 & 10.8 & 1,842 & 9.1 & 1,041 & 8.0 \\
\hline \multicolumn{11}{|l|}{ Grades preK-8 } \\
\hline $1995-96$ & 4,756 & 12.8 & 1,174 & 17.2 & 1,238 & 14.3 & 1,413 & 10.7 & 931 & 11.1 \\
\hline 1997-98 & 4,759 & 12.6 & 1,165 & 16.8 & 1,235 & 14.1 & 1,449 & 10.8 & 909 & 10.5 \\
\hline 1999-2000 & 4,789 & 12.5 & 1,168 & 16.7 & 1,222 & 13.9 & 1,487 & 10.9 & 913 & 10.4 \\
\hline $2001-02$ & 5,023 & 12.9 & 1,216 & 17.3 & 1,253 & 14.3 & 1,584 & 11.3 & 969 & 10.6 \\
\hline 2003-04 & 4,788 & 12.3 & 1,131 & 16.4 & 1,167 & 13.5 & 1,547 & 10.9 & 944 & 10.2 \\
\hline $2005-06$ & 4,724 & 12.1 & 1,063 & 15.9 & 1,142 & 13.3 & 1,551 & 10.7 & 969 & 10.5 \\
\hline 2007-08 & 4,546 & 11.7 & 1,047 & 16.0 & 1,065 & 12.6 & 1,525 & 10.4 & 909 & 9.9 \\
\hline $2009-10$ & 4,179 & 10.8 & 938 & 14.6 & 1,016 & 12.1 & 1,424 & 9.8 & 802 & 8.8 \\
\hline \multicolumn{11}{|l|}{ Grades 9-12 } \\
\hline $1995-96$ & 1,163 & 8.5 & 335 & 13.0 & 287 & 8.6 & 331 & 7.1 & 209 & 6.8 \\
\hline 1997-98 & 1,185 & 8.3 & 331 & 12.5 & 293 & 8.5 & 354 & 7.2 & 207 & 6.4 \\
\hline 1999-2000 & 1,229 & 8.4 & 340 & 12.6 & 299 & 8.6 & 376 & 7.5 & 215 & 6.3 \\
\hline 2001-02 & 1,296 & 8.6 & 365 & 13.1 & 302 & 8.6 & 390 & 7.5 & 239 & 6.8 \\
\hline 2003-04 & 1,311 & 8.4 & 382 & 13.1 & 294 & 8.2 & 397 & 7.4 & 238 & 6.4 \\
\hline $2005-06$ & 1,349 & 8.3 & 367 & 12.3 & 292 & 7.9 & 425 & 7.5 & 265 & 6.7 \\
\hline 2007-08 & 1,364 & 8.3 & 379 & 12.7 & 287 & 7.8 & 440 & 7.6 & 257 & 6.5 \\
\hline$\underline{2009-10}$ & 1,309 & 8.0 & 372 & 12.6 & 280 & 7.7 & 418 & 7.3 & 239 & 6.1 \\
\hline
\end{tabular}

NOTE: Prekindergarten students who are enrolled in private schools that do not offer kindergarten or higher grades are not included in this analysis. Ungraded students are prorated into preK-8 and 9-12 enrollment totals. Detail may not sum to totals because of rounding. For more information on geographic region, see Appendix C - Commonly Used Measures. For more information on the Private School Universe Survey, see Appendix B - Guide to Sources.

SOURCE: U.S. Department of Education, National Center for Education Statistics, Private School Universe Survey (PSS), various years, 1995-96 through 2009-10; and Common Core of Data (CCD), "State Nonfiscal Survey of Public Elementary/Secondary Education," various years, 1995-96 through 2009-10. 
Table A-5-3. Percentage distribution of students enrolled in private elementary and secondary schools, by school type and selected characteristics: 2009-10

\begin{tabular}{|c|c|c|c|c|c|c|c|c|c|c|}
\hline \multirow[b]{3}{*}{ Selected characteristic } & \multicolumn{10}{|c|}{ Percentage distribution, by school type } \\
\hline & \multirow[b]{2}{*}{ Total } & \multicolumn{4}{|c|}{ Catholic } & \multicolumn{4}{|c|}{ Other religious } & \multirow[b]{2}{*}{$\begin{array}{r}\text { Nonsec- } \\
\text { tarian }\end{array}$} \\
\hline & & Total & Parochial & Diocesan & $\begin{array}{r}\text { Private } \\
\text { (indepen- } \\
\text { dent) }\end{array}$ & Total & $\begin{array}{c}\text { Conser- } \\
\text { vative } \\
\text { Christian } \\
\end{array}$ & Affiliated & $\begin{array}{l}\text { Unaffili- } \\
\text { ated }\end{array}$ & \\
\hline Total & 100.0 & 39.4 & 15.6 & 16.6 & 7.2 & 37.8 & 13.4 & 9.4 & 15.0 & 22.8 \\
\hline \multicolumn{11}{|l|}{ School level } \\
\hline Elementary & 100.0 & 49.5 & 25.9 & 20.9 & 2.7 & 30.1 & 7.1 & 8.4 & 14.6 & 20.4 \\
\hline Secondary & 100.0 & 74.7 & 8.5 & 33.2 & 33.0 & 13.6 & 2.3 & 5.5 & 5.8 & 11.7 \\
\hline Combined & 100.0 & 6.7 & 1.6 & 2.0 & 3.1 & 61.5 & 28.9 & 12.8 & 19.7 & 31.8 \\
\hline \multicolumn{11}{|l|}{ Race/ethnicity } \\
\hline White & 100.0 & 41.7 & 16.2 & 17.9 & 7.6 & 39.2 & 13.7 & 10.1 & 15.5 & 19.0 \\
\hline Black & 100.0 & 35.1 & 13.1 & 13.8 & 8.2 & 41.8 & 18.0 & 8.9 & 14.8 & 23.1 \\
\hline Hispanic & 100.0 & 60.3 & 25.1 & 23.5 & 11.7 & 24.3 & 10.4 & 6.2 & 7.7 & 15.4 \\
\hline Asian/ & & & & & & & & & & \\
\hline Pacific Islander & 100.0 & 38.1 & 15.1 & 15.5 & 7.5 & 30.3 & 11.5 & 9.7 & 9.1 & 31.6 \\
\hline Pacific Islander & 100.0 & 40.3 & 17.7 & 16.7 & 5.9 & 44.6 & 12.5 & 5.4 & 26.7 & 15.1 \\
\hline $\begin{array}{l}\text { American Indian/ } \\
\text { Alaska Native }\end{array}$ & 100.0 & 41.0 & 10.3 & 18.2 & 12.5 & 34.1 & 17.1 & 5.6 & 11.4 & 24.9 \\
\hline Two or more races & 100.0 & 44.8 & 16.5 & 19.7 & 8.7 & 27.0 & 9.8 & 8.0 & 9.2 & 28.2 \\
\hline \multicolumn{11}{|l|}{ Enrollment } \\
\hline Less than 50 & 100.0 & 2.3 & 0.7 & 0.7 & 0.9 & 57.7 & 12.1 & 6.9 & 38.8 & 40.0 \\
\hline $50-149$ & 100.0 & 15.6 & 6.9 & 6.6 & 2.1 & 47.2 & 16.3 & 9.2 & 21.7 & 37.2 \\
\hline $150-299$ & 100.0 & 44.8 & 21.8 & 19.6 & 3.5 & 36.5 & 12.8 & 9.2 & 14.4 & 18.7 \\
\hline $300-499$ & 100.0 & 50.0 & 23.3 & 20.1 & 6.7 & 32.6 & 12.7 & 9.4 & 10.6 & 17.3 \\
\hline $500-749$ & 100.0 & 53.7 & 19.7 & 23.3 & 10.7 & 30.4 & 13.4 & 9.3 & 7.8 & 15.9 \\
\hline 750 or more & 100.0 & 42.0 & 6.6 & 17.3 & 18.2 & 36.5 & 12.7 & 11.0 & 12.8 & 21.5 \\
\hline \multicolumn{11}{|l|}{ Region } \\
\hline Northeast & 100.0 & 45.6 & 19.4 & 16.8 & 9.4 & 28.0 & 4.9 & 9.5 & 13.6 & 26.4 \\
\hline Midwest & 100.0 & 56.1 & 23.3 & 24.3 & 8.5 & 32.3 & 9.2 & 8.0 & 15.1 & 11.6 \\
\hline South & 100.0 & 26.8 & 9.9 & 12.0 & 5.0 & 48.7 & 19.4 & 11.3 & 18.0 & 24.5 \\
\hline West & 100.0 & 32.9 & 11.4 & 14.7 & 6.8 & 37.8 & 18.9 & 7.7 & 11.3 & 29.2 \\
\hline \multicolumn{11}{|l|}{ Locale } \\
\hline City & 100.0 & 44.2 & 16.0 & 18.2 & 10.0 & 33.8 & 10.8 & 10.2 & 12.8 & 21.9 \\
\hline Suburban & 100.0 & 40.6 & 17.0 & 17.0 & 6.6 & 35.4 & 13.2 & 9.2 & 13.0 & 23.9 \\
\hline Town & 100.0 & 47.1 & 22.5 & 22.4 & 2.2 & 39.6 & 15.1 & 7.7 & 16.7 & 13.3 \\
\hline Rural & 100.0 & 15.8 & 6.2 & 6.8 & 2.9 & 56.7 & 21.6 & 8.2 & 26.9 & 27.5 \\
\hline
\end{tabular}

NOTE: Prekindergarten students who are enrolled in private schools that do not offer kindergarten or higher grades are not included in this analysis. Catholic schools include parochial, diocesan, and private Catholic schools. Affiliated religious schools have a specific religious orientation or purpose but are not Catholic. Unaffiliated schools have a more general religious orientation or purpose but are not classified as Conservative Christian or affiliated with a specific religion. Nonsectarian schools do not have a religious orientation or purpose. An elementary school has one or more grades of kindergarten $(K)$ through grade 6 and does not have any grade higher than grade 8 . A secondary school has one or more of grades $7-12$ and does not have any grade lower than grade 7. A combined school offers both elementary and secondary education and typically has one or more of grades $\mathrm{K}$ through grade 6 and one or more of grades 9-12. Detail may not sum to totals because of rounding. For more information on geographic region and school locale, see Appendix C - Commonly Used Measures. For more information on the Private School Universe Survey, see Appendix B - Guide to Sources.

SOURCE: U.S. Department of Education, National Center for Education Statistics, Private School Universe Survey (PSS), $2009-10$. 
Table A-6-1. Number and percentage distribution of public school students enrolled in prekindergarten through 12th grade by race/ethnicity: October 1990-October 2010

[Numbers in thousands]

\begin{tabular}{|c|c|c|c|c|c|c|c|c|}
\hline October of year & Total & White & Black & Hispanic & Asian & $\begin{array}{r}\text { Native } \\
\text { Hawaiian/ } \\
\text { Pacific } \\
\text { Islander }\end{array}$ & $\begin{array}{r}\text { American } \\
\text { Indian/ } \\
\text { Alaska } \\
\text { Native }\end{array}$ & $\begin{array}{r}\text { Two or } \\
\text { more } \\
\text { races }\end{array}$ \\
\hline & \multicolumn{8}{|c|}{ Enrollment } \\
\hline 1990 & 43,086 & 28,991 & 7,202 & 5,054 & $1,304^{1}$ & $(1)$ & 407 & $\overline{-}$ \\
\hline 1991 & 43,463 & 29,103 & 7,373 & 5,159 & $1,374^{1}$ & $(1)$ & 367 & - \\
\hline 1992 & 44,041 & 29,304 & 7,524 & 5,310 & $1,455^{1}$ & $(1)$ & 351 & - \\
\hline 1993 & 45,079 & 30,094 & 7,576 & 5,457 & $1,480^{1}$ & ()$\left.^{1}\right)$ & 360 & - \\
\hline 1994 & 46,887 & 30,656 & 8,039 & 6,423 & $1,141^{1}$ & $(1)$ & 390 & - \\
\hline 1995 & 47,320 & 30,788 & 8,132 & 6,751 & $1,065^{1}$ & $(1)$ & 309 & - \\
\hline 1996 & 47,487 & 29,960 & 8,002 & 7,025 & $1,936^{1}$ & $(1)$ & 563 & - \\
\hline 1997 & 49,467 & 30,896 & 8,560 & 7,487 & $1,920^{1}$ & $(1)$ & 604 & - \\
\hline 1998 & 48,817 & 30,164 & 8,505 & 7,647 & $1,946^{1}$ & $(1)$ & 555 & - \\
\hline 1999 & 49,338 & 30,259 & 8,304 & 8,080 & $2,193^{1}$ & (1) & 501 & - \\
\hline 2000 & 49,198 & 29,963 & 8,337 & 8,214 & $2,044^{1}$ & (') & 641 & - \\
\hline 2001 & 50,005 & 30,427 & 8,391 & 8,400 & $2,125^{1}$ & $(1)$ & 662 & - \\
\hline 2002 & 50,443 & 30,426 & 8,434 & 8,981 & 1,980 & $(1)$ & 622 & - \\
\hline 2003 & 50,653 & 29,395 & 8,232 & 9,513 & 1,829 & 163 & 314 & 1,208 \\
\hline 2004 & 50,568 & 28,738 & 8,289 & 9,870 & 1,967 & 102 & 403 & 1,200 \\
\hline 2005 & 50,835 & 29,047 & 8,056 & 10,141 & 1,883 & 89 & 351 & 1,269 \\
\hline 2006 & 50,663 & 28,486 & 7,977 & 10,470 & 1,900 & 117 & 336 & 1,376 \\
\hline 2007 & 51,082 & 28,357 & 7,903 & 10,865 & 2,080 & 134 & 398 & 1,345 \\
\hline 2008 & 50,768 & 27,923 & 8,002 & 11,093 & 1,903 & 86 & 440 & 1,322 \\
\hline 2009 & 51,144 & 28,030 & 7,839 & 11,418 & 1,903 & 154 & 444 & 1,356 \\
\hline \multirow[t]{2}{*}{2010} & 51,719 & 27,675 & 7,757 & 12,066 & 2,145 & 186 & 378 & 1,512 \\
\hline & \multicolumn{8}{|c|}{ Percentage distribution } \\
\hline 1990 & 100.0 & 67.3 & 16.7 & 11.7 & $3.0^{1}$ & $(1)$ & 0.9 & $\overline{-}$ \\
\hline 1991 & 100.0 & 67.0 & 17.0 & 11.9 & $3.2^{1}$ & $(1)$ & 0.8 & - \\
\hline 1992 & 100.0 & 66.5 & 17.1 & 12.1 & $3.3^{1}$ & $(1)$ & 0.8 & - \\
\hline 1993 & 100.0 & 66.8 & 16.8 & 12.1 & $3.3^{1}$ & $(1)$ & 0.8 & - \\
\hline 1994 & 100.0 & 65.4 & 17.1 & 13.7 & $2.4^{1}$ & $(1)$ & 0.8 & - \\
\hline 1995 & 100.0 & 65.1 & 17.2 & 14.3 & $2.3^{1}$ & $(1)$ & 0.7 & - \\
\hline 1996 & 100.0 & 63.1 & 16.9 & 14.8 & $4.1^{1}$ & $(1)$ & 1.2 & - \\
\hline 1997 & 100.0 & 62.5 & 17.3 & 15.1 & $3.9^{1}$ & $(1)$ & 1.2 & - \\
\hline 1998 & 100.0 & 61.8 & 17.4 & 15.7 & $4.0^{1}$ & $(1)$ & 1.1 & - \\
\hline 1999 & 100.0 & 61.3 & 16.8 & 16.4 & $4.4^{1}$ & $(1)$ & 1.0 & - \\
\hline 2000 & 100.0 & 60.9 & 16.9 & 16.7 & $4.2^{1}$ & (') & 1.3 & - \\
\hline 2001 & 100.0 & 60.8 & 16.8 & 16.8 & $4.2^{1}$ & $\left({ }^{1}\right)$ & 1.3 & - \\
\hline 2002 & 100.0 & 60.3 & 16.7 & 17.8 & $3.9^{1}$ & $\left({ }^{1}\right)$ & 1.2 & - \\
\hline 2003 & 100.0 & 58.0 & 16.3 & 18.8 & 3.6 & 0.3 & 0.6 & 2.4 \\
\hline 2004 & 100.0 & 56.8 & 16.4 & 19.5 & 3.9 & 0.2 & 0.8 & 2.4 \\
\hline 2005 & 100.0 & 57.1 & 15.8 & 19.9 & 3.7 & 0.2 & 0.7 & 2.5 \\
\hline 2006 & 100.0 & 56.2 & 15.7 & 20.7 & 3.8 & 0.2 & 0.7 & 2.7 \\
\hline 2007 & 100.0 & 55.5 & 15.5 & 21.3 & 4.1 & 0.3 & 0.8 & 2.6 \\
\hline 2008 & 100.0 & 55.0 & 15.8 & 21.9 & 3.7 & 0.2 & 0.9 & 2.6 \\
\hline 2009 & 100.0 & 54.8 & 15.3 & 22.3 & 3.7 & 0.3 & 0.9 & 2.7 \\
\hline 2010 & 100.0 & 53.5 & 15.0 & 23.3 & 4.1 & 0.4 & 0.7 & 2.9 \\
\hline
\end{tabular}

- Not available.

1 From 1990 through 2002, data on Asian and Pacific Islander students were not reported separately; therefore, Native Hawaiian/Pacific Islander students are included with Asian students during this period.

NOTE: Race categories exclude persons of Hispanic ethnicity. Totals include other race/ethnicity categories not shown separately. Detail may not sum to totals because of rounding. Prior to 2003, respondents were not allowed to choose more than one race. For more information on the Current Population Survey (CPS), see Appendix B - Guide to Sources. For more information on race/ethnicity, see Appendix C - Commonly Used Measures. SOURCE: U.S. Department of Commerce, Census Bureau, Current Population Survey (CPS), October Supplement, 1990-2010. 
This indicator continues on page 142. 
Racial/Ethnic Enrollment in Public Schools

Table A-6-2. Number of public school students enrolled in prekindergarten through 12th grade, by race/ethnicity and region: Selected years, October 1990-October 2010

[Numbers in thousands]

\begin{tabular}{|c|c|c|c|c|c|c|c|c|}
\hline $\begin{array}{l}\text { Region and } \\
\text { October of year }\end{array}$ & Total & White & Black & Hispanic & Asian & $\begin{array}{r}\text { Native } \\
\text { Hawaiian/ } \\
\text { Pacific } \\
\text { Islander } \\
\end{array}$ & $\begin{array}{c}\text { American } \\
\text { Indian/ } \\
\text { Alaska } \\
\text { Native } \\
\end{array}$ & $\begin{array}{r}\text { Two or more } \\
\text { races }\end{array}$ \\
\hline \multicolumn{9}{|l|}{ Northeast } \\
\hline 1990 & 7,717 & 5,652 & 1,032 & 777 & $197^{1}$ & (') & $23 !$ & - \\
\hline 1995 & 8,350 & 5,877 & 1,254 & 972 & $177^{1}$ & (') & $14 !$ & - \\
\hline 2000 & 8,753 & 5,930 & 1,361 & 1,024 & 3991 & (') & 40 & - \\
\hline 2001 & 8,741 & 5,850 & 1,375 & 1,078 & $377^{1}$ & (') & 61 & - \\
\hline 2002 & 8,978 & 6,022 & 1,372 & 1,217 & $341^{1}$ & (1) & 26 & - \\
\hline 2003 & 8,895 & 5,746 & 1,429 & 1,237 & 321 & $\ddagger$ & $17 !$ & 142 \\
\hline 2004 & 8,742 & 5,534 & 1,385 & 1,223 & 442 & $7 !$ & $18 !$ & 133 \\
\hline 2005 & 8,876 & 5,600 & 1,361 & 1,319 & 449 & $7 !$ & $11 !$ & 128 \\
\hline 2006 & 8,648 & 5,464 & 1,305 & 1,348 & 379 & $\ddagger$ & $24 !$ & 128 \\
\hline 2007 & 8,535 & 5,463 & 1,135 & 1,305 & 484 & $\ddagger$ & $24 !$ & 121 \\
\hline 2008 & 8,334 & 5,003 & 1,236 & 1,416 & 494 & - & $9 !$ & 176 \\
\hline 2009 & 8,471 & 5,132 & 1,222 & 1,523 & 416 & $\ddagger$ & $6 !$ & 171 \\
\hline 2010 & 8,316 & 4,880 & 1,218 & 1,538 & 464 & $\ddagger$ & $\ddagger$ & 203 \\
\hline \multicolumn{9}{|l|}{ Midwest } \\
\hline 1990 & 10,843 & 8,848 & 1,430 & 295 & $131^{1}$ & (') & 114 & - \\
\hline 1995 & 11,286 & 8,900 & 1,614 & 518 & $107^{1}$ & (1) & 67 & - \\
\hline 2000 & 11,412 & 8,671 & 1,774 & 628 & $236^{1}$ & (1) & 103 & - \\
\hline 2001 & 11,685 & 8,967 & 1,755 & 574 & $246^{1}$ & (') & 142 & - \\
\hline 2002 & 11,516 & 8,660 & 1,699 & 737 & $311^{1}$ & (') & 109 & - \\
\hline 2003 & 11,143 & 8,271 & 1,584 & 738 & 231 & $22 !$ & 51 & 246 \\
\hline 2004 & 11,152 & 8,244 & 1,551 & 766 & 250 & $3 !$ & 61 & 277 \\
\hline 2005 & 11,057 & 8,142 & 1,558 & 818 & 200 & $2 !$ & 65 & 272 \\
\hline 2006 & 11,091 & 8,055 & 1,479 & 894 & 305 & $7 !$ & 62 & 288 \\
\hline 2007 & 11,146 & 7,984 & 1,480 & 974 & 291 & $14 !$ & 72 & 331 \\
\hline 2008 & 11,266 & 7,991 & 1,518 & 1,098 & 287 & - & 54 & 319 \\
\hline 2009 & 11,147 & 7,940 & 1,466 & 1,058 & 288 & $\ddagger$ & 86 & 307 \\
\hline 2010 & 11,009 & 7,655 & 1,458 & 1,119 & 284 & $\ddagger$ & 104 & 376 \\
\hline
\end{tabular}

See notes at end of table. 
Table A-6-2. Number of public school students enrolled in prekindergarten through 12th grade, by race/ethnicity and region: Selected years, October 1990-October 2010-Continued

[Numbers in thousands]

\begin{tabular}{|c|c|c|c|c|c|c|c|c|}
\hline $\begin{array}{l}\text { Region and } \\
\text { October of year }\end{array}$ & Total & White & Black & Hispanic & Asian & $\begin{array}{r}\text { Native } \\
\text { Hawaiian/ } \\
\text { Pacific } \\
\text { Islander } \\
\end{array}$ & $\begin{array}{r}\text { American } \\
\text { Indian/ } \\
\text { Alaska } \\
\text { Native } \\
\end{array}$ & $\begin{array}{r}\text { Two or more } \\
\text { races } \\
\end{array}$ \\
\hline \multicolumn{9}{|l|}{ South } \\
\hline 1990 & 15,144 & 8,983 & 4,226 & 1,604 & $175^{1}$ & (') & 105 & - \\
\hline 1995 & 17,144 & 10,044 & 4,669 & 2,107 & $165^{1}$ & (1) & 101 & - \\
\hline 2000 & 17,091 & 9,314 & 4,493 & 2,735 & $368^{1}$ & (1) & 181 & - \\
\hline 2001 & 17,336 & 9,507 & 4,521 & 2,745 & $429^{1}$ & (') & 134 & - \\
\hline 2002 & 17,557 & 9,458 & 4,643 & 2,956 & $325^{1}$ & (1) & 176 & - \\
\hline 2003 & 18,309 & 9,757 & 4,578 & 3,119 & 374 & $\ddagger$ & 95 & 378 \\
\hline 2004 & 18,498 & 9,767 & 4,616 & 3,152 & 432 & $15 !$ & 119 & 397 \\
\hline 2005 & 18,432 & 9,644 & 4,480 & 3,414 & 340 & $8 !$ & 111 & 434 \\
\hline 2006 & 18,467 & 9,398 & 4,558 & 3,555 & 344 & $\ddagger$ & 127 & 482 \\
\hline 2007 & 18,898 & 9,530 & 4,656 & 3,637 & 442 & $17 !$ & 163 & 453 \\
\hline 2008 & 18,860 & 9,715 & 4,540 & 3,657 & 396 & $12 !$ & 162 & 378 \\
\hline 2009 & 19,177 & 9,591 & 4,488 & 3,919 & 551 & 55 & 169 & 405 \\
\hline 2010 & 19,603 & 9,699 & 4,432 & 4,345 & 501 & $\ddagger$ & 147 & 458 \\
\hline \multicolumn{9}{|l|}{ West } \\
\hline 1990 & 9,383 & 5,508 & 514 & 2,378 & $801^{1}$ & (') & 165 & - \\
\hline 1995 & 10,539 & 5,967 & 595 & 3,154 & $616^{1}$ & (') & 126 & - \\
\hline 2000 & 11,942 & 6,048 & 708 & 3,827 & $1,041^{1}$ & (') & 318 & - \\
\hline 2001 & 12,243 & 6,102 & 739 & 4,003 & $1,073^{1}$ & (') & 326 & - \\
\hline 2002 & 12,391 & 6,286 & 721 & 4,070 & $1,004^{1}$ & (') & 310 & - \\
\hline 2003 & 12,306 & 5,621 & 641 & 4,420 & 903 & 128 & 150 & 443 \\
\hline 2004 & 12,176 & 5,193 & 736 & 4,729 & 842 & 78 & 205 & 393 \\
\hline 2005 & 12,470 & 5,661 & 657 & 4,590 & 893 & 71 & 163 & 434 \\
\hline 2006 & 12,457 & 5,569 & 634 & 4,673 & 873 & 107 & 123 & 478 \\
\hline 2007 & 12,503 & 5,380 & 632 & 4,949 & 863 & 100 & 140 & 440 \\
\hline 2008 & 12,308 & 5,214 & 707 & 4,922 & 727 & 74 & 214 & 449 \\
\hline 2009 & 12,350 & 5,367 & 664 & 4,919 & 649 & 95 & 183 & 474 \\
\hline 2010 & 12,791 & 5,440 & 650 & 5,065 & 896 & 148 & 117 & 476 \\
\hline
\end{tabular}

- Not available.

! Interpret with caution. The coefficient of variation (CV) for this estimate is 30 percent or greater.

$\ddagger$ Reporting standards not met. Either there are too few cases or the coefficient of variation (CV) for this estimate is 50 percent or greater.

1 From 1990 through 2002, Asian and Native Hawaiian/Pacific Islander students were not reported separately; therefore, Native Hawaiian/Pacific Islander students are included with Asian students during this period.

NOTE: Race categories exclude persons of Hispanic ethnicity. Totals include other race/ethnicity categories not shown separately. Detail may not sum to totals because of rounding. Prior to 2003, respondents were not allowed to choose more than one race. For more information on the Current Population Survey (CPS), see Appendix B - Guide to Sources. For more information on race/ethnicity, see Appendix C - Commonly Used Measures. SOURCE: U.S. Department of Commerce, Census Bureau, Current Population Survey (CPS), October Supplement, selected years, $1990-2010$. 
Racial/Ethnic Enrollment in Public Schools

Table A-6-3. Percentage distribution of public school students enrolled in prekindergarten through 12th grade, by race/ethnicity and region: Selected years, October 1990-October 2010

\begin{tabular}{|c|c|c|c|c|c|c|c|c|}
\hline $\begin{array}{l}\text { Region and } \\
\text { October of year }\end{array}$ & Total & White & Black & Hispanic & Asian & $\begin{array}{r}\text { Native } \\
\text { Hawaiian/ } \\
\text { Pacific } \\
\text { Islander } \\
\end{array}$ & $\begin{array}{c}\text { American } \\
\text { Indian/ } \\
\text { Alaska } \\
\text { Native } \\
\end{array}$ & $\begin{array}{r}\text { Two or more } \\
\text { races } \\
\end{array}$ \\
\hline \multicolumn{9}{|l|}{ Northeast } \\
\hline 1990 & 100.0 & 73.2 & 13.4 & $10.1 !$ & $\ddagger^{1}$ & ( 1 ) & $\ddagger$ & - \\
\hline 1995 & 100.0 & 70.4 & 15.0 & 11.6 & $\ddagger^{1}$ & (') & $\ddagger$ & - \\
\hline 2000 & 100.0 & 67.7 & 15.6 & 11.7 & $4.6 !^{1}$ & (') & $0.5 !$ & - \\
\hline 2001 & 100.0 & 66.9 & 15.7 & 12.3 & $4.3 !^{1}$ & (') & $0.7 !$ & - \\
\hline 2002 & 100.0 & 67.1 & 15.3 & 13.6 & $3.8 !^{1}$ & (') & $0.3 !$ & - \\
\hline 2003 & 100.0 & 64.6 & 16.1 & 13.9 & $3.6 !$ & $\ddagger$ & $0.2 !$ & 1.6 \\
\hline 2004 & 100.0 & 63.3 & 15.8 & 14.0 & $5.1 !$ & $\ddagger$ & $0.2 !$ & 1.5 \\
\hline 2005 & 100.0 & 63.1 & 15.3 & 14.9 & $5.1 !$ & $\ddagger$ & $0.1 !$ & 1.4 \\
\hline 2006 & 100.0 & 63.2 & 15.1 & 15.6 & $4.4 !$ & $\ddagger$ & $0.3 !$ & 1.5 \\
\hline 2007 & 100.0 & 64.0 & 13.3 & 15.3 & $5.7 !$ & $\ddagger$ & $0.3 !$ & 1.4 \\
\hline 2008 & 100.0 & 60.0 & 14.8 & 17.0 & $5.9 !$ & - & $0.1 !$ & 2.1 \\
\hline 2009 & 100.0 & 60.6 & 14.4 & 18.0 & $4.9 !$ & $\ddagger$ & $0.1 !$ & 2.0 \\
\hline 2010 & 100.0 & 58.7 & 14.6 & 18.5 & 5.6 & $\ddagger$ & $\ddagger$ & 2.4 \\
\hline \multicolumn{9}{|l|}{ Midwest } \\
\hline 1990 & 100.0 & 81.6 & 13.2 & 2.7 & $1.2^{1}$ & (') & 1 & - \\
\hline 1995 & 100.0 & 78.9 & 14.3 & 4.6 & $0.9^{1}$ & (1) & 0.6 & - \\
\hline 2000 & 100.0 & 76.0 & 15.5 & 5.5 & $2.1^{1}$ & (') & 0.9 & - \\
\hline 2001 & 100.0 & 76.7 & 15.0 & 4.9 & $2.1^{1}$ & (1) & 1.2 & - \\
\hline 2002 & 100.0 & 75.2 & 14.8 & 6.4 & $2.7^{1}$ & (') & 0.9 & - \\
\hline 2003 & 100.0 & 74.2 & 14.2 & 6.6 & 2.1 & $0.2 !$ & 0.5 & 2.2 \\
\hline 2004 & 100.0 & 73.9 & 13.9 & 6.9 & 2.2 & $\ddagger$ & 0.5 & 2.5 \\
\hline 2005 & 100.0 & 73.6 & 14.1 & 7.4 & 1.8 & $\ddagger$ & 0.6 & 2.5 \\
\hline 2006 & 100.0 & 72.6 & 13.3 & 8.1 & 2.7 & $0.1 !$ & 0.6 & 2.6 \\
\hline 2007 & 100.0 & 71.6 & 13.3 & 8.7 & 2.6 & $0.1 !$ & 0.6 & 3.0 \\
\hline 2008 & 100.0 & 70.9 & 13.5 & 9.7 & 2.5 & - & 0.5 & 2.8 \\
\hline 2009 & 100.0 & 71.2 & 13.1 & 9.5 & 2.6 & $\ddagger$ & 0.8 & 2.8 \\
\hline 2010 & 100.0 & 69.5 & 13.2 & 10.2 & 2.6 & $\ddagger$ & 0.9 & 3.4 \\
\hline
\end{tabular}

See notes at end of table. 
Table A-6-3. Percentage distribution of public school students enrolled in prekindergarten through 12th grade, by race/ethnicity and region: Selected years, October 1990-October 2010-Continued

\begin{tabular}{|c|c|c|c|c|c|c|c|c|}
\hline $\begin{array}{l}\text { Region and } \\
\text { October of year }\end{array}$ & Total & White & Black & Hispanic & Asian & $\begin{array}{r}\text { Native } \\
\text { Hawaiian/ } \\
\text { Pacific } \\
\text { Islander }\end{array}$ & $\begin{array}{c}\text { American } \\
\text { Indian/ } \\
\text { Alaska } \\
\text { Native } \\
\end{array}$ & $\begin{array}{r}\text { Two or more } \\
\text { races } \\
\end{array}$ \\
\hline \multicolumn{9}{|l|}{ South } \\
\hline 1990 & 100.0 & 59.3 & 27.9 & 10.6 & $1.2^{1}$ & (') & 0.7 & - \\
\hline 1995 & 100.0 & 58.6 & 27.2 & 12.3 & $1.0^{1}$ & (1) & 0.6 & - \\
\hline 2000 & 100.0 & 54.5 & 26.3 & 16.0 & $2.2^{1}$ & (') & 1.1 & - \\
\hline 2001 & 100.0 & 54.8 & 26.1 & 15.8 & $2.5^{1}$ & (') & 0.8 & - \\
\hline 2002 & 100.0 & 53.9 & 26.4 & 16.8 & $1.8^{1}$ & (1) & 1.0 & - \\
\hline 2003 & 100.0 & 53.3 & 25.0 & 17.0 & 2.0 & $\ddagger$ & 0.5 & 2.1 \\
\hline 2004 & 100.0 & 52.8 & 25.0 & 17.0 & 2.3 & $0.1 !$ & 0.6 & 2.1 \\
\hline 2005 & 100.0 & 52.3 & 24.3 & 18.5 & 1.8 & $\ddagger$ & 0.6 & 2.4 \\
\hline 2006 & 100.0 & 50.9 & 24.7 & 19.3 & 1.9 & $\ddagger$ & 0.7 & 2.6 \\
\hline 2007 & 100.0 & 50.4 & 24.6 & 19.2 & 2.3 & $0.1 !$ & 0.9 & 2.4 \\
\hline 2008 & 100.0 & 51.5 & 24.1 & 19.4 & 2.1 & $0.1 !$ & 0.9 & 2.0 \\
\hline 2009 & 100.0 & 50.0 & 23.4 & 20.4 & 2.9 & 0.3 & 0.9 & 2.1 \\
\hline 2010 & 100.0 & 49.5 & 22.6 & 22.2 & 2.6 & $\ddagger$ & 0.7 & 2.3 \\
\hline \multicolumn{9}{|l|}{ West } \\
\hline 1990 & 100.0 & 58.7 & 5.5 & 25.3 & $8.5^{1}$ & (') & 1.8 & - \\
\hline 1995 & 100.0 & 56.6 & 5.6 & 29.9 & $5.8^{1}$ & (1) & 1.2 & - \\
\hline 2000 & 100.0 & 50.6 & 5.9 & 32.0 & $8.7^{1}$ & (') & 2.7 & - \\
\hline 2001 & 100.0 & 49.8 & 6.0 & 32.7 & $8.8^{1}$ & (1) & 2.7 & - \\
\hline 2002 & 100.0 & 50.7 & 5.8 & 32.8 & $8.1^{1}$ & (1) & 2.5 & - \\
\hline 2003 & 100.0 & 45.7 & 5.2 & 35.9 & 7.3 & 1.0 & 1.2 & 3.6 \\
\hline 2004 & 100.0 & 42.6 & 6.0 & 38.8 & 6.9 & 0.6 & 1.7 & 3.2 \\
\hline 2005 & 100.0 & 45.4 & 5.3 & 36.8 & 7.2 & 0.6 & 1.3 & 3.5 \\
\hline 2006 & 100.0 & 44.7 & 5.1 & 37.5 & 7.0 & 0.9 & 1.0 & 3.8 \\
\hline 2007 & 100.0 & 43.0 & 5.1 & 39.6 & 6.9 & 0.8 & 1.1 & 3.5 \\
\hline 2008 & 100.0 & 42.4 & 5.7 & 40.0 & 5.9 & 0.6 & 1.7 & 3.6 \\
\hline 2009 & 100.0 & 43.5 & 5.4 & 39.8 & 5.3 & 0.8 & 1.5 & 3.8 \\
\hline$\underline{2010}$ & 100.0 & 42.5 & 5.1 & 39.6 & 7.0 & 1.2 & 0.9 & 3.7 \\
\hline
\end{tabular}

- Not available.

! Interpret with caution. The coefficient of variation (CV) for this estimate is 30 percent or greater.

$\ddagger$ Reporting standards not met. Either there are too few cases or the coefficient of variation (CV) for this estimate is 50 percent or greater.

1 From 1990 through 2002, Asian and Native Hawaiian/Pacific Islander students were not reported separately; therefore, Native Hawaiian/Pacific Islander students are included with Asian students during this period.

NOTE: Race categories exclude persons of Hispanic ethnicity. Totals include other race/ethnicity categories not shown separately. Detail may not sum to totals because of rounding. Prior to 2003, respondents were not allowed to choose more than one race. For more information on the Current Population Survey (CPS), see Appendix B - Guide to Sources. For more information on race/ethnicity, see Appendix C - Commonly Used Measures. SOURCE: U.S. Department of Commerce, Census Bureau, Current Population Survey (CPS), October Supplement, selected years, $1990-2010$. 
Racial/Ethnic Enrollment in Public Schools

Table A-6-4. Percentage distribution of public school students enrolled in prekindergarten through 12th grade, by race/ethnicity and state or jurisdiction: 2010

\begin{tabular}{|c|c|c|c|c|c|c|c|c|}
\hline State or jurisdiction & Total & White & Black & Hispanic & Asian & $\begin{array}{r}\text { Native } \\
\text { Hawaiian/ } \\
\text { Pacific } \\
\text { Islander }\end{array}$ & $\begin{array}{r}\text { American } \\
\text { Indian/ } \\
\text { Alaska } \\
\text { Native }\end{array}$ & $\begin{array}{c}\text { Two or } \\
\text { more } \\
\text { races }\end{array}$ \\
\hline United States & 100.0 & 51.7 & 15.3 & 24.0 & 4.2 & 0.2 & 0.8 & 3.5 \\
\hline Alabama & 100.0 & 56.8 & 34.3 & 5.2 & 0.9 & - & 0.6 & 2.0 \\
\hline Alaska & 100.0 & 49.9 & 3.4 & 8.3 & 5.2 & $1.0 !$ & 20.1 & 11.9 \\
\hline Arizona & 100.0 & 41.2 & 4.6 & 43.5 & 2.1 & $0.2 !$ & 5.3 & 2.8 \\
\hline Arkansas & 100.0 & 63.5 & 21.5 & 10.2 & 1.2 & 0.3 & 0.6 & 2.6 \\
\hline California & 100.0 & 25.3 & 5.9 & 53.7 & 10.4 & 0.4 & 0.3 & 3.8 \\
\hline Colorado & 100.0 & 56.5 & 4.2 & 32.0 & 2.4 & $\ddagger$ & 0.4 & 4.3 \\
\hline Connecticut & 100.0 & 60.0 & 12.0 & 20.8 & 3.4 & $\ddagger$ & $\ddagger$ & 3.3 \\
\hline Delaware & 100.0 & 47.4 & 30.7 & 15.1 & 2.6 & - & - & 4.2 \\
\hline District of Columbia & 100.0 & 5.9 & 76.9 & 14.1 & $1.2 !$ & - & - & $1.8 !$ \\
\hline Florida & 100.0 & 43.7 & 22.8 & 27.7 & 2.3 & $0.1 !$ & 0.2 & 2.8 \\
\hline Georgia & 100.0 & 44.2 & 37.6 & 12.1 & 3.2 & \# & 0.1 & 2.6 \\
\hline Hawaii & 100.0 & 11.5 & 1.9 & 15.5 & 26.0 & 14.9 & - & 30.2 \\
\hline Idaho & 100.0 & 77.3 & $0.5 !$ & 16.7 & 1.5 & $\ddagger$ & 1.1 & 2.8 \\
\hline Illinois & 100.0 & 51.5 & 17.9 & 23.7 & 3.9 & $\#$ & 0.1 & 2.8 \\
\hline Indiana & 100.0 & 73.5 & 11.8 & 9.3 & 1.6 & $\ddagger$ & $0.1 !$ & 3.5 \\
\hline lowa & 100.0 & 81.1 & 4.8 & 8.4 & 1.9 & - & $0.2 !$ & 3.5 \\
\hline Kansas & 100.0 & 68.1 & 6.5 & 17.5 & 2.4 & $\#$ & 1.0 & 4.4 \\
\hline Kentucky & 100.0 & 80.9 & 10.0 & 4.9 & 1.0 & $\#$ & $0.2 !$ & 2.9 \\
\hline Louisiana & 100.0 & 47.4 & 44.2 & 4.2 & 1.1 & $\ddagger$ & 0.8 & 2.0 \\
\hline Maine & 100.0 & 89.8 & 2.7 & 1.6 & 1.9 & - & $0.8 !$ & 3.2 \\
\hline Maryland & 100.0 & 43.8 & 34.9 & 11.2 & 5.3 & $\ddagger$ & $0.1 !$ & 4.4 \\
\hline Massachusetts & 100.0 & 66.6 & 8.9 & 15.3 & 5.5 & \# & $0.1 !$ & 3.0 \\
\hline Michigan & 100.0 & 67.6 & 17.6 & 7.0 & 2.7 & \# & 0.6 & 4.2 \\
\hline Minnesota & 100.0 & 72.9 & 7.3 & 8.0 & 5.3 & - & 1.2 & 5.2 \\
\hline Mississippi & 100.0 & 43.9 & 50.6 & 2.7 & 0.7 & - & $0.4 !$ & 1.5 \\
\hline
\end{tabular}

See notes at end of table. 
Table A-6-4. Percentage distribution of public school students enrolled in prekindergarten through 12th grade, by race/ethnicity and state or jurisdiction: 2010-Continued

\begin{tabular}{|c|c|c|c|c|c|c|c|c|}
\hline$\underline{\text { State or jurisdiction }}$ & Total & White & Black & Hispanic & Asian & $\begin{array}{r}\text { Native } \\
\text { Hawaiian/ } \\
\text { Pacific } \\
\text { Islander } \\
\end{array}$ & $\begin{array}{r}\text { American } \\
\text { Indian/ } \\
\text { Alaska } \\
\text { Native } \\
\end{array}$ & $\begin{array}{c}\text { Two or } \\
\text { more } \\
\text { races }\end{array}$ \\
\hline United States & 100.0 & 51.7 & 15.3 & 24.0 & 4.2 & 0.2 & 0.8 & 3.5 \\
\hline Missouri & 100.0 & 73.9 & 16.0 & 5.3 & 1.3 & 0.1 & $0.2 !$ & 3.1 \\
\hline Montana & 100.0 & 80.1 & $0.8 !$ & 5.0 & $0.5 !$ & - & 10.2 & 3.6 \\
\hline Nebraska & 100.0 & 71.9 & 6.2 & 15.6 & 1.4 & $0.1 !$ & 1.0 & 3.7 \\
\hline Nevada & 100.0 & 38.8 & 9.6 & 39.3 & 5.7 & 0.7 & 1.0 & 4.8 \\
\hline New Hampshire & 100.0 & 89.0 & 1.1 & 4.3 & 2.5 & $\ddagger$ & $\ddagger$ & 2.4 \\
\hline New Jersey & 100.0 & 49.7 & 15.6 & 23.4 & 7.9 & $\#$ & $0.2 !$ & 2.7 \\
\hline New Mexico & 100.0 & 25.6 & 1.1 & 59.0 & 0.8 & - & 11.0 & 2.3 \\
\hline New York & 100.0 & 47.8 & 17.6 & 24.1 & 7.0 & $\#$ & 0.2 & 2.8 \\
\hline North Carolina & 100.0 & 53.6 & 25.7 & 13.0 & 2.4 & 0.1 & 1.1 & 3.7 \\
\hline North Dakota & 100.0 & 83.4 & $1.4 !$ & 3.0 & $1.5 !$ & - & 6.6 & 4.1 \\
\hline Ohio & 100.0 & 74.3 & 15.2 & 4.5 & 1.6 & \# & 0.1 & 4.1 \\
\hline Oklahoma & 100.0 & 55.6 & 8.5 & 13.4 & 1.4 & $0.2 !$ & 9.1 & 11.7 \\
\hline Oregon & 100.0 & 65.8 & 2.5 & 20.7 & 3.7 & 0.4 & 1.6 & 5.0 \\
\hline Pennsylvania & 100.0 & 69.9 & 14.2 & 9.4 & 2.8 & $\#$ & $0.1 !$ & 3.3 \\
\hline Rhode Island & 100.0 & 63.2 & 7.1 & 21.1 & 3.0 & - & $\ddagger$ & 4.8 \\
\hline South Carolina & 100.0 & 52.1 & 36.3 & 7.1 & 0.9 & $\ddagger$ & $0.1 !$ & 3.3 \\
\hline South Dakota & 100.0 & 73.7 & 1.6 & 4.6 & $0.9 !$ & - & 14.5 & 4.4 \\
\hline Tennessee & 100.0 & 66.1 & 22.8 & 6.7 & 1.6 & $\#$ & $0.1 !$ & 2.6 \\
\hline Texas & 100.0 & 31.8 & 12.7 & 49.9 & 3.2 & 0.1 & 0.2 & 1.9 \\
\hline Utah & 100.0 & 74.8 & 1.3 & 17.2 & 1.4 & 1.0 & 1.1 & 2.9 \\
\hline Vermont & 100.0 & 91.3 & $3.3 !$ & 1.9 & $1.4 !$ & - & $\ddagger$ & 2.1 \\
\hline Virginia & 100.0 & 55.3 & 23.6 & 10.7 & 5.0 & $0.1 !$ & 0.1 & 4.7 \\
\hline Washington & 100.0 & 60.5 & 3.9 & 19.2 & 6.7 & 0.9 & 1.6 & 7.2 \\
\hline West Virginia & 100.0 & 90.6 & 2.8 & 2.0 & $0.6 !$ & - & $\ddagger$ & 3.9 \\
\hline Wisconsin & 100.0 & 73.9 & 9.0 & 9.8 & 3.1 & $\#$ & 0.9 & 3.1 \\
\hline Wyoming & 100.0 & 79.6 & $\ddagger$ & 13.4 & $1.3 !$ & - & 3.7 & $1.6 !$ \\
\hline
\end{tabular}

- Notavailable.

\# Rounds to zero.

! Interpret with caution. The coefficient of variation (CV) for this estimate is 30 percent or greater.

‡ Reporting standards not met. Either there are too few cases or the coefficient of variation (CV) for this estimate is 50 percent or greater. NOTE: The 2010 American Community Survey (ACS) includes noninstitutionalized and institutionalized group quarters. Due to this and other methodological differences between the Current Population Survey (CPS) and ACS, enrollment estimates from the two surveys are not directly comparable. For more information on the ACS, see Appendix B - Guide to Sources. Totals include other race/ethnicity categories not shown separately. Race categories exclude persons of Hispanic ethnicity. Detail may not sum to totals because of rounding. For more information on race/ ethnicity and region, see Appendix C - Commonly Used Measures.

SOURCE: U.S. Department of Commerce, Census Bureau, American Community Survey (ACS), 2010. 
Table A-7-1. Percentage distribution of 5- to 17-year-olds, by race/ethnicity and selected family characteristics:

\section{Selected years, 1990-2011}

\begin{tabular}{|c|c|c|c|c|c|c|c|c|}
\hline Family characteristic & 1990 & 2000 & 2006 & 2007 & 2008 & 2009 & 2010 & 2011 \\
\hline \multicolumn{9}{|l|}{ Total U.S. population } \\
\hline \multicolumn{9}{|l|}{ Parents' highest level of education } \\
\hline Less than high school completion' & 14.4 & 12.0 & 11.2 & 10.8 & 10.6 & 10.5 & 10.8 & 10.7 \\
\hline High school diploma or equivalent & 33.3 & 27.6 & 24.7 & 24.6 & 24.0 & 23.7 & 23.2 & 23.4 \\
\hline Some college & 26.0 & 29.9 & 29.1 & 29.2 & 29.5 & 29.8 & 29.9 & 29.0 \\
\hline Bachelor's degree or higher & 26.3 & 30.5 & 35.0 & 35.3 & 35.9 & 36.1 & 36.1 & 36.9 \\
\hline \multicolumn{9}{|l|}{ Family type ${ }^{2}$} \\
\hline Two-parent household & 71.9 & 68.4 & 66.5 & 68.7 & 68.0 & 68.2 & 67.4 & 67.1 \\
\hline Mother-only household & 21.5 & 22.5 & 23.3 & 23.2 & 23.4 & 23.1 & 23.7 & 24.3 \\
\hline Father-only household & 3.2 & 4.2 & 4.7 & 3.7 & 3.9 & 3.8 & 3.9 & 4.0 \\
\hline \multicolumn{9}{|l|}{ Poverty status } \\
\hline Poor & 18.6 & 16.8 & 17.2 & 16.6 & 17.2 & 18.2 & 19.7 & 20.9 \\
\hline Near-poor & 20.8 & 21.4 & 20.9 & 21.1 & 20.8 & 21.3 & 21.2 & 21.3 \\
\hline Nonpoor & 60.7 & 61.7 & 61.9 & 62.4 & 62.0 & 60.5 & 59.1 & 57.7 \\
\hline \multicolumn{9}{|l|}{ Citizenship } \\
\hline U.S.-born & - & 95.2 & 95.0 & 94.9 & 95.0 & 95.5 & 95.4 & 95.6 \\
\hline Naturalized U.S. citizen & - & 0.6 & 0.8 & 0.8 & 0.9 & 0.9 & 0.9 & 0.9 \\
\hline Non-U.S. citizen & - & 4.2 & 4.2 & 4.3 & 4.1 & 3.6 & 3.7 & 3.4 \\
\hline \multicolumn{9}{|l|}{ Immigration status } \\
\hline $\begin{array}{l}\text { Born outside the } 50 \text { states } \\
\text { and the District of Columbia }\end{array}$ & - & 5.9 & 5.9 & 6.0 & 5.9 & 5.3 & 5.4 & 5.1 \\
\hline First generation & - & 14.8 & 17.9 & 18.1 & 18.1 & 18.4 & 19.0 & 20.0 \\
\hline Second generation or more & - & 79.3 & 76.2 & 75.8 & 76.0 & 76.3 & 75.5 & 74.8 \\
\hline \multicolumn{9}{|l|}{ Total White population } \\
\hline \multicolumn{9}{|l|}{ Parents' highest level of education } \\
\hline Less than high school completion' & 7.3 & 4.7 & 4.0 & 3.7 & 3.3 & 3.4 & 3.7 & 3.4 \\
\hline High school diploma or equivalent & 33.7 & 26.0 & 21.7 & 21.9 & 20.9 & 20.1 & 19.5 & 19.4 \\
\hline Some college & 27.7 & 31.4 & 30.6 & 30.5 & 30.7 & 30.7 & 31.0 & 29.7 \\
\hline Bachelor's degree or higher & 31.4 & 37.9 & 43.7 & 43.9 & 45.1 & 45.8 & 45.8 & 47.6 \\
\hline \multicolumn{9}{|l|}{ Family type ${ }^{2}$} \\
\hline Two-parent household & 79.6 & 76.5 & 74.6 & 76.4 & 75.7 & 76.1 & 75.6 & 75.1 \\
\hline Mother-only household & 15.2 & 16.0 & 16.4 & 16.3 & 16.7 & 16.2 & 16.4 & 16.9 \\
\hline Father-only household & 3.1 & 4.4 & 5.1 & 4.2 & 4.6 & 4.3 & 4.3 & 4.6 \\
\hline \multicolumn{9}{|l|}{ Poverty status } \\
\hline Poor & 10.9 & 9.5 & 9.9 & 9.5 & 9.7 & 10.4 & 11.4 & 12.0 \\
\hline Near-poor & 18.2 & 16.7 & 15.7 & 15.6 & 15.7 & 16.3 & 16.6 & 16.4 \\
\hline Nonpoor & 70.9 & 73.8 & 74.4 & 74.8 & 74.6 & 73.3 & 72.0 & 71.6 \\
\hline \multicolumn{9}{|l|}{ Citizenship } \\
\hline U.S.-born & - & 98.8 & 98.5 & 98.5 & 98.6 & 98.8 & 98.8 & 98.7 \\
\hline Naturalized U.S. citizen & - & $0.2 !$ & 0.4 & 0.4 & 0.4 & 0.5 & 0.5 & 0.4 \\
\hline Non-U.S. citizen & - & 1.0 & 1.1 & 1.1 & 1.0 & 0.7 & 0.8 & 0.9 \\
\hline \multicolumn{9}{|l|}{ Immigration status } \\
\hline $\begin{array}{l}\text { Born outside the } 50 \text { states } \\
\text { and the District of Columbia }\end{array}$ & - & 2.0 & 2.0 & 2.1 & 2.0 & 1.7 & 1.7 & 1.8 \\
\hline First generation & - & 5.7 & 5.9 & 6.2 & 6.1 & 5.8 & 5.3 & 6.3 \\
\hline Second generation or more & - & 92.3 & 92.1 & 91.7 & 91.9 & 92.5 & 92.9 & 91.9 \\
\hline
\end{tabular}


Table A-7-1. Percentage distribution of 5- to 17-year-olds, by race/ethnicity and selected family characteristics: Selected years, 1990-2011-Continued

\begin{tabular}{|c|c|c|c|c|c|c|c|c|}
\hline Family characteristic & 1990 & 2000 & 2006 & 2007 & 2008 & 2009 & 2010 & 2011 \\
\hline \multicolumn{9}{|l|}{ Total Black population } \\
\hline \multicolumn{9}{|l|}{ Parents' highest level of education } \\
\hline Less than high school completion' & 23.2 & 14.7 & 13.8 & 12.1 & 11.5 & 11.4 & 11.5 & 10.8 \\
\hline High school diploma or equivalent & 39.4 & 35.0 & 33.4 & 32.5 & 33.2 & 32.5 & 29.9 & 30.2 \\
\hline Some college & 26.3 & 34.6 & 31.5 & 34.8 & 34.9 & 35.8 & 37.5 & 36.9 \\
\hline Bachelor's degree or higher & 11.0 & 15.7 & 21.2 & 20.7 & 20.4 & 20.3 & 21.1 & 22.1 \\
\hline \multicolumn{9}{|l|}{ Family type ${ }^{2}$} \\
\hline Two-parent household & 39.0 & 38.0 & 34.8 & 39.0 & 37.5 & 36.8 & 37.3 & 35.5 \\
\hline Mother-only household & 48.3 & 47.2 & 50.2 & 48.4 & 48.7 & 49.4 & 49.5 & 51.8 \\
\hline Father-only household & 3.5 & 4.0 & 4.3 & 4.0 & 3.7 & 3.8 & 3.9 & 3.9 \\
\hline \multicolumn{9}{|l|}{ Poverty status } \\
\hline Poor & 40.9 & 32.1 & 34.0 & 31.3 & 32.6 & 32.9 & 33.6 & 36.9 \\
\hline Near-poor & 25.1 & 27.8 & 26.3 & 27.0 & 26.1 & 27.3 & 27.3 & 26.6 \\
\hline Nonpoor & 34.0 & 40.2 & 39.7 & 41.7 & 41.3 & 39.7 & 39.1 & 36.6 \\
\hline \multicolumn{9}{|l|}{ Citizenship } \\
\hline U.S.-born & - & 97.8 & 97.1 & 96.6 & 97.2 & 97.6 & 96.5 & 96.6 \\
\hline Naturalized U.S. citizen & - & $0.4 !$ & $0.4 !$ & 0.7 & 0.4 & 0.5 & 0.8 & 1.0 \\
\hline Non-U.S. citizen & - & 1.8 & 2.5 & 2.7 & 2.4 & 1.9 & 2.7 & 2.4 \\
\hline \multicolumn{9}{|l|}{ Immigration status } \\
\hline $\begin{array}{l}\text { Born outside the } 50 \text { states } \\
\text { and the District of Columbia }\end{array}$ & - & 2.9 & 3.3 & 3.9 & 3.4 & 2.6 & 3.7 & 3.7 \\
\hline First generation & - & 6.4 & 9.0 & 8.8 & 9.0 & 9.2 & 11.1 & 10.3 \\
\hline Second generation or more & - & 90.7 & 87.7 & 87.3 & 87.6 & 88.2 & 85.2 & 86.0 \\
\hline \multicolumn{9}{|l|}{ Total Hispanic population } \\
\hline \multicolumn{9}{|l|}{ Parents' highest level of education } \\
\hline Less than high school completion' & 46.8 & 40.6 & 33.1 & 32.7 & 32.3 & 30.9 & 30.7 & 30.3 \\
\hline High school diploma or equivalent & 27.3 & 28.3 & 29.2 & 28.9 & 29.4 & 29.8 & 29.8 & 30.6 \\
\hline Some college & 17.5 & 21.2 & 23.3 & 23.2 & 23.3 & 24.3 & 23.5 & 23.4 \\
\hline Bachelor's degree or higher & 8.4 & 9.8 & 14.4 & 15.2 & 15.0 & 15.0 & 16.0 & 15.7 \\
\hline \multicolumn{9}{|l|}{ Family type ${ }^{2}$} \\
\hline Two-parent household & 66.7 & 63.9 & 65.3 & 67.1 & 67.2 & 67.3 & 64.5 & 64.7 \\
\hline Mother-only household & 26.1 & 25.6 & 24.7 & 25.8 & 25.2 & 25.2 & 27.4 & 27.5 \\
\hline Father-only household & 2.5 & 3.9 & 3.7 & 2.3 & 2.4 & 2.5 & 2.9 & 2.9 \\
\hline \multicolumn{9}{|l|}{ Poverty status } \\
\hline Poor & 34.7 & 30.8 & 27.5 & 25.8 & 27.7 & 29.5 & 32.5 & 34.2 \\
\hline Near-poor & 30.9 & 33.8 & 32.7 & 34.1 & 31.9 & 31.3 & 29.8 & 30.3 \\
\hline Nonpoor & 34.4 & 35.4 & 39.9 & 40.1 & 40.4 & 39.1 & 37.8 & 35.5 \\
\hline \multicolumn{9}{|l|}{ Citizenship } \\
\hline U.S.-born & - & 83.0 & 85.6 & 86.6 & 87.2 & 88.6 & 89.5 & 90.3 \\
\hline Naturalized U.S. citizen & - & 1.1 & 1.1 & 1.2 & 1.4 & 1.0 & 1.0 & 1.0 \\
\hline Non-U.S. citizen & - & 15.9 & 13.3 & 12.3 & 11.5 & 10.4 & 9.5 & 8.6 \\
\hline \multicolumn{9}{|l|}{ Immigration status } \\
\hline $\begin{array}{l}\text { Born outside the } 50 \text { states } \\
\text { and the District of Columbia }\end{array}$ & - & 19.7 & 16.4 & 15.7 & 15.0 & 13.3 & 12.1 & 11.1 \\
\hline First generation & - & 50.4 & 52.7 & 52.2 & 51.1 & 52.1 & 52.7 & 52.1 \\
\hline Second generation or more & - & 29.9 & 30.8 & 32.1 & 33.9 & 34.6 & 35.2 & 36.8 \\
\hline
\end{tabular}

See notes at end of table. 
Table A-7-1. Percentage distribution of 5- to 17-year-olds, by race/ethnicity and selected family characteristics: Selected years, 1990-2011-Continued

\begin{tabular}{|c|c|c|c|c|c|c|c|c|}
\hline Family characteristic & 1990 & 2000 & 2006 & 2007 & 2008 & 2009 & 2010 & 2011 \\
\hline \multicolumn{9}{|l|}{ Total Asian population ${ }^{3}$} \\
\hline \multicolumn{9}{|l|}{ Parents' highest level of education } \\
\hline Less than high school completion' & - & - & 9.8 & 10.1 & 9.7 & 9.4 & 6.9 & 7.3 \\
\hline High school diploma or equivalent & - & - & 18.6 & 15.7 & 15.4 & 14.6 & 17.2 & 16.3 \\
\hline Some college & - & - & 16.8 & 13.3 & 13.3 & 15.0 & 15.7 & 16.4 \\
\hline Bachelor's degree or higher & - & - & 54.8 & 60.9 & 61.5 & 61.1 & 60.2 & 60.1 \\
\hline \multicolumn{9}{|l|}{ Family type ${ }^{2}$} \\
\hline Two-parent household & - & - & 82.3 & 84.7 & 83.0 & 82.0 & 82.0 & 85.3 \\
\hline Mother-only household & - & - & 9.8 & 10.0 & 11.0 & 11.4 & 12.3 & 10.2 \\
\hline Father-only household & - & - & 3.7 & 1.9 & 2.7 & 3.0 & 2.8 & 1.4 \\
\hline \multicolumn{9}{|l|}{ Poverty status } \\
\hline Poor & - & - & 12.4 & 14.1 & 14.2 & 15.7 & 14.3 & 13.7 \\
\hline Near-poor & - & - & 17.2 & 14.1 & 17.1 & 16.1 & 18.0 & 18.3 \\
\hline Nonpoor & - & - & 70.4 & 71.8 & 68.7 & 68.2 & 67.7 & 68.0 \\
\hline \multicolumn{9}{|l|}{ Citizenship } \\
\hline U.S.-born & - & - & 74.7 & 73.6 & 70.9 & 73.5 & 72.3 & 77.1 \\
\hline Naturalized U.S. citizen & - & - & 7.5 & 5.5 & 7.9 & 6.9 & 7.8 & 7.5 \\
\hline Non-U.S. citizen & - & - & 17.9 & 20.9 & 21.2 & 19.6 & 19.9 & 15.4 \\
\hline \multicolumn{9}{|l|}{ Immigration status } \\
\hline \multicolumn{9}{|l|}{ Born outside the 50 states } \\
\hline First generation & - & - & 67.3 & 64.3 & 61.9 & 63.2 & 61.5 & 66.6 \\
\hline Second generation or more & - & - & 5.8 & 7.8 & 8.0 & 8.8 & 8.8 & 8.3 \\
\hline \multicolumn{9}{|c|}{$\begin{array}{l}\text { Total Native Hawaiian/ } \\
\quad \text { Pacific Islander population }{ }^{3}\end{array}$} \\
\hline \multicolumn{9}{|l|}{ Parents' highest level of education } \\
\hline Less than high school completion' & - & - & $\ddagger$ & $6.2 !$ & $\ddagger$ & $\ddagger$ & $\ddagger$ & $10.8 !$ \\
\hline High school diploma or equivalent & - & - & $\ddagger$ & 25.5 & 21.7 & 26.7 & 25.6 & 39.2 \\
\hline Some college & - & - & $\ddagger$ & 45.2 & 37.9 & 32.4 & 39.7 & 22.8 \\
\hline Bachelor's degree or higher & - & - & $\ddagger$ & 23.1 & 33.8 & 36.5 & 31.5 & 27.1 \\
\hline \multicolumn{9}{|l|}{ Family type ${ }^{2}$} \\
\hline Two-parent household & - & - & $\ddagger$ & 67.7 & 63.8 & 72.0 & 73.0 & 73.7 \\
\hline Mother-only household & - & - & $\ddagger$ & $18.7 !$ & $18.4 !$ & 21.1 & 15.0 & 15.0 \\
\hline Father-only household & - & - & $\ddagger$ & $2.0 !$ & $\ddagger$ & $\ddagger$ & $\ddagger$ & $\ddagger$ \\
\hline \multicolumn{9}{|l|}{ Poverty status } \\
\hline Poor & - & - & $\ddagger$ & $16.7 !$ & $14.3 !$ & 21.8 & 25.3 & 31.9 \\
\hline Near-poor & - & - & $\ddagger$ & 25.1 & 32.3 & 29.2 & $22.1 !$ & 24.5 \\
\hline Nonpoor & - & - & $\ddagger$ & 58.2 & 53.5 & 49.0 & 52.6 & 43.6 \\
\hline \multicolumn{9}{|l|}{ Citizenship } \\
\hline U.S.-born & - & - & $\ddagger$ & 83.9 & 85.4 & 94.4 & 91.8 & 92.2 \\
\hline Naturalized U.S. citizen & - & - & $\ddagger$ & $\ddagger$ & $\ddagger$ & $\ddagger$ & $\ddagger$ & $\ddagger$ \\
\hline Non-U.S. citizen & - & - & $\ddagger$ & 12.2 & $13.4 !$ & $\ddagger$ & $6.6 !$ & $5.5 !$ \\
\hline \multicolumn{9}{|l|}{ Immigration status } \\
\hline Born outside the 50 states & & & & & & & & \\
\hline and the District of Columbia & - & - & $\ddagger$ & 25.4 & 21.3 & $15.0 !$ & $9.0 !$ & 12.9 \\
\hline First generation & - & - & $\ddagger$ & 43.6 & 42.7 & 50.3 & 52.2 & 54.1 \\
\hline Second generation or more & - & - & $\ddagger$ & 31.1 & 36.0 & 34.7 & 38.8 & 33.0 \\
\hline
\end{tabular}

See notes at end of table. 
Table A-7-1. Percentage distribution of 5- to 17-year-olds, by race/ethnicity and selected family characteristics: Selected years, 1990-2011-Continued

\begin{tabular}{|c|c|c|c|c|c|c|c|c|}
\hline Family characteristic & 1990 & 2000 & 2006 & 2007 & 2008 & 2009 & 2010 & 2011 \\
\hline \multicolumn{9}{|l|}{$\begin{array}{l}\text { Total American Indian/ } \\
\text { Alaska Native population }\end{array}$} \\
\hline \multicolumn{9}{|l|}{ Parents' highest level of education } \\
\hline Less than high school completion' & 24.3 & 18.0 & 11.6 & 8.8 & 11.4 & $7.8 !$ & $9.8 !$ & 10.7 \\
\hline High school diploma or equivalent & 29.9 & 39.1 & 34.2 & 35.5 & 27.0 & 25.9 & 29.6 & 31.6 \\
\hline Some college & 33.6 & 33.4 & 40.5 & 36.4 & 41.7 & 40.3 & 40.9 & 38.5 \\
\hline Bachelor's degree or higher & $12.2 !$ & $9.5 !$ & 13.8 & 19.3 & 20.0 & 26.0 & 19.7 & 19.3 \\
\hline \multicolumn{9}{|l|}{ Family type ${ }^{2}$} \\
\hline Two-parent household & 63.4 & 52.8 & 39.8 & 44.9 & 47.0 & 47.9 & 50.1 & 52.2 \\
\hline Mother-only household & 25.0 & 31.6 & 37.3 & 37.0 & 35.3 & 33.6 & 29.6 & 28.9 \\
\hline Father-only household & $\ddagger$ & $5.7 !$ & 11.7 & 6.4 & $5.2 !$ & 4.0 & 4.6 & $5.2 !$ \\
\hline \multicolumn{9}{|l|}{ Poverty status } \\
\hline Poor & 30.8 & 42.6 & 29.3 & 39.1 & 25.2 & 28.5 & 31.2 & 33.5 \\
\hline Near-poor & 29.9 & 29.3 & 32.6 & 23.9 & 29.5 & 25.0 & 29.5 & 30.9 \\
\hline Nonpoor & 39.3 & 28.0 & 38.1 & 37.1 & 45.2 & 46.5 & 39.3 & 35.6 \\
\hline \multicolumn{9}{|l|}{ Citizenship } \\
\hline U.S.-born & - & 100.0 & 96.9 & 99.7 & 99.9 & 100.0 & 99.3 & 98.9 \\
\hline Naturalized U.S. citizen & - & - & $\ddagger$ & $\ddagger$ & \# & $\#$ & $\ddagger$ & $\ddagger$ \\
\hline Non-U.S. citizen & - & - & $\ddagger$ & \# & $\ddagger$ & \# & $\ddagger$ & $\ddagger$ \\
\hline \multicolumn{9}{|l|}{ Immigration status } \\
\hline $\begin{array}{l}\text { Born outside the } 50 \text { states } \\
\text { and the District of Columbia }\end{array}$ & - & $\ddagger$ & $\ddagger$ & $\ddagger$ & $\ddagger$ & \# & $\ddagger$ & $\ddagger$ \\
\hline First generation & - & $5.9 !$ & $\ddagger$ & $\ddagger$ & $4.8 !$ & $\ddagger$ & $2.9 !$ & $2.9 !$ \\
\hline Second generation or more & - & 93.1 & 93.7 & 97.7 & 95.1 & 98.1 & 96.2 & 96.0 \\
\hline \multicolumn{9}{|l|}{$\begin{array}{l}\text { Total two or more races } \\
\text { population }\end{array}$} \\
\hline \multicolumn{9}{|l|}{ Parents' highest level of education } \\
\hline Less than high school completion' & - & - & 5.4 & 4.5 & 3.7 & 3.9 & 4.8 & 5.3 \\
\hline High school diploma or equivalent & - & - & 21.5 & 22.1 & 17.9 & 21.2 & 22.7 & 22.9 \\
\hline Some college & - & - & 38.8 & 36.0 & 41.1 & 41.2 & 38.6 & 39.0 \\
\hline Bachelor's degree or higher & - & - & 34.2 & 37.4 & 37.3 & 33.7 & 33.8 & 32.8 \\
\hline \multicolumn{9}{|l|}{ Family type ${ }^{2}$} \\
\hline Two-parent household & - & - & 57.9 & 60.5 & 59.9 & 60.7 & 62.0 & 58.9 \\
\hline Mother-only household & - & - & 31.0 & 29.3 & 29.7 & 28.2 & 28.0 & 31.0 \\
\hline Father-only household & - & - & 5.6 & 3.7 & 4.3 & 4.2 & 3.6 & 3.1 \\
\hline \multicolumn{9}{|l|}{ Poverty status } \\
\hline Poor & - & - & 16.0 & 16.7 & 17.6 & 17.2 & 22.5 & 20.3 \\
\hline Near-poor & - & - & 21.6 & 21.3 & 21.4 & 23.8 & 20.8 & 24.1 \\
\hline Nonpoor & - & - & 62.3 & 62.0 & 61.0 & 59.0 & 56.7 & 55.6 \\
\hline \multicolumn{9}{|l|}{ Citizenship } \\
\hline U.S.-born & - & - & 99.2 & 99.5 & 99.5 & 99.4 & 99.5 & 99.7 \\
\hline Naturalized U.S. citizen & - & - & $0.5 !$ & $\ddagger$ & $\ddagger$ & $\ddagger$ & $\ddagger$ & $\ddagger$ \\
\hline Non-U.S. citizen & - & - & $\ddagger$ & $\ddagger$ & $\ddagger$ & $\ddagger$ & $\ddagger$ & $\ddagger$ \\
\hline \multicolumn{9}{|l|}{ Immigration status } \\
\hline $\begin{array}{l}\text { Born outside the } 50 \text { states } \\
\text { and the District of Columbia }\end{array}$ & - & - & 2.5 & 3.0 & 2.2 & 2.7 & 2.8 & 1.8 \\
\hline First generation & - & - & 17.9 & 17.9 & 20.1 & 15.3 & 16.8 & 16.8 \\
\hline Second generation or more & - & - & 79.6 & 79.1 & 77.7 & 81.9 & 80.4 & 81.4 \\
\hline
\end{tabular}

- Not available.

\# Rounds to zero.

! Interpret data with caution. The coefficient of variation (CV) for this estimate is 30 percent or greater

‡ Reporting standards not met. Either there are too few cases or the coefficient of variation (CV) is 50 percent or greater.

' Parents in this category did not earn a high school diploma or receive alternative credentials, such as a General Educational Development (GED) certificate.

2 Detail does not sum to totals because a small percentage of 5- to 17-year olds had no parents present in the home or were householders or spouses of householders.

${ }^{3}$ For 1990 and 2000, data for Asians and Pacific Islanders were not reported separately.

NOTE: Estimates are for all 5- to 17-year-olds regardless of their school enrollment status. Totals for 1990 and 2000 include other racial/ethnic groups not shown separately in the table. Prior to 1992, high school completers referred to those who completed 12 years of schooling, and some college meant completing 1 or more years of college. Beginning in 1992, high school completers referred to those who received a high school diploma or equivalency certificate, and some college meant completing any college at all. Race categories exclude persons of Hispanic ethnicity. Poor is defined to include families below the poverty threshold, near-poor is defined to include families at 100-199 percent of the poverty threshold, and nonpoor is defined to include families at 200 percent or more than the poverty threshold. First generation describes an individual born in the 50 states or the District of Columbia with at least one parent born outside the 50 states or the District of Columbia. Second generation or more describes an individual born in the 50 states or the District of Columbia whose parents were both born inside the 50 states or the District of Columbia. For more information on poverty, educational attainment, and race/ethnicity, see Appendix C - Commonly Used Measures. Some estimates are revised from previous publications. Detail may not sum to totals because of rounding. For more information on the Current Population Survey (CPS), see Appendix B - Guide to Sources.

SOURCE: U.S. Department of Commerce, Census Bureau, Current Population Survey (CPS), March Supplement, selected years, $1990-2011$. 


\section{English Language Learners in Public Schools}

Table A-8-1. Number of public school students and number and percentage of public school students who were English language learners (ELLS), by state: Selected school years, 2000-01 through 2009-10

\begin{tabular}{|c|c|c|c|c|}
\hline \multirow[b]{2}{*}{ State } & \multicolumn{4}{|c|}{ Total public school enrollment } \\
\hline & $2000-01$ & $2005-06$ & $2008-09$ & $2009-10$ \\
\hline Total' & $46,588,307$ & $48,013,931$ & $48,033,126$ & $48,023,353$ \\
\hline Total, reported & $46,588,307$ & $48,013,931$ & $48,033,126$ & $48,023,353$ \\
\hline Alabama & 728,532 & 743,626 & 745,668 & 748,889 \\
\hline Alaska & 131,985 & 133,288 & 130,236 & 131,265 \\
\hline Arizona & 871,882 & 943,841 & 979,320 & 958,968 \\
\hline Arkansas & 449,693 & 472,609 & 474,423 & 474,897 \\
\hline California & $5,976,924$ & $6,240,080$ & $6,163,045$ & $6,100,700$ \\
\hline Colorado & 723,696 & 779,219 & 812,068 & 825,242 \\
\hline Connecticut & 537,521 & 549,744 & 539,250 & 538,756 \\
\hline Delaware & 112,055 & 114,371 & 116,804 & 117,628 \\
\hline District of Columbia & 68,925 & 59,616 & 44,331 & 43,866 \\
\hline Florida & $2,431,884$ & $2,663,973$ & $2,623,067$ & $2,627,390$ \\
\hline Georgia & $1,444,937$ & $1,597,682$ & $1,649,598$ & $1,660,643$ \\
\hline Hawaii & 184,360 & 182,818 & 179,478 & 180,196 \\
\hline Idaho & 245,009 & 261,907 & 267,951 & 266,707 \\
\hline Illinois & $2,025,426$ & $2,097,924$ & $2,117,674$ & $2,101,198$ \\
\hline Indiana & 987,854 & $1,026,106$ & $1,028,259$ & $1,026,053$ \\
\hline lowa & 495,080 & 483,482 & 487,559 & 491,255 \\
\hline Kansas & 468,347 & 467,292 & 470,540 & 474,026 \\
\hline Kentucky & 643,730 & 679,621 & 669,858 & 679,901 \\
\hline Louisiana & 740,512 & 648,313 & 650,099 & 651,930 \\
\hline Maine & 211,190 & 195,174 & 190,972 & 188,694 \\
\hline Maryland & 852,920 & 860,021 & 843,781 & 848,252 \\
\hline Massachusetts & 825,104 & 808,121 & 794,982 & 792,874 \\
\hline Michigan & $1,704,883$ & $1,635,076$ & $1,537,515$ & $1,510,716$ \\
\hline Minnesota & 848,091 & 809,156 & 800,053 & 798,508 \\
\hline Mississippi & 496,513 & 493,952 & 491,194 & 491,651 \\
\hline
\end{tabular}

See notes at end of table. 
Table A-8-1. Number of public school students and number and percentage of public school students who were

English language learners (ELLS), by state: Selected school years, 2000-01 through 2009-10-Continued

\begin{tabular}{|c|c|c|c|c|c|c|c|c|}
\hline \multirow[b]{2}{*}{ State } & \multicolumn{4}{|c|}{ ELL enrollment } & \multicolumn{4}{|c|}{ Percent ELL enrollment } \\
\hline & 2000-01 & 2005-06 & 2008-09 & $2009-10$ & 2000-01 & 2005-06 & 2008-09 & 2009-10 \\
\hline Total' & $3,707,689$ & $4,416,404$ & $4,439,641$ & $4,660,275$ & 8.0 & 9.2 & 9.2 & 9.7 \\
\hline Total, reported & $3,462,796$ & $4,176,174$ & $4,293,065$ & $4,658,504$ & 7.4 & 8.7 & 8.9 & 9.7 \\
\hline Alabama & 7,226 & 16,550 & 19,523 & 19,497 & 1.0 & 2.2 & 2.6 & 2.6 \\
\hline Alaska & 19,314 & 20,743 & 11,937 & 14,581 & 14.6 & 15.6 & 9.2 & 11.1 \\
\hline Arizona & 131,865 & 166,195 & 118,868 & 78,793 & 15.1 & 17.6 & 12.1 & 8.2 \\
\hline Arkansas & 11,847 & 20,700 & 27,629 & 29,735 & 2.6 & 4.4 & 5.8 & 6.3 \\
\hline California & $1,473,703$ & $1,557,935$ & $1,498,660$ & $1,763,486$ & 24.7 & 25.0 & 24.3 & 28.9 \\
\hline Colorado & 60,839 & 99,790 & 88,254 & 94,391 & 8.4 & 12.8 & 10.9 & 11.4 \\
\hline Connecticut & 19,924 & 28,662 & 28,886 & 29,266 & 3.7 & 5.2 & 5.4 & 5.4 \\
\hline Delaware & 2,081 & 5,900 & 7,111 & 7,615 & 1.9 & 5.2 & 6.1 & 6.5 \\
\hline District of Columbia & 8,594 & 4,274 & 4,370 & 4,203 & 12.5 & 7.2 & 9.9 & 9.6 \\
\hline Florida & 187,526 & 221,624 & 226,037 & 230,440 & 7.7 & 8.3 & 8.6 & 8.8 \\
\hline Georgia & 54,444 & 86,615 & 82,000 & 86,668 & 3.8 & 5.4 & 5.0 & 5.2 \\
\hline Hawaii & 12,718 & 18,106 & 18,564 & 18,097 & 6.9 & 9.9 & 10.3 & 10.0 \\
\hline Idaho & 18,084 & 18,184 & 17,657 & 15,931 & 7.4 & 6.9 & 6.6 & 6.0 \\
\hline Illinois & 126,404 & $172,375^{2}$ & 204,737 & 179,850 & 6.2 & 8.2 & 9.7 & 8.6 \\
\hline Indiana & 30,929 & 56,400 & 45,527 & 48,364 & 3.1 & 5.5 & 4.4 & 4.7 \\
\hline lowa & 11,253 & 15,156 & 20,334 & 20,867 & 2.3 & 3.1 & 4.2 & 4.2 \\
\hline Kansas & 14,878 & 24,671 & 34,095 & 38,011 & 3.2 & 5.3 & 7.2 & 8.0 \\
\hline Kentucky & 4,030 & 10,138 & 14,589 & 14,244 & 0.6 & 1.5 & 2.2 & 2.1 \\
\hline Louisiana & 10,269 & 11,942 & 12,223 & 12,499 & 1.4 & 1.8 & 1.9 & 1.9 \\
\hline Maine & $2,062^{2}$ & 3,332 & $4,128^{2}$ & 4,467 & 1.0 & 1.7 & 2.2 & 2.4 \\
\hline Maryland & 24,213 & 31,416 & 39,9192 & 43,179 & 2.8 & 3.7 & 4.7 & 5.1 \\
\hline Massachusetts & 45,418 & 50,007 & 47,198 & 49,612 & 5.5 & 6.2 & 5.9 & 6.3 \\
\hline Michigan & 36,6672 & 60,212 & 55,593 & 53,565 & 2.2 & 3.7 & 3.6 & 3.5 \\
\hline Minnesota & 44,357 & 53,661 & 55,738 & 54,349 & 5.2 & 6.6 & 7.0 & 6.8 \\
\hline Mississippi & 2,176 & 2,859 & 6,543 & 6,061 & 0.4 & 0.6 & 1.3 & 1.2 \\
\hline
\end{tabular}

See notes at end of table. 


\section{English Language Learners in Public Schools}

Table A-8-1. Number of public school students and number and percentage of public school students who were

English language learners (ELLS), by state: Selected school years, 2000-01 through 2009-10-Continued

\begin{tabular}{|c|c|c|c|c|}
\hline \multirow[b]{2}{*}{ State } & \multicolumn{4}{|c|}{ Total public school enrollment } \\
\hline & $2000-01$ & $2005-06$ & $2008-09$ & $2009-10$ \\
\hline Total' & $46,588,307$ & $48,013,931$ & $48,033,126$ & $48,023,353$ \\
\hline Total, reported & $46,588,307$ & $48,013,931$ & $48,033,126$ & $48,023,353$ \\
\hline Missouri & 911,673 & 915,870 & 898,568 & 897,385 \\
\hline Montana & 154,700 & 145,259 & 141,786 & 141,693 \\
\hline Nebraska & 284,924 & 285,547 & 292,161 & 294,948 \\
\hline Nevada & 340,706 & 412,747 & 430,985 & 423,859 \\
\hline New Hampshire & 208,461 & 205,636 & 197,934 & 197,131 \\
\hline New Jersey & $1,297,372$ & $1,380,119$ & $1,359,082$ & $1,368,811$ \\
\hline New Mexico & 320,303 & 326,761 & 328,737 & 331,436 \\
\hline New York & $2,858,991$ & $2,790,140$ & $2,705,289$ & $2,721,522$ \\
\hline North Carolina & $1,277,500$ & $1,388,216$ & $1,452,064$ & $1,444,409$ \\
\hline North Dakota & 108,788 & 98,172 & 94,653 & 94,997 \\
\hline Ohio & $1,820,221$ & $1,769,274$ & $1,729,072$ & $1,672,054$ \\
\hline Oklahoma & 623,110 & 634,468 & 644,549 & 653,592 \\
\hline Oregon & 544,756 & 535,176 & 560,334 & 558,960 \\
\hline Pennsylvania & $1,771,473$ & $1,752,402$ & $1,687,148$ & $1,682,891$ \\
\hline Rhode Island & 156,275 & 138,934 & 131,056 & 130,623 \\
\hline South Carolina & 679,724 & 699,027 & 714,290 & 715,590 \\
\hline South Dakota & 127,986 & 121,718 & 126,624 & 123,558 \\
\hline Tennessee & 893,061 & 953,796 & 970,908 & 972,549 \\
\hline Texas & $4,021,641$ & $4,450,139$ & $4,646,668$ & $4,728,202$ \\
\hline Utah & 477,380 & 496,507 & 532,433 & 548,397 \\
\hline Vermont & 100,904 & 94,160 & 87,440 & 89,999 \\
\hline Virginia & $1,143,807$ & $1,201,142$ & $1,221,799$ & $1,231,205$ \\
\hline Washington & $1,004,843$ & $1,031,668$ & $1,035,907$ & $1,034,698$ \\
\hline West Virginia & 285,785 & 279,788 & 281,908 & 281,828 \\
\hline Wisconsin & 877,159 & 874,098 & 867,035 & 864,898 \\
\hline Wyoming & 89,711 & 86,155 & 86,971 & 87,913 \\
\hline
\end{tabular}

See notes at end of table. 
Table A-8-1. Number of public school students and number and percentage of public school students who were English language learners (ELLS), by state: Selected school years, 2000-01 through 2009-10-Continued

\begin{tabular}{|c|c|c|c|c|c|c|c|c|}
\hline \multirow[b]{2}{*}{ State } & \multicolumn{4}{|c|}{ ELL enrollment } & \multicolumn{4}{|c|}{ Percent ELL enrollment } \\
\hline & $2000-01$ & $2005-06$ & 2008-09 & $2009-10$ & 2000-01 & 2005-06 & 2008-09 & $2009-10$ \\
\hline Total & $3,707,689$ & $4,416,404$ & $4,439,641$ & $4,660,275$ & 8.0 & 9.2 & 9.2 & 9.7 \\
\hline Total, reported & $3,462,796$ & $4,176,174$ & $4,293,065$ & $4,658,504$ & 7.4 & 8.7 & 8.9 & 9.7 \\
\hline Missouri & 10,237 & 18,745 & 15,468 & 19,393 & 1.1 & 2.0 & 1.7 & 2.2 \\
\hline Montana & $8,406^{2}$ & 6,711 & 4,549 & 3,806 & 5.4 & 4.6 & 3.2 & 2.7 \\
\hline Nebraska & 11,276 & 17,449 & 18,388 & 19,323 & 4.0 & 6.1 & 6.3 & 6.6 \\
\hline Nevada & 23,4882 & 63,856 & 75,952 & 67,868 & 6.9 & 15.5 & 17.6 & 16.0 \\
\hline New Hampshire & 2,728 & $2,877^{2}$ & 3,496 & 3,821 & 1.3 & 1.4 & 1.8 & 1.9 \\
\hline New Jersey & $56,844^{2}$ & 50,426 & 53,960 & 55,450 & 4.4 & 3.7 & 4.0 & 4.1 \\
\hline New Mexico & 68,679 & 62,682 & $55,978^{2}$ & 51,257 & 21.4 & 19.2 & 17.0 & 15.5 \\
\hline New York & 230,625 & 193,701 & 183,736 & 200,433 & 8.1 & 6.9 & 6.8 & 7.4 \\
\hline North Carolina & 44,087 & 73,206 & 113,155 & 105,651 & 3.5 & 5.3 & 7.8 & 7.3 \\
\hline North Dakota & - & $2,213^{2}$ & 3,540 & 3,879 & - & 2.3 & 3.7 & 4.1 \\
\hline Ohio & 328 & 29,222 & 35,362 & 36,527 & \# & 1.7 & 2.0 & 2.2 \\
\hline Oklahoma & 38,042 & 47,380 & $38,314^{2}$ & 39,259 & 6.1 & 7.5 & 5.9 & 6.0 \\
\hline Oregon & 43,416 & 64,603 & 62,857 & 61,625 & 8.0 & 12.1 & 11.2 & 11.0 \\
\hline Pennsylvania & $24,857^{2}$ & 39,5982 & 44,853 & 44,359 & 1.4 & 2.3 & 2.7 & 2.6 \\
\hline Rhode Island & 10,198 & 7,090 & $6,466^{2}$ & 6,340 & 6.5 & 5.1 & 4.9 & 4.9 \\
\hline South Carolina & 5,121 & 14,372 & 31,422 & 34,661 & 0.8 & 2.1 & 4.4 & 4.8 \\
\hline South Dakota & 4,269 & 5,110 & 3,580 & 4,005 & 3.3 & 4.2 & 2.8 & 3.2 \\
\hline Tennessee & - & - & 27,433 & 27,550 & - & - & 2.8 & 2.8 \\
\hline Texas & 568,972 & 702,436 & 704,142 & 708,615 & 14.1 & 15.8 & 15.2 & 15.0 \\
\hline Utah & 38,998 & 49,915 & 43,957 & 46,591 & 8.2 & 10.1 & 8.3 & 8.5 \\
\hline Vermont & 942 & 1,771 & - & - & 0.9 & 1.9 & - & - \\
\hline Virginia & 36,802 & 72,184 & 86,745 & 86,475 & 3.2 & 6.0 & 7.1 & 7.0 \\
\hline Washington & 70,431 & 75,103 & 82,711 & 65,101 & 7.0 & 7.3 & 8.0 & 6.3 \\
\hline West Virginia & 920 & 1,942 & 1,617 & 1,605 & 0.3 & 0.7 & 0.6 & 0.6 \\
\hline Wisconsin & 22,542 & 30,130 & 47,798 & 45,041 & 2.6 & 3.4 & 5.5 & 5.2 \\
\hline Wyoming & 2,522 & 3,068 & 2,271 & 2,098 & 2.8 & 3.6 & 2.6 & 2.4 \\
\hline
\end{tabular}

- Not available.

\# Rounds to zero.

1 Includes imputed (or estimated) ELL enrollment data in cases where some states did not report these data. In 2009-10, the data for Vermont were imputed.

2 Percentages are imputed (or estimated).

NOTE: For more information on the Common Core of Data, see Appendix B - Guide to Sources. Detail may not sum to totals because of rounding. SOURCE: U.S. Department of Education, National Center for Education Statistics, Common Core of Data (CCD), "Public Elementary/Secondary School Universe Survey," 2000-01 (version 1a), 2005-06 (version 1a), 2008-09 (version 1a), and 2009-10 (version 1a). 


\section{English Language Learners in Public Schools}

Table A-8-2. Number of public school students and number and percentage of public school students who were English language learners (ELLs), by locale: School year 2009-10

\begin{tabular}{|c|c|c|c|}
\hline Locale & $\begin{array}{r}\text { Total public school } \\
\text { enrollment }\end{array}$ & ELL enrollment & Percent ELL enrollment \\
\hline Total & $48,023,353$ & $4,658,504$ & 9.7 \\
\hline City & $14,728,569$ & $2,230,902$ & 14.3 \\
\hline Large & $7,520,317$ & $1,331,503$ & 17.7 \\
\hline Midsize & $3,476,763$ & 488,732 & 14.1 \\
\hline Small & $3,731,489$ & 410,667 & 11.0 \\
\hline Suburban & $17,948,070$ & $1,710,003$ & 8.3 \\
\hline Large & $15,503,775$ & $1,527,763$ & 9.9 \\
\hline Midsize & $1,525,844$ & 112,352 & 7.4 \\
\hline Small & 918,451 & 69,888 & 7.6 \\
\hline Town & $5,794,191$ & 365,182 & 6.8 \\
\hline Fringe & 868,821 & 77,121 & 8. \\
\hline Distant & $2,992,047$ & 176,716 & 5. \\
\hline Remote & $1,933,323$ & 111,345 & 5.8 \\
\hline Rural & $9,551,976$ & 352,356 & 3. \\
\hline Fringe & $5,141,851$ & 228,438 & 4.4 \\
\hline Distant & $3,286,339$ & 81,690 & 2.5 \\
\hline Remote & $1,123,786$ & 42,228 & 3.8 \\
\hline
\end{tabular}

NOTE: Total ELL enrollment does not include data imputed for Vermont in 2009-10. For more information on locale, see Appendix C - Commonly Used Measures. For more information on the Common Core of Data, see Appendix B - Guide to Sources. Detail may not sum to totals because of rounding. SOURCE: U.S. Department of Education, National Center for Education Statistics, Common Core of Data (CCD), "Public Elementary/Secondary School Universe Survey," 2009-10 (version la). 
This page intentionally left blank. 


\section{Children and Youth with Disabilities}

Table A-9-1. Number and percentage distribution of children and youth ages 3-21 served under the Individuals with Disabilities Education Act (IDEA), Part B, and number served as a percentage of total public school enrollment, by disability type: Selected school years, 1980-81 through 2009-10

Disability type
$1980-81 \quad 1990-91 \quad 2000-01 \quad 2004-05 \quad 2005-06 \quad 2006-07 \quad 200$

2007-08 2008-09 2009-10

\section{All disabilities}

Specific learning disabilities

Speech or language impairments

Intellectual disability

Emotional disturbance

Hearing impairments

Orthopedic impairments

Other health impairments

Visual impairments

Multiple disabilities

Deaf-blindness

Autism

Traumatic brain injury

Developmental delay

Preschool disabled'

\section{All disabilities}

Specific learning disabilities

Speech or language impairments

Intellectual disability

Emotional disturbance

Hearing impairments

Orthopedic impairments

Other health impairments

Visual impairments

Multiple disabilities

Deaf-blindness

Autism

Traumatic brain injury

Developmental delay

Preschool disabled'

See notes at end of table.
Number served (in thousands)

\begin{tabular}{rrrrrrrrr}
\multicolumn{10}{c}{ Number served (in thousands) } \\
$\mathbf{4 , 1 4 4}$ & $\mathbf{4 , 7 1 0}$ & $\mathbf{6 , 2 9 6}$ & $\mathbf{6 , 7 1 9}$ & $\mathbf{6 , 7 1 3}$ & $\mathbf{6 , 6 8 6}$ & $\mathbf{6 , 6 0 6}$ & $\mathbf{6 , 4 8 3}$ & $\mathbf{6 , 4 8 1}$ \\
1,462 & 2,129 & 2,868 & 2,798 & 2,735 & 2,665 & 2,573 & 2,476 & 2,431 \\
1,168 & 985 & 1,409 & 1,463 & 1,468 & 1,475 & 1,456 & 1,426 & 1,416 \\
830 & 534 & 624 & 578 & 556 & 534 & 500 & 478 & 463 \\
347 & 389 & 481 & 489 & 477 & 464 & 442 & 420 & 407 \\
79 & 58 & 78 & 79 & 79 & 80 & 79 & 78 & 79 \\
58 & 49 & 83 & 73 & 71 & 69 & 67 & 70 & 65 \\
98 & 55 & 303 & 521 & 570 & 611 & 641 & 659 & 689 \\
31 & 23 & 29 & 29 & 29 & 29 & 29 & 29 & 29 \\
68 & 96 & 133 & 140 & 141 & 142 & 138 & 130 & 131 \\
3 & 1 & 1 & 2 & 2 & 2 & 2 & 2 & 2 \\
- & - & 94 & 191 & 223 & 258 & 296 & 336 & 378 \\
- & - & 16 & 24 & 24 & 25 & 25 & 26 & 25 \\
- & - & 178 & 332 & 339 & 333 & 358 & 354 & 368 \\
$\dagger$ & 390 & $\dagger$ & $\dagger$ & $\dagger$ & $\dagger$ & $\dagger$ & $\dagger$ & $\dagger$
\end{tabular}

Percentage distribution of children served

\begin{tabular}{rrrrrrrrr}
$\mathbf{1 0 0 . 0}$ & $\mathbf{1 0 0 . 0}$ & $\mathbf{1 0 0 . 0}$ & $\mathbf{1 0 0 . 0}$ & $\mathbf{1 0 0 . 0}$ & $\mathbf{1 0 0 . 0}$ & $\mathbf{1 0 0 . 0}$ & $\mathbf{1 0 0 . 0}$ & $\mathbf{1 0 0 . 0}$ \\
35.3 & 45.2 & 45.5 & 41.6 & 40.7 & 39.9 & 39.0 & 38.2 & 37.5 \\
28.2 & 20.9 & 22.4 & 21.8 & 21.9 & 22.1 & 22.0 & 22.0 & 21.8 \\
20.0 & 11.3 & 9.9 & 8.6 & 8.3 & 8.0 & 7.6 & 7.4 & 7.1 \\
8.4 & 8.3 & 7.6 & 7.3 & 7.1 & 6.9 & 6.7 & 6.5 & 6.3 \\
1.9 & 1.2 & 1.2 & 1.2 & 1.2 & 1.2 & 1.2 & 1.2 & 1.2 \\
1.4 & 1.0 & 1.3 & 1.1 & 1.1 & 1.0 & 1.0 & 1.1 & 1.0 \\
2.4 & 1.2 & 4.8 & 7.7 & 8.5 & 9.1 & 9.7 & 10.2 & 10.6 \\
0.7 & 0.5 & 0.5 & 0.4 & 0.4 & 0.4 & 0.4 & 0.4 & 0.4 \\
1.6 & 2.0 & 2.1 & 2.1 & 2.1 & 2.1 & 2.1 & 2.0 & 2.0 \\
0.1 & $\#$ & $\#$ & $\#$ & $\#$ & $\#$ & $\#$ & $\#$ & $\#$ \\
- & - & 1.5 & 2.8 & 3.3 & 3.9 & 4.5 & 5.2 & 5.8 \\
- & - & 0.2 & 0.4 & 0.4 & 0.4 & 0.4 & 0.4 & 0.4 \\
- & - & 2.8 & 4.9 & 5.1 & 5.0 & 5.4 & 5.5 & 5.7 \\
$\dagger$ & 8.3 & $\dagger$ & $\dagger$ & $\dagger$ & $\dagger$ & $\dagger$ & $\dagger$ & $\dagger$ \\
\hline
\end{tabular}


Table A-9-1. Number and percentage distribution of children and youth ages 3-21 served under the Individuals with Disabilities Education Act (IDEA), Part B, and number served as a percentage of total public school enrollment, by disability type: Selected school years, 1980-81 through 2009-10-Continued

\begin{tabular}{|c|c|c|c|c|c|c|c|c|c|}
\hline Disability type & $1980-81$ & $1990-91$ & $2000-01$ & $2004-05$ & $2005-06$ & $2006-07$ & $2007-08$ & $2008-09$ & $2009-10$ \\
\hline & & Numb & r served & a percen & age of tot & public sc & hool enroll & nent ${ }^{2}$ & \\
\hline All disabilities & 10.1 & 11.4 & 13.3 & 13.8 & 13.7 & 13.6 & 13.4 & 13.2 & 13.1 \\
\hline Specific learning disabilities & 3.6 & 5.2 & 6.1 & 5.7 & 5.6 & 5.4 & 5.2 & 5.0 & 4.9 \\
\hline Speech or language impairments & 2.9 & 2.4 & 3.0 & 3.0 & 3.0 & 3.0 & 3.0 & 2.9 & 2.9 \\
\hline Intellectual disability & 2.0 & 1.3 & 1.3 & 1.2 & 1.1 & 1.1 & 1.0 & 1.0 & 0.9 \\
\hline Emotional disturbance & 0.8 & 0.9 & 1.0 & 1.0 & 1.0 & 0.9 & 0.9 & 0.9 & 0.8 \\
\hline Hearing impairments & 0.2 & 0.1 & 0.2 & 0.2 & 0.2 & 0.2 & 0.2 & 0.2 & 0.2 \\
\hline Orthopedic impairments & 0.1 & 0.1 & 0.2 & 0.2 & 0.1 & 0.1 & 0.1 & 0.1 & 0.1 \\
\hline Other health impairments & 0.2 & 0.1 & 0.6 & 1.1 & 1.2 & 1.2 & 1.3 & 1.3 & 1.4 \\
\hline Visual impairments & 0.1 & 0.1 & 0.1 & 0.1 & 0.1 & 0.1 & 0.1 & 0.1 & 0.1 \\
\hline Multiple disabilities & 0.2 & 0.2 & 0.3 & 0.3 & 0.3 & 0.3 & 0.3 & 0.3 & 0.3 \\
\hline Deaf-blindness & $\#$ & $\#$ & \# & $\#$ & \# & $\#$ & \# & $\#$ & \# \\
\hline Autism & - & - & 0.2 & 0.4 & 0.5 & 0.5 & 0.6 & 0.7 & 0.8 \\
\hline Traumatic brain injury & - & - & \# & $\#$ & \# & 0.1 & 0.1 & 0.1 & 0.1 \\
\hline Developmental delay & - & - & 0.4 & 0.7 & 0.7 & 0.7 & 0.7 & 0.7 & 0.7 \\
\hline Preschool disabled' & $\dagger$ & 0.9 & $\dagger$ & $\dagger$ & $\dagger$ & $\dagger$ & $\dagger$ & $\dagger$ & $\dagger$ \\
\hline
\end{tabular}

- Not available.

† Not applicable.

\# Rounds to zero.

In 1980-81, data were collected for preschool-age children ages 3-5 by disability type; those data are combined above with data for children and youth ages 6-21. However, the 1986 Amendments to the Education of the Handicapped Act (now known as the Individuals with Disabilities Education Act [IDEA]) mandated that data not be collected by disability for students ages 3-5. For this reason, data from 1990-91 on preschoolers with disabilities are reported in a separate row. Beginning in 2000-01, states were again required to report data on preschool children by disability.

2 Based on the total prekindergarten through 12th-grade enrollment in public schools.

NOTE: Prior to October 1994, children and youth with disabilities were served under Title I of the Elementary and Secondary Education Act as well as under IDEA, Part B. Data reported in this table for years prior to 1995-96 include children and youth ages 0-21 served under Title I. Includes children and youth in the 50 states, the District of Columbia, and the Bureau of Indian Education schools. Data for 2007-08 and 2008-09 do not include Vermont. In 2006-07, the total number of 3- to 21-year-olds served under IDEA in Vermont was 14,010. Detail may not sum to totals because of rounding. For more information on student disabilities, see Appendix C - Commonly Used Measures. For more information on the Common Core of Data (CCD), see Appendix B - Guide to Sources.

SOURCE: U.S. Department of Education, Office of Special Education Programs, Annual Report to Congress on the Implementation of the Individuals with Disabilities Education Act, selected years, 1980 through 2009; and Individuals with Disabilities Education Act (IDEA) database, retrieved September 14, 2011, from http://www.ideadata.org/PartBdata.asp. National Center for Education Statistics, Statistics of Public Elementary and Secondary School Systems, 1980-81; and Common Core of Data (CCD), "State Nonfiscal Survey of Public Elementary/Secondary Education," selected years, 1990-91 through 2009-10. 


\section{Children and Youth with Disabilities}

Table A-9-2. Percentage distribution of students ages 6-21 served under the Individuals with Disabilities Education Act (IDEA), Part B, by educational environment and disability type: Selected school years, 1990-91 through 2009-10

\begin{tabular}{|c|c|c|c|c|c|c|c|c|c|c|c|}
\hline \multirow[b]{3}{*}{ Year and disability type } & \multirow[b]{3}{*}{$\begin{array}{r}\text { All } \\
\text { environ- } \\
\text { ments } \\
\end{array}$} & \multicolumn{10}{|c|}{ Educational environment } \\
\hline & & \multicolumn{3}{|c|}{$\begin{array}{l}\text { Regular school, } \\
\text { time in general classes }\end{array}$} & \multicolumn{2}{|c|}{$\begin{array}{c}\text { Separate school } \\
\text { for students } \\
\text { with disabilities } \\
\end{array}$} & \multicolumn{2}{|c|}{$\begin{array}{c}\text { Separate } \\
\text { residential } \\
\text { facility }\end{array}$} & \multirow{2}{*}{$\begin{array}{r}\text { Parentally } \\
\text { placed } \\
\text { in regular } \\
\text { private } \\
\text { schools } \\
\end{array}$} & \multirow{2}{*}{$\begin{array}{r}\text { Home- } \\
\text { bound/ } \\
\text { hospital } \\
\text { place- } \\
\text { ment }\end{array}$} & \multirow[b]{2}{*}{$\begin{array}{r}\text { Correc- } \\
\text { tional } \\
\text { facility }\end{array}$} \\
\hline & & $\begin{array}{r}80 \\
\text { percent } \\
\text { or more } \\
\end{array}$ & $\begin{array}{r}40-79 \\
\text { percent }\end{array}$ & $\begin{array}{r}\text { Less } \\
\text { than } 40 \\
\text { percent }\end{array}$ & Public & Private & Public & Private & & & \\
\hline \multicolumn{12}{|l|}{$\begin{array}{c}\text { All students with } \\
\text { disabilities }\end{array}$} \\
\hline 1990-91 & 100.0 & 33.1 & 36.4 & 25.0 & 2.9 & 1.3 & 0.6 & 0.3 & - & 0.5 & - \\
\hline $1995-96$ & 100.0 & 45.7 & 28.5 & 21.5 & 2.1 & 1.0 & 0.4 & 0.3 & - & 0.5 & - \\
\hline $1996-97$ & 100.0 & 46.1 & 28.3 & 21.4 & 2.0 & 1.0 & 0.4 & 0.3 & - & 0.5 & - \\
\hline 1997-98 & 100.0 & 46.8 & 28.8 & 20.4 & 1.8 & 1.0 & 0.4 & 0.3 & - & 0.5 & - \\
\hline 1998-99 & 100.0 & 46.0 & 29.9 & 20.0 & 1.8 & 1.1 & 0.4 & 0.3 & - & 0.5 & - \\
\hline 1999-2000 & 100.0 & 45.9 & 29.8 & 20.3 & 1.9 & 1.0 & 0.4 & 0.3 & - & 0.5 & - \\
\hline 2000-01 & 100.0 & 46.5 & 29.8 & 19.5 & 1.9 & 1.1 & 0.4 & 0.3 & - & 0.5 & - \\
\hline $2001-02$ & 100.0 & 48.2 & 28.5 & 19.2 & 1.7 & 1.2 & 0.4 & 0.4 & - & 0.4 & - \\
\hline $2002-03$ & 100.0 & 48.2 & 28.7 & 19.0 & 1.7 & 1.2 & 0.3 & 0.4 & - & 0.5 & - \\
\hline 2003-04 & 100.0 & 49.9 & 27.7 & 18.5 & 1.7 & 1.1 & 0.3 & 0.4 & - & 0.5 & - \\
\hline $2004-05$ & 100.0 & 51.5 & 26.5 & 17.9 & 1.8 & 1.2 & 0.3 & 0.3 & - & 0.4 & - \\
\hline 2005-06 & 100.0 & 54.2 & 25.1 & 16.7 & 1.8 & 1.2 & 0.3 & 0.3 & - & 0.4 & - \\
\hline 2006-07 & 100.0 & 54.8 & 23.8 & 16.4 & $2.9^{1}$ & (') & $0.4^{1}$ & (') & $1.0^{2}$ & 0.4 & 0.4 \\
\hline 2007-08 & 100.0 & 56.8 & 22.4 & 15.4 & $3.0^{1}$ & (') & $0.4^{1}$ & (') & $1.1^{2}$ & 0.4 & 0.4 \\
\hline \multirow[t]{2}{*}{ 2008-09 } & 100.0 & 58.5 & 21.4 & 14.9 & $2.9^{1}$ & (') & $0.4^{1}$ & (') & $1.1^{2}$ & 0.4 & 0.4 \\
\hline & \multicolumn{11}{|c|}{$2009-10$} \\
\hline $\begin{array}{c}\text { All students with } \\
\text { disabilities } \\
\text { Specific learning }\end{array}$ & 100.0 & 59.4 & 20.7 & 14.6 & $3.0^{1}$ & (') & $0.4^{1}$ & (') & $1.2^{2}$ & 0.4 & 0.4 \\
\hline disabilities & 100.0 & 63.3 & 26.6 & 8.0 & $0.6^{1}$ & (') & $0.1^{1}$ & (') & $0.9^{2}$ & 0.2 & 0.4 \\
\hline impairments & 100.0 & 86.3 & 5.6 & 4.6 & $0.3^{1}$ & (') & $\#^{1}$ & (') & $3.1^{2}$ & 0.1 & \# \\
\hline Intellectual disability & 100.0 & 17.4 & 26.7 & 48.2 & $6.3^{1}$ & ()$\left.^{1}\right)$ & $0.4^{1}$ & ( $)^{\prime}$ & $0.3^{2}$ & 0.5 & 0.3 \\
\hline Emotional disturbance & 100.0 & 40.6 & 18.8 & 22.2 & $13.2^{1}$ & (1) & $2.0^{1}$ & (') & $0.2^{2}$ & 1.1 & 2.0 \\
\hline Hearing impairments & 100.0 & 54.6 & 17.0 & 14.7 & $8.2^{1}$ & ()$\left.^{1}\right)$ & $4.0^{1}$ & ()$\left.^{1}\right)$ & $1.3^{2}$ & 0.2 & 0.1 \\
\hline Orthopedic impairments & 100.0 & 52.2 & 16.3 & 23.6 & $5.1^{1}$ & $(1)$ & $0.2^{1}$ & ()$\left.^{\prime}\right)$ & $0.9^{2}$ & 1.7 & 0.1 \\
\hline Other health impairments & 100.0 & 61.4 & 23.8 & 10.8 & $1.6^{1}$ & ()$\left.^{\prime}\right)$ & $0.2^{1}$ & ()$\left.^{1}\right)$ & $1.1^{2}$ & 0.9 & 0.3 \\
\hline Visual impairments & 100.0 & 62.6 & 13.5 & 12.0 & $6.2^{1}$ & ()$\left.^{\prime}\right)$ & $3.6^{1}$ & $(1)$ & $1.4^{2}$ & 0.7 & \# \\
\hline Multiple disabilities & 100.0 & 13.2 & 16.2 & 45.5 & $19.6^{1}$ & (1) & $1.9^{1}$ & (') & $0.4^{2}$ & 2.9 & 0.2 \\
\hline Deaf-blindness & 100.0 & 21.6 & 13.3 & 33.3 & $19.1^{1}$ & (1) & $9.9^{1}$ & (') & $0.6^{2}$ & 2.3 & 0.2 \\
\hline Autism & 100.0 & 37.4 & 18.3 & 34.8 & $8.0^{1}$ & $(1)$ & $0.6^{1}$ & (') & $0.7^{2}$ & 0.3 & $\#$ \\
\hline Traumatic brain injury & 100.0 & 46.4 & 23.8 & 21.5 & $5.2^{1}$ & (') & $0.6^{1}$ & (') & $0.7^{2}$ & 1.7 & 0.2 \\
\hline Developmental delay & 100.0 & 61.6 & 20.5 & 16.2 & $0.9^{1}$ & (1) & $0.1^{1}$ & (1) & $0.6^{2}$ & 0.2 & $\#$ \\
\hline
\end{tabular}

\section{- Not available.}

\# Rounds to zero.

' Data for 2006-07 and later years combine students in public and private schools as well as public and private residential facilities.

2 Students who are enrolled by their parents or guardians in regular private schools and have their basic education paid through private resources, but receive special education services at public expense. These students are not included under "Regular school, time in general classes."

NOTE: Includes children and youth in the 50 states, the District of Columbia, and the Bureau of Indian Education schools. Data for 2007-08 and 2008-09 do not include Vermont. Some data have been revised from previously published figures. Detail may not sum to totals because of rounding. For more information on the student disabilities presented, see Appendix C - Commonly Used Measures. For more information on the Common Core of Data (CCD), see Appendix B - Guide to Sources.

SOURCE: U.S. Department of Education, Office of Special Education Programs, Individuals with Disabilities Education Act (IDEA) database, retrieved

September 15, 2011, from https://www.ideadata.org/DACAnalyticTool/Intro 2.asp. 
This page intentionally left blank. 
Table A-10-1. Number and percentage of actual and projected undergraduate enrollment in degree-granting postsecondary institutions, by sex, attendance status, and control of institution: Selected years, fall 1970-2021

[Numbers in thousands]

\begin{tabular}{|c|c|c|c|c|c|c|c|c|c|}
\hline \multirow[b]{3}{*}{ Fall of year } & \multirow[b]{3}{*}{ Total } & \multicolumn{4}{|c|}{ Sex } & \multicolumn{4}{|c|}{ Attendance status } \\
\hline & & \multicolumn{2}{|c|}{ Male } & \multicolumn{2}{|c|}{ Female } & \multicolumn{2}{|c|}{ Full time } & \multicolumn{2}{|c|}{ Part time } \\
\hline & & Number & Percent & Number & Percent & Number & Percent & Number & Percent \\
\hline 1970 & 7,369 & 4,250 & 57.7 & 3,119 & 42.3 & 5,280 & 71.7 & 2,089 & 28.3 \\
\hline 1975 & 9,679 & 5,257 & 54.3 & 4,422 & 45.7 & 6,168 & 63.7 & 3,511 & 36.3 \\
\hline 1980 & 10,475 & 5,000 & 47.7 & 5,475 & 52.3 & 6,362 & 60.7 & 4,113 & 39.3 \\
\hline 1985 & 10,597 & 4,962 & 46.8 & 5,635 & 53.2 & 6,320 & 59.6 & 4,277 & 40.4 \\
\hline 1990 & 11,959 & 5,380 & 45.0 & 6,579 & 55.0 & 6,976 & 58.3 & 4,983 & 41.7 \\
\hline 1991 & 12,439 & 5,571 & 44.8 & 6,868 & 55.2 & 7,221 & 58.1 & 5,218 & 41.9 \\
\hline 1992 & 12,538 & 5,583 & 44.5 & 6,955 & 55.5 & 7,244 & 57.8 & 5,293 & 42.2 \\
\hline 1993 & 12,324 & 5,484 & 44.5 & 6,840 & 55.5 & 7,179 & 58.3 & 5,144 & 41.7 \\
\hline 1994 & 12,263 & 5,422 & 44.2 & 6,840 & 55.8 & 7,169 & 58.5 & 5,094 & 41.5 \\
\hline 1995 & 12,232 & 5,401 & 44.2 & 6,831 & 55.8 & 7,145 & 58.4 & 5,086 & 41.6 \\
\hline 1996 & 12,327 & 5,421 & 44.0 & 6,906 & 56.0 & 7,299 & 59.2 & 5,028 & 40.8 \\
\hline 1997 & 12,451 & 5,469 & 43.9 & 6,982 & 56.1 & 7,419 & 59.6 & 5,032 & 40.4 \\
\hline 1998 & 12,437 & 5,446 & 43.8 & 6,991 & 56.2 & 7,539 & 60.6 & 4,898 & 39.4 \\
\hline 1999 & 12,739 & 5,584 & 43.8 & 7,155 & 56.2 & 7,754 & 60.9 & 4,986 & 39.1 \\
\hline 2000 & 13,155 & 5,778 & 43.9 & 7,377 & 56.1 & 7,923 & 60.2 & 5,232 & 39.8 \\
\hline 2001 & 13,716 & 6,004 & 43.8 & 7,711 & 56.2 & 8,328 & 60.7 & 5,388 & 39.3 \\
\hline 2002 & 14,257 & 6,192 & 43.4 & 8,065 & 56.6 & 8,734 & 61.3 & 5,523 & 38.7 \\
\hline 2003 & 14,480 & 6,227 & 43.0 & 8,253 & 57.0 & 9,045 & 62.5 & 5,435 & 37.5 \\
\hline 2004 & 14,781 & 6,340 & 42.9 & 8,441 & 57.1 & 9,284 & 62.8 & 5,496 & 37.2 \\
\hline 2005 & 14,964 & 6,409 & 42.8 & 8,555 & 57.2 & 9,446 & 63.1 & 5,518 & 36.9 \\
\hline 2006 & 15,184 & 6,514 & 42.9 & 8,671 & 57.1 & 9,571 & 63.0 & 5,613 & 37.0 \\
\hline 2007 & 15,604 & 6,728 & 43.1 & 8,876 & 56.9 & 9,841 & 63.1 & 5,763 & 36.9 \\
\hline 2008 & 16,366 & 7,067 & 43.2 & 9,299 & 56.8 & 10,255 & 62.7 & 6,111 & 37.3 \\
\hline 2009 & 17,565 & 7,595 & 43.2 & 9,970 & 56.8 & 11,143 & 63.4 & 6,422 & 36.6 \\
\hline 2010 & 18,079 & 7,835 & 43.3 & 10,244 & 56.7 & 11,452 & 63.3 & 6,627 & 36.7 \\
\hline \multicolumn{10}{|l|}{ Projected } \\
\hline 2011 & 18,326 & 7,979 & 43.5 & 10,347 & 56.5 & 11,563 & 63.1 & 6,763 & 36.9 \\
\hline 2012 & 18,528 & 8,038 & 43.4 & 10,489 & 56.6 & 11,671 & 63.0 & 6,856 & 37.0 \\
\hline 2013 & 18,704 & 8,076 & 43.2 & 10,628 & 56.8 & 11,753 & 62.8 & 6,950 & 37.2 \\
\hline 2014 & 18,894 & 8,093 & 42.8 & 10,802 & 57.2 & 11,839 & 62.7 & 7,055 & 37.3 \\
\hline 2015 & 19,050 & 8,100 & 42.5 & 10,950 & 57.5 & 11,902 & 62.5 & 7,148 & 37.5 \\
\hline 2016 & 19,248 & 8,138 & 42.3 & 11,110 & 57.7 & 11,996 & 62.3 & 7,252 & 37.7 \\
\hline 2017 & 19,515 & 8,210 & 42.1 & 11,305 & 57.9 & 12,141 & 62.2 & 7,374 & 37.8 \\
\hline 2018 & 19,824 & 8,300 & 41.9 & 11,524 & 58.1 & 12,320 & 62.1 & 7,504 & 37.9 \\
\hline 2019 & 20,129 & 8,398 & 41.7 & 11,731 & 58.3 & 12,514 & 62.2 & 7,615 & 37.8 \\
\hline 2020 & 20,395 & 8,488 & 41.6 & 11,907 & 58.4 & 12,687 & 62.2 & 7,708 & 37.8 \\
\hline$\underline{2021}$ & 20,597 & 8,564 & 41.6 & 12,033 & 58.4 & 12,819 & 62.2 & 7,778 & 37.8 \\
\hline
\end{tabular}

See notes at end of table. 
Table A-10-1. Number and percentage of actual and projected undergraduate enrollment in degree-granting postsecondary institutions, by sex, attendance status, and control of institution: Selected years, fall 1970-2021-Continued

[Numbers in thousands]

\begin{tabular}{|c|c|c|c|c|c|c|c|c|c|}
\hline \multirow[b]{4}{*}{ Fall of year } & \multirow[b]{4}{*}{ Total } & \multicolumn{8}{|c|}{ Control of institution } \\
\hline & & \multicolumn{2}{|c|}{ Public } & \multicolumn{6}{|c|}{ Private } \\
\hline & & \multirow[b]{2}{*}{ Number } & \multirow[b]{2}{*}{ Percent } & \multicolumn{2}{|c|}{ Total } & \multicolumn{2}{|c|}{ Nonprofit } & \multicolumn{2}{|c|}{ For-profit } \\
\hline & & & & Number & Percent & Number & Percent & Number & Percent \\
\hline 1970 & 7,369 & 5,620 & 76.3 & 1,748 & 23.7 & 1,730 & 23.5 & 18 & 0.2 \\
\hline 1975 & 9,679 & 7,826 & 80.9 & 1,853 & 19.1 & 1,815 & 18.7 & 39 & 0.4 \\
\hline 1980 & 10,475 & 8,442 & 80.6 & 2,033 & 19.4 & 1,927 & 18.4 & 106 & 1.0 \\
\hline 1985 & 10,597 & 8,477 & 80.0 & 2,120 & 20.0 & 1,929 & 18.2 & 191 & 1.8 \\
\hline 1990 & 11,959 & 9,710 & 81.2 & 2,250 & 18.8 & 2,043 & 17.1 & 206 & 1.7 \\
\hline 1991 & 12,439 & 10,148 & 81.6 & 2,291 & 18.4 & 2,072 & 16.7 & 219 & 1.8 \\
\hline 1992 & 12,538 & 10,216 & 81.5 & 2,321 & 18.5 & 2,102 & 16.8 & 220 & 1.8 \\
\hline 1993 & 12,324 & 10,012 & 81.2 & 2,312 & 18.8 & 2,099 & 17.0 & 213 & 1.7 \\
\hline 1994 & 12,263 & 9,945 & 81.1 & 2,317 & 18.9 & 2,100 & 17.1 & 217 & 1.8 \\
\hline 1995 & 12,232 & 9,904 & 81.0 & 2,328 & 19.0 & 2,105 & 17.2 & 223 & 1.8 \\
\hline 1996 & 12,327 & 9,935 & 80.6 & 2,392 & 19.4 & 2,112 & 17.1 & 279 & 2.3 \\
\hline 1997 & 12,451 & 10,007 & 80.4 & 2,443 & 19.6 & 2,140 & 17.2 & 303 & 2.4 \\
\hline 1998 & 12,437 & 9,950 & 80.0 & 2,487 & 20.0 & 2,153 & 17.3 & 334 & 2.7 \\
\hline 1999 & 12,739 & 10,174 & 79.9 & 2,565 & 20.1 & 2,185 & 17.2 & 380 & 3.0 \\
\hline 2000 & 13,155 & 10,539 & 80.1 & 2,616 & 19.9 & 2,213 & 16.8 & 403 & 3.1 \\
\hline 2001 & 13,716 & 10,986 & 80.1 & 2,730 & 19.9 & 2,258 & 16.5 & 472 & 3.4 \\
\hline 2002 & 14,257 & 11,433 & 80.2 & 2,824 & 19.8 & 2,306 & 16.2 & 518 & 3.6 \\
\hline 2003 & 14,480 & 11,523 & 79.6 & 2,957 & 20.4 & 2,347 & 16.2 & 611 & 4.2 \\
\hline 2004 & 14,781 & 11,651 & 78.8 & 3,130 & 21.2 & 2,389 & 16.2 & 741 & 5.0 \\
\hline 2005 & 14,964 & 11,698 & 78.2 & 3,266 & 21.8 & 2,418 & 16.2 & 848 & 5.7 \\
\hline 2006 & 15,184 & 11,847 & 78.0 & 3,337 & 22.0 & 2,448 & 16.1 & 889 & 5.9 \\
\hline 2007 & 15,604 & 12,138 & 77.8 & 3,466 & 22.2 & 2,470 & 15.8 & 996 & 6.4 \\
\hline 2008 & 16,366 & 12,591 & 76.9 & 3,775 & 23.1 & 2,537 & 15.5 & 1,238 & 7.6 \\
\hline 2009 & 17,565 & 13,387 & 76.2 & 4,179 & 23.8 & 2,593 & 14.8 & 1,585 & 9.0 \\
\hline 2010 & 18,079 & 13,704 & 75.8 & 4,374 & 24.2 & 2,653 & 14.7 & 1,721 & 9.5 \\
\hline \multicolumn{10}{|l|}{ Projected } \\
\hline 2011 & 18,326 & 13,893 & 75.8 & 4,434 & 24.2 & - & - & - & - \\
\hline 2012 & 18,528 & 14,045 & 75.8 & 4,482 & 24.2 & - & - & - & - \\
\hline 2013 & 18,704 & 14,181 & 75.8 & 4,523 & 24.2 & - & - & - & - \\
\hline 2014 & 18,894 & 14,329 & 75.8 & 4,566 & 24.2 & - & - & - & - \\
\hline 2015 & 19,050 & 14,451 & 75.9 & 4,599 & 24.1 & - & - & - & - \\
\hline 2016 & 19,248 & 14,605 & 75.9 & 4,643 & 24.1 & - & - & - & - \\
\hline 2017 & 19,515 & 14,811 & 75.9 & 4,704 & 24.1 & - & - & - & - \\
\hline 2018 & 19,824 & 15,048 & 75.9 & 4,776 & 24.1 & - & - & - & - \\
\hline 2019 & 20,129 & 15,279 & 75.9 & 4,850 & 24.1 & - & - & - & - \\
\hline 2020 & 20,395 & 15,480 & 75.9 & 4,914 & 24.1 & - & - & - & - \\
\hline$\underline{2021}$ & 20,597 & 15,632 & 75.9 & 4,965 & 24.1 & - & - & - & - \\
\hline
\end{tabular}

- Not available.

NOTE: Projections are based on data through 2010. The most recent year of actual data is 2010 , and 2021 is the last year for which projected data are available. For more information on projections, see NCES 2012-044. Data through 1995 are for institutions of higher education, while later data are for degree-granting institutions. Detail may not sum to totals because of rounding. Some data have been revised from previously published figures For more information on the Integrated Postsecondary Education Data System (IPEDS), see Appendix B - Guide to Sources. For more information on the classification of postsecondary education institutions, see Appendix C - Commonly Used Measures. See Appendix D - Glossary for definitions of full-time and part-time enrollment.

SOURCE: U.S. Department of Education, National Center for Education Statistics, Higher Education General Information Survey (HEGIS), "Fall Enrollment in Colleges and Universities" surveys, 1970 through 1985; Integrated Postsecondary Education Data System (IPEDS), "Fall Enrollment Survey" (IPEDS-EF:90-99), and Spring 2001 through Spring 2011, Enrollment component; and Enrollment in Degree-Granting Institutions Model, $1980-2010$. 
Table A-10-2. Actual and projected undergraduate enrollment in degree-granting 4- and 2-year postsecondary institutions, by sex, attendance status, and control of institution: Selected years, fall 1970-2021

[In thousands]

\begin{tabular}{|c|c|c|c|c|c|c|c|c|c|}
\hline \multirow{3}{*}{$\begin{array}{l}\text { Fall of year and level of } \\
\text { institution }\end{array}$} & \multirow[b]{3}{*}{ Total } & \multicolumn{2}{|c|}{ Sex } & \multicolumn{2}{|c|}{ Attendance status } & \multicolumn{4}{|c|}{ Control of institution } \\
\hline & & & & & & & & Private & \\
\hline & & Male & Female & Full time & Part time & Public & Total & Nonprofit & For-profit \\
\hline \multicolumn{10}{|l|}{ 4-year institutions } \\
\hline 1970 & 5,050 & 2,875 & 2,174 & 4,051 & 999 & 3,425 & 1,624 & 1,617 & 8 \\
\hline 1975 & 5,714 & 3,093 & 2,620 & 4,407 & 1,306 & 3,994 & 1,720 & 1,702 & 18 \\
\hline 1980 & 5,950 & 2,954 & 2,996 & 4,608 & 1,342 & 4,114 & 1,836 & 1,813 & 23 \\
\hline 1985 & 6,066 & 2,960 & 3,106 & 4,629 & 1,437 & 4,207 & 1,858 & 1,820 & 38 \\
\hline 1990 & 6,719 & 3,147 & 3,572 & 5,092 & 1,627 & 4,713 & 2,006 & 1,954 & 52 \\
\hline 1995 & 6,740 & 3,073 & 3,667 & 5,168 & 1,571 & 4,626 & 2,113 & 2,030 & 84 \\
\hline 2000 & 7,207 & 3,220 & 3,988 & 5,706 & 1,501 & 4,842 & 2,365 & 2,154 & 211 \\
\hline 2005 & 8,476 & 3,729 & 4,748 & 6,800 & 1,676 & 5,514 & 2,962 & 2,375 & 588 \\
\hline 2006 & 8,666 & 3,809 & 4,857 & 6,928 & 1,738 & 5,623 & 3,043 & 2,409 & 634 \\
\hline 2007 & 8,986 & 3,957 & 5,029 & 7,148 & 1,838 & 5,814 & 3,172 & 2,437 & 736 \\
\hline 2008 & 9,395 & 4,131 & 5,264 & 7,423 & 1,972 & 5,951 & 3,443 & 2,501 & 942 \\
\hline 2009 & 10,044 & 4,399 & 5,645 & 7,895 & 2,149 & 6,285 & 3,759 & 2,559 & 1,200 \\
\hline 2010 & 10,398 & 4,570 & 5,828 & 8,086 & 2,311 & 6,486 & 3,912 & 2,621 & 1,291 \\
\hline \multicolumn{10}{|l|}{ Projected } \\
\hline 2011 & 10,554 & 4,665 & 5,889 & 8,191 & 2,363 & 6,585 & 3,969 & - & - \\
\hline 2015 & 10,934 & 4,735 & 6,199 & 8,418 & 2,516 & 6,818 & 4,116 & - & - \\
\hline 2016 & 11,035 & 4,758 & 6,277 & 8,479 & 2,556 & 6,880 & 4,155 & - & - \\
\hline 2017 & 11,174 & 4,798 & 6,376 & 8,572 & 2,602 & 6,966 & 4,208 & - & - \\
\hline 2018 & 11,339 & 4,850 & 6,490 & 8,690 & 2,649 & 7,068 & 4,271 & - & - \\
\hline 2019 & 11,509 & 4,907 & 6,601 & 8,821 & 2,688 & 7,173 & 4,336 & - & - \\
\hline 2020 & 11,659 & 4,962 & 6,697 & 8,941 & 2,718 & 7,266 & 4,393 & - & - \\
\hline 2021 & 11,780 & 5,010 & 6,770 & 9,039 & 2,741 & 7,341 & 4,439 & - & - \\
\hline \multicolumn{10}{|l|}{ 2-year institutions } \\
\hline 1970 & 2,319 & 1,374 & 945 & 1,229 & 1,090 & 2,195 & 124 & 113 & 11 \\
\hline 1975 & 3,966 & 2,164 & 1,802 & 1,761 & 2,205 & 3,832 & 134 & 113 & 21 \\
\hline 1980 & 4,525 & 2,047 & 2,478 & 1,754 & 2,771 & 4,328 & 198 & 114 & 83 \\
\hline 1985 & 4,531 & 2,002 & 2,529 & 1,691 & 2,840 & 4,270 & 261 & 109 & 153 \\
\hline 1990 & 5,240 & 2,233 & 3,007 & 1,884 & 3,356 & 4,996 & 244 & 89 & 154 \\
\hline 1995 & 5,492 & 2,329 & 3,164 & 1,977 & 3,515 & 5,277 & 215 & 75 & 140 \\
\hline 2000 & 5,948 & 2,559 & 3,390 & 2,217 & 3,731 & 5,697 & 251 & 59 & 192 \\
\hline 2005 & 6,488 & 2,680 & 3,808 & 2,647 & 3,841 & 6,184 & 304 & 44 & 260 \\
\hline 2006 & 6,518 & 2,705 & 3,814 & 2,643 & 3,875 & 6,225 & 293 & 39 & 254 \\
\hline 2007 & 6,618 & 2,770 & 3,847 & 2,692 & 3,925 & 6,324 & 294 & 33 & 260 \\
\hline 2008 & 6,971 & 2,936 & 4,035 & 2,832 & 4,139 & 6,640 & 331 & 35 & 296 \\
\hline 2009 & 7,521 & 3,197 & 4,325 & 3,249 & 4,273 & 7,101 & 420 & 35 & 385 \\
\hline 2010 & 7,681 & 3,265 & 4,416 & 3,365 & 4,316 & 7,218 & 463 & 33 & 430 \\
\hline \multicolumn{10}{|l|}{ Projected } \\
\hline 2011 & 7,773 & 3,314 & 4,458 & 3,372 & 4,401 & 7,308 & 465 & - & - \\
\hline 2015 & 8,116 & 3,365 & 4,751 & 3,484 & 4,632 & 7,633 & 483 & - & - \\
\hline 2016 & 8,213 & 3,381 & 4,833 & 3,518 & 4,696 & 7,725 & 488 & - & - \\
\hline 2017 & 8,341 & 3,412 & 4,930 & 3,569 & 4,772 & 7,845 & 496 & - & - \\
\hline 2018 & 8,485 & 3,451 & 5,035 & 3,630 & 4,855 & 7,980 & 505 & - & - \\
\hline 2019 & 8,620 & 3,491 & 5,129 & 3,693 & 4,928 & 8,106 & 514 & - & - \\
\hline 2020 & 8,736 & 3,526 & 5,209 & 3,746 & 4,989 & 8,214 & 521 & - & - \\
\hline$\underline{2021}$ & 8,817 & 3,554 & 5,263 & 3,780 & 5,037 & 8,291 & 526 & - & - \\
\hline
\end{tabular}

- Not available.

NOTE: Projections are based on data through 2010. The most recent year of actual data is 2010 , and 2021 is the last year for which projected data are available. For more information on projections, see NCES 2012-044. Beginning in 1980, 2-year institutions include schools accredited by the Accrediting Commission of Career Schools and Colleges of Technology. Data through 1995 are for institutions of higher education, while later data are for

degree-granting institutions. Detail may not sum to totals because of rounding. Some data have been revised from previously published figures. For more information on the Integrated Postsecondary Education Data System (IPEDS), see Appendix B - Guide to Sources. For more information on the classification of postsecondary education institutions, see Appendix C - Commonly Used Measures. See Appendix D - Glossary for definitions of fulltime and part-time enrollment.

SOURCE: U.S. Department of Education, National Center for Education Statistics, Higher Education General Information Survey (HEGIS), "Fall Enrollment in Colleges and Universities" surveys, 1970 through 1985; Integrated Postsecondary Education Data System (IPEDS), "Fall Enrollment Survey" (IPEDS-

EF:90-99), and Spring 2001 through Spring 2011, Enrollment component; and Enrollment in Degree-Granting Institutions Model, 1980-2010. 
Table A-10-3. Undergraduate enrollment of U.S. residents and percentage distribution of students in degree-granting postsecondary institutions, by race/ethnicity and sex: Selected years, fall 1976-2010

\begin{tabular}{|c|c|c|c|c|c|c|c|c|c|c|}
\hline \multirow[b]{2}{*}{ Race/ethnicity and sex } & \multicolumn{5}{|c|}{ Enrollment (in thousands) } & \multicolumn{5}{|c|}{ Percentage distribution of students } \\
\hline & 1976 & 1980 & 1990 & 2000 & 2010 & 1976 & 1980 & 1990 & 2000 & 2010 \\
\hline Total & 9,276 & 10,259 & 11,740 & 12,867 & 17,678 & 100.0 & 100.0 & 100.0 & 100.0 & 100.0 \\
\hline White & 7,740 & 8,481 & 9,273 & 8,983 & 10,898 & 83.4 & 82.7 & 79.0 & 69.8 & 61.6 \\
\hline Black & 943 & 1,019 & 1,147 & 1,549 & 2,677 & 10.2 & 9.9 & 9.8 & 12.0 & 15.1 \\
\hline Hispanic & 353 & 433 & 725 & 1,351 & 2,544 & 3.8 & 4.2 & 6.2 & 10.5 & 14.4 \\
\hline Asian/Pacific Islander & 169 & 249 & 500 & 846 & 1,088 & 1.8 & 2.4 & 4.3 & 6.6 & 6.2 \\
\hline Asian & - & - & - & - & 1,030 & - & - & - & - & 5.8 \\
\hline Pacific Islander & - & - & - & - & 58 & - & - & - & - & 0.3 \\
\hline American Indian/Alaska Native & 70 & 78 & 95 & 139 & 179 & 0.8 & 0.8 & 0.8 & 1.1 & 1.0 \\
\hline Two or more races & - & - & - & - & 294 & - & - & - & - & 1.7 \\
\hline Male & 4,800 & 4,858 & 5,254 & 5,628 & 7,633 & 100.0 & 100.0 & 100.0 & 100.0 & 100.0 \\
\hline White & 4,052 & 4,055 & 4,184 & 4,010 & 4,862 & 84.4 & 83.5 & 79.6 & 71.3 & 63.7 \\
\hline Black & 431 & 428 & 448 & 577 & 983 & 9.0 & 8.8 & 8.5 & 10.3 & 12.9 \\
\hline Hispanic & 192 & 211 & 327 & 583 & 1,080 & 4.0 & 4.3 & 6.2 & 10.4 & 14.1 \\
\hline Asian/Pacific Islander & 91 & 129 & 254 & 402 & 514 & 1.9 & 2.6 & 4.8 & 7.1 & 6.7 \\
\hline Asian & - & - & - & - & 488 & - & - & - & - & 6.4 \\
\hline Pacific Islander & - & - & - & - & 26 & - & - & - & - & 0.3 \\
\hline American Indian/Alaska Native & 35 & 35 & 40 & 56 & 72 & 0.7 & 0.7 & 0.8 & 1.0 & 0.9 \\
\hline Two or more races & - & - & - & - & 122 & - & - & - & - & 1.6 \\
\hline Female & 4,475 & 5,402 & 6,487 & 7,239 & 10,045 & 100.0 & 100.0 & 100.0 & 100.0 & 100.0 \\
\hline White & 3,688 & 4,426 & 5,088 & 4,973 & 6,036 & 82.4 & 81.9 & 78.4 & 68.7 & 60.1 \\
\hline Black & 513 & 591 & 699 & 972 & 1,694 & 11.5 & 10.9 & 10.8 & 13.4 & 16.9 \\
\hline Hispanic & 161 & 222 & 398 & 768 & 1,464 & 3.6 & 4.1 & 6.1 & 10.6 & 14.6 \\
\hline Asian/Pacific Islander & 78 & 120 & 246 & 444 & 574 & 1.7 & 2.2 & 3.8 & 6.1 & 5.7 \\
\hline Asian & - & - & - & - & 543 & - & - & - & - & 5.4 \\
\hline Pacific Islander & - & - & - & - & 32 & - & - & - & - & 0.3 \\
\hline American Indian/Alaska Native & 35 & 43 & 56 & 82 & 107 & 0.8 & 0.8 & 0.9 & 1.1 & 1.1 \\
\hline Two or more races & - & - & - & - & 171 & - & - & - & - & 1.7 \\
\hline
\end{tabular}

-Not available.

NOTE: Race categories exclude persons of Hispanic ethnicity. Because of underreporting and nonreporting of racial/ethnic data and nonresident aliens, some estimates are slightly lower than corresponding data in other published tables. For more information on race/ethnicity or the classification of postsecondary education institutions, see Appendix C - Commonly Used Measures. Data through 1995 are for institutions of higher education, while later data are for degree-granting institutions. For more information on the Integrated Postsecondary Education Data System (IPEDS), see Appendix B Guide to Sources. Detail may not sum to totals because of rounding.

SOURCE: U.S. Department of Education, National Center for Education Statistics, Higher Education General Information Survey (HEGIS), "Fall Enrollment in Colleges and Universities" surveys, 1976 and 1980; and Integrated Postsecondary Education Data System (IPEDS), "Fall Enrollment Survey" (IPEDS$\mathrm{EF}: 90)$, and Spring 2001 and Spring 2011, Enrollment component. 
Table A-11-1. Number and percentage distribution of actual and projected postbaccalaureate enrollment in degree-granting postsecondary institutions, by sex, attendance status, and control of institution: Fall 1976-2021

[Numbers in thousands]

\begin{tabular}{|c|c|c|c|c|c|c|c|c|c|}
\hline \multirow{3}{*}{ Fall of year } & \multirow[b]{3}{*}{ Total } & \multicolumn{4}{|c|}{ Sex } & \multicolumn{4}{|c|}{ Attendance status } \\
\hline & & \multicolumn{2}{|c|}{ Male } & \multicolumn{2}{|c|}{ Female } & \multicolumn{2}{|c|}{ Full-time } & \multicolumn{2}{|c|}{ Part-time } \\
\hline & & Number & Percent & Number & Percent & Number & Percent & Number & Percent \\
\hline 1976 & 1,578 & 905 & 57.3 & 673 & 42.7 & 684 & 43.3 & 894 & 56.7 \\
\hline 1977 & 1,569 & 892 & 56.8 & 677 & 43.2 & 699 & 44.5 & 870 & 55.5 \\
\hline 1978 & 1,576 & 880 & 55.8 & 696 & 44.2 & 705 & 44.7 & 871 & 55.3 \\
\hline 1979 & 1,572 & 863 & 54.9 & 709 & 45.1 & 715 & 45.5 & 857 & 54.5 \\
\hline 1980 & 1,622 & 874 & 53.9 & 748 & 46.1 & 736 & 45.4 & 886 & 54.6 \\
\hline 1981 & 1,617 & 867 & 53.6 & 750 & 46.4 & 732 & 45.3 & 885 & 54.7 \\
\hline 1982 & 1,601 & 861 & 53.8 & 740 & 46.2 & 737 & 46.0 & 864 & 54.0 \\
\hline 1983 & 1,619 & 865 & 53.5 & 753 & 46.5 & 747 & 46.2 & 872 & 53.8 \\
\hline 1984 & 1,624 & 857 & 52.8 & 767 & 47.2 & 751 & 46.2 & 873 & 53.8 \\
\hline 1985 & 1,650 & 856 & 51.9 & 794 & 48.1 & 756 & 45.8 & 895 & 54.2 \\
\hline 1986 & 1,706 & 867 & 50.8 & 839 & 49.2 & 767 & 45.0 & 938 & 55.0 \\
\hline 1987 & 1,720 & 864 & 50.2 & 857 & 49.8 & 769 & 44.7 & 952 & 55.3 \\
\hline 1988 & 1,739 & 864 & 49.7 & 875 & 50.3 & 794 & 45.7 & 944 & 54.3 \\
\hline 1989 & 1,796 & 879 & 48.9 & 917 & 51.1 & 820 & 45.7 & 976 & 54.3 \\
\hline 1990 & 1,860 & 904 & 48.6 & 955 & 51.4 & 845 & 45.4 & 1,015 & 54.6 \\
\hline 1991 & 1,920 & 931 & 48.5 & 989 & 51.5 & 894 & 46.6 & 1,026 & 53.4 \\
\hline 1992 & 1,950 & 941 & 48.3 & 1,009 & 51.7 & 918 & 47.1 & 1,032 & 52.9 \\
\hline 1993 & 1,981 & 944 & 47.6 & 1,037 & 52.4 & 948 & 47.9 & 1,033 & 52.1 \\
\hline 1994 & 2,016 & 950 & 47.1 & 1,066 & 52.9 & 969 & 48.1 & 1,047 & 51.9 \\
\hline 1995 & 2,030 & 941 & 46.4 & 1,089 & 53.6 & 984 & 48.4 & 1,047 & 51.6 \\
\hline 1996 & 2,041 & 932 & 45.7 & 1,108 & 54.3 & 1,004 & 49.2 & 1,036 & 50.8 \\
\hline 1997 & 2,052 & 927 & 45.2 & 1,124 & 54.8 & 1,019 & 49.7 & 1,032 & 50.3 \\
\hline 1998 & 2,070 & 923 & 44.6 & 1,147 & 55.4 & 1,025 & 49.5 & 1,045 & 50.5 \\
\hline 1999 & 2,110 & 931 & 44.1 & 1,179 & 55.9 & 1,050 & 49.7 & 1,061 & 50.3 \\
\hline 2000 & 2,157 & 944 & 43.7 & 1,213 & 56.3 & 1,087 & 50.4 & 1,070 & 49.6 \\
\hline 2001 & 2,212 & 956 & 43.2 & 1,256 & 56.8 & 1,120 & 50.6 & 1,093 & 49.4 \\
\hline 2002 & 2,355 & 1,010 & 42.9 & 1,345 & 57.1 & 1,212 & 51.5 & 1,143 & 48.5 \\
\hline 2003 & 2,431 & 1,033 & 42.5 & 1,398 & 57.5 & 1,281 & 52.7 & 1,150 & 47.3 \\
\hline 2004 & 2,491 & 1,047 & 42.0 & 1,444 & 58.0 & 1,326 & 53.2 & 1,166 & 46.8 \\
\hline 2005 & 2,524 & 1,047 & 41.5 & 1,476 & 58.5 & 1,351 & 53.5 & 1,173 & 46.5 \\
\hline 2006 & 2,575 & 1,061 & 41.2 & 1,514 & 58.8 & 1,386 & 53.8 & 1,188 & 46.2 \\
\hline 2007 & 2,644 & 1,088 & 41.2 & 1,556 & 58.8 & 1,429 & 54.0 & 1,215 & 46.0 \\
\hline 2008 & 2,737 & 1,122 & 41.0 & 1,615 & 59.0 & 1,493 & 54.5 & 1,244 & 45.5 \\
\hline 2009 & 2,862 & 1,174 & 41.0 & 1,688 & 59.0 & 1,579 & 55.2 & 1,283 & 44.8 \\
\hline 2010 & 2,937 & 1,210 & 41.2 & 1,728 & 58.8 & 1,631 & 55.5 & 1,307 & 44.5 \\
\hline \multicolumn{10}{|l|}{ Projected ${ }^{1}$} \\
\hline 2011 & 2,968 & 1,224 & 41.2 & 1,744 & 58.8 & 1,621 & 54.6 & 1,347 & 45.4 \\
\hline 2012 & 3,029 & 1,248 & 41.2 & 1,781 & 58.8 & 1,658 & 54.7 & 1,371 & 45.3 \\
\hline 2013 & 3,088 & 1,265 & 41.0 & 1,823 & 59.0 & 1,692 & 54.8 & 1,397 & 45.2 \\
\hline 2014 & 3,148 & 1,277 & 40.6 & 1,871 & 59.4 & 1,723 & 54.7 & 1,425 & 45.3 \\
\hline 2015 & 3,202 & 1,288 & 40.2 & 1,914 & 59.8 & 1,750 & 54.7 & 1,453 & 45.4 \\
\hline 2016 & 3,261 & 1,304 & 40.0 & 1,957 & 60.0 & 1,778 & 54.5 & 1,482 & 45.4 \\
\hline 2017 & 3,327 & 1,323 & 39.8 & 2,004 & 60.2 & 1,811 & 54.4 & 1,516 & 45.6 \\
\hline 2018 & 3,394 & 1,343 & 39.6 & 2,052 & 60.5 & 1,843 & 54.3 & 1,551 & 45.7 \\
\hline 2019 & 3,440 & 1,355 & 39.4 & 2,085 & 60.6 & 1,862 & 54.1 & 1,578 & 45.9 \\
\hline 2020 & 3,472 & 1,363 & 39.3 & 2,110 & 60.8 & 1,873 & 53.9 & 1,599 & 46.1 \\
\hline 2021 & 3,495 & 1,369 & 39.2 & 2,126 & 60.8 & 1,881 & 53.8 & 1,614 & 46.2 \\
\hline
\end{tabular}

See notes at end of table. 
Table A-11-1. Number and percentage distribution of actual and projected postbaccalaureate enrollment in degree-granting postsecondary institutions, by sex, attendance status, and control of institution: Fall 1976-2021-Continued

[Numbers in thousands]

\begin{tabular}{|c|c|c|c|c|c|c|c|c|c|}
\hline \multirow[b]{4}{*}{ Fall of year } & \multirow[b]{4}{*}{ Total } & \multicolumn{8}{|c|}{ Control of institution } \\
\hline & & \multicolumn{2}{|c|}{ Public } & \multicolumn{6}{|c|}{ Private } \\
\hline & & \multirow[b]{2}{*}{ Number } & \multirow[b]{2}{*}{ Percent } & \multicolumn{2}{|c|}{ Total } & \multicolumn{2}{|c|}{ Nonprofit } & \multicolumn{2}{|c|}{ For-profit } \\
\hline & & & & Number & Percent & Number & Percent & Number & Percent \\
\hline 1976 & 1,578 & 1,033 & 65.5 & 544 & 34.5 & 541 & 34.3 & 3 & 0.2 \\
\hline 1977 & 1,569 & 1,004 & 64.0 & 565 & 36.0 & 561 & 35.8 & 4 & 0.2 \\
\hline 1978 & 1,576 & 999 & 63.4 & 577 & 36.6 & 574 & 36.4 & 4 & 0.2 \\
\hline 1979 & 1,572 & 990 & 63.0 & 582 & 37.0 & 578 & 36.8 & 4 & 0.2 \\
\hline 1980 & 1,622 & 1,015 & 62.6 & 606 & 37.4 & 601 & 37.1 & 5 & 0.3 \\
\hline 1981 & 1,617 & 999 & 61.8 & 618 & 38.2 & 614 & 37.9 & 5 & 0.3 \\
\hline 1982 & 1,601 & 983 & 61.4 & 618 & 38.6 & 613 & 38.3 & 4 & 0.3 \\
\hline 1983 & 1,619 & 986 & 60.9 & 633 & 39.1 & 628 & 38.8 & 5 & 0.3 \\
\hline 1984 & 1,624 & 984 & 60.6 & 640 & 39.4 & 634 & 39.0 & 6 & 0.4 \\
\hline 1985 & 1,650 & 1,002 & 60.7 & 648 & 39.3 & 643 & 38.9 & 5 & 0.3 \\
\hline 1986 & 1,706 & 1,053 & 61.8 & 652 & 38.2 & 644 & 37.8 & 8 & 0.5 \\
\hline 1987 & 1,720 & 1,055 & 61.3 & 666 & 38.7 & 662 & 38.5 & 3 & 0.2 \\
\hline 1988 & 1,739 & 1,058 & 60.9 & 681 & 39.1 & - & - & - & - \\
\hline 1989 & 1,796 & 1,090 & 60.7 & 706 & 39.3 & - & - & - & - \\
\hline 1990 & 1,860 & 1,135 & 61.0 & 724 & 39.0 & 717 & 38.5 & 8 & 0.4 \\
\hline 1991 & 1,920 & 1,162 & 60.5 & 758 & 39.5 & 747 & 38.9 & 11 & 0.6 \\
\hline 1992 & 1,950 & 1,168 & 59.9 & 781 & 40.1 & 771 & 39.5 & 11 & 0.5 \\
\hline 1993 & 1,981 & 1,177 & 59.4 & 804 & 40.6 & 790 & 39.9 & 14 & 0.7 \\
\hline 1994 & 2,016 & 1,189 & 59.0 & 828 & 41.0 & 810 & 40.2 & 18 & 0.9 \\
\hline 1995 & 2,030 & 1,189 & 58.6 & 841 & 41.4 & 824 & 40.6 & 17 & 0.8 \\
\hline 1996 & 2,041 & 1,185 & 58.1 & 855 & 41.9 & 830 & 40.7 & 25 & 1.2 \\
\hline 1997 & 2,052 & 1,189 & 57.9 & 863 & 42.1 & 838 & 40.8 & 25 & 1.2 \\
\hline 1998 & 2,070 & 1,188 & 57.4 & 882 & 42.6 & 852 & 41.2 & 30 & 1.5 \\
\hline 1999 & 2,110 & 1,202 & 56.9 & 909 & 43.1 & 870 & 41.2 & 39 & 1.8 \\
\hline 2000 & 2,157 & 1,213 & 56.3 & 943 & 43.7 & 896 & 41.6 & 47 & 2.2 \\
\hline 2001 & 2,212 & 1,247 & 56.4 & 965 & 43.6 & 910 & 41.1 & 55 & 2.5 \\
\hline 2002 & 2,355 & 1,319 & 56.0 & 1,035 & 44.0 & 959 & 40.7 & 76 & 3.2 \\
\hline 2003 & 2,431 & 1,336 & 54.9 & 1,096 & 45.1 & 994 & 40.9 & 101 & 4.2 \\
\hline 2004 & 2,491 & 1,330 & 53.4 & 1,162 & 46.6 & 1,022 & 41.0 & 140 & 5.6 \\
\hline 2005 & 2,524 & 1,324 & 52.5 & 1,199 & 47.5 & 1,036 & 41.1 & 163 & 6.5 \\
\hline 2006 & 2,575 & 1,333 & 51.8 & 1,242 & 48.2 & 1,065 & 41.4 & 177 & 6.9 \\
\hline 2007 & 2,644 & 1,353 & 51.2 & 1,291 & 48.8 & 1,101 & 41.6 & 190 & 7.2 \\
\hline 2008 & 2,737 & 1,381 & 50.5 & 1,356 & 49.5 & 1,125 & 41.1 & 231 & 8.4 \\
\hline 2009 & 2,862 & 1,424 & 49.8 & 1,438 & 50.2 & 1,172 & 40.9 & 267 & 9.3 \\
\hline 2010 & 2,937 & 1,439 & 49.0 & 1,499 & 51.0 & 1,202 & 40.9 & 297 & 10.1 \\
\hline \multicolumn{10}{|l|}{ Projected $^{1}$} \\
\hline 2011 & 2,968 & 1,455 & 49.0 & 1,513 & 51.0 & - & - & - & - \\
\hline 2012 & 3,029 & 1,484 & 49.0 & 1,545 & 51.0 & - & - & - & 一 \\
\hline 2013 & 3,088 & 1,513 & 49.0 & 1,575 & 51.0 & - & - & - & 一 \\
\hline 2014 & 3,148 & 1,543 & 49.0 & 1,606 & 51.0 & - & - & - & - \\
\hline 2015 & 3,202 & 1,569 & 49.0 & 1,633 & 51.0 & - & - & - & - \\
\hline 2016 & 3,261 & 1,598 & 49.0 & 1,663 & 51.0 & - & - & - & - \\
\hline 2017 & 3,327 & 1,630 & 49.0 & 1,697 & 51.0 & - & - & - & 一 \\
\hline 2018 & 3,394 & 1,664 & 49.0 & 1,731 & 51.0 & - & - & - & 一 \\
\hline 2019 & 3,440 & 1,686 & 49.0 & 1,754 & 51.0 & - & - & - & 一 \\
\hline 2020 & 3,472 & 1,702 & 49.0 & 1,770 & 51.0 & - & - & - & 一 \\
\hline 2021 & 3,495 & 1,714 & 49.0 & 1,782 & 51.0 & 一 & - & 一 & 一 \\
\hline
\end{tabular}

-Not available

'Projections are based on reported data through 2010. The most recent year of actual data is 2010 , and 2021 is the last year for which projected data are available. For more information on projections, see NCES 2012-044.

NOTE: Postbaccalaureate enrollment is the number of students with a bachelor's degree who are enrolled in master's or doctoral programs, including those formerly classified as first-professional programs. Detail may not sum to totals because of rounding. For more information on the Integrated Postsecondary Education Data System (IPEDS), see Appendix B - Guide to Sources. For more information on the classification of postsecondary education institutions, see Appendix C - Commonly Used Measures. See Appendix D - Glossary for definitions of full-time and part-time enrollment. SOURCE: U.S. Department of Education, National Center for Education Statistics, Higher Education General Information Survey (HEGIS), "Fall Enrollment in Colleges and Universities" surveys, 1970 through 1985; Integrated Postsecondary Education Data System (IPEDS), "Fall Enrollment Survey" (IPEDSEF:90-99); IPEDS Spring 2001 through Spring 2011, Enrollment component; and Enrollment in Degree-Granting Institutions Model, 1980-2010. 


\section{Indicator 71}

\section{Postbaccaloureate Enrollment}

Table A-11-2. Postbaccalaureate enrollment of U.S. residents and percentage distribution of students in degreegranting postsecondary institutions, by race/ethnicity and sex: Selected years, fall 1976-fall 2010

\begin{tabular}{|c|c|c|c|c|c|c|c|c|c|c|}
\hline \multirow[b]{2}{*}{ Race/ethnicity and sex } & \multicolumn{5}{|c|}{ Enrollment (in thousands) } & \multicolumn{5}{|c|}{ Percentage distribution of students } \\
\hline & 1976 & 1980 & 1990 & 2000 & 2010 & 1976 & 1980 & 1990 & 2000 & 2010 \\
\hline Total & 1,492 & 1,523 & 1,687 & 1,916 & 2,628 & 100.0 & 100.0 & 100.0 & 100.0 & 100.0 \\
\hline White & 1,336 & 1,352 & 1,450 & 1,479 & 1,825 & 89.5 & 88.8 & 86.0 & 77.2 & 69.4 \\
\hline Black & 90 & 88 & 100 & 181 & 362 & 6.0 & 5.8 & 5.9 & 9.4 & 13.8 \\
\hline Hispanic & 31 & 39 & 58 & 111 & 198 & 2.1 & 2.6 & 3.4 & 5.8 & 7.5 \\
\hline Asian/Pacific Islander & 29 & 38 & 72 & 133 & 194 & 1.9 & 2.5 & 4.3 & 6.9 & 7.4 \\
\hline Asian & - & - & - & - & 188 & - & - & - & - & 7.2 \\
\hline Pacific Islander & - & - & - & - & 6 & - & - & - & - & 0.2 \\
\hline American Indian/Alaska Native & 6 & 6 & 7 & 13 & 17 & 0.4 & 0.4 & 0.4 & 0.7 & 0.6 \\
\hline Two or more races & - & - & - & - & 32 & - & - & - & - & 1.2 \\
\hline Male & 840 & 800 & 784 & 797 & 1,032 & 100.0 & 100.0 & 100.0 & 100.0 & 100.0 \\
\hline White & 762 & 718 & 677 & 625 & 745 & 90.7 & 89.8 & 86.4 & 78.4 & 72.2 \\
\hline Black & 39 & 36 & 37 & 58 & 106 & 4.6 & 4.5 & 4.7 & 7.3 & 10.3 \\
\hline Hispanic & 18 & 20 & 27 & 45 & 75 & 2.1 & 2.5 & 3.4 & 5.6 & 7.3 \\
\hline Asian/Pacific Islander & 17 & 23 & 40 & 64 & 87 & 2.0 & 2.9 & 5.1 & 8.0 & 8.4 \\
\hline Asian & - & - & - & - & 85 & - & - & - & - & 8.2 \\
\hline Pacific Islander & - & - & - & - & 3 & - & - & - & - & 0.3 \\
\hline American Indian/Alaska Native & 4 & 3 & 3 & 5 & 6 & 0.5 & 0.4 & 0.4 & 0.6 & 0.6 \\
\hline Two or more races & - & - & - & - & 12 & - & - & - & - & 1.2 \\
\hline Female & 651 & 723 & 902 & 1,119 & 1,597 & 100.0 & 100.0 & 100.0 & 100.0 & 100.0 \\
\hline White & 574 & 634 & 773 & 854 & 1,080 & 88.2 & 87.7 & 85.7 & 76.3 & 67.6 \\
\hline Black & 50 & 52 & 63 & 123 & 256 & 7.7 & 7.2 & 7.0 & 11.0 & 16.0 \\
\hline Hispanic & 13 & 18 & 31 & 66 & 123 & 2.0 & 2.5 & 3.4 & 5.9 & 7.7 \\
\hline Asian/Pacific Islander & 11 & 15 & 32 & 69 & 107 & 1.7 & 2.1 & 3.5 & 6.2 & 6.7 \\
\hline Asian & - & - & - & - & 103 & - & - & - & - & 6.4 \\
\hline Pacific Islander & - & - & - & - & 4 & - & - & - & - & 0.3 \\
\hline American Indian/Alaska Native & 3 & 3 & 4 & 8 & 11 & 0.5 & 0.4 & 0.4 & 0.7 & 0.7 \\
\hline Two or more races & - & - & - & - & 20 & - & - & - & - & 1.3 \\
\hline
\end{tabular}

\section{-Not available.}

NOTE: Postbaccalaureate enrollment is the number of students with a bachelor's degree who are enrolled in master's or doctoral programs, including those formerly classified as first-professional programs. Because of underreporting and nonreporting of racial/ethnic data and nonresident aliens, some estimates are slightly lower than corresponding data in other published tables. Race categories exclude persons of Hispanic ethnicity. For more information on race/ethnicity, see Appendix C - Commonly Used Measures. For more information on the Integrated Postsecondary Education Data System (IPEDS), see Appendix B - Guide to Sources. Detail may not sum to totals because of rounding.

SOURCE: U.S. Department of Education, National Center for Education Statistics, Higher Education General Information Survey (HEGIS), "Fall Enrollment in Colleges and Universities" surveys, 1976 and 1980; Integrated Postsecondary Education Data System (IPEDS), "Fall Enrollment Survey" (IPEDS-EF:90);

and IPEDS Spring 2001 and Spring 2011, Enrollment component. 
11

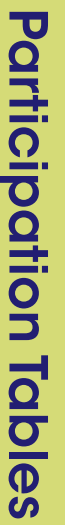

This page intentionally left blank. 
Characteristics of Elementary and Secondary Schools

Table A-12-1. Number and percentage distribution of schools, by control and selected school characteristics: School years $1999-2000$ and $2009-10$

\begin{tabular}{|c|c|c|c|c|c|c|c|c|c|c|}
\hline \multirow[b]{3}{*}{ School characteristic } & \multicolumn{5}{|c|}{$1999-2000$} & \multicolumn{5}{|c|}{$2009-10$} \\
\hline & \multirow[b]{2}{*}{ Total $^{1}$} & \multicolumn{3}{|c|}{ Public } & \multirow[b]{2}{*}{ Private } & \multirow[b]{2}{*}{ Total $^{1}$} & \multicolumn{3}{|c|}{ Public } & \multirow[b]{2}{*}{ Private } \\
\hline & & Total & $\begin{array}{l}\text { Tradi- } \\
\text { tional }\end{array}$ & Charter & & & Total & $\begin{array}{l}\text { Tradi- } \\
\text { tional }\end{array}$ & Charter & \\
\hline & \multicolumn{10}{|c|}{ Number } \\
\hline Total, all schools & 125,012 & 92,012 & 90,488 & 1,524 & 33,000 & 132,217 & 98,817 & 93,865 & 4,952 & 33,400 \\
\hline \multicolumn{11}{|l|}{ School level } \\
\hline Elementary & 86,431 & 64,131 & 63,299 & 832 & 22,300 & 88,540 & 67,140 & 64,461 & 2,679 & 21,400 \\
\hline Secondary & 24,865 & 22,365 & 21,971 & 394 & 2,500 & 27,451 & 24,651 & 23,322 & 1,329 & 2,800 \\
\hline Combined & 12,242 & 4,042 & 3,758 & 284 & 8,200 & 14,930 & 5,730 & 4,801 & 929 & 9,200 \\
\hline Other (ungraded) ${ }^{2}$ & 1,474 & 1,474 & 1,460 & 14 & $\dagger$ & 1,296 & 1,296 & 1,281 & 15 & $\dagger$ \\
\hline \multicolumn{11}{|l|}{ School type } \\
\hline Regular & 114,802 & 84,902 & 83,558 & 1,344 & 29,900 & 119,318 & 89,018 & 84,589 & 4,429 & 30,300 \\
\hline Special education & 3,347 & 1,947 & 1,940 & 7 & 1,400 & 3,889 & 2,089 & 2,006 & 83 & 1,800 \\
\hline Vocational & 1,048 & 1,048 & 1,040 & 8 & \# & 1,417 & 1,417 & 1,397 & 20 & \# \\
\hline Alternative & 5,815 & 4,115 & 3,950 & 165 & 1,700 & 7,593 & 6,293 & 5,873 & 420 & 1,300 \\
\hline & \multicolumn{10}{|c|}{ Percentage distribution } \\
\hline School level & 100.0 & 100.0 & 100.0 & 100.0 & 100.0 & 100.0 & 100.0 & 100.0 & 100.0 & 100.0 \\
\hline Elementary & 69.1 & 69.7 & 70.0 & 54.6 & 67.6 & 67.0 & 67.9 & 68.7 & 54.1 & 64.1 \\
\hline Secondary & 19.9 & 24.3 & 24.3 & 25.9 & 7.6 & 20.8 & 24.9 & 24.8 & 26.8 & 8.4 \\
\hline Combined & 9.8 & 4.4 & 4.2 & 18.6 & 24.8 & 11.3 & 5.8 & 5.1 & 18.8 & 27.5 \\
\hline Other (ungraded) ${ }^{2}$ & 1.2 & 1.6 & 1.6 & 0.9 & $\dagger$ & 1.0 & 1.3 & 1.4 & 0.3 & $\dagger$ \\
\hline School type & 100.0 & 100.0 & 100.0 & 100.0 & 100.0 & 100.0 & 100.0 & 100.0 & 100.0 & 100.0 \\
\hline Regular & 91.8 & 92.3 & 92.3 & 88.2 & 90.6 & 90.2 & 90.1 & 90.1 & 89.4 & 90.7 \\
\hline Special education & 2.7 & 2.1 & 2.1 & 0.5 & 4.2 & 2.9 & 2.1 & 2.1 & 1.7 & 5.4 \\
\hline Vocational & 0.8 & 1.1 & 1.1 & 0.5 & $\#$ & 1.1 & 1.4 & 1.5 & 0.4 & \# \\
\hline Alternative & 4.7 & 4.5 & 4.4 & 10.8 & 5.2 & 5.7 & 6.4 & 6.3 & 8.5 & 3.9 \\
\hline Enrollment size & 100.0 & 100.0 & 100.0 & 100.0 & 100.0 & 100.0 & 100.0 & 100.0 & 100.0 & 100.0 \\
\hline Fewer than 300 & 44.8 & 31.3 & 30.5 & 77.0 & 81.4 & 45.1 & 31.3 & 29.7 & 61.3 & 84.6 \\
\hline $300-499$ & 22.4 & 26.5 & 26.7 & 12.0 & 11.3 & 22.8 & 27.7 & 28.0 & 21.0 & 9.0 \\
\hline 500-999 & 25.6 & 32.8 & 33.2 & 8.7 & 6.3 & 25.1 & 32.1 & 33.1 & 14.0 & 5.3 \\
\hline 1,000 or more & 7.2 & 9.5 & 9.7 & 2.4 & 1.0 & 6.9 & 9.0 & 9.3 & 3.7 & 1.0 \\
\hline
\end{tabular}

See notes at end of table. 
Table A-12-1. Number and percentage distribution of schools, by control and selected school characteristics: School years 1999-2000 and 2009-10-Continued

\begin{tabular}{|c|c|c|c|c|c|c|c|c|c|c|}
\hline \multirow[b]{3}{*}{ School characteristic } & \multicolumn{5}{|c|}{$1999-2000$} & \multicolumn{5}{|c|}{$2009-10$} \\
\hline & \multirow[b]{2}{*}{ Total $^{1}$} & \multicolumn{3}{|c|}{ Public } & \multirow[b]{2}{*}{ Private } & \multirow[b]{2}{*}{ Total $^{1}$} & \multicolumn{3}{|c|}{ Public } & \multirow[b]{2}{*}{ Private } \\
\hline & & Total & $\begin{array}{l}\text { Tradi- } \\
\text { tional }\end{array}$ & Charter & & & Total & $\begin{array}{l}\text { Tradi- } \\
\text { tional }\end{array}$ & Charter & \\
\hline & & & & & Nun & ber & & & & \\
\hline \multirow[t]{2}{*}{ Total, all schools } & 125,012 & 92,012 & 90,488 & 1,524 & 33,000 & 132,217 & 98,817 & 93,865 & 4,952 & 33,400 \\
\hline & \multicolumn{10}{|c|}{ Percentage distribution } \\
\hline \multicolumn{11}{|l|}{ Racial/ethnic concentration of schools } \\
\hline More than 50 percent White & 73.5 & 70.9 & 71.2 & 51.1 & 80.3 & 65.6 & 62.3 & 63.4 & 40.5 & 75.2 \\
\hline More than 50 percent Black & 10.3 & 11.1 & 10.8 & 26.5 & 8.0 & 10.5 & 11.4 & 10.6 & 26.1 & 7.9 \\
\hline More than 50 percent Hispanic & 7.4 & 8.8 & 8.7 & 11.4 & 3.7 & 11.6 & 14.0 & 13.7 & 20.0 & 4.6 \\
\hline $\begin{array}{l}\text { Percentage of students in school eligible } \\
\text { for free or reduced-price lunch }\end{array}$ & - & 100.0 & 100.0 & 100.0 & - & - & 100.0 & 100.0 & 100.0 & - \\
\hline 0-25 percent & - & 30.6 & 30.6 & 35.8 & - & - & 20.4 & 20.4 & 19.2 & - \\
\hline 26-50 percent & - & 25.6 & 25.9 & 11.1 & - & - & 27.0 & 27.6 & 17.2 & - \\
\hline 51-75 percent & - & 16.8 & 16.9 & 10.2 & - & - & 25.5 & 25.7 & 20.9 & - \\
\hline 76-100 percent & - & 11.9 & 11.9 & 12.4 & - & - & 19.9 & 19.2 & 32.9 & - \\
\hline Missing/school did not participate & - & 15.0 & 14.7 & 30.6 & - & - & 7.2 & 7.1 & 9.8 & - \\
\hline Region & 100.0 & 100.0 & 100.0 & 100.0 & 100.0 & 100.0 & 100.0 & 100.0 & 100.0 & 100.0 \\
\hline Northeast & 18.4 & 16.1 & 16.3 & 7.2 & 24.7 & 17.4 & 15.5 & 15.9 & 9.1 & 22.9 \\
\hline Midwest & 27.7 & 28.9 & 29.0 & 24.9 & 24.1 & 26.3 & 26.7 & 26.8 & 24.0 & 25.2 \\
\hline South & 32.2 & 33.1 & 33.2 & 28.9 & 29.7 & 33.7 & 34.5 & 34.8 & 29.5 & 31.4 \\
\hline West & 21.7 & 21.8 & 21.6 & 38.9 & 21.4 & 22.6 & 23.3 & 22.5 & 37.4 & 20.4 \\
\hline School locale & - & - & - & - & - & 100.0 & 100.0 & 100.0 & 100.0 & 100.0 \\
\hline City & - & - & - & - & - & 27.7 & 26.1 & 24.6 & 54.8 & 32.4 \\
\hline Suburban & - & - & - & - & - & 29.3 & 27.4 & 27.7 & 21.1 & 34.8 \\
\hline Town & - & - & - & - & - & 13.1 & 14.2 & 14.5 & 8.0 & 10.0 \\
\hline Rural & - & - & - & - & - & 29.9 & 32.4 & 33.2 & 16.1 & 22.8 \\
\hline
\end{tabular}

- Not available.

† Not applicable.

\# Rounds to zero.

1 Total number of schools does not always equal the sum of schools by level because the total may include ungraded schools and schools that did not report grade spans.

2 Total is only for public schools, as data for private schools were not applicable.

NOTE: Schools that did not report enrollment were excluded from the percentage distribution. Combined schools are those that have both elementary and secondary grades. Public school data are universe estimates and are rounded to whole numbers. Private school data are sample estimates and are rounded to the nearest 100. Race categories exclude persons of Hispanic ethnicity. For more information on race/ethnicity, the free or reducedprice lunch program, region, and locale, see Appendix C - Commonly Used Measures. Detail may not sum to totals because of rounding. For more information on the Common Core of Data (CCD) or the Private School Survey (PSS), see Appendix B - Guide to Sources.

SOURCE: U.S. Department of Education, National Center for Education Statistics, Common Core of Data (CCD), "Public Elementary/Secondary School Universe Survey," 1999-2000 (version 1b) and 2009-10 (version 1b); and Private School Survey (PSS), 1999-2000 and 2009-10. 


\section{Concentration of Public School Students Eligible for Free or Reduced-Price Lunch}

Table A-13-1. Number of public school students and percentage distribution of students, by school concentration of students eligible for free or reduced-price lunch, race/ethnicity, and school level: School year 2009-10

\begin{tabular}{|c|c|c|c|c|c|c|c|}
\hline \multirow[b]{2}{*}{ Race/ethnicity and school level } & \multirow[b]{2}{*}{$\begin{array}{l}\text { Number of public } \\
\text { school students }^{1}\end{array}$} & \multicolumn{6}{|c|}{$\begin{array}{l}\text { Percentage distribution of school concentration of students eligible } \\
\text { for free or reduced-price lunch }\end{array}$} \\
\hline & & Total & $0-25$ & $26-50$ & $51-75$ & $76-100$ & $\begin{array}{r}\text { Missing/ } \\
\text { school } \\
\text { does not } \\
\text { participate } \\
\end{array}$ \\
\hline Total $^{2}$ & $49,136,240$ & 100.0 & 24.6 & 28.8 & 25.1 & 18.6 & 3.0 \\
\hline White & $26,311,473$ & 100.0 & 33.9 & 36.2 & 22.7 & 5.6 & 1.6 \\
\hline Black & $8,166,410$ & 100.0 & 8.5 & 19.8 & 29.7 & 37.3 & 4.7 \\
\hline Hispanic & $10,775,975$ & 100.0 & 11.8 & 18.0 & 28.5 & 37.4 & 4.3 \\
\hline Asian/Pacific Islander & $2,461,820$ & 100.0 & 37.3 & 25.8 & 18.5 & 11.6 & 6.9 \\
\hline American Indian/Alaska Native & 584,756 & 100.0 & 12.1 & 25.6 & 31.7 & 28.9 & 1.6 \\
\hline Race/ethnicity unknown & 835,806 & 100.0 & 26.5 & 30.4 & 26.3 & 15.4 & 1.4 \\
\hline Elementary & $31,537,864$ & 100.0 & 22.4 & 25.5 & 26.3 & 23.2 & 2.6 \\
\hline White & $16,446,316$ & 100.0 & 31.4 & 33.4 & 26.4 & 7.4 & 1.3 \\
\hline Black & $5,261,630$ & 100.0 & 6.9 & 16.0 & 27.7 & 45.6 & 3.9 \\
\hline Hispanic & $7,274,077$ & 100.0 & 10.6 & 14.7 & 26.2 & 44.7 & 3.8 \\
\hline Asian/Pacific Islander & $1,579,964$ & 100.0 & 36.9 & 23.9 & 18.3 & 14.2 & 6.8 \\
\hline American Indian/Alaska Native & 363,990 & 100.0 & 9.5 & 21.8 & 32.8 & 34.7 & 1.2 \\
\hline Race/ethnicity unknown & 611,887 & 100.0 & 24.6 & 28.7 & 27.6 & 18.2 & 0.9 \\
\hline Secondary & $15,993,562$ & 100.0 & 29.6 & 35.6 & 22.4 & 9.3 & 3.0 \\
\hline White & $8,984,410$ & 100.0 & 39.5 & 41.7 & 15.1 & 2.0 & 1.6 \\
\hline Black & $2,587,940$ & 100.0 & 11.9 & 28.3 & 34.2 & 20.6 & 5.1 \\
\hline Hispanic & $3,204,604$ & 100.0 & 14.5 & 25.9 & 34.0 & 21.2 & 4.5 \\
\hline Asian/Pacific Islander & 830,098 & 100.0 & 38.5 & 29.8 & 18.7 & 6.7 & 6.3 \\
\hline American Indian/Alaska Native & 188,626 & 100.0 & 17.4 & 34.5 & 29.7 & 16.7 & 1.7 \\
\hline Race/ethnicity unknown & 197,884 & 100.0 & 32.3 & 36.0 & 22.9 & 7.0 & 1.7 \\
\hline
\end{tabular}

1 Includes students enrolled in schools that did not report free or reduced-price lunch eligibility.

2 Includes students who attended combined elementary and secondary schools not shown separately.

NOTE: The National School Lunch Program is a federally assisted meal program. To be eligible for free lunch under the program, a student must be from a household with an income at or below 130 percent of the poverty threshold; to be eligible for reduced-price lunch, a student must be from a household with an income between 130 percent and 185 percent of the poverty threshold. Race categories exclude persons of Hispanic ethnicity. For more information on race/ethnicity, locale, and poverty, see Appendix C - Commonly Used Measures. For more information on the Common Core of Data (CCD), see Appendix B - Guide to Sources. Percent detail may not sum to percent totals because of rounding.

SOURCE: U.S. Department of Education, National Center for Education Statistics, Common Core of Data (CCD), "Public Elementary/Secondary School Universe Survey," 2009-10. 
Table A-13-2. Number of public school students and percentage distribution of students, by school concentration of students eligible for free or reduced-price lunch, school locale, and race/ethnicity: School year 2009-10

\begin{tabular}{|c|c|c|c|c|c|c|c|}
\hline \multirow[b]{2}{*}{ School locale and race/ethnicity } & \multirow[b]{2}{*}{$\begin{array}{l}\text { Number of public } \\
\text { school students }\end{array}$} & \multicolumn{6}{|c|}{$\begin{array}{c}\text { Percentage distribution of school concentration of students eligible } \\
\text { for free or reduced-price lunch }\end{array}$} \\
\hline & & Total & $0-25$ & $26-50$ & $51-75$ & $76-100$ & $\begin{array}{r}\text { Missing/ } \\
\text { school } \\
\text { does not } \\
\text { participate }\end{array}$ \\
\hline Total $^{2}$ & $49,136,240$ & 100.0 & 24.6 & 28.8 & 25.1 & 18.6 & 3.0 \\
\hline City & $14,431,591$ & 100.0 & 14.3 & 20.0 & 24.4 & 33.4 & 8.0 \\
\hline Suburban & $16,870,809$ & 100.0 & 38.0 & 27.7 & 19.6 & 13.7 & 1.0 \\
\hline Town & $5,900,330$ & 100.0 & 11.9 & 37.4 & 35.2 & 14.7 & 0.8 \\
\hline Rural & $11,933,156$ & 100.0 & 24.5 & 36.6 & 28.7 & 9.5 & 0.7 \\
\hline \multicolumn{8}{|l|}{ City } \\
\hline White & $4,497,625$ & 100.0 & 26.3 & 33.5 & 23.8 & 11.7 & 4.6 \\
\hline Black & $3,777,621$ & 100.0 & 4.0 & 13.3 & 25.3 & 48.0 & 9.4 \\
\hline Hispanic & $4,776,905$ & 100.0 & 8.4 & 11.9 & 24.8 & 45.9 & 9.0 \\
\hline Asian/Pacific Islander & $1,015,150$ & 100.0 & 26.6 & 20.9 & 19.7 & 17.6 & 15.1 \\
\hline American Indian/Alaska Native & 117,102 & 100.0 & 13.4 & 25.0 & 27.5 & 29.8 & 4.3 \\
\hline Race/ethnicity unknown & 247,188 & 100.0 & 16.4 & 25.8 & 29.5 & 27.1 & 1.2 \\
\hline \multicolumn{8}{|l|}{ Suburban } \\
\hline White & $9,239,268$ & 100.0 & 52.3 & 30.3 & 12.9 & 3.3 & 1.3 \\
\hline Black & $2,478,971$ & 100.0 & 14.9 & 26.8 & 31.5 & 26.0 & 0.7 \\
\hline Hispanic & $3,657,699$ & 100.0 & 15.6 & 21.4 & 28.9 & 33.4 & 0.7 \\
\hline Asian/Pacific Islander & $1,050,244$ & 100.0 & 47.1 & 27.0 & 16.8 & 8.0 & 1.1 \\
\hline American Indian/Alaska Native & 92,634 & 100.0 & 26.6 & 34.2 & 25.4 & 12.8 & 1.0 \\
\hline Race/ethnicity unknown & 351,993 & 100.0 & 35.6 & 30.9 & 20.6 & 11.3 & 1.6 \\
\hline \multicolumn{8}{|l|}{ Town } \\
\hline White & $3,974,415$ & 100.0 & 14.7 & 44.7 & 33.6 & 6.0 & 1.0 \\
\hline Black & 651,595 & 100.0 & 3.2 & 16.8 & 39.2 & 40.4 & 0.4 \\
\hline Hispanic & 951,609 & 100.0 & 6.7 & 21.5 & 38.1 & 33.3 & 0.5 \\
\hline Asian/Pacific Islander & 112,906 & 100.0 & 13.6 & 45.5 & 31.5 & 8.6 & 0.8 \\
\hline American Indian/Alaska Native & 126,060 & 100.0 & 9.2 & 29.7 & 38.1 & 22.2 & 0.8 \\
\hline Race/ethnicity unknown & 83,745 & 100.0 & 10.1 & 32.0 & 43.6 & 12.5 & 1.9 \\
\hline \multicolumn{8}{|l|}{ Rural } \\
\hline White & $8,600,009$ & 100.0 & 27.1 & 40.1 & 27.4 & 4.6 & 0.8 \\
\hline Black & $1,258,166$ & 100.0 & 12.1 & 27.0 & 34.5 & 25.8 & 0.6 \\
\hline Hispanic & $1,389,640$ & 100.0 & 17.3 & 27.6 & 33.3 & 21.3 & 0.6 \\
\hline Asian/Pacific Islander & 283,510 & 100.0 & 48.2 & 31.2 & 15.2 & 4.4 & 0.9 \\
\hline American Indian/Alaska Native & 248,958 & 100.0 & 7.7 & 20.6 & 32.8 & 37.9 & 0.9 \\
\hline Race/ethnicity unknown & 152,873 & 100.0 & 31.0 & 35.6 & 24.9 & 7.4 & 1.1 \\
\hline \multicolumn{8}{|c|}{$\begin{array}{l}\text { Includes students enrolled in schools that did not report free or reduced-price lunch eligibility. } \\
2 \text { Includes students enrolled in schools that did not report school locale information. } \\
\text { NOTE: The National School Lunch Program is a federally assisted meal program. To be eligible for free lunch under the program, a student must be } \\
\text { from a household with an income at or below } 130 \text { percent of the poverty threshold; to be eligible for reduced-price lunch, a student must be from a } \\
\text { household with an income between } 130 \text { percent and } 185 \text { percent of the poverty threshold. Race categories exclude persons of Hispanic ethnicity. For } \\
\text { more information on race/ethnicity, locale, and poverty, see Appendix C - Commonly Used Measures. For more information on the Common Core of } \\
\text { Data (CCD), see Appendix B - Guide to Sources. Percent detail may not sum to percent totals because of rounding. } \\
\text { SOURCE: U.S. Department of Education, National Center for Education Statistics, Common Core of Data (CCD), "Public Elementary/Secondary School } \\
\text { Universe Survey," 2009-10. }\end{array}$} \\
\hline
\end{tabular}

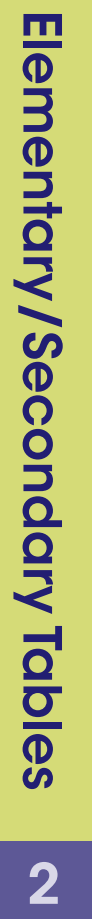


Table A-14-1. Percentage of public schools recording and reporting to the police at least one incident of crime that occurred at school, by type of incident: Selected school years, 1999-2000 through 2009-10

\begin{tabular}{|c|c|c|c|c|c|c|c|c|c|c|}
\hline \multirow[b]{2}{*}{ Type of incident } & \multicolumn{5}{|c|}{ Recorded incidents } & \multicolumn{5}{|c|}{ Reported incidents to police } \\
\hline & $\begin{array}{r}1999- \\
2000 \\
\end{array}$ & $\begin{array}{r}2003- \\
04 \\
\end{array}$ & $\begin{array}{r}2005- \\
06 \\
\end{array}$ & $\begin{array}{r}2007- \\
08\end{array}$ & $\begin{array}{r}2009- \\
10 \\
\end{array}$ & $\begin{array}{r}1999- \\
2000 \\
\end{array}$ & $\begin{array}{r}2003- \\
04\end{array}$ & $\begin{array}{r}2005- \\
06\end{array}$ & $\begin{array}{r}2007- \\
08\end{array}$ & $\begin{array}{r}2009- \\
10\end{array}$ \\
\hline Total & 86.4 & 88.5 & 85.7 & 85.5 & 85.0 & 62.5 & 65.2 & 60.9 & 62.0 & 60.0 \\
\hline Violent incidents & 71.4 & 81.4 & 77.7 & 75.5 & 73.8 & 36.0 & 43.6 & 37.7 & 37.8 & 39.9 \\
\hline $\begin{array}{l}\text { Physical attack or fight without a } \\
\text { weapon }\end{array}$ & 63.7 & 76.7 & 74.3 & 72.7 & 70.5 & 25.8 & 35.6 & 29.2 & 28.2 & 34.3 \\
\hline $\begin{array}{l}\text { Threat of physical attack without } \\
\text { a weapon }\end{array}$ & 52.2 & 53.0 & 52.2 & 47.8 & 46.4 & 18.9 & 21.0 & 19.7 & 19.5 & 15.2 \\
\hline Serious violent incidents & 19.7 & 18.3 & 17.1 & 17.2 & 16.4 & 14.8 & 13.3 & 12.6 & 12.6 & 10.4 \\
\hline Rape or attempted rape & 0.7 & 0.8 & 0.3 & 0.8 & 0.5 & 0.6 & 0.8 & 0.3 & 0.8 & 0.5 \\
\hline Sexual battery other than rape & 2.5 & 3.0 & 2.8 & 2.5 & 2.3 & 2.3 & 2.6 & 2.6 & 2.1 & 1.4 \\
\hline $\begin{array}{l}\text { Physical attack or fight with a } \\
\text { weapon }\end{array}$ & 5.2 & 4.0 & 3.0 & 3.0 & 3.9 & 3.9 & 2.8 & 2.2 & 2.1 & 2.2 \\
\hline $\begin{array}{l}\text { Threat of physical attack with } \\
\text { a weapon }\end{array}$ & 11.1 & 8.6 & 8.8 & 9.3 & 7.7 & 8.5 & 6.0 & 5.9 & 5.7 & 4.5 \\
\hline Robbery with a weapon & $0.5 !$ & 0.6 & 0.4 & $0.4 !$ & 0.2 & $0.3 !$ & 0.6 & 0.4 & $0.4 !$ & 0.2 \\
\hline Robbery without a weapon & 5.3 & 6.3 & 6.4 & 5.2 & 4.4 & 3.4 & 4.2 & 4.9 & 4.1 & 3.5 \\
\hline Theft/larceny' & 45.6 & 46.0 & 46.0 & 47.3 & 44.1 & 28.5 & 30.5 & 27.9 & 31.0 & 25.4 \\
\hline Other incidents & 72.7 & 64.0 & 68.2 & 67.4 & 68.1 & 52.0 & 50.0 & 50.6 & 48.7 & 46.3 \\
\hline $\begin{array}{l}\text { Possession of a firearm/explo- } \\
\text { sive device }\end{array}$ & 5.5 & 6.1 & 7.2 & 4.7 & 4.7 & 4.5 & 4.9 & 5.5 & 3.6 & 3.1 \\
\hline $\begin{array}{l}\text { Possession of a knife or sharp } \\
\text { object }\end{array}$ & 42.6 & - & 42.8 & 40.6 & 39.7 & 23.0 & - & 25.0 & 23.3 & 20.0 \\
\hline Distribution of illegal drugs & 12.3 & 12.9 & - & - & - & 11.4 & 12.4 & - & - & - \\
\hline $\begin{array}{l}\text { Possession or use of alcohol or } \\
\text { illegal drugs }\end{array}$ & 26.6 & 29.3 & - & - & - & 22.2 & 26.0 & - & - & - \\
\hline $\begin{array}{l}\text { Distribution, possession, or use } \\
\text { of illegal drugs }\end{array}$ & - & - & 25.9 & 23.2 & 24.6 & - & - & 22.8 & 20.7 & 21.4 \\
\hline $\begin{array}{l}\text { Inappropriate distribution, } \\
\text { possession, or use of } \\
\text { prescription drugs }\end{array}$ & - & - & - & - & 12.1 & - & - & - & - & 9.6 \\
\hline $\begin{array}{l}\text { Distribution, possession, or use } \\
\text { of alcohol }\end{array}$ & - & - & 16.2 & 14.9 & 14.1 & - & - & 11.6 & 10.6 & 10.0 \\
\hline $\begin{array}{l}\text { Student sexual harassment of } \\
\text { other students }\end{array}$ & 36.3 & - & - & - & - & 14.7 & - & - & - & - \\
\hline Vandalism & 51.4 & 51.4 & 50.5 & 49.3 & 45.8 & 32.7 & 34.3 & 31.9 & 30.8 & 26.8 \\
\hline
\end{tabular}

\section{- Not available.}

! Interpret data with caution. The coefficient of variation (CV) for this estimate is 30 percent or greater.

1 Theft/larceny (taking things worth over $\$ 10$ without personal confrontation) includes pocket picking, stealing a purse or backpack (if left unattended or no force was used to take it from owner), theft from a building, theft from a motor vehicle or of motor vehicle parts or accessories, theft of bicycles, theft from vending machines, and all other types of thefts.

NOTE: "At school" was defined to include activities that happen in school buildings, on school grounds, on school buses, and at places that hold school-sponsored events or activities. Respondents were instructed to include incidents that occurred before, during, or after normal school hours or when school activities or events were in session. For more information on the School Survey on Crime and Safety (SSOCS), see Appendix B - Guide to Sources.

SOURCE: U.S. Department of Education, National Center for Education Statistics, 1999-2000, 2003-04, 2005-06, 2007-08, and 2009-10 School Survey on Crime and Safety (SSOCS), 2000, 2004, 2006, 2008, and 2010. 
Table A-14-2. Percentage of public schools recording incidents of crime that occurred at school, by type of incident, number of incidents, and selected school characteristics: School year 2009-10

\begin{tabular}{|c|c|c|c|c|c|c|c|c|c|c|c|c|c|}
\hline \multirow[b]{3}{*}{ School characteristic } & \multicolumn{6}{|c|}{ Violent incidents $^{\top}$} & \multicolumn{5}{|c|}{ Serious violent incidents ${ }^{2}$} & \multirow[b]{2}{*}{ Theft $^{3}$} & \multirow{3}{*}{$\begin{array}{r}\text { Other }^{4} \\
\text { At } \\
\text { least } \\
\text { one }\end{array}$} \\
\hline & \multirow[b]{2}{*}{$\begin{array}{r}\text { At } \\
\text { least } \\
\text { one } \\
\end{array}$} & \multicolumn{5}{|c|}{ Number of incidents } & \multirow[b]{2}{*}{$\begin{array}{r}\text { At } \\
\text { least } \\
\text { one }\end{array}$} & \multicolumn{4}{|c|}{ Number of incidents } & & \\
\hline & & None & $1-2$ & $3-9$ & $\begin{array}{r}10- \\
19 \\
\end{array}$ & $\begin{array}{l}20 \text { or } \\
\text { more }\end{array}$ & & None & $1-2$ & $3-9$ & $\begin{array}{l}10 \text { or } \\
\text { more }\end{array}$ & $\begin{array}{r}\text { At } \\
\text { least } \\
\text { one } \\
\end{array}$ & \\
\hline Total & 73.8 & 26.2 & 7.6 & 29.0 & 17.8 & 19.4 & 16.4 & 83.6 & 10.9 & 4.0 & 1.5 & 44.1 & 68.1 \\
\hline \multicolumn{14}{|l|}{ School level } \\
\hline Primary & 64.4 & 35.6 & 7.6 & 31.5 & 13.8 & 11.4 & 13.0 & 87.0 & 8.6 & 3.5 & $0.9 !$ & 25.7 & 57.3 \\
\hline Middle & 90.5 & 9.5 & 6.0 & 25.8 & 24.4 & 34.3 & 18.9 & 81.1 & 13.1 & 3.9 & 1.9 & 65.2 & 81.9 \\
\hline High school & 90.9 & 9.1 & 8.4 & 22.7 & 25.1 & 34.8 & 27.6 & 72.4 & 16.3 & 8.4 & 2.9 & 82.6 & 92.2 \\
\hline Combined & 73.7 & 26.3 & $10.3 !$ & 29.0 & 18.6 & 15.8 & 15.5 & 84.5 & 12.5 & $\ddagger$ & $\ddagger$ & 60.5 & 72.5 \\
\hline \multicolumn{14}{|l|}{ Enrollment size } \\
\hline Less than 300 & 62.8 & 37.2 & 12.7 & 32.3 & 10.6 & 7.3 & 10.4 & 89.6 & 6.9 & $2.7 !$ & $\ddagger$ & 30.7 & 55.3 \\
\hline $300-499$ & 71.3 & 28.7 & 8.2 & 29.2 & 17.9 & 16.0 & 15.7 & 84.3 & 11.6 & 3.3 & $\ddagger$ & 36.4 & 63.3 \\
\hline 500-999 & 76.4 & 23.6 & 5.2 & 30.7 & 20.8 & 19.8 & 15.9 & 84.1 & 10.7 & 3.8 & $1.4 !$ & 46.7 & 72.5 \\
\hline 1,000 or more & 95.4 & 4.6 & 3.6 & 15.6 & 22.6 & 53.7 & 32.8 & 67.2 & 17.9 & 9.7 & 5.2 & 84.9 & 94.3 \\
\hline \multicolumn{14}{|l|}{ Locale } \\
\hline City & 74.9 & 25.1 & 4.5 & 27.7 & 17.7 & 25.0 & 21.7 & 78.3 & 14.4 & 5.7 & 1.7 & 47.6 & 73.5 \\
\hline Suburb & 73.5 & 26.5 & 6.3 & 29.7 & 18.3 & 19.3 & 15.5 & 84.5 & 9.9 & 3.6 & $2.0 !$ & 43.1 & 66.1 \\
\hline Town & 80.3 & 19.7 & 8.1 & 31.2 & 20.1 & 20.8 & 15.6 & 84.4 & 10.6 & 4.1 & $0.9 !$ & 46.2 & 74.1 \\
\hline Rural & 70.2 & 29.8 & 11.4 & 28.3 & 16.3 & 14.2 & 13.2 & 86.8 & 8.9 & 3.1 & $1.3 !$ & 41.1 & 62.6 \\
\hline \multicolumn{14}{|l|}{$\begin{array}{l}\text { Racial/ethnic } \\
\text { concentration }\end{array}$} \\
\hline $\begin{array}{l}\text { More than } 50 \\
\text { percent White }\end{array}$ & 71.3 & 28.7 & 9.4 & 29.3 & 16.3 & 16.4 & 13.9 & 86.1 & 9.1 & 3.3 & 1.4 & 42.0 & 64.2 \\
\hline $\begin{array}{l}\text { More than } 50 \\
\text { percent Black }\end{array}$ & 82.1 & 17.9 & $\ddagger$ & 24.9 & 26.2 & 29.3 & 21.0 & 79.0 & 13.4 & 6.1 & $\ddagger$ & 46.6 & 70.9 \\
\hline $\begin{array}{l}\text { More than } \\
50 \text { percent } \\
\text { Hispanic }\end{array}$ & 76.7 & 23.3 & 5.9 & 29.8 & 18.0 & 22.9 & 20.9 & 79.1 & 14.1 & 5.1 & 1.7 & 48.3 & 76.8 \\
\hline \multicolumn{14}{|l|}{$\begin{array}{l}\text { Percentage of students } \\
\text { in school eligible } \\
\text { for free or reduced- } \\
\text { price lunch }\end{array}$} \\
\hline 0-25 percent & 62.6 & 37.4 & 7.4 & 27.9 & 15.1 & 12.1 & 10.5 & 89.5 & 7.3 & 1.7 & $1.5 !$ & 40.3 & 56.2 \\
\hline 26-50 percent & 76.0 & 24.0 & 9.0 & 30.5 & 17.6 & 18.9 & 16.2 & 83.8 & 11.3 & 3.9 & 1.0 & 48.8 & 68.2 \\
\hline 51-75 percent & 73.8 & 26.2 & 7.9 & 27.4 & 17.5 & 21.0 & 15.8 & 84.2 & 10.4 & 4.4 & $1.0 !$ & 41.2 & 73.5 \\
\hline 76-100 percent & 81.4 & 18.6 & 5.9 & 30.0 & 20.8 & 24.7 & 22.9 & 77.1 & 14.2 & 6.0 & $2.7 !$ & 45.5 & 72.1 \\
\hline
\end{tabular}

! Interpret data with caution. The coefficient of variation (CV) for this estimate is 30 percent or greater.

‡ Reporting standards not met. Either there are too few cases or the coefficient of variation (CV) is 50 percent or greater.

' Violent incidents include serious violent incidents (rape or attempted rape, sexual battery other than rape, physical attack or fight with a weapon,

threat of physical attack with a weapon, and robbery with or without a weapon), physical attack or fight without a weapon, and threat of physical

attack without a weapon.

2 Serious violent incidents include rape or attempted rape, sexual battery other than rape, physical attack or fight with a weapon, threat of physical attack with a weapon, and robbery with or without a weapon.

${ }^{3}$ Theft/larceny (taking things worth over $\$ 10$ without personal confrontation) includes pocket picking, stealing a purse or backpack (if left unattended or no force was used to take it from owner), theft from a building, theft from a motor vehicle or of motor vehicle parts or accessories, theft of bicycles, theft from vending machines, and all other types of thefts.

${ }_{4}^{4}$ Other incidents include possession of a firearm or explosive device; possession of a knife or sharp object; distribution, possession, or use of illegal drugs or alcohol; inappropriate distribution, possession, or use of prescription drugs; and vandalism.

NOTE: "At school" was defined to include activities that happen in school buildings, on school grounds, on school buses, and at places that hold school-sponsored events or activities. Respondents were instructed to include incidents that occurred before, during, or after normal school hours or when school activities or events were in session. Detail may not sum to totals because of rounding. Race categories exclude persons of Hispanic ethnicity. For more information on race/ethnicity, locale, and poverty, see Appendix C - Commonly Used Measures. For more information on the School Survey on Crime and Safety (SSOCS), see Appendix B - Guide to Sources.

SOURCE: U.S. Department of Education, National Center for Education Statistics, 2009-10 School Survey on Crime and Safety (SSOCS), 2010. 


\section{Distance Education in Public High Schools}

Table A-15-1. Percentage of public school districts with any high school students enrolled in distance education courses and number of student enrollments in distance education, by selected district characteristics: School years 2002-03, 2004-05, and 2009-10

\begin{tabular}{|c|c|c|c|c|c|c|}
\hline \multirow[b]{2}{*}{ District characteristic } & \multicolumn{3}{|c|}{$\begin{array}{c}\text { Percent of public school districts with high } \\
\text { school students enrolled in distance } \\
\text { education }\end{array}$} & \multicolumn{3}{|c|}{$\begin{array}{c}\text { Number of public high school student } \\
\text { enrollments in distance education }\end{array}$} \\
\hline & 2002-03 & 2004-05 & 2009-10 & 2002-03 & 2004-05 & $2009-10$ \\
\hline All public school districts & 30 & 30 & 53 & 222,090 & 309,630 & $1,348,920$ \\
\hline \multicolumn{7}{|l|}{ District enrollment size } \\
\hline Less than 2,500 & 29 & 28 & 49 & 74,160 & 103,190 & $408,030 !$ \\
\hline 2,500 to 9,999 & 31 & 33 & 64 & 44,780 & 48,420 & 312,130 \\
\hline 10,000 or more & 47 & 48 & 73 & 103,150 & 157,440 & 628,760 \\
\hline \multicolumn{7}{|l|}{ Locale } \\
\hline City & 21 & 22 & 37 & $63,040 !$ & 70,540 & 405,740 \\
\hline Suburban & 22 & 27 & 45 & 62,170 & 136,260 & 434,260 \\
\hline Town & 37 & 33 & 66 & 24,790 & 27,030 & $246,850 !$ \\
\hline Rural & 34 & 32 & 56 & 71,970 & 75,220 & 262,070 \\
\hline \multicolumn{7}{|l|}{ Region } \\
\hline Northeast & 18 & 17 & 38 & 17,420 & 16,860 & 71,330 \\
\hline Southeast & 41 & 42 & 76 & 50,410 & 89,800 & 443,770 \\
\hline Central & 38 & 35 & 60 & 60,560 & 70,450 & 416,550 \\
\hline West & 25 & 27 & 48 & 93,700 & 132,520 & 417,270 \\
\hline \multicolumn{7}{|l|}{ Poverty concentration } \\
\hline Less than 10 percent & 27 & 29 & 52 & 57,310 & 80,150 & 231,890 \\
\hline 10 to 19 percent & 35 & 35 & 54 & 77,810 & 124,540 & 682,380 \\
\hline 20 percent or more & 36 & 32 & 54 & 83,100 & 78,590 & 434,640 \\
\hline
\end{tabular}

! Interpret with caution. The coefficient of variation (CV) for this estimate is 30 percent or greater.

NOTE: Distance education courses are defined as courses that are credit-granting, technology-delivered, have either the instructor in a different location than the students and/or have the course content developed in, or delivered from, a different location than that of the students. Poverty estimates for school districts were based on Title I data provided to the U.S. Department of Education by the U.S. Census Bureau. For more information on locale and region, see Appendix C - Commonly Used Measures. For more information on the Fast Response Survey System (FRSS), see Appendix B Guide to Sources.

SOURCE: U.S. Department of Education, National Center for Education Statistics (NCES), Fast Response Survey System (FRSS), "Distance Education Courses for Public School Elementary and Secondary Students: 2002-03," FRSS 84, 2003; "Distance Education Courses for Public Elementary and Secondary School Students: 2004-05," FRSS 89, 2005; and "Distance Education Courses for Public Elementary and Secondary School Students: 2009-10," FRSS 98, 2010. 
Table A-15-2. Percentage of public school districts that offered distance education, by locale and selected characteristics: School years 2004-05 and 2009-10

\begin{tabular}{|c|c|c|c|c|c|c|c|c|c|c|}
\hline \multirow[b]{3}{*}{ Selected characteristic } & & & \multicolumn{8}{|c|}{ Locale } \\
\hline & \multicolumn{2}{|c|}{ Total } & \multicolumn{2}{|c|}{ City } & \multicolumn{2}{|c|}{ Suburban } & \multicolumn{2}{|c|}{ Town } & \multicolumn{2}{|c|}{ Rural } \\
\hline & $2004-05$ & $2009-10$ & $2004-05$ & $2009-10$ & $2004-05$ & $2009-10$ & $2004-05$ & $2009-10$ & $2004-05$ & $2009-10$ \\
\hline & \multicolumn{10}{|c|}{ Percent of the public school districts that offered distance education } \\
\hline \multicolumn{11}{|l|}{ Delivery entities } \\
\hline Postsecondary institution in the & & & & & & & & & & \\
\hline United States & 47 & 50 & 35 & 30 & 46 & 37 & 48 & 44 & 49 & 61 \\
\hline $\begin{array}{l}\text { Independent vendor in the United } \\
\text { States }\end{array}$ & 14 & $\Delta 7$ & 10 & & 25 & 65 & 10 & 53 & 0 & 37 \\
\hline $\begin{array}{l}\text { Online charter school adminis- } \\
\text { tered by their district }\end{array}$ & 4 & 4 & $\ddagger$ & $10 !$ & $5 !$ & $4 !$ & $6 !$ & $5 !$ & $2 !$ & $3 !$ \\
\hline $\begin{array}{l}\text { Other schools administered by } \\
\text { their district }\end{array}$ & 8 & 6 & $17 !$ & 6 & 8 & 4 & $13 !$ & 7 & 5 & 5 \\
\hline Their district & 21 & 18 & 31 & 35 & 17 & 20 & 24 & 19 & 21 & 15 \\
\hline \multicolumn{11}{|l|}{$\begin{array}{l}\text { Another local school district, or } \\
\text { schools in another district, in }\end{array}$} \\
\hline \multicolumn{10}{|l|}{$\begin{array}{l}\text { Education service agencies within } \\
\text { their state }\end{array}$} & 17 \\
\hline State virtual school in their state & 24 & 33 & 24 & 35 & 24 & 30 & 25 & 35 & 24 & 34 \\
\hline \multicolumn{11}{|l|}{ State virtual school in another } \\
\hline Districts or schools in other states & 4 & 3 & $\ddagger$ & $1 !$ & $2 !$ & $3 !$ & $6 !$ & $4 !$ & 4 & $2 !$ \\
\hline \multicolumn{2}{|l|}{$\begin{array}{l}\text { Non-U.S.-based public or private } \\
\text { entity }\end{array}$} & 1 & $\ddagger$ & $2 !$ & $\ddagger$ & $1 !$ & $\#$ & $1 !$ & $\ddagger$ & $1 !$ \\
\hline \\
\hline $\begin{array}{l}\text { Internet courses using } \\
\text { synchronous computer- } \\
\text { based instruction }\end{array}$ & 13 & 14 & $8 !$ & $14 !$ & 14 & 10 & 13 & 13 & 13 & 15 \\
\hline \multicolumn{11}{|l|}{ Internet courses using } \\
\hline $\begin{array}{l}\text { asynchronous computer- } \\
\text { based instruction }\end{array}$ & 40 & 63 & 76 & 76 & 62 & 77 & 47 & 70 & 28 & 54 \\
\hline Two-way interactive video & 41 & 17 & 13 & $3 !$ & 22 & $3 !$ & 38 & 10 & 52 & 26 \\
\hline \multicolumn{11}{|l|}{$\begin{array}{c}\text { Allowable access locations for } \\
\text { internet-delivered courses }\end{array}$} \\
\hline School & 61 & 83 & 73 & 83 & 70 & 85 & 64 & 84 & 55 & 83 \\
\hline Home & 41 & 70 & 68 & 81 & 62 & 79 & 49 & 71 & 29 & 65 \\
\hline Other location & 5 & 13 & $13 !$ & 21 & 9 & 19 & 10 & 17 & 2 & 9 \\
\hline \multicolumn{11}{|l|}{$\begin{array}{l}\text { High school distance education } \\
\text { options }\end{array}$} \\
\hline \multicolumn{11}{|l|}{$\begin{array}{l}\text { Students can take a full course } \\
\text { load using only distance }\end{array}$} \\
\hline education & - & 22 & - & 31 & - & 24 & - & 29 & - & 17 \\
\hline \multicolumn{11}{|l|}{$\begin{array}{l}\text { Students can fulfill all high school } \\
\text { graduation requirements us- } \\
\text { ing only distance education }\end{array}$} \\
\hline courses courses & - & 12 & - & 20 & - & 15 & - & 18 & - & 8 \\
\hline
\end{tabular}

- Not available. In 2004-05, the survey did not include these questions.

\# Rounds to zero.

! Interpret with caution. The coefficient of variation (CV) for this estimate is 30 percent or greater.

$\ddagger$ Reporting standards not met. The coefficient of variation (CV) for this estimate is 50 percent or greater.

NOTE: Distance education courses are defined as courses that are credit-granting, technology-delivered, have either the instructor in a different location than the students and/or have the course content developed in, or delivered from, a different location than that of the students. Percentages are based on districts with students enrolled in distance education courses. For delivery entities, response options in the questionnaire were "yes," "no," and "don't know." Only the "yes" options are shown in the table. For instructional delivery, synchronous refers to simultaneous, or "real time," instruction. For more information on the Fast Response Survey System (FRSS), see Appendix B - Guide to Sources.

SOURCE: U.S. Department of Education, National Center for Education Statistics (NCES), Fast Response Survey System (FRSS), "Distance Education Courses for Public School Elementary and Secondary Students: 2004-05," FRSS 89, 2005; and "Distance Education Courses for Public Elementary and Secondary

School Students: 2009-10," FRSS 98, 2010. 
Table A-16-1. Number and percentage distribution of public high schools and 12th-grade students, by student retention rate: Academic years 1990-91 through 2009-10

\begin{tabular}{|c|c|c|c|c|c|c|c|c|c|c|c|c|}
\hline \multirow[b]{3}{*}{$\begin{array}{l}\text { Academic } \\
\text { year }\end{array}$} & \multicolumn{6}{|c|}{ Number } & \multicolumn{6}{|c|}{ Percentage distribution } \\
\hline & \multirow{2}{*}{\multicolumn{2}{|c|}{$\begin{array}{rr}\begin{array}{r}\text { Total low } \\
\text { reten- } \\
\text { tion }\end{array} \\
\end{array}$}} & \multicolumn{2}{|c|}{ Low retention } & \multirow[b]{2}{*}{$\begin{array}{r}71-90 \\
\text { percent } \\
\text { reten- } \\
\text { tion }\end{array}$} & \multirow[b]{2}{*}{$\begin{array}{r}91-150 \\
\text { percent } \\
\text { reten- } \\
\text { tion }\end{array}$} & \multirow[b]{2}{*}{ Total } & \multirow[b]{2}{*}{$\begin{array}{r}\text { Total low } \\
\text { reten- } \\
\text { tion } \\
\end{array}$} & \multicolumn{2}{|c|}{ Low retention } & \multirow[b]{2}{*}{$\begin{array}{r}71-90 \\
\text { percent } \\
\text { reten- } \\
\text { tion }\end{array}$} & \multirow[b]{2}{*}{$\begin{array}{r}91-150 \\
\text { percen } \\
\text { reten } \\
\text { tion }\end{array}$} \\
\hline & & & $\begin{array}{r}10-50 \\
\text { percent } \\
\text { reten- } \\
\text { tion }\end{array}$ & $\begin{array}{r}51-70 \\
\text { percent } \\
\text { reten- } \\
\text { tion }\end{array}$ & & & & & $\begin{array}{r}10-50 \\
\text { percent } \\
\text { reten- } \\
\text { tion }\end{array}$ & $\begin{array}{r}51-70 \\
\text { percent } \\
\text { reten- } \\
\text { tion }\end{array}$ & & \\
\hline & \multicolumn{12}{|c|}{ Regular public schools } \\
\hline 1990-91 & 12,879 & 3,112 & 680 & 2,432 & 5,408 & 4,359 & 100.0 & 24.2 & 5.3 & 18.9 & 42.0 & 33.8 \\
\hline 1991-92 & 12,764 & 2,917 & 562 & 2,355 & 5,291 & 4,556 & 100.0 & 22.9 & 4.4 & 18.5 & 41.5 & 35.7 \\
\hline 1992-93 & 12,907 & 2,824 & 557 & 2,267 & 5,271 & 4,812 & 100.0 & 21.9 & 4.3 & 17.6 & 40.8 & 37.3 \\
\hline 1993-94 & 12,877 & 3,004 & 617 & 2,387 & 5,206 & 4,667 & 100.0 & 23.3 & 4.8 & 18.5 & 40.4 & 36.2 \\
\hline 1994-95 & 13,214 & 3,346 & 707 & 2,639 & 5,388 & 4,480 & 100.0 & 25.3 & 5.4 & 20.0 & 40.8 & 33.9 \\
\hline 1995-96 & 13,401 & 3,704 & 848 & 2,856 & 5,596 & 4,101 & 100.0 & 27.6 & 6.3 & 21.3 & 41.8 & 30.6 \\
\hline 1996-97 & 13,304 & 3,835 & 860 & 2,975 & 5,534 & 3,935 & 100.0 & 28.8 & 6.5 & 22.4 & 41.6 & 29.6 \\
\hline 1997-98 & 13,767 & 4,013 & 917 & 3,096 & 5,844 & 3,910 & 100.0 & 29.1 & 6.7 & 22.5 & 42.4 & 28.4 \\
\hline 1998-99 & 13,865 & 4,280 & 1,012 & 3,268 & 5,875 & 3,710 & 100.0 & 30.9 & 7.3 & 23.6 & 42.4 & 26.8 \\
\hline 1999-2000 & 13,739 & 4,368 & 1,087 & 3,281 & 5,973 & 3,398 & 100.0 & 31.8 & 7.9 & 23.9 & 43.5 & 24.7 \\
\hline 2000-01 & 14,123 & 4,581 & 1,157 & 3,424 & 6,103 & 3,439 & 100.0 & 32.4 & 8.2 & 24.2 & 43.2 & 24.4 \\
\hline 2001-02 & 14,207 & 4,485 & 1,073 & 3,412 & 6,179 & 3,543 & 100.0 & 31.6 & 7.6 & 24.0 & 43.5 & 24.9 \\
\hline 2002-03 & 14,408 & 4,256 & 1,041 & 3,215 & 6,228 & 3,924 & 100.0 & 29.5 & 7.2 & 22.3 & 43.2 & 27.2 \\
\hline 2003-04 & 14,479 & 3,916 & 956 & 2,960 & 6,339 & 4,224 & 100.0 & 27.0 & 6.6 & 20.4 & 43.8 & 29.2 \\
\hline 2004-05 & 14,541 & 3,995 & 982 & 3,013 & 6,134 & 4,412 & 100.0 & 27.5 & 6.8 & 20.7 & 42.2 & 30.3 \\
\hline 2005-06 & 14,532 & 3,808 & 878 & 2,930 & 6,156 & 4,568 & 100.0 & 26.2 & 6.0 & 20.2 & 42.4 & 31.4 \\
\hline 2006-07 & 14,766 & 3,783 & 893 & 2,890 & 6,178 & 4,805 & 100.0 & 25.6 & 6.0 & 19.6 & 41.8 & 32.5 \\
\hline 2007-08 & 14,943 & 3,813 & 859 & 2,954 & 6,298 & 4,832 & 100.0 & 25.5 & 5.7 & 19.8 & 42.1 & 32.3 \\
\hline 2008-09 & 15,217 & 3,912 & 888 & 3,024 & 6,435 & 4,870 & 100.0 & 25.7 & 5.8 & 19.9 & 42.3 & 32.0 \\
\hline \multirow[t]{2}{*}{ 2009-10 } & 15,534 & 4,096 & 890 & 3,206 & 6,576 & 4,862 & 100.0 & 26.4 & 5.7 & 20.6 & 42.3 & 31.3 \\
\hline & \multicolumn{12}{|c|}{ 12th-grade students } \\
\hline 1990-91 & $1,798,719$ & 518,067 & 114,421 & 403,646 & 750,368 & 530,284 & 100.0 & 28.8 & 6.4 & 22.4 & 41.7 & 29.5 \\
\hline 1991-92 & $1,822,315$ & 490,219 & 100,218 & 390,001 & 762,372 & 569,724 & 100.0 & 26.9 & 5.5 & 21.4 & 41.8 & 31.3 \\
\hline 1992-93 & $1,884,258$ & 494,400 & 103,501 & 390,899 & 774,120 & 615,738 & 100.0 & 26.2 & 5.5 & 20.7 & 41.1 & 32.7 \\
\hline 1993-94 & $1,882,804$ & 538,419 & 115,328 & 423,091 & 761,452 & 582,933 & 100.0 & 28.6 & 6.1 & 22.5 & 40.4 & 31.0 \\
\hline 1994-95 & 1,992,341 & 620,815 & 136,566 & 484,249 & 810,129 & 561,397 & 100.0 & 31.2 & 6.9 & 24.3 & 40.7 & 28.2 \\
\hline 1995-96 & 2,024,841 & 666,828 & 161,833 & 504,995 & 834,130 & 523,883 & 100.0 & 32.9 & 8.0 & 24.9 & 41.2 & 25.9 \\
\hline 1996-97 & $2,055,853$ & 704,112 & 167,037 & 537,075 & 850,228 & 501,513 & 100.0 & 34.2 & 8.1 & 26.1 & 41.4 & 24.4 \\
\hline 1997-98 & $2,222,509$ & 758,106 & 171,159 & 586,947 & 928,202 & 536,201 & 100.0 & 34.1 & 7.7 & 26.4 & 41.8 & 24.1 \\
\hline 1998-99 & $2,267,627$ & 794,923 & 196,119 & 598,804 & 946,823 & 525,881 & 100.0 & 35.1 & 8.6 & 26.4 & 41.8 & 23.2 \\
\hline 1999-2000 & $2,270,127$ & 813,769 & 205,102 & 608,667 & 961,282 & 495,076 & 100.0 & 35.8 & 9.0 & 26.8 & 42.3 & 21.8 \\
\hline 2000-01 & $2,369,836$ & 844,788 & 216,551 & 628,237 & $1,004,888$ & 520,160 & 100.0 & 35.6 & 9.1 & 26.5 & 42.4 & 21.9 \\
\hline 2001-02 & $2,425,255$ & 829,249 & 198,284 & 630,965 & $1,028,742$ & 567,264 & 100.0 & 34.2 & 8.2 & 26.0 & 42.4 & 23.4 \\
\hline 2002-03 & $2,526,180$ & 805,402 & 193,918 & 611,484 & $1,073,273$ & 647,505 & 100.0 & 31.9 & 7.7 & 24.2 & 42.5 & 25.6 \\
\hline 2003-04 & $2,574,332$ & 774,576 & 187,378 & 587,198 & $1,091,764$ & 707,992 & 100.0 & 30.1 & 7.3 & 22.8 & 42.4 & 27.5 \\
\hline 2004-05 & $2,618,898$ & 789,553 & 194,903 & 594,650 & 1,091,069 & 738,276 & 100.0 & 30.1 & 7.4 & 22.7 & 41.7 & 28.2 \\
\hline 2005-06 & $2,659,715$ & 757,779 & 165,364 & 592,415 & $1,115,184$ & 786,752 & 100.0 & 28.5 & 6.2 & 22.3 & 41.9 & 29.6 \\
\hline 2006-07 & $2,736,581$ & 747,196 & 165,488 & 581,708 & $1,161,182$ & 828,203 & 100.0 & 27.3 & 6.0 & 21.3 & 42.4 & 30.3 \\
\hline 2007-08 & $2,818,130$ & 775,145 & 151,885 & 623,260 & $1,194,433$ & 848,552 & 100.0 & 27.5 & 5.4 & 22.1 & 42.4 & 30.1 \\
\hline 2008-09 & $2,865,977$ & 754,570 & 151,323 & 603,247 & $1,229,045$ & 882,362 & 100.0 & 26.3 & 5.3 & 21.0 & 42.9 & 30.8 \\
\hline 2009-10 & $2,910,437$ & 755,303 & 134,622 & 620,681 & $1,248,987$ & 906,147 & 100.0 & 26.0 & 4.6 & 21.3 & 42.9 & 31.1 \\
\hline
\end{tabular}


Table A-16-2. Number and percentage distribution of public high schools, by student retention rate and selected school characteristics: Academic year 2009-10

\begin{tabular}{|c|c|c|c|c|c|c|c|c|c|c|c|c|}
\hline \multirow[b]{3}{*}{ School characteristic } & \multicolumn{6}{|c|}{ Number } & \multicolumn{6}{|c|}{ Percentage distribution } \\
\hline & \multirow[b]{2}{*}{ Total } & \multicolumn{3}{|c|}{ Low retention } & \multirow[b]{2}{*}{$\begin{array}{r}71-90 \\
\text { percent } \\
\text { reten- } \\
\text { tion }\end{array}$} & \multirow[b]{2}{*}{$\begin{array}{r}91-150 \\
\text { percent } \\
\text { reten- } \\
\text { tion }\end{array}$} & \multirow[b]{2}{*}{ Total } & \multicolumn{3}{|c|}{ Low retention } & \multirow[b]{2}{*}{$\begin{array}{r}71-90 \\
\text { percent } \\
\text { reten- } \\
\text { tion }\end{array}$} & \multirow[b]{2}{*}{$\begin{array}{r}91-150 \\
\text { percent } \\
\text { reten- } \\
\text { tion }\end{array}$} \\
\hline & & $\begin{array}{r}\text { Total } \\
\text { low } \\
\text { reten- } \\
\text { tion } \\
\end{array}$ & $\begin{array}{r}10-50 \\
\text { percent } \\
\text { reten- } \\
\text { tion }\end{array}$ & $\begin{array}{r}51-70 \\
\text { percent } \\
\text { reten- } \\
\text { tion }\end{array}$ & & & & $\begin{array}{r}\text { Total } \\
\text { low } \\
\text { reten- } \\
\text { tion } \\
\end{array}$ & $\begin{array}{r}10-50 \\
\text { percent } \\
\text { reten- } \\
\text { tion }\end{array}$ & $\begin{array}{r}51-70 \\
\text { percent } \\
\text { reten- } \\
\text { tion }\end{array}$ & & \\
\hline \multicolumn{13}{|l|}{ Enrollment size } \\
\hline Under 300 & 4,008 & 799 & 220 & 579 & 1,586 & 1,623 & 100.0 & 19.9 & 5.5 & 14.4 & 39.6 & 40.5 \\
\hline $300-499$ & 2,772 & 729 & 155 & 574 & 1,236 & 807 & 100.0 & 26.3 & 5.6 & 20.7 & 44.6 & 29.1 \\
\hline $500-999$ & 3,646 & 1,044 & 217 & 827 & 1,618 & 984 & 100.0 & 28.6 & 6.0 & 22.7 & 44.4 & 27.0 \\
\hline 1,000 or more & 5,191 & 1,555 & 311 & 1,244 & 2,154 & 1,482 & 100.0 & 30.0 & 6.0 & 24.0 & 41.5 & 28.5 \\
\hline \multicolumn{13}{|l|}{$\begin{array}{l}\text { Percentage of students } \\
\text { in school eligible } \\
\text { for free or reduced- } \\
\text { price lunch }\end{array}$} \\
\hline 0-25 percent & 3,525 & 199 & 23 & 176 & 1,313 & 2,013 & 100.0 & 5.6 & 0.7 & 5.0 & 37.2 & 57.1 \\
\hline 26-50 percent & 6,168 & 1,145 & 104 & 1,041 & 3,128 & 1,895 & 100.0 & 18.6 & 1.7 & 16.9 & 50.7 & 30.7 \\
\hline 51-75 percent & 3,723 & 1,523 & 274 & 1,249 & 1,576 & 624 & 100.0 & 40.9 & 7.4 & 33.5 & 42.3 & 16.8 \\
\hline 76-100 percent & 1,542 & 928 & 362 & 566 & 419 & 195 & 100.0 & 60.2 & 23.5 & 36.7 & 27.2 & 12.6 \\
\hline $\begin{array}{l}\text { Missing/school did } \\
\text { not participate }\end{array}$ & 488 & 256 & 105 & 151 & 117 & 115 & 100.0 & 52.5 & 21.5 & 30.9 & 24.0 & 23.6 \\
\hline \multicolumn{13}{|l|}{$\begin{array}{l}\text { Racial/ethnic } \\
\text { concentration } \\
\text { More than } 50 \text { percent }\end{array}$} \\
\hline More than 50 percent & 11,038 & 1,752 & 165 & 1,587 & 5,008 & 4,278 & 100.0 & 15.9 & 1.5 & 14.4 & 45.4 & 38.8 \\
\hline $\begin{array}{l}\text { Black } \\
\text { More than } 50 \text { percent }\end{array}$ & 1,587 & 1,061 & 410 & 651 & 405 & 121 & 100.0 & 66.9 & 25.8 & 41.0 & 25.5 & 7.6 \\
\hline Hispanic & 1,368 & 662 & 183 & 479 & 528 & 178 & 100.0 & 48.4 & 13.4 & 35.0 & 38.6 & 13.0 \\
\hline \multicolumn{13}{|l|}{ Locale } \\
\hline City & 3,013 & 1,500 & 545 & 955 & 969 & 544 & 100.0 & 49.8 & 18.1 & 31.7 & 32.2 & 18.1 \\
\hline Suburban & 3,161 & 707 & 137 & 570 & 1,238 & 1,216 & 100.0 & 22.4 & 4.3 & 18.0 & 39.2 & 38.5 \\
\hline Town & 2,242 & 527 & 43 & 484 & 1,109 & 606 & 100.0 & 23.5 & 1.9 & 21.6 & 49.5 & 27.0 \\
\hline Rural & 7,201 & 1,393 & 178 & 1,215 & 3,278 & 2,530 & 100.0 & 19.3 & 2.5 & 16.9 & 45.5 & 35.1 \\
\hline \multicolumn{13}{|l|}{ Region } \\
\hline Northeast & 2,652 & 527 & 175 & 352 & 983 & 1,142 & 100.0 & 19.9 & 6.6 & 13.3 & 37.1 & 43.1 \\
\hline Midwest & 4,846 & 941 & 259 & 682 & 1,798 & 2,107 & 100.0 & 19.4 & 5.3 & 14.1 & 37.1 & 43.5 \\
\hline South & 5,284 & 1,963 & 300 & 1,663 & 2,536 & 785 & 100.0 & 37.1 & 5.7 & 31.5 & 48.0 & 14.9 \\
\hline West & 2,835 & 696 & 169 & 527 & 1,277 & 862 & 100.0 & 24.6 & 6.0 & 18.6 & 45.0 & 30.4 \\
\hline $\begin{array}{l}\text { NOTE: Retention rate is defin } \\
\text { Includes only regular public } \\
\text { limited to between } 10 \text { and } 1 \\
\text { categories exclude persons } \\
\text { Commonly Used Measures. } \\
\text { SOURCE: U.S. Department of } \\
\text { Survey," 2009-10. }\end{array}$ & $\begin{array}{l}\text { as the ni } \\
\text { hools the } \\
\text { percent } \\
\text { Hispanic } \\
\text { tail may r } \\
\text { lucation, }\end{array}$ & $\begin{array}{l}\text { ber of } 1 \\
\text { ad } 10 \text { o } \\
\text { liminat } \\
\text { nnicity. } \\
\text { sum to }\end{array}$ & $\begin{array}{l}2 \text { th-grade s } \\
r \text { more } 9 \text { th- } \\
\text { e outliers. FC } \\
\text { For more inf } \\
\text { totals beca }\end{array}$ & $\begin{array}{l}\text { tudents in a } \\
\text { grade stude } \\
\text { or more infor } \\
\text { "ormation or } \\
\text { luse of rounc }\end{array}$ & $\begin{array}{l}\text { given aca } \\
\text { ents in } 2005 \\
\text { rmation on } \\
n \text { free or rec } \\
\text { ding. }\end{array}$ & $\begin{array}{l}\text { demic year } \\
-06 \text { and } 10 \\
\text { the Commo } \\
\text { duced-price }\end{array}$ & $\begin{array}{l}\text { ided by } \\
\text { more } 12 \\
\text { Core of } \\
\text { hch, rac }\end{array}$ & $\begin{array}{l}\text { numbe } \\
\text { grade st } \\
\text { ta (CCD) } \\
\text { thnicity, }\end{array}$ & $\begin{array}{l}\text { r of 9th-gra } \\
\text { udents in } 20 \\
\text {, see Apper } \\
\text { locale, anc }\end{array}$ & $\begin{array}{l}\text { de student } \\
\text { D09-10. Rete } \\
\text { ndix B - Gu } \\
\text { d region, se }\end{array}$ & $\begin{array}{l}\text { s } 4 \text { years pri } \\
\text { ntion rates } \\
\text { ide to Souro } \\
\text { e Appendix }\end{array}$ & $\begin{array}{l}\text { ior. } \\
\text { were } \\
\text { ces. Race } \\
\text { x C- } \\
\text { niverse }\end{array}$ \\
\hline
\end{tabular}


Table A-17-1. Number and percentage distribution of full-time teachers, by school level, school type, and selected teacher characteristics: School years 2003-04 and 2007-08

\begin{tabular}{|c|c|c|c|c|c|c|}
\hline \multirow[b]{3}{*}{ Teacher characteristic } & \multicolumn{6}{|c|}{ All teachers } \\
\hline & \multicolumn{3}{|c|}{ 2003-04 } & \multicolumn{3}{|c|}{ 2007-08 } \\
\hline & All & Public & Private & All & Public & Private \\
\hline Total, number & $3,314,700$ & $2,948,200$ & 366,500 & $3,501,400$ & $3,114,700$ & 386,800 \\
\hline Total, percentage & 100.0 & 88.9 & 11.1 & 100.0 & 89.0 & 11.0 \\
\hline Sex & 100.0 & 100.0 & 100.0 & 100.0 & 100.0 & 100.0 \\
\hline Male & 25.2 & 25.5 & 23.1 & 24.9 & 24.8 & 25.5 \\
\hline Female & 74.8 & 74.5 & 76.9 & 75.1 & 75.2 & 74.5 \\
\hline Age & 100.0 & 100.0 & 100.0 & 100.0 & 100.0 & 100.0 \\
\hline Under 30 & 17.1 & 16.7 & 20.4 & 18.2 & 18.2 & 17.9 \\
\hline $30-39$ & 24.3 & 24.6 & 21.9 & 26.1 & 26.4 & 23.1 \\
\hline $40-49$ & 25.5 & 25.7 & 24.1 & 23.6 & 23.7 & 23.1 \\
\hline $50-59$ & 28.9 & 29.2 & 26.2 & 25.7 & 25.7 & 25.5 \\
\hline 60 and over & 4.2 & 3.9 & 7.4 & 6.4 & 5.9 & 10.5 \\
\hline Race/ethnicity & 100.0 & 100.0 & 100.0 & 100.0 & 100.0 & 100.0 \\
\hline White & 83.3 & 82.7 & 87.9 & 82.9 & 82.5 & 86.1 \\
\hline Black & 7.8 & 8.2 & 4.3 & 6.9 & 7.3 & 4.3 \\
\hline Hispanic & 6.2 & 6.4 & 4.5 & 7.2 & 7.3 & 6.0 \\
\hline Asian & 1.4 & 1.3 & 1.9 & 1.3 & 1.2 & 2.2 \\
\hline Native Hawaiian/Pacific Islander & 0.2 & 0.2 & $0.2 !$ & 0.2 & 0.2 & $0.3 !$ \\
\hline American Indian/Alaska Native & 0.5 & 0.5 & $\ddagger$ & 0.5 & 0.5 & 0.4 \\
\hline Two or more races & 0.7 & 0.7 & $0.7 !$ & 0.9 & 0.9 & 0.7 \\
\hline Locale & - & - & - & 100.0 & 100.0 & 100.0 \\
\hline City & - & - & - & 28.1 & 26.3 & 42.3 \\
\hline Suburban & - & - & - & 35.0 & 34.8 & 36.3 \\
\hline Town & - & - & - & 13.2 & 13.9 & 7.7 \\
\hline Rural & - & - & - & 23.8 & 25.1 & 13.7 \\
\hline Highest degree earned & 100.0 & 100.0 & 100.0 & 100.0 & 100.0 & 100.0 \\
\hline Less than bachelor's & $1.7 !$ & 1.0 & $\ddagger$ & 1.5 & 0.8 & 7.0 \\
\hline Bachelor's & 52.1 & 51.3 & 58.5 & 49.1 & 48.2 & 56.1 \\
\hline Postbaccalaureate & 46.1 & 47.6 & 34.1 & 49.5 & 51.0 & 36.8 \\
\hline Master's & 39.3 & 40.6 & 28.9 & 42.8 & 44.1 & 32.1 \\
\hline $\begin{array}{l}\text { Education specialist or } \\
\text { professional diploma }\end{array}$ & 5.6 & 5.9 & 3.3 & 5.7 & 6.1 & 2.6 \\
\hline Doctor's or first-professional & 1.2 & 1.1 & 1.9 & 1.0 & 0.8 & 2.1 \\
\hline $\begin{array}{l}\text { Average base salary, in constant } \\
2010-11 \text { dollars }\end{array}$ & $\$ 51,000$ & $\$ 52,700$ & $\$ 37,500$ & $\$ 50,300$ & $\$ 51,800$ & $\$ 37,800$ \\
\hline $\begin{array}{l}\text { Base salary, in constant } \\
2010-11 \text { dollars, percentage }\end{array}$ & 100.0 & 100.0 & 100.0 & 100.0 & 100.0 & 100.0 \\
\hline Less than $\$ 30,000$ & 5.1 & 1.9 & 30.6 & 4.9 & 1.9 & 28.8 \\
\hline$\$ 30,000-\$ 44,999$ & 34.7 & 33.7 & 42.8 & 39.2 & 38.3 & 45.8 \\
\hline$\$ 45,000-\$ 59,999$ & 35.5 & 37.4 & 20.0 & 32.6 & 34.3 & 18.4 \\
\hline$\$ 60,000-\$ 74,999$ & 16.0 & 17.4 & 5.2 & 15.3 & 16.6 & 5.2 \\
\hline$\$ 75,000$ or more & 8.7 & 9.6 & 1.5 & 8.1 & 8.8 & 1.7 \\
\hline
\end{tabular}

See notes at end of table. 
Table A-17-1. Number and percentage distribution of full-time teachers, by school level, school type, and selected teacher characteristics: School years 2003-04 and 2007-08-Continued

\begin{tabular}{|c|c|c|c|c|c|c|}
\hline \multirow[b]{3}{*}{ Teacher characteristic } & \multicolumn{6}{|c|}{ Elementary } \\
\hline & \multicolumn{3}{|c|}{$2003-04$} & \multicolumn{3}{|c|}{ 2007-08 } \\
\hline & All & Public & Private & All & Public & Private \\
\hline Total, number & $2,062,600$ & $1,884,600$ & 178,000 & $2,103,400$ & $1,936,400$ & 166,900 \\
\hline Total, percentage & 100.0 & 91.4 & 8.6 & 100.0 & 92.1 & 7.9 \\
\hline Sex & 100.0 & 100.0 & 100.0 & 100.0 & 100.0 & 100.0 \\
\hline Male & 15.9 & 16.3 & 12.1 & 15.4 & 15.6 & 12.8 \\
\hline Female & 84.1 & 83.7 & 87.9 & 84.6 & 84.4 & 87.2 \\
\hline Age & 100.0 & 100.0 & 100.0 & 100.0 & 100.0 & 100.0 \\
\hline Under 30 & 17.6 & 17.4 & 19.3 & 18.7 & 18.7 & 18.6 \\
\hline $30-39$ & 24.1 & 24.5 & 19.9 & 26.3 & 26.8 & 20.9 \\
\hline $40-49$ & 25.7 & 25.8 & 25.1 & 23.8 & 23.9 & 22.2 \\
\hline $50-59$ & 28.7 & 28.8 & 27.6 & 25.6 & 25.4 & 28.2 \\
\hline 60 and over & 3.8 & 3.4 & $8.1 !$ & 5.6 & 5.2 & 10.2 \\
\hline Race/ethnicity & 100.0 & 100.0 & 100.0 & 100.0 & 100.0 & 100.0 \\
\hline White & 82.0 & 81.6 & 86.3 & 82.3 & 82.0 & 85.7 \\
\hline Black & 8.5 & 8.8 & 5.5 & 7.2 & 7.4 & 5.2 \\
\hline Hispanic & 6.8 & 7.0 & 4.8 & 7.7 & 7.9 & 6.0 \\
\hline Asian & 1.4 & 1.3 & 1.9 & 1.3 & 1.3 & 2.0 \\
\hline Native Hawaiian/Pacific Islander & 0.2 & 0.2 & $0.2 !$ & $0.2 !$ & $0.2 !$ & $0.2 !$ \\
\hline American Indian/Alaska Native & 0.4 & 0.4 & $0.5 !$ & 0.4 & 0.4 & $0.4 !$ \\
\hline Two or more races & 0.8 & 0.7 & $\ddagger$ & 0.8 & 0.9 & $0.5 !$ \\
\hline Locale & - & - & - & 100.0 & 100.0 & 100.0 \\
\hline City & - & - & - & 28.4 & 27.2 & 42.0 \\
\hline Suburban & - & - & - & 35.9 & 35.5 & 40.4 \\
\hline Town & - & - & - & 13.3 & 13.6 & 9.0 \\
\hline Rural & - & - & - & 22.4 & 23.6 & 8.6 \\
\hline Highest degree earned & 100.0 & 100.0 & 100.0 & 100.0 & 100.0 & 100.0 \\
\hline Less than bachelor's & 1.0 & 0.3 & 7.6 & 0.8 & 0.2 & 7.1 \\
\hline Bachelor's & 53.8 & 52.7 & 65.1 & 50.7 & 49.6 & 63.3 \\
\hline Postbaccalaureate & 45.2 & 46.9 & 27.3 & 48.5 & 50.1 & 29.7 \\
\hline Master's & 38.5 & 40.0 & 23.3 & 42.3 & 43.6 & 27.3 \\
\hline $\begin{array}{l}\text { Education specialist or } \\
\text { professional diploma }\end{array}$ & 5.9 & 6.1 & 3.3 & 5.7 & 6.0 & 1.9 \\
\hline Doctor's or first-professional & 0.8 & 0.8 & 0.8 & 0.5 & 0.5 & $0.5 !$ \\
\hline $\begin{array}{l}\text { Average base salary, in constant } \\
2010-11 \text { dollars }\end{array}$ & $\$ 51,200$ & $\$ 52,700$ & $\$ 35,400$ & $\$ 50,300$ & $\$ 51,600$ & $\$ 35,600$ \\
\hline Base salary, in constant & & & & & & \\
\hline 2010-11 dollars, percentage & 100.0 & 100.0 & 100.0 & 100.0 & 100.0 & 100.0 \\
\hline Less than $\$ 30,000$ & 4.2 & 1.5 & 33.0 & 4.0 & 1.6 & 31.8 \\
\hline$\$ 30,000-\$ 44,999$ & 34.6 & 33.3 & 48.7 & 40.1 & 39.1 & 51.5 \\
\hline$\$ 45,000-\$ 59,999$ & 36.3 & 38.3 & 15.4 & 32.8 & 34.5 & 13.4 \\
\hline$\$ 60,000-\$ 74,999$ & 16.3 & 17.7 & 2.2 & 15.1 & 16.2 & 2.6 \\
\hline$\$ 75,000$ or more & 8.5 & 9.2 & $0.7 !$ & 7.9 & 8.5 & $0.7 !$ \\
\hline
\end{tabular}


Table A-17-1. Number and percentage distribution of full-time teachers, by school level, school type, and selected teacher characteristics: School years 2003-04 and 2007-08-Continued

\begin{tabular}{|c|c|c|c|c|c|c|}
\hline \multirow[b]{3}{*}{ Teacher characteristic } & \multicolumn{6}{|c|}{ Secondary } \\
\hline & \multicolumn{3}{|c|}{ 2003-04 } & \multicolumn{3}{|c|}{ 2007-08 } \\
\hline & All & Public & Private & All & Public & Private \\
\hline Total, number & 970,600 & 910,300 & 60,400 & $1,093,400$ & $1,032,800$ & 60,600 \\
\hline Total, percentage & 100.0 & 93.8 & 6.2 & 100.0 & 94.5 & 5.5 \\
\hline Sex & 100.0 & 100.0 & 100.0 & 100.0 & 100.0 & 100.0 \\
\hline Male & 43.5 & 43.2 & 48.2 & 41.7 & 41.3 & 47.1 \\
\hline Female & 56.5 & 56.8 & 51.8 & 58.3 & 58.7 & 52.9 \\
\hline Age & 100.0 & 100.0 & 100.0 & 100.0 & 100.0 & 100.0 \\
\hline Under 30 & 15.6 & 15.3 & 20.5 & 17.6 & 17.5 & 18.6 \\
\hline $30-39$ & 24.7 & 24.8 & 23.2 & 25.6 & 26.0 & 17.9 \\
\hline $40-49$ & 24.9 & 25.0 & 22.5 & 23.2 & 23.3 & 20.6 \\
\hline $50-59$ & 29.9 & 30.1 & 25.8 & 26.2 & 26.1 & 27.3 \\
\hline 60 and over & 4.9 & 4.7 & 7.9 & 7.5 & 7.0 & 15.6 \\
\hline Race/ethnicity & 100.0 & 100.0 & 100.0 & 100.0 & 100.0 & 100.0 \\
\hline White & 84.5 & 84.2 & 90.0 & 83.5 & 83.1 & 89.6 \\
\hline Black & 7.2 & 7.5 & $2.7 !$ & 6.7 & 7.0 & $1.9 !$ \\
\hline Hispanic & 5.5 & 5.5 & 4.6 & 6.9 & 7.0 & 5.7 \\
\hline Asian & 1.4 & 1.3 & $1.7 !$ & 1.3 & 1.3 & $1.7 !$ \\
\hline Native Hawaiian/Pacific Islander & 0.2 & 0.2 & $\ddagger$ & $0.2 !$ & $0.2 !$ & $\ddagger$ \\
\hline American Indian/Alaska Native & 0.5 & 0.6 & $\ddagger$ & 0.5 & 0.5 & $\ddagger$ \\
\hline Two or more races & 0.7 & 0.7 & $\ddagger$ & 0.9 & 0.9 & $\ddagger$ \\
\hline Locale & - & - & - & 100.0 & 100.0 & 100.0 \\
\hline City & - & - & - & 27.2 & 25.9 & 49.3 \\
\hline Suburban & - & - & - & 35.9 & 36.2 & 31.5 \\
\hline Town & - & - & - & 14.4 & 14.9 & 5.4 \\
\hline Rural & - & - & - & 22.4 & 22.9 & 13.8 \\
\hline Highest degree earned & 100.0 & 100.0 & 100.0 & 100.0 & 100.0 & 100.0 \\
\hline Less than bachelor's & 2.5 & 2.4 & 3.0 & 1.8 & 1.8 & $\ddagger$ \\
\hline Bachelor's & 47.3 & 47.4 & 46.0 & 44.6 & 44.5 & 46.3 \\
\hline Postbaccalaureate & 50.2 & 50.2 & 51.1 & 53.6 & 53.7 & 52.3 \\
\hline Master's & 42.7 & 42.6 & 43.8 & 45.9 & 45.9 & 45.0 \\
\hline $\begin{array}{l}\text { Education specialist or } \\
\text { professional diploma }\end{array}$ & 5.6 & 5.8 & 3.6 & 6.2 & 6.3 & 4.4 \\
\hline Doctor's or first-professional & 1.9 & 1.8 & 3.6 & 1.6 & 1.5 & $2.9 !$ \\
\hline $\begin{array}{l}\text { Average base salary, in constant } \\
2010-11 \text { dollars }\end{array}$ & $\$ 53,200$ & $\$ 53,800$ & $\$ 43,900$ & $\$ 52,700$ & $\$ 53,100$ & $\$ 44,600$ \\
\hline Base salary, in constant & & & & & & \\
\hline 2010-11 dollars, percentage & 100.0 & 100.0 & 100.0 & 100.0 & 100.0 & 100.0 \\
\hline Less than $\$ 30,000$ & 2.2 & 1.6 & 11.8 & 1.9 & 1.4 & 9.9 \\
\hline$\$ 30,000-\$ 44,999$ & 33.0 & 32.3 & 44.3 & 35.9 & 35.2 & 48.3 \\
\hline$\$ 45,000-\$ 59,999$ & 36.6 & 36.9 & 31.3 & 34.7 & 35.0 & 28.3 \\
\hline$\$ 60,000-\$ 74,999$ & 17.6 & 18.1 & 10.1 & 17.8 & 18.3 & 9.5 \\
\hline$\$ 75,000$ or more & 10.6 & 11.1 & 2.5 & 9.7 & 10.0 & 4.1 \\
\hline
\end{tabular}

- Not available.

$\dagger$ Not applicable.

! Interpret with caution. The coefficient of variation (CV) for this estimate is 30 percent or greater.

‡ Reporting standards not met (too few cases).

NOTE: Included in the total but not shown separately are full-time teachers in combined schools. There were 3.3 million full-time teachers in $2003-04$ and 3.5 million full-time teachers in 2007-08. This analysis focuses on full-time teachers who taught in elementary and secondary schools. These teachers made up 89 percent of all teachers in public and private schools in 2003-04 and 82 percent in 2007-08. Less than bachelor's includes teachers with an associate's degree, those with a vocational certificate, and those without a postsecondary degree. Education specialist/professional diploma includes teachers with a certificate of advanced graduate studies. For the definition of first-professional degrees and a list of these degrees, see Appendix D - Glossary. Average base salary was calculated in 2010-11 school year constant dollars and adjusted using the Consumer Price Index (CPI). For more information on the CPI, see Appendix C - Finance. Race categories exclude persons of Hispanic ethnicity. For more information on race/ethnicity, see Appendix C - Commonly Used Measures. For more information on the Schools and Staffing Survey (SASS), see Appendix B - Guide to Sources. Detail may not sum to totals because of rounding.

SOURCE: U.S. Department of Education, National Center for Education Statistics, Schools and Staffing Survey (SASS), "Public School Teacher and Private School Teacher Data Files," 2003-04 and 2007-08. 
This indicator continues on page 184.

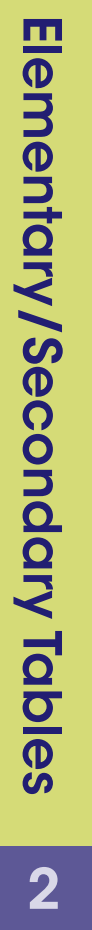


Table A-17-2. Number and percentage distribution of full-time teachers, by school level, school type, and selected teaching characteristics: School years 2003-04 and 2007-08

\begin{tabular}{|c|c|c|c|c|c|c|}
\hline \multirow[b]{3}{*}{ Teaching characteristic } & \multicolumn{6}{|c|}{ All teachers } \\
\hline & \multicolumn{3}{|c|}{$2003-04$} & \multicolumn{3}{|c|}{$2007-08$} \\
\hline & All & Public & Private & All & Public & Private \\
\hline Total, number & $3,314,700$ & $2,948,200$ & 366,500 & $3,501,400$ & $3,114,700$ & 386,800 \\
\hline Total, percentage & 100.0 & 88.9 & 11.1 & 100.0 & 89.0 & 11.0 \\
\hline \multicolumn{7}{|l|}{ Years of teaching experience, percentage } \\
\hline 3 or fewer & 16.7 & 15.9 & 22.6 & 17.4 & 17.1 & 20.4 \\
\hline $4-9$ & 27.0 & 27.0 & 27.1 & 27.8 & 27.8 & 27.5 \\
\hline $10-19$ & 26.4 & 26.5 & 25.9 & 27.5 & 27.8 & 24.9 \\
\hline 20 or more & 29.9 & 30.6 & 24.4 & 27.3 & 27.3 & 27.2 \\
\hline $\begin{array}{l}\text { Average years of teaching experience, } \\
\text { number }\end{array}$ & 13.9 & 14.1 & 12.7 & 13.5 & 13.5 & 13.4 \\
\hline \multirow{2}{*}{\multicolumn{7}{|c|}{$\begin{array}{l}\text { Main teaching assignment } \\
\text { Elementary-level teachers }\end{array}$}} \\
\hline & & & & & & \\
\hline General & 37.3 & 36.6 & 43.0 & 34.6 & 34.1 & 38.7 \\
\hline English & 1.9 & 1.9 & 1.7 & 2.6 & 2.6 & 2.6 \\
\hline English as a second language & 0.6 & 0.6 & $\ddagger$ & 0.5 & 0.5 & $\ddagger$ \\
\hline Mathematics & 0.7 & 0.6 & 1.3 & 0.8 & 0.7 & 1.4 \\
\hline Special education & 6.3 & 6.7 & 2.5 & 5.8 & 6.3 & 1.9 \\
\hline Other & 5.6 & 5.2 & 8.7 & 5.6 & 5.2 & 9.3 \\
\hline \multicolumn{7}{|l|}{ Secondary-level teachers } \\
\hline English & 8.6 & 8.7 & 8.5 & 9.2 & 9.4 & 8.1 \\
\hline English as a second language & 0.5 & 0.5 & $\ddagger$ & 0.5 & 0.5 & $\ddagger$ \\
\hline Foreign language & 2.4 & 2.2 & 3.9 & 2.4 & 2.1 & 4.5 \\
\hline Mathematics & 6.9 & 6.9 & 7.1 & 7.8 & 7.8 & 7.3 \\
\hline Science & 6.2 & 6.2 & 5.9 & 6.1 & 6.0 & 6.5 \\
\hline Social sciences & 5.8 & 5.8 & 5.9 & 6.5 & 6.5 & 6.7 \\
\hline Special education & 4.9 & 5.4 & 1.4 & 4.6 & 5.0 & 1.4 \\
\hline Vocational/technical & 4.8 & 5.3 & 0.9 & 4.4 & 4.9 & 0.8 \\
\hline Other & 7.5 & 7.3 & 9.0 & 8.5 & 8.2 & 10.5 \\
\hline \multicolumn{7}{|l|}{ Certification type } \\
\hline Regular & 83.5 & 88.0 & 47.5 & 84.7 & 89.1 & 49.6 \\
\hline Probationary & 3.4 & 3.7 & 1.3 & 3.6 & 3.8 & 2.1 \\
\hline Provisional & 4.2 & 4.3 & 2.9 & - & - & - \\
\hline Temporary & 2.2 & 2.2 & 1.7 & 4.0 & 4.1 & 3.4 \\
\hline Waiver or emergency & 0.6 & 0.6 & 0.5 & 2.0 & 2.1 & 1.2 \\
\hline No certification & 6.2 & 1.2 & 46.1 & 5.7 & 1.0 & 43.8 \\
\hline
\end{tabular}


Table A-17-2. Number and percentage distribution of full-time teachers, by school level, school type, and selected teaching characteristics: School years 2003-04 and 2007-08-Continued

\begin{tabular}{|c|c|c|c|c|c|c|}
\hline \multirow[b]{3}{*}{ Teaching characteristic } & \multicolumn{6}{|c|}{ Elementary } \\
\hline & \multicolumn{3}{|c|}{ 2003-04 } & \multicolumn{3}{|c|}{$2007-08$} \\
\hline & All & Public & Private & All & Public & Private \\
\hline Total, number & $2,062,600$ & $1,884,600$ & 178,000 & $2,103,400$ & $1,936,400$ & 166,900 \\
\hline Total, percentage & 100.0 & 91.4 & 8.6 & 100.0 & 92.1 & 7.9 \\
\hline \multicolumn{7}{|l|}{ Years of teaching experience, percentage } \\
\hline 3 or fewer & 16.3 & 15.8 & 21.4 & 17.3 & 17.0 & 20.2 \\
\hline $4-9$ & 27.1 & 27.2 & 26.2 & 27.9 & 28.0 & 25.9 \\
\hline $10-19$ & 27.0 & 27.1 & 26.7 & 27.8 & 27.9 & 25.5 \\
\hline 20 or more & 29.6 & 29.9 & 25.7 & 27.1 & 27.0 & 28.5 \\
\hline $\begin{array}{l}\text { Average years of teaching experience, } \\
\text { number }\end{array}$ & 13.9 & 14.0 & 13.1 & 13.5 & 13.5 & 13.7 \\
\hline \multicolumn{7}{|l|}{ Main teaching assignment } \\
\hline \multicolumn{7}{|l|}{ Elementary-level teachers } \\
\hline General & 56.3 & 55.4 & 65.8 & 53.8 & 53.1 & 61.9 \\
\hline English & 2.8 & 2.8 & 2.6 & 4.0 & 4.0 & 4.0 \\
\hline English as a second language & 0.9 & 1.0 & $\ddagger$ & 0.8 & 0.9 & $\ddagger$ \\
\hline Mathematics & 1.0 & 0.9 & 2.2 & 1.2 & 1.1 & 2.3 \\
\hline Special education & 8.9 & 9.6 & $\ddagger$ & 8.7 & 9.3 & 1.4 \\
\hline Other & 8.2 & 7.7 & 13.5 & 8.6 & 8.0 & 15.8 \\
\hline \multicolumn{7}{|l|}{ Secondary-level teachers } \\
\hline English & 5.1 & 5.2 & 4.6 & 5.2 & 5.2 & 4.7 \\
\hline English as a second language & 0.4 & 0.4 & $\ddagger$ & 0.3 & 0.4 & $\ddagger$ \\
\hline Foreign language & 0.6 & 0.7 & $0.3 !$ & 0.4 & 0.4 & 0.6 \\
\hline Mathematics & 3.5 & 3.5 & 2.9 & 4.2 & 4.3 & 2.6 \\
\hline Science & 3.3 & 3.4 & 2.0 & 2.8 & 2.8 & 3.0 \\
\hline Social sciences & 2.6 & 2.6 & 3.0 & 3.4 & 3.5 & 2.2 \\
\hline Special education & 2.3 & 2.5 & $\ddagger$ & 2.0 & 2.2 & $\ddagger$ \\
\hline Vocational/technical & 1.3 & 1.4 & $\ddagger$ & 0.8 & 0.9 & $\ddagger$ \\
\hline Other & 2.8 & 3.0 & 1.1 & 3.8 & 4.0 & 1.3 \\
\hline \multicolumn{7}{|l|}{ Certification type } \\
\hline Regular & 86.0 & 88.9 & 54.6 & 87.4 & 89.9 & 57.8 \\
\hline Probationary & 3.4 & 3.5 & 1.5 & 3.5 & 3.6 & 2.6 \\
\hline Provisional & 3.9 & 3.9 & 3.8 & - & - & - \\
\hline Temporary & 2.0 & 2.0 & $1.9 !$ & 4.0 & 4.1 & 3.0 \\
\hline Waiver or emergency & 0.6 & 0.6 & $0.4 !$ & 1.7 & 1.7 & 1.7 \\
\hline No certification & 4.2 & 1.0 & 37.9 & 3.4 & 0.7 & 34.9 \\
\hline
\end{tabular}

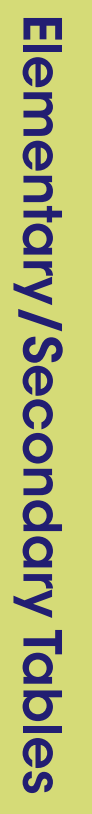


Table A-17-2. Number and percentage distribution of full-time teachers, by school level, school type, and selected teaching characteristics: School years 2003-04 and 2007-08-Continued

\begin{tabular}{|c|c|c|c|c|c|c|}
\hline \multirow[b]{3}{*}{ Teaching characteristic } & \multicolumn{6}{|c|}{ Secondary } \\
\hline & \multicolumn{3}{|c|}{$2003-04$} & \multicolumn{3}{|c|}{$2007-08$} \\
\hline & All & Public & Private & All & Public & Private \\
\hline Total, number & 970,600 & 910,300 & 60,400 & $1,093,400$ & $1,032,800$ & 60,600 \\
\hline Total, percentage & 100.0 & 93.8 & 6.2 & 100.0 & 94.5 & 5.5 \\
\hline \multicolumn{7}{|c|}{ Years of teaching experience, percentage } \\
\hline 3 or fewer & 16.4 & 16.0 & 23.0 & 16.8 & 16.8 & 16.4 \\
\hline $4-9$ & 26.7 & 26.7 & 28.0 & 28.0 & 28.0 & 26.9 \\
\hline $10-19$ & 25.1 & 25.3 & 21.2 & 27.3 & 27.4 & 25.3 \\
\hline 20 or more & 31.8 & 32.0 & 27.8 & 28.0 & 27.8 & 31.4 \\
\hline $\begin{array}{l}\text { Average years of teachir } \\
\text { number }\end{array}$ & 14.3 & 14.4 & 13.1 & 13.7 & 13.6 & 15.2 \\
\hline
\end{tabular}

Main teaching assignment

Elementary-level teachers

General

English

English as a second language

Mathematics

Special education

Other

Secondary-level teachers

English

English as a second language

Foreign language

Mathematics

Science

Social sciences

Special education

Vocational/technical

Other

$\begin{array}{rc}0.2 & 0.2 \\ \# & 0.1 ! \\ \ddagger & \ddagger \\ \ddagger & \ddagger \\ 0.5 & 0.6 \\ 0.4 & 0.4\end{array}$

$\begin{array}{ccc}0.2 ! & 0.2 ! & \ddagger \\ 0.1 ! & 0.1 ! & \ddagger \\ \ddagger & \ddagger & \ddagger \\ 0.1 ! & 0.1 ! & \ddagger \\ 0.6 & 0.6 & \ddagger \\ 0.2 & 0.2 & \ddagger\end{array}$

$\begin{array}{rrrrrr}15.7 & 15.5 & 17.5 & 16.8 & 16.8 & 15.3 \\ 0.8 & 0.8 & \ddagger & 0.9 & 0.9 & \ddagger \\ 5.8 & 5.5 & 11.6 & 5.6 & 5.4 & 9.6 \\ 13.5 & 13.5 & 14.3 & 14.3 & 14.3 & 13.7 \\ 11.9 & 11.8 & 13.5 & 12.1 & 11.9 & 14.8 \\ 12.2 & 12.2 & 12.3 & 12.2 & 12.2 & 13.4 \\ 10.1 & 10.7 & 1.9 ! & 9.3 & 9.7 & 2.3 ! \\ 12.5 & 13.1 & 3.3 & 11.5 & 12.1 & 2.8 \\ 16.2 & 15.7 & 24.8 & 16.1 & 15.5 & 26.1\end{array}$

Certification type

$\begin{array}{ll}\text { Regular } & 83.8\end{array}$

Probationary

Provisional

86.5

4.0

43.0

$1.1 !$

86.1

88.0

54.8

Temporary

4.7

4.9

$\begin{array}{ll}2.5 & 2.5\end{array}$

Waiver or emergency

$\begin{array}{ll}0.7 & 0.7\end{array}$

No certification

- Not available.

! Interpret with caution. The coefficient of variation (CV) for this estimate is 30 percent or greater.

$\ddagger$ Reporting standards not met (too few cases)

NOTE: Included in the total but not shown separately are full-time teachers in combined schools. The Schools and Staffing Survey questionnaire was redesigned in 2007-08; the teacher certification question no longer included provisional certification as an option. Probationary refers to a teaching certificate granted to those who have satisfied all requirements for certification except the completion of a probationary period. No certification refers

to those who do not hold a teaching certificate in the state in which they currently teach. For more information on the Schools and Staffing Survey

(SASS), see Appendix B - Guide to Sources. Detail may not sum to totals because of rounding.

SOURCE: U.S. Department of Education, National Center for Education Statistics, Schools and Staffing Survey (SASS), "Public School Teacher and Private School Teacher Data Files," 2003-04 and 2007-08. 


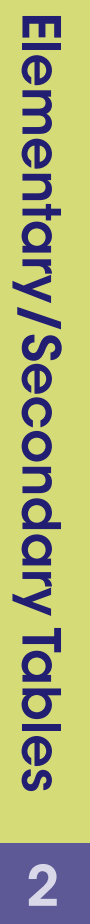

This page intentionally left blank. 
Table A-18-1. Number and percentage distribution of school principals, by school level, school type, and selected principal characteristics: School years 1999-2000 and 2007-08

\begin{tabular}{|c|c|c|c|c|c|c|}
\hline \multirow[b]{3}{*}{ Principal characteristic } & \multicolumn{6}{|c|}{ All principals } \\
\hline & \multicolumn{3}{|c|}{ 1999-2000 } & \multicolumn{3}{|c|}{$2007-08$} \\
\hline & Total & Public & Private & Total & Public & Private \\
\hline Total, number & 110,000 & 83,800 & 26,200 & 118,400 & 90,500 & 28,000 \\
\hline Total, percentage & 100.0 & 76.2 & 23.8 & 100.0 & 76.4 & 23.6 \\
\hline Sex & 100.0 & 100.0 & 100.0 & 100.0 & 100.0 & 100.0 \\
\hline Male & 53.7 & 56.2 & 45.4 & 49.0 & 49.7 & 46.7 \\
\hline Female & 46.3 & 43.8 & 54.6 & 51.0 & 50.3 & 53.3 \\
\hline Age & 100.0 & 100.0 & 100.0 & 100.0 & 100.0 & 100.0 \\
\hline Under 40 & 11.1 & 10.1 & 14.3 & 18.6 & 19.1 & 17.0 \\
\hline $40-44$ & 12.7 & 12.5 & 13.2 & 14.0 & 14.7 & 11.6 \\
\hline $45-49$ & 22.6 & 23.4 & 19.9 & 14.4 & 15.1 & 12.2 \\
\hline $50-54$ & 30.0 & 32.4 & 22.3 & 18.5 & 19.4 & 15.7 \\
\hline 55 and over & 23.7 & 21.6 & 30.4 & 34.4 & 31.6 & 43.5 \\
\hline Race/ethnicity & 100.0 & 100.0 & 100.0 & 100.0 & 100.0 & 100.0 \\
\hline White & 83.9 & 82.3 & 88.9 & 82.4 & 80.9 & 87.3 \\
\hline Black & 9.8 & 11.0 & 6.0 & 9.7 & 10.6 & 6.5 \\
\hline Hispanic & 4.7 & 5.2 & 3.2 & 5.9 & 6.5 & 4.0 \\
\hline Asian & 0.9 & 0.8 & 1.3 & 0.8 & 0.6 & 1.2 \\
\hline $\begin{array}{l}\text { Native Hawaiian/ } \\
\text { Pacific Islander }\end{array}$ & - & - & - & $0.1 !$ & $0.1 !$ & $\ddagger$ \\
\hline American Indian/Alaska Native & 0.7 & 0.8 & 0.6 & 0.6 & 0.7 & $\ddagger$ \\
\hline Two or more races & - & - & - & 0.6 & $0.5 !$ & $0.7 !$ \\
\hline Highest degree earned & 100.0 & 100.0 & 100.0 & 100.0 & 100.0 & 100.0 \\
\hline Bachelor's or less & 8.7 & 1.8 & 30.7 & 8.8 & 1.5 & 32.6 \\
\hline Master's & 53.4 & 54.2 & 51.0 & 58.5 & 61.1 & 50.2 \\
\hline $\begin{array}{l}\text { Education specialist or profes- } \\
\text { sional diploma }\end{array}$ & 28.1 & 33.8 & 9.9 & 24.5 & 29.0 & 10.0 \\
\hline $\begin{array}{l}\text { Doctor's or } \\
\quad \text { first-professional }\end{array}$ & 9.8 & 10.2 & 8.5 & 8.1 & 8.4 & 7.2 \\
\hline Number of years as a principal & 100.0 & 100.0 & 100.0 & 100.0 & 100.0 & 100.0 \\
\hline 3 or fewer & 29.6 & 29.9 & 28.7 & 34.4 & 34.8 & 32.9 \\
\hline $4-9$ & 29.9 & 30.9 & 26.]6 & 33.2 & 35.5 & 25.9 \\
\hline $10-19$ & 27.8 & 27.7 & 28.0 & 22.7 & 22.6 & 23.0 \\
\hline 20 or more & 12.7 & 11.4 & 16.6 & 9.7 & 7.0 & 18.3 \\
\hline $\begin{array}{l}\text { Number of years of teaching } \\
\text { experience prior to becoming a } \\
\text { principal }\end{array}$ & 100.0 & 100.0 & 100.0 & 100.0 & 100.0 & 100.0 \\
\hline 3 or fewer & 9.9 & 5.4 & 24.0 & 10.1 & 4.6 & 28.1 \\
\hline $4-9$ & 29.7 & 30.1 & 28.5 & 31.5 & 33.4 & 25.1 \\
\hline $10-19$ & 43.1 & 46.4 & 32.5 & 41.1 & 44.4 & 30.4 \\
\hline 20 or more & 17.3 & 18.1 & 15.0 & 17.2 & 17.5 & 16.4 \\
\hline $\begin{array}{l}\text { Median annual salary, } \\
\text { in constant } 2010-11 \text { dollars }\end{array}$ & $\$ 79,700$ & $\$ 84,900$ & $\$ 50,400$ & $\$ 83,500$ & $\$ 88,200$ & $\$ 52,200$ \\
\hline
\end{tabular}

See notes at end of table. 
Table A-18-1. Number and percentage distribution of school principals, by school level, school type, and selected principal characteristics: School years 1999-2000 and 2007-08-Continued

\begin{tabular}{|c|c|c|c|c|c|c|}
\hline \multirow[b]{3}{*}{ Principal characteristic } & \multicolumn{6}{|c|}{ Elementary } \\
\hline & \multicolumn{3}{|c|}{ 1999-2000 } & \multicolumn{3}{|c|}{ 2007-08 } \\
\hline & Total & Public & Private & Total & Public & Private \\
\hline Total, number & 75,900 & 60,100 & 15,800 & 78,500 & 62,300 & 16,100 \\
\hline Total, percentage & 100.0 & 79.2 & 20.8 & 100.0 & 79.5 & 20.5 \\
\hline Sex & 100.0 & 100.0 & 100 & 100.0 & 100.0 & 100.0 \\
\hline Male & 44.9 & 48.2 & 32.4 & 40.1 & 41.1 & 36.3 \\
\hline Female & 55.1 & 51.8 & 67.6 & 59.9 & 58.9 & 63.7 \\
\hline Age & 100.0 & 100.0 & 100 & 100.0 & 100.0 & 100.0 \\
\hline Under 40 & 10.5 & 9.9 & 12.9 & 18.5 & 19.2 & 15.9 \\
\hline $40-44$ & 12.5 & 12.6 & 12.5 & 13.9 & 14.8 & 10.5 \\
\hline $45-49$ & 22.6 & 23.7 & 18.6 & 14.4 & 14.8 & 13.2 \\
\hline $50-54$ & 30.0 & 32.0 & 22.4 & 17.7 & 18.6 & 14.3 \\
\hline 55 and over & 24.3 & 21.8 & 33.6 & 35.4 & 32.6 & 46.1 \\
\hline Race/ethnicity & 100.0 & 100.0 & 100 & 100.0 & 100.0 & 100.0 \\
\hline White & 82.2 & 81.2 & 86.2 & 80.7 & 79.5 & 85.4 \\
\hline Black & 11.1 & 11.8 & 8.1 & 10.1 & 10.9 & 6.9 \\
\hline Hispanic & 5.1 & 5.6 & 3.2 & 7.0 & 7.6 & 5.1 \\
\hline Asian & 1.0 & 0.7 & 1.9 & 0.9 & $0.7 !$ & 1.6 \\
\hline $\begin{array}{l}\text { Native Hawaiian/ } \\
\text { Pacific Islander }\end{array}$ & - & - & - & $0.1 !$ & $\ddagger$ & $\ddagger$ \\
\hline American Indian/Alaska Native & 0.6 & 0.7 & $0.6 !$ & $0.6 !$ & $0.7 !$ & $\ddagger$ \\
\hline Two or more races & - & - & - & 0.5 & $0.5 !$ & $0.8 !$ \\
\hline Highest degree earned & 100.0 & 100.0 & 100 & 100.0 & 100.0 & 100.0 \\
\hline Bachelor's or less & 7.6 & 1.8 & 29.3 & 7.6 & 1.2 & 32.2 \\
\hline Master's & 54.1 & 53.9 & 54.7 & 59.4 & 61.3 & 52.0 \\
\hline $\begin{array}{l}\text { Education specialist or professional } \\
\text { diploma }\end{array}$ & 29.5 & 34.6 & 9.9 & 25.3 & 29.1 & 10.5 \\
\hline $\begin{array}{l}\text { Doctor's or } \\
\quad \text { first-professional }\end{array}$ & 8.9 & 9.7 & 6.1 & 7.7 & 8.3 & 5.2 \\
\hline Number of years as a principal & 100.0 & 100.0 & 100 & 100.0 & 100.0 & 100.0 \\
\hline 3 or fewer & 29.6 & 29.5 & 29.9 & 34.0 & 34.1 & 33.5 \\
\hline $4-9$ & 28.9 & 30.0 & 24.8 & 33.2 & 35.3 & 25.0 \\
\hline $10-19$ & 28.5 & 28.5 & 28.5 & 22.9 & 23.0 & 22.7 \\
\hline 20 or more & 13.0 & 12.0 & 16.8 & 9.9 & 7.6 & 18.7 \\
\hline $\begin{array}{l}\text { Number of years of teaching ex- } \\
\text { perience prior to becoming a } \\
\text { principal }\end{array}$ & 100.0 & 100.0 & 100 & 100.0 & 100.0 & 100.0 \\
\hline 3 or fewer & 7.8 & 4.9 & 18.8 & 7.9 & 3.2 & 25.9 \\
\hline $4-9$ & 29.1 & 29.5 & 27.4 & 31.0 & 33.0 & 23.1 \\
\hline $10-19$ & 44.8 & 47.1 & 36 & 43.5 & 46.2 & 33.0 \\
\hline 20 or more & 18.4 & 18.5 & 17.8 & 17.6 & 17.5 & 17.9 \\
\hline $\begin{array}{l}\text { Median annual salary, } \\
\text { in constant } 2010-11 \text { dollars }\end{array}$ & $\$ 79,600$ & $\$ 84,800$ & $\$ 47,000$ & $\$ 83,500$ & $\$ 87,700$ & $\$ 52,200$ \\
\hline
\end{tabular}


Table A-18-1. Number and percentage distribution of school principals, by school level, school type, and selected principal characteristics: School years 1999-2000 and 2007-08-Continued

\begin{tabular}{|c|c|c|c|c|c|c|}
\hline \multirow[b]{3}{*}{ Principal characteristic } & \multicolumn{6}{|c|}{ Secondary } \\
\hline & \multicolumn{3}{|c|}{$1999-2000$} & \multicolumn{3}{|c|}{$2007-08$} \\
\hline & Total & Public & Private & Total & Public & Private \\
\hline Total, number & 23,100 & 20,500 & 2,600 & 24,500 & 21,600 & 2,900 \\
\hline Total, percentage & 100.0 & 88.6 & 11.4 & 100.0 & 88.0 & 12.0 \\
\hline Sex & 100.0 & 100.0 & 100.0 & 100.0 & 100.0 & 100.0 \\
\hline Male & 76.9 & 78.2 & 66.3 & 70.6 & 71.5 & 64.4 \\
\hline Female & 23.1 & 21.8 & 33.7 & 29.4 & 28.5 & 35.6 \\
\hline Age & 100.0 & 100.0 & 100.0 & 100.0 & 100.0 & 100.0 \\
\hline Under 40 & 9.9 & 10.0 & 9.6 & 18.7 & 19.0 & 16.2 \\
\hline $40-44$ & 13.1 & 12.9 & 14.6 & 14.4 & 14.6 & 12.9 \\
\hline $45-49$ & 22.8 & 23.1 & 20.4 & 15.1 & 15.4 & 12.8 \\
\hline $50-54$ & 32.8 & 33.5 & 28.0 & 21.0 & 21.5 & 17.3 \\
\hline 55 and over & 21.4 & 20.6 & 27.3 & 30.8 & 29.5 & 40.8 \\
\hline Race/ethnicity & 100.0 & 100.0 & 100.0 & 100.0 & 100.0 & 100.0 \\
\hline White & 86.6 & 85.6 & 94.5 & 85.0 & 84.1 & 91.2 \\
\hline Black & 7.6 & 8.4 & $\ddagger$ & 9.2 & 9.8 & $4.9 !$ \\
\hline Hispanic & 4.0 & 4.1 & $3.1 !$ & 4.1 & 4.5 & $\ddagger$ \\
\hline Asian & $0.7 !$ & $0.8 !$ & $\ddagger$ & $\ddagger$ & $\ddagger$ & $\ddagger$ \\
\hline $\begin{array}{l}\text { Native Hawaiian/ } \\
\text { Pacific Islander }\end{array}$ & - & - & - & $0.1 !$ & $0.1 !$ & $\ddagger$ \\
\hline American Indian/Alaska Native & 1.1 & 1.1 & $\ddagger$ & $0.6 !$ & $0.4 !$ & $\ddagger$ \\
\hline Two or more races & - & - & - & $\ddagger$ & $\ddagger$ & $\ddagger$ \\
\hline Highest degree earned & 100.0 & 100.0 & 100.0 & 100.0 & 100.0 & 100.0 \\
\hline Bachelor's or less & 2.9 & 1.4 & 14.5 & 3.3 & $1.3 !$ & 18.0 \\
\hline Master's & 56.1 & 55.7 & 58.6 & 60.8 & 61.0 & 59.5 \\
\hline $\begin{array}{l}\text { Education specialist or } \\
\text { professional diploma }\end{array}$ & 29.5 & 31.3 & 16.0 & 26.6 & 28.6 & 11.8 \\
\hline $\begin{array}{l}\text { Doctor's or } \\
\quad \text { first-professional }\end{array}$ & 11.5 & 11.6 & 10.9 & 9.3 & 9.1 & 10.7 \\
\hline Number of years as a principal & 100.0 & 100.0 & 100.0 & 100.0 & 100.0 & 100.0 \\
\hline 3 or fewer & 29.6 & 30.3 & 23.4 & 35.0 & 35.5 & 31.0 \\
\hline $4-9$ & 33.5 & 33.7 & 32.0 & 35.6 & 36.6 & 28.8 \\
\hline $10-19$ & 26.2 & 25.9 & 28.8 & 22.7 & 22.5 & 24.3 \\
\hline 20 or more & 10.8 & 10.1 & 15.8 & 6.6 & 5.4 & 15.9 \\
\hline $\begin{array}{l}\text { Number of years of teaching } \\
\text { experience prior to becoming } \\
\text { a principal }\end{array}$ & 100.0 & 100.0 & 100.0 & 100.0 & 100.0 & 100.0 \\
\hline 3 or fewer & 7.4 & 6.4 & 15.5 & 8.4 & 6.8 & 20.4 \\
\hline $4-9$ & 31.1 & 31.6 & 27.3 & 34.5 & 34.9 & 31.5 \\
\hline $10-19$ & 44.0 & 44.8 & 37.7 & 39.7 & 41.5 & 26.7 \\
\hline 20 or more & 17.5 & 17.2 & 19.6 & 17.4 & 16.8 & 21.4 \\
\hline $\begin{array}{l}\text { Median annual salary, in constant } \\
2010-11 \text { dollars }\end{array}$ & $\$ 86,500$ & $\$ 88,600$ & $\$ 67,800$ & $\$ 89,800$ & $\$ 91,900$ & $\$ 68,900$ \\
\hline
\end{tabular}

- Not available.

! Interpret data with caution. The coefficient of variation (CV) for this estimate is 30 percent or greater.

$\ddagger$ Reporting standards not met. Either there are too few cases or the coefficient of variation (CV) for this estimate is 50 percent or greater.

NOTE: Included in the total but not shown separately are principals in combined schools. This analysis focuses on principals in elementary and

secondary schools. These principals made up 90 percent of all principals in 1999-2000 and 87 percent in 2007-08. Race categories exclude persons of Hispanic ethnicity. In 1999-2000, "Asian" and "Native Hawaiian/Pacific Islander" were not reported separately; therefore, "Native Hawaiian/Pacific Islander" is included in "Asian." Respondents were not able to report two or more races in the 1999-2000 questionnaire. For more information on race/ ethnicity, see Appendix C - Commonly Used Measures. Education specialist or professional diploma is a certificate of advanced graduate studies that advances educators in their instructional leadership skills beyond the master's level of competence. For a list of first-professional degrees, see Appendix D - Glossary. Annual salary was calculated in 2010-11 school year constant dollars and adjusted using the Consumer Price Index (CPI). For more information on the CPI, see Appendix C - Finance. Detail may not sum to totals because of rounding. For more information on the Schools and Staffing Survey (SASS), see Appendix B - Guide to Sources.

SOURCE: U.S. Department of Education, National Center for Education Statistics, Schools and Staffing Survey (SASS), "Public School Principal and

Private School Principal Data Files," 1999-2000 and 2007-08, and "Charter School Principal Data File," 1999-2000. 
This page intentionally left blank.

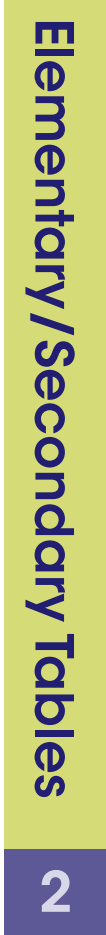


Table A-19-1. Total revenues, gross domestic product, and percentage distribution for public elementary and secondary schools, by revenue source: School years 1988-89 through 2008-09

\begin{tabular}{|c|c|c|c|c|c|c|c|c|c|c|c|c|c|}
\hline \multirow[b]{3}{*}{ Year } & \multicolumn{6}{|c|}{ Revenues, in millions of constant 2010-11 dollars } & \multirow{3}{*}{$\begin{array}{r}\text { Gross } \\
\text { domestic } \\
\text { product } \\
\text { in millions } \\
\text { of constant } \\
2010 \text { dollars } \\
\end{array}$} & \multicolumn{6}{|c|}{ Percentage distribution } \\
\hline & \multirow[b]{2}{*}{ Total } & \multirow[b]{2}{*}{ Federal } & \multirow[b]{2}{*}{ State } & \multicolumn{3}{|c|}{ Local } & & \multirow[b]{2}{*}{ Total } & \multirow[b]{2}{*}{$\begin{array}{l}\text { Fed- } \\
\text { eral } \\
\end{array}$} & \multirow[b]{2}{*}{ State } & \multicolumn{3}{|c|}{ Local } \\
\hline & & & & Total & $\begin{array}{r}\text { From } \\
\text { prop- } \\
\text { erty } \\
\text { taxes } \\
\end{array}$ & $\begin{array}{r}\text { From } \\
\text { other } \\
\text { sources }\end{array}$ & & & & & Total & $\begin{array}{r}\text { From } \\
\text { prop- } \\
\text { erty } \\
\text { taxes } \\
\end{array}$ & $\begin{array}{r}\text { From } \\
\text { Other } \\
\text { sourc- } \\
\text { es } \\
\end{array}$ \\
\hline 1988-99 & $\$ 350,238$ & $\$ 21,709$ & $\$ 167,386$ & $\$ 161,142$ & $\$ 125,353$ & $\$ 35,789$ & $\$ 8,441,162$ & 100.0 & 6.2 & 47.8 & 46.0 & 35.8 & 10.2 \\
\hline 1989-90 & 363,081 & 22,112 & 171,033 & 169,936 & 130,345 & 39,591 & $8,743,950$ & 100.0 & 6.1 & 47.1 & 46.8 & 35.9 & 10.9 \\
\hline 1990-91 & 368,735 & 22,744 & 173,891 & 172,100 & 132,697 & 39,403 & $8,903,768$ & 100.0 & 6.2 & 47.2 & 46.7 & 36.0 & 10.7 \\
\hline 1991-92 & 375,330 & 24,789 & 174,054 & 176,487 & 137,400 & 39,088 & $8,886,284$ & 100.0 & 6.6 & 46.4 & 47.0 & 36.6 & 10.4 \\
\hline 1992-93 & 384,068 & 26,772 & 175,889 & 181,407 & 135,160 & 46,247 & $9,189,993$ & 100.0 & 7.0 & 45.8 & 47.2 & 35.2 & 12.0 \\
\hline 1993-94 & 393,361 & 27,732 & 177,621 & 188,008 & 147,818 & 40,190 & $9,447,706$ & 100.0 & 7.1 & 45.2 & 47.8 & 37.6 & 10.2 \\
\hline 1994-95 & 401,530 & 27,316 & 187,762 & 186,451 & 144,028 & 42,424 & $9,834,258$ & 100.0 & 6.8 & 46.8 & 46.4 & 35.9 & 10.6 \\
\hline 1995-96 & 411,703 & 27,338 & 195,576 & 188,789 & 145,656 & 43,134 & $10,083,992$ & 100.0 & 6.6 & 47.5 & 45.9 & 35.4 & 10.5 \\
\hline 1996-97 & 424,346 & 27,933 & 203,692 & 192,721 & 148,205 & 44,515 & $10,456,559$ & 100.0 & 6.6 & 48.0 & 45.4 & 34.9 & 10.5 \\
\hline 1997-98 & 445,540 & 30,350 & 215,501 & 199,689 & 151,989 & 47,700 & $10,923,776$ & 100.0 & 6.8 & 48.4 & 44.8 & 34.1 & 10.7 \\
\hline 1998-99 & 466,876 & 32,957 & 227,537 & 206,382 & 160,586 & 45,796 & $11,405,170$ & 100.0 & 7.1 & 48.7 & 44.2 & 34.4 & 9.8 \\
\hline 1999-2000 & 487,065 & 35,390 & 241,105 & 210,570 & 162,905 & 47,665 & $11,953,773$ & 100.0 & 7.3 & 49.5 & 43.2 & 33.4 & 9.8 \\
\hline 2000-01 & 506,913 & 36,754 & 252,073 & 218,086 & 167,443 & 50,642 & $12,449,327$ & 100.0 & 7.3 & 49.7 & 43.0 & 33.0 & 10.0 \\
\hline 2001-02 & 520,602 & 41,132 & 256,318 & 223,151 & 175,100 & 48,051 & $12,580,023$ & 100.0 & 7.9 & 49.2 & 42.9 & 33.6 & 9.2 \\
\hline 2002-03 & 534,296 & 45,544 & 260,133 & 228,618 & 180,293 & 48,325 & $12,813,329$ & 100.0 & 8.5 & 48.7 & 42.8 & 33.7 & 9.0 \\
\hline 2003-04 & 548,887 & 49,805 & 258,252 & 240,830 & 190,795 & 50,034 & $13,136,536$ & 100.0 & 9.1 & 47.1 & 43.9 & 34.8 & 9.1 \\
\hline 2004-05 & 562,380 & 51,665 & 263,522 & 247,192 & 193,600 & 53,592 & $13,600,499$ & 100.0 & 9.2 & 46.9 & 44.0 & 34.4 & 9.5 \\
\hline 2005-06 & 578,411 & 52,832 & 269,030 & 256,549 & 198,068 & 58,480 & $14,028,624$ & 100.0 & 9.1 & 46.5 & 44.4 & 34.2 & 10.1 \\
\hline 2006-07 & 601,835 & 51,064 & 285,488 & 265,282 & 203,915 & 61,367 & $14,403,818$ & 100.0 & 8.5 & 47.4 & 44.1 & 33.9 & 10.2 \\
\hline 2007-08 & 610,410 & 49,806 & 295,058 & 265,461 & 205,205 & 60,346 & $14,680,519$ & 100.0 & 8.2 & 48.3 & 43.5 & 33.6 & 9.9 \\
\hline 2008-09 & 610,853 & 58,433 & 285,392 & 267,029 & 211,996 & 55,032 & $14,685,220$ & 100.0 & 9.6 & 46.7 & 43.7 & 34.7 & 9.0 \\
\hline
\end{tabular}


This indicator continues on page 194.

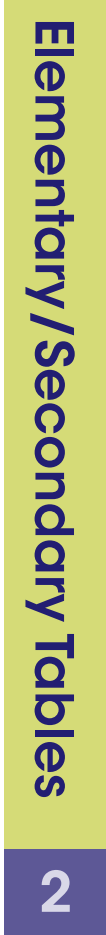


Table A-19-2. Total revenues and percentage distribution for public elementary and secondary schools, by revenue source and state: School year 2008-09

\begin{tabular}{|c|c|c|c|c|c|c|c|c|c|c|c|c|}
\hline \multirow[b]{3}{*}{ State } & \multicolumn{6}{|c|}{ Revenues, in millions of constant 2010-11 dollars } & \multicolumn{6}{|c|}{ Percentage distribution } \\
\hline & \multirow[b]{2}{*}{ Total } & \multirow[b]{2}{*}{ Federal } & \multirow[b]{2}{*}{ State } & \multicolumn{3}{|c|}{ Local } & \multirow[b]{2}{*}{ Total } & \multirow[b]{2}{*}{$\begin{array}{l}\text { Fed- } \\
\text { eral }\end{array}$} & \multirow[b]{2}{*}{ State } & \multicolumn{3}{|c|}{ Local } \\
\hline & & & & Total & $\begin{array}{r}\text { From } \\
\text { property } \\
\text { taxes } \\
\end{array}$ & $\begin{array}{r}\text { From } \\
\text { other } \\
\text { sources }\end{array}$ & & & & Total & $\begin{array}{r}\text { From } \\
\text { prop- } \\
\text { erty } \\
\text { taxes }\end{array}$ & $\begin{array}{r}\text { From } \\
\text { other } \\
\text { sourc- } \\
\text { es }\end{array}$ \\
\hline United States & $\$ 610,853.0$ & $\$ 58,432.6$ & $\$ 285,391.9$ & $\$ 267,028.5$ & $\$ 211,996.5$ & $\$ 55,032.0$ & 100.0 & 9.6 & 46.7 & 43.7 & 34.7 & 9.0 \\
\hline Alabama & $7,456.3$ & 800.9 & $4,291.0$ & $2,364.3$ & $1,074.9$ & $1,289.4$ & 100.0 & 10.7 & 57.5 & 31.7 & 14.4 & 17.3 \\
\hline Alaska & $2,330.9$ & 324.4 & $1,503.4$ & 503.0 & 234.1 & 268.9 & 100.0 & 13.9 & 64.5 & 21.6 & 10.0 & 11.5 \\
\hline Arkansas & $4,968.7$ & 573.2 & $2,764.8$ & $1,630.6$ & $1,357.1$ & 273.6 & 100.0 & 11.5 & 55.6 & 32.8 & 27.3 & 5.5 \\
\hline California & $72,807.6$ & $9,460.8$ & $41,824.1$ & $21,522.7$ & $16,774.1$ & $4,748.6$ & 100.0 & 13.0 & 57.4 & 29.6 & 23.0 & 6.5 \\
\hline Colorado & $8,604.5$ & 595.6 & $3,780.3$ & $4,228.5$ & $3,401.1$ & 827.4 & 100.0 & 6.9 & 43.9 & 49.1 & 39.5 & 9.6 \\
\hline Connecticut & $10,167.9$ & 454.1 & $3,957.4$ & $5,756.4$ & $5,574.3$ & 182.2 & 100.0 & 4.5 & 38.9 & 56.6 & 54.8 & 1.8 \\
\hline Delaware & $1,807.8$ & 146.7 & $1,127.8$ & 533.3 & 448.2 & 85.1 & 100.0 & 8.1 & 62.4 & 29.5 & 24.8 & 4.7 \\
\hline $\begin{array}{l}\text { District of } \\
\text { Columbia }\end{array}$ & $1,700.5$ & 181.0 & 0.0 & $1,519.5$ & 316.3 & $1,203.2$ & 100.0 & 10.6 & 0.0 & 89.4 & 18.6 & 70.8 \\
\hline Hawaii & $2,770.5$ & 404.6 & $2,271.2$ & 94.6 & 0.0 & 94.6 & 100.0 & 14.6 & 82.0 & 3.4 & 0.0 & 3.4 \\
\hline Idaho & $2,311.1$ & 236.0 & $1,555.1$ & 520.0 & 423.5 & 96.5 & 100.0 & 10.2 & 67.3 & 22.5 & 18.3 & 4.2 \\
\hline Illinois & $27,308.1$ & $3,241.1$ & $7,544.5$ & $16,522.5$ & $14,213.5$ & $2,309.0$ & 100.0 & 11.9 & 27.6 & 60.5 & 52.0 & 8.5 \\
\hline Indiana & $12,946.9$ & $1,475.8$ & $5,113.9$ & $6,357.2$ & $4,938.8$ & $1,418.4$ & 100.0 & 11.4 & 39.5 & 49.1 & 38.1 & 11.0 \\
\hline lowa & $5,685.4$ & 457.1 & $2,621.7$ & $2,606.6$ & $1,737.4$ & 869.2 & 100.0 & 8.0 & 46.1 & 45.8 & 30.6 & 15.3 \\
\hline Kansas & $5,930.7$ & 467.2 & $3,423.0$ & $2,040.4$ & $1,551.8$ & 488.6 & 100.0 & 7.9 & 57.7 & 34.4 & 26.2 & 8.2 \\
\hline Kentucky & $6,840.4$ & 753.3 & $3,916.2$ & $2,170.9$ & $1,497.9$ & 673.0 & 100.0 & 11.0 & 57.3 & 31.7 & 21.9 & 9.8 \\
\hline Louisiana & $8,343.0$ & $1,302.0$ & $3,852.5$ & $3,188.5$ & $1,237.6$ & $1,950.9$ & 100.0 & 15.6 & 46.2 & 38.2 & 14.8 & 23.4 \\
\hline Maine & $2,652.8$ & 253.1 & $1,160.8$ & $1,238.8$ & $1,166.7$ & 72.1 & 100.0 & 9.5 & 43.8 & 46.7 & 44.0 & 2.7 \\
\hline Maryland & $13,490.4$ & 715.7 & $5,869.7$ & $6,905.0$ & $3,271.5$ & $3,633.6$ & 100.0 & 5.3 & 43.5 & 51.2 & 24.3 & 26.9 \\
\hline Massachusetts & $15,555.6$ & $1,314.5$ & $6,217.3$ & $8,023.7$ & $7,421.5$ & 602.3 & 100.0 & 8.5 & 40.0 & 51.6 & 47.7 & 3.9 \\
\hline New Hampshire & $2,798.6$ & 151.7 & $1,033.3$ & $1,613.5$ & $1,528.4$ & 85.1 & 100.0 & 5.4 & 36.9 & 57.7 & 54.6 & 3.0 \\
\hline
\end{tabular}

See notes at end of table. 
Table A-19-2. Total revenues and percentage distribution for public elementary and secondary schools, by revenue source and state: School year 2008-09-Continued

\begin{tabular}{|c|c|c|c|c|c|c|c|c|c|c|c|c|}
\hline \multirow[b]{3}{*}{ State } & \multicolumn{6}{|c|}{ Revenues, in millions of constant 2010-11 dollars } & \multicolumn{6}{|c|}{ Percentage distribution } \\
\hline & \multirow[b]{2}{*}{ Total } & \multirow[b]{2}{*}{ Federal } & \multirow[b]{2}{*}{ State } & \multicolumn{3}{|c|}{ Local } & \multirow[b]{2}{*}{ Total } & \multirow[b]{2}{*}{$\begin{array}{l}\text { Fed- } \\
\text { eral }\end{array}$} & \multirow[b]{2}{*}{ State } & \multicolumn{3}{|c|}{ Local } \\
\hline & & & & Total & $\begin{array}{r}\text { From } \\
\text { property } \\
\text { taxes }\end{array}$ & $\begin{array}{r}\text { From } \\
\text { other } \\
\text { sources }\end{array}$ & & & & Total & $\begin{array}{r}\text { From } \\
\text { prop- } \\
\text { erty } \\
\text { taxes }\end{array}$ & $\begin{array}{r}\text { From } \\
\text { other } \\
\text { sourc- } \\
\text { es }\end{array}$ \\
\hline United States & $\$ 610,853.0$ & $\$ 58,432.6$ & $\$ 285,391.9$ & $\$ 267,028.5$ & $\$ 211,996.5$ & $\$ 55,032.0$ & 100.0 & 9.6 & 46.7 & 43.7 & 34.7 & 9.0 \\
\hline New Jersey & $26,041.8$ & $1,072.0$ & $10,841.3$ & $14,128.5$ & $13,254.4$ & 874.2 & 100.0 & 4.1 & 41.6 & 54.3 & 50.9 & 3.4 \\
\hline New Mexico & $3,934.7$ & 586.1 & $2,756.2$ & 592.4 & 455.7 & 136.7 & 100.0 & 14.9 & 70.0 & 15.1 & 11.6 & 3.5 \\
\hline North Dakota & $1,135.6$ & 166.3 & 420.2 & 549.0 & 439.4 & 109.6 & 100.0 & 14.6 & 37.0 & 48.3 & 38.7 & 9.6 \\
\hline Ohio & $23,644.9$ & $1,736.2$ & $11,245.5$ & $10,663.2$ & $8,663.4$ & $1,999.8$ & 100.0 & 7.3 & 47.6 & 45.1 & 36.6 & 8.5 \\
\hline Oklahoma & $5,901.5$ & 793.9 & $3,133.8$ & $1,973.9$ & $1,397.6$ & 576.2 & 100.0 & 13.5 & 53.1 & 33.4 & 23.7 & 9.8 \\
\hline Oregon & $6,329.6$ & 690.7 & $3,210.8$ & $2,428.1$ & $1,892.8$ & 535.3 & 100.0 & 10.9 & 50.7 & 38.4 & 29.9 & 8.5 \\
\hline Pennsylvania & $26,401.0$ & $1,924.1$ & $10,217.9$ & $14,259.0$ & $10,750.6$ & $3,508.4$ & 100.0 & 7.3 & 38.7 & 54.0 & 40.7 & 13.3 \\
\hline Tennessee & $8,532.4$ & 963.2 & $3,923.8$ & $3,645.5$ & $1,728.2$ & $1,917.3$ & 100.0 & 11.3 & 46.0 & 42.7 & 20.3 & 22.5 \\
\hline Texas & $48,371.0$ & $5,165.3$ & $20,572.3$ & $22,633.4$ & $20,105.4$ & $2,528.0$ & 100.0 & 10.7 & 42.5 & 46.8 & 41.6 & 5.2 \\
\hline Utah & $4,679.0$ & 582.0 & $2,459.3$ & $1,637.7$ & $1,191.4$ & 446.3 & 100.0 & 12.4 & 52.6 & 35.0 & 25.5 & 9.5 \\
\hline Vermont & $1,018.1$ & 105.9 & $1,386.7$ & 125.6 & 2.1 & 123.5 & 100.0 & 6.5 & 85.7 & 7.8 & 0.1 & 7.6 \\
\hline Virginia & $15,413.4$ & 942.0 & $6,492.8$ & $7,978.7$ & $4,025.4$ & $3,953.3$ & 100.0 & 6.1 & 42.1 & 51.8 & 26.1 & 25.6 \\
\hline Washington & $12,260.6$ & $1,427.0$ & $7,360.8$ & $3,472.8$ & $2,814.7$ & 658.1 & 100.0 & 11.6 & 60.0 & 28.3 & 23.0 & 5.4 \\
\hline West Virginia & $3,379.8$ & 377.0 & $1,997.2$ & $1,005.6$ & 890.7 & 114.9 & 100.0 & 11.2 & 59.1 & 29.8 & 26.4 & 3.4 \\
\hline Wisconsin & $11,157.1$ & $1,341.5$ & $4,953.5$ & $4,862.1$ & $4,438.2$ & 423.9 & 100.0 & 12.0 & 44.4 & 43.6 & 39.8 & 3.8 \\
\hline Wyoming & $1,726.2$ & 114.0 & 973.5 & 638.7 & 424.3 & 214.4 & 100.0 & 6.6 & 56.4 & 37.0 & 24.6 & 12.4 \\
\hline
\end{tabular}

NOTE: Detail may not sum to totals because of rounding. Both the District of Columbia and Hawaii have only one school district each; therefore, neither is comparable to the other states. Revenues are in constant 2010-11 dollars, adjusted using the Consumer Price Index (CPI). For more information about the $\mathrm{CPI}$ and revenues for public elementary and secondary schools, see Appendix C - Finance. For more information about the Common Core of Data, see Appendix B - Guide to Sources.

SOURCE: U.S. Department of Education, National Center for Education Statistics, Common Core of Data (CCD), "National Public Education Financial Survey," 2008-09. 
Table A-20-1. Total expenditures per student in fall enrollment in public elementary and secondary schools, percentage distribution of current expenditures, and percent change of total expenditures by type and object: School years 1988-89, 1998-99, and 2008-09

\begin{tabular}{|c|c|c|c|c|c|c|c|c|c|}
\hline \multirow[b]{2}{*}{ Type and object } & \multicolumn{3}{|c|}{ Expenditures } & \multicolumn{3}{|c|}{$\begin{array}{c}\text { Percentage distribution of } \\
\text { current expenditures }\end{array}$} & \multicolumn{3}{|c|}{ Percent change of expenditures } \\
\hline & 1988-891 & 1998-99 & 2008-09 & 1988-891 & 1998-99 & 2008-09 & $\begin{array}{r}1988-891 \\
\text { to } \\
1998-99 \\
\end{array}$ & $\begin{array}{r}1998-99 \\
\text { to } \\
2008-09 \\
\end{array}$ & $\begin{array}{r}1988-891 \\
\text { to } \\
2008-09 \\
\end{array}$ \\
\hline & \multicolumn{9}{|c|}{ [In current dollars] } \\
\hline Total expenditures ${ }^{2}$ & $\$ 4,734$ & $\$ 7,531$ & $\$ 12,274$ & $\dagger$ & $\dagger$ & $\dagger$ & 59.1 & 63.0 & 159.3 \\
\hline Current expenditures & 4,307 & 6,508 & 10,591 & 100.0 & 100.0 & 100.0 & 51.1 & 62.7 & 145.9 \\
\hline Salaries & 2,798 & 4,225 & 6,384 & 65.0 & 64.9 & 60.3 & 51.0 & 51.1 & 128.2 \\
\hline Employee benefits & 694 & 1,078 & 2,157 & 16.1 & 16.6 & 20.4 & 55.3 & 100.1 & 210.6 \\
\hline Purchased services & 361 & 583 & 1,035 & 8.4 & 9.0 & 9.8 & 61.3 & 77.5 & 186.4 \\
\hline Supplies & 309 & 507 & 826 & 7.2 & 7.8 & 7.8 & 64.2 & 63.0 & 167.6 \\
\hline Tuition and other & 71 & 115 & 189 & 1.7 & 1.8 & 1.8 & 60.7 & 64.9 & 165.0 \\
\hline Capital outlay & 349 & 847 & 1,343 & $\dagger$ & $\dagger$ & $\dagger$ & 142.3 & 58.5 & 284.2 \\
\hline \multirow[t]{2}{*}{ Interest on school debt } & 77 & 176 & 341 & $\dagger$ & $\dagger$ & $\dagger$ & 128.4 & 93.4 & 341.7 \\
\hline & \multicolumn{9}{|c|}{ [In constant 2010-11 dollars] } \\
\hline Total expenditures ${ }^{2}$ & $\$ 8,634$ & $\$ 10,122$ & $\$ 12,643$ & $t$ & $t$ & $\dagger$ & 17.2 & 24.9 & 46.4 \\
\hline Current expenditures & 7,856 & 8,747 & 10,909 & 100.0 & 100.0 & 100.0 & 11.3 & 24.7 & 38.9 \\
\hline Salaries & 5,103 & 5,679 & 6,575 & 65.0 & 64.9 & 60.3 & 11.3 & 15.8 & 28.8 \\
\hline Employee benefits & 1,267 & 1,449 & 2,222 & 16.1 & 16.6 & 20.4 & 14.4 & 53.3 & 75.4 \\
\hline Purchased services & 659 & 783 & 1,066 & 8.4 & 9.0 & 9.8 & 18.9 & 36.0 & 61.7 \\
\hline Supplies & 563 & 682 & 851 & 7.2 & 7.8 & 7.8 & 21.0 & 24.9 & 51.1 \\
\hline Tuition and other & 130 & 154 & 195 & 1.7 & 1.8 & 1.8 & 18.4 & 26.4 & 49.7 \\
\hline Capital outlay & 637 & 1,138 & 1,383 & $\dagger$ & $\dagger$ & $\dagger$ & 78.5 & 21.5 & 116.9 \\
\hline Interest on school debt & 141 & 237 & 351 & $\dagger$ & $\dagger$ & $\dagger$ & 68.3 & 48.2 & 149.4 \\
\hline
\end{tabular}

\footnotetext{
t Not applicable.
}

1 Includes estimated data for 1988-89 for food services and enterprise operations by object because those data were not collected for that year.

2 Excludes "Other current expenditures" such as community services, private school programs, adult education, and other programs not allocable to expenditures per student at public schools.

NOTE: Detail may not sum to totals because of rounding. Estimates are revised from previous editions. Expenditures have been adjusted for the effects of inflation using the Consumer Price Index (CPI) and are in 2010-11 constant dollars. The category of total expenditures is broken down by type (current expenditures, capital outlay, and interest on debt). Current expenditures, which is one component of total expenditures, can be broken down by both the service or commodity bought (object) as well as the activity that is supported by the service or commodity bought (function). Detail expenditures of operations and maintenance, student transportation, food services, and enterprise operations are not shown. For more information about the CPI and classifications of expenditures, see Appendix C - Finance. For more information about the Common Core of Data (CCD), see Appendix B - Guide to Sources.

SOURCE: U.S. Department of Education, National Center for Education Statistics, Common Core of Data (CCD), "National Public Education Financial Survey," 1988-89, 1998-99, and 2008-09. 
Table A-20-2. Current expenditures per student in fall enrollment in public elementary and secondary schools, percentage distribution of current expenditures, and percent change of current expenditures, by function and object: School years 1988-89, 1998-99, and 2008-09

\begin{tabular}{|c|c|c|c|c|c|c|c|c|c|}
\hline \multirow[b]{2}{*}{ Function and object } & \multicolumn{3}{|c|}{$\begin{array}{c}\text { Expenditures } \\
\text { [in constant 2010-11 dollars] }\end{array}$} & \multicolumn{3}{|c|}{$\begin{array}{c}\text { Percentage distribution of } \\
\text { current expenditures }\end{array}$} & \multicolumn{3}{|c|}{$\begin{array}{l}\text { Percent change of } \\
\text { current expenditures }\end{array}$} \\
\hline & $1988-89$ & 1998-99 & 2008-09 & $1988-89$ & $1998-99$ & 2008-09 & $\begin{array}{r}1988-89 \\
\text { to } \\
1998-99\end{array}$ & $\begin{array}{r}1998-99 \\
\text { to } \\
2008-09\end{array}$ & $\begin{array}{r}1988-89 \\
\text { to } \\
2008-09\end{array}$ \\
\hline Current expenditures & $\$ 7,856$ & $\$ 8,747$ & $\$ 10,909$ & 100.0 & 100.0 & 100.0 & 11.3 & 24.7 & 38.9 \\
\hline Instruction & 4,781 & 5,394 & 6,649 & 60.9 & 61.7 & 61.0 & 12.8 & 23.3 & 39.1 \\
\hline Salaries & 3,507 & 3,916 & 4,487 & 44.6 & 44.8 & 41.1 & 11.7 & 14.6 & 27.9 \\
\hline Employee benefits & 842 & 983 & 1,493 & 10.7 & 11.2 & 13.7 & 16.7 & 51.9 & 77.3 \\
\hline Purchased services & 117 & 159 & 267 & 1.5 & 1.8 & 2.5 & 36.0 & 68.3 & 128.9 \\
\hline Supplies & 177 & 248 & 280 & 2.2 & 2.8 & 2.6 & 40.4 & 12.9 & 58.5 \\
\hline Tuition and other & 53 & 88 & 122 & 0.7 & 1.0 & 1.1 & 67.4 & 38.3 & 131.6 \\
\hline Administration & 881 & 947 & 1,181 & 11.2 & 10.8 & 10.8 & 7.5 & 24.8 & 34.2 \\
\hline Salaries & 545 & 592 & 695 & 6.9 & 6.8 & 6.4 & 8.7 & 17.4 & 27.6 \\
\hline Employee benefits & 149 & 157 & 243 & 1.9 & 1.8 & 2.2 & 5.1 & 55.4 & 63.3 \\
\hline Purchased services & 102 & 129 & 169 & 1.3 & 1.5 & 1.6 & 26.7 & 31.3 & 66.3 \\
\hline Supplies & 25 & 30 & 32 & 0.3 & 0.3 & 0.3 & 17.3 & 8.2 & 27.0 \\
\hline Other & 44 & 39 & 42 & 0.6 & 0.4 & 0.4 & -10.8 & 6.0 & -5.5 \\
\hline Student and staff support ${ }^{1}$ & 641 & 824 & 1,116 & 8.2 & 9.4 & 10.2 & 28.6 & 35.4 & 74.1 \\
\hline Salaries & 447 & 555 & 711 & 5.7 & 6.3 & 6.5 & 24.3 & 28.0 & 59.1 \\
\hline Employee benefits & 107 & 137 & 227 & 1.4 & 1.6 & 2.1 & 28.3 & 65.6 & 112.4 \\
\hline Purchased services & 37 & 75 & 120 & 0.5 & 0.9 & 1.1 & 103.4 & 60.7 & 226.8 \\
\hline Supplies & 35 & 48 & 49 & 0.4 & 0.5 & 0.5 & 35.4 & 4.1 & 40.9 \\
\hline Other & 4 & 10 & 9 & 0.1 & 0.1 & 0.1 & 127.1 & -12.1 & 99.6 \\
\hline Operation and maintenance & 868 & 849 & 1,064 & 11.1 & 9.7 & 9.8 & -2.2 & 25.4 & 22.6 \\
\hline Student transportation & 333 & 353 & 456 & 4.2 & 4.0 & 4.2 & 6.1 & 29.1 & 37.0 \\
\hline Food services & 334 & 355 & 416 & 4.2 & 4.1 & 3.8 & 6.3 & 17.4 & 24.8 \\
\hline Enterprise operations ${ }^{2}$ & 19 & 25 & 26 & 0.2 & 0.3 & 0.2 & 34.9 & 2.4 & 38.1 \\
\hline
\end{tabular}

1 Includes expenditures for student support services and instructional support services

${ }^{2}$ Includes expenditures for operations funded by sales of products or services, along with amounts for direct program support made available by state education agencies for local school districts.

NOTE: Detail may not sum to totals because of rounding. Estimates are revised from previous editions. Expenditures are in constant 2010-11 dollars, adjusted using the Consumer Price Index (CPI). For more information about the CPI, see Appendix C - Finance. Current expenditures can be broken down by both the service or commodity bought (object) as well as the activity that is supported by the service or commodity bought (function). Breakouts of operation and maintenance, student transportation, food services and enterprise operations by object are also available, but are not shown. For more information about classifications of expenditures, see Appendix C - Finances. For more information about the Common Core of Data (CCD), see Appendix B - Guide to Sources.

SOURCE: U.S. Department of Education, National Center for Education Statistics, Common Core of Data (CCD), "National Public Education Financial Survey," 1988-89, 1998-99, and 2008-09. 
Variations in Instruction Expenditures

Table A-21-1. Variation and percentage distribution of variation in instruction expenditures per student in unified public elementary and secondary school districts, by source of variation: School years 1989-90 through 2008-09

\begin{tabular}{|c|c|c|c|c|c|c|}
\hline \multirow[b]{2}{*}{ School year } & \multicolumn{3}{|c|}{ Theil coefficient } & \multicolumn{3}{|c|}{ Percentage distribution } \\
\hline & Total & $\begin{array}{r}\text { Between-state } \\
\text { component }\end{array}$ & $\begin{array}{l}\text { Within-state } \\
\text { component }\end{array}$ & Total & $\begin{array}{r}\text { Between-state } \\
\text { component }\end{array}$ & $\begin{array}{l}\text { Within-state } \\
\text { component }\end{array}$ \\
\hline $1989-90$ & 0.045 & 0.032 & 0.013 & 100.0 & 72.0 & 28.0 \\
\hline 1990-91 & 0.047 & 0.035 & 0.012 & 100.0 & 73.8 & 26.2 \\
\hline 1991-92 & 0.043 & 0.032 & 0.011 & 100.0 & 73.6 & 26.4 \\
\hline 1992-93 & 0.044 & 0.032 & 0.011 & 100.0 & 74.2 & 25.8 \\
\hline 1993-94 & 0.041 & 0.030 & 0.010 & 100.0 & 74.3 & 25.7 \\
\hline 1994-95 & 0.039 & 0.029 & 0.010 & 100.0 & 74.2 & 25.8 \\
\hline 1995-96 & 0.037 & 0.028 & 0.009 & 100.0 & 74.8 & 25.2 \\
\hline 1996-97 & 0.035 & 0.026 & 0.009 & 100.0 & 73.7 & 26.3 \\
\hline 1997-98 & 0.033 & 0.025 & 0.009 & 100.0 & 74.0 & 26.0 \\
\hline 1998-99 & 0.034 & 0.025 & 0.009 & 100.0 & 74.2 & 25.8 \\
\hline 1999-2000 & 0.034 & 0.025 & 0.008 & 100.0 & 74.9 & 25.1 \\
\hline 2000-01 & 0.037 & 0.028 & 0.009 & 100.0 & 75.7 & 24.3 \\
\hline 2001-02 & 0.037 & 0.028 & 0.009 & 100.0 & 76.1 & 23.9 \\
\hline 2002-03 & 0.039 & 0.030 & 0.009 & 100.0 & 77.6 & 22.4 \\
\hline 2003-04 & 0.042 & 0.033 & 0.009 & 100.0 & 77.9 & 22.1 \\
\hline 2004-05 & 0.046 & 0.036 & 0.010 & 100.0 & 78.7 & 21.3 \\
\hline $2005-06$ & 0.049 & 0.038 & 0.011 & 100.0 & 78.1 & 21.9 \\
\hline $2006-07$ & 0.051 & 0.040 & 0.011 & 100.0 & 78.6 & 21.4 \\
\hline 2007-08 & 0.052 & 0.041 & 0.011 & 100.0 & 78.2 & 21.8 \\
\hline 2008-09 & 0.050 & 0.039 & 0.010 & 100.0 & 79.4 & 20.6 \\
\hline $\begin{array}{l}\text { NOTE: Detail } \mathrm{m} \\
\text { variation for gr } \\
\text { be decompos } \\
\text { and increasins } \\
\text { per student an } \\
\text { Public elemen } \\
\text { percent of all } \\
\text { Data (CCD), sE } \\
\text { SOURCE: U.S. D } \\
\text { District Fiscal- }\end{array}$ & $\begin{array}{l}\text { cause o } \\
\text { states wit } \\
\text { easuring } \\
\text { ases in th } \\
\text { and the } \\
\text { iffied dist } \\
\text { second } \\
\text { to Sourc } \\
\text { on, Natio }\end{array}$ & $\begin{array}{l}\text { unding. Some da } \\
\text { the country) and } \\
\text { tween-state and } \\
\text { ariation, with a m } \\
\text { sifications of exp } \\
\text { s are those distric } \\
\text { school students } \\
\text { Center for Educa }\end{array}$ & $\begin{array}{l}\text { ve been revised } \\
\text { ates relative var } \\
\text {-state variation } \\
\text { um possible valu } \\
\text { rres for element } \\
\text { t serve both elen } \\
\text { nrolled in unifiec } \\
\text { tatistics (NCES), }\end{array}$ & $\begin{array}{l}\text { ly publish } \\
\text { y differen } \\
\text { es per stu } \\
\text { hore infor } \\
\text { idary edu } \\
\text { econdar } \\
\text { cts. For m }\end{array}$ & $\begin{array}{l}\text { igures. The Theil } \\
\text { that may exist an } \\
\text { t. It has a minimu } \\
\text { on on the variatic } \\
\text { ion, see Appendi } \\
\text { ades. In } 2008-09 \text {, } \\
\text { information on th } \\
\text { CD), "NCES Longi } \\
\text { 2002-03 through }\end{array}$ & $\begin{array}{l}\text { ent measures } \\
\text { hem. It can } \\
\text { e of zero, } \\
\text { xpenditures } \\
\text { inance. } \\
\text { ximately } 92 \\
\text { imon Core of } \\
\text { I School }\end{array}$ \\
\hline
\end{tabular}


This page intentionally left blank.

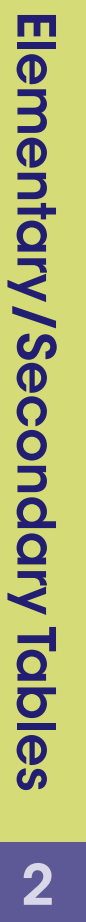




\section{Education Expenditures by Country}

Table A-22-1. Annual educational expenditures on public and private institutions per student and as a percentage of gross domestic product (GDP), and GDP per capita, by country and level of education: 2008

\begin{tabular}{|c|c|c|c|c|c|c|}
\hline \multirow[b]{2}{*}{ Country } & \multicolumn{2}{|c|}{ Expenditures per student } & \multicolumn{3}{|c|}{ Expenditures as a percentage of GDP } & \multirow[b]{2}{*}{ GDP per capita } \\
\hline & $\begin{array}{r}\text { Elementary and } \\
\text { secondary }\end{array}$ & Postsecondary & Total $^{1}$ & $\begin{array}{r}\text { Elementary and } \\
\text { secondary }\end{array}$ & Postsecondary & \\
\hline OECD average & $\$ 8,169$ & $\$ 13,461$ & 5.9 & 3.8 & 1.5 & $\$ 33,910$ \\
\hline Australia & 7,814 & 15,043 & 5.2 & 3.6 & 1.5 & 39,532 \\
\hline Austria & 10,994 & 15,043 & 5.4 & 3.6 & 1.3 & 39,849 \\
\hline Belgium & 9,706 & 15,020 & 6.6 & 4.4 & 1.4 & 36,879 \\
\hline Canada ${ }^{2}$ & 8,388 & 20,903 & 6.0 & 3.6 & 2.5 & 38,883 \\
\hline Chile $^{3}$ & 2,635 & 6,829 & 7.1 & 4.2 & 2.2 & 14,578 \\
\hline Czech Republic & 5,236 & 8,318 & 4.5 & 2.8 & 1.2 & 25,845 \\
\hline Denmark & 10,429 & 17,634 & 7.1 & 4.3 & 1.7 & 39,494 \\
\hline Estonia & 6,054 & 5,780 & 5.8 & 3.9 & 1.3 & 21,802 \\
\hline Finland & 8,068 & 15,402 & 5.9 & 3.8 & 1.7 & 37,795 \\
\hline France & 8,559 & 14,079 & 6.0 & 3.9 & 1.4 & 34,233 \\
\hline Germany & 7,859 & 15,390 & 4.8 & 3.0 & 1.2 & 37,171 \\
\hline Greece & - & - & - & - & - & 29,920 \\
\hline Hungary ${ }^{4,5}$ & 4,626 & 7,327 & 4.8 & 3.0 & 0.9 & 20,700 \\
\hline Iceland & 9,745 & 10,429 & 7.9 & 5.1 & 1.3 & 39,029 \\
\hline Ireland & 8,915 & 16,284 & 5.6 & 4.1 & 1.4 & 42,644 \\
\hline Israel & 5,780 & 12,568 & 7.3 & 4.2 & 1.6 & 27,690 \\
\hline Italy ${ }^{6}$ & 9,071 & 9,553 & 4.8 & 3.3 & 1.0 & 33,271 \\
\hline Japan & 8,301 & 14,890 & 4.9 & 2.8 & 1.5 & 33,902 \\
\hline Korea, Republic of & 6,723 & 9,081 & 7.6 & 4.2 & 2.6 & 26,877 \\
\hline Luxembourg7 & 16,909 & - & - & 2.9 & - & 89,732 \\
\hline Mexico & 2,284 & 7,504 & 5.8 & 3.7 & 1.2 & 15,190 \\
\hline Netherlands & 9,251 & 17,245 & 5.6 & 3.7 & 1.5 & 42,887 \\
\hline New Zealand & 6,496 & 10,526 & 6.6 & 4.5 & 1.6 & 29,231 \\
\hline Norway 5 & 12,070 & 18,942 & 7.3 & 5.0 & 1.7 & 43,659 \\
\hline Poland 4 & 4,682 & 7,063 & 5.7 & 3.6 & 1.5 & 18,062 \\
\hline Portugal ${ }^{4}$ & 6,276 & 10,373 & 5.2 & 3.4 & 1.3 & 24,962 \\
\hline Slovak Republic ${ }^{8}$ & 4,006 & 6,560 & 4.0 & 2.6 & 0.9 & 23,205 \\
\hline Slovenia & 8,555 & 9,263 & 5.4 & 3.7 & 1.1 & 29,241 \\
\hline Spain & 8,522 & 13,366 & 5.1 & 3.1 & 1.2 & 33,173 \\
\hline Sweden & 9,524 & 20,014 & 6.3 & 4.0 & 1.6 & 39,321 \\
\hline Switzerland ${ }^{9}$ & 13,775 & 21,648 & 5.7 & 4.3 & 1.3 & 45,517 \\
\hline Turkey & - & - & - & - & - & 14,963 \\
\hline United Kingdom & 9,169 & 15,310 & 5.7 & 4.2 & 1.2 & 36,817 \\
\hline United States & 10,995 & 29,910 & 7.2 & 4.1 & 2.7 & 46,901 \\
\hline
\end{tabular}

- Not available.

' Includes expenditures for preprimary, elementary/secondary, postsecondary nontertiary, and postsecondary education, and education not classified by level.

2 Data are for 2007. Postsecondary data include public academic institutions only.

${ }^{3}$ Data are for 2009.

${ }^{4}$ Expenditures per student include public institutions only.

${ }^{5}$ Expenditures as a percentage of GDP include public institutions only

${ }^{6}$ Elementary and secondary expenditures per student include public institutions only.

${ }^{7}$ Luxembourg data are excluded from percentages because of anomalies with respect to their GDP per capita data. (Large revenues from international finance institutions distort the wealth of the population.) Expenditures include public institutions only.

${ }^{8}$ Expenditures on tertiary vocational programs (International Standard Classification of Education [ISCED] level 5B) are included under elementary and secondary.

${ }^{9}$ Expenditures per student and postsecondary expenditures as a percentage of GDP include public institutions only

NOTE: Education expenditures are from public revenue sources (governments) and private revenue sources. Private sources include payments from households for school-based expenses such as tuition, transportation fees, book rentals, or food services, as well as funds raised by institutions through endowments or returns on investments. Per-student expenditures are calculated based on public and private full-time-equivalent (FTE) enrollment figures and on current expenditures and capital outlays from both public and private sources, where data are available. Elementary/secondary expenditures generally include postsecondary nontertiary (ISCED level 4) education. Postsecondary nontertiary expenditures are included under postsecondary for Canada and are not available for France, Greece, Italy, Luxembourg, Portugal, and the United States. Postsecondary includes all tertiary-level data (ISCED levels 5A, 5B, and 6). Purchasing power parity (PPP) indices are used to convert other currencies to U.S. dollars. Withincountry consumer price indices are used to adjust the PPP indices to account for inflation because the fiscal year has a different starting date in different countries. Organization for Economic Co-operation and Development (OECD) average reflects the unweighted average of countries reporting data. For more information on classification of expenditures for international comparisons, see Appendix $\mathrm{C}$ - Finance. For more information on the International Standard Classification of Education (ISCED), see Appendix C - International Education Definitions.

SOURCE: Organization for Economic Co-operation and Development (OECD), Center for Educational Research and Innovation. (2011). Education at a Glance, 2011: OECD Indicators, tables B1.1a, B1.2, B2.1, and X2.1. 
This page intentionally left blank.

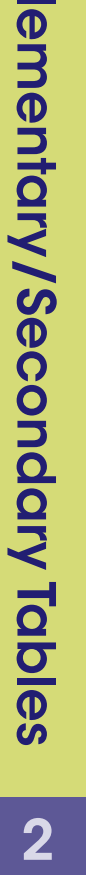


Table A-23-1. Average reading scale scores, selected percentile scores, and percentage of students at each achievement level, by grade: Selected years, 1992-2011

Grade, scale score, percentile,

\section{and percentage at achievement level}

Grade 4

Average scale score

Percentile

10th

25th

50 th

75 th

90th

Percentage at each achievement level

Below Basic

At or above Basic

At or above Proficient

At Advanced

\section{Grade 8}

Average scale score

Percentile

10 th
25 th
50 th
75 th
90 th

Percentage at each achievement level

Below Basic

At or above Basic

At or above Proficient

At Advanced

\section{Grade 12}

Average scale score

Percentile

10th

25th

50 th

75 th

90th

Percentage at each achievement level

Below Basic

At or above Basic

At or above Proficient

At Advanced

- Not available.
1 Testing accomodations (e.g., extended time, small group testing) for children with disabilities and English language learners were not permitted during these assessments. Students were tested with and without accommodations in 1998.

NOTE: Average reading scale scores include public and private school students. The National Assessment of Educational Progress (NAEP) reading scale ranges from 0 to 500. Achievement levels define what students should know and be able to do: Basic indicates partial mastery of fundamental skills, Proficient indicates demonstrated competency over challenging subject matter, and Advanced indicates superior performance. The 12th-grade NAEP reading assessment was not administered in 2003, 2007, or 2011. For more information on NAEP, see Appendix B - Guide to Sources.

SOURCE: U.S. Department of Education, National Center for Education Statistics, National Assessment of Educational Progress (NAEP), selected years,

1992-2011 Reading Assessments, NAEP Data Explorer.

$\begin{array}{llllllllll}217 & 214 & 217 & 215 & 219 & 218 & 219 & 221 & 221 & 221 \\ 170 & 159 & 167 & 163 & 170 & 169 & 171 & 174 & 175 & 174 \\ 194 & 189 & 193 & 191 & 196 & 195 & 196 & 199 & 199 & 200 \\ 219 & 219 & 220 & 217 & 221 & 221 & 221 & 224 & 223 & 224 \\ 242 & 243 & 244 & 242 & 244 & 244 & 244 & 246 & 245 & 246 \\ 261 & 263 & 263 & 262 & 263 & 264 & 263 & 264 & 264 & 264\end{array}$

$\begin{array}{rrrrrrrrrr}38 & 40 & 38 & 40 & 36 & 37 & 36 & 33 & 33 & 33 \\ 62 & 60 & 62 & 60 & 64 & 63 & 64 & 67 & 67 & 67 \\ 29 & 30 & 31 & 29 & 31 & 31 & 31 & 33 & 33 & 34 \\ 6 & 7 & 7 & 7 & 7 & 8 & 8 & 8 & 8 & 8\end{array}$

$\begin{array}{lllllllll}260 & 260 & 264 & 263 & 264 & 263 & 262 & 263 & 264\end{array}$

$\begin{array}{llllllllll}213 & 211 & 217 & 216 & 220 & 217 & 216 & 217 & 219 & 221 \\ 237 & 236 & 242 & 241 & 244 & 242 & 240 & 242 & 243 & 244 \\ 262 & 262 & 267 & 266 & 267 & 266 & 265 & 265 & 267 & 267 \\ 285 & 286 & 288 & 288 & 288 & 288 & 286 & 287 & 288 & 289 \\ 305 & 305 & 305 & 306 & 305 & 306 & 305 & 305 & 305 & 307\end{array}$

$\begin{array}{rrrrrrrrrr}31 & 30 & 26 & 27 & 25 & 26 & 27 & 26 & 25 & 24 \\ 69 & 70 & 74 & 73 & 75 & 74 & 73 & 74 & 75 & 76 \\ 29 & 30 & 33 & 32 & 33 & 32 & 31 & 31 & 32 & 34 \\ 3 & 3 & 3 & 3 & 3 & 3 & 3 & 3 & 3 & 3\end{array}$

$\begin{array}{llllllllll}292 & 287 & 291 & 290 & 287 & - & 286 & - & 288 & - \\ 249 & 239 & 242 & 240 & 237 & - & 235 & - & 238 & - \\ 271 & 264 & 268 & 267 & 263 & - & 262 & - & 264 & - \\ 294 & 290 & 293 & 293 & 289 & - & 288 & - & 291 & - \\ 315 & 313 & 317 & 317 & 312 & - & 313 & - & 315 & - \\ 333 & 332 & 337 & 336 & 332 & - & 333 & - & 335 & -\end{array}$

$\begin{array}{rrrrrrrrrr}20 & 25 & 23 & 24 & 26 & - & 27 & - & 26 & - \\ 80 & 75 & 77 & 76 & 74 & - & 73 & - & 74 & - \\ 40 & 36 & 40 & 40 & 36 & - & 35 & - & 38 & - \\ 4 & 4 & 6 & 6 & 5 & - & 5 & - & 5 & -\end{array}$


Table A-23-2. Average reading scale scores, by grade and selected student and school characteristics: Selected years, 1992-2011

\begin{tabular}{|c|c|c|c|c|c|c|c|c|}
\hline \multirow[b]{2}{*}{ Student or school characteristic } & \multicolumn{3}{|c|}{ Grade 4} & \multicolumn{3}{|c|}{ Grade 8} & \multicolumn{2}{|c|}{ Grade 12} \\
\hline & $1992^{1}$ & 2009 & 2011 & $1992^{1}$ & 2009 & 2011 & $1992^{1}$ & 2009 \\
\hline Total & 217 & 221 & 221 & 260 & 264 & 265 & 292 & 288 \\
\hline \multicolumn{9}{|l|}{ Sex } \\
\hline Male & 213 & 218 & 218 & 254 & 259 & 261 & 287 & 282 \\
\hline Female & 221 & 224 & 225 & 267 & 269 & 270 & 297 & 294 \\
\hline \multicolumn{9}{|l|}{ Race/ethnicity } \\
\hline White & 224 & 230 & 231 & 267 & 273 & 274 & 297 & 296 \\
\hline Black & 192 & 205 & 205 & 237 & 246 & 249 & 273 & 269 \\
\hline Hispanic & 197 & 205 & 206 & 241 & 249 & 252 & 279 & 274 \\
\hline Asian/Pacific Islander & 216 & 235 & 235 & 268 & 274 & 275 & 290 & 298 \\
\hline Asian $^{2}$ & - & - & 236 & - & - & 277 & - & - \\
\hline Native Hawaiian/Pacific Islander² & - & - & 216 & - & - & 254 & - & - \\
\hline American Indian/Alaska Native & $\ddagger$ & 204 & 202 & $\ddagger$ & 251 & 252 & $\ddagger$ & 283 \\
\hline \multicolumn{9}{|l|}{ English language learner (ELL) } \\
\hline Yes & $\ddagger$ & 188 & 188 & $\ddagger$ & 219 & 224 & $\ddagger$ & 240 \\
\hline No & $\ddagger$ & 224 & 225 & $\ddagger$ & 266 & 267 & $\ddagger$ & 290 \\
\hline \multicolumn{9}{|l|}{ Student with disability (SD) } \\
\hline Yes & $\ddagger$ & 190 & 186 & $\ddagger$ & 230 & 231 & $\ddagger$ & 253 \\
\hline No & $\ddagger$ & 224 & 225 & $\ddagger$ & 267 & 269 & $\ddagger$ & 291 \\
\hline \multicolumn{9}{|c|}{ Student eligible for free or reduced-price lunch } \\
\hline Yes & - & 206 & 207 & - & 249 & 252 & - & 273 \\
\hline No & - & 232 & 235 & - & 273 & 275 & - & 294 \\
\hline \multicolumn{9}{|l|}{ School type } \\
\hline Public & 215 & 220 & 220 & 258 & 262 & 264 & 290 & 287 \\
\hline Traditional public ${ }^{3}$ & - & 220 & 220 & - & 262 & 264 & - & 287 \\
\hline Public charter ${ }^{3}$ & - & 212 & 218 & - & 257 & 261 & - & 276 \\
\hline Private & 232 & 235 & 234 & 278 & 282 & 282 & 308 & $\ddagger$ \\
\hline \multicolumn{9}{|l|}{ School locale } \\
\hline City & - & 216 & 216 & - & 259 & 260 & - & 286 \\
\hline Suburban & - & 225 & 226 & - & 268 & 269 & - & 292 \\
\hline Town & - & 218 & 218 & - & 261 & 264 & - & 287 \\
\hline Rural & - & 222 & 223 & - & 265 & 267 & - & 286 \\
\hline \multicolumn{9}{|c|}{$\begin{array}{l}\text { Percentage of students in school eligible for free or } \\
\text { reduced-price lunch }\end{array}$} \\
\hline 0-25 percent & - & 237 & 238 & - & 277 & 279 & - & 299 \\
\hline 26-50 percent & - & 223 & 226 & - & 265 & 268 & - & 286 \\
\hline 51-75 percent & - & 215 & 217 & - & 256 & 258 & - & 276 \\
\hline 76-100 percent & - & 202 & 203 & - & 243 & 247 & - & 266 \\
\hline
\end{tabular}

- Not available.

I Reporting standards not met.

'Testing accommodations (e.g., extended time, small group testing) for children with disabilities and English language learners were not permitted during this assessment.

2 Separate estimates for Asians and Native Hawaiians/Pacific Islanders were not available prior to 2011.

${ }^{3}$ Separate estimates for traditional public and public charter schools were not available in 1992.

NOTE: Average reading scale scores include public and private school students. The National Assessment of Educational Progress (NAEP) reading scale ranges from 0 to 500. The 12th-grade NAEP Reading Assessment was not administered in 2011. Race categories exclude persons of Hispanic ethnicity. For more information on NAEP, see Appendix B - Guide to Sources. For more information on race/ethnicity, free or reduced-priced lunch, or school locale, see Appendix C - Commonly Used Measures.

SOURCE: U.S. Department of Education, National Center for Education Statistics, National Assessment of Educational Progress (NAEP), selected years, 1992-2011 Reading Assessments, NAEP Data Explorer. 
Table A-23-3. Average reading scale scores and achievement-level results for public school students, by grade and state or jurisdiction: 2009 and 2011

\begin{tabular}{|c|c|c|c|c|c|c|c|c|c|c|c|c|c|c|c|}
\hline \multirow{4}{*}{$\begin{array}{l}\text { State or } \\
\text { jurisdiction }\end{array}$} & \multicolumn{6}{|c|}{ Grade 4} & \multicolumn{6}{|c|}{ Grade 8} & \multicolumn{3}{|c|}{ Grade 12} \\
\hline & \multirow{2}{*}{\multicolumn{2}{|c|}{$\begin{array}{c}\text { Average } \\
\text { score }\end{array}$}} & \multicolumn{4}{|c|}{$\begin{array}{c}\text { Percentage of } \\
\text { students }\end{array}$} & \multicolumn{6}{|c|}{$\begin{array}{c}\text { Percentage of } \\
\text { students }\end{array}$} & \multirow{3}{*}{$\begin{array}{c}\begin{array}{c}\text { Aver- } \\
\text { age } \\
\text { score }\end{array} \\
2009\end{array}$} & \multicolumn{2}{|c|}{$\begin{array}{c}\text { Percentage of } \\
\text { students }\end{array}$} \\
\hline & & & \multicolumn{2}{|c|}{$\begin{array}{c}\text { At or above } \\
\text { Basic } \\
\end{array}$} & \multicolumn{2}{|c|}{$\begin{array}{c}\text { At or above } \\
\text { Proficient } \\
\end{array}$} & \multicolumn{2}{|c|}{$\begin{array}{c}\text { Average } \\
\text { score }\end{array}$} & \multicolumn{2}{|c|}{$\begin{array}{c}\text { At or above } \\
\text { Basic } \\
\end{array}$} & \multicolumn{2}{|c|}{$\begin{array}{c}\text { At or above } \\
\text { Proficient } \\
\end{array}$} & & \multirow{2}{*}{$\begin{array}{r}\begin{array}{c}\text { At or } \\
\text { above } \\
\text { Basic }\end{array} \\
2009\end{array}$} & \multirow{2}{*}{$\begin{array}{c}\begin{array}{c}\text { At or } \\
\text { above } \\
\text { Proficient }\end{array} \\
2009\end{array}$} \\
\hline & 2009 & 2011 & 2009 & 2011 & 2009 & 2011 & 2009 & 2011 & 2009 & 2011 & 2009 & 2011 & & & \\
\hline United States & 220 & 220 & 66 & 66 & 32 & 32 & 262 & 264 & 74 & 75 & 30 & 32 & 287 & 73 & 37 \\
\hline Alabama & 216 & 220 & 62 & 67 & 28 & 31 & 255 & 258 & 66 & 69 & 24 & 26 & - & - & - \\
\hline Alaska & 211 & 208 & 59 & 56 & 27 & 26 & 259 & 261 & 72 & 73 & 27 & 31 & - & - & - \\
\hline Arizona & 210 & 212 & 56 & 58 & 25 & 26 & 258 & 260 & 68 & 71 & 27 & 28 & - & - & - \\
\hline Arkansas & 216 & 217 & 63 & 63 & 29 & 30 & 258 & 259 & 69 & 71 & 27 & 28 & 280 & 68 & 29 \\
\hline California & 210 & 211 & 54 & 56 & 24 & 25 & 253 & 255 & 64 & 65 & 22 & 24 & - & - & - \\
\hline Colorado & 226 & 223 & 72 & 71 & 40 & 39 & 266 & 271 & 78 & 81 & 32 & 40 & - & - & - \\
\hline Connecticut & 229 & 227 & 76 & 73 & 42 & 42 & 272 & 275 & 81 & 83 & 43 & 45 & 292 & 78 & 43 \\
\hline Delaware & 226 & 225 & 73 & 72 & 35 & 36 & 265 & 266 & 78 & 77 & 31 & 33 & - & - & - \\
\hline District of & & & & & & & & & & & & & & & \\
\hline Columbia & 202 & 201 & 44 & 44 & 17 & 19 & 242 & 242 & 51 & 51 & 14 & 16 & - & - & - \\
\hline Florida & 226 & 225 & 73 & 71 & 36 & 35 & 264. & 262 & 76 & 73 & 32 & 30 & 283 & 70 & 32 \\
\hline Georgia & 218 & 221 & 63 & 66 & 29 & 32 & 260 & 262 & 72 & 74 & 27 & 28 & - & - & - \\
\hline Hawaii & 211 & 214 & 57 & 59 & 26 & 27 & 255 & 257 & 67 & 68 & 22 & 26 & - & - & - \\
\hline Idaho & 221 & 221 & 69 & 69 & 32 & 33 & 265 & 268 & 77 & 81 & 33 & 34 & 290 & 78 & 39 \\
\hline Illinois & 219 & 219 & 65 & 65 & 32 & 33 & 265 & 266 & 77 & 77 & 33 & 34 & 292 & 78 & 40 \\
\hline Indiana & 223 & 221 & 70 & 68 & 34 & 33 & 268 & 265 & 79 & 78 & 32 & 32 & - & - & - \\
\hline lowa & 221 & 221 & 69 & 69 & 34 & 33 & 265 & 265 & 77 & 77 & 32 & 33 & 291 & 79 & 39 \\
\hline Kansas & 224 & 224 & 72 & 71 & 35 & 36 & 267 & 267 & 80 & 79 & 33 & 35 & - & - & - \\
\hline Kentucky & 226 & 225 & 72 & 72 & 36 & 35 & 267 & 269 & 79 & 79 & 33 & 36 & - & - & - \\
\hline Louisiana & 207 & 210 & 51 & 55 & 18 & 23 & 253 & 255 & 64 & 66 & 20 & 22 & - & - & - \\
\hline Maine & 224 & 222 & 70 & 70 & 35 & 32 & 268 & 270 & 80 & 80 & 35 & 39 & - & - & - \\
\hline Maryland & 226 & 231 & 70 & 75 & 37 & 43 & 267 & 271 & 77 & 80 & 36 & 40 & - & - & - \\
\hline Massachusetts & 234 & 237 & 80 & 83 & 47 & 50 & 274 & 275 & 83 & 84 & 43 & 46 & 295 & 80 & 46 \\
\hline Michigan & 218 & 219 & 64 & 66 & 30 & 31 & 262 & 265 & 72 & 77 & 31 & 32 & - & - & - \\
\hline Minnesota & 223 & 222 & 70 & 70 & 37 & 35 & 270 & 270 & 82 & 81 & 38 & 39 & - & - & - \\
\hline Mississippi & 211 & 209 & 55 & 55 & 22 & 22 & 251 & 254 & 62 & 65 & 19 & 21 & - & - & - \\
\hline
\end{tabular}

See notes at end of table. 
Table A-23-3. Average reading scale scores and achievement-level results for public school students, by grade and state or jurisdiction: 2009 and $2011-$ Continued

\begin{tabular}{|c|c|c|c|c|c|c|c|c|c|c|c|c|c|c|c|}
\hline \multirow{4}{*}{$\begin{array}{l}\text { State or } \\
\text { jurisdiction }\end{array}$} & \multicolumn{6}{|c|}{ Grade 4} & \multicolumn{6}{|c|}{ Grade 8} & \multicolumn{3}{|c|}{ Grade 12} \\
\hline & \multirow{2}{*}{\multicolumn{2}{|c|}{$\begin{array}{c}\text { Average } \\
\text { score }\end{array}$}} & \multicolumn{4}{|c|}{$\begin{array}{c}\text { Percentage of } \\
\text { students }\end{array}$} & \multirow{2}{*}{\multicolumn{2}{|c|}{$\begin{array}{l}\text { Average } \\
\text { score }\end{array}$}} & \multicolumn{4}{|c|}{$\begin{array}{c}\text { Percentage of } \\
\text { students }\end{array}$} & \multirow{3}{*}{$\begin{array}{r}\begin{array}{c}\text { Aver- } \\
\text { age } \\
\text { score }\end{array} \\
2009\end{array}$} & \multicolumn{2}{|c|}{$\begin{array}{c}\text { Percentage of } \\
\text { students }\end{array}$} \\
\hline & & & \multicolumn{2}{|c|}{$\begin{array}{c}\text { At or above } \\
\text { Basic }\end{array}$} & \multicolumn{2}{|c|}{$\begin{array}{c}\text { At or above } \\
\text { Proficient }\end{array}$} & & & \multicolumn{2}{|c|}{$\begin{array}{c}\text { At or above } \\
\text { Basic }\end{array}$} & \multicolumn{2}{|c|}{$\begin{array}{c}\text { At or above } \\
\text { Proficient }\end{array}$} & & \multirow{2}{*}{$\begin{array}{l}\begin{array}{c}\text { At or } \\
\text { above } \\
\text { Basic }\end{array} \\
2009\end{array}$} & \multirow{2}{*}{$\begin{array}{c}\begin{array}{c}\text { At or } \\
\text { above } \\
\text { Proficient }\end{array} \\
2009\end{array}$} \\
\hline & 2009 & 2011 & 2009 & 2011 & 2009 & 2011 & 2009 & 2011 & 2009 & 2011 & 2009 & 2011 & & & \\
\hline United States & 220 & 220 & 66 & 66 & 32 & 32 & 262 & 264 & 74 & 75 & 30 & 32 & 287 & 73 & 37 \\
\hline Missouri & 224 & 220 & 70 & 67 & 36 & 34 & 267 & 267 & 79 & 79 & 34 & 35 & - & - & - \\
\hline Montana & 225 & 225 & 73 & 73 & 35 & 36 & 270 & 273 & 84 & 86 & 38 & 42 & - & - & - \\
\hline Nebraska & 222 & 223 & 70 & 70 & 35 & 36 & 267 & 268 & 80 & 81 & 35 & 35 & - & - & - \\
\hline Nevada & 211 & 213 & 57 & 58 & 24 & 25 & 254 & 258 & 65 & 69 & 22 & 26 & - & - & - \\
\hline \multicolumn{16}{|l|}{ New } \\
\hline Hampshire & 229 & 230 & 77 & 78 & 41 & 43 & 271 & 272 & 81 & 84 & 39 & 40 & 293 & 79 & 44 \\
\hline New Jersey & 229 & 231 & 76 & 78 & 40 & 44 & 273 & 275 & 83 & 84 & 42 & 45 & 288 & 74 & 39 \\
\hline New Mexico & 208 & 208 & 52 & 53 & 20 & 21 & 254 & 256 & 66 & 68 & 22 & 22 & - & - & - \\
\hline New York & 224 & 222 & 71 & 68 & 36 & 35 & 264 & 266 & 75 & 76 & 33 & 35 & - & - & - \\
\hline North Carolina & 219 & 221 & 65 & 68 & 32 & 34 & 260 & 263 & 70 & 74 & 29 & 31 & - & - & - \\
\hline North Dakota & 226 & 226 & 76 & 74 & 35 & 36 & 269 & 269 & 86 & 83 & 34 & 34 & - & - & - \\
\hline Ohio & 225 & 224 & 71 & 71 & 36 & 34 & 269 & 268 & 80 & 79 & 37 & 37 & - & - & - \\
\hline Oklahoma & 217 & 215 & 65 & 64 & 28 & 27 & 259 & 260 & 73 & 73 & 26 & 27 & - & - & - \\
\hline Oregon & 218 & 216 & 65 & 63 & 31 & 30 & 265 & 264 & 76 & 76 & 33 & 33 & - & - & - \\
\hline Pennsylvania & 224 & 227 & 70 & 74 & 37 & 41 & 271 & 268 & 81 & 77 & 40 & 38 & - & - & - \\
\hline Rhode Island & 223 & 222 & 69 & 70 & 36 & 35 & 260 & 265 & 72 & 76 & 28 & 33 & - & - & - \\
\hline South Carolina & 216 & 215 & 62 & 61 & 28 & 28 & 257 & 260 & 68 & 72 & 24 & 27 & - & - & - \\
\hline South Dakota & 222 & 220 & 70 & 69 & 33 & 31 & 270 & 269 & 84 & 83 & 37 & 35 & 292 & 82 & 40 \\
\hline Tennessee & 217 & 215 & 63 & 60 & 28 & 26 & 261 & 259 & 73 & 70 & 28 & 27 & - & - & - \\
\hline Texas & 219 & 218 & 65 & 64 & 28 & 28 & 260. & 261 & 73 & 74 & 27 & 27 & - & - & - \\
\hline Utah & 219 & 220 & 67 & 68 & 31 & 33 & 266 & 267 & 78 & 79 & 33 & 35 & - & - & - \\
\hline Vermont & 229 & 227 & 75 & 73 & 41 & 41 & 272. & 274 & 84 & 82 & 41 & 44 & - & - & - \\
\hline Virginia & 227 & 226 & 74 & 72 & 38 & 39 & 266 & 267 & 78 & 78 & 32 & 36 & - & - & - \\
\hline Washington & 221 & 221 & 68 & 67 & 33 & 34 & 267 & 268 & 78 & 77 & 36 & 37 & - & - & - \\
\hline West Virginia & 215 & 214 & 62 & 61 & 26 & 27 & 255 & 256 & 67 & 68 & 22 & 24 & 279 & 68 & 29 \\
\hline Wisconsin & 220 & 221 & 67 & 68 & 33 & 34 & 266 & 267 & 78 & 79 & 34 & 35 & - & - & - \\
\hline Wyoming & 223 & 224 & 72 & 71 & 33 & 34 & 268 & 270 & 82 & 82 & 34 & 38 & - & - & - \\
\hline
\end{tabular}

\section{- Not available.}

NOTE: At the state level, the National Assessment of Educational Progress (NAEP) includes only students in public schools, while the national results reported elsewhere in this indicator include both public and private school students. Eleven states participated in the pilot state NAEP reading assessment at grade 12 in 2009. The 12th-grade NAEP Reading Assessment was not administered in 2011. The NAEP reading scale ranges from 0 to 500. Achievement levels define what students should know and be able to do: Basic indicates partial mastery of fundamental skills, and Proficient indicates demonstrated competency over challenging subject matter. For more information on NAEP, see Appendix B - Guide to Sources.

SOURCE: U.S. Department of Education, National Center for Education Statistics, National Assessment of Educational Progress (NAEP), 2009 and 2011

Reading Assessments, NAEP Data Explorer. 
Table A-24-1. Average mathematics scale scores, selected percentile scores, and percentage of students at each achievement level, by grade: Selected years, 1990-2011

Grade, scale score, percentile, and

percentage at achievement level

\section{Grade 4}

Average scale score

Percentile

10 th

25th

50th

75 th

90th

$1990^{1} 1992^{1} \quad 1996^{1}$

$1996 \quad 2000$

2003

2005

2007

2009

2011

Percentage at each achievement

level

Below Basic

At or above Basic

At or above Proficient

At Advanced

$\begin{array}{llllllllll}213 & 220 & 224 & 224 & 226 & 235 & 238 & 240 & 240 & 241 \\ 171 & 177 & 182 & 182 & 184 & 197 & 200 & 202 & 202 & 203 \\ 193 & 199 & 204 & 203 & 205 & 216 & 220 & 222 & 221 & 222 \\ 214 & 221 & 226 & 225 & 227 & 236 & 239 & 242 & 241 & 242 \\ 235 & 242 & 246 & 245 & 248 & 255 & 258 & 260 & 260 & 261 \\ 253 & 259 & 262 & 262 & 265 & 270 & 273 & 275 & 275 & 276\end{array}$

Grade 8

Average scale score

Percentile

10th

25th

50th

75 th

90th

$\begin{array}{rrr}50 & 41 & 36 \\ 50 & 59 & 64 \\ 13 & 18 & 21 \\ 1 & 2 & 2\end{array}$

37
63
21
2

$\begin{array}{rrrrrr}35 & 23 & 20 & 18 & 18 & 18 \\ 65 & 77 & 80 & 82 & 82 & 82 \\ 24 & 32 & 36 & 39 & 39 & 40 \\ 3 & 4 & 5 & 6 & 6 & 7\end{array}$

Percentage at each achievement

level

Below Basic

At or above Basic

At or above Proficient

At Advanced

$\begin{array}{llllllllll}263 & 268 & 272 & 270 & 273 & 278 & 279 & 281 & 283 & 284 \\ 215 & 221 & 224 & 221 & 223 & 230 & 231 & 235 & 236 & 237 \\ 239 & 243 & 248 & 245 & 249 & 254 & 255 & 258 & 259 & 260 \\ 264 & 269 & 273 & 273 & 275 & 279 & 280 & 283 & 284 & 285 \\ 288 & 294 & 298 & 297 & 300 & 303 & 304 & 306 & 308 & 309 \\ 307 & 315 & 317 & 316 & 320 & 323 & 324 & 327 & 329 & 329\end{array}$

\section{Grade 12}

Average scale score

Percentile

10th

25th

50 th

75 th

90th

Percentage at each achievement level

Below Basic

At or above Basic

At or above Proficient

At Advanced

$\begin{array}{rrrrrrrrrr}48 & 42 & 38 & 39 & 37 & 32 & 31 & 29 & 27 & 27 \\ 52 & 58 & 62 & 61 & 63 & 68 & 69 & 71 & 73 & 73 \\ 15 & 21 & 24 & 23 & 26 & 29 & 30 & 32 & 34 & 35 \\ 2 & 3 & 4 & 4 & 5 & 5 & 6 & 7 & 8 & 8 \\ & & & & & & & & & \\ - & - & - & - & - & - & 150 & - & 153 & - \\ - & - & - & - & - & - & 105 & - & 110 & - \\ - & - & - & - & - & - & 127 & - & 130 & - \\ - & - & - & - & - & - & 151 & - & 154 & - \\ - & - & - & - & - & - & 174 & - & 177 & - \\ - & - & - & - & - & - & 194 & - & 197 & -\end{array}$

- Not available.

${ }^{1}$ Testing accommodations (e.g., extended time, small group testing) for children with disabilities and English language learners were not permitted during these assessments. Students in grades 4 and 8 were tested with and without accommodations in 1996.

NOTE: Average mathematics scale scores include public and private school students. At grades 4 and 8 , the National Assessment of Educational Progress (NAEP) mathematics scale ranges from 0 to 500 . The framework for the 12th-grade mathematics assessment was revised in 2005; as a result the 2005 and 2009 results cannot be compared with those from previous years. At grade 12, mathematics scores on the revised assessment range from 0 to 300. The 12th-grade mathematics assessment was not administered in 2007 or 2011 . Achievement levels define what students should know and be able to do: Basic indicates partial mastery of fundamental skills, Proficient indicates demonstrated competency over challenging subject matter, and Advanced indicates superior performance. For more information on NAEP, see Appendix B - Guide to Sources.

SOURCE: U.S. Department of Education, National Center for Education Statistics, National Assessment of Educational Progress (NAEP), selected years,

1990-2011 Mathematics Assessments, NAEP Data Explorer. 
Table A-24-2. Average mathematics scale scores, by grade and selected student and school characteristics: Selected years, 1990-2011

\begin{tabular}{|c|c|c|c|c|c|c|c|c|}
\hline \multirow[b]{2}{*}{ Student or school characteristic } & \multicolumn{3}{|c|}{ Grade 4} & \multicolumn{3}{|c|}{ Grade 8} & \multicolumn{2}{|c|}{ Grade 12} \\
\hline & $1990^{1}$ & 2009 & 2011 & $1990^{1}$ & 2009 & 2011 & 2005 & 2009 \\
\hline Total & 213 & 240 & 241 & 263 & 283 & 284 & 150 & 153 \\
\hline \multicolumn{9}{|l|}{ Sex } \\
\hline Male & 214 & 241 & 241 & 263 & 284 & 284 & 151 & 155 \\
\hline Female & 213 & 239 & 240 & 262 & 282 & 283 & 149 & 152 \\
\hline \multicolumn{9}{|l|}{ Race/ethnicity } \\
\hline White & 220 & 248 & 249 & 270 & 293 & 293 & 157 & 161 \\
\hline Black & 188 & 222 & 224 & 237 & 261 & 262 & 127 & 131 \\
\hline Hispanic & 200 & 227 & 229 & 246 & 266 & 270 & 133 & 138 \\
\hline Asian/Pacific Islander & 225 & 255 & 256 & 275 & 301 & 303 & 163 & 175 \\
\hline Asian $^{2}$ & - & - & 257 & - & - & 305 & - & - \\
\hline Native Hawaiian/Pacific Islander ${ }^{2}$ & - & - & 236 & - & - & 269 & - & - \\
\hline American Indian/Alaska Native & $\ddagger$ & 225 & 225 & $\ddagger$ & 266 & 265 & 134 & 144 \\
\hline \multicolumn{9}{|l|}{ English language learner (ELL) } \\
\hline Yes & $\ddagger$ & 218 & 219 & $\ddagger$ & 243 & 244 & 120 & 117 \\
\hline No & $\ddagger$ & 242 & 243 & $\ddagger$ & 285 & 286 & 151 & 154 \\
\hline \multicolumn{9}{|l|}{ Student with disability (SD) } \\
\hline Yes & $\ddagger$ & 221 & 218 & $\ddagger$ & 249 & 250 & 114 & 120 \\
\hline No & $\ddagger$ & 242 & 244 & $\ddagger$ & 287 & 288 & 153 & 156 \\
\hline \multicolumn{9}{|l|}{$\begin{array}{l}\text { Student eligible for free or reduced- } \\
\text { price lunch }\end{array}$} \\
\hline Yes & - & 227 & 229 & - & 266 & 269 & 132 & 137 \\
\hline No & - & 250 & 252 & - & 294 & 296 & 155 & 160 \\
\hline \multicolumn{9}{|l|}{ School type } \\
\hline Public & 212 & 239 & 240 & 262 & 282 & 283 & 149 & 152 \\
\hline Traditional public ${ }^{3}$ & - & 239 & 240 & - & 282 & 283 & - & 153 \\
\hline Public charter ${ }^{3}$ & - & 231 & 237 & - & 275 & 281 & - & 138 \\
\hline Private & 224 & 246 & 247 & 271 & 296 & 296 & $\ddagger$ & $\ddagger$ \\
\hline \multicolumn{9}{|l|}{ School locale } \\
\hline City & - & 235 & 236 & - & 279 & 279 & - & 152 \\
\hline Suburban & - & 243 & 244 & - & 287 & 287 & - & 157 \\
\hline Town & - & 238 & 237 & - & 279 & 282 & - & 151 \\
\hline Rural & - & 241 & 243 & - & 284 & 286 & - & 151 \\
\hline \multicolumn{9}{|l|}{$\begin{array}{l}\text { Percentage of students in school eligible } \\
\text { for free or reduced-price lunch }\end{array}$} \\
\hline 0-25 percent & - & 254 & 255 & - & 298 & 300 & 158 & 166 \\
\hline 26-50 percent & - & 242 & 245 & - & 284 & 287 & 147 & 150 \\
\hline 51-75 percent & - & 234 & 237 & - & 274 & 276 & 136 & 140 \\
\hline 76-100 percent & - & 223 & 226 & - & 260 & 264 & 122 & 130 \\
\hline
\end{tabular}

- Not available.

‡ Reporting standards not met (too few cases).

${ }^{1}$ Testing accommodations (e.g., extended time, small group testing) for children with disabilities and English language learners were not permitted during this assessment.

2 Separate estimates for Asians and Native Hawaiians/Pacific Islanders were not available prior to 2011.

${ }^{3}$ Separate estimates for traditional public and public charter schools were not available in 1992.

NOTE: Average mathematics scale scores include public and private school students. At grades 4 and 8 , the National Assessment of Educational Progress (NAEP) mathematics scale ranges from 0 to 500. The framework for the 12th-grade mathematics assessment was revised in 2005; as a result, the 2005 and 2009 results cannot be compared with those from previous years. The 12th-grade mathematics assessment was not administered in 2011. At grade 12, mathematics scores on the revised assessment range from 0 to 300 . For more information on NAEP, see Appendix B - Guide to Sources. Race categories exclude persons of Hispanic ethnicity. For more information on race/ethnicity or free or reduced-priced lunch, see Appendix $\mathrm{C}$ Commonly Used Measures.

SOURCE: U.S. Department of Education, National Center for Education Statistics, National Assessment of Educational Progress (NAEP), selected years, 1990-2011 Mathematics Assessments, NAEP Data Explorer. 
Table A-24-3. Average mathematics scale scores and percentage of students at selected achievement levels for public school students, by grade and state or jurisdiction: 2009 and 2011

\begin{tabular}{|c|c|c|c|c|c|c|c|c|c|c|c|c|c|c|c|}
\hline \multirow[b]{4}{*}{$\underline{S t a t e}$ or jurisdiction } & \multicolumn{6}{|c|}{ Grade 4} & \multicolumn{6}{|c|}{ Grade 8} & \multicolumn{3}{|c|}{ Grade 12} \\
\hline & \multirow{2}{*}{\multicolumn{2}{|c|}{$\begin{array}{r}\text { Average } \\
\text { score } \\
\end{array}$}} & \multicolumn{4}{|c|}{ Percentage of students } & \multicolumn{6}{|c|}{ Percentage of students } & \multirow{3}{*}{$\begin{array}{r}\begin{array}{r}\text { Aver- } \\
\text { age } \\
\text { score }\end{array} \\
2009\end{array}$} & \multicolumn{2}{|c|}{$\begin{array}{c}\text { Percentage of } \\
\text { students }\end{array}$} \\
\hline & & & \multicolumn{2}{|c|}{$\begin{array}{r}\text { At or above } \\
\text { Basic }\end{array}$} & \multicolumn{2}{|c|}{$\begin{array}{l}\text { At or above } \\
\text { Proficient }\end{array}$} & \multicolumn{2}{|c|}{$\begin{array}{r}\text { Average } \\
\text { score }\end{array}$} & \multicolumn{2}{|c|}{$\begin{array}{r}\text { At or above } \\
\text { Basic }\end{array}$} & \multicolumn{2}{|c|}{$\begin{array}{r}\text { At or above } \\
\text { Proficient }\end{array}$} & & $\begin{array}{r}\text { At or } \\
\text { above } \\
\text { Basic }\end{array}$ & $\begin{array}{r}\text { At or } \\
\text { above } \\
\text { Profi- } \\
\text { cient }\end{array}$ \\
\hline & 2009 & 2011 & 2009 & 2011 & 2009 & 2011 & 2009 & 2011 & 2009 & 2011 & 2009 & 2011 & & 2009 & 2009 \\
\hline United States & 239 & 240 & 81 & 82 & 38 & 40 & 282 & 283 & 71 & 72 & 33 & 34 & 152 & 63 & 25 \\
\hline Alabama & 228 & 231 & 70 & 75 & 24 & 27 & 269 & 269 & 58 & 60 & 20 & 20 & - & - & - \\
\hline Alaska & 237 & 236 & 78 & 78 & 38 & 37 & 283 & 283 & 75 & 74 & 33 & 35 & - & - & - \\
\hline Arizona & 230 & 235 & 71 & 77 & 28 & 34 & 277 & 279 & 67 & 68 & 29 & 31 & - & - & - \\
\hline Arkansas & 238 & 238 & 80 & 81 & 36 & 37 & 276 & 279 & 67 & 70 & 27 & 29 & 146 & 59 & 16 \\
\hline California & 232 & 234 & 72 & 74 & 30 & 34 & 270 & 273 & 59 & 61 & 23 & 25 & - & - & - \\
\hline Colorado & 243 & 244 & 84 & 84 & 45 & 47 & 287 & 292 & 76 & 80 & 40 & 43 & - & - & - \\
\hline Connecticut & 245 & 242 & 86 & 82 & 46 & 45 & 289 & 287 & 78 & 75 & 40 & 38 & 156 & 69 & 29 \\
\hline Delaware & 239 & 240 & 84 & 84 & 36 & 39 & 284 & 283 & 75 & 74 & 32 & 32 & - & - & - \\
\hline $\begin{array}{l}\text { District of } \\
\text { Columbia }\end{array}$ & 219 & 222 & 56 & 60 & 17 & 22 & 254 & 260 & 40 & 48 & 11 & 17 & - & - & - \\
\hline Florida & 242 & 240 & 86 & 84 & 40 & 37 & 279 & 278 & 70 & 68 & 29 & 28 & 148 & 59 & 19 \\
\hline Georgia & 236 & 238 & 78 & 80 & 34 & 37 & 278 & 278 & 67 & 68 & 27 & 28 & - & - & - \\
\hline Hawaii & 236 & 239 & 77 & 80 & 37 & 40 & 274 & 278 & 65 & 68 & 25 & 30 & - & - & - \\
\hline Idaho & 241 & 240 & 85 & 83 & 41 & 39 & 287 & 287 & 78 & 77 & 38 & 37 & 153 & 66 & 23 \\
\hline Illinois & 238 & 239 & 80 & 80 & 38 & 38 & 282 & 283 & 73 & 73 & 33 & 33 & 154 & 67 & 26 \\
\hline Indiana & 243 & 244 & 87 & 87 & 42 & 44 & 287 & 285 & 78 & 77 & 36 & 34 & - & - & - \\
\hline lowa & 243 & 243 & 87 & 86 & 41 & 43 & 284 & 285 & 76 & 77 & 34 & 34 & 156 & 71 & 25 \\
\hline Kansas & 245 & 246 & 89 & 90 & 46 & 48 & 289 & 290 & 79 & 80 & 39 & 41 & - & - & - \\
\hline Kentucky & 239 & 241 & 81 & 85 & 37 & 39 & 279 & 282 & 70 & 72 & 27 & 31 & - & - & - \\
\hline Louisiana & 229 & 231 & 72 & 73 & 23 & 26 & 272 & 273 & 62 & 63 & 20 & 22 & - & - & - \\
\hline Maine & 244 & 244 & 87 & 87 & 45 & 45 & 286 & 289 & 78 & 78 & 35 & 39 & - & - & - \\
\hline Maryland & 244 & 247 & 85 & 86 & 44 & 48 & 288 & 288 & 75 & 74 & 40 & 40 & - & - & - \\
\hline Massachusetts & 252 & 253 & 92 & 93 & 57 & 58 & 299 & 299 & 85 & 86 & 52 & 51 & 163 & 75 & 36 \\
\hline Michigan & 236 & 236 & 78 & 78 & 35 & 35 & 278 & 280 & 68 & 71 & 31 & 31 & - & - & - \\
\hline Minnesota & 249 & 249 & 89 & 88 & 54 & 53 & 294 & 295 & 83 & 83 & 47 & 48 & - & - & - \\
\hline Mississippi & 227 & 230 & 69 & 72 & 22 & 25 & 265 & 269 & 54 & 58 & 15 & 19 & - & - & - \\
\hline Missouri & 241 & 240 & 83 & 83 & 41 & 41 & 286 & 282 & 77 & 73 & 35 & 32 & - & - & - \\
\hline Montana & 244 & 244 & 88 & 87 & 45 & 45 & 292 & 293 & 82 & 83 & 44 & 46 & - & - & - \\
\hline Nebraska & 239 & 240 & 82 & 83 & 38 & 39 & 284 & 283 & 75 & 74 & 35 & 33 & - & - & - \\
\hline Nevada & 235 & 237 & 79 & 79 & 32 & 36 & 274 & 278 & 63 & 67 & 25 & 29 & - & - & - \\
\hline New Hampshire & 251 & 252 & 92 & 92 & 56 & 57 & 292 & 292 & 82 & 82 & 43 & 44 & 160 & 74 & 32 \\
\hline
\end{tabular}

See notes at end of table. 
Table A-24-3. Average mathematics scale scores and percentage of students at selected achievement levels for public school students, by grade and state or jurisdiction: 2009 and 2011 -Continued

\begin{tabular}{|c|c|c|c|c|c|c|c|c|c|c|c|c|c|c|c|}
\hline \multirow[b]{4}{*}{ State or jurisdiction } & \multicolumn{6}{|c|}{ Grade 4} & \multicolumn{6}{|c|}{ Grade 8} & \multicolumn{3}{|c|}{ Grade 12} \\
\hline & \multirow{2}{*}{\multicolumn{2}{|c|}{$\begin{array}{r}\text { Average } \\
\text { score }\end{array}$}} & \multicolumn{4}{|c|}{ Percentage of students } & \multicolumn{6}{|c|}{ Percentage of students } & \multirow{3}{*}{$\begin{array}{r}\begin{array}{r}\text { Aver- } \\
\text { age } \\
\text { score }\end{array} \\
2009 \\
\end{array}$} & \multicolumn{2}{|c|}{$\begin{array}{c}\text { Percentage of } \\
\text { students }\end{array}$} \\
\hline & & & \multicolumn{2}{|c|}{$\begin{array}{r}\text { At or above } \\
\text { Basic }\end{array}$} & \multicolumn{2}{|c|}{$\begin{array}{l}\text { At or above } \\
\text { Proficient }\end{array}$} & \multicolumn{2}{|c|}{$\begin{array}{r}\text { Average } \\
\text { score }\end{array}$} & \multicolumn{2}{|c|}{$\begin{array}{r}\text { At or above } \\
\text { Basic }\end{array}$} & \multicolumn{2}{|c|}{$\begin{array}{l}\text { At or above } \\
\text { Proficient }\end{array}$} & & $\begin{array}{r}\text { At or } \\
\text { above } \\
\text { Basic }\end{array}$ & $\begin{array}{r}\text { At or } \\
\text { above } \\
\text { Profi- } \\
\text { cient }\end{array}$ \\
\hline & 2009 & 2011 & 2009 & 2011 & 2009 & 2011 & 2009 & 2011 & 2009 & 2011 & 2009 & 2011 & & 2009 & 2009 \\
\hline United States & 239 & 240 & 81 & 82 & 38 & 40 & 282 & 283 & 71 & 72 & 33 & 34 & 152 & 63 & 25 \\
\hline New Jersey & 247 & 248 & 88 & 89 & 49 & 51 & 293 & 294 & 80 & 82 & 44 & 47 & 156 & 67 & 31 \\
\hline New Mexico & 230 & 233 & 72 & 75 & 26 & 30 & 270 & 274 & 59 & 64 & 20 & 24 & - & - & - \\
\hline New York & 241 & 238 & 83 & 80 & 40 & 36 & 283 & 280 & 73 & 70 & 34 & 30 & - & - & - \\
\hline North Carolina & 244 & 245 & 87 & 88 & 43 & 44 & 284 & 286 & 74 & 75 & 36 & 37 & - & - & - \\
\hline North Dakota & 245 & 245 & 91 & 90 & 45 & 46 & 293 & 292 & 86 & 85 & 43 & 43 & - & - & - \\
\hline Ohio & 244 & 244 & 85 & 86 & 45 & 45 & 286 & 289 & 76 & 79 & 36 & 39 & - & - & 一 \\
\hline Oklahoma & 237 & 237 & 82 & 83 & 33 & 33 & 276 & 279 & 68 & 72 & 24 & 27 & - & - & - \\
\hline Oregon & 238 & 237 & 80 & 77 & 37 & 37 & 285 & 283 & 75 & 72 & 37 & 33 & - & - & - \\
\hline Pennsylvania & 244 & 246 & 84 & 87 & 46 & 48 & 288 & 286 & 78 & 74 & 40 & 39 & - & - & - \\
\hline Rhode Island & 239 & 242 & 81 & 84 & 39 & 43 & 278 & 283 & 68 & 73 & 28 & 34 & - & - & - \\
\hline South Carolina & 236 & 237 & 78 & 79 & 34 & 36 & 280 & 281 & 69 & 70 & 30 & 32 & - & - & - \\
\hline South Dakota & 242 & 241 & 86 & 86 & 42 & 40 & 291 & 291 & 83 & 82 & 42 & 42 & 160 & 77 & 29 \\
\hline Tennessee & 232 & 233 & 74 & 75 & 28 & 30 & 275 & 274 & 65 & 64 & 25 & 24 & - & - & - \\
\hline Texas & 240 & 241 & 85 & 85 & 38 & 39 & 287 & 290 & 78 & 81 & 36 & 40 & - & - & - \\
\hline Utah & 240 & 243 & 81 & 85 & 41 & 43 & 284 & 283 & 75 & 73 & 35 & 35 & - & - & - \\
\hline Vermont & 248 & 247 & 89 & 89 & 51 & 49 & 293 & 294 & 81 & 82 & 43 & 46 & - & - & - \\
\hline Virginia & 243 & 245 & 85 & 87 & 43 & 46 & 286 & 289 & 76 & 78 & 36 & 40 & - & - & - \\
\hline Washington & 242 & 243 & 84 & 83 & 43 & 45 & 289 & 288 & 78 & 77 & 39 & 40 & - & - & - \\
\hline West Virginia & 233 & 235 & 77 & 78 & 28 & 31 & 270 & 273 & 61 & 65 & 19 & 21 & 141 & 52 & 13 \\
\hline Wisconsin & 244 & 245 & 85 & 86 & 45 & 47 & 288 & 289 & 79 & 79 & 39 & 41 & - & - & - \\
\hline Wyoming & 242 & 244 & 87 & 88 & 40 & 44 & 286 & 288 & 78 & 80 & 35 & 37 & - & - & - \\
\hline
\end{tabular}

\section{- Not available.}

NOTE: At the state level, the National Assessment of Educational Progress (NAEP) includes only students in public schools, while the national results reported elsewhere in this indicator include both public and private school students. Achievement levels define what students should know and be able to do: Basic indicates partial mastery of fundamental skills, and Proficient indicates demonstrated competency over challenging subject matter. At grades 4 and 8 , the NAEP mathematics scale ranges from 0 to 500. The framework for the 12th-grade mathematics assessment was revised in 2005; scores on the revised assessment range from 0 to 300 . Twelfth-grade students were assessed in mathematics using the revised assessment in 2005 and 2009 but state-level data are not available for 2005. In 2009, 11 states participated in the 12th-grade pilot state NAEP mathematics assessment. The 12th-grade mathematics assessment was not administered in 2011. For more information on NAEP, see Appendix B - Guide to Sources.

SOURCE: U.S. Department of Education, National Center for Education Statistics, National Assessment of Educational Progress (NAEP), 2009 and 2011

Mathematics Assessments, NAEP Data Explorer. 


\section{Indicator 25}

\section{U.S. History, Geography, and Civics Performance}

Table A-25-1. Average U.S. history scale scores, by grade and selected characteristics: Selected years, 1994-2010

\begin{tabular}{|c|c|c|c|c|c|c|c|c|c|c|c|c|c|c|c|}
\hline \multirow[b]{2}{*}{ Characteristic } & \multicolumn{5}{|c|}{ Grade 4} & \multicolumn{5}{|c|}{ Grade 8} & \multicolumn{5}{|c|}{ Grade 12} \\
\hline & $1994^{1}$ & $2001^{1}$ & 2001 & 2006 & 2010 & 19941 & $2001^{1}$ & 2001 & 2006 & 2010 & $1994^{1}$ & $2001^{1}$ & 2001 & 2006 & 2010 \\
\hline Total & 205 & 209 & 208 & 211 & 214 & 259 & 262 & 260 & 263 & 266 & 286 & 287 & 287 & 290 & 288 \\
\hline \multicolumn{16}{|l|}{ Sex } \\
\hline Male & 203 & 209 & 207 & 211 & 215 & 259 & 264 & 261 & 264 & 268 & 288 & 288 & 288 & 292 & 290 \\
\hline Female & 206 & 209 & 209 & 211 & 213 & 259 & 261 & 260 & 261 & 263 & 285 & 286 & 286 & 288 & 286 \\
\hline \multicolumn{16}{|l|}{ Race/ethnicity } \\
\hline White & 214 & 219 & 217 & 223 & 224 & 266 & 270 & 268 & 273 & 274 & 292 & 292 & 292 & 297 & 296 \\
\hline Black & 176 & 186 & 186 & 191 & 198 & 238 & 243 & 240 & 244 & 250 & 265 & 269 & 267 & 270 & 268 \\
\hline Hispanic & 175 & 183 & 184 & 194 & 198 & 243 & 242 & 240 & 248 & 252 & 267 & 273 & 271 & 275 & 275 \\
\hline Asian/Pacific Islander & 204 & 212 & 216 & 214 & 221 & 261 & 265 & 264 & 270 & 275 & 283 & 295 & 294 & 296 & 293 \\
\hline $\begin{array}{c}\text { American Indian/ } \\
\text { Alaska Native }\end{array}$ & $\ddagger$ & $\ddagger$ & $\ddagger$ & 190 & 193 & 245 & 257 & 255 & 244 & 259 & 272 & 285 & 283 & 278 & 278 \\
\hline \multicolumn{16}{|l|}{ English language learner } \\
\hline Yes & $\ddagger$ & $\ddagger$ & 167 & 181 & 184 & $\ddagger$ & $\ddagger$ & 220 & 228 & 233 & $\ddagger$ & $\ddagger$ & 241 & 254 & 244 \\
\hline No & $\ddagger$ & $\ddagger$ & 210 & 215 & 217 & $\ddagger$ & $\ddagger$ & 262 & 265 & 268 & $\ddagger$ & $\ddagger$ & 288 & 292 & 290 \\
\hline \multicolumn{16}{|l|}{ Student with disability } \\
\hline Yes & $\ddagger$ & $\ddagger$ & 185 & 193 & 189 & $\ddagger$ & $\ddagger$ & 229 & 238 & 242 & $\ddagger$ & $\ddagger$ & 253 & 267 & 263 \\
\hline No & $\ddagger$ & $\ddagger$ & 211 & 214 & 217 & $\ddagger$ & $\ddagger$ & 264 & 266 & 269 & $\ddagger$ & $\ddagger$ & 289 & 292 & 291 \\
\hline \multicolumn{16}{|l|}{$\begin{array}{l}\text { Student eligibility for free or } \\
\text { reduced-price lunch }\end{array}$} \\
\hline Eligible & - & 189 & 188 & 195 & 199 & - & 245 & 242 & 247 & 253 & - & 271 & 269 & 273 & 273 \\
\hline Not eligible & - & 220 & 219 & 224 & 227 & - & 269 & 267 & 273 & 275 & - & 289 & 289 & 295 & 294 \\
\hline \multicolumn{16}{|l|}{$\begin{array}{l}\text { Percent of students in } \\
\text { school eligible for free } \\
\text { or reduced-price lunch }\end{array}$} \\
\hline $0-25$ & - & 225 & 223 & 227 & 229 & - & 273 & 272 & 277 & 279 & - & 293 & 293 & 297 & 298 \\
\hline $26-50$ & - & 212 & 210 & 217 & 219 & - & 262 & 260 & 265 & 269 & - & 283 & 281 & 285 & 288 \\
\hline $51-75$ & - & 200 & 199 & 204 & 210 & - & 252 & 247 & 254 & 260 & - & 272 & 270 & 276 & 279 \\
\hline $76-100$ & - & 181 & 181 & 187 & 191 & - & 237 & 233 & 238 & 247 & - & 264 & 262 & 273 & 266 \\
\hline \multicolumn{16}{|l|}{ School type } \\
\hline Public & 203 & 207 & 206 & 210 & 212 & 257 & 260 & 258 & 261 & 265 & 284 & 286 & 286 & 289 & 287 \\
\hline Traditional public & - & - & - & $\ddagger$ & 212 & - & - & - & $\ddagger$ & 265 & - & - & - & - & 288 \\
\hline Public charter & - & - & - & $\ddagger$ & 212 & - & - & - & $\ddagger$ & 268 & - & - & - & - & 260 \\
\hline Private & 222 & 226 & 227 & 227 & $\ddagger$ & 278 & 279 & 278 & $\ddagger$ & 280 & 299 & 298 & 299 & $\ddagger$ & 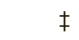 \\
\hline
\end{tabular}

- Not available.

$\ddagger$ Reporting standards not met (too few cases).

1 Testing accommodations (e.g., extended time, small group testing) for children with disabilities and English language learners were not permitted in 1994. Students were tested with and without accommodations in 2001. For the two 2001 columns, the footnoted column represents the sample without accommodations.

NOTE: The National Assessment of Educational Progress (NAEP) U.S. history scale ranges from 0 to 500 . Race categories exclude persons of Hispanic ethnicity. For more information on race/ethnicity or free or reduced-priced lunch eligibility, see Appendix C - Commonly Used Measures. For more information on NAEP, see Appendix B - Guide to Sources.

SOURCE: U.S. Department of Education, National Center for Education Statistics, National Assessment of Educational Progress (NAEP), selected years, 1994-2010 U.S. History Assessments, NAEP Data Explorer. 
Table A-25-2. Average geography scale scores, by grade and selected characteristics: Selected years, 1994-2010

\begin{tabular}{|c|c|c|c|c|c|c|c|c|c|c|c|c|}
\hline \multirow[b]{2}{*}{ Characteristic } & \multicolumn{4}{|c|}{ Grade 4} & \multicolumn{4}{|c|}{ Grade 8} & \multicolumn{4}{|c|}{ Grade 12} \\
\hline & $1994^{1}$ & $2001^{1}$ & 2001 & 2010 & $1994^{1}$ & $2001^{1}$ & 2001 & 2010 & $1994^{1}$ & $2001^{1}$ & 2001 & 2010 \\
\hline Total & 206 & 209 & 208 & 213 & 260 & 262 & 260 & 261 & 285 & 285 & 284 & 282 \\
\hline \multicolumn{13}{|l|}{ Sex } \\
\hline Male & 208 & 212 & 183 & 215 & 262 & 264 & 262 & 263 & 288 & 287 & 287 & 285 \\
\hline Female & 203 & 207 & 211 & 211 & 258 & 260 & 258 & 259 & 281 & 282 & 281 & 280 \\
\hline \multicolumn{13}{|l|}{ Race/ethnicity } \\
\hline White & 218 & 220 & 219 & 224 & 269 & 271 & 269 & 272 & 290 & 291 & 291 & 290 \\
\hline Black & 166 & 181 & 180 & 192 & 229 & 234 & 233 & 241 & 258 & 260 & 258 & 261 \\
\hline Hispanic & 177 & 183 & 185 & 197 & 238 & 239 & 237 & 244 & 269 & 269 & 268 & 270 \\
\hline Asian/Pacific Islander & 211 & 211 & 214 & 224 & 262 & 265 & 264 & 268 & 283 & 285 & 284 & 285 \\
\hline $\begin{array}{l}\text { American Indian/ } \\
\text { Alaska Native }\end{array}$ & $\ddagger$ & $\ddagger$ & $\ddagger$ & 201 & 251 & 265 & 261 & 250 & $\ddagger$ & $\ddagger$ & $\ddagger$ & 277 \\
\hline \multicolumn{13}{|l|}{ English language learner } \\
\hline Yes & $\ddagger$ & $\ddagger$ & 166 & 183 & $\ddagger$ & $\ddagger$ & 216 & 223 & $\ddagger$ & $\ddagger$ & 246 & 247 \\
\hline No & $\ddagger$ & $\ddagger$ & 210 & 216 & $\ddagger$ & $\ddagger$ & 262 & 263 & $\ddagger$ & $\ddagger$ & 285 & 283 \\
\hline \multicolumn{13}{|l|}{ Student with disability } \\
\hline Yes & $\ddagger$ & $\ddagger$ & - & 191 & $\ddagger$ & $\ddagger$ & 227 & 237 & $\ddagger$ & $\ddagger$ & 255 & 261 \\
\hline No & $\ddagger$ & $\ddagger$ & - & 216 & $\ddagger$ & $\ddagger$ & 264 & 264 & $\ddagger$ & $\ddagger$ & 286 & 284 \\
\hline \multicolumn{13}{|l|}{$\begin{array}{l}\text { Student eligibility for free or } \\
\text { reduced-price lunch }\end{array}$} \\
\hline Eligible & - & 186 & 185 & 197 & - & 242 & 239 & 246 & - & 269 & 268 & 269 \\
\hline Not eligible & - & 221 & 221 & 227 & - & 270 & 269 & 272 & - & 287 & 287 & 288 \\
\hline \multicolumn{13}{|l|}{$\begin{array}{l}\text { Percent of students in } \\
\text { school eligible for free } \\
\text { or reduced-price lunch }\end{array}$} \\
\hline $0-25$ & - & 226 & 225 & 228 & - & 274 & 274 & 276 & - & 290 & 290 & 291 \\
\hline $26-50$ & - & 214 & 213 & 219 & - & 263 & 260 & 263 & - & 282 & 281 & 282 \\
\hline $51-75$ & - & 198 & 196 & 208 & - & 248 & 245 & 257 & - & 268 & 266 & 273 \\
\hline $76-100$ & - & 176 & 178 & 189 & - & 232 & 226 & 239 & - & 260 & 258 & 260 \\
\hline \multicolumn{13}{|l|}{ School type } \\
\hline Public & 204 & 207 & 206 & 211 & 258 & 261 & 259 & 260 & 283 & 284 & 283 & 281 \\
\hline Traditional public & - & - & - & 211 & - & - & - & 260 & - & - & - & 282 \\
\hline Public charter & - & - & - & 217 & - & - & - & 258 & - & - & - & 263 \\
\hline Private & 221 & 226 & 226 & $\ddagger$ & 276 & 274 & 274 & 276 & 294 & 291 & 292 & $\ddagger$ \\
\hline
\end{tabular}

- Not available.

‡ Reporting standards not met (too few cases)

' Testing accommodations (e.g., extended time, small group testing) for children with disabilities and English language learners were not permitted in 1994. Students were tested with and without accommodations in 2001. For the two 2001 columns, the footnoted column represents the sample without accommodations.

NOTE: The National Assessment of Educational Progress (NAEP) geography scale ranges from 0 to 500 . Race categories exclude persons of Hispanic ethnicity. For more information on race/ethnicity or free or reduced-priced lunch eligibility, see Appendix C - Commonly Used Measures. For more information on NAEP, see Appendix B - Guide to Sources.

SOURCE: U.S. Department of Education, National Center for Education Statistics, National Assessment of Educational Progress (NAEP), selected years,

1994-2010 Geography Assessments, NAEP Data Explorer. 
U.S. History, Geography, and Civics Performance

Table A-25-3. Average civics scale scores, by grade and selected characteristics: Selected years, 1998-2010

\begin{tabular}{|c|c|c|c|c|c|c|c|c|c|}
\hline \multirow[b]{2}{*}{ Characteristic } & \multicolumn{3}{|c|}{ Grade 4} & \multicolumn{3}{|c|}{ Grade 8} & \multicolumn{3}{|c|}{ Grade 12} \\
\hline & 1998 & 2006 & 2010 & 1998 & 2006 & 2010 & 1998 & 2006 & 2010 \\
\hline Total & 150 & 154 & 157 & 150 & 150 & 151 & 150 & 151 & 148 \\
\hline \multicolumn{10}{|l|}{ Sex } \\
\hline Male & 149 & 153 & 153 & 148 & 149 & 150 & 148 & 150 & 148 \\
\hline Female & 151 & 155 & 160 & 152 & 151 & 152 & 152 & 152 & 148 \\
\hline \multicolumn{10}{|l|}{ Race/ethnicity } \\
\hline White & 158 & 164 & 167 & 158 & 161 & 160 & 157 & 158 & 156 \\
\hline Black & 130 & 140 & 143 & 131 & 133 & 135 & 130 & 131 & 127 \\
\hline Hispanic & 123 & 138 & 140 & 127 & 131 & 137 & 132 & 134 & 137 \\
\hline Asian/Pacific Islander & 147 & 154 & 164 & 151 & 154 & 158 & 149 & 155 & 153 \\
\hline American Indian/Alaska Native & $\ddagger$ & 124 & 143 & $\ddagger$ & 127 & 136 & $\ddagger$ & 131 & 134 \\
\hline \multicolumn{10}{|l|}{ English language learner } \\
\hline Yes & 102 & 120 & 124 & 96 & 107 & 106 & 105 & 110 & 99 \\
\hline No & 151 & 158 & 161 & 151 & 153 & 154 & 151 & 152 & 150 \\
\hline \multicolumn{10}{|l|}{ Student with disability } \\
\hline Yes & 120 & 133 & 134 & 113 & 120 & 120 & 110 & 114 & 113 \\
\hline No & 152 & 157 & 160 & 153 & 154 & 155 & 152 & 154 & 152 \\
\hline \multicolumn{10}{|l|}{$\begin{array}{l}\text { Student eligibility for free or } \\
\text { reduced-price lunch }\end{array}$} \\
\hline Eligible & 132 & 139 & 143 & 131 & 132 & 136 & 130 & 133 & 132 \\
\hline Not eligible & 160 & 166 & 169 & 157 & 160 & 163 & 153 & 156 & 155 \\
\hline \multicolumn{10}{|l|}{$\begin{array}{l}\text { Percent of students in school eligible } \\
\text { for free or reduced-price lunch }\end{array}$} \\
\hline $0-25$ & 163 & 169 & 171 & 161 & 163 & 166 & 156 & 158 & 157 \\
\hline $26-50$ & 153 & 157 & 162 & 149 & 150 & 153 & 142 & 146 & 148 \\
\hline $51-75$ & 140 & 148 & 153 & 134 & 141 & 146 & 131 & 137 & 137 \\
\hline $76-100$ & 122 & 133 & 135 & 127 & 127 & 129 & 127 & 129 & 126 \\
\hline \multicolumn{10}{|l|}{ School type } \\
\hline Public & 148 & 153 & 156 & 148 & 148 & 150 & 148 & 150 & 147 \\
\hline Traditional public & - & $\ddagger$ & 156 & - & $\ddagger$ & 150 & - & - & 148 \\
\hline Public charter & - & $\ddagger$ & 157 & - & $\ddagger$ & 155 & - & - & 121 \\
\hline Private & 164 & $\ddagger$ & $\ddagger$ & 169 & $\ddagger$ & 169 & 163 & $\ddagger$ & $\ddagger$ \\
\hline
\end{tabular}

- Not available.

$\ddagger$ Reporting standards not met (too few cases).

NOTE: The National Assessment of Educational Progress (NAEP) civics scale ranges from 0 to 300. Race categories exclude persons of Hispanic

ethnicity. For more information on race/ethnicity or free or reduced-priced lunch eligibility, see Appendix C - Commonly Used Measures. For more

information on NAEP, see Appendix B - Guide to Sources.

SOURCE: U.S. Department of Education, National Center for Education Statistics, National Assessment of Educational Progress (NAEP), selected years,

1998-2010 Civics Assessments, NAEP Data Explorer. 
Table A-25-4. Average scale scores and achievement-level results for 12th-grade students, by subject and selected characteristics: 1994, 1998, and 2010

\begin{tabular}{|c|c|c|c|c|c|c|c|c|c|c|c|c|c|c|c|c|c|c|}
\hline \multirow[b]{4}{*}{ Characteristic } & \multirow{2}{*}{\multicolumn{6}{|c|}{$\begin{array}{c}\text { U.S. History } \\
\begin{array}{c}\text { Percentage of } \\
\text { students }\end{array} \\
\end{array}$}} & \multirow{2}{*}{\multicolumn{6}{|c|}{$\begin{array}{c}\text { Geography } \\
\text { Percentage of } \\
\text { students }\end{array}$}} & \multirow{2}{*}{\multicolumn{6}{|c|}{$\begin{array}{c}\text { Civics } \\
\begin{array}{c}\text { Percentage of } \\
\text { students }\end{array}\end{array}$}} \\
\hline & & & & & & & & & & & & & & & & & & \\
\hline & \multicolumn{2}{|c|}{$\begin{array}{c}\text { Average } \\
\text { score }\end{array}$} & \multicolumn{2}{|c|}{$\begin{array}{l}\text { At or } \\
\text { above } \\
\text { Basic }\end{array}$} & \multicolumn{2}{|c|}{$\begin{array}{l}\text { At or } \\
\text { above } \\
\text { Profi- } \\
\text { cient }\end{array}$} & \multicolumn{2}{|c|}{$\begin{array}{c}\text { Average } \\
\text { score }\end{array}$} & \multicolumn{2}{|c|}{$\begin{array}{l}\text { At or } \\
\text { above } \\
\text { Basic }\end{array}$} & \multicolumn{2}{|c|}{$\begin{array}{l}\text { At or } \\
\text { above } \\
\text { Profi- } \\
\text { cient }\end{array}$} & \multicolumn{2}{|c|}{$\begin{array}{c}\text { Average } \\
\text { score }\end{array}$} & \multicolumn{2}{|c|}{$\begin{array}{c}\text { At or } \\
\text { above } \\
\text { Basic }\end{array}$} & \multicolumn{2}{|c|}{$\begin{array}{l}\text { At or } \\
\text { above } \\
\text { Profi- } \\
\text { cient }\end{array}$} \\
\hline & $1994^{1}$ & 2010 & $1994^{1}$ & 2010 & $1994^{1}$ & 2010 & $1994^{1}$ & 2010 & $1994^{1}$ & 2010 & 1994 & 2010 & 1998 & 2010 & 1998 & 2010 & 1998 & 2010 \\
\hline Total & 286 & 288 & 43 & 45 & 11 & 12 & 285 & 282 & 70 & 70 & 27 & 20 & 150 & 148 & 65 & 64 & 26 & 24 \\
\hline \multicolumn{19}{|l|}{ Sex } \\
\hline Male & 288 & 290 & 45 & 49 & 12 & 14 & 288 & 285 & 73 & 73 & 32 & 23 & 148 & 148 & 62 & 63 & 27 & 25 \\
\hline Female & 285 & 286 & 40 & 41 & 9 & 10 & 281 & 280 & 67 & 66 & 22 & 17 & 152 & 148 & 68 & 64 & 26 & 22 \\
\hline \multicolumn{19}{|l|}{ Race/ethnicity } \\
\hline White & 292 & 296 & 50 & 55 & 13 & 15 & 290 & 290 & 78 & 81 & 32 & 27 & 157 & 156 & 73 & 73 & 32 & 30 \\
\hline Black & 265 & 268 & 17 & 20 & 2 & 3 & 258 & 261 & 33 & 36 & 5 & 3 & 130 & 127 & 41 & 38 & 9 & 8 \\
\hline Hispanic & 267 & 275 & 22 & 28 & 4 & 5 & 269 & 270 & 48 & 52 & 10 & 8 & 132 & 137 & 45 & 50 & 10 & 13 \\
\hline $\begin{array}{c}\text { Asian/Pacific } \\
\text { Islander }\end{array}$ & 283 & 293 & 40 & 50 & 12 & 17 & 283 & 285 & 67 & 73 & 26 & 23 & 149 & 153 & 63 & 70 & 27 & 29 \\
\hline $\begin{array}{l}\text { American Indian/ } \\
\text { Alaska Native }\end{array}$ & 272 & 278 & 21 & 29 & 3 & 3 & $\ddagger$ & 277 & $\ddagger$ & 62 & $\ddagger$ & 13 & $\ddagger$ & 134 & $\ddagger$ & 47 & $\ddagger$ & 16 \\
\hline \multicolumn{19}{|l|}{$\begin{array}{l}\text { English language } \\
\text { learner }\end{array}$} \\
\hline Yes & $\ddagger$ & 244 & $\ddagger$ & 3 & $\ddagger$ & \# & $\ddagger$ & 247 & $\ddagger$ & 18 & $\ddagger$ & $\#$ & 105 & 99 & 16 & 11 & 3 & \# \\
\hline No & $\ddagger$ & 290 & $\ddagger$ & 47 & $\ddagger$ & 13 & $\ddagger$ & 283 & $\ddagger$ & 71 & $\ddagger$ & 21 & 151 & 150 & 66 & 66 & 27 & 25 \\
\hline \multicolumn{19}{|l|}{ Student with disability } \\
\hline Yes & $\ddagger$ & 263 & $\ddagger$ & 19 & $\ddagger$ & 4 & $\ddagger$ & 261 & $\ddagger$ & 39 & $\ddagger$ & 6 & 110 & 113 & 22 & 24 & 5 & 6 \\
\hline No & $\ddagger$ & 291 & $\ddagger$ & 47 & $\ddagger$ & 13 & $\ddagger$ & 284 & $\ddagger$ & 73 & $\ddagger$ & 21 & 152 & 152 & 67 & 68 & 27 & 26 \\
\hline \multicolumn{19}{|l|}{$\begin{array}{l}\text { Student eligibility for } \\
\text { free or reduced- } \\
\text { price lunch }\end{array}$} \\
\hline Eligible & - & 273 & - & 25 & - & 4 & - & 269 & - & 50 & - & 7 & 130 & 132 & 42 & 44 & 10 & 11 \\
\hline Not eligible & - & 294 & - & 53 & - & 15 & - & 288 & - & 78 & - & 26 & 153 & 155 & 69 & 72 & 29 & 29 \\
\hline \multicolumn{19}{|l|}{$\begin{array}{l}\text { Percent of students in- } \\
\text { school eligible for } \\
\text { free or reduced- } \\
\text { price lunch }\end{array}$} \\
\hline $0-25$ & - & 298 & - & 57 & - & 17 & - & 291 & - & 82 & - & 29 & 156 & 157 & - & 74 & - & 32 \\
\hline $26-50$ & - & 288 & - & 43 & - & 10 & - & 282 & - & 70 & - & 18 & 142 & 148 & - & 64 & - & 22 \\
\hline $51-75$ & - & 279 & - & 32 & - & 7 & - & 273 & - & 58 & - & 9 & 131 & 137 & - & 50 & - & 14 \\
\hline $76-100$ & - & 266 & - & 17 & - & 2 & - & 260 & - & 36 & - & 3 & 127 & 126 & - & 37 & - & 8 \\
\hline \multicolumn{19}{|l|}{ School type } \\
\hline Public & 284 & 287 & 41 & 43 & 10 & 11 & 283 & 281 & 68 & 68 & 26 & 19 & 148 & 147 & 63 & 63 & 25 & 23 \\
\hline Traditional public & - & 288 & - & 44 & - & 11 & - & 282 & - & 69 & - & 19 & - & 148 & - & 63 & - & 23 \\
\hline Public charter & - & 260 & - & 16 & - & 3 & - & 263 & - & 41 & - & 4 & - & 121 & - & 35 & - & 9 \\
\hline Private & 299 & $\ddagger$ & 59 & $\ddagger$ & 18 & $\ddagger$ & 294 & $\ddagger$ & 83 & $\ddagger$ & 36 & $\ddagger$ & 163 & $\ddagger$ & 80 & $\ddagger$ & 38 & $\ddagger$ \\
\hline
\end{tabular}

- Not available.

\# Rounds to zero.

$\ddagger$ Reporting standards not met (too few cases)

1 Testing accommodations (e.g., extended time, small group testing) for children with disabilities and English language learners were not permitted in 1994.

NOTE: The National Assessment of Educational Progress (NAEP) U.S. history and geography scores range from 0 to 500 ; civics scores range from 0 to 300. The achievement levels define what students should know and be able to do. Basic indicates partial mastery of fundamental skills, and Proficient indicates demonstrated competency over challenging subject matter. Race categories exclude persons of Hispanic ethnicity. For more information on race/ethnicity or free or reduced-priced lunch eligibility, see Appendix C - Commonly Used Measures. For more information on NAEP, see Appendix B - Guide to Sources.

SOURCE: U.S. Department of Education, National Center for Education Statistics, National Assessment of Educational Progress (NAEP), 1994 and 2010 U.S. History Assessments, 1994 and 2010 Geography Assessments, 1998 and 2010 Civics Assessments, NAEP Data Explorer. 


\section{International Reading, Mathematics, and Science Proficiency}

Table A-26-1. Percentage of 15-year-old students scoring at selected Program for International Student Assessment proficiency levels on the combined reading literacy scale, by country: 2000 and 2009

\begin{tabular}{|c|c|c|c|c|c|c|}
\hline \multirow[b]{2}{*}{ Country } & \multicolumn{2}{|c|}{ Percent in 2000} & \multicolumn{2}{|c|}{ Percent in 2009} & \multicolumn{2}{|c|}{$\begin{array}{l}\text { Percentage point change } \\
\text { (PISA 2009 - PISA 2000) }\end{array}$} \\
\hline & $\begin{array}{l}\text { Below } \\
\text { level } 2\end{array}$ & $\begin{array}{r}\text { Level } 5 \\
\text { and above } \\
\end{array}$ & $\begin{array}{l}\text { Below } \\
\text { level } 2\end{array}$ & $\begin{array}{r}\text { Level } 5 \\
\text { and above } \\
\end{array}$ & $\begin{array}{l}\text { Below } \\
\text { level } 2\end{array}$ & $\begin{array}{r}\text { Level } 5 \\
\text { and above } \\
\end{array}$ \\
\hline OECD average ${ }^{\prime}$ & 19.3 & 8.9 & 18.8 & 7.6 & $t$ & $t$ \\
\hline OECD trend average ${ }^{2}$ & 19.3 & 8.9 & 18.5 & 8.1 & $-0.8 *$ & $-0.9 *$ \\
\hline \multicolumn{7}{|l|}{ OECD countries } \\
\hline Australia & 12.5 & 17.6 & 14.2 & 12.8 & 1.8 & $-4.9 *$ \\
\hline Austria & 19.3 & 7.5 & 27.6 & 4.9 & $8.3^{*}$ & $-2.6 *$ \\
\hline Belgium & 19.0 & 12.0 & 17.7 & 11.2 & -1.2 & -0.8 \\
\hline Canada & 9.6 & 16.8 & 10.3 & 12.8 & 0.7 & $-4.0 *$ \\
\hline Chile & 48.2 & 0.5 & 30.6 & 1.3 & $-17.6 *$ & $0.8^{*}$ \\
\hline Czech Republic & 17.5 & 7.0 & 23.1 & 5.1 & $5.6^{*}$ & $-1.9 *$ \\
\hline Denmark & 17.9 & 8.1 & 15.2 & 4.7 & $-2.7^{*}$ & $-3.4 *$ \\
\hline Estonia $^{2}$ & - & - & 13.3 & 6.1 & $\dagger$ & $\dagger$ \\
\hline Finland & 7.0 & 18.5 & 8.1 & 14.5 & 1.2 & $-4.0 *$ \\
\hline France & 15.2 & 8.5 & 19.8 & 9.6 & $4.6^{*}$ & 1.1 \\
\hline Germany & 22.6 & 8.8 & 18.5 & 7.6 & $-4.2 *$ & -1.2 \\
\hline Greece & 24.4 & 5.0 & 21.3 & 5.6 & -3.1 & 0.6 \\
\hline Hungary & 22.7 & 5.1 & 17.6 & 6.1 & $-5.1 *$ & 1.0 \\
\hline Iceland & 14.5 & 9.1 & 16.8 & 8.5 & $2.3^{*}$ & -0.5 \\
\hline Ireland & 11.0 & 14.2 & 17.2 & 7.0 & $6.2 *$ & $-7.3 *$ \\
\hline Israel & 33.2 & 4.2 & 26.5 & 7.4 & -6.7 & $3.3^{*}$ \\
\hline Italy & 18.9 & 5.3 & 21.0 & 5.8 & 2.1 & 0.5 \\
\hline Japan & 10.1 & 9.9 & 13.6 & 13.4 & 3.5 & $3.6^{*}$ \\
\hline Korea, Republic of & 5.8 & 5.7 & 5.8 & 12.9 & $\#$ & $7.2 *$ \\
\hline Luxembourg $^{2}$ & - & - & 26.0 & 5.7 & $\dagger$ & $\dagger$ \\
\hline Mexico & 44.1 & 0.9 & 40.1 & 0.4 & $-4.0 *$ & -0.5 \\
\hline Netherlands ${ }^{2}$ & $\ddagger$ & $\ddagger$ & 14.3 & 9.8 & $\dagger$ & $\dagger$ \\
\hline New Zealand & 13.7 & 18.7 & 14.3 & 15.7 & 0.6 & $-3.0 *$ \\
\hline Norway & 17.5 & 11.2 & 15.0 & 8.4 & -2.5 & $-2.8 *$ \\
\hline Poland & 23.2 & 5.9 & 15.0 & 7.2 & $-8.2^{*}$ & 1.3 \\
\hline Portugal & 26.3 & 4.2 & 17.6 & 4.8 & $-8.6^{*}$ & 0.6 \\
\hline Slovak Republic ${ }^{2}$ & - & - & 22.2 & 4.5 & $\dagger$ & $\dagger$ \\
\hline Slovenia ${ }^{2}$ & - & - & 21.2 & 4.6 & $\dagger$ & $\dagger$ \\
\hline Spain & 16.3 & 4.2 & 19.6 & 3.3 & $3.3^{*}$ & -0.9 \\
\hline Sweden & 12.6 & 11.2 & 17.4 & 9.0 & $4.9 *$ & $-2.2 *$ \\
\hline Switzerland & 20.4 & 9.2 & 16.8 & 8.1 & $-3.6^{*}$ & -1.1 \\
\hline Turkey² & - & - & 24.5 & 1.9 & $\dagger$ & $\dagger$ \\
\hline United Kingdom² & $\ddagger$ & $\ddagger$ & 18.4 & 8.0 & $\dagger$ & $\dagger$ \\
\hline United States & 17.9 & 12.2 & 17.6 & 9.9 & -0.3 & -2.4 \\
\hline
\end{tabular}

See notes at end of table. 
Table A-26-1. Percentage of 15-year-old students scoring at selected Program for International Student Assessment proficiency levels on the combined reading literacy scale, by country: 2000 and 2009-Continued

\begin{tabular}{|c|c|c|c|c|c|c|}
\hline \multirow[b]{2}{*}{ Country } & \multicolumn{2}{|c|}{ Percent in 2000} & \multicolumn{2}{|c|}{ Percent in 2009} & \multicolumn{2}{|c|}{$\begin{array}{l}\text { Percentage point change } \\
\text { (PISA 2009 - PISA 2000) }\end{array}$} \\
\hline & $\begin{array}{l}\text { Below } \\
\text { level } 2\end{array}$ & $\begin{array}{r}\text { Level } 5 \\
\text { and above }\end{array}$ & $\begin{array}{l}\text { Below } \\
\text { level } 2\end{array}$ & $\begin{array}{r}\text { Level } 5 \\
\text { and above }\end{array}$ & $\begin{array}{l}\text { Below } \\
\text { level } 2\end{array}$ & $\begin{array}{r}\text { Level } 5 \\
\text { and above }\end{array}$ \\
\hline \multicolumn{7}{|l|}{ Non-OECD countries } \\
\hline Albania & 70.4 & $\ddagger$ & 56.7 & $\ddagger$ & $-13.7^{*}$ & $\dagger$ \\
\hline Argentina & 43.9 & 1.7 & 51.6 & 1.0 & 7.7 & -0.7 \\
\hline Azerbaijan & - & - & 72.8 & $\#$ & $\dagger$ & $\dagger$ \\
\hline Brazil & 55.8 & $\ddagger$ & 49.6 & 1.3 & $-6.2 *$ & $\dagger$ \\
\hline Bulgaria & 40.3 & 2.2 & 41.0 & 2.8 & 0.7 & 0.6 \\
\hline Chinese Taipei & - & - & 15.6 & 5.2 & $\dagger$ & $\dagger$ \\
\hline Colombia & - & - & 47.1 & 0.6 & $\dagger$ & $\dagger$ \\
\hline Croatia & - & - & 22.4 & 3.2 & $\dagger$ & $\dagger$ \\
\hline Dubai-UAE & - & - & 31.0 & 5.3 & $\dagger$ & $\dagger$ \\
\hline Hong Kong-China & 9.1 & 9.5 & 8.3 & 12.4 & -0.8 & $2.9 *$ \\
\hline Indonesia & 68.7 & \# & 53.4 & \# & $-15.2 *$ & $\#$ \\
\hline Jordan & - & - & 48.0 & 0.2 & $\dagger$ & $\dagger$ \\
\hline Kazakhstan & - & - & 58.7 & 0.4 & $\dagger$ & $\dagger$ \\
\hline Kyrgyz Republic & - & - & 83.2 & $\ddagger$ & $\dagger$ & $\dagger$ \\
\hline Latvia & 30.1 & 4.2 & 17.6 & 2.9 & $-12.5 *$ & -1.2 \\
\hline Liechtenstein & 22.1 & 5.1 & 15.7 & 4.6 & $-6.4^{*}$ & -0.4 \\
\hline Lithuania & - & - & 24.4 & 2.9 & $\dagger$ & $\dagger$ \\
\hline Macao-China & - & - & 14.9 & 2.9 & $\dagger$ & $\dagger$ \\
\hline Montenegro, Republic of & - & - & 49.5 & 0.6 & $\dagger$ & $\dagger$ \\
\hline Panama & - & - & 65.3 & 0.5 & $\dagger$ & $\dagger$ \\
\hline Peru & 79.5 & $\ddagger$ & 64.8 & 0.5 & $-14.8 *$ & $\dagger$ \\
\hline Qatar & - & - & 63.5 & 1.7 & $\dagger$ & $\dagger$ \\
\hline Romania & 41.3 & 2.2 & 40.4 & 0.7 & -0.9 & $-1.5 *$ \\
\hline Russian Federation & 27.4 & 3.2 & 27.4 & 3.2 & -0.1 & $\#$ \\
\hline Serbia, Republic of & - & - & 32.8 & 0.8 & $\dagger$ & $\dagger$ \\
\hline Shanghai-China & - & - & 4.1 & 19.5 & $\dagger$ & $\dagger$ \\
\hline Singapore & - & - & 12.5 & 15.7 & $\dagger$ & $\dagger$ \\
\hline Thailand & 37.1 & $\ddagger$ & 42.9 & $\ddagger$ & $5.8^{*}$ & $\dagger$ \\
\hline Trinidad and Tobago & - & - & 44.8 & 2.3 & $\dagger$ & $\dagger$ \\
\hline Tunisia & - & - & 50.2 & $\ddagger$ & $\dagger$ & $\dagger$ \\
\hline Uruguay & - & - & 41.9 & 1.8 & $\dagger$ & $\dagger$ \\
\hline
\end{tabular}

- Not available.

† Not applicable.

\# Rounds to zero.

$\ddagger$ Reporting standards not met (too few cases)

$* p<.05$. Significant percentage point change from 2000 to 2009 at the .05 level of statistical significance.

1 The Organization for Economic Co-operation and Development (OECD) average is based on 34 OECD countries in 2009 and 27 OECD countries in 2000.

2 The OECD trend average used for the analysis of reading literacy trends is based on the averages of 27 OECD countries with comparable data for 2000 and 2009, with each country weighted equally. The seven current OECD members not included in the OECD average used to report on trends in reading literacy were the Slovak Republic, Turkey, Estonia, and Slovenia, which did not participate in the 2000 Program for International Student Assessment (PISA); Luxembourg, which experienced substantial changes in its assessment conditions between 2000 and 2003 ; and the Netherlands and the United Kingdom, which did not meet the PISA response rate standards in 2000.

NOTE: Proficiency in reading was defined in terms of levels based on student performance scores on each reading literacy scale. Reading literacy was assessed along a continuum, with proficiency below level 2 indicative of the low-performing students and proficiency level 5 and above indicative of the high-performing students. In reading, proficiency below level 2 is defined by scoring below 407 , and proficiency at level 5 and above is defined by scoring 626 and above. Scores are reported on a scale from 0 to 1,000. Because PISA is principally an OECD study, the results for non-OECD countries are displayed separately from those of the OECD countries and are not included in the OECD average. Italics indicate education systems in nonnational entities. UAE is the United Arab Emirates. For more information on PISA, see Appendix B - Guide to Sources.

SOURCE: Fleischman, H.L., Hopstock, P.J., Pelczar, M.P., and Shelley, B.E. (2010). Highlights From PISA 2009: Performance of U.S. 15-Year-Old Students in Reading, Mathematics, and Science Literacy in an International Context (NCES 2011-004), table R7A; OECD. (2010). PISA 2009 Results: Learning Trends Changes in Student Performance Since 2000 (Volume V), table V.2.2; and OECD, previously unpublished tabulations (October 2011). 


\section{International Reading, Mathematics, and Science Proficiency}

Table A-26-2. Percentage of 15-year-old students scoring at selected PISA proficiency levels on the mathematics literacy scale, by country: 2003 and 2009

\begin{tabular}{|c|c|c|c|c|c|c|}
\hline \multirow[b]{2}{*}{ Country } & \multicolumn{2}{|c|}{ Percent in 2003} & \multicolumn{2}{|c|}{ Percent in 2009} & \multicolumn{2}{|c|}{$\begin{array}{c}\text { Percentage point change } \\
\text { (PISA 2009 - PISA 2003) }\end{array}$} \\
\hline & $\begin{array}{l}\text { Below } \\
\text { level } 2\end{array}$ & $\begin{array}{r}\text { Level } 5 \\
\text { and above }\end{array}$ & $\begin{array}{l}\text { Below } \\
\text { level } 2\end{array}$ & $\begin{array}{r}\text { Level } 5 \\
\text { and above }\end{array}$ & $\begin{array}{l}\text { Below } \\
\text { level } 2\end{array}$ & $\begin{array}{r}\text { Level } 5 \\
\text { and above }\end{array}$ \\
\hline OECD average ${ }^{1}$ & 20.8 & 14.6 & 22.0 & 12.7 & $\dagger$ & $t$ \\
\hline OECD trend average ${ }^{2}$ & 20.8 & 14.6 & 22.1 & 12.8 & $1.3 *$ & $-1.8 *$ \\
\hline \multicolumn{7}{|l|}{ OECD countries } \\
\hline Australia & 14.3 & 19.8 & 15.9 & 16.4 & 1.5 & $-3.3 *$ \\
\hline Austria & 18.8 & 14.3 & 23.2 & 12.9 & $4.5^{*}$ & -1.3 \\
\hline Belgium & 16.5 & 26.4 & 19.1 & 20.4 & $2.6^{*}$ & $-6.1^{*}$ \\
\hline Canada & 10.1 & 20.3 & 11.5 & 18.3 & 1.4 & $-2.0 *$ \\
\hline Chile $^{2}$ & - & - & 51.0 & 1.3 & $\dagger$ & $\dagger$ \\
\hline Czech Republic & 16.6 & 18.3 & 22.3 & 11.6 & $5.8 *$ & $-6.6 *$ \\
\hline Denmark & 15.4 & 15.9 & 17.1 & 11.6 & 1.6 & $-4.4^{*}$ \\
\hline Estonia $^{2}$ & - & - & 12.6 & 12.1 & $\dagger$ & $\dagger$ \\
\hline Finland & 6.8 & 23.4 & 7.8 & 21.7 & 1.1 & -1.7 \\
\hline France & 16.6 & 15.1 & 22.5 & 13.7 & $5.9 *$ & -1.4 \\
\hline Germany & 21.6 & 16.2 & 18.6 & 17.8 & -3.0 & 1.6 \\
\hline Greece & 38.9 & 4.0 & 30.3 & 5.7 & $-8.6 *$ & $1.7^{*}$ \\
\hline Hungary & 23.0 & 10.7 & 22.3 & 10.1 & -0.7 & -0.6 \\
\hline Iceland & 15.0 & 15.5 & 17.0 & 13.6 & $2.0^{*}$ & $-1.9 *$ \\
\hline Ireland & 16.8 & 11.4 & 20.8 & 6.7 & $4.0^{*}$ & $-4.7^{*}$ \\
\hline$|s r a e|^{2}$ & - & - & 39.5 & 5.9 & $\dagger$ & $\dagger$ \\
\hline Italy & 31.9 & 7.0 & 24.9 & 9.0 & $-7.0 *$ & $1.9 *$ \\
\hline Japan & 13.3 & 24.3 & 12.5 & 20.9 & -0.8 & -3.4 \\
\hline Korea, Republic of & 9.5 & 24.8 & 8.1 & 25.6 & -1.4 & 0.8 \\
\hline Luxembourg & 21.7 & 10.8 & 23.9 & 11.4 & $2.2^{*}$ & 0.5 \\
\hline Mexico & 65.9 & 0.4 & 50.8 & 0.7 & $-15.1 *$ & $0.3^{*}$ \\
\hline Netherlands & 10.9 & 25.5 & 13.4 & 19.9 & 2.5 & $-5.6 *$ \\
\hline New Zealand & 15.1 & 20.7 & 15.4 & 18.9 & 0.3 & -1.8 \\
\hline Norway & 20.8 & 11.4 & 18.2 & 10.2 & -2.7 & -1.2 \\
\hline Poland & 22.0 & 10.1 & 20.5 & 10.4 & -1.6 & 0.3 \\
\hline Portugal & 30.1 & 5.4 & 23.7 & 9.6 & $-6.4^{*}$ & $4.3^{*}$ \\
\hline Slovak Republic & 19.9 & 12.7 & 21.0 & 12.7 & 1.1 & $\#$ \\
\hline Slovenia ${ }^{2}$ & - & - & 20.3 & 14.2 & $\dagger$ & $\dagger$ \\
\hline Spain & 23.0 & 7.9 & 23.7 & 8.0 & 0.8 & 0.1 \\
\hline Sweden & 17.3 & 15.8 & 21.1 & 11.4 & $3.8^{*}$ & $-4.4 *$ \\
\hline Switzerland & 14.5 & 21.2 & 13.5 & 24.1 & -1.1 & 2.9 \\
\hline Turkey & 52.2 & 5.5 & 42.1 & 5.6 & $-10.1 *$ & 0.2 \\
\hline United Kingdom² & $\ddagger$ & $\ddagger$ & 20.2 & 9.8 & $\dagger$ & $\dagger$ \\
\hline United States & 25.7 & 10.1 & 23.4 & 9.9 & -2.3 & -0.2 \\
\hline
\end{tabular}

\footnotetext{
See notes at end of table.
} 
Table A-26-2. Percentage of 15-year-old students scoring at selected PISA proficiency levels on the mathematics literacy scale, by country: 2003 and 2009-Continued

\begin{tabular}{|c|c|c|c|c|c|c|}
\hline \multirow[b]{2}{*}{ Country } & \multicolumn{2}{|c|}{ Percent in 2003} & \multicolumn{2}{|c|}{ Percent in 2009} & \multicolumn{2}{|c|}{$\begin{array}{l}\text { Percentage point change } \\
\text { (PISA 2009 - PISA 2003) }\end{array}$} \\
\hline & $\begin{array}{l}\text { Below } \\
\text { level } 2\end{array}$ & $\begin{array}{r}\text { Level } 5 \\
\text { and above }\end{array}$ & $\begin{array}{l}\text { Below } \\
\text { level } 2\end{array}$ & $\begin{array}{r}\text { Level } 5 \\
\text { and above }\end{array}$ & $\begin{array}{l}\text { Below } \\
\text { level } 2\end{array}$ & $\begin{array}{r}\text { Level } 5 \\
\text { and above }\end{array}$ \\
\hline \multicolumn{7}{|l|}{ Non-OECD countries } \\
\hline Albania & - & - & 67.7 & 0.4 & $\dagger$ & $\dagger$ \\
\hline Argentina & - & - & 63.6 & 0.9 & $\dagger$ & $\dagger$ \\
\hline Azerbaijan & - & - & 45.3 & 1.1 & $\dagger$ & $\dagger$ \\
\hline Brazil & 75.2 & 1.2 & 69.1 & 0.8 & $-6.0 *$ & -0.4 \\
\hline Bulgaria & - & - & 47.1 & 3.8 & $\dagger$ & $\dagger$ \\
\hline Chinese Taipei & - & - & 12.8 & 28.6 & $\dagger$ & $\dagger$ \\
\hline Colombia & - & - & 70.4 & $\ddagger$ & $\dagger$ & $\dagger$ \\
\hline Croatia & - & - & 33.2 & 4.9 & $\dagger$ & $\dagger$ \\
\hline Dubai-UAE & - & - & 38.8 & 6.5 & $\dagger$ & $\dagger$ \\
\hline Hong Kong-China & 10.4 & 30.7 & 8.8 & 30.7 & -1.6 & $\#$ \\
\hline Indonesia & 78.1 & $\ddagger$ & 76.7 & $\ddagger$ & -1.5 & $\dagger$ \\
\hline Jordan & - & - & 65.3 & $\ddagger$ & $\dagger$ & $\dagger$ \\
\hline Kazakhstan & - & - & 59.1 & 1.2 & $\dagger$ & $\dagger$ \\
\hline Kyrgyz Republic & - & - & 86.6 & \# & $\dagger$ & $\dagger$ \\
\hline Latvia & 23.7 & 8.0 & 22.6 & 5.7 & -1.2 & $-2.3 *$ \\
\hline Liechtenstein & 12.3 & 25.6 & 9.5 & 18.1 & -2.8 & -7.6 \\
\hline Lithuania & - & - & 26.3 & 7.0 & $\dagger$ & $\dagger$ \\
\hline Macao-China & 11.2 & 18.7 & 11.0 & 17.1 & -0.2 & -1.5 \\
\hline Montenegro, Republic of ${ }^{3}$ & - & - & 58.4 & 1.0 & $\dagger$ & $\dagger$ \\
\hline Panama & - & - & 78.8 & $\ddagger$ & $\dagger$ & $\dagger$ \\
\hline Peru & - & - & 73.5 & 0.6 & $\dagger$ & $\dagger$ \\
\hline Qatar & - & - & 73.8 & 1.8 & $\dagger$ & $\dagger$ \\
\hline Romania & - & - & 47.0 & 1.3 & $\dagger$ & $\dagger$ \\
\hline Russian Federation & 30.2 & 7.0 & 28.6 & 5.2 & -1.6 & -1.8 \\
\hline Serbia, Republic of ${ }^{3}$ & 42.1 & 2.3 & 40.6 & 3.5 & -1.5 & 1.2 \\
\hline Shanghai-China & - & - & 4.9 & 50.4 & $\dagger$ & $\dagger$ \\
\hline Singapore & - & - & 9.8 & 35.6 & $\dagger$ & $\dagger$ \\
\hline Thailand & 54.0 & 1.6 & 52.5 & 1.3 & -1.4 & -0.4 \\
\hline Trinidad and Tobago & - & - & 53.2 & 2.5 & $\dagger$ & $\dagger$ \\
\hline Tunisia & 78.0 & $\ddagger$ & 73.6 & $\ddagger$ & $-4.4^{*}$ & $\dagger$ \\
\hline Uruguay & 48.1 & 2.8 & 47.6 & 2.4 & -0.5 & -0.4 \\
\hline
\end{tabular}

- Not available.

† Not applicable.

\# Rounds to zero.

$\ddagger$ Reporting standards not met (too few cases).

* $p<.05$. Significant percentage point change from 2003 to 2009 at the .05 level of statistical significance.

1 The Organization for Economic Co-operation and Development (OECD) average is based on 34 OECD countries in 2009 and 29 OECD countries in 2003.

2 The OECD trend average used for the analysis of mathematics literacy trends is based on the averages of the 29 OECD countries with comparable data for 2003 and 2009, with each country weighted equally. The five current OECD members not included in the OECD averages used to report on trends in mathematics literacy were Chile, Estonia, Israel, and Slovenia, which did not participate in 2003; and the United Kingdom, which did not meet the Program for International Student Assessment (PISA) response rate standards for the 2003 assessment.

${ }^{3}$ The Republics of Montenegro and Serbia were a united country under the PISA 2003 assessment.

NOTE: Proficiency in mathematics was defined in terms of levels based on student performance scores on each mathematics literacy scale. Mathematics literacy was assessed along a continuum, with proficiency below level 2 indicative of the low-performing students and proficiency level 5 and above indicative of the high-performing students. In mathematics, proficiency below level 2 is defined by scoring below 420 , and proficiency level 5 and above is defined by scoring 607 and above. Scores are reported on a scale from 0 to 1,000. Because PISA is principally an OECD study, the results for non-OECD countries are displayed separately from those of the OECD countries and are not included in the OECD average. Italics indicate education systems in non-national entities. UAE is the United Arab Emirates. For more information on PISA, see Appendix B - Guide to Sources. SOURCE: Fleischman, H.L., Hopstock, P.J., Peczar, M.P., and Shelley, B.E. (2010). Highlights From PISA 2009: Performance of U.S. 15-Year-Old Students in Reading, Mathematics, and Science Literacy in an International Context (NCES 2011-004), table M4A; OECD. (2010). PISA 2009 Results: Learning Trends Changes in Student Performance Since 2000 (Volume V), table V.3.2; and OECD, previously unpublished tabulations (October 2011). 

Proficiency

Table A-26-3. Percentage of 15-year-old students scoring at selected PISA proficiency levels on the science literacy scale, by country: 2006 and 2009

\begin{tabular}{|c|c|c|c|c|c|c|}
\hline \multirow[b]{2}{*}{ Country } & \multicolumn{2}{|c|}{ Percent in 2006} & \multicolumn{2}{|c|}{ Percent in 2009} & \multicolumn{2}{|c|}{$\begin{array}{c}\text { Percentage point change } \\
\text { (PISA } 2009 \text { - PISA 2006) }\end{array}$} \\
\hline & $\begin{array}{l}\text { Below } \\
\text { level } 2\end{array}$ & $\begin{array}{r}\text { Level } 5 \\
\text { and above }\end{array}$ & $\begin{array}{l}\text { Below } \\
\text { level } 2\end{array}$ & $\begin{array}{r}\text { Level } 5 \\
\text { and above }\end{array}$ & $\begin{array}{l}\text { Below } \\
\text { level } 2\end{array}$ & $\begin{array}{r}\text { Level } 5 \\
\text { and above }\end{array}$ \\
\hline OECD average ${ }^{1}$ & 19.8 & 8.9 & 18.0 & 8.5 & $-1.9 *$ & $-0.4^{*}$ \\
\hline \multicolumn{7}{|l|}{ OECD countries } \\
\hline Australia & 12.9 & 14.6 & 12.6 & 14.5 & -0.3 & -0.1 \\
\hline Austria & 16.3 & 10.0 & 20.9 & 8.0 & $4.6 *$ & $-1.9 *$ \\
\hline Belgium & 17.0 & 10.1 & 18.0 & 10.1 & 1.0 & $\#$ \\
\hline Canada & 10.0 & 14.4 & 9.6 & 12.1 & -0.5 & $-2.3 *$ \\
\hline Chile & 39.7 & 1.9 & 32.3 & 1.1 & $-7.4^{*}$ & $-0.8 *$ \\
\hline Czech Republic & 15.5 & 11.6 & 17.3 & 8.4 & 1.8 & $-3.2 *$ \\
\hline Denmark & 18.4 & 6.8 & 16.6 & 6.7 & -1.9 & -0.1 \\
\hline Estonia & 7.7 & 11.5 & 8.3 & 10.4 & 0.7 & -1.1 \\
\hline Finland & 4.1 & 20.9 & 6.0 & 18.7 & $1.9 *$ & -2.2 \\
\hline France & 21.2 & 8.0 & 19.3 & 8.1 & -1.9 & 0.1 \\
\hline Germany & 15.4 & 11.8 & 14.8 & 12.8 & -0.6 & 1.0 \\
\hline Greece & 24.0 & 3.4 & 25.3 & 3.1 & 1.2 & -0.4 \\
\hline Hungary & 15.0 & 6.9 & 14.1 & 5.4 & -0.9 & -1.5 \\
\hline Iceland & 20.6 & 6.3 & 17.9 & 7.0 & $-2.6 *$ & 0.6 \\
\hline Ireland & 15.5 & 9.4 & 15.2 & 8.7 & -0.3 & -0.7 \\
\hline Israel & 36.1 & 5.2 & 33.1 & 3.9 & -3.0 & -1.3 \\
\hline Italy & 25.3 & 4.6 & 20.6 & 5.8 & $-4.6 *$ & $1.2 *$ \\
\hline Japan & 12.0 & 15.1 & 10.7 & 16.9 & -1.4 & 1.9 \\
\hline Korea, Republic of & 11.2 & 10.3 & 6.3 & 11.6 & $-4.9 *$ & 1.3 \\
\hline Luxembourg & 22.1 & 5.9 & 23.7 & 6.7 & 1.6 & 0.8 \\
\hline Mexico & 50.9 & 0.3 & 47.4 & 0.2 & $-3.6 *$ & -0.1 \\
\hline Netherlands & 13.0 & 13.1 & 13.2 & 12.7 & 0.2 & -0.4 \\
\hline New Zealand & 13.7 & 17.6 & 13.4 & 17.6 & -0.3 & $\#$ \\
\hline Norway & 21.1 & 6.1 & 15.8 & 6.4 & $-5.3 *$ & 0.3 \\
\hline Poland & 17.0 & 6.8 & 13.1 & 7.5 & $-3.8 *$ & 0.8 \\
\hline Portugal & 24.5 & 3.1 & 16.5 & 4.2 & $-8.0 *$ & 1.0 \\
\hline Slovak Republic & 20.2 & 5.8 & 19.3 & 6.2 & -0.9 & 0.5 \\
\hline Slovenia & 13.9 & 12.9 & 14.8 & 9.9 & 0.9 & $-3.0 *$ \\
\hline Spain & 19.6 & 4.9 & 18.2 & 4.0 & -1.4 & -0.9 \\
\hline Sweden & 16.4 & 7.9 & 19.1 & 8.1 & $2.8 *$ & 0.2 \\
\hline Switzerland & 16.1 & 10.5 & 14.0 & 10.7 & -2.0 & 0.3 \\
\hline Turkey & 46.6 & 0.9 & 30.0 & 1.1 & $-16.6 *$ & 0.2 \\
\hline United Kingdom & 16.7 & 13.7 & 15.0 & 11.4 & -1.7 & $-2.4 *$ \\
\hline United States & 24.4 & 9.1 & 18.1 & 9.2 & $-6.3 *$ & 0.1 \\
\hline
\end{tabular}

See notes at end of table. 
Table A-26-3. Percentage of 15-year-old students scoring at selected PISA proficiency levels on the science literacy scale, by country: 2006 and $2009-$ Continued

\begin{tabular}{|c|c|c|c|c|c|c|}
\hline \multirow[b]{2}{*}{ Country } & \multicolumn{2}{|c|}{ Percent in 2006} & \multicolumn{2}{|c|}{ Percent in 2009} & \multicolumn{2}{|c|}{$\begin{array}{c}\text { Percentage point change } \\
\text { (PISA 2009 - PISA 2006) }\end{array}$} \\
\hline & $\begin{array}{l}\text { Below } \\
\text { level } 2 \\
\end{array}$ & $\begin{array}{r}\text { Level } 5 \\
\text { and above } \\
\end{array}$ & $\begin{array}{l}\text { Below } \\
\text { level } 2\end{array}$ & $\begin{array}{r}\text { Level } 5 \\
\text { and above } \\
\end{array}$ & $\begin{array}{l}\text { Below } \\
\text { level } 2 \\
\end{array}$ & $\begin{array}{r}\text { Level } 5 \\
\text { and above } \\
\end{array}$ \\
\hline \multicolumn{7}{|l|}{ Non-OECD countries } \\
\hline Albania & - & - & 57.3 & $\ddagger$ & $\dagger$ & $\dagger$ \\
\hline Argentina & 56.3 & $\ddagger$ & 52.4 & 0.7 & -3.8 & $\dagger$ \\
\hline Azerbaijan & 72.5 & $\#$ & 70.0 & $\#$ & -2.5 & $\#$ \\
\hline Brazil & 61.0 & $\ddagger$ & 54.2 & 0.6 & $-6.8 *$ & $\dagger$ \\
\hline Bulgaria & 42.6 & 3.1 & 38.8 & 2.6 & -3.8 & -0.4 \\
\hline Chinese Taipei & 11.6 & 14.6 & 11.1 & 8.8 & -0.6 & $-5.8 *$ \\
\hline Colombia & 60.2 & $\ddagger$ & 54.1 & 0.1 & $-6.1 *$ & $\dagger$ \\
\hline Croatia & 17.0 & 5.1 & 18.5 & 3.7 & 1.5 & -1.4 \\
\hline Dubai-UAE & - & - & 30.5 & 5.6 & $\dagger$ & $\dagger$ \\
\hline Hong Kong-China & 8.7 & 15.9 & 6.6 & 16.2 & -2.1 & 0.3 \\
\hline Indonesia & 61.6 & \# & 65.6 & $\#$ & 4.0 & $\#$ \\
\hline Jordan & 44.3 & $\ddagger$ & 45.6 & 0.5 & 1.3 & $\dagger$ \\
\hline Kazakhstan & - & - & 55.4 & 0.3 & $\dagger$ & $\dagger$ \\
\hline Kyrgyz Republic & 86.3 & $\#$ & 82.0 & $\#$ & $-4.4^{*}$ & $\#$ \\
\hline Latvia & 17.4 & 4.1 & 14.7 & 3.1 & -2.7 & -1.0 \\
\hline Liechtenstein & 12.9 & 12.2 & 11.3 & 9.7 & -1.6 & -2.5 \\
\hline Lithuania & 20.3 & 5.0 & 17.0 & 4.6 & $-3.3 *$ & -0.4 \\
\hline Macao-China & 10.3 & 5.3 & 9.6 & 4.8 & -0.7 & -0.5 \\
\hline Montenegro, Republic of & 50.2 & $\ddagger$ & 53.6 & $\ddagger$ & $3.3^{*}$ & $\dagger$ \\
\hline Panama & - & - & 65.1 & $\ddagger$ & $\dagger$ & $\dagger$ \\
\hline Peru & - & - & 68.3 & $\ddagger$ & $\dagger$ & $\dagger$ \\
\hline Qatar & 79.1 & $\ddagger$ & 65.2 & 1.4 & $-13.9 *$ & $\dagger$ \\
\hline Romania & 46.9 & $\ddagger$ & 41.4 & 0.4 & -5.5 & $\dagger$ \\
\hline Russian Federation & 22.2 & 4.2 & 22.0 & 4.4 & -0.2 & 0.2 \\
\hline Serbia, Republic of & 38.5 & 0.8 & 34.4 & 1.0 & $-4.1 *$ & 0.2 \\
\hline Shanghai-China & - & - & 3.2 & 24.3 & $\dagger$ & $\dagger$ \\
\hline Singapore & - & - & 11.5 & 19.9 & $\dagger$ & $\dagger$ \\
\hline Thailand & 46.1 & $\ddagger$ & 42.8 & 0.6 & -3.3 & $\dagger$ \\
\hline Trinidad and Tobago & - & - & 49.9 & 1.9 & $\dagger$ & $\dagger$ \\
\hline Tunisia & 62.8 & $\ddagger$ & 53.7 & $\ddagger$ & $-9.0 *$ & $\dagger$ \\
\hline Uruguay & 42.1 & 1.4 & 42.6 & 1.5 & 0.4 & 0.1 \\
\hline
\end{tabular}

- Not available.

† Not applicable.

\# Rounds to zero.

‡ Reporting standards not met (too few cases)

$* p<.05$. Significant percentage point change from 2006 to 2009 at the .05 level of statistical significance

The Organization for Economic Co-operation and Development (OECD) average used for the analysis of science literacy trends is based on the averages of the 34 OECD countries with comparable data for 2006 and 2009 and with each country weighted equally.

NOTE: Proficiency in science was defined in terms of levels based on student performance scores on each science literacy scale. Science literacy was assessed along a continuum, with proficiency below level 2 indicative of the low-performing students and proficiency level 5 and above indicative of the high-performing students. In science, proficiency below level 2 is defined by scoring below 410 in science and proficiency level 5 and above is defined by scoring 633 and above. Scores are reported on a scale from 0 to 1,000. Because the Program for International Student Assessment (PISA) is principally an OECD study, the results for non-OECD countries are displayed separately from those of the OECD Countries and are not included in the OECD average. Italics indicate education systems in non-national entities. UAE refers to United Arab Emirates. For more information on PISA, see Appendix B - Guide to Sources.

SOURCE: Fleischman, H.L., Hopstock, P.J., Pelczar, M.P., and Shelley, B.E. (2010). Highlights From PISA 2009: Performance of U.S. 15-Year-Old Students in Reading, Mathematics, and Science Literacy in an International Context (NCES 2011-004), table S4A; OECD. (2010). PISA 2009 Results: Learning Trends Changes in Student Performance Since 2000 (Volume V), table V.3.5; and OECD, previously unpublished tabulations (October 2011). 
Table A-27-1. Percentage of high school students who participated in various extracurricular activities, by type of activity, grade level, and sex: Selected years, 1990 through 2010

\begin{tabular}{|c|c|c|c|c|c|c|c|c|c|c|c|c|}
\hline \multirow[b]{2}{*}{ Sex and year } & \multicolumn{2}{|c|}{$\begin{array}{c}\text { Newspaper/ } \\
\text { yearbook }\end{array}$} & \multicolumn{2}{|c|}{$\begin{array}{c}\text { Music/ } \\
\text { performing arts }\end{array}$} & \multicolumn{2}{|c|}{ Athletic teams } & \multicolumn{2}{|c|}{ Academic clubs } & \multicolumn{2}{|c|}{$\begin{array}{c}\text { Student council/ } \\
\text { government }\end{array}$} & \multicolumn{2}{|c|}{$\begin{array}{l}\text { Other school } \\
\text { clubs/activities }\end{array}$} \\
\hline & $\begin{array}{l}\text { 10th } \\
\text { grade }\end{array}$ & $\begin{array}{l}\text { 12th } \\
\text { grade }\end{array}$ & $\begin{array}{l}\text { 10th } \\
\text { grade }\end{array}$ & $\begin{array}{l}12 \text { th } \\
\text { grade }\end{array}$ & $\begin{array}{l}\text { 10th } \\
\text { grade }\end{array}$ & $\begin{array}{l}\text { 12th } \\
\text { grade }\end{array}$ & $\begin{array}{l}\text { 10th } \\
\text { grade }\end{array}$ & $\begin{array}{r}12 \text { th } \\
\text { grade }\end{array}$ & $\begin{array}{l}10 \text { th } \\
\text { grade }\end{array}$ & $\begin{array}{l}12 \text { th } \\
\text { grade }\end{array}$ & $\begin{array}{r}10 \text { th } \\
\text { grade }\end{array}$ & $\begin{array}{l}12 \text { th } \\
\text { grade }\end{array}$ \\
\hline \multicolumn{13}{|l|}{ Total } \\
\hline 1990 & - & 9.2 & - & 22.1 & - & 35.9 & - & 13.2 & - & 11.0 & - & 34.6 \\
\hline 1995 & 5.7 & 10.4 & 25.8 & 23.3 & 45.0 & 37.2 & - & 13.3 & - & 10.4 & 32.5 & 31.8 \\
\hline 2000 & 5.3 & 11.0 & 25.8 & 27.6 & 44.6 & 37.0 & - & 17.1 & - & 11.0 & 33.0 & 33.1 \\
\hline 2005 & 4.2 & 10.7 & 25.2 & 24.5 & 45.4 & 38.6 & - & 12.8 & - & 10.5 & 28.1 & 33.2 \\
\hline 2006 & 4.1 & 10.1 & 23.8 & 26.8 & 46.0 & 37.9 & - & 14.0 & - & 9.1 & 27.5 & 32.5 \\
\hline 2007 & 4.1 & 9.1 & 22.7 & 25.7 & 44.9 & 35.7 & - & 14.5 & - & 9.1 & 27.2 & 32.6 \\
\hline 2008 & 3.6 & 9.1 & 23.2 & 25.8 & 44.6 & 37.7 & - & 12.2 & - & 9.2 & 29.2 & 32.9 \\
\hline 2009 & 4.0 & 8.7 & 21.2 & 23.9 & 43.7 & 38.4 & - & 14.1 & - & 9.6 & 28.5 & 31.8 \\
\hline 2010 & 4.2 & 9.6 & 23.1 & 22.9 & 43.4 & 39.7 & - & 14.5 & - & 9.3 & 27.8 & 32.0 \\
\hline \multicolumn{13}{|l|}{ Male } \\
\hline 1990 & - & 6.4 & - & 16.5 & - & 43.3 & - & 11.7 & - & 8.9 & - & 28.2 \\
\hline 1995 & 4.0 & 7.5 & 19.0 & 16.9 & 50.0 & 44.1 & - & 9.4 & - & 6.9 & 24.4 & 23.7 \\
\hline 2000 & 3.6 & 6.6 & 18.4 & 22.1 & 48.5 & 45.7 & - & 14.1 & - & 7.5 & 24.5 & 24.5 \\
\hline 2005 & 2.6 & 6.2 & 18.0 & 18.2 & 50.9 & 42.9 & - & 10.2 & - & 6.7 & 19.4 & 24.8 \\
\hline 2006 & 2.7 & 4.8 & 16.7 & 20.5 & 49.5 & 41.5 & - & 10.4 & - & 5.5 & 21.7 & 24.1 \\
\hline 2007 & 2.7 & 4.4 & 16.2 & 21.2 & 49.4 & 40.0 & - & 10.1 & - & 6.4 & 20.2 & 25.4 \\
\hline 2008 & 2.6 & 5.6 & 17.5 & 21.5 & 48.7 & 43.3 & - & 8.2 & - & 7.4 & 22.1 & 26.6 \\
\hline 2009 & 2.8 & 5.8 & 15.2 & 17.8 & 48.5 & 46.0 & - & 11.6 & - & 5.9 & 21.2 & 23.6 \\
\hline 2010 & 2.9 & 6.3 & 16.5 & 17.9 & 48.1 & 44.0 & - & 10.8 & - & 6.0 & 20.0 & 23.9 \\
\hline \multicolumn{13}{|l|}{ Female } \\
\hline 1990 & - & 12.7 & - & 28.7 & - & 27.9 & - & 15.2 & - & 13.6 & - & 42.1 \\
\hline 1995 & 7.3 & 13.2 & 32.5 & 29.3 & 40.3 & 31.5 & - & 16.4 & - & 13.4 & 40.2 & 39.6 \\
\hline 2000 & 6.8 & 15.0 & 32.3 & 32.5 & 41.3 & 29.9 & - & 20.1 & - & 14.3 & 40.8 & 41.7 \\
\hline 2005 & 5.6 & 14.9 & 32.1 & 30.4 & 40.1 & 34.0 & - & 15.7 & - & 14.3 & 36.5 & 42.0 \\
\hline 2006 & 5.5 & 15.0 & 30.8 & 33.2 & 42.6 & 34.0 & - & 17.6 & - & 12.8 & 33.4 & 41.0 \\
\hline 2007 & 5.2 & 12.9 & 29.0 & 29.2 & 40.6 & 31.5 & - & 18.2 & - & 11.6 & 34.0 & 39.5 \\
\hline 2008 & 4.5 & 11.8 & 28.3 & 29.9 & 41.0 & 32.4 & - & 15.7 & - & 10.5 & 35.8 & 37.4 \\
\hline 2009 & 5.0 & 11.3 & 26.6 & 30.0 & 39.5 & 31.3 & - & 16.5 & - & 13.1 & 35.2 & 40.0 \\
\hline 2010 & 5.5 & 12.6 & 29.7 & 27.7 & 39.0 & 36.0 & - & 18.3 & - & 12.2 & 35.3 & 40.8 \\
\hline
\end{tabular}

- Not available.

NOTE: Percentages reflect the proportion of seniors who responded that they participated in these activities "to a considerable extent" or "to a great extent." The response rates for this survey do not meet National Center for Education Statistics (NCES) standards. The 10th- and 12th-grade data for "other school clubs/activities" are not comparable because the available response alternatives were not the same. For more information on Monitoring the Future, see Appendix B - Guide to Sources.

SOURCE: University of Michigan, Institute for Social Research, Monitoring the Future, selected years, $1990-2010$. 
Table A-27-2. Percentage of high school seniors who participated in various extracurricular activities, by type of activity, sex, college plans, and region: 2010

\begin{tabular}{|c|c|c|c|c|c|c|}
\hline Sex, college plans, and region & $\begin{array}{r}\text { Newspaper/ } \\
\text { yearbook }\end{array}$ & $\begin{array}{r}\text { Music/ } \\
\text { performing } \\
\text { arts } \\
\end{array}$ & $\begin{array}{r}\text { Athletic } \\
\text { teams }\end{array}$ & $\begin{array}{r}\text { Academic } \\
\text { clubs } \\
\end{array}$ & $\begin{array}{r}\text { Student council/ } \\
\text { government }\end{array}$ & $\begin{array}{r}\text { Other school } \\
\text { clubs/ } \\
\text { activities } \\
\end{array}$ \\
\hline Total & 9.6 & 22.9 & 39.7 & 14.5 & 9.3 & 32.0 \\
\hline \multicolumn{7}{|l|}{ Sex } \\
\hline Male & 6.3 & 17.9 & 44.0 & 10.8 & 6.0 & 23.9 \\
\hline Female & 12.6 & 27.7 & 36.0 & 18.3 & 12.2 & 40.8 \\
\hline \multicolumn{7}{|l|}{ College plans } \\
\hline Yes & 10.6 & 25.2 & 42.8 & 17.0 & 10.9 & 36.6 \\
\hline No & 4.7 & 14.3 & 24.7 & 4.9 & $2.2 !$ & 14.8 \\
\hline \multicolumn{7}{|l|}{ Region } \\
\hline Northeast & 8.3 & 23.0 & 43.6 & 13.5 & 10.4 & 30.5 \\
\hline North central & 9.3 & 26.1 & 43.3 & 15.7 & 9.2 & 30.3 \\
\hline South & 8.5 & 22.3 & 35.6 & 15.3 & 9.1 & 34.1 \\
\hline West & 12.7 & 20.6 & 39.7 & 12.7 & 8.9 & 31.4 \\
\hline
\end{tabular}


Table A-28-1. Percentage distribution and average NAEP reading scale scores of 4 th-, 8 th-, and 12 th-grade students, by the number of days of school they reported missing in the previous month: Various years, 1992-2011

\begin{tabular}{|c|c|c|c|c|c|c|c|c|c|c|c|c|}
\hline \multirow[b]{3}{*}{ Year } & \multicolumn{4}{|c|}{ Grade 4} & \multicolumn{4}{|c|}{ Grade 8} & \multicolumn{4}{|c|}{ Grade 12} \\
\hline & \multirow[b]{2}{*}{0 days } & \multirow[b]{2}{*}{ 1-2 days } & \multirow{2}{*}{\multicolumn{2}{|c|}{$\begin{array}{rr}5 \text { or more } \\
3-4 \text { days } & \text { days } \\
\end{array}$}} & \multirow[b]{2}{*}{0 days } & \multirow{2}{*}{\multicolumn{3}{|c|}{ 1-2 days $3-4$ days $\begin{array}{r}5 \text { or more } \\
\text { days }\end{array}$}} & \multirow[b]{2}{*}{0 days } & \multirow[b]{2}{*}{ 1-2 days } & \multirow[b]{2}{*}{ 3-4 days } & \multirow{2}{*}{$\begin{array}{r}5 \text { or more } \\
\text { days }\end{array}$} \\
\hline & & & & & & & & & & & & \\
\hline & \multicolumn{12}{|c|}{ Percent distribution } \\
\hline $1992^{1}$ & - & - & - & - & 44 & 33 & 13 & 8 & 35 & 39 & 17 & 9 \\
\hline $1994^{1}$ & 52 & 30 & 11 & 7 & 44 & 33 & 13 & 9 & 34 & 37 & 17 & 10 \\
\hline $1998^{1}$ & 53 & 31 & 11 & 5 & 44 & 34 & 14 & 8 & 34 & 39 & 17 & 10 \\
\hline 1998 & 53 & 30 & 11 & 6 & 44 & 34 & 14 & 8 & 35 & 39 & 17 & 9 \\
\hline 2002 & 52 & 30 & 11 & 6 & 45 & 35 & 13 & 7 & 36 & 40 & 17 & 8 \\
\hline 2003 & 49 & 30 & 13 & 8 & 44 & 35 & 14 & 8 & - & - & - & - \\
\hline 2005 & 52 & 29 & 12 & 7 & 45 & 35 & 13 & 7 & 36 & 39 & 16 & 9 \\
\hline 2007 & 51 & 30 & 12 & 7 & 45 & 35 & 13 & 7 & - & - & - & - \\
\hline 2009 & 52 & 29 & 11 & 7 & 46 & 35 & 13 & 7 & 38 & 39 & 15 & 8 \\
\hline \multirow[t]{2}{*}{2011} & 51 & 30 & 12 & 7 & 45 & 35 & 13 & 6 & - & - & - & - \\
\hline & \multicolumn{12}{|c|}{ Average scale score } \\
\hline $1992^{1}$ & - & - & - & - & 263 & 264 & 256 & 244 & 296 & 295 & 287 & 279 \\
\hline $1994^{1}$ & 217 & 215 & 208 & 198 & 264 & 264 & 252 & 244 & 291 & 291 & 281 & 273 \\
\hline $1998^{1}$ & 220 & 218 & 211 & 209 & 268 & 265 & 258 & 250 & 295 & 294 & 286 & 276 \\
\hline 1998 & 218 & 214 & 206 & 204 & 268 & 264 & 257 & 249 & 294 & 293 & 285 & 277 \\
\hline 2002 & 222 & 219 & 214 & 205 & 268 & 267 & 259 & 250 & 289 & 290 & 284 & 275 \\
\hline 2003 & 221 & 218 & 215 & 209 & 267 & 265 & 258 & 248 & - & - & - & - \\
\hline 2005 & 222 & 219 & 215 & 207 & 266 & 264 & 256 & 247 & 290 & 288 & 283 & 273 \\
\hline 2007 & 224 & 221 & 216 & 208 & 267 & 264 & 255 & 245 & - & - & - & - \\
\hline 2009 & 224 & 221 & 216 & 207 & 268 & 265 & 257 & 248 & 292 & 290 & 284 & 273 \\
\hline 2011 & 225 & 221 & 216 & 207 & 269 & 266 & 258 & 248 & - & - & - & - \\
\hline
\end{tabular}

- Not available.

'Testing accommodations (e.g., extended time, small group testing) for children with disabilities and English language learners were not permitted in 1992 and 1994; students were tested with and without accommodations in 1998. The footnoted row represents the sample without accommodations. NOTE: From 1992 to 2000, students responded to the question "How many days of school did you miss last month?" After 2001, students were asked "How many days were you absent from school in the last month?" Detail may not sum to totals because of rounding. The 4th-grade National Assessment of Educational Progress (NAEP) reading assessment did not include the absenteeism question in 1992. The 12th-grade NAEP reading assessment was not administered in 2003, 2007, or 2011. The NAEP reading scale ranges from 0-500. For more information on NAEP, see Appendix B - Guide to Sources. SOURCE: U.S. Department of Education, National Center for Education Statistics, National Assessment of Educational Progress (NAEP), various years, 1992-2011 Reading Assessments, NAEP Data Explorer. 
Table A-28-2. Percentage of 8th- and 12th-grade students performing at or above Basic proficiency on NAEP reading assessments, by number of days of school missed in the previous month and selected characteristics: 2009 and 2011

\begin{tabular}{|c|c|c|c|c|c|c|c|c|c|c|c|c|}
\hline & \multicolumn{6}{|c|}{ Grade 8-2011 } & \multicolumn{6}{|c|}{ Grade 12-2009 } \\
\hline & \multicolumn{3}{|c|}{ Percent at or above Basic } & \multicolumn{3}{|c|}{ Percentage distribution } & \multicolumn{3}{|c|}{ Percent at or above Basic } & \multicolumn{3}{|c|}{ Percentage distribution } \\
\hline & 0 days & $\begin{array}{r}1-2 \\
\text { days }\end{array}$ & $\begin{array}{l}3 \text { or } \\
\text { more } \\
\text { days }\end{array}$ & 0 days & $\begin{array}{r}1-2 \\
\text { days } \\
\end{array}$ & $\begin{array}{l}3 \text { or } \\
\text { more } \\
\text { days }\end{array}$ & 0 days & $\begin{array}{r}1-2 \\
\text { days }\end{array}$ & $\begin{array}{l}3 \text { or } \\
\text { more } \\
\text { days }\end{array}$ & 0 days & $\begin{array}{r}1-2 \\
\text { days }\end{array}$ & $\begin{array}{l}3 \text { or } \\
\text { more } \\
\text { days }\end{array}$ \\
\hline Total & 80 & 78 & 66 & 45 & 35 & 19 & 77 & 76 & 67 & 38 & 39 & 23 \\
\hline \multicolumn{13}{|l|}{ Student characteristic } \\
\hline \multicolumn{13}{|l|}{ Sex } \\
\hline Male & 76 & 74 & 60 & 47 & 34 & 18 & 72 & 70 & 60 & 41 & 37 & 21 \\
\hline Female & 84 & 81 & 71 & 44 & 36 & 20 & 83 & 81 & 74 & 35 & 41 & 24 \\
\hline \multicolumn{13}{|l|}{ Race/ethnicity } \\
\hline White & 88 & 86 & 77 & 45 & 37 & 18 & 85 & 83 & 73 & 36 & 40 & 23 \\
\hline Black & 65 & 60 & 49 & 45 & 32 & 23 & 60 & 58 & 51 & 39 & 38 & 23 \\
\hline Hispanic & 68 & 66 & 54 & 44 & 35 & 21 & 64 & 63 & 56 & 38 & 39 & 23 \\
\hline Asian/Pacific & & & & & & & & & & & & \\
\hline Islander & 85 & 83 & 69 & 62 & 27 & 11 & 83 & 81 & 78 & 50 & 33 & 16 \\
\hline $\begin{array}{c}\text { American Indian/ } \\
\text { Alaska Native }\end{array}$ & & & 55 & 31 & 35 & & 77 & 07 & 70 & 30 & 36 & 34 \\
\hline Two or more races & 84 & 79 & 68 & $\begin{array}{l}34 \\
43\end{array}$ & 36 & 3 & 83 & 83 & 84 & 39 & $\begin{array}{l}30 \\
37\end{array}$ & $\begin{array}{l}34 \\
23\end{array}$ \\
\hline \multicolumn{13}{|l|}{$\begin{array}{l}\text { English language } \\
\text { learner }\end{array}$} \\
\hline Yes & 32 & 30 & 21 & 46 & 31 & 23 & 25 & 21 & 16 & 43 & 37 & 19 \\
\hline No & 82 & 80 & 68 & 45 & 36 & 19 & 79 & 77 & 68 & 38 & 39 & 23 \\
\hline \multicolumn{13}{|l|}{$\begin{array}{l}\text { Classified as having a } \\
\text { disability }\end{array}$} \\
\hline Yes & 43 & 39 & 30 & 39 & 35 & 26 & 43 & 42 & 29 & 36 & 36 & 29 \\
\hline No & 83 & 81 & 71 & 46 & 35 & 18 & 80 & 79 & 71 & 38 & 40 & 22 \\
\hline \multicolumn{13}{|l|}{$\begin{array}{l}\text { Student eligibility for } \\
\text { free or reduced-price } \\
\text { lunch }\end{array}$} \\
\hline Eligible & 67 & 65 & 54 & 42 & 35 & 23 & 63 & 62 & 56 & 36 & 39 & 26 \\
\hline Not eligible & 88 & 86 & 78 & 48 & 36 & 16 & 82 & 81 & 72 & 38 & 40 & 22 \\
\hline \multicolumn{13}{|l|}{ School characteristic } \\
\hline \multicolumn{13}{|l|}{ School location } \\
\hline City & 75 & 72 & 58 & 45 & 34 & 21 & 73 & 75 & 66 & 37 & 40 & 23 \\
\hline Suburban & 83 & 80 & 69 & 47 & 35 & 18 & 80 & 79 & 69 & 38 & 40 & 22 \\
\hline Town & 79 & 76 & 68 & 44 & 36 & 20 & 77 & 76 & 67 & 37 & 39 & 24 \\
\hline Rural & 81 & 80 & 70 & 45 & 36 & 19 & 78 & 74 & 65 & 39 & 38 & 23 \\
\hline \multicolumn{13}{|l|}{$\begin{array}{l}\text { Percent of students in } \\
\text { school eligible for } \\
\text { free or reduced-price } \\
\text { lunch }\end{array}$} \\
\hline $0-25$ & 90 & 89 & 81 & 49 & 35 & 16 & 85 & 85 & 77 & 38 & 41 & 22 \\
\hline $26-50$ & 83 & 80 & 73 & 45 & 36 & 19 & 77 & 75 & 66 & 38 & 39 & 23 \\
\hline $51-75$ & 74 & 72 & 60 & 44 & 35 & 21 & 68 & 65 & 56 & 38 & 39 & 23 \\
\hline $76-100$ & 61 & 61 & 47 & 43 & 34 & 23 & 57 & 53 & 48 & 35 & 39 & 26 \\
\hline
\end{tabular}

NOTE. The National Assessment of Educational Progress (NAEP) reading assessment was not administered to 12 th graders in 2011. For more information on NAEP, see Appendix B - Guide to Sources. Race categories exclude persons of Hispanic ethnicity. For more information on free or reduced-price lunch, locale, or race/ethnicity, see Appendix C - Commonly Used Measures.

SOURCE: U.S. Department of Education, National Center for Education Statistics, National Assessment of Educational Progress (NAEP), 2009 and 2011 Reading Assessments, NAEP Data Explorer. 


\section{Youth Neither in School nor Working}

Table A-29-1. Percentage of youth ages 16-24 who were neither enrolled in school nor working, by selected characteristics: Selected years, 1990-2011

\begin{tabular}{|c|c|c|c|c|c|c|}
\hline Characteristic & 1990 & 1995 & 2000 & 2005 & 2010 & 2011 \\
\hline Total & 13.7 & 13.9 & 11.5 & 13.1 & 15.5 & 14.5 \\
\hline \multicolumn{7}{|l|}{ Sex } \\
\hline Male & 9.8 & 10.5 & 8.8 & 11.1 & 15.0 & 14.0 \\
\hline Female & 17.6 & 17.3 & 14.3 & 15.2 & 16.0 & 15.0 \\
\hline \multicolumn{7}{|l|}{ Age } \\
\hline 16-17 & 4.6 & 4.0 & 3.8 & 3.6 & 3.3 & 2.9 \\
\hline 18-19 & 13.1 & 13.7 & 11.2 & 13.1 & 14.9 & 13.0 \\
\hline $20-24$ & 17.4 & 18.0 & 15.0 & 17.2 & 20.8 & 19.7 \\
\hline \multicolumn{7}{|l|}{ Household type (family relationship) } \\
\hline Family householder or spouse of householder & - & - & 24.4 & 27.3 & 30.2 & 29.2 \\
\hline Child of householder & - & - & 7.0 & 8.8 & 11.2 & 10.2 \\
\hline Not in family groups & - & - & 10.8 & 11.4 & 14.5 & 14.9 \\
\hline Other & - & - & 18.3 & 18.7 & 23.0 & 19.7 \\
\hline \multicolumn{7}{|l|}{ Race/ethnicity ${ }^{2}$} \\
\hline White & 11.1 & 10.5 & 8.3 & 10.2 & 12.6 & 12.3 \\
\hline Black & 22.2 & 22.6 & 19.2 & 20.0 & 22.4 & 19.4 \\
\hline Hispanic & 21.3 & 22.8 & 18.8 & 18.4 & 20.0 & 18.4 \\
\hline Asian/Pacific Islander & - & - & - & 9.6 & 12.3 & 9.0 \\
\hline \multicolumn{7}{|l|}{ Citizenship 3} \\
\hline U.S.-born & - & - & - & - & 15.1 & 14.0 \\
\hline Naturalized U.S. citizen & - & - & - & - & 13.5 & 14.3 \\
\hline Non-U.S. citizen & - & - & - & - & 21.9 & 20.0 \\
\hline \multicolumn{7}{|l|}{ Family poverty ${ }^{4}$} \\
\hline Poor & 32.9 & 32.0 & 24.5 & 27.7 & 29.0 & 27.4 \\
\hline Nonpoor & 10.3 & 9.9 & 8.9 & 10.1 & 12.2 & 11.0 \\
\hline \multicolumn{7}{|l|}{ Geographic region } \\
\hline Northeast & 12.3 & 13.1 & 10.2 & 12.6 & 13.0 & 13.6 \\
\hline Midwest & 12.9 & 11.7 & 10.0 & 12.0 & 14.2 & 12.4 \\
\hline South & 14.5 & 15.2 & 12.8 & 14.8 & 17.0 & 15.8 \\
\hline West & 14.9 & 15.0 & 12.0 & 12.0 & 16.5 & 15.0 \\
\hline
\end{tabular}

- Not available.

1 "Householder" refers to the person (or one of the people) in whose name the housing unit is owned or rented (maintained) or, if there is no such person, any adult member, excluding roomers, boarders, or paid employees. If the house is owned or rented jointly by a married couple, the householder may be either spouse. "Child of householder" includes unmarried college students living in dormitories. "Not in family groups" includes nonfamily householders, unrelated persons in households, and those living in group quarters. "Other" includes other relatives living with the householder (not a spouse or child), as well as those in related or unrelated subfamilies.

${ }^{2}$ Race categories exclude persons of Hispanic ethnicity. Other races/ethnicities are included in the total but are not shown separately. Prior to 2003. estimates for "Asian/Pacific Islander" only were not available.

${ }^{3}$ U.S.-born includes foreign-born U.S. citizens. Naturalized U.S. citizens are those who, having been born in another country or otherwise reared as a foreigner, have been granted U.S. citizenship and the rights and privileges of that status.

${ }^{4}$ Poor is defined to include families below the poverty threshold; nonpoor is defined to include families at or above the poverty threshold. NOTE: The data presented here represent the percentage of civilian, noninstitutionalized 16- to 24-year-olds who are neither enrolled in school nor working. For more information on the Current Population Survey (CPS), see Appendix B - Guide to Sources. For more information on poverty or race/ ethnicity, see Appendix C - Commonly Used Measures.

SOURCE: U.S. Department of Commerce, Census Bureau, Current Population Survey (CPS), March Supplement and Annual Social and Economic Supplement, selected years, 1990-2011 
Table A-29-2. Number and percentage distribution of youth ages 16-24 who were neither enrolled in school nor working, by selected characteristics: 2011

\begin{tabular}{|c|c|c|c|}
\hline \multirow[b]{2}{*}{ Characteristic } & \multirow[b]{2}{*}{$\begin{array}{r}\text { Total youth ages } \\
16-24\end{array}$} & \multicolumn{2}{|c|}{ Neither enrolled in school nor working } \\
\hline & & Number & $\begin{array}{r}\text { Percentage } \\
\text { distribution }\end{array}$ \\
\hline Total & $38,374,000$ & $5,558,000$ & 100.0 \\
\hline \multicolumn{4}{|l|}{ Sex } \\
\hline Male & $19,585,000$ & $2,734,000$ & 49.2 \\
\hline Female & $18,790,000$ & $2,823,000$ & 50.8 \\
\hline \multicolumn{4}{|l|}{ Age } \\
\hline $16-17$ & $8,723,000$ & 254,000 & 4.6 \\
\hline $18-19$ & $8,125,000$ & $1,059,000$ & 19.1 \\
\hline $20-24$ & $21,525,000$ & $4,245,000$ & 76.4 \\
\hline \multicolumn{4}{|l|}{ Household type (family relationship)' } \\
\hline Family householder or spouse of householder & $5,622,000$ & $1,644,000$ & 29.6 \\
\hline Child of householder & $23,502,000$ & $2,405,000$ & 43.3 \\
\hline Not in family groups & $6,547,000$ & 977,000 & 17.6 \\
\hline Other & $2,704,000$ & 531,000 & 9.6 \\
\hline \multicolumn{4}{|l|}{ Race/ethnicity ${ }^{2}$} \\
\hline White & $22,638,000$ & $2,784,000$ & 50.1 \\
\hline Black & $5,438,000$ & $1,053,000$ & 18.9 \\
\hline Hispanic & $7,573,000$ & $1,390,000$ & 25.0 \\
\hline Asian/Pacific Islander & $1,680,000$ & 151,000 & 2.7 \\
\hline \multicolumn{4}{|l|}{ Citizenship ${ }^{3}$} \\
\hline U.S.-born & $34,661,000$ & $4,868,000$ & 87.6 \\
\hline Naturalized U.S. citizen & 933,000 & 133,000 & 2.4 \\
\hline Non-U.S. citizen & $2,780,000$ & 556,000 & 10.0 \\
\hline \multicolumn{4}{|l|}{ Family poverty ${ }^{4}$} \\
\hline Poor & $8,111,000$ & $2,223,000$ & 40.0 \\
\hline Nonpoor & $30,263,000$ & $3,334,000$ & 60.0 \\
\hline \multicolumn{4}{|l|}{ Geographic region } \\
\hline Northeast & $7,099,000$ & 965,000 & 17.4 \\
\hline Midwest & $8,279,000$ & $1,026,000$ & 18.5 \\
\hline South & $13,789,000$ & $2,181,000$ & 39.2 \\
\hline West & $9,207,000$ & $1,386,000$ & 24.9 \\
\hline
\end{tabular}

1 "Householder" refers to the person (or one of the people) in whose name the housing unit is owned or rented (maintained) or, if there is no such person, any adult member, excluding roomers, boarders, or paid employees. If the house is owned or rented jointly by a married couple. the householder may be either spouse. "Child of householder" includes unmarried college students living in dormitories. "Not in family groups" includes nonfamily householders, unrelated persons in households, and those living in group quarters. "Other" includes other relatives living with the householder (not a spouse or child), as well as those in related or unrelated subfamilies.

2 Race categories exclude persons of Hispanic ethnicity. Other races/ethnicities are included in the total but are not shown separately.

${ }^{3}$ U.S.-born includes foreign-born U.S. citizens. Naturalized U.S. citizens are those who, having been born in another country or otherwise reared as a foreigner, have been granted U.S. citizenship and the rights and privileges of that status.

${ }^{4}$ Poor is defined to include families below the poverty threshold; nonpoor is defined to include families at or above the poverty threshold. NOTE: The data presented here represent the percentage of civilian, noninstitutionalized 16- to 24-year-olds who are neither enrolled in school nor working. For more information on the Current Population Survey (CPS), see Appendix B - Guide to Sources. For more information on poverty or race/ ethnicity, see Appendix C - Commonly Used Measures.

SOURCE: U.S. Department of Commerce, Census Bureau, Current Population Survey (CPS), March Supplement and Annual Social and Economic Supplement, 2011 


\section{Employment of High Schooll Students}

Table A-30-1. Percentage of high school students ages 16 years and older who were employed, by hours worked per week and sex: Selected years, 1980 to 2010

\begin{tabular}{|c|c|c|c|c|c|c|c|c|c|}
\hline \multirow[b]{2}{*}{ Year } & \multicolumn{3}{|c|}{ Percent employed } & \multicolumn{3}{|c|}{$\begin{array}{l}\text { Percent employed less than } 15 \text { hours } \\
\text { per week }\end{array}$} & \multicolumn{3}{|c|}{$\begin{array}{c}\text { Percent employed } 15 \text { or more hours } \\
\text { per week }\end{array}$} \\
\hline & Total & Males & Females & Total & Males & Females & Total & Males & Females \\
\hline 1980 & 35.6 & 36.9 & 34.2 & 14.2 & 14.0 & 14.5 & 20.5 & 22.1 & 18.9 \\
\hline 1985 & 31.6 & 32.1 & 31.0 & 12.6 & 12.2 & 13.0 & 18.5 & 19.5 & 17.3 \\
\hline 1990 & 32.3 & 33.1 & 31.3 & 11.9 & 11.4 & 12.3 & 19.7 & 21.0 & 18.3 \\
\hline 1995 & 33.6 & 33.1 & 34.2 & 11.9 & 11.1 & 12.9 & 20.5 & 20.8 & 20.2 \\
\hline 2000 & 34.1 & 33.2 & 35.1 & 11.9 & 11.2 & 12.6 & 21.1 & 21.1 & 21.0 \\
\hline 2002 & 30.5 & 27.9 & 33.4 & 11.1 & 9.7 & 12.7 & 18.5 & 17.4 & 19.7 \\
\hline 2004 & 27.2 & 26.2 & 28.3 & 10.4 & 9.9 & 11.0 & 16.0 & 15.5 & 16.6 \\
\hline 2006 & 27.6 & 26.5 & 28.8 & 9.9 & 8.8 & 11.0 & 17.0 & 16.8 & 17.1 \\
\hline 2008 & 22.6 & 20.0 & 25.4 & 9.2 & 8.1 & 10.3 & 12.8 & 11.4 & 14.1 \\
\hline 2010 & 16.2 & 14.0 & 18.5 & 7.3 & 6.3 & 8.4 & 8.3 & 7.2 & 9.4 \\
\hline
\end{tabular}

NOTE: Percent employed includes those who were employed but not at work during the survey week. Hours worked per week refers to the number of hours the respondent worked at all jobs during the survey week. The estimates of the percentage of high school students ages 16 years old and older who worked less than 15 hours per week or 15 or more hours per week exclude those who were employed but not at work during the survey week.

Therefore, detail may not sum to total percentage employed. For more information on the Current Population Survey (CPS), see Appendix B - Guide to Sources.

SOURCE: U.S. Department of Commerce, Census Bureau, Current Population Survey (CPS), October Supplement, selected years, 1980-2010. 
Table A-30-2. Percentage distribution of high school students ages 16 years and older who were employed, by hours worked per week and selected student characteristics: 2010

\begin{tabular}{|c|c|c|}
\hline \multirow[b]{2}{*}{ Characteristic } & \multicolumn{2}{|c|}{ Hours worked per week } \\
\hline & Less than 15 hours & 15 or more hours \\
\hline Total & 47.0 & 53.0 \\
\hline \multicolumn{3}{|l|}{ Sex } \\
\hline Male & 46.5 & 53.5 \\
\hline Female & 47.3 & 52.7 \\
\hline \multicolumn{3}{|l|}{ Age } \\
\hline 16 to 17 years old & 51.9 & 48.1 \\
\hline 18 years old and older & 33.7 & 66.3 \\
\hline \multicolumn{3}{|l|}{ Family income } \\
\hline Low income & 37.5 & 62.5 \\
\hline Middle income & 43.9 & 56.1 \\
\hline High income & 55.7 & 44.3 \\
\hline \multicolumn{3}{|l|}{ Race/ethnicity } \\
\hline White & 47.5 & 52.5 \\
\hline Black & 43.6 & 56.4 \\
\hline Hispanic & 44.9 & 55.1 \\
\hline Asian & $\ddagger$ & $\ddagger$ \\
\hline Pacific Islander & $\ddagger$ & $\ddagger$ \\
\hline American Indian/Alaska Native & $\ddagger$ & $\ddagger$ \\
\hline Two or more races & $\ddagger$ & $\ddagger$ \\
\hline \multicolumn{3}{|l|}{ Nativity } \\
\hline Native-born & 48.4 & 51.6 \\
\hline Foreign-born & $24.5 !$ & 75.5 \\
\hline
\end{tabular}

! Interpret data with caution. The coefficient of variation (CV) for this estimate is 30 percent or greater.

‡ Reporting standards not met (too few cases).

NOTE: Hours worked per week refers to the number of hours the respondent worked at all jobs during the survey week. These estimates exclude those who were employed but not at work during the survey week. Low income refers to the bottom 20 percent of family incomes, high income refers to the top 20 percent of family incomes, and middle income refers to the 60 percent in between. Native-born refers to high school students born in the 50 states and the District of Columbia. Race categories exclude persons of Hispanic ethnicity. For more information on race/ethnicity, see Appendix $\mathrm{C}$ Commonly Used Measures. For more information on the Current Population Survey (CPS), see Appendix B - Guide to Sources. Detail may not sum to 100 percent because of rounding.

SOURCE: U.S. Department of Commerce, Census Bureau, Current Population Survey (CPS), October Supplement, 2010. 
Table A-31-1. Percentage of high school graduates who completed selected mathematics and science courses in high school, by year and selected student and school characteristics: Selected years, 1990-2009

\begin{tabular}{|c|c|c|c|c|c|c|}
\hline \multirow[b]{2}{*}{$\begin{array}{l}\text { Year and student or school } \\
\text { characteristic }\end{array}$} & \multicolumn{6}{|c|}{ Mathematics } \\
\hline & Algebra I & Geometry' & $\begin{array}{r}\text { Algebra II/ } \\
\text { trigono- } \\
\text { metry }^{2} \\
\end{array}$ & $\begin{array}{r}\text { Analysis/ } \\
\text { pre- } \\
\text { calculus }^{2} \\
\end{array}$ & $\begin{array}{c}\text { Statistics/ } \\
\text { probability }\end{array}$ & Calculus $^{1}$ \\
\hline \multicolumn{7}{|l|}{1990} \\
\hline Total $^{5}$ & 76.9 & 64.1 & 53.6 & 13.4 & 1.0 & 6.5 \\
\hline \multicolumn{7}{|l|}{ Sex } \\
\hline Male & 75.1 & 63.0 & 51.8 & 14.1 & 1.2 & 7.6 \\
\hline Female & 78.6 & 65.0 & 55.2 & 12.8 & 0.8 & 5.6 \\
\hline \multicolumn{7}{|l|}{ Race/ethnicity } \\
\hline White & 76.8 & 66.4 & 56.9 & 14.9 & 1.0 & 6.9 \\
\hline Black & 77.9 & 56.3 & 43.9 & 6.2 & $1.1 !$ & 2.8 \\
\hline Hispanic & 81.0 & 54.1 & 39.9 & 7.1 & $\ddagger$ & 3.8 \\
\hline Asian/Pacific Islander & 71.3 & 71.5 & 69.3 & 25.2 & $\ddagger$ & 18.4 \\
\hline American Indian/Alaska Native & 76.5 & 55.7 & 53.9 & $\ddagger$ & $\ddagger$ & $\ddagger$ \\
\hline \multicolumn{7}{|l|}{ School type } \\
\hline Traditional public & 76.0 & 61.9 & 51.4 & 12.2 & 0.8 & 6.2 \\
\hline Public charter & - & - & - & - & - & - \\
\hline Private & 86.1 & 85.5 & 75.5 & 25.3 & $2.6 !$ & 9.7 \\
\hline \multicolumn{7}{|l|}{$\begin{array}{l}\text { Percentage of students in school } \\
\text { eligible for free or reduced-price } \\
\text { lunch }\end{array}$} \\
\hline 0-25 percent & 77.0 & 67.4 & 57.8 & 15.3 & 1.1 & 7.5 \\
\hline 26-50 percent & 71.3 & 45.4 & 44.6 & 5.5 & $\ddagger$ & 3.8 \\
\hline 51-75 percent & 81.8 & 56.0 & 40.1 & 5.6 & \# & \\
\hline 76-100 percent & 96.0 & 89.4 & 78.7 & $\ddagger$ & \# & \# \\
\hline \multicolumn{7}{|l|}{ Locale } \\
\hline City & - & - & - & - & - & - \\
\hline Suburban & - & - & - & - & - & - \\
\hline Town & - & - & - & - & - & - \\
\hline Rural & - & - & - & - & - & - \\
\hline \multicolumn{7}{|l|}{$\begin{array}{l}\text { Student disability and English } \\
\text { language learner (ELL) status }\end{array}$} \\
\hline \multicolumn{7}{|l|}{ Students with disabilities (SD) } \\
\hline Yes & 37.3 & 11.8 & 8.3 & $\ddagger$ & $\ddagger$ & $\ddagger$ \\
\hline No & 77.7 & 65.1 & 54.5 & 13.6 & 1.0 & 6.7 \\
\hline \multicolumn{7}{|l|}{ ELL } \\
\hline Yes & 66.6 & 42.2 & 37.1 & $\ddagger$ & $\ddagger$ & $\ddagger$ \\
\hline No & 77.0 & 64.2 & 53.7 & 13.4 & 1.0 & 6.6 \\
\hline
\end{tabular}

See notes at end of table. 
Table A-31-1. Percentage of high school graduates who completed selected mathematics and science courses in high school, by year and selected student and school characteristics: Selected years, 1990-2009Continued

\begin{tabular}{|c|c|c|c|c|c|}
\hline \multirow[b]{2}{*}{$\begin{array}{l}\text { Year and student or school } \\
\text { characteristic }\end{array}$} & \multicolumn{5}{|c|}{ Science } \\
\hline & Biology ${ }^{1}$ & Chemistry' & Physics ${ }^{1}$ & $\begin{array}{l}\text { Biology and } \\
\text { chemistry }^{3}\end{array}$ & $\begin{array}{r}\text { Biology, } \\
\text { chemistry, } \\
\text { and physics } \\
\end{array}$ \\
\hline \multicolumn{6}{|l|}{1990} \\
\hline Total $^{5}$ & 91.3 & 49.2 & 21.3 & 47.8 & 18.7 \\
\hline \multicolumn{6}{|l|}{ Sex } \\
\hline Male & 90.0 & 48.1 & 25.1 & 46.6 & 21.8 \\
\hline Female & 92.5 & 50.2 & 17.7 & 48.9 & 16.0 \\
\hline \multicolumn{6}{|l|}{ Race/ethnicity } \\
\hline White & 91.5 & 51.8 & 22.8 & 50.5 & 20.5 \\
\hline Black & 91.3 & 40.3 & 14.5 & 39.5 & 12.0 \\
\hline Hispanic & 90.2 & 38.3 & 12.7 & 36.4 & 10.0 \\
\hline Asian/Pacific Islander & 90.2 & 63.5 & 38.0 & 60.0 & 33.4 \\
\hline American Indian/Alaska Native & 90.5 & 35.5 & $\ddagger$ & 34.2 & $\ddagger$ \\
\hline \multicolumn{6}{|l|}{ School type } \\
\hline Traditional public & 90.7 & 47.4 & 20.2 & 46.0 & 17.8 \\
\hline Public charter & - & - & - & - & - \\
\hline Private & 97.2 & 66.7 & 31.4 & 65.2 & 28.2 \\
\hline \multicolumn{6}{|l|}{$\begin{array}{l}\text { Percentage of students in school } \\
\text { eligible for free or reduced-price } \\
\text { lunch }\end{array}$} \\
\hline 0-25 percent & 92.4 & 54.0 & 22.8 & 52.8 & 21.0 \\
\hline 26-50 percent & 88.8 & 36.5 & 15.3 & 35.5 & 12.8 \\
\hline 51-75 percent & 93.6 & 33.5 & 12.7 & 33.0 & 11.7 \\
\hline 76-100 percent & 99.0 & $\ddagger$ & $\ddagger$ & $\ddagger$ & $\ddagger$ \\
\hline \multicolumn{6}{|l|}{ Locale } \\
\hline City & - & - & - & - & - \\
\hline Suburban & - & - & - & - & - \\
\hline Town & - & - & - & - & - \\
\hline Rural & - & - & - & - & - \\
\hline \multicolumn{6}{|l|}{$\begin{array}{l}\text { Student disability and English } \\
\text { language learner (ELL) status } 6\end{array}$} \\
\hline \multicolumn{6}{|l|}{ Students with disabilities (SD) } \\
\hline Yes & 65.0 & 7.7 & $\ddagger$ & $\ddagger$ & $\ddagger$ \\
\hline No & 91.8 & 50.0 & 21.6 & 48.6 & 19.1 \\
\hline \multicolumn{6}{|l|}{ ELL } \\
\hline Yes & 70.5 & $\ddagger$ & $\ddagger$ & $\ddagger$ & $\ddagger$ \\
\hline No & 91.4 & 49.3 & 21.3 & 48.0 & 18.8 \\
\hline
\end{tabular}

See notes at end of table. 
Table A-31-1. Percentage of high school graduates who completed selected mathematics and science courses in high school, by year and selected student and school characteristics: Selected years, 1990-2009Continued

\begin{tabular}{|c|c|c|c|c|c|c|}
\hline \multirow[b]{2}{*}{$\begin{array}{l}\text { Year and student or school } \\
\text { characteristic }\end{array}$} & \multicolumn{6}{|c|}{ Mathematics } \\
\hline & Algebra II & Geometry' & $\begin{array}{c}\text { Algebra II/ } \\
\text { trigono- } \\
\text { metry }\end{array}$ & $\begin{array}{r}\text { Analysis/ } \\
\text { pre- } \\
\text { calculus }{ }^{2} \\
\end{array}$ & $\begin{array}{l}\text { Statistics/ } \\
\text { probability }\end{array}$ & Calculus $^{1}$ \\
\hline \multicolumn{7}{|l|}{2000} \\
\hline Total $^{5}$ & 66.5 & 78.3 & 68.3 & 26.6 & 5.7 & 11.6 \\
\hline \multicolumn{7}{|l|}{ Sex } \\
\hline Male & 65.0 & 74.8 & 65.2 & 25.3 & 5.8 & 12.1 \\
\hline Female & 68.0 & 81.4 & 71.1 & 27.8 & 5.6 & 11.1 \\
\hline \multicolumn{7}{|l|}{ Race/ethnicity } \\
\hline White & 65.1 & 79.2 & 69.6 & 28.1 & 6.1 & 12.5 \\
\hline Black & 70.1 & 77.8 & 64.7 & 16.1 & $3.7 !$ & 4.6 \\
\hline Hispanic & 73.2 & 72.6 & 60.0 & 19.3 & 2.3 & 5.6 \\
\hline Asian/Pacific Islander & 58.1 & 81.3 & 81.3 & 48.7 & 11.4 & 30.4 \\
\hline American Indian/Alaska Native & 68.7 & 65.0 & 60.3 & $\ddagger$ & $\ddagger$ & $\ddagger$ \\
\hline \multicolumn{7}{|l|}{ School type } \\
\hline Traditional public & 65.3 & 77.0 & 67.1 & 24.1 & 5.5 & 10.9 \\
\hline Public charter & - & - & - & - & - & - \\
\hline Private & 79.1 & 92.3 & 81.9 & 53.8 & $7.8 !$ & 18.2 \\
\hline \multicolumn{7}{|l|}{$\begin{array}{l}\text { Percentage of students in school } \\
\text { eligible for free or reduced-price } \\
\text { lunch }\end{array}$} \\
\hline 0-25 percent & 66.8 & 80.3 & 68.1 & 29.6 & 6.5 & 13.4 \\
\hline 26-50 percent & 64.8 & 72.5 & 67.2 & 19.1 & 3.5 & 8.8 \\
\hline 51-75 percent & 72.7 & 77.5 & 66.7 & 18.0 & $3.4 !$ & 4.8 \\
\hline 76-100 percent & 81.7 & 83.1 & 68.1 & 23.9 & $\ddagger$ & 5.4 \\
\hline \multicolumn{7}{|l|}{ Locale } \\
\hline City & - & - & - & - & - & - \\
\hline Suburban & - & - & - & - & - & - \\
\hline Town & - & - & - & - & - & - \\
\hline Rural & - & - & - & - & - & - \\
\hline \multicolumn{7}{|l|}{$\begin{array}{l}\text { Student disability and English } \\
\text { language learner (ELL) status }{ }^{6}\end{array}$} \\
\hline \multicolumn{7}{|l|}{ Students with disabilities (SD) } \\
\hline Yes & 45.2 & 36.1 & 22.9 & $6.7 !$ & $\ddagger$ & $\ddagger$ \\
\hline No & 67.3 & 79.9 & 70.1 & 27.4 & 5.9 & 11.9 \\
\hline \multicolumn{7}{|l|}{ ELL } \\
\hline Yes & 62.3 & 57.8 & 45.8 & 15.0 & $\ddagger$ & $\ddagger$ \\
\hline No & 66.5 & 78.5 & 68.6 & 26.7 & 5.7 & 11.6 \\
\hline
\end{tabular}

See notes at end of table. 
Table A-31-1. Percentage of high school graduates who completed selected mathematics and science courses in high school, by year and selected student and school characteristics: Selected years, 1990-2009Continued

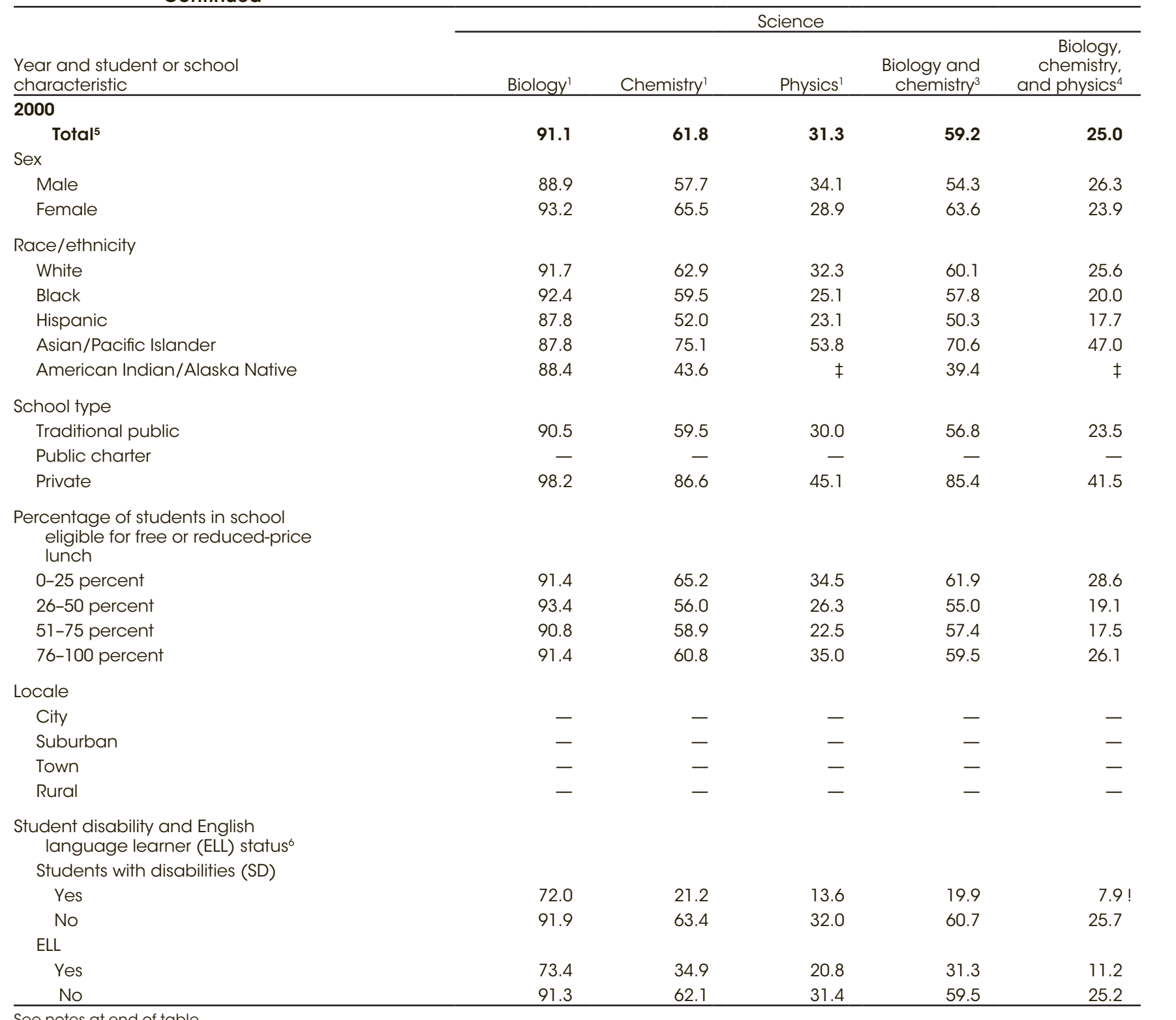


Table A-31-1. Percentage of high school graduates who completed selected mathematics and science courses in high school, by year and selected student and school characteristics: Selected years, 1990-2009Continued

\begin{tabular}{|c|c|c|c|c|c|c|}
\hline \multirow[b]{2}{*}{$\begin{array}{l}\text { Year and student or school } \\
\text { characteristic }\end{array}$} & \multicolumn{6}{|c|}{ Mathematics } \\
\hline & Algebra I & Geometry ${ }^{1}$ & $\begin{array}{r}\text { Algebra II/ } \\
\text { trigono } \\
\text { metry }^{2}\end{array}$ & $\begin{array}{r}\text { Analysis/ } \\
\text { pre- } \\
\text { calculus }^{2} \\
\end{array}$ & $\begin{array}{r}\text { Statistics/ } \\
\text { probability }{ }^{2} \\
\end{array}$ & Calculus $^{1}$ \\
\hline \multicolumn{7}{|l|}{2005} \\
\hline Total $^{5}$ & 68.4 & 83.8 & 71.3 & 29.4 & 7.7 & 13.6 \\
\hline \multicolumn{7}{|l|}{ Sex } \\
\hline Male & 66.8 & 81.9 & 68.0 & 28.0 & 7.7 & 14.0 \\
\hline Female & 69.8 & 85.6 & 74.4 & 30.8 & 7.8 & 13.2 \\
\hline \multicolumn{7}{|l|}{ Race/ethnicity } \\
\hline White & 66.8 & 83.9 & 72.4 & 32.0 & 8.5 & 15.3 \\
\hline Black & 75.4 & 85.0 & 69.3 & 17.9 & 5.8 & 5.5 \\
\hline Hispanic & 70.2 & 81.0 & 63.1 & 20.4 & 3.4 & 6.4 \\
\hline Asian/Pacific Islander & 65.4 & 87.1 & 79.5 & 48.8 & 12.9 & 30.0 \\
\hline American Indian/Alaska Native & 70.1 & 73.8 & 67.2 & 15.8 & $\ddagger$ & $\ddagger$ \\
\hline \multicolumn{7}{|l|}{ School type } \\
\hline Traditional public & 67.6 & 83.0 & 69.3 & 27.6 & 7.7 & 12.5 \\
\hline Public charter & 84.5 & 78.1 & 69.3 & $\ddagger$ & $\ddagger$ & $\ddagger$ \\
\hline Private & 74.4 & 91.2 & 89.6 & 45.3 & 8.3 & 23.9 \\
\hline \multicolumn{7}{|l|}{$\begin{array}{l}\text { Percentage of students in school } \\
\text { eligible for free or reduced-price } \\
\text { lunch }\end{array}$} \\
\hline 0-25 percent & 65.4 & 82.2 & 70.9 & 34.0 & 10.2 & 15.7 \\
\hline 26-50 percent & 69.5 & 84.2 & 69.8 & 23.4 & 6.7 & 10.8 \\
\hline 51-75 percent & 74.3 & 82.2 & 66.3 & 19.2 & 3.3 & 6.9 \\
\hline 76-100 percent & 75.1 & 88.2 & 69.4 & 18.2 & $2.8 !$ & 4.9 \\
\hline \multicolumn{7}{|l|}{ Locale } \\
\hline City & - & - & - & - & - & - \\
\hline Suburban & - & - & - & - & - & - \\
\hline Town & - & - & - & - & - & - \\
\hline Rural & - & - & - & - & - & - \\
\hline \multicolumn{7}{|l|}{$\begin{array}{l}\text { Student disability and English } \\
\text { language learner (ELL) status }\end{array}$} \\
\hline \multicolumn{7}{|l|}{ Students with disabilities (SD) } \\
\hline Yes & 49.5 & 47.8 & 27.9 & 6.0 & 2.2 & 2.0 \\
\hline No & 69.9 & 87.0 & 75.2 & 31.6 & 8.3 & 14.7 \\
\hline \multicolumn{7}{|l|}{ ELL } \\
\hline Yes & 63.7 & 70.1 & 48.0 & 13.8 & 3.9 & 6.1 \\
\hline No & 68.4 & 84.3 & 72.0 & 30.0 & 7.9 & 13.8 \\
\hline
\end{tabular}

See notes at end of table. 
Table A-31-1. Percentage of high school graduates who completed selected mathematics and science courses in high school, by year and selected student and school characteristics: Selected years, 1990-2009Continued

\begin{tabular}{|c|c|c|c|c|c|}
\hline \multirow[b]{2}{*}{$\begin{array}{l}\text { Year and student or school } \\
\text { characteristic }\end{array}$} & \multicolumn{5}{|c|}{ Science } \\
\hline & Biology ${ }^{1}$ & Chemistry ${ }^{\urcorner}$ & Physics $^{1}$ & $\begin{array}{r}\text { Biology and } \\
\text { chemistry }^{3}\end{array}$ & $\begin{array}{r}\text { Biology, } \\
\text { chemistry, } \\
\text { and physics } \\
\end{array}$ \\
\hline \multicolumn{6}{|l|}{2005} \\
\hline Total $^{5}$ & 92.5 & 66.4 & 32.9 & 64.3 & 27.4 \\
\hline \multicolumn{6}{|l|}{ Sex } \\
\hline Male & 91.0 & 62.7 & 34.9 & 60.3 & 28.2 \\
\hline Female & 93.9 & 70.0 & 31.0 & 68.0 & 26.5 \\
\hline \multicolumn{6}{|l|}{ Race/ethnicity } \\
\hline White & 92.8 & 67.4 & 34.8 & 65.3 & 29.0 \\
\hline Black & 93.7 & 63.6 & 25.8 & 62.0 & 21.3 \\
\hline Hispanic & 89.2 & 59.3 & 23.4 & 57.2 & 18.8 \\
\hline Asian/Pacific Islander & 92.4 & 79.7 & 50.3 & 75.5 & 42.9 \\
\hline American Indian/Alaska Native & 91.5 & 48.9 & 18.1 & 47.6 & $\ddagger$ \\
\hline \multicolumn{6}{|l|}{ School type } \\
\hline Traditional public & 92.1 & 64.2 & 30.6 & 62.0 & 24.8 \\
\hline Public charter & 91.6 & 72.2 & $36.7 !$ & 67.0 & $33.9 !$ \\
\hline Private & 96.1 & 86.8 & 53.8 & 85.1 & 49.9 \\
\hline \multicolumn{6}{|l|}{$\begin{array}{l}\text { Percentage of students in school } \\
\text { eligible for free or reduced-price } \\
\text { lunch }\end{array}$} \\
\hline 0-25 percent & 92.8 & 68.4 & 35.3 & 65.9 & 28.7 \\
\hline 26-50 percent & 93.0 & 61.0 & 26.9 & 59.1 & 21.8 \\
\hline 51-75 percent & 86.7 & 57.0 & 20.9 & 54.1 & 16.1 \\
\hline 76-100 percent & 90.2 & 67.6 & 21.2 & 64.1 & 17.8 \\
\hline \multicolumn{6}{|l|}{ Locale } \\
\hline City & - & - & - & - & - \\
\hline Suburban & - & - & - & - & - \\
\hline Town & - & - & - & - & - \\
\hline Rural & - & - & - & - & - \\
\hline \multicolumn{6}{|l|}{$\begin{array}{l}\text { Student disability and English } \\
\text { language learner (ELL) status }\end{array}$} \\
\hline \multicolumn{6}{|l|}{ Students with disabilities (SD) } \\
\hline Yes & 71.6 & 26.6 & 13.2 & 24.8 & 6.6 \\
\hline No & 94.4 & 69.9 & 34.5 & 67.8 & 29.0 \\
\hline \multicolumn{6}{|l|}{ ELL } \\
\hline Yes & 81.4 & 46.1 & 20.2 & 43.0 & 13.8 \\
\hline $\mathrm{No}$ & 92.9 & 67.0 & 33.2 & 64.9 & 27.6 \\
\hline
\end{tabular}

See notes at end of table. 
Table A-31-1. Percentage of high school graduates who completed selected mathematics and science courses in high school, by year and selected student and school characteristics: Selected years, 1990-2009Continued

\begin{tabular}{|c|c|c|c|c|c|c|}
\hline \multirow[b]{2}{*}{$\begin{array}{l}\text { Year and student or school } \\
\text { characteristic }\end{array}$} & \multicolumn{6}{|c|}{ Mathematics } \\
\hline & Algebra I' & Geometry & $\begin{array}{r}\text { Algebra II/ } \\
\text { trigo- } \\
\text { nometry }\end{array}$ & $\begin{array}{r}\text { Analysis/pre- } \\
\text { calculus }^{2} \\
\end{array}$ & $\begin{array}{r}\text { Statistics/ } \\
\text { probability }\end{array}$ & Calculus $^{1}$ \\
\hline \multicolumn{7}{|l|}{2009} \\
\hline Total $^{5}$ & 68.9 & 88.3 & 75.8 & 35.3 & 10.8 & 15.9 \\
\hline \multicolumn{7}{|l|}{ Sex } \\
\hline Male & 68.5 & 86.6 & 73.8 & 33.8 & 10.7 & 16.1 \\
\hline Female & 69.3 & 89.9 & 77.8 & 36.6 & 10.9 & 15.7 \\
\hline \multicolumn{7}{|l|}{ Race/ethnicity } \\
\hline White & 67.0 & 88.8 & 77.4 & 37.9 & 11.6 & 17.5 \\
\hline Black & 77.2 & 88.4 & 70.6 & 22.7 & 7.9 & 6.1 \\
\hline Hispanic & 75.4 & 87.0 & 71.4 & 26.5 & 7.5 & 8.6 \\
\hline Asian/Pacific Islander & 53.3 & 86.1 & 83.0 & 60.5 & 17.6 & 42.2 \\
\hline American Indian/Alaska Native & 74.8 & 81.6 & 66.6 & 18.5 & $\ddagger$ & $\ddagger$ \\
\hline \multicolumn{7}{|l|}{ School type } \\
\hline Traditional public & 68.2 & 88.1 & 74.9 & 34.0 & 10.7 & 15.4 \\
\hline Public charter & 79.0 & 86.9 & 77.8 & 34.1 & & $\ddagger$ \\
\hline Private & 74.7 & 90.0 & 84.6 & 47.5 & 12.5 & 23.3 \\
\hline \multicolumn{7}{|l|}{$\begin{array}{l}\text { Percentage of students in school } \\
\text { eligible for free or reduced-price } \\
\text { lunch }\end{array}$} \\
\hline 0-25 percent & 61.3 & 89.7 & 80.1 & 43.1 & 14.8 & 22.6 \\
\hline 26-50 percent & 70.9 & 88.4 & 74.7 & 29.7 & 8.6 & 11.8 \\
\hline 51-75 percent & 75.8 & 87.4 & 69.3 & 25.4 & 7.5 & 9.8 \\
\hline 76-100 percent & 80.1 & 88.8 & 70.7 & 25.5 & 5.1 & 7.5 \\
\hline \multicolumn{7}{|l|}{ Locale } \\
\hline City & 72.5 & 89.1 & 74.9 & 36.7 & 10.6 & 15.5 \\
\hline Suburban & 62.8 & 89.4 & 78.7 & 39.0 & 13.1 & 19.5 \\
\hline Town & 76.9 & 86.4 & 71.4 & 30.1 & 8.4 & 10.7 \\
\hline Rural & 70.2 & 86.3 & 74.5 & 30.0 & 8.6 & 13.5 \\
\hline \multicolumn{7}{|l|}{$\begin{array}{l}\text { Student disability and English } \\
\text { language learner (ELL) status }{ }^{6}\end{array}$} \\
\hline \multicolumn{7}{|l|}{ Students with disabilities (SD) } \\
\hline Yes & 56.0 & 61.1 & 39.5 & 9.7 & 3.9 & 3.0 \\
\hline No & 70.1 & 90.7 & 79.1 & 37.6 & 11.4 & 17.1 \\
\hline \multicolumn{7}{|l|}{ ELL } \\
\hline Yes & 73.3 & 76.2 & 58.1 & 19.4 & 4.4 & 4.7 \\
\hline No & 68.8 & 88.5 & 76.2 & 35.6 & 10.9 & 16.2 \\
\hline
\end{tabular}

See notes at end of table. 
Table A-31-1. Percentage of high school graduates who completed selected mathematics and science courses in high school, by year and selected student and school characteristics: Selected years, 1990-2009Continued

\begin{tabular}{|c|c|c|c|c|c|}
\hline \multirow[b]{2}{*}{$\begin{array}{l}\text { Year and student or school } \\
\text { characteristic }\end{array}$} & \multicolumn{5}{|c|}{ Science } \\
\hline & Biology ${ }^{1}$ & Chemistry $^{\top}$ & Physics $^{1}$ & $\begin{array}{r}\text { Biology and } \\
\text { chemistry }^{3}\end{array}$ & $\begin{array}{r}\text { Biology, } \\
\text { chemistry, } \\
\text { and physics }{ }^{4}\end{array}$ \\
\hline \multicolumn{6}{|l|}{2009} \\
\hline Total $^{5}$ & 95.6 & 70.4 & 36.1 & 68.3 & 30.1 \\
\hline \multicolumn{6}{|l|}{ Sex } \\
\hline Male & 94.9 & 67.4 & 39.2 & 65.0 & 31.9 \\
\hline Female & 96.2 & 73.4 & 33.0 & 71.4 & 28.3 \\
\hline \multicolumn{6}{|l|}{ Race/ethnicity } \\
\hline White & 95.6 & 71.5 & 37.6 & 68.9 & 31.4 \\
\hline Black & 96.3 & 65.3 & 26.9 & 64.3 & 21.9 \\
\hline Hispanic & 94.8 & 65.7 & 28.6 & 64.2 & 22.7 \\
\hline Asian/Pacific Islander & 95.8 & 84.8 & 61.1 & 82.7 & 54.4 \\
\hline American Indian/Alaska Native & 94.5 & 44.5 & 19.8 & 43.9 & 13.6 \\
\hline \multicolumn{6}{|l|}{ School type } \\
\hline Traditional public & 95.3 & 68.9 & 34.6 & 66.9 & 28.8 \\
\hline Public charter & 94.0 & 56.8 & 40.0 & 55.7 & $23.2 !$ \\
\hline Private & 98.6 & 87.4 & 49.5 & 83.3 & 43.9 \\
\hline \multicolumn{6}{|l|}{$\begin{array}{l}\text { Percentage of students in school } \\
\text { eligible for free or reduced-price } \\
\text { lunch }\end{array}$} \\
\hline 0-25 percent & 96.4 & 76.3 & 46.5 & 74.9 & 40.4 \\
\hline 26-50 percent & 94.5 & 64.0 & 27.6 & 61.6 & 22.2 \\
\hline 51-75 percent & 95.6 & 65.6 & 29.4 & 64.2 & 22.7 \\
\hline 76-100 percent & 95.6 & 69.4 & 26.6 & 68.2 & 22.8 \\
\hline \multicolumn{6}{|l|}{ Locale } \\
\hline City & 96.4 & 74.0 & 38.8 & 70.8 & 31.6 \\
\hline Suburban & 97.1 & 76.7 & 43.8 & 75.4 & 38.6 \\
\hline Town & 92.2 & 62.3 & 24.0 & 60.4 & 18.9 \\
\hline Rural & 93.7 & 59.6 & 26.0 & 57.2 & 19.7 \\
\hline \multicolumn{6}{|l|}{$\begin{array}{l}\text { Student disability and English } \\
\text { language learner (ELL) status }\end{array}$} \\
\hline \multicolumn{6}{|l|}{ Students with disabilities (SD) } \\
\hline Yes & 82.4 & 35.4 & 19.3 & 33.8 & 12.0 \\
\hline No & 96.8 & 73.6 & 37.6 & 71.4 & 31.7 \\
\hline \multicolumn{6}{|l|}{ ELL } \\
\hline Yes & 86.9 & 47.4 & 23.2 & 43.8 & 15.4 \\
\hline No & 95.7 & 70.9 & 36.3 & 68.7 & 30.3 \\
\hline \multicolumn{6}{|c|}{$\begin{array}{l}\text { - Not available. } \\
\text { \# Rounds to zero. } \\
\text { ! Interpret data with caution. The coefficient of variation (CV) for this estimate is } 30 \text { percent or greater. } \\
\text { † Reporting standards not met. Either there are too few cases or the coefficient of variation (CV) is } 50 \text { percent or greater. } \\
\text { I Percentages are for students who earned at least one Carnegie credit. } \\
2 \text { Percentages are for students who earned at least one-half of a Carnegie credit. Courses listed are composites made up of individual courses that are } \\
\text { relatively similar in content. For example, algebra II/trigonometry comprises courses including trigonometry and pre-IB algebra II/trigonometry. } \\
{ }^{3} \text { Percentages are for students who earned at least one Carnegie credit each in biology and chemistry. } \\
{ }^{4} \text { Percentages are for students who earned at least one Carnegie credit each in biology, chemistry, and physics. } \\
{ }^{5} \text { Includes other racial/ethnic groups not shown separately in the table and cases that were missing information on race/ethnicity and/or sex of } \\
\text { student. } \\
{ }^{6} \text { In } 2009 \text {, the exclusion rate for Students with Disabilities was } 3 \text { percent for grade 12, and the exclusion rate for English Language Learner (ELL) students } \\
\text { was } 1 \text { percent for grade } 12 \text {. The } 2009 \text { SD estimates included students with a "504" plan. } \\
\text { NOTE: For a transcript to be included in the analyses, it had to meet three requirements: (1) the graduate received either a standard or honors diploma, } \\
\text { (2) the graduate's transcript contained } 16 \text { or more Carnegie credits, and (3) the graduate's transcript contained more than } 0 \text { Carnegie credits in } \\
\text { English courses. Race categories exclude persons of Hispanic ethnicity. For more information on race/ethnicity, free or reduced-price lunch, or locale, } \\
\text { see Appendix C - Commonly Used Measures. For more information on the National Assessment of Educational Progress (NAEP) or the High School } \\
\text { Transcript Study (HSTS), please see Appendix B - Guide to Sources. } \\
\text { SOURCE: U.S. Department of Education, National Center for Education Statistics, High School Transcript Study (HSTS), Selected years, } 1990-2009 .\end{array}$} \\
\hline
\end{tabular}


Table A-31-2. Average National Assessment of Educational Progress (NAEP) 12th-grade mathematics scale scores of high school graduates, by highest mathematics course taken and selected student and school characteristics: 2009

\begin{tabular}{|c|c|c|c|c|c|c|c|}
\hline$\underline{\text { Student and school chacteristics }}$ & $\begin{array}{r}\text { Algebra I or } \\
\text { below }^{1}\end{array}$ & Geometry & $\begin{array}{r}\begin{array}{r}\text { Algebra II/ } \\
\text { trigonom- } \\
\text { etry }^{2}\end{array} \\
\end{array}$ & $\begin{array}{r}\text { Analysis/ } \\
\text { precalcu- } \\
\text { lus }^{2}\end{array}$ & $\begin{array}{r}\text { Statistics/ } \\
\text { probabil- } \\
\text { ity }\end{array}$ & $\begin{array}{r}\text { Advanced } \\
\text { math- } \\
\text { ematics, } \\
\text { other }^{3} \\
\end{array}$ & Calculus \\
\hline Total $^{4}$ & 114 & 127 & 143 & 166 & 164 & 154 & 193 \\
\hline \multicolumn{8}{|l|}{ Sex } \\
\hline Male & 117 & 128 & 145 & 169 & 165 & 156 & 197 \\
\hline Female & 111 & 126 & 142 & 163 & 162 & 153 & 190 \\
\hline \multicolumn{8}{|l|}{ Race/ethnicity } \\
\hline White & 117 & 133 & 150 & 172 & 169 & 160 & 194 \\
\hline Black & 104 & 114 & 129 & 147 & 139 & 138 & 170 \\
\hline Hispanic & 109 & 122 & 136 & 155 & 154 & 142 & 179 \\
\hline Asian/Pacific Islander & $\ddagger$ & 129 & 149 & 170 & 176 & 164 & 203 \\
\hline American Indian/Alaska Native & $\ddagger$ & $\ddagger$ & 143 & $\ddagger$ & $\ddagger$ & $\ddagger$ & $\ddagger$ \\
\hline \multicolumn{8}{|l|}{ School type } \\
\hline Traditional public & 114 & 127 & 143 & 166 & 164 & 155 & 193 \\
\hline Public charter & $\ddagger$ & $\ddagger$ & 137 & 141 & 132 & $\ddagger$ & $\ddagger$ \\
\hline Private & $\ddagger$ & 123 & 146 & 169 & 168 & 146 & 193 \\
\hline \multicolumn{8}{|l|}{$\begin{array}{l}\text { Percentage of students in school } \\
\text { eligible for free or reduced- } \\
\text { price lunch }\end{array}$} \\
\hline 0-25 percent & 116 & 134 & 151 & 173 & 173 & 162 & 199 \\
\hline 26-50 percent & 115 & 127 & 144 & 165 & 162 & 154 & 189 \\
\hline 51-75 percent & 111 & 123 & 136 & 156 & 149 & 146 & 179 \\
\hline 76-100 percent & 107 & 115 & 126 & 144 & 137 & 131 & 163 \\
\hline \multicolumn{8}{|l|}{ Locale } \\
\hline City & 110 & 125 & 140 & 163 & 163 & 151 & 195 \\
\hline Suburban & 112 & 127 & 144 & 169 & 167 & 157 & 195 \\
\hline Town & 114 & 129 & 144 & 166 & 164 & 152 & 191 \\
\hline Rural & 117 & 129 & 145 & 165 & 157 & 155 & 187 \\
\hline \multicolumn{8}{|l|}{$\begin{array}{l}\text { Student disability and English } \\
\text { language learner (ELL) status }{ }^{5}\end{array}$} \\
\hline \multicolumn{8}{|l|}{ Students with disabilities (SD) } \\
\hline Yes & 103 & 114 & 126 & 166 & 136 & 134 & 197 \\
\hline No & 122 & 129 & 144 & 166 & 164 & 156 & 193 \\
\hline \multicolumn{8}{|l|}{ ELL } \\
\hline Yes & 104 & 113 & 121 & 144 & $\ddagger$ & 129 & $\ddagger$ \\
\hline No & 114 & 128 & 144 & 166 & 164 & 155 & 193 \\
\hline
\end{tabular}

‡ Reporting standards not met (too few cases).

1 Includes basic math, general math, applied math, pre-algebra, and algebra I.

${ }_{2}^{2}$ Courses listed are composites made up of individual courses that are relatively similar in content. For example, algebra II/trigonometry comprises courses including trigonometry and pre-IB algebra II/trigonometry.

${ }_{3}^{3}$ Includes courses such as actuarial sciences, pure mathematics, discrete math, and advanced functions and modeling.

${ }^{4}$ Includes other racial/ethnic groups not shown separately in the table and cases that were missing information on race/ethnicity and/or sex of student.

${ }^{5}$ In 2009, the exclusion rate for SD students was 4 percent for grade 4 , 3 percent for grade 8 , and 3 percent for grade 12, and the exclusion rate for ELL students was 2 percent for grade 4, 1 percent for grade 8 and 1 percent for grade 12. The 2009 SD estimates included students with a "504" plan.

NOTE: The scale of the National Assessment for Educational Progress (NAEP) mathematics assessment for grade 12 ranges from 0 to 300 . For a transcript to be included in the analyses, it had to meet three requirements: (1) the graduate received either a standard or honors diploma, (2) the graduate's transcript contained 16 or more Carnegie credits, and (3) the graduate's transcript contained more than 0 Carnegie credits in English courses. Race categories exclude persons of Hispanic ethnicity. For more information on race/ethnicity, see Appendix C - Commonly Used Measures. For more information on the National Assessment of Educational Progress (NAEP) or the High School Transcript Study (HSTS), see Appendix B - Guide to Sources. SOURCE: U.S. Department of Education, National Center for Education Statistics, National Assessment of Educational Progress (NAEP), 2009 Mathematics Assessment; and High School Transcript Study (HSTS), 2009. 
This page intentionally left blank.

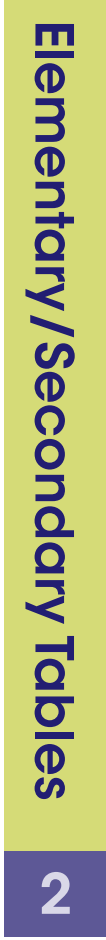




\section{Public High School Graduation Rates}

Table A-32-1. Averaged freshman graduation rate for public high school students and number of graduates, by state or jurisdiction: Selected school years, 1990-91 through 2008-09

\begin{tabular}{|c|c|c|c|c|c|c|c|}
\hline \multirow[b]{2}{*}{ State or jurisdiction } & \multicolumn{7}{|c|}{ Averaged freshman graduation rate } \\
\hline & 1990-91 & $1995-96$ & $2000-01$ & 2005-06 & $2006-07$ & $2007-08$ & 2008-09 \\
\hline United States & 73.7 & 71.0 & 71.7 & $73.4^{1}$ & 73.9 & $74.7^{1}$ & $75.5^{1}$ \\
\hline Alabama & 69.8 & 62.7 & 63.7 & 66.2 & 67.1 & 69.0 & 69.9 \\
\hline Alaska & 74.6 & 68.3 & 68.0 & 66.5 & 69.0 & 69.1 & 72.6 \\
\hline Arizona & 76.7 & 60.8 & 74.2 & 70.5 & 69.6 & 70.7 & 72.5 \\
\hline Arkansas & 76.6 & 74.2 & 73.9 & 80.4 & 74.4 & 76.4 & 74.0 \\
\hline California & 69.6 & 67.6 & 71.6 & 69.2 & 70.7 & 71.2 & 71.0 \\
\hline Colorado & 76.3 & 74.8 & 73.2 & 75.5 & 76.6 & 75.4 & 77.6 \\
\hline Connecticut & 80.2 & 76.1 & 77.5 & 80.9 & 81.8 & 82.2 & 75.4 \\
\hline Delaware & 72.5 & 70.4 & 71.0 & 76.3 & 71.9 & 72.1 & 73.7 \\
\hline District of Columbia & 54.5 & 49.7 & 60.2 & 65.4 & 54.8 & 56.0 & 62.4 \\
\hline Florida & 65.6 & 62.3 & 61.2 & 63.6 & 65.0 & 66.9 & 68.9 \\
\hline Georgia & 70.3 & 61.9 & 58.7 & 62.4 & 64.1 & 65.4 & 67.8 \\
\hline Hawaii & 75.9 & 74.5 & 68.3 & 75.5 & 75.4 & 76.0 & 75.3 \\
\hline Idaho & 79.6 & 80.5 & 79.6 & 80.5 & 80.4 & 80.1 & 80.6 \\
\hline Illinois & 76.6 & 75.2 & 75.6 & 79.7 & 79.5 & 80.4 & 77.7 \\
\hline Indiana & 76.9 & 73.6 & 72.1 & 73.3 & 73.9 & 74.1 & 75.2 \\
\hline lowa & 84.4 & 84.3 & 82.8 & 86.9 & 86.5 & 86.4 & 85.7 \\
\hline Kansas & 80.8 & 77.1 & 76.5 & 77.5 & 78.8 & 79.0 & 80.2 \\
\hline Kentucky & 72.9 & 71.3 & 69.8 & 77.2 & 76.4 & 74.4 & 77.6 \\
\hline Louisiana & 57.5 & 61.7 & 63.7 & 59.5 & 61.3 & 63.5 & 67.3 \\
\hline Maine & 80.7 & 73.7 & 76.4 & 76.3 & 78.5 & 79.1 & 79.9 \\
\hline Maryland & 77.5 & 78.3 & 78.7 & 79.9 & 80.0 & 80.4 & 80.1 \\
\hline Massachusetts & 79.1 & 78.0 & 78.9 & 79.5 & 80.8 & 81.5 & 83.3 \\
\hline Michigan & 72.1 & 71.4 & 75.4 & 72.2 & 77.0 & 76.3 & 75.3 \\
\hline Minnesota & 90.8 & 86.1 & 83.6 & 86.2 & 86.5 & 86.4 & 87.4 \\
\hline Mississippi & 63.3 & 59.7 & 59.7 & 63.5 & 63.5 & 63.9 & 62.0 \\
\hline Missouri & 76.0 & 75.0 & 75.5 & 81.0 & 81.9 & 82.4 & 83.1 \\
\hline Montana & 84.4 & 83.9 & 80.0 & 81.9 & 81.5 & 82.0 & 82.0 \\
\hline Nebraska & 86.7 & 85.6 & 83.8 & 87.0 & 86.3 & 83.8 & 82.9 \\
\hline Nevada & 77.0 & 65.8 & 70.0 & 55.8 & 54.2 & 56.3 & 56.3 \\
\hline New Hampshire & 78.6 & 77.5 & 77.8 & 81.1 & 81.7 & 83.3 & 84.3 \\
\hline New Jersey & 81.4 & 82.8 & 85.4 & 84.8 & 84.4 & 84.6 & 85.3 \\
\hline New Mexico & 70.1 & 63.7 & 65.9 & 67.3 & 59.1 & 66.8 & 64.8 \\
\hline New York & 66.1 & 63.6 & 61.5 & 67.4 & 68.9 & 70.9 & 73.5 \\
\hline North Carolina & 71.3 & 66.5 & 66.5 & 71.8 & 68.6 & 72.8 & 75.1 \\
\hline North Dakota & 87.6 & 89.5 & 85.4 & 82.2 & 83.1 & 83.8 & 87.4 \\
\hline Ohio & 77.5 & 74.5 & 76.5 & 79.2 & 78.7 & 79.0 & 79.6 \\
\hline Oklahoma & 76.5 & 75.6 & 75.8 & 77.8 & 77.8 & 78.0 & 77.3 \\
\hline Oregon & 72.7 & 68.3 & 68.3 & 73.0 & 73.8 & 76.7 & 76.5 \\
\hline Pennsylvania & 79.7 & 80.0 & 79.0 & 83.5 & 83.0 & 82.7 & 80.5 \\
\hline Rhode Island & 75.0 & 72.7 & 73.5 & 77.8 & 78.4 & 76.4 & 75.3 \\
\hline South Carolina & 66.6 & 60.9 & 56.5 & 61.0 & 58.9 & 62.2 & 66.0 \\
\hline South Dakota & 83.8 & 84.5 & 77.4 & 84.5 & 82.5 & 84.4 & 81.7 \\
\hline Tennessee & 69.8 & 66.6 & 59.0 & 70.7 & 72.6 & 74.9 & 77.4 \\
\hline Texas & 72.2 & 66.1 & 70.8 & 72.5 & 71.9 & 73.1 & 75.4 \\
\hline Utah & 77.5 & 76.9 & 81.6 & 78.6 & 76.6 & 74.3 & 79.4 \\
\hline Vermont & 79.5 & 85.3 & 80.2 & 82.3 & 88.5 & 89.3 & 89.6 \\
\hline Virginia & 76.2 & 76.2 & 77.5 & 74.5 & 75.5 & 77.0 & 78.4 \\
\hline Washington & 75.7 & 75.5 & 69.2 & 72.9 & 74.8 & 71.9 & 73.7 \\
\hline West Virginia & 76.6 & 77.0 & 75.9 & 76.9 & 78.2 & 77.3 & 77.0 \\
\hline Wisconsin & 85.2 & 83.6 & 83.3 & 87.5 & 88.5 & 89.6 & 90.7 \\
\hline Wyoming & 81.1 & 77.7 & 73.4 & 76.1 & 75.8 & 76.0 & 75.2 \\
\hline
\end{tabular}


Table A-32-1. Averaged freshman graduation rate for public high school students and number of graduates, by state or jurisdiction: Selected school years, 1990-91 through 2008-09-Continued

\begin{tabular}{|c|c|c|c|c|c|c|c|}
\hline \multirow[b]{2}{*}{$\underline{\text { State or jurisdiction }}$} & \multicolumn{7}{|c|}{ Number of graduates } \\
\hline & $1990-91$ & $1995-96$ & $2000-01$ & $2005-06$ & $2006-07$ & 2007-08 & $2008-09$ \\
\hline United States & $2,234,893$ & $2,273,109$ & $2,569,200$ & $2,815,544^{1}$ & $2,893,045$ & $3,001,337^{1}$ & $3,039,015^{1}$ \\
\hline Alabama & 39,042 & 35,043 & 37,082 & 37,918 & 38,912 & 41,346 & 42,082 \\
\hline Alaska & 5,458 & 5,945 & 6,812 & 7,361 & 7,666 & 7,855 & 8,008 \\
\hline Arizona & 31,282 & 30,008 & 46,733 & 54,091 & 55,954 & 61,667 & 62,374 \\
\hline Arkansas & 25,668 & 25,094 & 27,100 & 28,790 & 27,166 & 28,725 & 28,057 \\
\hline California & 234,164 & 259,071 & 315,189 & 343,515 & 356,641 & 374,561 & 372,310 \\
\hline Colorado & 31,293 & 32,608 & 39,241 & 44,424 & 45,628 & 46,082 & 47,459 \\
\hline Connecticut & 27,290 & 26,319 & 30,388 & 36,222 & 37,541 & 38,419 & 34,968 \\
\hline Delaware & 5,223 & 5,609 & 6,614 & 7,275 & 7,205 & 7,388 & 7,839 \\
\hline District of Columbia & 3,369 & 2,696 & 2,808 & 3,150 & 2,944 & 3,352 & 3,517 \\
\hline Florida & 87,419 & 89,242 & 111,112 & 134,686 & 142,284 & 149,046 & 153,461 \\
\hline Georgia & 60,088 & 56,271 & 62,499 & 73,498 & 77,829 & 83,505 & 88,003 \\
\hline Hawaii & 8,974 & 9,387 & 10,102 & 10,922 & 11,063 & 11,613 & 11,508 \\
\hline Idaho & 11,961 & 14,667 & 15,941 & 16,096 & 16,242 & 16,567 & 16,807 \\
\hline Illinois & 103,329 & 104,626 & 110,624 & 126,817 & 130,220 & 135,143 & 131,670 \\
\hline Indiana & 57,892 & 56,330 & 56,172 & 57,920 & 59,887 & 61,901 & 63,663 \\
\hline lowa & 28,593 & 31,689 & 33,774 & 33,693 & 34,127 & 34,573 & 33,926 \\
\hline Kansas & 24,414 & 25,786 & 29,360 & 29,818 & 30,139 & 30,737 & 30,368 \\
\hline Kentucky & 35,835 & 36,641 & 36,957 & 38,449 & 39,099 & 39,339 & 41,851 \\
\hline Louisiana & 33,489 & 36,467 & 38,314 & 33,275 & 34,274 & 34,401 & 35,622 \\
\hline Maine & 13,151 & 11,795 & 12,654 & 12,950 & 13,151 & 14,350 & 14,093 \\
\hline Maryland & 39,014 & 41,785 & 49,222 & 55,536 & 57,564 & 59,171 & 58,304 \\
\hline Massachusetts & 50,216 & 47,993 & 54,393 & 61,272 & 63,903 & 65,197 & 65,258 \\
\hline Michigan & 88,234 & 85,530 & 96,515 & 102,582 & 111,838 & 115,183 & 112,742 \\
\hline Minnesota & 46,474 & 50,481 & 56,581 & 58,898 & 59,497 & 60,409 & 59,729 \\
\hline Mississippi & 23,665 & 23,032 & 23,748 & 23,848 & 24,186 & 24,795 & 24,505 \\
\hline Missouri & 46,928 & 49,011 & 54,138 & 58,417 & 60,275 & 61,717 & 62,969 \\
\hline Montana & 9,013 & 10,139 & 10,628 & 10,283 & 10,122 & 10,396 & 10,077 \\
\hline Nebraska & 16,500 & 18,014 & 19,658 & 19,764 & 19,873 & 20,035 & 19,501 \\
\hline Nevada & 9,370 & 10,374 & 15,127 & 16,455 & 17,149 & 18,815 & 19,904 \\
\hline New Hampshire & 10,059 & 10,094 & 12,294 & 13,988 & 14,452 & 14,982 & 14,757 \\
\hline New Jersey & 67,003 & 67,704 & 76,130 & 90,049 & 93,013 & 94,994 & 95,085 \\
\hline New Mexico & 15,157 & 15,402 & 18,199 & 17,822 & 16,131 & 18,264 & 17,931 \\
\hline New York & 133,562 & 134,401 & 141,884 & 161,817 & 168,333 & 176,310 & 180,917 \\
\hline North Carolina & 62,792 & 57,014 & 63,288 & 76,710 & 76,031 & 83,307 & 86,712 \\
\hline North Dakota & 7,573 & 8,027 & 8,445 & 7,192 & 7,159 & 6,999 & 7,232 \\
\hline Ohio & 107,484 & 102,098 & 111,281 & 117,356 & 117,658 & 120,758 & 122,203 \\
\hline Oklahoma & 33,007 & 33,060 & 37,458 & 36,497 & 37,100 & 37,630 & 37,219 \\
\hline Oregon & 24,597 & 26,570 & 29,939 & 32,394 & 33,446 & 34,949 & 35,138 \\
\hline Pennsylvania & 104,770 & 105,981 & 114,436 & 127,830 & 128,603 & 130,298 & 130,658 \\
\hline Rhode Island & 7,744 & 7,689 & 8,603 & 10,108 & 10,384 & 10,347 & 10,028 \\
\hline South Carolina & 32,999 & 30,182 & 30,026 & 34,970 & 35,108 & 35,303 & 39,114 \\
\hline South Dakota & 7,127 & 8,532 & 8,881 & 8,589 & 8,346 & 8,582 & 8,123 \\
\hline Tennessee & 44,847 & 43,792 & 40,642 & 50,880 & 54,502 & 57,486 & 60,368 \\
\hline Texas & 174,306 & 171,844 & 215,316 & 240,485 & 241,193 & 252,121 & 264,275 \\
\hline Utah & 22,219 & 26,293 & 31,036 & 29,050 & 28,276 & 28,167 & 30,463 \\
\hline Vermont & 5,212 & 5,867 & 6,856 & 6,779 & 7,317 & 7,392 & 7,209 \\
\hline Virginia & 58,441 & 58,166 & 66,067 & 69,597 & 73,997 & 77,369 & 79,651 \\
\hline Washington & 42,514 & 49,862 & 55,081 & 60,213 & 62,801 & 61,625 & 62,764 \\
\hline West Virginia & 21,064 & 20,335 & 18,440 & 16,763 & 17,407 & 17,489 & 17,690 \\
\hline Wisconsin & 49,340 & 52,651 & 59,341 & 63,003 & 63,968 & 65,183 & 65,410 \\
\hline Wyoming & 5,728 & 5,892 & 6,071 & 5,527 & 5,441 & 5,494 & 5,493 \\
\hline $\begin{array}{l}\text { The 2005-06 national } \\
\text { includes graduates fror } \\
\text { NOTE: The averaged fre } \\
\text { count is the sum of the } \\
\text { divided by } 3 \text {. Ungraded } \\
\text { those who earned regu } \\
\text { For more information or } \\
\text { Common Core of Data } \\
\text { SOURCE: U.S. Departme } \\
\text { Dropout and Completi } \\
\text { 1990-91, Version 1b; } 19\end{array}$ & $\begin{array}{l}\text { lude imputed } \\
\text { schools. The } 2 \\
\text { lation rate is th } \\
\text { 7-graders } 5 \text { yec } \\
\text { e allocated to } \\
\text { or diplomas fo } \\
\text { student progr } \\
\text { ppendix B - G } \\
\text { on, National C } \\
\text { school year } 20 \\
1 \text { b; } 2000-01,\end{array}$ & $\begin{array}{l}\text { ta for the Distr } \\
\text { 8-09 nationa } \\
\text { number of gro } \\
\text { earlier, the nu } \\
\text { dividual grade } \\
\text { dvanced aca } \\
\text { s and persiste } \\
\text { e to Sources. } \\
\text { ter for Educat } \\
\text {-08; 2008-09, } \\
\text { sion 1b; } 2005\end{array}$ & $\begin{array}{l}\text { of Columbia, } \\
\text { imates inclu } \\
\text { ates divided } \\
\text { ber of 9th-grc } \\
\text { roportional } \\
\text { mic achiever } \\
\text { see Appen } \\
\text { Statistics, Co } \\
\text { son la; and }\end{array}$ & $\begin{array}{l}\text { nsylvania, an } \\
\text { mputed data } \\
\text { ne estimated } \\
4 \text { years earlie } \\
\text { ich state's enr } \\
\text { (e.g., honors } \\
\text { - Commonly } \\
\text { on Core of Do } \\
\text { e Nonfiscal S }\end{array}$ & $\begin{array}{l}\text { Uth Caroling } \\
\text { California and } \\
\text { iman enrollm } \\
\text { nd the numb } \\
\text { ent in those } \\
\text { oma) as def } \\
\text { d Measures. } \\
\text { CCD), "NCES } \\
\text { of Public Ele }\end{array}$ & $\begin{array}{l}\text { he } 2007-08 \text { esti } \\
\text { levada. } \\
\text { ht count } 4 \text { years } \\
\text { of } 10 \text { th-grader } \\
\text { ades. Graduate } \\
\text { d by the state } \\
\text { or more informa } \\
\text { ommon Core o }\end{array}$ & $\begin{array}{l}\text { ate for Maine } \\
\text { arlier. This } \\
\text { years earlier, } \\
\text { nclude only } \\
\text { urisdiction. } \\
\text { n on the } \\
\text { ata State } \\
\text { yducation," }\end{array}$ \\
\hline
\end{tabular}




\section{Indicator 33}

\section{Status Dropout Rates}

Table A-33-1. Status dropout rates of 16- through 24-year-olds in the civilian, noninstitutionalized population, by race/ ethnicity: October Current Population Survey (CPS) 1990-2010

\begin{tabular}{|c|c|c|c|c|c|c|}
\hline \multirow[b]{2}{*}{ Year } & \multirow[b]{2}{*}{ Total $^{1}$} & \multicolumn{4}{|c|}{ Race/ethnicity } & \multirow[b]{2}{*}{$\begin{array}{r}\text { American } \\
\text { Indian/ } \\
\text { Alaska Native } \\
\end{array}$} \\
\hline & & White & Black & Hispanic & $\begin{array}{r}\text { Asian/Pacific } \\
\text { Islander }\end{array}$ & \\
\hline 1990 & 12.1 & 9.0 & 13.2 & 32.4 & $4.9 !$ & $16.4 !$ \\
\hline 1991 & 12.5 & 8.9 & 13.6 & 35.3 & $3.5 !$ & $18.7 !$ \\
\hline 1992 & 11.0 & 7.7 & 13.7 & 29.4 & 5.7 & $17.5 !$ \\
\hline 1993 & 11.0 & 7.9 & 13.6 & 27.5 & 5.8 & $14.6 !$ \\
\hline 1994 & 11.5 & 7.7 & 12.6 & 30.0 & 5.8 & $10.2 !$ \\
\hline 1995 & 12.0 & 8.6 & 12.1 & 30.0 & 3.9 & $13.4 !$ \\
\hline 1996 & 11.1 & 7.3 & 13.0 & 29.4 & 5.3 & 13.0 \\
\hline 1997 & 11.0 & 7.6 & 13.4 & 25.3 & 6.9 & 14.5 \\
\hline 1998 & 11.8 & 7.7 & 13.8 & 29.5 & 4.1 & 11.8 \\
\hline 1999 & 11.2 & 7.3 & 12.6 & 28.6 & 4.3 & $\ddagger$ \\
\hline 2000 & 10.9 & 6.9 & 13.1 & 27.8 & 3.8 & 14.0 \\
\hline 2001 & 10.7 & 7.3 & 10.9 & 27.0 & 3.6 & 13.1 \\
\hline 2002 & 10.5 & 6.5 & 11.3 & 25.7 & 3.9 & 16.8 \\
\hline 2003 & 9.9 & 6.3 & 10.9 & 23.5 & 3.9 & 15.0 \\
\hline 2004 & 10.3 & 6.8 & 11.8 & 23.8 & 3.6 & 17.0 \\
\hline 2005 & 9.4 & 6.0 & 10.4 & 22.4 & 2.9 & 14.0 \\
\hline 2006 & 9.3 & 5.8 & 10.7 & 22.1 & 3.6 & 14.7 \\
\hline 2007 & 8.7 & 5.3 & 8.4 & 21.4 & 6.1 & 19.3 \\
\hline 2008 & 8.0 & 4.8 & 9.9 & 18.3 & 4.4 & 14.6 \\
\hline 2009 & 8.1 & 5.2 & 9.3 & 17.6 & 3.4 & 13.2 \\
\hline$\underline{2010}$ & 7.4 & 5.1 & 8.0 & 15.1 & 4.2 & 12.4 \\
\hline
\end{tabular}

! Interpret data with caution. The coefficient of variation (CV) for this estimate is 30 percent or greater.

$\ddagger$ Reporting standards not met (too few cases).

1 Total includes other race/ethnicity categories not separately shown.

NOTE: This table uses a different data source than tables A-SDE-2 and A-SDE-3; therefore, estimates for 2010 are not directly comparable to the estimates in tables A-SDE-2 and A-SDE-3. Race categories exclude persons of Hispanic ethnicity. For more information on race/ethnicity and the status dropout

rate, see Appendix C - Commonly Used Measures. For more information on the Current Population Survey (CPS), see Appendix B - Guide to Sources.

SOURCE: U.S. Department of Commerce, Census Bureau, Current Population Survey (CPS), October Supplement, $1990-2010$. 
Table A-33-2. Number of status dropouts and status dropout rates of 16- through 24-year-olds in the noninstitutionalized group quarters and household population, by nativity and selected characteristics: American Community Survey (ACS) 2010

\begin{tabular}{|c|c|c|c|c|c|}
\hline Characteristics & $\begin{array}{r}\text { Number of } \\
\text { status dropouts }\end{array}$ & $\begin{array}{r}\text { Status dropout } \\
\text { rate }\end{array}$ & $\begin{array}{r}\text { Percent of all } \\
\text { status dropouts }\end{array}$ & $\begin{array}{r}\text { Dropout rate } \\
\text { for those born } \\
\text { in the United } \\
\text { States }^{1}\end{array}$ & $\begin{array}{l}\text { Dropout rate } \\
\text { for those born } \\
\text { outside of the } \\
\text { United States }\end{array}$ \\
\hline Total $^{2}$ & $3,098,150$ & 7.9 & 100.0 & 6.5 & 18.4 \\
\hline \multicolumn{6}{|l|}{ Sex } \\
\hline Male & $1,840,700$ & 9.3 & 59.4 & 7.4 & 22.3 \\
\hline Female & $1,257,450$ & 6.5 & 40.6 & 5.6 & 13.8 \\
\hline \multicolumn{6}{|l|}{ Race/ethnicity } \\
\hline White & $1,141,870$ & 5.1 & 36.9 & 5.2 & 4.0 \\
\hline Black & 504,660 & 9.1 & 16.3 & 9.3 & 5.8 \\
\hline Hispanic & $1,286,750$ & 16.3 & 41.5 & 9.8 & 30.7 \\
\hline Asian & 50,940 & 2.8 & 1.6 & 1.9 & 3.7 \\
\hline $\begin{array}{l}\text { Native Hawaiian/Pacific } \\
\text { Islander }\end{array}$ & 3,520 & 4.5 & 0.1 & $3.8 !$ & $6.0 !$ \\
\hline $\begin{array}{l}\text { American Indian/Alaska } \\
\text { Native }\end{array}$ & 46,300 & 14.9 & 1.5 & 15.0 & $\ddagger$ \\
\hline Two or more races & 56,480 & 5.8 & 1.8 & 5.9 & 5.0 \\
\hline \multicolumn{6}{|l|}{ Male } \\
\hline White & 655,160 & 5.8 & 35.6 & 5.8 & 4.8 \\
\hline Black & 283,800 & 10.5 & 15.4 & 10.8 & 6.2 \\
\hline Hispanic & 806,820 & 19.5 & 43.8 & 11.3 & 35.8 \\
\hline Asian & 30,040 & 3.2 & 1.6 & 2.2 & 4.3 \\
\hline $\begin{array}{l}\text { Native Hawaiian/Pacific } \\
\quad \text { Islander } \\
\text { American Indian/Alaska }\end{array}$ & 1,670 & 4.3 & 0.1 & $2.7 !$ & $7.6 !$ \\
\hline Native & 25,910 & 16.6 & 1.4 & 16.8 & $\ddagger$ \\
\hline Two or more races & 32,790 & 6.9 & 1.8 & 7.0 & 5.5 \\
\hline \multicolumn{6}{|l|}{ Female } \\
\hline White & 486,710 & 4.4 & 38.7 & 4.5 & 3.1 \\
\hline Black & 220,860 & 7.7 & 17.6 & 7.9 & 5.5 \\
\hline Hispanic & 479,930 & 12.7 & 38.2 & 8.3 & 24.0 \\
\hline Asian & 20,890 & 2.3 & 1.7 & 1.5 & 3.1 \\
\hline $\begin{array}{l}\text { Native Hawaiian/Pacific } \\
\text { Islander } \\
\text { American Indian/Alaska }\end{array}$ & $1,850 !$ & $4.8 !$ & $0.1 !$ & $5.0 !$ & $\ddagger$ \\
\hline Native & 20,390 & 13.1 & 1.6 & 13.2 & $\ddagger$ \\
\hline Two or more races & 23,690 & 4.9 & 1.9 & 4.9 & $4.5 !$ \\
\hline \multicolumn{6}{|l|}{ Age } \\
\hline 16 & 104,090 & 2.4 & 3.4 & 2.3 & 4.3 \\
\hline 17 & 162,760 & 3.8 & 5.3 & 3.5 & 7.3 \\
\hline 18 & 302,500 & 6.5 & 9.8 & 5.8 & 12.6 \\
\hline 19 & 371,570 & 8.5 & 12.0 & 7.5 & 16.9 \\
\hline $20-24$ & $2,157,240$ & 10.1 & 69.6 & 8.1 & 22.4 \\
\hline \multicolumn{6}{|l|}{ Region } \\
\hline Northeast & 407,520 & 5.9 & 13.2 & 4.7 & 13.4 \\
\hline Midwest & 569,100 & 6.8 & 18.4 & 6.2 & 15.0 \\
\hline South & $1,319,310$ & 9.2 & 42.6 & 7.6 & 21.2 \\
\hline West & 802,220 & 8.6 & 25.9 & 6.5 & 19.8 \\
\hline
\end{tabular}

Interpret data with caution. The coefficient of variation (CV) for this estimate is 30 percent or greater.

$\ddagger$ Reporting standards not met (too few cases).

1 United States refers to the 50 states and the District of Columbia.

2 Total includes other race/ethnicity categories not separately shown.

NOTE: Detail may not sum to totals because of rounding. This table uses a different data source than table A-SDE-1; therefore, estimates are not directly comparable to the 2010 estimates in table A-SDE-1. Noninstitutionalized group quarters include college and university housing, military quarters,

facilities for workers and religious groups, and temporary shelters for the homeless. Among those counted in noninstitutionalized group quarters in the American Community Survey (ACS), only the residents of military barracks are not included in the civilian noninstitutionalized population in the Current Population Survey. Race categories exclude persons of Hispanic ethnicity. For more information on race/ethnicity, region, and the status dropout rate, see Appendix C - Commonly Used Measures. For more information on the ACS, see Appendix B - Guide to Sources.

SOURCE: U.S. Department of Commerce, Census Bureau, American Community Survey (ACS), 2010. 
Table A-33-3. Number of status dropouts and status dropout rates of 16-through 24-year-olds in the institutionalized group quarters and noninstitutionalized group quarters and household population, by selected characteristics: American Community Survey (ACS) 2010

\begin{tabular}{|c|c|c|c|c|c|}
\hline \multirow[b]{2}{*}{ Characteristics } & \multirow[b]{2}{*}{$\begin{array}{r}\text { Total status } \\
\text { dropout } \\
\text { rate }\end{array}$} & \multicolumn{2}{|c|}{ Institutionalized group quarters ${ }^{1}$} & \multicolumn{2}{|c|}{$\begin{array}{l}\text { Noninstitutionalized group } \\
\text { quarters and households }{ }^{2}\end{array}$} \\
\hline & & $\begin{array}{l}\text { Number } \\
\text { of status } \\
\text { dropouts }\end{array}$ & $\begin{array}{r}\begin{array}{r}\text { Status dropout } \\
\text { rate }\end{array} \\
\end{array}$ & $\begin{array}{l}\text { Number } \\
\text { of status } \\
\text { dropouts }\end{array}$ & $\begin{array}{r}\text { Status dropout } \\
\text { rate }\end{array}$ \\
\hline Total $^{3}$ & 8.3 & 196,340 & 37.4 & $3,098,150$ & 7.9 \\
\hline \multicolumn{6}{|l|}{ Sex } \\
\hline Male & 10.0 & 179,420 & 38.6 & $1,840,700$ & 9.3 \\
\hline Female & 6.6 & 16,920 & 27.9 & $1,257,450$ & 6.5 \\
\hline \multicolumn{6}{|l|}{ Race/ethnicity } \\
\hline White & 5.3 & 49,490 & 28.8 & $1,141,870$ & 5.1 \\
\hline Black & 10.3 & 86,370 & 42.0 & 504,660 & 9.1 \\
\hline Hispanic & 16.7 & 51,990 & 44.1 & $1,286,750$ & 16.3 \\
\hline Asian & 2.8 & 1,550 & 28.1 & 50,940 & 2.8 \\
\hline Native Hawaiian/Pacific Islander & 4.8 & $\ddagger$ & $\ddagger$ & 3,520 & 4.5 \\
\hline American Indian/Alaska Native & 15.4 & 2,900 & 38.9 & 46,300 & 14.9 \\
\hline Two or more races & 6.1 & 3,550 & 23.3 & 56,480 & 5.8 \\
\hline \multicolumn{6}{|l|}{ Race/ethnicity by sex } \\
\hline \multicolumn{6}{|l|}{ Male } \\
\hline White & 6.1 & 41,110 & 29.1 & 655,160 & 5.8 \\
\hline Black & 12.7 & 82,320 & 43.8 & 283,800 & 10.5 \\
\hline Hispanic & 20.2 & 48,320 & 44.6 & 806,820 & 19.5 \\
\hline Asian & 3.4 & 1,520 & 30.8 & 30,040 & 3.2 \\
\hline Native Hawaiian/Pacific Islander & 4.9 & $\ddagger$ & $\ddagger$ & 1,670 & 4.3 \\
\hline American Indian/Alaska Native & 17.6 & 2,620 & 40.8 & 25,910 & 16.6 \\
\hline Two or more races & 7.3 & 3,040 & 21.8 & 32,790 & 6.9 \\
\hline \multicolumn{6}{|l|}{ Female } \\
\hline White & 4.5 & 8,380 & 27.3 & 486,710 & 4.4 \\
\hline Black & 7.8 & 4,040 & 23.0 & 220,860 & 7.7 \\
\hline Hispanic & 12.8 & 3,670 & 39.1 & 479,930 & 12.7 \\
\hline Asian & 2.3 & $\ddagger$ & $\ddagger$ & 20,890 & 2.3 \\
\hline Native Hawaiian/Pacific Islander & $4.8 !$ & $\#$ & \# & $1,850 !$ & $4.8 !$ \\
\hline American Indian/Alaska Native & 13.2 & $\ddagger$ & $\ddagger$ & 20,390 & 13.1 \\
\hline Two or more races & 4.9 & $\ddagger$ & $\ddagger$ & 23,690 & 4.9 \\
\hline \multicolumn{6}{|l|}{ Age } \\
\hline 16 & 2.5 & 5,550 & 15.5 & 104,090 & 2.4 \\
\hline 17 & 4.0 & 7,650 & 17.9 & 162,760 & 3.8 \\
\hline 18 & 6.7 & 13,730 & 36.7 & 302,500 & 6.5 \\
\hline 19 & 8.9 & 23,710 & 43.7 & 371,570 & 8.5 \\
\hline $20-24$ & 10.6 & 145,710 & 41.0 & $2,157,240$ & 10.1 \\
\hline \multicolumn{6}{|l|}{ Region } \\
\hline Northeast & 6.3 & 30,040 & 36.7 & 407,520 & 5.9 \\
\hline Midwest & 7.2 & 35,840 & 33.5 & 569,100 & 6.8 \\
\hline South & 9.6 & 88,670 & 39.8 & $1,319,310$ & 9.2 \\
\hline West & 8.9 & 41,790 & 36.7 & 802,220 & 8.6 \\
\hline
\end{tabular}

\# Rounds to zero.

! Interpret data with caution. The coefficient of variation (CV) for this estimate is 30 percent or greater.

$\ddagger$ Reporting standards not met. Either there are too few cases or the coefficient of variation (CV) is 50 percent or greater.

1 Institutionalized group quarters include adult and juvenile correctional facilities, nursing facilities, and other health care facilities.

${ }^{2}$ Noninstitutionalized group quarters include college and university housing, military quarters, facilities for workers and religious groups, and temporary shelters for the homeless. Among those counted in noninstitutionalized group quarters in the American Community Survey (ACS), only the residents of military barracks are not included in the civilian noninstitutionalized population in the Current Population Survey.

${ }^{3}$ Total includes other race/ethnicity categories not separately shown.

NOTE: This table uses a different data source than table A-SDE-1; therefore, total status dropout rate estimates are not directly comparable to the 2010

estimates in table A-SDE-1. Detail may not sum to totals because of rounding. For more information on race/ethnicity, region, and the status dropout

rate, see Appendix C - Commonly Used Measures. For more information on the ACS, see Appendix B - Guide to Sources.

SOURCE: U.S. Department of Commerce, Census Bureau, American Community Survey (ACS), 2010. 
This page intentionally left blank.

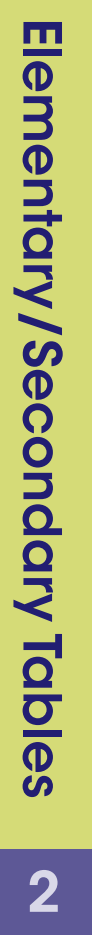


Table A-34-1. Percentage of high school completers who were enrolled in 2- or 4-year colleges the October immediately following high school completion, by family income: 1975-2010

\begin{tabular}{|c|c|c|c|c|c|c|c|}
\hline \multirow[b]{2}{*}{ Year } & \multirow[b]{2}{*}{ Total } & \multicolumn{2}{|c|}{ Low income } & \multirow[b]{2}{*}{$\begin{array}{l}\text { Middle } \\
\text { income }\end{array}$} & \multirow[b]{2}{*}{$\begin{array}{r}\text { High } \\
\text { income }\end{array}$} & \multicolumn{2}{|c|}{ Gap between High income and } \\
\hline & & Annual & $\begin{array}{r}\text { Moving } \\
\text { average }\end{array}$ & & & $\begin{array}{r}\text { Low } \\
\text { income } \\
\end{array}$ & $\begin{array}{r}\text { Middle } \\
\text { income }\end{array}$ \\
\hline 1975 & 50.7 & 31.2 & 34.8 & 46.2 & 64.5 & 29.7 & 18.3 \\
\hline 1976 & 48.8 & 39.3 & 32.3 & 40.5 & 63.0 & 30.6 & 22.5 \\
\hline 1977 & 50.6 & 27.7 & 32.4 & 44.2 & 66.3 & 33.8 & 22.0 \\
\hline 1978 & 50.1 & 31.4 & 29.8 & 44.3 & 64.0 & 34.2 & 19.6 \\
\hline 1979 & 49.3 & 30.5 & 31.5 & 43.2 & 63.2 & 31.6 & 19.9 \\
\hline 1980 & 49.3 & 32.4 & 32.3 & 42.5 & 65.2 & 32.9 & 22.8 \\
\hline 1981 & 53.9 & 33.9 & 33.0 & 49.2 & 67.6 & 34.6 & 18.4 \\
\hline 1982 & 50.6 & 32.8 & 33.7 & 41.7 & 70.9 & 37.1 & 29.2 \\
\hline 1983 & 52.7 & 34.6 & 34.1 & 45.2 & 70.3 & 36.3 & 25.1 \\
\hline 1984 & 55.2 & 34.7 & 36.4 & 48.4 & 74.0 & 37.6 & 25.6 \\
\hline 1985 & 57.7 & 40.2 & 36.0 & 50.6 & 74.6 & 38.5 & 24.0 \\
\hline 1986 & 53.8 & 33.9 & 36.7 & 48.5 & 71.0 & 34.3 & 22.6 \\
\hline 1987 & 56.8 & 36.8 & 37.5 & 50.1 & 73.8 & 36.3 & 23.8 \\
\hline 1988 & 58.9 & 42.5 & 42.4 & 54.7 & 72.8 & 30.4 & 18.1 \\
\hline 1989 & 59.6 & 48.5 & 45.9 & 55.3 & 70.7 & 24.8 & 15.3 \\
\hline 1990 & 60.1 & 46.9 & 45.0 & 54.4 & 76.6 & 31.6 & 22.2 \\
\hline 1991 & 62.5 & 39.5 & 42.2 & 58.4 & 78.2 & 36.0 & 19.8 \\
\hline 1992 & 61.9 & 40.8 & 43.5 & 57.1 & 79.0 & 35.5 & 22.0 \\
\hline 1993 & 62.6 & 50.4 & 44.7 & 56.9 & 79.3 & 34.6 & 22.4 \\
\hline 1994 & 61.9 & 43.3 & 42.0 & 57.8 & 77.9 & 35.9 & 20.1 \\
\hline 1995 & 61.9 & 34.2 & 42.0 & 56.0 & 83.5 & 41.4 & 27.4 \\
\hline 1996 & 65.0 & 48.3 & 47.0 & 62.8 & 78.0 & 31.0 & 15.2 \\
\hline 1997 & 67.0 & 57.0 & 50.5 & 60.7 & 82.2 & 31.7 & 21.5 \\
\hline 1998 & 65.6 & 46.4 & 50.4 & 64.7 & 77.5 & 27.0 & 12.8 \\
\hline 1999 & 62.9 & 48.0 & 48.0 & 60.1 & 75.4 & 27.4 & 15.3 \\
\hline 2000 & 63.3 & 49.7 & 47.1 & 59.5 & 76.9 & 29.8 & 17.4 \\
\hline 2001 & 61.8 & 43.5 & 48.5 & 56.6 & 80.0 & 31.5 & 23.5 \\
\hline 2002 & 65.2 & 52.3 & 49.2 & 61.9 & 78.8 & 29.5 & 16.9 \\
\hline 2003 & 63.9 & 52.0 & 51.1 & 59.1 & 77.9 & 26.9 & 18.9 \\
\hline 2004 & 66.7 & 48.5 & 51.4 & 63.2 & 80.1 & 28.8 & 17.0 \\
\hline 2005 & 68.6 & 53.5 & 51.0 & 65.1 & 81.2 & 30.2 & 16.1 \\
\hline 2006 & 66.0 & 50.9 & 54.5 & 61.4 & 80.7 & 26.2 & 19.3 \\
\hline 2007 & 67.2 & 58.4 & 55.2 & 63.3 & 78.2 & 23.0 & 14.8 \\
\hline 2008 & 68.6 & 55.5 & 56.0 & 65.3 & 81.9 & 25.9 & 16.6 \\
\hline 2009 & 70.1 & 54.1 & 53.2 & 66.8 & 84.2 & 31.0 & 17.4 \\
\hline 2010 & 68.1 & 50.6 & 52.3 & 66.8 & 82.2 & 29.9 & 15.5 \\
\hline
\end{tabular}

1 Due to the small sample size for the low-income category, data are subject to relatively large sampling errors. Therefore, moving averages are used to produce more stable estimates. The 3-year moving average is an arithmetic average of the year indicated, the year immediately preceding, and the year immediately following. For 1975 and 2010, a 2-year moving average is used: data for 1975 reflect an average of 1975 and 1976 , and data for 2010 reflect an average of 2009 and 2010.

2 Refers to the moving average rates for the low-income category.

NOTE: Includes high school completers ages 16-24, who account for about 98 percent of all high school completers in a given year. Before 1992, high school completer referred to those who had completed 12 years of schooling. As of 1992, high school completer refers to those who have received a high school diploma or equivalency certificate. Low income refers to the bottom 20 percent of all family incomes, high income refers to the top 20 percent of all family incomes, and middle income refers to the 60 percent in between. For more information on the Current Population Survey (CPS), see Appendix B - Guide to Sources. For more information on educational attainment and family income, see Appendix C - Commonly Used Measures. SOURCE: U.S. Department of Commerce, Census Bureau, Current Population Survey (CPS), October Supplement, 1975-2010. 
Table A-34-2. Percentage of high school completers who were enrolled in 2- or 4-year colleges the October immediately following high school completion, by race/ethnicity: 1975-2010

\begin{tabular}{|c|c|c|c|c|c|c|c|c|c|c|}
\hline \multirow[b]{2}{*}{ Year } & \multirow[b]{2}{*}{ White } & \multicolumn{2}{|c|}{ Black } & \multicolumn{2}{|c|}{ Hispanic } & \multicolumn{2}{|c|}{ Asian } & \multicolumn{3}{|c|}{ Gap between White and } \\
\hline & & Annual & $\begin{array}{r}\text { Moving } \\
\text { average }\end{array}$ & Annual & $\begin{array}{r}\text { Moving } \\
\text { average }^{1}\end{array}$ & Annual & $\begin{array}{r}\text { Moving } \\
\text { average }\end{array}$ & Black $^{2}$ & Hispanic ${ }^{2}$ & Asian $^{2}$ \\
\hline 1975 & 51.1 & 41.7 & 43.0 & 58.0 & 55.2 & - & - & $8.1 !$ & $\ddagger$ & - \\
\hline 1976 & 48.8 & 44.4 & 45.3 & 52.7 & 53.6 & - & - & $\ddagger$ & $\ddagger$ & - \\
\hline 1977 & 50.8 & 49.5 & 46.8 & 50.8 & 48.8 & - & - & $\ddagger$ & $\ddagger$ & - \\
\hline 1978 & 50.5 & 46.4 & 47.5 & 42.0 & 46.1 & - & - & $\ddagger$ & $\ddagger$ & - \\
\hline 1979 & 49.9 & 46.7 & 45.2 & 45.0 & 46.3 & - & - & $\ddagger$ & $\ddagger$ & - \\
\hline 1980 & 49.8 & 42.7 & 44.0 & 52.3 & 49.6 & - & - & $\ddagger$ & $\ddagger$ & - \\
\hline 1981 & 54.9 & 42.7 & 40.3 & 52.1 & 48.7 & - & - & 14.6 & $\ddagger$ & - \\
\hline 1982 & 52.7 & 35.8 & 38.8 & 43.2 & 49.4 & - & - & 13.9 & $\ddagger$ & - \\
\hline 1983 & 55.0 & 38.2 & 38.0 & 54.2 & 46.7 & - & - & 17.1 & $\ddagger$ & - \\
\hline 1984 & 59.0 & 39.8 & 39.9 & 44.3 & 49.3 & - & - & 19.1 & $\ddagger$ & - \\
\hline 1985 & 60.1 & 42.2 & 39.5 & 51.0 & 46.1 & - & - & 20.5 & $13.9 !$ & - \\
\hline 1986 & 56.8 & 36.9 & 43.5 & 44.0 & 42.3 & - & - & 13.3 & $14.5 !$ & - \\
\hline 1987 & 58.6 & 52.2 & 44.2 & 33.5 & 45.0 & - & - & 14.4 & $13.6 !$ & - \\
\hline 1988 & 61.1 & 44.4 & 49.7 & 57.1 & 48.5 & - & - & $11.4 !$ & $12.6 !$ & - \\
\hline 1989 & 60.7 & 53.4 & 48.0 & 55.1 & 52.7 & - & - & 12.7 & $\ddagger$ & - \\
\hline 1990 & 63.0 & 46.8 & 48.9 & 42.7 & 52.5 & - & - & 14.1 & $\ddagger$ & - \\
\hline 1991 & 65.4 & 46.4 & 47.2 & 57.2 & 52.6 & - & - & 18.2 & $12.8 !$ & - \\
\hline 1992 & 64.3 & 48.2 & 50.0 & 55.0 & 58.2 & - & - & 14.3 & $\ddagger$ & - \\
\hline 1993 & 62.9 & 55.6 & 51.3 & 62.2 & 55.7 & - & - & $11.6 !$ & $\ddagger$ & - \\
\hline 1994 & 64.5 & 50.8 & 52.4 & 49.1 & 55.0 & - & - & 12.1 & $9.5 !$ & - \\
\hline 1995 & 64.3 & 51.2 & 52.9 & 53.7 & 51.6 & - & - & 11.4 & 12.7 & - \\
\hline 1996 & 67.4 & 56.0 & 55.4 & 50.8 & 57.6 & - & - & 12.1 & $9.8 !$ & - \\
\hline 1997 & 68.2 & 58.5 & 58.8 & 65.6 & 55.3 & - & - & $9.4 !$ & 12.9 & - \\
\hline 1998 & 68.5 & 61.9 & 59.8 & 47.4 & 51.9 & - & - & $8.8 !$ & 16.6 & - \\
\hline 1999 & 66.3 & 58.9 & 58.6 & 42.3 & 47.4 & - & - & $7.7 !$ & 18.9 & - \\
\hline 2000 & 65.7 & 54.9 & 56.4 & 52.9 & 48.6 & - & - & $9.3 !$ & 17.1 & - \\
\hline 2001 & 64.3 & 55.0 & 56.4 & 51.7 & 52.8 & - & - & $7.9 !$ & 11.4 & - \\
\hline 2002 & 69.1 & 59.4 & 57.3 & 53.6 & 54.8 & - & - & 11.8 & 14.3 & - \\
\hline 2003 & 66.2 & 57.5 & 59.9 & 58.6 & 57.7 & 84.1 & 80.0 & $6.2 !$ & $8.4 !$ & $-13.8 !$ \\
\hline 2004 & 68.8 & 62.5 & 58.8 & 61.8 & 57.7 & 75.6 & 81.6 & 10.0 & 11.1 & -12.8 \\
\hline 2005 & 73.2 & 55.7 & 58.2 & 54.0 & 57.5 & 86.7 & 80.9 & 15.0 & 15.7 & $-7.7 !$ \\
\hline 2006 & 68.5 & 55.5 & 55.6 & 57.9 & 58.5 & 82.3 & 85.1 & 12.9 & 10.0 & -16.6 \\
\hline 2007 & 69.5 & 55.7 & 55.7 & 64.0 & 62.0 & 88.8 & 85.8 & 13.9 & $7.5 !$ & -16.3 \\
\hline 2008 & 71.7 & 55.7 & 60.3 & 63.9 & 62.3 & 88.4 & 90.1 & 11.4 & 9.4 & -18.4 \\
\hline 2009 & 71.3 & 69.5 & 62.4 & 59.3 & 60.9 & 92.1 & 88.1 & 8.9 & 10.4 & -16.8 \\
\hline 2010 & 70.5 & 62.0 & 65.8 & 59.7 & 59.5 & 84.7 & 88.4 & $\ddagger$ & $11.0 !$ & -17.9 \\
\hline
\end{tabular}

- Not available.

! Interpret with caution. The coefficient of variation (CV) for this estimate is 30 percent or greater.

¥ Reporting standards not met. The coefficient of variation (CV) for this estimate is 50 percent or greater.

1 Due to the small sample sizes for the Black. Hispanic, and Asian categories, data are subject to relatively large sampling errors. Therefore, moving averages are used to produce more stable estimates. The 3-year moving average is an arithmetic average of the year indicated, the year immediately preceding, and the year immediately following. For 1975 and 2010, a 2-year moving average is used: data for 1975 reflect an average of 1975 and 1976, and data for 2010 reflect an average of 2009 and 2010.

2 Refers to the moving average rates for the Black, Hispanic, and Asian categories.

NOTE: Includes high school completers ages 16-24, who account for about 98 percent of all high school completers in a given year. Before 1992, high school completer referred to those who had completed 12 years of schooling. As of 1992, high school completer refers to those who have received a high school diploma or equivalency certificate. Race categories exclude persons of Hispanic ethnicity. From 2003 onward, data for Asians and Pacific Islanders were collected separately. Separate data for the Asian category are not available prior to 2003 . For more information on the Current Population Survey (CPS), see Appendix B - Guide to Sources. For more information on educational attainment and race/ethnicity, see Appendix C Commonly Used Measures.

SOURCE: U.S. Department of Commerce, Census Bureau, Current Population Survey (CPS), October Supplement, 1975-2010. 
Immediate Transition to College

Table A-34-3. Percentage of high school completers who were enrolled in 2- or 4-year colleges the October immediately following high school completion, by sex and level of institution: 1975-2010

\begin{tabular}{|c|c|c|c|c|c|c|c|c|}
\hline \multirow[b]{2}{*}{ Year } & \multicolumn{2}{|c|}{ Total } & \multicolumn{3}{|c|}{ Male } & \multicolumn{3}{|c|}{ Female } \\
\hline & 2-year & 4-year ${ }^{1}$ & Total & 2-year' & 4-year ${ }^{1}$ & Total & 2-year & 4-year ${ }^{1}$ \\
\hline 1975 & 18.2 & 32.6 & 52.6 & 19.0 & 33.6 & 49.0 & 17.4 & 31.6 \\
\hline 1976 & 15.6 & 33.3 & 47.2 & 14.5 & 32.7 & 50.3 & 16.6 & 33.8 \\
\hline 1977 & 17.5 & 33.1 & 52.1 & 17.2 & 35.0 & 49.3 & 17.8 & 31.5 \\
\hline 1978 & 17.0 & 33.1 & 51.1 & 15.6 & 35.5 & 49.3 & 18.3 & 31.0 \\
\hline 1979 & 17.5 & 31.8 & 50.4 & 16.9 & 33.5 & 48.4 & 18.1 & 30.3 \\
\hline 1980 & 19.4 & 29.9 & 46.7 & 17.1 & 29.7 & 51.8 & 21.6 & 30.2 \\
\hline 1981 & 20.5 & 33.5 & 54.8 & 20.9 & 33.9 & 53.1 & 20.1 & 33.0 \\
\hline 1982 & 19.1 & 31.5 & 49.1 & 17.5 & 31.6 & 52.0 & 20.6 & 31.4 \\
\hline 1983 & 19.2 & 33.5 & 51.9 & 20.2 & 31.7 & 53.4 & 18.4 & 35.1 \\
\hline 1984 & 19.4 & 35.8 & 56.0 & 17.7 & 38.4 & 54.5 & 21.0 & 33.5 \\
\hline 1985 & 19.6 & 38.1 & 58.6 & 19.9 & 38.8 & 56.8 & 19.3 & 37.5 \\
\hline 1986 & 19.3 & 34.5 & 55.8 & 21.3 & 34.5 & 51.9 & 17.3 & 34.6 \\
\hline 1987 & 18.9 & 37.9 & 58.3 & 17.3 & 41.0 & 55.3 & 20.3 & 35.0 \\
\hline 1988 & 21.9 & 37.1 & 57.1 & 21.3 & 35.8 & 60.7 & 22.4 & 38.3 \\
\hline 1989 & 20.7 & 38.9 & 57.6 & 18.3 & 39.3 & 61.6 & 23.1 & 38.5 \\
\hline 1990 & 20.1 & 40.0 & 58.0 & 19.6 & 38.4 & 62.2 & 20.6 & 41.6 \\
\hline 1991 & 24.9 & 37.7 & 57.9 & 22.9 & 35.0 & 67.1 & 26.8 & 40.3 \\
\hline 1992 & 23.0 & 38.9 & 60.0 & 22.1 & 37.8 & 63.8 & 23.9 & 40.0 \\
\hline 1993 & 22.8 & 39.8 & 59.9 & 22.9 & 37.0 & 65.2 & 22.8 & 42.4 \\
\hline 1994 & 21.0 & 40.9 & 60.6 & 23.0 & 37.5 & 63.2 & 19.1 & 44.1 \\
\hline 1995 & 21.5 & 40.4 & 62.6 & 25.3 & 37.4 & 61.3 & 18.1 & 43.2 \\
\hline 1996 & 23.1 & 41.9 & 60.1 & 21.5 & 38.5 & 69.7 & 24.6 & 45.1 \\
\hline 1997 & 22.8 & 44.3 & 63.6 & 21.4 & 42.2 & 70.3 & 24.1 & 46.2 \\
\hline 1998 & 24.4 & 41.3 & 62.4 & 24.4 & 38.0 & 69.1 & 24.3 & 44.8 \\
\hline 1999 & 21.0 & 41.9 & 61.4 & 21.0 & 40.5 & 64.4 & 21.1 & 43.3 \\
\hline 2000 & 21.4 & 41.9 & 59.9 & 23.1 & 36.8 & 66.2 & 20.0 & 46.2 \\
\hline 2001 & 19.6 & 42.1 & 60.1 & 18.6 & 41.4 & 63.5 & 20.6 & 42.8 \\
\hline 2002 & 21.6 & 43.6 & 62.1 & 20.4 & 41.7 & 68.4 & 22.8 & 45.6 \\
\hline 2003 & 21.5 & 42.5 & 61.2 & 21.9 & 39.3 & 66.5 & 21.0 & 45.5 \\
\hline 2004 & 22.4 & 44.2 & 61.4 & 21.8 & 39.6 & 71.5 & 23.1 & 48.5 \\
\hline 2005 & 24.0 & 44.6 & 66.5 & 24.7 & 41.8 & 70.4 & 23.4 & 47.0 \\
\hline 2006 & 24.7 & 41.3 & 65.8 & 24.9 & 40.9 & 66.1 & 24.5 & 41.7 \\
\hline 2007 & 24.1 & 43.1 & 66.1 & 22.7 & 43.4 & 68.3 & 25.5 & 42.8 \\
\hline 2008 & 27.7 & 40.9 & 65.9 & 24.9 & 41.0 & 71.6 & 30.6 & 40.9 \\
\hline 2009 & 27.7 & 42.4 & 66.0 & 25.1 & 40.9 & 73.8 & 30.1 & 43.8 \\
\hline$\underline{2010}$ & 26.7 & 41.4 & 62.8 & 28.5 & 34.3 & 74.0 & 24.6 & 49.5 \\
\hline
\end{tabular}

' From 1975 through 1986, due to a skip pattern in the Current Population Survey (CPS), about 3-9 percent of high school completers ages 16-24 who immediately enrolled in college were not asked the question about the level of institution attended. Such respondents were assumed to have had the same probability of enrolling in a 2-or 4-year institution as those who were asked the question.

NOTE: Includes high school completers ages 16-24, who account for about 98 percent of all high school completers in each year. Before 1992, high school completer referred to those who had completed 12 years of schooling. As of 1992, high school completer refers to those who have received a high school diploma or equivalency certificate. For more information on the Current Population Survey (CPS), see Appendix B - Guide to Sources. For more information on educational attainment, see Appendix C - Commonly Used Measures. Detail may not sum to totals because of rounding.

SOURCE: U.S. Department of Commerce, Census Bureau, Current Population Survey (CPS), October Supplement, 1975-2010. 
This page intentionally left blank.

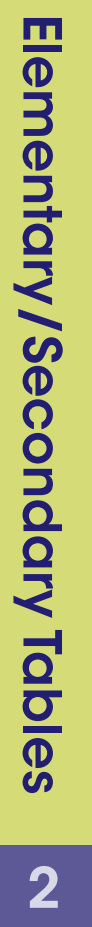


Table A-35-1. Percentage of 12th-grade students with definite plans to engage in various postsecondary activities, by sex, race/ethnicity, and parents' highest level of education: 1990, 2000, and 2010

\begin{tabular}{|c|c|c|c|c|c|}
\hline \multirow[b]{2}{*}{ Characteristic } & \multicolumn{5}{|c|}{ Student has definite plans to } \\
\hline & $\begin{array}{r}\text { Attend a } \\
\text { technical or } \\
\text { vocational } \\
\text { school }\end{array}$ & $\begin{array}{r}\text { Serve in the } \\
\text { armed } \\
\text { forces }\end{array}$ & $\begin{array}{r}\text { Graduate } \\
\text { from a 2- } \\
\text { year college } \\
\text { program } \\
\end{array}$ & $\begin{array}{r}\text { Graduate } \\
\text { from a 4- } \\
\text { year college } \\
\text { program } \\
\end{array}$ & $\begin{array}{r}\text { Attend } \\
\text { graduate or } \\
\text { professional } \\
\text { school after } \\
\text { college } \\
\end{array}$ \\
\hline \multicolumn{6}{|l|}{1990} \\
\hline Total & 8.7 & 6.6 & 16.3 & 48.1 & 15.2 \\
\hline \multicolumn{6}{|l|}{ Sex } \\
\hline Male & 9.0 & 10.1 & 13.9 & 45.8 & 14.2 \\
\hline Female & 8.3 & 2.7 & 18.6 & 50.8 & 16.4 \\
\hline \multicolumn{6}{|l|}{ Race/ethnicity? } \\
\hline White & 8.1 & 5.1 & 16.1 & 50.5 & 14.3 \\
\hline Black & 11.9 & 16.9 & 15.9 & 38.1 & 16.1 \\
\hline Hispanic & 11.1 & 7.9 & 16.8 & 37.9 & 15.1 \\
\hline \multicolumn{6}{|l|}{ Parents' highest level of education } \\
\hline High school completion or less & 11.6 & 7.8 & 17.0 & 31.7 & 9.0 \\
\hline Some college & 8.3 & 7.3 & 18.8 & 47.1 & 14.2 \\
\hline Bachelor's degree & 7.4 & 5.4 & 16.4 & 58.0 & 14.3 \\
\hline Graduate or professional degree & 4.7 & 4.5 & 11.6 & 72.1 & 31.2 \\
\hline \multicolumn{6}{|l|}{2000} \\
\hline Total & 8.0 & 4.8 & 16.8 & 56.3 & 20.0 \\
\hline \multicolumn{6}{|l|}{ Sex } \\
\hline Male & 9.2 & 7.6 & 15.0 & 51.7 & 16.5 \\
\hline Female & 6.7 & 2.3 & 18.3 & 61.0 & 23.2 \\
\hline \multicolumn{6}{|l|}{ Race/ethnicity ${ }^{\urcorner}$} \\
\hline White & 7.7 & 4.0 & 16.4 & 57.1 & 16.9 \\
\hline Black & 10.2 & 9.4 & 17.1 & 57.2 & 25.4 \\
\hline Hispanic & 8.0 & 6.6 & 17.0 & 43.5 & 22.1 \\
\hline \multicolumn{6}{|l|}{ Parents' highest level of education } \\
\hline High school completion or less & 10.5 & 6.3 & 18.9 & 40.1 & 14.2 \\
\hline Some college & 8.1 & 5.1 & 19.3 & 54.8 & 18.6 \\
\hline Bachelor's degree & 6.7 & 4.3 & 16.6 & 61.8 & 18.1 \\
\hline Graduate or professional degree & 5.4 & 3.2 & 11.4 & 75.8 & 32.9 \\
\hline \multicolumn{6}{|l|}{2010} \\
\hline Total & 7.1 & 5.3 & 22.6 & 59.7 & 23.6 \\
\hline \multicolumn{6}{|l|}{ Sex } \\
\hline Male & 7.2 & 8.7 & 20.2 & 53.3 & 17.8 \\
\hline Female & 6.8 & 2.2 & 24.6 & 66.5 & 29.0 \\
\hline \multicolumn{6}{|l|}{ Race/ethnicity } \\
\hline White & 7.2 & 4.6 & 21.6 & 61.4 & 19.7 \\
\hline Black & 7.5 & 6.4 & 19.8 & 59.5 & 30.8 \\
\hline Hispanic & 7.1 & 5.8 & 27.1 & 50.4 & 26.7 \\
\hline \multicolumn{6}{|l|}{ Parents' highest level of education } \\
\hline High school completion or less & 9.3 & 6.1 & 25.4 & 46.0 & 19.0 \\
\hline Some college & 7.3 & 6.1 & 24.9 & 57.0 & 22.9 \\
\hline Bachelor's degree & 5.9 & 4.9 & 22.0 & 65.6 & 20.8 \\
\hline Graduate or professional degree & 4.9 & 3.7 & 16.2 & 77.8 & 36.5 \\
\hline
\end{tabular}


This page intentionally left blank.

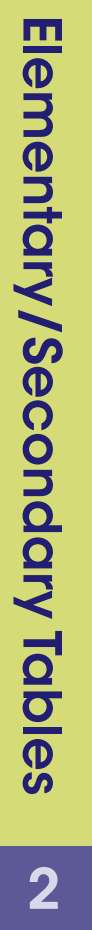


Table A-36-1. Number and percentage distribution of fall undergraduate enrollment in degree-granting institutions, by control and level of institution and selected student characteristics: Fall 2010

\begin{tabular}{|c|c|c|c|c|c|c|c|}
\hline \multirow[b]{3}{*}{ Student characteristic } & \multicolumn{7}{|c|}{ Fall enrollment } \\
\hline & \multirow[b]{2}{*}{ Total, all institutions } & \multicolumn{2}{|c|}{ Public } & \multicolumn{2}{|c|}{ Private nonprofit } & \multicolumn{2}{|c|}{ Private for-profit } \\
\hline & & 4-year & 2-year & 4-year & 2-year & 4-year & 2-year \\
\hline Total & $18,078,672$ & $6,486,252$ & $7,218,038$ & $2,620,744$ & 32,660 & $1,290,801$ & 430,177 \\
\hline \multicolumn{8}{|l|}{ Sex } \\
\hline Male & $7,835,163$ & $2,965,138$ & $3,110,993$ & $1,117,961$ & 12,504 & 486,938 & 141,629 \\
\hline Female & $10,243,509$ & $3,521,114$ & $4,107,045$ & $1,502,783$ & 20,156 & 803,863 & 288,548 \\
\hline \multicolumn{8}{|l|}{ Race/ethnicity of U.S. resident } \\
\hline White & $10,897,654$ & $4,152,584$ & $4,116,728$ & $1,760,349$ & 17,664 & 660,325 & 190,004 \\
\hline Black & $2,676,501$ & 779,602 & $1,075,976$ & 338,537 & 7,465 & 360,616 & 114,305 \\
\hline Hispanic & $2,543,581$ & 771,537 & $1,288,164$ & 211,277 & 2,943 & 174,386 & 95,274 \\
\hline Asian & $1,030,299$ & 418,778 & 420,794 & 140,818 & 1,377 & 34,997 & 13,535 \\
\hline Native Hawaiian/Pacific Islander & 57,574 & 15,899 & 25,884 & 6,410 & 154 & 7,168 & 2,059 \\
\hline American Indian/Alaska Native & 179,278 & 60,118 & 81,504 & 17,880 & 1,884 & 13,875 & 4,017 \\
\hline Two or more races & 293,501 & 107,446 & 112,484 & 43,050 & 208 & 22,486 & 7,827 \\
\hline Nonresident alien & 400,284 & 180,288 & 96,504 & 102,423 & 965 & 16,948 & 3,156 \\
\hline \multicolumn{8}{|l|}{ Attendance status } \\
\hline Full time & $11,451,568$ & $5,043,049$ & $2,952,480$ & $2,174,284$ & 23,101 & 869,042 & 389,612 \\
\hline Part time & $6,627,104$ & $1,443,203$ & $4,265,558$ & 446,460 & 9,559 & 421,759 & 40,565 \\
\hline
\end{tabular}

\footnotetext{
See notes at end of table.
} 
Table A-36-1. Number and percentage distribution of fall undergraduate enrollment in degree-granting institutions, by control and level of institution and selected student characteristics: Fall 2010-Continued

\begin{tabular}{|c|c|c|c|c|c|c|c|}
\hline \multirow[b]{3}{*}{ Student characteristic } & \multicolumn{7}{|c|}{ Percentage distribution } \\
\hline & \multirow[b]{2}{*}{ Total, all institutions } & \multicolumn{2}{|c|}{ Public } & \multicolumn{2}{|c|}{ Private nonprofit } & \multicolumn{2}{|c|}{ Private for-profit } \\
\hline & & 4-year & 2 2-year & 4-year & 2-year & 4-year & 2-year \\
\hline Total & 100.0 & 35.9 & 39.9 & 14.5 & 0.2 & 7.1 & 2.4 \\
\hline \multicolumn{8}{|l|}{ Sex } \\
\hline Male & 100.0 & 37.8 & 39.7 & 14.3 & 0.2 & 6.2 & 1.8 \\
\hline Female & 100.0 & 34.4 & 40.1 & 14.7 & 0.2 & 7.8 & 2.8 \\
\hline \multicolumn{8}{|l|}{ Race/ethnicity of U.S. resident } \\
\hline White & 100.0 & 38.1 & 37.8 & 16.2 & 0.2 & 6.1 & 1.7 \\
\hline Black & 100.0 & 29.1 & 40.2 & 12.6 & 0.3 & 13.5 & 4.3 \\
\hline Hispanic & 100.0 & 30.3 & 50.6 & 8.3 & 0.1 & 6.9 & 3.7 \\
\hline Asian & 100.0 & 40.6 & 40.8 & 13.7 & 0.1 & 3.4 & 1.3 \\
\hline Native Hawaiian/Pacific Islander & 100.0 & 27.6 & 45.0 & 11.1 & 0.3 & 12.5 & 3.6 \\
\hline American Indian/Alaska Native & 100.0 & 33.5 & 45.5 & 10.0 & 1.1 & 7.7 & 2.2 \\
\hline Two or more races & 100.0 & 36.6 & 38.3 & 14.7 & 0.1 & 7.7 & 2.7 \\
\hline Nonresident alien & 100.0 & 45.0 & 24.1 & 25.6 & 0.2 & 4.2 & 0.8 \\
\hline \multicolumn{8}{|l|}{ Attendance status } \\
\hline Full time & 100.0 & 44.0 & 25.8 & 19.0 & 0.2 & 7.6 & 3.4 \\
\hline Part time & 100.0 & 21.8 & 64.4 & 6.7 & 0.1 & 6.4 & 0.6 \\
\hline
\end{tabular}

NOTE: Degree-granting institutions grant associate's or higher degrees and participate in Title IV federal financial aid programs. Institutions in this indicator are classified based on the highest degree offered. Race categories exclude persons of Hispanic ethnicity. For more information on the classification of postsecondary institutions or race/ethnicity, see Appendix C - Commonly Used Measures. For more information on IPEDS, see Appendix B - Guide to Sources. Detail may not sum to totals due to rounding.

SOURCE: U.S. Department of Education, National Center for Education Statistics, Integrated Postsecondary Education Data System (IPEDS), Spring 2011, Enrollment component. 
Characteristics of Undergraduate Institutions

Table A-36-2. Number and percentage distribution of degree-granting institutions, retention rates, and overall graduation rates, by student attendance status, acceptance rate, and level and control of institution: 2010

\begin{tabular}{|c|c|c|c|c|c|}
\hline \multirow[b]{2}{*}{ Acceptance rate and control of institution } & \multicolumn{2}{|c|}{$\begin{array}{c}\text { Degree-granting institutions, } \\
2010-11 \\
\end{array}$} & \multicolumn{2}{|c|}{ Retention rate $^{1}$} & \multirow{2}{*}{$\begin{array}{r}\text { Overall graduation rate } \\
\text { by fall } 2010 \text { (2004 } \\
\text { cohort for } 4 \text {-year institu- } \\
\text { tions and } 2007 \text { cohort } \\
\text { for } 2 \text {-year institutions) }\end{array}$} \\
\hline & Number & distribution & Full time & Part time & \\
\hline & \multicolumn{5}{|c|}{ 4-year institutions } \\
\hline All institutions & 2,421 & 100.0 & 78.7 & 44.6 & 58.3 \\
\hline Open admissions (no application criteria) & 560 & 23.1 & 61.4 & 40.7 & 29.2 \\
\hline 75 percent or more accepted & 587 & 24.2 & 75.5 & 45.1 & 54.5 \\
\hline 50.0 to 74.9 percent accepted & 793 & 32.8 & 79.5 & 51.2 & 60.7 \\
\hline 25.0 to 49.9 percent accepted & 421 & 17.4 & 85.1 & 55.3 & 70.3 \\
\hline Less than 25 percent accepted & 60 & 2.5 & 96.1 & 82.5 & 87.2 \\
\hline Public institutions & 637 & 100.0 & 79.5 & 50.0 & 56.0 \\
\hline Open admissions (no application criteria) & 113 & 17.7 & 62.7 & 40.7 & 28.8 \\
\hline 75 percent or more accepted & 190 & 29.8 & 75.9 & 50.2 & 53.0 \\
\hline 50.0 to 74.9 percent accepted & 243 & 38.1 & 81.2 & 53.3 & 59.9 \\
\hline 25.0 to 49.9 percent accepted & 81 & 12.7 & 85.4 & 64.7 & 62.2 \\
\hline Less than 25 percent accepted & 10 & 1.6 & 95.3 & 79.5 & 82.2 \\
\hline Private nonprofit institutions & 1,216 & 100.0 & 80.0 & 46.8 & 65.4 \\
\hline Open admissions (no application criteria) & 161 & 13.2 & 63.5 & 44.3 & 36.4 \\
\hline 75 percent or more accepted & 322 & 26.5 & 76.7 & 48.2 & 58.9 \\
\hline 50.0 to 74.9 percent accepted & 499 & 41.0 & 78.1 & 47.0 & 63.8 \\
\hline 25.0 to 49.9 percent accepted & 187 & 15.4 & 86.4 & 51.4 & 79.3 \\
\hline Less than 25 percent accepted & 47 & 3.9 & 96.4 & 83.9 & 90.5 \\
\hline Private for-profit institutions & 568 & 100.0 & 52.3 & 37.5 & 28.4 \\
\hline Open admissions (no application criteria) & 286 & 50.4 & 54.9 & 39.4 & 23.0 \\
\hline 75 percent or more accepted & 75 & 13.2 & 41.1 & 32.5 & 38.0 \\
\hline 50.0 to 74.9 percent accepted & 51 & 9.0 & 51.7 & 49.0 & 32.9 \\
\hline 25.0 to 49.9 percent accepted & 153 & 26.9 & 56.1 & 31.1 & 34.3 \\
\hline \multirow[t]{2}{*}{ Less than 25 percent accepted } & 3 & 0.5 & - & - & - \\
\hline & \multicolumn{5}{|c|}{ 2-year institutions } \\
\hline All institutions & 1,628 & 100.0 & 60.8 & 41.6 & 29.9 \\
\hline Public institutions & 977 & 60.0 & 59.9 & 41.4 & 20.4 \\
\hline Private nonprofit institutions & 80 & 4.9 & 59.0 & 52.6 & 51.0 \\
\hline Private for-profit institutions & 571 & 35.1 & 67.4 & 53.0 & 60.3 \\
\hline
\end{tabular}

\section{- Not available.}

${ }^{1}$ For 4-year institutions, the retention rate is the percentage of first-time, bachelor's degree-seeking students who return to the institution to continue their studies in the following fall (in this case, fall 2010). For 2-year institutions, the retention rate is the percentage of first-time, degree/certificate-seeking students enrolled in the fall who either return to the institution or successfully complete their program by the following fall.

2 The overall graduation rate is the percentage of full-time, first-time students who graduated or transferred out of the institution within 150 percent of normal program completion time. For a bachelor's degree, this represents 6 years; for an associate's degree, this represents 3 years. Students who transferred to another institution and graduated are not counted as completers at their initial institution.

NOTE: Degree-granting institutions grant associate's or higher degrees and participate in Title IV federal financial aid programs. Institutions in this indicator are classified based on the highest degree offered. For more information on the classification of postsecondary institutions, see Appendix $\mathrm{C}-$ Commonly Used Measures. For more information on IPEDS, see Appendix B - Guide to Sources. Detail may not sum to totals due to rounding. SOURCE: U.S. Department of Education, National Center for Education Statistics, Integrated Postsecondary Education Data System (IPEDS), Spring 2011, Enrollment component, Graduation Rates component, and Institutional Characteristics component. 
This page intentionally left blank.

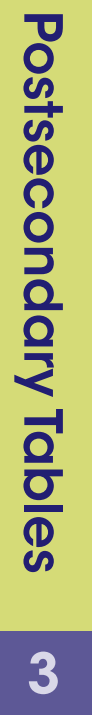


Table A-37-1. Percentage of 16- to 24-year-old college students who were employed, by attendance status, hours worked per week, and level and control of institution: Selected years, October 1970 through October 2010

\begin{tabular}{|c|c|c|c|c|c|c|c|c|}
\hline \multirow{3}{*}{$\begin{array}{l}\text { Level and control } \\
\text { of institution and } \\
\text { year }\end{array}$} & \multicolumn{4}{|c|}{ Full-time students } & \multicolumn{4}{|c|}{ Part-time students } \\
\hline & \multirow[b]{2}{*}{$\begin{array}{r}\text { Percent } \\
\text { employed }^{2}\end{array}$} & \multicolumn{3}{|c|}{ Hours worked per week' } & \multirow[b]{2}{*}{$\begin{array}{r}\text { Percent } \\
\text { employed }^{2}\end{array}$} & \multicolumn{3}{|c|}{ Hours worked per week ${ }^{1}$} \\
\hline & & $\begin{array}{r}\text { Less than } \\
20 \text { hours }\end{array}$ & $\begin{array}{l}20-34 \\
\text { hours }\end{array}$ & $\begin{array}{r}35 \text { or more } \\
\text { hours }\end{array}$ & & $\begin{array}{l}\text { Less than } \\
20 \text { hours }\end{array}$ & $\begin{array}{l}20-34 \\
\text { hours }\end{array}$ & $\begin{array}{r}35 \text { or more } \\
\text { hours }\end{array}$ \\
\hline \multicolumn{9}{|l|}{ Total } \\
\hline 1970 & 33.8 & 19.3 & 10.4 & 3.8 & 82.2 & 5.0 & 15.8 & 60.3 \\
\hline 1975 & 35.3 & 18.2 & 12.0 & 4.7 & 80.9 & 6.0 & 19.5 & 52.6 \\
\hline 1980 & 40.0 & 21.5 & 14.0 & 3.9 & 84.5 & 7.9 & 22.5 & 52.6 \\
\hline 1985 & 44.2 & 21.8 & 17.3 & 4.3 & 86.1 & 6.0 & 26.8 & 52.5 \\
\hline 1990 & 45.7 & 20.6 & 19.3 & 4.8 & 83.7 & 4.0 & 26.0 & 52.7 \\
\hline 1995 & 47.2 & 19.1 & 20.3 & 6.5 & 82.9 & 8.6 & 30.4 & 42.3 \\
\hline 2000 & 52.0 & 20.1 & 21.7 & 8.9 & 84.9 & 8.6 & 27.8 & 47.5 \\
\hline 2001 & 47.0 & 17.4 & 20.6 & 7.9 & 84.5 & 8.1 & 25.8 & 48.9 \\
\hline 2002 & 47.8 & 17.3 & 20.9 & 8.5 & 78.9 & 8.7 & 25.3 & 43.4 \\
\hline 2003 & 47.7 & 17.1 & 20.7 & 8.8 & 79.0 & 7.8 & 27.2 & 42.8 \\
\hline 2004 & 49.0 & 17.7 & 21.6 & 8.6 & 81.5 & 8.5 & 27.4 & 44.1 \\
\hline 2005 & 49.1 & 17.8 & 21.1 & 9.0 & 85.0 & 10.2 & 27.1 & 47.1 \\
\hline 2006 & 46.5 & 15.1 & 22.0 & 8.1 & 81.0 & 7.3 & 27.6 & 45.5 \\
\hline 2007 & 45.5 & 15.4 & 20.7 & 8.7 & 81.2 & 6.8 & 27.2 & 45.9 \\
\hline 2008 & 45.3 & 15.6 & 20.1 & 8.7 & 79.4 & 9.3 & 24.7 & 44.4 \\
\hline 2009 & 40.6 & 15.6 & 17.6 & 6.2 & 76.2 & 10.1 & 27.5 & 36.9 \\
\hline 2010 & 39.8 & 14.9 & 17.2 & 6.6 & 73.4 & 10.7 & 28.3 & 32.8 \\
\hline \multicolumn{9}{|c|}{ Enrolled in public 4-year institutions } \\
\hline 1990 & 43.0 & 19.8 & 18.6 & 3.7 & 87.4 & $4.2 !$ & 27.9 & 54.7 \\
\hline 1995 & 48.8 & 19.4 & 22.6 & 5.6 & 86.7 & 9.6 & 30.8 & 45.0 \\
\hline 2000 & 50.5 & 19.1 & 21.5 & 9.0 & 87.3 & 8.5 & 26.4 & 50.9 \\
\hline 2001 & 45.9 & 16.6 & 20.9 & 7.5 & 86.7 & 7.5 & 27.9 & 49.5 \\
\hline 2002 & 47.7 & 17.2 & 21.0 & 8.0 & 78.5 & 7.5 & 22.8 & 47.4 \\
\hline 2003 & 47.5 & 17.3 & 20.7 & 8.2 & 81.7 & 9.3 & 27.3 & 43.7 \\
\hline 2004 & 49.7 & 17.4 & 22.0 & 8.8 & 83.0 & 9.0 & 27.4 & 44.3 \\
\hline 2005 & 49.6 & 17.8 & 22.7 & 8.0 & 86.3 & 9.0 & 26.8 & 49.7 \\
\hline 2006 & 46.6 & 13.9 & 22.9 & 8.6 & 80.5 & 7.1 & 26.4 & 46.0 \\
\hline 2007 & 44.7 & 14.9 & 20.1 & 8.9 & 78.3 & 6.4 & 23.1 & 48.5 \\
\hline 2008 & 44.1 & 15.1 & 19.2 & 8.8 & 83.9 & 9.3 & 24.7 & 49.5 \\
\hline 2009 & 40.6 & 14.7 & 18.7 & 5.8 & 78.7 & 11.1 & 25.7 & 39.8 \\
\hline$\underline{2010}$ & 40.8 & 15.2 & 18.0 & 6.6 & 70.4 & 10.5 & 26.9 & 32.1 \\
\hline
\end{tabular}

See notes at end of table. 
Table A-37-1. Percentage of 16- to 24-year-old college students who were employed, by attendance status, hours worked per week, level and control of institution, and year: Selected years, October 1970 through October 2010-Continued

\begin{tabular}{|c|c|c|c|c|c|c|c|c|}
\hline \multirow{3}{*}{$\begin{array}{l}\text { Level and control } \\
\text { of institution and } \\
\text { year }\end{array}$} & \multicolumn{4}{|c|}{ Full-time students } & \multicolumn{4}{|c|}{ Part-time students } \\
\hline & \multirow[b]{2}{*}{$\begin{array}{r}\text { Percent } \\
\text { employed }^{2}\end{array}$} & \multicolumn{3}{|c|}{ Hours worked per week ${ }^{1}$} & \multirow[b]{2}{*}{$\begin{array}{r}\text { Percent } \\
\text { employed }^{2}\end{array}$} & \multicolumn{3}{|c|}{ Hours worked per week 1} \\
\hline & & $\begin{array}{l}\text { Less than } \\
20 \text { hours }\end{array}$ & $\begin{array}{l}20-34 \\
\text { hours }\end{array}$ & $\begin{array}{r}35 \text { or more } \\
\text { hours }\end{array}$ & & $\begin{array}{l}\text { Less than } \\
20 \text { hours }\end{array}$ & $\begin{array}{l}20-34 \\
\text { hours }\end{array}$ & $\begin{array}{r}35 \text { or more } \\
\text { hours }\end{array}$ \\
\hline \multicolumn{9}{|c|}{ Enrolled in private 4-year institutions } \\
\hline 1990 & 38.1 & 24.0 & 9.9 & 3.5 & 89.9 & $\ddagger$ & 31.9 & 53.1 \\
\hline 1995 & 38.6 & 21.6 & 10.7 & 4.6 & 80.1 & 14.9 & 26.8 & 36.5 \\
\hline 2000 & 45.8 & 23.6 & 14.9 & 5.4 & 78.0 & $\ddagger$ & 18.5 & 52.6 \\
\hline 2001 & 38.7 & 19.7 & 11.6 & 6.3 & 83.6 & $7.9 !$ & 23.3 & 51.6 \\
\hline 2002 & 39.8 & 17.4 & 15.1 & 6.0 & 77.6 & 16.6 & 17.4 & 42.1 \\
\hline 2003 & 41.1 & 19.0 & 12.8 & 8.4 & 69.2 & $9.3 !$ & 17.5 & 40.7 \\
\hline 2004 & 40.6 & 19.6 & 15.0 & 5.3 & 73.0 & $\ddagger$ & 21.2 & 49.2 \\
\hline 2005 & 42.3 & 20.1 & 13.8 & 7.0 & 88.5 & $10.6 !$ & 34.5 & 43.2 \\
\hline 2006 & 36.9 & 18.1 & 12.4 & 5.1 & 83.0 & $6.1 !$ & 21.0 & 55.9 \\
\hline 2007 & 38.7 & 18.0 & 13.0 & 6.7 & 83.9 & $\ddagger$ & $14.3 !$ & 61.2 \\
\hline 2008 & 38.0 & 18.5 & 12.4 & 5.6 & 84.4 & $\ddagger$ & 21.4 & 55.3 \\
\hline 2009 & 35.2 & 18.6 & 10.7 & 5.1 & 93.9 & $7.5 !$ & 22.1 & 62.4 \\
\hline 2010 & 35.6 & 15.7 & 12.2 & 6.0 & 78.6 & $\ddagger$ & $23.4 !$ & 45.6 \\
\hline \multicolumn{9}{|c|}{ Enrolled in public 2-year institutions } \\
\hline 1990 & 61.2 & 19.1 & 31.2 & 9.2 & 81.5 & 4.1 & 24.9 & 51.1 \\
\hline 1995 & 52.9 & 15.6 & 25.3 & 10.9 & 81.1 & 6.1 & 32.5 & 40.5 \\
\hline 2000 & 63.9 & 20.6 & 29.9 & 11.9 & 85.5 & 9.9 & 30.0 & 44.9 \\
\hline 2001 & 58.1 & 18.0 & 28.0 & 10.6 & 83.2 & 8.9 & 25.2 & 47.4 \\
\hline 2002 & 55.1 & 17.4 & 26.3 & 11.0 & 79.2 & 8.6 & 29.8 & 39.6 \\
\hline 2003 & 54.7 & 15.4 & 28.1 & 10.3 & 80.6 & 6.6 & 29.6 & 43.4 \\
\hline 2004 & 55.1 & 17.0 & 27.1 & 10.3 & 81.9 & 9.0 & 28.7 & 43.1 \\
\hline 2005 & 54.2 & 15.6 & 24.2 & 13.4 & 82.0 & 10.8 & 25.8 & 44.8 \\
\hline 2006 & 55.3 & 15.8 & 28.8 & 9.2 & 80.7 & 8.2 & 30.0 & 42.2 \\
\hline 2007 & 54.0 & 15.2 & 28.7 & 9.6 & 83.4 & 7.1 & 33.7 & 40.9 \\
\hline 2008 & 52.9 & 14.6 & 26.9 & 10.7 & 74.8 & 9.7 & 25.9 & 37.8 \\
\hline 2009 & 45.4 & 16.0 & 20.5 & 7.8 & 71.8 & 10.3 & 30.6 & 29.4 \\
\hline 2010 & 40.6 & 14.0 & 19.1 & 6.8 & 74.7 & 11.6 & 30.1 & 31.0 \\
\hline
\end{tabular}

! Interpret with caution. The coefficient of variation (CV) for this estimate is 30 percent or greater.

$\ddagger$ Reporting standards not met. The coefficient of variation for this estimate is 50 percent or greater.

${ }^{1}$ Excludes those who were employed but not at work during the survey week; therefore, detail may not sum to total percentage employed. Hours worked per week refers to the number of hours the respondent worked at all jobs during the survey week.

2 Includes those who were employed but not at work during the survey week.

NOTE: Trend information for both 2-and 4-year public institutions and private 4-year institutions prior to 1990 was not available due to missing values. College includes both 2- and 4-year institutions. College students were classified as full-time if they were taking at least 12 hours of classes (or at least 9 hours of graduate classes) during an average school week and as part-time if they were taking fewer hours. For more information on classification of postsecondary education institutions, see Appendix C - Commonly Used Measures. For more information on the Current Population Survey (CPS), see Appendix B - Guide to Sources.

SOURCE: U.S. Department of Commerce, Census Bureau, Current Population Survey (CPS), October Supplement, selected years, $1970-2010$. 
Table A-37-2. Percentage of 16- to 24-year-old college students who were employed, by attendance status, hours worked per week, and selected characteristics: October 2010

\begin{tabular}{|c|c|c|c|c|c|c|c|c|}
\hline \multirow[b]{3}{*}{ Characteristic } & \multicolumn{4}{|c|}{ Full-time students } & \multicolumn{4}{|c|}{ Part-time students } \\
\hline & \multirow[b]{2}{*}{$\begin{array}{r}\text { Percent } \\
\text { employed }^{2}\end{array}$} & \multicolumn{3}{|c|}{ Hours worked per week } & \multirow[b]{2}{*}{$\begin{array}{r}\text { Percent } \\
\text { employed }\end{array}$} & \multicolumn{3}{|c|}{ Hours worked per week } \\
\hline & & $\begin{array}{l}\text { Less than } \\
20 \text { hours }\end{array}$ & $\begin{array}{l}20-34 \\
\text { hours }\end{array}$ & $\begin{array}{r}35 \text { or more } \\
\text { hours }\end{array}$ & & $\begin{array}{l}\text { Less than } \\
20 \text { hours }\end{array}$ & $\begin{array}{l}20-34 \\
\text { hours }\end{array}$ & $\begin{array}{r}35 \text { or more } \\
\text { hours }\end{array}$ \\
\hline Total & 39.8 & 14.9 & 17.2 & 6.6 & 73.4 & 10.7 & 28.3 & 32.8 \\
\hline \multicolumn{9}{|l|}{ Sex } \\
\hline Male & 36.7 & 12.8 & 16.9 & 6.2 & 72.9 & 8.7 & 29.3 & 32.5 \\
\hline Female & 42.4 & 16.7 & 17.5 & 7.0 & 73.8 & 12.4 & 27.4 & 33.1 \\
\hline \multicolumn{9}{|l|}{ Race/ethnicity } \\
\hline White & 43.6 & 17.6 & 18.1 & 6.8 & 76.4 & 11.5 & 28.4 & 34.2 \\
\hline Black & 33.3 & 9.3 & 15.9 & 6.6 & 65.9 & $7.3 !$ & 29.4 & 29.2 \\
\hline Hispanic & 34.9 & 10.1 & 17.2 & 7.2 & 71.9 & 10.3 & 29.7 & 30.6 \\
\hline Asian & 30.5 & 11.9 & 13.5 & 4.5 & $\ddagger$ & $\ddagger$ & $\ddagger$ & $\ddagger$ \\
\hline Pacific Islander & $\ddagger$ & $\ddagger$ & $\ddagger$ & $\ddagger$ & $\ddagger$ & $\ddagger$ & $\ddagger$ & $\ddagger$ \\
\hline $\begin{array}{c}\text { American Indian/ } \\
\text { Alaska Native }\end{array}$ & $\ddagger$ & $\ddagger$ & $\ddagger$ & $\ddagger$ & $\ddagger$ & $\ddagger$ & $\ddagger$ & $\ddagger$ \\
\hline Two or more races & 36.4 & 16.9 & $14.8 !$ & $\ddagger$ & $\ddagger$ & $\ddagger$ & $\ddagger$ & $\ddagger$ \\
\hline \multicolumn{9}{|c|}{ Level and control of institution } \\
\hline 2-year & 40.3 & 13.8 & 18.8 & 7.0 & 75.0 & 11.4 & 29.8 & 31.9 \\
\hline Public & 40.6 & 14.0 & 19.1 & 6.8 & 74.7 & 11.6 & 30.1 & 31.0 \\
\hline Private & 35.5 & $11.0 !$ & 14.7 & $9.8 !$ & $\ddagger$ & $\ddagger$ & $\ddagger$ & $\ddagger$ \\
\hline 4-year & 39.6 & 15.3 & 16.6 & 6.5 & 71.5 & 9.8 & 26.4 & 33.9 \\
\hline Public & 40.8 & 15.2 & 18.0 & 6.6 & 70.4 & 10.5 & 26.9 & 32.1 \\
\hline Private & 35.6 & 15.7 & 12.2 & 6.0 & 78.6 & $\ddagger$ & $23.4 !$ & 45.6 \\
\hline \multicolumn{9}{|l|}{ Student enrollment level } \\
\hline Undergraduate & 39.9 & 15.3 & 17.5 & 6.1 & 72.0 & 11.1 & 29.4 & 29.6 \\
\hline \multicolumn{9}{|l|}{ Sex } \\
\hline Male & 37.5 & 13.2 & 17.3 & 6.0 & 72.4 & 8.7 & 30.5 & 30.7 \\
\hline Female & 42.1 & 17.2 & 17.6 & 6.2 & 71.6 & 13.5 & 28.4 & 28.6 \\
\hline \multicolumn{9}{|l|}{ Race/ethnicity } \\
\hline White & 43.8 & 17.9 & 18.5 & 6.2 & 74.8 & 12.1 & 29.8 & 30.3 \\
\hline Black & 32.5 & 9.9 & 14.9 & 5.9 & 64.2 & $7.7 !$ & 30.8 & 25.7 \\
\hline Hispanic & 35.5 & 10.1 & 17.8 & 7.3 & 71.4 & 10.5 & 29.5 & 30.1 \\
\hline Asian & 30.5 & 13.2 & 13.6 & $3.0 !$ & $\ddagger$ & $\ddagger$ & $\ddagger$ & $\ddagger$ \\
\hline Pacific Islander & $\ddagger$ & $\ddagger$ & $\ddagger$ & $\ddagger$ & $\ddagger$ & $\ddagger$ & $\ddagger$ & $\ddagger$ \\
\hline $\begin{array}{l}\text { American Indian/ } \\
\text { Alaska Native }\end{array}$ & $\ddagger$ & $\ddagger$ & $\ddagger$ & $\ddagger$ & $\ddagger$ & $\ddagger$ & $\ddagger$ & $\ddagger$ \\
\hline Two or more races & 36.7 & 16.8 & $15.2 !$ & $\ddagger$ & $\ddagger$ & $\ddagger$ & $\ddagger$ & $\ddagger$ \\
\hline \multicolumn{9}{|l|}{$\begin{array}{l}\text { Level and control of } \\
\text { institution }\end{array}$} \\
\hline 2-year & 40.4 & 14.0 & 19.0 & 6.7 & 74.3 & 11.7 & 30.5 & 30.2 \\
\hline Public & 40.7 & 14.2 & 19.2 & 6.6 & 74.0 & 12.0 & 30.8 & 29.2 \\
\hline Private & 36.0 & $11.5 !$ & 16.5 & $\ddagger$ & $\ddagger$ & $\ddagger$ & $\ddagger$ & $\ddagger$ \\
\hline 4-year & 39.7 & 15.8 & 16.8 & 5.9 & 68.8 & 10.4 & 28.0 & 28.7 \\
\hline Public & 40.9 & 15.4 & 18.2 & 6.3 & 67.7 & 10.7 & 28.4 & 27.5 \\
\hline Private & 35.5 & 17.3 & 11.8 & 4.3 & 77.3 & $\ddagger$ & $24.6 !$ & 38.8 \\
\hline Graduate & 37.7 & 10.3 & 14.2 & 12.6 & 89.8 & $\ddagger$ & $15.5 !$ & 69.2 \\
\hline
\end{tabular}

! Interpret with caution. The coefficient of variation (CV) for this estimate is 30 percent or greater.

$\ddagger$ Reporting standards not met. Either there are too few cases or the coefficient of variation (CV) for this estimate is 50 percent or greater.

Excludes those who were employed but not at work during the survey week; therefore, detail may not sum to total percentage employed. Hours worked per week refers to the number of hours the respondent worked at all jobs during the survey week.

2 Includes those who were employed but not at work during the survey week.

NOTE: College includes both 2- and 4-year institutions. College students were classified as full-time if they were taking at least 12 hours of classes (or at least 9 hours of graduate classes) during an average school week and as part-fime if they were taking fewer hours. For more information on classification of postsecondary education institutions, see Appendix C - Commonly Used Measures. Race categories exclude persons of Hispanic ethnicity. For more information on race/ethnicity, see Appendix C - Commonly Used Measures. For more information on the Current Population Survey (CPS), see Appendix B - Guide to Sources.

SOURCE: U.S. Department of Commerce, Census Bureau, Current Population Survey (CPS), October Supplement, 2010. 
This page intentionally left blank.

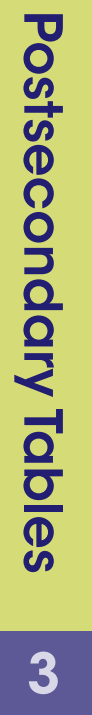


Table A-38-1. Number of associate's and bachelor's degrees awarded by degree-granting institutions, percentage of total, number and percentage awarded to females, and percent change, by selected fields of study: Academic years $1999-2000$ and $2009-10$

\begin{tabular}{|c|c|c|c|c|c|c|c|c|c|c|c|}
\hline \multirow[b]{2}{*}{$\begin{array}{l}\text { Level of degree and } \\
\text { field of study }\end{array}$} & \multicolumn{4}{|c|}{ 1999-2000 } & \multicolumn{4}{|c|}{$2009-10$} & \multicolumn{3}{|c|}{ 1999-2000 to 2009-10 } \\
\hline & Number & $\begin{array}{r}\text { Percent } \\
\text { of } \\
\text { total }\end{array}$ & $\begin{array}{r}\text { Number } \\
\text { to } \\
\text { females }\end{array}$ & $\begin{array}{r}\text { Percent } \\
\text { to } \\
\text { females }\end{array}$ & Number & $\begin{array}{r}\text { Percent } \\
\text { of } \\
\text { total }\end{array}$ & $\begin{array}{r}\text { Number } \\
\text { to } \\
\text { females }\end{array}$ & $\begin{array}{r}\text { Percent } \\
\text { to } \\
\text { females }\end{array}$ & $\begin{array}{r}\text { Change } \\
\text { in num- } \\
\text { ber of } \\
\text { degrees }\end{array}$ & $\begin{array}{l}\text { Percent } \\
\text { change }\end{array}$ & $\begin{array}{r}\text { Percent } \\
\text { change } \\
\text { for } \\
\text { females }\end{array}$ \\
\hline \multicolumn{12}{|l|}{ Associate's degrees } \\
\hline Total' & 564,933 & 100.0 & 340,212 & 60.2 & 849,452 & 100.0 & 526,536 & 62.0 & 284,519 & 50.4 & 54.8 \\
\hline $\begin{array}{l}\text { Liberal arts and sciences, } \\
\text { general studies, and } \\
\text { humanities }\end{array}$ & 187,454 & 33.2 & 117,708 & 62.8 & 284,775 & 33.5 & 174,074 & 61.1 & 97,321 & 51.9 & 47.9 \\
\hline $\begin{array}{l}\text { Health professions and } \\
\text { related programs }\end{array}$ & 86,676 & 15.3 & 74,804 & 86.3 & 177,686 & 20.9 & 151,782 & 85.4 & 91,010 & 105.0 & 102.9 \\
\hline $\begin{array}{l}\text { Business, management, } \\
\text { marketing, and } \\
\text { personal and culinary } \\
\text { services }\end{array}$ & 95,309 & 16.9 & 65,429 & 68.6 & 133,371 & 15.7 & 85,203 & 63.9 & 38,062 & 39.9 & 30.2 \\
\hline $\begin{array}{c}\text { Engineering and } \\
\text { engineering } \\
\text { technologies }\end{array}$ & 59,458 & 10.5 & 7,584 & 12.8 & 55,280 & 6.5 & 5,713 & 10.3 & $-4,178$ & -7.0 & -24.7 \\
\hline $\begin{array}{l}\text { Homeland security, } \\
\text { law enforcement, fire- } \\
\text { fighting, and related } \\
\text { protective services }\end{array}$ & 16,298 & 2.9 & 5,791 & 35.5 & 37,260 & 4.4 & 17,384 & 46.7 & 20,962 & 128.6 & 200.2 \\
\hline $\begin{array}{l}\text { Computer and informa- } \\
\text { tion sciences and } \\
\text { support services }\end{array}$ & 28,185 & 5.0 & 12,036 & 42.7 & 32,466 & 3.8 & 7,784 & 24.0 & 4,281 & 15.2 & -35.3 \\
\hline $\begin{array}{l}\text { Visual and performing } \\
\text { arts }\end{array}$ & 17,100 & 3.0 & 9,101 & 53.2 & 19,567 & 2.3 & 11,881 & 60.7 & 2,467 & 14.4 & 30.5 \\
\hline $\begin{array}{l}\text { Multi/interdisciplinary } \\
\text { studies }\end{array}$ & 11,784 & 2.1 & 6,263 & 53.1 & 17,671 & 2.1 & 10,711 & 60.6 & 5,887 & 50.0 & 71.0 \\
\hline Education & 8,510 & 1.5 & 6,615 & 77.7 & 17,048 & 2.0 & 14,696 & 86.2 & 8,538 & 100.3 & 122.2 \\
\hline $\begin{array}{l}\text { Social sciences and } \\
\text { history }\end{array}$ & 5,136 & 0.9 & 3,345 & 65.1 & 10,649 & 1.3 & 6,840 & 64.2 & 5,513 & 107.3 & 104.5 \\
\hline $\begin{array}{l}\text { Legal professions and } \\
\text { studies }\end{array}$ & 8,842 & 1.6 & 7,901 & 89.4 & 10,003 & 1.2 & 8,800 & 88.0 & 1,161 & 13.1 & 11.4 \\
\hline $\begin{array}{l}\text { Family and consumer } \\
\text { sciences/human } \\
\text { sciences }\end{array}$ & 8,031 & 1.4 & 7,359 & 91.6 & 9,573 & 1.1 & 9,078 & 94.8 & 1,542 & 19.2 & 23.4 \\
\hline $\begin{array}{c}\text { Communication and } \\
\text { communications } \\
\text { technologies }\end{array}$ & 5,379 & 1.0 & 2,485 & 46.2 & 7,258 & 0.9 & 2,893 & 39.9 & 1,879 & 34.9 & 16.4 \\
\hline Psychology & 1,455 & 0.3 & 1,129 & 77.6 & 6,582 & 0.8 & 5,311 & 80.7 & 5,127 & 352.4 & 370.4 \\
\hline $\begin{array}{l}\text { Agriculture and natural } \\
\text { resources }\end{array}$ & 6,666 & 1.2 & 2,313 & 34.7 & 5,894 & 0.7 & 2,111 & 35.8 & -772 & -11.6 & -8.7 \\
\hline $\begin{array}{l}\text { Public administration } \\
\text { and social service } \\
\text { professions }\end{array}$ & 3,656 & 0.6 & 3,101 & 84.8 & 4,526 & 0.5 & 3,864 & 85.4 & 870 & 23.8 & 24.6 \\
\hline $\begin{array}{c}\text { Physical sciences } \\
\text { and science } \\
\text { technologies }\end{array}$ & 2,471 & 0.4 & 1,162 & 47.0 & 4,140 & 0.5 & 1,591 & 38.4 & 1,669 & 67.5 & 36.9 \\
\hline Precision production & 2,308 & 0.4 & 266 & 11.5 & 2,787 & 0.3 & 178 & 6.4 & 479 & 20.8 & -33.1 \\
\hline $\begin{array}{l}\text { Biological and } \\
\text { biomedical sciences }\end{array}$ & 1,448 & 0.3 & 960 & 66.3 & 2,664 & 0.3 & 1,813 & 68.1 & 1,216 & 84.0 & 88.9 \\
\hline $\begin{array}{c}\text { Parks, recreation, leisure, } \\
\text { and fitness studies }\end{array}$ & 819 & 0.1 & 323 & 39.4 & 2.016 & 0.2 & 793 & 39.3 & 1,197 & 146.2 & 145.5 \\
\hline
\end{tabular}

See notes at end of table. 
Table A-38-1. Number of associate's and bachelor's degrees awarded by degree-granting institutions, percentage of total, number and percentage awarded to females, and percent change, by selected fields of study: Academic years 1999-2000 and 2009-10-Continued

\begin{tabular}{|c|c|c|c|c|c|c|c|c|c|c|c|}
\hline \multirow[b]{2}{*}{$\begin{array}{l}\text { Level of degree and } \\
\text { field of study }\end{array}$} & \multicolumn{4}{|c|}{ 1999-2000 } & \multicolumn{4}{|c|}{$2009-10$} & \multicolumn{3}{|c|}{ 1999-2000 to 2009-10 } \\
\hline & Number & $\begin{array}{r}\text { Percent } \\
\text { of } \\
\text { total } \\
\end{array}$ & $\begin{array}{r}\text { Number } \\
\text { to } \\
\text { females }\end{array}$ & $\begin{array}{r}\text { Percent } \\
\text { to } \\
\text { females }\end{array}$ & Number & $\begin{array}{r}\text { Percent } \\
\text { of } \\
\text { total } \\
\end{array}$ & $\begin{array}{r}\text { Number } \\
\text { to } \\
\text { females }\end{array}$ & $\begin{array}{r}\text { Percent } \\
\text { to } \\
\text { females }\end{array}$ & $\begin{array}{r}\text { Change } \\
\text { in num- } \\
\text { ber of } \\
\text { degrees } \\
\end{array}$ & $\begin{array}{l}\text { Percent } \\
\text { change }\end{array}$ & $\begin{array}{r}\text { Percent } \\
\text { change } \\
\text { for } \\
\text { females }\end{array}$ \\
\hline \multicolumn{12}{|l|}{ Bachelor's degrees } \\
\hline Total $^{1}$ & $1,237,875$ & 100.0 & 707,508 & 57.2 & $1,650,014$ & 100.0 & 943,381 & 57.2 & 412,139 & 33.3 & 33.3 \\
\hline $\begin{array}{l}\text { Business, management, } \\
\text { marketing, and } \\
\text { personal and } \\
\text { culinary services }\end{array}$ & 256,070 & 20.7 & 127,549 & 49.8 & 358,293 & 21.7 & 174,992 & 48.8 & 102,223 & 39.9 & 37.2 \\
\hline $\begin{array}{l}\text { Social sciences and } \\
\text { history }\end{array}$ & 127,101 & 10.3 & 65,039 & 51.2 & 172,780 & 10.5 & 85,374 & 49.4 & 45,679 & 35.9 & 31.3 \\
\hline $\begin{array}{l}\text { Health professions and } \\
\text { related programs }\end{array}$ & 80,863 & 6.5 & 67,521 & 83.5 & 129,634 & 7.9 & 110,328 & 85.1 & 48,771 & 60.3 & 63.4 \\
\hline Education & 108,034 & 8.7 & 81,931 & 75.8 & 101,265 & 6.1 & 80,539 & 79.5 & $-6,769$ & -6.3 & -1.7 \\
\hline Psychology & 74,194 & 6.0 & 56,743 & 76.5 & 97,216 & 5.9 & 74,941 & 77.1 & 23,022 & 31.0 & 32.1 \\
\hline $\begin{array}{l}\text { Visual and performing } \\
\text { arts }\end{array}$ & 58,791 & 4.7 & 34,788 & 59.2 & 91,802 & 5.6 & 56,034 & 61.0 & 33,011 & 56.1 & 61.1 \\
\hline $\begin{array}{l}\text { Engineering and } \\
\text { engineering } \\
\text { technologies }\end{array}$ & 73,323 & 5.9 & 13,655 & 18.6 & 88,729 & 5.4 & 14,896 & 16.8 & 15,406 & 21.0 & 9.1 \\
\hline $\begin{array}{l}\text { Biological and } \\
\text { biomedical } \\
\text { sciences }\end{array}$ & 63,630 & 5.1 & 37,051 & 58.2 & 86,400 & 5.2 & 50,535 & 58.5 & 22,770 & 35.8 & 36.4 \\
\hline $\begin{array}{l}\text { Communication and } \\
\text { communications } \\
\text { technologies }\end{array}$ & 57,058 & 4.6 & 34,906 & 61.2 & 86,048 & 5.2 & 54,008 & 62.8 & 28,990 & 50.8 & 54.7 \\
\hline $\begin{array}{l}\text { English language and } \\
\text { literature/letters }\end{array}$ & 50,106 & 4.0 & 33,982 & 67.8 & 53,231 & 3.2 & 36,181 & 68.0 & 3,125 & 6.2 & 6.5 \\
\hline $\begin{array}{l}\text { Liberal arts and scienc- } \\
\text { es, general studies, } \\
\text { and humanities }\end{array}$ & 36,104 & 2.9 & 23,854 & 66.1 & 46,953 & 2.8 & 30,334 & 64.6 & 10,849 & 30.0 & 27.2 \\
\hline $\begin{array}{l}\text { Homeland security, law } \\
\text { enforcement, fire- } \\
\text { fighting, and related } \\
\text { protective services }\end{array}$ & 24,877 & 2.0 & 10,808 & 43.4 & 43,667 & 2.6 & 21,402 & 49.0 & 18,790 & 75.5 & 98.0 \\
\hline $\begin{array}{l}\text { Computer and informa- } \\
\text { tion sciences and } \\
\text { support services }\end{array}$ & 37,788 & 3.1 & 10,603 & 28.1 & 39,589 & 2.4 & 7,179 & 18.1 & 1,801 & 4.8 & -32.3 \\
\hline $\begin{array}{l}\text { Multi/interdisciplinary } \\
\text { studies }\end{array}$ & 27,936 & 2.3 & 18,717 & 67.0 & 37,648 & 2.3 & 25,519 & 67.8 & 9,712 & 34.8 & 36.3 \\
\hline $\begin{array}{l}\text { Parks, recreation, } \\
\text { leisure, and fitness } \\
\text { studies }\end{array}$ & 17,571 & 1.4 & 9,021 & 51.3 & 33,318 & 2.0 & 15,697 & 47.1 & 15,747 & 89.6 & 74.0 \\
\hline $\begin{array}{l}\text { Agriculture and natural } \\
\text { resources }\end{array}$ & 24,238 & 2.0 & 10,395 & 42.9 & 26,336 & 1.6 & 12,817 & 48.7 & 2,098 & 8.7 & 23.3 \\
\hline $\begin{array}{l}\text { Public administration } \\
\text { and social service } \\
\text { professions }\end{array}$ & 20,185 & 1.6 & 16,369 & 81.1 & 25,414 & 1.5 & 20,836 & 82.0 & 5,229 & 25.9 & 27.3 \\
\hline $\begin{array}{c}\text { Physical sciences } \\
\text { and science } \\
\text { technologies }\end{array}$ & 18,427 & 1.5 & 7,408 & 40.2 & 23,379 & 1.4 & 9,517 & 40.7 & 4,952 & 26.9 & 28.5 \\
\hline $\begin{array}{l}\text { Family and consumer } \\
\text { sciences/human } \\
\text { sciences }\end{array}$ & 16,321 & 1.3 & 14,288 & 87.5 & 21,818 & 1.3 & 19,132 & 87.7 & 5,497 & 33.7 & 33.9 \\
\hline $\begin{array}{l}\text { Foreign languages, } \\
\text { literatures, and } \\
\text { linguistics }\end{array}$ & 15,886 & 1.3 & 11,270 & 70.9 & 21,516 & 1.3 & 14,906 & 69.3 & 5,630 & 35.4 & 32.3 \\
\hline
\end{tabular}


Table A-39-1. Number of master's and doctor's degrees awarded by degree-granting institutions, percentage of total, number and percentage awarded to females, and percent change, by selected fields of study: Academic years $1999-2000$ and $2009-10$

\begin{tabular}{|c|c|c|c|c|c|c|c|c|c|c|c|}
\hline \multirow[b]{2}{*}{ Field of study } & \multicolumn{4}{|c|}{ 1999-2000 } & \multicolumn{4}{|c|}{$2009-10$} & \multicolumn{3}{|c|}{$1999-2000$ to $2009-10$} \\
\hline & Number & $\begin{array}{l}\text { Percent } \\
\text { of total } \\
\end{array}$ & $\begin{array}{r}\text { Number } \\
\text { to fe- } \\
\text { males }\end{array}$ & $\begin{array}{r}\text { Percent } \\
\text { to fe- } \\
\text { males }\end{array}$ & Number & $\begin{array}{r}\text { Percent } \\
\text { of total } \\
\end{array}$ & $\begin{array}{r}\text { Number } \\
\text { to fe- } \\
\text { males }\end{array}$ & $\begin{array}{r}\text { Percent } \\
\text { to fe- } \\
\text { males }\end{array}$ & $\begin{array}{r}\text { Change } \\
\text { in num- } \\
\text { ber of } \\
\text { degrees }\end{array}$ & $\begin{array}{l}\text { Percent } \\
\text { change }\end{array}$ & $\begin{array}{r}\text { Percent } \\
\text { change } \\
\text { for fe- } \\
\text { males }\end{array}$ \\
\hline $\begin{array}{l}\text { Master's degrees } \\
\text { Total' }\end{array}$ & 463,185 & 100.0 & 267,056 & 57.7 & 693,025 & 100.0 & 417,828 & 60.3 & 229,840 & 49.6 & 56.5 \\
\hline Education & 123,045 & 26.6 & 93,964 & 76.4 & 182,139 & 26.3 & 140,843 & 77.3 & 59,094 & 48.0 & 49.9 \\
\hline Business & 111,532 & 24.1 & 44,454 & 39.9 & 177,684 & 25.6 & 80,975 & 45.6 & 66,152 & 59.3 & 82.2 \\
\hline $\begin{array}{l}\text { Health professions } \\
\text { and related } \\
\text { programs }\end{array}$ & 42,593 & 9.2 & 33,093 & 77.7 & 69,084 & 10.0 & 56,213 & 81.4 & 26,491 & 62.2 & 69.9 \\
\hline $\begin{array}{l}\text { Engineering and } \\
\text { engineering } \\
\text { technologies }\end{array}$ & 26,648 & 5.8 & 5,596 & 21.0 & 39,346 & 5.7 & 8,825 & 22.4 & 12,698 & 47.7 & 57.7 \\
\hline $\begin{array}{l}\text { Public administra- } \\
\text { tion and social } \\
\text { services }\end{array}$ & 25,594 & 5.5 & 18,786 & 73.4 & 35,729 & 5.2 & 26,864 & 75.2 & 10,135 & 39.6 & 43.0 \\
\hline Psychology & 15,740 & 3.4 & 11,919 & 75.7 & 23,752 & 3.4 & 18,955 & 79.8 & 8,012 & 50.9 & 59.0 \\
\hline $\begin{array}{l}\text { Social sciences } \\
\text { and history }\end{array}$ & 14,066 & 3.0 & 7,042 & 50.1 & 20,222 & 2.9 & 10,259 & 50.7 & 6,156 & 43.8 & 45.7 \\
\hline $\begin{array}{l}\text { Computer and infor- } \\
\text { mation sciences }\end{array}$ & 14,990 & 3.2 & 5,012 & 33.4 & 17,953 & 2.6 & 4,936 & 27.5 & 2,963 & 19.8 & -1.5 \\
\hline $\begin{array}{l}\text { Visual and performing } \\
\text { arts }\end{array}$ & 10,918 & 2.4 & 6,246 & 57.2 & 15,552 & 2.2 & 9,027 & 58.0 & 4,634 & 42.4 & 44.5 \\
\hline $\begin{array}{l}\text { Theology and religious } \\
\text { vocations }\end{array}$ & 11,663 & 2.5 & 3,995 & 34.3 & 12,824 & 1.9 & 4,522 & 35.3 & 1,161 & 10.0 & 13.2 \\
\hline $\begin{array}{l}\text { Biological and bio- } \\
\text { medical sciences }\end{array}$ & 6,850 & 1.5 & 3,679 & 53.7 & 10,725 & 1.5 & 6,114 & 57.0 & 3,875 & 56.6 & 66.2 \\
\hline $\begin{array}{l}\text { English language and } \\
\text { literature/letters }\end{array}$ & 7,022 & 1.5 & 4,707 & 67.0 & 9,201 & 1.3 & 6,195 & 67.3 & 2,179 & 31.0 & 31.6 \\
\hline $\begin{array}{l}\text { Communication and } \\
\text { communications } \\
\text { technologies }\end{array}$ & 5,525 & 1.2 & 3,495 & 63.3 & 8,099 & 1.2 & 5,440 & 67.2 & 2,574 & 46.6 & 55.7 \\
\hline Library science & 4,577 & 1.0 & 3,630 & 79.3 & 7,448 & 1.1 & 6,054 & 81.3 & 2,871 & 62.7 & 66.8 \\
\hline $\begin{array}{l}\text { Architecture and } \\
\text { related services }\end{array}$ & 4,268 & 0.9 & 1,760 & 41.2 & 7,280 & 1.1 & 3,268 & 44.9 & 3,012 & 70.6 & 85.7 \\
\hline $\begin{array}{l}\text { Homeland security, } \\
\text { law enforcement, } \\
\text { and firefighting }\end{array}$ & 2,609 & 0.6 & 1,075 & 41.2 & 6,714 & 1.0 & 3,574 & 53.2 & 4,105 & 157.3 & 232.5 \\
\hline $\begin{array}{l}\text { Physical sciences } \\
\text { and science } \\
\text { technologies }\end{array}$ & 4,888 & 1.1 & 1,721 & 35.2 & 6,063 & 0.9 & 2,411 & 39.8 & 1,175 & 24.0 & 40.1 \\
\hline $\begin{array}{l}\text { Multi/interdisciplinary } \\
\text { studies }\end{array}$ & 3,418 & 0.7 & 2,206 & 64.5 & 5,973 & 0.9 & 3,855 & 64.5 & 2,555 & 74.8 & 74.8 \\
\hline $\begin{array}{l}\text { Legal professions and } \\
\text { studies }\end{array}$ & 3,750 & 0.8 & 1,558 & 41.5 & 5,734 & 0.8 & 2,931 & 51.1 & 1,984 & 52.9 & 88.1 \\
\hline $\begin{array}{l}\text { Mathematics and } \\
\text { statistics }\end{array}$ & 3,208 & 0.7 & 1,459 & 45.5 & 5,634 & 0.8 & 2,258 & 40.1 & 2,426 & 75.6 & 54.8 \\
\hline
\end{tabular}

See notes at end of table. 
Table A-39-1. Number of master's and doctor's degrees awarded by degree-granting institutions, percentage of total, number and percentage awarded to females, and percent change, by selected fields of study: Academic years $1999-2000$ and $2009-10-$ Continued

\begin{tabular}{|c|c|c|c|c|c|c|c|c|c|c|c|}
\hline \multirow[b]{2}{*}{ Field of study } & \multicolumn{4}{|c|}{ 1999-2000 } & \multicolumn{4}{|c|}{ 2009-10 } & \multicolumn{3}{|c|}{ 1999-2000 to 2009-10 } \\
\hline & Number & $\begin{array}{r}\text { Percent } \\
\text { of total }\end{array}$ & $\begin{array}{r}\text { Number } \\
\text { to fe- } \\
\text { males }\end{array}$ & $\begin{array}{r}\text { Percent } \\
\text { to fe- } \\
\text { males } \\
\end{array}$ & Number & $\begin{array}{l}\text { Percent } \\
\text { of total }\end{array}$ & $\begin{array}{c}\text { Number } \\
\text { to fe- } \\
\text { males }\end{array}$ & $\begin{array}{r}\text { Percent } \\
\text { to fe- } \\
\text { males } \\
\end{array}$ & $\begin{array}{l}\text { Change } \\
\text { in num- } \\
\text { ber of } \\
\text { degrees }\end{array}$ & $\begin{array}{l}\text { Percent } \\
\text { change }\end{array}$ & $\begin{array}{r}\text { Percent } \\
\text { change } \\
\text { for fe- } \\
\text { males }\end{array}$ \\
\hline $\begin{array}{c}\text { Doctor's degrees }^{2} \\
\text { Total }^{1}\end{array}$ & 118,736 & 100.0 & 53,806 & 45.3 & 158,558 & 100.0 & 81,953 & 51.7 & 39,822 & 33.5 & 52.3 \\
\hline $\begin{array}{l}\text { Health professions } \\
\text { and related }\end{array}$ & & & & & & & & & & & \\
\hline programs & 37,829 & 31.9 & 17,845 & 47.2 & 57,746 & 36.4 & 33,800 & 58.5 & 19,917 & 52.7 & 89.4 \\
\hline $\begin{array}{l}\text { Legal professions and } \\
\text { studies }\end{array}$ & 38,226 & 32.2 & 17,539 & 45.9 & 44,626 & 28.1 & 21,074 & 47.2 & 6,400 & 16.7 & 20.2 \\
\hline Education & 6,409 & 5.4 & 4,114 & 64.2 & 9,233 & 5.8 & 6,210 & 67.3 & 2,824 & 44.1 & 50.9 \\
\hline $\begin{array}{c}\text { Engineering and } \\
\text { engineering } \\
\text { technologies }\end{array}$ & 5,367 & 4.5 & 828 & 15.4 & 7,771 & 4.9 & 1,787 & 23.0 & 2,404 & 44.8 & 115.8 \\
\hline $\begin{array}{l}\text { Biological and bio- } \\
\text { medical sciences }\end{array}$ & 5,463 & 4.6 & 2,395 & 43.8 & 7,666 & 4.8 & 4,066 & 53.0 & 2,203 & 40.3 & 69.8 \\
\hline Psychology & 4,731 & 4.0 & 3,202 & 67.7 & 5,540 & 3.5 & 4,062 & 73.3 & 809 & 17.1 & 26.9 \\
\hline $\begin{array}{l}\text { Physical sciences and } \\
\text { science } \\
\text { technologies }\end{array}$ & 4,017 & 3.4 & 1,015 & 25.3 & 5,063 & 3.2 & 1,659 & 32.8 & 1,046 & 26.0 & 63.4 \\
\hline $\begin{array}{l}\text { Social sciences and } \\
\text { history }\end{array}$ & 4,095 & 3.4 & 1,688 & 41.2 & 4,238 & 2.7 & 1,946 & 45.9 & 143 & 3.5 & 15.3 \\
\hline Business & 1,194 & 1.0 & 382 & 32.0 & 2,245 & 1.4 & 910 & 40.5 & 1,051 & 88.0 & 138.2 \\
\hline $\begin{array}{l}\text { Theology and religious } \\
\text { vocations }\end{array}$ & 1,630 & 1.4 & 334 & 20.5 & 2,070 & 1.3 & 545 & 26.3 & 440 & 27.0 & 63.2 \\
\hline $\begin{array}{l}\text { Computer and } \\
\text { information } \\
\text { sciences }\end{array}$ & 779 & 0.7 & 131 & 16.8 & 1,599 & 1.0 & 349 & 21.8 & 820 & 105.3 & 166.4 \\
\hline $\begin{array}{l}\text { Visual and performing } \\
\text { arts }\end{array}$ & 1,127 & 0.9 & 590 & 52.4 & 1,599 & 1.0 & 899 & 56.2 & 472 & 41.9 & 52.4 \\
\hline $\begin{array}{l}\text { Mathematics and } \\
\text { statistics }\end{array}$ & 1,075 & 0.9 & 272 & 25.3 & 1,592 & 1.0 & 476 & 29.9 & 517 & 48.1 & 75.0 \\
\hline $\begin{array}{l}\text { English language and } \\
\text { literature/letters }\end{array}$ & 1,470 & 1.2 & 859 & 58.4 & 1,332 & 0.8 & 810 & 60.8 & -138 & -9.4 & -5.7 \\
\hline $\begin{array}{l}\text { Agriculture and } \\
\text { natural resources }\end{array}$ & 1,168 & 1.0 & 365 & 31.3 & 1,147 & 0.7 & 522 & 45.5 & -21 & -1.8 & 43.0 \\
\hline $\begin{array}{l}\text { Foreign languages, } \\
\text { literatures, and } \\
\text { linguistics }\end{array}$ & 1,086 & 0.9 & 640 & 58.9 & 1,091 & 0.7 & 645 & 59.1 & 5 & 0.5 & 0.8 \\
\hline $\begin{array}{l}\text { Public administration } \\
\text { and social } \\
\text { services }\end{array}$ & 537 & 0.5 & 310 & 57.7 & 838 & 0.5 & 515 & 61.5 & 301 & 56.1 & 66.1 \\
\hline $\begin{array}{l}\text { Philosophy and } \\
\text { religious studies } \\
\text { Multi/interdisciplinary }\end{array}$ & 598 & 0.5 & 213 & 35.6 & 667 & 0.4 & 217 & 32.5 & 69 & 11.5 & 1.9 \\
\hline studies & 509 & 0.4 & 278 & 54.6 & 631 & 0.4 & 366 & 58.0 & 122 & 24.0 & 31.7 \\
\hline $\begin{array}{c}\text { Communication and } \\
\text { communications } \\
\text { technologies }\end{array}$ & 357 & 0.3 & 189 & 52.9 & 573 & 0.4 & 348 & 60.7 & 216 & 60.5 & 84.1 \\
\hline
\end{tabular}

'Includes other fields not shown separately. These 20 fields were selected out of 54 fields total because they were the top fields in which master's or doctor's degrees were awarded in 2009-10. In 2009-10, these selected fields awarded 96 percent of master's degrees, and 99 percent of doctor's degrees.

${ }^{2}$ Includes Ph.D., Ed.D., and comparable degrees at the doctoral level. Includes most degrees formerly classified as first-professional, such as M.D., D.D.S., and law degrees.

NOTE: Includes only institutions that participated in Title IV federal financial aid programs. The new Classification of Instructional Programs was initiated in 2009-10. The estimates for 1999-2000 have been reclassified when necessary to make them conform to the new taxonomy. For more information on the Integrated Postsecondary Education Data System (IPEDS) classification of institutions and degree levels, see Appendix C - Commonly Used Measures. For more information on IPEDS, see Appendix B - Guide to Sources.

SOURCE: U.S. Department of Education, National Center for Education Statistics, Integrated Postsecondary Education Data System (IPEDS), Fall 2000 and Fall 2010, Completions component. 


\section{Price of Attending an Undergraduate Institution}

Table A-40-1. Average total costs of attending an undergraduate institution for first-time, full-time students, by control and level of institution, living arrangement, and component of student costs: Academic years 2009-10 and 2010-11

\begin{tabular}{|c|c|c|c|c|c|c|c|c|}
\hline \multirow{3}{*}{$\begin{array}{l}\text { Living arrangement and component } \\
\text { of student costs }\end{array}$} & \multicolumn{4}{|c|}{$2009-10$} & \multicolumn{4}{|c|}{$2010-11$} \\
\hline & \multirow{2}{*}{$\begin{array}{r}\text { All institu- } \\
\text { tions }\end{array}$} & \multirow{2}{*}{$\begin{array}{r}\text { Public, in } \\
\text { state }\end{array}$} & \multicolumn{2}{|c|}{ Private } & \multirow{2}{*}{$\begin{array}{r}\text { All institu- } \\
\text { tions }\end{array}$} & \multirow{2}{*}{$\begin{array}{r}\text { Public, in } \\
\text { state }\end{array}$} & \multicolumn{2}{|c|}{ Private } \\
\hline & & & Nonprofit & For-profit & & & Nonprofit & For-profit \\
\hline & \multicolumn{8}{|c|}{ 4-year institutions } \\
\hline \multicolumn{9}{|l|}{ Average total costs } \\
\hline On campus & $\$ 26,380$ & $\$ 19,312$ & $\$ 38,240$ & $\$ 28,555$ & $\$ 27,435$ & $\$ 20,114$ & $\$ 39,772$ & $\$ 30,130$ \\
\hline Off campus, living with family & 19,491 & 12,103 & 30,456 & 18,969 & 19,940 & 12,561 & 31,630 & 20,226 \\
\hline Off campus, not living with family & 28,312 & 20,952 & 38,753 & 27,412 & 29,390 & 21,665 & 40,148 & 29,114 \\
\hline Tuition and fees & 13,994 & 6,893 & 25,702 & 13,242 & 14,551 & 7,249 & 26,769 & 14,236 \\
\hline Books and supplies & 1,055 & 1,166 & 1,179 & 523 & 1,134 & 1,194 & 1,217 & 799 \\
\hline \multicolumn{9}{|l|}{ Room, board, and other expenses } \\
\hline Room and board & 8,561 & 8,134 & 9,071 & 10,420 & 8,921 & 8,502 & 9,464 & 9,370 \\
\hline Other & 2,770 & 3,118 & 2,288 & 4,370 & 2,829 & 3,169 & 2,323 & 5,726 \\
\hline \multicolumn{9}{|l|}{ Off campus, living with family } \\
\hline Other & 4,442 & 4,044 & 3,575 & 5,204 & 4,256 & 4,118 & 3,645 & 5,191 \\
\hline \multicolumn{9}{|l|}{ Off campus, not living with family } \\
\hline Room and board & 8,584 & 8,924 & 8,140 & 8,472 & 8,679 & 9,085 & 8,391 & 8,543 \\
\hline \multirow[t]{2}{*}{ Other } & 4,680 & 3,968 & 3,732 & 5,175 & 5,026 & 4,137 & 3,772 & 5,536 \\
\hline & \multicolumn{8}{|c|}{ 2-year institutions } \\
\hline \multicolumn{9}{|l|}{ Average total costs } \\
\hline On campus & $\$ 14,398$ & $\$ 11,815$ & $\$ 23,553$ & $\$ 29,352$ & $\$ 15,267$ & $\$ 12,398$ & $\$ 24,654$ & $\$ 29,587$ \\
\hline Off campus, living with family & 9,822 & 7,579 & 17,311 & 20,477 & 10,451 & 7,933 & 17,334 & 21,143 \\
\hline Off campus, not living with family & 17,294 & 14,873 & 25,754 & 28,201 & 17,934 & 15,278 & 25,773 & 28,805 \\
\hline Tuition and fees & 4,816 & 2,640 & 12,698 & 14,918 & 5,230 & 2,794 & 12,839 & 15,373 \\
\hline Books and supplies & 1,255 & 1,235 & 1,229 & 1,392 & 1,324 & 1,292 & 1,276 & 1,514 \\
\hline \multicolumn{9}{|l|}{ Room, board, and other expenses } \\
\hline \multicolumn{9}{|l|}{ On campus } \\
\hline Room and board & 5,518 & 5,186 & 7,061 & 8,979 & 5,719 & 5,384 & 7,460 & 8,628 \\
\hline Other & 2,809 & 2,754 & 2,565 & 4,063 & 2,994 & 2,928 & 3,079 & 4,071 \\
\hline \multicolumn{9}{|l|}{ Off campus, living with family } \\
\hline Other & 3,751 & 3,704 & 3,384 & 4,167 & 3,897 & 3,847 & 3,219 & 4,256 \\
\hline \multicolumn{9}{|l|}{ Off campus, not living with family } \\
\hline Room and board & 7,494 & 7,344 & 8,105 & 7,933 & 7,539 & 7,428 & 8,267 & 7,836 \\
\hline Other & 3,729 & 3,654 & 3,721 & 3,958 & 3,841 & 3,763 & 3,391 & 4,082 \\
\hline
\end{tabular}

NOTE: Excludes students who have already attended another postsecondary institution or who began their studies on a part-time basis. The tuition and fees included in total costs are the lower of either in-district or in-state tuition and fees. Data illustrating the average total cost of attendance are weighted by the number of students at the institution receiving Title IV aid. For more information on the Integrated Postsecondary Education Data System (IPEDS), see Appendix B - Guide to Sources.

SOURCE: U.S. Department of Education, National Center for Education Statistics, Integrated Postsecondary Education Data System (IPEDS), Spring 2010 and Spring 2011, Student Financial Aid components; and Fall 2010, Institutional Characteristics component. 
Table A-40-2. Average amount of grant and scholarship aid and average net price for first-time, full-time students receiving aid and percentage distribution of students, by institution control and level and income level: Academic year 2009-10

\begin{tabular}{|c|c|c|c|c|c|c|c|c|}
\hline \multirow{3}{*}{$\begin{array}{l}\text { Average amount of grant and } \\
\text { scholarship aid from all sources } \\
\text { and net price }\end{array}$} & \multicolumn{4}{|c|}{ Average per student } & \multicolumn{4}{|c|}{ Percentage distribution } \\
\hline & \multirow{2}{*}{$\begin{array}{r}\text { All } \\
\text { institutions }\end{array}$} & \multirow[b]{2}{*}{ Public } & \multicolumn{2}{|c|}{ Private } & \multirow{2}{*}{$\begin{array}{r}\text { All } \\
\text { institutions } \\
\end{array}$} & \multirow[b]{2}{*}{ Public } & \multicolumn{2}{|c|}{ Private } \\
\hline & & & Nonprofit & For-profit & & & Nonprofit & For-profit \\
\hline & \multicolumn{8}{|c|}{ 4-year institutions } \\
\hline \multicolumn{9}{|l|}{ Grant and scholarship aid } \\
\hline All income levels & $\$ 8,450$ & $\$ 5,960$ & $\$ 15,300$ & $\$ 4,150$ & 100.0 & 100.0 & 100.0 & 100.0 \\
\hline$\$ 0-30,000$ & 9,000 & 9,060 & 17,160 & 4,620 & 39.8 & 34.6 & 25.6 & 74.8 \\
\hline$\$ 30,001-48,000$ & 10,470 & 8,270 & 18,380 & 3,950 & 14.9 & 16.4 & 14.1 & 12.4 \\
\hline$\$ 48,001-75,000$ & 8,720 & 4,880 & 16,430 & 2,090 & 15.4 & 17.2 & 17.9 & 6.9 \\
\hline$\$ 75,001-110,000$ & 6,960 & 2,300 & 14,360 & 1,090 & 14.2 & 15.9 & 18.2 & 3.5 \\
\hline$\$ 110,001$ or more & 6,200 & 1,680 & 11,410 & 940 & 15.8 & 15.9 & 24.2 & 2.3 \\
\hline \multicolumn{9}{|l|}{ Net price } \\
\hline All income levels & 17,360 & 12,030 & 22,160 & 23,430 & 100.0 & 100.0 & 100.0 & 100.0 \\
\hline$\$ 0-30,000$ & 14,950 & 7,850 & 16,370 & 22,490 & 39.8 & 34.6 & 25.6 & 74.8 \\
\hline$\$ 30,001-48,000$ & 14,160 & 9,430 & 17,600 & 23,930 & 14.9 & 16.4 & 14.1 & 12.4 \\
\hline$\$ 48,001-75,000$ & 17,140 & 13,410 & 20,690 & 26,380 & 15.4 & 17.2 & 17.9 & 6.9 \\
\hline$\$ 75,001-110,000$ & 20,160 & 16,470 & 24,300 & 29,400 & 14.2 & 15.9 & 18.2 & 3.5 \\
\hline \multirow[t]{2}{*}{$\$ 110,001$ or more } & 24,170 & 17,840 & 30,430 & 33,210 & 15.8 & 15.9 & 24.2 & 2.3 \\
\hline & \multicolumn{8}{|c|}{ 2-year institutions } \\
\hline \multicolumn{9}{|l|}{ Grant and scholarship aid } \\
\hline All income levels & $\$ 4,370$ & $\$ 4,510$ & $\$ 6,120$ & $\$ 4,100$ & 100.0 & 100.0 & 100.0 & 100.0 \\
\hline$\$ 0-30,000$ & 5,060 & 5,390 & 6,410 & 4,550 & 68.2 & 64.6 & 63.9 & 74.1 \\
\hline$\$ 30,001-48,000$ & 4,290 & 4,480 & 5,820 & 3,850 & 15.5 & 16.3 & 18.0 & 14.1 \\
\hline$\$ 48,001-75,000$ & 2,240 & 2,250 & 5,280 & 2,080 & 9.4 & 10.7 & 10.1 & 7.1 \\
\hline$\$ 75,001-110,000$ & 810 & 700 & 5,130 & 910 & 4.7 & 5.6 & 5.3 & 3.1 \\
\hline$\$ 110,001$ or more & 570 & 470 & 6,520 & 540 & 2.3 & 2.7 & 2.7 & 1.6 \\
\hline \multicolumn{9}{|l|}{ Net price } \\
\hline All income levels & 13,510 & 6,470 & 16,450 & 24,890 & 100.0 & 100.0 & 100.0 & 100.0 \\
\hline$\$ 0-30,000$ & 13,220 & 5,480 & 15,420 & 24,130 & 68.2 & 64.6 & 63.9 & 74.1 \\
\hline$\$ 30,001-48,000$ & 13,100 & 6,500 & 17,980 & 25,400 & 15.5 & 16.3 & 18.0 & 14.1 \\
\hline$\$ 48,001-75,000$ & 14,380 & 8,970 & 17,270 & 27,690 & 9.4 & 10.7 & 10.1 & 7.1 \\
\hline$\$ 75,001-110,000$ & 15,790 & 10,840 & 19,660 & 30,170 & 4.7 & 5.6 & 5.3 & 3.1 \\
\hline$\$ 110,001$ or more & 16,920 & 11,110 & 21,220 & 32,530 & 2.3 & 2.7 & 2.7 & 1.6 \\
\hline \multicolumn{9}{|c|}{$\begin{array}{l}\text { NOTE: Data on average amount of grant and scholarship aid and net price are only for students receiving Title IV financial aid and include both } \\
\text { dependent and independent students. These data are weighted by the number of first-time, full-time students at the institution receiving Title IV aid. } \\
\text { Title IV aid includes grant aid, work study aid, and loan aid. Grant aid refers to federal, state, and local government, as well as institutional, grants and } \\
\text { scholarships. Year-to-year changes in cost may be affected by changes in enrollment. For those Title IV recipients, net price is reported by income } \\
\text { category and includes students who received federal aid, even if none of that aid was provided in the form of grants. While Title IV status defines the } \\
\text { cohort of students for which the data are reported, the definition of net price remains the same-total cost of attendance minus grant aid. Detail may } \\
\text { not sum to total due to rounding. For more information on the Integrated Postsecondary Education Data System (IPEDS), see Appendix B - Guide to } \\
\text { Sources. } \\
\text { SOURCE: U.S. Department of Education, National Center for Education Statistics, Integrated Postsecondary Education Data System (IPEDS), Spring 2011, } \\
\text { Student Financial Aid component. }\end{array}$} \\
\hline
\end{tabular}


Undergraduate Crants and Loans

Table A-41-1. Participation of full-time, first-time, degree-seeking undergraduate students in financial aid programs, by institution control, level, and type of aid: Academic year 2009-10

\begin{tabular}{|c|c|c|c|c|c|c|}
\hline \multirow[b]{2}{*}{ Level of institution and type of aid } & \multicolumn{3}{|c|}{ All institutions } & \multicolumn{3}{|c|}{ Public } \\
\hline & $\begin{array}{r}\text { Number } \\
\text { receiving } \\
\text { aid }\end{array}$ & $\begin{array}{r}\text { Percent } \\
\text { receiving } \\
\text { aid }\end{array}$ & $\begin{array}{l}\text { Average } \\
\text { amount } \\
\text { of aid } \\
\text { received }\end{array}$ & $\begin{array}{r}\text { Number } \\
\text { receiving } \\
\text { aid }\end{array}$ & $\begin{array}{r}\text { Percent } \\
\text { receiving } \\
\text { aid }\end{array}$ & $\begin{array}{l}\text { Average } \\
\text { amount } \\
\text { of aid } \\
\text { received }\end{array}$ \\
\hline & \multicolumn{6}{|c|}{ 4-year institutions } \\
\hline Any student financial aid & $1,492,400$ & 85.0 & - & 832,600 & 81.5 & - \\
\hline Grant or scholarship aid & $1,292,100$ & 73.6 & $\$ 9,526$ & 681,400 & 66.7 & $\$ 6,931$ \\
\hline Federal grants & 693,300 & 39.5 & 4,885 & 351,200 & 34.4 & 4,965 \\
\hline Pell grants & 672,600 & 38.3 & 4,267 & 341,600 & 33.5 & 4,338 \\
\hline Other federal grants & 395,700 & 22.5 & 1,306 & 239,600 & 23.5 & 1,093 \\
\hline State/local government grant or scholarships & 533,800 & 30.4 & 3,374 & 381,500 & 37.4 & 3,300 \\
\hline Institutional grants or scholarships & 841,500 & 47.9 & 8,462 & 396,400 & 38.8 & 4,339 \\
\hline Student loan aid & $1,030,000$ & 58.7 & 7,213 & 511,000 & 50.0 & 6,063 \\
\hline Federal student loans & $1,015,000$ & 57.8 & 6,391 & 502,000 & 49.2 & 5,434 \\
\hline \multirow[t]{2}{*}{ Other student loans } & 105,800 & 6.0 & 8,919 & 46,300 & 4.5 & 8,011 \\
\hline & \multicolumn{6}{|c|}{ 2-year institutions } \\
\hline Any student financial aid & 831,300 & 75.5 & - & 550,500 & 70.3 & - \\
\hline Grant or scholarship aid & 737,300 & 66.9 & 4,635 & 493,800 & 63.0 & 4,544 \\
\hline Federal grants & 624,300 & 56.7 & 4,470 & 389,800 & 49.7 & 4,453 \\
\hline Pell grants & 612,700 & 55.6 & 4,315 & 381,800 & 48.7 & 4,336 \\
\hline Other federal grants & 181,600 & 16.5 & 808 & 98,700 & 12.6 & 811 \\
\hline State/local government grant or scholarships & 282,100 & 25.6 & 1,618 & 260,500 & 33.2 & 1,460 \\
\hline Institutional grants or scholarships & 108,100 & 9.8 & 1,579 & 77,800 & 9.9 & 1,646 \\
\hline Student loan aid & 430,600 & 39.1 & 6,536 & 186,000 & 23.7 & 4,627 \\
\hline Federal student loans & 424,000 & 38.5 & 6,253 & 184,500 & 23.6 & 4,571 \\
\hline Other student loans & 37,600 & 3.4 & 4,336 & 3,800 & 0.5 & 4,476 \\
\hline
\end{tabular}

See notes at end of table. 
Table A-41-1. Participation of full-time, first-time, degree-seeking undergraduate students in financial aid programs, by institution control, level, and type of aid: Academic year 2009-10-Continued

\begin{tabular}{|c|c|c|c|c|c|c|}
\hline \multirow[b]{3}{*}{ Level and control of institution and type of aid } & \multicolumn{6}{|c|}{ Private } \\
\hline & \multicolumn{3}{|c|}{ Nonprofit } & \multicolumn{3}{|c|}{ For-profit } \\
\hline & $\begin{array}{r}\text { Number } \\
\text { receiving } \\
\text { aid }\end{array}$ & $\begin{array}{r}\text { Percent } \\
\text { receiving } \\
\text { aid }\end{array}$ & $\begin{array}{l}\text { Average } \\
\text { amount } \\
\text { of aid } \\
\text { received }\end{array}$ & $\begin{array}{r}\text { Number } \\
\text { receiving } \\
\text { aid }\end{array}$ & $\begin{array}{r}\text { Percent } \\
\text { receiving } \\
\text { aid }\end{array}$ & $\begin{array}{r}\text { Average } \\
\text { amount } \\
\text { of aid } \\
\text { received }\end{array}$ \\
\hline & \multicolumn{6}{|c|}{ 4-year institutions } \\
\hline Any student financial aid & 436,300 & 88.8 & - & 223,500 & 91.8 & - \\
\hline Grant or scholarship aid & 413,700 & 84.2 & $\$ 16,037$ & 197,000 & 80.9 & $\$ 4,832$ \\
\hline Federal grants & 158,800 & 32.3 & 5,099 & 183,200 & 75.3 & 4,547 \\
\hline Pell grants & 151,200 & 30.8 & 4,043 & 179,700 & 73.8 & 4,322 \\
\hline Other federal grants & 118,100 & 24.0 & 1,680 & 38,000 & 15.6 & 1,484 \\
\hline State/local government grant or scholarships & 136,300 & 27.7 & 3,658 & 16,000 & 6.6 & 2,715 \\
\hline Institutional grants or scholarships & 387,800 & 79.0 & 13,733 & 57,300 & 23.5 & 1,311 \\
\hline Student loan aid & 309,400 & 63.0 & 7,466 & 209,700 & 86.1 & 9,641 \\
\hline Federal student loans & 304,400 & 62.0 & 6,129 & 208,600 & 85.7 & 9,074 \\
\hline \multirow[t]{2}{*}{ Other student loans } & 42,200 & 8.6 & 10,534 & 17,300 & 7.1 & 7,408 \\
\hline & \multicolumn{6}{|c|}{ 2-year institutions } \\
\hline Any student financial aid & 9,000 & 89.4 & - & 271,800 & 88.3 & - \\
\hline Grant or scholarship aid & 8,600 & 84.8 & 6,762 & 234,900 & 76.3 & 4,749 \\
\hline Federal grants & 6,700 & 66.9 & 4,294 & 227,800 & 74.0 & 4,503 \\
\hline Pell grants & 6,600 & 65.8 & 4,044 & 224,300 & 72.8 & 4,286 \\
\hline Other federal grants & 2,100 & 20.7 & 1,024 & 80,800 & 26.2 & 800 \\
\hline State/local government grant or scholarships & 2,900 & 29.1 & 3,000 & 18,700 & 6.1 & 3,597 \\
\hline Institutional grants or scholarships & 4,200 & 41.5 & 4,798 & 26,100 & 8.5 & 865 \\
\hline Student loan aid & 5,900 & 58.6 & 6,078 & 238,700 & 77.5 & 8,035 \\
\hline Federal student loans & 5,800 & 57.8 & 5,871 & 233,600 & 75.9 & 7,591 \\
\hline Other student loans & 200 & 2.3 & 7,353 & 33,600 & 10.9 & 4,300 \\
\hline
\end{tabular}

- Not available.

NOTE: Any student financial aid includes students who were awarded any Federal Work-Study, loans to students, or grant or scholarship aid from the federal government, state/local government, the institution, or other sources known to the institution. The number receiving any financial aid may not equal the sum of the number receiving other types of aid as students may receive more than one type of financial aid.

SOURCE: U.S. Department of Education, National Center for Education Statistics, Integrated Postsecondary Education Data System (IPEDS), Spring 2011,

Student Financial Aid component. 
Table A-41-2. Participation of full-time, first-time, degree-seeking undergraduate students in financial aid programs, by institution control, level, and type of aid: Academic years 2006-07 through 2009-10

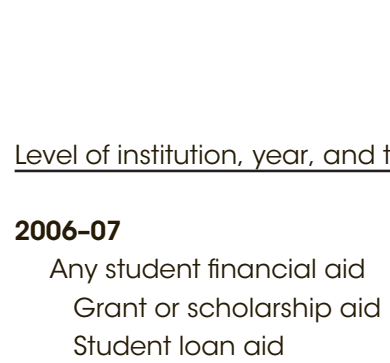

\section{7-08}

Any student financial aid Grant or scholarship aid Student loan aid

\section{8-09}

Any student financial aid Grant or scholarship aid Student loan aid

\section{9-10}

Any student financial aid Grant or scholarship aid Student loan aid

\section{6-07}

Any student financial aid Grant or scholarship aid Student loan aid

2007-08

Any student financial aid Grant or scholarship aid Student loan aid

\section{8-09}

Any student financial aid Grant or scholarship aid Student loan aid

2009-10

Any student financial aid Grant or scholarship aid Student loan aid
All institutions

Number receiving aid
Percent receiving

\section{Average amount} of aid received
Public

\begin{tabular}{rrr} 
Public & \\
$\begin{array}{r}\text { Number } \\
\text { receiving } \\
\text { aid }\end{array}$ & $\begin{array}{r}\text { Percent } \\
\text { receiving } \\
\text { aid }\end{array}$ & $\begin{array}{r}\text { Average } \\
\text { amount } \\
\text { of aid } \\
\text { received }\end{array}$ \\
\hline
\end{tabular}
4-year institutions

\begin{tabular}{rrrrrr}
$1,243,600$ & 75.5 & - & 716,300 & 75.5 & - \\
- & - & - & - & - & - \\
813,600 & 49.4 & $\$ 5,193$ & 415,400 & 43.8 & $\$ 4,433$ \\
& & & & & \\
$1,330,000$ & 79.6 & - & 753,600 & 77.2 & - \\
$1,129,600$ & 67.6 & 8,070 & 609,600 & 62.4 & 5,721 \\
878,400 & 52.6 & 6,198 & 442,000 & 45.2 & 5,190 \\
& & & & & \\
$1,438,400$ & 82.0 & - & 792,000 & 78.6 & - \\
$1,231,700$ & 70.3 & 8,614 & 646,800 & 64.2 & 6,120 \\
977,900 & 55.8 & 7,268 & 472,200 & 46.9 & 5,972 \\
& & & & & \\
$1,492,400$ & 85.0 & - & 832,600 & 81.5 & - \\
$1,292,100$ & 73.6 & 9,526 & 681,400 & 66.7 & 6,931 \\
$1,030,000$ & 58.7 & 7,213 & 511,000 & 50.0 & 6,063 \\
& \multicolumn{5}{c}{ 2-year institutions } \\
\hline \multicolumn{7}{c}{}
\end{tabular}

$\begin{array}{rrrrrr}522,700 & 67.1 & - & 380,500 & 61.4 & - \\ - & - & - & - & - & - \\ 241,500 & 31.0 & \$ 4,410 & 121,300 & 19.6 & \$ 2,877\end{array}$

$\begin{array}{rrrrrr}584,500 & 67.8 & - & 419,600 & 62.5 & - \\ 506,900 & 58.8 & 3,351 & 373,200 & 55.6 & 3,245\end{array}$

$\begin{array}{llllll}275,800 & 32.0 & 5,407 & 130,300 & 19.4 & 3,488\end{array}$

\begin{tabular}{rrrrrr}
650,900 & 70.5 & - & 454,600 & 65.6 & - \\
566,200 & 61.4 & 3,858 & 406,300 & 58.6 & 3,720 \\
322,000 & 34.9 & 6,082 & 145,900 & 21.1 & 4,152 \\
& & & & & \\
831,300 & 75.5 & - & 550,500 & 70.3 & - \\
737,300 & 66.9 & 4,635 & 493,800 & 63.0 & 4,544 \\
430,600 & 39.1 & 6,536 & 186,000 & 23.7 & 4,627 \\
\hline
\end{tabular}

See notes at end of table. 
Table A-41-2. Participation of full-time, first-time, degree-seeking undergraduate students in financial aid programs, by institution control, level, and type of aid: Academic years 2006-07 through 2009-10-Continued

\begin{tabular}{|c|c|c|c|c|c|c|}
\hline \multirow[b]{3}{*}{ Level of institution, year, and type of aid } & \multicolumn{6}{|c|}{ Private } \\
\hline & \multicolumn{3}{|c|}{ Nonprofit } & \multicolumn{3}{|c|}{ For-profit } \\
\hline & $\begin{array}{r}\text { Number } \\
\text { receiving } \\
\text { aid }\end{array}$ & $\begin{array}{r}\text { Percent } \\
\text { receiving } \\
\text { aid }\end{array}$ & $\begin{array}{r}\text { Average } \\
\text { amount } \\
\text { of aid } \\
\text { received }\end{array}$ & $\begin{array}{r}\text { Number } \\
\text { receiving } \\
\text { aid }\end{array}$ & $\begin{array}{r}\text { Percent } \\
\text { receiving } \\
\text { aid }\end{array}$ & $\begin{array}{l}\text { Average } \\
\text { amount } \\
\text { of aid } \\
\text { received }\end{array}$ \\
\hline & \multicolumn{6}{|c|}{ 4-year institutions } \\
\hline \multicolumn{7}{|l|}{ 2006-07 } \\
\hline Any student financial aid & 400,000 & 85.3 & - & 127,200 & 55.4 & - \\
\hline Grant or scholarship aid & - & - & - & - & - & - \\
\hline Student loan aid & 278,700 & 59.4 & $\$ 5,558$ & 119,500 & 52.0 & $\$ 6,989$ \\
\hline \multicolumn{7}{|l|}{ 2007-08 } \\
\hline Any student financial aid & 416,400 & 86.0 & - & 160,000 & 76.0 & - \\
\hline Grant or scholarship aid & 394,800 & 81.6 & 13,175 & 125,100 & 59.5 & 3,403 \\
\hline Student loan aid & 291,900 & 60.3 & 6,435 & 144,500 & 68.7 & 8,799 \\
\hline \multicolumn{7}{|l|}{ 2008-09 } \\
\hline Any student financial aid & 424,900 & 87.2 & - & 221,500 & 85.7 & - \\
\hline Grant or scholarship aid & 401,400 & 82.4 & 14,746 & 183,500 & 71.0 & 3,989 \\
\hline Student loan aid & 295,300 & 60.6 & 7,638 & 210,300 & 81.4 & 9,660 \\
\hline \multicolumn{7}{|l|}{ 2009-10 } \\
\hline Any student financial aid & 436,300 & 88.8 & - & 223,500 & 91.8 & - \\
\hline Grant or scholarship aid & 413,700 & 84.2 & 16,037 & 197,000 & 80.9 & 4,832 \\
\hline \multirow[t]{2}{*}{ Student loan aid } & 309,400 & 63.0 & 7,466 & 209,700 & 86.1 & 9,641 \\
\hline & \multicolumn{6}{|c|}{ 2-year institutions } \\
\hline \multicolumn{7}{|l|}{ 2006-07 } \\
\hline Any student financial aid & 7,200 & 82.5 & - & 135,000 & 89.3 & - \\
\hline Grant or scholarship aid & - & - & - & - & - & - \\
\hline Student loan aid & 4,700 & 53.5 & $\$ 4,715$ & 115,500 & 76.4 & $\$ 6,007$ \\
\hline \multicolumn{7}{|l|}{ 2007-08 } \\
\hline Any student financial aid & 8,500 & 84.8 & - & 156,400 & 87.0 & - \\
\hline Grant or scholarship aid & 7,800 & 77.5 & 5,574 & 125,800 & 70.0 & 3,528 \\
\hline Student loan aid & 5,400 & 54.1 & 5,323 & 140,100 & 77.9 & 7,195 \\
\hline \multicolumn{7}{|l|}{ 2008-09 } \\
\hline Any student financial aid & 8,300 & 86.8 & - & 187,900 & 85.4 & - \\
\hline Grant or scholarship aid & 7,700 & 80.1 & 6,010 & 152,300 & 69.2 & 4,116 \\
\hline Student loan aid & 5,600 & 58.1 & 6,089 & 170,500 & 77.5 & 7,734 \\
\hline \multicolumn{7}{|l|}{ 2009-10 } \\
\hline Any student financial aid & 9,000 & 89.4 & - & 271,800 & 88.3 & - \\
\hline Grant or scholarship aid & 8,600 & 84.8 & 6,762 & 234,900 & 76.3 & 4,749 \\
\hline Student loan aid & 5,900 & 58.6 & 6,078 & 238,700 & 77.5 & 8,035 \\
\hline
\end{tabular}

- Not available.

NOTE: Any student financial aid includes students who were awarded any Federal Work-Study, loans to students, or grant or scholarship aid from the federal government, state/local government, the institution, or other sources known to the institution. Grant or scholarship aid for first-time, full-time students includes grants from the federal government, state/local government, and the institution. Student loan aid for first-time, full-time students includes loans from the federal government and other sources, including private sources, and does not include PLUS loans or loans made to anyone other than the student.

SOURCE: U.S. Department of Education, National Center for Education Statistics, Integrated Postsecondary Education Data System (IPEDS), Spring 2008 through Spring 2011, Student Financial Aid component. 
Table A-42-1. Total and per full-time-equivalent (FTE) student revenue of postsecondary degree-granting institutions, by control of institution and source of funds: Academic years 2004-05 and 2009-10 [Numbers in 2010-11 constant dollars]

\begin{tabular}{|c|c|c|c|c|c|c|}
\hline \multirow[b]{2}{*}{ Control of institution and source of funds } & \multirow{2}{*}{$\begin{array}{r}\text { Total 2004-05 } \\
\text { revenue } \\
\text { (in millions) }\end{array}$} & \multirow{2}{*}{$\begin{array}{r}\text { Total 2009-10 } \\
\text { revenue } \\
\text { (in millions) }\end{array}$} & \multicolumn{2}{|c|}{$\begin{array}{c}\text { Percentage distribution } \\
\text { of total revenue }\end{array}$} & \multicolumn{2}{|c|}{ Revenue per FTE student ${ }^{1}$} \\
\hline & & & $2004-05$ & $2009-10$ & $2004-05$ & $2009-10$ \\
\hline \multicolumn{7}{|l|}{ Public institutions } \\
\hline Total & $\$ 270,772$ & $\$ 309,396$ & 100.0 & 100.0 & $\$ 28,966$ & $\$ 28,781$ \\
\hline Operating revenues & 157,692 & 171,789 & 58.2 & 55.5 & 16,869 & 15,980 \\
\hline Tuition and fees ${ }^{2}$ & 44,420 & 57,049 & 16.4 & 18.4 & 4,752 & 5,307 \\
\hline Grants and contracts & 51,166 & 45,820 & 18.9 & 14.8 & 5,473 & 4,262 \\
\hline Federal $^{3}$ & 34,672 & 28,966 & 12.8 & 9.4 & 3,709 & 2,694 \\
\hline State & 7,861 & 7,042 & 2.9 & 2.3 & 841 & 655 \\
\hline Local & 8,633 & 9,813 & 3.2 & 3.2 & 923 & 913 \\
\hline Auxiliary enterprises & 20,377 & 22,617 & 7.5 & 7.3 & 2,180 & 2,104 \\
\hline Hospitals & 25,103 & 29,822 & 9.3 & 9.6 & 2,685 & 2,774 \\
\hline Other operating revenues ${ }^{4}$ & 16,627 & 16,481 & 6.1 & 5.3 & 1,779 & 1,533 \\
\hline Nonoperating revenues & 98,602 & 122,186 & 36.4 & 39.5 & 10,548 & 11,366 \\
\hline Federal appropriations & 2,057 & 2,195 & 0.8 & 0.7 & 220 & 204 \\
\hline State appropriations & 63,790 & 63,705 & 23.6 & 20.6 & 6,824 & 5,926 \\
\hline Local appropriations & 8,863 & 10,154 & 3.3 & 3.3 & 948 & 945 \\
\hline Government grants & 4,519 & 24,576 & 1.7 & 7.9 & 483 & 2,286 \\
\hline Gifts $^{5}$ & 5,311 & 5,994 & 2.0 & 1.9 & 568 & 558 \\
\hline Investment income & 10,980 & 10,248 & 4.1 & 3.3 & 1,175 & 953 \\
\hline Other nonoperating revenues & 3,083 & 5,314 & 1.1 & 1.7 & 330 & 494 \\
\hline Other revenues ${ }^{6}$ & 14,479 & 15,421 & 5.3 & 5.0 & 1,549 & 1,434 \\
\hline Government capital appropriations & 5,412 & 6,162 & 2.0 & 2.0 & 579 & 573 \\
\hline \multicolumn{7}{|l|}{ Private nonprofit institutions } \\
\hline Total & 161,594 & 172,063 & 100.0 & 100.0 & 56,315 & 54,425 \\
\hline Tuition and fees ${ }^{2}$ & 47,728 & 57,483 & 29.5 & 33.4 & 16,633 & 18,182 \\
\hline Federal government 3,7 & 22,713 & 23,372 & 14.1 & 13.6 & 7,915 & 7,393 \\
\hline State governments & 1,695 & 1,756 & 1.0 & 1.0 & 591 & 555 \\
\hline Local governments & 563 & 481 & 0.3 & 0.3 & 196 & 152 \\
\hline Private gifts, grants, and contracts ${ }^{5}$ & 19,300 & 18,378 & 11.9 & 10.7 & 6,726 & 5,813 \\
\hline Investment return & 35,088 & 28,994 & 21.7 & 16.9 & 12,228 & 9,171 \\
\hline Educational activities ${ }^{8}$ & 4,146 & 4,918 & 2.6 & 2.9 & 1,445 & 1,556 \\
\hline Auxiliary enterprises ${ }^{9}$ & 12,480 & 14,362 & 7.7 & 8.3 & 4,349 & 4,543 \\
\hline Hospitals & 11,966 & 16,872 & 7.4 & 9.8 & 4,170 & 5,337 \\
\hline Other & 5,917 & 5,447 & 3.7 & 3.2 & 2,062 & 1,723 \\
\hline \multicolumn{7}{|l|}{ Private for-profit institutions } \\
\hline Total & 12,659 & 25,179 & 100.0 & 100.0 & 16,063 & 15,675 \\
\hline Tuition and fees ${ }^{2}$ & 11,030 & 22,822 & 87.1 & 90.6 & 13,996 & 14,207 \\
\hline Federal government ${ }^{3}$ & 777 & 1,990 & 6.1 & 7.9 & 986 & 1,239 \\
\hline State and local governments & 73 & 116 & 0.6 & 0.5 & 93 & 72 \\
\hline Private gifts, grants, and contracts & 8 & 39 & 0.1 & 0.2 & 10 & 24 \\
\hline Investment return & 28 & 41 & 0.2 & 0.2 & 36 & 25 \\
\hline Educational activities $^{8}$ & 267 & 444 & 2.1 & 1.8 & 339 & 277 \\
\hline Auxiliary enterprises ${ }^{9}$ & 291 & 495 & 2.3 & 2.0 & 369 & 308 \\
\hline Other & 184 & -769 & 1.5 & -3.1 & 233 & -479 \\
\hline
\end{tabular}

1 Full-time-equivalent (FTE) enrollment includes full-time students plus the full-time equivalent of part-time students.

${ }^{2}$ Net of allowances and discounts.

${ }^{3}$ Excludes Federal Direct Student Loans (FDSL). FDSL is included in tuition and fees.

${ }^{4}$ Includes sales and service of educational activities.

${ }^{5}$ Includes contracts and contributions from affiliated entities.

${ }^{6}$ Other revenue includes capital appropriations, grants, and gifts; additions to permanent endowments; and other revenue.

7 Includes independent operations.

${ }^{8}$ Revenue from educational activities for which tuition is not charged

${ }^{9}$ Revenue from auxiliary enterprise operations for which fees or charges were collected.

NOTE: Operating revenue is revenue received for providing a service or a product. Nonoperating revenues are for all activities. All sectors have operating and nonoperating revenue. Data are adjusted by the Consumer Price Index (CPI) to constant $2010-11$ dollars. For more information on the CPI, see Appendix C - Finance. Detail may not sum to totals because of rounding. For more information on the Integrated Postsecondary Education Data System (IPEDS) and IPEDS classification of institutions, see Appendix B - Guide to Sources.

SOURCE: U.S. Department of Education, National Center for Education Statistics, Integrated Postsecondary Education Data System, Spring 2005 and Spring 2010, Enrollment component; and Spring 2006 through Spring 2011, Finance component. 
This indicator continues on page 270.

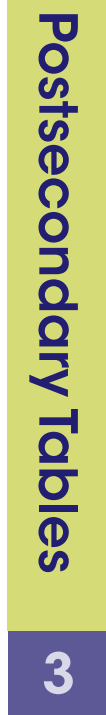


Table A-42-2. Total and per full-time-equivalent (FTE) student revenue of postsecondary degree-granting institutions, by institution level, institution control, and source of funds: Academic years 2004-05 and 2009-10 [Numbers in 2010-11 constant dollars]

\begin{tabular}{|c|c|c|c|c|c|c|c|c|}
\hline \multirow{3}{*}{$\begin{array}{l}\text { Control of institution and source } \\
\text { of funds }\end{array}$} & \multicolumn{4}{|c|}{ Total revenue (in millions) } & \multicolumn{4}{|c|}{ Percentage distribution of total revenue } \\
\hline & \multicolumn{2}{|c|}{ 2-year institutions } & \multicolumn{2}{|c|}{ 4-year institutions } & \multicolumn{2}{|c|}{ 2-year institutions } & \multicolumn{2}{|c|}{ 4-year institutions } \\
\hline & $2004-05$ & $2009-10$ & $2004-05$ & $2009-10$ & $2004-05$ & $2009-10$ & $2004-05$ & $2009-10$ \\
\hline \multicolumn{9}{|l|}{ Public institutions } \\
\hline Total & $\$ 47,325$ & $\$ 56,329$ & $\$ 223,448$ & $\$ 253,067$ & 100.0 & 100.0 & 100.0 & 100.0 \\
\hline Operating revenues & 18,904 & 16,594 & 138,788 & 155,195 & 39.9 & 29.5 & 62.1 & 61.3 \\
\hline Tuition and fees ${ }^{2}$ & 7,906 & 9,167 & 36,514 & 47,882 & 16.7 & 16.3 & 16.3 & 18.9 \\
\hline Grants and contracts & 8,137 & 4,372 & 43,029 & 41,448 & 17.2 & 7.8 & 19.3 & 16.4 \\
\hline Federal $^{3}$ & 5,466 & 2,168 & 29,206 & 26,797 & 11.5 & 3.8 & 13.1 & 10.6 \\
\hline State & 1,983 & 1,635 & 5,878 & 5,407 & 4.2 & 2.9 & 2.6 & 2.1 \\
\hline Local & 688 & 569 & 7,945 & 9,243 & 1.5 & 1.0 & 3.6 & 3.7 \\
\hline Auxiliary enterprises & 2,062 & 2,116 & 18,315 & 20,501 & 4.4 & 3.8 & 8.2 & 8.1 \\
\hline Hospitals & \# & \# & 25,103 & 29,822 & $\#$ & \# & 11.2 & 11.8 \\
\hline Other operating revenues ${ }^{4}$ & 800 & 939 & 15,827 & 15,542 & 1.7 & 1.7 & 7.1 & 6.1 \\
\hline Nonoperating revenues & 26,111 & 36,904 & 72,491 & 85,282 & 55.2 & 65.5 & 32.4 & 33.7 \\
\hline Federal appropriations & 171 & 149 & 1,886 & 2,047 & 0.4 & 0.3 & 0.8 & 0.8 \\
\hline State appropriations & 14,020 & 14,009 & 49,769 & 49,696 & 29.6 & 24.9 & 22.3 & 19.6 \\
\hline Local appropriations & 8,519 & 9,713 & 344 & 440 & 18.0 & 17.2 & 0.2 & 0.2 \\
\hline Government grants & 2,195 & 11,784 & 2,324 & 12,793 & 4.6 & 20.9 & 1.0 & 5.1 \\
\hline $\mathrm{Gifts}^{5}$ & 319 & 235 & 4,991 & 5,759 & 0.7 & 0.4 & 2.2 & 2.3 \\
\hline Investment income & 481 & 388 & 10,499 & 9,860 & 1.0 & 0.7 & 4.7 & 3.9 \\
\hline Other nonoperating revenues & 405 & 626 & 2,677 & 4,688 & 0.9 & 1.1 & 1.2 & 1.9 \\
\hline Other revenues ${ }^{6}$ & 2,310 & 2,831 & 12,169 & 12,590 & 4.9 & 5.0 & 5.4 & 5.0 \\
\hline $\begin{array}{c}\text { Government capital } \\
\text { appropriations }\end{array}$ & 1,603 & 2,078 & 3,809 & 4,084 & 3.4 & 3.7 & 1.7 & 1.6 \\
\hline \multicolumn{9}{|l|}{ Private nonprofit institutions } \\
\hline Total & 717 & 530 & 160,877 & 171,533 & 100.0 & 100.0 & 100.0 & 100.0 \\
\hline Tuition and fees ${ }^{2}$ & 402 & 305 & 47,326 & 57,178 & 56.1 & 57.6 & 29.4 & 33.3 \\
\hline Federal government ${ }^{3,7}$ & 89 & 72 & 22,624 & 23,300 & 12.4 & 13.5 & 14.1 & 13.6 \\
\hline State governments & 27 & 13 & 1,668 & 1,743 & 3.7 & 2.5 & 1.0 & 1.0 \\
\hline Local governments & 4 & 1 & 558 & 480 & 0.6 & 0.2 & 0.3 & 0.3 \\
\hline Private gifts, grants, and contracts 5 & 78 & 52 & 19,222 & 18,326 & 10.9 & 9.8 & 11.9 & 10.7 \\
\hline Investment return & 26 & 21 & 35,061 & 28,973 & 3.7 & 4.0 & 21.8 & 16.9 \\
\hline Educational activities $^{8}$ & 16 & 8 & 4,130 & 4,911 & 2.2 & 1.4 & 2.6 & 2.9 \\
\hline Auxiliary enterprises ${ }^{9}$ & 46 & 36 & 12,434 & 14,326 & 6.4 & 6.9 & 7.7 & 8.4 \\
\hline Hospitals & \# & \# & 11,966 & 16,872 & $\#$ & $\#$ & 7.4 & 9.8 \\
\hline Other & 28 & 22 & 5,888 & 5,425 & 4.0 & 4.1 & 3.7 & 3.2 \\
\hline \multicolumn{9}{|l|}{ Private for-profit institutions } \\
\hline Total & 3,790 & 5,816 & 8,869 & 19,363 & 100.0 & 100.0 & 100.0 & 100.0 \\
\hline Tuition and fees ${ }^{2}$ & 3,116 & 5,154 & 7,914 & 17,668 & 82.2 & 88.6 & 89.2 & 91.2 \\
\hline Federal government ${ }^{3}$ & 378 & 740 & 399 & 1,251 & 10.0 & 12.7 & 4.5 & 6.5 \\
\hline State and local governments & 49 & 46 & 24 & 71 & 1.3 & 0.8 & 0.3 & 0.4 \\
\hline Private gifts, grants, and contracts & 4 & 3 & 5 & 36 & 0.1 & 0.0 & 0.1 & 0.2 \\
\hline Investment return & 8 & 4 & 20 & 37 & 0.2 & 0.1 & 0.2 & 0.2 \\
\hline Educational activities $^{8}$ & 67 & 60 & 200 & 384 & 1.8 & 1.0 & 2.3 & 2.0 \\
\hline Auxiliary enterprises ${ }^{9}$ & 58 & 115 & 232 & 380 & 1.5 & 2.0 & 2.6 & 2.0 \\
\hline Other & 109 & -306 & 75 & -463 & 2.9 & -5.3 & 0.8 & -2.4 \\
\hline
\end{tabular}

See notes at end of table. 
Table A-42-2. Total and per full-time-equivalent (FTE) student revenue of postsecondary degree-granting institutions, by institution level, institution control, and source of funds: Academic years 2004-05 and 2009-10Continued

[Numbers in 2010-11 constant dollars]

\begin{tabular}{|c|c|c|c|c|}
\hline \multirow{3}{*}{$\begin{array}{l}\text { Control of institution and source } \\
\text { of funds }\end{array}$} & \multicolumn{4}{|c|}{ Revenue per FTE student ${ }^{1}$} \\
\hline & \multicolumn{2}{|c|}{ 2-year institutions } & \multicolumn{2}{|c|}{ 4-year institutions } \\
\hline & $2004-05$ & $2009-10$ & $2004-05$ & $2009-10$ \\
\hline \multicolumn{5}{|l|}{ Public institutions } \\
\hline Total & $\$ 12,765$ & $\$ 13,107$ & $\$ 39,614$ & $\$ 39,221$ \\
\hline Operating revenues & 5,099 & 3,861 & 24,605 & 24,052 \\
\hline Tuition and fees ${ }^{2}$ & 2,132 & 2,133 & 6,473 & 7,421 \\
\hline Grants and contracts & 2,195 & 1,017 & 7,628 & 6,424 \\
\hline Federal $^{3}$ & 1,474 & 504 & 5,178 & 4,153 \\
\hline State & 535 & 380 & 1,042 & 838 \\
\hline Local & 186 & 132 & 1,408 & 1,433 \\
\hline Auxiliary enterprises & 556 & 492 & 3,247 & 3,177 \\
\hline Hospitals & $\#$ & $\#$ & 4,450 & 4,622 \\
\hline Other operating revenues ${ }^{4}$ & 216 & 218 & 2,806 & 2,409 \\
\hline Nonoperating revenues & 7,043 & 8,587 & 12,852 & 13,217 \\
\hline Federal appropriations & 46 & 35 & 334 & 317 \\
\hline State appropriations & 3,782 & 3,260 & 8,823 & 7,702 \\
\hline Local appropriations & 2,298 & 2,260 & 61 & 68 \\
\hline Government grants & 592 & 2,742 & 412 & 1,983 \\
\hline Gifts $^{5}$ & 86 & 55 & 885 & 893 \\
\hline Investment income & 130 & 90 & 1,861 & 1,528 \\
\hline Other nonoperating revenues & 109 & 146 & 475 & 727 \\
\hline Other revenues ${ }^{6}$ & 623 & 659 & 2,157 & 1,951 \\
\hline $\begin{array}{l}\text { Government capital } \\
\text { appropriations }\end{array}$ & 432 & 484 & 675 & 633 \\
\hline \multicolumn{5}{|l|}{ Private nonprofit institutions } \\
\hline Total & 20,826 & 20,543 & 56,746 & 54,703 \\
\hline Tuition and fees ${ }^{2}$ & 11,680 & 11,826 & 16,693 & 18,235 \\
\hline Federal government ${ }^{3,7}$ & 2,585 & 2,779 & 7,980 & 7,431 \\
\hline State governments & 779 & 519 & 588 & 556 \\
\hline Local governments & 122 & 35 & 197 & 153 \\
\hline Private gifts, grants, and contracts ${ }^{5}$ & 2,274 & 2,012 & 6,780 & 5,844 \\
\hline Investment return & 769 & 823 & 12,367 & 9,240 \\
\hline Educational activities $^{8}$ & 458 & 293 & 1,457 & 1,566 \\
\hline Auxiliary enterprises ${ }^{9}$ & 1,333 & 1,411 & 4,386 & 4,569 \\
\hline Hospitals & \# & $\#$ & 4,221 & 5,381 \\
\hline Other & 826 & 845 & 2,077 & 1,730 \\
\hline \multicolumn{5}{|l|}{ Private for-profit institutions } \\
\hline Total & 16,167 & 15,659 & 16,019 & 15,679 \\
\hline Tuition and fees ${ }^{2}$ & 13,294 & 13,877 & 14,294 & 14,307 \\
\hline Federal government $^{3}$ & 1,614 & 1,991 & 720 & 1,013 \\
\hline State and local governments & 207 & 123 & 44 & 57 \\
\hline Private gifts, grants, and contracts & 15 & 7 & 8 & 29 \\
\hline Investment return & 35 & 11 & 36 & 30 \\
\hline Educational activities ${ }^{8}$ & 286 & 162 & 362 & 311 \\
\hline Auxiliary enterprises ${ }^{9}$ & 249 & 310 & 420 & 307 \\
\hline Other & 466 & -824 & 135 & -375 \\
\hline
\end{tabular}

\# Rounds to zero.

${ }^{1}$ Full-time-equivalent (FTE) enrollment includes full-time students plus the full-time equivalent of part-time students.

2 Net of allowances and discounts.

${ }^{3}$ Excludes Federal Direct Student Loans (FDSL). FDSL is reported in tuition and fees.

4 Includes sales and service of educational activities.

5 Includes contracts and contributions from affiliated entities.

- Other revenue includes capital appropriations, grants, and gifts; additions to permanent endowments; and other revenue.

7 Includes independent operations.

${ }^{8}$ Revenue from educational activities for which tuition is not charged.

${ }^{9}$ Revenue from auxiliary enterprise operations for which fees or charges were collected.

NOTE: Operating revenue is revenue received for providing a service or a product. Nonoperating revenues are for all activities. All sectors have

operating and nonoperating revenue. Data are adjusted by the Consumer Price Index (CPI) to constant $2010-11$ dollars. For more information on the CPI, see Appendix C - Finance. Detail may not sum to totals because of rounding. For more information on the Integrated Postsecondary Education Data System (IPEDS) and IPEDS classification of institutions, see Appendix B - Guide to Sources.

SOURCE: U.S. Department of Education, National Center for Education Statistics, Integrated Postsecondary Education Data System, Spring 2005 and Spring 2010, Enrollment component; and Spring 2006 and Spring 2011, Finance component. 
Table A-43-1. Total and per full-time-equivalent student expenses, by control of institution and purpose for degreegranting postsecondary institutions: Academic years 2004-05 and 2009-10

[Numbers in 2010-11 constant dollars]

\begin{tabular}{|c|c|c|c|c|c|c|}
\hline \multirow[b]{3}{*}{ Control of institution and purpose } & \multicolumn{4}{|c|}{ Total expenses } & \multirow{2}{*}{\multicolumn{2}{|c|}{ Expenses per FTE student ${ }^{1}$}} \\
\hline & \multicolumn{2}{|c|}{ Dollars (in millions) } & \multicolumn{2}{|c|}{ Percentage distribution } & & \\
\hline & $2004-05$ & $2009-10$ & $2004-05$ & $2009-10$ & $2004-05$ & $2009-10$ \\
\hline \multicolumn{7}{|l|}{ Public institutions $^{2}$} \\
\hline Total & $\$ 248,811$ & $\$ 286,996$ & 100.0 & 100.0 & $\$ 26,616$ & $\$ 26,697$ \\
\hline Instruction & 68,784 & 77,818 & 27.6 & 27.1 & 7,358 & 7,239 \\
\hline Research & 26,001 & 28,640 & 10.5 & 10.0 & 2,781 & 2,664 \\
\hline Public service & 10,932 & 11,736 & 4.4 & 4.1 & 1,169 & 1,092 \\
\hline Academic support & 16,440 & 19,256 & 6.6 & 6.7 & 1,759 & 1,791 \\
\hline Student services & 11,579 & 13,401 & 4.7 & 4.7 & 1,239 & 1,247 \\
\hline Institutional support & 20,126 & 23,139 & 8.1 & 8.1 & 2,153 & 2,152 \\
\hline Operation and maintenance of plant & 15,656 & 18,413 & 6.3 & 6.4 & 1,675 & 1,713 \\
\hline Depreciation & 11,060 & 14,593 & 4.4 & 5.1 & 1,183 & 1,357 \\
\hline Scholarships/fellowships ${ }^{3}$ & 9,688 & 15,744 & 3.9 & 5.5 & 1,036 & 1,465 \\
\hline Auxiliary enterprises & 19,214 & 20,866 & 7.7 & 7.3 & 2,055 & 1,941 \\
\hline Hospitals & 23,181 & 27,208 & 9.3 & 9.5 & 2,480 & 2,531 \\
\hline Other & 16,150 & 16,181 & 6.5 & 5.6 & 1,728 & 1,505 \\
\hline \multicolumn{7}{|l|}{ Private nonprofit institutions ${ }^{4}$} \\
\hline Total & 127,284 & 148,045 & 100.0 & 100.0 & 44,358 & 46,827 \\
\hline Instruction & 41,806 & 48,436 & 32.8 & 32.7 & 14,569 & 15,321 \\
\hline Research & 14,773 & 16,479 & 11.6 & 11.1 & 5,148 & 5,212 \\
\hline Public service & 2,307 & 2,132 & 1.8 & 1.4 & 804 & 674 \\
\hline Academic support & 10,771 & 13,198 & 8.5 & 8.9 & 3,754 & 4,175 \\
\hline Student services & 9,445 & 11,645 & 7.4 & 7.9 & 3,292 & 3,683 \\
\hline Institutional support & 16,938 & 19,822 & 13.3 & 13.4 & 5,903 & 6,270 \\
\hline Auxiliary enterprises & 12,619 & 14,165 & 9.9 & 9.6 & 4,398 & 4,480 \\
\hline Net grant aid to students & 1,233 & 849 & 1.0 & 0.6 & 430 & 268 \\
\hline Hospitals & 10,585 & 13,438 & 8.3 & 9.1 & 3,689 & 4,250 \\
\hline Independent operations & 4,870 & 5,258 & 3.8 & 3.6 & 1,697 & 1,663 \\
\hline Other & 1,937 & 2,625 & 1.5 & 1.8 & 675 & 830 \\
\hline \multicolumn{7}{|l|}{ Private for-profit institutions ${ }^{4}$} \\
\hline Total & 10,182 & 20,373 & 100.0 & 100.0 & 12,920 & 12,683 \\
\hline Instruction & 2,668 & 4,846 & 26.2 & 23.8 & 3,385 & 3,017 \\
\hline Research and public service & 9 & 14 & 0.1 & 0.1 & 11 & 8 \\
\hline Student services, academic and institutional support & 6,564 & 13,349 & 64.5 & 65.5 & 8,329 & 8,310 \\
\hline Auxiliary enterprises & 311 & 475 & 3.1 & 2.3 & 395 & 296 \\
\hline Net grant aid to students & 63 & 123 & 0.6 & 0.6 & 80 & 76 \\
\hline Other & 567 & 1,567 & 5.6 & 7.7 & 719 & 976 \\
\hline
\end{tabular}

1 Full-time-equivalent (FTE) students includes full-time students plus the full-time equivalent of part-time students.

2 For 2009-10 data, all expenses reported by institutions for operations and maintenance, depreciation, and interest have been aggregated into the general categories of operations and maintenance, depreciation, and interest, even in cases where a particular expense was originally disaggregated into a purpose category. Interest expenses are included in other expenses.

${ }^{3}$ Excludes discounts and allowances. In 2009-10, approximately 57 percent of the total scholarships were reported under discounts and allowances. Scholarships and fellowships are reported in other expenses for private institutions.

${ }^{4}$ Operations and maintenance, depreciation, and interest expenses are distributed among appropriate categories.

NOTE: Data are collected on different surveys within the Integrated Postsecondary Education Data System for each sector. Private institutions report fewer data items than public institutions, and private for-profit institutions report fewer data items than private nonprofit institutions. Data are adjusted by the Consumer Price Index (CPI) to constant 2010-11 dollars. For more information on the CPI, see Appendix C - Finance. Detail may not sum to totals because of rounding. For more information on IPEDS, see Appendix B - Guide to Sources.

SOURCE: U.S. Department of Education, National Center for Education Statistics, Integrated Postsecondary Education Data System, Spring 2005 and

Spring 2010, Enrollment component; and Spring 2006 and Spring 2011, Finance component. 
This indicator continues on page 274. 
Table A-43-2. Total and per full-time-equivalent student expenses, by level and control of institution and purpose for degree-granting postsecondary institutions: Academic years 2004-05 and 2009-10

[Numbers in 2010-11 constant dollars]

\begin{tabular}{|c|c|c|c|c|c|c|c|c|}
\hline \multirow[b]{3}{*}{ Control of institution and purpose } & \multicolumn{4}{|c|}{ Total expenses (in millions) } & \multicolumn{4}{|c|}{ Percentage distribution of total expenses } \\
\hline & \multicolumn{2}{|c|}{ 2-year institutions } & \multicolumn{2}{|c|}{ 4-year institutions } & \multicolumn{2}{|c|}{ 2-year institutions } & \multicolumn{2}{|c|}{ 4-year institutions } \\
\hline & $2004-05$ & $2009-10$ & 2004-05 & $2009-10$ & 2004-05 & $2009-10$ & 2004-05 & $2009-10$ \\
\hline \multicolumn{9}{|l|}{ Public institutions ${ }^{2}$} \\
\hline Total & $\$ 44,509$ & $\$ 52,175$ & $\$ 204,302$ & $\$ 234,820$ & 100.0 & 98.1 & 100.0 & 100.0 \\
\hline Instruction & 17,245 & 18,385 & 51,539 & 59,433 & 38.7 & 35.2 & 25.2 & 25.3 \\
\hline Research & 25 & 21 & 25,976 & 28,618 & 0.1 & $\#$ & 12.7 & 12.2 \\
\hline Public service & 764 & 769 & 10,168 & 10,968 & 1.7 & 1.5 & 5.0 & 4.7 \\
\hline Academic support & 3,276 & 3,594 & 13,164 & 15,662 & 7.4 & 6.9 & 6.4 & 6.7 \\
\hline Student services & 4,112 & 4,470 & 7,466 & 8,930 & 9.2 & 8.6 & 3.7 & 3.8 \\
\hline Institutional support & 6,115 & 6,464 & 14,011 & 16,676 & 13.7 & 12.4 & 6.9 & 7.1 \\
\hline Operation and maintenance of plant & 3,794 & 4,464 & 11,861 & 13,949 & 8.5 & 8.6 & 5.8 & 5.9 \\
\hline Depreciation & 1,679 & 2,035 & 9,382 & 12,558 & 3.8 & 3.9 & 4.6 & 5.3 \\
\hline Scholarships/fellowships ${ }^{3}$ & 3,400 & 6,470 & 6,288 & 9,274 & 7.6 & 12.4 & 3.1 & 3.9 \\
\hline Auxiliary enterprises & 2,388 & 2,383 & 16,826 & 18,483 & 5.4 & 4.6 & 8.2 & 7.9 \\
\hline Hospitals & 0 & 0 & 23,181 & 27,208 & 0.0 & 0.0 & 11.3 & 11.6 \\
\hline Other & 1,710 & 3,122 & 14,440 & 13,059 & 3.8 & 4.1 & 7.1 & 5.6 \\
\hline \multicolumn{9}{|l|}{ Private nonprofit institutions } \\
\hline Total & 697 & 500 & 126,588 & 147,544 & 100.0 & 100.0 & 100.0 & 100.0 \\
\hline Instruction & 239 & 169 & 41,567 & 48,267 & 34.3 & 33.7 & 32.8 & 32.7 \\
\hline Research & 1 & 1 & 14,773 & 16,478 & 0.1 & 0.1 & 11.7 & 11.2 \\
\hline Public service & 8 & 5 & 2,299 & 2,126 & 1.1 & 1.0 & 1.8 & 1.4 \\
\hline Academic support & 40 & 44 & 10,732 & 13,155 & 5.7 & 8.7 & 8.5 & 8.9 \\
\hline Student services & 104 & 71 & 9,341 & 11,574 & 15.0 & 14.1 & 7.4 & 7.8 \\
\hline Institutional support & 201 & 138 & 16,737 & 19,684 & 28.8 & 27.6 & 13.2 & 13.3 \\
\hline Auxiliary enterprises & 52 & 35 & 12,567 & 14,130 & 7.4 & 7.0 & 9.9 & 9.6 \\
\hline Net grant aid to students & 21 & 7 & 1,212 & 841 & 3.0 & 1.5 & 1.0 & 0.6 \\
\hline Hospitals & 0 & 0 & 10,585 & 13,438 & 0.0 & 0.0 & 8.4 & 9.1 \\
\hline Independent operations & 0 & 0 & 4,870 & 5,258 & 0.0 & 0.0 & 3.8 & 3.6 \\
\hline Other & 32 & 31 & 1,905 & 2,593 & 4.5 & 6.2 & 1.5 & 1.8 \\
\hline \multicolumn{9}{|l|}{ Private for-profit institutions } \\
\hline Total & 3,276 & 4,781 & 6,906 & 15,592 & 100.0 & 100.0 & 100.0 & 100.0 \\
\hline Instruction & 1,019 & 1,521 & 1,649 & 3,325 & 31.1 & 31.8 & 23.9 & 21.3 \\
\hline Research and public service & 5 & 3 & 4 & 11 & 0.1 & 0.1 & 0.1 & 0.1 \\
\hline $\begin{array}{l}\text { Student services, academic and } \\
\text { institutional support }\end{array}$ & 1,825 & 2,549 & 4,739 & 10,799 & 55.7 & 53.3 & 68.6 & 69.3 \\
\hline Auxiliary enterprises & 104 & 131 & 208 & 344 & 3.2 & 2.7 & 3.0 & 2.2 \\
\hline Net grant aid to students & 19 & 49 & 45 & 74 & 0.6 & 1.0 & 0.6 & 0.5 \\
\hline Other & 305 & 528 & 262 & 1,039 & 9.3 & 11.0 & 3.8 & 6.7 \\
\hline
\end{tabular}

\footnotetext{
See notes at end of table.
} 
Table A-43-2. Total and per full-time-equivalent student expenses, by level and control of institution and purpose for degree-granting postsecondary institutions: Academic years 2004-05 and 2009-10-Continued [Numbers in 2010-11 constant dollars]

\begin{tabular}{|c|c|c|c|c|}
\hline \multirow[b]{3}{*}{ Control of institution and purpose } & \multicolumn{4}{|c|}{ Expenses per FTE student ${ }^{1}$} \\
\hline & \multicolumn{2}{|c|}{ 2-year institutions } & \multicolumn{2}{|c|}{ 4-year institutions } \\
\hline & 2004-05 & $2009-10$ & $2004-05$ & $2009-10$ \\
\hline \multicolumn{5}{|l|}{ Public institutions $^{2}$} \\
\hline Total & $\$ 12,005$ & $\$ 12,140$ & $\$ 36,220$ & $\$ 36,393$ \\
\hline Instruction & 4,652 & 4,278 & 9,137 & 9,211 \\
\hline Research & 7 & 5 & 4,605 & 4,435 \\
\hline Public service & 206 & 179 & 1,803 & 1,700 \\
\hline Academic support & 884 & 836 & 2,334 & 2,427 \\
\hline Student services & 1,109 & 1,040 & 1,324 & 1,384 \\
\hline Institutional support & 1,649 & 1,504 & 2,484 & 2,584 \\
\hline Operation and maintenance of plant & 1,023 & 1,039 & 2,103 & 2,162 \\
\hline Depreciation & 453 & 473 & 1,663 & 1,946 \\
\hline Scholarships/fellowships ${ }^{3}$ & 917 & 1,505 & 1,115 & 1,437 \\
\hline Auxiliary enterprises & 644 & 554 & 2,983 & 2,865 \\
\hline Hospitals & 0 & 0 & 4,110 & 4,217 \\
\hline Other & 461 & 726 & 2,560 & 2,024 \\
\hline \multicolumn{5}{|l|}{ Private nonprofit institutions } \\
\hline Total & 20,238 & 19,411 & 44,651 & 47,053 \\
\hline Instruction & 6,944 & 6,549 & 14,662 & 15,393 \\
\hline Research & 18 & 23 & 5,211 & 5,255 \\
\hline Public service & 223 & 199 & 811 & 678 \\
\hline Academic support & 1,154 & 1,698 & 3,785 & 4,195 \\
\hline Student services & 3,031 & 2,735 & 3,295 & 3,691 \\
\hline Institutional support & 5,831 & 5,355 & 5,904 & 6,277 \\
\hline Auxiliary enterprises & 1,503 & 1,361 & 4,433 & 4,506 \\
\hline Net grant aid to students & 615 & 284 & 428 & 268 \\
\hline Hospitals & 0 & 0 & 3,734 & 4,285 \\
\hline Independent operations & 0 & 0 & 1,718 & 1,677 \\
\hline Other & 918 & 1,207 & 672 & 827 \\
\hline \multicolumn{5}{|l|}{ Private for-profit institutions } \\
\hline Total & 13,975 & 12,873 & 12,473 & 12,626 \\
\hline Instruction & 4,347 & 4,095 & 2,978 & 2,692 \\
\hline Research and public service & 20 & 7 & 7 & 9 \\
\hline Student services, academic and institutional support & 7,785 & 6,864 & 8,560 & 8,745 \\
\hline Auxiliary enterprises & 442 & 353 & 375 & 279 \\
\hline Net grant aid to students & 80 & 132 & 80 & 60 \\
\hline Other & 1,301 & 1,422 & 472 & 841 \\
\hline
\end{tabular}

\# Rounds to zero.

' Full-time-equivalent (FTE) students includes full-time students plus the full-time equivalent of part-time students

${ }^{2}$ For 2009-10 data, all expenses reported by institutions for operations and maintenance, depreciation, and interest have been aggregated into the general categories of operations and maintenance, depreciation, and interest, even in cases where a particular expense was originally disaggregated into a purpose category. Interest expenses are included in other expenses.

${ }^{3}$ Excludes discounts and allowances. In 2009-10, approximately 57 percent of the total scholarships were reported under discounts and allowances. NOTE: Data are collected on different surveys within the Integrated Postsecondary Education Data System (IPEDS) for each sector. Private institutions report fewer data items than public institutions, and private for-profit institutions report fewer data items than private nonprofit institutions. Data are adjusted by the Consumer Price Index (CPI) to constant 2010-11 dollars. For more information on the CPI, see Appendix C - Finance. Detail may not sum to totals because of rounding. For more information on IPEDS, see Appendix B - Guide to Sources.

SOURCE: U.S. Department of Education, National Center for Education Statistics, Integrated Postsecondary Education Data System, Spring 2005 and Spring 2010, Enrollment component; and Spring 2006 and Spring 2011, Finance component. 


\section{Faculty Salaries, Benefits, and Total Compensation}

Table A-44-1. Percentage distribution of full-time faculty and average total compensation, salary, and fringe benefits in current-year dollars for faculty on 9- and 10-month contracts at degree-granting institutions, by academic rank and control and level of institution: Academic years 1989-90, 1999-2000, and 2010-11

[In current-year dollars]

\begin{tabular}{|c|c|c|c|c|c|c|}
\hline \multirow[b]{2}{*}{ Academic rank and control and level of institution } & \multicolumn{2}{|c|}{ 1989-90 } & \multicolumn{2}{|c|}{ 1999-2000 } & \multicolumn{2}{|c|}{ 2010-11 } \\
\hline & $\begin{array}{r}\text { Percent } \\
\text { distribution } \\
\text { of faculty }\end{array}$ & Average & $\begin{array}{r}\text { Percent } \\
\text { distribution } \\
\text { of faculty } \\
\end{array}$ & Average & $\begin{array}{r}\text { Percent } \\
\text { distribution } \\
\text { of faculty }\end{array}$ & Average \\
\hline Total compensation & 100.0 & $\$ 48,300$ & 100.0 & $\$ 69,100$ & 100.0 & $\$ 97,200$ \\
\hline \multicolumn{7}{|l|}{ Salary } \\
\hline All faculty & 100.0 & 40,100 & 100.0 & 55,900 & 100.0 & 75,500 \\
\hline Professor & 30.7 & 52,900 & 30.7 & 74,400 & 27.0 & 105,000 \\
\hline Associate professor & 24.6 & 39,500 & 24.2 & 54,500 & 23.2 & 75,100 \\
\hline Assistant professor & 24.1 & 32,700 & 23.0 & 45,000 & 23.5 & 63,100 \\
\hline Other faculty & 20.7 & 30,400 & 22.1 & 43,000 & 26.2 & 56,500 \\
\hline All institutions & 100.0 & 40,100 & 100.0 & 55,900 & 100.0 & 75,500 \\
\hline Public doctoral universities & 27.9 & 44,500 & 28.3 & 62,300 & 34.0 & 81,600 \\
\hline Private doctoral universities & 12.2 & 49,000 & 12.2 & 71,900 & 16.9 & 94,900 \\
\hline Nonprofit & 12.2 & 49,000 & 12.2 & 71,900 & 16.8 & 95,000 \\
\hline For-profit & - & - & $\#$ & 74,800 & 0.1 & 61,700 \\
\hline Public master's colleges/universities & 20.4 & 40,400 & 18.5 & 52,800 & 12.6 & 68,200 \\
\hline Private master's colleges/universities & 7.2 & 35,200 & 9.3 & 49,800 & 8.2 & 65,500 \\
\hline Nonprofit & 7.2 & 35,300 & 9.3 & 49,900 & 8.1 & 65,700 \\
\hline For-profit & \# & 23,700 & 0.1 & 31,900 & 0.1 & 53,400 \\
\hline Public other 4-year colleges & 2.8 & 35,600 & 2.6 & 47,900 & 3.4 & 61,000 \\
\hline Private other 4-year colleges & 9.5 & 32,600 & 7.3 & 46,600 & 4.8 & 65,500 \\
\hline Nonprofit & 9.4 & 32,600 & 7.2 & 46,800 & 4.8 & 65,700 \\
\hline For-profit & 0.1 & 23,700 & 0.1 & 28,100 & 0.1 & 51,100 \\
\hline Public 2-year colleges & 19.4 & 34,400 & 21.4 & 48,200 & 19.9 & 62,300 \\
\hline Private 2-year colleges & 0.6 & 24,500 & 0.4 & 35,900 & 0.2 & 45,100 \\
\hline Nonprofit & 0.6 & 24,500 & 0.4 & 37,600 & 0.1 & 46,300 \\
\hline For-profit & - & - & $\#$ & 24,500 & $\#$ & 40,100 \\
\hline \multicolumn{7}{|l|}{ Fringe benefits } \\
\hline All institutions & 100.0 & 8,200 & 100.0 & 13,200 & 100.0 & 21,700 \\
\hline Public doctoral universities & 27.9 & 9,600 & 28.3 & 14,300 & 34.0 & 22,800 \\
\hline Private doctoral universities & 12.2 & 9,700 & 12.2 & 17,700 & 16.9 & 26,100 \\
\hline Nonprofit & 12.2 & 9,700 & 12.2 & 17,700 & 16.8 & 26,100 \\
\hline For-profit & - & - & $\#$ & 10,700 & 0.1 & 16,300 \\
\hline Public master's colleges/universities & 20.4 & 9,000 & 18.5 & 12,500 & 12.6 & 21,100 \\
\hline Private master's colleges/universities & 7.2 & 7,500 & 9.3 & 12,400 & 8.2 & 18,800 \\
\hline Nonprofit & 7.2 & 7,500 & 9.3 & 12,400 & 8.1 & 18,900 \\
\hline For-profit & $\#$ & 3,300 & 0.1 & 6,000 & 0.1 & 11,000 \\
\hline Public other 4-year colleges & 2.8 & 7,400 & 2.6 & 11,100 & 3.4 & 19,200 \\
\hline Private other 4-year colleges & 9.5 & 6,300 & 7.3 & 11,600 & 4.8 & 19,300 \\
\hline Nonprofit & 9.4 & 6,400 & 7.2 & 11,700 & 4.8 & 19,500 \\
\hline For-profit & 0.1 & 900 & 0.1 & 3,800 & 0.1 & 8,200 \\
\hline Public 2-year colleges & 19.4 & 6,100 & 21.4 & 11,100 & 19.9 & 19,000 \\
\hline Private 2-year colleges & 0.6 & 3,900 & 0.4 & 9,000 & 0.2 & 11,300 \\
\hline Nonprofit & 0.6 & 3,900 & 0.4 & 9,800 & 0.1 & 11,800 \\
\hline For-profit & - & - & 0.1 & 3,700 & $\#$ & 9,100 \\
\hline
\end{tabular}

\section{- Not available.}

\# Rounds to zero.

NOTE: Average total compensation is the sum of salary and fringe benefits (which may include benefits such as retirement plans, medical/dental plans, group life insurance, or other benefits). Institutions are classified based on the number of highest degrees awarded. For more information on the classification of postsecondary institutions, see Appendix C - Commonly Used Measures. Salaries reflect an average of all faculty on 9- and 10-month contracts rather than a weighted average based on contract length that appears in some other reports of the National Center for Education Statistics. Faculty categories are defined by the institution. Other faculty includes instructors, lecturers, and faculty with no academic rank. Data through 1995 are for institutions of higher education, while later data are for degree-granting institutions. Degree-granting institutions grant associate's or higher degrees and participate in Title IV federal financial aid programs. The degree-granting classification is very similar to the earlier higher education classification, but it includes more 2-year colleges and excludes a few higher education institutions that did not grant degrees. Beginning in 2007, Integrated

Postsecondary Education Data System (IPEDS) includes institutions with fewer than 15 full-time employees; these institutions did not report staff data prior to 2007. For more information on the IPEDS, see Appendix B - Guide to Sources.

SOURCE: U.S. Department of Education, National Center for Education Statistics, Integrated Postsecondary Education Data System (IPEDS), "Salaries, Tenure, and Fringe Benefits of Full-Time Instructional Faculty Survey" (IPEDS-SA:89-99); "Completions Survey" (IPEDS-C:89-99), Fall 2010, Completions component and Winter 2010-11, Human Resources component, Salaries section. 
Table A-44-2. Inflation-adjusted average total compensation, salary, and fringe benefits for full-time faculty on 9- and 10-month contracts at degree-granting institutions, with percentage change, by academic rank and control and level of institutions: Academic years 1989-90, 1999-2000, and 2010-11

[In constant 2010-11 dollars]

\begin{tabular}{|c|c|c|c|c|c|}
\hline \multirow[b]{2}{*}{ Academic rank and control and level of institution } & \multicolumn{3}{|c|}{ Average } & \multirow{2}{*}{$\begin{array}{r}\text { Percent change } \\
\text { in average, } \\
1989-90 \text { to } \\
2010-11\end{array}$} & \multirow{2}{*}{$\begin{array}{r}\text { Percent change } \\
\text { in average, } \\
1999-2000 \text { to } \\
2010-11\end{array}$} \\
\hline & 1989-90 & 1999-2000 & $2010-11$ & & \\
\hline Total compensation & $\$ 84,200$ & $\$ 90,300$ & $\$ 97,200$ & 15.5 & 7.7 \\
\hline \multicolumn{6}{|l|}{ Salary } \\
\hline All faculty & 69,800 & 73,000 & 75,500 & 8.1 & 3.4 \\
\hline Professor & 92,200 & 97,200 & 105,000 & 13.9 & 8.0 \\
\hline Associate professor & 68,700 & 71,200 & 75,100 & 9.3 & 5.5 \\
\hline Assistant professor & 57,000 & 58,700 & 63,100 & 10.8 & 7.5 \\
\hline Other faculty & 52,900 & 56,100 & 56,500 & 6.7 & 0.6 \\
\hline All institutions & 69,800 & 73,000 & 75,500 & 8.1 & 3.4 \\
\hline Public doctoral universities & 77,600 & 81,300 & 81,600 & 5.3 & 0.4 \\
\hline Private doctoral universities & 85,300 & 93,900 & 94,900 & 11.2 & 1.1 \\
\hline Nonprofit & 85,300 & 93,900 & 95,000 & 11.4 & 1.2 \\
\hline For-profit & - & 97,600 & 61,700 & - & -36.8 \\
\hline Public master's colleges/universities & 70,300 & 68,900 & 68,200 & -3.1 & -1.1 \\
\hline Private master's colleges/universities & 61,300 & 65,000 & 65,500 & 6.9 & 0.8 \\
\hline Nonprofit & 61,400 & 65,100 & 65,700 & 7.1 & 0.9 \\
\hline For-profit & 41,200 & 41,600 & 53,400 & 29.6 & 28.4 \\
\hline Public other 4-year colleges & 62,000 & 62,500 & 61,000 & -1.5 & -2.4 \\
\hline Private other 4-year colleges & 56,700 & 60,900 & 65,500 & 15.6 & 7.5 \\
\hline Nonprofit & 56,800 & 61,100 & 65,700 & 15.7 & 7.5 \\
\hline For-profit & 41,200 & 36,700 & 51,100 & 24.0 & 39.1 \\
\hline Public 2-year colleges & 60,000 & 63,000 & 62,300 & 3.9 & -1.1 \\
\hline Private 2-year colleges & 42,600 & 46,900 & 45,100 & 6.0 & -3.8 \\
\hline Nonprofit & 42,600 & 49,100 & 46,300 & 8.8 & -5.6 \\
\hline For-profit & - & 32,000 & 40,100 & - & 25.5 \\
\hline \multicolumn{6}{|l|}{ Fringe benefits } \\
\hline All institutions & 14,300 & 17,300 & 21,700 & 51.5 & 25.9 \\
\hline Public doctoral universities & 16,700 & 18,700 & 22,800 & 36.4 & 21.6 \\
\hline Private doctoral universities & 16,900 & 23,100 & 26,100 & 54.4 & 12.7 \\
\hline Nonprofit & 16,900 & 23,100 & 26,100 & 54.7 & 12.9 \\
\hline For-profit & - & 14,000 & 16,300 & - & 16.0 \\
\hline Public master's colleges/universities & 15,600 & 16,300 & 21,100 & 35.1 & 29.7 \\
\hline Private master's colleges/universities & 13,100 & 16,200 & 18,800 & 44.1 & 16.2 \\
\hline Nonprofit & 13,100 & 16,200 & 18,900 & 44.8 & 16.6 \\
\hline For-profit & 5,700 & 7,900 & 11,000 & 93.0 & 39.8 \\
\hline Public other 4-year colleges & 12,900 & 14,500 & 19,200 & 48.5 & 32.7 \\
\hline Private other 4-year colleges & 11,000 & 15,200 & 19,300 & 75.4 & 27.6 \\
\hline Nonprofit & 11,100 & 15,200 & 19,500 & 76.0 & 28.0 \\
\hline For-profit & 1,500 & 5,000 & 8,200 & 453.8 & 65.4 \\
\hline Public 2-year colleges & 10,600 & 14,500 & 19,000 & 79.9 & 31.1 \\
\hline Private 2-year colleges & 6,800 & 11,800 & 11,300 & 65.3 & -4.4 \\
\hline Nonprofit & 6,800 & 12,800 & 11,800 & 72.8 & -7.9 \\
\hline For-profit & - & 4,800 & 9,100 & - & 88.8 \\
\hline
\end{tabular}

- Not available.

NOTE: Average total compensation is the sum of salary and fringe benefits (which may include benefits such as retirement plans, medical/dental plans, group life insurance, or other benefits). Institutions are classified based on the number of highest degrees awarded. For more information on the classification of postsecondary institutions, see Appendix C - Commonly Used Measures. Salaries reflect an average of all faculty on 9- and 10-month contracts rather than a weighted average based on contract length that appears in some other reports of the National Center for Education Statistics. Faculty categories are defined by the institution. Other faculty includes instructors, lecturers, and faculty with no academic rank. Salaries, benefits, and compensation adjusted by the Consumer Price Index (CPI) to constant 2010-11 dollars. Data through 1995 are for institutions of higher education, while later data are for degree-granting institutions. Degree-granting institutions grant associate's or higher degrees and participate in Title IV federal financial aid programs. The degree-granting classification is very similar to the earlier higher education classification, but it includes more 2-year colleges and excludes a few higher education institutions that did not grant degrees. Beginning in 2007, Integrated Postsecondary Education Data System (IPEDS) includes institutions with fewer than 15 full-time employees; these institutions did not report staff data prior to 2007 . For more information on the CPI, see Appendix C - Finance. For more information on IPEDS, see Appendix B - Guide to Sources.

SOURCE: U.S. Department of Education, National Center for Education Statistics, Integrated Postsecondary Education Data System (IPEDS), "Salaries, Tenure, and Fringe Benefits of Full-Time Instructional Faculty Survey" (IPEDS-SA:89-99); "Completions Survey" (IPEDS-C:89-99), Fall 2010, Completions component and Winter 2010-11, Human Resources component, Salaries section. 


\section{Postsecondary Graduation Rates}

Table A-45-1. Percentage of students seeking a bachelor's degree at 4-year institutions who completed a bachelor's degree, by control of institution, sex, and time to degree attainment: Starting cohort years 1996 and 2004

\begin{tabular}{|c|c|c|c|c|c|c|c|c|}
\hline \multirow[b]{2}{*}{ Sex and time to degree attainment } & \multicolumn{4}{|c|}{1996 starting cohort } & \multicolumn{4}{|c|}{2004 starting cohort } \\
\hline & Total & Public & $\begin{array}{r}\text { Private } \\
\text { nonprofit }\end{array}$ & $\begin{array}{l}\text { Private } \\
\text { for-profit }\end{array}$ & Total & Public & $\begin{array}{r}\text { Private } \\
\text { nonprofit }\end{array}$ & $\begin{array}{r}\text { Private } \\
\text { for-profit }\end{array}$ \\
\hline \multicolumn{9}{|l|}{ All students } \\
\hline 4 years & 33.7 & 26.0 & 48.6 & 21.8 & 37.9 & 31.3 & 52.4 & 20.4 \\
\hline 5 years & 50.2 & 45.9 & 59.2 & 25.4 & 53.9 & 50.6 & 62.9 & 25.8 \\
\hline 6 years & 55.4 & 51.7 & 63.1 & 28.0 & 58.3 & 56.0 & 65.4 & 28.4 \\
\hline \multicolumn{9}{|l|}{ Male } \\
\hline 4 years & 28.5 & 20.8 & 43.6 & 22.3 & 32.9 & 26.1 & 47.7 & 23.3 \\
\hline 5 years & 46.2 & 41.6 & 55.8 & 25.6 & 50.5 & 46.8 & 60.0 & 27.6 \\
\hline 6 years & 52.0 & 48.1 & 60.4 & 28.0 & 55.5 & 53.0 & 63.0 & 30.2 \\
\hline \multicolumn{9}{|l|}{ Female } \\
\hline 4 years & 38.0 & 30.3 & 52.6 & 21.1 & 42.1 & 35.7 & 56.2 & 17.7 \\
\hline 5 years & 53.6 & 49.5 & 61.8 & 25.1 & 56.8 & 53.7 & 65.2 & 24.1 \\
\hline 6 years & 58.2 & 54.7 & 65.4 & 27.9 & 60.6 & 58.5 & 67.3 & 26.8 \\
\hline
\end{tabular}

NOTE: The graduation rate was calculated as the total number of students who completed a degree within 150 percent of the normal time to degree attainment (for example, for bachelor's degrees, 6 years) divided by the number of students in the revised cohort (i.e., the cohort minus any allowable exclusions). For this indicator, the revised cohorts are the spring 2011 estimates of the number of students who entered a 4-year institution in fall 2004 and the spring 2003 estimates of the number of students who entered a 4-year institution in fall 1996 as first-time, full-time undergraduates seeking a bachelor's or equivalent degree. Students who transferred to another institution and graduated are not counted as completers at their initial institution. For more information on the Integrated Postsecondary Education Data System (IPEDS), see Appendix B - Guide to Sources.

SOURCE: U.S. Department of Education, National Center for Education Statistics, Integrated Postsecondary Education Data System (IPEDS), Spring 2003 and Spring 2011, Graduation Rates and Institutional Characteristics components. 
Table A-45-2. Percentage of students seeking a bachelor's degree at 4-year institutions who completed a bachelor's degree within 6 years, by selected characteristics: Starting cohort years 1996 and 2004

\begin{tabular}{|c|c|c|c|c|c|c|}
\hline $\begin{array}{l}\text { Control of institution, sex, and admissions } \\
\text { acceptance rate }\end{array}$ & Total & White & Black & Hispanic & $\begin{array}{r}\text { Asian/ } \\
\text { Pacific } \\
\text { Islander }\end{array}$ & 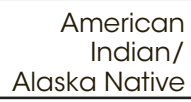 \\
\hline & \multicolumn{6}{|c|}{1996 starting cohort } \\
\hline Total & 55.4 & 58.1 & 38.9 & 45.7 & 63.4 & 38.0 \\
\hline Public & 51.7 & 54.3 & 36.8 & 42.1 & 59.5 & 35.3 \\
\hline Male & 48.1 & 50.8 & 30.3 & 37.5 & 55.2 & 33.1 \\
\hline Female & 54.7 & 57.4 & 41.0 & 45.7 & 63.5 & 37.0 \\
\hline Private nonprofit & 63.1 & 65.7 & 44.6 & 55.7 & 73.5 & 48.1 \\
\hline Male & 60.4 & 63.0 & 38.9 & 52.1 & 71.5 & 46.7 \\
\hline Female & 65.4 & 67.9 & 48.4 & 58.3 & 75.0 & 49.2 \\
\hline Private for-profit & 28.0 & 33.2 & 19.2 & 24.6 & 28.9 & 23.1 \\
\hline Male & 28.0 & 32.3 & 19.4 & 26.7 & 31.7 & 30.8 \\
\hline \multirow[t]{2}{*}{ Female } & 27.9 & 34.5 & 19.0 & 21.9 & 24.9 & 17.3 \\
\hline & \multicolumn{6}{|c|}{2004 starting cohort } \\
\hline Total & 58.3 & 61.5 & 39.5 & 50.1 & 68.7 & 39.4 \\
\hline Public & 56.0 & 58.9 & 38.3 & 47.8 & 66.2 & 37.0 \\
\hline Open admissions & 28.8 & 32.9 & 17.0 & 28.4 & 34.4 & 10.6 \\
\hline 90 percent or more accepted & 44.2 & 47.0 & 29.3 & 30.9 & 41.6 & 27.9 \\
\hline 75.0 to 89.9 percent accepted & 54.9 & 57.3 & 39.8 & 45.8 & 59.6 & 38.0 \\
\hline 50.0 to 74.9 percent accepted & 59.9 & 63.1 & 41.5 & 53.6 & 67.5 & 43.8 \\
\hline 25.0 to 49.9 percent accepted & 62.2 & 68.6 & 42.1 & 51.8 & 68.0 & 48.7 \\
\hline Less than 25.0 percent accepted & 82.2 & 83.0 & 49.2 & 80.0 & 90.2 & 78.1 \\
\hline Private nonprofit & 65.4 & 67.9 & 44.9 & 60.5 & 76.2 & 50.7 \\
\hline Open admissions & 36.4 & 43.8 & 22.2 & 31.2 & 43.4 & 25.9 \\
\hline 90 percent or more accepted & 50.0 & 52.9 & 32.6 & 40.7 & 51.1 & 40.0 \\
\hline 75.0 to 89.9 percent accepted & 60.3 & 63.3 & 40.5 & 51.1 & 59.1 & 41.7 \\
\hline 50.0 to 74.9 percent accepted & 63.8 & 66.6 & 44.9 & 58.4 & 69.2 & 50.0 \\
\hline 25.0 to 49.9 percent accepted & 79.3 & 82.3 & 58.2 & 73.7 & 88.3 & 69.8 \\
\hline Less than 25.0 percent accepted & 90.5 & 92.7 & 69.2 & 90.7 & 95.5 & 85.1 \\
\hline Private for-profit & 28.4 & 35.3 & 21.3 & 28.9 & 38.9 & 19.2 \\
\hline Male & 30.2 & 37.0 & 21.2 & 29.1 & 43.5 & 18.5 \\
\hline Female & 26.8 & 33.4 & 21.3 & 28.7 & 33.3 & 19.6 \\
\hline
\end{tabular}

NOTE: The graduation rate was calculated as the total number of students who completed a degree within 150 percent of the normal time to degree attainment (for example, for bachelor's degrees, 6 years) divided by the number of students in the revised cohort (i.e., the cohort minus any allowable exclusions). For this indicator, the revised cohorts are the spring 2011 estimates of the number of students who entered a 4 -year institution in fall 2004 and the spring 2003 estimates of the number of students who entered a 4-year institution in fall 1996 as first-time, full-time undergraduates seeking a bachelor's or equivalent degree. Students who transferred to another institution and graduated are not counted as completers at their initial institution. Admissions acceptance rate data is not included for for-profit institutions due to the high acceptance rates at most of these institutions. Included in the totals, but not shown separately, are estimates for persons with unknown race/ethnicity and nonresident aliens. Race categories exclude persons of Hispanic ethnicity. For more information on race/ethnicity and classification of postsecondary education institutions, see Appendix C - Commonly Used Measures. For more information on the Integrated Postsecondary Education Data System (IPEDS), see Appendix B - Guide to Sources.

SOURCE: U.S. Department of Education, National Center for Education Statistics, Integrated Postsecondary Education Data System (IPEDS), Spring 2003 and Spring 2011, Graduation Rates and Institutional Characteristics components. 
Table A-45-3. Percentage of students seeking a certificate or associate's degree at 2-year institutions who completed a certificate or associate's degree within 150 percent of the normal time required to do so, by race/ ethnicity, control of institution, and sex: Starting cohort years 2000 and 2007

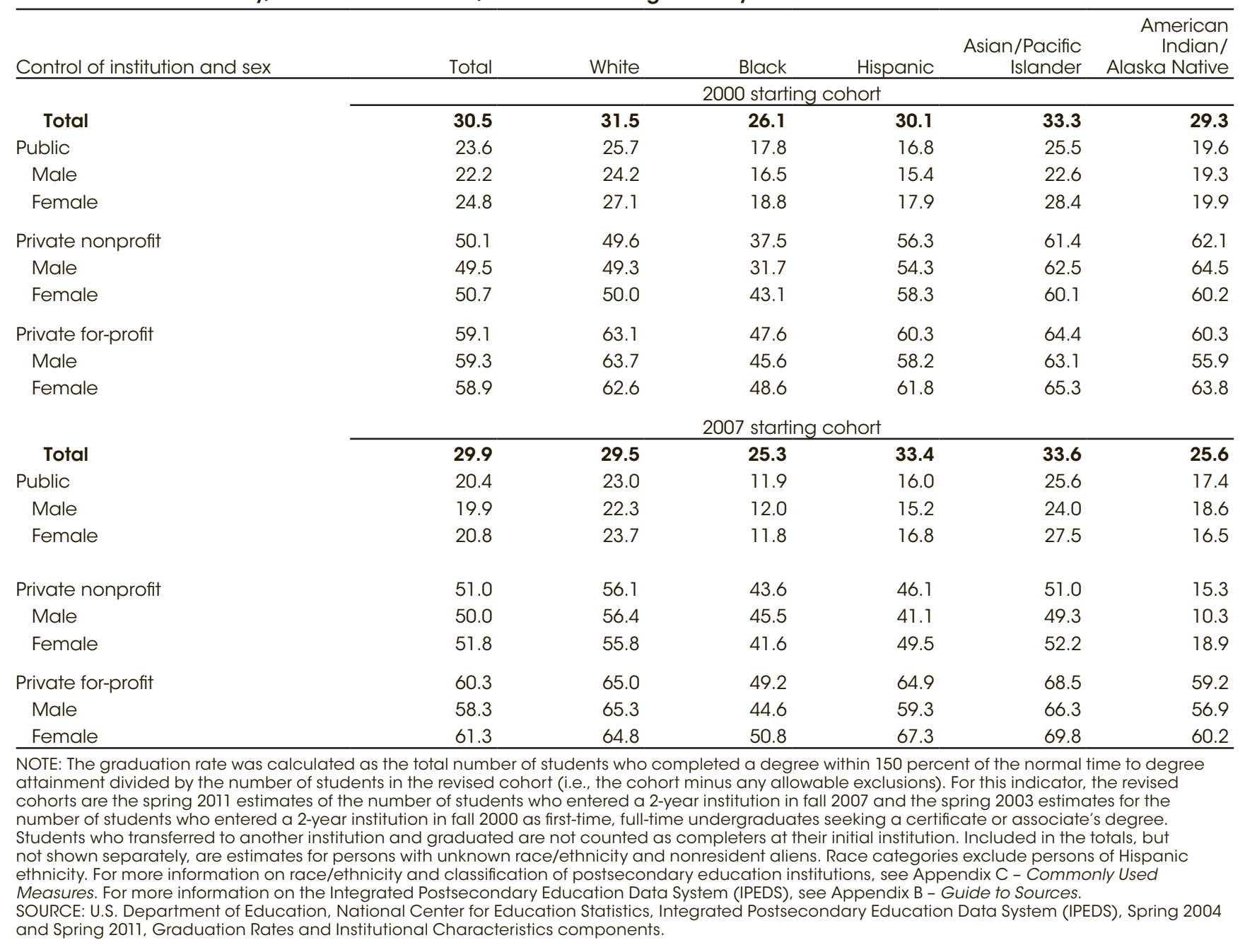


This page intentionally left blank. 
Table A-46-1. Number and percentage distribution of degrees conferred by postsecondary degree-granting institutions, by control of institution and level of degree: Academic years 1999-2000 through 2009-10

\begin{tabular}{|c|c|c|c|c|c|c|c|c|c|c|}
\hline \multirow{3}{*}{$\begin{array}{l}\text { Level of } \\
\text { degree and } \\
\text { academic year }\end{array}$} & \multicolumn{5}{|c|}{ Number of degrees conferred } & \multicolumn{5}{|c|}{ Percentage distribution of degrees conferred } \\
\hline & \multirow[b]{2}{*}{ Total } & \multirow[b]{2}{*}{ Public } & \multicolumn{3}{|c|}{ Private } & \multirow[b]{2}{*}{ Total } & \multirow[b]{2}{*}{ Public } & \multicolumn{3}{|c|}{ Private } \\
\hline & & & Total & Nonprofit & For-profit & & & Total & Nonprofit & For-profit \\
\hline \multicolumn{11}{|l|}{ Associate's } \\
\hline 1999-2000 & 564,933 & 448,446 & 116,487 & 46,337 & 70,150 & 100.0 & 79.4 & 20.6 & 8.2 & 12.4 \\
\hline 2000-01 & 578,865 & 456,487 & 122,378 & 45,711 & 76,667 & 100.0 & 78.9 & 21.1 & 7.9 & 13.2 \\
\hline $2001-02$ & 595,133 & 471,660 & 123,473 & 45,761 & 77,712 & 100.0 & 79.3 & 20.7 & 7.7 & 13.1 \\
\hline 2002-03 & 634,016 & 498,279 & 135,737 & 46,183 & 89,554 & 100.0 & 78.6 & 21.4 & 7.3 & 14.1 \\
\hline 2003-04 & 665,301 & 524,875 & 140,426 & 45,759 & 94,667 & 100.0 & 78.9 & 21.1 & 6.9 & 14.2 \\
\hline 2004-05 & 696,660 & 547,519 & 149,141 & 45,344 & 103,797 & 100.0 & 78.6 & 21.4 & 6.5 & 14.9 \\
\hline 2005-06 & 713,066 & 557,134 & 155,932 & 46,442 & 109,490 & 100.0 & 78.1 & 21.9 & 6.5 & 15.4 \\
\hline 2006-07 & 728,114 & 566,535 & 161,579 & 43,829 & 117,750 & 100.0 & 77.8 & 22.2 & 6.0 & 16.2 \\
\hline 2007-08 & 750,164 & 578,520 & 171,644 & 44,788 & 126,856 & 100.0 & 77.1 & 22.9 & 6.0 & 16.9 \\
\hline 2008-09 & 787,325 & 596,098 & 191,227 & 46,929 & 144,298 & 100.0 & 75.7 & 24.3 & 6.0 & 18.3 \\
\hline 2009-10 & 849,452 & 640,113 & 209,339 & 46,673 & 162,666 & 100.0 & 75.4 & 24.6 & 5.5 & 19.1 \\
\hline \multicolumn{11}{|l|}{ Bachelor's } \\
\hline 1999-2000 & $1,237,875$ & 810,855 & 427,020 & 406,958 & 20,062 & 100.0 & 65.5 & 34.5 & 32.9 & 1.6 \\
\hline 2000-01 & $1,244,171$ & 812,438 & 431,733 & 408,701 & 23,032 & 100.0 & 65.3 & 34.7 & 32.8 & 1.9 \\
\hline 2001-02 & $1,291,900$ & 841,180 & 450,720 & 424,322 & 26,398 & 100.0 & 65.1 & 34.9 & 32.8 & 2.0 \\
\hline 2002-03 & $1,348,811$ & 875,596 & 473,215 & 442,060 & 31,155 & 100.0 & 64.9 & 35.1 & 32.8 & 2.3 \\
\hline 2003-04 & $1,399,542$ & 905,718 & 493,824 & 451,518 & 42,306 & 100.0 & 64.7 & 35.3 & 32.3 & 3.0 \\
\hline 2004-05 & $1,439,264$ & 932,443 & 506,821 & 457,963 & 48,858 & 100.0 & 64.8 & 35.2 & 31.8 & 3.4 \\
\hline 2005-06 & $1,485,242$ & 955,369 & 529,873 & 467,836 & 62,037 & 100.0 & 64.3 & 35.7 & 31.5 & 4.2 \\
\hline 2006-07 & $1,524,092$ & 975,513 & 548,579 & 477,805 & 70,774 & 100.0 & 64.0 & 36.0 & 31.4 & 4.6 \\
\hline 2007-08 & $1,563,069$ & 996,435 & 566,634 & 490,685 & 75,949 & 100.0 & 63.7 & 36.3 & 31.4 & 4.9 \\
\hline 2008-09 & $1,601,368$ & $1,020,435$ & 580,933 & 496,260 & 84,673 & 100.0 & 63.7 & 36.3 & 31.0 & 5.3 \\
\hline 2009-10 & $1,650,014$ & $1,049,057$ & 600,957 & 503,164 & 97,793 & 100.0 & 63.6 & 36.4 & 30.5 & 5.9 \\
\hline \multicolumn{11}{|l|}{ Master's } \\
\hline 1999-2000 & 463,185 & 243,157 & 220,028 & 209,720 & 10,308 & 100.0 & 52.5 & 47.5 & 45.3 & 2.2 \\
\hline 2000-01 & 473,502 & 246,054 & 227,448 & 215,815 & 11,633 & 100.0 & 52.0 & 48.0 & 45.6 & 2.5 \\
\hline 2001-02 & 487,313 & 249,820 & 237,493 & 223,229 & 14,264 & 100.0 & 51.3 & 48.7 & 45.8 & 2.9 \\
\hline 2002-03 & 518,699 & 265,643 & 253,056 & 238,069 & 14,987 & 100.0 & 51.2 & 48.8 & 45.9 & 2.9 \\
\hline 2003-04 & 564,272 & 285,138 & 279,134 & 250,894 & 28,240 & 100.0 & 50.5 & 49.5 & 44.5 & 5.0 \\
\hline 2004-05 & 580,151 & 291,505 & 288,646 & 253,564 & 35,082 & 100.0 & 50.2 & 49.8 & 43.7 & 6.0 \\
\hline 2005-06 & 599,731 & 293,517 & 306,214 & 261,090 & 45,124 & 100.0 & 48.9 & 51.1 & 43.5 & 7.5 \\
\hline 2006-07 & 610,597 & 291,971 & 318,626 & 267,690 & 50,936 & 100.0 & 47.8 & 52.2 & 43.8 & 8.3 \\
\hline 2007-08 & 630,666 & 299,983 & 330,683 & 275,829 & 54,854 & 100.0 & 47.6 & 52.4 & 43.7 & 8.7 \\
\hline 2008-09 & 662,079 & 308,206 & 353,873 & 290,393 & 63,480 & 100.0 & 46.6 & 53.4 & 43.9 & 9.6 \\
\hline 2009-10 & 693,025 & 322,243 & 370,782 & 299,911 & 70,871 & 100.0 & 46.5 & 53.5 & 43.3 & 10.2 \\
\hline \multicolumn{11}{|l|}{ Doctor's $^{1}$} \\
\hline 1999-2000 & 118,736 & 60,655 & 58,081 & 56,972 & 1,109 & 100.0 & 51.1 & 48.9 & 48.0 & 0.9 \\
\hline 2000-01 & 119,585 & 60,820 & 58,765 & 57,722 & 1,043 & 100.0 & 50.9 & 49.1 & 48.3 & 0.9 \\
\hline 2001-02 & 119,663 & 61,061 & 58,602 & 57,707 & 895 & 100.0 & 51.0 & 49.0 & 48.2 & 0.7 \\
\hline 2002-03 & 121,579 & 61,611 & 59,968 & 58,894 & 1,074 & 100.0 & 50.7 & 49.3 & 48.4 & 0.9 \\
\hline 2003-04 & 126,087 & 64,205 & 61,882 & 60,447 & 1,435 & 100.0 & 50.9 & 49.1 & 47.9 & 1.1 \\
\hline 2004-05 & 134,387 & 67,511 & 66,876 & 65,278 & 1,598 & 100.0 & 50.2 & 49.8 & 48.6 & 1.2 \\
\hline 2005-06 & 138,056 & 70,036 & 68,020 & 66,066 & 1,954 & 100.0 & 50.7 & 49.3 & 47.9 & 1.4 \\
\hline 2006-07 & 144,690 & 73,085 & 71,605 & 69,239 & 2,366 & 100.0 & 50.5 & 49.5 & 47.9 & 1.6 \\
\hline 2007-08 & 149,378 & 75,533 & 73,845 & 70,679 & 3,166 & 100.0 & 50.6 & 49.4 & 47.3 & 2.1 \\
\hline 2008-09 & 154,425 & 77,268 & 77,157 & 73,446 & 3,711 & 100.0 & 50.0 & 50.0 & 47.6 & 2.4 \\
\hline 2009-10 & 158,558 & 78,779 & 79,779 & 75,166 & 4,613 & 100.0 & 49.7 & 50.3 & 47.4 & 2.9 \\
\hline
\end{tabular}

'Includes Ph.D., Ed.D., and comparable degrees at the doctoral level. Includes most degrees formerly classified as first-professional, such as M.D., D.D.S., and law degrees.

NOTE: Includes only postsecondary institutions that participated in Title IV federal financial aid programs. For more information on the Integrated Postsecondary Education Data System (IPEDS), see Appendix B - Guide to Sources. For more information on the IPEDS classification of institutions and degree levels, see Appendix C - Commonly Used Measures. See the glossary for the definition of doctor's degree. Detail may not sum to totals because of rounding.

SOURCE: U.S. Department of Education, National Center for Education Statistics, Integrated Postsecondary Education Data System (IPEDS), Fall 2000 through Fall 2010, Completions component. 
This page intentionally left blank. 


\section{Indicator 47}

\section{Degrees Earned}

Table A-47-1. Number of degrees conferred by degree-granting institutions and percentage of degrees conferred to females, by level of degree: Academic years 1999-2000 through 2009-10

\begin{tabular}{|c|c|c|c|c|c|c|c|c|}
\hline \multirow[b]{2}{*}{$\begin{array}{l}\text { Academic } \\
\text { year }\end{array}$} & \multicolumn{2}{|c|}{ Associate's } & \multicolumn{2}{|c|}{ Bachelor's } & \multicolumn{2}{|c|}{ Master's } & \multicolumn{2}{|c|}{ Doctor's $^{1}$} \\
\hline & Number & $\begin{array}{r}\text { Percent } \\
\text { conferred } \\
\text { to females }\end{array}$ & Number & $\begin{array}{r}\text { Percent } \\
\text { conferred } \\
\text { to females }\end{array}$ & Number & $\begin{array}{r}\text { Percent } \\
\text { conferred } \\
\text { to females }\end{array}$ & Number & $\begin{array}{r}\text { Percent } \\
\text { conferred } \\
\text { to females }\end{array}$ \\
\hline 1999-2000 & 564,933 & 60.2 & $1,237,875$ & 57.2 & 463,185 & 57.7 & 118,736 & 45.3 \\
\hline 2000-01 & 578,865 & 60.0 & 1,244, 171 & 57.3 & 473,502 & 58.2 & 119,585 & 46.3 \\
\hline 2001-02 & 595,133 & 60.0 & 1,291,900 & 57.4 & 487,313 & 58.4 & 119,663 & 47.6 \\
\hline 2002-03 & 634,016 & 60.0 & $1,348,811$ & 57.5 & 518,699 & 58.5 & 121,579 & 48.4 \\
\hline 2003-04 & 665,301 & 60.9 & $1,399,542$ & 57.5 & 564,272 & 58.7 & 126,087 & 49.3 \\
\hline 2004-05 & 696,660 & 61.6 & $1,439,264$ & 57.4 & 580,151 & 59.1 & 134,387 & 50.0 \\
\hline 2005-06 & 713,066 & 62.1 & $1,485,242$ & 57.5 & 599,731 & 59.7 & 138,056 & 50.1 \\
\hline 2006-07 & 728,114 & 62.2 & 1,524,092 & 57.4 & 610,597 & 60.3 & 144,690 & 50.7 \\
\hline 2007-08 & 750,164 & 62.3 & $1,563,069$ & 57.3 & 630,774 & 60.3 & 149,270 & 50.9 \\
\hline 2008-09 & 787,325 & 62.1 & $1,601,368$ & 57.2 & 662,146 & 60.2 & 154,358 & 51.0 \\
\hline \multirow[t]{2}{*}{ 2009-10 } & 849,452 & 62.0 & $1,650,014$ & 57.2 & 693,025 & 60.3 & 158,558 & 51.7 \\
\hline & \multicolumn{8}{|c|}{ Increase in the number of degrees conferred } \\
\hline \multirow[t]{2}{*}{$\begin{array}{c}1999-2000 \text { to } \\
2009-10\end{array}$} & 284,519 & $\dagger$ & 412,139 & $\dagger$ & 229,840 & $\dagger$ & 39,822 & $\dagger$ \\
\hline & \multicolumn{8}{|c|}{ Percentage change in the number of degrees conferred } \\
\hline \multicolumn{9}{|l|}{ 1999-2000 to } \\
\hline \multicolumn{9}{|c|}{$\begin{array}{l}\text { T Not applicable. } \\
\text { 'Includes Ph.D., Ed.D., and comparable degrees at the doctoral level. Includes most degrees formerly classified as first-professional, such as M.D., } \\
\text { D.D.S., and law degrees. } \\
\text { NOTE: Degree-granting institutions grant associate's or higher degrees and participate in Title IV federal financial aid programs. For more information } \\
\text { on the Integrated Postsecondary Education Data System (IPEDS) classification of degree levels, see Appendix C - Commonly Used Measures. For more } \\
\text { information on IPEDS, see Appendix B - Guide to Sources. See the glossary for the definition of doctor's degree. } \\
\text { SOURCE: U.S. Department of Education, National Center for Education Statistics, Integrated Postsecondary Education Data System (IPEDS), } \\
\text { "Completions Survey" (IPEDS-C:96-99); and Fall } 2000 \text { through Fall 2010, Completions component. }\end{array}$} \\
\hline
\end{tabular}


Table A-47-2. Number and percentage change in degrees conferred to U.S. residents by degree-granting institutions, percentage distribution of degrees conferred, and percentage of degrees conferred to females, by level of degree and race/ethnicity: Academic years 1999-2000, 2004-05, and 2009-10

\begin{tabular}{|c|c|c|c|c|c|c|c|c|c|c|}
\hline \multirow[b]{2}{*}{$\begin{array}{l}\text { Level of degree } \\
\text { and race/ethnicity }\end{array}$} & \multicolumn{3}{|c|}{ Number } & \multirow[b]{2}{*}{$\begin{array}{r}\text { Percent } \\
\text { change, } \\
1999- \\
2000 \text { to } \\
2009-10\end{array}$} & \multicolumn{3}{|c|}{ Percentage distribution } & \multicolumn{3}{|c|}{ Percent conferred to females } \\
\hline & 1999-2000 & 2004-05 & $2009-10$ & & 1999-2000 & 2004-05 & $2009-10$ & 1999-2000 & 2004-05 & 2009-10 \\
\hline Associate's & 554,845 & 682,576 & 833,337 & 50.2 & 100.0 & 100.0 & 100.0 & 60.3 & 61.6 & 62.0 \\
\hline White & 408,772 & 475,513 & 552,863 & 35.2 & 73.7 & 69.7 & 66.3 & 59.8 & 60.3 & 60.9 \\
\hline Black & 60,221 & 86,402 & 113,905 & 89.1 & 10.9 & 12.7 & 13.7 & 65.2 & 68.6 & 68.3 \\
\hline Hispanic & 51,573 & 78,557 & 112,211 & 117.6 & 9.3 & 11.5 & 13.5 & 59.4 & 62.2 & 62.4 \\
\hline Asian/Pacific Islander & 27,782 & 33,669 & 44,021 & 58.5 & 5.0 & 4.9 & 5.3 & 56.8 & 59.0 & 58.5 \\
\hline $\begin{array}{c}\text { American Indian/ } \\
\text { Alaska Native }\end{array}$ & 6,497 & 8,435 & 10,337 & 59.1 & 1.2 & 1.2 & 1.2 & 65.8 & 67.1 & 64.9 \\
\hline Bachelor's & $1,198,809$ & $1,393,903$ & $1,602,480$ & 33.7 & 100.0 & 100.0 & 100.0 & 57.5 & 57.7 & 57.4 \\
\hline White & 929,106 & $1,049,141$ & $1,167,499$ & 25.7 & 77.5 & 75.3 & 72.9 & 56.6 & 56.5 & 56.0 \\
\hline Black & 108,013 & 136,122 & 164,844 & 52.6 & 9.0 & 9.8 & 10.3 & 65.7 & 66.3 & 65.9 \\
\hline Hispanic & 75,059 & 101,124 & 140,316 & 86.9 & 6.3 & 7.3 & 8.8 & 59.6 & 60.9 & 60.7 \\
\hline Asian/Pacific Islander & 77,912 & 97,209 & 117,422 & 50.7 & 6.5 & 7.0 & 7.3 & 54.0 & 55.0 & 54.5 \\
\hline $\begin{array}{l}\text { American Indian/ } \\
\text { Alaska Native }\end{array}$ & 8,719 & 10,307 & 12,399 & 42.2 & 0.7 & 0.7 & 0.8 & 60.3 & 59.8 & 60.7 \\
\hline Master's & 406,761 & 506,567 & 611,693 & 50.4 & 100.0 & 100.0 & 100.0 & 60.0 & 61.7 & 62.6 \\
\hline White & 324,981 & 383,246 & 445,038 & 36.9 & 79.9 & 75.7 & 72.8 & 59.6 & 60.8 & 61.8 \\
\hline Black & 36,595 & 55,330 & 76,458 & 108.9 & 9.0 & 10.9 & 12.5 & 68.2 & 70.8 & 71.1 \\
\hline Hispanic & 19,384 & 31,639 & 43,535 & 124.6 & 4.8 & 6.2 & 7.1 & 60.1 & 63.6 & 64.3 \\
\hline Asian/Pacific Islander & 23,538 & 33,042 & 42,702 & 81.4 & 5.8 & 6.5 & 7.0 & 52.0 & 53.9 & 54.3 \\
\hline $\begin{array}{l}\text { American Indian/ } \\
\text { Alaska Native }\end{array}$ & 2,263 & 3,310 & 3,960 & 75.0 & 0.6 & 0.7 & 0.6 & 62.7 & 64.7 & 64.3 \\
\hline Doctor's ${ }^{1}$ & 106,494 & 118,369 & 140,505 & 31.9 & 100.0 & 100.0 & 100.0 & 47.0 & 52.0 & 53.3 \\
\hline White & 82,984 & 89,763 & 104,426 & 25.8 & 77.9 & 75.8 & 74.3 & 45.4 & 50.1 & 51.4 \\
\hline Black & 7,080 & 8,527 & 10,417 & 47.1 & 6.6 & 7.2 & 7.4 & 61.0 & 65.9 & 65.2 \\
\hline Hispanic & 5,039 & 6,115 & 8,085 & 60.4 & 4.7 & 5.2 & 5.8 & 48.4 & 53.2 & 55.0 \\
\hline $\begin{array}{l}\text { Asian/Pacific Islander } \\
\text { American Indian/ }\end{array}$ & 10,684 & 13,176 & 16,625 & 55.6 & 10.0 & 11.1 & 11.8 & 48.8 & 55.1 & 56.5 \\
\hline Alaska Native & 707 & 788 & 952 & 34.7 & 0.7 & 0.7 & 0.7 & 52.9 & 53.0 & 54.8 \\
\hline
\end{tabular}

'Includes Ph.D., Ed.D., and comparable degrees at the doctoral level. Includes most degrees formerly classified as first-professional, such as M.D., D.D.S., and law degrees.

NOTE: Degree-granting institutions grant associate's or higher degrees and participate in Title IV federal financial aid programs. Reported racial/ethnic distributions of students by type of degree, field of degree, and sex were used to estimate race/ethnicity for students whose race/ethnicity was not reported. Race categories exclude persons of Hispanic ethnicity. Nonresident aliens are excluded because information about their race/ethnicity is not available. Detail may not sum to totals because of rounding. For more information on race/ethnicity and the Integrated Postsecondary Education Data System (IPEDS) classification of degree levels, see Appendix C - Commonly Used Measures. For more information on IPEDS, see Appendix B - Guide to Sources. See the glossary for the definition of doctor's degree.

SOURCE: U.S. Department of Education, National Center for Education Statistics, Integrated Postsecondary Education Data System (IPEDS),

"Completions Survey" (IPEDS-C:99); and Fall 2000, Fall 2005, and Fall 2010, Completions component. 
Table A-48-1. Percentage of 25- to 29-year-olds who attained selected levels of education, by race/ethnicity and sex: Selected years, 1980-2011

\begin{tabular}{|c|c|c|c|c|c|c|c|c|c|c|c|c|}
\hline \multirow{2}{*}{$\begin{array}{l}\text { Educational } \\
\text { attainment }\end{array}$} & \multicolumn{3}{|c|}{ Total $^{1}$} & \multicolumn{3}{|c|}{ White } & \multicolumn{3}{|c|}{ Black } & \multicolumn{3}{|c|}{ Hispanic } \\
\hline & Total & Male & Female & Total & Male & Female & Total & Male & Female & Total & Male & Female \\
\hline \multicolumn{13}{|c|}{$\begin{array}{l}\text { At least high } \\
\text { school diploma } \\
\text { or equivalency }\end{array}$} \\
\hline 1980 & 85.4 & 85.4 & 85.5 & 89.2 & 89.1 & 89.2 & 76.7 & 74.7 & 78.3 & 58.0 & 57.0 & 58.9 \\
\hline 1985 & 86.1 & 85.9 & 86.4 & 89.5 & 89.2 & 89.9 & 80.5 & 80.6 & 80.5 & 60.9 & 58.6 & 63.1 \\
\hline 1990 & 85.7 & 84.4 & 87.0 & 90.1 & 88.6 & 91.7 & 81.7 & 81.4 & 82.0 & 58.2 & 56.6 & 59.9 \\
\hline 1995 & 86.8 & 86.3 & 87.4 & 92.5 & 92.0 & 93.0 & 86.7 & 88.4 & 85.3 & 57.1 & 55.7 & 58.7 \\
\hline 2000 & 88.1 & 86.7 & 89.4 & 94.0 & 92.9 & 95.2 & 86.8 & 87.6 & 86.2 & 62.8 & 59.2 & 66.4 \\
\hline 2005 & 86.2 & 85.0 & 87.4 & 92.8 & 91.8 & 93.8 & 87.0 & 86.6 & 87.3 & 63.3 & 63.2 & 63.4 \\
\hline 2006 & 86.4 & 84.4 & 88.5 & 93.4 & 92.3 & 94.6 & 86.3 & 84.2 & 88.0 & 63.2 & 60.5 & 66.6 \\
\hline 2007 & 87.0 & 84.9 & 89.1 & 93.5 & 92.7 & 94.2 & 87.7 & 87.4 & 87.9 & 65.0 & 60.5 & 70.7 \\
\hline 2008 & 87.8 & 85.8 & 89.9 & 93.7 & 92.6 & 94.7 & 87.5 & 85.7 & 89.2 & 68.3 & 65.6 & 71.9 \\
\hline 2009 & 88.6 & 87.5 & 89.8 & 94.6 & 94.4 & 94.8 & 88.9 & 88.8 & 89.0 & 68.9 & 66.2 & 72.5 \\
\hline 2010 & 88.8 & 87.4 & 90.2 & 94.5 & 94.6 & 94.4 & 89.6 & 87.9 & 91.1 & 69.4 & 65.7 & 74.1 \\
\hline 2011 & 89.0 & 87.5 & 90.7 & 94.4 & 93.4 & 95.5 & 88.1 & 88.0 & 88.2 & 71.5 & 69.2 & 74.3 \\
\hline \multicolumn{13}{|c|}{$\begin{array}{l}\text { At least some } \\
\text { college }\end{array}$} \\
\hline 1980 & 44.7 & 47.6 & 41.9 & 48.0 & 51.1 & 44.9 & 32.4 & 32.6 & 32.3 & 23.2 & 25.9 & 20.5 \\
\hline 1985 & 43.7 & 44.2 & 43.3 & 46.4 & 46.8 & 46.0 & 34.4 & 34.2 & 34.5 & 26.9 & 26.9 & 27.0 \\
\hline 1990 & 44.5 & 43.7 & 45.3 & 48.3 & 47.3 & 49.3 & 36.1 & 35.0 & 36.9 & 23.4 & 22.9 & 23.9 \\
\hline 1995 & 54.1 & 52.3 & 55.8 & 59.8 & 57.5 & 62.1 & 45.1 & 45.3 & 44.8 & 28.7 & 26.7 & 30.9 \\
\hline 2000 & 58.3 & 55.1 & 61.5 & 64.1 & 60.5 & 67.7 & 52.7 & 50.4 & 54.6 & 32.8 & 29.0 & 36.6 \\
\hline 2005 & 56.9 & 52.3 & 61.5 & 64.5 & 59.9 & 69.1 & 49.0 & 41.8 & 55.1 & 32.7 & 31.8 & 33.9 \\
\hline 2006 & 57.8 & 53.3 & 62.4 & 66.3 & 62.1 & 70.4 & 49.9 & 44.8 & 54.3 & 31.7 & 28.3 & 35.9 \\
\hline 2007 & 57.7 & 52.5 & 63.0 & 65.6 & 61.1 & 70.0 & 50.0 & 45.9 & 53.6 & 33.9 & 28.2 & 41.1 \\
\hline 2008 & 59.2 & 53.9 & 64.8 & 67.1 & 62.4 & 71.9 & 51.0 & 44.5 & 56.7 & 35.9 & 30.8 & 42.5 \\
\hline 2009 & 59.9 & 54.7 & 65.3 & 68.1 & 63.5 & 72.9 & 53.4 & 45.2 & 60.6 & 34.5 & 30.7 & 39.5 \\
\hline 2010 & 61.2 & 55.9 & 66.8 & 69.3 & 64.9 & 73.9 & 54.7 & 48.8 & 60.0 & 36.8 & 30.2 & 45.1 \\
\hline 2011 & 62.1 & 56.8 & 67.7 & 69.8 & 64.7 & 75.1 & 54.9 & 49.9 & 59.4 & 38.8 & 34.5 & 44.2 \\
\hline \multicolumn{13}{|c|}{$\begin{array}{l}\text { Bachelor's degree } \\
\text { or higher }\end{array}$} \\
\hline 1980 & 22.5 & 24.0 & 21.0 & 25.0 & 26.8 & 23.2 & 11.6 & 10.5 & 12.4 & 7.7 & 8.4 & 6.9 \\
\hline 1985 & 22.2 & 23.1 & 21.3 & 24.4 & 25.5 & 23.3 & 11.6 & 10.3 & 12.6 & 11.1 & 10.9 & 11.2 \\
\hline 1990 & 23.2 & 23.7 & 22.8 & 26.4 & 26.6 & 26.2 & 13.4 & 15.1 & 11.9 & 8.1 & 7.3 & 9.1 \\
\hline 1995 & 24.7 & 24.5 & 24.9 & 28.8 & 28.4 & 29.2 & 15.4 & 17.4 & 13.7 & 8.9 & 7.8 & 10.1 \\
\hline 2000 & 29.1 & 27.9 & 30.1 & 34.0 & 32.3 & 35.8 & 17.8 & 18.4 & 17.4 & 9.7 & 8.3 & 11.0 \\
\hline 2005 & 28.8 & 25.5 & 32.2 & 34.5 & 30.7 & 38.2 & 17.6 & 14.2 & 20.5 & 11.2 & 10.2 & 12.4 \\
\hline 2006 & 28.4 & 25.3 & 31.6 & 34.3 & 31.4 & 37.2 & 18.7 & 15.2 & 21.7 & 9.5 & 6.9 & 12.8 \\
\hline 2007 & 29.6 & 26.3 & 33.0 & 35.5 & 31.9 & 39.2 & 19.5 & 18.9 & 20.0 & 11.6 & 8.6 & 15.4 \\
\hline 2008 & 30.8 & 26.8 & 34.9 & 37.1 & 32.6 & 41.7 & 20.4 & 19.0 & 21.6 & 12.4 & 10.0 & 15.5 \\
\hline 2009 & 30.6 & 26.6 & 34.8 & 37.2 & 32.6 & 42.0 & 18.9 & 14.8 & 22.6 & 12.2 & 11.0 & 13.8 \\
\hline 2010 & 31.7 & 27.8 & 35.7 & 38.6 & 34.8 & 42.4 & 19.4 & 15.0 & 23.3 & 13.5 & 10.8 & 16.8 \\
\hline 2011 & 32.2 & 28.4 & 36.1 & 39.2 & 35.5 & 43.0 & 20.1 & 17.0 & 22.9 & 12.8 & 9.6 & 16.8 \\
\hline \multicolumn{13}{|c|}{$\begin{array}{l}\text { Master's degree } \\
\text { or higher }\end{array}$} \\
\hline 1995 & 4.5 & 4.9 & 4.1 & 5.3 & 5.6 & 5.0 & 1.8 & $2.2 !$ & $1.4 !$ & 1.6 & $2.0 !$ & $1.2 !$ \\
\hline 2000 & 5.4 & 4.7 & 6.2 & 5.8 & 4.9 & 6.7 & 3.7 & $2.1 !$ & 4.9 & 2.1 & 1.5 & 2.7 \\
\hline 2005 & 6.3 & 5.2 & 7.3 & 7.5 & 6.2 & 8.8 & 2.6 & $1.1 !$ & 4.0 & 2.1 & 1.7 & 2.6 \\
\hline 2006 & 6.4 & 5.1 & 7.8 & 7.5 & 5.8 & 9.2 & 3.2 & $1.7 !$ & 4.5 & 1.5 & 1.1 & 2.0 \\
\hline 2007 & 6.3 & 5.0 & 7.6 & 7.6 & 5.7 & 9.4 & 3.5 & 3.3 & 3.7 & 1.5 & $0.6 !$ & 2.6 \\
\hline 2008 & 7.0 & 5.3 & 8.7 & 8.2 & 5.9 & 10.4 & 4.4 & 3.4 & 5.2 & 2.0 & 1.2 & 2.9 \\
\hline 2009 & 7.4 & 6.1 & 8.8 & 8.9 & 7.4 & 10.4 & 4.2 & 3.2 & 5.1 & 1.9 & 1.2 & 2.7 \\
\hline 2010 & 6.8 & 5.2 & 8.5 & 7.7 & 6.3 & 9.2 & 4.7 & 2.9 & 6.2 & 2.5 & 1.5 & 3.8 \\
\hline 2011 & 6.9 & 5.1 & 8.8 & 8.1 & 5.9 & 10.4 & 4.0 & 1.9 & 5.8 & 2.7 & 1.8 & 3.8 \\
\hline
\end{tabular}

See notes at end of table. 
Table A-48-1. Percentage of 25- to 29-year-olds who attained selected levels of education, by race/ethnicity and sex: Selected years, 1980-2011-Continued

\begin{tabular}{|c|c|c|c|c|c|c|c|c|c|}
\hline \multirow[b]{2}{*}{ Educational attainment } & \multicolumn{3}{|c|}{ Asian/Pacific Islander } & \multicolumn{3}{|c|}{$\begin{array}{c}\text { American Indian/ } \\
\text { Alaska Native }\end{array}$} & \multicolumn{3}{|c|}{ Two or more races } \\
\hline & Total & Male & Female & Total & Male & Female & Total & Male & Female \\
\hline \multicolumn{10}{|c|}{$\begin{array}{l}\text { At least high school diploma } \\
\text { or equivalency }\end{array}$} \\
\hline 1980 & - & - & - & - & - & - & - & - & - \\
\hline 1985 & - & - & - & - & - & - & - & - & - \\
\hline 1990 & 89.9 & 95.3 & 85.1 & - & - & - & - & - & - \\
\hline 1995 & 90.8 & 90.5 & 91.2 & - & - & - & - & - & - \\
\hline 2000 & 93.7 & 92.1 & 95.2 & - & - & - & - & - & - \\
\hline 2005 & 95.6 & 96.8 & 94.6 & 80.2 & 73.0 & 87.1 & 91.4 & 89.1 & 94.2 \\
\hline 2006 & 96.4 & 97.2 & 95.6 & 79.8 & 75.0 & 83.3 & 89.3 & 89.2 & 89.4 \\
\hline 2007 & 96.8 & 95.9 & 97.7 & 84.5 & 76.6 & 90.2 & 90.5 & 92.9 & 87.9 \\
\hline 2008 & 95.9 & 95.6 & 96.1 & 86.7 & 90.5 & 84.2 & 94.2 & 92.7 & 95.9 \\
\hline 2009 & 95.4 & 96.4 & 94.5 & 81.1 & 77.5 & 83.4 & 88.5 & 92.0 & 84.8 \\
\hline 2010 & 93.7 & 93.8 & 93.6 & 89.9 & 93.2 & 86.8 & 88.5 & 87.9 & 89.1 \\
\hline 2011 & 95.4 & 94.2 & 96.6 & 84.9 & 84.5 & 85.3 & 90.7 & 86.2 & 94.0 \\
\hline \multicolumn{10}{|l|}{ At least some college } \\
\hline 1980 & - & - & - & - & - & - & - & - & - \\
\hline 1985 & - & - & - & - & - & - & - & - & - \\
\hline 1990 & 62.8 & 69.3 & 57.0 & - & - & - & - & - & - \\
\hline 1995 & 76.4 & 75.4 & 77.6 & - & - & - & - & - & - \\
\hline 2000 & 78.2 & 79.3 & 77.3 & - & - & - & - & - & - \\
\hline 2005 & 80.3 & 78.2 & 82.3 & 44.2 & 36.3 & 51.8 & 63.5 & 52.6 & 76.4 \\
\hline 2006 & 80.9 & 80.0 & 81.8 & 47.5 & 39.1 & 53.7 & 60.2 & 54.7 & 65.7 \\
\hline 2007 & 80.4 & 78.6 & 82.1 & 48.9 & 42.5 & 53.5 & 54.3 & 45.2 & 64.4 \\
\hline 2008 & 80.2 & 78.9 & 81.5 & 52.3 & 46.4 & 56.0 & 63.2 & 63.9 & 62.5 \\
\hline 2009 & 78.6 & 80.2 & 77.1 & 49.4 & 36.8 & 57.6 & 64.3 & 62.0 & 66.7 \\
\hline 2010 & 76.3 & 75.9 & 76.7 & 57.5 & 53.8 & 60.9 & 61.8 & 55.2 & 67.7 \\
\hline 2011 & 79.8 & 74.9 & 84.6 & 49.6 & 45.8 & 54.5 & 64.2 & 56.9 & 69.5 \\
\hline \multicolumn{10}{|c|}{ Bachelor's degree or higher } \\
\hline 1980 & - & 一 & 一 & 一 & 一 & 一 & 一 & - & 一 \\
\hline 1985 & - & - & - & - & - & - & - & - & - \\
\hline 1990 & 42.2 & 47.6 & 37.4 & - & - & - & - & - & - \\
\hline 1995 & 43.1 & 42.0 & 44.5 & - & - & - & - & - & - \\
\hline 2000 & 54.3 & 55.5 & 53.1 & - & - & - & - & - & - \\
\hline 2005 & 60.0 & 58.5 & 61.4 & 16.4 & $14.5 !$ & $18.2 !$ & 28.0 & 24.5 & 32.1 \\
\hline 2006 & 59.6 & 58.7 & 60.4 & $9.5 !$ & $\ddagger$ & $\ddagger$ & 23.3 & 20.8 & 25.7 \\
\hline 2007 & 59.4 & 58.5 & 60.3 & $6.4 !$ & $\ddagger$ & $\ddagger$ & 26.3 & 23.3 & 29.6 \\
\hline 2008 & 57.9 & 54.1 & 61.6 & 14.3 & $17.7 !$ & $12.2 !$ & 26.6 & 25.7 & 27.7 \\
\hline 2009 & 56.4 & 55.2 & 57.6 & 15.9 & $15.2 !$ & 16.3 & 29.7 & 24.6 & 35.0 \\
\hline 2010 & 52.5 & 49.0 & 55.8 & 18.6 & $18.9 !$ & $18.4 !$ & 29.8 & 24.9 & 34.0 \\
\hline 2011 & 56.0 & 50.8 & 61.0 & 17.3 & $15.4 !$ & $19.7 !$ & 32.4 & 34.1 & 31.2 \\
\hline \multicolumn{10}{|l|}{ Master's degree or higher } \\
\hline 1995 & 10.9 & 12.6 & 8.9 & - & - & - & - & - & - \\
\hline 2000 & 15.5 & 17.2 & 13.9 & - & - & - & - & - & - \\
\hline 2005 & 16.9 & 19.7 & 14.4 & $\ddagger$ & $\#$ & $\ddagger$ & $7.0 !$ & $\ddagger$ & $10.0 !$ \\
\hline 2006 & 20.1 & 20.5 & 19.7 & $\ddagger$ & $\#$ & $\ddagger$ & 7.1 & $5.9 !$ & $8.3 !$ \\
\hline 2007 & 17.5 & 18.4 & 16.5 & \# & $\#$ & \# & $6.2 !$ & $9.8 !$ & $\ddagger$ \\
\hline 2008 & 19.9 & 20.9 & 18.9 & $\ddagger$ & \# & $\ddagger$ & $6.9 !$ & $7.8 !$ & $\ddagger$ \\
\hline 2009 & 21.1 & 20.4 & 21.7 & $\ddagger$ & $\#$ & $\ddagger$ & $6.5 !$ & $5.0 !$ & $7.9 !$ \\
\hline 2010 & 17.9 & 15.0 & 20.6 & $\ddagger$ & $\ddagger$ & $\ddagger$ & $5.3 !$ & $\#$ & $10.0 !$ \\
\hline 2011 & 16.7 & 18.0 & 15.4 & $\ddagger$ & $\ddagger$ & $\ddagger$ & 6.1 & $\ddagger$ & 9.9 \\
\hline
\end{tabular}

- Not available.

\# Rounds to zero.

! Interpret data with caution. The coefficient of variation (CV) for this estimate is 30 percent or greater.

f Reporting standards not met. Either there are too few cases or the coefficient of variation (CV) is 50 percent or greater.

1 Included in the totals but not shown separately are estimates for persons from other racial/ethnic groups.

NOTE: Detail may not sum to totals as estimates of educational attainment represent the percentage who achieved at least the cited credential. In 1992, the question on educational attainment was revised. Prior to 1992, a high school diploma meant completing 12 years of schooling; some college meant completing 1 or more years of college; a bachelor's degree meant completing 4 years of college; and data on attainment of a master's

degree were not available. From 1992 onward, a high school diploma means a high school diploma or equivalency certificate; some college means completing any college at all; and a bachelor's degree means earning a bachelor's degree. Race categories exclude persons of Hispanic ethnicity. For more information on race/ethnicity and educational attainment, see Appendix C - Commonly Used Measures. For more information on the Current Population Survey (CPS), see Appendix B - Guide to Sources.

SOURCE: U.S. Department of Commerce, Census Bureau, Current Population Survey (CPS), Annual Social and Economic Supplement, selected years, 1980-2011. 
Table A-49-1. Median annual earnings and percentage of full-time, full-year wage and salary workers ages 25-34, by educational attainment, sex, and race/ethnicity: Selected years, 1995-2010

\begin{tabular}{|c|c|c|c|c|c|c|c|c|c|}
\hline \multirow{2}{*}{$\begin{array}{l}\text { Educational attainment, sex, } \\
\text { and race/ethnicity }\end{array}$} & \multicolumn{8}{|c|}{ Median earnings [In constant 2010 dollars] } & \multirow{2}{*}{$\begin{array}{r}\text { Percentage of } \\
\text { labor force } \\
\text { participants } \\
\text { who worked } \\
\text { full-time for } \\
\text { a full year in } \\
2010^{1} \\
\end{array}$} \\
\hline & 1995 & 2000 & 2005 & 2006 & 2007 & 2008 & 2009 & 2010 & \\
\hline Total & $\$ 35,800$ & $\$ 38,000$ & $\$ 36,800$ & $\$ 37,000$ & $\$ 36,800$ & $\$ 36,500$ & $\$ 38,600$ & $\$ 37,400$ & 61.9 \\
\hline Less than high school completion ${ }^{2}$ & 22,700 & 22,900 & 22,900 & 21,600 & 23,100 & 21,600 & 21,200 & 21,000 & 44.9 \\
\hline High school diploma or equivalent & 29,700 & 31,700 & 31,100 & 31,300 & 30,500 & 30,400 & 30,400 & 29,900 & 57.0 \\
\hline Some college & 33,300 & 36,500 & 35,000 & 34,000 & 34,600 & 32,400 & 33,700 & 32,900 & 58.1 \\
\hline Associate's degree & 35,500 & 38,000 & 37,900 & 36,600 & 36,600 & 36,400 & 36,500 & 37,000 & 63.6 \\
\hline Bachelor's degree or higher & 47,200 & 50,600 & 49,000 & 48,500 & 50,300 & 50,600 & 50,700 & 48,700 & 71.4 \\
\hline Bachelor's degree & 44,300 & 50,500 & 45,600 & 47,000 & 47,100 & 46,600 & 45,700 & 45,000 & 71.2 \\
\hline Master's degree or higher & 56,700 & 60,700 & 55,800 & 54,100 & 58,500 & 55,600 & 60,200 & 54,700 & 71.7 \\
\hline Male & 38,500 & 40,500 & 39,100 & 37,900 & 39,900 & 40,500 & 40,700 & 39,900 & 64.5 \\
\hline $\begin{array}{l}\text { Less than high school } \\
\text { completion }{ }^{2}\end{array}$ & 25,400 & 25,200 & 24,500 & 23,700 & 24,200 & 24,300 & 23,000 & 24,000 & 47.4 \\
\hline $\begin{array}{l}\text { High school diploma or } \\
\text { equivalent }\end{array}$ & 34,300 & 36,500 & 33,400 & 32,400 & 32,400 & 32,400 & 33,400 & 32,800 & 60.6 \\
\hline Some college & 37,100 & 40,300 & 39,000 & 37,600 & 38,600 & 36,700 & 39,300 & 37,900 & 62.0 \\
\hline Associate's degree & 36,900 & 44,300 & 43,400 & 40,700 & 41,800 & 40,800 & 42,400 & 39,900 & 68.6 \\
\hline Bachelor's degree or higher & 53,200 & 58,100 & 55,800 & 53,700 & 54,200 & 55,600 & 55,300 & 52,800 & 75.0 \\
\hline Bachelor's degree & 50,000 & 56,700 & 50,200 & 53,300 & 52,500 & 53,600 & 51,300 & 49,800 & 75.4 \\
\hline Master's degree or higher & 63,300 & 69,500 & 61,400 & 62,600 & 64,900 & 65,100 & 70,400 & 64,200 & 74.0 \\
\hline Female & 31,200 & 35,100 & 33,500 & 33,500 & 34,600 & 34,400 & 35,500 & 34,900 & 58.7 \\
\hline $\begin{array}{l}\text { Less than high school } \\
\text { completion }{ }^{2}\end{array}$ & 18,500 & 19,000 & 18,800 & 19,300 & 18,700 & 16,700 & 19,300 & 17,800 & 39.4 \\
\hline equivalent & 25,200 & 27,700 & 26,700 & 25,500 & 25,300 & 25,200 & 25,400 & 25,000 & 51.1 \\
\hline Some college & 28,600 & 31,600 & 31,200 & 30,200 & 31,500 & 29,300 & 29,700 & 29,500 & 53.6 \\
\hline Associate's degree & 34,300 & 33,700 & 32,700 & 32,400 & 32,600 & 32,900 & 31,400 & 34,700 & 59.1 \\
\hline Bachelor's degree or higher & 42,600 & 45,600 & 44,400 & 44,300 & 45,100 & 45,500 & 45,700 & 44,000 & 68.0 \\
\hline Bachelor's degree & 39,900 & 44,200 & 41,900 & 43,100 & 41,900 & 42,200 & 40,800 & 40,000 & 67.2 \\
\hline Master's degree or higher & 49,400 & 52,600 & 52,400 & 51,800 & 52,800 & 51,400 & 54,900 & 49,800 & 70.0 \\
\hline White & 37,200 & 41,400 & 39,100 & 40,000 & 42,000 & 40,500 & 40,700 & 40,000 & 63.3 \\
\hline $\begin{array}{l}\text { Less than high school } \\
\text { completion }\end{array}$ & 25,100 & 26,300 & 25,600 & 27,000 & 25,200 & 25,900 & 25,100 & 25,000 & 39.5 \\
\hline $\begin{array}{l}\text { High school diploma or } \\
\text { equivalent }\end{array}$ & 31,400 & 35,000 & 33,400 & 32,400 & 31,500 & 31,600 & 32,500 & 32,000 & 57.1 \\
\hline Some college & 34,300 & 37,900 & 35,600 & 35,900 & 36,700 & 33,400 & 35,600 & 34,800 & 57.0 \\
\hline Associate's degree & 37,100 & 40,100 & 38,700 & 37,400 & 38,700 & 39,500 & 40,500 & 39,700 & 63.9 \\
\hline Bachelor's degree or higher & 48,600 & 50,600 & 49,800 & 48,500 & 50,400 & 50,600 & 50,700 & 49,500 & 71.7 \\
\hline Bachelor's degree & 45,800 & 50,600 & 45,800 & 47,900 & 47,200 & 47,500 & 45,700 & 45,900 & 71.5 \\
\hline Master's degree or higher & 56,900 & 60,600 & 55,800 & 53,900 & 57,500 & 55,500 & 58,500 & 54,300 & 72.3 \\
\hline
\end{tabular}

See notes at end of table. 
Table A-49-1. Median annual earnings and percentage of full-time, full-year wage and salary workers ages 25-34, by educational attainment, sex, and race/ethnicity: Selected years, 1995-2010-Continued

Median earnings [In constant 2010 dollars]

Percentage of

labor force

participants

who worked

full-time for

Educational attainment, sex

\begin{tabular}{|c|c|c|c|c|c|c|c|c|c|}
\hline and race/ethnicity & 1995 & 2000 & 2005 & 2006 & 2007 & 2008 & 2009 & 2010 & $2010^{1}$ \\
\hline Black & $\$ 30,000$ & $\$ 31,700$ & $\$ 31,900$ & $\$ 32,400$ & $\$ 31,500$ & $\$ 30,400$ & $\$ 30,500$ & $\$ 31,600$ & 57.7 \\
\hline Less than high school & & & & & & & & & \\
\hline completion $^{2}$ & 19,800 & 21,000 & 22,800 & 19,300 & 19,800 & 18,300 & 22,600 & 20,300 & 30.5 \\
\hline High school diploma or & & & & & & & & & \\
\hline equivalent & 25,700 & 27,700 & 25,600 & 27,000 & 27,200 & 26,300 & 25,400 & 25,000 & 53.6 \\
\hline Some college & 31,400 & 32,800 & 32,400 & 30,000 & 31,400 & 30,000 & 29,500 & 29,300 & 56.2 \\
\hline Associate's degree & 31,400 & 31,500 & 31,100 & 31,200 & 31,000 & 31,100 & 28,200 & 31,400 & 61.5 \\
\hline Bachelor's degree or higher & 39,200 & 43,800 & 43,300 & 42,800 & 41,800 & 44,900 & 45,300 & 41,000 & 72.4 \\
\hline Bachelor's degree & 37,200 & 41,500 & 39,400 & 39,800 & 41,000 & 40,500 & 40,700 & 39,500 & 71.1 \\
\hline Master's degree or higher & 47,400 & 51,100 & 48,100 & 51,200 & 47,300 & 53,100 & 54,000 & 49,100 & 76.5 \\
\hline Hispanic & 26,800 & 28,400 & 27,900 & 28,000 & 28,400 & 29,300 & 29,300 & 30,000 & 59.4 \\
\hline Less than high school & & & & & & & & & \\
\hline $\begin{array}{l}\text { complefion² } \\
\text { High school diploma or }\end{array}$ & 21,300 & 21,500 & 22,200 & 21,000 & 21,600 & 20,200 & 20,200 & 19,900 & 50.4 \\
\hline equivalent & 26,900 & 29,100 & 26,700 & 27,800 & 27,100 & 27,100 & 26,200 & 27,800 & 59.0 \\
\hline Some college & 27,900 & 33,500 & 35,000 & 31,800 & 32,500 & 30,400 & 32,800 & 31,700 & 64.5 \\
\hline Associate's degree & 34,000 & 37,500 & 37,900 & 34,100 & 31,500 & 32,300 & 31,200 & 33,900 & 65.1 \\
\hline Bachelor's degree or higher & 42,600 & 46,000 & 45,500 & 45,300 & 45,500 & 45,200 & 46,300 & 44,100 & 68.1 \\
\hline Bachelor's degree & 40,200 & 44,300 & 44,100 & 43,100 & 42,100 & 42,100 & 45,100 & 41,700 & 68.1 \\
\hline Master's degree or higher & $\ddagger$ & 48,300 & 56,200 & 51,100 & 60,900 & 52,600 & 53,800 & 48,800 & 68.2 \\
\hline Asian $^{3}$ & 36,200 & 45,400 & 44,500 & 48,400 & 47,000 & 50,200 & 50,000 & 45,700 & 65.1 \\
\hline Less than high school & & & & & & & & & \\
\hline completion² & $\ddagger$ & $\ddagger$ & $\ddagger$ & $\ddagger$ & $\ddagger$ & $\ddagger$ & $\ddagger$ & $\ddagger$ & $\ddagger$ \\
\hline $\begin{array}{l}\text { High school diploma or } \\
\text { equivalent }\end{array}$ & 28,400 & 31,600 & 30,000 & 29,600 & 29,300 & 28,300 & 26,300 & 29,200 & 55.9 \\
\hline Some college & 26,500 & 36,400 & 33,100 & 34,200 & 36,600 & 33,400 & 38,600 & 34,700 & 58.2 \\
\hline Associate's degree & 28,600 & 37,400 & 38,000 & 38,500 & 36,900 & 32,000 & 36,900 & $\ddagger$ & 56.5 \\
\hline Bachelor's degree or higher & 47,100 & 62,400 & 55,800 & 58,500 & 57,800 & 60,300 & 60,200 & 59,900 & 71.1 \\
\hline Bachelor's degree & 43,100 & 56,800 & 55,800 & 53,500 & 51,800 & 55,300 & 50,600 & 54,000 & 72.2 \\
\hline Master's degree or higher & 54,300 & 72,400 & 60,800 & 64,700 & 68,100 & 70,100 & 71,100 & 68,300 & 69.4 \\
\hline Native Hawaiian/Pacific Islander ${ }^{3}$ & - & - & $\ddagger$ & 31,500 & 36,200 & $\ddagger$ & $\ddagger$ & $\ddagger$ & 62.2 \\
\hline American Indian/Alaska Native & 33,200 & 31,600 & 32,900 & 28,100 & 32,300 & 29,200 & 30,500 & 31,500 & 52.9 \\
\hline Two or more races & - & 一 & 38,000 & 37,100 & 34,100 & 34,000 & 34,200 & 34,800 & 60.2 \\
\hline
\end{tabular}

- Not available.

$\ddagger$ Reporting standards not met. Either there are too few cases or the coefficient of variation (CV) is 50 percent or greater.

Full-time, full-year wage workers as a percentage of the population ages 25-34 who reported working or looking for work in 2010.

2 Young adults in this category did not earn a high school diploma or receive alternative credentials such as a General Educational Development

(GED) certificate.

${ }^{3}$ For 1995 and 2000, data for Asians and Pacific Islanders were not reported separately; therefore, Pacific Islanders are included with Asians during this period.

NOTE: Earnings are presented in constant dollars by means of the Consumer Price Index (CPI) to eliminate inflationary factors and to allow for direct comparison across years. For more information on the CPI, see Appendix C - Finance. Full-year workers refers to those who were employed 50 or more weeks during the previous year; full-time workers refers to those who were usually employed 35 or more hours per week. Beginning in 2005 , estimates were calculated using a revised method. Therefore, estimates in this table differ slightly from previously published figures. For more information on the Current Population Survey, see Appendix B - Guide to Sources. Race categories exclude persons of Hispanic ethnicity. Estimates for educational attainment categories for Native Hawaiian/Pacific Islander, American Indian/Alaska Native, and Two or more races subgroups did not meet reporting standards. For more information on race/ethnicity, see Appendix C - Commonly Used Measures.

SOURCE: U.S. Department of Commerce, Census Bureau, Current Population Survey (CPS), Annual Social and Economic Supplement, selected years, 1996-2011. 


\section{APPENDIX B Guide to Sources}




\section{National Center for Education Statistics (NCES) Sources}

\section{Common Core of Data}

The Common Core of Data (CCD) is the Department of Education's primary database on public elementary and secondary education in the United States. It is a comprehensive, annual, national statistical database of all public elementary and secondary schools and school districts containing data designed to be comparable across all states. This database can be used to select samples for other NCES surveys and provide basic information and descriptive statistics on public elementary and secondary schools and schooling in general. Some of the CCD's component surveys date back to the 1930s. The integrated CCD was first implemented in the 1986-87 school year.

The CCD collects statistical information annually from approximately 100,000 public elementary and secondary schools and approximately 18,000 public school districts (including supervisory unions and regional education service agencies) in the 50 states, the District of Columbia, Department of Defense dependents schools (DoDDS), and the outlying areas. Three categories of information are collected in the CCD survey: general descriptive information on schools and school districts; data on students and staff; and fiscal data. The general descriptive information includes name, address, phone number, and type of locale; the data on students and staff include selected demographic characteristics; and the fiscal data pertain to revenues and current expenditures.

The EDFacts data collection system is the primary collection tool for the CCD. NCES works collaboratively with the Department of Education's Performance Information Management Service to develop the CCD collection procedures and data definitions. Coordinators from State Education Agencies (SEAs) submit the CCD data at different levels (school, agency, and state) to the EDFacts collection system. Prior to submitting CCD files to EDFacts, SEAs must collect and compile information from their respective Local Education Agencies (LEAs) through established administrative records systems within their state or jurisdiction.

Once SEAs have completed their submissions, the CCD survey staff analyzes and verifies the data for quality assurance. Even though the CCD is a universe collection and thus not subject to sampling errors, nonsampling errors can occur. The two potential sources of nonsampling errors are nonresponse and inaccurate reporting. NCES attempts to minimize nonsampling errors through the use of annual training of SEA coordinators, extensive quality reviews, and survey editing procedures. In addition, each year, SEAs are given the opportunity to revise their state-level aggregates from the previous survey cycle.
The CCD survey consists of six components: the Public Elementary/Secondary School Universe Survey, the Local Education Agency (School District) Universe Survey, the State Aggregate Nonfiscal Survey of Public Elementary/ Secondary Education, the National Public Education Financial Survey (NPEFS), the School District Fiscal Data Survey, and the Teacher Compensation Survey.

\section{Public Elementary/Secondary School Universe Survey}

The Public Elementary/Secondary School Universe Survey collects information on all public schools providing education services to prekindergarten, kindergarten, grade $1-12$, and ungraded students. Data include the school's operating status, locale, and type, as well as the student enrollment for every grade; number of students in each racial/ethnic group and eligible for free-lunch programs; and number of reported full-time-equivalent (FTE) teachers.

\section{Local Education Agency (School District) Universe}

The Local Education Agency Universe Survey collects information on all school districts and administrative units providing education services to prekindergarten, kindergarten, grade 1-12, and ungraded students. Data include county location, metropolitan status, and type; the total number of students enrolled for every grade; number of ungraded students; number of English language learner (ELL) students served in appropriate programs; and number of instructional, support, and administrative staff. Data also include the number of high school graduates, other completers, and dropouts. Since 2007-08, the high school dropout and completion data have been separated from the LEA universe survey data and released as standalone data.

\section{State Nonfiscal Survey of Public Elementary/ Secondary Education}

The State Nonfiscal Survey of Public Elementary/ Secondary Education collects information on all students and staff aggregated to the state level, including the number of students by grade level; counts of FTE staff by major employment category; and high school completers by race/ethnicity.

\section{National Public Education Financial Survey}

The National Public Education Financial Survey (NPEFS) collects detailed finance data at the state level, including average daily attendance, school district revenues by source (local, state, federal), and expenditures by function (instruction, support services, and noninstruction) and object (salaries, supplies, etc.). It also reports capital outlay and debt service expenditures.

\section{School District Finance Survey}

The School District Finance Survey collects detailed data by school district, including revenues by source, 
expenditures by function and subfunction, and enrollment.

\section{Teacher Compensation Survey}

The Teacher Compensation Survey collects total compensation, teacher status, and demographic data about individual teachers from multiple states.

Further information about the CCD and its survey components is available at http://www.nces.ed.gov/ccd/.

\section{Fast Response Survey System}

The Fast Response Survey System (FRSS) was established in 1975 to collect issue-oriented data quickly, with a minimal burden on respondents. The FRSS, whose surveys collect and report data on key education issues at the elementary and secondary levels, was designed to meet the data needs of Department of Education analysts, planners, and decisionmakers when information cannot be collected quickly through NCES's large recurring surveys. Findings from FRSS surveys have been included in congressional reports, testimony to congressional subcommittees, NCES reports, and other Department of Education reports. The findings are also often used by state and local education officials.

Data collected through FRSS surveys are representative at the national level, drawing from a universe that is appropriate for each study. The FRSS collects data from state education agencies and national samples of other educational organizations and participants, including local education agencies, public and private elementary and secondary schools, elementary and secondary school teachers and principals, and public libraries and school libraries. To ensure a minimal burden on respondents, the surveys are generally limited to three pages of questions, with a response burden of about 30 minutes per respondent. Sample sizes are relatively small (usually about 1,000 to 1,500 respondents per survey) so that data collection can be completed quickly.

Further information about the FRSS is available at http:// nces.ed.gov/surveys/frss.

\section{Integrated Postsecondary Education Data System}

The Integrated Postsecondary Education Data System (IPEDS) is the core program that NCES uses for collecting data on postsecondary education. IPEDS is a single, comprehensive system that encompasses all identified institutions whose primary purpose is to provide postsecondary education. Before IPEDS, some of the same information was collected through the Higher Education General Information Survey (HEGIS).

IPEDS consists of eight interrelated components that are collected in the fall, winter, and spring each year. Data on institutional characteristics and completions are collected in the fall. Data on employees by assigned position (EAP), salaries, and fall staff are collected in the winter. Data on enrollment, student financial aid, finances, and graduation rates are collected in the spring. During the winter 2005-06 survey, the EAP, fall staff, and salaries components were merged into the human resources component. In 2007-08, the enrollment component was broken into two separate components: 12-month enrollment (collected in the fall) and fall enrollment (collected in the spring).

Researchers can use IPEDS to analyze information on (1) enrollments of undergraduates, first-time freshmen, and graduate and first-professional students by race/ ethnicity and sex; (2) institutional revenue and expenditure patterns by source of income and type of expense; (3) completions (awards) by level of program, level of award, race/ethnicity, and sex; (4) characteristics of postsecondary institutions, including tuition, room and board charges, and calendar systems; (5) status of career and technical education programs; and (6) other issues of interest.

Beginning in 1993, the IPEDS survey completion became mandatory for all postsecondary institutions with a Program Participation Agreement (PPA) with the Office of Postsecondary Education (OPE), U.S. Department of Education - that is, institutions that participate in or are eligible to participate in any federal student financial assistance program authorized by Title IV of the Higher Education Act of 1965, as amended (20 USC $1094[a]$ [17]). Such programs include Pell Gants and Stafford Loans given to students at 4-year and higher (4 year), 2-but-less-than 4-year (2 year), and less than 2 -year postsecondary institutions, including degree and non-degree granting institutions. For institutions not eligible to participate in Title IV programs, participation in the IPEDS is voluntary. Prior to 1993 , only nationallevel estimates from a sample of institutions are available for private less-than-2-year institutions.

Further information about the IPEDS classification of educational institutions is available in Appendix C Commonly Used Measures. Further information about IPEDS is available at http://nces.ed.gov/ipeds/.

\section{National Assessment of Educational Progress}

The National Assessment of Educational Progress (NAEP) is a series of cross-sectional studies initially implemented in 1969 to assess the educational achievement of U.S. students and monitor changes in those achievements. At the national level, NAEP is divided into two assessments: long-term trend NAEP and main NAEP.

\section{Long-term trend}

NAEP long-term trend assessments are designed to inform the nation of changes in the basic achievement 
of America's youth. Nationally representative samples of students have been assessed in science, mathematics, and reading at ages 9, 13, and 17 since the early 1970s. Students were assessed in writing at grades 4, 8, and 11 between 1984 and 1996. To measure trends accurately, assessment items (mostly multiple choice) and procedures have remained unchanged since the first assessment in each subject. Recent trend assessments were conducted in 1994, 1996, 1999, 2004, and 2008. Results are reported as average scale scores for the nation, for regions, and for various subgroups of the population, such as racial and ethnic groups.

\section{Main}

In the main national NAEP, a nationally representative sample of students is assessed at grades 4, 8, and 12 in various academic subjects. Student assessments are not designed to permit comparison across grades. The main state NAEP assessed students at both grades 4 and 8 in at least one subject in 1990, 1992, 1994, 1996, 1998, 2000, 2002, and 2003. Since 2003, the main state NAEP has assessed students in at least two subjects, reading and mathematics, every 2 years at grades 4 and 8 .

The assessments are based on frameworks developed by the National Assessment Governing Board (NAGB). Items include both multiple-choice and constructed-response (requiring written answers) items. Results are reported in two ways: by average score and by achievement level. Average scores are reported for the nation, for participating states and jurisdictions, and for subgroups of the population. Percentages of students meeting certain achievement levels are also reported for these groups. The achievement levels, developed by NAGB, are at or above Basic, at or above Proficient, and at or above Advanced.

From 1990 until 2001, main NAEP was conducted for states and other jurisdictions that chose to participate.

In 2002, under the provisions of the No Child Left Behind Act of 2001, all states began to participate in main NAEP and an aggregate of all state samples replaced the separate national sample.

Mathematics assessments were administered in 2000, 2003, 2005, 2007, 2009, and 2011. In 2005, NAGB called for the development of a new mathematics framework. The revisions made to the mathematics framework for the 2005 assessment were intended to reflect recent curricular emphases and better assess the specific objectives for students at each grade level.

The revised mathematics framework focuses on two dimensions: mathematical content and cognitive demand. By considering these two dimensions for each item in the assessment, the framework ensures that NAEP assesses an appropriate balance of content, as well as a variety of ways of knowing and doing mathematics.
For grades 4 and 8 , comparisons over time can be made among the assessments prior to and after the implementation of the 2005 framework. The changes to the grade 12 assessment were too drastic to allow the results to be directly compared with previous years. The changes to the grade 12 assessment included adding more questions on algebra, data analysis, and probability to reflect changes in high school mathematics standards and coursework, as well as the merging of the measurement and geometry content areas. The reporting scale for grade 12 mathematics was changed from $0-500$ to $0-300$.

For more information regarding the 2005 framework revisions, see http://nces.ed.gov/nationsreportcard/ mathematics/whatmeasure.asp.

Reading assessments were administered in 2000, 2002, 2003, 2005, 2007, 2009, and 2011. In 2009, a new framework was developed for the 4th-, 8th-, and 12 th-grade NAEP reading assessments.

Both a content alignment study and a reading trend or bridge study were conducted to determine if the "new" assessment was comparable to the "old" assessment. Overall, the results of the special analyses suggested that the old and new assessments were similar in terms of their item and scale characteristics and the results they produced for important demographic groups of students. Thus, it was determined that the results of the 2009 reading assessment could still be compared to those from earlier assessment years, thereby maintaining the trend lines first established in 1992. For more information regarding the 2009 reading framework revisions, see http://nces.ed.gov/nationsreportcard/reading/ whatmeasure.aspnationsreportcard/reading/whatmeasure. asp.

Science assessments were administered in 1995-96, 2000, 2005, and 2009. In 2009, a new framework was developed for the 4th-, 8th-, and 12th-grade NAEP science assessment. The 2009 science framework organizes science content into three broad content areas, physical science, life science, and Earth and space sciences, thus keeping the content current with key developments in science curriculum standards, assessments, and research.

The 2009 framework change rendered the results from the 2009 assessment not comparable to the results from previous assessment years. For more information regarding the 2009 science framework and the specific content areas, see http://www.nagb.org/publications/ frameworks/science-09.pdf.

Other assessments administered by NAEP include the geography assessments in 1993-94, 2000-01, and 200910; the U.S. history assessments in 2001, 2006, and 2010; and the civics assessments in 1998, 2006, and 2010.

For additional information on NAEP, including technical aspects of scoring and assessment validity and more 
specific information on achievement levels, see http://nces. ed.gov/nationsreportcard/.

\section{Analysis of Special Needs Students}

Until 1996, the main NAEP assessments excluded certain subgroups of students identified as "special needs students," that is, students with disabilities and students with limited-English-proficiency. For the 1996 and 2000 mathematics assessments and the 1998 and 2000 reading assessments, the main NAEP included a separate assessment with provisions for accommodating these students (e.g., extended time, small group testing, mathematics questions read aloud, etc.). Thus, for these years, there are results for both the unaccommodated assessment and the accommodated assessment. For the 2002, 2003, and 2005 reading assessments and the 2003 and 2005 mathematics assessments, the main NAEP did not include a separate unaccommodated assessment-only a single accommodated assessment was administered. The switch to a single accommodated assessment instrument was made after it was determined that accommodations in NAEP did not have any significant effect on student scores.

Since 1992, the percentage of students with disabilities excluded from the NAEP reading assessment has ranged from 3 to 5 percent. English language learners were excluded at a rate of between 1 and 2 percent.

Since 2005, the percentage of students with disabilities excluded from the NAEP mathematics assessment has ranged from 2 to 4 percent. English language learners were excluded at a rate of 1 percent or less.

Exclusion rates were also recorded for the science, geography, history, and civics assessments. For students with disabilities, the exclusion rates from these assessments generally ranged from 1 to 3 percent. The science assessment and accommodated history assessment had exclusion rates as high as 4 percent for students with disabilities. The unaccommodated geography and history assessments had exclusion rates as high as 7 percent. For English language learners, exclusion rates ranged from less than 1 to 2 percent.

Further information about exclusion rates for specific assessments and years is available at http://nces.ed.gov/ nationsreportcard/about/inclusion.asp.

\section{Private School Universe Survey}

The purposes of the Private School Universe Survey (PSS) data collection activities are (1) to build an accurate and complete list of private schools to serve as a sampling frame for NCES sample surveys of private schools and (2) to report data on the total number of private schools, teachers, and students in the survey universe. Begun in 1989 under the U.S. Census Bureau, the PSS has been conducted every 2 years, and data for the 1989-90,
1991-92, 1993-94, 1995-96, 1997-98, 1999-2000, 2001-02, 2003-04, 2005-2006, 2007-08, and 2009-10 school years have been released.

The target population for this universe survey is all private schools in the United States that meet the PSS criteria of a private school (i.e., the private school is an institution that provides instruction for any of grades $\mathrm{K}$ through 12 , has one or more teachers to give instruction, is not administered by a public agency, and is not operated in a private home). The survey universe is composed of schools identified from a variety of sources. The main source is a list frame initially developed for the 1989-90 PSS. The list is updated regularly by matching it with lists provided by nationwide private school associations, state departments of education, and other national guides and sources that list private schools. The other source is an area frame search in approximately 124 geographic areas, conducted by the U.S. Census Bureau.

The PSS groups elementary and secondary schools according to one of seven program emphases: regular, Montessori, special program emphasis, special education, vocational, alternative, and early childhood.

Private schools are assigned to one of three major categories (Catholic, other religious, or nonsectarian) and, within each major category, one of three subcategories based on the school's religious affiliation provided by respondents.

Further information on the PSS is available at http://nces. ed.gov/surveys/pss.

\section{Program for International Student Assessment}

Within the United States, NCES is responsible for administering assessments for the Program for International Student Assessment (PISA). PISA is a system of international assessments that focus on 15-year-olds' capabilities in reading literacy, mathematics literacy, and science literacy. PISA also includes measures of general, or cross-curricular, competencies such as learning strategies. PISA emphasizes functional skills that students have acquired as they near the end of mandatory schooling. PISA is organized by the Organization for Economic Co-operation and Development (OECD), an intergovernmental organization of industrialized countries, and was administered for the first time in 2000, when 43 countries participated. In 2003, forty-one countries participated in the assessment; in 2006, fifty-seven jurisdictions (30 OECD members and 27 nonmembers) participated; and in 2009, sixty-five jurisdictions (34 OECD members and 31 nonmembers) participated.

PISA is a 2-hour paper-and-pencil exam. Assessment items include a combination of multiple-choice and open-ended 
questions that require students to come up with their own response. PISA scores are reported on a scale with a mean score of 500 and a standard deviation of 100 .

PISA is implemented on a 3-year cycle that began in 2000. Each PISA assessment cycle focuses on one subject in particular, although all three subjects are assessed every 3 years. These cycles allow countries to compare changes in trends for each of the three subject areas over time.

In the first cycle, PISA 2000, reading literacy was the major focus, occupying roughly two-thirds of assessment time. For 2003, PISA focused on mathematics literacy as well as the ability of students to solve problems in real-life settings. In 2006, PISA focused on science literacy. In 2009, PISA focused on reading literacy again.

To implement PISA, each of the participating countries scientifically draws a nationally representative sample of 15 -year-olds, regardless of grade level. In the United States, nearly 5,600 students from public and nonpublic schools took the PISA 2006 assessment.

In each country, the assessment is translated into the primary language of instruction; in the United States, all materials are written in English.

For more detailed information on sampling, administration, response rates, and other technical issues related to PISA data, see http://nces.ed.gov/ pubs2011/2011004.pdf.

The OECD developed the PISA 2009 Assessment Framework: Key Competencies in Reading, Mathematics, and Science to design the PISA 2009 assessment in a collaborative effort of the PISA Governing Board and an international consortium. The PISA 2009 framework acts as a blueprint for the assessment, outlining what should be assessed.

Reading literacy in PISA 2009 is defined as "understanding, using, reflecting on, and engaging with written texts in order to achieve one's goals, to develop one's knowledge and potential, and to participate in society."

Mathematics literacy in PISA 2009 is defined as "an individual's capacity to identify and understand the role that mathematics plays in the world, to make well-founded judgments and to use and engage with mathematics in ways that meet the needs of that individual's life as a constructive, concerned and reflective citizen."

Science literacy in PISA 2009 is defined as "scientific knowledge and use of that knowledge to identify questions, to acquire new knowledge, to explain scientific phenomena, and to draw evidence based conclusions about science-related issues, understanding of the characteristic features of science as a form of human knowledge and inquiry, awareness of how science and technology shape our material, intellectual, and cultural environments, and willingness to engage in science-related issues, and with the ideas of science, as a reflective citizen." Details on the PISA 2009 framework and the reading, science, and mathematics literacy competencies can be found at http://www.oecd.org/ dataoecd/11/40/44455820.pdf.

The PISA 2000 and 2009 OECD averages used in the analysis of trends in reading literacy scores over time are based on the averages of the 27 OECD countries with comparable data for 2000 and 2009. As a result, the reading literacy OECD average score for PISA 2000 differs from previously published reports and the reading literacy OECD average score for PISA 2009 differs from the OECD average score used for analyses other than trend comparisons. The seven current OECD members not included in the OECD average for trend analysis include the Slovak Republic and Turkey, which joined PISA in 2003; Estonia and Slovenia, which joined PISA in 2006; Luxembourg, which experienced substantial changes in its assessment conditions between 2000 and 2003; and the Netherlands and the United Kingdom, which did not meet the PISA response rate standards in 2000. Though reading literacy scores can be compared for all PISA administrative cycles (2000, 2003, 2006, and 2009), the U.S. averages in 2000 and 2009 are compared with OECD average scores in 2000 and 2009 because reading literacy was the major domain assessed in those years.

The PISA mathematics framework was revised in 2003. Because of changes in the framework, it is not possible to compare mathematics learning outcomes from PISA 2000 with those from PISA 2003, 2006, and 2009. The PISA science framework was revised in 2006. Because of changes in the framework, it is not possible to compare science learning outcomes from PISA 2000 and 2003 with those from PISA 2006 and 2009. Details on the changes to PISA since 2000 can be found at http://www.oecd.org/document/61/0,374

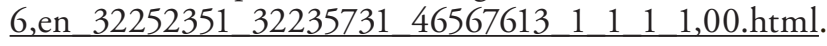

The PISA 2003 and 2009 OECD averages used in the analysis of trends in mathematics literacy scores over time are based on the 29 OECD countries with comparable data for 2003 and 2009. The five current members not included in the OECD average for trend analysis include Chile, Estonia, Israel, Slovenia, which did not participate in 2003, and the United Kingdom, which did not meet PISA response rate standards for the 2003 assessment.

For science literacy trends, all 34 OECD countries are used.

The OECD excluded the data for Austria from the trend analysis in PISA 2009 Results: Learning Trends - Changes in Student Performance Since 2000 (Volume V) because of a concern over a data collection issue in 2009; however, after consultation with Austrian officials, NCES kept the Austrian data in the U.S. trend reporting. 
For more information on the OECD, see Appendix C International Education Definitions.

Further information about PISA is available at http://nces. ed.gov/Surveys/PISA and http://www.pisa.oecd.org.

\section{Schools and Staffing Survey}

The Schools and Staffing Survey (SASS) is a set of linked questionnaires used to collect data on the nation's public and private elementary and secondary teaching force, characteristics of schools and school principals, demand for teachers, and school/school district policies. SASS data are collected through a mail questionnaire with telephone follow-up. SASS was first conducted for NCES by the Census Bureau during the 1987-88 school year. SASS subsequently was conducted in 1990-91, 1993-94, 1999-2000, 2003-04, and 2007-08. The 1990-91, 1993-94, 1999-2000, 2003-04, and 2007-08 SASS also obtained data on Bureau of Indian Education (BIE) schools (schools funded or operated by the BIE). The universe of charter schools in operation in 1998-99 was given the Charter School Questionnaire to complete as part of the 1999-2000 SASS. In subsequent SASS administrations, charter schools were not administered a separate questionnaire, but were included in the public school sample.

Teacher certification is one way in which SASS stratifies the teacher subgroups. The regular certification category includes regular or standard state certificates and advanced professional certificates (for both public and private school teachers) and full certificates granted by an accrediting or certifying body other than the state (for private school teachers only). Probationary certificates are for those who have satisfied all requirements except the completion of a probationary period. Provisional certificates are for those who are still participating in an alternative certification program. Temporary certificates are for those who require additional college coursework and/or student teaching. Waivers or emergency certificates are for those with insufficient teacher preparation who must complete a regular certification program in order to continue teaching. No certification indicates that the teacher did not hold any certification in the state where the teacher had taught.

Further information on SASS is available at http://nces. ed.gov/surveys/sass.

\section{School Survey on Crime and Safety}

The School Survey on Crime and Safety (SSOCS) is administered to public primary, middle, high, and combined school principals in the spring of evennumbered school years. SSOCS is administered at the end of the school year to allow principals to report the most complete information possible. SSOCS was first administered in the spring of the 1999-2000 school year (SSOCS:2000). It has since been administered in the spring of the 2003-04, 2005-06, 2007-08, and 2009-10 school years (SSOCS:2004, SSOCS:2006, SSOCS:2008, and SSOCS:2010). SSOCS focuses on incidents of specific crimes/offenses and a variety of specific discipline issues in public schools. It also covers characteristics of school policies, school violence prevention programs and policies, and school characteristics that have been associated with school crime. The survey was conducted with a nationally representative sample of regular public elementary, middle, and high schools in the 50 states and the District of Columbia. Special education, alternative, and vocational schools; schools in the other jurisdictions; and schools that taught only prekindergarten, kindergarten, or adult education were not included in the sample.

Further information about SSOCS is available at http:// nces.ed.gov/surveys/ssocs.

\section{Non-NCES Sources}

\section{American Community Survey (ACS)}

The Census Bureau introduced the American Community Survey (ACS) in 1996. Fully implemented in 2005, it provides a large monthly sample of demographic, socioeconomic, and housing data comparable in content to the Long Form of the Decennial Census. Aggregated over time, these data will serve as a replacement for the Long Form of the Decennial Census. The survey includes questions mandated by federal law, federal regulations, and court decisions.

Since 2005, the survey has been mailed to approximately 250,000 addresses in the United States and Puerto Rico each month, or about 2.5 percent of the population annually. A larger proportion of addresses in small governmental units (e.g., American Indian reservations, small counties, and towns) also receive the survey. The monthly sample size is designed to approximate the ratio used in the 2000 Census, which requires more intensive distribution in these areas. The ACS covers the U.S. resident population, which includes the entire civilian, noninstitutionalized population; incarcerated persons; institutionalized persons; and the active duty military who are in the United States. In 2006, the ACS began interviewing residents in group quarter facilities. Institutionalized group quarters include adult and juvenile correctional facilities, nursing facilities, and other health care facilities. Noninstitutionalized group quarters include college and university housing, military barracks, and other noninstitutional facilities such as workers and religious group quarters and temporary shelters for the homeless.

National-level data from the ACS are available from 2000 onward. Annual results were available for areas with populations of 65,000 or more beginning in the summer of 2006; for areas with populations of 20,000 or more in the summer of 2008; and for all areas-down to the census tract level. This schedule is based on the time it 
will take to collect data from a sample size large enough to produce accurate results for different size geographic units.

Further information about the ACS is available at http:// www.census.gov/acs/www/.

\section{Current Population Survey}

The Current Population Survey (CPS) is a monthly survey of about 60,000 households conducted by the U.S. Census Bureau for the Bureau of Labor Statistics. The CPS is the primary source of information of labor force statistics for the U.S. noninstitutionalized population (e.g., excludes military personnel and their families living on bases and inmates of institutions). In addition, supplemental questionnaires are used to provide further information about the U.S. population. Specifically, in October, detailed questions regarding school enrollment and school characteristics are asked. In March, detailed questions regarding income are asked.

The current sample design, introduced in July 2001, includes about 72,000 households. Each month about 58,900 of the 72,000 households are eligible for interview, and of those, 7 to 10 percent are not interviewed because of temporary absence or unavailability. Information is obtained each month from those in the household who are 15 years of age and older and demographic data are collected for children $0-14$ years of age. Prior to July 2001, data were collected in the CPS from about 50,000 dwelling units. The samples are initially selected based on the decennial census files and are periodically updated to reflect new housing construction.

The estimation procedure employed for monthly CPS data involves inflating weighted sample results to independent estimates of characteristics of the civilian noninstitutional population in the United States by age, sex, and race. These independent estimates are based on statistics from decennial censuses; statistics on births, deaths, immigration, and emigration; and statistics on the population in the armed services.

\section{Supplemental Questionnaires}

Each year, the Annual Social and Economic (ASEC) Supplement and October supplemental questionnaires contain questions of relevance to education policy. The ASEC Supplement, formerly known as the March CPS Supplement, is a primary source of detailed information on income and work experience in the United States. The October Supplement routinely gathers data on school enrollment, school characteristics, and educational attainment for elementary, secondary, and postsecondary education. Related data are also collected about preschooling and the general adult population. In addition, NCES funds additional items on educationrelated topics such as language proficiency, disabilities, computer use and access, student mobility, and private school tuition. Responses are collected for all household members age 3 and over.

CPS interviewers initially used printed questionnaires. However, since 1994, the Census Bureau has used Computer-Assisted Personal and Telephone Interviewing (CAPI and CATI) to collect data. These technologies allow interviewers to administer a complex questionnaire with increasing consistency and reductions in interviewer error. In 1994, the survey methodology for CPS was changed, and weights were adjusted. Further information about the CPS data collections is available at http://www. census.gov/apsd/techdoc/cps/cps-main.html.

\section{Monitoring the Future Survey}

The National Institute on Drug Abuse of the U.S. Department of Health and Human Services is the primary supporter of the long-term study entitled Monitoring the Future: A Continuing Study of American Youth, conducted by the University of Michigan Institute for Social Research. One component of the study deals with student drug abuse. Results of the national sample survey have been published annually since 1975 .

Approximately 50,000 public and private school students are surveyed each year. Students complete self-administered questionnaires given to them in their classrooms by University of Michigan personnel. Each year, 8th-, 10th-, and 12th-graders are surveyed (12th-graders since 1975, and 8th-and 10th-graders since 1991). The 8th- and 10th-grade surveys are anonymous, while the 12 th-grade survey is confidential. The 10th-grade samples involve about 17,000 students in 140 schools each year, while the 8 th-grade samples have approximately 18,000 students in about 150 schools. The 12th-grade sample includes about 16,000 students in approximately 133 schools. Beginning with the class of 1976, a randomly selected sample from each senior class has been followed in the years after high school on a continuing basis.

From 1990 to 2010, the student response rate for 10th-graders ranged from 85 to 89 percent, and the student response rate for 12th-graders ranged from 79 to 86 percent.

Further information on Monitoring the Future is available at http://www.monitoringthefuture.org. 
This page intentionally left blank. 
300 The Condition of Education 2012 


\section{APPENDIX C Notes}

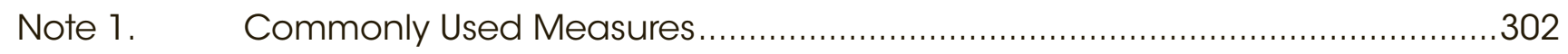

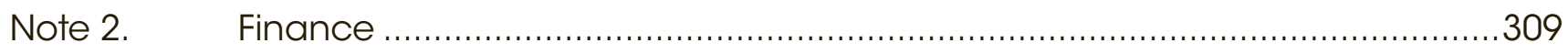

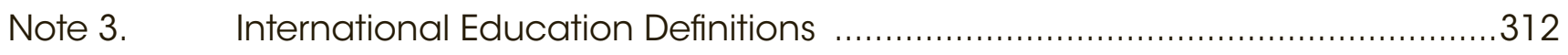




\section{Commonly Used Measures}

Certain common measures such as race/ethnicity, poverty, and region are used in the various surveys cited in The Condition of Education 2012. The definitions for these variables can vary across surveys and sometimes between different time periods of a single survey. This note describes how several common measures used in various indicators in this volume are defined in each of the surveys.

\section{Race/Ethnicity}

The categories denoting race and ethnicity in The Condition of Education are in accordance with the 1997 Office of Management and Budget (OMB) standard classification scheme. The 1997 standards emphasize self-reporting or self-identification as the preferred method for collecting data on race and ethnicity. However, while the federal categories provide a standardized format for purposes of collecting and presenting data on race and ethnicity, the standard was not designed to capture the full complexity of race and ethnicity in the United States.

Under the OMB standards, "Hispanic or Latino" is an ethnicity category, not a race category. Agencies that collect data on race and ethnicity separately must collect data on Hispanic ethnicity regardless of race. Thus if respondents are classified as Hispanic, they are not categorized into racial groups.

Ethnicity is categorized as follows:

- Hispanic or Latino: A person of Cuban, Mexican, Puerto Rican, South or Central American, or other Spanish culture or origin, regardless of race.

Race categories presented in The Condition of Education 2012 exclude persons of Hispanic ethnicity.

Racial groupings are as follows:

American Indian or Alaska Native: A person having origins in any of the original peoples of North and South America (including Central America) who maintains tribal affiliation or community attachment.

- Asian: A person having origins in any of the original peoples of the Far East, Southeast Asia, and the Indian subcontinent; this includes, for example, people from Cambodia, China, India, Japan, Korea, Malaysia, Pakistan, the Philippines, Thailand, and Vietnam.

- Black or African American: A person having origins in any of the Black racial groups of Africa.

- Native Hawaiian or Other Pacific Islander: A person having origins in any of the original peoples of Hawaii, Guam, Samoa, or other Pacific Islands.
White: A person having origins in any of the original peoples of Europe, North Africa, or the Middle East.

- Two or more races: A person who reported any combination of two or more races and not Hispanic/ Latino ethnicity.

In The Condition of Education, the following terms are typically used to represent the above categories: White, Black, Hispanic, Asian, Pacific Islander, American Indian/ Alaska Native, and Two or more races. Not all categories are shown in all indicators. In some cases, categories are omitted because there are insufficient data in some of the smaller categories or because the data collection design did not distinguish between groups. For example, in the Common Core of Data (CCD) prior to 2010-11, the categories Asian and Pacific Islander are combined and "Two or more races" is used by some, not all, reporting districts. In other cases, omissions occur because only comparable data categories are shown. For example, the category "Two or more races," which was introduced in the 2000 Census and became a regular category for data collection in the Current Population Survey (CPS) in 2003, is sometimes excluded from indicators that present a historical series of data with constant categories, and it is sometimes included within the category "Other." For further details on these classifications, see the source documentation of the particular survey and http://www. census.gov/popest/race.html.

\section{Locale}

Federal departments and agencies use various classification systems to define community types. Indicators in The Condition of Education use the National Center for Education Statistics (NCES) system of locale codes.

NCES revised its definitions of school locale types in 2006 after working with the Census Bureau to create a new locale classification system. The revision capitalizes on improved geocoding technology and the $2000 \mathrm{OMB}$ definitions of metro areas that rely less on population size and county boundaries than on proximity of an address to an urbanized area.

Referred to as the "urban-centric" classification system to distinguish it from the previous "metro-centric" classification system, the new classification system has four major locale categories_city, suburban, town, and rural-each of which is subdivided into three subcategories (see exhibit B-1). 
Exhibit B-1. National Center for Education Statistics urban-centric locale categories

\begin{tabular}{|c|c|}
\hline Locale & Definition \\
\hline \multicolumn{2}{|l|}{ City } \\
\hline Large & Territory inside an urbanized area and inside a principal city with population of 250,000 or more \\
\hline Midsize & $\begin{array}{l}\text { Territory inside an urbanized area and inside a principal city with population less than } 250,000 \text { and greater } \\
\text { than or equal to } 100,000\end{array}$ \\
\hline Small & Territory inside an urbanized area and inside a principal city with population less than 100,000 \\
\hline \multicolumn{2}{|c|}{ Suburban } \\
\hline Large & Territory outside a principal city and inside an urbanized area with population of 250,000 or more \\
\hline Midsize & $\begin{array}{l}\text { Territory outside a principal city and inside an urbanized area with population less than } 250,000 \text { and } \\
\text { greater than or equal to } 100,000\end{array}$ \\
\hline Small & Territory outside a principal city and inside an urbanized area with population less than 100,000 \\
\hline \multicolumn{2}{|l|}{ Town } \\
\hline Fringe & Territory inside an urban cluster that is less than or equal to 10 miles from an urbanized area \\
\hline Distant & $\begin{array}{l}\text { Territory inside an urban cluster that is more than } 10 \text { miles and less than or equal to } 35 \text { miles from an urban- } \\
\text { ized area }\end{array}$ \\
\hline Remote & Territory inside an urban cluster that is more than 35 miles from an urbanized area \\
\hline \multicolumn{2}{|l|}{ Rural } \\
\hline Fringe & $\begin{array}{l}\text { Census-defined rural territory that is less than or equal to } 5 \text { miles from an urbanized area, as well as rural } \\
\text { territory that is less than or equal to } 2.5 \text { miles from an urban cluster. }\end{array}$ \\
\hline Distant & $\begin{array}{l}\text { Census-defined rural territory that is more than } 5 \text { miles but less than or equal to } 25 \text { miles from an urbanized } \\
\text { area, as well as rural territory that is more than } 2.5 \text { miles but less than or equal to } 10 \text { miles from an urban } \\
\text { cluster. }\end{array}$ \\
\hline Remote & $\begin{array}{l}\text { Census-defined rural territory that is more than } 25 \text { miles from an urbanized area and is also more than } 10 \\
\text { miles from an urban cluster }\end{array}$ \\
\hline
\end{tabular}

SOURCE: U.S. Department of Education, National Center for Education Statistics. Common Core of Data (CCD). Identification of Locale Codes, retrieved April 10, 2009, from http://nces.ed.gov/ccd/rural locales.asp.

The resulting 12 categories are based on a few key concepts that the Census Bureau uses to define an area's urbanicity: principal city, urbanized area, and urban cluster. A principal city is a city that contains the primary population and economic center of a metropolitan statistical area, which, in turn, is defined as one or more contiguous counties that have a "core" area with a large population nucleus and adjacent communities that are highly integrated economically or socially with the core. Urbanized areas and urban clusters are densely settled "cores" of Census-defined blocks with adjacent densely settled surrounding areas. Core areas with populations of 50,000 or more are designated as urbanized areas; core areas with populations between 25,000 and 50,000 are designated as urban clusters. Rural areas are designated by the Census Bureau as those areas that do not lie inside an urbanized area or urban cluster.

For more information about urban areas, see http:// www.census.gov/geo/www/ua/ua 2k.html. For more information about core based statistical areas, see http://www.census.gov/population/www/metroareas/ metroarea.html.
Assignments of locale codes to local education agencies (LEAs) are based on enrolled-weighted locale assignments of the schools operated by the LEA. If a majority of students in the LEA attend schools located in a single locale, the LEA is assigned to that locale. Most LEAs in the CCD are assigned based on a majority locale. If a majority of students in an LEA do not attend schools within a single locale, the LEA is reevaluated to see if a majority of its students are located in one of the four primary categories (city, suburban, town, and rural). If so, then the LEA is assigned to the largest subcategory within that primary category. If the LEA does not have a majority of its students in a specific locale or within a primary category, then the LEA is assigned the locale that accounts for a plurality of its students. In cases where an LEA does not enroll students or does not report student enrollment to the CCD, the LEA is assigned a locale based on its reported address location.

Although geographic locale assignments are included in the CCD and other NCES surveys, data products and publications often consolidate the full set of locales and present data only for the four primary categories. 


\section{Poverty}

Data on household income and the number of people living in the household are combined with estimates of the poverty threshold, published by the Census Bureau, to determine the poverty status of children (or adults). The thresholds used to determine poverty status for an individual differ for each survey year. The weighted average poverty thresholds for various household sizes for 1990, 1995, and 2000 through 2010 are shown in exhibit B-2. (For thresholds for other years, see http://www. census.gov/hhes/www/poverty/data/threshld/index. $\underline{\mathrm{html}}$.)

Eligibility or approval for the National School Lunch Program also serves as a proxy measure of poverty status. The National School Lunch Program is a federally assisted meal program operated in public and private nonprofit schools and residential child care centers. Unlike the poverty thresholds discussed above, which rely on dollar amounts determined by the Census Bureau, eligibility for the National School Lunch Program relies on the federal income poverty guidelines of the Department of Health and Human Services.

In The Condition of Education, a high-poverty school is defined as a school in which 76 percent or more of the students are eligible for free or reduced-price lunch. A low-poverty school is a school in which 25 percent or fewer of students were eligible for free or reduced-price lunch. To be eligible for free lunch, a student must be from a household with an income at or below 130 percent of the federal poverty guideline; to be eligible for reducedprice lunch, a student must be from a household with an income between 130 percent and 185 percent of the federal poverty guideline.

Exhibit B-2. Weighted average poverty thresholds, by household size: Selected years, 1990-2010 [In current dollars]

\begin{tabular}{|c|c|c|c|c|c|c|c|c|}
\hline \multirow[b]{2}{*}{ Year } & \multicolumn{8}{|c|}{ Household size } \\
\hline & 2 & 3 & 4 & 5 & 6 & 7 & 8 & 9 or more \\
\hline 1990 & $\$ 8,509$ & $\$ 10,419$ & $\$ 13,359$ & $\$ 15,792$ & $\$ 17,839$ & $\$ 20,241$ & $\$ 22,582$ & $\$ 26,848$ \\
\hline 1995 & 9,933 & 12,158 & 15,569 & 18,408 & 20,804 & 23,552 & 26,237 & 31,280 \\
\hline 2000 & 11,239 & 13,738 & 17,603 & 20,819 & 23,528 & 26,754 & 29,701 & 35,060 \\
\hline 2001 & 11,569 & 14,128 & 18,104 & 21,405 & 24,195 & 27,517 & 30,627 & 36,286 \\
\hline 2002 & 11,756 & 14,348 & 18,392 & 21,744 & 24,576 & 28,001 & 30,907 & 37,062 \\
\hline 2003 & 12,015 & 14,680 & 18,810 & 22,245 & 25,122 & 28,544 & 31,589 & 37,656 \\
\hline 2004 & 12.334 & 15,067 & 19,307 & 22,831 & 25,788 & 29,236 & 32,641 & 39,048 \\
\hline 2005 & 12,755 & 15,577 & 19,971 & 23,613 & 26,683 & 30,249 & 33,610 & 40,288 \\
\hline 2006 & 13,167 & 16,079 & 20,614 & 24,382 & 27,560 & 31,205 & 34,774 & 41,499 \\
\hline 2007 & 13,542 & 16,537 & 21,201 & 21,201 & 28,345 & 32,094 & 35,764 & 42,681 \\
\hline 2008 & 14,051 & 17,163 & 22,025 & 26,049 & 29,456 & 33,529 & 37,220 & 44,346 \\
\hline 2009 & 13,991 & 17,098 & 21,954 & 25,991 & 29,405 & 33,372 & 37,252 & 44,366 \\
\hline 2010 & 14,218 & 17,374 & 22,314 & 26,439 & 29,897 & 34,009 & 37,934 & 45,220 \\
\hline
\end{tabular}

SOURCE: U.S. Census Bureau, Current Population Survey (CPS). Retrieved March 9, 2011, from http://www.census.gov/hhes/www/povertyl. 


\section{Geographic Region}

The regional classification systems in exhibit B-3 represent the four geographical regions of the United States as defined by the Census Bureau of the U.S. Department of Commerce.

Exhibit B-3. U.S. Census Bureau, Regional Classification

\begin{tabular}{|c|c|c|c|c|c|c|c|}
\hline \multicolumn{2}{|l|}{ Northeast } & \multicolumn{2}{|l|}{ South } & \multicolumn{2}{|l|}{ Midwest } & \multicolumn{2}{|l|}{ West } \\
\hline $\begin{array}{l}\text { Connecticut } \\
\text { (CT) }\end{array}$ & New York (NY) & Alabama (AL) & Mississippi (MS) & Illinois (IL) & Missouri (MO) & Alaska (AK) & Nevada (NV) \\
\hline Maine (ME) & $\begin{array}{l}\text { Pennsylvania } \\
\text { (PA) }\end{array}$ & Arkansas (AR) & $\begin{array}{l}\text { North Carolina } \\
\text { (NC) }\end{array}$ & Indiana (IN) & Nebraska (NE) & Arizona (AZ) & $\begin{array}{l}\text { New Mexico } \\
\text { (NM) }\end{array}$ \\
\hline $\begin{array}{l}\text { Massachusetts } \\
\text { (MA) }\end{array}$ & $\begin{array}{l}\text { Rhode Island } \\
\text { (RI) }\end{array}$ & Delaware (DE) & Oklahoma (OK) & lowa (IA) & $\begin{array}{l}\text { North Dakota } \\
\text { (ND) }\end{array}$ & California (CA) & Oregon (OR) \\
\hline $\begin{array}{l}\text { New Hampshire } \\
(\mathrm{NH})\end{array}$ & Vermont (VT) & $\begin{array}{l}\text { District of Co- } \\
\text { lumbia (DC) }\end{array}$ & $\begin{array}{l}\text { South Carolina } \\
\text { (SC) }\end{array}$ & Kansas (KS) & Ohio $(\mathrm{OH})$ & Colorado (CO) & Utah (UT) \\
\hline \multirow[t]{5}{*}{ New Jersey (NJ) } & & Florida (FL) & Tennessee (TN) & Michigan (MI) & $\begin{array}{l}\text { South Dakota } \\
\text { (SD) }\end{array}$ & Hawaii $(H I)$ & $\begin{array}{l}\text { Washington } \\
\text { (WA) }\end{array}$ \\
\hline & & Georgia (GA) & Texas (TX) & Minnesota (MN) & Wisconsin (WI) & Idaho (ID) & Wyoming (WY) \\
\hline & & Kentucky (KY) & Virginia (VA) & & & Montana (MT) & \\
\hline & & Louisiana (LA) & $\begin{array}{l}\text { West Virginia } \\
\text { (WV) }\end{array}$ & & & & \\
\hline & & Maryland (MD) & & & & & \\
\hline
\end{tabular}

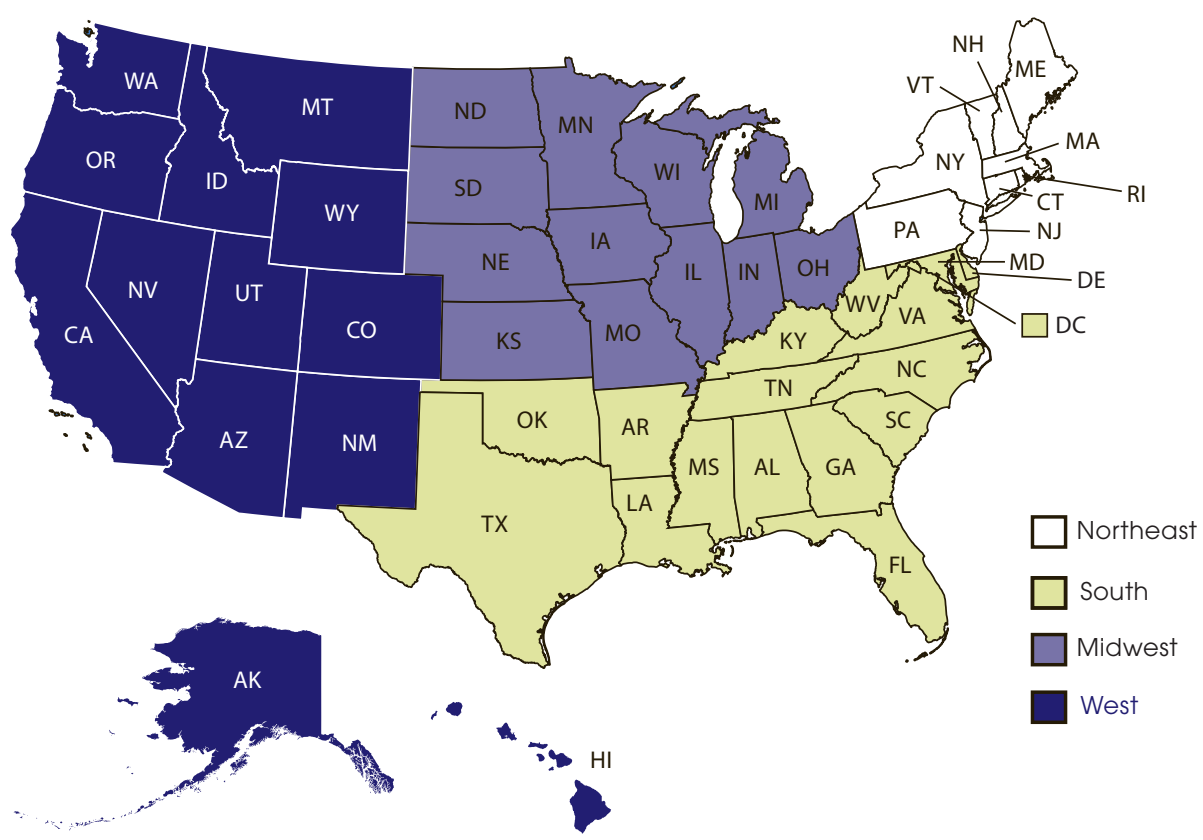

SOURCE: U.S. Census Bureau. Census Regions and Divisions of the United States, retrieved November 7, 2011, from http://www.census.gov/geo/www/us regdiv.pdf. 


\section{Averaged Freshman Graduation Rate}

The averaged freshman graduation rate (AFGR) is a measure of the percentage of the incoming freshman class that graduates 4 years later. The AFGR is the number of graduates with a regular diploma divided by the estimated count of incoming freshmen 4 years earlier, as reported through the NCES Common Core of Data (CCD), the survey system based on state education departments' annual administrative records. (For more information on the CCD, see Appendix B - Guide to Sources.) The estimated count of incoming freshmen is the sum of the number of 8 th-graders 5 years earlier, the number of 9th-graders 4 years earlier (when current-year seniors were freshmen), and the number of 10th-graders 3 years earlier, divided by 3 . The intent of this averaging is to account for the high rate of grade retention in the freshman year, which adds 9th-grade repeaters from the previous year to the number of students in the incoming freshman class each year. Ungraded students are allocated to individual grades proportional to each state's enrollment in those grades. The AFGR treats students who transfer out of a school or district in the same way as it treats students from that school or district who drop out.

\section{Status Dropout Rate}

Status dropout rates measure the percentage of individuals within a given age range who are not enrolled in school and lack a high school credential, irrespective of when they dropped out. As such, these rates can be used to gauge the need for further education and training within that population. Status dropout rates are distinct from event dropout rates, which measure the proportion of students who drop out of high school in a given year; event dropout rates have been reported in a previous volume of The Condition of Education (NCES 2004-077, indicator 16) and are featured in the annual report Trends in High School Dropout and Completion Rates in the United States (see, for example, NCES 2011-012).

Data from both the American Community Survey (ACS) and the October Current Population Survey (CPS) are used in The Condition of Education to estimate the percentage of the population ages 16 through 24 who are not in school and have not earned a high school credential (either a diploma or an equivalency credential such as a General Educational Development [GED] certificate), irrespective of when they dropped out.

Within the CPS, the status dropout rate is the percentage of civilian, noninstitutionalized young people ages 16 through 24 who are not in school and have not earned a high school credential (either a diploma or equivalency credential such as a General Educational Development [GED] certificate). The numerator of the status dropout rate for a given year is the number of individuals ages 16 through 24 who, as of October of that year, have not completed a high school credential and are not currently enrolled in school. The denominator is the total number of individuals ages 16 through 24 in the United States in October of that year. Status dropout rates count as dropouts individuals who never attended school and immigrants who did not complete the equivalent of a high school education in their home country. The inclusion of these individuals is appropriate because the status dropout rate is designed to report the percentage of youth and young adults in the United States who lack what is now considered a basic level of education. However, the status dropout rate should not be used as a measure of the performance of U.S. schools because it counts as dropouts individuals who may have never attended a U.S. school.

The ACS first collected in 2009 allows for more detailed comparisons of status dropout rates by race/ ethnicity, nativity, and sex, and, unlike the CPS, includes institutionalized persons, incarcerated persons, and active duty military personnel living in barracks in the United States. The CPS provides several decades of historical trends on status dropouts that are not available from the ACS. The disadvantage of using CPS data to compute status dropout rates for the civilian, noninstitutionalized population is that military personnel and incarcerated or institutionalized persons are excluded. A disadvantage of both the CPS and ACS is that the datasets include as dropouts individuals who never attended U.S. schools, including immigrants who did not complete the equivalent of a high school education in their home country. Estimates of status dropout rates from the ACS and CPS are not directly comparable due to methodological differences, such as differing sampling frames, modes of administration, and question wording. For more information on the CPS and the ACS, see Appendix B - Guide to Sources.

\section{Educational Attainment}

This measure uses March CPS data to estimate the percentage of civilian, noninstitutionalized people ages 25 through 29 who have achieved certain levels of educational attainment. Estimates of educational attainment represent the percentage of adults who completed at least the cited credential. Attainment estimates do not differentiate between those who graduated from public schools, those who graduated from private schools, and those who earned a GED. These estimates also include individuals who earned their credential or completed their highest level of education outside of the United States.

From 1972 to 1991, two CPS questions provided data on the number of years of school completed: (1) "What is the highest grade or year of regular school...has ever attended?" and (2) "Did...complete that grade (year)?" An individual's educational attainment was considered to be his or her last fully completed year of school. Individuals who completed 12 years of schooling were deemed to be high school graduates, as were those who began but did not complete the first year of college. Respondents who completed 16 or more years of schooling were counted as college graduates.

Beginning in 1992, the CPS combined the two questions into the following question: "What is the highest level of 
school... completed or the highest degree...received?" This change means that some data collected before 1992 are not strictly comparable with data collected from 1992 onward, and that care must be taken when making comparisons across years. The revised question changed the response categories from "highest grade completed" to "highest level of schooling or degree completed." The revised question emphasizes credentials received rather than the last grade level attended or completed. The new categories include the following:

- High school graduate, high school diploma, or the equivalent (e.g., GED)

- Some college but no degree

- Associate's degree in college, occupational/ vocational program

- Associate's degree in college, academic program (e.g., A.A., A.S., A.A.S.)

- Bachelor's degree (e.g., B.A., A.B., B.S.)

- Master's degree (e.g., M.A., M.S., M.Eng., M.Ed., M.S.W., M.B.A.)

- Professional school degree (e.g., M.D., D.D.S., D.V.M., LL.B., J.D.)

- Doctorate degree (e.g., Ph.D., Ed.D.)

\section{High School Completion}

Since 1988, an additional question has also asked respondents if they have a high school diploma or the equivalent, such as a GED. People who respond "yes" are classified as high school completers. Before 1988, the number of individuals who earned a high school equivalency certificate was small compared to the number of high school graduates, so the subsequent increase caused by including equivalency certificate recipients in the total number of people counted as "high school completers" was small in the years immediately after the change was made.

Before 1992, the CPS considered individuals who completed 12th grade to be high school graduates. A revision in 1992 added the response category " 12 th grade, no diploma." Individuals who select this response are not counted as graduates. Historically, the number of individuals in this category has been small.

\section{Some College}

Based on the question used in 1992 and in subsequent surveys, the response for an individual who attended college for less than a full academic year would be "some college but no degree." Before 1992, the appropriate response would have been "attended first year of college and did not complete it," thereby excluding those individuals with $1-3$ years of college from the calculation of the percentage of the population. With the revised question, such respondents are placed in the "some college but no degree" category. The percentage of individuals with some college might be larger than the percentage with 1-3 years of college, because "some college" includes those who have not completed one entire year. Therefore, it is not appropriate to make comparisons between the percentage of those with "some college but no degree" (using the post1991 question) and the percentage of those who completed "1-3 years of college" (using the two pre-1992 questions).

\section{College Completion}

Some students attend college for 4 or more years without earning a bachelor's degree, so some researchers are concerned that the college completion rate, based on the pre-1992 category "4th year or higher of college completed," overstates the number of respondents with a bachelor's degree (or higher). In fact, however, the completion rates among those ages 25-29 in 1992 and 1993 were similar to the completion rates for 1990 and 1991, before the change in the question's wording. Thus, there appears to be good reason to conclude that the change has not affected the completion rates reported in The Condition of Education 2012.

An advantage of using CPS data to compute educational attainment estimates is that estimates can be computed on an annual basis for various demographic subgroups of adults. A disadvantage of using CPS data to compute the educational attainment rate is that these data exclude all military personnel living in barracks and incarcerated or institutionalized persons.

For more information on the CPS, see Appendix B - Guide to Sources.

\section{Classification of Postsecondary Education Institutions and Degrees}

The U.S. Department of Education's Integrated
Postsecondary Education Data System (IPEDS) employs
various categories to classify postsecondary institutions.

The term postsecondary institutions is the category used to refer to institutions with formal instructional programs and a curriculum designed primarily for students who have completed the requirements for a high school diploma or its equivalent. This includes programs whose purpose is academic or vocational, as well as continuing professional education programs, and excludes avocational and adult basic education programs. For many analyses, however, comparing all institutions in this broad universe of postsecondary institutions would not be appropriate. Thus, postsecondary institutions are placed in one of three levels, based on the highest award offered at the institution:

4-year-and-above institutions: Institutions or branches that offer programs of at least 4 years' duration or offer programs at or above the baccalaureate level. These institutions award a 4-year degree or higher in one or more programs or award a postbaccalaureate or postmaster's. Includes schools that offer postbaccalaureate certificates only or those that offer graduate programs only. Also includes freestanding medical, law, or other first-professional schools.

- 2-year but less-than-4-year institutions: A postsecondary institution that offers programs of at least 2 but less 
than 4 years' duration. Includes occupational and vocational schools with programs of at least 1,800 contact hours and academic institutions with programs of less than 4 years' duration. Does not include 4-year institutions that offer accelerated versions of their bachelor's degree programs, in which a bachelor's degree may be obtained in less than 4 years.

- Less-than-2-year institutions: Institutions or branches that offer programs of less than 2 years' duration below the baccalaureate level. Includes occupational and vocational schools with programs that do not exceed 1,800 contact hours.

IPEDS also classifies institutions at each of the three levels of institutions by financial control:

- Public institutions: Institutions whose programs and activities are operated by publicly elected or appointed school officials and which are supported primarily by public funds.

- Private not-for-profit institutions: Institutions in which the individual(s) or agency in control receives no compensation other than wages, rent, or other expenses for the assumption of risk. These include both independent not-for-profit schools and those affiliated with a religious organization.

- Private for-profit institutions: Institutions in which the individual(s) or agency in control receives compensation other than wages, rent, or other expenses for the assumption of risk (e.g., proprietary schools).

An institution in any of these nine possible sectors formed by the various combinations of institution level and financial control, above, can also be classified as degree- or non-degree-granting, based on whether the institution offers students a formal award such as a degree or certificate:

- Degree-granting institutions offer associate's, bachelor's, master's, doctoral, and/or first-professional degrees that a state agency recognizes or authorizes.

- Non-degree-granting institutions offer other kinds of credentials and exist at all types of financial control (i.e., public, private not-for-profit, and private for-profit institutions).

The number of 4-year-and-above non-degree-granting institutions is small compared with the total number of non-degree-granting institutions.

Institutions in any of the nine sectors can also be Title IV-participating or not. For an institution to participate in federal Title IV Higher Education Act, Part C, financial aid programs, it must offer a program of study at least 300 clock hours in length; have accreditation recognized by the U.S. Department of Education; have been in business for at least 2 years; and have a Title IV participation agreement with the U.S. Department of Education. All indicators in this volume using IPEDS data present only Title IV-participating institutions. For more information on the Higher Education Act of 2008, see http://www2. ed.gov/policy/highered/leg/hea08/index.html.

In some indicators based on IPEDS data, 4-year-andabove degree-granting institutions are further classified according to the highest degree awarded:

- Doctoral institutions award at least 20 doctoral degrees per year.

- Master's institutions award at least 20 master's degrees per year.

The remaining institutions are considered to be other 4 -year degree-granting institutions. The number of degrees awarded by an institution in a given year is obtained for each institution from data published in the IPEDS "Completions Survey" (IPEDS-C).

The structure of the IPEDS collection of data on degrees conferred changed beginning with the 2007-08 academic year. Prior to 2007-08, colleges reported the number of first-professional degrees separate from the number of doctoral degrees. In addition, doctoral degrees were reported as a single category. In the 2008-09 academic year, institutions were required (optional in the 2007-08 academic year) to discontinue reporting first-professional degrees as a separate category and to integrate them into the master's and doctoral degrees categories; additionally, required in the 2008-09 academic year, the doctoral degrees could be reported in three different classifications: professional practice, research/scholarship, and other. In order to present consistent national data over time, the data for the institutions reporting in the new structure were cross-walked to the old structure. The master's and doctoral degrees awarded in fields of study classified in the Classification of Instruction Programs (CIP) as "formerly considered first-professional" were reclassified as firstprofessional degree awards. Therefore, data presented in The Condition of Education on completed degrees from 2007-08 onward may not match reported totals within other publications. The specific fields and CIP programs cross-walked in this manner were the following:

— 51.0401 Dentistry (D.D.S. or D.M.D.)

- 51.1201 Medicine (M.D.)

- 51.1701 Optometry (O.D.)

- 51.1901 Osteopathic medicine (D.O.)

- 51.2001 Pharmacy (Pharm.D.)

- 51.2101 Podiatry (Pod.D. or D.P.) or podiatric medicine (D.P.M.)

- 51.2401 Veterinary medicine (D.V.M.)

- 51.0101 Chiropractic (D.C. or D.C.M.)

— 22.0101 Law (LL.B. or J.D.)

- 39.0602 Theology (M. Div., M.H.L., B.D., or Ord. and M.H.L./Rav.).

Further information about IPEDS is available in Appendix B - Guide to Sources.

Further information about the various IPEDS classifications is available at http://nces.ed.gov/ipeds/. 


\section{Note 2 \\ Finance \\ Using the Consumer Price Index (CPI) to Adjust for Inflation}

The Consumer Price Index (CPI) represents changes in the prices of all goods and services purchased for consumption by households. Indexes vary for specific areas or regions, periods of time, major groups of consumer expenditures, and population groups. The CPI reflects spending patterns for two population groups: (1) all urban consumers and urban wage earners and (2) clerical workers. The all-urban consumer group represents about 87 percent of the total U.S. population.

CPIs are calculated for both the calendar year and the school year using the U.S. All Items CPI for All Urban Consumers (CPI-U). The calendar year CPI is the same as the annual CPI-U. The school year CPI is calculated by adding the monthly CPI-U figures, beginning with July of the first year and ending with June of the following year, and then dividing that figure by 12 . Data for the CPI-U are available on the Bureau of Labor Statistics (BLS) website (http://www.bls.gov/cpi/). Also, figures for both the calendar year CPI and the school year CPI can be obtained from the Digest of Education Statistics 2011 (NCES 2012-001), an annual publication of the National Center for Education Statistics (NCES).

Although the CPI has many uses, its principal function in The Condition of Education is to convert monetary figures (salaries, expenditures, income, etc.) into inflationadjusted dollars to allow for comparisons over time.

The reader should be aware that there are alternative price indexes to the CPI that could be used to make these adjustments. These alternative adjustments might produce findings that differ from the ones presented here. For more detailed information on how the CPI is calculated or on the other types of price indexes, go to the BLS website (http://www.bls.gov/cpi/).

\section{Classifications of Expenditures for Public Elementary and Secondary Schools}

Total expenditures for elementary and secondary education includes all expenditures allocable to per student costs. The three major categories of total expenditures are current expenditures (all current expenditures for regular school programs), capital outlay, and interest on debt. Total expenditures includes expenditures on education by other agencies or equivalent institutions (e.g., the Department of Health and Human Services and the Department of Agriculture), but excludes "Other current expenditures" such as community services, private school programs, adult education, and other programs not allocable to expenditures per student at public schools.

Current expenditures includes expenditures for the day-to-day operation of schools and school districts. Seven subfunctions make up these current expenditures: instruction, administration, student and staff support, operation and maintenance, transportation, food services, and enterprise operations. Thus, current expenditures includes items such as salaries for school personnel, benefits, supplies, purchased services, student transportation, schoolbooks and materials, and energy costs.

Instruction expenditures includes expenditures for activities related to the interaction between teachers and students. Includes salaries and benefits for teachers and instructional aides, textbooks, supplies, and purchased services such as instruction via television. Also included are tuition expenditures to other local education agencies.

- Administration expenditures includes expenditures for school administration (i.e., the office of the principal, full-time department chairpersons, and graduation expenses), general administration (the superintendent and board of education and their immediate staff), and other support services expenditures.

- Student and staff support expenditures includes expenditures for student support (attendance and social work, guidance, health, psychological services, speech pathology, audiology, and other student support services), instructional staff services (instructional staff training, educational media [libraries and audiovisual], and other instructional staff support services), and other support services (business support services, central support services, and other support services not reported elsewhere).

- Operation and maintenance expenditures includes expenditures for supervision of operations and maintenance; operating buildings (heating, lighting, ventilating, repair, and replacement); care and upkeep of grounds and equipment; vehicle operations and maintenance (other than student transportation); security; and other operations and maintenance services.

- Transportation includes expenditures for vehicle operation, monitoring, and vehicle servicing and maintenance.

Food services includes all expenditures associated with providing food to students and staff in a school or school district. The services include preparing and serving regular and incidental meals or snacks in connection with school activities, as well as the delivery of food to schools. 
Enterprise operations includes expenditures for activities that are financed, at least in part, by user charges, similar to a private business. These include operations funded by sales of products or services, together with amounts for direct program support made by state education agencies for local school districts.

Current expenditures and each of its seven subfunctions can be further broken down by the object of the expenditure: salaries, employee benefits, purchased services, supplies, tuition, and other.

Capital outlay includes direct expenditures for construction of buildings, roads, and other improvements and for purchases of equipment, land, and existing structures. Includes amounts for additions, replacements, and major alterations to fixed works and structures; the initial installation or extension of service systems and other built-in equipment; and site improvement. The category also encompasses architectural and engineering services, including the development of blueprints.

Interest on debt includes expenditures for long-term debt service interest payments (i.e., those longer than 1 year).

\section{Classifications of Revenue for Public Elementary and Secondary Schools}

Public school revenue is classified by source (federal, state, or local). Revenue from federal sources includes direct grants-in-aid to schools or agencies, funds distributed through a state or intermediate agency, and revenue in lieu of taxes to compensate a school district for nontaxable federal institutions within a district's boundary. Revenue from state sources includes both direct funds from state governments and revenue in lieu of taxation. Revenue from local sources includes revenue from such sources as local property and nonproperty taxes, investments, and revenue from student activities, textbook sales, transportation and tuition fees, and food services. Intermediate revenue comes from sources that are not local or state education agencies, but that are at an intermediate level between local and state education agencies and possess independent fundraising capabilityfor example, county or municipal agencies. Intermediate revenue is included in local revenue totals.

\section{The Variation in Expenditures per Student and the Theil Coefficient}

The Theil coefficient is used as a measure of the variation in expenditures per pupil in regular public elementary and secondary schools in the United States. A comparison of the values of Theil coefficients for groups within a set (i.e., districts within a state) will indicate relative dispersion and any variations that may exist among them.

The Theil coefficient has a convenient property when the individual units of observation (e.g., school districts) can be aggregated into subgroups (e.g., states): this property allows the total variation to be decomposed into a measure of the variation within the subgroups and a measure of the variation between the subgroups. Hence, in the examination of the variation in instructional expenditures in the United States, the national variation can be decomposed into measures of between-state and within-state variation. The between-state and within-state components indicate whether the national variation in instruction expenditures per student is primarily due to differences in expenditures between states or within states. The Theil coefficient can range from zero, indicating no variation, to a maximum possible value of 1.0.

The between-state Theil coefficient, $\mathrm{T}_{\mathrm{B}}$, equals

$$
T_{B}=\sum_{k=1}^{K}\left(P_{k} \bar{X}_{k} / \bar{X}\right) \ln \left(\bar{X}_{k} / \bar{X}\right)
$$

where $P_{k}$ is the enrollment in state $k, \bar{X}_{k}$ is the studentweighted mean expenditure per student in state $k$, and $\bar{X}$ is the student-weighted mean expenditure per student for the country.

The within-state Theil coefficient, $T_{w}$, equals

$T_{W}=\sum_{k=1}^{K}\left(P_{k} \bar{X}_{k} \mid \bar{X}\right) \mathrm{T}_{\mathrm{k}}$

where $T_{k}$ is the Theil coefficient for state $k$. $T_{k}$ equals

$T_{k}=\frac{\sum_{j=1}^{J_{k}} P_{j k} X_{j k} \ln \left(X_{j k} \mid \bar{X}_{k}\right)}{\sum_{j=1}^{J_{k}} P_{j k} X_{j k}}$

where $P_{j k}$ is the enrollment of district $j$ in state $k$ and $X_{j k}$ is the mean expenditure per student of district $j$ in state $k$.

The national Theil coefficient, $\mathrm{T}$, is

$T=T_{W}+T_{B}$

\section{Classifications of Expenditures for International Comparisons}

International finance data include data on public and private expenditures for instructional and noninstructional educational institutions. Instructional educational institutions are educational institutions that directly provide instructional programs (i.e., teaching) to individuals in an organized group setting or through distance education. Business enterprises or other institutions that provide short-term courses of training or instruction to individuals on a "one-to-one" basis are not included. Noninstructional educational institutions are educational institutions that provide administrative, advisory, or professional services to other educational institutions, although they do not enroll 
students themselves. Examples include national, state, and provincial bodies in the private sector; organizations that provide education-related services, such as vocational and psychological counseling; and educational research institutions.

Public expenditures corresponds to the nonrepayable current and capital expenditures of all levels of the government directly related to education. Expenditures that are not directly related to education (e.g., culture, sports, youth activities) are, in principle, not included. Expenditures on education by other ministries or equivalent institutions (e.g., Health and Agriculture) are included. Public subsidies for students' living expenses are excluded to ensure international comparability of the data.

Private expenditures refers to expenditures funded by private sources (i.e., households and other private entities). "Households" means students and their families. "Other private entities" includes private business firms and nonprofit organizations, including religious organizations, charitable organizations, and business and labor associations. Private expenditures are composed of school fees, the cost of materials (such as textbooks and teaching equipment), transportation costs (if organized by the school), the cost of meals (if provided by the school), boarding fees, and expenditures by employers on initial vocational training.

Current expenditures includes final consumption expenditures (e.g., compensation of employees, consumption of intermediate goods and services, consumption of fixed capital, and military expenditures); property income paid; subsidies; and other current transfers paid.

Capital expenditures includes spending to acquire and improve fixed capital assets, land, intangible assets, government stocks, and nonmilitary, nonfinancial assets, as well as spending to finance net capital transfers. 


\section{International Education Definitions}

\section{Organization for Economic Co-operation and Development (OECD)}

The Organization for Economic Co-operation and Development (OECD) is an intergovernmental organization of 34 industrialized countries that serves as a forum for member countries to cooperate in research and policy development on social and economic topics of common interest. These countries include: Australia, Austria, Belgium, Canada, Chile, the Czech Republic, Denmark, Estonia, Finland, France, Germany, Greece, Hungary, Iceland, Ireland, Israel, Italy, Japan, Korea, Luxembourg, Mexico, Netherlands, New Zealand, Norway, Poland, Portugal, Slovak Republic, Slovenia, Spain, Sweden, Switzerland, Turkey, United Kingdom, and United States. Currently, 25 nonmembers participate as regular observers or full participants in OECD committees.

The Program for International Student Assessment (PISA) is a system of international assessments organized by the OECD that focuses on 15-year-olds' capabilities in reading literacy, mathematics literacy, and science literacy. PISA also includes measures of general, or crosscurricular, competencies such as learning strategies. The measures emphasize functional skills that students have acquired as they near the end of mandatory schooling. PISA was administered for the first time in 2000, when 43 countries participated. Forty-one countries participated in the 2003 administration of PISA; 57 jurisdictions (30 OECD members and 27 nonmembers) participated in 2006; and 65 jurisdictions (34 OECD members and 31 nonmembers) participated in 2009.

For more information on the history, membership, and research conducted by the OECD, see http://www.oecd. org/home/0,3675, en 2649201185111111 1,00.html. For more information on PISA, see Appendix B - Guide to Sources.

\section{International Standard Classification of Education (ISCED)}

The 1997 International Standard Classification of Education (ISCED) is used to compare educational systems in different countries. ISCED is the standard used by many countries to report education statistics to the United Nations Educational, Scientific, and Cultural Organization (UNESCO) and the OECD. ISCED divides educational systems into the following seven categories, based on six levels of education.

ISCED Level 0: Education preceding the first level (early childhood education) usually begins at age 3 , 4, or 5 (sometimes earlier) and lasts from 1 to 3 years, when it is provided. In the United States, this level includes nursery school and kindergarten.

ISCED Level 1: Education at the first level (primary or elementary education) usually begins at age 5,6 , or 7 and continues for about 4 to 6 years. For the United States, the first level starts with 1st grade and ends with 6 th grade.

- ISCED Level 2: Education at the second level (lower secondary education) typically begins at about age 11 or 12 and continues for about 2 to 6 years. For the United States, the second level starts with 7 th grade and typically ends with 9th grade. Education at the lower secondary level continues the basic programs of the first level, although teaching is typically more subject focused, often using more specialized teachers who conduct classes in their field of specialization. The main criterion for distinguishing lower secondary education from primary education is whether programs begin to be organized in a more subjectoriented pattern, using more specialized teachers conducting classes in their field of specialization. If there is no clear breakpoint for this organizational change, lower secondary education is considered to begin at the end of 6 years of primary education. In countries with no clear division between lower secondary and upper secondary education, and where lower secondary education lasts for more than 3 years, only the first 3 years following primary education are counted as lower secondary education.

- ISCED Level 3: Education at the third level (upper secondary education) typically begins at age 15 or 16 and lasts for approximately 3 years. In the United States, the third level starts with 10th grade and ends with 12th grade. Upper secondary education is the final stage of secondary education in most OECD countries. Instruction is often organized along subject-matter lines, in contrast to the lower secondary level, and teachers typically must have a higher level, or more subject-specific, qualification. There are substantial differences in the typical duration of programs both across and between countries, ranging from 2 to 5 years of schooling. The main criteria for classifications are (1) national boundaries between lower and upper secondary education and (2) admission into educational programs, which usually requires the completion of lower secondary education or a combination of basic education and life experience that demonstrates the ability to handle the subject matter in upper secondary schools.

- ISCED Level 4: Education at the fourth level (postsecondary nontertiary education) straddles the boundary between secondary and postsecondary education. This program of study, which is primarily vocational in nature, is generally taken after the 
completion of secondary school and typically lasts from 6 months to 2 years. Although the content of these programs may not be significantly more advanced than upper secondary programs, these programs serve to broaden the knowledge of participants who have already gained an upper secondary qualification.

- ISCED Level 5: Education at the fifth level (first stage of tertiary education) includes programs with more advanced content than those offered at the two previous levels. Entry into programs at the fifth level normally requires successful completion of either of the two previous levels.

- ISCED Level 5A: Tertiary-type A programs provide an education that is largely theoretical and is intended to provide sufficient qualifications for gaining entry into advanced research programs and professions with high skill requirements. Entry into these programs normally requires the successful completion of an upper secondary education; admission is competitive in most cases. The minimum cumulative theoretical duration at this level is 3 years of full-time enrollment. In the United States, tertiary-type A programs include first university programs that last approximately 4 years and lead to the award of a bachelor's degree and second university programs that lead to a master's degree.

- ISCED Level 5B: Tertiary-type B programs are typically shorter than tertiary-type A programs and focus on practical, technical, or occupational skills for direct entry into the labor market, although they may cover some theoretical foundations in the respective programs. They have a minimum duration of 2 years of full-time enrollment at the tertiary level. In the United States, such programs are often provided at community colleges and lead to an associate's degree.

ISCED Level 6: Education at the sixth level (advanced research qualification) is provided in graduate and professional schools that generally require a university degree or diploma as a minimum condition for admission. Programs at this level lead to the award of an advanced, postgraduate degree, such as a Ph.D. The theoretical duration of these programs is 3 years of full-time enrollment in most countries (for a cumulative total of at least 7 years at levels five and six), although the length of actual enrollment is often longer. Programs at this level are devoted to advanced study and original research. 
314 The Condition of Education 2012 


\section{APPENDIX D \\ Glossary}


Achievement levels: National Assessment of Educational Progress (NAEP) achievement levels are set through a National Assessment Governing Board process and define what students should know and be able to do at different levels of performance. The NAEP achievement levels are Basic, Proficient, and Advanced. The definitions of these levels, which apply across all grades and subject areas, are as follows:

Basic: This level denotes partial mastery of prerequisite knowledge and skills that are fundamental for proficient work at each grade.

Proficient: This level represents solid academic performance for each grade assessed. Students reaching this level have demonstrated competency over challenging subject matter, including subject-matter knowledge, application of such knowledge to real-world situations, and analytical skills appropriate to the subject matter.

Advanced: This level signifies superior performance at each grade assessed.

Alternative school: A public elementary/secondary school that (1) addresses needs of students that typically cannot be met in a regular school, (2) provides nontraditional education, (3) serves as an adjunct to a regular school, or (4) falls outside the categories of regular, special education, or vocational education. Some examples of alternative schools are schools for potential dropouts; residential treatment centers for substance abuse (if they provide elementary or secondary education); schools for chronic truants; and schools for students with behavioral problems.

Associate's degree: An award that normally requires at least 2 but less than 4 years of full-time-equivalent college work.

Bachelor's degree: A degree granted for the successful completion of a baccalaureate program of studies, usually requiring at least 4 years (or the equivalent) of full-time college-level study.

Catholic school: Catholic schools are categorized according to governance as parochial, diocesan, or private schools.

Charter school: A publicly funded school that, in accordance with an enabling statute, has been granted a charter exempting it from selected state or local rules and regulations. A public charter school may be a newly created school, or it may previously have been a traditional public or private school. In return for funding and autonomy, the charter school must meet accountability standards. A school's charter is typically reviewed every 3 to 5 years and can be revoked if guidelines on curriculum and management are not followed or standards are not met. Charter schools provide free public elementary and/or secondary education and can be administered by regular school districts, state education agencies (SEAs), or chartering organizations. See also Public school.

\section{Classification of Instructional Programs (CIP):}

A taxonomic coding scheme for secondary and postsecondary instructional programs. It is intended to facilitate the organization, collection, and reporting of program data using classifications that capture the majority of reportable data. The CIP is the accepted federal government statistical standard on instructional program classifications and is used in a variety of education information surveys and databases.

College: A postsecondary education institution.

Combined school: A school offering both elementary and secondary education. A combined school typically has one or more of grades kindergarten $(\mathrm{K})$ through 6 and one or more of grades 9-12. For example, schools with grades $\mathrm{K}-12$, 6-9, or $1-12$ are classified as combined schools. Alternatively, according to 2007-08 Schools and Staffing Survey, defined as a school with at least one grade lower than 7 and at least one grade higher than 8; schools with only ungraded classes are included with combined schools.

Constant dollars: Dollar amounts that have been adjusted by means of price and cost indexes to eliminate inflationary factors and allow for direct comparison across years.

Consumer Price Index (CPI): This price index measures the average change in the cost of a fixed-market basket of goods and services purchased by consumers.

Current expenditures: For elementary/secondary schools, these include all charges for current outlays plus capital outlays and interest on school debt. For postsecondary institutions, these include current outlays plus capital outlays. For the government, these include charges net of recoveries and other correcting transactions, other than retirement of debt, investment in securities, extension of credit, or agency transactions. Also, government expenditures include only external transactions, such as the provision of prerequisites or other payments in kind. Aggregates for groups of governments exclude intergovernmental transactions among the governments.

Examples of current expenditures include salaries for school personnel, fixed charges, student transportation, book and materials, and energy costs. Expenditures for state administration are excluded. 
Disabilities: Any of the disabilities classified in the U.S. Department of Education's Office of Special Education Programs (OSEP), which collects information on students with disabilities as part of the implementation of the Individuals with Disabilities Education Act (IDEA). Categories of disabilities include autism, deaf-blindness, developmental delay, emotional disturbance, hearing impairment, intellectual disability, multiple disabilities, orthopedic impairment, other health impairment, specific learning disabilities, speech or language impairments, traumatic brain injury, visual impairments, and preschool disability. (For more detailed definitions of these categories, see the part B and C data dictionaries at http:// www.ideadata.org/618DataCollection.asp.)

Doctor's degree: An earned degree carrying the title of Doctor. The Doctor of Philosophy degree (Ph.D.) is the highest academic degree and requires mastery within a field of knowledge and demonstrated ability to perform scholarly research. Other doctor's degrees are awarded for fulfilling specialized requirements in professional fields, such as education (Ed.D.), musical arts (D.M.A.), business administration (D.B.A.), and engineering (D. Eng. or D.E.S.). Many doctor's degrees in both academic and professional fields require an earned master's degree as a prerequisite. Degrees formerly referred to as firstprofessional degrees, such as M.D., J.D., and D.D.S., are now included under this heading. See also Firstprofessional degree.

Dropout: The term is used to describe both the event of leaving school before completing high school and the status of an individual who is not in school and who is not a high school completer. High school completers include both graduates of school programs as well as those completing high school through equivalency programs such as the General Educational Development (GED) progam. Transferring from a public school to a private school is not regarded as a dropout event. A person who drops out of school may later return and graduate but is called a "dropout" at the time he or she leaves school. Measures to describe these behaviors include the event dropout rate (or the closely related school persistence rate), the status dropout rate, and the high school completion rate. See also Status dropout rate, Appendix C - Commonly Used Measures.

Early childhood school: Early childhood program schools serve students in prekindergarten, kindergarten, transitional (or readiness) kindergarten, and/or transitional first (or prefirst) grade.

Education specialist/professional diploma: A certificate of advanced graduate studies that advance educators in their instructional and leadership skills beyond the master's level of competence.
Elementary school: A school with one or more of grades K-6 that does not have any grade higher than grade 8 . For example, schools with grades $\mathrm{K}-6,1-3$, or $6-8$ are classified as elementary.

Elementary/secondary school: Elementary/secondary schools include regular schools (i.e., schools that are part of state and local school systems and private elementary/ secondary schools, both religiously affiliated and nonsectarian); alternative schools; vocational education schools; and special education schools.

Employment status: Employment status includes employed (either full or part time), unemployed (looking for work or on layoff), or not in the labor force (due to being retired, having unpaid employment, or some other reason).

According to the October Current Population Survey (CPS), employed persons are persons age 16 or older who, during the reference week, (1) did any work at all (at least 1 hour) as paid employees or (2) were not working but had jobs or businesses from which they were temporarily absent because of vacation, illness, bad weather, child care problems, maternity or paternity leave, labor-management dispute, job training, or other family or personal reasons, whether or not they were paid for the time off or were seeking other jobs.

English language learner: A person for whom English is a second language and who has not yet attained proficiency in the English language. See also LimitedEnglish proficient.

Expenditures: Charges incurred, whether paid or unpaid. Expenditure types include the following:

Current expenditures: Short-term spending that is fully expensed in the fiscal period in which it is incurred. Current expenditures are in contrast to capital expenditures, which refer to spending on long-term assets that are capitalized and amortized over their useful life. See also Current expenditures.

Instructional expenditures (elementary/secondary): Current expenditures for activities directly associated with the interaction between teachers and students. These include teacher salaries and benefits, supplies (such as textbooks), and purchased instructional services.

Expenditures per student: Charges incurred for a particular period of time divided by a student unit of measure, such as enrollment, average daily attendance, or average daily membership. See also Appendix C - Finances.

Faculty: Persons identified by the institution as such and whose assignments include conducting instruction, research, or public service as a principal activity 
(or activities). They may hold academic rank titles of professor, associate professor, assistant professor, instructor, lecturer, or the equivalent of any of those academic ranks. Faculty may also include the chancellor/ president, provost, vice provosts, deans, directors. or the equivalent, as well as associate deans, assistant deans, and executive officers of academic departments (chairpersons, heads, or the equivalent) if their principal activity is instruction combined with research and/or public service. Graduate, instruction, and research assistants are not included in this category.

Family income: Family income includes all monetary income from all sources (including jobs, businesses, interest, rent, and social security payments) over a 12 -month period. The income of nonrelatives living in the household is excluded, but the income of all family members age 15 or older (age 14 or older in years prior to 1989), including those temporarily living outside of the household, is included. In the October CPS, family income is determined from a single question asked of the household respondent.

Financial aid: Grants, loans, assistantships, scholarships, fellowships, tuition waivers, tuition discounts, veteran's benefits, employer aid (tuition reimbursement), and other monies (other than from relatives/friends) provided to students to help them meet expenses. This includes Title IV subsidized and unsubsidized loans made directly to students.

First-professional degree: As of fall 2010, the term firstprofessional degree is no longer used as reporting category in postsecondary education data collection. Degrees formerly reported under this category are now reported as a doctor's degree or master's degree. For example, Medical Doctorate (M.D.), Juris Prudence Doctorate (J.D.), Pharmacy Doctorate (Pharm.D), Doctorate of Veterinary Medicine (D.V.M) are now reported as doctor's degree, while Master's of Divinity (M.Div), Master's of Rabbinical Studies (M.H.L), and Master's of Law (L.L.M.) are reported as master's degree. See also Doctor's degree and Master's degree.

Four-year postsecondary institution: A postsecondary education institution that can award a bachelor's degree or higher. See also Postsecondary education and Appendix C - Commonly Used Measures.

Free or reduced-price lunch: See National School Lunch Program.

Full-time enrollment: The number of students enrolled in postsecondary education courses with a total credit load equal to at least 75 percent of the normal full-time course load.

Full-time-equivalent (FTE) enrollment: For institutions of higher education, enrollment of full-time students, plus the full-time equivalent of part-time students. The full-time equivalent of the part-time students is estimated using different factors depending on the level and control of institution and level of student.

GED certificate: This award is received following successful completion of the General Educational Development (GED) test. The GED program, sponsored by the American Council on Education, enables individuals to demonstrate that they have acquired a level of learning comparable to that of high school graduates. See also High school equivalency certificate.

Graduate: An individual who has received formal recognition for the successful completion of a prescribed program of studies.

Gross domestic product (GDP): Gross national product (GNP) less net property income from abroad. Both GNP and GDP aggregate only the incomes of residents of a nation, corporate and individual, derived directly from the current production of goods and services by individuals, businesses, and government; gross private domestic investment in infrastructure; and total exports of goods and services. The goods and services included are largely those bought for final use (excluding illegal transactions) in the market economy. A number of inclusions, however, represent imputed values, the most important of which is rental value of owner-occupied housing.

Head Start: A local public or private nonprofit or for-profit entity designated by the Department of Health and Human Services' Administration for Children and Families to operate a Head Start program to serve children age 3 to compulsory school age, pursuant to section 641(b) and (d) of the Head Start Act.

High school: A secondary school offering the final years of high school study necessary for graduation, in which the lowest grade is not lower than grade 9. Usually includes grades 10,11 , and 12 or grades $9,10,11$, and 12. Alternatively, according to the 2007-08 Schools and Staffing Survey, defined as a school with no grade lower than 7 and at least one grade higher than 8 .

High school completer: An individual who has been awarded a high school diploma or an equivalent credential, including a General Educational Development (GED) credential.

High school diploma: A formal document regulated by the state certifying the successful completion of a prescribed secondary school program of studies. In some states or communities, high school diplomas are differentiated by type, such as an academic diploma, a general diploma, or a vocational diploma. 
High school equivalency certificate: A formal document certifying that an individual has met the state requirements for high school graduation equivalency by obtaining satisfactory scores on an approved examination and meeting other performance requirements (if any) set by a state education agency or other appropriate body. One particular version of this certificate is the General Educational Development (GED) test. The GED test is a comprehensive test used primarily to appraise the educational development of students who have not completed their formal high school education and who may earn a high school equivalency certificate by achieving satisfactory scores. GEDs are awarded by the states or other agencies, and the test is developed and distributed by the GED Testing Service of the American Council on Education.

Hours worked per week: According to the October Current Population Survey, the number of hours a respondent worked in all jobs in the week prior to the survey interview.

Individuals with Disabilities Education Act (IDEA): IDEA is a federal law requiring services to children with disabilities throughout the nation. IDEA governs how states and public agencies provide early intervention, special education, and related services to more than 6.8 million eligible infants, toddlers, children, and youth with disabilities. Infants and toddlers with disabilities (birth-age 2) and their families receive early intervention services under IDEA, Part C. Children and youth (ages 3-21) receive special education and related services under IDEA, Part B.

Inflation: A rise in the general level of prices of goods and services in an economy over a period of time, which generally corresponds to a decline in the real value of money or a loss of purchasing power. See also Constant dollars and Purchasing Power Parity indexes.

Limited-English proficient: Refers to an individual who was not born in the United States or whose native language is a language other than English, or who comes from an environment where a language other than English has had a significant impact on the individual's level of English language proficiency. It may also refer to an individual who is migratory, whose native language is a language other than English, and who comes from an environment where a language other than English is dominant; and whose difficulties in speaking, reading, writing, or understanding the English language may be sufficient to deny the individual the ability to meet the state's proficient level of achievement on state assessments as specified under the No Child Left Behind Act, the ability to successfully achieve in classrooms where the language of instruction is English, or the opportunity to participate fully in society. See also English language learner.

Magnet school or program: A special school or program designed to reduce, prevent, or eliminate racial isolation and/or to provide an academic or social focus on a particular theme.

Master's degree: A degree awarded for successful completion of a program generally requiring 1 or 2 years of full-time college-level study beyond the bachelor's degree. One type of master's degree, which includes the Master of Arts degree, or M.A., and the Master of Science degree, or M.S., is awarded in the liberal arts and sciences for advanced scholarship in a subject field or discipline and for demonstrated ability to perform scholarly research. A second type of master's degree is awarded for the completion of a professionally oriented program-for example, an M.Ed in education, an M.B.A. in business administration, an M.F.A. in fine arts, an M.M. in music, an M.S.W. in social work, or an M.P.A. in public administration. A third type of master's degree is awarded in professional fields for study beyond the first-professional degree-for example, the Master of Laws (LL.M.) and Master of Science (M.S.) in various medical specializations.

Median earnings: The amount which divides the income distribution into two equal groups, half having income above that amount and half having income below that amount. Earnings include all wage and salary income. Unlike mean earnings, median earnings either do not change or change very little in response to extreme observations. The March Current Population Survey collects information on earnings from individuals who were full-year workers (individuals who were employed 50 or more weeks in the previous year) and full-time workers (those who were usually employed 35 or more hours per week).

Middle school: A school with no grade lower than 5 and no grade higher than 8 .

Montessori school: Montessori schools provide instruction using Montessori teaching methods.

National School Lunch Program: Established by President Truman in 1946, the program is a federally assisted meal program operated in public and private nonprofit schools and residential child care centers. To be eligible for free lunch, a student must be from a household with an income at or below 130 percent of the federal poverty guideline; to be eligible for reduced-price lunch, 
a student must be from a household with an income between 130 percent and 185 percent of the federal poverty guideline. See also Appendix C - Commonly Used Measures.

Nonresident alien: A person who is not a citizen of the United States, who is in this country on a temporary basis, and who does not have the right to remain indefinitely.

Nonsectarian school: Nonsectarian schools do not have a religious orientation or purpose and are categorized as regular, special program emphasis, or special education schools. See also Regular school, Special program emphasis school, and Special education school.

Nursery school: An instructional program for groups of children during the year or years preceding kindergarten, which provides educational experiences under the direction of teachers. See also Prekindergarten and Preschool.

Other religious school: Other religious schools have a religious orientation or purpose, but are not Roman Catholic. Other religious schools are categorized according to religious association membership as Conservative Christian, other affiliated, or unaffiliated.

Part-time enrollment: The number of students enrolled in postsecondary education courses with a total credit load of less than 75 percent of the normal full-time credit load.

Postbaccalaureate enrollment: The number of students with a bachelor's degree who are enrolled in graduate-level courses. See also Doctor's degree and Master's degree.

Postsecondary education: The provision of a formal instructional program whose curriculum is designed primarily for students who are beyond the compulsory age for high school. This includes programs whose purpose is academic, vocational, and continuing professional education, and excludes avocational and adult basic education programs. See also Appendix C - Commonly Used Measures.

Prekindergarten: Preprimary education for children typically ages 3-4 who have not yet entered kindergarten. It may offer a program of general education or special education and may be part of a collaborative effort with Head Start.

Preschool: An instructional program enrolling children generally younger than 5 years of age and organized to provide children with educational experiences under professionally qualified teachers during the year or years immediately preceding kindergarten (or prior to entry into elementary school when there is no kindergarten). See also Nursery school and Prekindergarten.

Primary school: A school with at least one grade lower than 5 and no grade higher than 8.

Private institution: An institution that is controlled by an individual or agency other than a state, a subdivision of a state, or the federal government; that is usually not supported primarily by public funds; and that is not operated by publicly elected or appointed officials. See also Appendix C - Commonly Used Measures. Types of private institutions include:

Private for-profit institution: A private institution in which the individual(s) or agency in control receives compensation other than wages, rent, or other expenses for the assumption of risk.

Private nonprofit institution: A private institution in which the individual(s) or agency in control receives no compensation, other than wages, rent, or other expenses for the assumption of risk. These include both independent nonprofit institutions and those affiliated with a religious organization.

Private schools: Private elementary/secondary schools surveyed by the Private School Universe Survey (PSS) are assigned to one of three major categories (Catholic, other religious, or nonsectarian) and, within each major category, one of three subcategories based on the school's religious affiliation provided by respondents.

Catholic: Catholic schools are categorized according to governance, provided by Catholic school respondents, into parochial, diocesan, and private schools.

Other religious: Other religious schools have a religious orientation or purpose, but are not Roman Catholic. Other religious schools are categorized according to religious association membership, provided by respondents, into Conservative Christian, other affiliated, and unaffiliated schools. Conservative Christian schools are those "Other religious" schools with membership in at least one of four associations: Accelerated Christian Education, American Association of Christian Schools, Association of Christian Schools International, or Oral Roberts University Education Fellowship. Affiliated schools are those "Other religious" schools not classified as Conservative Christian with membership in at least 1 of 11 associations-Association of Christian Teachers and Schools, Christian Schools International, Evangelical Lutheran Education Association, Friends Council on Education, General Conference of the Seventh-Day Adventist Church, Islamic School League of America, National Association of Episcopal Schools, National Christian School Association, National Society for Hebrew Day Schools, Solomon Schechter Day Schools, and Southern Baptist Association of Christian Schoolsor indicating membership in "other religious school 
associations." Unaffiliated schools are those "Other religious" schools that have a religious orientation or purpose, but are not classified as Conservative Christian or affiliated.

Nonsectarian: Nonsectarian schools do not have a religious orientation or purpose and are categorized according to program emphasis, provided by respondents, into regular, special emphasis, and special education schools. Regular schools are those that have a regular elementary/ secondary or early childhood program emphasis. Special emphasis schools are those that have a Montessori, vocational/technical, alternative, or special program emphasis. Special education schools are those that have a special education program emphasis.

Property tax: The sum of money collected from a tax levied against the value of property.

Public institution: A postsecondary education institution whose programs and activities are operated by publicly elected or appointed school officials and which is supported primarily by public funds. See also Appendix C - Commonly Used Measures.

Public school: A school that provides educational services for at least one of grades $\mathrm{K}-12$ (or comparable ungraded levels), has one or more teachers to give instruction, has an assigned administrator, receives public funds as primary support, and is operated by an education or chartering agency. Public schools include regular, special education, vocational/technical, alternative, and charter schools. They also include schools in juvenile detention centers, schools located on military bases and operated by the Department of Defense, and Bureau of Indian Education-funded schools operated by local public school districts. See also Special education school, Vocational school, Alternative school, Charter school, and Traditional public school.

Purchasing Power Parity (PPP) indexes: PPP exchange rates, or indexes, are the currency exchange rates that equalize the purchasing power of different currencies, meaning that when a given sum of money is converted into different currencies at the PPP exchange rates, it will buy the same basket of goods and services in all countries. PPP indexes are the rates of currency conversion that eliminate the difference in price levels among countries. Thus, when expenditures on gross domestic product (GDP) for different countries are converted into a common currency by means of PPP indexes, they are expressed at the same set of international prices, so that comparisons among countries reflect only differences in the volume of goods and services purchased.

Regular school: A public elementary/secondary school providing instruction and education services that does not focus primarily on special education, vocational/technical education, or alternative education, or on any of the particular themes associated with magnet/special program emphasis schools.

Revenues: Funds that are appropriated to schools and education institutions. See also Appendix C - Finance.

Salary: The total amount regularly paid or stipulated to be paid to an individual, before deductions, for personal services rendered while on the payroll of a business or organization.

Secondary school: A school with one or more of grades $7-12$ that does not have any grade lower than grade 7 . For example, schools with grades 9-12, 7-9, 10-12, or 7-8 are classified as secondary.

Special education school: An elementary/secondary school that (1) focuses primarily on special education, including instruction for any of the following groups of students: hard of hearing, deaf, speech impaired, health impaired, orthopedically impaired, intellectually disabled, seriously emotionally disturbed, multi-handicapped, visually handicapped, deaf and blind, and the learning disabled; and (2) adapts curriculum, materials, or instruction for students served.

Special program emphasis school: A science/ mathematics school, a performing arts high school, a foreign language immersion school, and a talented/gifted school are examples of schools that offer a special program emphasis.

STEM fields: Science, Technology, Engineering, and Mathematics (STEM) fields of study that are considered to be of particular relevance to advanced societies. For the purposes of The Condition of Education 2012, STEM fields include agriculture and natural resources, biological and biomedical sciences, computer and information sciences and support services, engineering and engineering technologies, mathematics and statistics, physical sciences, and science technologies.

Student membership: Student membership is an annual headcount of students enrolled in school on October 1 or the school day closest to that date. The Common Core of Data (CCD) allows a student to be reported for only a single school or agency. For example, a vocational school (identified as a "shared time" school) may provide classes for students from a number of districts and show no membership.

Title I school: A school designated under appropriate state and federal regulations as a high-poverty school 
that is eligible for participation in programs authorized by Title I of the Reauthorization of the Elementary and Secondary Education Act, P.L. 107-110.

Title IV institution: An institution that has a written agreement with the Secretary of Education that allows the institution to participate in any of the Title IV federal student financial assistance programs (other than the State Student Incentive Grant [SSIG] and the National Early Intervention Scholarship and Partnership [NEISP] programs).

Traditional public school: Traditional public schools are publicly funded schools other than public charter schools. See also Public school and Charter school.

Tuition: The amount of money charged to students for instructional services. Tuition may be charged per term, per course, or per credit.

Two-year postsecondary institution: A postsecondary education institution that does not confer bachelor's or higher degrees, but does provide 2-year programs that result in a certificate or an associate's degree, or 2-year programs that fulfill part of the requirements for a bachelor's degree at a 4-year institution. See also Postsecondary education and Appendix C - Commonly Used Measures.

Undergraduate student: A student enrolled in a 4- or 5-year bachelor's degree program, an associate's degree program, or a vocational or technical program below the baccalaureate level.

Vocational school: A secondary school that focuses primarily on vocational, technical, or career education and provides education and training in one or more occupations. It may be part of a regular district (along with academic schools) or in a vocational district (serving more than one academic school district). 
This page intentionally left blank.

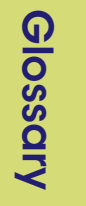

Appendix D-Glossary 323 
324 The Condition of Education 2012 


\section{APPENDIX E Bibliography}




\section{NCES Publications}

Aud, S., Hussar, W., Kena, G., Bianco, K., Frohlich, L., Kemp, J., and Tahan, K. (2011). The Condition of Education 2011 (NCES 2011-033). National Center for Education Statistics, U.S. Department of Education. Washington, DC: U.S. Government Printing Office.

Fleischman, H.L., Hopstock, P.J., Pelczar, M.P., and Shelley, B.E. (2010). Highlights From PISA 2009:

Performance of U.S. 15-Year-Old Students in Reading, Mathematics, and Science Literacy in an International Context (NCES 2011-004). National Center for Education Statistics, Institute of Education Sciences, U.S. Department of Education. Washington, DC.

Hussar, W.J., and Bailey, T.M. (2012). Projections of Education Statistics to 2021 (NCES 2012-044). National Center for Education Statistics, Institute of Education Sciences, U.S. Department of Education. Washington, DC: U.S. Government Printing Office.

Nord, C., Roey, S., Perkins, R., Lyons, M., Lemanski, N., Brown, J., and Schuknecht, J. (2011). The Nation's Report Card: America's High School Graduates (NCES 2011-462). U.S. Department of Education, National Center for Education Statistics. Washington, DC: U.S. Government Printing Office.

Robers, S., Zhang, J., and Truman, J. (2012). Indicators of School Crime and Safety: 2011 (NCES 2012-002/

NCJ 236021). National Center for Education Statistics, U.S. Department of Education, and Bureau of Justice Statistics, Office of Justice Programs, U.S. Department of Justice. Washington, DC: U.S. Government Printing Office.

Snyder, T.D., and Dillow, S.A. (2012). Digest of Education Statistics 2011 (NCES 2012-001). National Center for Education Statistics, Institute of Education Sciences, U.S. Department of Education. Washington, DC: U.S. Government Printing Office.

U.S. Department of Education, Institute of Education Sciences, National Center for Education Statistics (2011). The Nation's Report Card: Civics 2010 (NCES 2011-466). Washington, DC: Author.

U.S. Department of Education, Institute of Education Sciences, National Center for Education Statistics (2011). The Nation's Report Card: Geography 2010 (NCES 2011467). Washington, DC: Author.

U.S. Department of Education, Institute of Education Sciences, National Center for Education Statistics (2011). The Nation's Report Card: Mathematics 2011 (NCES 2012458). Washington, DC: Author.
U.S. Department of Education, Institute of Education Sciences, National Center for Education Statistics (2011). The Nation's Report Card: Reading 2011 (NCES 2012457). Washington, DC: Author.

U.S. Department of Education, Institute of Education Sciences, National Center for Education Statistics (2011). The Nation's Report Card: U.S. History 2010 (NCES 2011468). Washington, DC: Author.

U.S. Department of Education, Institute of Education Sciences, National Center for Education Statistics. (2010). The Nation's Report Card: Grade 12 Reading and Mathematics 2009 National and Pilot State Results (NCES 2011-455). Washington, DC: Author.

U.S. Department of Education, National Center for Education Statistics. (2011). Classification of Instructional Programs 2010. Retrieved March 20, 2012 from http:// nces.ed.gov/ipeds/cipcode/.

\section{Other Publications}

Education Commission of the States. (2010). ECS

StateNotes: State Characteristics, Kindergarten.

Retrieved March 20, 2012, from http://www.ecs.org/ clearinghouse/90/71/9071.pdf.

Education Commission of the States. (2011). District Offering of Full-Day Kindergarten. Retrieved March 20, 2012, from http://ecs.force.com/ecsforum/mbtab2?rep=K D33\&SID =a0i70000000XkGj\&Q=Q2207\&Q1=Q2208.

Higher Education Opportunity Act, Public Law 110-315 (2008). Washington, DC: U.S. Government Printing Office.

Individuals with Disabilities Education Improvement Act of 2004,20 U.S.C. $\$ 1400$ et seq. (2004).

Nelson, B., Berman, P., Ericson, J., Kamprath, N., Perry, R., Silverman, D., and Solomon, D. (2000). The State of Charter Schools 2000: Fourth-Year Report. U.S. Department of Education, Washington, DC: Office of Educational Research and Improvement. Retrieved March 20, 2012, from http://www2.ed.gov/PDFDocs/4yrrpt.pdf.

Office of Management and Budget Revisions to the Standards for the Classification of Federal Data on Race and Ethnicity, 62 Federal Register 58782-58790 (Oct. 30, 1997).

Organization for Economic Co-operation and Development (2010). PISA 2009 Results: Learning Trends - Changes in Student Performance Since 2000 (Volume V). OECD Publishing. Retrieved March 20, 2012, from http://www.oecd.org/document/60/0,334

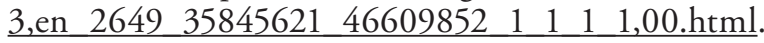


Organization for Economic Co-operation and Development, Center for Educational Research and Innovation (2011). Education at a Glance, 2011: OECD Indicators. Retrieved March 20, 2012, from http://www. oecd.org/edu/eag2011.

Theil, H. (1975). Theory and Measurement of Consumer Demand: Volume 1. Amsterdam: North-Holland Publishing Company.

U.S. Department of Commerce, Bureau of Economic Analysis. (n.d.) National Income and Product Accounts Tables. Retrieved March 20, 2012, from http://www.bea. gov/national/nipaweb/Index.asp.

U.S. Department of Commerce, Census Bureau. (2012). Poverty Thresholds. Retrieved March 20, 2012, from http://www.census.gov/hhes/www/poverty/data/threshld/ index.html.

U.S. Department of Education, Office of Special Education and Rehabilitative Services, Office of Special Education Programs. (2011). 30th Annual Report to Congress on the Implementation of the Individuals with Disabilities Education Act, 2008. Washington, DC: Author.

U.S. Department of Labor, Bureau of Labor Statistics. (n.d.) Consumer Price Index. Retrieved March 20, 2012, from http://www.bls.gov/cpi/.

\section{NCES Surveys}

The Common Core of Data (CCD). Available: http://nces. ed.gov/ccd/.

Fast Response Survey System (FRSS). Available: http:// nces.ed.gov/surveys/frss.

Higher Education General Information Survey (HEGIS). Available: http://www.icpsr.umich.edu/icpsrweb/ICPSR/ series/00030.

Integrated Postsecondary Education Data System (IPEDS). Available: http://nces.ed.gov/ipeds/.

National Assessment of Educational Progress (NAEP). Available: http://nces.ed.gov/nationsreportcard/.

Private School Universe Survey (PSS). Available: http:// nces.ed.gov/surveys/pss/.

School Survey on Crime and Safety (SSOCS). Available: http://nces.ed.gov/surveys/ssocs.

Schools and Staffing Survey (SASS). Available: http://nces. ed.gov/surveys/SASS/.

\section{Surveys From Other Agencies}

Organization for Economic Co-operation and Development (OECD), Program for International Student Assessment (PISA). Available: http://nces.ed.gov/Surveys/ PISA.

U.S. Department of Commerce, Census Bureau, American Community Survey (ACS). Available: http:// www.census.gov/acs/www/.

U.S. Department of Commerce, Census Bureau, Current Population Survey (CPS). Available: http://www.census. gov/cps/.

U.S. Department of Health and Human Services, National Institute on Drug Abuse, Monitoring the Future. Available: http://www.monitoringthefuture.org. 


\section{APPENDIX F Index}


Appendix F is the cumulative index for the 2008-2012 print editions of The Condition of Education.

The year of publication appears in bold type. Arabic numerals (e.g., 2, 3, 4) following the year refer to Indicator numbers. References beginning with "TF" (e.g., TF2, TF3, TF4) refer to page numbers in the Topics in Focus.

Please note that some indicators may no longer appear in the Indicator List on The Condition of Education website and can only be found in the print editions (PDFs).

Absenteeism of elementary/secondary students, 2012:28, 2012: TF8

Academic clubs, participation in high school, 2012:27

Academic Competitiveness Grant (ACG), 2012:40

Academic preparation. See Coursetaking by high school students

Academic rank, 2008:42, 2009:43, 2010:44, 2011:44, 2012:44

Academic support, 2009:46, 2010:49, 2011:50, 2012:43

Accommodations. See Testing accommodations

Achievement levels/tests

civics performance through elementary/secondary level, 2012:25

coursetaking by students affecting, 2012:31

for high school students in past 20 years, 2012:TF9TF10

geography performance through elementary/secondary level, 2012:25

international comparisons (See International comparisons)

mathematics performance in 4th, 8 th, and 12 th grade, 2011:12, 2011:13, 2012:24

mathematics performance in 4th and 8th grade, 2008:13, 2009:13, 2010:11, 2010:12 (See also Mathematics)

reading performance through elementary/secondary level, 2008:12, 2009:12, 2010:9, 2010:10, 2011:10, 2011:11, 2012:23 (See also Reading)

science performance in 4 th, 8 th, and 12 th grade, 2011:13, 2011:14 (See also Science)

U.S. history performance through elementary/secondary level, 2012:25

writing performance in 8th and 12th grade, 2008:14

Administration, expenditures in public elementary/ secondary schools for, 2008:35, 2009:34, 2010:34, 2011:36, 2012:20
Adult literacy. See Literacy

Advanced degrees. See Educational attainment; Graduate degrees

Affiliated schools, 2008:4, 2009:5, 2010:3, 2011:4, 2012:5. See also Private elementary/secondary schools

Age/Age comparisons. See also Grade-level studies compulsory school attendance, 2008:1, 2009:1, 2010:1, 2011:1, 2012:1

crime in schools, 2008:28

educational attainment, 2011:25

employment of high school students, 2012:30

enrollment in postsecondary education by level and control of institution, 2011:TF8

home activities and early childhood development, 2009:2

mathematics performance, 2008:17, 2009:14, 2010:13

preprimary education enrollment by, 2008:2, 2012:2

principals at elementary/secondary schools, 2010:29, 2011:33, 2012: 18

reading performance, 2008:17, 2009:14, 2010:13 remedial coursetaking by undergraduates, 2011:22 youth neither enrolled nor working, 2012:29

Algebra. See also Mathematics

coursetaking by high school students, 2012:31, 2012: TF7

international comparisons of skill levels, 2010:15

Alternative schools, 2009:31, 2010:24, 2010:31, 2011:27

American Community Survey (ACS), 2008:7, 2009:8, 2009:20, 2010:5, 2010:19, 2011:1, 2011:6, 2011:20, 2012:1, 2012:33

American students studying abroad, 2010:40

Art, 2010: 14

Assessment of students. See Achievement levels/tests

Assistantships, graduate education, 2010:48, 2011:48

Associate's degrees, 2008:26, 2009:24, 2010:23, 2011:26

awarded by field of study, 2008:39, 2009:40, 2010:41, 2011:40, 2012:38

awarded by level and control of institution, 2011:TF7

awarded by public and private institutions, 2008:41, 2009:42, 2010:43, 2011:42, 2012:46

completion rates, 2011:23, 2011:TF14, 2012:45

earnings of young adults affected by, 2008:20, 2009:17, 2010:17, 2011:17, 2012:49

increase in degrees earned, 2012:47

Athletics, participation in high school, 2012:27

At-risk students, 2010:24, 2011:27 
“At school" definition, 2012:14

Attainment in education. See Educational attainment

Attendance patterns, elementary/secondary education, 2012:28, 2012:TF8

Attendance status, postsecondary education. See also Fulltime enrollment at postsecondary institutions; Parttime enrollment at postsecondary institutions

employment of college students, 2012:37

by level and control of institution, 2011:TF8, 2011:TF9

undergraduate enrollment, 2008:9, 2009:10, 2010:7, 2011:8, 2012:10, 2012:36

Attrition rates

principals, 2011:34

teachers, 2008:31, 2011:32

Auxiliary enterprises, 2009:46, 2010:49, 2011:50, 2012:42, 2012:43

Averaged freshman graduation rate from high school, 2008:21, 2009:19, 2010:18, 2011:19, 2012:32, 2012:TF11, 2012:TF12

Bachelor's degrees. See also Educational attainment awarded by field of study, 2008:39, 2009:40, 2010:41, 2011:40, 2012:38

awarded by level and control of institution, 2011:TF7TF8

awarded by public and private institutions, 2008:41, 2009:42, 2010:43, 2011:42, 2012:46

awarded by race/ethnicity, 2008:25, 2009:23, 2010:22, 2011:24, 2012:48

completion rates, 2011:23, 2011:TF13-TF14, 2012:45

earnings of young adults affected by, 2008:20, 2009:17, 2010:17, 2011:17, 2012:49

increase in degrees earned, 2008:26, 2009:24, 2010:23, 2011:26, 2012:47

international comparisons of attainment, 2011:25

parents attaining, 2008:6, 2012:7

time to completion, 2009:22, 2010:21

women earning, 2008:27

Benefits to faculty at postsecondary institutions, 2008:42, 2009:43, 2010:44, 2011:44, 2012:44

Biology

coursetaking by high school students, 2012:31, 2012:TF7

international comparisons for 8th-grade skills, 2010:16

Business, degrees in, 2008:39, 2008:40, 2009:40,

2009:41, 2010:41, 2010:42, 2010:48, 2011:40,
2011:41, 2012:38, 2012:39

Byrd scholarships, 2010:46, 2011:46

Calculus. See also Mathematics

coursetaking by high school students, 2012:31, 2012:TF7

Capital outlay, 2009:34, 2010:34, 2011:36, 2012:20

Carnegie units for secondary education, mathematics and science courses taken by high school students, 2012:31

Catholic schools, 2008:4, 2009:5, 2010:3, 2011:4, 2012:5. See also Private elementary/secondary schools enrollment in high schools, 2012:TF6TF7

Center-based child care programs, enrollment in, 2008:2

Certificate programs, 2011:TF14

Certification for teachers, 2010:27, 2011:31, 2012:17

National Board for Professional Teaching Standards (NBPTS), 2010:37

newly hired elementary/secondary teachers, 2010:28

Certification of attendance, 2008:22

Charter schools, 2010:24, 2010:32, 2011:3, 2011:27, 2012:4

characteristics and distribution of, 2012:12

high school enrollment, 2012:TF7

Chemistry

coursetaking by high school students, 2012:31, 2012:TF7

international comparisons for 8th-grade skills, 2010:16

Child care, arrangements by type of care, 2008:2, 2012:2

Choice of school, elementary/secondary education. See School choice

Choices of students for high school curriculum. See Coursetaking by high school students

Church-related private schools. See Private elementary/ secondary schools; Religious affiliation, private elementary/secondary schools

Civics performance through elementary secondary level, 2012:25, 2012:TF10

Classification of Instructional Programs, 2008:39, 2008:40, 2009:40, 2009:41, 2010:41, 2010:42, 2011:40, 2011:41, 2012:38, 2012:39

Classification of Postsecondary Education Institutions, 2010:7, 2011:8, 2012:10

Class size in elementary/secondary schools, pupil/teacher ratio as proxy measure for, 2008:33, 2009:31, 2010:31 
Cognitive skills, 2009:3

College education. See Postsecondary education

College preparation. See Transition to postsecondary education

Colleges. See Four-year institutions; Postsecondary education; Two-year institutions

Common Core of Data (CCD), 2010:24, 2010:32, 2011:3, 2011:27, 2012:4, 2012:12

Community colleges. See Two-year institutions

Community type. See Urbanicity

Comparable Wage Index (CWI), 2008:36, 2008:37

Compensation to faculty, 2008:42, 2009:43, 2010:44, 2011:44, 2012:44. See also Benefits to faculty at postsecondary institutions; Salaries

Completion rates of high school education, 2008:23, 2008:25, 2009:20, 2009:23, 2010:19, 2010:22, 2011:20, 2011:24, 2012:33, 2012: 48

Compulsory age of school attendance, 2008:1, 2009:1, 2010:1, 2011:1, 2012:1, 2012:TF6

Computer sciences, degrees in, 2008:39, 2008:40, 2009:40, 2009:41, 2010:41, 2010:42, 2011:40, 2011:41, 2012:38, 2012:39

Conservative Christian schools, 2008:4, 2009:5, 2010:3, 2011:4, 2012:5

Consumer Price Index (CPI)

annual earnings of young adults measured by, 2008:20, 2009:17, 2010:17, 2011:17, 2012:49

current expenditures for public elementary/secondary education, 2008:35, 2009:34, 2010:34, 2011:36, 2012:20

expenditures per student by school district, 2009:36, 2010:36

faculty salaries measured by, 2008:42, 2009:43, 2010:44, 2011:44

revenues to school districts, 2009:33, 2010:33, 2011:35, 2012:19

salaries of principals, 2010:29, 2011:33, 2012:18

Consumer Price Index for All Urban Consumers (CPI-U), 2010:46, 2010:47, 2011:46, 2011:47, 2011:TF11

Control of postsecondary institution, 2011:TF7-TF15

Cost of attending college

by level and control of institution, 2011:TF11-TF12

graduate studies, 2010:48, 2011:48

net price of, 2010:47, 2011:47, 2012:40

student loans and default rates, 2011:49

Coursetaking by high school students, 2012:31, 2012: TF7-TF8

mathematics and science courses, 2012:31
Crime in schools, 2008:28, 2009:27, 2010:26, 2011:30, 2012:14, 2012:TF8

Current expenditures for public elementary/secondary education, 2008:35, 2008:37, 2009:34, 2009:36, 2010:34, 2010:36, 2011:36, 2012:20

Current Population Survey (CPS)

early education and child care, 2012:2

earnings of young adults, 2008:20, 2009:17, 2010:17, 2011:17

educational attainment, 2008:25, 2009:23, 2010:22, 2011:24, 2012:48

enrollment rates in college, 2010:20, 2011:21, 2012:34 enrollment trends by age, 2011:1, 2012:1

language spoken at home, 2008:7, 2009:8, 2010:5

status dropout rates, 2009:20, 2010:19, 2011:20, 2012:33

young adults not in school or working, 2012:29

Curriculum, high school. See Coursetaking by high school students

Data and chance, international comparisons of skill levels in, 2010: 15

Data display, international comparisons of skill levels in, 2010:15

Degrees earned. See also Associate's degrees; Bachelor's degrees; Educational attainment; Graduate degrees awarded by field of study, 2008:39, 2008:40, 2009:40, 2009:41, 2010:41, 2010:42, 2011:40, 2011:41, 2012:38, 2012:39

awarded by level and control of institution, 2011:TF13-TF14

awarded by public and private institutions, 2008:41, 2009:42, 2010:43, 2011:42, 2011:TF7-TF9, 2012:46

awarded by race/ethnicity, 2008:25, 2008:26, 2009:23, 2009:24, 2010:22, 2010:23, 2011:24, 2011:26, 2012:47, 2012:48

characteristics of undergraduate institutions, 2011:39, 2012:36

newly hired elementary/secondary teachers, 2010:28

principals at elementary/secondary schools, 2011:33, 2012:18

teachers at elementary/secondary schools, 2010:27, 2011:31, 2012:17

women earning, 2008:27

Delayed entrants (teachers), 2010:28

Delayed entry to kindergarten. See Kindergarten 
Delivery of education, postsecondary level, 2011:TF9

Dependency status for undergraduate students, 2011:43

Direct-entry teachers, 2010:28

Disabilities, students with

high school graduation rates of, 2008:22

public school enrollment, 2008:8, 2009:9, 2010:6,

2011:7, 2012:9

testing accommodations, 2008:12, 2008:13, 2009:12, 2009:13, 2010:9, 2010:10, 2010:11, 2010:12, 2011:10, 2011:11, 2011:12, 2011:13, 2012:23, 2012:24, 2012:25

Distance education, 2008: 10

by institution level and control, 2011:TF9, 2011:TF10 high school students taking courses through, 2012:15, 2012:TF8

undergraduates taking courses through, 2011:43

Doctoral degrees, 2008:26, 2009:24, 2010:23, 2011:26,

2012:47. See also Graduate degrees

awarded by field of study, 2008:40, 2009:41, 2010:42, 2011:41, 2012:39

awarded by public and private institutions, 2008:41, 2009:42, 2010:43, 2011:42, 2012:46

increase in degrees earned, 2012:47

rate of enrollment, 2012:11

women earning, 2008:27

Doctoral institutions, criteria for designation as, 2008:42, 2009:43, 2010:44, 2011:44, 2012:44

Dropout rates

by race/ethnicity, 2008:23, 2009:20, 2010:19, 2011:20, 2012:33

students with disabilities, 2008:22

youth neither enrolled nor working, 2012:29

Early childhood education. See Preprimary education

Early Childhood Longitudinal Study Birth Cohort of 2001 (ECLS-B)

early education and child care, 2008:2

home activities and early childhood development, 2009:2

knowledge and skills of young children, 2009:3

Earnings, young adults, 2008:20, 2009:17, 2010:17, 2011:17, 2012:49. See also Income

Earth sciences, 2010:16

Economics performance of high school seniors, 2008:15
Education, degrees in, 2008:39, 2008:40, 2009:40, 2009:41, 2010:41, 2010:42, 2011:40, 2011:41, 2012:38, 2012:39

Educational attainment. See also Degrees earned awarded by race/ethnicity, 2008:25, 2009:23, 2010:22, 2011:24, 2012:48

earnings of young adults and, 2008:20, 2009:17, 2010:17, 2011:17, 2012:49 (See also Income)

employment status by, 2011:18

graduate degree completion (See Graduate degrees)

international comparisons, 2011:25

parents of high school students, 2012:TF12-TF13 (See also under Parents)

parents of school-age children, 2008:6, 2012:7 (See also under Parents)

Education for All Handicapped Children Act (EAHCA), 2012:9

Eighth grade

absenteeism in, 2012:28

art and music achievement, 2010:14

civics performance in, 2012:25

geography performance in, 2012:25

international comparisons of mathematics performance, 2009: 15, 2010:15

international comparisons of science performance, 2009:16, 2010:16

mathematics performance in, 2008:13, 2009:13, 2010:11, 2010:12, 2011:12, 2011:13, 2012:24

reading and mathematics achievement gaps, 2008:16, 2011:11, 2011:13

reading performance in, 2008:12, 2009:12, 2010:9, 2010:10, 2011:10, 2011:11, 2012:23

science performance in, 2011:14

U.S. history performance in, 2012:25

writing performance in, 2008:14

Elementary schools

staff in public schools, 2008:32, 2010:30

student/teacher ratios, 2008:33, 2009:31, 2010:31

Elementary/secondary education, 2008:28-38, 2009:4-9, 2009:25-37, 2010:2-6, 2010:24-38, 2011:2-7, 2011:27-38, 2012:3-9, 2012:12-35. See also Private elementary/secondary schools; Public elementary/secondary schools

children who spoke a language other than English at home, 2008:7, 2009:8, 2010:5, 2011:6, 2012:8

crime in schools, 2008:28, 2009:27, 2010:26, 2011:30, 2012: 14 
disabilities, students with, 2010:6, 2011:7, 2012:9 (See also Disabilities, students with)

enrollment, 2008:1, 2008:3, 2009:1, 2009:4, 2010:1, 2011:1, 2012:1

enrollment, public schools, 2010:2, 2011:2, 2012:3

grade retention of students, 2009:18

graduation rates, 2008:21, 2009:19, 2010:18, 2011:19, 2012:32

high school graduation rates by students with disabilities, 2008:22

high school students, 2012:TF6-TF13

international comparisons for mathematics, 2009:15, 2010:15

international comparisons of expenditures for, 2008:38, 2009:37, 2010:38, 2011:38, 2012:22

mathematics achievement (See Mathematics)

parental educational attainment (See Parents, level of education)

principals, 2010:29, 2011:33, 2012:18

private schools, 2008:4, 2009:5, 2010:3, 2011:4, 2012:5 (See also Private elementary/secondary schools)

race/ethnicity in, 2008:5, 2009:7, 2010:4, 2011:5, 2012:6 (See also Race/ethnicity)

reading achievement (See Reading)

retention rates for high school, 2012:16

school choice, 2009:32

science achievement (See Science)

staff in public schools, 2010:30

teachers, 2012:17

teachers/teaching (See Teachers/Teaching)

Emotional disturbances, 2008:22

Employee benefits, 2009:34, 2010:34, 2011:36, 2012:20

Employer financial aid for adult education, 2010:48, 2011:48

Employment status. See also Unemployment

by educational attainment, 2011:18

of high school students, 2012:30, 2012:TF8-TF9

of students while earning postsecondary degree,

2008:43, 2009:44, 2010:45, 2011:45, 2012:37

(See also Working while attending school

(postsecondary education))

young adults, earnings of, 2009:17, 2010:17, 2011:17, 2012: 49

Endowments, 2009:46, 2010:49, 2011:50, 2012:42

Engineering, coursetaking by high school students, 2012: TF7
Engineering, degrees in, 2008:39, 2008:40, 2009:40, 2009:41, 2010:41, 2010:42, 2011:40, 2011:41, 2012:38, 2012:39

English and literature, degrees in, 2008:40

English as a Second Language (ESL). See English language learners

English language learners. See also Limited English proficiency (LEP)

language spoken at home, 2008:7, 2009:8, 2010:5, 2011:6, 2012:8

testing accommodations for, 2012:23, 2012:24, 2012:25

English Speakers of Other Languages (ESOL). See English language learners; Limited English proficiency (LEP)

Enrollment, elementary/secondary schools

by age, 2008:1, 2009:1, 2010:1, 2011:1, 2012:1

charter schools, 2010:32, 2011:3, 2012:4

distance education by high school students, 2012:15

grade retention of students, 2009:18

in high schools, 2012:TF6-TF7

past and projected, 2008:3, 2009:4, 2010:2, 2011:2, 2012:3

private elementary/secondary schools, 2008:4, 2009:5, 2010:3, 2011:4, 2012:5 (See also Private elementary/secondary schools)

public schools, 2008:30, 2009:26 (See also Public elementary/secondary schools)

student/teacher ratios, 2008:33, 2009:31, 2010:31

Enrollment, postsecondary education

by age, 2008:1, 2009:1, 2010:1, 2011:1, 2012:1

by institution level and control, 2011:TF7-TF9

expenditures of institutions per full-time equivalent student, 2012:43

immediately after high school, 2008:24, 2009:21, 2010:20, 2011:21, 2012:34, 2012:TF12

revenues of institutions per full-time equivalent student, 2012: 42

undergraduate level, 2008:9, 2009:10, 2010:7, 2011:8, 2012:10 (See also Undergraduate students)

Event dropout rates. See Dropout rates

Expenditures for elementary/secondary education

by category of expenditure, 2008:35, 2009:34, 2010:34, 2011:36, 2012:20

by poverty level of school district, 2008:37, 2009:36, 2010:36

international comparisons, 2008:38, 2009:37, 2010:38, 2011:38, 2012:22 
per student, 2008:36, 2009:35, 2010:35, 2011:37, 2012:21

Expenditures for postsecondary institutions, 2009:46,

2010:49, 2011:50, 2011:TF9-TF10, 2012:43

Expulsions from elementary/secondary schools, 2009:28

Extended families. See Families

Extracurricular activities in high school, 2012:27, 2012:TF8

Faculty, postsecondary education. See also Teachers/ Teaching

salaries and benefits for, 2008:42, 2009:43, 2010:44, 2011:44, 2012:44

Families, 2008:6, 2012:7. See also Income, family; Parents child care, 2008:2, 2012:2

child development activities, 2009:2

home activities of, 2009:2

Family and consumer science, degrees in, 2009:40, 2010:41, 2011:40, 2012:38

Fathers. See Parents

Federal Family Education Loan (FFEL) Program, 2011:49, 2011:TF13, 2011:TF15

Federal government

grants to students, 2009:45, 2010:46, 2011:46, 2012: 41

revenues to postsecondary institutions, 2009:46, 2010: 49

revenues to school districts, 2008:34, 2009:33, 2010:33, 2011:35, 2012:19

student loans increasing from, 2010:46, 2011:46, 2012: 41

Federal Student Aid Direct Loan and Federal Family Education Loan Programs Cohort Default Rate, 2011:49, 2011:TF15

Federal Supplemental Educational Opportunity Grant (FSEOG), 2012:40

Federal Work-Study program, 2012:40

Field of study

degrees earned, 2008:39, 2008:40, 2009:40, 2009:41, 2010:41, 2010:42, 2011:40, 2011:41, 2012:38, 2012:39

degrees earned by women, 2008:27

United States students studying abroad, 2010:40

Fights in school. See Violence at schools

Financial Accounting Standards Board (GASB), 2012:42

Financial aid to students, 2009:45 by institution level and control, 2011:TF11-TF13

cost of attending college, 2010:47, 2011:47, 2012:40

grants, 2010:48, 2011:48 (See also Grants and scholarships)

source information on, 2011:TF15

student loans, 2010:46, 2011:46 (See also Student loans)

student loans from federal government, 2012:41

Firefighting, degrees in, 2012:38, 2012:39

First-professional degrees, 2008:26, 2008:40, 2009:24, 2009:41, 2010:23, 2010:42, 2011:26, 2011:41. See Doctoral degrees from Condition of Education 2012 onwards

awarded by public and private institutions, 2008:41, 2009:42, 2010:43, 2011:42

cost of programs, 2010:48, 2011:48

rate of enrollment, 2008:11, 2009:11, 2010:8, 2011:9

First-time students, financial aid to, 2009: 45

Fitness studies, 2011:40, 2012:38

Five New Basics curriculum, 2012:TF7

Food services expenditures, 2008:35, 2009:34, 2010:34, 2011:36, 2012:20

Foreign-born children, 2009:20, 2010:19, 2011:20, 2012:30, 2012:33. See also Immigrants/ Immigration

Foreign students in postsecondary institutions, 2008:10, 2008: 11, 2008:26, 2009:11, 2009:24, 2009:39, 2010:8, 2010:23, 2010:39, 2011:9, 2011:26, 2012:11, 2012:47

For-profit private postsecondary institutions, 2011:39, 2012:36

degrees conferred at, 2011:42, 2012:46

distance education courses, 2011:43, 2011:TF9, 2011:TF10

enrollment trends, 2011:TF7-TF9

expenses, 2011:TF9-TF10

expenses for, 2012:43

financial aid to students, 2012:41

graduation rates, 2011:TF13-TF14

revenues and expenses for, 2011:50

revenues for, 2012:42

student financing, 2011:TF11-TF13

student loans and default rates, 2011:49

Fourth grade

absenteeism in, 2012:28

civics performance in, 2012:25

geography performance in, 2012:25 
international comparisons of mathematics performance, 2009: 15, 2010:15

international comparisons of reading literacy in, 2008: 18

international comparisons of science performance, 2009:16, 2010:16

mathematics performance in, 2008:13, 2009:13, 2010:11, 2010:12, 2011:12, 2011:13, 2012:24

reading and mathematics achievement gaps, 2008:16 reading performance in, 2008:12, 2009:12, 2010:9, 2010:10, 2011:10, 2011:11, 2012:23

science performance in, 2011:14

U.S. history performance in, 2012:25

Four-year institutions. See also Postsecondary education characteristics of, 2011:39, 2012:36

distance education courses at, 2011:43

enrollment rates, 2008:9, 2008:24, 2009:10, 2009:21, 2010:7, 2010:20, 2011:8, 2011:21, 2012:10, 2012:34

expenses for, 2012:43

faculty salaries and benefits at, 2008:42, 2009:43, 2010:44, 2011:44, 2012:44

financial aid to first-year students, 2009:45

financial aid to students, 2012:41

graduation rates, 2011:23, 2012:45

net price for, 2010:47, 2011:47, 2012:40

number of, 2009:42, 2010:43, 2011:42

racial/ethnic concentration in, 2009:38, 2010:39

remedial coursetaking by undergraduates, 2011:22

revenues and expenses for, 2011:50

revenues for, 2012:42

student loans and default rates, 2011:49

students working while attending, 2008:43, 2009:44, 2010:45, 2011:45, 2012:37

time to completion for bachelor's degree, 2009:22, 2010:21

undergraduate enrollment, 2010:24, 2011:27 (See also Undergraduate students)

Free or reduced-price lunch (FRPL) programs, 2008:29, 2009: 25

art and music achievement, 2010:14

characteristics of elementary/secondary schools, 2012:12

charter schools, 2011:3

coursetaking by high school students, 2012:31

crime in schools, 2009:27, 2010:26, 2012:14 mathematics achievement gap through elementary/ secondary level, 2011:13

poverty levels measured by, 2008:29, 2009:25, 2010:25, 2011:28, 2012:13

public charter schools, 2012:4

public school characteristics, 2010:24, 2011:27

reading achievement gap through elementary/secondary level, 2011:11

retention rates in high schools, 2012:16

science achievement through elementary/secondary level, 2011:14

students per staff member, 2008:32, 2010:30

student/teacher ratio, 2009:31, 2010:31

teacher pay incentives in schools offering, 2010:37 turnover rates for teachers, 2008:31

Freshman undergraduates. See also Undergraduate students, in-state and out-of-state attendance at college, 2008:10 remedial coursetaking by, 2011:22

Fringe benefits to faculty at postsecondary institutions, 2012: 44

Full-day preprimary programs, 2012:2

Full-time enrollment at postsecondary institutions. See also Enrollment, postsecondary education

by level and control of institution, 2011:TF8-TF11

employment during, 2008:43, 2009:44, 2010:45, 2011:45, 2012:37

price of attendance, 2010:47, 2011:47, 2012:40

undergraduate students, past and projected, 2008:9, 2009:10, 2010:7, 2011:8, 2012:10

Full-time-equivalent (FTE) enrollment in postsecondary education, 2011:TF10

Full-time-equivalent teachers, 2010:31

Full-time/full-year worker, 2009:17, 2010:17, 2011:17, 2012:49

G-8 countries, 2009:29

Gender. See Sex

Geographic regions. See Regional distributions

Geography performance through elementary secondary level, 2012:25, 2012:TF9-TF10

Geometry. See also Mathematics

coursetaking by high school students, 2012:31, 2012:TF7

international comparisons of skill levels, 2010:15

Governmental Accounting Standards Board (GASB), 2012:42 
Government appropriations for public postsecondary institutions, 2009:46, 2010:49. See also Federal government; States/State governments

Grade-level studies. See also Age/Age comparisons

civics performance through elementary/secondary level, 2012:25

geography performance through elementary/secondary level, 2012:25

mathematics performance in $4 \mathrm{th}, 8 \mathrm{th}$, and $12 \mathrm{th}$ grade, 2011:12, 2011:13, 2012:24

mathematics performance in 4th and 8th grade, 2008:13, 2009:13, 2010:11, 2010:12

reading performance through elementary/secondary level, 2008:12, 2009:12, 2010:9, 2010:10, 2011:10, 2011:11, 2012:23

science performance in $4 \mathrm{th}, 8 \mathrm{th}$, and $12 \mathrm{th}$ grade, 2011:14

U.S. history performance through elementary/secondary level, 2012:25

Grade retention of elementary/secondary students, 2009: 18

Graduate degrees. See also Doctoral degrees; Firstprofessional degrees; Master's degrees awarded by field of study, 2008:40, 2009:41, 2010:42, 2011:41, 2012:39

women earning, 2008:27

Graduate students

cost of attending graduate program, 2010:48, 2011:48

international students in postsecondary institutions, 2009:39

rate of enrollment, 2008:11, 2009:11, 2010:8, 2011:9, 2012: 11

Graduation rates from high school, 2008:21, 2009:19, 2010:18, 2011:19, 2012:32, 2012:TF10-TF12. See also High school education

Grants and scholarships, 2010:46, 2011:46, 2012:41

by level and control of institution, 2011:TF11 cost of attending college, 2010:47, 2011:47, 2012:40 cost of graduate education, 2010:48, 2011:48 for first-time students, 2009:45

Gross domestic product (GDP)

expenditures for elementary/secondary education, 2008:38, 2009:37, 2010:38, 2011:38, 2012:22

revenues for postsecondary education, 2009:46

Group of Eight (G-8) countries, 2009:29

Guidance counselors, 2008:32, 2010:30

Guns at schools, 2008:28
Handicapped students. See Disabilities, students with Head Start programs, 2008:2

Health professions, degrees in, 2008:39, 2008:40, 2009:40, 2009:41, 2010:41, 2010:42, 2011:40, 2011:41, 2012:38, 2012:39

Hearing impairments, 2008:22

Higher education. See Postsecondary education

High income, 2009:21, 2010:20, 2011:21, 2012:34

High school completers, 2008:25, 2009:17, 2009:21, 2009:23, 2010:17, 2010:20, 2010:22, 2011:17, 2011:21, 2011:24, 2012:34, 2012:48, 2012:49

employment status, 2011:18

in past 20 years, 2012:TF10-TF12

High school education, 2012:TF6-TF13. See also Educational attainment; Elementary/secondary education

achievement levels for students in past 20 years, 2012:TF9-TF10

completion rates by race/ethnicity, 2008:25, 2009:23, 2010:22, 2011:24, 2012:48

coursetaking by students, 2012:TF7-TF8 (See also Coursetaking by high school students)

definition in Current Population Survey, 2012:48

earnings of young adults affected by, 2008:20, 2009:17, 2010:17, 2011:17, 2012:49

graduation rates, 2008:21, 2009:19, 2010:18, 2011:19, 2012:32

graduation rates by students with disabilities, 2008:22 international comparisons of attainment, 2011:25

Historically Black Colleges and Universities (HBCUs), 2009:38, 2010:39

History, degrees in, 2008:39, 2008:40, 2009:40, 2010:41, 2011:40, 2012:38

History, U.S., performance through elementary secondary level, 2012:25, 2012:TF9

Home activities, child development and, 2009:2

Homeland security, degrees in, 2012:38, 2012:39

Homeschooling

percentage and characteristics of students, 2009:6 school choice, 2009:32

Homework, parents helping with, 2009:30

Hospitals, 2009:46, 2010:49

Humanities, 2008:39, 2008:40, 2009:40, 2010:41, 2011:40, 2012:38 
IDEA (Individuals with Disabilities Education Act) (1975).

See Individuals with Disabilities Education Act

(IDEA) (1975)

Immediate college enrollment rate, 2012:TF12

Immigrants/Immigration

dropout rates from high school, 2008:23, 2009:20,

2010:19, 2011:20, 2012:33

employment of high school students, 2012:30

Income, 2009:21, 2010:20, 2011:21, 2012:34. See also

Poverty levels; Salaries

earnings of young adults, 2008:20, 2009:17, 2010:17, 2011:17, 2012:49

family

cost of attending college, 2010:47, 2011:47, 2012: 40

employment of high school students, 2012:30

enrollment rates in college affected by, 2008:24, 2009:21, 2010:20, 2011:21, 2012:34, 2012:TF12

grants and loans to undergraduates, 2010:46, 2011:46 (See also Grants and scholarships)

poverty levels for school-age children, 2011:29

Individualized Education Program (IEP), 2010:24, 2011:27

Individuals with Disabilities Education Act (IDEA) (1975), 2008:8, 2008:22, 2009:9, 2010:6, 2011:7, 2012:9

Information sciences, degrees in, 2008:39, 2008:40, 2009:40, 2009:41, 2010:41, 2010:42, 2011:40, 2011:41, 2012:38, 2012:39

In-state college attendance, 2008:10

Institutional financial aid, 2009:45

Institutional support, 2009:46, 2010:49, 2011:50, 2012:43

Instruction

distance education enrollment by high school students, 2012:15

in economics in secondary school, 2008:15

expenditures in public elementary/secondary schools for, 2008:35, 2008:36, 2009:34, 2009:35, 2010:34, 2010:35, 2011:36, 2011:37, 2012:20, 2012:21

Instructional aides for elementary/secondary schools, 2008:32, 2010:30

Instructional staff, 2008:32, 2010:30. See also Faculty, postsecondary education; Teachers/Teaching
Integrated Postsecondary Education Data System (IPEDS), 2009:39, 2010:7, 2011:8, 2011:23, 2011:TF15, 2012:10, 2012:45

degrees conferred by degree-granting institutions, 2011:TF8

expenses per student, 2011:TF10

Intellectual disability, 2008:22, 2011:7, 2012:9

Interactive video delivery of distance education courses, 2012:15

Interest on school debt, expenditures in public elementary/ secondary schools for, 2009:34, 2010:34, 2011:36, 2012:20

International comparisons

educational attainment, 2011:25

expenditures for education, 2008:38, 2009:37, 2010:38, 2011:38, 2012:22

mathematics and science literacy, 2011:16

mathematics literacy, 2012:26

mathematics performance for 4th and 8th grade, 2009: 15, 2010:15

reading assessments, 2008:18, 2011:15

reading literacy, 2012:26

science assessments, 2008:19

science literacy, 2012:26

science performance for 4th and 8th grade, 2009:16, 2010:16

teachers' professional development, 2009:29

United States students studying abroad, 2010:40

International economy, 2008: 15

International Standard Classification of Education (ISCED), 2011:25

International students in postsecondary institutions, 2009:39. See also Foreign students in postsecondary institutions

Internet, distance education delivery, 2012:15

Investments as source of revenues for postsecondary institutions, 2009:46, 2010:49, 2011:50, 2012:42

Item Response Theory (IRT), 2011:15

Kindergarten, enrollment, 2008:1, 2009:1, 2010:1, 2011:1, 2012:1, 2012:2. See also Preprimary education

1

Language and learning disabilities, 2010:6, 2011:7, 2012:9 
Language spoken at home

early development of children, 2009:2

school-age children, 2012:8

trends in school-age children, 2008:7, 2009:8, 2010:5, 2011:6

Law degrees, 2008:40, 2009:41, 2010:42, 2011:41, 2012:39

Law enforcement, degrees in, 2012:38, 2012:39

Learner outcomes. See Outcomes of education

Learning disabilities, 2008:8, 2008:22, 2009:9, 2010:6, 2011:7, 2012:9

"Leavers"

turnover rate for principals, 2011:34

turnover rate for teachers, 2008:31, 2011:32

Leisure reading. See Reading

Leisure studies, 2011:40, 2012:38

Liberal arts, degrees in, 2008:39

Life sciences, 2010:16

Limited English Proficiency (LEP). See also English language learners; Language spoken at home in public elementary/secondary schools, 2010:24, 2011:27

testing accommodations for, 2008:12, 2009:12, 2010:9, 2010:10, 2011:10, 2011:11

Literacy. See also Reading

early childhood development skills, 2009:3

international comparisons, 2011:15, 2012:26

mathematics (See Mathematics)

science (See Science)

Loans to students for college, 2009:45. See also Student loans

Locale. See Urbanicity

Local sources of revenues

for postsecondary institutions, 2009:46, 2010:49

for public schools, 2008:34, 2009:33, 2010:33, 2011:35, 2012:19

Long Form Decennial Census, language spoken at home, 2011:6

Longitudinal studies, early education for Birth Cohort of 2001 (ECLS-B), 2008:2, 2009:2, 2009:3

Long-term trend assessments, reading and mathematics performance, 2008:17, 2009:14, 2010:13

Low income, 2009:21, 2010:20, 2011:21, 2012:34. See also Poverty levels

mathematics achievement gap through elementary/ secondary level, 2011:13 reading achievement gap through elementary/secondary level, 2011:11

science achievement through elementary/secondary level, 2011:14

Low-retention schools, 2012:16, 2012:TF11

Macroeconomics, 2008:15

Magnet schools, 2010:24, 2011:27

Marital status for undergraduate students, 2011:43

Market economy, 2008:15

Master's degrees, 2008:26, 2009:24, 2010:23, 2011:26.

See also Graduate degrees

awarded by field of study, 2008:40, 2009:41, 2010:42, 2011:41, 2012:39

awarded by public and private institutions, 2008:41, 2009:42, 2010:43, 2011:42, 2012:46

awarded by race/ethnicity, 2010:22, 2011:24, 2012:48

earnings of young adults affected by, 2008:20, 2009:17, 2010:17, 2011:17, 2012:49

increase in degrees earned, 2012:47

women earning, 2008:27

Mathematics

achievement gap at elementary/secondary level, 2010:12, 2011:13

Black-White achievement gap, 2008:16

coursetaking by high school students, 2012:31, 2012:TF7

degrees in, 2008:40, 2009:40, 2009:41, 2010:41, 2010:42, 2011:40, 2011:41, 2012:38, 2012:39

early childhood development, 2009:3

eighth-grade performance, 2008:13, 2009:13, 2010:11, 2011:12, 2012:24

fourth-grade performance, 2008:13, 2009:13, 2010:11, 2011:12, 2012:24

Hispanic-White achievement gap, 2008:16

international comparisons, 2009:15, 2010:15, 2011:16, 2012:26, 2012: TF10

long-term trend study, 2008:17, 2009:14, 2010:13

twelfth-grade performance, 2011:12, 2012:24, 2012:TF9

Maximum compulsory age of school attendance, 2008:1, 2009:1, 2010:1, 2011:1, 2012:1

Medical degrees, 2008:40, 2009:41, 2010:42, 2011:41, 2012:39

Men, enrollment rates in college, 2008:9. See also Sex 
Metropolitan areas. See Urbanicity

Microeconomics, 2008:15

Middle income, 2009:21, 2010:20, 2011:21, 2012:34

Middle schools. See also Elementary/secondary education, staff in public schools, 2008:32, 2010:30

Midwestern region schools. See Regional distributions

Mobility of students, in-state and out-of-state attendance of college freshmen, 2008:10

Mobility of teachers, newly hired elementary/secondary teachers, 2010:28. See also Teachers/Teaching

Montessori schools, 2010:3, 2011:4

Mothers. See also Parents as heads of households in families, 2012:7

level of education grade retention of students, 2009:18

home activities and early childhood development, 2009:2

Motor skill development, 2009:3

"Movers" turnover rate for principals, 2011:34

turnover rate for teachers, 2008:31, 2011:32

Music

achievement, 2010:14

participation in high school, 2012:27

National Assessment of Educational Progress (NAEP)

absenteeism of elementary/secondary students, 2012:28, 2012: TF8

art and music achievement, 2010:14

civics performance through elementary/secondary level, 2012:25

economics performance in 12th grade, 2008: 15

geography performance through elementary/secondary level, 2012:25

high school student achievement levels in past 20 years, 2012:TF9-TF10

mathematics coursetaking and performance in high school, 2012:31

mathematics performance through elementary/ secondary level, 2010:11, 2010:12, 2011:12, 2011:13, 2012:24

reading and mathematics achievement gaps, 2008:16 reading and mathematics long-term trend study, 2008:17, 2009:14, 2010:13 reading performance through elementary/secondary level, 2008:12, 2009:12, 2010:9, 2010:10, 2011:10, 2011:11, 2012:23

science performance through elementary/secondary level, 2011:14

U.S. history performance through elementary/secondary level, 2012:25

writing performance in 8 th and 12th grade, 2008:14

National Board for Professional Teaching Standards (NBPTS), 2010:37

National economy, 2008:15

National Household Education Surveys Program (NHES), 2009:18, 2009:30, 2009:32

private school enrollment, 2009:5

National Postsecondary Student Aid Study (NPSAS), 2010:48, 2011:48, 2011:TF15

distance education courses, 2011:TF10

remedial coursetaking by undergraduates, 2011:22

National School Lunch Programs, 2008:29, 2009:25, 2010:25, 2011:28. See also Free or reduced-price lunch programs

National Science and Mathematics Access to Retain Talent Grant (National SMART Grant), 2012:40

A Nation at Risk: The Imperative for Educational Reform, 2012:TF7

Net price of college attendance, 2010:47, 2011:47, 2012:40. See also Cost of attending college

Newly hired teachers, 2010:28. See also Teachers/Teaching

Newspaper/yearbook, participation in high school, 2012:27

Nonresident aliens in U.S. postsecondary institutions, 2008:10, 2008:11, 2008:26, 2009:11, 2009:24, 2009:39, 2010:8, 2010:23, 2010:39, 2011:9, 2011:26, 2012:11, 2012:47

Nonsectarian private schools, 2008:4, 2009:5, 2010:3, 2011:4, 2012:5. See also Private elementary/ secondary schools

Non-U.S. citizens. See Immigrants/Immigration; Nonresident aliens in U.S. postsecondary institutions

Northeastern region schools. See Regional distributions

Not-for-profit private postsecondary institutions, 2011:39, 2012:36

degrees conferred at, 2011:42, 2012:46

distance education courses, 2011:43, 2011:TF9-TF10

enrollment trends, 2011:TF7-TF9

expenses, 2011:TF9-TF10, 2012:43

financial aid to students, 2012:41 
graduation rates, 2011:TF13-TF14

revenues and expenses for, 2011:50

revenues for, 2012:42

student financing, 2011:TF11-TF13

student loans and default rates, 2011:49

Number content domain, international comparisons of skill levels in, 2010:15

Numeracy skills. See Mathematics

Occupational coursetaking. See Vocational education/ schools

Occupations. See Field of study

Office of Special Education Programs (OSEP), 2008:22

Open admissions policies for postsecondary institutions, 2012:36

Open Doors 2008: Report on International Educational Exchange (2008), 2009:39

Open Doors U.S. Study Abroad Survey, 2010:40

Operating revenue for postsecondary institutions, 2012:42

Organization for Economic Co-operation and

Development (OECD)

educational attainment, 2011:25

expenditures for education, 2008:38, 2009:37, 2010:38, 2011:38, 2012:22

mathematics and science literacy, international comparisons, 2011:16, 2012:26

mathematics literacy, international comparisons, 2012: TF10

Program for International Student Assessment (PISA) administered by (See Program for International Student Assessment (PISA))

reading literacy, international comparisons, 2011:15, 2012:26, 2012: TF 10

science literacy, international comparisons, 2008:19

Outcomes of education, 2008:12-20, 2009:12-17,

2010:9-17, 2011:10-18

economics performance in 12th grade, 2008:15

employment status, 2011:18

science performance in elementary/secondary education (See under Science)

writing performance in 8th and 12th grade, 2008:14

youth neither enrolled nor working, 2012:29

Out-of-state college attendance, 2008:10
Parent Loans for Undergraduate Students (PLUS), 2010:46, 2010:47, 2011:46, 2011:47

Parents. See also Families

bachelor's degree completion, 2008:6, 2012:7

homeschooling, 2009:6

involvement with children's education, 2009:30

level of education

art and music achievement of children, 2010:14

college completion time for children affected by, 2009:22

college enrollment rate of their children affected by, 2008:24, 2009:21, 2010:20

economics performance of children in 12th grade affected by, 2008:15

expectations of twelfth-grade students for postsecondary degree affected by, 2012:35, 2012: TF12-TF13

grade retention of students, 2009:18

home activities and early childhood development, 2009:2

preprimary education of children affected by, 2008:2, 2012:2

two-parent households, 2008:6, 2012:7

Parochial schools, 2008:4, 2009:5, 2010:3, 2011:4, 2012:5. See also Catholic schools

Part-time enrollment at postsecondary institutions

by level and control of institution, 2011:TF8-TF9

employment during, 2008:43, 2009:44, 2010:45, 2011:45, 2012:37

graduate students, 2010:48, 2011:48

undergraduate students, 2008:9, 2009:10, 2010:7, 2011:8, 2012:10

Pay incentives for teachers, 2010:37

Pell Grants, 2010:46, 2011:46, 2011:TF11, 2012:40. See also Grants and scholarships

Performing arts

degrees in, 2008:39, 2008:40, 2009:40, 2010:41, 2011:40, 2012:38

participation in high school, 2012:27

Perkins loans, 2010:46, 2011:46

cost of graduate education, 2010:48, 2011:48

Persistence in education

elementary/secondary education, 2008:21-23, 2009:18-20, 2010:18-23, 2011:19-26 (See also Dropout rates) 
postsecondary education, 2008:25-27, 2009:22-

24, 2010:21-23, 2011:23-26, 2011:39,

2011:TF13-TF14 (See also Degrees earned)

Pharmacy degrees, 2008:40

Philosophy, degrees in, 2009:40, 2010:41, 2011:40, 2012:38

Physical sciences, 2010:16

Physics

coursetaking by high school students, 2012:31, 2012: TF7

international comparisons for 8th-grade skills, 2010:16

PIRLS (Progress in International Reading Literacy Study), 2008: 18

PISA (Program for International Student Assessment). See Program for International Student Assessment (PISA)

Playing with children, 2009:2

Population, enrollment rates and, 2008:1, 2009:1, 2010:1, 2011:1, 2012:1

Postbaccalaureate programs, enrollment, 2010:8, 2011:9, 2012:11. See also Graduate degrees; Graduate students

distance education, 2011:43

Postsecondary education, 2008:39-43, 2009:10-11, 2009:38-46, 2010:7-8, 2010:39-49, 2011:3950, 2011:TF7-TF15, 2012:36-48. See also Enrollment, postsecondary education; Four-year institutions; Private postsecondary institutions; Public postsecondary institutions; Two-year institutions

cost of attending college, 2010:47, 2010:48, 2011:47, 2011:48, 2012:40

definition, 2011:TF15

degrees conferred, 2011:TF7-TF9

distance education, 2011:TF9-TF10

employment while enrolled in, 2008:43, 2009:44, 2010: $45,2011: 45$, 2012:37

enrollment trends, 2011:8-9, 2011:TF7-TF9, 2012:10-11

expectations of twelfth-grade students for, 2012:35, 2012: TF12-TF13

expenses, 2011:TF9-TF10, 2012:43

faculty, 2008:42, 2009:43, 2010:44, 2011:44, 2012:44 (See also Faculty, postsecondary education)

federal grants and loans to undergraduates, 2010:46, 2011:46, 2012:41

graduate enrollment, 2008:11, 2009:11, 2010:8, 2011:9, 2012:11

graduation rates, 2011:23, 2011:TF13-TF14, 2012:45 in-state and out-of-state attendance of college freshmen, 2008: 10

international comparisons of expenditures for, 2008:38, 2009:37, 2010:38, 2011:38, 2012:22

percentage of public school students enrolled after graduation, 2010:24, 2011:27

public support for, 2009:46, 2010:49

racial/ethnic concentration in, 2009:38, 2010:39

remedial coursetaking by institution control and level, 2011:22

revenues, 2012:42

revenues and expenses, 2011:50

student financing, 2011:TF11-TF13

time to completion for bachelor's degrees, 2009:22, 2010:21

transition to college, 2008:24, 2009:21, 2010:20, 2011:21, 2012:34

undergraduate institutions, characteristics of, 2011:39, 2012:36

undergraduate students (See Undergraduate students)

Poverty levels

art and music achievement, 2010:14

characteristics of elementary/secondary schools, 2012:12

charter schools, 2011:3

cognitive skills in young children, 2009:3

crime in schools, 2009:27, 2010:26, 2011:30, 2012:14

expenditures per student by school district, 2008:37, 2009:36, 2010:36

for school-age children, 2008:6, 2011:29, 2012:7

grade retention of elementary/secondary students, 2009:18

home activities and early childhood development, 2009:2

in public schools by locale and race/ethnicity, 2008:29, 2009:25, 2010:25, 2011:28, 2012:13

language spoken at home, 2008:7, 2009:8, 2010:5, 2011:6

mathematics achievement gap through elementary/ secondary level, 2011:13

parental involvement with children's education affected by, 2009:30

public charter schools, 2012:4

public school characteristics, 2010:24, 2011:27

reading achievement gap through elementary/secondary level, 2011:11

retention rates in high schools affected by, 2012:16 
science achievement through elementary/secondary level, 2011:14

students per staff member at public elementary/ secondary schools, 2010:30

teacher pay incentives by, 2010:37

turnover rates for teachers affected by, 2008:31

young adults not in school or working, 2012:29

Preparing for college. See Cost of attending college

Preprimary education

enrollment in, 2008:1, 2008:2, 2009:1, 2010:1, 2011:1, 2012:1, 2012:2

home environment, 2009:2

Preschool programs. See Preprimary education

Principals, 2010:29, 2011:33, 2012:18

Private elementary/secondary schools. See also Catholic schools

art and music achievement, 2010:14

characteristics of, 2012:12

enrollment in high schools, 2012:TF6-TF7

enrollment trends in, 2008:4, 2009:5, 2010:3, 2011:4, 2012:5

newly hired elementary/secondary teachers at, 2010:28

principals at, 2010:29, 2011:33, 2012:18

school choice, 2009:32

teachers at, 2010:27, 2011:31, 2012:17

turnover rate for principals at, 2011:34

turnover rate for teachers at, 2008:31, 2011:32 (See also

Turnover rates for teachers)

Private nursery schools, 2012:2. See also Preprimary education

Private postsecondary institutions, 2012:36. See also

Postsecondary education

characteristics of undergraduate, 2011:23

degrees conferred at, 2008:41, 2009:42, 2010:43, 2011:42, 2012:46

distance education, 2011:43, 2011:TF9-TF10

enrollment trends, 2011:TF7-TF9

expenses, 2011:TF9-TF10, 2012:43

faculty salaries and benefits at, 2008:42, 2009:43, 2010:44, 2011:44, 2012:44

financial aid to first-year students, 2009:45 (See also Financial aid to students)

financial aid to students, 2012:41

graduate enrollment, 2012:11

graduation rates, 2011:23, 2011:TF13-TF14, 2012:45

net price for graduate and first-professional studies, 2010:48, 2011:48 net price for undergraduate studies, 2010:47, 2011:47, 2012:40

racial/ethnic concentration in, 2010:39

remedial coursetaking by undergraduates, 2011:22

revenues and expenses for, 2011:50

revenues for, 2009:46, 2010:49, 2012:42

student financing, 2011:TF11-TF13

student loans and default rates, 2011:49

students working while attending, 2008:43, 2009:44, 2010:45, 2011:45, 2012:37

time to completion for bachelor's degree, 2009:22, 2010:21

undergraduate enrollment, 2012:10

Private School Survey (PSS), 2009:5, 2010:3

Private School Universe Survey (PSS), 2011:4, 2012:5

Problem-solving skills, 2009:3

Professional instructional staff, 2008:32, 2010:30. See also Teachers/Teaching

Proficiency, subject

civics through elementary/secondary level, 2012:25 economics performance in 12th grade, 2008:15 geography through elementary/secondary level, 2012:25 mathematics achievement gap through elementary/ secondary level, 2010:12, 2011:13

mathematics through elementary/secondary level, 2008:13, 2009:13, 2010:11, 2011:12, 2012:24

reading achievement gap at elementary/secondary level, 2010:10, 2011:11

reading through elementary/secondary level, 2008:12, 2009:12, 2010:9, 2011:10, 2012:23

science through elementary/secondary level, 2011:14

U.S. history through elementary/secondary level, 2012: 25

writing performance in 8th and 12th grade, 2008:14

Program for International Student Assessment (PISA)

mathematics and science literacy, international comparisons, 2011:16

mathematics literacy, U.S. compared to other countries, 2012:TF9-TF10

reading, mathematics and science literacy, international comparisons, 2012:26

reading literacy, international comparisons, 2011:15

reading literacy, U.S. compared to other countries, 2012:TF9-TF10

science literacy, international comparisons, 2008:19

Progress in International Reading Literacy Study (PIRLS), 2008: 18 
Projections

elementary/secondary school enrollment, 2008:3,

2009:4, 2010:2, 2011:2, 2012:3

graduate enrollment in college, 2010:8, 2011:9, 2012:11

high school enrollment, 2012:TF6

undergraduate enrollment in college, 2008:9, 2009:10, 2010:7, 2011:8, 2012:10

Property taxes as source of revenue for public schools,

2008:34, 2009:33, 2010:33, 2011:35, 2012:19

Protective services, degrees in, 2012:38, 2012:39

Psychology, degrees in, 2008:39, 2008:40, 2009:40, 2009:41, 2010:41, 2010:42, 2011:40, 2011:41, 2012:38, 2012:39

PTO/PTA organizations, 2009:30

Public administration, degrees in, 2008:40, 2009:40, 2009:41, 2010:41, 2010:42, 2011:40, 2011:41, 2012:38, 2012:39

Public charter schools, 2012:4

Public elementary/secondary schools

art and music achievement, 2010:14

characteristics of, 2010:24, 2011:27, 2012:12

civics performance, 2012:25

crime in, 2010:26, 2011:30, 2012:14

disabilities, students with enrolled in, 2008:8, 2009:9, 2010:6, 2011:7, 2012:9

distance education enrollment by high school students in, 2012:15

enrollment, 2008:3, 2009:4, 2010:2, 2011:2, 2012:3

by locale and race/ethnicity, 2008:30, 2009:26

in high schools, 2012:TF6-TF7

expenditures

by category, 2008:35, 2009:34, 2010:34, 2011:36

by district poverty, 2008:37, 2009:36, 2010:36

by objects of expenditure, 2012:20

per student, 2008:36, 2009:35, 2010:35, 2011:37, 2012: 21

geography performance, 2012:25

graduation rates from by state, 2008:21, 2009:19,

2010:18, 2011:19, 2012:32

mathematics performance, 2008:13, 2009:13, 2010:11, 2011:12, 2012:24

newly hired elementary/secondary teachers at, 2010:28

poverty levels by locale and race/ethnicity, 2008:29, 2009:25, 2010:25, 2011:28, 2012:13

principals at, 2010:29, 2011:33, 2012:18 racial distribution in, 2008:5, 2009:7, 2010:4, 2011:5, 2012:6

reading performance, 2008:12, 2009:12, 2010:9, 2011:10, 2012:23

retention rate for high school, 2012:16

revenues, changes in sources for, 2008:34, 2009:33, 2010:33, 2011:35, 2012:19

school choice, 2009:32

science performance, 2011:14

staff at, 2008:32, 2010:30

student/teacher ratios, 2008:33, 2009:31, 2010:31

teacher salaries and pay incentives, 2010:37

teachers at, 2010:27, 2011:31, 2012:17

teacher turnover rate at, 2008:31, 2011:32

turnover rate for principals at, 2011:34

U.S. history performance, 2012:25

writing performance, 2008: 14

Public nursery schools, 2012:2. See also Preprimary education

Public postsecondary institutions, 2012:36

characteristics of undergraduate, 2011:23

degrees conferred at, 2008:41, 2009:42, 2010:43, 2011:42, 2012:46

distance education, 2011:43, 2011:TF9-TF10

enrollment trends, 2011:TF7-TF9

expenses, 2011:TF9-TF10, 2012:43

faculty salaries and benefits at, 2008:42, 2009:43, 2010:44, 2011:44, 2012:44

financial aid to first-year students, 2009:45

financial aid to students, 2012:41

graduate enrollment, 2012:11

graduation rates, 2011:23, 2011:TF13-TF14, 2012:45

net price for graduate and first-professional studies, 2010:48, 2011:48

net price for undergraduate studies, 2010:47, 2011:47, 2012: 40

$\mathrm{racial} /$ ethnic concentration in, 2009:38, 2010:39

remedial coursetaking by undergraduates, 2011:22

revenues and expenses for, 2011:50

revenues for, 2009:46, 2010:49, 2012:42

student financing, 2011:TF11-TF13

student loans and default rates, 2011:49

students working while attending, 2008:43, 2009:44, 2010:45, 2011:45, 2012:37

time to completion for bachelor's degree, 2009:22, 2010:21 
undergraduate enrollment, 2012:10

Public revenue. See Revenues for education

Purchasing power parity (PPP) indices, 2008:38, 2009:37, 2010:38, 2011:38, 2012:22

Qualifications of teachers. See Teachers/Teaching

Race/ethnicity

absenteeism of elementary/secondary students, 2012:28

art and music achievement, 2010:14

charter schools, 2010:32

chosen public schools, 2009:32

civics performance through elementary/secondary level, 2012:25

cost of attending college, 2011:47

coursetaking by high school students, 2012:31

crime in schools, 2010:26, 2011:30

degrees earned by, 2008:26, 2009:24, 2010:23, 2011:26, 2012:47

disabilities, students with in elementary/secondary schools, 2008:8, 2009:9, 2010:6, 2011:7, 2012:9

distribution in elementary/secondary schools by locale and control, 2012:12

dropout rates from high school, 2008:23, 2009:20, 2010:19, 2011:20, 2012:33

early childhood development skills, 2009:3

earnings of young adults, 2008:20, 2009:17, 2010:17, 2011:17, 2012:49

educational attainment by, 2008:25, 2009:23, 2010:22, 2011:24, 2012:48

employment of high school students, 2012:30

employment status, 2011:18

employment status of college students, 2008:43, 2011:45, 2012:37

English language learners, 2012:8

enrollment rates in postsecondary institutions, 2008:24, 2009:21, 2009:38, 2010:20, 2010:39, 2011:8, 2011:21, 2011:39, 2011:TF8, 2012:10, 2012:34, 2012:36

expectations of twelfth-grade students for postsecondary degree, 2012:35

family environment and, 2008:6, 2012:7

geography performance through elementary/secondary level, 2012:25 grade retention of elementary/secondary students, 2009:18

graduate enrollment rates in college, 2008:11, 2009:11, 2010:8, 2011:9, 2012:11

graduation rates, 2012:45

graduation rates from postsecondary institutions, 2011:23

high school enrollment, 2012:TF6

home activities and early childhood development, 2009:2

homeschooling, 2009:6

language spoken at home, 2008:7, 2009:8, 2010:5, 2011:6

mathematics achievement gap through elementary/ secondary level, 2010:12, 2011:13

mathematics performance through elementary/ secondary level, 2008:13, 2009:13, 2010:11, 2011:12, 2012:24

parental involvement with children's education, 2009:30 parents' level of education (See Parents)

poverty and, 2008:29, 2009:25, 2010:25, 2011:28

poverty distribution in public schools by, 2012:13

preprimary education, 2008:2, 2012:2

private school enrollment, 2008:4, 2009:5, 2010:3, 2011:4, 2012:5

public school characteristics, 2011:27

public school enrollment, 2008:5, 2008:30, 2009:7, 2009:26, 2010:4, 2011:5, 2012:6

reading achievement gap through elementary/secondary level, 2010:10, 2011:11

reading and mathematics achievement gap, 2008:16 reading and mathematics long-term trend study,

2008:17, 2009:14, 2010:13

reading literacy, international comparisons, 2011:15

reading literacy in 4th grade, 2008: 18

reading performance through elementary/secondary level, 2008:12, 2009:12, 2010:9, 2011:10, 2012:23

remedial coursetaking at undergraduate level by, 2011:22

retention rates in high schools affected by, 2012:16

science literacy, 2008:19

science performance through elementary/secondary level, 2011:14

status dropout rates for high school, 2012:TF11-TF12

suspensions/expulsions from elementary/secondary schools, 2009:28 
teachers at elementary/secondary schools, 2010:27, 2011:31, 2012:17

time to completion for bachelor's degree, 2009:22, 2010:21

turnover rates for teachers, 2011:32

U.S. history, geography and civics achievement, 2012:TF9-TF10

U.S. history performance through elementary/secondary level, 2012:25

writing performance in 8th and 12th grade, 2008:14 young adults not in school or working, 2012:29

Reading

absenteeism of students affecting performance, 2012:28

achievement gap through elementary/secondary level, 2010:10, 2011:11

Black-White achievement gap, 2008:16

early literacy activities, 2009:2

eighth-grade performance, 2008:12, 2009:12, 2010:9, 2011:10, 2012:23

fourth-grade performance, 2008:12, 2009:12, 2010:9, 2011:10, 2012:23

Hispanic-White achievement gap, 2008:16

international comparisons, 2008:18, 2011:15, 2012:26, 2012:TF10

long-term trend study, 2008:17, 2009:14, 2010:13

twelfth-grade performance, 2011:10, 2012:23, 2012: TF9

Real-time instruction, 2012:15

Recreation and leisure studies, 2011:40, 2012:38

Re-entrants (teachers), 2010:28

Regional distributions

art and music achievement, 2010:14

charter schools, 2009:32, 2010:32, 2011:3

elementary/secondary school enrollment, 2008:3, 2009:4, 2010:2, 2011:2, 2012:3

grade retention of elementary/secondary students, 2009: 18

high school enrollment, 2012:TF6

poverty levels for school-age children, 2011:29

private school enrollment, 2008:4, 2009:5, 2010:3, 2011:4, 2012:5

public charter schools, 2012:4

public school characteristics, 2010:24

public school enrollment, 2008:5, 2009:7, 2010:4, 2011:5, 2012:6

revenue sources for public elementary/secondary schools, 2008:34, 2009:33, 2010:33 turnover rates for teachers, 2011:32

young adults not in school or working, 2012:29

Relatives of families. See Families

Religious affiliation, private elementary/secondary schools, 2008:4, 2009:5, 2010:3, 2011:4, 2012:5. See also Catholic schools; Private elementary/secondary schools

Religious studies, degrees in, 2009:40, 2009:41, 2010:41, 2010:42, 2011:40, 2011:41, 2012:38, 2012:39

Remedial coursetaking, postsecondary education, 2011:22

Repayment of school debt. See Student loans

Retention rates of elementary/secondary students, 2009:18, 2012:16, 2012:TF11-TF12

Retention rates of students in postsecondary education, 2011:39, 2011:TF13-TF14, 2012:36

Retirement of principals, 2011:34

Retirement of teachers, 2008:31, 2011:32

Returning teachers, 2010:28

Revenues for education

changes in sources for public elementary/secondary schools, 2008:34, 2009:33, 2010:33, 2011:35, 2012:19 (See also Public elementary/secondary schools)

postsecondary institutions, 2009:46, 2010:49, 2011:50, 2012:42

Risk factors, alternative schools for students with, 2010:24, 2011:27

Rural areas. See Urbanicity

Salaries. See also Income

faculty at postsecondary institutions, 2008:42, 2009:43, 2010:44, 2011:44, 2012: 44

principals at elementary/secondary schools, 2010:29, 2011:33, 2012: 18

teacher pay incentives, 2010:37

teachers' as part of expenses, 2008:35, 2009:34, 2010:34, 2011:36

teachers' as part of school expenses, 2012:20

Scholarships and grants. See also Grants and scholarships cost of attending college, 2010:47, 2011:47, 2012:40

School choice, 2009:32

School climate

crime in schools, 2008:28, 2009:27, 2010:26, 2011:30, 2012:14, 2012:TF8

violent incidences at public schools, 2008:28, 2009:27, 2010:26, 2012:14 (See also Violence at schools) 
School clubs, participation in high school, 2012:27

School counselors, 2008:32, 2010:30

School discipline, 2009:28

School districts

expenditures by, 2008:37, 2009:36, 2010:36

instruction expenditures per student, 2008:36, 2009:35, 2010:35, 2011:37, 2012:21

teacher pay incentives in, 2010:37

School lunch programs. See Free or reduced-price lunch programs

Schools and Staffing Survey (SASS), 2010:37

principal turnover, 2011:34

teacher turnover, 2011:32

School size, 2008:33, 2009:31, 2010:31

public school characteristics, 2011:27

School Survey on Crime and Safety, 2008:28, 2009:27, 2010:26, 2012:14

Science

coursetaking by high school students, 2012:31, 2012: TF7

degrees in, 2008:40, 2009:40, 2009:41, 2010:41, 2010:42, 2011:40, 2011:41, 2012:38, 2012:39

eighth-grade performance, 2011:14

fourth-grade performance, 2011:14

international comparisons, 2008:19, 2009:16, 2010:16, 2011:16, 2012:26

twelfth-grade performance, 2011:14

Secondary education. See Elementary/secondary education;

High school education

Secondary schools

staff in public schools, 2008:32, 2010:30

student/teacher ratios, 2008:33, 2009:31, 2010:31

Security and protective services, degrees in, 2011:40, 2012:38

Seniors in high school. See Twelfth grade

Services purchased for public schools, 2009:34, 2010:34, 2011:36, 2012:20

Sex

art and music achievement, 2010:14

coursetaking by high school students, 2012:31

crime in schools, 2011:30

degrees earned by, 2010:23, 2011:26, 2012:47

degrees earned by field of study, 2009:40, 2010:41, 2011:40, 2012:38

degrees earned by women, 2008:27

dropout rates from high school, 2012:33 earnings of young adults, 2008:20, 2009:17, 2010:17, 2011:17, 2012:49

economics performance in 12th grade, 2008:15

educational attainment by, 2009:23, 2010:22, 2011:24, 2012:48

employment of college students, 2008:43, 2009:44, 2010:45, 2011:45, 2012:37

employment of high school students, 2012:30, 2012:TF8-TF9

enrollment rates in college, 2008:9, 2008:24, 2009:10, 2009:21, 2010:7, 2010:20, 2011:8, 2011:21, 2012:10, 2012:34

expectations of twelfth-grade students for postsecondary degree, 2012:35, 2012:TF12

extracurricular activities, participation in high school by, 2012:27, 2012:TF8

grade retention of elementary/secondary students, 2009: 18

graduate degrees by field of study, 2009:41, 2010:42, 2011:41, 2012:39

graduate enrollment, 2008:11, 2009:11, 2010:8, 2011:9, 2012:11

graduation rates from postsecondary institutions, 2011:23, 2012:45

mathematics achievement gap in 4 th, 8 th, and 12 th grade, 2011:13

mathematics achievement gap in 4th and 8th grade, 2010:12

mathematics and science literacy, international comparisons, 2011:16

mathematics literacy, international comparisons, 2012:26

mathematics performance for 4th and 8 th grade, international comparisons of, 2009:15, 2010:15

mathematics performance in 4th and 8 th grade, 2008:13, 2009:13, 2010:11

newly hired elementary/secondary teachers, 2010:28

principals at elementary/secondary schools, 2010:29, 2011:33, 2012:18

reading achievement gap through elementary/secondary level, 2010:10, 2011:11

reading literacy, international comparisons, 2008:18, 2011:15, 2012:26

reading performance through elementary/secondary level, 2008: 12, 2009:12, 2010:9

remedial coursetaking at undergraduate level by, 2011:22

science literacy, international comparisons, 2008:19, 2012:26 
science performance for 4th and 8th grade, international comparisons of, 2009:16, 2010:16

suspensions/expulsions from elementary/secondary schools, 2009:28

teachers at elementary/secondary schools, 2010:27, 2011:31, 2012: 17

time to completion for bachelor's degree, 2010:21

U.S. history, geography and civics achievement, 2012:TF9-TF10

writing performance in 8th and 12th grade, 2008:14

young adults not in school or working, 2012:29

Skills for mathematics, 2010:15

Social sciences, degrees in, 2008:39, 2008:40, 2009:40, 2009:41, 2010:41, 2010:42, 2011:40, 2011:41, 2012:38, 2012:39

Social services, degrees in, 2009:40, 2010:41, 2011:40, 2012:38

Socioeconomic status (SES). See Poverty levels

Southern region schools. See Regional distributions

Special education

disabilities, students with in elementary/secondary schools, 2008:8, 2009:9, 2010:6, 2011:7, 2012:9

high school graduation rates for students with disabilities, 2008:22

percentage of public schools, 2010:24, 2011:27

Special needs schools, 2009:31, 2010:31

Speech impairments, 2012:9

Sports, participation in high school, 2012:27

Staff. See also Faculty, postsecondary education; Principals;

Teachers/Teaching

at public elementary/secondary schools, 2008:32, 2010:30

Stafford loan program

cost of graduate education, 2010:48, 2011:48

to undergraduate students, 2010:46, 2011:46

States/State governments

averaged freshman graduation rate from high school, 2012:TF12

charter schools, 2010:32, 2011:3

civics performance comparisons for elementary/ secondary level, 2012:25

dropout rates for students with disabilities, 2008:22

elementary/secondary school enrollment, 2012:3

English language learners, 2012:8

enrollment trends by age, 2011:1, 2012:1

expenditures per student in public elementary/ secondary schools, 2008:36, 2009:35, 2010:35, 2011:37, 2012:21

geography performance comparisons for elementary/ secondary level, 2012:25

graduation rates from high school, 2008:21, 2009:19, 2010:18, 2011:19, 2012:32

in-state and out-of-state attendance of college freshmen, 2008: 10

language spoken at home, 2009:8, 2010:5, 2011:6

mathematics performance comparisons for elementary/ secondary level, 2008:13, 2009:13, 2010:11, 2011:12, 2012:24

poverty levels for school-age children, 2011:29

poverty levels in public schools, 2010:25

public charter schools, 2012:4

public school characteristics, 2010:24

public school enrollment, 2012:6

reading performance comparisons for elementary/ secondary level, 2008:12, 2009:12, 2010:9, 2011:10, 2012:23

revenues to postsecondary institutions, 2009:46, 2010:49, 2011:50

revenues to school districts from, 2008:34, 2009:33, 2010:33, 2011:35, 2012:19

U.S. history performance comparisons for elementary/ secondary level, 2012:25

Statistics

coursetaking by high school students, 2012:31, 2012: TF7

degrees in, 2012:38, 2012:39

Statistics, degrees in, 2008:40, 2009:40, 2009:41, 2010:41, 2010:42, 2011:40, 2011:41

Status dropout rates for high school, 2008:23, 2009:20, 2010:19, 2011:20, 2012:33, 2012:TF11-TF12. See also Dropout rates

"Stayers"

turnover rate for principals, 2011:34

turnover rate for teachers, 2008:31, 2011:32

STEM fields, 2009:39, 2011:40, 2011:41, 2012:38, 2012:39, 2012:TF7. See also Engineering, degrees in; Mathematics; Science

Student absenteeism, 2012:28

Student council, participation in high school, 2012:27

Student loans. See also Financial aid to students by level and control of institution, 2011:TF11-TF13 cost of college attendance, 2010:47, 2011:47, 2012:40 default rates of, 2011:49, 2011:TF13 increases in number of, 2010:46, 2011:46, 2012:41 
Student Right-To-Know Act, 2010:21

Student services, 2009:46, 2010:49, 2011:50, 2012:43

Student services professional staff, 2008:32, 2010:30

Student/teacher ratios, public schools, 2008:33, 2009:31, 2010:31

Student victimization, crime in schools, 2008:28, 2009:27, 2010:26, 2011:30, 2012:14. See also Violence at schools

Study abroad, 2010:40

Suburban areas. See Urbanicity

Supplemental Educational Opportunity Grants (SEOG), 2010:46, 2011:46

Supplemental Loans to Students (SLS), 2011:46, 2011:TF15

Supplies for public schools, 2009:34, 2010:34, 2011:36, 2012:20

Suspensions from elementary/secondary schools, 2009:28

Synchronous instruction, 2012:15

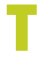

Tax credits for postsecondary education costs, 2010:47, 2011:47, 2012:40

Teacher Education Assistance for College and Higher Education (TEACH) Grant, 2012:40

Teachers/Teaching, 2008:32, 2010:27, 2010:30, 2011:31, 2012:17. See also Faculty, postsecondary education international comparisons of professional development, 2009:29

newly hired, 2010:28

pay incentives for, 2010:37

salaries as school expenditures, 2008:35, 2009:34, 2010:34, 2011:36, 2012:20

student/teacher ratios at public schools, 2008:33, 2009:31, 2010:31

turnover rates for, 2008:31, 2011:32

Technology, coursetaking by high school students, 2012:TF7

Technology for delivering distance education, 2012:15

Tenth grade, extracurricular activity participation in, 2012:27

Testing accommodations

mathematics performance in 4 th, 8 th, and 12 th grade, 2011:12, 2011:13, 2012:24

mathematics performance in 4th and 8th grade, 2008:13, 2009:13, 2010:11, 2010:12

reading performance through elementary/secondary level, 2008:12, 2009:12, 2010:9, 2010:10, 2011:10, 2011:11, 2012:23
U.S. history, geography, and civics performance through elementary/secondary level, 2012:25

Tests. See Achievement levels/tests

Theft at schools, 2008:28, 2009:27, 2010:26, 2011:30, 2012: 14

Theil coefficient, 2008:36, 2009:35, 2010:35, 2011:37, 2012:21

Theology, degrees in, 2009:41, 2010:42, 2011:41, 2012:39

Time spent working for high school students, 2012:30

Time to completion for bachelor's degree, 2009:22, 2010:21, 2011:23, 2012:45

TIMSS (Trends in International Mathematics and Science Study). See Trends in International Mathematics and Science Study (TIMSS)

Title I, 2010:24, 2011:27

Title IV postsecondary institutions

characteristics of, 2011:39, 2012:36

degrees awarded at, 2008:41, 2009:42, 2010:43, 2011:42, 2012:46

fields of study for undergraduate and graduate programs, 2012:38-39

financial aid to first-time students, 2009:45

financial aid to students, 2012:40

in-state and out-of-state attendance at college, 2008:10

Total compensation for faculty, 2009:43, 2010:44, 2011:44, 2012: 44

Total expenditures for elementary/secondary education. See Expenditures for elementary/secondary education

Transfers, principals, 2011:34

Transfers, teacher

newly hired elementary/secondary teachers, 2010:28

as part of teacher turnover, 2008:31, 2011:32

Transition to postsecondary education

enrollment rates in college, 2008:24, 2009:21, 2010:20, 2011:21, 2012:34

expectations of twelfth-grade students for a degree, 2012:35, 2012: TF12-TF13

Transportation expenditures, 2008:35, 2009:34, 2010:34, 2011:36, 2012:20

Trends in International Mathematics and Science Study (TIMSS)

international comparisons of teachers, 2009:29

mathematics performance in 4th and 8 th grade, 2009: 15, 2010:15

science performance in 4th and 8th grade, 2009:16, 2010:16

Tribal colleges, 2009:38, 2010:39 
Trigonometry, coursetaking by high school students, 2012:31, 2012: TF7

Tuition/fees for postsecondary education. See also Cost of attending college

by level and control of institution, 2011:TF12

cost of attending an undergraduate institution, 2012:40

revenues for institutions, 2009:46, 2010:49, 2011:50, 2012:42

student loans and default rates, 2011:49

Turnover rates for teachers, 2008:31, 2011:32

Twelfth grade

absenteeism in, 2012:28

civics performance in, 2012:25

economics performance in, 2008: 15

expectations of students for postsecondary degree, 2012:35, 2012:TF12-TF13

extracurricular activities, participation in, 2012:27

geography performance in, 2012:25

mathematics performance in, 2011:12, 2011:13, 2012:24

reading performance in, 2008:12, 2009:12, 2011:10, 2011:11, 2012:23

science performance in, 2011:14

U.S. history performance in, 2012:25

Two-parent households, 2008:6, 2012:7. See also Parents

Two-year institutions. See also Postsecondary education

characteristics of, 2011:39, 2012:36

distance education courses at, 2011:43

enrollment rates, 2008:9, 2008:24, 2009:10, 2009:21, 2010:7, 2010:20, 2011:8, 2011:21, 2012:10, 2012:34

expenses for, 2012:43

faculty salaries and benefits at, 2008:42, 2009:43, 2010:44, 2011:44, 2012:44

financial aid to first-year students, 2009:45

financial aid to students, 2012:41

graduation rates, 2011:23, 2012:45

net price for, 2010:47, 2011:47, 2012:40

number of, 2009:42, 2010:43, 2011:42

racial/ethnic concentration in, 2009:38, 2010:39

remedial coursetaking by undergraduates, 2011:22

revenues and expenses for, 2011:50

revenues for, 2012:42

student loans and default rates, 2011:49

students working while attending, 2008:43, 2009:44, 2010:45, 2011:45, 2012:37
Unaffiliated schools, 2008:4, 2009:5, 2010:3, 2011:4, 2012:5. See also Private elementary/secondary schools

Undergraduate students. See also Postsecondary education cost of attending college, 2010:47, 2011:47, 2012:40 distance education courses, 2011:43 financial aid to (See Financial aid to students) in-state and out-of-state attendance at college, 2008:10 international students in postsecondary institutions, 2009:39 (See also Nonresident aliens in U.S. postsecondary institutions)

rate of enrollment, 2008:9, 2009:10, 2010:7, 2011:8, 2012:10

remedial coursetaking by, 2011:22

student loans to, 2010:46, 2011:46

student loans to from federal government, 2012:41

Unemployment, 2011:18

youth not in school or working, 2012:29

Unified school districts, 2008:36, 2009:35, 2010:35, 2011:37, 2012:21

U.S. history performance through elementary secondary level, 2012:25, 2012:TF9

Universities. See Four-year institutions; Postsecondary education

Urbanicity

art and music achievement, 2010:14

characteristics of elementary/secondary schools, 2012:12

charter schools in central cities, 2009:32

crime in schools, 2008:28, 2009:27, 2012:14

distance education enrollment by high school students, 2012:15

English language learners, 2012:8

expenditures per student by school district, 2008:37, 2009:36, 2010:36

poverty levels in public schools, 2008:29, 2009:25, 2010:25, 2011:28, 2012:13

private school enrollments, 2008:4

public school characteristics, 2011:27

public school enrollments, 2008:30, 2009:26

students per staff member at public elementary/ secondary schools, 2008:32

student/teacher ratios at public schools, 2009:31, 2010:31

teacher pay incentives by, 2010:37

teachers at elementary/secondary schools, 2012:17 
Verbalization in young children, 2009:3

Video delivery of distance education courses, 2012:15

Violence at schools

declining, 2012:TF8

public schools experiencing, 2008:28, 2009:27, 2010:26, 2011:30, 2012:14

Visual arts

degrees in, 2008:39, 2008:40, 2009:40, 2010:41, 2011:40, 2012:38

eighth-grade performance, 2010:14

Visual impairments, 2008:22

Vocational education/schools, 2009:31, 2010:31 percentage of public schools as, 2010:24, 2011:27

Volunteerism, parental involvement with children's education, 2009:30

Weapons in schools, 2008:28, 2009:27, 2010:26, 2012:14

Western region schools. See Regional distributions

William D. Ford Federal Direct Loan Program, 2011:49, 2011:TF13, 2011:TF15

Women. See also Sex

degrees by field of study, 2009:40, 2010:41, 2011:40, 2012:38

earning degrees, 2008:27

enrollment rates in college, 2008:9

graduate enrollment rates, 2008: 11
Work experience. See also Principals; Teachers/Teaching principals at elementary/secondary schools, 2011:34, 2012:18

teachers at elementary/secondary schools, 2011:32, 2012: 17

Working while attending school (postsecondary education), 2008:43, 2009:44, 2010:45, 2011:45, 2012:37. See also Employment status

Work-Study program, 2012:40

Writing, proficiency levels in 8th and 12th grades, 2008:14

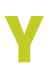

Years of experience principals at elementary/secondary schools, 2011:34, 2012: 18

teachers at elementary/secondary schools, 2011:32, 2012:17

Young adults

annual earnings of, 2008:20, 2009:17, 2010:17, 2011:17, 2012:49

employment of high school students, 2012:30

status dropout rates for high school, 2008:23, 2009:20, 2010:19, 2011:20, 2012:33

unemployed and not in school, 2012:29 
This page intentionally left blank. 

www.ed.gov 省 OF ies.ed.gov $\star$ 纱,

SOSTATES OF 